\title{
Water Resources Data Michigan Water Year 1987
}

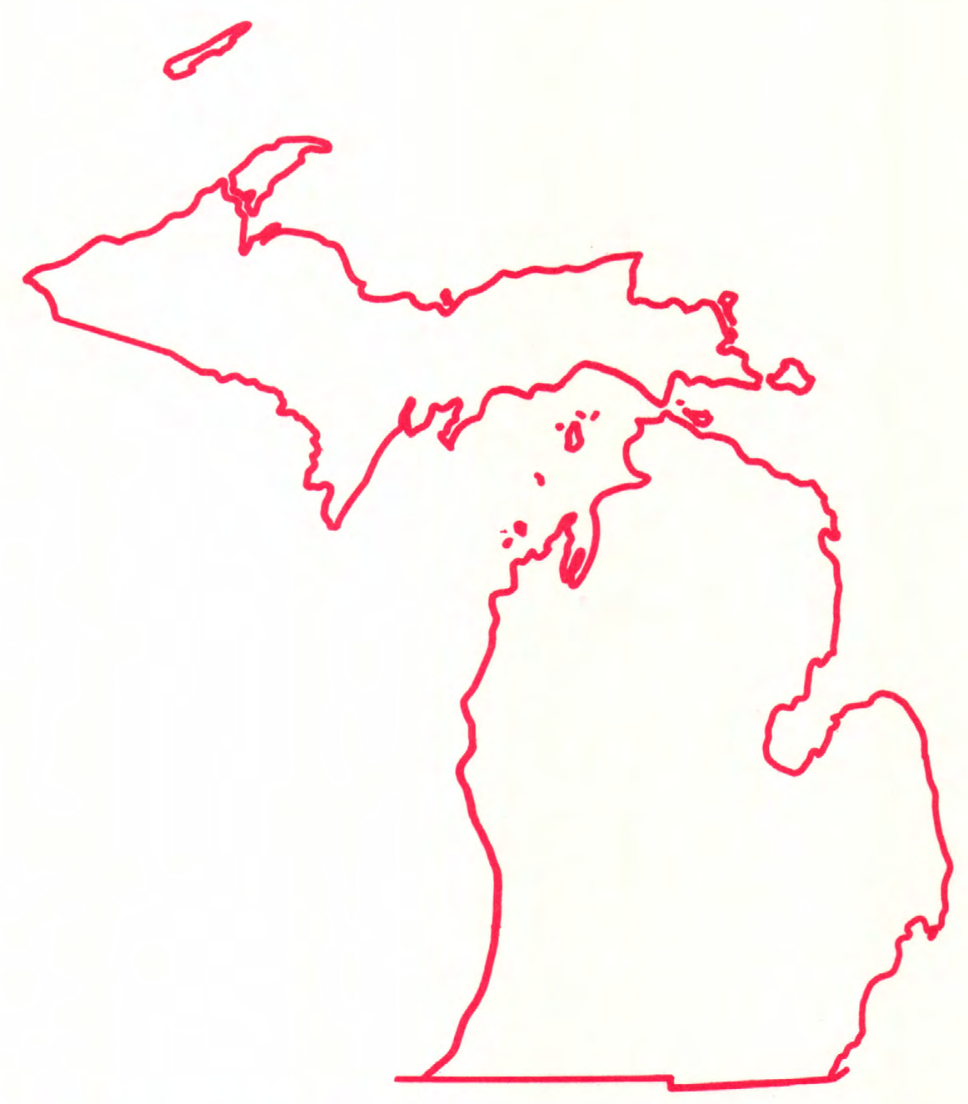

U.S. GEOLOGICAL SURVEY WATER-DATA REPORT MI-87-1 Prepared in cooperation with the State of Michigan and with other agencies 


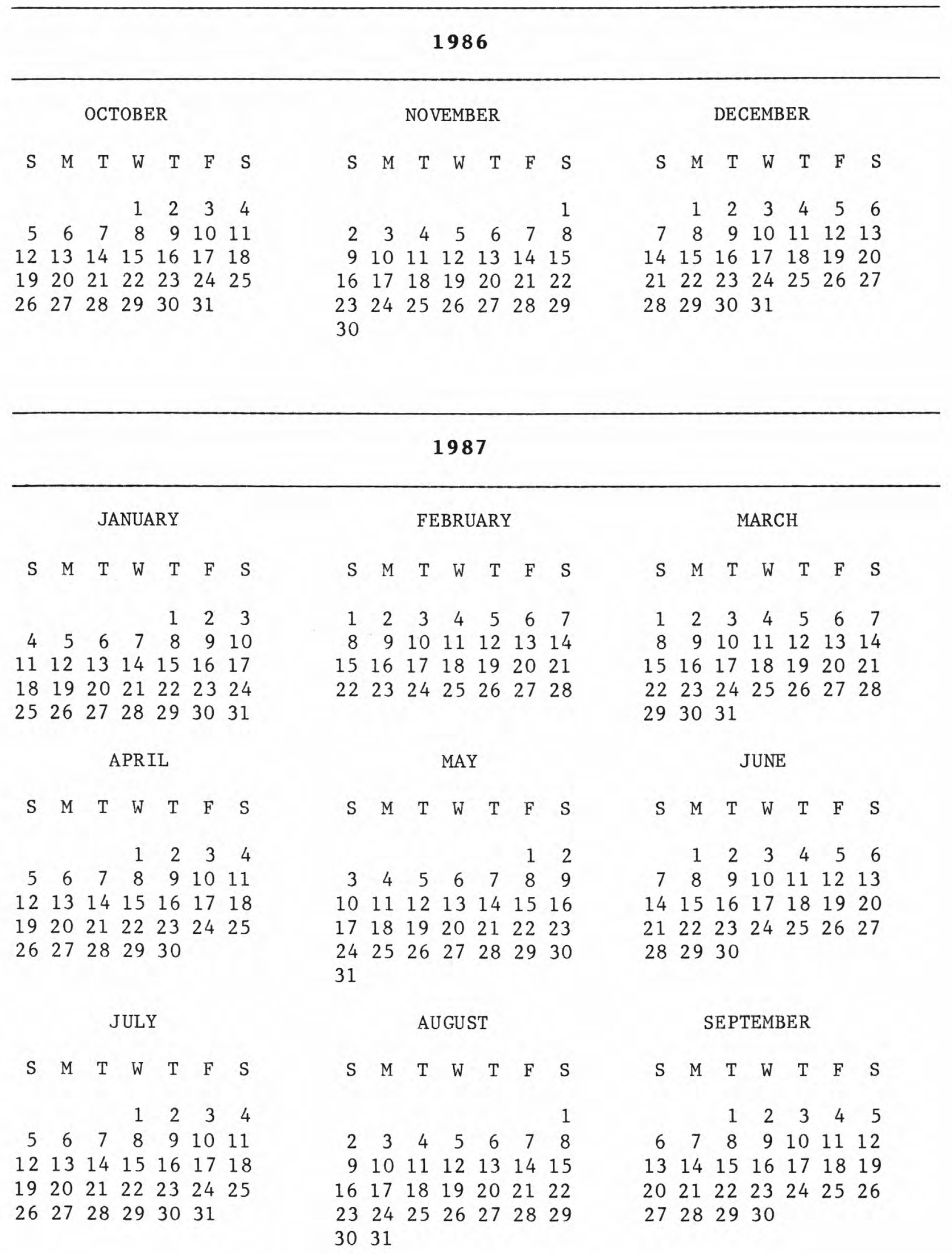




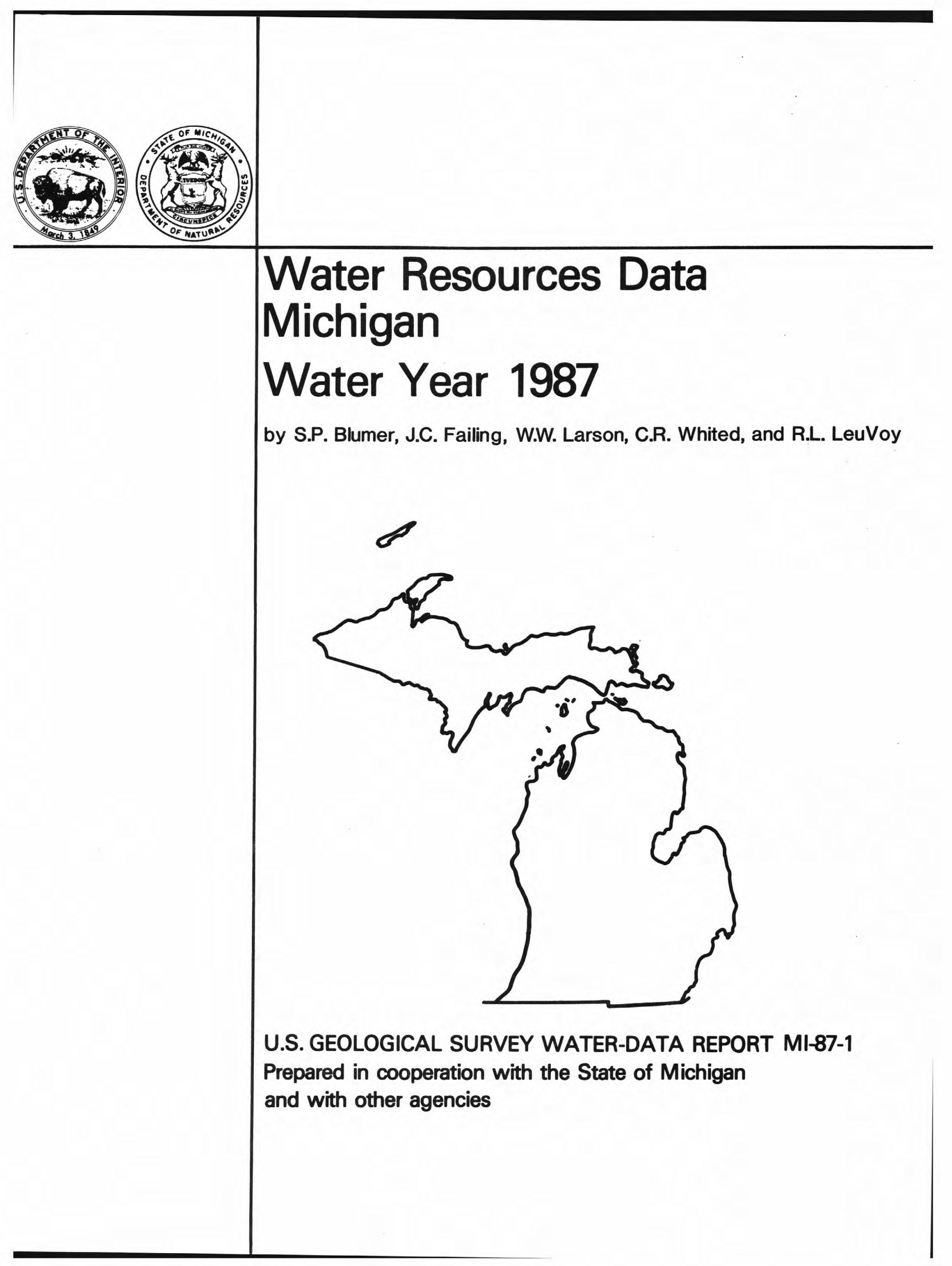


DONALD PAUL HODEL, Secretary

GEOLOGICAL SURVEY

Dallas L. Peck, Director

For information on the water program in Michigan write to District Chief, water Resources Division

U.S. Geological Survey
6520 Mercantile Way, Suite 5

Lansing, Michigan 48911

1988 
This volume of the annual hydrologic data report of Michigan is one of a series of annual reports that document hydrologic data gathered from the U.S. Geological Survey's surface- and ground-water data-

collection networks in each state, puerto Rico, and the Trust Territories. These records of streamflow. ground-water levels, and quality of water provide the hydrologic information needed by state, local, and federal agencies, and the private sector for developing and manaing our Nation's land and water resources.

This report is the culmination of a concerted effort by dedicated personnel of the U.S. Geological Survey who collected, compiled, analyzed, verified, and organized the data, and who typed, edited, and assembled the report. In addition to the authors, who had primary responsibility for assuring that the information contained herein is accurate, complete, and adheres to Geological survey policy and established guidelines, the following individuals contributed significantly to the collection, processing, and tabulation of the data:
S.M. Beall
J.M. Ellis
D.V. Eagle
P.J. Klimek
C.L. Ebsch

J.C. Knudsen

G. Lansky.

R.G. Nettleton

C.E. Oberst

M.F. Soper

T.J. Spicer

This report was prepared in cooperation with the State of Michigan and with other agencies under the general supervision of T.R. Cummings, District Chief, Michigan, and S.P. Sauer, Regional Hydrologist, Northeast Region. 


\begin{tabular}{|c|c|c|}
\hline $\begin{array}{l}\text { REPORT DOCUMENTATION } \\
\text { PAGE }\end{array}$ & $\begin{array}{l}\text { 1. REPORT NO. } \\
\text { USGS / WRD / HD-88/231 }\end{array}$ & 3. Recipient's Accession No. \\
\hline \multirow{2}{*}{\multicolumn{2}{|c|}{$\begin{array}{l}\text { 4. Title and Subtitle } \\
\text { Water Resources Data - Michigan } \\
\text { Water Year } 1987\end{array}$}} & \begin{tabular}{|r|}
$\begin{array}{r}\text { 5. Report Date } \\
\text { May } 1988\end{array}$ \\
\end{tabular} \\
\hline & & 6. \\
\hline $\begin{array}{r}\text { 7. Author(s) } \text { S. P. BIt } \\
\text { C. R. Whited }\end{array}$ & $\begin{array}{l}\text { mer, J. C. Failing, W. W. Larson, } \\
\text { and R. L. LeuVoy }\end{array}$ & $\begin{array}{l}\text { 8. Performing Organization Rept. No. } \\
\text { USGS-WDR-MI }-87-1\end{array}$ \\
\hline \multirow{2}{*}{\multicolumn{2}{|c|}{$\begin{array}{l}\text { 9. Performing Organization Name and Address } \\
\text { U.S. Geological Survey, Water Resources Division } \\
6520 \text { Mercantile Way, Suite } 5 \\
\text { Lansing, Michigan } 48911\end{array}$}} & 10. Project/Task/Work Unit No. \\
\hline & & $\begin{array}{l}\text { 11. Contract(C) or Grant(G) No. } \\
\text { (C) } \\
\text { (G) }\end{array}$ \\
\hline \multirow{2}{*}{\multicolumn{2}{|c|}{$\begin{array}{l}\text { 12. Sponsoring Organization Name and Address } \\
\text { U.S. Geological Survey, Water Resources Division } \\
6520 \text { Mercantile Way, Suite } 5 \\
\text { Lansing, Michigan } 48911\end{array}$}} & $\begin{array}{l}\text { 13. Type of Report \& Period Covered } \\
\text { Annua } 1-\text { Oct. } 1,1986 \\
\text { Sept. } 30,1987 \\
\end{array}$ \\
\hline & & 14. \\
\hline
\end{tabular}

Prepared in cooperation with the State of Michigan and with other agencies.

16. Abstract (Limit: 200 words)

Water resources data for the 1987 water year for Michigan consists of records of stage, discharge, and water quality of streams; stage and contents of lakes and reservoirs; and water levels and water temperature of ground water. This report contains discharge records for 135 streamflow-gaging stations; stage only records for 15 lake-gaging stations; stage and contents for 5 lakes and reservoirs; water-quality records for 24 streamflow-gaging stations; water-level records for 52 observation wells; and water-temperature records for 6 observation wells. Also included are 52 crest-stage partial-record stations and 8 low-flow partial-record stations. Additional water data were collected at various sites not involved in the systematic data-collection program. Miscellaneous data were collected at 100 measuring sites and 23 water-quality sampling sites. These data represent that part of the National Water Data System collected by the U.S. Geological Survey and cooperating State, Local, and Federal agencies in Michigan.

17. Document Analysis Descriptors

*Michigan, *Hydrologic data, *Surface water, *Ground water, *Water quality, Flow rate, Gaging stations, Lakes, Reservoirs, Chemical analyses, Sediments, Water temperatures, Sampling sites, Water levels, Water analyses.

b. Identifiers/Open-Ended Terms

c. COSATI Field/Group

18. Avallability statemen:

No restriction on distribution. This report may be purchased from: National Technical Information Service, Springfield, VA 22161

\begin{tabular}{|l|l|}
\begin{tabular}{|l|} 
19. Socurity Class (This Report) \\
UNCLAS SI FI ED
\end{tabular} & $\begin{array}{c}\text { 21. No. of Pages } \\
292\end{array}$ \\
\hline $\begin{array}{l}\text { 20. Socurity Cless (This Page) } \\
\text { UNCLASS I FI ED }\end{array}$ & 22. Price \\
\hline
\end{tabular}




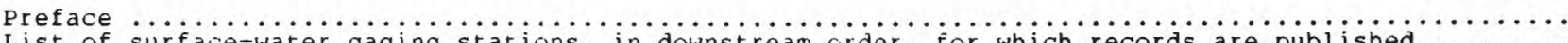
List of surface-water gaging stations, in downstream order, for which records are published $\ldots . . .$. List of counties for which records of ground-water levels are published $\ldots \ldots \ldots \ldots \ldots \ldots \ldots \ldots \ldots \ldots$

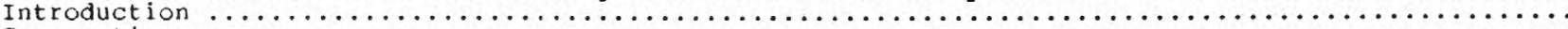
cooperal

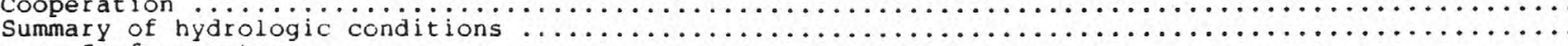

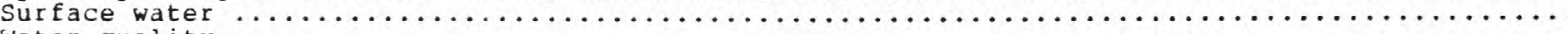

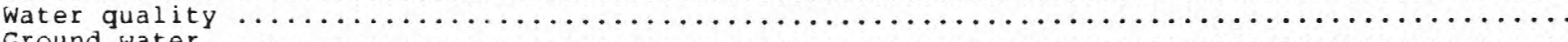
Ground water

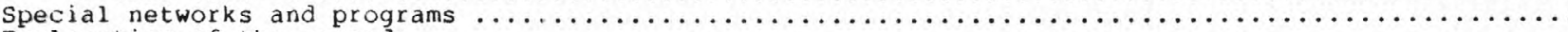
Explanation of the records .

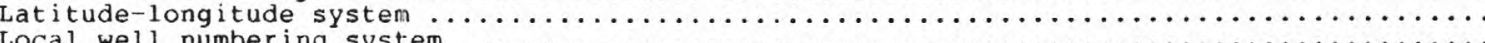

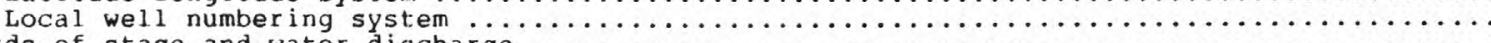

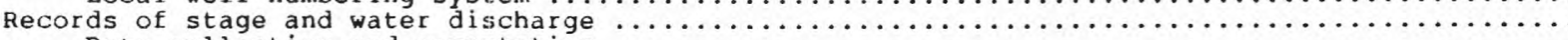

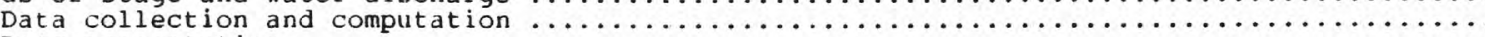
Data presentation

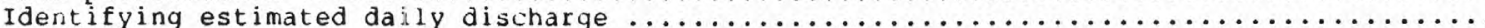

Accuracy of the records

Accuracy of the records

.

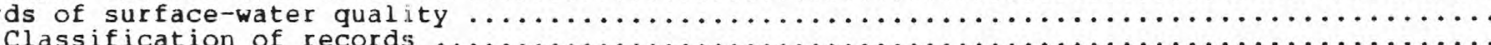

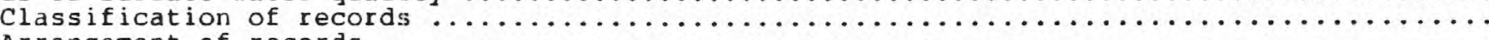
Arrangement of records

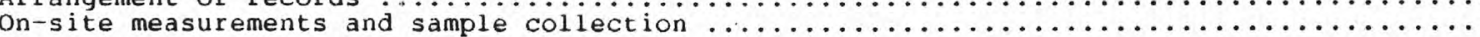

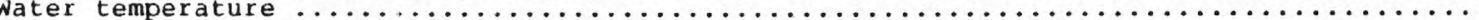

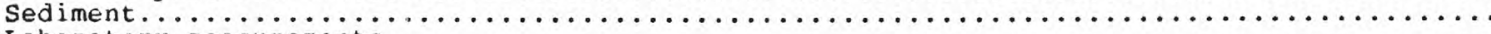

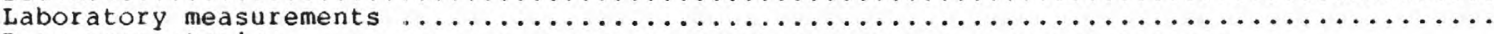

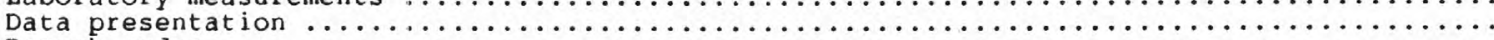

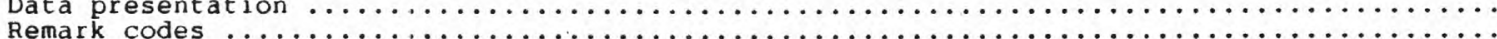

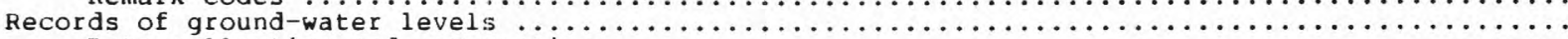

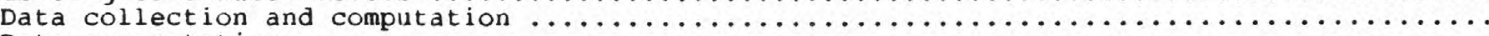

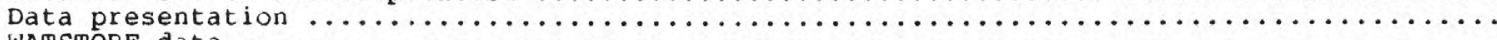

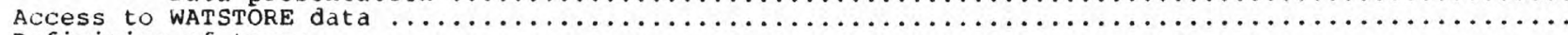

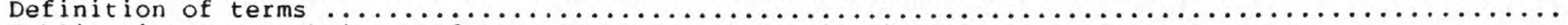

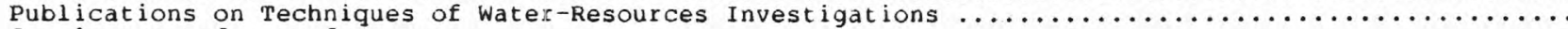

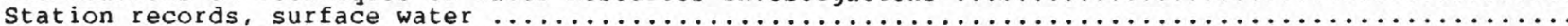

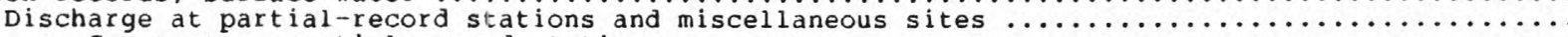

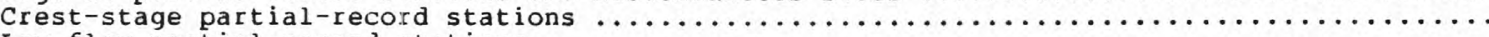
Low-flow partial-record stations.

Miscellaneous sites

Analyses of samples collected at water-quality partial-record stations and miscellaneous sites

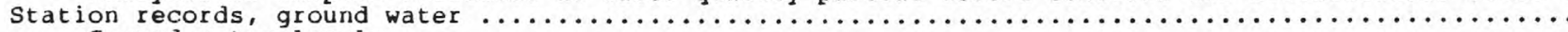

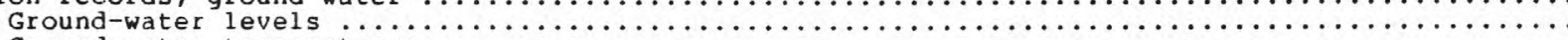

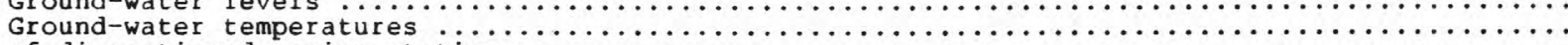

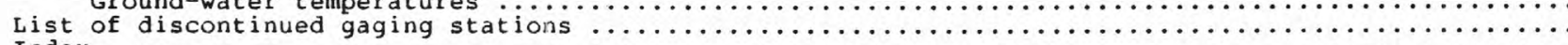
Index

Figure 1. Comparison of discharge at three long-term representative gaging stations during 1987

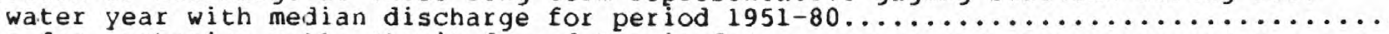

2. System for numbering wells (latitude and longitude)

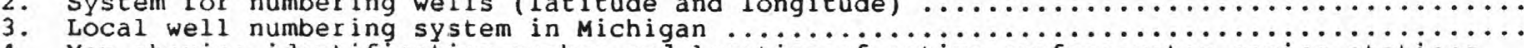

4. Map showing identification number and location of active surface-water gaging stations

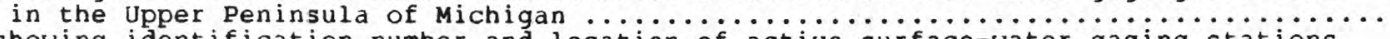

Map showing identification number and location of active surface-water gaging stations

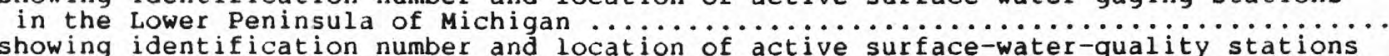

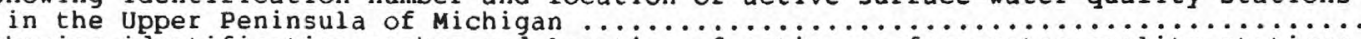

7. Map showing identification number and location of active surface-water-quality stations

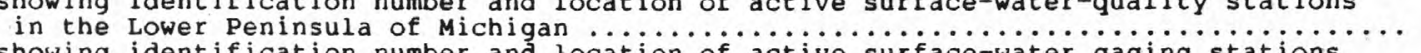

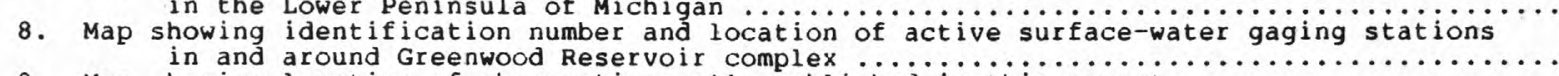

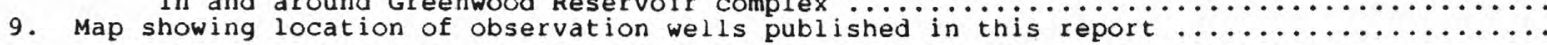


Letters after station name designate type of data: (d) discharge, (c) chemical, (g) gage height, (m) microbiological, (p) pesticide, (r) radio-chemical, ( $t$ ) water temperature, (s) sediment

ST. LAWRENCE RIVER BASIN

STREAMS TR IBUTARY TO LAKE SUPERIOR

Washington Creek at Windigo $(d, c, m, r, t, s) . \dot{c}_{\text {. }}$. . . . . . . . . . . . . . . . . . . . . . . . . 26

Middle Branch Ontonagon River near Paulding (d). . . . . . . . . . . . . . . . . . . . . 31

Bond Falls Reservoir:

Bond Falls Canal near Paulding (d)

Bond Falis Reservoir near Paulding (d)

Middle Branch Ontonagon River near Trout Creek (d)

Middle Branch Ontonagon River near Rockland (d)

Lake Gogebic near Bergland (g)

West Branch Ontonagon River near Bergland (d)

South Branch Ontonagon River:

Cisco Lake near Watersmeet (g) . . .

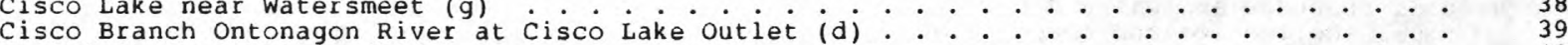

Ontonagon River near Rockland $(d, c, m, s)$. . . . . . . . . . . . . . . . . . . . . . . . . 40

Portage River (Portage Lake):

Sturgeon River near Sidnaw (d) . . . . . . . . . . . . . . . . . . . . . . . . . . .

Sturgeon River near Alston (d) . . . . . . . . . . . . . . . . . . . . . . . . . . . . . . . 44

Trap Rock River near Lake Linden (d) . . . . . . . . . . . . . . . . . . . . . . . . . . . 45

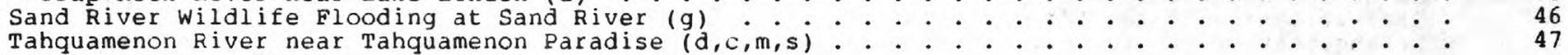

STREAMS TRIBUTARY TO ST. MARYS RIVER

St. Marys River above Sault Ste. Marie $(\mathrm{d}, \mathrm{c}, \mathrm{m}, \mathrm{r})$. . . . . . . . . . . . . . . . . . . . 50

STREAMS TRIBUTARY TO LAKE MICHIGAN

Manistique Lake near Curtis (g)

Manistique River near Manistique (d)

Indian Lake near Manistique (g)

Sturgeon River near Nahma Junction ( $\dot{d})$

Middle Branch Escanaba River at Humboldt (d)

Greenwood Reservoir near Greenwood (d)

Greenwood Diversion near Greenwood (d)

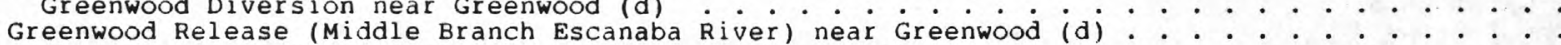

Schweitzer Creek (head of East Branch Escanaba River):

Schweitzer Reservoir near Palmer (d)

Schweitzer Creek near Palmer (d)

Escanaba River at Cornell (d,c,m,s)

Ford River near Hyde $(d, c, m, s)$

Brule River near Florence, WI (d)

Paint River at Crystal Falls (d)

Paint River near Alpha (d)

Lake Michigamme near Champion ( $g$ )

Michigamme River near Crystal Falls

Menuminee River near Florence, WI (d)

Menominee River below Pemene Creek near.

St. Joseph River near Burlington (d) Coldwater River:

Hog Creek near Allen (d)

Coldwater River near Hodunk

Nottawa Creek near Athens (d)

Portage River:

Gourdneck Creek

Gourdneck Canal near Schoolcraft (d)

Prairie River near nottawa (d)

St. Joseph River at Mottville (d)

Pigeon River near Scott, IN (d)

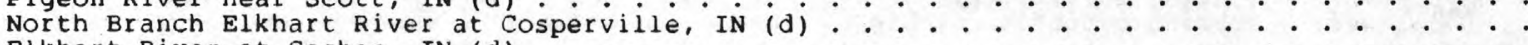

Elkhart River at Goshen, IN (d)

St. Joseph River at Elkhart, IN (d)

St. Joseph River at Niles (d,c,m,s)

Dowagiac River at Sumnerville

Black River:

South Branch Black River near Bangor

(d)

Kalamazoo River near Marengo (d)

Battle Creek at Battle Creek (d)

Kalamazoo River near Battle Creek (d)

Augusta Creek near Augusta (d,c,s)

Kalamazoo River at Comstock (d,c,s)

Portage Creek at Portage (d,c,s)

Portage Creek near Kalamazoo (d)

West Fork Portage Creek near Oshtemo (d)

West Fork Portage Creek at Kalamazoo

Kallamazoo River near Fennville (d,c,m,s) Rabbit River near Hopkins (d) 
Macatawa River near Zeeland (d)

110

Grand River at Jackson (d)

Red Cedar River near williamston (d)

Deer Creek near Dansville (d)

Sloan Creek near Williamston (d)

Grand River at Lansing (d)

Looking Glass River near Eagle (d)

Maple River at Maple Rapids (d)

Grand River at Icnia (d)

Thornapple River near Hastings (d)

Thornapple River near Caledonia (d)

Grand River at Grand Rapids (d)

Grand River at Eastmanville (d,c;m,s)

Muskegon River:

Higgins Lake near Roscommon (g)

Houghton Lake near Houghton Lake Height "

Clam River at Vogel Center (d)

Muskegon River at Evart (d)

Little Muskegon River near Moriey (d)

Muskegon River at Newaygo (d)

Muskegon River near Bridgeton (d,cim, s)

Bear Creek near Muskegon (d)

White River near whitehall (d)

Pere Marquette River at Scottville (d)

Manistee River near Sherman (d)

Manistee River near Manistee (d)

Manistee River at Manistee (d,c,m, s)

Boardman River near Mayfield (d)

Elk Lake near Elk Rapids (g)

Jordan River near East Jordan

112

TREAMS TRIBUTARY TO LAKE HURON

Pine River near Rudyard (d)
Burt Lake (head of Cheboygan River)

Crooked Lake near Conway ( $g$ )
Sturgeon River near Wolverine

Burt Lake at Indian River (g)

Pigeon River near Vanderbilt (d)

Mullett Lake near Cheboygan (g)

(continuation

Cheboygan Pond at Cheboygan (g)

Thunder Bay River near Alpena $(d, c, m, s)$

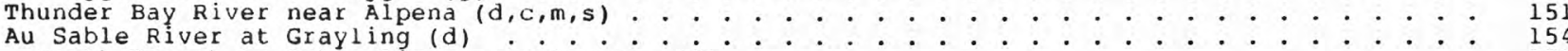

South Branch Au Sable River near Luzerne (d)

orth Branch Au Sable River:

Otsego Lake near Gaylord (g)

Au Sable River at Mio (a)

Au Sable River near Au Sable $(\dot{d}, \dot{c}, \dot{m}, \dot{s})$

Rifle River near Sterling ( $d, c, m, s)$

Flint River: at Owosso (d)

South Branch Flint River:

Farmers Creek near Lapeer (d)

South Branch Flint River near Columbiavilie (d)

Holloway Reservoir near otisville (d)

Flint River near otisville (d)

Kearsley Creek near Davison (d)

Flint River near flint (d)

Cass River at Cass City (d)

Cass River at Frankenmuth (d)

Tittabawassee River:

Chippewa River near Mount pleasant (d)

Pine River at Alma (d)

Pine River near Midland (d)

Tittabawassee River at Midland $(\dot{d})$

Tittabawassee River near Midland $(d, c, m, s)$

Saginaw River at Saginaw (d)

Pigeon River near Caseville (d,c, m,

STREAMS TRIBUTARY TO ST. CLAIR RIVER

St. Clair River at Port Huron

Black River near Fargo (d)
Belle River:

North Branch Belle River at Imlay City (d) 
ST. LAWRENCE RIVER BASIN--COnt inued

STREAMS TRIBUTARY TO ST. CLAIR RIVER--CONt i nued

Belle River at Memphis (d)
STREAMS TRIBUTARY TO LAKE ST. CLAIR

Clinton River:

Sashataw Creek near Drayton plains $(\mathrm{d})$. . . . . . . . . . . . . . . . . . . . 190

Clinton River near Drayton plains (d) . . . . . . . . . . . . . . . . . . . 19

Galloway Creek near Auburn Heights (d) . . . . . . . . . . . . . . . . . . . . . . . . . . 192

Paint Creek at Rochester (d) . . . . . . . . . . . . . . . . . . . . . . 19

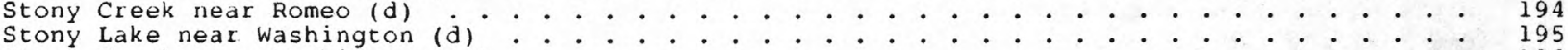

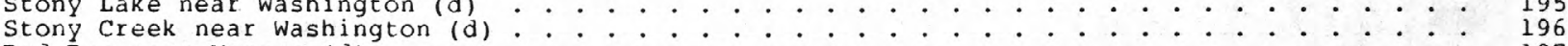

Red Run near Warren (d) . . . . . . . . . . . . . . . .......... 197

Big Beaver Creek near Warren $(d)$. . . . . . . . . . . . . . . . . . . . . . . 198

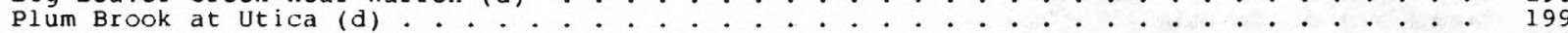

Clinton River near Fraser (d) . . . . . . . . . . . . . . . . . . 200

North Branch Clinton River:

East Pond Creek at Romeo (d) . . . . . . . . . . . . . . . . . . . . . . 201

Coon Creek:

East Branch Coon Creek at Armada (d) . . . . . . . . . . . . . . . . . . . . 202

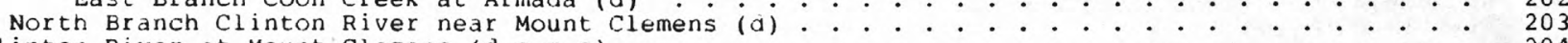

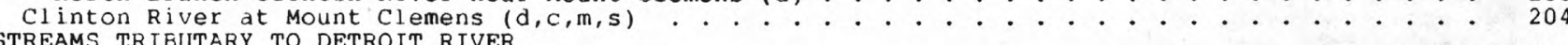

STREAMS TRIEUTARY TO DETROIT RIVER

River Rouge at Birmingham (d)

Evans Ditch at Southfield (d)

River Rouger Rouge at Farmington $(\mathrm{d})$. . . . . . . . . . . . . . . . . . . . . 210

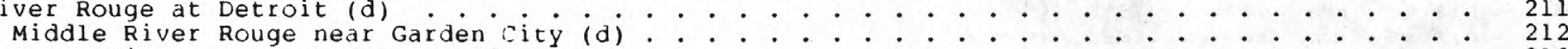

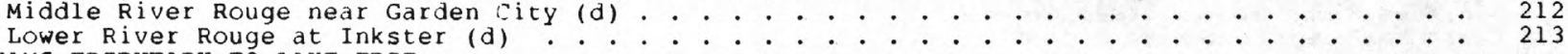

STREAMS TRIBUTARY TO LAKE ERIE

Huron River at milford (d) . . . . . . . . . . . . 214

Kent Lake near New Hudson $(g)$. . . . . . . . . . . . . . . . . . . . . . . . . . . . . . 215

Huron River near New Hudson $(d) .$. . . . . . . . . . . . . . . . . . . . . . . . . . . 216

Huron River near Hamburg $(d)$. . . . . . . . . . . . . . . . . . . . . . . . . . . . 217

Huron River at Delhi Mills (e)
Huron River at Ann Arbor (d)

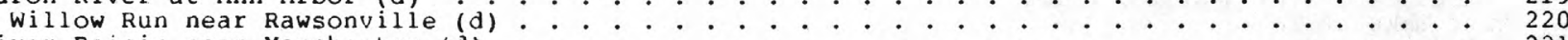

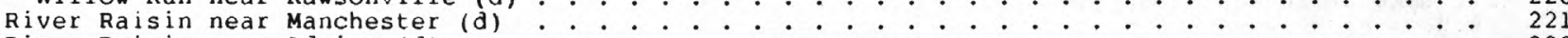

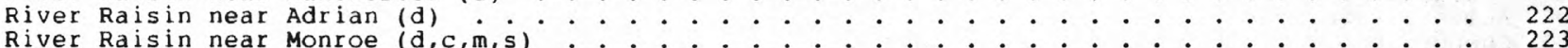


Chippewa

Clinton.

Crawford

Delta

Dickinson

Eaton

Genesee

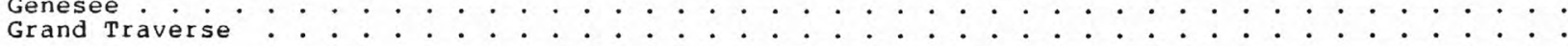

Ingham

Iosco

Iron

Jackson

Kal amazoo

Kent

259

Lake

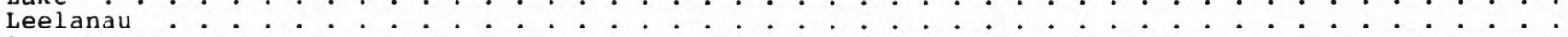

Lenawee . . . . . . . . . . . . Livingston

Mackinac

Marquette

Monroe

Muskegon

Oakland

Oceana

Onemaw

otsego

Presque Isle

260

260

261

Roscommon

261

262
262

262

263

263
264

Saginaw.

Sanilac.

264

264

265

265

266

266

267

Schoolcraft

Van Buren

Washtenaw 

The Water Resources Division of the U.S. Geological Survey, in cooperation with state agencies, btains a large amount of data pertaining to the water resources of Michigan each water year. These data, ccumulated during many water years, constitute a valuable data base for developing an improved nderstanding of the water resources of the State. To make these data readily available to interested larties outside the Geological survey, the data are published annually in this report series entitled Water Resources Data - Michigan."

This report includes records on both surface and ground water in the State. Specifically, it ontains: (1) Discharge records for 135 streamflow-gaging stations, 52 crest-stage partial-record tations, 8 low-flow partial-record stations, and 100 miscellaneous sites; (2) stage only records for 15 ake-gaging stations: (3) stage and content records for 5 lakes and reservoirs; (4) water-quality records ake-gaging stations; (3) stage and content records for 5 lakes and reservolrs; (4) water-qualit recor ier 24 streamflow-gaging stations and 23 miscellaneous sites; (5) water-level records for 52 observation lational water Data system collected by the U.S. Geological Survey and cooperating State, Local, and ederal agencies in Michigan.

This series of annual reports for Michigan began with the 1961 water year with a report that contained only data relating to the quantities of surface water. For the 1964 water year, a similar report was introduced that contained only data relating to water quality. Beginning with the 1975 . juality of surface and ground water, and ground-water levels.

Prior to introduction of this series and for several water years concurrent with it, water-resources lata for Michigan were published in U.S. Geological Survey Water-Supply Papers. Data on stream discharge and stage and on lake or reservoir contents and stage, through September 1960, were published annually inder the title "Surface-water Supply of the United States, Part 4." For the 1961 through 1970 water pars, the data were published in two 5 -year reports. Data on chemical quality, temperature, and suspended sediment for the 1941 through 1970 water years were published annualy under the title "Quality of Surface Waters of the United States," and water levels for the 1935 through 1974 water years were jublished under the title "Ground-Water Levels in the United States." The above mentioned Water-Supply ?apers may be consulted in the libraries of the principal cities of the United States and may be purchased Erom Books and Open-File Reports and Investigations, Geological Survey, Federal Center, Bldg. 4l, Box 25425, Denver, CO 80225 .

Publications similar to this report are published annually by the Geological Survey for all States. These official Survey reports have an identification number consisting of the two-letter State abbreviation, the last two digits of the water year, and the volume number. For example, this volume is identified as "U.S. Geological Survey water-Data Report MI-87-1." For archiving and general distribution, the reports for 1971-74 water years also are identified as water-data reports. These water-data reports are for sale in paper copy or in microfiche by the National Technical Information Service, U.S. Department of Commerce, Springfield, VA 22161.

Additional information, including current prices, for ordering specific reports may be obtained from the District Chief at the address given on the back of the title page or by telephone (517) 377-1608.

\section{COOPERATION}

The U.S. Geological Survey and agencies of the State of Michigan have had cooperative agreements for the collection of water-resource records since 1930. Organizations that assisted in collecting the data in this report through cooperative agreement with the Survey are:

Michigan Department of Agriculture, P.E. Kindinger, Director, through Environmental Division, C.E. Lietzau, Director.

Michigan Department of Natural Resources, G.E. Guyer, Director, through Land and Water Management Division, D.J. Hall, Chief, and Geological Survey Division, T.R. Segall, Chief.

Michigan Department of Transportation, J.P. Pitz, Director.

Assistance with funds or services was given by the U.S. Army Corps of Engineers in collecting records for 11 gaging stations published in this report. Assistance was also furnished by the National Weather Service, National Oceanic Atmospheric Administration, U.S. Department of Commerce, and U.S. Environmental Protection Agency.

The following organizations aided in collecting reisords:

Macomb County Board of Supervisors; Oakland County Drain Commission; Genesee County Drain Commission; Kalamazoo County; Wayne County; Huron-Clinton Metropolitan Authority; Cities of Ann Arbor, Cadillac, Clare, Coldwater, Flint, Imlay City, Kalamazoo, Lansing, Mason, Portage, and Ypsilanti; American Aggregate Co.; Consumers Power Co.; Cleveland Cliffs Iron Co.; Fisher Body Division; Michigan Power Co.; Michigan Sugar Co.; Swift-Eckrich, Inc.; Upper Peninsula Power Co.; and Wisconsin-Electric Power Co.

organizations that supplied data are acknowledged in the station descriptions. 
In the Upper Peninsula, streamflow was in the deficient to normal range during most of the 1987 water year. At Sturgeon River near Sidnaw, streamflow was in the normal range in october, but dropped to deficient through most of the year. Streamflow returned to the normal range and, in fact, was excessive in August when the second highest monthly mean discharge was recorded in 47 years of record. During April, May, and June, when streamflows generally are elevated because of snowmelt and spring rains, the recorded monthly flows were only 32 to 38 percent of the median. The minimum daily flow for May tied the record low recorded in 1977.

In the Lower Peninsula, streamflow was excessive in October as a result of record precipitation in September 1986 and additional precipitation received in early October. The monthly mean discharge for October was the highest recorded at Muskegon River at Evart in 55 years of record. The monthly mean discharge for October at the Red Cedar River at East Lansing was the second highest in 57 years of record. Streamflow steadily decreased from November through March. By April, streamflow had reached the deficient range and did not return to the normal range until August. During the deficient period, the lowest recorded mean monthly streamflow for June occurred at Muskegon River at Evart. The monthly and annual mean discharge is compared with the median discharge during 1951-80 at the three index stations (fig. 1 ).

Several stations recorded the maximum discharge for 1987 early in october because of the high antecedent soil moisture coupled with additional rain at the beginning of the month. A relatively mild winter and dry conditions later in the year did not contribute high runoff. Some of the maximum discharges that occurred in early october are not considered independent peak discharges because the discharges were contiguous with an actual peak discharge that occurred in September 1986. Numerous stations that normally record several independent peak discharges above a predetermined base discharge did not even record an independent peak discharge that reached the base discharge.

New minimum discharges were recorded at only a few stations; however, numerous stations recorded low flows. To assist in assessing the magnitude of the 1987 low-flow conditions, the 7-day, lo-year low flow discharge ( $7 Q 10)$ was determined for each station. The minimum discharge and $7 Q 10$ are shown below for only those stations at which the minimum discharge for the year was less than or equal to the 7 Q 10 . The 7 -day low flow discharge is a statistic derived from the lowest mean flow recorded in 7 consecutive days for each year the station has been operated. The lo-year recurrence interval is the average number of appreciably affected by regulation, diversion, and irrigation demands are compared, because these stations tend to represent the natural hydrologic conditions. Streamflow at many stations downstream from flowrequlating structures were less than the 7010 . It is not known whether the lowest flows downstream from regulation are entirely the result of regulation or natural low flow, or a combination thereof.

\begin{tabular}{|c|c|c|c|}
\hline $\begin{array}{l}\text { Station } \\
\text { No. }\end{array}$ & Station Name & $\begin{array}{l}1987 \text { Water Year } \\
\text { Minimum } \\
\text { Discharge } \\
\left(\mathrm{ft}^{3} / \mathrm{s}\right)\end{array}$ & $\begin{array}{c}\text { 7-day, 10-year } \\
\text { Low Flow } \\
\text { Discharge } \\
\left(\mathrm{ft}^{3} / \mathrm{s}\right)\end{array}$ \\
\hline $\begin{array}{l}04096515 \\
04108600 \\
04108800 \\
04111379 \\
04111500 \\
04112000 \\
04121300 \\
04121500 \\
04121900 \\
04122100 \\
04127918 \\
04142000 \\
04143900 \\
04148140 \\
04150800 \\
04175600\end{array}$ & $\begin{array}{l}\text { Hog Creek near Allen } \\
\text { Rabbit River near Hopkins } \\
\text { Macatawa River near Zeeland } \\
\text { Red Cedar River near Williamston } \\
\text { Deer Creek near Dansville } \\
\text { Sloan Creek near Williamston } \\
\text { Clam River at Vogel Center } \\
\text { Muskegon River at Evart } \\
\text { Little Muskegon River near Morley } \\
\text { Bear Creek near Muskegon } \\
\text { Pine River near Rudyard } \\
\text { Rifle River near Sterling } \\
\text { Shiawassee River at Linden } \\
\text { Rearsley Creek near Davison } \\
\text { Cass River at Wajamega } \\
\text { River Raisin near Manchester }\end{array}$ & $\begin{array}{l}2.0 \\
8.5 \\
.90 \\
3.8 \\
.09 \\
\text { a.04 } \\
\text { b } 48 \\
\text { b281 } \\
\text { b2 } 24 \\
\text { b2 } 2.3 \\
51 \\
\text { b1 } 20 \\
\text { b2 } 2.8 \\
\text { b3 } 3.8 \\
\text { b2 } 20 \\
\text { b6 } 6.6\end{array}$ & $\begin{array}{l}2.6 \\
10 \\
1.6 \\
7.4 \\
.14 \\
53.05 \\
317 \\
44 \\
2.6 \\
58 \\
120 \\
3.1 \\
4.2 \\
22 \\
11\end{array}$ \\
\hline \multicolumn{4}{|c|}{$\begin{array}{l}\text { a Minimum daily discharge. } \\
\text { b Occasional slight regulation by upstream dams. }\end{array}$} \\
\hline
\end{tabular}

In the 1987 water year, water levels in the Great Lakes bordering Michigan finally began to recede, but not before two more monthly records were exceeded on Lakes Michigan-Huron and Lake Erie in January. Only slight $r$ ises in lake levels occurred during spring and summer; normally lake levels would $r$ ise to their seasonal highs during this period. Below-normal precipitation coupled with high rates of evaporation over the Great Lakes caused last years record high water levels to guickly approach or parallel the longterm averages. By September, the level of Lake Superior had been in its normal range for six consecutive months, and actually dropped below its long-term average in July. Levels of Lakes Michigan-Huron dropped to the normal range in August, after 41 consecutive months of above-normal water levels. Lake Erie was in the above-normal range for the $40 \mathrm{th}$ consecutive month at the end of the water year. Although lake levels declined from the previous year's highs, erosion continues to be a problem for shoreline-property owners. 

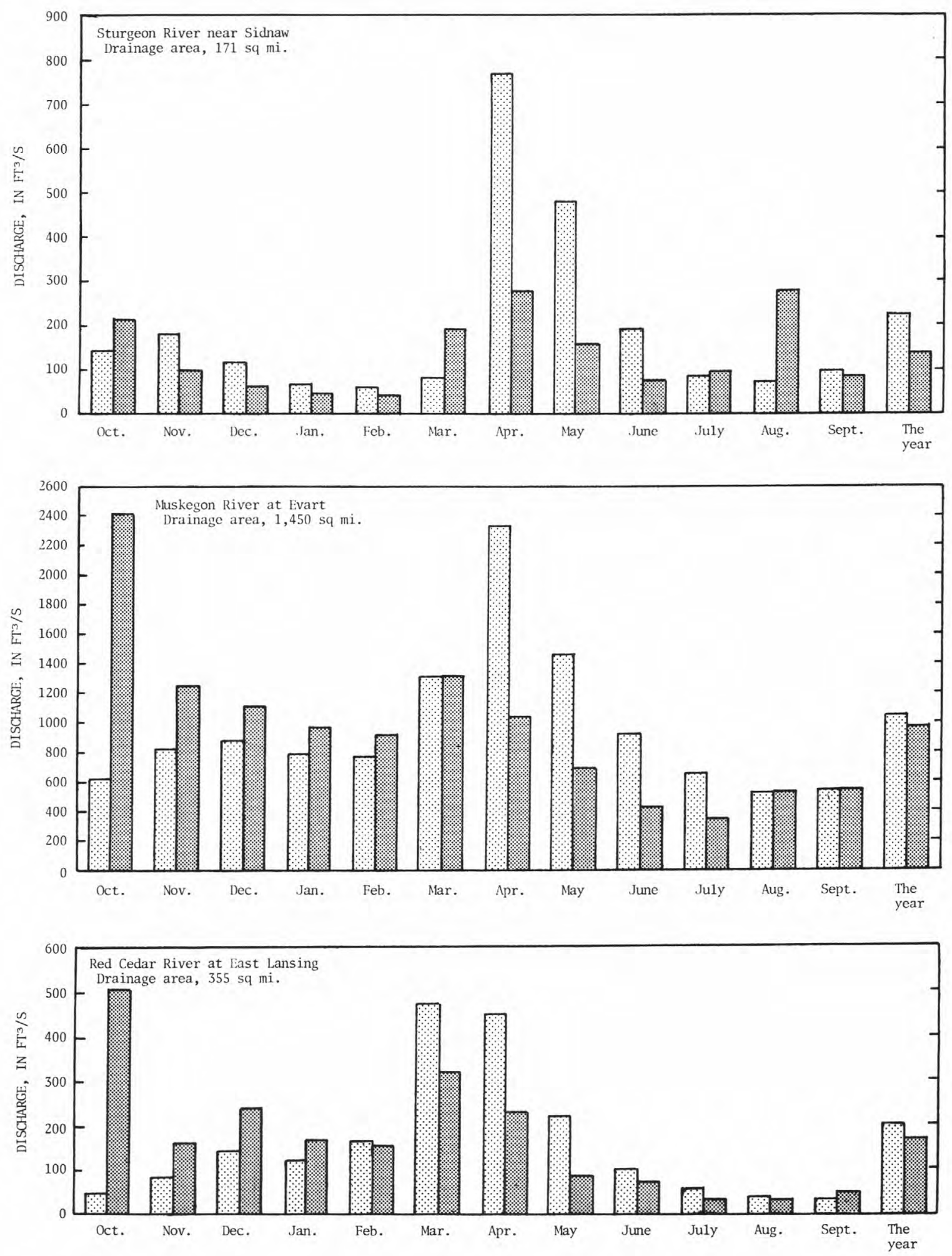

Median of monthly and yearly mean discharge for period 1951-80.

Monthly and yearly mean discharge during 1987 water year.

Figure 1.--Discharge during 1987 water year compared with median discharge for period 1951-80 for three representative stations. 
Surface-water quality data were collected at 18 NASQAN stations in 1987. Concentrations of dissolved solids and suspended sediments, analyzed from samples collected quarterly or bimonthly at the stations, generally tall within the range previously sampled. Although data are collected on an established frequency, it is desirable to sample rivers when either high or low stages occur to determine waterquality characteristics at both extremes. During a period of high flow, runoff from the land is the dominant contributor to a river's discharge and chemical character. During a period of low flow, ground water usually influences a river's water discharge and chemical character. Several high-flow samples were collected during October and November. Numerous low-flow samples were collected during the summer months to record the characteristics of below-normal runoff. In 1987, dissolved-solids concentrations measured during low flow conditions generally reflect the influence of ground water on chemical character.

Inland lakes upstream from several water sampling stations tend to moderate the effects of high and low streamflow on measured water-quality characteristics. The quality of water collected at stations near the mouths of rivers tributary to the Great lakes probabiy is affected by higher-than-normal lake levels, which lessened the influence of surface runoff or inflow of ground water.

\section{Ground water}

The principal aquifers in Michigan are glacial outwash deposits and sandstone, limestone, and dolomite bedrock. The following table lists the aquifers and some of their characteristics.

\begin{tabular}{|c|c|c|c|c|c|}
\hline \multirow{3}{*}{$\begin{array}{l}\text { Aquifer name } \\
\text { and description }\end{array}$} & \multicolumn{4}{|c|}{ Well characteristics } & \multirow{3}{*}{ Remarks } \\
\hline & \multicolumn{2}{|c|}{ Depth $(f t)$} & \multicolumn{2}{|c|}{ Yield (gal/min) } & \\
\hline & $\begin{array}{c}\text { Common } \\
\text { range }\end{array}$ & $\begin{array}{c}\text { May } \\
\text { exceed }\end{array}$ & $\begin{array}{c}\text { Common } \\
\text { range }\end{array}$ & $\begin{array}{c}\text { May } \\
\text { exceed }\end{array}$ & \\
\hline \multicolumn{6}{|l|}{ Glacial aquifers: } \\
\hline $\begin{array}{l}\text { Outwash: Mostly sand } \\
\text { and gravel. }\end{array}$ & $25-200$ & 400 & $1-1,000$ & 2,000 & $\begin{array}{l}\text { Water generally hard; iron } \\
\text { concentrations common; deep } \\
\text { wells may produce salty } \\
\text { water in places. }\end{array}$ \\
\hline $\begin{array}{l}\text { Lacustrine sand: Mostly } \\
\text { sand, some gravel. }\end{array}$ & $25-100$ & 200 & $80-500$ & 500 & $\begin{array}{l}\text { Used for domestic supplies } \\
\text { in Saginaw Bay and Detroit } \\
\text { areas; is salty in places } \\
\text { at depth. }\end{array}$ \\
\hline $\begin{array}{l}\text { Till: Intermixed clay, } \\
\text { silt, sand, gravel and } \\
\text { boulders; abundant sand } \\
\text { and gravel lenses in } \\
\text { some areas. }\end{array}$ & $25-200$ & 400 & $5-200$ & 200 & $\begin{array}{l}\text { Primary source of domestic } \\
\text { supply in western Upper } \\
\text { Peninsula. }\end{array}$ \\
\hline \multicolumn{6}{|l|}{ Bedrock aquifers: } \\
\hline $\begin{array}{l}\text { Saginaw Formation: } \\
\text { Sandstone, siltstone, } \\
\text { some shale, limestone, } \\
\text { and coal. }\end{array}$ & $25-300$ & 500 & $100-300$ & 1,000 & $\begin{array}{l}\text { One of Michigan's most } \\
\text { important bedrock aquifers; } \\
\text { water generally hard; salty } \\
\text { in places at depth. }\end{array}$ \\
\hline $\begin{array}{l}\text { Marshall Formation: } \\
\text { Sandstone and siltstone. }\end{array}$ & $25-200$ & 400 & $100-500$ & 1,500 & $\begin{array}{l}\text { Another of Michigan's import- } \\
\text { ant bedrock aquifers; salty } \\
\text { in places and at depth. }\end{array}$ \\
\hline $\begin{array}{l}\text { Silurian-Devonian rocks: } \\
\text { Limestone and dolomite; } \\
\text { some shale and sandstone. }\end{array}$ & $25-150$ & 200 & $10-300$ & 500 & $\begin{array}{l}\text { Important aquifer in parts } \\
\text { of eastern Upper Peninsula; } \\
\text { water commonly hard. }\end{array}$ \\
\hline $\begin{array}{l}\text { Cambrian-ordovician rocks: } \\
\text { Sandstone, limestone, } \\
\text { and dolomite. }\end{array}$ & $25-150$ & 200 & $10-100$ & 500 & $\begin{array}{l}\text { Important aquifer in eastern } \\
\text { Upper Peninsula; water com- } \\
\text { monly very hard; salty in } \\
\text { places and at depth. }\end{array}$ \\
\hline $\begin{array}{l}\text { Precambrian sandstone: } \\
\text { Sandstone interbedded } \\
\text { with siltstone. }\end{array}$ & $25-400$ & 500 & $5-50$ & 100 & $\begin{array}{l}\text { Important aquifer in western } \\
\text { Upper Peninsula; salty in } \\
\text { places. }\end{array}$ \\
\hline
\end{tabular}


Glacial deposits cover most of the state. The outwash sand and gravels in these deposits are the most productive aquifers in the state. Lacustrine sand also is very productive. Poorly sorted, relatively impermeable mixtures of clay, silt, sand, and gravel, that form some till deposits tend to be poor aquifers: clay deposits generally yieldiitte or no water. In most areas of the state, glacial poor aquifers; clay deposits generally yield little or no water. In most areas of the State, glacial in some areas are more than $800 \mathrm{ft}$ thick. Sandstone, limestone, and dolomite are the principal bedrock in some areas are more than 800 ft thick. Sandstone, limestone, and dolomite are the principal bedrock Where deeply buried, however, these rocks commonly yield brackish or salty water.

Annual recharge to aquifers in Michigan ranges from 3 to 18 inches and is derived from precipitation which averages 31 inches annualiy.

Water levels were measured in 112 wells during 1987 . Of these, 53 were selected to a statewide network of observation wells (figure 9), which is designed to provide statewide areal coverage and to define ground-water conditions in the important aquifers in the State. Water levels in the network observation wells were near average at the beginning of the water year. However, levels declined throughout most of the water year. By years end, levels were at or near record lows in all but the southcentral and southwestern part of the Lower Peninsula. In those areas, ground-water levels had returned to near normal.

Natural chemical characteristics of ground water in Michigan are determined primarily by the geologic environment through which the water flows. Natural ground water generally is suitable for human consumption and most other uses. Water from glacial deposits, at places, contains elevated concentrations of iron [2.5-5.0 mg/L (milligrams per liter)]; water from carbonate rocks is likely to be very hard (400 to $900 \mathrm{mg} / \mathrm{L}$ as calcium carbonate); and water from the Saginaw aquifer in the Saginaw Bay-Thumb area commonly is very mineralized $(2,000$ to $80,000 \mathrm{mg} / \mathrm{L}$ of dissolved solids). Throughout the State, salty water underlies freshwater at depths ranging from about $100 \mathrm{ft}$ in the eastern part of the Lower Peninsula to about $900 \mathrm{ft}$ in the northern part. Average dissolved-solids concentration of water from bedrock (535 $\mathrm{mg} / \mathrm{L}$ ) is about twice as great as the average concentration from glacial deposits (24l mg/L) (Cummings. mg L)

\section{REFERENCES CITED}

Cummings, T. R., 1980, Chemical and Physical Characteristics of Natural Ground Waters in Michigan--A Preliminary Report: U.S. Geological Survey Open-File Report 80-953, $34 \mathrm{p}$.

Geological' Survey Water-Resources Investigations Report $83-4288,57 \mathrm{p}$ 
Hydrologic Bench-Mark Network is a network of 57 sites in small drainage basins around the country whose purpose is to provide consistent data on the hydrology, including water quality, and related factors in representative undeveloped watersheds nationwide, and to provide analyses on a continuing basis to compare and contrast conditions observed in basins more obviously affected by the activities of man.

National Stream quality Accounting Network (NASQAN) is a nation-wide data-collection network designed by the U.S. Geological Survey to meet many of the information needs of government agencies and other groups involved in natural or regional water-quality planning and management. The 500 or so sites in NASQAN are generally located at the downstream ends of hydrologic accounting units designated by the U.S. Geological Survey office of Water Data Coordination in consultation with the Water Resources Council. The objectives of NASQAN are (1) to obtain information on the quality and quantity of water moving within and from the United States through a systematic and uniform process of data collection, summarization, analysis, and reporting such that the data may be used for, (2) description of the areal variability of water quality in the Nation's rivers through analysis of data from this and other programs, (3) detection of changes or trends with time in the pattern of occurrence of water-quality characteristics, and (4) providing a nationally consistent data base useful for water quality assessment and hydrologic research.

Radiochemical program is a network of regularly sampled water-quality stations where samples are collected to be analyzed for radioisotopes. The streams that are sampled represent major drainage basins in the conterminous United States.

\title{
EXPLANATION OF THE RECORDS
}

The surface-water and ground-water records published in this report are for the 1987 water year that began October 1, 1986, and ended September 30, 1987. A calendar of the water year is provided on the inside of the front cover. The records contain streamflow data, stage and content data for lakes and reservoirs, water-quality data for surface water, and ground-water level data. The locations of the stations and wells where the data were collected are shown in figures 4-9. The following sections of the introductory text are presented to provide users with a more detailed explanation of how the hydrologic data published in this report were collected, analyzed, computed, and arranged for presentation.

\section{Station Identification Numbers}

Each data station, whether streamsite or well, in this report is assigned a unique identification number. This number is unique in that it applies specifically to a given station and to no other. The number usualiy is assigned when a station is first established and is retained for that station number usually is assigned when a station is first established and is retained for that station
indefinitely. The systems used by the U.S. Geological Survey to assign identification numbers for surface-water stations and for ground-water well sites differ, but both are based on geographic location. The "downstream order" system is used for all surface-water stations except some lakes and the "latitudelongitude" system is used for wells and lakes.

\author{
Downstream order system
}

Since October 1, 1950, the order of listing hydrologic-station records in survey reports is in a downstream direction along the main stream. All stations on a tributary entering upstream from a mainstream station are listed before that station. A station on a tributary that enters between two mainstream stations is listed between them. A similar order is followed in listing stations on first rank, second rank, and other ranks of tributaries. The rank of any tributary with respect to the stream to which it is immediately tributary is indicated by an indention in the "List of stations" in the front of this report. Each indention represents one rank. This downstream order and system of indention shows which stations are on tributaries between any two stations and the rank of the tributary on which each station is situated.

The station-identification number is assigned according to downstream order. In assigning station numbers, no distinction is made between partial-record stations and other stations; therefore, the station number for a partial-record station indicates downstream-order position in a 1 ist made up of both types of stations. Gaps are left in the series of numbers to allow for new stations that may be established; hence, the numbers are not consecutive. The complete eight-digit number for each station, such as 04037500 , which appears just to the left of the station name, includes the two-digit part number "04" plus 04037500 , which appears just to the left of the station name, includes the two-digit Part number "04" plus
the six-digit downstream-order number "037500." The Part number designates the major river basin; for example, Part "04" is the St. Lawrence River basin.

\section{Latitude-Longitude System}

The identification numbers for wells are assigned according to the grid system of latitude and longitude. The number consists of 15 digits. The first six digits denote the degrees, minutes, and seconds of latitude, the next seven digits denote degrees, minutes, and seconds of longitude, and the last two digits (assigned sequentially) identify the wells or other sites within a l-second grid. This siteidentification number, once assigned, is a pure number and has no locational significance. In the rare instance where the initial determination of latitude and longitude are found to be in error, the station will retain its initial identification number; however, its true latitude and longitude will be listed in the LOCATION paragraph of the station description. (See figure 2.) 


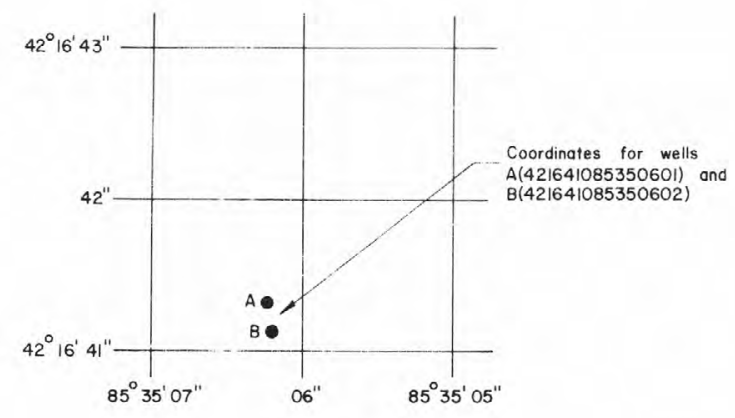

Figure 2. System for numbering wells (latitude and longitude).

Local Well Numbering System

The local well number indicates the location of wells within the rectangular subdivision of land with reference to the Michigan meridian and base line. The first two segments of the well number designate township and range, the third segment of the number designates the section and the letters $A$ through $D$ designate successively smaller subdivisions of the section as shown in figure 3 . Thus, a well designated as $32 \mathrm{~N} 6 \mathrm{E} 16 \mathrm{CCCB}$ would be located to the nearest 2.5 acres and would be within the shaded area in section as. In the event that two or more wells are located in the same 2.5 acre tract, a sequential number 16. In the event that two or more wells are located in the same 2.5 acre tract, a sequentia
designation follows the letter designations--for example, 16CCCB1, 16CCCB2, 16CCCB3, etc.

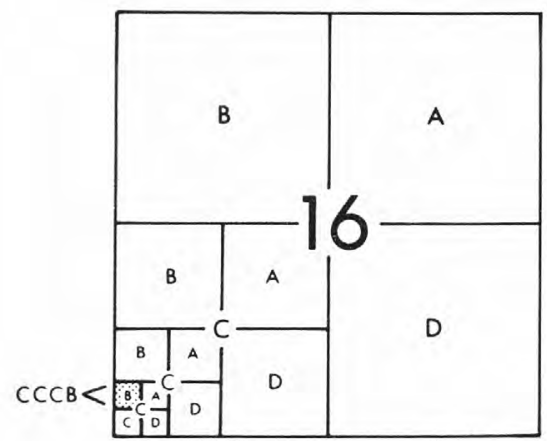

Figure 3. Local well numbering system in Michigan.

Records of Stage and water Discharge

Records of stage and water discharge may be complete or partial. Complete records of discharge are those obtained using a continuous stage-recording device through which either instantaneous or mean daily discharges may be computed for anytime, or any period of time, during the period of record. Complete records of lake or reservoir content, similarly, are those for which stage or content may be computed or estimated with reasonable accuracy for any time, or period of time. They may be obtained using a continuous stage-recording device, but need not be. Because daily mean discharges and end-of-month contents commonly are published for such stations, they are referred to as "daily stations."

By contrast, partial records are obtained through discrete measurements without using a continuous stage-recording device and pertain only to a few flow characteristics, or perhaps only one. The nature of the partial record is indicated by table titles such as "Crest-stage partial records," or "Low-flow partial records." Records of miscellaneous discharge measurements or of measurements from special studies, such as low-flow seepage studies, may be considered as partial records, but they are presented separately in this report. Location of all complete-record water-discharge stations for which data are given in this report are shown in figures 4 and 5.

Data collection and computation

The data obtained at a complete-record gaging station on a stream or canal consist of a continuous record of stage, individual measurements of discharge throughout a range of stages, and notations regarding factors that may affect the relationships between stage and discharge. These data, together with supplemental information, such as weather records, are used to compute daily discharges. The data obtained at a complete-record gaging station on a lake or reservoir consist of a record of stage and of notations regarding factors that may affect the relationship between stage and lake content. These data notations regarding factors that may affect the relationship between stage and lake content. These dat storage. 
Continuous records of stage are obtained with analog recorders that trace continuous graphs of stage or with digital recorders that punch stage values on paper tapes at selected time intervals. Measurements of discharge are made with current meters using methods adopted by the Geological survey as a result of experience accumulated since 1880. These methods are described in standard textbooks, in Water-Supply Paper 2175, and in U.S. Geological Survey Techniques of Water-Resources Investigations, Book 3, Chapter A6.

In computing discharge records, results of individual measurements are plotted against the corresponding stages, and stage-discharge relation curves are then constructed. From these curves, rating tables indicating the approximate discharge for any stage within the range of the measurements are prepared. If it is necessary to define extremes of discharge outside the range of the current-meter measurements, the curves are extended using: (1) logarithmic plotting; (2) velocity-area studies; (3) results of indirect measurements of peak discharge, such as slope-area or contracted-opening measurements, and computations of flow over dams or weirs; or (4) step-backwater techniques.

Daily mean discharges are computed by applying the daily mean stages (gage heights) to the stagedischarge curves or tables. If the stage-discharge relation is subject to change because of $\mathrm{frequent}$ or cont inual change in the physical features that form the control, the daily mean discharge is determined by the shifting-control method, in which correction factors based on the individual discharge measurements and notes of the personnel making the measurements are applied to the gage heights before the discharges are determined from the curves or tables. This shifting-control method also is used if the stagedischarge relation is changed temporarily because of aquatic growth or debris on the control. For some stations, formation of ice in the winter may so obscure the stage-discharge relations that daily mean discharges must be estimated from other information such as temperature and precipitation records, notes of observations, and records for other stations in the same or nearby basins for comparable periods.

At some stream-gaging stations, the stage-discharge relation is affected by the backwater from reservoirs, tributary streams, or other sources. This necessitates the use of the slope method in which the slope or fall in a reach of the stream is a factor in computing discharge. The slope or fall is obtained by means of an auxiliary gage set at some distance from the base gage. At some stations the stage-discharge relation is affected by changing stage; at these stations the rate of change in stage is used as a factor in computing discharge.

In computing records of lake or reservoir contents, it is necessary to have available from surveys, curves or tables defining the relationship of stage and content. The application of stage to the stagecontent curves or tables gives the contents from which daily, monthly, or yearly changes then are determined. If the stage-content relationship changes because of deposition of sediment in a lake or reservoir, periodic resurveys may be necessary to redefine the relationship. Even when this is done, the contents computed may become increasingly in error as the lapsed time since the last survey increases. Discharges over lake or reservoir spillways are computed from stage-discharge relationships much as other stream discharges are computed.

For some gaging stations, there are periods when no gage-height record is obtained, or the recorded gage height is so faulty that it cannot be used to compute daily discharge or contents. This happens when the recorder stops or otherwise fails to operate properly, intakes are plugged, the float is frozen in the well, or for various other reasons. For such periods, the daily discharges are estimated from the recorded range in stage, previous or following record, discharge measurements, weather records, and comparison with other station records from the same or nearby basins. Likewise, daily contents may be estimated from operator's logs, previous or following record, inflow-outflow studies, and other information. Information explaining how estimated daily-discharge values are identified in station records is included in the next two sections, "Data presentation" (REMARKS paragraph) and "Identifying Estimated Daily Discharge."

\section{Data Presentation}

The records published for each gaging station consist of two parts, the manuscript or station description and the data table for the current water year. The manuscript provides, under various headings, descriptive information, such as station location; period of record; average discharge; historical extremes; record accuracy; and other remarks pertinent to station operation and regulation. The following information, as appropriate, is provided with each continuous record of discharge or lake content. Comments to follow clarify information presented under the various headings of the station description.

LOCATION.--Information on locations is obtained from the most accurate maps available. The location of the gage with respect to the cultural and physical features in the vicinity and with respect to the reference place mentioned in the station name is given. River mileages, given for only a few stations, prepared by the Water Resources Council or were provided by the U.S. Army Corps of Engineers.

DRAINAGE AREA.--Drainage areas are measured using the most accurate maps available. Because the type of maps available varies from one drainage basin to another, the accuracy of drainage areas likewise varies. Drainage areas are updated as better maps become available.

PERIOD OF RECORD. - This indicates the period for which there are published records for the station or for an equivalent station. An equivalent station is one that was in operation at a time that the present station was not, and whose location was such that records from it can reasonably be considered equivalent with records from the present station.

REVISED RECORDS.--Published records, because of new information, occasionally are found to be incorrect, and revisions are printed in later reports. Listed under this heading are all the reports in which revisions have been published for the station and the water years to which the revisions apply. If a revision did not include daily, monthly, or annual figures of discharge, that fact is noted after the year dates as follows: "(M)" means that only the instantaneous maximum discharge was revised; "(m)" that only the instantaneous minimum was revised; and "(P)" that only peak discharges were revised. If the drainage area has been revised, the report in which the most recently revised figure was first published is given.

GAGE.--The type of gage in current use, the datum of the current gage referred to National Geodetio Vertical Datum of 1929 (see glossary), and a condensed history of the types, locations, and datums of previous gages are given under this heading. 
REMARKS.--All periods of estimated daily-discharge record will either be identified by date in this paragraph of the station description for water-discharge stations or flagged in the daily-discharge table. (See next section, "Identifying Estimated Daily Discharge." ) If a remarks statement is used to identify estimated record, the paragraph will begin with this information presented as the first entry. The paragraph is also used to present information relative to the accuracy of the records, to special methods of computation, to conditions that affect natural flow at the station and, possibly, to other pertinent items. For reservoir stations, information is given on the dam forming the reservoir, the capacity, outlet works and spillway, and purpose and use of the reservoir.

COOPERATION.--Records provided by a cooperating organization or obtained for the Geological Survey by a cooperating organization are identified here.

AVERAGE DISCHARGE.--The discharge value given is the arithmetic mean of the water-year mean discharges. It is computed only for stations having at least 5 water years of complete record, and only water years of complete record are included in the computation. It is not computed for stations where diversions, storage, or other water-use practices cause the value to be meaningless. If water developments significantly altering flow at a station are put into use after the station has been in operation for a period of years, a new average is computed as soon as 5 water years of record have accumulated following the development.

EXTREMES FOR PERIOD OF RECORD.--Extremes may include maximum and minimum stages and maximum and minimum discharges or content. Unless otherwise qualified, the maximum discharge or content is the instantaneous maximum corresponding to the highest stage that occurred. The highest stage may have been obtained from a graphic or digital recorder, a crest-stage gage, or by direct observation of a nonrecording gage. If the maximum stage did not occur on the same day as the maximum discharge or content, it is given separately. Similarly, the minimum is the instantaneous minimum discharge, unless otherwise qualified, and was determined and is reported in the same manner as the maximum.

EXTREMES OUTSIDE PERIOD OF RECORD.---Included here is information concerning major floods or unusually low flows that occurred outside the stated period of record. The information may or may not have been obtained by the U.S. Geological Survey.

EXTREMES FOR CURRENT YEAR.--Extremes given here are similar to those for the period of record, except the peak discharge listing may include secondary peaks. For stations meeting certain criteria, all peak discharges and stages occurring during the water year and greater than a selected base discharge are presented under this heading. The peaks greater than the base discharge, excluding the highest one, are referred to as secondary peaks. Peak discharges are not published for canals, ditches, drains, or streams for which the peaks are subject to substantial control by man. The time of occurrence for peaks is
expressed in 24-hour local standard time. For example, $12: 30 \mathrm{a} . \mathrm{m}$. is 0030 , and $1: 30 \mathrm{p.m}$. is 1330 . The minimum for the current water year appears below the table of peak data.

REVISIONS. - If a critical error in published records is discovered, a revision is included in the first report published following discovery of the error.

Although rare, occasionally the records of a discontinued gaging station may need revision. Because, for these stations, there would be no current or, possibly, future station manuscript published to document the revision in a "Revised Records" entry, users of data for these stations who obtained the record from previously published data reports may wish to contact the of $\mathrm{fices}$ whose addresses are given on the back of the title page of this report to determine if the published records were ever revised after the station was discontinued. Of course, if the data were obtained by computer retrieval, the data would be current and there would be no need to check because any published revision of data is always accompanied by revision of the corresponding data in computer storage.

Manuscript information for lake or reservoir stations differs from that for stream stations in the nature of the "Remarks" and in the inclusion of a skeleton stage-capacity table when daily contents are given.

The daily table for stream-gaging stations gives mean discharge for each day and is followed by monthly and yearly summaries. In the monthly summary below the daily table, the line headed "TOTAL" gives the sum of the daily figures. The line headed "MEAN" gives the average flow in cubic feet per second during the month. The Iines headed "MAX" and "MIN" give the maximum and minimum daily discharges. respectively, for the month. Discharge for the month also is usually expressed in cubic feet per second per square mile ( 1 ine headed "CFSM"), or in inches ( 1 ine headed "IN."), or in acre-feet ( 1 ine headed "ACFT"). Figures for cubic feet per second per square mile and runoff in inches are omitted if there is extensive regulation or diversion or if the drainage area includes large noncontributing areas. In the yearly summary below the monthly summary, the figures shown are the appropriate discharges for the calendar and water years. At some stations monthly and (or) yearly observed discharges are adjusted for reservoir storage or diversion, or diversions or reservoir contents are given. These figures are ident if ied by a symbol and corresponding footnote.

Data collected at partial-record stations follow the information for continuous-record sites. Data for partial-record discharge stations are presented in two tables. The first is a table of annual maximum stage and discharge at crest-stage partial-record stations, and the second is a table of discharge measurements at low-flow partial-record stations. The tables of partial-record stations are followed by a listing of discharge measurements made at sites other than continuous-record or partial-record stations. These measurements are generally made in times of drought or flood to give better areal coverage to those events. Those measurements and others collected for some special reason are called measurements at miscelianeous sites.

Identifying Estimated Daily Discharge

Estimated daily-discharge values published in the water-discharge tables of annual State data reports are identified either by flagging individual daily values with the letter symbol " $e$ " and printing a table footnote, "e Estimated," or by listing the dates of the estimated record in the REMARKS paragraph of the station description.

\section{Accuracy of the Records}

The accuracy of streamflow records depends primarily on: (1) The stability of the stage-discharge relation or, if the control is unstable, the frequency of discharge measurements; and (2) the accuracy of measurements of stage, measurements of discharge, and interpretation of records. 
The accuracy attributed to the records is indicated under "REMARKS." "Excellent" means that about 95 percent of the daily discharges are within 5 percent of their true values; "good, "within 10 percent; and "Eair," within 15 percent. Records that do not meet the criteria mentioned are rated "poor." Different accuracies may be attributed to different parts of a given record.

Daily mean discharges in this report are given to the nearest hundredth of a cubic foot per second for values less than $1 \mathrm{ft}^{3} / \mathrm{s}$; to the nearest tenth between 1.0 and $10 \mathrm{ft}^{3} / \mathrm{s}$; to whole numbers between 10 and $1,000 \mathrm{ft}^{3} / \mathrm{s}$; and to 3 significant figures for more than $1,000 \mathrm{ft}^{3} / \mathrm{s}$. The number of significant figures used is based solely on the magnitude of the discharge value.

Discharge at many stations, as indicated by the monthly mean, may not reflect natural runoff due to the effects of diversion, consumption, regulation by storage, increase or decrease in evaporation due to artificial causes, or to other factors. For such stations, figures of cubic feet per second per square mile and of runoff, in inches, are not published unless satisfactory adjustments can be made for diversions, for changes in contents of reservoirs, or for other changes incident to use and control.

Evaporation from a reservoir is not included in the adjustments for changes in reservoir contents, unless it is so stated. Even at those stations where adjustments are made, large errors in computed runoff may occur if adjustments or losses are large in comparison with the observed discharge.

\section{Other Records Available}

Information used in the preparation of the records in this publication, such as dischargemeasurement notes, gage-height records, temperature measurements, and rating tables are on $f i l e$ in the measurement notes, gage-height records, temperature measurements, and rating tables are on $f$ ile in the
Michigan District office. Also, most of the daily mean discharges are in computer-readable form and have been analyzed statistically. Information on the availability of the unpublished information or on the results of statistical analyses of the published records may be obtained from the Michigan District office.

\section{Records of Surface-Water Quality} Records of surface-water quality ordinarily are obtained at or near stream-gaging stations because
interpretation of records of surface-water quality nearly always requires corresponding discharge data. Records of surface-water quality in this report may involve a variety of types of data and measurement frequencies.

\section{Classification of Records}

Water-quality data for surface-water sites are grouped into one of three classifications. A continuing-record station is a site where data are collected on a regularly scheduled basis. Frequency may be once or more times daily, weekly, monthly, or quarterly. A partial-record station is a site where limited water-quality data are collected systematically over a period of years. Frequency of sampling is usually less than quarterly. A miscellaneous sampling site is a location other than a continuing or partial-record station where random samples are collected to give better areal coverage to define waterquality conditions in the river basin.

A careful distinction needs to be made between "continuing records", as used in this report, and "continuous recordings," which refers to a continuous graph or a series of' discrete values punched"at short intervals on a paper tape. Some records of water quality, such as temperature and specific conductance, may be obtained through continuous recordings; however, because of costs, most data are obtained oniy monthly or less frequently. Locations of stations for which records on the quality of surface water appear in this report are shown in figures 6-7.

\section{Arrangement of Records}

Water-quality records collected at a surface-water daily record station are published immediately following that record, regardless of the frequency of sample collection. Station number and name are the same for both records. Where a surface-water daily record station is not available or where the water quality differs significantly from that at the nearby surface-water station, the continuing water-quality record is published with its own station number and name in the regular downstream-order sequence. Waterquality data for miscellaneous sampling sites appear in a separate table following the table of discharge measurements at miscellaneous sites.

\section{On-site Measurements and Sample collection}

In obtaining water-quality data, a major concern needs to be assuring that the data obtained represent the in situ quality of the water. To assure this, certain measurements, such as water temperature, $\mathrm{pH}$, and dissolved oxygen, need to be made on site when the samples are taken. To assure that measurements made in the laboratory also represent the in situ water, carefully prescribed procedures need to be followed in collecting the samples, in treating the samples to prevent changes in quality pending analysis, and in shipping the samples to the laboratory. Procedures for on site measurements and for collecting, treating, and shipping samples are given in pubiications on "Techniques of Water-Resources Investigations," "Book 1,' Chap. D2; Book 3, Chap. C2; Book 5 , Chap. A1, A3, and A4. All of these references are 1 isted under "PUBLICATIONS ON TECHNIQUES OF WATER-RESOURCES INVESTIGATIONS" which appears at the end of the introductory text. Also, detailed information on collecting, treating, and shipping samples may be obtained from the Geological Survey Michigan District office.

One sample can define adequately the water quality at a given time if the mixture of solutes throughout the stream cross section is homogeneous. However, the concentration of solutes at different locations in the cross section may vary widely with different rates of water discharge, depending on the source of material and the turbulence and mixing of the stream. Some streams must be sampled through several vertical sections to obtain a representative sample needed for an accurate mean concentration and for use in calculating load. Many samples obtained for the National Stream Quality Accounting Network (see definitions) are obtained from at least several verticals. Whether samples are obtained from the centroid of flow or from several verticals depends on flow conditions and other factors which must be evaluated by the collector.

Chemical-quality data published in this report are considered to be the most representative values available for the stations 1 isted. The values reported represent water-quality conditions at the time of sampling as much as possible, consistent with available sampling techniques and methods of analysis. 
For chemical-quality stations equipped with digital monitors, the records consist of daily maximum, minimum, and mean values for each constituent measured and are based upon hourly punches beginning at oló hours and ending at 2400 hours for the day of record. More detailed records (hourly values) may be obtained from the Geological Survey Michigan District office whose address is given on the back of the title page of this report.

Water Temperature

Water temperatures are measured at all the water-quality stations. In addition, water temperatures are taken at time of discharge measurements for water-discharge stations. Large streams have a small diurnal temperature change; shallow streams may have a daily range of several degrees and may follow closely the changes in air temperature. Some streams may be affected by waste-heat discharges.

At stations where recording instruments are used, either mean temperatures and/or maximum and minimum temperatures for each day are published. Water temperatures measured at the time of waterdischarge measurements are on file in the Michigan District office.

\section{Sediment}

Suspended-sediment concentrations are determined from samples collected by using depth-integrating samplers. Samples usually are obtained at several verticals in the cross section.

At some stations, suspended-sediment samples were collected periodically at many verticals in the stream cross section. Although data collected periodically may represent conditions only at the time of observations, such data are useful in establishing seasonal relations between quality and streamflow and in predicting long-term sediment-discharge characteristics of the stream.

\section{Laboratory Measurements}

Sediment samples were analyzed in the Geological Survey laboratory in Harrisburg, Pennsylvania. All other samples were analyzed in the Geological Survey laboratories in Arvada, Colorado. Methods used in analyzing sediment samples and computing sediment records are given in TWRI, Book 5, Chap. Cl. Methods used by the Geological Survey laboratories are given in TWRI, Book 1, Chap. D2; Book 3, Chap. C2; Book 5, Chap. A1, A3, and A4.

Data Presentation

For continuing-record stations, information pertinent to the history of station operation is provided in descriptive headings preceding the tabular data. These descriptive headings give details regarding location, drainage area, period of record, type of data available, instrumentation, general remarks, cooperation, and extremes for parameters currently measured daily. Tables of chemical, physical, biological, radiochemical data, and so forth, obtained at a frequency less than daily are presented first. Tables of "daily values" of specific conductance and water temperature then follow in sequence.

In the descriptive headings, if the location is identical to that of the discharge gaging station, neither the LOCATION nor the DRAINAGE AREA statements are repeated. The following information, as appropriate, is provided with each continuous-record station. Comments that follow clarify information presented under the various headings of the station description.

LOCATION.--See Data Presentation under "Records of stage and Water Discharge;" same comments apply. apply.

DRAINAGE AREA.--See Data Presentation under "Records of stage and water Discharge;" same comments

PERIOD OF RECORD.--This indicates the periods for which there are published water-quality records for the station. The periods are shown separately for records of parameters measured daily or continuously and those measured less than daily. For those measured daily or continuously, periods of record are given for the parameters individualiy.

INSTRUMENTATION.--Information is given only if a water-quality monitor or temperature recorder is or was in operation at a station.

REMARKS.--Remarks provide added information pertinent to the collection, analysis, or computation of the records.

COOPERATION.--Records provided by a cooperating organization or obtained for the Geological Survey by a cooperating organization are identified here.

EXTREMES.--Maximums and minimums are given only for parameters measured daily or more frequently. None are given for parameters measured weekly or less frequently, because the true maximums or minimums may not have been sampled. Extremes, when given, are provided for both the period of record and for the current water year.

REVISIONS.--If errors in published water-quality records are discovered after publication, appropriate updates are made to the Water-Quality File in the U.S. Geological Survey's computerized data system, WATSTORE, and subsequently by monthly transfer of update transactions to the U.S. Environmental Protection Agency's STORET system. Because the usual volume of updates makes it impractical to document individual changes in the State data-report series or elsewhere, potential users of U.S. Geological Survey water-quality data are encouraged to obtain all required data from the appropriate computer file to insure the most recent updates.

The surface-water quality records for miscellaneous sampling sites are published in a separate table following the table of discharge measurements at miscellaneous sites. No descriptive statements are given for these records. Each station is published with its own station number and name in the regular downstream-order sequence. 
Remark Codes

The following remark codes may appear with the water-quality data in this report:

\begin{tabular}{|c|c|}
\hline PRINTED OUTPUT & REMARK \\
\hline $\mathrm{E}$ & Estimated value \\
\hline$>$ & $\begin{array}{l}\text { Actual value is known to be greater than } \\
\text { the value shown }\end{array}$ \\
\hline$<$ & $\begin{array}{l}\text { Actual value is known to be less than the } \\
\text { value shown }\end{array}$ \\
\hline K & $\begin{array}{l}\text { Results based on colony count outside the } \\
\text { acceptance range (non-ideal colony count) }\end{array}$ \\
\hline$L$ & $\begin{array}{l}\text { Biological organism count less than } 0.5 \\
\text { percent (organism may be observed) rather than } \\
\text { counted }\end{array}$ \\
\hline $\mathrm{D}$ & $\begin{array}{l}\text { Biological organism count equal to or } \\
\text { greater than } 15 \text { percent (dominant) }\end{array}$ \\
\hline$d$ & Biological organism estimated as dominant \\
\hline
\end{tabular}

\section{Records of Ground-water Levels}

Only water-level data from a national network of observation wells are given in this report. These data are intended to provide a sampling and historical record of water-level changes in the Nation's most important aquifers. Locations of the observation wells in this network in Michigan are shown in figure 9 .

Data Collection and Computation

Measurements of water levels are made in many types of wells under varying conditions, but the methods of measurement are standardized to the extent possible. The equipment and measuring techniques used at each observation well ensure that measurements at each well are of consistent accuracy and reliability.

Tables of water-level data are presented by counties arranged in alphabetical order. The prime identification number for a given well is the 15 -digit number that appears in the upper ieft corner of the table. The secondary identification number is the local well number, an alphanumeric number, derived from the township-range location of the well.

Water-level records are obtained from direct measurements with a steel tape or from the graph or punched tape of a water-stage recorder. The water-level measurements in this report are given in feet with reference to land-surface datum (isd). Land-surface datum is a datum plane that is approximately at land surface at each well. If known, the elevation of the land-surface datum is given in the well description. The height of the measuring point (MP) above or below land-surface datum is given in each well description. Water levels in wells equipped with recording gages are reported for every fifth day and the end of each month (eom).

Water levels are reported to as many significant figures as can be justified by the local conditions. For example, in a measurement of a depth to water of several hundred feet, the error of determining the absolute value of the total depth to water may be a few tenths of a foot, whereas the error in determining the net change of water level between successive measurements may be only a hundredth or a few hundredths of a foot. For lesser depths to water, the accuracy is greater. Accordingly, most measurements are reported to a hundredth of a foot, but some are given to a tenth of a foot or a larger unit.

\section{Data Presentation}

Each well record consists of two parts, the station description and the data table of water levels observed during the water year. The description of the well is presented first through use of descriptive headings preceding the tabular data. The comments to follow clarify information presented under the various headings.

LOCATION, - This paragraph follows the well-identification number and reports the latitude and longitude (given in degrees, minutes, and seconds); the hydrologic-unit number; the distance and direction from a geographic point of reference; and the owner's name. the well.

AQUIFER. - This entry designates by name (if a name exists) and geologic age the aquifer(s) open to

WELL CHARACTERISTICS.--This entry describes the well in terms of depth, diameter, casing depth and/or screened interval, method of construction, use, and additional information such as casing breaks, collapsed screen, and other changes since construction.

INSTRUMENTATION.--This paragraph provides information on both the frequency of measurement and the collection method used, allowing the user to better evaluate the reported water-level extremes by knowing whether they are based on weekly, monthly, or some other frequency of measurement.

DATUM.--This entry describes both the measuring point and the land-surface elevation at the well. The measuring point is described physically (such as top of collar, notch in top of casing, plug in pump base and so on), and in relation to land surface (such as $1.3 \mathrm{ft}$ above land-surface datum). The elevation of the land-surface datum is described in feet above (or below) National Geodetic Vertical Datum of 1929 (NGVD of 1929); it is reported with a precision depending on the method of determination. 
REMARKS. - This entry describes factors that may influence the water level in a well or the measurement of the water level. It should identify wells that also are water-quality observation wells, and may be used to acknowledge the assistance of local (non-Survey) observers.

PERIOD OF RECORD. - This entry indicates the period for which there are published records for the wel1. It reports the month and year of the start of publication of water-level records by the U.S. Geological survey and the words "to current year" if the records are to be continued into the following year. Periods for which water-level records are available, but are not published by the Geological Survey, may be noted.

EXTREMES FOR PERIOD OF RECORD. - This entry contains the highest and lowest water levels of the period of published record, with respect to land-surface datum, and the dates of their occurrence.

A table of water levels follows the station description for each well. Water levels are reported in feet below land-surface datum and all taped measurements of water level are 1 isted. For wells equipped with recorders, only abbreviated tables are published; generally, only water-level lows are listed for with recorders, only abbreviated tables are published; generally, only water-level lows are listed for and their dates of occurrence are shown on a line below the abbreviated table. Because all values are not published for wells with recorders, the extremes may be values that are not listed in the table. Missing records are indicated by dashes in place of the water level.

\section{ACCESS TO WATSTORE DATA}

The National WATer Data STOrage and REtrieval system (WATSTORE) was established for handling water data collected through the activities of the U.S. Geological Survey and to provide for more effective and efficient means of releasing the data to the pubilic. The system is operated and maintained on the central computer facilities of the Survey at its National Center in Reston, virginia.

WATSTORE can provide a variety of useful products ranging from simple data tables to complex statistical analyses. A minimal fee, plus the actual computer cost incurred in producing a desired product, is charged to the requester. Information about the availability of specific types of data, the acquisition of data or products, and user charges can be obtained locally from the Michigan District acquisitice.

General inquiries about WATSTORE may be directed to:

Chief Hydrologist
U.S. Geological Survey
409 National Center
12201 Sunrise Valley Drive
Reston, Virginia 22092

\section{DEFINITION OF TERMS}

Terms related to streamflow, water-quality, and other hydrologic data, as used in this report, are defined below. See also table for converting English units to International System (SI) Units on the inside of the back cover.

Acre-foot (AC-FT, acre-ft) is the quantity of water required to cover 1 acre to a depth of 1 foot and is equivalent to 43,560 cubic feet or about 326,000 gallons or 1,233 cubic meters.

Adenosine triphosphate (ATP) is an organic, phosphate-rich, compound important in the transfer of energy in organisms. Its central role in living cells makes it an excellent indicator of the presence of living material in water. A measure of ATP therefore provides a sensitive and rapid estimate of biomass. ATP is reported in micrograms per liter of the original water sample.

Algae are mostly aquatic single-celled, colonial, or multi-celled plants, containing chlorophyll and lacking roots, stems, and leaves.

Algal growth potential (AGP) is the maximum algal dry weight biomass that can be produced in a natural water sample under standardized laboratory conditions. The growth potential is the algal biomass present at stationary phase and is expressed as miliigrams dry weight of algae produced per liter of sample.

Aquifer is a geologic formation, group of formations, or part of a formation that contains sufficient saturated permeable material to yield significant quantities of water to wells and springs.

Artesian means confined and is used to describe a well in which the water level stands above the top of the aquifer tapped by the well. A flowing artesian well is one in which the water level is above the land surface.

Bacteria are microscopic unicellular organisms, typically spherical, rodlike, or spiral and threadilke in shape, often clumped into colonies. Some bacteria cause disease, while others perform an essential role in nature in the recycling of materials; for example, by decomposing organic matter into a form available for reuse by plants.

Total coliform bacteria are a particular group of bacteria that are used as indicators of possible sewage pollution. They are characterized as aerobic or facultative anaerobic, gramnegative, nonspore-forming, rod-shaped bacteria which ferment lactose with gas formation within 48 hours at $35^{\circ} \mathrm{C}$. In the laboratory these bacteria are defined as all the organisms that produce colonies with a golden-green metallic sheen within 24 hours when incubated at $35^{\circ} \mathrm{C}$ plus or minus $1.0^{\circ} \mathrm{C}$ on $M-E n d o$ medium (nutrient medium for bacterial growth). Their concentrations are expressed as number of colonies per $100 \mathrm{~mL}$ of sample.

Fecal coliform bacteria are bacteria that are present in the intestine or feces of warmblooded animals. They are often used as indicators of the sanitary quality of the water. In the laboratory they are defined as all organisms that produce blue colonies within 24 hours when incubated at $44.5^{\circ} \mathrm{C}$ plus or minus $0.2^{\circ} \mathrm{C}$ on M-FC medium (nutrient medium for bacterial growth). Their concentrations are expressed as number of colonies per $100 \mathrm{~mL}$ of sample. 
Fecal streptococcal bacteria are bacteria found also in the intestine of warm-blooded animals. The ir presence in water is considered to verify fecal pollution. They are characterized as Grampositive, cocci bacteria which are capable of growth in brain-heart infusion broth. In the laboratory they are defined as all the organisms which produce red or pink colonies within 48 hours at $35^{\circ} \mathrm{C}$ plus or minus $1.0^{\circ} \mathrm{C}$ on $\mathrm{KF}-\mathrm{streptococcus} \mathrm{medium} \mathrm{(nutrient} \mathrm{medium} \mathrm{for} \mathrm{bacterial} \mathrm{growth).}$ Their concentrations are expressed as number of colonies per $100 \mathrm{~mL}$ of sample.

Bed material is the sediment mixture of which a streambed, lake, pond, reservoir, or estuary bottom is composed.

Biochemical oxygen demand (BOD) is a measure of the quantity of dissolved oxygen, in milligrams per liter, necessary for the decomposition of organic matter by micro-organisms, such as bacteria.

Biomass is the amount of living matter present at any given time, expressed as the mass per unit area or volume of habitat.

Ash mass is the mass or amount of residue present after the residue from the dry mass determination has been ashed in a muffle furnace at a temperature of $500^{\circ} \mathrm{C}$ for 1 hour. The ash mass values of zooplankton and phytoplankton are expressed in grams per cubic meter ( $\mathrm{g} / \mathrm{m}^{3}$ ), and periphyton and benthic organisms in grams per square meter $\left(\mathrm{g} / \mathrm{m}^{2}\right)$.

Dry mass refers to the mass of residue present after drying in an oven at $105^{\circ} \mathrm{C}$ for zooplankton and periphyton, until the mass remains unchanged. This mass represents the total organic matter, ash and sediment, in the sample. Dry-mass values are expressed in the same units as ash mass.

Organic mass or volatile mass of the living substance is the difference between the dry mass and ash mass and represents the actual mass of the living matter. The organic mass is expressed in the same units as for ash mass and dry mass.

Wet mass is the mass of living matter plus contained water.

Bottom material: See Bed material.

Cells/volume refers to the number of cells of any organism which is counted by using a microscope and grid or counting cell. Many planktonic organisms are multicelled and are counted according to the number of contained cells per sample, usually mililiters (mL) or liters (L).

Chemical oxygen demand (COD) is a measure of the chemically oxidizable material in the water and furnishes an approximation of the amount of organic and reducing material present. The determined value may correlate with natural water color or with carbonaceous organic pollution from sewage or industrial wastes.

Chlorophyll refers to the green pigments of plants. Chlorophyll a and $\underline{b}$ are the two most common green pigments in plants.

Color unit is produced by one milligram per liter of platinum in the form of the chloroplatinate ion. color is expressed in units of the platinum-cobalt scale.

Contents is the volume of water in a reservoir or lake. Unless otherwise indicated, volume is computed on the basis of a level pool and does not include bank storage.

Control designates a feature downstream from the gage that determines the stage-discharge relation at the gage. This feature may be a natural constriction of the channel, an artificial structure, or a uniform cross section over a long reach of the channel.

Control structure as used in this report is a structure on a stream or canal that is used to regulate the flow or stage of the stream or to prevent the intrusion of salt water.

Cubic feet per second per square mile (CFSM) is the average number of cubic feet of water flowing per second from each square mile of area drained, assuming that the runoff is distributed uniformly in time and area.

Cubic foot per second $\left(\mathrm{ft}^{3} / \mathrm{s}\right)$ is the rate of discharge representing a volume of 1 cubic foot passing a given point during 1 second and is equivalent to 7.48 gallons per second or 448.8 gallons per minute or 0.02832 cubic meters per second.

Cubic foot per second-day $\left[\left(\mathrm{ft}^{3} / \mathrm{s}\right) / \mathrm{d}\right]$ is the volume of water represented by a flow of 1 cubic foot per second for 24 hours. It is equivalent to 86,400 cubic feet, approximately 1.9835 acre-feet, about 646,000 gallons, or 2,445 cubic meters.

Discharge is the volume of water (or more broadly, volume of fluid plus suspended sediment) that passes a given point within a given period of time.

Mean discharge (MEAN) is the arithmetic mean of individual daily mean discharges during a specific period.

Instantaneous discharge is the discharge at a particular instant of time.

Dissolved refers to that material in a representative water sample which passes through a 0.45 um membrane filter. This is a convenient operational definition used by Federal agencies that collect water data. Determinations of "dissolved" constituents are made on subsamples of the filtrate.

Dissolved-solids concentration of water is determined either analytically by the "residue-onevaporation" method, or mathematically by totaling the concentrations of individual constituents reported in a comprehensive chemical analysis. During the analytical determination of dissolved solids, the bicarbonate (generally a major dissolved component of water) is converted to carbonate. Therefore, in the mathematical calculation of dissolved-solids concentration, the bicarbonate value, in milligrams per liter, is multiplied by 0.492 to reflect the change. 
Drainage area of a stream at a specified location is that area, measured in a horizontal plane, enclosed by a topographic divide from which direct surface runoff from precipitation normally drains by gravity into the stream above the specified point. Figures of drainage area given herein include all closed basins, or noncontributing areas, within the area unless otherwise specified.

Drainage basin is a part of the surface of the earth that is occupied by a drainage system, which consists of a surface stream or a body of impounded surface water together with all tributary surface streams and bodies of impounded surface water.

Gage height (G.H.) is the water-surface elevation referred to some arbitrary gage datum. Gage height is of ten used interchangeably with the more general term "stage," although gage height is more appropriate when used with a reading on a gage.

Gaging station is a particular site on a stream, canal, lake, or reservoir where systematic observations of hydrologic data are obtained.

Hardness of water is a physical-chemical characteristic that is commonly recognized by the increased quantity of soap required to produce lather. It is computed as the sum of equivalents of polyvalent cations and is expressed as the equivalent concentration of calcium carbonate (CaCO3).

Hydrologic Bench-Mark Network is a network of 57 sites in small drainage basins around the country whose purpose is to provide consistent data on the hydrology, including water quality, and related factors in representative undeveloped watersheds nationwide, and to provide analyses on a continuing basis to compare and contrast conditions observed in basins more obviously affected by the activities of man.

Hydrologic unit is a geographic area representing part or all of a surface drainage basin or distinct hydrologic feature as delineated by the office of Water Data Coordination on the State Hydrologic Unit Maps; each hydrologic unit is identified by an eight-digit number.

Land-surface datum (1sd) is a datum plane that is approximately at land surface at each ground-water observation well.

Measuring point (MP) is an arbitrary permanent reference point from which the distance to the water surface in a well is measured to obtain the water level.

Metamorphic stage refers to the stage of development that an organism exhibits during its transformation from an immature form to an adult form. This developmental process exists for most insects, and the degree of difference from the immature stage to the adult form varies from relatively slight to pronounced, with many intermediates. Examples of metamorphic stages of insects, are egg-larvaadult or egg-nymph-adult.

Methylene blue active substances (MBAS) are apparent detergents. The determination depends on the formation of a blue color when methylene blue dye reacts with synthetic anionic detergent compounds.

Micrograms per gram $(u g / g)$ is a unit expressing the concentration of a chemical constituent as the mass (micrograms) of the element per unit mass (gram) of material analyzed.

Micrograms per liter (UG/L, Ug/L) is a unit expressing the concentration of chemical constituents in solution as mass (micrograms) of solute per unit volume (liter) of water. One thousand micrograms per liter is equivalent to one milligram per liter.

Milligrams per liter (MG/L, $\mathrm{mg} / \mathrm{L}$ ) is a unit for expressing the concentration of chemical constituents in solution. Milligrams per liter represents the mass of solute per unit volume (liter) of water. Concentration of suspended sediment also is expressed in $\mathrm{mg} / \mathrm{L}$ and is based on the mass of dry sediment per liter of water-sediment mixture.

National Geodetic Vertical Datum of 1929 (NGVD of 1929) is a geodetic datum derived from a general adjustment of the first order level nets of both the United States and Canada. It was formerly called "Sea Level Datum of 1929 " or "mean sea level" in this series of reports. Although the datum was derived from the average sea level over a period of many years at 26 tide stations along the Atlantic, Gulf of Mexico, and Pacific Coasts, it does not necessarily represent local mean sea level at any particular place.

National Stream Quality Accounting Network (NASQAN) is a nationwide data-collection network designed by the U.S. Geological Survey to meet many of the information needs of government agencies and other groups involved in natural or regional water-quality planning and management. The 500 or so sites in NASQAN are generally located at the downstream ends of hydrologic accounting units designated by the U.S. Geological Survey office of Water Data Coordination in consultation with the Water Resources Council. The objectives of NASQAN are (1) to obtain information on the quality and quantity of water moving within and from the United States through a systematic and uniform process of data collection, summarization, analysis, and reporting such that the data may be used for, (2) description of the areal variability of water quality in the Nation's rivers through analysis of data from this and other programs, (3) detection water quality in the Nation's rivers through analysis of data from this and other programs, (3) detectio
of changes or trends with time in the pattern of occurrence of water-quality characteristics, and (4) providing a nationally consistent data base useful for water-quality assessment and hydrologic research.

organism is any living entity.

Organism count/area refers to the number of organisms collected and enumerated in a sample and adjusted to the number per area habitat, usually square meter $\left(\mathrm{m}^{2}\right)$, acre, or hectare. Periphyton, benthic organisms, and macrophytes are expressed in these terms.

Organism count/volume refers to the number of organisms collected and enumerated in a sample and adjusted to the number per sample volume, usually milliliter (mL) or liter (L). Numbers of planktonic organisms can be expressed in these terms.

Total organism count is the total number of organisms collected and enumerated in any particular sample. 
Parameter code is a 5-digit number used in the U.S. Geological Survey computerized data system, WATSTORE, to uniquely identify a specific constituent. The codes used in WATSTORE are the same as those used in the U.S. Environmental protection Agency data system, STORET. The Environmental Protection Agency assigns and approves all requests for new codes.

Partial-record station is a particular site where limited streamflow and/or water-quality data are collected systematically over a period of years for use in hydrologic analyses.

Particle size is the diameter, in millimeters (mm), of a particle determined by either sieve or sedimentation methods. Sedimentation methods (pipet, bottom-withdrawal tube, visual-accumulation tube) determine fall diameter of particles in either distilled water (chemically dispersed) or in native water (the river water at the time and point of sampling).

Particle-size classification used in this report agrees with the recommendation made by the American Geophysical Union Subcommittee on Sediment Terminology. The classification is as follows:

\begin{tabular}{|c|c|c|}
\hline classification & Size & $(\mathrm{mm})$ \\
\hline 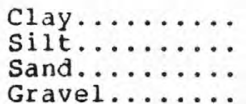 & $\begin{array}{l}0.00024 \\
.004 \\
.062 \\
2.0\end{array}$ & $\begin{array}{l}-\quad 0.004 \\
-\quad .062 \\
-\quad 2.0 \\
-\quad 64.0\end{array}$ \\
\hline
\end{tabular}

Method of analysis

Sedimentation
Sedimentation
Sedimentation or sieve
Sieve

The particle-size distributions given in this report are not necessarily representative of all particles in transport in the stream. Most of the organic matter is removed, and the sample is subjected to mechanical and chemical dispersion before analysis in distilled water. Chemical dispersion is not used for native-water analysis.

Percent composition is a unit for expressing the ratio of a particular part of a sample or population to the total sample or population, in terms of types, numbers, mass, or volume.

Periphyton is the assemblage of microorganisms attached to and living upon submerged solid surfaces. While primarily consisting of algae, they also include bacteria, fungi, protozoa, rotifers, and other small organisms.

Pesticides are chemical compounds used to control undesirable organisms. Major categories of pesticides include insecticides, miticides, fungicides, herbicides, and rodenticides.

picocurie (PC, pci) is one trillionth $\left(1 \times 10^{-12}\right)$ of the amount of radioactivity represented by a curie ( $\mathrm{Ci}$ ). A curie is the amount of radioactivity that yields $3.7 \times 10^{10}$ radioactive disintegrations per second. A picocurie yields $2.22 \mathrm{dpm}$ (disintegrations per minute).

Plankton is the community of suspended, floating, or weakly swimming organisms that live in the open water of lakes and rivers.

Phytoplankton is the plant part of the plankton. They are usually microscopic and their movement is subject to the water currents. Phytoplankton growth is dependent upon solar radiation and nutrient substances. Because they are able to incorporate as well as release materials to the surrounding water, the phytoplankton have a profound effect upon the quality of the water. They are the primary food producers in the aquatic environment and are commonly known as algae.

Blue-green algae are a group of phytoplankton organisms having a blue pigment, in addition to the green pigment called chlorophyll. Blue-green algae often cause nuisance conditions in water.

Diatoms are the unicellular or colonial algae having a siliceous shell. Their concentrations are expressed as number of cells per milliliter (cells/mL) of sample.

Green algae have chlorophyll pigments similar in color to those of higher green plants. Some forms produce algae mats or floating "moss" in lakes. Their concentrations are expressed as number of cells per milliliter (cells $/ \mathrm{mL}$ ) of sample.

Zooplankton is the animal part of the plankton. Zooplankton are capable of extensive movements within the water column and are often large enough to be seen with the unaided eye. Zooplankton are secondary consumers feeding upon bacteria, phytoplankton, and detritus. Because they are the grazers in the aquatic environment, the zooplankton are a vital part of the aquatic food web. The zooplankton community is dominated by small crustaceans and rotifers.

Polychlorinated biphenyls (PCBs) are industrial chemicals that are mixtures of chlorinated biphenyl compounds having various percentages of chlorine. They are similar in structure to organochlorine insecticides.

Primary productivity is a measure of the rate at which new organic matter is formed and accumulated through photosynthetic and chemosynthetic activity of producer organisms (chiefly, green plants). The rate of primary production is estimated by measuring the amount of oxygen released (oxygen method) or the amount of carbon assimilated by the plants (carbon method).

Milligrams of carbon per area or volume per unit time $\left[\mathrm{mg} \mathrm{c} /\left(\mathrm{m}^{2}\right.\right.$.time)] for periphyton and macrophytes and $\left[\mathrm{mg} \mathrm{c} /\left(\mathrm{m}^{3}\right.\right.$.time $\left.)\right]$ for phytoplankton are units for expressing primary productivity. They define the amount of carbon dioxide consumed as measured by radioactive carbon (carbon 14 ). The carbon 14 method is of greater sensitivity than the oxygen light and dark bottle method and is preferred for use in unenriched waters. Unit time may be either the hour or day, depending on the incubation period. 
Milligrams of oxygen per area or volume per unit time $\left[\mathrm{mgO}_{2} /\left(\mathrm{m}^{2}\right.\right.$.time $)$ for periphyton and macrophytes and $\left[\mathrm{mgO}_{2} /\left(\mathrm{m}^{3}\right.\right.$. time) for phytoplankton are the units for expressing primary productivity. They define production and respiration rates as estimated from changes in the measured dissolvedoxygen concentration. The oxygen light and dark bottle method is preferred if the rate of primary production is sufficient for accurate measurements to be made within 24 hours. Unit time may be either the hour or day, depending on the incubation period.

Radiochemical program is a network of regularly sampled water-quality stations where samples are collected to be analyzed for radioisotopes. The streams that are sampled represent major drainage basins in the conterminous United States.

Recoverable from bottom material is the amount of a given constituent that is in solution after a representative sample of bottom material has been digested by a method (usually using an acid or mixture of acids) that results in dissolution of readily soluble substances. complete dissolution of all bottom material is not achieved by the digestion treatment and thus the determination represents less than the total amount (that is, less than 95 percent) of the constituent in the sample. To achieve comparability of analytical data, equivalent digestion procedures would be required of all iaboratories performing such analyses because different digestion procedures are likely to produce different analytical results.

Return period is the average time interval between occurrences of a hydrological event of a given or greater magnitude, usually expressed in years. May also be called recurrence interval.

Runoff in inches (IN., in.) shows the depth to which the drainage area would be covered if all the runoff for a given time period were uniformly distributed on it.

Sediment is solid material that originates mostly from disintegrated rocks and is transported by, suspended in, or deposited from water; it includes chemical and biochemical precipitates and decomposed organic material, such as humus. The quantity, characteristics, and cause of the occurrence of sediment in streams are influenced by environmental factors. Some major factors are degree of slope, length of slope, soil characteristics, land usage, and quantity and intensity of precipitation.

Bed load is the sediment that is transported in a stream by rolling, sliding, or skipping along the bed and very close to it. In this report, bed load is considered to consist of particles in transit within $0.25 \mathrm{ft}$ of the streambed.

Bed load discharge (tons per day) is the quantity of bed load measured by dry weight that moves past a section as bed load in a given time.

Suspended sediment is the sediment that at any given time is maintained in suspension by the upward components of turbulent currents or that exists in suspension as a colloid.

Suspended-sediment concentration is the velocity-weighted concentration of suspended sediment in the sampled zone (from the water surface to a point approximately 0.3 ft above the bed) expressed as milligrams of dry sediment per liter of water-sediment mixture (mg/L).

Mean concentration is the time-weighted concentration of suspended sediment passing a stream section during a 24 -hour day.

Suspended-sediment discharge (tons/day) is the rate at which dry mass of sediment passes a section of a stream or is the quantity of sediment, as measured by dry mass or volume, that passes a section in a given time. It is calculated in units of tons per day as follows: concentration (mg/L) $x$ discharge ( $\left.\mathrm{ft}^{3} / \mathrm{s}\right) \times 0.0027$.

Suspended-sediment load is a general term that refers to material in suspension. It is not synonymous with either discharge or concentration.

Total-sediment discharge (tons/day) is the sum of the suspended-sediment discharge and the bedload discharge. It is the total quantity of sediment, as measured by dry mass or volume, that passes a section during a given time.

Total-sediment load or total load is a term which refers to the total sediment (bed load plus suspended-sediment load) that is in transport. It is not synonymous with total-sediment discharge.

7-day 10-year low flow $(7 \circ 10)$ is the discharge at the 10-year recurrence interval taken from a frequency curve of annual values of the lowest mean discharge for 7 consecutive days (the 7 -day low flow).

Sodium-adsorption-ratio (SAR) is the expression of relative activity of sodium ions in exchange reactions within soil and is an index of sodium or alkali hazard to the soil. Waters range in respect to sodium hazard from those which can be used for irrigation on almost all soils to those which are generally unsatisfactory for irrigation.

Solute is any substance that is dissolved in water.

Specific conductance is a measure of the ability of a water to conduct an electrical current. It is expressed in microsiemens per centimeter at $25^{\circ} \mathrm{C}$. Specific conductance is related to the type and concentration of ions in solution and can be used for approximating the dissolved-solids content of the water. Commonly, the concentration of dissolved solids (in milligrams per 1 iter) is about 65 percent of the specific conductance (in microsiemens). This relation is not constant from stream to stream, and it may vary in the same source with changes in the composition of the water.

Stage-discharge relation is the relation between gage height (stage) and volume of water, per unit of time, flowing in a channel.

Streamflow is the discharge that occurs in a natural channel. Although the term "discharge" can be applied to the flow of a canal, the word "streamflow" uniquely describes the discharge in a surface stream course. The term "streamflow" is more general than "runoff" as streamflow may be applied to discharge whether or not it is affected by diversion or regulation.

Substrate is the physical surface upon which an organism lives. 
Natural substrate refers to any naturally occurring emersed or submersed solid surface, such as a rock or tree, upon which an organism lives.

Artificial substrate is a device which is purposely placed in a stream or lake for colonization of organisms. The artificial substrate simplifies the community structure by standardizing the substrate from which each sample is taken. Examples of artificial substrates are basket samplers (made of wire cages filled with clean streamside rocks) and multiplate samplers (made of hardboard) for benthic organism collection, and plexiglass strips for periphyton collection.

Surface area of a lake is that area outlined on the latest U.S.G.S. topographic map as the boundary of the lake and measured by a planimeter in acres. In localities not covered by topographic maps, the areas are computed from the best maps available at the time planimetered. All areas shown are those for the stage when the planimetered map was made.

Surficial bed material is the part $(0.1$ to $0.2 \mathrm{ft}$ ) of the bed material that is sampled using U.S. Series Bed-Material Samplers.

Suspended (as used in tables of chemical analyses) refers to the amount (concentration) of undissolved material in a water-sediment mixture. It is associated with the material retained on a $0.45-$ micrometer filter.

Suspended, recoverable is the amount of a given constituent that is in solution after the part of a representative water-suspended sediment sample that is retained on a 0.45 um membrane filter has been digested by a method (usually using a dilute acid solution) that results in dissolution of only readily soluble substances. Complete dissolution of all the particulate matter is not achieved by the digestion treatment and thus the determination represents something less than the "total" amount (that is, less than 95 percent) of the constituent present in the sample. To achieve comparability of analytical data, equivalent digestion procedures are required of all laboratories performing such analyses because different digestion procedures are likely to produce different analytical results.

Determinations of "suspended, recoverable" constituents are made either by analyzing portions of the material collected on the filter or, more commonly, by difference, based on determinations of (1) dissolved and (2) total recoverable concentrations of the constituent.

Suspended, total is the total amount of a given constituent in the part of a representative watersuspended sediment sample that is retained on a 0.45 um membrane filter. This term is used only when the analytical procedure assures measurement of at least 95 percent of the constituent determined. $\mathrm{A}$ knowledge of the expected form of the constituent in the sample, as well as the analytical methodology used. is required to determine when the results should be reported as "suspended, total."

Determinations of "suspended, total" constituents are made either by analyzing portions of the material collected on the filter or, more commonly, by difference, based on determinations of (l) dissolved and (2) total concentrations of the constituent.

Taxonomy is the division of biology concerned with the classification and naming of organisms. The classification of organisms is based upon a hierarchial scheme beginning with kingdom and ending with Species at the base. The higher the classification level, the fewer features the organisms have in common. For example, the taxonomy of a particular mayfly, Hexagenia limbata, is the following:

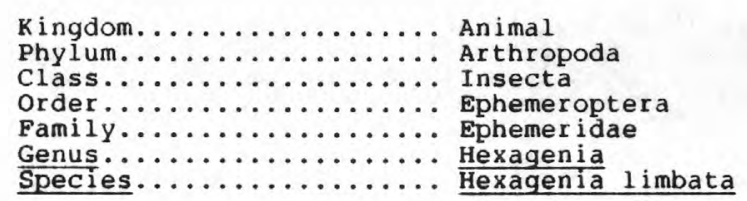

Thermograph is an instrument that continuously records variations of temperature on a chart. The more general term "temperature recorder" is used in the table headings and refers to any instrument that records temperature whether on a chart, a tape, or any other medium.

Time-weighted average is computed by multiplying the number of days in the sampling period by the concentrations of individual constituents for the corresponding period and dividing the sum of the products by the total number of days. A time-weighted average represents the composition of water that would be contained in a vessel or reservoir that had received equal quantities of water from the stream each day for the year. Tons per acre-foot indicates the dry mass of dissolved solids in 1 acre-foot of water. It is
computed by multiplying the concentration of the constituent, in milligrams per liter, by 0.00136 .

Tons per day (T/DAY) is the quantity of a substance in solution or suspension that passes a stream section during a 24 -hour period.

Total is the total amount of a given constituent in a representative water-suspended sediment sample, regardless of the constituent's physical or chemical form. This term is used only when the analytical procedure assures measurement of at least 95 percent of the constituent present in both the dissolved and suspended phases of the sample. A knowledge of the expected form of the constituent in the sample, as well as the analytical methodology used, is required to judge when the results should be reported as "total." (Note that the word "total" does double duty here, indicating both that the sample consists of a water-suspended sediment mixture and that the analytical method determined all of the constituent in the sample.)

Total discharge is the total quantity of any individual constituent, as measured by dry mass or volume, that passes through a stream cross-section per unit of time. This term needs to be qualified, such as "total sediment discharge," "total chloride discharge," and so on. 
Total, recoverable is the amount of a given constituent that is in solution after a representative water-suspended sediment sample has been digested by a method (usually using a dilute acid solution) that results in dissolution of only readily soluble substances. Complete dissolution of all particulate matter is not achieved by the digestion treatment, and thus the determination represents something less than the "total" amount (that is, less than 95 percent) of the constituent present in the dissolved and suspended phases of the sample. To achieve comparability of analytical data, equivalent digestion procedures are required of all laboratories performing such analyses because different digestion procedures are likely to produce different analytical results.

Water year in Geological Survey reports dealing with surface-water supply is the 12 -month period, october 1 through september 30. The water year is designated by the calendar year in which it ends and which includes 9 of the 12 months. Thus, the year ending September 30 , 1987, is called the "1987 water year."

WDR is used as an abbreviation for "Water-Data Report" in the REVISED RECORDS paragraph to refer to State annual hydrologic-data reports (WRD was used as an abbreviation for "Water-Resources Data" in reports published prior to 1976 ).

Weighted average is used in this report to indicate discharge-weighted average. It is computed by multiplying the discharge for a sampling period by the concentrations of individual constituents for the corresponding period and dividing the sum of the products by the sum of the discharges. A dischargeweighted average approximates the composition of water that would be found in a reservoir containing all the water passing a given location during the water year after thorough mixing in the reservoir.

WSP is used as an abbreviaton for "Water-Supply Paper" in reference to previously published reports. 
The U.S. Geological Survey publishes a series of manuals describing procedures for planning and conducting specialized work in water-resources investigations. The material is grouped under major subject headings called books and is further divided into sections and chapters. For example, Section A of Book 3 (Applications of Hydraulics) pertains to surface water. The chapter, the unit of publication, is limited to a narrow field of subject matter. This format permits flexibility in revision and publication as the need arises.

The reports listed below are for sale by the U.S. Geological Survey, Books and 0pen- File Reports Section, Federal Center, Box 25425, Denver, Colorado 80225 (authorized agent of the Superintendent of Documents, Government Printing officel). Prepayment is required. Remittance should be sent by check or money order payable to the U.S. Geological Survey. Prices are not included because they are subject to change. Current prices can be obtained by writing to the above address. When ordering or inquiring about prices for any of these publications, please give the title, book number, chapter number, and "U.S. Geological survey Techniques of Water-Resources Investigations."

1-D1. Water temperature--influential factors, field measurement, and data presentation, by $H$. H. Stevens, Jr., J. F. Ficke, and G. F. Smoot: USGS--TWRI Book 1, Chapter D1. 1975.65 pages.

1-D2. Guidelines for collection and field analysis of ground-water samples for selected unstable constituents, by W. W. Wood: USGS--TWRI Book 1, Chapter D2. 1976. 24 pages.

2-D1. Application of surface geophysics to ground-water investigations, by A. A. R. Zohdy, G. P. Eaton, and D. R. Mabey: USGS--TWRI Book 2, Chapter D1. 1974. 116 pages.

2-E1. Application of borehole geophysics to water-resources investigations, by W. S. Keys and L. M. MacCary: USGS--TWRI Book 2, Chapter E1. 1971. 126 pages.

3-A1. General field and office procedures for indirect discharge measurements, by M. A. Benson and Tate Dalrymple: USGS--TWRI Book 3, Chapter A1. 1967. 30 pages.

3-A2. Measurement of peak discharge by the slope-area-method, by Tate Dalrymple and M. A. Benson: USGS--TWRI Book 3, Chapter A2. 1967. 12 pages.

3-A3. Measurement of peak discharge at culverts by indirect methods, by G. L. Bodhaine: USGS-TWRI Book 3, Chapter A3. 1968. 60 pages.

3-A4. Measurement of peak discharge at width contractions by indirect methods, by H. F. Matthai: USGS--TWRI Book 3, Chapter A4. 1967. 44 Pages.

3-A5. Measurement of peak discharge at dams by indirect methods, by Harry Hulsing: USGS--TWRI Book 3, Chapter A5. 1967. 29 pages.

3-A6. General procedure for gaging streams, by R. W. Carter and Jacob Davidian: USliS--TWRI Book 3 , Chapter A6. 1968.13 pages.

3-A7. Stage measurements at gaging stations, by T. J. Buchanan and W. P. Somers: USGS--TWRI Book 3 , Chapter A7. 1968. 28 pages.

3-A8. Discharge measurements at gaging stations, by T. J. Buchanan and W. P. Somers: USGS--TWRI Book 3, Chapter A8. 1969. 65 pages.

3-A9. Measurement of time of travel and dispersion in streams by dye tracing, by E. F. Hubbard, F. A. Kilpatrick, L. A. Martens, and J. F. Wilson, Jr.: USGS--TWRI Book 3, Chapter A9. 1982. 44 pages.

3-A10. Discharge ratings at gaging stations, by E. J. Kennedy: USGS--TWRI Book 3, Chapter AlU. 1984. 59 pages.

3-A11. Measurement of discharge by moving-boat method, by G. F. Smoot and C. E. Novak: USGS--TWRI Book 3, Chapter A11. 1969. 22 pages.

3-A13. Computation of continuous records of streamflow, by E. J. Kennedy: USGS--TWRI Book 3, Chapter A13. 1983. 53 pages.

3-A14. Use of flumes in measuring discharge, by F. A. Kilpatrick and V. R. Schneider: USGS--TWRI Book 3, Chapter A14. 1983. 46 pages.

3-A15. Computation of water-surface profiles in open channels, by Jacob Davidian: USGS--TWRI Book 3 , Chapter A15. 1984.48 pages.

3-B1. Aquifer-test design, observation, and data analysis, by R. W. Stallman: USGS--TWRI Book 3, Chapter B1. 1971. 26 pages.

3-B2. Introduction to ground-water hydraulics, a programed text for self-instruction, by G. D. Bennett: USGS--TWRI Book 3, Chapter B2. 1976. 172 pages.

3-B3. Type curves for selected problems of flow to wells in confined aquifers, by J. E. Reed: USGS-TWRI Book 3, Chapter B3. 1980. 106 pages. 
3-C1. Fluvial sediment concepts by H. P. Guy: USGS--TWRI Book 3, Chapter C1. 1970. 55 pages.

3-C2. Field methods for measurement of fluvial sediment. by H. P. Guy and V. W. Norman: USGS-TWRI Book 3, Chapter C2. 1970. 59 pages.

3-C3. Computation of fluvial-sediment discharge: by George Porterfield: USGS--TWRI Book 3, Chapter C3. 1972.66 pages.

4-A1. Some statistical tools in hydrology, by H. C. Riggs: USGS--TWRI Book 4, Chapter Al. 1968. 39 pages.

4-A2. Frequency curves: by H. C. Riggs: USGS--TWRI Book 4, Chapter A2. 1968.15 pages.

4-B1. Low-flow investigations, by H. C. Riggs: USGS--TWRI Book 4, Chapter B1. 1972.18 pages.

4-B2. Storage analyses for water supply, by H. C. Riggs and C. H. Hardison: USGS--TWRI Book 4, Chapter B2. 1973. 20 pages.

4-B3. Regional analyses of streamflow characteristics. by H. C. Riggs: USGS--TWRI Book 4, Chapter B3. 1973.15 pages.

4-D1. Computation of rate and volume of stream depletion by wells by C. T. Jenkins: USGS--TWRI Book 4, Chapter D1. 1970. 17 pages.

5-A1. Methods for determination of inorganic substances in water and fluvial sediments by $M$. W. Skougstad and others, editors: USGS--TWRI Book 5, Chapter A1. 1979.626 pages.

5-A2. Determination of minor elements in water by emission spectroscopy. Dy P. R. Barneti and E. C. Mallory, Jr.: USGS--TWRI Book 5, Chapter A2. 1971. 31 pages.

5-A3. Methods for analysis of organic substances in water. by D. F. Goerlitz and Eugene Brown: USGS--TWRI Book 5, Chapter A3. 1972. 40 pages.

5-A4. Methods for collection and analysis of aquatic biological and microbiological samples edited by P. E. Greeson, T. A. Ehlke, G. A. Irwin, B. W. Lium, and K. V. Slack: USGS--TWRI Book 5, Chapter A4. 1977. 332 pages.

5-A5. Methods for determination of radioactive substances in water and fluvial sediments. by L. L. Thatcher, V. J. Janzer, and K. W. Edwards: USGS--TWRI Book 5, Chapter A5. 1977. 95 pages.

5-A6. Quality assurance practices for the chemical and biological analyses of water and fluvial sedments, by L. C. Friedman and D. E. Erdmann: USGS--TWRI Book 5, Chapter A6. 1982. 181 pages.

5-C1. Laboratory theory and methods for sediment analysis. by H. P. Guy: USGS--TWRI Book 5, Chapter C1. 1969. 58 pages.

7-C1. Finite difference model for aquifer simulation in two dimensions with results of numerical experiments, by P. C. Trescott, G. F. Pinder, and S. P. Larson: USGS--TWRI Book 7, Chapter C1. 1976 . 116 pages.

7-C2. Computer model of two-dimensional solute transport and dispersion in ground water. by L. F. Konikow and J. D. Bredehoeft: USGS--TWRI Book 7, Chapter C2. 1978. 90 pages.

7-C3. A model for simulation of flow in singular and interconnected channels by $R$. W. Schaffrannek, R. A. Baltzer, and D. E. Goldberg: USGS--TWRI Book 7, Chapter C3. 1981.110 pages.

8-A1. Methods of measuring water levels in deep wells by M. S. Garber and F. C. Koopman: USliS-TWRI Book 8, Chapter A1. 1968. 23 pages

8-A2. Installation and service manual for U.S. Geological Survey manometers by J. D. Craig: USGS--TWRI Book 8, Chapter A2. 1983. 57 pages.

8-B2. Calibration and maintenance of vertical-axis type current meters. by G. F. Smoot and C. E. Novak: USGS--TWRI Book 8, Chapter B2. 1968. 15 pages. 


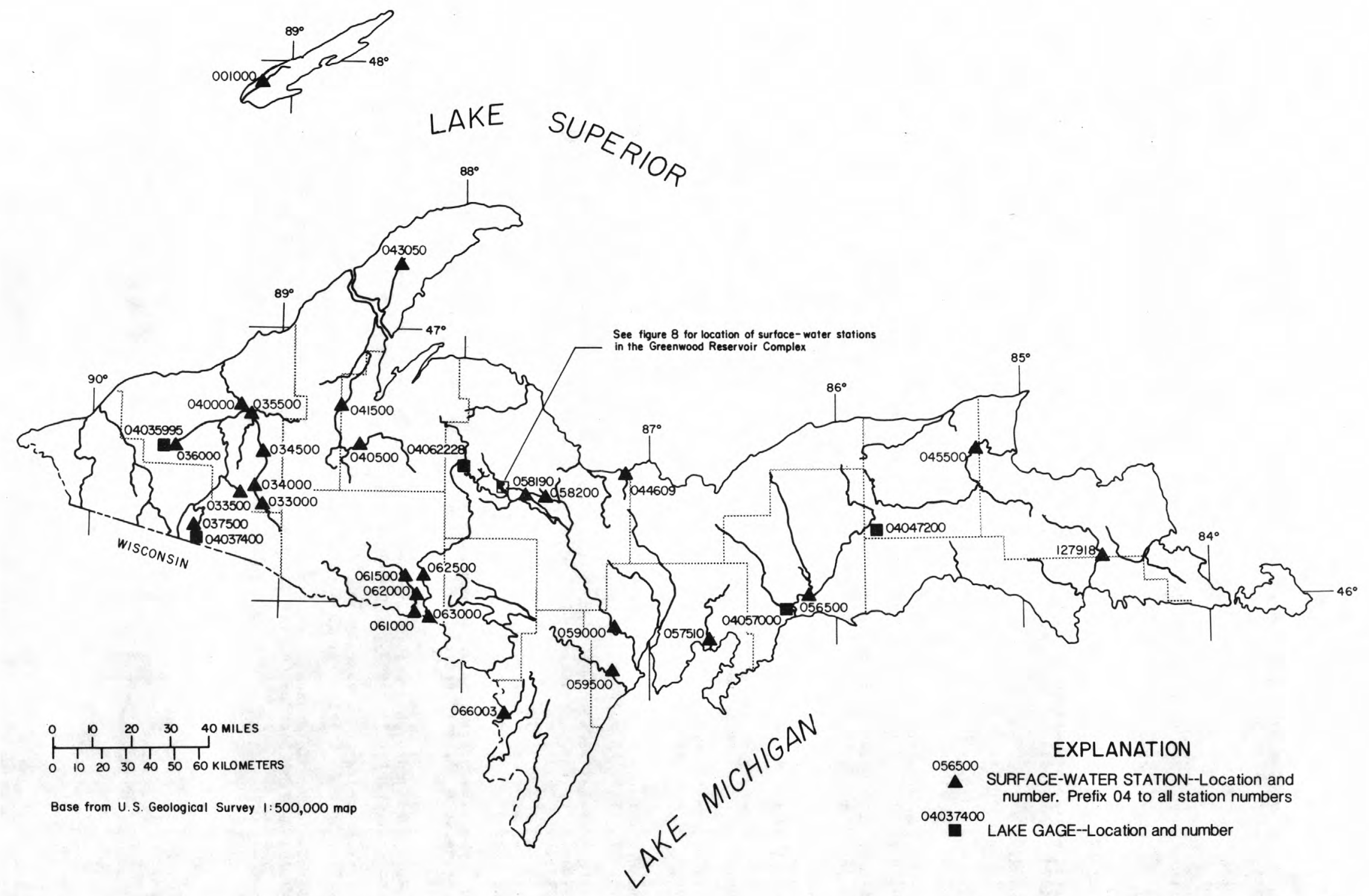




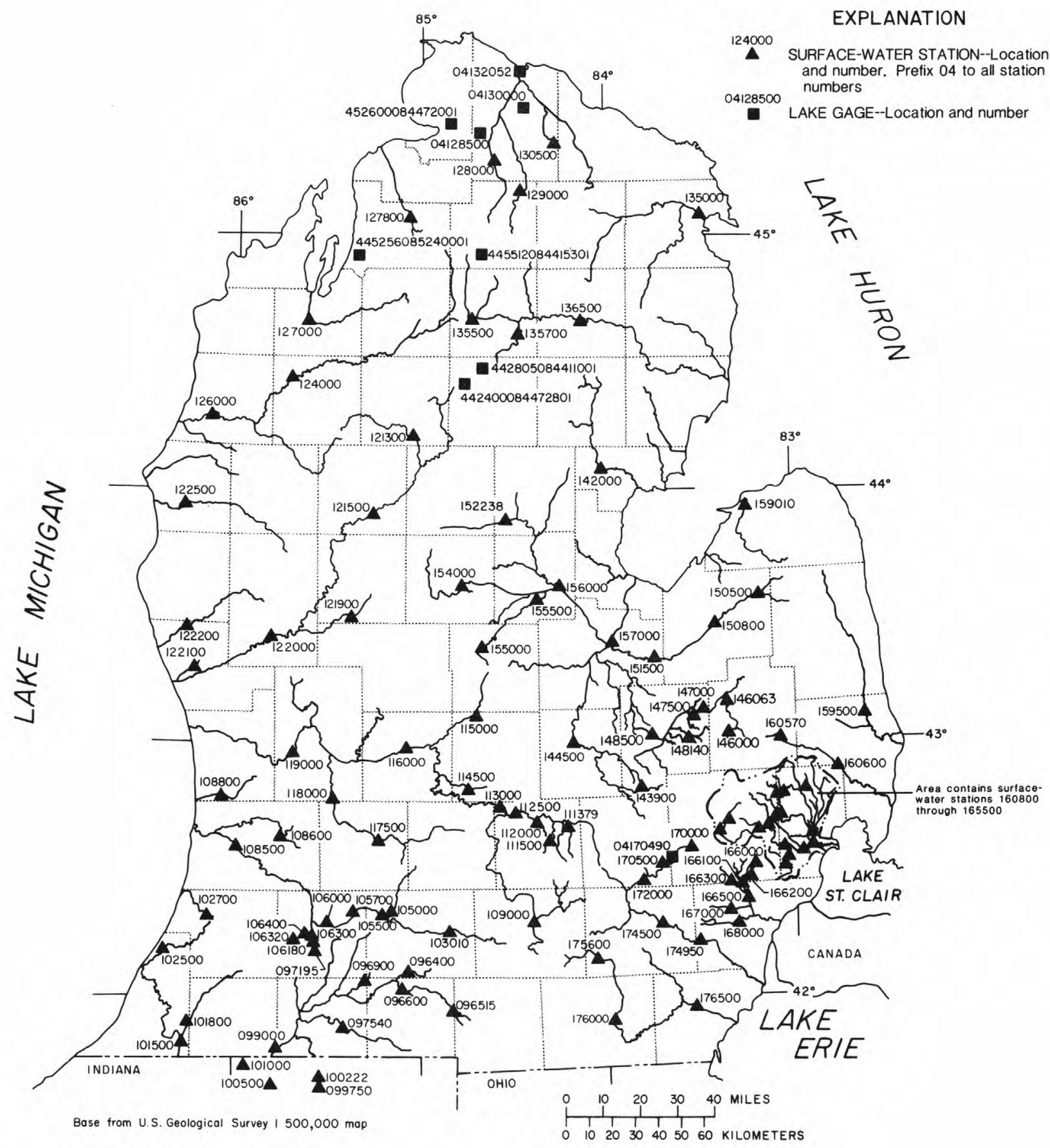

Figure 5.--Identification number and location of active surface-water gaging stations in the Lower Peninsula of Michigan. 


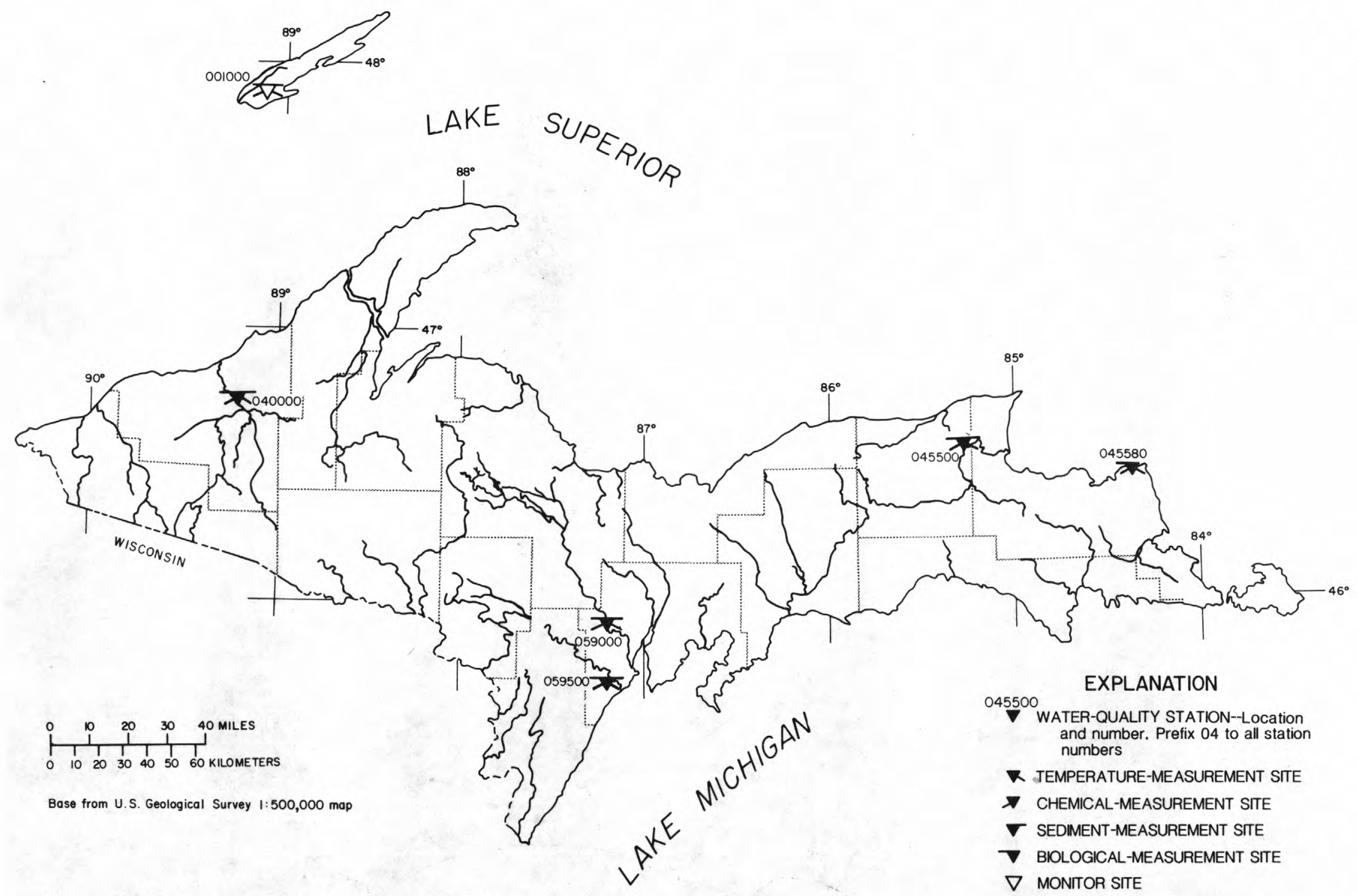

Figure 6.--Identification number and location of active surface-waterquality stations in the Upper Peninsula of Michigan. 


\section{EXPLANATION}

135000 WATER-QUALTY STATION--Location and number. Prefix 04 to all station numbers

Z TEMPERATURE-MEASUREMENT STTE

7 CHEMICAL-MEASUREMENT STTE

$\boldsymbol{\nabla}$ SEDIMENT-MEASUREMENT STIE

$\checkmark$ BIOLOGICAL-MEASUREMENT SITE

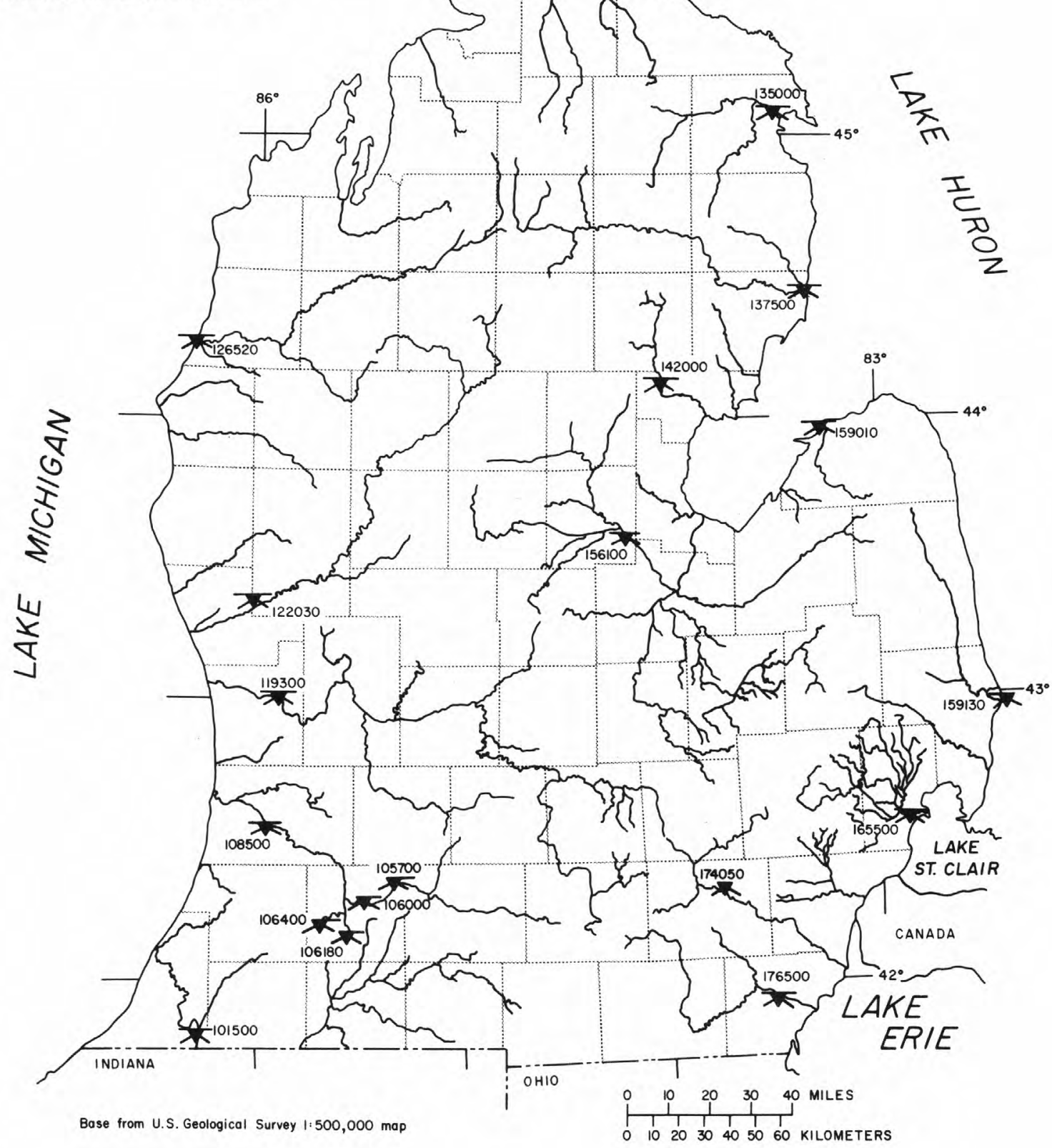

Figure 7.--Identification number and location of active surface-waterquality stations in the Lower Peninsula of Michigan. 
LOCATION.--Lat $47^{\circ} 55^{\prime} 23^{\prime \prime}$, long $89^{\circ} 08^{\prime} 42^{\prime \prime}$, in NWl/4 sec. 28 , T.64 N., R. 38 W. Keweenaw County, Isle Royale National Park, Hydrologic Unit 04020300 , on left bank $0.8 \mathrm{mi}$ northeast of Windigo, and $35 \mathrm{mi}$ southwest of Rock Harbor.

DRAINAGE AREA. $-13.2 \mathrm{mi}^{2}$.

\section{WATER-DISCHARGE RECORDS}

PERIOD OF RECORD.--October 1964 to current year.

GAGE.--Water-stage recorder and concrete control. Elevation of gage is $605 \mathrm{ft}$ above National Geodetic Vertical Datum of 1929 , from topographic map.

REMARKS.--Estimated daily discharges: Jan. 17, 18, Jan. 20 to Feb. 8, Feb. 14, and Mar. 7-16. Water-discharge records good except for estimated daily discharges, which are fair. Recording rain gage at station and capacity rain gage located near mouth.

AVERAGE DISCHARGE.--23 years, $17.2 \mathrm{ft}^{3} / \mathrm{s}, 17.70 \mathrm{in} / \mathrm{yr}$.

EXTREMES FOR PERIOD OF RECORD.--Maximum discharge, $480 \mathrm{ft}^{3} / \mathrm{s}$, May 1, 1972, gage height, $6.82 \mathrm{ft}$, from rating curve extended above $160 \mathrm{ft} / \mathrm{s}$ based on runoff characteristics of nearby stations; maximum gage height, $6.88 \mathrm{ft}$, Jan. 13, 1975, backwater from ice; minimum daily discharge, 0.44 $\mathrm{ft}^{3} / \mathrm{s}$, Aug. 25, 1977 ; minimum gage height, 2.55 ft, Aug. 29, 30, 31, Sept. 2, 3, 7, 9, 10, il, 12,1976 .

EXTREMES FOR CURRENT YEAR.--Maximum discharge, $95 \mathrm{ft}^{3} / \mathrm{s}$, Sept. 20 , gage height, $4.45 \mathrm{ft}$, no peak discharge above base discharge of $110 \mathrm{ft} / \mathrm{s}$; maximum gage height, $4.82 \mathrm{ft}$, Mar. 9, backwater from ice; minimum discharge, $0.91 \mathrm{ft}^{3} / \mathrm{s}, \mathrm{Jul} Y 31$, gage height, $2.67 \mathrm{ft}$.

DISCHARGE, IN CUBIC FEET PER SECOND, WATER YEAR OCTOBER 1986 TO SEPTEMBER 1987 MEAN VALUES

\begin{tabular}{|c|c|c|c|c|c|c|c|c|c|c|c|c|}
\hline DAY & OCT & NOV & $\mathrm{DEC}$ & JAN & FEB & MAR & APR & MAY & JUN & JUL & AUG & SEP \\
\hline $\begin{array}{l}1 \\
2 \\
3 \\
4 \\
5\end{array}$ & $\begin{array}{l}4.2 \\
4.1 \\
3.9 \\
3.6 \\
3.8\end{array}$ & $\begin{array}{l}4.9 \\
4.4 \\
5.3 \\
5.7 \\
5.2\end{array}$ & $\begin{array}{l}6.2 \\
6.1 \\
6.4 \\
6.2 \\
5.8\end{array}$ & $\begin{array}{l}4.1 \\
4.1 \\
4.2 \\
4.2 \\
4.2\end{array}$ & $\begin{array}{l}2.6 \\
2.6 \\
2.6 \\
2.6 \\
2.6\end{array}$ & $\begin{array}{l}3.2 \\
3.3 \\
3.5 \\
3.6 \\
3.7\end{array}$ & $\begin{array}{l}19 \\
17 \\
15 \\
15 \\
17\end{array}$ & $\begin{array}{l}6.3 \\
5.9 \\
5.5 \\
5.2 \\
4.9\end{array}$ & $\begin{array}{l}9.9 \\
21 \\
16 \\
12 \\
11\end{array}$ & $\begin{array}{l}1.2 \\
2.0 \\
1.9 \\
1.6 \\
1.3\end{array}$ & $\begin{array}{l}5.0 \\
6.8 \\
3.9 \\
2.7 \\
2.1\end{array}$ & $\begin{array}{l}3.6 \\
3.3 \\
2.9 \\
2.7 \\
3.2\end{array}$ \\
\hline $\begin{array}{r}6 \\
7 \\
8 \\
9 \\
10\end{array}$ & $\begin{array}{l}3.9 \\
3.9 \\
4.6 \\
4.2 \\
3.8\end{array}$ & $\begin{array}{l}8 \cdot 3 \\
18 \\
25 \\
24 \\
20\end{array}$ & $\begin{array}{l}5.6 \\
5.3 \\
5.0 \\
5.0 \\
4.8\end{array}$ & $\begin{array}{l}4.3 \\
4.5 \\
4.4 \\
4.2 \\
4.3\end{array}$ & $\begin{array}{l}2.6 \\
2.6 \\
2.7 \\
2.8 \\
2.8\end{array}$ & $\begin{array}{l}4.9 \\
14 \\
32 \\
40 \\
29\end{array}$ & $\begin{array}{l}22 \\
28 \\
32 \\
34 \\
39\end{array}$ & $\begin{array}{l}4.7 \\
4.5 \\
4.3 \\
4.2 \\
3.8\end{array}$ & $\begin{array}{l}8.8 \\
8.0 \\
6.9 \\
6.1 \\
5.4\end{array}$ & $\begin{array}{l}1.2 \\
1.2 \\
1.1 \\
1.5 \\
2.4\end{array}$ & $\begin{array}{l}1.8 \\
1.7 \\
1.5 \\
1.3 \\
1.2\end{array}$ & $\begin{array}{r}10 \\
8.5 \\
6.5 \\
5.6 \\
5.0\end{array}$ \\
\hline $\begin{array}{l}11 \\
12 \\
13 \\
14 \\
15\end{array}$ & $\begin{array}{l}3.8 \\
11 \\
11 \\
21 \\
28\end{array}$ & $\begin{array}{l}18 \\
13 \\
10 \\
8.5 \\
7.4\end{array}$ & $\begin{array}{l}4.7 \\
4.5 \\
4.2 \\
4.5 \\
4.6\end{array}$ & $\begin{array}{l}4.2 \\
4.1 \\
4.1 \\
4.1 \\
3.8\end{array}$ & $\begin{array}{l}2.8 \\
2.9 \\
2.8 \\
2.8 \\
2.9\end{array}$ & $\begin{array}{r}21 \\
15 \\
11 \\
8.0 \\
6.9\end{array}$ & $\begin{array}{l}38 \\
35 \\
31 \\
29 \\
27\end{array}$ & $\begin{array}{l}3.6 \\
3.4 \\
3.4 \\
3.5 \\
3.2\end{array}$ & $\begin{array}{l}6.2 \\
6.9 \\
7.2 \\
5.9 \\
4.9\end{array}$ & $\begin{array}{l}1.8 \\
1.9 \\
1.7 \\
1.5 \\
1.3\end{array}$ & $\begin{array}{l}1.1 \\
30 \\
25 \\
14 \\
13\end{array}$ & $\begin{array}{l}5.3 \\
5.1 \\
32 \\
19 \\
12\end{array}$ \\
\hline $\begin{array}{l}16 \\
17 \\
18 \\
19 \\
20\end{array}$ & $\begin{array}{l}24 \\
19 \\
15 \\
12 \\
10\end{array}$ & $\begin{array}{l}6.6 \\
6.1 \\
5.1 \\
4.9 \\
6.0\end{array}$ & $\begin{array}{l}4.5 \\
4.6 \\
4.5 \\
4.4 \\
4.2\end{array}$ & $\begin{array}{l}3.4 \\
3.2 \\
3.1 \\
3.1 \\
3.0\end{array}$ & $\begin{array}{l}2.8 \\
2.8 \\
2.8 \\
2.8 \\
2.8\end{array}$ & $\begin{array}{l}6.5 \\
6.4 \\
6.4 \\
7.0 \\
9.1\end{array}$ & $\begin{array}{l}24 \\
23 \\
22 \\
20 \\
19\end{array}$ & $\begin{array}{l}3.1 \\
8.1 \\
25 \\
23 \\
22\end{array}$ & $\begin{array}{l}4.1 \\
3.4 \\
3.2 \\
2.9 \\
2.4\end{array}$ & $\begin{array}{l}1.2 \\
1.2 \\
1.9 \\
6.4 \\
5.0\end{array}$ & $\begin{array}{l}11 \\
7.8 \\
12 \\
18 \\
12\end{array}$ & $\begin{array}{l}8.9 \\
7.0 \\
6.2 \\
34 \\
66\end{array}$ \\
\hline $\begin{array}{l}21 \\
22 \\
23 \\
24 \\
25\end{array}$ & $\begin{array}{l}9.2 \\
8.1 \\
7.2 \\
6.5 \\
6.2\end{array}$ & $\begin{array}{l}5.8 \\
5.7 \\
5.9 \\
6.0 \\
6.0\end{array}$ & $\begin{array}{l}4.1 \\
4.1 \\
4.1 \\
4.1 \\
4.1\end{array}$ & $\begin{array}{l}2.9 \\
2.9 \\
2.8 \\
2.8 \\
2.7\end{array}$ & $\begin{array}{l}2.8 \\
2.9 \\
3.1 \\
3.0 \\
3.0\end{array}$ & $\begin{array}{l}14 \\
19 \\
32 \\
51 \\
77\end{array}$ & $\begin{array}{l}18 \\
14 \\
12 \\
11 \\
9.6\end{array}$ & $\begin{array}{l}18 \\
36 \\
45 \\
34 \\
27\end{array}$ & $\begin{array}{l}2.1 \\
1.9 \\
1.8 \\
1.6 \\
1.5\end{array}$ & $\begin{array}{l}4.2 \\
3.7 \\
3.2 \\
2.5 \\
2.0\end{array}$ & $\begin{array}{l}9.2 \\
7.8 \\
6.1 \\
5.0 \\
4.4\end{array}$ & $\begin{array}{l}60 \\
30 \\
19 \\
14 \\
11\end{array}$ \\
\hline $\begin{array}{l}26 \\
27 \\
28 \\
29 \\
30 \\
31\end{array}$ & $\begin{array}{l}5.7 \\
5.5 \\
5.4 \\
5.3 \\
4.9 \\
5.0\end{array}$ & $\begin{array}{l}7.2 \\
7.0 \\
7.6 \\
7.1 \\
6.6 \\
-.--\end{array}$ & $\begin{array}{l}4.0 \\
4.0 \\
4.0 \\
4.0 \\
4.0 \\
4.1\end{array}$ & $\begin{array}{l}2.7 \\
2.7 \\
2.7 \\
2.6 \\
2.6 \\
2.6\end{array}$ & $\begin{array}{l}2.9 \\
2.9 \\
3.1 \\
--- \\
--- \\
---\end{array}$ & $\begin{array}{l}71 \\
50 \\
40 \\
34 \\
27 \\
22\end{array}$ & $\begin{array}{l}9.1 \\
8.6 \\
7.8 \\
7.2 \\
6.6 \\
-.-\end{array}$ & $\begin{array}{l}23 \\
19 \\
19 \\
15 \\
16 \\
18\end{array}$ & $\begin{array}{l}1.5 \\
2.1 \\
1.7 \\
1.4 \\
1.3 \\
---\end{array}$ & $\begin{array}{l}1.6 \\
1.3 \\
1.2 \\
1.1 \\
1.1 \\
1.0\end{array}$ & $\begin{array}{l}4.1 \\
4.1 \\
3.5 \\
3.2 \\
4.6 \\
4.2\end{array}$ & $\begin{array}{l}9.6 \\
8.6 \\
8.0 \\
7.9 \\
7.8 \\
---1\end{array}$ \\
\hline $\begin{array}{l}\text { TOTAL } \\
\text { MEAN } \\
\text { MAX } \\
\text { MIN } \\
\text { CFSM } \\
\text { IN. }\end{array}$ & $\begin{array}{r}263.8 \\
8.51 \\
28 \\
3.6 \\
.65 \\
.74\end{array}$ & $\begin{array}{r}271.3 \\
9.04 \\
25 \\
4.4 \\
.69 \\
.76\end{array}$ & $\begin{array}{r}145.7 \\
4.70 \\
6.4 \\
4.0 \\
.36 \\
.41\end{array}$ & $\begin{array}{r}108.6 \\
3.50 \\
4.5 \\
2.6 \\
.27 \\
.31\end{array}$ & $\begin{array}{r}78.4 \\
2.80 \\
3.1 \\
2.6 \\
.21 \\
.22\end{array}$ & $\begin{array}{r}671.5 \\
21.7 \\
77 \\
3.2 \\
1.64 \\
1.89\end{array}$ & $\begin{array}{r}609.9 \\
20.3 \\
39 \\
6.6 \\
1.54 \\
1.72\end{array}$ & $\begin{array}{r}417.6 \\
13.5 \\
45 \\
3.1 \\
1.02 \\
1.18\end{array}$ & $\begin{array}{r}169.1 \\
5.64 \\
21 \\
1.3 \\
.43 \\
.48\end{array}$ & $\begin{array}{r}62.2 \\
2.01 \\
6.4 \\
1.0 \\
.15 \\
.18\end{array}$ & $\begin{array}{r}228.1 \\
7.36 \\
30 \\
1.1 \\
.56 \\
.64\end{array}$ & $\begin{array}{r}422.7 \\
14.1 \\
66 \\
2.7 \\
1.07 \\
1.19\end{array}$ \\
\hline $\begin{array}{ll}\text { CAL YR } \\
\text { WTR YR }\end{array}$ & $\begin{array}{l}1986 \\
1987\end{array}$ & L & & $\begin{array}{lc}\text { AN } & 15.1 \\
\text { AN } & 9.45\end{array}$ & $\begin{array}{l}\text { MAX } \\
\text { MAX }\end{array}$ & $\begin{array}{l}\text { MIN } \\
\text { MIN }\end{array}$ & $\begin{array}{l}1.5 \\
1.0\end{array}$ & $\begin{array}{rr}\text { SM } & 1.14 \\
\text { SM } & .72\end{array}$ & $\begin{array}{l}\text { IN } \\
\text { IN }\end{array}$ & & & \\
\hline
\end{tabular}


PERIOD OF RECORD.--Water years 1965 to current year.

PERIOD OF DAILY RECORD.--

WATER TEMPERATURE: October 1964 to current year.

INSTRUMENTATION.--Water-temperature recorder since oct. 20, 1964. Digital recorder set for one-hourinterval punches.

REMARKS.--In addition to the daily-temperature record, quarterly samples were collected at or near gage. Samples for the analyses of stable hydrogen and oxygen isotopes were also collected; analytical results from the samples were not published.

EXTREMES FOR PERIOD OF DAILY RECORD.--

WATER TEMPERATURE: Maximum, $24.5^{\circ} \mathrm{C}$, July 8,1987 ; minimum, $0.0^{\circ} \mathrm{C}$ on many days during winter.

EXTREMES FOR CURRENT YEAR --

WATER TEMPERATURE: Maximum, $24.5^{\circ} \mathrm{C}$, July 8 ; minimum, $0.0^{\circ} \mathrm{C}$ on many days during winter.

WATER QUALITY DATA, WATER YEAR OCTOBER 1986 TO SEPTEMBER 1987

\begin{tabular}{|c|c|c|c|c|c|c|c|c|c|c|}
\hline DATE & TIME & $\begin{array}{c}\text { STREAM- } \\
\text { FLOW, } \\
\text { INSTAN- } \\
\text { TANEOUS } \\
\text { (CFS) }\end{array}$ & $\begin{array}{l}\text { SPE- } \\
\text { CIFIC } \\
\text { CON- } \\
\text { DUCT- } \\
\text { ANCE } \\
\text { (US/CM) }\end{array}$ & $\begin{array}{c}\text { PH } \\
\text { (STAND- } \\
\text { ARD } \\
\text { UNITS) }\end{array}$ & $\begin{array}{l}\text { TEMPER- } \\
\text { ATURE } \\
\text { (DEG C) }\end{array}$ & $\begin{array}{l}\text { TUR- } \\
\text { BID- } \\
\text { ITY } \\
\text { (NTU) }\end{array}$ & $\begin{array}{c}\text { OXYGEN, } \\
\text { DIS- } \\
\text { SOLVED } \\
\text { (MG/L) }\end{array}$ & $\begin{array}{l}\text { DIS- } \\
\text { SOLVED } \\
\text { (PER- } \\
\text { CENT } \\
\text { SATUR- } \\
\text { ATION) }\end{array}$ & $\begin{array}{l}\text { FORM, } \\
\text { FECAL, } \\
0.7 \\
\text { UM-MF } \\
\text { (COLS.' } \\
100 \text { ML) }\end{array}$ & $\begin{array}{l}\text { TOCOCCI } \\
\text { FECAL, } \\
\text { KF AGAR } \\
\text { (COLS. } \\
\text { PER } \\
100 \mathrm{ML} \text { ) }\end{array}$ \\
\hline & & & & & & & & & & \\
\hline $29 \ldots$ & 1215 & 5.0 & 122 & 7.7 & 4.5 & 1.2 & 12.3 & 96 & K13 & $\mathrm{K} 2$ \\
\hline $03 \ldots$ & 1400 & 2.6 & 152 & 7.4 & 0.0 & 1.1 & 13.4 & 93 & -- & -- \\
\hline $\mathrm{G} 6 \ldots$ & 1330 & 4.7 & 119 & 8.0 & 10.0 & 1.6 & 10.7 & 96 & 13 & $<1$ \\
\hline $11 \ldots$ & 1225 & 1.1 & 200 & 7.8 & 17.0 & 2.4 & 8.9 & 94 & 280 & 230 \\
\hline DATE & $\begin{array}{l}\text { HARD- } \\
\text { NESS } \\
\text { (MG/L } \\
\text { AS } \\
\text { CACO3) }\end{array}$ & $\begin{array}{l}\text { HARD- } \\
\text { NESS } \\
\text { NONCARB } \\
\text { WH WAT } \\
\text { TOT FLD } \\
\text { MG / L AS } \\
\text { CACO3 }\end{array}$ & $\begin{array}{l}\text { CALCIUM } \\
\text { DIS- } \\
\text { SOLVED } \\
\text { (MG/L } \\
\text { AS CA) }\end{array}$ & $\begin{array}{c}\text { MAGNE- } \\
\text { SIUM, } \\
\text { DIS- } \\
\text { SOLVED } \\
\text { (MG/L } \\
\text { AS MG) }\end{array}$ & $\begin{array}{l}\text { SODIUM, } \\
\text { DIS- } \\
\text { SOLVED } \\
\text { (MG/L } \\
\text { AS NA) }\end{array}$ & $\begin{array}{l}\text { PERCENT } \\
\text { SODIUM }\end{array}$ & $\begin{array}{l}\text { SODIUM } \\
\text { AD- } \\
\text { SORP- } \\
\text { TION } \\
\text { RATIO }\end{array}$ & $\begin{array}{l}\text { POTAS- } \\
\text { SIUM, } \\
\text { DIS- } \\
\text { SOLVED } \\
\text { (MG/L } \\
\text { AS K K) }\end{array}$ & $\begin{array}{c}\text { BICAR- } \\
\text { BONATE } \\
\text { WH WAT } \\
\text { TOTAL } \\
\text { FIELD } \\
\text { MG } / \mathrm{L} \text { AS } \\
\mathrm{HCO3}\end{array}$ & $\begin{array}{c}\text { CAR- } \\
\text { BONATE } \\
\text { WH WAT } \\
\text { TOTAL } \\
\text { FIELD } \\
\text { MG/L AS } \\
\mathrm{CO} 3^{-}\end{array}$ \\
\hline & & & & & & & & & & \\
\hline $29 \ldots$ & 60 & 5 & 16 & 4.9 & 2.9 & 9 & 0.2 & 0.6 & 67 & 0 \\
\hline $\mathrm{Y}_{\mathrm{Y}} 3 \mathrm{\cdots}$ & 74 & 7 & 20 & 5.9 & 4.0 & 10 & 0.2 & 0.4 & 81 & 0 \\
\hline $56 \ldots$ & 56 & 4 & 15 & 4.5 & 3.1 & 11 & 0.2 & 0.6 & 64 & 0 \\
\hline $11 \ldots$ & 99 & 15 & 27 & 7.6 & 5.5 & 11 & 0.2 & 0.7 & 100 & 0 \\
\hline DATE & $\begin{array}{l}\text { ALKA- } \\
\text { LINITY } \\
\text { WH WAT } \\
\text { TOTAL } \\
\text { FIELD } \\
\text { MG/L AS } \\
\text { CACO3 }\end{array}$ & $\begin{array}{c}\text { CARBON } \\
\text { DIOXIDE } \\
\text { DIS- } \\
\text { SOLVED } \\
\text { (MG/L } \\
\text { AS CO2) }\end{array}$ & $\begin{array}{l}\text { SULFATE } \\
\text { DIS- } \\
\text { SOLVED } \\
\text { (MG/L } \\
\text { AS SO4) }\end{array}$ & $\begin{array}{l}\text { CHLO- } \\
\text { RIDE, } \\
\text { DIS- } \\
\text { SOLVED } \\
\text { (MG/L } \\
\text { AS CL) }\end{array}$ & $\begin{array}{l}\text { FLUO- } \\
\text { RIDE, } \\
\text { DIS- } \\
\text { SOLVED } \\
\text { (MG/L } \\
\text { AS F) }\end{array}$ & $\begin{array}{l}\text { SILICA, } \\
\text { DIS- } \\
\text { SOLVED } \\
\text { (MG/L } \\
\text { AS } \\
\text { SIO2) }\end{array}$ & $\begin{array}{l}\text { SOLIDS, } \\
\text { RESIDUE } \\
\text { AT } 180 \\
\text { DEG.C } \\
\text { DIS-- } \\
\text { SOLVED } \\
(M G / L)\end{array}$ & $\begin{array}{l}\text { SOLIDS, } \\
\text { SUM OF } \\
\text { CONSTI- } \\
\text { TUENTS, } \\
\text { DIS- } \\
\text { SOLVED } \\
\text { (MG/L) }\end{array}$ & $\begin{array}{c}\text { SOLIDS, } \\
\text { DIS- } \\
\text { SOLVED } \\
\text { (TONS } \\
\text { PER } \\
\text { AC-FT) }\end{array}$ & $\begin{array}{c}\text { SOLIDS, } \\
\text { DIS- } \\
\text { SOLVED } \\
\text { (TONS } \\
\text { PER } \\
\text { DAY) }\end{array}$ \\
\hline $9 \ldots$ & 55 & 2.1 & 14 & 2.6 & $<0.1$ & 13 & 100 & 87 & 0.14 & 1.4 \\
\hline 3 & 67 & 5.1 & 13 & 3.9 & $<0.1$ & 16 & 100 & 100 & 0.14 & 0.7 \\
\hline $6 \ldots$ & 52 & 1.1 & 10 & 2.7 & $<0.1$ & 9.1 & 83 & 77 & 0.11 & 1.1 \\
\hline $1 \ldots$ & 84 & 2.6 & 12 & 6.4 & 0.1 & 15 & 120 & 120 & 0.16 & 0.37 \\
\hline
\end{tabular}


04001000 WASHINGTON CREEK AT WINDIGO, MI--Continued

WATER QUALITY DATA, WATER YEAR OCTOBER 1986 TO SEPTEMBER 1987

\begin{tabular}{|c|c|c|c|c|c|c|c|c|c|c|}
\hline DATE & $\begin{array}{c}\text { NITRO- } \\
\text { GEN, } \\
\text { NITRITE } \\
\text { DIS- } \\
\text { SOLVED } \\
\text { (MG/L } \\
\text { AS N) }\end{array}$ & $\begin{array}{c}\text { NITRO- } \\
\text { GEN, } \\
\text { NO2+NO3 } \\
\text { DIS- } \\
\text { SOLVED } \\
\text { (MG/L } \\
\text { AS N) }\end{array}$ & $\begin{array}{l}\text { NITRO- } \\
\text { GEN, } \\
\text { AMMONIA } \\
\text { TOTAL } \\
\text { (MG/L } \\
\text { AS N) }\end{array}$ & $\begin{array}{l}\text { NITRO- } \\
\text { GEN, } \\
\text { AMMONIA } \\
\text { DIS- } \\
\text { SOLVED } \\
\text { (MG/L } \\
\text { AS N) }\end{array}$ & $\begin{array}{l}\text { NITRO- } \\
\text { GEN, } \\
\text { ORGANIC } \\
\text { TOTAL } \\
\text { (MG/L } \\
\text { AS N) }\end{array}$ & $\begin{array}{l}\text { NITRO- } \\
\text { GEN, AM- } \\
\text { MONIA + } \\
\text { ORGANIC } \\
\text { TOTAL } \\
\text { (MG/L } \\
\text { AS N) }\end{array}$ & $\begin{array}{c}\text { PHOS- } \\
\text { PHORUS, } \\
\text { TOTAL } \\
\text { (MG/L } \\
\text { AS P) }\end{array}$ & $\begin{array}{c}\text { PHOS- } \\
\text { PHORUS, } \\
\text { DIS- } \\
\text { SOLVED } \\
\text { (MG/L } \\
\text { AS P) }\end{array}$ & $\begin{array}{l}\text { PHOS- } \\
\text { PHORUS, } \\
\text { ORTHO, } \\
\text { DIS- } \\
\text { SOLVED } \\
\text { (MG/L } \\
\text { AS P) }\end{array}$ & $\begin{array}{l}\text { ALUM- } \\
\text { INUM, } \\
\text { DIS- } \\
\text { SOLVED } \\
\text { (UG/L } \\
\text { AS AL) }\end{array}$ \\
\hline $\begin{array}{l}\mathrm{T} \\
29 \ldots\end{array}$ & $<0.01$ & $<0.10$ & 0.03 & 0.04 & 0.47 & 0.5 & 0.01 & $<0.01$ & $<0.01$ & 20 \\
\hline $\begin{array}{l}\mathrm{EB} \\
03 \ldots \\
\mathrm{AY}\end{array}$ & $<0.01$ & 0.12 & 0.02 & 0.03 & 0.68 & 0.7 & $<0.01$ & 0.01 & $<0.01$ & 20 \\
\hline $06 \ldots$ & $<0.01$ & $<0.10$ & 0.04 & 0.02 & 0.76 & 0.8 & 0.01 & 0.02 & 0.01 & $<10$ \\
\hline $11 \ldots$ & $<0.01$ & $<0.10$ & 0.04 & 0.05 & 1.3 & 1.3 & 0.03 & 0.01 & $<0.01$ & $<10$ \\
\hline
\end{tabular}

DATE ARSENIC BARIUM, BERYLSOLVED SOLVED(UG $L$ SOLVED $\begin{array}{ll}\text { (UG/L } & \text { (UG/L } \\ \text { AS AS) } & \text { AS BA) }\end{array}$ SOLVE (UG/L

CADMIUM DISSOLVED (UG/L AS CD)
CHRO-

MIUM, COBALT, COPPER, IRON, LEAD, LITHIUM DISDISSOLV AS CR ) COBALT, COPPER
DISSOLVED (UG/L SOLVED (UG/L
DIS-

SOLVED

SOLVED

(UG/L
SOLVED SOLVED (UG/L (UG/L AS PB) AS LI)
OCT
$29 \ldots$
FEB
$03 \ldots$
MAY
$06 \ldots$
AUG

$11 \ldots$

$<1$
$<1$
$<1$

$<0.5$
2
$<0.5$
$<0.5$

1
1
$<1$
$<1$

$\begin{array}{ll}<1 & < \\ <1 & < \\ <1 & <\end{array}$

$<3$
$<3$
$<3$
$<3$

$\begin{array}{ll}2 & 330 \\ 1 & 350 \\ 4 & 160 \\ 2 & 320\end{array}$

$\begin{array}{rr}<5 & <4 \\ <5 & 5 \\ <5 & <4 \\ <5 & <4\end{array}$

MANGA-

NESE,

DIS-

SOLVED

(UG/L MERCURY
DISSOLVED (UG/L

AS HG)

MOLYB-

DIS-

SOLVED

(UG/L

AS MO)

$\begin{array}{ll}<0.1 & <10 \\ <0.1 & <10 \\ <0.1 & <10 \\ 0.2 & <10\end{array}$

$<10$

10
15
12
23

$$
0.2
$$

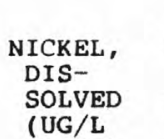

(US NI) $\begin{array}{lc}\text { SELE- } & \\ \text { NIUM, } & \text { SILVER, } \\ \text { DIS- } & \text { DIS- } \\ \text { SOLVED } & \text { SOLVED } \\ \text { (UG } / L & \text { (UG/L }\end{array}$

STRON-
TIUM,
DIS-
SOLVED
(UG/L

AS SR)
VANA-
DIUM,
DIS-
SOLVED
(UG/L
AS V)

$\begin{array}{lll}<1 & <1 & <1 \\ <1 & <1 & <1 \\ <1 & <1 & <1 \\ 4 & <1 & <1\end{array}$

$<1$

4

$\begin{array}{ll}29 & <6 \\ 41 & <6 \\ 31 & <6 \\ 56 & <6\end{array}$

0
0
0


04001000 WASHINGTON CREEK AT WINDIGO, MI--Continued

TEMPERATURE, WATER (DEG. C), WATER YEAR OCTOBER 1986 TO SEPTEMBER 1987

\begin{tabular}{|c|c|c|c|c|c|c|c|c|c|c|c|c|}
\hline DAY & MAX & MIN & MEAN & MAX & MIN & MEAN & MAX & MIN & MEAN & MAX & & MEAN \\
\hline \multicolumn{4}{|c|}{ OCTOBER } & \multicolumn{3}{|c|}{ NOVEMBER } & \multicolumn{3}{|c|}{ DECEMBER } & \multicolumn{3}{|c|}{ JANUARY } \\
\hline $\begin{array}{l}1 \\
2 \\
3 \\
4 \\
5\end{array}$ & $\begin{array}{r}10.5 \\
10.0 \\
10.0 \\
9.0 \\
8.5\end{array}$ & $\begin{array}{l}8.0 \\
7.0 \\
8.5 \\
7.5 \\
7.0\end{array}$ & $\begin{array}{l}9.5 \\
8.5 \\
9.5 \\
8.0 \\
8.0\end{array}$ & $\begin{array}{r}3.5 \\
1.0 \\
2.0 \\
.0 \\
1.5\end{array}$ & $\begin{array}{r}1.5 \\
.0 \\
.0 \\
.0 \\
.0\end{array}$ & $\begin{array}{r}2.5 \\
.5 \\
1.0 \\
.0 \\
.5\end{array}$ & $\begin{array}{l}.0 \\
.0 \\
.0 \\
.0 \\
.0\end{array}$ & $\begin{array}{l}.0 \\
.0 \\
.0 \\
.0 \\
.0\end{array}$ & $\begin{array}{l}.0 \\
.0 \\
.0 \\
.0 \\
.0\end{array}$ & $\begin{array}{l}.0 \\
.0 \\
.0 \\
.0 \\
.0\end{array}$ & $\begin{array}{l}.0 \\
.0 \\
.0 \\
.0 \\
.0\end{array}$ & $\begin{array}{l}.0 \\
.0 \\
.0 \\
.0 \\
.0\end{array}$ \\
\hline $\begin{array}{r}6 \\
7 \\
8 \\
9 \\
10\end{array}$ & $\begin{array}{l}7.0 \\
8.0 \\
8.0 \\
6.0 \\
5.5\end{array}$ & $\begin{array}{l}5.0 \\
6.5 \\
6.0 \\
3.5 \\
2.5\end{array}$ & $\begin{array}{l}6.0 \\
7.5 \\
7.0 \\
4.5 \\
4.0\end{array}$ & $\begin{array}{r}2.0 \\
2.0 \\
3.5 \\
1.0 \\
.0\end{array}$ & $\begin{array}{r}1.0 \\
2.0 \\
1.0 \\
.0 \\
.0\end{array}$ & $\begin{array}{r}1.5 \\
2.0 \\
3.0 \\
.0 \\
.0\end{array}$ & $\begin{array}{l}.0 \\
.0 \\
.0 \\
.0 \\
.0\end{array}$ & $\begin{array}{l}.0 \\
.0 \\
.0 \\
.0 \\
.0\end{array}$ & $\begin{array}{l}.0 \\
.0 \\
.0 \\
.0 \\
.0\end{array}$ & $\begin{array}{l}.0 \\
.0 \\
.0 \\
.0 \\
.0\end{array}$ & $\begin{array}{l}.0 \\
.0 \\
.0 \\
.0 \\
.0\end{array}$ & $\begin{array}{l}.0 \\
.0 \\
.0 \\
.0 \\
.0\end{array}$ \\
\hline $\begin{array}{l}11 \\
12 \\
13 \\
14 \\
15\end{array}$ & $\begin{array}{l}6.5 \\
6.0 \\
5.0 \\
4.5 \\
4.5\end{array}$ & $\begin{array}{l}5.5 \\
4.5 \\
4.5 \\
3.5 \\
3.0\end{array}$ & $\begin{array}{l}6.0 \\
5.0 \\
4.5 \\
4.0 \\
4.0\end{array}$ & $\begin{array}{l}.0 \\
.0 \\
.0 \\
.0 \\
.0\end{array}$ & $\begin{array}{l}.0 \\
.0 \\
.0 \\
.0 \\
.0\end{array}$ & $\begin{array}{l}.0 \\
.0 \\
.0 \\
.0 \\
.0\end{array}$ & $\begin{array}{l}.0 \\
.0 \\
.0 \\
.0 \\
.0\end{array}$ & $\begin{array}{l}.0 \\
.0 \\
.0 \\
.0 \\
.0\end{array}$ & $\begin{array}{l}.0 \\
.0 \\
.0 \\
.0 \\
.0\end{array}$ & $\begin{array}{l}.0 \\
.0 \\
.0 \\
.0 \\
.0\end{array}$ & $\begin{array}{l}.0 \\
.0 \\
.0 \\
.0 \\
.0\end{array}$ & $\begin{array}{l}.0 \\
.0 \\
.0 \\
.0 \\
.0\end{array}$ \\
\hline $\begin{array}{l}16 \\
17 \\
18 \\
19 \\
20\end{array}$ & $\begin{array}{l}5.0 \\
5.0 \\
4.0 \\
5.0 \\
6.5\end{array}$ & $\begin{array}{l}4.5 \\
3.5 \\
2.5 \\
2.5 \\
3.5\end{array}$ & $\begin{array}{l}4.5 \\
4.0 \\
3.0 \\
3.5 \\
5.0\end{array}$ & $\begin{array}{l}.0 \\
.0 \\
.0 \\
.0 \\
.0\end{array}$ & $\begin{array}{l}.0 \\
.0 \\
.0 \\
.0 \\
.0\end{array}$ & $\begin{array}{l}.0 \\
.0 \\
.0 \\
.0 \\
.0\end{array}$ & $\begin{array}{l}.0 \\
.0 \\
.0 \\
.0 \\
.0\end{array}$ & $\begin{array}{l}.0 \\
.0 \\
.0 \\
.0 \\
.0\end{array}$ & $\begin{array}{l}.0 \\
.0 \\
.0 \\
.0 \\
.0\end{array}$ & $\begin{array}{l}.0 \\
.0 \\
.0 \\
.0 \\
.0\end{array}$ & $\begin{array}{l}.0 \\
.0 \\
.0 \\
.0 \\
.0\end{array}$ & $\begin{array}{l}.0 \\
.0 \\
.0 \\
.0 \\
.0\end{array}$ \\
\hline $\begin{array}{l}21 \\
22 \\
23 \\
24 \\
25\end{array}$ & $\begin{array}{l}6.0 \\
7.5 \\
6.5 \\
6.0 \\
5.0\end{array}$ & $\begin{array}{l}4.5 \\
4.5 \\
6.0 \\
4.0 \\
3.0\end{array}$ & $\begin{array}{l}5.5 \\
6.0 \\
6.5 \\
5.0 \\
4.0\end{array}$ & $\begin{array}{l}.0 \\
.0 \\
.0 \\
.0 \\
.0\end{array}$ & $\begin{array}{l}.0 \\
.0 \\
.0 \\
.0 \\
.0\end{array}$ & $\begin{array}{l}.0 \\
.0 \\
.0 \\
.0 \\
.0\end{array}$ & $\begin{array}{l}.0 \\
.0 \\
.0 \\
.0 \\
.0\end{array}$ & $\begin{array}{l}.0 \\
.0 \\
.0 \\
.0 \\
.0\end{array}$ & $\begin{array}{l}.0 \\
.0 \\
.0 \\
.0 \\
.0\end{array}$ & $\begin{array}{l}.0 \\
.0 \\
.0 \\
.0 \\
.0\end{array}$ & $\begin{array}{l}.0 \\
.0 \\
.0 \\
.0 \\
.0\end{array}$ & $\begin{array}{l}.0 \\
.0 \\
.0 \\
.0 \\
.0\end{array}$ \\
\hline $\begin{array}{l}26 \\
27 \\
28 \\
29 \\
30 \\
31\end{array}$ & $\begin{array}{l}5.0 \\
5.0 \\
6.0 \\
6.0 \\
2.5 \\
5.0\end{array}$ & $\begin{array}{l}3.0 \\
3.0 \\
4.5 \\
3.0 \\
1.5 \\
2.5\end{array}$ & $\begin{array}{l}4.0 \\
4.0 \\
5.5 \\
4.5 \\
2.0 \\
4.0\end{array}$ & $\begin{array}{r}.0 \\
.0 \\
.0 \\
.0 \\
.0 \\
-0\end{array}$ & $\begin{array}{r}.0 \\
.0 \\
.0 \\
.0 \\
.0 \\
-.-\end{array}$ & $\begin{array}{r}.0 \\
.0 \\
.0 \\
.0 \\
.0 \\
---\end{array}$ & $\begin{array}{l}.0 \\
.0 \\
.0 \\
.0 \\
.0 \\
.0\end{array}$ & $\begin{array}{l}.0 \\
.0 \\
.0 \\
.0 \\
.0 \\
.0\end{array}$ & $\begin{array}{l}.0 \\
.0 \\
.0 \\
.0 \\
.0 \\
.0\end{array}$ & $\begin{array}{l}.0 \\
.0 \\
.0 \\
.0 \\
.0 \\
.0\end{array}$ & $\begin{array}{l}.0 \\
.0 \\
.0 \\
.0 \\
.0 \\
.0\end{array}$ & $\begin{array}{l}.0 \\
.0 \\
.0 \\
.0 \\
.0 \\
.0\end{array}$ \\
\hline MONTH & 10.5 & 1.5 & 5.5 & 3.5 & .0 & .5 & .0 & .0 & .0 & .0 & .0 & .0 \\
\hline \multirow[t]{2}{*}{ DAY } & $\operatorname{MAX}$ & MIN & MEAN & MAX & MIN & MEAN & MAX & MIN & MEAN & MAX & MIN & MEAN \\
\hline & \multicolumn{3}{|c|}{ FEBRUARY } & \multicolumn{3}{|c|}{ MARCH } & \multicolumn{3}{|c|}{ APRIL } & \multicolumn{3}{|c|}{ MAY } \\
\hline $\begin{array}{l}1 \\
2 \\
3 \\
4 \\
5\end{array}$ & $\begin{array}{l}.0 \\
.0 \\
.0 \\
.0 \\
.0\end{array}$ & $\begin{array}{l}.0 \\
.0 \\
.0 \\
.0 \\
.0\end{array}$ & $\begin{array}{l}.0 \\
.0 \\
.0 \\
.0 \\
.0\end{array}$ & $\begin{array}{l}.0 \\
.0 \\
.0 \\
.0 \\
.0\end{array}$ & $\begin{array}{l}.0 \\
.0 \\
.0 \\
.0 \\
.0\end{array}$ & $\begin{array}{l}.0 \\
.0 \\
.0 \\
.0 \\
.0\end{array}$ & $\begin{array}{l}.0 \\
.0 \\
.0 \\
.0 \\
.0\end{array}$ & $\begin{array}{l}.0 \\
.0 \\
.0 \\
.0 \\
.0\end{array}$ & $\begin{array}{l}.0 \\
.0 \\
.0 \\
.0 \\
.0\end{array}$ & $\begin{array}{l}11.0 \\
11.0 \\
11.0 \\
11.0 \\
12.5\end{array}$ & $\begin{array}{l}4.0 \\
4.0 \\
3.5 \\
3.5 \\
5.0\end{array}$ & $\begin{array}{l}7.0 \\
7.0 \\
7.0 \\
7.0 \\
8.5\end{array}$ \\
\hline $\begin{array}{r}6 \\
7 \\
8 \\
9 \\
10\end{array}$ & $\begin{array}{l}.0 \\
.0 \\
.0 \\
.0 \\
.0\end{array}$ & $\begin{array}{l}.0 \\
.0 \\
.0 \\
.0 \\
.0\end{array}$ & $\begin{array}{l}.0 \\
.0 \\
.0 \\
.0 \\
.0\end{array}$ & $\begin{array}{l}.0 \\
.0 \\
.0 \\
.0 \\
.0\end{array}$ & $\begin{array}{l}.0 \\
.0 \\
.0 \\
.0 \\
.0\end{array}$ & $\begin{array}{l}.0 \\
.0 \\
.0 \\
.0 \\
.0\end{array}$ & $\begin{array}{l}1.0 \\
2.5 \\
3.5 \\
5.0 \\
5.0\end{array}$ & $\begin{array}{r}.0 \\
.0 \\
.0 \\
1.0 \\
2.0\end{array}$ & $\begin{array}{r}.0 \\
1.0 \\
1.5 \\
2.5 \\
3.5\end{array}$ & $\begin{array}{l}14.0 \\
13.0 \\
13.5 \\
15.5 \\
13.0\end{array}$ & $\begin{array}{l}7.0 \\
7.0 \\
6.0 \\
8.5 \\
8.5\end{array}$ & $\begin{array}{l}10.5 \\
10.0 \\
10.0 \\
11.5 \\
11.0\end{array}$ \\
\hline $\begin{array}{l}11 \\
12 \\
13 \\
14 \\
15\end{array}$ & $\begin{array}{l}.0 \\
.0 \\
.0 \\
.0 \\
.0\end{array}$ & $\begin{array}{l}.0 \\
.0 \\
.0 \\
.0 \\
.0\end{array}$ & $\begin{array}{l}.0 \\
.0 \\
.0 \\
.0 \\
.0\end{array}$ & $\begin{array}{l}.0 \\
.0 \\
.0 \\
.0 \\
.0\end{array}$ & $\begin{array}{l}.0 \\
.0 \\
.0 \\
.0 \\
.0\end{array}$ & $\begin{array}{l}.0 \\
.0 \\
.0 \\
.0 \\
.0\end{array}$ & $\begin{array}{l}5.5 \\
5.5 \\
5.0 \\
6.5 \\
4.5\end{array}$ & $\begin{array}{l}2.0 \\
2.5 \\
2.5 \\
3.5 \\
3.5\end{array}$ & $\begin{array}{l}3.5 \\
4.0 \\
4.0 \\
4.5 \\
4.0\end{array}$ & $\begin{array}{l}13.5 \\
13.5 \\
14.5 \\
16.0 \\
15.5\end{array}$ & $\begin{array}{l}8.0 \\
6.0 \\
9.5 \\
9.5 \\
8.0\end{array}$ & $\begin{array}{r}10.5 \\
9.5 \\
11.5 \\
12.5 \\
12.0\end{array}$ \\
\hline $\begin{array}{l}16 \\
17 \\
18 \\
19 \\
20\end{array}$ & $\begin{array}{l}.0 \\
.0 \\
.0 \\
.0 \\
.0\end{array}$ & $\begin{array}{l}.0 \\
.0 \\
.0 \\
.0 \\
.0\end{array}$ & $\begin{array}{l}.0 \\
.0 \\
.0 \\
.0 \\
.0\end{array}$ & $\begin{array}{l}.0 \\
.0 \\
.0 \\
.0 \\
.0\end{array}$ & $\begin{array}{l}.0 \\
.0 \\
.0 \\
.0 \\
.0\end{array}$ & $\begin{array}{l}.0 \\
.0 \\
.0 \\
.0 \\
.0\end{array}$ & $\begin{array}{r}6.5 \\
8.0 \\
10.0 \\
12.5 \\
13.0\end{array}$ & $\begin{array}{l}3.5 \\
3.5 \\
5.0 \\
7.0 \\
9.5\end{array}$ & $\begin{array}{r}4.5 \\
5.5 \\
7.5 \\
9.5 \\
11.0\end{array}$ & $\begin{array}{r}15.0 \\
12.5 \\
10.5 \\
8.5 \\
10.0\end{array}$ & $\begin{array}{r}10.5 \\
9.5 \\
7.5 \\
8.0 \\
7.5\end{array}$ & $\begin{array}{r}12.5 \\
11.0 \\
9.0 \\
8.0 \\
8.5\end{array}$ \\
\hline $\begin{array}{l}21 \\
22 \\
23 \\
24 \\
25\end{array}$ & $\begin{array}{l}.0 \\
.0 \\
.0 \\
.0 \\
.0\end{array}$ & $\begin{array}{l}.0 \\
.0 \\
.0 \\
.0 \\
.0\end{array}$ & $\begin{array}{l}.0 \\
.0 \\
.0 \\
.0 \\
.0\end{array}$ & $\begin{array}{l}.0 \\
.0 \\
.0 \\
.0 \\
.0\end{array}$ & $\begin{array}{l}.0 \\
.0 \\
.0 \\
.0 \\
.0\end{array}$ & $\begin{array}{l}.0 \\
.0 \\
.0 \\
.0 \\
.0\end{array}$ & $\begin{array}{r}10.5 \\
9.5 \\
10.0 \\
9.5 \\
9.0\end{array}$ & $\begin{array}{l}7.5 \\
5.5 \\
4.0 \\
4.5 \\
6.5\end{array}$ & $\begin{array}{l}9.0 \\
7.5 \\
7.0 \\
7.0 \\
7.5\end{array}$ & $\begin{array}{r}10.5 \\
8.5 \\
8.5 \\
11.5 \\
11.5\end{array}$ & $\begin{array}{l}8.5 \\
5.5 \\
4.5 \\
6.0 \\
8.5\end{array}$ & $\begin{array}{r}9.5 \\
6.5 \\
6.5 \\
8.5 \\
10.0\end{array}$ \\
\hline $\begin{array}{l}26 \\
27 \\
28 \\
29 \\
30 \\
31\end{array}$ & $\begin{array}{r}.0 \\
.0 \\
.0 \\
-.- \\
--- \\
---\end{array}$ & $\begin{array}{r}.0 \\
.0 \\
.0 \\
-0- \\
--- \\
---\end{array}$ & $\begin{array}{r}.0 \\
.0 \\
.0 \\
--- \\
--- \\
---\end{array}$ & $\begin{array}{l}.0 \\
.0 \\
.0 \\
.0 \\
.0 \\
.0\end{array}$ & $\begin{array}{l}.0 \\
.0 \\
.0 \\
.0 \\
.0 \\
.0\end{array}$ & $\begin{array}{l}.0 \\
.0 \\
.0 \\
.0 \\
.0 \\
.0\end{array}$ & $\begin{array}{r}10.5 \\
9.0 \\
8.5 \\
11.0 \\
10.0 \\
\end{array}$ & $\begin{array}{l}5.5 \\
6.5 \\
5.5 \\
6.0 \\
5.0 \\
---\end{array}$ & $\begin{array}{l}8.0 \\
8.0 \\
7.0 \\
8.0 \\
7.0 \\
---0\end{array}$ & $\begin{array}{l}10.5 \\
14.5 \\
16.0 \\
18.0 \\
18.5 \\
19.0\end{array}$ & $\begin{array}{l}10.0 \\
10.0 \\
12.5 \\
13.5 \\
15.0 \\
15.5\end{array}$ & $\begin{array}{l}10.0 \\
12.0 \\
14.5 \\
16.0 \\
16.5 \\
17.0\end{array}$ \\
\hline MONTH & .0 & .0 & .0 & .0 & .0 & .0 & 13.0 & .0 & 5.0 & 19.0 & 3.5 & 10.5 \\
\hline
\end{tabular}


04001000 WASHINGTON CREEK AT WINDIGO, MI--Cont inued

TEMPERATURE, WATER (DEG. C), WATER YEAR OCTOBER 1986 TO SEPTEMBER 1987

\begin{tabular}{|c|c|c|c|c|c|c|c|c|c|c|c|c|}
\hline DAY & MAX & MIN & MEAN & MAX & MIN & MEAN & MAX & MIN & MEAN & MAX & MIN & MEAN \\
\hline \multicolumn{4}{|c|}{ JUNE } & \multicolumn{3}{|c|}{ JULY } & \multicolumn{3}{|c|}{ AUGUST } & \multicolumn{3}{|c|}{ SEPTEMBER } \\
\hline $\begin{array}{l}1 \\
2 \\
3 \\
4 \\
5\end{array}$ & $\begin{array}{l}20.0 \\
17.5 \\
16.0 \\
13.5 \\
15.0\end{array}$ & $\begin{array}{l}15.0 \\
15.0 \\
13.5 \\
11.0 \\
10.0\end{array}$ & $\begin{array}{l}17.0 \\
16.5 \\
14.5 \\
12.5 \\
12.5\end{array}$ & $\begin{array}{l}18.0 \\
17.5 \\
17.0 \\
20.0 \\
20.0\end{array}$ & $\begin{array}{l}12.0 \\
14.5 \\
14.5 \\
13.0 \\
14.5\end{array}$ & $\begin{array}{l}15.0 \\
16.0 \\
16.0 \\
16.0 \\
17.0\end{array}$ & $\begin{array}{l}17.5 \\
20.5 \\
20.5 \\
18.5 \\
17.5\end{array}$ & $\begin{array}{l}17.0 \\
16.5 \\
17.0 \\
15.5 \\
12.5\end{array}$ & $\begin{array}{l}17.5 \\
18.0 \\
18.5 \\
17.0 \\
15.0\end{array}$ & $\begin{array}{l}14.0 \\
13.5 \\
12.5 \\
15.0 \\
15.5\end{array}$ & $\begin{array}{l}12.0 \\
12.0 \\
10.0 \\
12.5 \\
13.5\end{array}$ & $\begin{array}{l}13.0 \\
12.5 \\
11.5 \\
13.5 \\
14.5\end{array}$ \\
\hline $\begin{array}{r}6 \\
7 \\
8 \\
9 \\
10\end{array}$ & $\begin{array}{l}13.5 \\
15.5 \\
14.0 \\
15.0 \\
15.5\end{array}$ & $\begin{array}{r}11.5 \\
11.5 \\
12.0 \\
9.5 \\
10.0\end{array}$ & $\begin{array}{l}12.5 \\
13.5 \\
13.0 \\
12.0 \\
12.5\end{array}$ & $\begin{array}{l}18.5 \\
23.0 \\
24.5 \\
19.5 \\
20.0\end{array}$ & $\begin{array}{l}17.0 \\
16.0 \\
18.0 \\
16.5 \\
15.0\end{array}$ & $\begin{array}{l}17.5 \\
19.0 \\
20.5 \\
17.5 \\
17.0\end{array}$ & $\begin{array}{l}18.5 \\
19.0 \\
20.5 \\
18.5 \\
20.0\end{array}$ & $\begin{array}{l}14.5 \\
15.0 \\
14.5 \\
15.5 \\
14.5\end{array}$ & $\begin{array}{l}16.5 \\
17.0 \\
17.0 \\
17.0 \\
17.0\end{array}$ & $\begin{array}{l}16.0 \\
15.5 \\
15.0 \\
14.5 \\
14.5\end{array}$ & $\begin{array}{l}14.5 \\
13.0 \\
14.0 \\
13.0 \\
13.5\end{array}$ & $\begin{array}{l}15.0 \\
14.5 \\
14.5 \\
14.0 \\
14.0\end{array}$ \\
\hline $\begin{array}{l}11 \\
12 \\
13 \\
14 \\
15\end{array}$ & $\begin{array}{l}13.5 \\
17.0 \\
18.0 \\
19.5 \\
19.5\end{array}$ & $\begin{array}{l}12.5 \\
12.0 \\
13.0 \\
14.0 \\
13.5\end{array}$ & $\begin{array}{l}13.0 \\
14.0 \\
15.5 \\
16.5 \\
16.5\end{array}$ & $\begin{array}{l}18.0 \\
18.5 \\
17.0 \\
17.5 \\
18.5\end{array}$ & $\begin{array}{l}16.0 \\
16.0 \\
14.5 \\
13.0 \\
12.0\end{array}$ & $\begin{array}{l}17.0 \\
17.0 \\
16.0 \\
14.5 \\
15.0\end{array}$ & $\begin{array}{l}21.5 \\
19.0 \\
18.0 \\
19.0 \\
20.0\end{array}$ & $\begin{array}{l}15.5 \\
16.5 \\
16.0 \\
17.0 \\
18.0\end{array}$ & $\begin{array}{l}18.0 \\
17.5 \\
17.0 \\
18.0 \\
18.5\end{array}$ & $\begin{array}{l}15.5 \\
14.5 \\
14.0 \\
14.0 \\
14.0\end{array}$ & $\begin{array}{l}14.0 \\
12.5 \\
13.0 \\
11.5 \\
11.5\end{array}$ & $\begin{array}{l}14.5 \\
14.0 \\
13.5 \\
13.0 \\
13.0\end{array}$ \\
\hline $\begin{array}{l}21 \\
22 \\
23 \\
24 \\
25\end{array}$ & $\begin{array}{l}19.5 \\
21.5 \\
23.0 \\
22.5 \\
20.0\end{array}$ & $\begin{array}{l}14.5 \\
15.0 \\
16.0 \\
17.5 \\
17.0\end{array}$ & $\begin{array}{l}17.0 \\
18.0 \\
19.0 \\
20.0 \\
18.5\end{array}$ & $\begin{array}{l}20.5 \\
21.0 \\
22.5 \\
23.0 \\
22.5\end{array}$ & $\begin{array}{l}15.0 \\
17.0 \\
18.5 \\
18.5 \\
16.5\end{array}$ & $\begin{array}{l}17.5 \\
18.5 \\
20.0 \\
20.5 \\
19.0\end{array}$ & $\begin{array}{l}16.5 \\
16.0 \\
15.5 \\
15.0 \\
15.0\end{array}$ & $\begin{array}{l}14.5 \\
14.5 \\
13.5 \\
11.5 \\
13.0\end{array}$ & $\begin{array}{l}15.5 \\
15.5 \\
14.5 \\
13.5 \\
14.0\end{array}$ & $\begin{array}{l}13.5 \\
14.0 \\
14.0 \\
12.5 \\
11.0\end{array}$ & $\begin{array}{r}12.5 \\
12.5 \\
12.5 \\
10.5 \\
9.0\end{array}$ & $\begin{array}{l}13.0 \\
13.0 \\
13.0 \\
11.0 \\
10.0\end{array}$ \\
\hline $\begin{array}{l}26 \\
27 \\
28 \\
29 \\
30 \\
31\end{array}$ & $\begin{array}{l}17.5 \\
18.0 \\
18.5 \\
17.5 \\
19.0 \\
-\end{array}$ & $\begin{array}{r}15.5 \\
14.0 \\
13.5 \\
13.5 \\
13.5 \\
---\end{array}$ & $\begin{array}{l}16.5 \\
15.5 \\
15.5 \\
15.5 \\
15.5 \\
--.\end{array}$ & $\begin{array}{l}22.0 \\
21.5 \\
21.5 \\
21.5 \\
22.0 \\
18.5\end{array}$ & $\begin{array}{l}16.0 \\
14.5 \\
14.5 \\
15.5 \\
17.0 \\
16.5\end{array}$ & $\begin{array}{l}18.5 \\
17.5 \\
18.0 \\
18.0 \\
19.0 \\
17.5\end{array}$ & $\begin{array}{l}15.0 \\
16.0 \\
16.0 \\
16.0 \\
16.5 \\
14.5\end{array}$ & $\begin{array}{l}13.5 \\
13.5 \\
13.0 \\
12.5 \\
14.5 \\
13.0\end{array}$ & $\begin{array}{l}14.0 \\
14.5 \\
14.5 \\
14.5 \\
15.5 \\
13.5\end{array}$ & $\begin{array}{l}10.5 \\
13.0 \\
14.0 \\
14.0 \\
13.0 \\
---\end{array}$ & $\begin{array}{r}8.5 \\
10.5 \\
12.0 \\
13.0 \\
10.5 \\
---\end{array}$ & $\begin{array}{r}9.5 \\
11.5 \\
13.0 \\
13.5 \\
11.5 \\
-\end{array}$ \\
\hline MONTH & 23.0 & 9.5 & 16.0 & 24.5 & 12.0 & 17.5 & 21.5 & 11.5 & 16.0 & 16.0 & 8.5 & 13.0 \\
\hline
\end{tabular}


04033000 MIDDLE BRANCH ONTONAGON RIVER NEAR PAULDING, MI

LOCATION. - Lat $46^{\circ} 21^{\prime} 25^{\prime \prime}$, long $89^{\circ} 04^{\prime} 38^{\prime \prime}$, in SEl/4 NEl/4 sec. 29, T.46 N., R. 38 W., Ontonagon County, Hydrologic Unit 04020102 , Ottawa National Forest, on right bank 25 ft downstream from bridge on Forest Service Road 172, $2.4 \mathrm{mi}$ upstream from Bond Falls Reservoir, and $5.7 \mathrm{mi}$ southeast of paulding.

DRAINAGE AREA. $--164 \mathrm{mi}^{2}$.

PERIOD OF RECORD.--June 1942 to current year. Monthly discharge only for some periods, published in wSP 1307.

REVISED RECORDS.--WSP 1911: Drainage area.

GAGE.--water-stage recorder. Datum of gage is $1,485.66 \mathrm{ft}$ above National Geodetic Vertical Datum of 1929 (levels by Michigan Department of Natural Resources). Prior to Sept. 28, 1942, nonrecording gage at same site and datum.

REMARKS.--Estimated daily discharges: Nov. 12 to Mar. 14. Records good except for estimated daily discharges, which are fair. Several measurements of water temperature were made during the year.

AVERAGE DISCHARGE. --45 years, $174 \mathrm{ft}^{3} / \mathrm{s}, 14.41 \mathrm{in} / \mathrm{yr}^{2}$

EXTREMES FOR PERIOD OF RECORD.--Maximum discharge, $2,050 \mathrm{ft}^{3} \mathrm{~s}$, Apr. 30, 1951, gage height, 10.0 ft, from floodmark; minimum, $27 \mathrm{ft}^{3}, \mathrm{~s}$, Nov. 22, 1946, result of freezeup; minimum gage height, 2.96 ft, Nov. 26,1942 , result of freezeup.

EXTREMES FOF CURRENT YEAR.--Maximum discharge, $405 \mathrm{ft}^{3} / \mathrm{s}$, Oct. 12,13 , gage height, $5.45 \mathrm{ft}$; maximum gage height, $5.64 \mathrm{ft}$, Feb. 16 , backwater from ice; minimum discharge, $68 \mathrm{ft} / \mathrm{s}$, Nov. 11, gage height, $3.48 \mathrm{ft}$, result of freezeup.

DISCHARGE, IN CUBIC FEET PER SECOND, WATER YEAR OCTOBER 1986 TO SEPTEMBER 1987 MEAN VALUES

\begin{tabular}{|c|c|c|c|c|c|c|c|c|c|c|c|c|}
\hline DAY & OCT & NOV & DEC & JAN & FEB & MAR & APR & MAY & JUN & JUL & AUG & SEP \\
\hline $\begin{array}{l}1 \\
2 \\
3 \\
4 \\
5\end{array}$ & $\begin{array}{l}140 \\
133 \\
133 \\
133 \\
134\end{array}$ & $\begin{array}{l}164 \\
162 \\
151 \\
146 \\
142\end{array}$ & $\begin{array}{l}130 \\
125 \\
120 \\
110 \\
105\end{array}$ & $\begin{array}{l}105 \\
108 \\
108 \\
108 \\
108\end{array}$ & $\begin{array}{r}96 \\
98 \\
100 \\
100 \\
100\end{array}$ & $\begin{array}{l}120 \\
120 \\
120 \\
125 \\
130\end{array}$ & $\begin{array}{l}172 \\
156 \\
147 \\
149 \\
152\end{array}$ & $\begin{array}{l}120 \\
117 \\
114 \\
111 \\
109\end{array}$ & $\begin{array}{l}245 \\
241 \\
224 \\
196 \\
183\end{array}$ & $\begin{array}{r}95 \\
103 \\
176 \\
162 \\
133\end{array}$ & $\begin{array}{l}115 \\
130 \\
132 \\
129 \\
117\end{array}$ & $\begin{array}{r}100 \\
101 \\
101 \\
99 \\
97\end{array}$ \\
\hline $\begin{array}{r}6 \\
7 \\
8 \\
9 \\
10\end{array}$ & $\begin{array}{l}136 \\
132 \\
140 \\
139 \\
130\end{array}$ & $\begin{array}{l}143 \\
144 \\
161 \\
182 \\
175\end{array}$ & $\begin{array}{l}100 \\
100 \\
100 \\
100 \\
100\end{array}$ & $\begin{array}{l}108 \\
105 \\
105 \\
105 \\
105\end{array}$ & $\begin{array}{l}100 \\
105 \\
105 \\
110 \\
110\end{array}$ & $\begin{array}{l}130 \\
140 \\
160 \\
145 \\
135\end{array}$ & $\begin{array}{l}168 \\
176 \\
176 \\
172 \\
172\end{array}$ & $\begin{array}{l}108 \\
105 \\
105 \\
104 \\
105\end{array}$ & $\begin{array}{l}168 \\
151 \\
140 \\
132 \\
125\end{array}$ & $\begin{array}{l}124 \\
191 \\
187 \\
164 \\
212\end{array}$ & $\begin{array}{l}118 \\
114 \\
111 \\
110 \\
111\end{array}$ & $\begin{array}{r}101 \\
103 \\
99 \\
99 \\
97\end{array}$ \\
\hline $\begin{array}{l}11 \\
12 \\
13 \\
14 \\
15\end{array}$ & $\begin{array}{l}133 \\
322 \\
376 \\
312 \\
289\end{array}$ & $\begin{array}{l}135 \\
125 \\
120 \\
120 \\
115\end{array}$ & $\begin{array}{l}98 \\
98 \\
98 \\
98 \\
98\end{array}$ & $\begin{array}{l}105 \\
105 \\
105 \\
105 \\
105\end{array}$ & $\begin{array}{l}110 \\
110 \\
110 \\
110 \\
110\end{array}$ & $\begin{array}{l}130 \\
130 \\
125 \\
125 \\
125\end{array}$ & $\begin{array}{l}170 \\
164 \\
157 \\
157 \\
168\end{array}$ & $\begin{array}{l}115 \\
113 \\
108 \\
106 \\
104\end{array}$ & $\begin{array}{l}129 \\
137 \\
126 \\
117 \\
111\end{array}$ & $\begin{array}{l}291 \\
359 \\
334 \\
287 \\
244\end{array}$ & $\begin{array}{l}108 \\
108 \\
153 \\
192 \\
185\end{array}$ & $\begin{array}{l}100 \\
111 \\
116 \\
115 \\
116\end{array}$ \\
\hline $\begin{array}{l}16 \\
17 \\
18 \\
19 \\
20\end{array}$ & $\begin{array}{l}270 \\
248 \\
222 \\
205 \\
192\end{array}$ & $\begin{array}{l}120 \\
120 \\
120 \\
125 \\
130\end{array}$ & $\begin{array}{r}98 \\
98 \\
98 \\
98 \\
100\end{array}$ & $\begin{array}{r}100 \\
96 \\
94 \\
94 \\
94\end{array}$ & $\begin{array}{l}115 \\
115 \\
115 \\
115 \\
115\end{array}$ & $\begin{array}{l}127 \\
124 \\
123 \\
126 \\
132\end{array}$ & $\begin{array}{l}166 \\
161 \\
154 \\
143 \\
141\end{array}$ & $\begin{array}{l}105 \\
108 \\
120 \\
177 \\
195\end{array}$ & $\begin{array}{r}106 \\
104 \\
105 \\
103 \\
98\end{array}$ & $\begin{array}{l}214 \\
191 \\
174 \\
177 \\
169\end{array}$ & $\begin{array}{l}153 \\
133 \\
123 \\
128 \\
121\end{array}$ & $\begin{array}{l}107 \\
122 \\
125 \\
160 \\
176\end{array}$ \\
\hline $\begin{array}{l}21 \\
22 \\
23 \\
24 \\
25\end{array}$ & $\begin{array}{l}186 \\
178 \\
172 \\
166 \\
159\end{array}$ & $\begin{array}{l}130 \\
130 \\
135 \\
135 \\
140\end{array}$ & $\begin{array}{l}100 \\
100 \\
100 \\
100 \\
100\end{array}$ & $\begin{array}{l}94 \\
94 \\
94 \\
94 \\
94\end{array}$ & $\begin{array}{l}120 \\
120 \\
120 \\
120 \\
120\end{array}$ & $\begin{array}{l}137 \\
143 \\
161 \\
182 \\
195\end{array}$ & $\begin{array}{l}141 \\
140 \\
137 \\
132 \\
130\end{array}$ & $\begin{array}{l}172 \\
166 \\
163 \\
150 \\
140\end{array}$ & $\begin{array}{r}97 \\
98 \\
106 \\
94 \\
93\end{array}$ & $\begin{array}{l}178 \\
166 \\
145 \\
155 \\
167\end{array}$ & $\begin{array}{ll}1 & 20 \\
1 & 17 \\
11 & 2 \\
1 & 07 \\
1 & 04\end{array}$ & $\begin{array}{l}155 \\
141 \\
136 \\
122 \\
116\end{array}$ \\
\hline $\begin{array}{l}26 \\
27 \\
28 \\
29 \\
30 \\
31\end{array}$ & $\begin{array}{l}151 \\
147 \\
143 \\
144 \\
140 \\
143\end{array}$ & $\begin{array}{l}140 \\
140 \\
135 \\
130 \\
130\end{array}$ & $\begin{array}{l}105 \\
105 \\
105 \\
105 \\
105 \\
105\end{array}$ & $\begin{array}{l}94 \\
94 \\
94 \\
94 \\
94 \\
96\end{array}$ & $\begin{array}{l}120 \\
120 \\
120 \\
--- \\
---\end{array}$ & $\begin{array}{l}188 \\
180 \\
174 \\
163 \\
159 \\
166\end{array}$ & $\begin{array}{l}137 \\
141 \\
138 \\
131 \\
122 \\
--\end{array}$ & $\begin{array}{l}138 \\
137 \\
145 \\
156 \\
262 \\
284\end{array}$ & $\begin{array}{r}94 \\
103 \\
108 \\
101 \\
98 \\
---\end{array}$ & $\begin{array}{l}145 \\
131 \\
124 \\
118 \\
115 \\
112\end{array}$ & $\begin{array}{r}103 \\
102 \\
99 \\
98 \\
100 \\
102\end{array}$ & $\begin{array}{l}110 \\
109 \\
107 \\
106 \\
107 \\
--1\end{array}$ \\
\hline $\begin{array}{l}\text { TOTAL } \\
\text { MEAN } \\
\text { MAX } \\
\text { MIN } \\
\text { CFSM } \\
\text { IN. }\end{array}$ & $\begin{array}{r}5648 \\
182 \\
376 \\
130 \\
1.11 \\
1.28\end{array}$ & $\begin{array}{r}4145 \\
138 \\
182 \\
115 \\
.84 \\
.94\end{array}$ & $\begin{array}{r}3202 \\
103 \\
130 \\
98 \\
.63 \\
.73\end{array}$ & $\begin{array}{r}3104 \\
100 \\
108 \\
94 \\
.61 \\
.70\end{array}$ & $\begin{array}{r}3109 \\
111 \\
120 \\
96 \\
.68 \\
.71\end{array}$ & $\begin{array}{r}4440 \\
143 \\
195 \\
120 \\
.87 \\
1.01\end{array}$ & $\begin{array}{r}4570 \\
152 \\
176 \\
122 \\
.93 \\
1.04\end{array}$ & $\begin{array}{r}4262 \\
137 \\
284 \\
104 \\
.84 \\
.97\end{array}$ & $\begin{array}{r}3933 \\
131 \\
245 \\
93 \\
.80 \\
.89\end{array}$ & $\begin{array}{r}5543 \\
179 \\
359 \\
95 \\
1.09 \\
1.26\end{array}$ & $\begin{array}{r}3755 \\
121 \\
192 \\
98 \\
.74 \\
.85\end{array}$ & $\begin{array}{r}3454 \\
115 \\
176 \\
97 \\
.70 \\
.78\end{array}$ \\
\hline $\begin{array}{ll}\text { CAL YR } \\
\text { WTR YR }\end{array}$ & $\begin{array}{l}1986 \\
1987\end{array}$ & $\begin{array}{ll}\text { I } & 62 \\
\text { I } & 49\end{array}$ & $\mathrm{ME}$ & $\begin{array}{l}172 \\
135\end{array}$ & $\begin{array}{lr}\text { MAX } & 1010 \\
\text { MAX } & 376\end{array}$ & $\begin{array}{l}\text { MIN } \\
\text { MIN }\end{array}$ & $\begin{array}{l}\text { CFSM } \\
\text { CFSM }\end{array}$ & $\begin{array}{r}1.05 \\
.82\end{array}$ & $\begin{array}{l}\text { IN } 14 . \\
\text { IN } 11 .\end{array}$ & & & \\
\hline
\end{tabular}




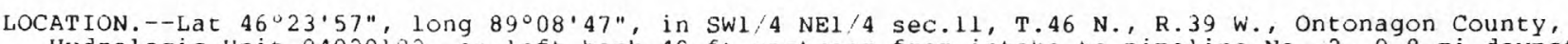

Hydrologic unit 04020102 , On left bank 40 ft upstream from intake to pipeline No. 2 , 0.8 mi downstream from Bond Falls Reservoir on Middle Branch Ontonagon River, and $1.6 \mathrm{mi}$ east of Paulding.

PERIOD OF RECORD.--July 1942 to current year.

GAGE.--Water-stage recorder and concrete control. Datum of qage is $1,441.59 \mathrm{ft}$ above National Geodetic Vertical Datum of 1929. Prior to Oct. 1, 1968 , nonrecording gage at datum $3.00 \mathrm{ft}$ higher.

REMARKS.--Estimated daily discharges: Jan. 24, 25. Records excellent except those below 5 ft $3 / \mathrm{s}$,

which are poor. Canal diverts water from Bond Falls Reservoir (station 04034000) to South Branch Ontonagon River; water is used for power production at Victoria Dam near Rockland. Several

measurements of water temperature were made during the year.

AVERAGE DISCHARGE. -45 years, $143 \mathrm{ft}^{3} / \mathrm{s}$.

EXTREMES FOR PERIOD OF RECORD.--Maximum daily discharge, $368 \mathrm{ft}^{3}$ /s, May 5, 1960 ; no flow for several days in 1963-70, 1973-75, 1982, 1987.

DISCHARGE, IN CUBIC FEET PER SECOND, WATER YEAR OCTOBER 1986 TO SEPTEMBER 1987

\begin{tabular}{|c|c|c|c|c|c|c|c|c|c|c|c|c|}
\hline DAY & OCT & NOV & DEC & JAN & FEB & MAR & APR & MAY & JUN & JUL & AUG & SEP \\
\hline $\begin{array}{l}1 \\
2 \\
3 \\
4 \\
5\end{array}$ & $\begin{array}{l}6.0 \\
6.2 \\
6.4 \\
6.4 \\
6.3\end{array}$ & $\begin{array}{r}8.5 \\
8.5 \\
8.5 \\
8.5 \\
58\end{array}$ & $\begin{array}{l}129 \\
164 \\
195 \\
195 \\
195\end{array}$ & $\begin{array}{l}202 \\
201 \\
201 \\
196 \\
193\end{array}$ & $\begin{array}{l}200 \\
199 \\
198 \\
197 \\
197\end{array}$ & $\begin{array}{l}128 \\
128 \\
120 \\
106 \\
106\end{array}$ & $\begin{array}{l}.00 \\
.00 \\
.30 \\
.50 \\
.80\end{array}$ & $\begin{array}{l}66 \\
59 \\
59 \\
59 \\
59\end{array}$ & $\begin{array}{l}32 \\
11 \\
11 \\
11 \\
11\end{array}$ & $\begin{array}{l}19 \\
27 \\
27 \\
27 \\
27\end{array}$ & $\begin{array}{l}202 \\
201 \\
201 \\
161 \\
113\end{array}$ & $\begin{array}{l}106 \\
105 \\
104 \\
105 \\
105\end{array}$ \\
\hline $\begin{array}{r}6 \\
7 \\
8 \\
9 \\
10\end{array}$ & $\begin{array}{r}6.4 \\
6.5 \\
6.5 \\
40 \\
78\end{array}$ & $\begin{array}{l}110 \\
109 \\
103 \\
102 \\
109\end{array}$ & $\begin{array}{l}194 \\
194 \\
194 \\
192 \\
192\end{array}$ & $\begin{array}{l}200 \\
199 \\
198 \\
198 \\
197\end{array}$ & $\begin{array}{l}196 \\
195 \\
194 \\
193 \\
192\end{array}$ & $\begin{array}{r}62 \\
4.4 \\
4.0 \\
3.8 \\
3.8\end{array}$ & $\begin{array}{c}1.2 \\
1.3 \\
1.3 \\
1.1 \\
.90\end{array}$ & $\begin{array}{l}59 \\
59 \\
59 \\
59 \\
60\end{array}$ & $\begin{array}{r}36 \\
59 \\
139 \\
255 \\
255\end{array}$ & $\begin{array}{l}28 \\
28 \\
28 \\
29 \\
28\end{array}$ & $\begin{array}{l}106 \\
106 \\
106 \\
106 \\
105\end{array}$ & $\begin{array}{l}105 \\
104 \\
103 \\
102 \\
103\end{array}$ \\
\hline $\begin{array}{l}11 \\
12 \\
13 \\
14 \\
15\end{array}$ & $\begin{array}{r}79 \\
58 \\
7.1 \\
6.9 \\
6.8\end{array}$ & $\begin{array}{l}142 \\
189 \\
247 \\
310 \\
309\end{array}$ & $\begin{array}{l}191 \\
188 \\
190 \\
190 \\
189\end{array}$ & $\begin{array}{l}196 \\
196 \\
196 \\
195 \\
194\end{array}$ & $\begin{array}{l}192 \\
191 \\
191 \\
189 \\
189\end{array}$ & $\begin{array}{l}3.4 \\
3.4 \\
3.4 \\
3.4 \\
3.4\end{array}$ & $\begin{array}{l}.80 \\
.50 \\
.00 \\
.00 \\
.00\end{array}$ & $\begin{array}{l}59 \\
59 \\
59 \\
59 \\
59\end{array}$ & $\begin{array}{r}255 \\
170 \\
76 \\
68 \\
68\end{array}$ & $\begin{array}{l}29 \\
29 \\
29 \\
30 \\
30\end{array}$ & $\begin{array}{l}105 \\
106 \\
106 \\
106 \\
106\end{array}$ & $\begin{array}{l}103 \\
103 \\
102 \\
102 \\
102\end{array}$ \\
\hline $\begin{array}{l}16 \\
17 \\
18 \\
19 \\
20\end{array}$ & $\begin{array}{l}6.8 \\
6.8 \\
7.0 \\
7.1 \\
7.4\end{array}$ & $\begin{array}{l}309 \\
307 \\
306 \\
304 \\
303\end{array}$ & $\begin{array}{l}189 \\
189 \\
188 \\
188 \\
188\end{array}$ & $\begin{array}{l}194 \\
194 \\
192 \\
192 \\
198\end{array}$ & $\begin{array}{l}178 \\
183 \\
184 \\
184 \\
183\end{array}$ & $\begin{array}{l}3.3 \\
3.3 \\
3.4 \\
3.4 \\
3.4\end{array}$ & $\begin{array}{l}.00 \\
.00 \\
.00 \\
.00 \\
.00\end{array}$ & $\begin{array}{l}59 \\
59 \\
59 \\
59 \\
34\end{array}$ & $\begin{array}{l}67 \\
61 \\
54 \\
53 \\
54\end{array}$ & $\begin{array}{r}65 \\
109 \\
109 \\
109 \\
109\end{array}$ & $\begin{array}{c}106 \\
77 \\
11 \\
9.1 \\
57\end{array}$ & $\begin{array}{l}102 \\
102 \\
101 \\
102 \\
101\end{array}$ \\
\hline $\begin{array}{l}21 \\
22 \\
23 \\
24 \\
25\end{array}$ & $\begin{array}{l}7.6 \\
7.7 \\
7.7 \\
7.9 \\
8.0\end{array}$ & $\begin{array}{l}302 \\
301 \\
299 \\
297 \\
257\end{array}$ & $\begin{array}{l}187 \\
186 \\
186 \\
186 \\
184\end{array}$ & $\begin{array}{l}206 \\
205 \\
203 \\
202 \\
201\end{array}$ & $\begin{array}{l}183 \\
182 \\
180 \\
180 \\
180\end{array}$ & $\begin{array}{l}3.4 \\
3.4 \\
4.7 \\
3.9 \\
1.0\end{array}$ & $\begin{array}{r}.00 \\
145^{.00} \\
140^{\circ} \\
154\end{array}$ & $\begin{array}{l}7.6 \\
41 \\
77 \\
71 \\
71\end{array}$ & $\begin{array}{l}54 \\
54 \\
54 \\
54 \\
54\end{array}$ & $\begin{array}{l}109 \\
109 \\
109 \\
109 \\
109\end{array}$ & $\begin{array}{l}108 \\
105 \\
105 \\
105 \\
105\end{array}$ & $\begin{array}{ll}1 & 01 \\
1 & 01 \\
1 & 01 \\
1 & 01 \\
1 & 0\end{array}$ \\
\hline $\begin{array}{l}26 \\
27 \\
28 \\
29 \\
30 \\
31\end{array}$ & $\begin{array}{l}8.0 \\
8.0 \\
8.1 \\
8.4 \\
8.5 \\
8.4\end{array}$ & $\begin{array}{l}167 \\
131 \\
131 \\
129 \\
129 \\
---\end{array}$ & $\begin{array}{l}184 \\
184 \\
183 \\
193 \\
203 \\
202\end{array}$ & $\begin{array}{l}201 \\
203 \\
203 \\
203 \\
201 \\
201\end{array}$ & $\begin{array}{l}178 \\
157 \\
128 \\
--- \\
--- \\
---\end{array}$ & $\begin{array}{l}.30 \\
.30 \\
.70 \\
.60 \\
.00 \\
.00\end{array}$ & $\begin{array}{r}153 \\
136 \\
108 \\
99 \\
88\end{array}$ & $\begin{array}{l}62 \\
52 \\
52 \\
53 \\
52 \\
52\end{array}$ & $\begin{array}{r}54 \\
54 \\
54 \\
54 \\
38 \\
-\end{array}$ & $\begin{array}{l}109 \\
109 \\
151 \\
201 \\
201 \\
201\end{array}$ & $\begin{array}{l}105 \\
105 \\
105 \\
105 \\
105 \\
106\end{array}$ & $\begin{array}{l}101 \\
101 \\
102 \\
101 \\
101 \\
-\end{array}$ \\
\hline $\begin{array}{l}\text { TOTAL } \\
\text { MEAN } \\
\text { MAX } \\
\text { MIN }\end{array}$ & $\begin{array}{r}449.9 \\
14.5 \\
79 \\
6.0\end{array}$ & $\begin{array}{r}5494.0 \\
183 \\
310 \\
8.5\end{array}$ & $\begin{array}{r}5812 \\
187 \\
203 \\
129\end{array}$ & $\begin{array}{r}6161 \\
199 \\
206 \\
192\end{array}$ & $\begin{array}{r}5193 \\
185 \\
200 \\
128\end{array}$ & $\begin{array}{r}718.10 \\
23.2 \\
128 \\
.00\end{array}$ & $\begin{array}{r}957.70 \\
31.9 \\
154 \\
.00\end{array}$ & $\begin{array}{r}1753.6 \\
56.6 \\
77 \\
7.6\end{array}$ & $\begin{array}{r}2270 \\
75.7 \\
255 \\
11\end{array}$ & $\begin{array}{r}2433 \\
78.5 \\
201 \\
19\end{array}$ & $\begin{array}{r}3355.1 \\
108 \\
202 \\
9.1\end{array}$ & $\begin{array}{r}3072 \\
102 \\
106 \\
100\end{array}$ \\
\hline $\begin{array}{ll}\text { CAL } & \text { YR } \\
\text { WTR } & \text { YR }\end{array}$ & $\begin{array}{l}1986 \\
1987\end{array}$ & $\begin{array}{l}\text { POTAL } \\
\text { TOTAL }\end{array}$ & $\begin{array}{l}90 \\
.40\end{array}$ & $\begin{array}{ll}\text { MEAN } & 168 \\
\text { MEAN } & 103\end{array}$ & $\begin{array}{l}\text { MAX } \\
\text { MAX }\end{array}$ & $\begin{array}{l}325 \\
310\end{array}$ & $\begin{array}{l}3.0 \\
.00\end{array}$ & & & & & \\
\hline
\end{tabular}


LOCATION. - Lat $46^{\circ} 24^{\prime} 29^{\prime \prime}$, long $89^{\circ} 07^{\prime} 42^{\prime \prime}$, in SWl/4 sec.1, T.46 N., R. 39 w., Ontonagon County, Hydrologic Unit 04020102, at Bond Falis Dam on Middle Branch Ontonagon River, $2.5 \mathrm{mi}$ east of Paulding.

DRAINAGE AREA. - $190 \mathrm{mi}^{2}$.

PERIOD OF RECORD.--June 1942 to current year. Prior to October 1950 , monthend contents only published in WSP 1307 .

REVISED RECORDS.--WSP 1911: Drainage area.

GAGE.--Nonrecording gage read once daily. Datum of gage is $1,335.59$ ft above National Geodetic Vertical Datum of 1929 .

REMARKS.--Reservoir is formed by earthfill and concrete dam with one taintor gate; dam completed in 1937. Usable capacity, 41,300 acre-ft between gage heights of $120 \mathrm{ft}$ (maximum drawdown) and 141 ft (full pond). Dead storage unknown. Water diverted to South Branch Ontonagon River through Bond Falls Canal (station 04033500); water used for power production at Victoria Dam near Rockland.

COOPERATION.--Gage-height record provided by Upper Peninsula Power co. and converted to acre-feet by U.S. Geological Survey.

EXTREMES FOR PERIOD OF RECORD (SINCE 1947).--Maximum contents observed, 42,980 acre-ft, July 3, 1953, gage height, $141.7 \mathrm{ft}$, of which 1,680 acre-ft was uncontrolled storage; no usable storage at times; minimum gage height observed, $116.0 \mathrm{ft}$, Mar. $21,1970$.

EXTREMES FOR CURRENT YEAR.--Maximum contents, 29,360 acre-ft, Nov. 9, 10, gage height, 135.8 ft; minimum, 5,340 acre-ft, Feb. 28, Mar. 1, Mar. 3-8, gage height, $123.4 \mathrm{ft}$.

MONTHEND GAGE HEIGHT AND CONTENTS AT 1200, WATER YEAR OCTOBER 1986 TO SEPTEMBER 1987

Date

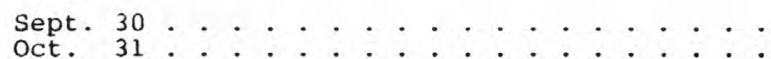

Nov $30 \cdot \cdot \cdot \cdot \cdot \cdot \cdot \cdot \cdot \cdot \cdot \cdot \cdot \cdot \cdot \cdot \cdot \cdot$

Dec. $31 \div . \div .5 . \div .5$

CAL YR 1986 . . . . . . . . . . . .

Jan. 31 . . . . . . . . . . . . .

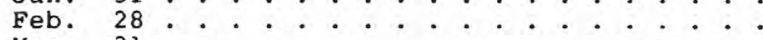

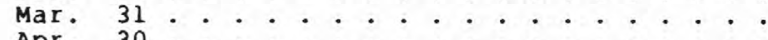

Apr. $30 \cdot \cdot \cdot \cdot \cdot \cdot \cdot \cdot \cdot \cdot \cdot \cdot \cdot \cdot \cdot \cdot \cdot \cdot$

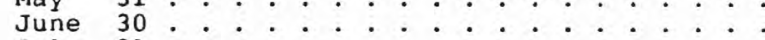

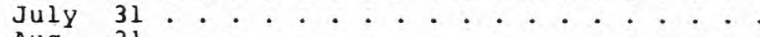

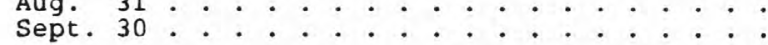

WTR YR 1987

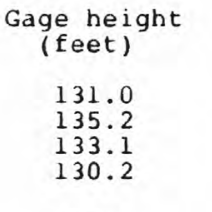

Contents (acre-feet)

$--$

126.6

123.4

127.1

130.0

131.2

131.1

132.8

131.8

131.3

$-$

19,500
28,040
23,700

17,980

$--$

11,140

5,340

17,600

19,900

19,700

23,100

21,100

20,100
Change in contents (acre- (equivalent feet) in $\mathrm{ft}^{3} / \mathrm{s}$ )

$+8,540$

$-4,340$

$+139$

-72.9
-93.0

$-14,940$

$-20.6$

$-6,840$

$-5,800$

$+6,750$

$+5,510$

$+2,300$

$-200$

$+3,400$

$-2,000$

$-1,000$

$+600$
$-111$

$-104$

$+110$

+92.6
+37.4

$-3.4$

$+55.3$

$-32.5$

$-16.8$

$+0.8$ 
LOCATION.--Lat $46^{\circ} 28^{\prime} 40^{\prime \prime}$, long $89^{\circ} 05^{\prime} 25^{\prime \prime}$, in Swl/4 sec.8, T.47 N., R.38 w., Ontonagon County, Hydrologic Unit 04020102 , on right bank $0.1 \mathrm{mi}$ upstream from State Highway $28,3.8 \mathrm{mi}$ west of village of Trout Creek, and $7.5 \mathrm{mi}$ downstream from Bond Falls Reservoir.

DRAINAGE AREA. --203 $\mathrm{mi}^{2}$.

PERIOD OF RECORD.--June 1942 to current year.

REVISED RECORDS.--WSP 1911: Drainage area.

GAGE.--Water-stage recorder. Datum of gage is 1,132.03 ft above National Geodetic Vertical Datum of 1929 (levels by Michigan Department of Natural Resources). Prior to Nov. 4, 1942, nonrecording gage at same site and datum.

REMARKS.--Estimated daily discharge: Nov. 14, 15, 20, Dec. 9, 10, Jan. 17-28, Feb. 5-7, 9, 10, and Mar. 29 to Apr. 1. Records good except for estimated daily discharges, which are fair. Flow regulated by Bond Falls Reservoir (station 04034000) $7.5 \mathrm{mi}$ upstream. Diversion to South Branch Ontonagon River 8.5 mi upstream by Bond Falls Canal (station 04033500). Several measurements of water temperature were made during the year.

AVERAGE DISCHARGE. --45 years, $65.8 \mathrm{ft}^{3} / \mathrm{s}$

EXTREMES FOR PERIOD OF RECORD.--Maximum discharge, 1,750 ft3/s, Nov. 7, 1951, gage height, 5.05 ft; minimum, $14 \mathrm{ft}^{3} / \mathrm{s}$, sometime during period Jan. 23 to Feb. 13,1947 , gage height, $1.14 \mathrm{ft}$, from recorded range in stage, caused by ice jams upstream.

EXTREMES FOR CURRENT YEAR, --Maximum discharge, $128 \mathrm{ft}^{3} / \mathrm{s}$, May 29 , gage height, $2.08 \mathrm{ft}$; minimum daily, $43 \mathrm{ft}^{3} / \mathrm{s}$, Jan. 16, Feb. 8, Apr. 30, May 2-9, 13, 15.

DISCHARGE, IN CUBIC FEET PER SECOND, WATER YEAR OCTOBER 1986 TO SEPTEMBER 1987 MEAN VALUES

\begin{tabular}{|c|c|c|c|c|c|c|c|c|c|c|c|c|}
\hline DAY & OCT & NOV & DEC & JAN & FEB & MAR & APR & MAY & JUN & JUL & AUG & SEP \\
\hline $\begin{array}{l}1 \\
2 \\
3 \\
4 \\
5\end{array}$ & $\begin{array}{l}51 \\
52 \\
53 \\
52 \\
53\end{array}$ & $\begin{array}{l}54 \\
53 \\
54 \\
53 \\
53\end{array}$ & $\begin{array}{l}51 \\
51 \\
52 \\
48 \\
51\end{array}$ & $\begin{array}{l}48 \\
48 \\
48 \\
48 \\
48\end{array}$ & $\begin{array}{l}45 \\
45 \\
45 \\
45 \\
45\end{array}$ & $\begin{array}{l}45 \\
45 \\
45 \\
45 \\
49\end{array}$ & $\begin{array}{l}49 \\
49 \\
49 \\
49 \\
51\end{array}$ & $\begin{array}{l}44 \\
43 \\
43 \\
43 \\
43\end{array}$ & $\begin{array}{l}52 \\
57 \\
55 \\
55 \\
55\end{array}$ & $\begin{array}{l}53 \\
59 \\
57 \\
55 \\
55\end{array}$ & $\begin{array}{l}61 \\
63 \\
58 \\
57 \\
57\end{array}$ & $\begin{array}{r}57 \\
47 \\
46 \\
47 \\
47\end{array}$ \\
\hline $\begin{array}{r}6 \\
7 \\
8 \\
9 \\
10\end{array}$ & $\begin{array}{l}53 \\
53 \\
58 \\
54 \\
53\end{array}$ & $\begin{array}{l}53 \\
53 \\
55 \\
53 \\
53\end{array}$ & $\begin{array}{l}50 \\
50 \\
47 \\
50 \\
50\end{array}$ & $\begin{array}{l}48 \\
48 \\
48 \\
48 \\
48\end{array}$ & $\begin{array}{l}45 \\
45 \\
43 \\
45 \\
45\end{array}$ & $\begin{array}{l}51 \\
58 \\
55 \\
50 \\
51\end{array}$ & $\begin{array}{l}52 \\
52 \\
50 \\
49 \\
48\end{array}$ & $\begin{array}{l}43 \\
43 \\
43 \\
43 \\
44\end{array}$ & $\begin{array}{l}55 \\
55 \\
55 \\
53 \\
53\end{array}$ & $\begin{array}{l}58 \\
60 \\
57 \\
59 \\
58\end{array}$ & $\begin{array}{l}57 \\
57 \\
57 \\
57 \\
56\end{array}$ & $\begin{array}{l}50 \\
48 \\
48 \\
48 \\
48\end{array}$ \\
\hline $\begin{array}{l}11 \\
12 \\
13 \\
14 \\
15\end{array}$ & $\begin{array}{l}57 \\
88 \\
62 \\
60 \\
60\end{array}$ & $\begin{array}{l}51 \\
52 \\
52 \\
51 \\
52\end{array}$ & $\begin{array}{l}50 \\
49 \\
50 \\
51 \\
52\end{array}$ & $\begin{array}{l}46 \\
47 \\
47 \\
46 \\
45\end{array}$ & $\begin{array}{l}46 \\
45 \\
45 \\
44 \\
44\end{array}$ & $\begin{array}{l}50 \\
50 \\
51 \\
50 \\
50\end{array}$ & $\begin{array}{l}48 \\
48 \\
47 \\
47 \\
48\end{array}$ & $\begin{array}{l}47 \\
44 \\
43 \\
44 \\
43\end{array}$ & $\begin{array}{l}57 \\
54 \\
53 \\
53 \\
52\end{array}$ & $\begin{array}{l}61 \\
60 \\
58 \\
57 \\
57\end{array}$ & $\begin{array}{l}55 \\
62 \\
74 \\
60 \\
58\end{array}$ & $\begin{array}{l}51 \\
50 \\
51 \\
49 \\
48\end{array}$ \\
\hline $\begin{array}{l}16 \\
17 \\
18 \\
19 \\
20\end{array}$ & $\begin{array}{l}58 \\
56 \\
55 \\
55 \\
55\end{array}$ & $\begin{array}{l}53 \\
53 \\
49 \\
49 \\
53\end{array}$ & $\begin{array}{l}50 \\
51 \\
50 \\
49 \\
49\end{array}$ & $\begin{array}{l}43 \\
45 \\
45 \\
45 \\
45\end{array}$ & $\begin{array}{l}46 \\
46 \\
46 \\
46 \\
46\end{array}$ & $\begin{array}{l}49 \\
49 \\
49 \\
50 \\
51\end{array}$ & $\begin{array}{l}48 \\
48 \\
47 \\
46 \\
46\end{array}$ & $\begin{array}{l}44 \\
45 \\
48 \\
53 \\
49\end{array}$ & $\begin{array}{l}52 \\
52 \\
52 \\
52 \\
52\end{array}$ & $\begin{array}{l}57 \\
57 \\
58 \\
59 \\
59\end{array}$ & $\begin{array}{l}59 \\
60 \\
59 \\
59 \\
60\end{array}$ & $\begin{array}{l}48 \\
48 \\
49 \\
54 \\
52\end{array}$ \\
\hline $\begin{array}{l}21 \\
22 \\
23 \\
24 \\
25\end{array}$ & $\begin{array}{l}54 \\
54 \\
54 \\
54 \\
54\end{array}$ & $\begin{array}{l}53 \\
52 \\
52 \\
52 \\
52\end{array}$ & $\begin{array}{l}46 \\
52 \\
49 \\
49 \\
50\end{array}$ & $\begin{array}{l}45 \\
45 \\
44 \\
44 \\
44\end{array}$ & $\begin{array}{l}46 \\
45 \\
45 \\
45 \\
45\end{array}$ & $\begin{array}{l}52 \\
54 \\
56 \\
59 \\
58\end{array}$ & $\begin{array}{l}46 \\
46 \\
45 \\
45 \\
46\end{array}$ & $\begin{array}{l}47 \\
52 \\
50 \\
48 \\
46\end{array}$ & $\begin{array}{l}53 \\
52 \\
52 \\
52 \\
54\end{array}$ & $\begin{array}{l}58 \\
58 \\
57 \\
58 \\
57\end{array}$ & $\begin{array}{l}61 \\
58 \\
57 \\
57 \\
57\end{array}$ & $\begin{array}{l}51 \\
51 \\
49 \\
48 \\
47\end{array}$ \\
\hline $\begin{array}{l}26 \\
27 \\
28 \\
29 \\
30 \\
31\end{array}$ & $\begin{array}{l}55 \\
54 \\
54 \\
55 \\
53 \\
54\end{array}$ & $\begin{array}{r}52 \\
52 \\
52 \\
51 \\
50 \\
-\end{array}$ & $\begin{array}{l}49 \\
49 \\
48 \\
48 \\
48 \\
48\end{array}$ & $\begin{array}{l}44 \\
44 \\
44 \\
45 \\
46 \\
45\end{array}$ & $\begin{array}{r}45 \\
45 \\
45 \\
--- \\
--- \\
---\end{array}$ & $\begin{array}{l}55 \\
53 \\
53 \\
50 \\
50 \\
50\end{array}$ & $\begin{array}{r}45 \\
46 \\
45 \\
44 \\
43 \\
---\end{array}$ & $\begin{array}{l}47 \\
48 \\
50 \\
60 \\
82 \\
55\end{array}$ & $\begin{array}{r}53 \\
55 \\
54 \\
54 \\
53 \\
---\end{array}$ & $\begin{array}{l}57 \\
57 \\
57 \\
57 \\
57 \\
57\end{array}$ & $\begin{array}{l}57 \\
57 \\
57 \\
57 \\
63 \\
58\end{array}$ & $\begin{array}{l}47 \\
49 \\
48 \\
48 \\
48\end{array}$ \\
\hline $\begin{array}{l}\text { TOTAL } \\
\text { MEAN } \\
\text { MAX } \\
\text { MIN }\end{array}$ & $\begin{array}{r}1733 \\
55.9 \\
88 \\
51\end{array}$ & $\begin{array}{r}1567 \\
52.2 \\
55 \\
49\end{array}$ & $\begin{array}{r}1537 \\
49.6 \\
52 \\
46\end{array}$ & $\begin{array}{r}1424 \\
45.9 \\
48 \\
43\end{array}$ & $\begin{array}{r}1263 \\
45.1 \\
46 \\
43\end{array}$ & $\begin{array}{r}1583 \\
51.1 \\
59 \\
45\end{array}$ & $\begin{array}{r}1422 \\
47.4 \\
52 \\
43\end{array}$ & $\begin{array}{r}1477 \\
47.6 \\
82 \\
43\end{array}$ & $\begin{array}{r}1606 \\
53.5 \\
57 \\
52\end{array}$ & $\begin{array}{r}1784 \\
57.5 \\
61 \\
53\end{array}$ & $\begin{array}{r}1825 \\
58.9 \\
74 \\
55\end{array}$ & $\begin{array}{r}1472 \\
49.1 \\
57\end{array}$ \\
\hline
\end{tabular}

$\begin{array}{llllllll}\text { CAL YR } 1986 & \text { TOTAL } & 19489 & \text { MEAN } 53.4 & \text { MAX } 188 & \text { MIN } 37\end{array}$ 
LOCATION. - Lat $46^{\circ} 41^{\prime} 57^{\prime \prime}$, long $89^{\circ} 09^{\prime} 36^{\prime \prime}$, in SEl/4 sec. 27, T.50 N., R. 39 w., Ontonagon County, Hydrologic Unit 04020102 , on left bank $10 \mathrm{ft}$ upstream from bridge on U.S. Highway 45 , 700 ft downstream from East Branch, and $2.8 \mathrm{mi}$ soucheast of Rockland.

DRAINAGE AREA. $-671 \mathrm{mi}^{2}$.

PERIOD OF RECORD.-JU1Y 1942 to current year.

GAGE.--Water-stage recorder. Datum of gage is $661.1 \mathrm{ft}$ above National Geodetic Vertical Datum of 1929. Prior to Apr. 1, 1959, nonrecording gage at site $400 \mathrm{ft}$ upstream at same datum. Apr. 1 , 1959 to Oct. 21, 1968, nonrecording gage at present site and datum.

REMARKS.-Estimated däily discharges: Nov. 12 to Mar. 17, and Mar. 30 to Apr. 2 . Records good except for estimated daily discharges, which are fair. Regulation by Bond Fall Reservoir (station 04034000 ) 30.0 mi upstream. Diversion to South Branch Ontonagon River by Bond Falls Canal (station 04033500 ) 31.0 mi upstream. Several measurements of water temperature were made during the year.

AVERAGE DISCHARGE- -45 years, $530 \mathrm{ft}^{3} / \mathrm{s}$.

EXTREMES FOR PERIOD OF RECORD.--Maximum discharge, 27,000 ft $3 / \mathrm{s}$, Aug. 22, 1942, gage height, 21.2 $\mathrm{ft}$, from floodmarks, from rating curve extended above $7,500 \mathrm{ft} / \mathrm{s}$, on basis of slope-area measurement of peak flow; minimum observed, $142 \mathrm{ft}^{3} / \mathrm{s}$, Dec. 3, 1963, discharge measurement; minimum daily, $145 \mathrm{ft}^{3} / \mathrm{s}$, Dec, 3, 1963.

EXTREMES FOR CURRENT YEAR.--Maximum discharge, 2,780 $\mathrm{ft}^{3} \mathrm{~s}$, Mar. 24 , gage height, 6.63 ft; maximum gage height, $7.59 \mathrm{ft}$, Mar. 8, backwater from ice; minimum discharge, $170 \mathrm{ft} / \mathrm{s}, \mathrm{Apr} .3, \mathrm{gage}$ height, $3.52 \mathrm{ft}$; minimum daily, $185 \mathrm{ft}^{3} / \mathrm{s}, \mathrm{July} 31$.

DISCHARGE, IN CUBIC FEET PER SECOND, WATER YEAR OCTOBER 1986 TO SEPTEMBER 1987 MEAN VALUES

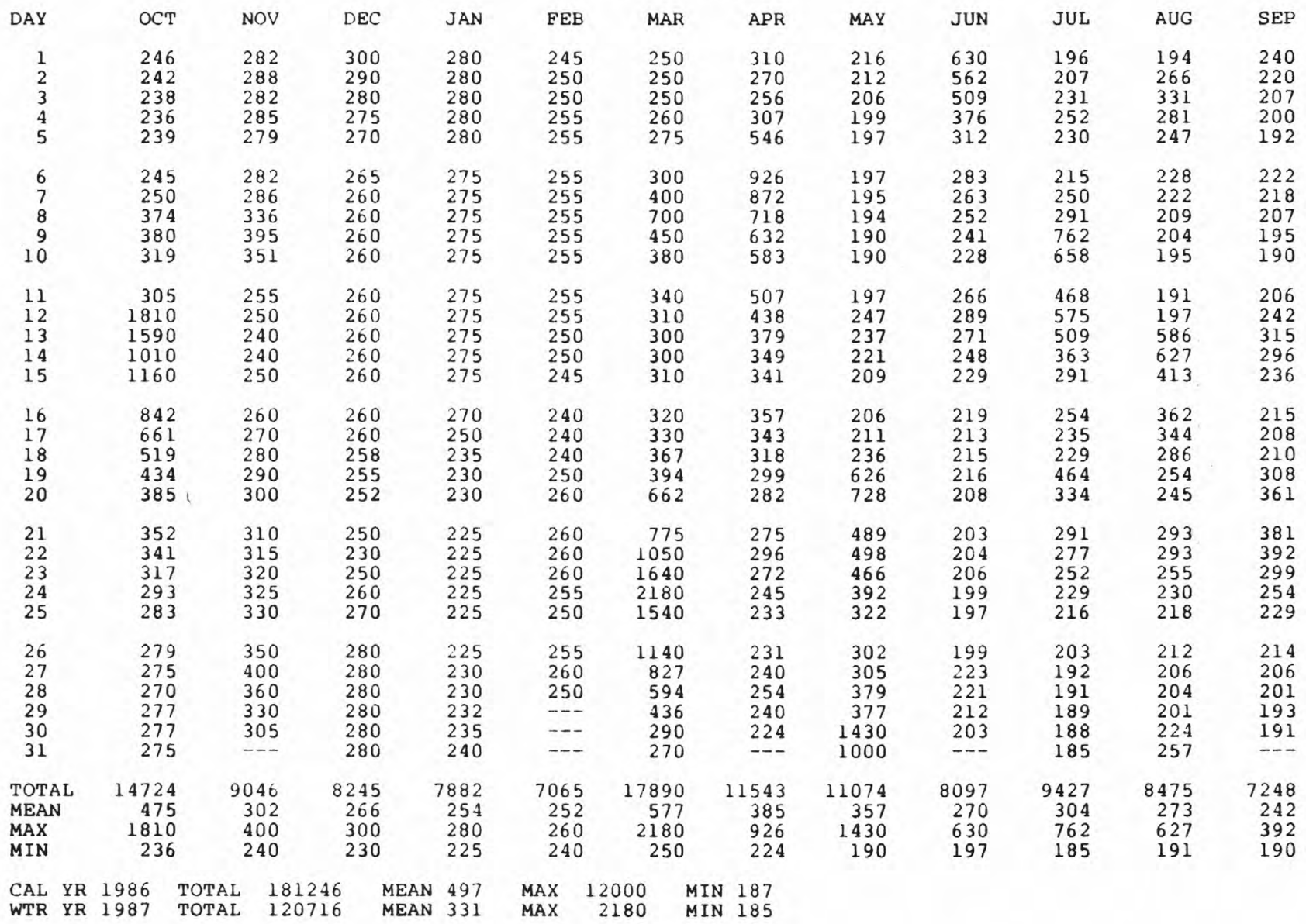


LOCATION.--Lat $46^{\circ} 35^{\prime} 19^{\prime \prime}$, long $89^{\circ} 32^{\prime} 52^{\prime \prime}$, in SWl $/ 4$ NWl $/ 4$ sec.3, T. 48 N., R. 42 W., Ontonagon County,

Hydrologic Unit 04020102 , at upstream side of dam on lake outlet, $1.0 \mathrm{mi}$ southeast of Bergland, and $4.3 \mathrm{mi}$ east of Merriweather.

DRA INAGE AREA. $--162 \mathrm{mi}^{2}$.

PERIOD OF RECORD.--July 1958 to September 1959 (no winter record), February 1969 to current year.

GAGE.--Water-stage recorder. Datum of gage is $1,293.70 \mathrm{ft}$ above National Geodetic Vertical Datum of 1929. July 1958 to September 1959, nonrecording gage at mouth of Merriweather Creek at different datum.

REMARKS.--Lake Gogebic is used as a storage reservoir by Upper Peninsula Power Company for power

production at Victoria Dam near Rockland. Lake level is controlled at the outlet by a concrete dam

with removable flash boards. Major inlets to Lake Gogebic are Slate River, Trout Brook, and

Merriweather Creek. Streamflow records are currently collected at the outlet, West Branch ontonagon

River (station 04036000). Surface area of lake is 14,780 acres.

EXTREMES FOR PERIOD OF RECORD.--Maximum daily gage height, $3.30 \mathrm{ft}, \mathrm{Apr} .22,1971$; minimum daily, -0.32 ft, Apr. $5,6,1970$.

EXTREMES FOR CURRENT YEAR.--Maximum gage height, $2.72 \mathrm{ft}$, July 20 , result of wind action; maximum daily, $2.00 \mathrm{ft}$, July 22; minimum gage height, $0.02 \mathrm{ft}$, Mar. 20 , result of wind action; minimum daily, 0.07 ft, Mar. 20 .

GAGE HEIGHT (FEET ABOVE DATUM), WATER YEAR OCTOBER 1986 TO SEPTEMBER 1987 MEAN VALUES

\begin{tabular}{|c|c|c|c|c|c|c|c|c|c|c|c|c|}
\hline DAY & OCT & NOV & DEC & JAN & FEB & MAR & APR & MAY & JUN & JUL & AUG & SEP \\
\hline $\begin{array}{l}1 \\
2 \\
3 \\
4 \\
5\end{array}$ & $\begin{array}{l}1.59 \\
1.59 \\
1.55 \\
1.55 \\
1.54\end{array}$ & $\begin{array}{l}1.57 \\
1.56 \\
1.50 \\
1.46 \\
1.48\end{array}$ & $\begin{array}{l}1.23 \\
1.23 \\
1.26 \\
1.27 \\
1.25\end{array}$ & $\begin{array}{l}.94 \\
.93 \\
.93 \\
.92 \\
.91\end{array}$ & $\begin{array}{l}.79 \\
.79 \\
.80 \\
.79 \\
.74\end{array}$ & $\begin{array}{l}.17 \\
.19 \\
.17 \\
.15 \\
.13\end{array}$ & $\begin{array}{l}.69 \\
.72 \\
.73 \\
.75 \\
.75\end{array}$ & $\begin{array}{l}1.02 \\
1.01 \\
1.00 \\
1.02 \\
1.03\end{array}$ & $\begin{array}{l}1.71 \\
1.78 \\
1.79 \\
1.79 \\
1.76\end{array}$ & $\begin{array}{l}1.56 \\
1.61 \\
1.62 \\
1.62 \\
1.63\end{array}$ & $\begin{array}{l}1.89 \\
1.89 \\
1.91 \\
1.83 \\
1.83\end{array}$ & $\begin{array}{l}1.66 \\
1.64 \\
1.69 \\
1.68 \\
1.65\end{array}$ \\
\hline $\begin{array}{r}6 \\
7 \\
8 \\
9 \\
10\end{array}$ & $\begin{array}{l}1.53 \\
1.52 \\
1.51 \\
1.50 \\
1.53\end{array}$ & $\begin{array}{l}1.43 \\
1.40 \\
1.70 \\
1.53 \\
1.41\end{array}$ & $\begin{array}{l}1.23 \\
1.22 \\
1.22 \\
1.22 \\
1.21\end{array}$ & $\begin{array}{l}.90 \\
.90 \\
.90 \\
.89 \\
.87\end{array}$ & $\begin{array}{l}.69 \\
.67 \\
.63 \\
.61 \\
.57\end{array}$ & $\begin{array}{l}.13 \\
.13 \\
.12 \\
.14 \\
.15\end{array}$ & $\begin{array}{l}.77 \\
.78 \\
.78 \\
.77 \\
.78\end{array}$ & $\begin{array}{l}1.02 \\
1.02 \\
1.04 \\
1.06 \\
1.01\end{array}$ & $\begin{array}{l}1.77 \\
1.78 \\
1.75 \\
1.72 \\
1.69\end{array}$ & $\begin{array}{l}1.63 \\
1.68 \\
1.71 \\
1.76 \\
1.83\end{array}$ & $\begin{array}{l}1.87 \\
1.82 \\
1.82 \\
1.79 \\
1.76\end{array}$ & $\begin{array}{l}1.69 \\
1.69 \\
1.68 \\
1.68 \\
1.69\end{array}$ \\
\hline $\begin{array}{l}11 \\
12 \\
13 \\
14 \\
15\end{array}$ & $\begin{array}{l}1.47 \\
1.55 \\
1.72 \\
1.78 \\
1.88\end{array}$ & $\begin{array}{l}1.37 \\
1.36 \\
1.37 \\
1.36 \\
1.33\end{array}$ & $\begin{array}{l}1.20 \\
1.18 \\
1.17 \\
1.15 \\
1.14\end{array}$ & $\begin{array}{l}.87 \\
.85 \\
.85 \\
.84 \\
.83\end{array}$ & $\begin{array}{l}.54 \\
.51 \\
.49 \\
.46 \\
.43\end{array}$ & $\begin{array}{l}.16 \\
.15 \\
.14 \\
.13 \\
.13\end{array}$ & $\begin{array}{l}.78 \\
.78 \\
.77 \\
.74 \\
.79\end{array}$ & $\begin{array}{r}1.02 \\
1.01 \\
1.05 \\
.99 \\
1.00\end{array}$ & $\begin{array}{l}1.77 \\
1.73 \\
1.71 \\
1.72 \\
1.71\end{array}$ & $\begin{array}{l}1.86 \\
1.91 \\
1.88 \\
1.88 \\
1.89\end{array}$ & $\begin{array}{l}1.80 \\
1.78 \\
1.76 \\
1.75 \\
1.78\end{array}$ & $\begin{array}{l}1.67 \\
1.68 \\
1.72 \\
1.69 \\
1.67\end{array}$ \\
\hline $\begin{array}{l}16 \\
17 \\
18 \\
19 \\
20\end{array}$ & $\begin{array}{l}1.91 \\
1.95 \\
1.97 \\
1.97 \\
1.98\end{array}$ & $\begin{array}{l}1.32 \\
1.32 \\
1.30 \\
1.29 \\
1.31\end{array}$ & $\begin{array}{l}1.13 \\
1.12 \\
1.11 \\
1.10 \\
1.08\end{array}$ & $\begin{array}{l}.83 \\
.82 \\
.82 \\
.81 \\
.81\end{array}$ & $\begin{array}{r}.41 \\
.38 \\
.36 \\
.34 \\
.32\end{array}$ & $\begin{array}{l}.12 \\
.11 \\
.09 \\
.08 \\
.07\end{array}$ & $\begin{array}{l}.87 \\
.90 \\
.91 \\
.95 \\
.98\end{array}$ & $\begin{array}{r}1.01 \\
.95 \\
.95 \\
1.09 \\
1.15\end{array}$ & $\begin{array}{l}1.70 \\
1.71 \\
1.71 \\
1.67 \\
1.67\end{array}$ & $\begin{array}{l}1.94 \\
1.94 \\
1.89 \\
1.99 \\
1.99\end{array}$ & $\begin{array}{l}1.80 \\
1.81 \\
1.79 \\
1.75 \\
1.78\end{array}$ & $\begin{array}{l}1.66 \\
1.64 \\
1.66 \\
1.71 \\
1.71\end{array}$ \\
\hline $\begin{array}{l}21 \\
22 \\
23 \\
24 \\
25\end{array}$ & $\begin{array}{l}1.96 \\
1.97 \\
1.91 \\
1.87 \\
1.82\end{array}$ & $\begin{array}{l}1.30 \\
1.28 \\
1.30 \\
1.30 \\
1.28\end{array}$ & $\begin{array}{l}1.06 \\
1.05 \\
1.03 \\
1.02 \\
1.01\end{array}$ & $\begin{array}{r}.80 \\
.81 \\
.82 \\
-.- \\
---\end{array}$ & $\begin{array}{l}.30 \\
.28 \\
.25 \\
.23 \\
.22\end{array}$ & $\begin{array}{l}.08 \\
.11 \\
.14 \\
.19 \\
.28\end{array}$ & $\begin{array}{r}.92 \\
.96 \\
.94 \\
.97 \\
1.01\end{array}$ & $\begin{array}{l}1.20 \\
1.17 \\
1.22 \\
1.25 \\
1.27\end{array}$ & $\begin{array}{l}1.66 \\
1.66 \\
1.67 \\
1.65 \\
1.63\end{array}$ & $\begin{array}{l}1.99 \\
2.00 \\
1.98 \\
1.94 \\
1.95\end{array}$ & $\begin{array}{l}1.80 \\
1.75 \\
1.74 \\
1.74 \\
1.68\end{array}$ & $\begin{array}{l}1.70 \\
1.75 \\
1.75 \\
1.72 \\
1.72\end{array}$ \\
\hline $\begin{array}{l}26 \\
27 \\
28 \\
29 \\
30 \\
31\end{array}$ & $\begin{array}{l}1.78 \\
1.76 \\
1.71 \\
1.66 \\
1.64 \\
1.67\end{array}$ & $\begin{array}{l}1.27 \\
1.27 \\
1.26 \\
1.25 \\
1.24 \\
-\end{array}$ & $\begin{array}{r}1.00 \\
.99 \\
.98 \\
.97 \\
.96 \\
.96\end{array}$ & $\begin{array}{l}--8 \\
.80 \\
.79 \\
.79 \\
.81 \\
.81\end{array}$ & $\begin{array}{l}.20 \\
.18 \\
.15 \\
-.- \\
--- \\
---\end{array}$ & $\begin{array}{l}.38 \\
.45 \\
.51 \\
.56 \\
.61 \\
.64\end{array}$ & $\begin{array}{r}1.01 \\
1.00 \\
1.04 \\
.98 \\
1.01 \\
-\end{array}$ & $\begin{array}{l}1.31 \\
1.35 \\
1.42 \\
1.47 \\
1.60 \\
1.65\end{array}$ & $\begin{array}{l}1.62 \\
1.60 \\
1.58 \\
1.57 \\
1.56 \\
-\end{array}$ & $\begin{array}{l}1.93 \\
1.92 \\
1.92 \\
1.91 \\
1.89 \\
1.88\end{array}$ & $\begin{array}{l}1.65 \\
1.69 \\
1.70 \\
1.69 \\
1.76 \\
1.69\end{array}$ & $\begin{array}{l}1.69 \\
1.74 \\
1.75 \\
1.70 \\
1.67 \\
\end{array}$ \\
\hline $\begin{array}{l}\text { MEAN } \\
\text { MAX } \\
\text { MIN }\end{array}$ & $\begin{array}{l}1.72 \\
1.98 \\
1.47\end{array}$ & $\begin{array}{l}1.37 \\
1.70 \\
1.24\end{array}$ & $\begin{array}{r}1.12 \\
1.27 \\
.96\end{array}$ & $\begin{array}{l}--- \\
--- \\
---\end{array}$ & $\begin{array}{l}.47 \\
.80 \\
.15\end{array}$ & $\begin{array}{l}.21 \\
.64 \\
.07\end{array}$ & $\begin{array}{r}.86 \\
1.04 \\
.69\end{array}$ & $\begin{array}{r}1.14 \\
1.65 \\
.95\end{array}$ & $\begin{array}{l}1.69 \\
1.79 \\
1.56\end{array}$ & $\begin{array}{l}1.84 \\
2.00 \\
1.56\end{array}$ & $\begin{array}{l}1.78 \\
1.91 \\
1.65\end{array}$ & $\begin{array}{l}1.69 \\
1.75 \\
1.64\end{array}$ \\
\hline
\end{tabular}


04036000 WEST BRANCH ONTONAGON RIVER NEAR BERGLAND, MI

LOCATION. - Lat $46^{\circ} 35^{\prime} 15^{\prime \prime}$, long $89^{\circ} 32^{\prime} 30^{\prime \prime}$, in SWI/4 NEl/4 sec.3. T.48 N., R.42 W. Ontonagon County,

Hydrologic Unit 04020102 , on right bank $0.4 \mathrm{mi}$ downstream from dam at outlet of Lake Gogebic, and 1.5 mi east of Bergland.

DRAINAGE AREA. $--162 \mathrm{mi}^{2}$.

PERIOD OF RECORD.--July 1942 to current year.

REVISED RECORDS.--WSP 1911: Drainage area.

GAGE.--Water-stage recorder. Datum of gage is $1,290.81 \mathrm{ft}$ above National Geodetic Vertical Datum of 1929. Prior to Nov. 5, 1942 , nonrecording gage $0.4 \mathrm{mi}$ upstream at different datum.

REMARKS. - No estimated daily discharges. Records excellent except those below 5.0 ft $3 / \mathrm{s}$, which are fair. Flow regulated by Lake Gogebic (station 04035995), usable capacity, 35, 200 acre-ft. Several measurements of water temperature were made during the year.

AVERAGE DISCHARGE. --45 years, $175 \mathrm{ft}^{3} / \mathrm{s}, 14.67 \mathrm{in} / \mathrm{yr}^{\mathrm{r}}$.

EXTREMES FOR PERIOD OF RECORD.--Maximum discharge, 1,400 ft $3 / \mathrm{s}$, Apr. 26, 1960, gage height, $5.98 \mathrm{ft}$; minimum daily, $0.70 \mathrm{ft}^{3} / \mathrm{s}$, Sept. 26 to Oct. $19,1963$.

EXTREMES FOR CURRENT YEAR.--Maximum discharge, $368 \mathrm{ft}^{3} / \mathrm{s}$, Oct. 31 , gage height, $3.43 \mathrm{ft}$; minimum daily, $0.82 \mathrm{ft}^{3} / \mathrm{s}$, Sept. 3, 4 .

DISCHARGE, IN CUBIC FEET PER SECOND, WATER YEAR OCTOBER 1986 TO SEPTEMBER 1987 MEAN VALUES

\begin{tabular}{|c|c|c|c|c|c|c|c|c|c|c|c|c|}
\hline DAY & OCT & NOV & $\mathrm{DEC}$ & JAN & FEB & MAR & APR & MAY & JUN & JUL & AUG & SEP \\
\hline $\begin{array}{l}1 \\
2 \\
3 \\
4 \\
5\end{array}$ & $\begin{array}{l}181 \\
146 \\
110 \\
109 \\
108\end{array}$ & $\begin{array}{l}274 \\
272 \\
250 \\
243 \\
192\end{array}$ & $\begin{array}{l}109 \\
108 \\
112 \\
119 \\
110\end{array}$ & $\begin{array}{r}103 \\
100 \\
99 \\
98 \\
95\end{array}$ & $\begin{array}{r}73 \\
73 \\
73 \\
73 \\
166\end{array}$ & $\begin{array}{l}142 \\
146 \\
144 \\
139 \\
137\end{array}$ & $\begin{array}{l}18 \\
46 \\
68 \\
68 \\
91\end{array}$ & $\begin{array}{l}1.8 \\
1.6 \\
1.5 \\
1.5 \\
1.5\end{array}$ & $\begin{array}{l}4.7 \\
7.1 \\
5.7 \\
5.6 \\
5.6\end{array}$ & $\begin{array}{l}11 \\
11 \\
12 \\
12 \\
12\end{array}$ & $\begin{array}{r}13 \\
12 \\
12 \\
9.9 \\
6.3\end{array}$ & $\begin{array}{r}1.0 \\
.86 \\
.82 \\
.82 \\
.86\end{array}$ \\
\hline $\begin{array}{r}6 \\
7 \\
8 \\
9 \\
10\end{array}$ & $\begin{array}{r}106 \\
107 \\
99 \\
98 \\
105\end{array}$ & $\begin{array}{l}151 \\
147 \\
217 \\
176 \\
162\end{array}$ & $\begin{array}{l}109 \\
107 \\
104 \\
105 \\
110\end{array}$ & $\begin{array}{l}91 \\
93 \\
95 \\
89 \\
87\end{array}$ & $\begin{array}{l}238 \\
228 \\
214 \\
215 \\
212\end{array}$ & $\begin{array}{l}138 \\
137 \\
134 \\
136 \\
136\end{array}$ & $\begin{array}{l}132 \\
166 \\
196 \\
209 \\
209\end{array}$ & $\begin{array}{l}1.5 \\
1.6 \\
1.7 \\
1.7 \\
1.9\end{array}$ & $\begin{array}{r}5.7 \\
6.6 \\
6.6 \\
108 \\
202\end{array}$ & $\begin{array}{l}12 \\
12 \\
13 \\
14 \\
14\end{array}$ & $\begin{array}{l}4.9 \\
4.9 \\
4.3 \\
3.7 \\
3.7\end{array}$ & $\begin{array}{l}1.0 \\
1.0 \\
1.0 \\
1.0 \\
1.0\end{array}$ \\
\hline $\begin{array}{l}11 \\
12 \\
13 \\
14 \\
15\end{array}$ & $\begin{array}{r}95 \\
43 \\
9.0 \\
8.5 \\
13\end{array}$ & $\begin{array}{l}170 \\
132 \\
136 \\
134 \\
126\end{array}$ & $\begin{array}{l}135 \\
148 \\
145 \\
144 \\
138\end{array}$ & $\begin{array}{l}89 \\
84 \\
84 \\
82 \\
79\end{array}$ & $\begin{array}{l}206 \\
197 \\
190 \\
190 \\
186\end{array}$ & $\begin{array}{l}137 \\
137 \\
135 \\
135 \\
134\end{array}$ & $\begin{array}{l}208 \\
207 \\
209 \\
204 \\
117\end{array}$ & $\begin{array}{l}2.4 \\
2.4 \\
2.6 \\
3.3 \\
2.9\end{array}$ & $\begin{array}{r}103 \\
123 \\
104 \\
13 \\
13\end{array}$ & $\begin{array}{l}14 \\
14 \\
14 \\
13 \\
13\end{array}$ & $\begin{array}{l}3.7 \\
3.5 \\
3.5 \\
3.1 \\
2.7\end{array}$ & $\begin{array}{l}1.0 \\
1.0 \\
1.0 \\
1.0 \\
1.0\end{array}$ \\
\hline $\begin{array}{l}16 \\
17 \\
18 \\
19 \\
20\end{array}$ & $\begin{array}{r}15 \\
100 \\
156 \\
157 \\
157\end{array}$ & $\begin{array}{l}127 \\
124 \\
120 \\
118 \\
121\end{array}$ & $\begin{array}{l}137 \\
136 \\
135 \\
129 \\
127\end{array}$ & $\begin{array}{l}79 \\
78 \\
76 \\
72 \\
73\end{array}$ & $\begin{array}{l}180 \\
177 \\
176 \\
172 \\
168\end{array}$ & $\begin{array}{l}134 \\
133 \\
129 \\
126 \\
125\end{array}$ & $\begin{array}{r}12 \\
4.2 \\
3.6 \\
3.1 \\
2.9\end{array}$ & $\begin{array}{l}3.0 \\
3.1 \\
3.1 \\
3.1 \\
3.1\end{array}$ & $\begin{array}{l}13 \\
13 \\
13 \\
13 \\
13\end{array}$ & $\begin{array}{l}13 \\
13 \\
13 \\
14 \\
16\end{array}$ & $\begin{array}{l}2.7 \\
2.7 \\
2.1 \\
2.1 \\
2.1\end{array}$ & $\begin{array}{l}1.0 \\
1.0 \\
1.0 \\
1.1 \\
1.2\end{array}$ \\
\hline $\begin{array}{l}21 \\
22 \\
23 \\
24 \\
25\end{array}$ & $\begin{array}{l}156 \\
205 \\
219 \\
265 \\
309\end{array}$ & $\begin{array}{l}119 \\
117 \\
118 \\
120 \\
118\end{array}$ & $\begin{array}{l}126 \\
124 \\
119 \\
117 \\
116\end{array}$ & $\begin{array}{l}72 \\
73 \\
77 \\
78 \\
78\end{array}$ & $\begin{array}{l}165 \\
162 \\
158 \\
155 \\
152\end{array}$ & $\begin{array}{r}126 \\
131 \\
133 \\
139 \\
76\end{array}$ & $\begin{array}{l}2.9 \\
2.8 \\
2.7 \\
2.6 \\
2.4\end{array}$ & $\begin{array}{l}3.5 \\
4.0 \\
3.7 \\
3.7 \\
3.7\end{array}$ & $\begin{array}{l}13 \\
13 \\
13 \\
13 \\
12\end{array}$ & $\begin{array}{r}94 \\
131 \\
122 \\
66 \\
15\end{array}$ & $\begin{array}{l}2.1 \\
2.1 \\
1.7 \\
1.5 \\
1.5\end{array}$ & $\begin{array}{l}1.2 \\
1.4 \\
1.4 \\
1.2 \\
1.1\end{array}$ \\
\hline $\begin{array}{l}26 \\
27 \\
28 \\
29 \\
30 \\
31\end{array}$ & $\begin{array}{l}300 \\
290 \\
307 \\
307 \\
302 \\
310\end{array}$ & $\begin{array}{l}117 \\
1117 \\
112 \\
110 \\
109 \\
---\end{array}$ & $\begin{array}{l}112 \\
111 \\
110 \\
106 \\
105 \\
105\end{array}$ & $\begin{array}{l}75 \\
74 \\
73 \\
72 \\
74 \\
74\end{array}$ & $\begin{array}{l}147 \\
145 \\
139 \\
--- \\
---\end{array}$ & $\begin{array}{l}24 \\
23 \\
21 \\
20 \\
18 \\
18\end{array}$ & $\begin{array}{l}2.2 \\
2.2 \\
1.9 \\
1.8 \\
1.8 \\
-\end{array}$ & $\begin{array}{l}4.0 \\
4.5 \\
5.9 \\
5.4 \\
6.1 \\
6.1\end{array}$ & $\begin{array}{l}12 \\
12 \\
11 \\
11 \\
11 \\
-\end{array}$ & $\begin{array}{l}15 \\
15 \\
15 \\
15 \\
15 \\
15\end{array}$ & $\begin{array}{l}1.4 \\
1.2 \\
1.1 \\
1.1 \\
1.2 \\
1.1\end{array}$ & $\begin{array}{l}1.1 \\
1.0 \\
1.1 \\
1.2 \\
1.1 \\
-\end{array}$ \\
\hline $\begin{array}{l}\text { TOTAL } \\
\text { MEAN } \\
\text { MAX } \\
\text { MIN }\end{array}$ & $\begin{array}{r}4892.5 \\
1.58 \\
310 \\
8.5\end{array}$ & $\begin{array}{r}4549 \\
152 \\
274 \\
109\end{array}$ & $\begin{array}{r}3718 \\
120 \\
148 \\
104\end{array}$ & $\begin{array}{r}2566 \\
82.8 \\
103 \\
72\end{array}$ & $\begin{array}{r}4630 \\
165 \\
238 \\
73\end{array}$ & $\begin{array}{r}3443 \\
111 \\
146 \\
18\end{array}$ & $\begin{array}{r}2197.1 \\
73.2 \\
209 \\
1.8\end{array}$ & $\begin{array}{r}95.9 \\
3.09 \\
6.1 \\
1.5\end{array}$ & $\begin{array}{r}899.6 \\
30.0 \\
202 \\
4.7\end{array}$ & $\begin{array}{r}778 \\
25.1 \\
131 \\
11\end{array}$ & $\begin{array}{r}118.9 \\
3.84 \\
13 \\
1.1\end{array}$ & $\begin{array}{r}31.46 \\
1.05 \\
1.4 \\
.82\end{array}$ \\
\hline
\end{tabular}

$\begin{array}{lllllllllllll}\text { CAL } & \text { YR } & 1986 & \text { TOTAL } & 51907.50 & \text { MEAN } & 142 & \text { MAX } 868 & \text { MIN } 8.5 & \text { CFSM } & .88 & \text { IN } 11.92\end{array}$ 
LOCATION. - Lat $46^{\circ} 15^{\prime} 10^{\prime \prime}$, long $89^{\circ} 27^{\prime} 07^{\prime \prime}$, in NE1/4 sec.32, T.45 N., R.41 W., Gogebic County, Hydrologic Unit 04020102 , on left bank at outlet, $10 \mathrm{ft}$ upstream from dam, $13 \mathrm{mi}$ west of Watersmeet.

DRAINAGE AREA. $--50.6 \mathrm{mi}^{2}$.

PERIOD OF RECORD.--JulY 1942 to current year.

GAGE.--Water-stage recorder. Datum of gage is $1,679.53 \mathrm{ft}$ above National Geodetic Vertical Datum of 1929 (levels by Michigan Department of Natural Resources). Prior to Oct. 28, 1969, nonrecording gage at same site and datum.

REMARKS. --Cisco Lake is the downstream lake in a chain of lakes used as storage reservoirs by Upper Peninsula Power Company for power production at Victoria Dam near Rockland. Lake level is controlled at the outlet by a concrete dam of two bays with removable flash boards. The major inlet to Cisco Lake is the combined out let from Lindsley Lake and Thousand Island Lake. Streamflow records are currently collected at the outlet, Cisco Branch Ontonagon River (station 04037500). The lake level is maintained at an elevation of about $1,682.5 \mathrm{ft}$, above NGVD, during winter months and $1,683.5 \mathrm{ft}$, above NGVD, during summer months. Surface area of lake is 506 acres.

EXTREMES FOR PERIOD OF RECORD.--Maximum gage height, $4.69 \mathrm{ft}$, July 19, 1942; minimum, 1.72 ft, Mar. 20-22, 1948 .

EXTREMES FOR CURRENT YEAR.--Maximum gage height, $4.14 \mathrm{ft}$, Aug. 13; minimum recorded, 2.89 ft, Nov. 9 , but may have been lower during periods of no gage-height record.

GAGE HEIGHT (FEET ABOVE DATUM), WATER YEAR OCTOBER 1986 TO SEPTEMBER 1987

\begin{tabular}{|c|c|c|c|c|c|c|c|c|c|c|c|c|}
\hline DAY & OCT & NOV & DEC & JAN & FEB & MAR & APR & MAY & JUN & JUL & AUG & SEP \\
\hline $\begin{array}{l}1 \\
2 \\
3 \\
4 \\
5\end{array}$ & $\begin{array}{l}3.94 \\
3.93 \\
3.89 \\
3.87 \\
3.81\end{array}$ & $\begin{array}{l}3.11 \\
3.09 \\
3.06 \\
3.05 \\
3.03\end{array}$ & $\begin{array}{l}2.96 \\
2.96 \\
2.97 \\
2.96 \\
2.96\end{array}$ & $\begin{array}{l}3.03 \\
3.06 \\
3.05 \\
3.03 \\
3.02\end{array}$ & $\begin{array}{l}2.99 \\
3.00 \\
2.98 \\
2.97 \\
2.97\end{array}$ & $\begin{array}{l}2.98 \\
3.00 \\
2.98 \\
2.98 \\
2.96\end{array}$ & $\begin{array}{l}3.04 \\
3.04 \\
3.02 \\
2.99 \\
2.97\end{array}$ & $\begin{array}{l}3.13 \\
3.14 \\
3.13 \\
3.13 \\
3.13\end{array}$ & $\begin{array}{l}3.63 \\
3.65 \\
3.64 \\
3.65 \\
3.67\end{array}$ & $\begin{array}{l}3.71 \\
3.75 \\
3.76 \\
3.77 \\
3.78\end{array}$ & $\begin{array}{l}3.94 \\
3.97 \\
3.98 \\
3.95 \\
3.95\end{array}$ & $\begin{array}{l}3.91 \\
3.92 \\
3.94 \\
3.96 \\
3.94\end{array}$ \\
\hline $\begin{array}{r}6 \\
7 \\
8 \\
9 \\
10\end{array}$ & $\begin{array}{l}3.81 \\
3.78 \\
3.75 \\
3.73 \\
3.74\end{array}$ & $\begin{array}{l}3.00 \\
2.98 \\
3.03 \\
2.91 \\
2.93\end{array}$ & $\begin{array}{r}2.94 \\
2.94 \\
2.96 \\
--- \\
-\end{array}$ & $\begin{array}{r}3.01 \\
3.01 \\
- \\
-\end{array}$ & $\begin{array}{l}2.96 \\
2.95 \\
2.96 \\
2.96 \\
2.96\end{array}$ & $\begin{array}{l}2.96 \\
2.96 \\
2.96 \\
2.95 \\
2.97\end{array}$ & $\begin{array}{l}2.95 \\
2.95 \\
2.96 \\
2.99 \\
3.01\end{array}$ & $\begin{array}{l}3.11 \\
3.10 \\
3.12 \\
3.11 \\
3.12\end{array}$ & $\begin{array}{l}3.68 \\
3.68 \\
3.67 \\
3.67 \\
3.68\end{array}$ & $\begin{array}{l}3.79 \\
3.81 \\
3.81 \\
3.86 \\
3.90\end{array}$ & $\begin{array}{l}3.97 \\
3.95 \\
3.96 \\
3.96 \\
3.97\end{array}$ & $\begin{array}{l}3.98 \\
3.99 \\
3.98 \\
4.00 \\
4.00\end{array}$ \\
\hline $\begin{array}{l}11 \\
12 \\
13 \\
14 \\
15\end{array}$ & $\begin{array}{l}3.70 \\
3.78 \\
3.78 \\
3.73 \\
3.70\end{array}$ & $\begin{array}{c}2.93 \\
- \\
- \\
-- \\
--\end{array}$ & $\begin{array}{l}--- \\
-- \\
--- \\
3.06\end{array}$ & $\begin{array}{l}2.98 \\
2.99 \\
2.99 \\
3.01\end{array}$ & $\begin{array}{l}2.97 \\
2.97 \\
2.97 \\
2.97 \\
2.97\end{array}$ & $\begin{array}{l}2.98 \\
2.99 \\
3.01 \\
3.02 \\
3.02\end{array}$ & $\begin{array}{l}3.01 \\
3.00 \\
3.01 \\
3.01 \\
3.02\end{array}$ & $\begin{array}{l}3.11 \\
3.13 \\
3.15 \\
3.10 \\
3.12\end{array}$ & $\begin{array}{l}3.72 \\
3.70 \\
3.72 \\
3.70 \\
3.71\end{array}$ & $\begin{array}{l}3.95 \\
4.00 \\
3.97 \\
3.96 \\
3.94\end{array}$ & $\begin{array}{l}3.98 \\
3.99 \\
4.11 \\
4.07 \\
4.03\end{array}$ & $\begin{array}{l}4.01 \\
4.02 \\
4.03 \\
4.03 \\
4.01\end{array}$ \\
\hline $\begin{array}{l}16 \\
17 \\
18 \\
19 \\
20\end{array}$ & $\begin{array}{l}3.66 \\
3.63 \\
3.59 \\
3.55 \\
3.51\end{array}$ & $\begin{array}{r}3.00 \\
-\cdots \\
---\end{array}$ & $\begin{array}{l}3.03 \\
3.01 \\
3.00 \\
2.99 \\
2.98\end{array}$ & $\begin{array}{r}3.01 \\
- \\
-1.02 \\
-\end{array}$ & $\begin{array}{l}2.97 \\
2.98 \\
2.98 \\
2.99 \\
3.00\end{array}$ & $\begin{array}{l}3.03 \\
3.03 \\
3.02 \\
2.99 \\
2.98\end{array}$ & $\begin{array}{l}3.04 \\
3.06 \\
3.07 \\
3.12 \\
3.10\end{array}$ & $\begin{array}{l}3.14 \\
3.14 \\
3.17 \\
3.26 \\
3.28\end{array}$ & $\begin{array}{l}3.71 \\
3.72 \\
3.71 \\
3.71 \\
3.69\end{array}$ & $\begin{array}{l}3.94 \\
3.92 \\
3.93 \\
3.96 \\
3.97\end{array}$ & $\begin{array}{l}3.98 \\
3.93 \\
3.94 \\
3.93 \\
3.93\end{array}$ & $\begin{array}{l}4.00 \\
3.99 \\
4.00 \\
4.01 \\
4.00\end{array}$ \\
\hline $\begin{array}{l}21 \\
22 \\
23 \\
24 \\
25\end{array}$ & $\begin{array}{l}3.47 \\
3.43 \\
3.39 \\
3.36 \\
3.33\end{array}$ & $\begin{array}{l}--- \\
--12 \\
3.13\end{array}$ & $\begin{array}{l}2.97 \\
2.99 \\
2.97 \\
2.98 \\
2.99\end{array}$ & $\begin{array}{l}--- \\
--- \\
--- \\
--- \\
---\end{array}$ & $\begin{array}{l}3.01 \\
3.02 \\
3.02 \\
3.01 \\
3.00\end{array}$ & $\begin{array}{l}2.97 \\
2.97 \\
2.97 \\
2.96 \\
2.97\end{array}$ & $\begin{array}{l}3.08 \\
3.11 \\
3.09 \\
3.10 \\
3.14\end{array}$ & $\begin{array}{l}3.31 \\
3.29 \\
3.31 \\
3.33 \\
3.35\end{array}$ & $\begin{array}{l}3.70 \\
3.70 \\
3.70 \\
3.68 \\
3.68\end{array}$ & $\begin{array}{l}4.00 \\
4.00 \\
3.98 \\
3.99 \\
3.99\end{array}$ & $\begin{array}{l}3.95 \\
3.92 \\
3.91 \\
3.91 \\
3.91\end{array}$ & $\begin{array}{l}3.97 \\
3.97 \\
3.95 \\
3.94 \\
3.94\end{array}$ \\
\hline $\begin{array}{l}26 \\
27 \\
28 \\
29 \\
30 \\
31\end{array}$ & $\begin{array}{l}3.29 \\
3.26 \\
3.22 \\
3.18 \\
3.18 \\
3.18\end{array}$ & $\begin{array}{l}3.07 \\
3.04 \\
3.02 \\
2.99 \\
2.96 \\
\end{array}$ & $\begin{array}{l}3.00 \\
3.01 \\
3.02 \\
3.02 \\
3.03 \\
3.04\end{array}$ & $\begin{array}{l}3.04 \\
3.02 \\
3.01 \\
3.00 \\
3.01 \\
3.01\end{array}$ & $\begin{array}{r}2.99 \\
2.97 \\
2.97 \\
-.- \\
--- \\
---\end{array}$ & $\begin{array}{l}2.98 \\
3.00 \\
3.01 \\
3.03 \\
3.06 \\
3.06\end{array}$ & $\begin{array}{l}3.14 \\
3.09 \\
3.13 \\
3.10 \\
3.13 \\
---\end{array}$ & $\begin{array}{l}3.37 \\
3.39 \\
3.43 \\
3.47 \\
3.57 \\
3.59\end{array}$ & $\begin{array}{l}3.65 \\
3.68 \\
3.69 \\
3.70 \\
3.70 \\
-\end{array}$ & $\begin{array}{l}3.97 \\
3.96 \\
3.94 \\
3.93 \\
3.93 \\
3.93\end{array}$ & $\begin{array}{l}3.91 \\
3.90 \\
3.91 \\
3.92 \\
3.92 \\
3.90\end{array}$ & $\begin{array}{l}3.95 \\
3.96 \\
3.96 \\
3.95 \\
3.93\end{array}$ \\
\hline $\begin{array}{l}\text { MEAN } \\
\text { MAX } \\
\text { MIN }\end{array}$ & $\begin{array}{l}3.59 \\
3.94 \\
3.18\end{array}$ & $\begin{array}{l}--- \\
--- \\
---\end{array}$ & $\begin{array}{l}-- \\
-- \\
--\end{array}$ & $\begin{array}{l}--- \\
--- \\
---\end{array}$ & $\begin{array}{l}2.98 \\
3.02 \\
2.95\end{array}$ & $\begin{array}{l}2.99 \\
3.06 \\
2.95\end{array}$ & $\begin{array}{l}3.05 \\
3.14 \\
2.95\end{array}$ & $\begin{array}{l}3.23 \\
3.59 \\
3.10\end{array}$ & $\begin{array}{l}3.69 \\
3.72 \\
3.63\end{array}$ & $\begin{array}{l}3.91 \\
4.00 \\
3.71\end{array}$ & $\begin{array}{l}3.95 \\
4.11 \\
3.90\end{array}$ & $\begin{array}{l}3.97 \\
4.03 \\
3.91\end{array}$ \\
\hline
\end{tabular}




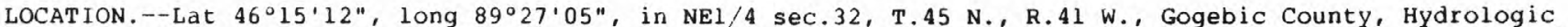
Unit 04020102 , on left bank 80 ft downstream from Cisco Lake Dam, 2.5 mi upstream from Langford Creek, $5.0 \mathrm{mi}$ upstream from U.S. Highway 2 , and $13 \mathrm{mi}$ west of Watersmeet.

DRAINAGE AREA. - $-50.7 \mathrm{mi}^{2}$.

PERIOD OF RECORD.--October 1944 to current year.

REVISED RECORDS.--WSP 1911: Drainage area.

GAGE.--Water-stage recorder. Datum of gage is $1,672.69 \mathrm{ft}$ above National Geodetic Vertical Datum of 1929 . Prior to oct. 1, 1968, nonrecording gage at same site and at datum $4.00 \mathrm{ft}$ higher.

REMARKS.--No estimated daily discharges. Records good except those below $1.5 \mathrm{ft}^{3} / \mathrm{s}$, which are poor. Flow regulated by Cisco Lake (station 04037400). Several measurements of water temperature were made during the year.

AVERAGE DISCHARGE. --43 years, $47.3 \mathrm{ft}^{3} / \mathrm{s}, 12.67 \mathrm{in} / \mathrm{Yr}^{\mathrm{r}}$.

EXTREMES FOR PERIOD OF RECORD,--Maximum discharge, $288 \mathrm{ft}^{3} / \mathrm{s}$, May 1-4, 1951, gage height, $6.10 \mathrm{ft}$, present datum; minimum daily, $0.09 \mathrm{ft}^{3}, \mathrm{~s}$, June $4-23,1977$.

EXTREMES FOR CURRENT YEAR.--Maximum discharge, $151 \mathrm{ft}^{3} / \mathrm{s}$, Oct. 13, gage height, $5.43 \mathrm{ft} ; \mathrm{minimum}$ daily, $0.22 \mathrm{ft}^{3} / \mathrm{s}, \mathrm{Apr} .30$, May 1 .

DISCHARGE, IN CUBIC FEET PER SECOND, WATER YEAR OCTOBER 1986 TO SEPTEMBER 1987 MEAN VALUES

\begin{tabular}{|c|c|c|c|c|c|c|c|c|c|c|c|c|}
\hline DAY & OCT & NOV & DEC & JAN & FEB & MAR & APR & MAY & JUN & JUL & AUG & SEP \\
\hline $\begin{array}{l}1 \\
2 \\
3 \\
4 \\
5\end{array}$ & $\begin{array}{l}49 \\
48 \\
70 \\
86 \\
83\end{array}$ & $\begin{array}{l}86 \\
85 \\
83 \\
83 \\
82\end{array}$ & $\begin{array}{l}63 \\
49 \\
49 \\
49 \\
48\end{array}$ & $\begin{array}{l}14 \\
30 \\
47 \\
47 \\
46\end{array}$ & $\begin{array}{l}44 \\
44 \\
44 \\
43 \\
43\end{array}$ & $\begin{array}{l}44 \\
45 \\
44 \\
44 \\
43\end{array}$ & $\begin{array}{l}69 \\
66 \\
68 \\
65 \\
62\end{array}$ & $\begin{array}{l}.22 \\
.25 \\
.25 \\
.25 \\
.25\end{array}$ & $\begin{array}{l}3.4 \\
3.2 \\
2.0 \\
1.3 \\
.68\end{array}$ & $\begin{array}{l}.24 \\
.26 \\
.31 \\
.29 \\
.26\end{array}$ & $\begin{array}{l}.42 \\
.39 \\
.41 \\
.37 \\
.35\end{array}$ & $\begin{array}{l}.28 \\
.28 \\
.27 \\
.29 \\
.24\end{array}$ \\
\hline $\begin{array}{r}6 \\
7 \\
8 \\
9 \\
10\end{array}$ & $\begin{array}{l}81 \\
81 \\
77 \\
76 \\
76\end{array}$ & $\begin{array}{l}80 \\
78 \\
84 \\
77 \\
48\end{array}$ & $\begin{array}{l}48 \\
47 \\
29 \\
11 \\
12\end{array}$ & $\begin{array}{l}45 \\
46 \\
45 \\
45 \\
44\end{array}$ & $\begin{array}{l}42 \\
32 \\
24 \\
24 \\
24\end{array}$ & $\begin{array}{r}43 \\
43 \\
43 \\
25 \\
8.9\end{array}$ & $\begin{array}{l}66 \\
36 \\
10 \\
11 \\
22\end{array}$ & $\begin{array}{l}.25 \\
.25 \\
.25 \\
.25 \\
.25\end{array}$ & $\begin{array}{l}.55 \\
.55 \\
.48 \\
.40 \\
.37\end{array}$ & $\begin{array}{l}.25 \\
.27 \\
.28 \\
.32 \\
.34\end{array}$ & $\begin{array}{l}.38 \\
.34 \\
.33 \\
.34 \\
.34\end{array}$ & $\begin{array}{r}.35 \\
.35 \\
.30 \\
.38 \\
.43\end{array}$ \\
\hline $\begin{array}{l}11 \\
12 \\
13 \\
14 \\
15\end{array}$ & $\begin{array}{r}74 \\
80 \\
111 \\
145 \\
143\end{array}$ & $\begin{array}{l}5.0 \\
3.0 \\
.85 \\
.70 \\
.70\end{array}$ & $\begin{array}{l}12 \\
13 \\
13 \\
14 \\
30\end{array}$ & $\begin{array}{l}44 \\
29 \\
9.6 \\
10 \\
10\end{array}$ & $\begin{array}{l}24 \\
24 \\
24 \\
24 \\
24\end{array}$ & $\begin{array}{l}9.5 \\
9.7 \\
10 \\
10 \\
11\end{array}$ & $\begin{array}{l}38 \\
43 \\
35 \\
32 \\
17\end{array}$ & $\begin{array}{l}.25 \\
.25 \\
.25 \\
.25 \\
.25\end{array}$ & $\begin{array}{l}.38 \\
.37 \\
.38 \\
.79 \\
.75\end{array}$ & $\begin{array}{l}29 \\
72 \\
71 \\
69 \\
68\end{array}$ & $\begin{array}{r}.40 \\
79^{.78} \\
134 \\
130\end{array}$ & $\begin{array}{l}19 \\
30 \\
31 \\
30 \\
43\end{array}$ \\
\hline $\begin{array}{l}16 \\
17 \\
18 \\
19 \\
20\end{array}$ & $\begin{array}{l}140 \\
136 \\
132 \\
127 \\
122\end{array}$ & $\begin{array}{l}.70 \\
.70 \\
.70 \\
.70 \\
.70\end{array}$ & $\begin{array}{l}50 \\
48 \\
48 \\
47 \\
47\end{array}$ & $\begin{array}{l}11 \\
19 \\
27 \\
27 \\
27\end{array}$ & $\begin{array}{r}17 \\
8.5 \\
8.9 \\
9.2 \\
9.6\end{array}$ & $\begin{array}{l}11 \\
30 \\
47 \\
46 \\
45\end{array}$ & $\begin{array}{l}2.2 \\
1.3 \\
.55 \\
.39 \\
.25\end{array}$ & $\begin{array}{l}.25 \\
.25 \\
.27 \\
.29 \\
.27\end{array}$ & $\begin{array}{l}.61 \\
.41 \\
.37 \\
.39 \\
.40\end{array}$ & $\begin{array}{r}52 \\
17 \\
.63 \\
.35 \\
.32\end{array}$ & $\begin{array}{r}125 \\
69 \\
29 \\
29 \\
29\end{array}$ & $\begin{array}{l}51 \\
51 \\
51 \\
52 \\
50\end{array}$ \\
\hline $\begin{array}{l}21 \\
22 \\
23 \\
24 \\
25\end{array}$ & $\begin{array}{l}119 \\
115 \\
112 \\
109 \\
105\end{array}$ & $\begin{array}{l}9.82 \\
9.3 \\
17 \\
40 \\
76\end{array}$ & $\begin{array}{l}46 \\
46 \\
28 \\
13 \\
13\end{array}$ & $\begin{array}{l}28 \\
28 \\
28 \\
29 \\
29\end{array}$ & $\begin{array}{l}9 \cdot 9 \\
10 \\
18 \\
35 \\
44\end{array}$ & $\begin{array}{l}45 \\
45 \\
45 \\
44 \\
26\end{array}$ & $\begin{array}{l}.26 \\
.27 \\
.26 \\
.25 \\
.25\end{array}$ & $\begin{array}{l}.25 \\
.25 \\
.26 \\
.27 \\
.25\end{array}$ & $\begin{array}{l}.40 \\
.40 \\
.37 \\
.31 \\
.33\end{array}$ & $\begin{array}{l}14 \\
29 \\
29 \\
29 \\
29\end{array}$ & $\begin{array}{l}29 \\
17 \\
1.4 \\
1.4 \\
1.1\end{array}$ & $\begin{array}{c}49 \\
49 \\
48 \\
20 \\
1.1\end{array}$ \\
\hline $\begin{array}{l}26 \\
27 \\
28 \\
29 \\
30 \\
31\end{array}$ & $\begin{array}{r}102 \\
99 \\
97 \\
93 \\
92 \\
91\end{array}$ & $\begin{array}{l}88 \\
86 \\
83 \\
82 \\
80\end{array}$ & $\begin{array}{l}13 \\
14 \\
14 \\
14 \\
14 \\
15\end{array}$ & $\begin{array}{l}35 \\
45 \\
44 \\
44 \\
44 \\
44\end{array}$ & $\begin{array}{l}44 \\
44 \\
43 \\
--- \\
--- \\
---\end{array}$ & $\begin{array}{l}9.9 \\
11 \\
11 \\
11 \\
12 \\
43\end{array}$ & $\begin{array}{l}.25 \\
.25 \\
.25 \\
.23 \\
.22 \\
.--\end{array}$ & $\begin{array}{l}.26 \\
.29 \\
.29 \\
.55 \\
1.1 \\
1.9\end{array}$ & $\begin{array}{l}.31 \\
.31 \\
.29 \\
.28 \\
.26 \\
----\end{array}$ & $\begin{array}{lr}28 & \\
27 & \\
26 & \\
25 & \\
12 & \\
& .55\end{array}$ & $\begin{array}{r}1.0 \\
1.0 \\
.98 \\
.52 \\
.31 \\
.28\end{array}$ & $\begin{array}{r}1.0 \\
1.0 \\
1.0 \\
.90 \\
.75 \\
- \\
---\end{array}$ \\
\hline $\begin{array}{l}\text { TOTAL } \\
\text { MEAN } \\
\text { MAX } \\
\text { MIN }\end{array}$ & $\begin{array}{r}3071 \\
99.1 \\
145 \\
48\end{array}$ & $\begin{array}{r}1361.87 \\
45.4 \\
88 \\
.70\end{array}$ & $\begin{array}{r}957 \\
30.9 \\
63 \\
11\end{array}$ & $\begin{array}{r}1020.6 \\
32.9 \\
47 \\
9.6\end{array}$ & $\begin{array}{r}785.1 \\
28.0 \\
44 \\
8.5\end{array}$ & $\begin{array}{r}915.0 \\
29.5 \\
47 \\
8.9\end{array}$ & $\begin{array}{r}647.18 \\
21.6 \\
69 \\
.22\end{array}$ & $\begin{array}{r}10.72 \\
.35 \\
1.99 \\
.22\end{array}$ & $\begin{array}{r}21.04 \\
.70 \\
3.4 \\
.26\end{array}$ & $\begin{array}{r}630.67 \\
20.3 \\
72 \\
.24\end{array}$ & $\begin{array}{r}682.84 \\
22.0 \\
134 \\
.28\end{array}$ & $\begin{array}{r}582.92 \\
19.4 \\
52 \\
.24\end{array}$ \\
\hline $\begin{array}{ll}\text { CAL YR } \\
\text { WTR YR }\end{array}$ & $\begin{array}{l}986 \\
987\end{array}$ & $\begin{array}{l}\text { TOTAL } \\
\text { TOTAL }\end{array}$ & $\begin{array}{l}08 \\
94\end{array}$ & $\begin{array}{ll}\text { MEAN } & 42 \\
\text { MEAN } & 29\end{array}$ & $\begin{array}{l}\text { MAX } \\
\text { MAX }\end{array}$ & $\begin{array}{l}177 \\
145\end{array}$ & $\begin{array}{ll}\text { IN } & .57 \\
\text { IN } & .22\end{array}$ & $\begin{array}{l}\text { CFSM } \\
\text { CFSM }\end{array}$ & $\begin{array}{l}84 \\
58\end{array}$ & $\begin{array}{r}11.38 \\
7.84\end{array}$ & & \\
\hline
\end{tabular}


LOCATION.--Lat $46^{\circ} 43^{\prime} 15^{\prime \prime}$, long $89^{\circ} 12^{\prime} 25^{\prime \prime}$, in NEl/4 sec.20, T.50 N., R.39 w., Ontonagon County, Hydrologic Unit 04020102 , on left bank $50 \mathrm{ft}$ downstream from bridge on Victoria Road, $1.8 \mathrm{mi}$ southwest of Rockland, and $2.4 \mathrm{mi}$ downstream from confluence of Middle and West Branches.

DRAINAGE AREA. --1,340 $\mathrm{mi}^{2}$.

\section{WATER-DISCHARGE RECORDS}

PERIOD OF RECORD.--June 1942 to current year.

REVISED RECORDS.--WSP 1387: 1943, 1946-47. WSP 1911: Drainage area.

GAGE.--Water-stage recorder. Datum of gage is $638.72 \mathrm{ft}$ above National Geodetic Vertical Datum of 1929 . Prior to Nov. 23, 1943, nonrecording gage and Nov. 23, 1943 to Oct. 17, 1967, water-stage recorder at site $50 \mathrm{ft}$ upstream at same datum.

REMARKS. - Estimated daily discharges: Dec. 6 to Mar. 19. Water-discharge records good except for estimated daily discharges, which are fair. Flow regulated by victoria powerplant on west Branch 5 mi upstream; Bond Falls Reservoir (station 04034000) $34 \mathrm{mi}$ upstream; Gogebic and Cisco Lakes, combined usable capacity, 50,800 acre-ft, in headwaters.

AVERAGE DISCHARGE. -45 years, $1,423 \mathrm{ft}^{3} / \mathrm{s}, 14.42 \mathrm{in} / \mathrm{yr}$.

EXTREMES FOR PERIOD OF RECORD.--Maximum discharge, 42,000 $\mathrm{ft}^{3} / \mathrm{s}$, Aug. 22, 1942, gage height, 28.6 $\mathrm{ft}$, from floodmark, from rating curve extended above $14,000 \mathrm{ft} \mathrm{f}^{3 / 5}$ on basis of slope-area measurement of peak flow; minimum daily, $192 \mathrm{ft} 3 / \mathrm{s}, \mathrm{Jul}_{\mathrm{Y}} 28,29,1963$.

EXTREMES FOR CURRENT YEAR.--Maximum discharge, 5,490 $\mathrm{ft}^{3} / \mathrm{s}$, Mar. 25, gage height, $10.51 \mathrm{ft}$, no peak discharge above base discharge of $9,000 \mathrm{ft}^{3} / \mathrm{s} ;$ maximum gage height, $15.03 \mathrm{ft}, \mathrm{Mar}$. 8 , backwater from ice; minimum daily discharge, $245 \mathrm{ft}^{3} / \mathrm{s}$, July 1 .

DISCHARGE, IN CUBIC FEET PER SECOND, WATER YEAR OCTOBER 1986 TO SEPTEMBER 1987 MEAN VALUES

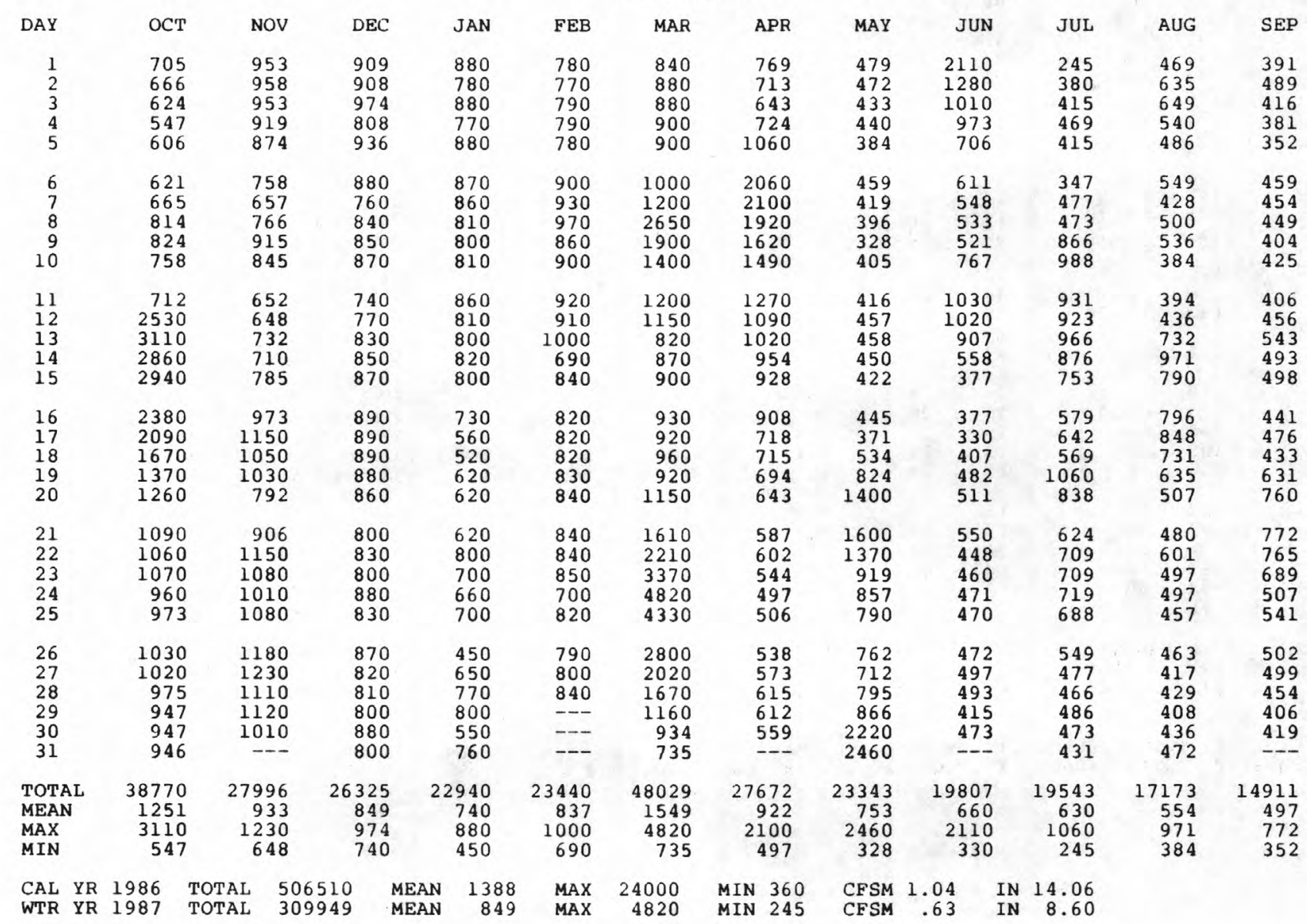


PERIOD OF RECORD.--Water years 1967, 1972 to current year.

PERIOD OF DAILY RECORD.--

SPECIFIC CONDUCTANCE: October 1974 to September 1981.

WATER TEMPERATURE: October 1974 to September 1981.

INSTRUMENTATION. --Water-quality monitor from Oct. 15, 1975 to Sept. 30, 1977.

REMARKS.--Quarterly samples were collected at or near victoria Road bridge. Daily record for water years 1975, 1978-81 is from once-daily observer samples.

EXTREMES FOR PERIOD OF DAILY RECORD.--

SPECIFIC CONDUCTANCE (water years 1975-80): Maximum recorded (more than 20 percent missing record), 192 microsiemens, Mar. 26, 1977, May 28, 1978; minimum recorded, 45 microsiemens, Dec. 2 , 1975.

WATER TEMPERATURE (water years 1975-77, 1979-80): Maximum, 28.0 ${ }^{\circ} \mathrm{C}$, July 19, 1977; minimum, 0.0 ${ }^{\circ} \mathrm{C}$ on many days during winter.

WATER QUALITY DATA, WATER YEAR OCTOBER 1986 TO SEPTEMBER 1987

\begin{tabular}{|c|c|c|c|c|c|c|c|c|c|c|}
\hline DATE & TIME & $\begin{array}{l}\text { STREAM- } \\
\text { FLOW, } \\
\text { INSTAN- } \\
\text { TANEOUS } \\
\text { (CFS) }\end{array}$ & $\begin{array}{l}\text { SPE- } \\
\text { CIFIC } \\
\text { CON- } \\
\text { DUCT- } \\
\text { ANCE } \\
\text { (US/CM) }\end{array}$ & $\begin{array}{c}\text { PH } \\
\text { (STAND- } \\
\text { ARD } \\
\text { UNITS) }\end{array}$ & $\begin{array}{l}\text { TEMPER- } \\
\text { ATURE } \\
\text { (DEG C) }\end{array}$ & $\begin{array}{l}\text { TUR- } \\
\text { BID- } \\
\text { ITY } \\
\text { (NTU) }\end{array}$ & $\begin{array}{c}\text { OXYGEN, } \\
\text { DIS- } \\
\text { SOLVED } \\
\text { (MG/L) }\end{array}$ & $\begin{array}{c}\text { OXYGEN, } \\
\text { DIS- } \\
\text { SOLVED } \\
\text { (PER- } \\
\text { CENT } \\
\text { SATUR- } \\
\text { ATION) }\end{array}$ & $\begin{array}{l}\text { COLI- } \\
\text { FORM, } \\
\text { FECAL, } \\
0.7 \\
\text { UM-MF } \\
\text { (COLS.' } \\
100 \mathrm{ML} \text { ) }\end{array}$ & $\begin{array}{c}\text { STREP- } \\
\text { TOCOCCI } \\
\text { FECAL, } \\
\text { KF AGAR } \\
\text { (COLS. } \\
\text { PER } \\
100 \mathrm{ML} \text { ) }\end{array}$ \\
\hline & & & & & & & & & & \\
\hline $28 \ldots$ & 1530 & 899 & 111 & 7.6 & 8.0 & 9.3 & 11.4 & 99 & K 4 & K5 \\
\hline $13 \ldots$ & 1445 & 795 & 151 & 7.7 & 0.0 & 9.1 & 14.4 & 102 & K 3 & K 2 \\
\hline $21 \ldots$ & 1550 & 596 & 138 & 8.0 & 14.0 & 18 & 10.3 & 101 & K8 & K2 \\
\hline & 1345 & 494 & 144 & 7.7 & 25.0 & 5.0 & 8.2 & 102 & K12 & 6 \\
\hline
\end{tabular}

\section{DATE}

HARD-
NESS
(MG/L
AS
CACO3)

HARD-

NESS

NONCARB CALCIUM SIUM, SODIUM,

WH WAT DIS-

TOT FLD SOLVED

MG AS

$\mathrm{CACO} 3$

SOLVED

(MG $/ L$

DIS-

SOLVED SOLVED

AS MG)

(MG / L

PERCENT SODIUM

SODIUM
AD-
SORP-
TION
RATIO

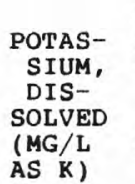

BICAR-

BONATE

WH WAT WH WAT

TOTAL TOTAL

FIELD FIELD

MG/L AS MG/L AS

$\mathrm{HCO} 3$

$\mathrm{CO} 3{ }^{\mathrm{AS}}$

\begin{tabular}{|c|c|c|}
\hline $28 \ldots$ & 54 & 4 \\
\hline JAN & & \\
\hline${ }_{A P R}^{13} \cdots$ & 73 & 8 \\
\hline${ }_{\text {JUL }}^{21} \ldots$ & 64 & 4 \\
\hline 29. & 77 & 4 \\
\hline
\end{tabular}

$\begin{array}{ll}4.1 & 2.3 \\ 5.6 & 2.6 \\ 4.7 & 2.6 \\ 5.9 & 3.0\end{array}$

\section{1}

1.1

1.0

0.1

0.1

1.0

1.2

SOLIDS, SOLIDS,

ALKA-

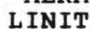

LINIT

WH WAT

CARBON
DIOXIDE SULFATE

CHLO-

RIDE,

DIS-

DIS-

FIELD SOLVED SOLVED

DATE

CACO 3

AS $\mathrm{CO} 2)$ AS SO 4 )

SOLVED

(MG/L

AS CL)

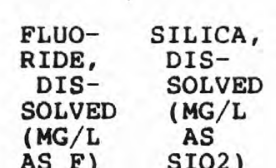

SOLIDS,

RES IDUE

AT 180

DEG. C

SOLVED

(MG/L)

SUM OF SOLIDS, SOLIDS,

CONSTI-

TUENTS,

DIS-

SOLVED

(MG/L)

SOLVED

(TONS

PER

DIS-

SOLVED

(TONS

PER

OCT
$28 \ldots$
JAN
$13 \ldots$
APR
$21 \ldots$
JUL

50

$2.7 \quad 11$

2.2

$<0.1$

6.8

82

73

$0.11 \quad 199$

$\begin{array}{lll}2.4 & 8.4 & 3.0\end{array}$

$<0.1$

11

$<0.1$

7.1

94

91

$0.13 \quad 202$

2.0

0.2

8.2

84

88

$0.11 \quad 135$

2.8

9.7

1.8

97

95

$0.13 \quad 129$ 
04040000 ONTONAGON RIVER NEAR ROCKLAND, MI--Cont inued

WATER QUALITY DATA, WATER YEAR OCTOBER 1986 TO SEPTEMBER 1987

\begin{tabular}{|c|c|c|c|c|c|c|c|c|c|c|}
\hline DATE & $\begin{array}{l}\text { NITRO- } \\
\text { GEN, } \\
\text { NITRITE } \\
\text { DIS- } \\
\text { SOLVED } \\
\text { (MG/L } \\
\text { AS N) }\end{array}$ & $\begin{array}{c}\text { NITRO- } \\
\text { GEN, } \\
\text { NO2+NO3 } \\
\text { DIS- } \\
\text { SOLVED } \\
\text { (MG/L } \\
\text { AS N) }\end{array}$ & $\begin{array}{l}\text { NITRO- } \\
\text { GEN, } \\
\text { AMMONIA } \\
\text { TOTAL } \\
\text { (MG/L } \\
\text { AS N) }\end{array}$ & $\begin{array}{l}\text { NITRO- } \\
\text { GEN, } \\
\text { AMMONIA } \\
\text { DIS- } \\
\text { SOLVED } \\
\text { (MG/L } \\
\text { AS N) }\end{array}$ & $\begin{array}{l}\text { NITRO- } \\
\text { GEN, } \\
\text { ORGANIC } \\
\text { TOTAL } \\
\text { (MG/L } \\
\text { AS N) }\end{array}$ & $\begin{array}{l}\text { NITRO- } \\
\text { GEN, AM- } \\
\text { MONIA + } \\
\text { ORGANIC } \\
\text { TOTAL } \\
\text { (MG/L } \\
\text { AS N) }\end{array}$ & $\begin{array}{l}\text { PHOS- } \\
\text { PHORUS, } \\
\text { TOTAL } \\
\text { (MG/L } \\
\text { AS P) }\end{array}$ & $\begin{array}{c}\text { PHOS- } \\
\text { PHORUS, } \\
\text { DIS- } \\
\text { SOLVED } \\
\text { (MG/L } \\
\text { AS P) }\end{array}$ & $\begin{array}{l}\text { PHOS- } \\
\text { PHORUS, } \\
\text { ORTHO, } \\
\text { DIS- } \\
\text { SOLVED } \\
\text { (MG/L } \\
\text { AS P) }\end{array}$ & $\begin{array}{l}\text { ALUM- } \\
\text { INUM, } \\
\text { DIS- } \\
\text { SOLVED } \\
\text { (UG/L } \\
\text { AS AL) }\end{array}$ \\
\hline \multicolumn{11}{|l|}{ OCT } \\
\hline $\begin{array}{l}28 \ldots \\
\text { JAN }\end{array}$ & $<0.01$ & $<0.10$ & 0.02 & 0.04 & 0.48 & 0.5 & 0.01 & $<0.01$ & $<0.01$ & 20 \\
\hline$\underset{A P R}{13} \ldots$ & $<0.01$ & 0.12 & 0.03 & 0.04 & 0.47 & 0.5 & 0.04 & 0.01 & $<0.01$ & $<10$ \\
\hline $\mathrm{UL}^{21 \ldots}$ & $<0.01$ & $<0.10$ & 0.05 & 0.04 & 0.35 & 0.4 & 0.03 & 0.04 & $<0.01$ & 40 \\
\hline $29 \ldots$ & $<0.01$ & $<0.10$ & $<0.01$ & 0.02 & 0.39 & 0.4 & 0.04 & $<0.01$ & $<0.01$ & $<10$ \\
\hline
\end{tabular}

\begin{tabular}{|c|c|c|c|c|c|c|c|c|c|c|}
\hline DATE & $\begin{array}{l}\text { ARSENIC } \\
\text { DIS- } \\
\text { SOLVED } \\
\text { (UG/L } \\
\text { AS AS) }\end{array}$ & $\begin{array}{l}\text { BAR IUM, } \\
\text { DIS- } \\
\text { SOLVED } \\
\text { (UG/L } \\
\text { AS BA) }\end{array}$ & $\begin{array}{l}\text { BERYL- } \\
\text { LIUM, } \\
\text { DIS- } \\
\text { SOLVED } \\
\text { (UG/L } \\
\text { AS BE) }\end{array}$ & $\begin{array}{l}\text { CADMIUM } \\
\text { DIS- } \\
\text { SOLVED } \\
\text { (UG/L } \\
\text { AS CD) }\end{array}$ & $\begin{array}{l}\text { CHRO- } \\
\text { MIUM, } \\
\text { DIS- } \\
\text { SOLVED } \\
\text { (UG/L } \\
\text { AS CR) }\end{array}$ & $\begin{array}{l}\text { COBALT, } \\
\text { DIS- } \\
\text { SOLVED } \\
\text { (UG/L } \\
\text { AS CO) }\end{array}$ & $\begin{array}{l}\text { COPPER, } \\
\text { DIS- } \\
\text { SOLVED } \\
\text { (UG/L } \\
\text { AS CU) }\end{array}$ & $\begin{array}{l}\text { IRON, } \\
\text { DIS- } \\
\text { SOLVED } \\
\text { (UG/L } \\
\text { AS FE) }\end{array}$ & $\begin{array}{l}\text { LEAD, } \\
\text { DIS- } \\
\text { SOLVED } \\
\text { (UG/L } \\
\text { AS PB) }\end{array}$ & $\begin{array}{l}\text { LITHIUM } \\
\text { DIS- } \\
\text { SOLVED } \\
\text { (UG/L } \\
\text { AS LI) }\end{array}$ \\
\hline $\begin{array}{l}\mathrm{T} \\
28 \ldots \\
\mathrm{N}\end{array}$ & $<1$ & 23 & $<0.5$ & 1 & $<1$ & $<3$ & 3 & 95 & $<5$ & $<4$ \\
\hline $3 \ldots$ & 1 & 26 & $<0.5$ & $<1$ & $<1$ & $<3$ & 2 & 89 & $<5$ & $<4$ \\
\hline $1 \ldots$ & $<1$ & 30 & 0.5 & 1 & $<1$ & $<3$ & $<1$ & 82 & $<5$ & $<4$ \\
\hline $9 \ldots$ & 1 & 31 & $<0.5$ & $<1$ & $<1$ & $<3$ & 2 & 64 & $<5$ & 12 \\
\hline DATE & $\begin{array}{l}\text { MANGA- } \\
\text { NESE, } \\
\text { DIS- } \\
\text { SOLVED } \\
\text { (UG/L } \\
\text { AS MN) }\end{array}$ & $\begin{array}{c}\text { MERCURY } \\
\text { DIS- } \\
\text { SOLVED } \\
\text { (UG/L } \\
\text { AS HG) }\end{array}$ & $\begin{array}{l}\text { MOLYB- } \\
\text { DENUM, } \\
\text { DIS- } \\
\text { SOLVED } \\
\text { (UG/L } \\
\text { AS MO) }\end{array}$ & $\begin{array}{l}\text { NICKEL, } \\
\text { DIS- } \\
\text { SOLVED } \\
\text { (UG/L } \\
\text { AS NI) }\end{array}$ & $\begin{array}{l}\text { SELE- } \\
\text { NIUM, } \\
\text { DIS- } \\
\text { SOLVED } \\
\text { (UG/L } \\
\text { AS SE) }\end{array}$ & $\begin{array}{c}\text { SILVER, } \\
\text { DIS- } \\
\text { SOLVED } \\
\text { (UG/L } \\
\text { AS AG) }\end{array}$ & $\begin{array}{l}\text { STRON- } \\
\text { TIUM, } \\
\text { DIS- } \\
\text { SOLVED } \\
\text { (UG/L } \\
\text { AS SR) }\end{array}$ & $\begin{array}{l}\text { VANA- } \\
\text { DIUM, } \\
\text { DIS- } \\
\text { SOLVED } \\
\text { (UG/L } \\
\text { AS V) }\end{array}$ & $\begin{array}{l}\text { ZINC, } \\
\text { DIS- } \\
\text { SOLVED } \\
\text { (UG/L } \\
\text { AS ZN) }\end{array}$ & $\begin{array}{l}\text { SEDI - } \\
\text { MENT, } \\
\text { SUS- } \\
\text { PENDED } \\
\text { (MG/L ) }\end{array}$ \\
\hline $8 \ldots$ & 17 & $<0.1$ & $<10$ & $<1$ & $<1$ & $<1$ & 35 & $<6$ & 6 & 18 \\
\hline $3 \ldots$ & 7 & $<0.1$ & $<10$ & $<1$ & $<1$ & $<1$ & 43 & $<6$ & 5 & 26 \\
\hline $1 \ldots$ & 16 & $<0.1$ & $<10$ & 3 & $<1$ & $<1$ & 43 & $<6$ & $<3$ & 29 \\
\hline $9 \ldots$ & 8 & $<0.1$ & $<10$ & $<1$ & $<1$ & $<1$ & 54 & $<6$ & 11 & 16 \\
\hline
\end{tabular}


LOCATION,--Lat $46^{\circ} 35^{\prime} 03^{\prime \prime}$, long $88^{\circ} 34^{\prime} 33^{\prime \prime}$, in NEl/4 SEl/4 sec.5, T.48 N., R.34 W., Baraga County, Hydrologic Unit 04020104 , on right bank $30 \mathrm{ft}$ downstream from highway bridge, 3.0 mi downstream from Rock River, $3.5 \mathrm{mi}$ northwest of Covington, $6.5 \mathrm{mi}$ upstream from Perch River, $8.5 \mathrm{mi}$ northeast of Sidnaw, and at mile 71 .

DRAINAGE AREA. $--171 \mathrm{mi}^{2}$.

PERIOD OF RECORD.--October 1912 to September 1915, April 1943 to current year. Monthly discharge only for some periods, published in WSP 1307.

REVISED RECORDS.--WSP 1507: Drainage area.

GAGE.--Water-stage recorder. Datum of gage is 1,214.40 ft above National Geodetic Vertical Datum of 1929. October 1912 to September 1915, nonrecording gage at site 200 ft upstream at different datum. Apr. 2, 1943 to Oct. 1, 1946, nonrecording gage at present site and datum.

REMARKS.--Estimated daily discharges: Nov. 10-13, 19, Dec. 3 to Mar. 19, and Mar. 30 to Apr. 2 . Records good except for estimated daily discharges, which are fair. Several measurements of water temperature were made during the year. National Weather service gage-height telemeter at station.

AVERAGE DISCHARGE. - -47 years, $216 \mathrm{ft}^{3} / \mathrm{s}, 17.15 \mathrm{in} / \mathrm{yr}$.

EXTREMES FOR PERIOD OF RECORD.--Maximum discharge, 4,630 ft $3 / \mathrm{s}$, Apr. 24, 1960, gage height, 11.63 $\mathrm{ft}$; minimum, $2.7 \mathrm{ft}^{3} / \mathrm{s}$, Sept. 13, 1976, gage height, $3.17 \mathrm{ft}$.

EXTREMES FOR CURRENT YEAR.--Maximum discharge, 1,130 $\mathrm{ft}^{3} / \mathrm{s}$, Aug. 13, gage height, $7.01 \mathrm{ft}$; minimum, $15 \mathrm{ft}^{3} / \mathrm{s}$, July 1 , 2, gage height, $3.26 \mathrm{ft}$.

DISCHARGE, IN CUBIC FEET PER SECOND, WATER YEAR OCTOBER 1986 TO SEPTEMBER 1987

\begin{tabular}{|c|c|c|c|c|c|c|c|c|c|c|c|c|}
\hline & & & & & & EAAN VA & & & & & & \\
\hline DAY & OCT & NOV & DEC & JAN & FEB & MAR & APR & MAY & JUN & JUL & AUG & SEP \\
\hline $\begin{array}{l}1 \\
2 \\
3 \\
4 \\
5\end{array}$ & $\begin{array}{l}65 \\
60 \\
56 \\
54 \\
54\end{array}$ & $\begin{array}{l}116 \\
116 \\
113 \\
106 \\
102\end{array}$ & $\begin{array}{l}79 \\
78 \\
78 \\
77 \\
77\end{array}$ & $\begin{array}{l}49 \\
48 \\
48 \\
47 \\
47\end{array}$ & $\begin{array}{l}41 \\
41 \\
40 \\
40 \\
40\end{array}$ & $\begin{array}{l}41 \\
43 \\
43 \\
42 \\
41\end{array}$ & $\begin{array}{l}230 \\
220 \\
215 \\
215 \\
243\end{array}$ & $\begin{array}{r}118 \\
106 \\
93 \\
84 \\
77\end{array}$ & $\begin{array}{l}269 \\
250 \\
202 \\
166 \\
137\end{array}$ & $\begin{array}{l}16 \\
17 \\
31 \\
37 \\
30\end{array}$ & $\begin{array}{l}201 \\
619 \\
622 \\
616 \\
473\end{array}$ & $\begin{array}{l}91 \\
85 \\
76 \\
68 \\
61\end{array}$ \\
\hline $\begin{array}{r}6 \\
7 \\
8 \\
9 \\
10\end{array}$ & $\begin{array}{r}57 \\
59 \\
96 \\
106 \\
100\end{array}$ & $\begin{array}{r}99 \\
97 \\
116 \\
132 \\
115\end{array}$ & $\begin{array}{l}76 \\
76 \\
74 \\
74 \\
72\end{array}$ & $\begin{array}{l}47 \\
47 \\
47 \\
46 \\
46\end{array}$ & $\begin{array}{l}40 \\
40 \\
40 \\
40 \\
40\end{array}$ & $\begin{array}{r}43 \\
90 \\
190 \\
160 \\
140\end{array}$ & $\begin{array}{l}321 \\
378 \\
383 \\
384 \\
398\end{array}$ & $\begin{array}{l}71 \\
65 \\
60 \\
57 \\
50\end{array}$ & $\begin{array}{r}119 \\
99 \\
87 \\
74 \\
63\end{array}$ & $\begin{array}{l}25 \\
25 \\
45 \\
38 \\
56\end{array}$ & $\begin{array}{l}342 \\
262 \\
206 \\
165 \\
137\end{array}$ & $\begin{array}{l}61 \\
56 \\
51 \\
50 \\
46\end{array}$ \\
\hline $\begin{array}{l}11 \\
12 \\
13 \\
14 \\
15\end{array}$ & $\begin{array}{r}97 \\
476 \\
572 \\
559 \\
551\end{array}$ & $\begin{array}{r}105 \\
98 \\
93 \\
90 \\
93\end{array}$ & $\begin{array}{l}71 \\
70 \\
67 \\
63 \\
62\end{array}$ & $\begin{array}{l}46 \\
45 \\
46 \\
46 \\
45\end{array}$ & $\begin{array}{l}40 \\
40 \\
40 \\
39 \\
39\end{array}$ & $\begin{array}{r}125 \\
115 \\
105 \\
100 \\
94\end{array}$ & $\begin{array}{l}439 \\
429 \\
398 \\
360 \\
347\end{array}$ & $\begin{array}{l}48 \\
43 \\
42 \\
41 \\
38\end{array}$ & $\begin{array}{l}66 \\
74 \\
72 \\
63 \\
52\end{array}$ & $\begin{array}{r}74 \\
136 \\
181 \\
182 \\
158\end{array}$ & $\begin{array}{l}116 \\
120 \\
963 \\
674 \\
546\end{array}$ & $\begin{array}{l}48 \\
57 \\
58 \\
60 \\
62\end{array}$ \\
\hline $\begin{array}{l}16 \\
17 \\
18 \\
19 \\
20\end{array}$ & $\begin{array}{l}497 \\
447 \\
383 \\
320 \\
274\end{array}$ & $\begin{array}{l}92 \\
90 \\
87 \\
86 \\
85\end{array}$ & $\begin{array}{l}60 \\
60 \\
60 \\
59 \\
58\end{array}$ & $\begin{array}{l}44 \\
44 \\
44 \\
44 \\
44\end{array}$ & $\begin{array}{l}39 \\
40 \\
40 \\
40 \\
40\end{array}$ & $\begin{array}{r}88 \\
84 \\
86 \\
94 \\
120\end{array}$ & $\begin{array}{l}342 \\
317 \\
285 \\
253 \\
222\end{array}$ & $\begin{array}{r}39 \\
36 \\
37 \\
131 \\
237\end{array}$ & $\begin{array}{l}44 \\
38 \\
33 \\
28 \\
25\end{array}$ & $\begin{array}{r}129 \\
107 \\
92 \\
126 \\
200\end{array}$ & $\begin{array}{l}402 \\
309 \\
231 \\
191 \\
181\end{array}$ & $\begin{array}{r}59 \\
58 \\
60 \\
95 \\
137\end{array}$ \\
\hline $\begin{array}{l}21 \\
22 \\
23 \\
24 \\
25\end{array}$ & $\begin{array}{l}239 \\
210 \\
181 \\
161 \\
147\end{array}$ & $\begin{array}{l}85 \\
86 \\
87 \\
92 \\
92\end{array}$ & $\begin{array}{l}56 \\
54 \\
55 \\
57 \\
56\end{array}$ & $\begin{array}{l}44 \\
44 \\
43 \\
43 \\
42\end{array}$ & $\begin{array}{l}40 \\
40 \\
40 \\
40 \\
40\end{array}$ & $\begin{array}{l}163 \\
224 \\
335 \\
462 \\
536\end{array}$ & $\begin{array}{l}232 \\
259 \\
228 \\
196 \\
170\end{array}$ & $\begin{array}{l}210 \\
273 \\
329 \\
309 \\
261\end{array}$ & $\begin{array}{l}23 \\
22 \\
21 \\
21 \\
19\end{array}$ & $\begin{array}{l}209 \\
186 \\
160 \\
134 \\
113\end{array}$ & $\begin{array}{l}198 \\
179 \\
153 \\
129 \\
110\end{array}$ & $\begin{array}{l}166 \\
158 \\
141 \\
119 \\
105\end{array}$ \\
\hline $\begin{array}{l}26 \\
27 \\
28 \\
29 \\
30 \\
31\end{array}$ & $\begin{array}{l}134 \\
125 \\
116 \\
114 \\
110 \\
110\end{array}$ & $\begin{array}{r}100 \\
97 \\
96 \\
92 \\
85 \\
---\end{array}$ & $\begin{array}{l}55 \\
53 \\
51 \\
50 \\
50 \\
50\end{array}$ & $\begin{array}{l}41 \\
41 \\
41 \\
41 \\
41 \\
41\end{array}$ & $\begin{array}{r}40 \\
40 \\
40 \\
--- \\
--- \\
---\end{array}$ & $\begin{array}{l}535 \\
482 \\
430 \\
352 \\
280 \\
250\end{array}$ & $\begin{array}{l}153 \\
160 \\
163 \\
153 \\
134 \\
-\end{array}$ & $\begin{array}{l}265 \\
277 \\
299 \\
259 \\
401 \\
348\end{array}$ & $\begin{array}{l}19 \\
19 \\
20 \\
19 \\
18 \\
-\end{array}$ & $\begin{array}{l}95 \\
81 \\
71 \\
60 \\
52 \\
45\end{array}$ & $\begin{array}{l}96 \\
84 \\
75 \\
67 \\
89 \\
96\end{array}$ & $\begin{array}{r}88 \\
80 \\
79 \\
76 \\
73 \\
---\end{array}$ \\
\hline $\begin{array}{l}\text { TOTAL } \\
\text { MEAN } \\
\text { MAX } \\
\text { MIN } \\
\text { CFSM } \\
\text { IN. }\end{array}$ & $\begin{array}{r}6530 \\
211 \\
572 \\
54 \\
1.23 \\
1.42\end{array}$ & $\begin{array}{r}2943 \\
98.1 \\
132 \\
85 \\
.57 \\
.64\end{array}$ & $\begin{array}{r}1978 \\
63.8 \\
79 \\
50 \\
.37 \\
.43\end{array}$ & $\begin{array}{r}1382 \\
44.6 \\
49 \\
41 \\
.26 \\
.30\end{array}$ & $\begin{array}{r}1119 \\
40.0 \\
41 \\
39 \\
.23 \\
.24\end{array}$ & $\begin{array}{r}5893 \\
190 \\
536 \\
41 \\
1.11 \\
1.28\end{array}$ & $\begin{array}{r}8227 \\
274 \\
439 \\
134 \\
1.60 \\
1.79\end{array}$ & $\begin{array}{r}4704 \\
152 \\
401 \\
36 \\
.89 \\
1.02\end{array}$ & $\begin{array}{r}2162 \\
72.1 \\
269 \\
18 \\
.42 \\
.47\end{array}$ & $\begin{array}{r}2911 \\
93.9 \\
209 \\
16 \\
.55 \\
.63\end{array}$ & $\begin{array}{r}8652 \\
279 \\
963 \\
67 \\
1.63 \\
1.88\end{array}$ & $\begin{array}{r}2424 \\
80.8 \\
166 \\
46 \\
.47 \\
.53\end{array}$ \\
\hline
\end{tabular}

CAL YR 1986 TOTAL 64663 MEAN 177 MAX $1800 \quad$ MIN $14 \quad$ CFSM $1.04 \quad$ IN 14.07

WTR YR 1987 TOTAL 48925 MEAN 134 MAX 963 MIN 16 CFSM .78 IN 10.64 
LOCATION.--Lat $46^{\circ} 43^{\prime} 35^{\prime \prime}$, long $88^{\circ} 39^{\prime} 43^{\prime \prime}$, in SEl/4 sec.15, T.50 N., R. 35 W., Baraga County, Hydrologic Unit 04020104, on right bank in powerhouse of Upper Peninsula Power Co. at Prickett Dam, $4.0 \mathrm{mi}$ upstream from clear Creek, $5.0 \mathrm{mi}$ southeast of Alston, and at mile 45 .

DRAINAGE AREA. - - $346 \mathrm{mi}^{2}$.

PERIOD OF RECORD.--February 1932 to June 1941 , October 1942 to current year. Monthly discharge only for some periods, published in WSP 1307.

GAGE. - Water-stage recorder. Datum of gage is $710.3 \mathrm{ft}$ mean tide at New York City datum (levels by U.S. Army Corps of Engineers): Prior to Jan. 5, 1948, nonrecording gage and Jan. 5 , 1948 to Sept. 30,1963 , water-stage recorder at same site at datum $40.00^{\prime} \mathrm{ft}$ lower.

REMARKS. - No estimated daily discharges. Records good. Flow regulated by powerplant at station. Several measurements of water temperature were made during the year.

AVERAGE DISCHARGE. - -53 years (water years 1933-40, 1943-87), $422 \mathrm{ft}^{3} / \mathrm{s}, 16.56 \mathrm{in} / \mathrm{yr}^{\mathrm{r}}$.

EXTREMES FOR PERIOD OF RECORD.--Maximum discharge, 7,360 $\mathrm{ft}^{3} / \mathrm{s}$, Apr. 24, 1960, gage height, 13.09 $\mathrm{ft}$, present datum; minimum daily, $1 \mathrm{ft}^{3} / \mathrm{s}, \mathrm{Aug}$. 14-19, 1960 .

EXTREMES FOR CURRENT YEAR.--Maximum discharge, 2,050 $\mathrm{ft}^{3} / \mathrm{s}$, Aug. 13, gage height, $6.92 \mathrm{ft}$; minimum daily, $14 \mathrm{ft}^{3} / \mathrm{s}$, Jan. 1 .

DISCHARGE, IN CUBIC FEET PER SECOND, WATER YEAR OCTOBER 1986 TO SEPTEMBER 1987 MEAN VALUES

\begin{tabular}{|c|c|c|c|c|c|c|c|c|c|c|c|c|}
\hline DAY & OC'T & NOV & DEC & JAN & FEB & MAR & APR & MAY & JUN & JUL & AUG & SEP \\
\hline $\begin{array}{l}1 \\
2 \\
3 \\
4 \\
5\end{array}$ & $\begin{array}{l}218 \\
220 \\
206 \\
215 \\
216\end{array}$ & $\begin{array}{l}261 \\
262 \\
256 \\
251 \\
229\end{array}$ & $\begin{array}{l}251 \\
234 \\
257 \\
164 \\
198\end{array}$ & $\begin{array}{l}14 \\
210 \\
210 \\
212 \\
213\end{array}$ & $\begin{array}{l}149 \\
174 \\
195 \\
193 \\
191\end{array}$ & $\begin{array}{r}15 \\
192 \\
316 \\
341 \\
376\end{array}$ & $\begin{array}{l}312 \\
312 \\
312 \\
260 \\
243\end{array}$ & $\begin{array}{l}261 \\
272 \\
275 \\
221 \\
225\end{array}$ & $\begin{array}{l}625 \\
636 \\
624 \\
378 \\
377\end{array}$ & $\begin{array}{l}133 \\
134 \\
136 \\
135 \\
134\end{array}$ & $\begin{array}{l}290 \\
641 \\
740 \\
640 \\
829\end{array}$ & $\begin{array}{l}184 \\
219 \\
178 \\
188 \\
220\end{array}$ \\
\hline $\begin{array}{r}6 \\
7 \\
8 \\
9 \\
10\end{array}$ & $\begin{array}{l}191 \\
216 \\
193 \\
268 \\
267\end{array}$ & $\begin{array}{l}204 \\
305 \\
353 \\
247 \\
222\end{array}$ & $\begin{array}{l}203 \\
205 \\
213 \\
206 \\
205\end{array}$ & $\begin{array}{l}213 \\
170 \\
175 \\
212 \\
215\end{array}$ & $\begin{array}{l}191 \\
188 \\
169 \\
113 \\
184\end{array}$ & $\begin{array}{l}412 \\
409 \\
411 \\
596 \\
308\end{array}$ & $\begin{array}{l}266 \\
417 \\
615 \\
615 \\
615\end{array}$ & $\begin{array}{l}222 \\
197 \\
197 \\
196 \\
198\end{array}$ & $\begin{array}{l}326 \\
325 \\
274 \\
222 \\
222\end{array}$ & $\begin{array}{l}135 \\
137 \\
112 \\
137 \\
203\end{array}$ & $\begin{array}{l}648 \\
644 \\
552 \\
277 \\
237\end{array}$ & $\begin{array}{r}219 \\
16 \\
222 \\
220 \\
220\end{array}$ \\
\hline $\begin{array}{l}11 \\
12 \\
13 \\
14 \\
15\end{array}$ & $\begin{array}{r}408 \\
724 \\
1580 \\
970 \\
740\end{array}$ & $\begin{array}{l}248 \\
209 \\
253 \\
249 \\
249\end{array}$ & $\begin{array}{l}202 \\
204 \\
204 \\
160 \\
168\end{array}$ & $\begin{array}{r}15 \\
215 \\
216 \\
195 \\
218\end{array}$ & $\begin{array}{r}189 \\
187 \\
187 \\
187 \\
15\end{array}$ & $\begin{array}{l}371 \\
408 \\
345 \\
312 \\
258\end{array}$ & $\begin{array}{l}616 \\
435 \\
645 \\
614 \\
613\end{array}$ & $\begin{array}{l}196 \\
195 \\
171 \\
170 \\
160\end{array}$ & $\begin{array}{l}144 \\
144 \\
112 \\
112 \\
129\end{array}$ & $\begin{array}{l}221 \\
211 \\
306 \\
253 \\
298\end{array}$ & $\begin{array}{r}276 \\
275 \\
1010 \\
1090 \\
875\end{array}$ & $\begin{array}{r}220 \\
220 \\
16 \\
223 \\
220\end{array}$ \\
\hline $\begin{array}{l}16 \\
17 \\
18 \\
19 \\
20\end{array}$ & $\begin{array}{ll}6 & 13 \\
614 \\
614 \\
616 \\
411\end{array}$ & $\begin{array}{l}179 \\
177 \\
211 \\
184 \\
222\end{array}$ & $\begin{array}{l}158 \\
206 \\
209 \\
144 \\
213\end{array}$ & $\begin{array}{r}217 \\
15 \\
15 \\
218 \\
215\end{array}$ & $\begin{array}{l}191 \\
192 \\
190 \\
191 \\
192\end{array}$ & $\begin{array}{l}211 \\
209 \\
209 \\
260 \\
261\end{array}$ & $\begin{array}{l}602 \\
404 \\
399 \\
409 \\
413\end{array}$ & $\begin{array}{l}172 \\
173 \\
173 \\
417 \\
440\end{array}$ & $\begin{array}{l}134 \\
192 \\
126 \\
183 \\
112\end{array}$ & $\begin{array}{l}306 \\
306 \\
308 \\
310 \\
310\end{array}$ & $\begin{array}{l}591 \\
463 \\
646 \\
645 \\
603\end{array}$ & $\begin{array}{r}204 \\
221 \\
216 \\
16 \\
16\end{array}$ \\
\hline $\begin{array}{l}21 \\
22 \\
23 \\
24 \\
25\end{array}$ & $\begin{array}{l}412 \\
506 \\
407 \\
345 \\
331\end{array}$ & $\begin{array}{l}208 \\
233 \\
234 \\
210 \\
140\end{array}$ & $\begin{array}{lll}2 & 1 & 2 \\
2 & 1 & 2 \\
2 & 1 & 2 \\
2 & 1 & 2 \\
2 & 1 & 3\end{array}$ & $\begin{array}{r}216 \\
203 \\
215 \\
15 \\
15\end{array}$ & $\begin{array}{r}191 \\
15 \\
191 \\
153 \\
191\end{array}$ & $\begin{array}{r}259 \\
309 \\
434 \\
1120 \\
865\end{array}$ & $\begin{array}{l}413 \\
411 \\
429 \\
427 \\
375\end{array}$ & $\begin{array}{l}414 \\
430 \\
634 \\
629 \\
615\end{array}$ & 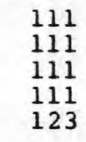 & $\begin{array}{l}311 \\
480 \\
299 \\
308 \\
273\end{array}$ & $\begin{array}{l}379 \\
328 \\
327 \\
199 \\
302\end{array}$ & $\begin{array}{l}198 \\
199 \\
205 \\
203 \\
205\end{array}$ \\
\hline $\begin{array}{l}26 \\
27 \\
28 \\
29 \\
30 \\
31\end{array}$ & $\begin{array}{l}348 \\
257 \\
261 \\
398 \\
262 \\
262\end{array}$ & $\begin{array}{l}209 \\
201 \\
205 \\
298 \\
297 \\
---\end{array}$ & $\begin{array}{l}212 \\
214 \\
213 \\
199 \\
210 \\
209\end{array}$ & $\begin{array}{l}195 \\
420 \\
581 \\
497 \\
400 \\
279\end{array}$ & $\begin{array}{l}191 \\
193 \\
192 \\
--- \\
--- \\
---\end{array}$ & $\begin{array}{l}851 \\
750 \\
674 \\
609 \\
593 \\
356\end{array}$ & $\begin{array}{l}324 \\
274 \\
275 \\
274 \\
273 \\
---\end{array}$ & $\begin{array}{l}396 \\
394 \\
427 \\
432 \\
666 \\
888\end{array}$ & $\begin{array}{l}110 \\
111 \\
114 \\
134 \\
133 \\
-\end{array}$ & $\begin{array}{l}222 \\
224 \\
224 \\
223 \\
224 \\
214\end{array}$ & $\begin{array}{l}303 \\
271 \\
163 \\
220 \\
222 \\
220\end{array}$ & $\begin{array}{l}205 \\
205 \\
218 \\
216 \\
213 \\
-\end{array}$ \\
\hline $\begin{array}{l}\text { TOTAL } \\
\text { MEAN } \\
\text { MAX } \\
\text { MIN } \\
\text { CFSM } \\
\text { IN. }\end{array}$ & $\begin{array}{r}13289 \\
429 \\
1580 \\
191 \\
1.24 \\
1.43\end{array}$ & $\begin{array}{r}7006 \\
234 \\
353 \\
140 \\
.68 \\
.75\end{array}$ & $\begin{array}{r}6322 \\
204 \\
257 \\
144 \\
.59 \\
.68\end{array}$ & $\begin{array}{r}6419 \\
207 \\
581 \\
14 \\
.60 \\
.69\end{array}$ & $\begin{array}{r}4785 \\
171 \\
195 \\
15 \\
.49 \\
.51\end{array}$ & $\begin{array}{r}13040 \\
421 \\
1120 \\
15 \\
1.22 \\
1.40\end{array}$ & $\begin{array}{r}12592 \\
420 \\
645 \\
243 \\
1.21 \\
1.35\end{array}$ & $\begin{array}{r}10456 \\
337 \\
888 \\
160 \\
.97 \\
1.12\end{array}$ & $\begin{array}{r}6566 \\
219 \\
636 \\
110 \\
.63 \\
.71\end{array}$ & $\begin{array}{r}7227 \\
233 \\
480 \\
112 \\
.67 \\
.78\end{array}$ & $\begin{array}{r}14906 \\
481 \\
1090 \\
163 \\
1.39 \\
1.60\end{array}$ & $\begin{array}{r}5525 \\
184 \\
223 \\
16 \\
.53 \\
.59\end{array}$ \\
\hline $\begin{array}{l}\text { CAL YR } \\
\text { WTR YR }\end{array}$ & $\begin{array}{l}1986 \\
1987\end{array}$ & $\begin{array}{ll}\mathrm{L} & 14 \\
\mathrm{~L} & 10\end{array}$ & & $\begin{array}{l}384 \\
\text { NN } 296\end{array}$ & $\begin{array}{l}\text { MAX } \\
\text { MAX }\end{array}$ & $\begin{array}{l}\text { MI } \\
\text { MI }\end{array}$ & $\begin{array}{l}14 \\
14\end{array}$ & $\begin{array}{lr}\text { SM } & 1.1 \\
\text { SM } & .8\end{array}$ & $\begin{array}{l}\text { IN } \\
\text { IN }\end{array}$ & & & \\
\hline
\end{tabular}


04043050 TRAP ROCK RIVER NEAR LAKE LINDEN, MI

LOCATION.--Lat $47^{\circ} 13^{\prime} 43^{\prime \prime}$, long $88^{\circ} 23^{\prime} 07^{\prime \prime}$, in SEl'4 SEl/4 sec. 20 , T.56 N., R.32 W., Houghton County, Hydrologic Unit 04020103 , on right bank $20 \mathrm{ft}$ upstream from bridge on county highway, 2.0 mi northeast of Lake Linden, and $3.0 \mathrm{mi}$ upstream from mouth.

DRAINAGE AREA. $--28.0 \mathrm{mi}^{2}$.

PERIOD OF RECORD.--October 1966 to current year.

GAGE.--Water-stage recorder. Datum of gage is 621.7 ft above National Geodetic Vertical Datum of 1929.

REMARKS.--Estimated daily discharges: Nov. 18, 19, 27, Dec. 6, 7, 20, 21, Jan. 9, 24-30, Feb. 5-10, 2427, Mar. 2, 3, 9-13, 15-17 and Mar. 30 to Apr. 3. Records good. Small diversions for sprinkler

irrigation. Several measurements of water temperature were made during the year.

AVERAGE DISCHARGE. - - 21 years, $46.3 \mathrm{ft}^{3} / \mathrm{s}, 22.46 \mathrm{in} / \mathrm{yr}$.

EXTREMES FOR PERIOD OF RECORD. - Maximum discharge, 1,590 fta/s, May 10, 1979, gage height, $10.72 \mathrm{ft}$; minimum daily, $6.8 \mathrm{ft}^{3} / \mathrm{s}$, Oct. 3, 1976; minimum gage height, 3.81 ft, June 29, 1987 .

EXTREMES FOR CURRENT YEAR,--Maximum discharge, $280 \mathrm{ft}^{3} / \mathrm{s}$, Mar. 25 , gage height, $5.84 \mathrm{ft}$, no peak discharge above base discharge of $380 \mathrm{ft}^{3} / \mathrm{s}$; minimum, $11 \mathrm{ft} / \mathrm{s}$, sept. 9, 10 ; minimum gage height, $3.81 \mathrm{ft}$, June 29.

DISCHARGE, IN CUBIC FEET PER SECOND, WATER YEAR OCTOBER 1986 TO SEPTEMBER 1987

\begin{tabular}{|c|c|c|c|c|c|c|c|c|c|c|c|c|}
\hline \multirow[b]{2}{*}{ DAY } & \multirow[b]{2}{*}{ OCT } & \\
\hline & & NOV & DEC & JAN & FEB & MAR & APR & MAY & JUN & JUL & AUG & SEP \\
\hline $\begin{array}{l}1 \\
2 \\
3 \\
4 \\
5\end{array}$ & $\begin{array}{l}26 \\
21 \\
19 \\
20 \\
20\end{array}$ & $\begin{array}{l}26 \\
24 \\
22 \\
23 \\
22\end{array}$ & $\begin{array}{l}29 \\
28 \\
29 \\
28 \\
30\end{array}$ & $\begin{array}{l}24 \\
23 \\
23 \\
23 \\
22\end{array}$ & $\begin{array}{l}18 \\
19 \\
19 \\
19 \\
18\end{array}$ & $\begin{array}{l}19 \\
19 \\
18 \\
18 \\
18\end{array}$ & $\begin{array}{l}50 \\
54 \\
50 \\
47 \\
69\end{array}$ & $\begin{array}{l}21 \\
20 \\
20 \\
19 \\
19\end{array}$ & $\begin{array}{l}35 \\
45 \\
33 \\
26 \\
24\end{array}$ & $\begin{array}{l}13 \\
16 \\
20 \\
16 \\
14\end{array}$ & $\begin{array}{r}27 \\
106 \\
59 \\
35 \\
29\end{array}$ & $\begin{array}{l}13 \\
13 \\
12 \\
12 \\
12\end{array}$ \\
\hline $\begin{array}{r}6 \\
7 \\
8 \\
9 \\
10\end{array}$ & $\begin{array}{l}19 \\
18 \\
48 \\
34 \\
25\end{array}$ & $\begin{array}{l}23 \\
37 \\
43 \\
48 \\
36\end{array}$ & $\begin{array}{l}30 \\
28 \\
28 \\
28 \\
27\end{array}$ & $\begin{array}{l}23 \\
24 \\
23 \\
22 \\
22\end{array}$ & $\begin{array}{l}18 \\
18 \\
18 \\
18 \\
18\end{array}$ & $\begin{array}{r}22 \\
60 \\
115 \\
92 \\
65\end{array}$ & $\begin{array}{l}111 \\
151 \\
153 \\
156 \\
171\end{array}$ & $\begin{array}{l}18 \\
18 \\
17 \\
16 \\
15\end{array}$ & $\begin{array}{l}22 \\
22 \\
21 \\
20 \\
19\end{array}$ & $\begin{array}{l}14 \\
14 \\
14 \\
21 \\
46\end{array}$ & $\begin{array}{l}24 \\
22 \\
19 \\
17 \\
16\end{array}$ & $\begin{array}{ll}1 & 2 \\
1 & 3 \\
1 & 2 \\
1 & 2 \\
1 & 2\end{array}$ \\
\hline $\begin{array}{l}11 \\
12 \\
13 \\
14 \\
15\end{array}$ & $\begin{array}{l}22 \\
95 \\
87 \\
61 \\
81\end{array}$ & $\begin{array}{l}33 \\
29 \\
30 \\
30 \\
29\end{array}$ & $\begin{array}{l}28 \\
27 \\
27 \\
27 \\
27\end{array}$ & $\begin{array}{l}22 \\
22 \\
21 \\
21 \\
20\end{array}$ & $\begin{array}{l}18 \\
18 \\
18 \\
18 \\
17\end{array}$ & $\begin{array}{l}50 \\
40 \\
35 \\
31 \\
30\end{array}$ & $\begin{array}{r}150 \\
119 \\
95 \\
80 \\
79\end{array}$ & $\begin{array}{l}15 \\
15 \\
16 \\
16 \\
16\end{array}$ & $\begin{array}{l}25 \\
31 \\
25 \\
21 \\
19\end{array}$ & $\begin{array}{l}31 \\
38 \\
29 \\
24 \\
21\end{array}$ & $\begin{array}{l}16 \\
29 \\
60 \\
35 \\
27\end{array}$ & $\begin{array}{l}19 \\
25 \\
25 \\
26 \\
19\end{array}$ \\
\hline $\begin{array}{l}16 \\
17 \\
18 \\
19 \\
20\end{array}$ & $\begin{array}{l}67 \\
51 \\
38 \\
33 \\
30\end{array}$ & $\begin{array}{l}28 \\
28 \\
27 \\
27 \\
27\end{array}$ & $\begin{array}{l}25 \\
25 \\
25 \\
25 \\
25\end{array}$ & $\begin{array}{l}20 \\
19 \\
19 \\
19 \\
19\end{array}$ & $\begin{array}{l}17 \\
17 \\
17 \\
17 \\
17\end{array}$ & $\begin{array}{l}29 \\
28 \\
27 \\
29 \\
35\end{array}$ & $\begin{array}{l}82 \\
67 \\
55 \\
49 \\
42\end{array}$ & $\begin{array}{r}16 \\
35 \\
126 \\
118 \\
101\end{array}$ & $\begin{array}{l}18 \\
17 \\
17 \\
16 \\
15\end{array}$ & $\begin{array}{r}18 \\
17 \\
23 \\
103 \\
104\end{array}$ & $\begin{array}{l}24 \\
22 \\
19 \\
18 \\
17\end{array}$ & $\begin{array}{l}17 \\
15 \\
14 \\
24 \\
58\end{array}$ \\
\hline $\begin{array}{l}21 \\
22 \\
23 \\
24 \\
25\end{array}$ & $\begin{array}{l}28 \\
25 \\
24 \\
22 \\
21\end{array}$ & $\begin{array}{l}27 \\
27 \\
29 \\
32 \\
31\end{array}$ & $\begin{array}{l}24 \\
25 \\
24 \\
24 \\
24\end{array}$ & $\begin{array}{l}19 \\
18 \\
18 \\
18 \\
18\end{array}$ & $\begin{array}{l}17 \\
17 \\
18 \\
17 \\
17\end{array}$ & $\begin{array}{r}49 \\
65 \\
100 \\
185 \\
222\end{array}$ & $\begin{array}{l}37 \\
33 \\
31 \\
28 \\
26\end{array}$ & $\begin{array}{l}68 \\
78 \\
81 \\
62 \\
47\end{array}$ & $\begin{array}{l}15 \\
14 \\
14 \\
13 \\
13\end{array}$ & $\begin{array}{l}48 \\
31 \\
25 \\
21 \\
19\end{array}$ & $\begin{array}{l}16 \\
31 \\
23 \\
18 \\
17\end{array}$ & $\begin{array}{l}77 \\
43 \\
30 \\
24 \\
20\end{array}$ \\
\hline $\begin{array}{l}26 \\
27 \\
28 \\
29 \\
30 \\
31\end{array}$ & $\begin{array}{l}21 \\
21 \\
21 \\
22 \\
22 \\
22\end{array}$ & $\begin{array}{r}40 \\
40 \\
39 \\
37 \\
32 \\
- \\
\end{array}$ & $\begin{array}{l}24 \\
24 \\
24 \\
23 \\
23 \\
23\end{array}$ & $\begin{array}{l}18 \\
18 \\
18 \\
18 \\
18 \\
18\end{array}$ & $\begin{array}{r}17 \\
17 \\
18 \\
--- \\
---\end{array}$ & $\begin{array}{r}168 \\
126 \\
110 \\
97 \\
70 \\
58\end{array}$ & $\begin{array}{r}27 \\
26 \\
25 \\
24 \\
22 \\
---\end{array}$ & $\begin{array}{l}45 \\
46 \\
45 \\
38 \\
60 \\
46\end{array}$ & $\begin{array}{r}13 \\
13 \\
13 \\
12 \\
13 \\
---\end{array}$ & $\begin{array}{l}18 \\
16 \\
16 \\
15 \\
15 \\
14\end{array}$ & $\begin{array}{l}16 \\
15 \\
15 \\
17 \\
16 \\
14\end{array}$ & $\begin{array}{r}18 \\
17 \\
16 \\
16 \\
15 \\
-\end{array}$ \\
\hline $\begin{array}{l}\text { TOTAL } \\
\text { MEAN } \\
\text { MAX } \\
\text { MIN } \\
\text { CFSM } \\
\text { IN. }\end{array}$ & $\begin{array}{r}1064 \\
34.3 \\
95 \\
18 \\
1.23 \\
1.41\end{array}$ & $\begin{array}{r}926 \\
30.9 \\
48 \\
22 \\
1.10 \\
1.23\end{array}$ & $\begin{array}{r}808 \\
26.1 \\
30 \\
23 \\
.93 \\
1.07\end{array}$ & $\begin{array}{r}630 \\
20.3 \\
24 \\
18 \\
.73 \\
.84\end{array}$ & $\begin{array}{r}495 \\
17.7 \\
19 \\
17 \\
.63 \\
.66\end{array}$ & $\begin{array}{r}2030 \\
65.5 \\
222 \\
18 \\
2.34 \\
2.70\end{array}$ & $\begin{array}{r}2109 \\
70.3 \\
171 \\
22 \\
2.51 \\
2.80\end{array}$ & $\begin{array}{r}1273 \\
41.1 \\
126 \\
15 \\
1.47 \\
1.69\end{array}$ & $\begin{array}{r}604 \\
20.1 \\
45 \\
12 \\
.72 \\
.80\end{array}$ & $\begin{array}{r}834 \\
26.9 \\
104 \\
13 \\
.96 \\
1.11\end{array}$ & $\begin{array}{r}819 \\
26.4 \\
106 \\
14 \\
.94 \\
1.09\end{array}$ & $\begin{array}{r}641 \\
21.4 \\
77 \\
12 \\
.76 \\
.85\end{array}$ \\
\hline
\end{tabular}

$\begin{array}{lllllllllll}\text { CAL YR } 1986 & \text { TOTAL } & 17787 & \text { MEAN } & 48.7 & \text { MAX } & 495 & \text { MIN } 13 & \text { CFSM } 1.74 & \text { IN } & 23.63 \\ \text { WTR YR } & 1987 & \text { TOTAL } & 12233 & \text { MEAN } 33.5 & \text { MAX } 222 & \text { MIN } 12 & \text { CFSM } 1.20 & \text { IN } & 16.25\end{array}$ 
LOCATION. - Lat $46^{\circ} 29^{\prime} 14^{\prime \prime}$, long $87^{\circ} 07^{\prime} 30^{\prime \prime}$, in SWl/4 NEl/4 sec.12, T.47 N., R. 23 W., Marquette County, Hydrologic Unit 04020201, on right bank at dam at Sand River, 1.2 miles upstream from mouth.

DRAINAGE AREA. - - $28.6 \mathrm{mi}^{2}$. Area of Sand River wildlife Flooding is $0.6 \mathrm{mi}^{2}$.

PERIOD OF RECORD.--October 1983 to current year (gage heights only).

GAGE, - Water-stage recorder. Datum of gage is $600.0 \mathrm{ft}$ above National Geodetic Vertical Datum of 1929 (Michigan Department of Natural Resources bench mark).

REMARKS.--Pond level regulated by concrete dam with two 20-foot stop-log bays and a 20 -foot radial gate. Gage-height telemeter at station.

EXTREMES FOR PERIOD OF RECORD.--Maximum gage height, $11.51 \mathrm{ft,} \mathrm{Apr.} \mathrm{20,} \mathrm{1985;} \mathrm{minimum,} \mathrm{5.81} \mathrm{ft,} \mathrm{Apr.} \mathrm{12,}$ 1985 .

EXTREMES FOR CURRENT YEAR.--Maximum gage height recorded, $9.84 \mathrm{ft}$, Oct. 16-18, but may have been higher during period of no gage-height record, July 16-29; minimum, $7.23 \mathrm{ft}, \mathrm{Jan}$. 26-28.

GAGE HEIGHT (FEET ABOVE DATUM), WATER YEAR OCTOBER 1986 TO SEPTEMBER 1987

\begin{tabular}{|c|c|c|c|c|c|c|c|c|c|c|c|c|}
\hline DAY & OCT & NOV & DEC & JAN & FEB & MAR & APR & MAY & JUN & JUL & AUG & SEP \\
\hline $\begin{array}{l}1 \\
2 \\
3 \\
4 \\
5\end{array}$ & $\begin{array}{l}8.69 \\
8.70 \\
8.72 \\
8.72 \\
8.72\end{array}$ & $\begin{array}{l}9.61 \\
9.61 \\
9.61 \\
9.61 \\
9.61\end{array}$ & $\begin{array}{l}8.53 \\
8.20 \\
8.00 \\
7.84 \\
7.70\end{array}$ & $\begin{array}{l}7.31 \\
7.32 \\
7.33 \\
7.32 \\
7.32\end{array}$ & $\begin{array}{l}7.26 \\
7.27 \\
7.28 \\
7.28 \\
7.28\end{array}$ & $\begin{array}{l}7.32 \\
7.32 \\
7.32 \\
7.32 \\
7.33\end{array}$ & $\begin{array}{l}8.34 \\
8.29 \\
8.24 \\
8.20 \\
8.23\end{array}$ & $\begin{array}{l}9.33 \\
9.36 \\
9.39 \\
9.42 \\
9.44\end{array}$ & $\begin{array}{l}9.58 \\
9.58 \\
9.56 \\
9.52 \\
9.49\end{array}$ & $\begin{array}{l}8.62 \\
8.60 \\
8.58 \\
8.54 \\
8.51\end{array}$ & $\begin{array}{l}8.91 \\
8.99 \\
9.00 \\
8.98 \\
8.95\end{array}$ & $\begin{array}{l}8.10 \\
8.08 \\
8.07 \\
8.06 \\
8.03\end{array}$ \\
\hline $\begin{array}{r}6 \\
7 \\
8 \\
9 \\
10\end{array}$ & $\begin{array}{l}8.72 \\
8.74 \\
8.77 \\
8.78 \\
8.81\end{array}$ & $\begin{array}{l}9.60 \\
9.60 \\
9.64 \\
9.58 \\
9.56\end{array}$ & $\begin{array}{l}7.59 \\
7.49 \\
7.43 \\
7.40 \\
7.37\end{array}$ & $\begin{array}{l}7.33 \\
7.34 \\
7.34 \\
7.33 \\
7.32\end{array}$ & $\begin{array}{l}7.28 \\
7.28 \\
7.29 \\
7.28 \\
7.28\end{array}$ & $\begin{array}{l}7.40 \\
7.57 \\
7.74 \\
7.84 \\
7.90\end{array}$ & $\begin{array}{l}8.31 \\
8.42 \\
8.53 \\
8.63 \\
8.75\end{array}$ & $\begin{array}{l}9.46 \\
9.46 \\
9.47 \\
9.48 \\
9.46\end{array}$ & $\begin{array}{l}9.47 \\
9.44 \\
9.40 \\
9.37 \\
9.33\end{array}$ & $\begin{array}{l}8.47 \\
8.44 \\
8.40 \\
8.36 \\
8.33\end{array}$ & $\begin{array}{l}8.93 \\
8.89 \\
8.86 \\
8.81 \\
8.77\end{array}$ & $\begin{array}{l}8.00 \\
7.98 \\
7.95 \\
7.93 \\
7.91\end{array}$ \\
\hline $\begin{array}{l}11 \\
12 \\
13 \\
14 \\
15\end{array}$ & $\begin{array}{l}8.84 \\
9.06 \\
9.42 \\
9.69 \\
9.80\end{array}$ & $\begin{array}{l}9.55 \\
9.54 \\
9.49 \\
9.26 \\
9.09\end{array}$ & $\begin{array}{l}7.34 \\
7.33 \\
7.32 \\
7.32 \\
7.32\end{array}$ & $\begin{array}{l}7.31 \\
7.31 \\
7.31 \\
7.31 \\
7.31\end{array}$ & $\begin{array}{l}7.28 \\
7.29 \\
7.29 \\
7.29 \\
7.29\end{array}$ & $\begin{array}{l}7.96 \\
7.95 \\
7.90 \\
7.85 \\
7.78\end{array}$ & $\begin{array}{l}8.77 \\
8.69 \\
8.59 \\
8.51 \\
8.51\end{array}$ & $\begin{array}{l}9.48 \\
9.48 \\
9.49 \\
9.45 \\
9.43\end{array}$ & $\begin{array}{l}9.32 \\
9.30 \\
9.28 \\
9.23 \\
9.19\end{array}$ & $\begin{array}{l}8.37 \\
8.58 \\
8.86 \\
9.01 \\
9.08\end{array}$ & $\begin{array}{l}8.74 \\
8.70 \\
8.66 \\
8.64 \\
8.62\end{array}$ & $\begin{array}{l}7.90 \\
7.89 \\
7.89 \\
7.90 \\
7.90\end{array}$ \\
\hline $\begin{array}{l}16 \\
17 \\
18 \\
19 \\
20\end{array}$ & $\begin{array}{l}9.84 \\
9.84 \\
9.83 \\
9.80 \\
9.77\end{array}$ & $\begin{array}{l}8.98 \\
8.88 \\
8.79 \\
8.72 \\
8.67\end{array}$ & $\begin{array}{l}7.33 \\
7.33 \\
7.34 \\
7.35 \\
7.35\end{array}$ & $\begin{array}{l}7.30 \\
7.28 \\
7.27 \\
7.26 \\
7.26\end{array}$ & $\begin{array}{l}7.29 \\
7.28 \\
7.27 \\
7.27 \\
7.27\end{array}$ & $\begin{array}{l}7.73 \\
7.69 \\
7.66 \\
7.67 \\
7.68\end{array}$ & $\begin{array}{l}8.53 \\
8.51 \\
8.41 \\
8.27 \\
8.09\end{array}$ & $\begin{array}{l}9.41 \\
9.39 \\
9.37 \\
9.50 \\
9.64\end{array}$ & $\begin{array}{l}9.14 \\
9.10 \\
9.06 \\
9.01 \\
8.97\end{array}$ & $\begin{array}{l}--- \\
--- \\
--- \\
--- \\
---\end{array}$ & $\begin{array}{l}8.60 \\
8.57 \\
8.53 \\
8.50 \\
8.46\end{array}$ & $\begin{array}{l}7.89 \\
7.89 \\
7.89 \\
7.94 \\
7.99\end{array}$ \\
\hline $\begin{array}{l}21 \\
22 \\
23 \\
24 \\
25\end{array}$ & $\begin{array}{l}9.75 \\
9.73 \\
9.70 \\
9.67 \\
9.65\end{array}$ & $\begin{array}{l}8.64 \\
8.60 \\
8.59 \\
8.60 \\
8.60\end{array}$ & $\begin{array}{l}7.32 \\
7.32 \\
7.32 \\
7.32 \\
7.32\end{array}$ & $\begin{array}{l}7.25 \\
7.25 \\
7.25 \\
7.24 \\
7.24\end{array}$ & $\begin{array}{l}7.28 \\
7.29 \\
7.29 \\
7.29 \\
7.29\end{array}$ & $\begin{array}{l}7.73 \\
7.81 \\
7.98 \\
8.25 \\
8.51\end{array}$ & $\begin{array}{l}8.24 \\
8.46 \\
8.64 \\
8.77 \\
8.90\end{array}$ & $\begin{array}{l}9.72 \\
9.70 \\
9.70 \\
9.70 \\
9.70\end{array}$ & $\begin{array}{l}8.93 \\
8.90 \\
8.87 \\
8.84 \\
8.82\end{array}$ & $\begin{array}{l}--- \\
--- \\
--- \\
--- \\
---\end{array}$ & $\begin{array}{l}8.46 \\
8.43 \\
8.39 \\
8.35 \\
8.31\end{array}$ & $\begin{array}{l}8.01 \\
8.03 \\
8.05 \\
8.05 \\
8.05\end{array}$ \\
\hline $\begin{array}{l}26 \\
27 \\
28 \\
29 \\
30 \\
31\end{array}$ & $\begin{array}{l}9.64 \\
9.64 \\
9.62 \\
9.63 \\
9.63 \\
9.64\end{array}$ & $\begin{array}{l}8.60 \\
8.61 \\
8.62 \\
8.63 \\
8.62 \\
\end{array}$ & $\begin{array}{l}7.32 \\
7.32 \\
7.31 \\
7.31 \\
7.31 \\
7.31\end{array}$ & $\begin{array}{l}7.23 \\
7.23 \\
7.23 \\
7.24 \\
7.25 \\
7.26\end{array}$ & $\begin{array}{r}7.29 \\
7.29 \\
7.30 \\
- \\
- \\
-\end{array}$ & $\begin{array}{l}8.68 \\
8.71 \\
8.65 \\
8.58 \\
8.47 \\
8.38\end{array}$ & $\begin{array}{r}9.00 \\
9.09 \\
9.17 \\
9.24 \\
9.28 \\
---\end{array}$ & $\begin{array}{l}9.69 \\
9.69 \\
9.68 \\
9.65 \\
9.63 \\
9.61\end{array}$ & $\begin{array}{l}8.78 \\
8.75 \\
8.72 \\
8.69 \\
8.66 \\
-\end{array}$ & $\begin{array}{r}--- \\
--- \\
-- \\
8.98 \\
8.93\end{array}$ & $\begin{array}{l}8.29 \\
8.26 \\
8.22 \\
8.20 \\
8.17 \\
8.13\end{array}$ & $\begin{array}{l}8.05 \\
8.06 \\
8.05 \\
8.03 \\
8.02\end{array}$ \\
\hline $\begin{array}{l}\text { MEAN } \\
\text { MAX } \\
\text { MIN }\end{array}$ & $\begin{array}{l}9.34 \\
9.84 \\
8.69\end{array}$ & $\begin{array}{l}9.10 \\
9.64 \\
8.59\end{array}$ & $\begin{array}{l}7.46 \\
8.53 \\
7.31\end{array}$ & $\begin{array}{l}7.29 \\
7.34 \\
7.23\end{array}$ & $\begin{array}{l}7.28 \\
7.30 \\
7.26\end{array}$ & $\begin{array}{l}7.89 \\
8.71 \\
7.32\end{array}$ & $\begin{array}{l}8.59 \\
9.28 \\
8.09\end{array}$ & $\begin{array}{l}9.53 \\
9.72 \\
9.33\end{array}$ & $\begin{array}{l}9.14 \\
9.58 \\
8.66\end{array}$ & $\begin{array}{l}--- \\
--- \\
---\end{array}$ & $\begin{array}{l}8.59 \\
9.00 \\
8.13\end{array}$ & $\begin{array}{l}7.99 \\
8.10 \\
7.89\end{array}$ \\
\hline
\end{tabular}


04045500 TAHQUAMENON RIVER NEAR TAHQUAMENON PARADISE, MI

(National stream quality accounting network station)

LOCATION.--Lat $46^{\circ} 34^{\prime} 30^{\prime \prime}$, long $85^{\circ} 16^{\prime} 10^{\prime \prime}$, in NEl/4 sec.11, T.48 N., R. 8 W., Luce County, Hydrologic Unit 04020202 , on left bank $0.7 \mathrm{mi}$ upstream from Tahquamenon (Big) Falls, $11.5 \mathrm{mi}$ west of Tahquamenon Paradise, and $19 \mathrm{mi}$ northeast of Newberry.

DRAINAGE AREA. $--790 \mathrm{mi}^{2}$.

WATER-DISCHARGE RECORDS

PERIOD OF RECORD. - August 1953 to current year.

GAGE. - water-stage recorder. Elevation of gage is $697 \mathrm{ft}$ from river-profile map.

REMARKS. - No estimated daily discharges. Water-discharge records good.

AVERAGE DISCHARGE. - -34 years, $931 \mathrm{ft}^{3} / \mathrm{s}, 16.00 \mathrm{in}, \mathrm{Yr}$.

EXTREMES FOR PERIOD OF RECORD. --Maximum discharge, $6,990 \mathrm{ft}^{3} / \mathrm{s}$, May 10, 1960, gage height, $10.26 \mathrm{ft}$; minimum, $157 \mathrm{ft}^{3} ; \mathrm{s}, \mathrm{July} 26,1955$; minimum gage height, $2.86 \mathrm{ft}$, July $7,1963$.

EXTREMES FOR CURRENT YEAR.--Maximum discharge, $2,170 \mathrm{ft}^{3} / \mathrm{s}$, Mar. $30,31, \mathrm{gage}$ height, $6.54 \mathrm{ft}$, minimum, $254 \mathrm{ft}^{3}$ 's, July 8,9 , gage height, $3.27 \mathrm{tt}$.

DISCHARGE, IN CUBIC FEET PER SECOND, WATER YEAR OCTOBER 1986 TO SEPTEMBER 1987 MEAN VALUES

\begin{tabular}{|c|c|c|c|c|c|c|c|c|c|c|c|c|}
\hline DAY & OCT & NOV & $\mathrm{DEC}$ & JAN & FEB & MAR & APR & MAY & JUN & JUL & AUG & SEP \\
\hline $\begin{array}{l}1 \\
2 \\
3 \\
4 \\
5\end{array}$ & $\begin{array}{l}526 \\
513 \\
495 \\
501 \\
504\end{array}$ & $\begin{array}{l}579 \\
585 \\
575 \\
567 \\
561\end{array}$ & $\begin{array}{l}751 \\
722 \\
702 \\
666 \\
625\end{array}$ & $\begin{array}{l}434 \\
435 \\
427 \\
418 \\
432\end{array}$ & $\begin{array}{l}318 \\
323 \\
332 \\
339 \\
343\end{array}$ & $\begin{array}{l}365 \\
371 \\
370 \\
369 \\
365\end{array}$ & $\begin{array}{l}2060 \\
1930 \\
1850 \\
1730 \\
1640\end{array}$ & $\begin{array}{l}896 \\
801 \\
716 \\
643 \\
590\end{array}$ & $\begin{array}{l}825 \\
748 \\
687 \\
633 \\
556\end{array}$ & $\begin{array}{l}367 \\
348 \\
322 \\
308 \\
303\end{array}$ & $\begin{array}{l}458 \\
460 \\
490 \\
486 \\
477\end{array}$ & $\begin{array}{l}363 \\
365 \\
366 \\
357 \\
339\end{array}$ \\
\hline $\begin{array}{r}6 \\
7 \\
8 \\
9 \\
10\end{array}$ & $\begin{array}{l}520 \\
551 \\
576 \\
639 \\
674\end{array}$ & $\begin{array}{l}546 \\
534 \\
555 \\
527 \\
519\end{array}$ & $\begin{array}{l}020 \\
597 \\
558 \\
522 \\
507\end{array}$ & $\begin{array}{l}431 \\
433 \\
431 \\
408 \\
409\end{array}$ & $\begin{array}{l}339 \\
348 \\
351 \\
355 \\
352\end{array}$ & $\begin{array}{l}382 \\
414 \\
504 \\
580 \\
615\end{array}$ & $\begin{array}{l}1610 \\
1640 \\
1700 \\
1730 \\
1740\end{array}$ & $\begin{array}{l}522 \\
484 \\
457 \\
420 \\
390\end{array}$ & $\begin{array}{l}507 \\
642 \\
851 \\
911 \\
918\end{array}$ & $\begin{array}{l}285 \\
279 \\
263 \\
269 \\
302\end{array}$ & $\begin{array}{l}450 \\
400 \\
375 \\
340 \\
323\end{array}$ & $\begin{array}{l}322 \\
309 \\
302 \\
290 \\
285\end{array}$ \\
\hline $\begin{array}{l}11 \\
12 \\
13 \\
14 \\
15\end{array}$ & $\begin{array}{r}674 \\
736 \\
984 \\
1140 \\
1230\end{array}$ & $\begin{array}{l}507 \\
474 \\
433 \\
432 \\
437\end{array}$ & $\begin{array}{l}487 \\
467 \\
454 \\
442 \\
433\end{array}$ & $\begin{array}{l}426 \\
419 \\
408 \\
404 \\
405\end{array}$ & $\begin{array}{l}364 \\
369 \\
370 \\
369 \\
370\end{array}$ & $\begin{array}{l}624 \\
624 \\
613 \\
590 \\
564\end{array}$ & $\begin{array}{l}1740 \\
1740 \\
1750 \\
1720 \\
1710\end{array}$ & $\begin{array}{l}367 \\
366 \\
375 \\
339 \\
345\end{array}$ & $\begin{array}{l}884 \\
932 \\
979 \\
969 \\
926\end{array}$ & $\begin{array}{l}374 \\
441 \\
472 \\
472 \\
460\end{array}$ & $\begin{array}{l}324 \\
315 \\
296 \\
287 \\
291\end{array}$ & $\begin{array}{l}273 \\
274 \\
284 \\
291 \\
302\end{array}$ \\
\hline $\begin{array}{l}16 \\
17 \\
18 \\
19 \\
20\end{array}$ & $\begin{array}{l}1290 \\
1310 \\
1300 \\
1250 \\
1190\end{array}$ & $\begin{array}{l}438 \\
430 \\
434 \\
432 \\
429\end{array}$ & $\begin{array}{l}430 \\
431 \\
441 \\
455 \\
462\end{array}$ & $\begin{array}{l}386 \\
365 \\
350 \\
358 \\
357\end{array}$ & $\begin{array}{l}361 \\
354 \\
350 \\
343 \\
337\end{array}$ & $\begin{array}{l}536 \\
512 \\
498 \\
496 \\
518\end{array}$ & $\begin{array}{l}1680 \\
1650 \\
1600 \\
1540 \\
1490\end{array}$ & $\begin{array}{l}350 \\
338 \\
350 \\
401 \\
473\end{array}$ & $\begin{array}{l}842 \\
752 \\
650 \\
551 \\
485\end{array}$ & $\begin{array}{l}418 \\
381 \\
344 \\
587 \\
988\end{array}$ & $\begin{array}{l}296 \\
301 \\
321 \\
367 \\
429\end{array}$ & $\begin{array}{l}302 \\
298 \\
292 \\
297 \\
310\end{array}$ \\
\hline $\begin{array}{l}21 \\
22 \\
23 \\
24 \\
25\end{array}$ & $\begin{array}{r}1110 \\
1040 \\
944 \\
870 \\
791\end{array}$ & $\begin{array}{l}433 \\
446 \\
506 \\
641 \\
744\end{array}$ & $\begin{array}{l}463 \\
452 \\
444 \\
440 \\
436\end{array}$ & $\begin{array}{l}351 \\
347 \\
347 \\
342 \\
323\end{array}$ & $\begin{array}{l}336 \\
336 \\
343 \\
350 \\
354\end{array}$ & $\begin{array}{r}570 \\
647 \\
782 \\
1020 \\
1300\end{array}$ & $\begin{array}{l}1360 \\
1330 \\
1280 \\
1260 \\
1240\end{array}$ & $\begin{array}{l}522 \\
584 \\
653 \\
668 \\
650\end{array}$ & $\begin{array}{l}416 \\
367 \\
339 \\
307 \\
301\end{array}$ & $\begin{array}{r}1100 \\
1120 \\
1080 \\
1010 \\
939\end{array}$ & $\begin{array}{l}455 \\
448 \\
444 \\
426 \\
391\end{array}$ & $\begin{array}{l}465 \\
611 \\
673 \\
682 \\
668\end{array}$ \\
\hline $\begin{array}{l}26 \\
27 \\
28 \\
29 \\
30 \\
31\end{array}$ & $\begin{array}{l}726 \\
675 \\
649 \\
615 \\
607 \\
605\end{array}$ & $\begin{array}{l}814 \\
870 \\
887 \\
878 \\
831 \\
---\end{array}$ & $\begin{array}{l}432 \\
430 \\
423 \\
422 \\
428 \\
435\end{array}$ & $\begin{array}{l}321 \\
322 \\
319 \\
316 \\
316 \\
317\end{array}$ & $\begin{array}{l}353 \\
355 \\
355 \\
--- \\
--- \\
---\end{array}$ & $\begin{array}{l}1540 \\
1760 \\
1940 \\
2080 \\
2140 \\
2120\end{array}$ & $\begin{array}{r}1200 \\
1120 \\
1080 \\
1030 \\
968 \\
---\end{array}$ & $\begin{array}{l}672 \\
847 \\
970 \\
984 \\
933 \\
863\end{array}$ & $\begin{array}{l}365 \\
418 \\
430 \\
404 \\
383 \\
---\end{array}$ & $\begin{array}{l}847 \\
765 \\
688 \\
613 \\
542 \\
498\end{array}$ & $\begin{array}{l}366 \\
341 \\
326 \\
332 \\
336 \\
349\end{array}$ & $\begin{array}{l}625 \\
581 \\
538 \\
487 \\
459 \\
\end{array}$ \\
\hline $\begin{array}{l}\text { TOTAL } \\
\text { MEAN } \\
\text { MAX } \\
\text { MIN } \\
\text { CFSM } \\
\text { IN. }\end{array}$ & $\begin{array}{r}25235 \\
814 \\
1310 \\
495 \\
1.03 \\
1.19\end{array}$ & $\begin{array}{r}17050 \\
568 \\
887 \\
429 \\
.72 \\
.80\end{array}$ & $\begin{array}{r}15577 \\
502 \\
751 \\
422 \\
.64 \\
.73\end{array}$ & $\begin{array}{r}11763 \\
379 \\
435 \\
316 \\
.48 \\
.55\end{array}$ & $\begin{array}{r}9769 \\
349 \\
370 \\
318 \\
.44 \\
.46\end{array}$ & $\begin{array}{r}25809 \\
833 \\
2140 \\
365 \\
1.05 \\
1.22\end{array}$ & $\begin{array}{r}46118 \\
1537 \\
2060 \\
968 \\
1.95 \\
2.17\end{array}$ & $\begin{array}{r}17969 \\
580 \\
984 \\
338 \\
.73 \\
.85\end{array}$ & $\begin{array}{r}18978 \\
633 \\
979 \\
301 \\
.80 \\
.89\end{array}$ & $\begin{array}{r}17185 \\
554 \\
1120 \\
263 \\
.70 \\
.81\end{array}$ & $\begin{array}{r}11700 \\
377 \\
490 \\
287 \\
.48 \\
.55\end{array}$ & $\begin{array}{r}12010 \\
400 \\
682 \\
273 \\
.51 \\
.57\end{array}$ \\
\hline
\end{tabular}

$\begin{array}{lllllllllllll}\text { CAL YR } 1986 & \text { TOTAL } & 292944 & \text { MEAN } 803 & \text { MAX } & 5330 & \text { MIN } 210 & \text { CFSM } & 1.02 & \text { IN } 13.79\end{array}$

WTR YR 1987 TOTAL 229163 MEAN 628 MAX 2140 MIN 263 CFSM .80 IN 10.79 
PERIOD OF RECORD.--Water years 1967, 1973 to current year.

PERIOD OF DAILY RECORD.--

SPECIFIC CONDUCTANCE: October 1974 to September 1981.

WATER TEMPERATURE: October 1974 to September 1981 .

INSTRUMENTATION. --Water-quality monitor from Oct. 1, 1975 to Sept. 30, 1981.

REMARKS. - Quarterly cross-sectional samples were collected during the year at cableway 40 ft downstream

from gage. Samples for the analyses of stable hydrogen and oxygen isotopes were also collected;

analytical results of these samples were not published.

EXTREMES FOR PERIOD OF DAILY RECORD.--

SPECIFIC CONDUCTANCE (water years 1976-77, 1979-81): Maximum recorded (more than 20 percent missing

record), 238 microsiemens, Jan. 24, 1977; minimum, 34 microsiemens, Apr. 17, $18,1976$.

WATER TEMPERATURE (water years i976-77, 1979-81): Maximum, $26.5^{\circ} \mathrm{C}$, May 21 , 1977; minimum, $0.0^{\circ} \mathrm{C}$ on many days during winter.

WATER QUALITY DATA, WATER YEAR OCTOBER 1986 TO SEPTEMBER 1987

\begin{tabular}{|c|c|c|c|c|c|c|c|c|c|c|}
\hline DATE & T IME & $\begin{array}{l}\text { STREAM- } \\
\text { FLOW, } \\
\text { INSTAN- } \\
\text { TANEOUS } \\
\text { (CFS) }\end{array}$ & $\begin{array}{l}\text { SPE- } \\
\text { CIFIC } \\
\text { CON- } \\
\text { DUCT- } \\
\text { ANCE } \\
\text { (US/CM) }\end{array}$ & $\begin{array}{c}\text { PH } \\
\text { ( STAND- } \\
\text { ARD } \\
\text { UNITS ) }\end{array}$ & $\begin{array}{l}\text { TEMPER- } \\
\text { ATURE } \\
\text { (DEG C) }\end{array}$ & $\begin{array}{l}\text { TUR- } \\
\text { BID- } \\
\text { ITY } \\
\text { (NTU) }\end{array}$ & $\begin{array}{c}\text { OXYGEN, } \\
\text { DIS- } \\
\text { SOLVED } \\
\text { (MG/L) }\end{array}$ & $\begin{array}{l}\text { OXYGEN, } \\
\text { DIS- } \\
\text { SOLVED } \\
\text { (PER- } \\
\text { CENT } \\
\text { SATUR- } \\
\text { ATION) }\end{array}$ & $\begin{array}{l}\text { COLI- } \\
\text { FORM, } \\
\text { FECAL, } \\
0.7 \\
\text { UM-MF } \\
\text { (COLS.' } \\
100 \mathrm{ML} \text { ) }\end{array}$ & $\begin{array}{c}\text { STREP- } \\
\text { TOCOCCI } \\
\text { FECAL, } \\
\text { KF AGAR } \\
\text { (COLS. } \\
\text { PER } \\
100 \mathrm{ML} \text { ) }\end{array}$ \\
\hline
\end{tabular}

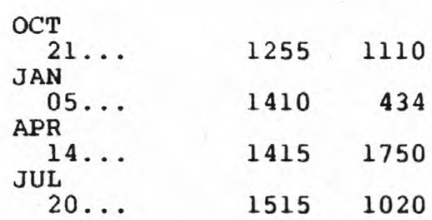

$\begin{array}{rrrr}110 & 7.2 & 6.0 & 1.0 \\ 163 & 7.4 & 0.0 & 2.4 \\ 80 & 7.3 & 10.0 & 1.5 \\ 145 & 7.8 & 21.5 & 2.2\end{array}$

8.4
10.0
8.5
6.3

69
70
78
74

$\begin{array}{rr}\text { K10 } & 23 \\ 52 & 18 \\ K 2 & \text { K2 } \\ 280 & 300\end{array}$

DATE

$\begin{array}{ccc} & \text { HARD- } & \\ \text { NESS } & \\ \text { HARD- } & \text { NONCARB } & \text { CALCIUM } \\ \text { NESS } & \text { WH WAT } & \text { DIS- } \\ \text { (MG/L } & \text { TOT FLD } & \text { SOLVED } \\ \text { AS } & \text { MG/L AS } & \text { (MG/L } \\ \text { CACO3) } & \text { CACO3 } & \text { AS CA) }\end{array}$
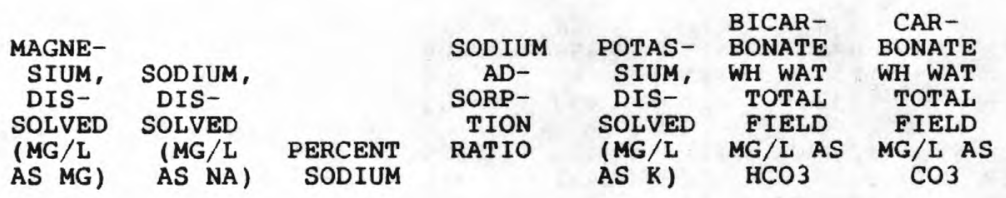

OCT $21 \ldots$

$\begin{array}{lll}62 & 14 & 17 \\ 84 & 15 & 23 \\ 40 & 11 & 11 \\ 78 & 19 & 22\end{array}$

$\begin{array}{ll}4.8 & 1.6 \\ 6.4 & 2.1 \\ 3.1 & 1.3 \\ 5.6 & 1.8\end{array}$

0.1

0.8

$0.1 \quad 0.7$

58

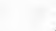

OPR ...

JUL $14 \ldots$

$20 \ldots$

$$
0.1
$$

0.6

0.1

0.4

SOLIDS, SOLIDS,

RESIDUE SUM OF

AT 180 CONSTI-

DEG. C TUENTS,

RIDE, RIDE,

DIS-

SOLVED

TOTAL

DATE FIELD
MG/L AS

$\begin{array}{cc}\text { DIS- } & \text { DIS- } \\ \text { SOLVED } & \text { SOLVED }\end{array}$

SOLVED

(MG $/ L$

(MG/L

SOLVED

(MG/L

AS

SOLVED

(MG/L)

SOLVED

(MG/L)

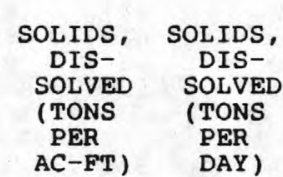

OCT $21 \ldots$

$$
48
$$

$$
5.8 \quad 21
$$

$$
2.6
$$

$<0.1$

$$
7.3
$$

93

84

$0.13 \quad 279$

5.316

2.6

$<0.1$

9.7

111

100

0.15130

APR $14 \ldots$

$\begin{array}{ll}2.8 & 9.8\end{array}$

$<0.1$

4.8

67

50

$0.09 \quad 317$

20 ...

59

1.816

$1.8 \quad 0.1$

7.0

127

91

0.17350 
04045500 TAHQUAMENON RIVER NEAR TAHQUAMENON PARADISE, MI--Continued

WATER QUALITY DATA, WATER YEAR OCTOBER 1986 TO SEPTEMBER 1987

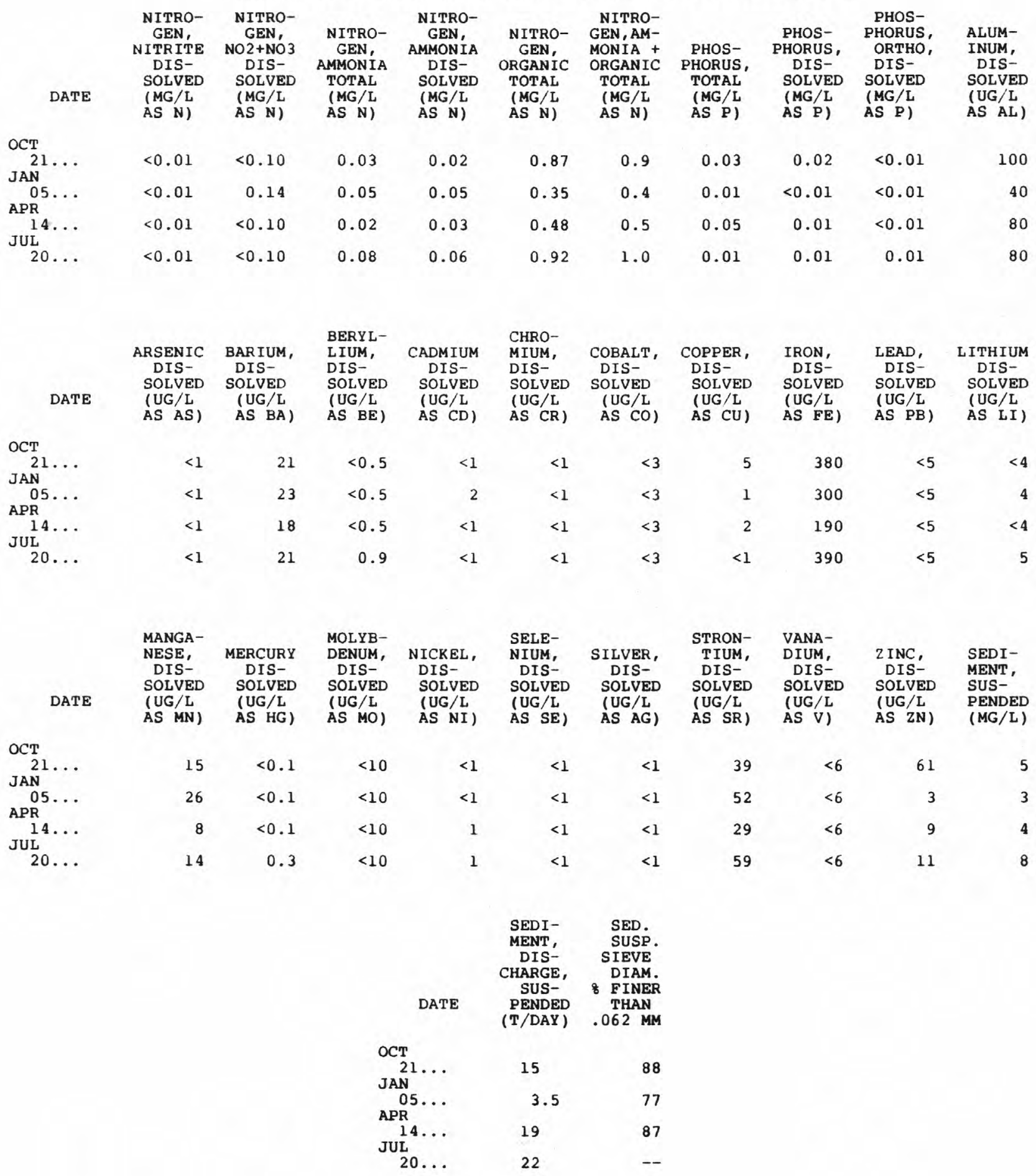


04045580 ST. MARYS RIVER ABOVE SAULT STE. MARIE, MI

(National stream quality accounting network and radiochemical station)

LOCATION. - Lat $46^{\circ} 29^{\prime} 29^{\prime \prime}$, long $84^{\circ} 25^{\prime} 17^{\prime \prime}$, in NWl/4 sec.10, T. 47 N., R.I w., Chippewa County, Hydrologic Unit 04020300 , at Sauit Ste. Marie municipal raw-water intake at Big Point, $2.6 \mathrm{mi}$ west of the

International Bridge, at Sault Ste. Marie.

DRAINAGE AREA. $--80,900 \mathrm{mi}^{2}$, approximately.

PERIOD OF RECORD.--Water years 1970 to current year.

PERIOD OF DAILY RECORD.--

SPECIFIC CONDUCTANCE: March 1974 to September 1981.

WATER TEMPERATURE: March 1974 to September 1981.

REMARKS.--Quarterly samples were collected at the raw-water tap in Sault ste. Marie municipal water plant at Big Point. Intake is $1,500 \mathrm{ft}$ from water plant at a depth of $30 \mathrm{ft}, 10 \mathrm{ft}$ above bottom of channel. Samples for the analyses of stable hydrogen and oxygen isotopes were also collected; analytical results from these samples were not published. Since the 1983 water year, water temperature has been measured in the stream near the water plant. Before 1983, water temperature was measured at the raw-water tap.

COOPERATION,--Discharge figures are monthly means provided by U.S. Army Corps of Engineers, Sault Ste. Marie.

EXTREMES FOR PERIOD OF DAILY RECORD.--

SPECIFIC CONDUCTANCE (water years 1975-81): Maximum daily, 113 microsiemens, Oct. 26, 1980; minimum daily, 76 microsiemens, Apr. 24, 1975.

WATER TEMPERATURE (water years 1975-81): Maximum daily, $24.0^{\circ} \mathrm{C}, \mathrm{July} 25,1979 ; \mathrm{minimum}$ daily, 0,0 ${ }^{\circ} \mathrm{C}$, Mar. 14, 15, 1974, Feb. 1, 1979.

WATER QUALITY DATA, WATER YEAR OCTOBER 1986 TO SEPTEMBER 1987

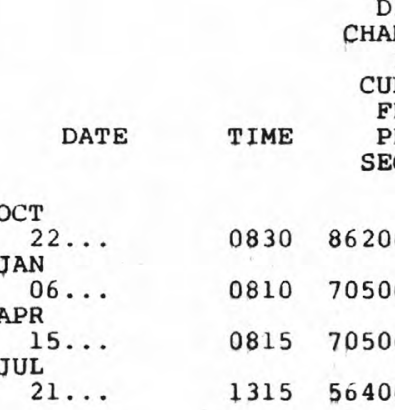

OCT

JAN 22

06.

APR

15 ...

JUL 21.

$\begin{array}{cc} & \text { ALKA- } \\ & \text { LINITY } \\ & \text { WH WAT } \\ & \text { TOTAL } \\ \text { FIELD } \\ \text { DATE } \\ \text { MG } / \text { A AS } \\ & \text { CACO3 }\end{array}$

OCT
$22 \ldots$
JAN
$06 \ldots$
APR
$15 \ldots$
JUL
$21 \ldots$

39

42

42

41

47

44

44

44
DIS-

CHARGE, SPE-

IN CIFIC

INIC CIFIC

FEET DUCT-

PER ANCE

ANCE
(US/CM)

$\mathrm{PH}$

( STAND- TEMPER-

ARD

UNITS )

ATURE
(DEG C)

TUR-

(NTU)

OXYGEN,

DIS-

SOLVED
(MG/L)

7.3

8.0

0.5

11.1

13.8

0.2

11.4

7.5

0.6

8.6

8.0

24.0

0.4

MAGNE-

HARD-

NESS

NONCARB CALCIUM

WH WAT

TOT FLD SOLVED

MG/L AS (MG/L

$\mathrm{CACO} 3$ AS $\mathrm{CA}$ )

$\begin{array}{ll}8 & 14 \\ 2 & 13 \\ 2 & 13 \\ 3 & 13\end{array}$

$\begin{array}{cc}\text { CARBON } & \\ \text { DIOXIDE } & \text { SULFATE } \\ \text { DIS- } & \text { DIS- } \\ \text { SOLVED } & \text { SOLVED } \\ \text { (MG/L } & (M G / L \\ \text { AS CO2) } & \text { AS SO4) }\end{array}$

$\begin{array}{lll}\text { CHLO- } & \text { FLUO- } & \text { SILICA, } \\ \text { RIDE, } & \text { RIDE, } & \text { DIS- } \\ \text { DIS- } & \text { DIS- } & \text { SOLVED } \\ \text { SOLVED } & \text { SOLVED } & \text { (MG/L } \\ \text { (MG/L } & \text { (MG/L } & \text { AS } \\ \text { AS CL) } & \text { AS F) } & \text { SIO2) }\end{array}$

SODIUM ADSORPDIS- DISSOLVED SOLVED (MG/L (MG/L AS MG)

AS NA)

$\begin{array}{ll}2.9 & 1.3 \\ 2.9 & 1.4 \\ 2.9 & 1.4 \\ 2.8 & 1.4\end{array}$

ERCENT

RATIO

SODIUM

$\begin{array}{ll}0.1 & 0.8 \\ 0.1 & 0.5 \\ 0.1 & 0.5 \\ 0.1 & 0.4\end{array}$

OXYGEN, DISSOLVED (PER-

CENT

SATUR-

AT ION)

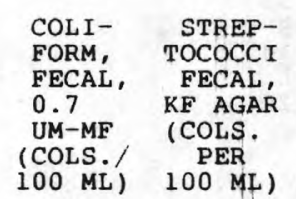

$100 \mathrm{ML}$ ) $100 \mathrm{ML}$ )

97

98

98

105

POTAS-

SIUM,

DIS-

SOLVED

(MG/L

AS $\mathrm{K}$ )

$\begin{array}{ll}<1 & <1 \\ <1 & <1 \\ <1 & \text { K2 } \\ \text { K4 } & \text { K2 }\end{array}$

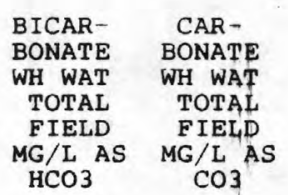

$\mathrm{HCO} 3$

$\mathrm{CO} 3$

SOLIDS, SOLIDS ,

RESIDUE SUM OF

AT 180

DEG.

DIS-

SOLVED

CONST I

TUENTS

DIS-

(MG/L)

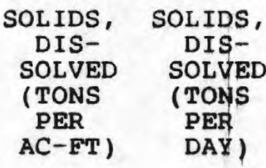

\section{4 \\ $<0.1$}

2.4

48

50

0.0611200

$\begin{array}{llll}3.2 & 4.1 & 1.6\end{array}$

$<0.1$

2.5

52

51

0.079900

1.6

3.8

1.2

$<0.1$

2.5

55

51

0.0810500

$0.7 \quad 3.8$

0.4

$0.07 \quad 7770$ 
04045580 ST. MARYS RIVER ABOVE SAULT STE. MARIE, MI--Continued

WATER QUALITY DATA, WATER YEAR OCTOBER 1986 TO SEPTEMBER 1987

\begin{tabular}{|c|c|c|c|c|c|c|c|c|c|c|}
\hline DATE & $\begin{array}{l}\text { NITRO- } \\
\text { GEN, } \\
\text { NITRITE } \\
\text { DIS- } \\
\text { SOLVED } \\
\text { (MG/L } \\
\text { AS N) }\end{array}$ & $\begin{array}{c}\text { NITRO- } \\
\text { GEN, } \\
\text { NO2+NO3 } \\
\text { DIS- } \\
\text { SOLVED } \\
\text { (MG/L } \\
\text { AS N) }\end{array}$ & $\begin{array}{l}\text { NITRO- } \\
\text { GEN, } \\
\text { AMMONIA } \\
\text { TOTAL } \\
\text { (MG/L } \\
\text { AS N) }\end{array}$ & $\begin{array}{l}\text { NITRO- } \\
\text { GEN, } \\
\text { AMMONIA } \\
\text { DIS- } \\
\text { SOLVED } \\
\text { (MG/L } \\
\text { AS N) }\end{array}$ & $\begin{array}{c}\text { NITRO- } \\
\text { GEN, } \\
\text { ORGANIC } \\
\text { TOTAL } \\
\text { (MG/L } \\
\text { AS N) }\end{array}$ & $\begin{array}{l}\text { NITRO- } \\
\text { GEN, AM- } \\
\text { MONIA + } \\
\text { ORGANIC } \\
\text { TOTAL } \\
\text { (MG/L } \\
\text { AS N) }\end{array}$ & $\begin{array}{c}\text { PHOS- } \\
\text { PHORUS, } \\
\text { TOTAL } \\
\text { (MG/L } \\
\text { AS P) }\end{array}$ & $\begin{array}{c}\text { PHOS- } \\
\text { PHORUS, } \\
\text { DIS- } \\
\text { SOLVED } \\
\text { (MG/L } \\
\text { AS P) }\end{array}$ & $\begin{array}{l}\text { PHOS- } \\
\text { PHORUS, } \\
\text { ORTHO, } \\
\text { DIS- } \\
\text { SOLVED } \\
\text { (MG/L } \\
\text { AS P) }\end{array}$ & $\begin{array}{l}\text { ALUM- } \\
\text { INUM, } \\
\text { DIS- } \\
\text { SOLVED } \\
\text { (UG/L } \\
\text { AS AL) }\end{array}$ \\
\hline $\begin{array}{l}\mathrm{OCT} \\
22 \ldots \\
\text { JAN }\end{array}$ & $<0.01$ & 0.29 & 0.02 & $<0.01$ & -- & $<0.2$ & 0.01 & $<0.01$ & $<0.01$ & 20 \\
\hline $\begin{array}{c}06 \ldots \\
\text { APR }\end{array}$ & $<0.01$ & 0.30 & 0.01 & 0.01 & 0.39 & 0.4 & $<0.01$ & $<0.01$ & $<0.01$ & $<10$ \\
\hline${ }_{\text {JUL }}^{15 \ldots}$ & $<0.01$ & 0.29 & $<0.01$ & $<0.01$ & 0.99 & 1.0 & $<0.01$ & $<0.01$ & $<0.01$ & $<10$ \\
\hline $21 \ldots$ & $<0.01$ & 0.26 & 0.02 & -- & 0.48 & 0.5 & $<0.01$ & $<0.01$ & $<0.01$ & $<10$ \\
\hline DATE & $\begin{array}{c}\text { ARSENIC } \\
\text { DIS- } \\
\text { SOLVED } \\
\text { (UG/L } \\
\text { AS AS) }\end{array}$ & $\begin{array}{l}\text { BAR IUM, } \\
\text { DIS- } \\
\text { SOLVED } \\
\text { (UG/L } \\
\text { AS BA) }\end{array}$ & $\begin{array}{l}\text { BERYL- } \\
\text { LIUM, } \\
\text { DIS- } \\
\text { SOLVED } \\
\text { (UG/I } \\
\text { AS BE) }\end{array}$ & $\begin{array}{c}\text { CADMIUM } \\
\text { DIS- } \\
\text { SOLVED } \\
\text { (UG/L } \\
\text { AS CD) }\end{array}$ & $\begin{array}{l}\text { CHRO- } \\
\text { MIUM, } \\
\text { DIS- } \\
\text { SOLVED } \\
\text { (UG/L } \\
\text { AS CR) }\end{array}$ & $\begin{array}{l}\text { COBALT, } \\
\text { DIS- } \\
\text { SOLVED } \\
\text { (UG/L } \\
\text { AS CO) }\end{array}$ & $\begin{array}{l}\text { COPPER, } \\
\text { DIS- } \\
\text { SOLVED } \\
\text { (UG/I } \\
\text { AS CU) }\end{array}$ & $\begin{array}{l}\text { IRON, } \\
\text { DIS- } \\
\text { SOLVED } \\
\text { (UG/L } \\
\text { AS FE) }\end{array}$ & $\begin{array}{l}\text { LEAD, } \\
\text { DIS- } \\
\text { SOLVED } \\
\text { (UG/L } \\
\text { AS PB) }\end{array}$ & $\begin{array}{c}\text { LITHIUM } \\
\text { DIS- } \\
\text { SOLVED } \\
\text { (UG/L } \\
\text { AS LI) }\end{array}$ \\
\hline OCT & & & & & & & & & & \\
\hline$\underset{\text { JAN }}{22 \ldots}$ & $<1$ & 41 & $<0.5$ & $<1$ & $<1$ & $<3$ & 4 & 12 & $<5$ & $<4$ \\
\hline$\underset{A P R}{06 \cdots}$ & $<1$ & 14 & $<0.5$ & $<1$ & $<1$ & $<3$ & 3 & 4 & $<5$ & $<4$ \\
\hline JUL $15 \ldots$ & $<1$ & 17 & $<0.5$ & $<1$ & 8 & $<3$ & 2 & 7 & $<5$ & $<4$ \\
\hline $21 \ldots$ & $<1$ & 12 & 0.5 & $<1$ & $<1$ & $<3$ & 1 & $<3$ & $<5$ & 4 \\
\hline DATE & $\begin{array}{l}\text { MANGA- } \\
\text { NESE, } \\
\text { DIS- } \\
\text { SOLVED } \\
\text { (UG/L } \\
\text { AS MN) }\end{array}$ & $\begin{array}{c}\text { MERCURY } \\
\text { DIS- } \\
\text { SOLVED } \\
\text { (UG/L } \\
\text { AS HG) }\end{array}$ & $\begin{array}{l}\text { MOLYB- } \\
\text { DENUM, } \\
\text { DIS- } \\
\text { SOLVED } \\
\text { (UG/I } \\
\text { AS MO) }\end{array}$ & $\begin{array}{l}\text { NICKEL, } \\
\text { DIS- } \\
\text { SOLVED } \\
\text { (UG/L } \\
\text { AS NI) }\end{array}$ & $\begin{array}{l}\text { SELE- } \\
\text { NIUM, } \\
\text { DIS- } \\
\text { SOLVED } \\
\text { (UG/L } \\
\text { AS SE) }\end{array}$ & $\begin{array}{c}\text { SILVER, } \\
\text { DIS- } \\
\text { SOLVED } \\
\text { (UG/L } \\
\text { AS AG) }\end{array}$ & $\begin{array}{l}\text { STRON- } \\
\text { TIUM, } \\
\text { DIS- } \\
\text { SOLVED } \\
\text { (UG/L } \\
\text { AS SR) }\end{array}$ & $\begin{array}{l}\text { VANA- } \\
\text { DIUM, } \\
\text { DIS- } \\
\text { SOLVED } \\
\text { (UG/L } \\
\text { AS V) }\end{array}$ & $\begin{array}{l}\text { Z INC, } \\
\text { DIS- } \\
\text { SOLVED } \\
\text { (UG/L } \\
\text { AS ZN) }\end{array}$ & $\begin{array}{l}\text { GROSS } \\
\text { ALPHA, } \\
\text { DIS- } \\
\text { SOLVED } \\
\text { (UG/L } \\
\text { AS } \\
\text { U-NAT) }\end{array}$ \\
\hline OCT & & & & & & & & & & \\
\hline$\underset{\text { JAN }}{22} \ldots$ & 2 & $<0.1$ & $<10$ & $<1$ & $<1$ & $<1$ & 22 & $<6$ & 64 & $<0.4$ \\
\hline $\begin{array}{c}06 \cdots \\
\mathrm{APR}\end{array}$ & $<1$ & $<0.1$ & $<10$ & $<1$ & $<1$ & $<1$ & 23 & $<6$ & 55 & - \\
\hline JUL $15 \ldots$ & 1 & $<0.1$ & $<10$ & $<1$ & $<1$ & $<1$ & 23 & $<6$ & 70 & $<0.4$ \\
\hline $21 \ldots$ & 2 & 0.2 & $<10$ & $<1$ & $<1$ & $<1$ & 21 & $<6$ & 57 & - \\
\hline
\end{tabular}

\begin{tabular}{|c|c|c|c|c|c|c|c|}
\hline DATE & $\begin{array}{l}\text { GROSS } \\
\text { ALPHA, } \\
\text { SUSP } \\
\text { TOTAL } \\
\text { (UG/L } \\
\text { AS } \\
\text { U-NAT) }\end{array}$ & $\begin{array}{l}\text { GROSS } \\
\text { BETA, } \\
\text { DIS- } \\
\text { SOLVED } \\
\text { (PCI/L } \\
\text { AS } \\
\text { CS-137) }\end{array}$ & $\begin{array}{c}\text { GROSS } \\
\text { BETA, } \\
\text { SUSP. } \\
\text { TOTAL } \\
\text { (PCI/L } \\
\text { AS } \\
\text { CS-137) }\end{array}$ & $\begin{array}{l}\text { GROSS } \\
\text { BETA, } \\
\text { DIS- } \\
\text { SOLVED } \\
\text { (PCI/L } \\
\text { AS SR/ } \\
\text { YT-90) }\end{array}$ & $\begin{array}{l}\text { GROSS } \\
\text { BETA, } \\
\text { SUSP. } \\
\text { TOTAL } \\
\text { (PCI/L } \\
\text { AS SR/ } \\
\text { YT-90) }\end{array}$ & $\begin{array}{c}\text { RADIUM } \\
226, \\
\text { DIS- } \\
\text { SOLVED, } \\
\text { RADON } \\
\text { METHOD } \\
(\mathrm{PCI} / \mathrm{L})\end{array}$ & $\begin{array}{l}\text { URANIUM } \\
\text { DIS- } \\
\text { SOLVED, } \\
\text { EXTRAC- } \\
\text { TION } \\
\text { (UG/L) }\end{array}$ \\
\hline
\end{tabular}

\begin{tabular}{|c|c|c|c|c|c|c|c|}
\hline $\begin{array}{l}\mathrm{OCT} \\
22 \ldots\end{array}$ & $<0.4$ & 0.9 & $<0.4$ & 0.8 & $<0.4$ & 0.04 & 0.04 \\
\hline $\begin{array}{l}\text { JAN } \\
06 \ldots \\
\text { APR }\end{array}$ & -- & -- & -- & -- & -- & -- & -- \\
\hline${ }_{\text {JUL }}^{15} \ldots$ & $<0.4$ & 1.0 & $<0.4$ & 0.9 & $<0.4$ & 0.03 & 0.04 \\
\hline $21 \ldots$ & - & -- & -- & -- & -- & - & - \\
\hline
\end{tabular}




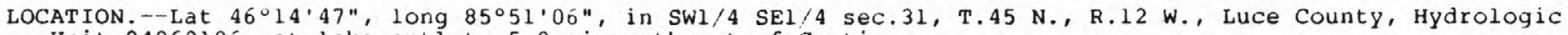
Unit 04060106 , at lake outlet, $5.8 \mathrm{mi}$ northwest of Curtis.

DRAINAGE AREA.--118 $\mathrm{mi}^{2}$, approximately.

PERIOD OF RECORD. --April 1942 to current year.

GAGE.-Water-stage recorder. Datum of gage is $683.08 \mathrm{ft}$ above National Geodetic Vertical Datum of 1929

(levels by Michigan Department of Natural Resources). Prior to Apr. 15, 1943 and Oct. 1 , 1968 to Oct.

4, 1976, nonrecording gage at same datum.

REMARKS. --Lake level controlled by concrete dam with removable flash boards constructed in 1978 on the outlet, and by a dam on Portage Creek, one of the inlets. From 1948 to 1978 lake level controlled by timber dam with removable flash boards on outlet. Occasionally during periods of high flow, backwater from Fox River raises the lake level. Major inlets to Manistique Lake are Helmer Creek from North Manistique Lake, Portage Creek from South Manistique Lake, and Fork Lake Outlet. The outlet is Manistique River. Streamflow records were collected for South Manistique Lake Outlet (station 04046500) from May 1942 to September 1944, for North Manistique Lake Outlet (station 04047000) from August 1942 to September 1944, and for Manistique River (station 04047500) from Apr. 1942 to June 1950.

Established legal level; $686.00 \mathrm{ft}$ above NGVD, established by Circuit Court, January 1948. Surface area of lake is 10,100 acres.

EXTREMES FOR PERIOD OF RECORD.--Maximum gage height, $6.28 \mathrm{ft}$, May 14,15 or 16 , 1960 , from floodmark; minimum, $1.33 \mathrm{ft}$, Aug. 10, 1948, result of dam construction.

EXTREMES FOR CURRENT YEAR.--Maximum daily gage height, $3.15 \mathrm{ft}$, June 17; minimum daily, 2.40 ft, Mar. 21, 22 .

GAGE HEIGHT (FEET ABOVE DATUM), WATER YEAR OCTOBER 1986 TO SEPTEMBER 1987 MEAN VALUES

\begin{tabular}{|c|c|c|c|c|c|c|c|c|c|c|c|c|}
\hline DAY & OCT & NOV & $\mathrm{DEC}$ & JAN & FEB & MAR & APR & MAY & JUN & JUL & AUG & SEP \\
\hline $\begin{array}{l}1 \\
2 \\
3 \\
4 \\
5\end{array}$ & $\begin{array}{l}3.11 \\
3.09 \\
3.07 \\
3.06 \\
3.00\end{array}$ & $\begin{array}{l}2.90 \\
2.88 \\
2.87 \\
2.88 \\
2.87\end{array}$ & $\begin{array}{l}2.72 \\
2.72 \\
2.73 \\
2.74 \\
2.74\end{array}$ & $\begin{array}{l}2.64 \\
2.63 \\
2.63 \\
2.62 \\
2.62\end{array}$ & $\begin{array}{l}2.55 \\
2.56 \\
2.57 \\
2.57 \\
2.57\end{array}$ & $\begin{array}{l}2.49 \\
2.50 \\
2.51 \\
2.51 \\
2.50\end{array}$ & $\begin{array}{l}2.59 \\
2.62 \\
2.62 \\
2.62 \\
2.61\end{array}$ & $\begin{array}{l}2.89 \\
2.91 \\
2.91 \\
2.89 \\
2.88\end{array}$ & $\begin{array}{l}2.98 \\
3.02 \\
2.98 \\
2.99 \\
3.01\end{array}$ & $\begin{array}{l}2.99 \\
2.98 \\
2.95 \\
2.95 \\
2.96\end{array}$ & $\begin{array}{l}2.85 \\
2.85 \\
2.86 \\
2.82 \\
2.85\end{array}$ & $\begin{array}{l}2.93 \\
2.92 \\
2.93 \\
2.93 \\
2.92\end{array}$ \\
\hline $\begin{array}{r}6 \\
7 \\
8 \\
9 \\
10\end{array}$ & $\begin{array}{l}3.02 \\
3.00 \\
3.02 \\
3.02 \\
3.02\end{array}$ & $\begin{array}{l}2.86 \\
2.85 \\
2.83 \\
2.70 \\
2.79\end{array}$ & $\begin{array}{l}2.74 \\
2.73 \\
2.73 \\
2.72 \\
2.72\end{array}$ & $\begin{array}{l}2.62 \\
2.62 \\
2.62 \\
2.62 \\
2.61\end{array}$ & $\begin{array}{l}2.56 \\
2.56 \\
2.55 \\
2.55 \\
2.53\end{array}$ & $\begin{array}{l}2.50 \\
2.49 \\
2.48 \\
2.48 \\
2.48\end{array}$ & $\begin{array}{l}2.61 \\
2.62 \\
2.63 \\
2.64 \\
2.65\end{array}$ & $\begin{array}{l}2.83 \\
2.84 \\
2.83 \\
2.81 \\
2.84\end{array}$ & $\begin{array}{l}3.00 \\
3.04 \\
3.00 \\
3.01 \\
3.02\end{array}$ & $\begin{array}{l}2.93 \\
2.95 \\
2.94 \\
2.96 \\
2.94\end{array}$ & $\begin{array}{l}2.85 \\
2.82 \\
2.85 \\
2.86 \\
2.85\end{array}$ & $\begin{array}{l}2.92 \\
2.92 \\
2.92 \\
2.92 \\
2.93\end{array}$ \\
\hline $\begin{array}{l}11 \\
12 \\
13 \\
14 \\
15\end{array}$ & $\begin{array}{l}2.99 \\
3.06 \\
3.08 \\
3.08 \\
3.08\end{array}$ & $\begin{array}{l}2.78 \\
2.72 \\
2.79 \\
2.79 \\
2.78\end{array}$ & $\begin{array}{l}2.72 \\
2.72 \\
2.72 \\
2.71 \\
2.70\end{array}$ & $\begin{array}{l}2.60 \\
2.59 \\
2.59 \\
2.58 \\
2.58\end{array}$ & $\begin{array}{l}2.53 \\
2.52 \\
2.52 \\
2.52 \\
2.51\end{array}$ & $\begin{array}{l}2.48 \\
2.47 \\
2.46 \\
2.46 \\
2.45\end{array}$ & $\begin{array}{l}2.65 \\
2.65 \\
2.67 \\
2.71 \\
2.78\end{array}$ & $\begin{array}{l}2.77 \\
2.82 \\
2.80 \\
2.77 \\
2.79\end{array}$ & $\begin{array}{l}3.07 \\
3.10 \\
3.13 \\
3.13 \\
3.13\end{array}$ & $\begin{array}{l}2.96 \\
2.97 \\
2.93 \\
2.90 \\
2.92\end{array}$ & $\begin{array}{l}2.87 \\
2.85 \\
2.85 \\
2.88 \\
2.89\end{array}$ & $\begin{array}{l}2.93 \\
2.93 \\
2.95 \\
2.95 \\
2.96\end{array}$ \\
\hline $\begin{array}{l}16 \\
17 \\
18 \\
19 \\
20\end{array}$ & $\begin{array}{l}3.08 \\
3.09 \\
3.07 \\
3.06 \\
3.06\end{array}$ & $\begin{array}{l}2.78 \\
2.77 \\
2.75 \\
2.75 \\
2.76\end{array}$ & $\begin{array}{l}2.70 \\
2.70 \\
2.70 \\
2.69 \\
2.68\end{array}$ & $\begin{array}{l}2.58 \\
2.57 \\
2.57 \\
2.56 \\
2.56\end{array}$ & $\begin{array}{l}2.50 \\
2.50 \\
2.50 \\
2.49 \\
2.49\end{array}$ & $\begin{array}{l}2.44 \\
2.43 \\
2.42 \\
2.42 \\
2.41\end{array}$ & $\begin{array}{l}2.78 \\
2.79 \\
2.82 \\
2.83 \\
2.82\end{array}$ & $\begin{array}{l}2.78 \\
2.79 \\
2.84 \\
2.87 \\
2.84\end{array}$ & $\begin{array}{l}3.14 \\
3.15 \\
3.13 \\
3.13 \\
3.14\end{array}$ & $\begin{array}{l}2.90 \\
2.87 \\
2.88 \\
3.05 \\
3.06\end{array}$ & $\begin{array}{l}2.91 \\
2.93 \\
2.94 \\
2.96 \\
2.98\end{array}$ & $\begin{array}{l}2.96 \\
2.99 \\
2.96 \\
2.98 \\
3.02\end{array}$ \\
\hline $\begin{array}{l}21 \\
22 \\
23 \\
24 \\
25\end{array}$ & $\begin{array}{l}3.05 \\
3.04 \\
3.03 \\
3.02 \\
3.00\end{array}$ & $\begin{array}{l}2.75 \\
2.74 \\
2.75 \\
2.76 \\
2.76\end{array}$ & $\begin{array}{l}2.68 \\
2.68 \\
2.67 \\
2.66 \\
2.65\end{array}$ & $\begin{array}{l}2.55 \\
2.56 \\
2.56 \\
2.58 \\
2.58\end{array}$ & $\begin{array}{l}2.48 \\
2.49 \\
2.50 \\
2.49 \\
2.48\end{array}$ & $\begin{array}{l}2.40 \\
2.40 \\
2.41 \\
2.42 \\
2.44\end{array}$ & $\begin{array}{l}2.80 \\
2.90 \\
2.89 \\
2.92 \\
2.93\end{array}$ & $\begin{array}{c}2.85 \\
- \\
-\cdots \\
---\end{array}$ & $\begin{array}{l}3.11 \\
3.09 \\
3.07 \\
3.06 \\
3.08\end{array}$ & $\begin{array}{l}3.06 \\
3.07 \\
3.04 \\
3.03 \\
3.02\end{array}$ & $\begin{array}{l}3.01 \\
2.96 \\
2.95 \\
2.95 \\
2.97\end{array}$ & $\begin{array}{l}3.02 \\
3.00 \\
2.97 \\
2.96 \\
2.95\end{array}$ \\
\hline $\begin{array}{l}26 \\
27 \\
28 \\
29 \\
30 \\
31\end{array}$ & $\begin{array}{l}2.99 \\
2.98 \\
2.97 \\
2.93 \\
2.94 \\
2.93\end{array}$ & $\begin{array}{r}2.75 \\
2.74 \\
2.73 \\
2.73 \\
2.73 \\
-\end{array}$ & $\begin{array}{l}2.65 \\
2.65 \\
2.64 \\
2.65 \\
2.65 \\
2.65\end{array}$ & $\begin{array}{l}2.57 \\
2.57 \\
2.56 \\
2.55 \\
2.56 \\
2.56\end{array}$ & $\begin{array}{r}2.48 \\
2.48 \\
2.47 \\
--- \\
-- \\
---\end{array}$ & $\begin{array}{l}2.46 \\
2.48 \\
2.49 \\
2.52 \\
2.55 \\
2.56\end{array}$ & $\begin{array}{l}2.93 \\
2.83 \\
2.90 \\
2.84 \\
2.88 \\
-\end{array}$ & $\begin{array}{l}2.91 \\
2.93 \\
2.94 \\
2.95 \\
2.96 \\
2.97\end{array}$ & $\begin{array}{l}3.08 \\
3.06 \\
3.04 \\
3.04 \\
3.00\end{array}$ & $\begin{array}{l}2.99 \\
2.95 \\
2.93 \\
2.91 \\
2.89 \\
2.89\end{array}$ & $\begin{array}{l}2.97 \\
2.95 \\
2.94 \\
2.94 \\
2.94 \\
2.91\end{array}$ & $\begin{array}{l}2.96 \\
2.99 \\
2.98 \\
2.98 \\
2.93\end{array}$ \\
\hline $\begin{array}{l}\text { MEAN } \\
\text { MAX } \\
\text { MIN }\end{array}$ & $\begin{array}{l}3.03 \\
3.11 \\
2.93\end{array}$ & $\begin{array}{l}2.78 \\
2.90 \\
2.70\end{array}$ & $\begin{array}{l}2.70 \\
2.74 \\
2.64\end{array}$ & $\begin{array}{l}2.59 \\
2.64 \\
2.55\end{array}$ & $\begin{array}{l}2.52 \\
2.57 \\
2.47\end{array}$ & $\begin{array}{l}2.47 \\
2.56 \\
2.40\end{array}$ & $\begin{array}{l}2.75 \\
2.93 \\
2.59\end{array}$ & $\begin{array}{l}-- \\
---\end{array}$ & $\begin{array}{l}3.06 \\
3.15 \\
2.98\end{array}$ & $\begin{array}{l}2.96 \\
3.07 \\
2.87\end{array}$ & $\begin{array}{l}2.90 \\
3.01 \\
2.82\end{array}$ & $\begin{array}{l}2.95 \\
3.02 \\
2.92\end{array}$ \\
\hline
\end{tabular}


04056500 MANISTIQUE RIVER NEAR MANISTIQUE, MI

LOCATION.--Lat $46^{\circ} 01^{\prime} 50^{\prime \prime}$, long $86^{\circ} 09^{\prime} 40^{\prime \prime}$, in SEl/4 sec.15, T.42 N., R.15 W. Schoolcraft County, Hydrologic Unit 04060106 , on left bank $1.0 \mathrm{mi}$ downstream from West Branch, $6.0 \mathrm{mi}$ northeast of Manistique, and at mile 19.5 .

DRAINAGE AREA. $--1,100 \mathrm{mi}^{2}$, approximately.

PERIOD OF RECORD.--March 1938 to current year.

REVISED RECORDS. --WSP 1387: 1940-42(M)，1943, 1945. WSP 1627, 1727: 1938, 1939.

GAGE. - Water-stage recorder. Elevation of gage is $608 \mathrm{ft}$, from river-profile map. Prior to July 15 , 1939, non-recording gage at site $1,600 \mathrm{ft}$ upstream at different datum.

REMARKS.--Estimated daily discharges: Nov. 13 to Mar. 23. Records good except for estimated daily discharges, which are fair. Since July 1948, slight regulation by dam on outlet of Manistique Lake. Several measurements of water temperature were made during the year.

AVERAGE DISCHARGE. - -49 years, $1,436 \mathrm{ft}^{3} / \mathrm{s}, 17.73 \mathrm{in} / \mathrm{yr}$.

EXTREMES FOR PERIOD OF RECORD.--Maximum discharge, 16,900 ft $3 / \mathrm{s}$, May 11, 1960, gage height, 12.85 $\mathrm{ft}$; minimum, $288 \mathrm{ft} / \mathrm{s}$, Oct. 4, 1948; minimum gage height, 1.01 ft, Aug. $23,1941$.

EXTREMES FOR CURRENT YEAR.--Maximum discharge, 2,600 $\mathrm{ft}^{3} / \mathrm{s}$, Apr. 11 , gage height, $7.27 \mathrm{ft}$; minimum, $445 \mathrm{ft}^{3} / \mathrm{s}$, Sept. 12, gage height, $2.40 \mathrm{ft}$.

DISCHARGE, IN CUBIC FEET PER SECOND, WATER YEAR OCTOBER 1986 TO SEPTEMBER 1987 MEAN VALUES

\begin{tabular}{|c|c|c|c|c|c|c|c|c|c|c|c|c|}
\hline$D A Y$ & OCT & NOV & DEC & JAN & FEB & MAR & APR & MAY & JUN & JUL & AUG & SEP \\
\hline $\begin{array}{l}1 \\
2 \\
3 \\
4 \\
5\end{array}$ & $\begin{array}{l}872 \\
852 \\
836 \\
828 \\
829\end{array}$ & $\begin{array}{l}909 \\
900 \\
897 \\
892 \\
879\end{array}$ & $\begin{array}{l}760 \\
710 \\
680 \\
660 \\
630\end{array}$ & $\begin{array}{l}640 \\
640 \\
640 \\
640 \\
640\end{array}$ & $\begin{array}{l}500 \\
520 \\
520 \\
540 \\
540\end{array}$ & $\begin{array}{l}580 \\
580 \\
580 \\
580 \\
600\end{array}$ & $\begin{array}{l}2360 \\
2210 \\
2070 \\
1970 \\
1940\end{array}$ & $\begin{array}{l}1330 \\
1240 \\
1150 \\
1080 \\
1020\end{array}$ & $\begin{array}{l}853 \\
869 \\
907 \\
897 \\
847\end{array}$ & $\begin{array}{l}506 \\
513 \\
525 \\
518 \\
514\end{array}$ & $\begin{array}{l}622 \\
657 \\
701 \\
716 \\
685\end{array}$ & $\begin{array}{l}512 \\
516 \\
508 \\
495 \\
482\end{array}$ \\
\hline $\begin{array}{r}6 \\
7 \\
8 \\
9 \\
10\end{array}$ & $\begin{array}{r}856 \\
876 \\
942 \\
997 \\
1020\end{array}$ & $\begin{array}{l}872 \\
862 \\
856 \\
866 \\
860\end{array}$ & $\begin{array}{l}600 \\
570 \\
550 \\
540 \\
530\end{array}$ & $\begin{array}{l}640 \\
640 \\
640 \\
640 \\
640\end{array}$ & $\begin{array}{l}540 \\
550 \\
560 \\
560 \\
560\end{array}$ & $\begin{array}{l}620 \\
660 \\
800 \\
940 \\
980\end{array}$ & $\begin{array}{l}2000 \\
2180 \\
2400 \\
2540 \\
2590\end{array}$ & $\begin{array}{l}977 \\
936 \\
898 \\
866 \\
836\end{array}$ & $\begin{array}{l}789 \\
745 \\
750 \\
771 \\
767\end{array}$ & $\begin{array}{l}501 \\
484 \\
464 \\
458 \\
468\end{array}$ & $\begin{array}{l}651 \\
620 \\
583 \\
548 \\
530\end{array}$ & $\begin{array}{l}475 \\
467 \\
466 \\
478 \\
469\end{array}$ \\
\hline $\begin{array}{l}11 \\
12 \\
13 \\
14 \\
15\end{array}$ & $\begin{array}{l}1010 \\
1030 \\
1250 \\
1480 \\
1560\end{array}$ & $\begin{array}{l}839 \\
743 \\
700 \\
680 \\
680\end{array}$ & $\begin{array}{l}530 \\
530 \\
530 \\
530 \\
530\end{array}$ & $\begin{array}{l}635 \\
630 \\
620 \\
620 \\
620\end{array}$ & $\begin{array}{l}580 \\
580 \\
600 \\
600 \\
580\end{array}$ & $\begin{array}{r}1000 \\
980 \\
960 \\
940 \\
900\end{array}$ & $\begin{array}{l}2590 \\
2580 \\
2560 \\
2530 \\
2500\end{array}$ & $\begin{array}{l}823 \\
821 \\
805 \\
794 \\
783\end{array}$ & $\begin{array}{l}747 \\
768 \\
846 \\
889 \\
831\end{array}$ & $\begin{array}{l}485 \\
532 \\
613 \\
688 \\
733\end{array}$ & $\begin{array}{l}521 \\
517 \\
508 \\
508 \\
526\end{array}$ & $\begin{array}{l}457 \\
448 \\
464 \\
492 \\
512\end{array}$ \\
\hline $\begin{array}{l}16 \\
17 \\
18 \\
19 \\
20\end{array}$ & $\begin{array}{l}1590 \\
1580 \\
1530 \\
1460 \\
1370\end{array}$ & $\begin{array}{l}680 \\
680 \\
680 \\
680 \\
680\end{array}$ & $\begin{array}{l}550 \\
570 \\
590 \\
620 \\
640\end{array}$ & $\begin{array}{l}610 \\
570 \\
570 \\
560 \\
560\end{array}$ & $\begin{array}{l}580 \\
560 \\
560 \\
550 \\
540\end{array}$ & $\begin{array}{l}860 \\
820 \\
800 \\
800 \\
830\end{array}$ & $\begin{array}{l}2460 \\
2440 \\
2400 \\
2330 \\
2220\end{array}$ & $\begin{array}{l}774 \\
762 \\
743 \\
756 \\
807\end{array}$ & $\begin{array}{l}762 \\
681 \\
636 \\
624 \\
598\end{array}$ & $\begin{array}{l}723 \\
672 \\
626 \\
616 \\
783\end{array}$ & $\begin{array}{l}546 \\
572 \\
611 \\
672 \\
686\end{array}$ & $\begin{array}{l}513 \\
499 \\
480 \\
483 \\
509\end{array}$ \\
\hline $\begin{array}{l}21 \\
22 \\
23 \\
24 \\
25\end{array}$ & $\begin{array}{l}1280 \\
1210 \\
1150 \\
1100 \\
1050\end{array}$ & $\begin{array}{l}680 \\
700 \\
720 \\
780 \\
880\end{array}$ & $\begin{array}{l}660 \\
680 \\
675 \\
670 \\
660\end{array}$ & $\begin{array}{l}560 \\
560 \\
550 \\
540 \\
520\end{array}$ & $\begin{array}{l}540 \\
540 \\
540 \\
560 \\
560\end{array}$ & $\begin{array}{r}900 \\
1000 \\
1150 \\
1280 \\
1570\end{array}$ & $\begin{array}{l}2090 \\
1990 \\
1970 \\
1970 \\
1920\end{array}$ & $\begin{array}{l}878 \\
903 \\
888 \\
863 \\
847\end{array}$ & $\begin{array}{l}581 \\
554 \\
532 \\
511 \\
504\end{array}$ & $\begin{array}{l}1000 \\
1130 \\
1250 \\
1280 \\
1140\end{array}$ & $\begin{array}{l}670 \\
678 \\
684 \\
660 \\
617\end{array}$ & $\begin{array}{l}551 \\
575 \\
575 \\
557 \\
536\end{array}$ \\
\hline $\begin{array}{l}26 \\
27 \\
28 \\
29 \\
30 \\
31\end{array}$ & $\begin{array}{r}1020 \\
986 \\
963 \\
948 \\
930 \\
911\end{array}$ & $\begin{array}{l}920 \\
910 \\
900 \\
860 \\
820 \\
---\end{array}$ & $\begin{array}{l}660 \\
650 \\
645 \\
640 \\
640 \\
640\end{array}$ & $\begin{array}{l}510 \\
510 \\
500 \\
500 \\
500 \\
500\end{array}$ & $\begin{array}{l}560 \\
560 \\
560 \\
--- \\
--- \\
---\end{array}$ & $\begin{array}{l}1920 \\
2200 \\
2410 \\
2530 \\
2510 \\
2450\end{array}$ & $\begin{array}{l}1820 \\
1710 \\
1610 \\
1530 \\
1440 \\
---\end{array}$ & $\begin{array}{r}842 \\
866 \\
945 \\
1000 \\
973 \\
898\end{array}$ & $\begin{array}{l}525 \\
585 \\
588 \\
559 \\
531 \\
---\end{array}$ & $\begin{array}{l}984 \\
863 \\
777 \\
718 \\
678 \\
645\end{array}$ & $\begin{array}{l}579 \\
548 \\
529 \\
517 \\
513 \\
517\end{array}$ & $\begin{array}{l}519 \\
508 \\
496 \\
488 \\
488\end{array}$ \\
\hline $\begin{array}{l}\text { TOTAL } \\
\text { MEAN } \\
\text { MAX } \\
\text { MIN } \\
\text { CFSM } \\
\text { IN. }\end{array}$ & $\begin{array}{r}34316 \\
1107 \\
1590 \\
828 \\
1.01 \\
1.16\end{array}$ & $\begin{array}{r}24005 \\
800 \\
920 \\
680 \\
.73 \\
.81\end{array}$ & $\begin{array}{r}19070 \\
615 \\
760 \\
530 \\
.56 \\
.64\end{array}$ & $\begin{array}{r}18145 \\
585 \\
640 \\
500 \\
.53 \\
.61\end{array}$ & $\begin{array}{r}15540 \\
555 \\
600 \\
500 \\
.51 \\
.53\end{array}$ & $\begin{array}{r}35730 \\
1153 \\
2530 \\
580 \\
1.05 \\
1.21\end{array}$ & $\begin{array}{r}64920 \\
2164 \\
2590 \\
1440 \\
1.97 \\
2.20\end{array}$ & $\begin{array}{r}28104 \\
907 \\
1330 \\
743 \\
.83 \\
.95\end{array}$ & $\begin{array}{r}21047 \\
702 \\
907 \\
504 \\
.64 \\
.71\end{array}$ & $\begin{array}{r}21887 \\
706 \\
1280 \\
458 \\
.64 \\
.74\end{array}$ & $\begin{array}{r}18492 \\
597 \\
716 \\
508 \\
.54 \\
.63\end{array}$ & $\begin{array}{r}15018 \\
501 \\
575 \\
448 \\
.46 \\
.51\end{array}$ \\
\hline $\begin{array}{l}\text { CAL YR } \\
\text { WTR YR }\end{array}$ & $\begin{array}{l}1986 \\
1987\end{array}$ & $\begin{array}{l}A L \\
A L\end{array}$ & $\begin{array}{l}39 \\
74\end{array}$ & $\begin{array}{lr}\text { AN } & 1266 \\
\text { AN } & 867\end{array}$ & $\begin{array}{l}\text { MAX } \\
\text { MAX }\end{array}$ & $\begin{array}{l}9690 \\
2590\end{array}$ & $\begin{array}{l}\text { MIN } 499 \\
\text { MIN } 448\end{array}$ & $\begin{array}{l}\text { CFSM } \\
\text { CFSM }\end{array}$ & $\begin{array}{l}\text { IN } \\
\text { IN }\end{array}$ & $\begin{array}{l}15.63 \\
10.70\end{array}$ & & \\
\hline
\end{tabular}


LOCATION. --Lat $45^{\circ} 59^{\prime} 30^{\prime \prime}$, long $86^{\circ} 17^{\prime} 15^{\prime \prime}$, in SWl/4 NEl/4 sec.34, T.42 N., R.16 W., Schoolcraft

County, Hydrologic Unit 04060106 , on east shore, just upstream from highway bridge over outlet of Indian Lake, $2.0 \mathrm{mi}$ northwest of Manistique.

DRAINAGE AREA. $--302 \mathrm{mi}^{2}$.

PERIOD OF RECORD.--March 1938 to current year.

GAGE.--Water-stage recorder. Datum of gage is $608.66 \mathrm{ft}$ above National Geodetic Vertical Datum of 1929

(levels by Michigan Department of Natural Resources). Prior to July 9, 1942, nonrecording gage at site $0.5 \mathrm{mi}$ northwest at same datum.

REMARKS, --Indian Lake is regulated by two vertical lift gates in concrete and earth-fill dam 1.5 mi downstream from lake on outlet. Major inlets to Indian Lake are Silver Creek, Dufour Creek, Indian River, Dead Creek, Smith Creek and Big Spring. Streamflow records for Indian River (station 04057000), at lake outlet, were collected from March 1938 to September 1971; annual peak discharge $1972-82$. Established legal level; $613.27 \mathrm{ft}$, above NGVD. Surface area of lake is 8,660 acres.

EXTREMES FOR PERIOD OF RECORD.--Maximum daily gage height, 7.79 ft, June 24, 1943; minimum daily, 3.01 ft, Feb. 20, 1948 .

EXTREMES FOR CURRENT YEAR.--Maximum daily gage height, $4.84 \mathrm{ft}$, Oct. 1 ; minimum daily recorded, 3.18 ft, Jan. 29, but may have been lower during period of no gage-height record.

GAGE HEIGHT (FEET ABOVE DATUM), WATER YEAR OCTOBER 1986 TO SEPTEMBER 1987

\begin{tabular}{|c|c|c|c|c|c|c|c|c|c|c|c|c|}
\hline DAY & OCT & NOV & DEC & JAN & FEB & MAR & APR & MAY & JUN & JUL & AUG & SEP \\
\hline $\begin{array}{l}1 \\
2 \\
3 \\
4 \\
5\end{array}$ & $\begin{array}{l}4.84 \\
4.81 \\
4.78 \\
4.74 \\
4.75\end{array}$ & $\begin{array}{l}4.46 \\
4.44 \\
4.41 \\
4.37 \\
4.36\end{array}$ & $\begin{array}{l}3.71 \\
3.70 \\
3.73 \\
3.71 \\
3.66\end{array}$ & $\begin{array}{l}3.38 \\
3.37 \\
3.37 \\
3.36 \\
3.36\end{array}$ & $\begin{array}{l}3.23 \\
3.24 \\
3.26 \\
3.25 \\
3.25\end{array}$ & $\begin{array}{c}--- \\
--- \\
--- \\
--- \\
3.25\end{array}$ & $\begin{array}{l}3.70 \\
3.74 \\
3.74 \\
3.73 \\
3.73\end{array}$ & $\begin{array}{l}3.94 \\
3.94 \\
3.94 \\
3.95 \\
3.94\end{array}$ & $\begin{array}{l}4.13 \\
4.21 \\
4.27 \\
4.26 \\
4.25\end{array}$ & $\begin{array}{l}4.40 \\
4.39 \\
4.40 \\
4.41 \\
4.38\end{array}$ & $\begin{array}{l}4.39 \\
4.51 \\
4.58 \\
4.61 \\
4.57\end{array}$ & $\begin{array}{l}4.50 \\
4.46 \\
4.43 \\
4.42 \\
4.41\end{array}$ \\
\hline $\begin{array}{r}6 \\
7 \\
8 \\
9 \\
10\end{array}$ & $\begin{array}{l}4.69 \\
4.67 \\
4.68 \\
4.65 \\
4.62\end{array}$ & $\begin{array}{l}4.31 \\
4.24 \\
4.27 \\
4.27 \\
4.11\end{array}$ & $\begin{array}{l}3.66 \\
3.64 \\
3.61 \\
3.61 \\
3.60\end{array}$ & $\begin{array}{l}3.37 \\
3.37 \\
3.35 \\
3.34 \\
3.35\end{array}$ & $\begin{array}{r}3.24 \\
3.24 \\
-- \\
-- \\
---\end{array}$ & $\begin{array}{l}3.25 \\
3.26 \\
3.26 \\
3.27 \\
3.27\end{array}$ & $\begin{array}{l}3.75 \\
3.77 \\
3.81 \\
3.84 \\
3.88\end{array}$ & $\begin{array}{l}3.97 \\
3.96 \\
3.96 \\
4.00 \\
3.97\end{array}$ & $\begin{array}{l}4.23 \\
4.27 \\
4.38 \\
4.37 \\
4.34\end{array}$ & $\begin{array}{l}4.36 \\
4.36 \\
4.35 \\
4.35 \\
4.35\end{array}$ & $\begin{array}{l}4.55 \\
4.56 \\
4.53 \\
4.50 \\
4.50\end{array}$ & $\begin{array}{l}4.41 \\
4.39 \\
4.37 \\
4.37 \\
4.34\end{array}$ \\
\hline $\begin{array}{l}11 \\
12 \\
13 \\
14 \\
15\end{array}$ & $\begin{array}{l}4.60 \\
4.68 \\
4.73 \\
4.77 \\
4.77\end{array}$ & $\begin{array}{l}4.05 \\
3.75 \\
3.77 \\
3.87 \\
3.91\end{array}$ & $\begin{array}{l}3.56 \\
3.53 \\
3.49 \\
3.47 \\
3.45\end{array}$ & $\begin{array}{l}3.34 \\
3.33 \\
3.33 \\
3.33 \\
3.30\end{array}$ & $\begin{array}{l}--- \\
--- \\
--- \\
---\end{array}$ & $\begin{array}{l}3.26 \\
3.26 \\
3.26 \\
3.26 \\
3.25\end{array}$ & $\begin{array}{l}3.90 \\
3.93 \\
3.95 \\
3.96 \\
4.00\end{array}$ & $\begin{array}{l}3.97 \\
3.97 \\
3.95 \\
3.95 \\
3.96\end{array}$ & $\begin{array}{l}4.34 \\
4.38 \\
4.38 \\
4.39 \\
4.39\end{array}$ & $\begin{array}{l}4.36 \\
4.39 \\
4.42 \\
4.41 \\
4.38\end{array}$ & $\begin{array}{l}4.48 \\
4.47 \\
4.46 \\
4.47 \\
4.49\end{array}$ & $\begin{array}{l}4.33 \\
4.32 \\
4.35 \\
4.36 \\
4.34\end{array}$ \\
\hline $\begin{array}{l}16 \\
17 \\
18 \\
19 \\
20\end{array}$ & $\begin{array}{l}4.78 \\
4.77 \\
4.77 \\
4.76 \\
4.75\end{array}$ & $\begin{array}{l}3.93 \\
3.91 \\
3.91 \\
3.88 \\
3.89\end{array}$ & $\begin{array}{l}3.44 \\
3.44 \\
3.45 \\
3.45 \\
3.45\end{array}$ & $\begin{array}{l}3.29 \\
3.26 \\
3.24 \\
3.23 \\
3.22\end{array}$ & $\begin{array}{l}--- \\
--- \\
--- \\
--- \\
---\end{array}$ & $\begin{array}{l}3.25 \\
3.25 \\
3.24 \\
3.24 \\
3.24\end{array}$ & $\begin{array}{l}4.04 \\
4.05 \\
4.05 \\
4.05 \\
4.06\end{array}$ & $\begin{array}{l}3.94 \\
3.94 \\
3.92 \\
3.93 \\
3.95\end{array}$ & $\begin{array}{l}4.38 \\
4.36 \\
4.34 \\
4.35 \\
4.35\end{array}$ & $\begin{array}{l}4.37 \\
4.38 \\
4.38 \\
4.38 \\
4.41\end{array}$ & $\begin{array}{l}4.52 \\
4.58 \\
4.58 \\
4.60 \\
4.58\end{array}$ & $\begin{array}{l}4.31 \\
4.29 \\
4.29 \\
4.32 \\
4.38\end{array}$ \\
\hline $\begin{array}{l}21 \\
22 \\
23 \\
24 \\
25\end{array}$ & $\begin{array}{l}4.73 \\
4.72 \\
4.69 \\
4.66 \\
4.63\end{array}$ & $\begin{array}{l}3.87 \\
3.85 \\
3.85 \\
3.83 \\
3.82\end{array}$ & $\begin{array}{l}3.45 \\
3.43 \\
3.43 \\
3.42 \\
3.42\end{array}$ & $\begin{array}{l}3.23 \\
3.23 \\
3.27 \\
3.23 \\
3.21\end{array}$ & $\begin{array}{l}--- \\
--- \\
--- \\
--- \\
---\end{array}$ & $\begin{array}{l}3.25 \\
3.26 \\
3.28 \\
3.32 \\
3.38\end{array}$ & $\begin{array}{l}4.05 \\
4.03 \\
4.07 \\
4.05 \\
4.04\end{array}$ & $\begin{array}{l}3.96 \\
3.98 \\
3.99 \\
3.98 \\
3.98\end{array}$ & $\begin{array}{l}4.35 \\
4.35 \\
4.35 \\
4.34 \\
4.35\end{array}$ & $\begin{array}{l}4.43 \\
4.45 \\
4.48 \\
4.50 \\
4.50\end{array}$ & $\begin{array}{l}4.57 \\
4.60 \\
4.59 \\
4.56 \\
4.53\end{array}$ & $\begin{array}{l}4.43 \\
4.46 \\
4.49 \\
4.47 \\
4.45\end{array}$ \\
\hline $\begin{array}{l}26 \\
27 \\
28 \\
29 \\
30 \\
31\end{array}$ & $\begin{array}{l}4.60 \\
4.58 \\
4.56 \\
4.54 \\
4.49 \\
4.48\end{array}$ & $\begin{array}{r}3.81 \\
3.79 \\
3.77 \\
3.76 \\
3.73 \\
---\end{array}$ & $\begin{array}{l}3.41 \\
3.40 \\
3.39 \\
3.40 \\
3.40 \\
3.39\end{array}$ & $\begin{array}{l}3.19 \\
3.19 \\
3.19 \\
3.18 \\
3.22 \\
3.22\end{array}$ & $\begin{array}{l}--- \\
--- \\
--- \\
--- \\
--- \\
---\end{array}$ & $\begin{array}{l}3.41 \\
3.48 \\
3.53 \\
3.62 \\
3.65 \\
3.66\end{array}$ & $\begin{array}{l}4.02 \\
4.03 \\
4.02 \\
3.99 \\
3.95 \\
-\end{array}$ & $\begin{array}{l}3.99 \\
4.02 \\
4.05 \\
4.07 \\
4.08 \\
4.08\end{array}$ & $\begin{array}{c}4.40 \\
4.42 \\
4.43 \\
4.42 \\
4.43 \\
-.--\end{array}$ & $\begin{array}{l}4.50 \\
4.47 \\
4.46 \\
4.44 \\
4.43 \\
4.41\end{array}$ & $\begin{array}{l}4.51 \\
4.51 \\
4.50 \\
4.49 \\
4.51 \\
4.53\end{array}$ & $\begin{array}{l}4.44 \\
4.41 \\
4.41 \\
4.42 \\
4.43\end{array}$ \\
\hline $\begin{array}{l}\text { MEAN } \\
\text { MAX } \\
\text { MIN }\end{array}$ & $\begin{array}{l}4.69 \\
4.84 \\
4.48\end{array}$ & $\begin{array}{l}4.01 \\
4.46 \\
3.73\end{array}$ & $\begin{array}{l}3.51 \\
3.73 \\
3.39\end{array}$ & $\begin{array}{l}3.29 \\
3.38 \\
3.18\end{array}$ & $\begin{array}{l}--- \\
--- \\
---\end{array}$ & $\begin{array}{l}--- \\
--- \\
---\end{array}$ & $\begin{array}{l}3.93 \\
4.07 \\
3.70\end{array}$ & $\begin{array}{l}3.98 \\
4.08 \\
3.92\end{array}$ & $\begin{array}{l}4.34 \\
4.43 \\
4.13\end{array}$ & $\begin{array}{l}4.41 \\
4.50 \\
4.35\end{array}$ & $\begin{array}{l}4.53 \\
4.61 \\
4.39\end{array}$ & $\begin{array}{l}4.39 \\
4.50 \\
4.29\end{array}$ \\
\hline
\end{tabular}


04057510 STURGEON RIVER NEAR NAHMA JUNCTION, MI

LOCATION,--Lat $45^{\circ} 56^{\prime} 35^{\prime \prime}$, long $86^{\circ} 42^{\prime} 20^{\prime \prime}$, in SWl/4 SEl/4 sec.17, T.41 N., R.19 W., Delta County,

Hydrologic Unit 04030112 , Hiawatha National Forest, on left bank 30 ft upstream from bridge on Forest Service Road 2231, $500 \mathrm{ft}$ downstream from Mormon Creek, $0.1 \mathrm{mi}$ east of Federal Forest Highway 13 , and $3.2 \mathrm{mi}$ north of Nahma Junction.

DRAINAGE AREA. $--183 \mathrm{mi}^{2}$.

PERIOD OF RECORD.--October 1966 to current year.

GAGE.--Water-stage recorder. Datum of gage is $610.99 \mathrm{ft}$ above National Geodetic Vertical Datum of 1929.

REMARKS.--Estimated daily discharges: Nov. 12 to Mar. 24. Records good except for estimated daily

discharges, which are fair. Several measurements of water temperature were made during the year.

AVERAGE DISCHARGE. --21 years, $205 \mathrm{ft}^{3} / \mathrm{s}, 15.21 \mathrm{in} / \mathrm{yr}^{2}$

EXTREMES FOR PERIOD OF RECORD.--Maximum discharge, 2,120 ft $3 / \mathrm{s}$, Apr. 21, 1985, gage height, 11.50 ft; minimum, $35 \mathrm{ft}^{3} / \mathrm{s}$, Sept. 11, 12, 13, 14, 1976, gage height, $3.58 \mathrm{ft}$.

EXTREMES FOR CURRENT YEAR.--Maximum discharge, $424 \mathrm{ft}^{3} / \mathrm{s}$, Oct. 13, gage height, $5.65 \mathrm{ft}$; minimum, $58 \mathrm{ft}^{3} / \mathrm{s}$, Sept. 11, gage height, $3.80 \mathrm{ft}$.

DISCHARGE, IN CUBIC FEET PER SECOND, WATER YEAR OCTOBER 1986 TO SEPTEMBER 1987

\begin{tabular}{|c|c|c|c|c|c|c|c|c|c|c|c|c|}
\hline DAY & OCT & NOV & DEC & JAN & FEB & MAR & APR & MAY & JUN & JUL & AUG & SEP \\
\hline $\begin{array}{l}1 \\
2 \\
3 \\
4 \\
5\end{array}$ & $\begin{array}{l}216 \\
185 \\
175 \\
167 \\
152\end{array}$ & $\begin{array}{l}135 \\
133 \\
130 \\
129 \\
124\end{array}$ & $\begin{array}{l}86 \\
80 \\
74 \\
70 \\
66\end{array}$ & $\begin{array}{l}72 \\
72 \\
72 \\
72 \\
72\end{array}$ & $\begin{array}{l}64 \\
64 \\
66 \\
66 \\
68\end{array}$ & $\begin{array}{l}66 \\
68 \\
68 \\
70 \\
74\end{array}$ & $\begin{array}{l}209 \\
209 \\
197 \\
185 \\
215\end{array}$ & $\begin{array}{l}142 \\
133 \\
123 \\
116 \\
110\end{array}$ & $\begin{array}{l}156 \\
230 \\
273 \\
206 \\
169\end{array}$ & $\begin{array}{l}69 \\
65 \\
82 \\
82 \\
72\end{array}$ & $\begin{array}{r}96 \\
225 \\
223 \\
172 \\
139\end{array}$ & $\begin{array}{l}69 \\
69 \\
67 \\
65 \\
62\end{array}$ \\
\hline $\begin{array}{r}6 \\
7 \\
8 \\
9 \\
10\end{array}$ & $\begin{array}{l}146 \\
140 \\
221 \\
234 \\
190\end{array}$ & $\begin{array}{l}121 \\
119 \\
120 \\
121 \\
116\end{array}$ & $\begin{array}{l}64 \\
62 \\
60 \\
60 \\
60\end{array}$ & $\begin{array}{l}72 \\
72 \\
72 \\
72 \\
72\end{array}$ & $\begin{array}{l}68 \\
70 \\
70 \\
70 \\
70\end{array}$ & $\begin{array}{r}82 \\
100 \\
125 \\
140 \\
135\end{array}$ & $\begin{array}{l}279 \\
350 \\
386 \\
387 \\
385\end{array}$ & $\begin{array}{r}105 \\
99 \\
95 \\
91 \\
87\end{array}$ & $\begin{array}{l}141 \\
134 \\
135 \\
118 \\
105\end{array}$ & $\begin{array}{l}67 \\
65 \\
61 \\
60 \\
63\end{array}$ & $\begin{array}{r}122 \\
111 \\
101 \\
95 \\
95\end{array}$ & $\begin{array}{l}65 \\
68 \\
64 \\
62 \\
60\end{array}$ \\
\hline $\begin{array}{l}11 \\
12 \\
13 \\
14 \\
15\end{array}$ & $\begin{array}{l}165 \\
267 \\
415 \\
369 \\
337\end{array}$ & $\begin{array}{r}112 \\
100 \\
98 \\
96 \\
94\end{array}$ & $\begin{array}{l}60 \\
60 \\
60 \\
60 \\
60\end{array}$ & $\begin{array}{l}72 \\
72 \\
72 \\
72 \\
72\end{array}$ & $\begin{array}{l}70 \\
70 \\
70 \\
68 \\
68\end{array}$ & $\begin{array}{l}130 \\
125 \\
115 \\
115 \\
110\end{array}$ & $\begin{array}{l}379 \\
363 \\
338 \\
319 \\
329\end{array}$ & $\begin{array}{l}86 \\
84 \\
81 \\
82 \\
84\end{array}$ & $\begin{array}{r}101 \\
118 \\
109 \\
97 \\
87\end{array}$ & $\begin{array}{r}95 \\
134 \\
168 \\
158 \\
136\end{array}$ & $\begin{array}{l}90 \\
84 \\
83 \\
98 \\
98\end{array}$ & $\begin{array}{l}59 \\
69 \\
73 \\
71 \\
69\end{array}$ \\
\hline $\begin{array}{l}16 \\
17 \\
18 \\
19 \\
20\end{array}$ & $\begin{array}{l}320 \\
299 \\
266 \\
238 \\
218\end{array}$ & $\begin{array}{l}92 \\
92 \\
92 \\
92 \\
94\end{array}$ & $\begin{array}{l}60 \\
62 \\
62 \\
64 \\
66\end{array}$ & $\begin{array}{l}72 \\
70 \\
68 \\
68 \\
66\end{array}$ & $\begin{array}{l}66 \\
66 \\
66 \\
66 \\
66\end{array}$ & $\begin{array}{l}105 \\
100 \\
100 \\
105 \\
110\end{array}$ & $\begin{array}{l}325 \\
307 \\
290 \\
266 \\
240\end{array}$ & $\begin{array}{l}80 \\
77 \\
76 \\
82 \\
89\end{array}$ & $\begin{array}{l}79 \\
73 \\
69 \\
71 \\
80\end{array}$ & $\begin{array}{r}118 \\
105 \\
96 \\
120 \\
225\end{array}$ & $\begin{array}{l}101 \\
125 \\
114 \\
119 \\
115\end{array}$ & $\begin{array}{r}67 \\
68 \\
69 \\
96 \\
129\end{array}$ \\
\hline $\begin{array}{l}21 \\
22 \\
23 \\
24 \\
25\end{array}$ & $\begin{array}{l}204 \\
192 \\
179 \\
169 \\
160\end{array}$ & $\begin{array}{r}96 \\
98 \\
105 \\
110 \\
110\end{array}$ & $\begin{array}{l}68 \\
70 \\
74 \\
74 \\
72\end{array}$ & $\begin{array}{l}64 \\
64 \\
62 \\
62 \\
62\end{array}$ & $\begin{array}{l}64 \\
64 \\
64 \\
64 \\
66\end{array}$ & $\begin{array}{l}120 \\
150 \\
170 \\
200 \\
266\end{array}$ & $\begin{array}{l}235 \\
232 \\
265 \\
272 \\
239\end{array}$ & $\begin{array}{l}87 \\
84 \\
81 \\
80 \\
76\end{array}$ & $\begin{array}{l}75 \\
71 \\
66 \\
62 \\
60\end{array}$ & $\begin{array}{l}246 \\
239 \\
213 \\
180 \\
153\end{array}$ & $\begin{array}{r}110 \\
108 \\
99 \\
92 \\
87\end{array}$ & $\begin{array}{l}162 \\
148 \\
128 \\
113 \\
102\end{array}$ \\
\hline $\begin{array}{l}26 \\
27 \\
28 \\
29 \\
30 \\
31\end{array}$ & $\begin{array}{l}153 \\
149 \\
145 \\
143 \\
139 \\
133\end{array}$ & $\begin{array}{r}110 \\
105 \\
100 \\
97 \\
92 \\
---\end{array}$ & $\begin{array}{l}72 \\
72 \\
72 \\
72 \\
72 \\
72\end{array}$ & $\begin{array}{l}62 \\
62 \\
62 \\
62 \\
62 \\
62\end{array}$ & $\begin{array}{r}66 \\
66 \\
66 \\
--- \\
-- \\
--\end{array}$ & $\begin{array}{l}316 \\
322 \\
307 \\
287 \\
240 \\
222\end{array}$ & $\begin{array}{l}213 \\
200 \\
189 \\
171 \\
155 \\
---\end{array}$ & $\begin{array}{l}81 \\
93 \\
91 \\
85 \\
80 \\
81\end{array}$ & $\begin{array}{r}65 \\
102 \\
99 \\
86 \\
77 \\
---\end{array}$ & $\begin{array}{r}134 \\
122 \\
113 \\
106 \\
101 \\
97\end{array}$ & $\begin{array}{l}83 \\
79 \\
76 \\
75 \\
75 \\
72\end{array}$ & $\begin{array}{r}94 \\
88 \\
86 \\
84 \\
84 \\
-\end{array}$ \\
\hline $\begin{array}{l}\text { TOTAL } \\
\text { MEAN } \\
\text { MAX } \\
\text { MIN } \\
\text { CFSM } \\
\text { IN. }\end{array}$ & $\begin{array}{r}6486 \\
209 \\
415 \\
133 \\
1.14 \\
1.32\end{array}$ & $\begin{array}{r}3233 \\
108 \\
135 \\
92 \\
.59 \\
.66\end{array}$ & $\begin{array}{r}2086 \\
67.3 \\
86 \\
60 \\
.37 \\
.42\end{array}$ & $\begin{array}{r}2110 \\
68.1 \\
72 \\
62 \\
.37 \\
.43\end{array}$ & $\begin{array}{r}1872 \\
66.9 \\
70 \\
64 \\
.37 \\
.38\end{array}$ & $\begin{array}{r}4643 \\
150 \\
322 \\
66 \\
.82 \\
.94\end{array}$ & $\begin{array}{r}8129 \\
271 \\
387 \\
155 \\
1.48 \\
1.65\end{array}$ & $\begin{array}{r}2841 \\
91.6 \\
142 \\
76 \\
.50 \\
.58\end{array}$ & $\begin{array}{r}3314 \\
110 \\
273 \\
60 \\
.60 \\
.67\end{array}$ & $\begin{array}{r}3745 \\
121 \\
246 \\
60 \\
.66 \\
.76\end{array}$ & $\begin{array}{r}3362 \\
108 \\
225 \\
72 \\
.59 \\
.68\end{array}$ & $\begin{array}{r}2510 \\
83.7 \\
162 \\
59 \\
.46 \\
.51\end{array}$ \\
\hline
\end{tabular}

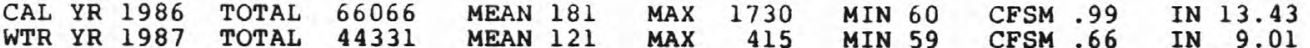




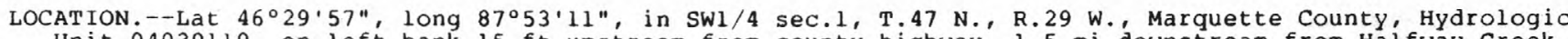
Unit 04030110 , on left bank $15 \mathrm{ft}$ upstream from county highway, $1.5 \mathrm{mi}$ downstream from Halfway Creek, and $0.3 \mathrm{mi}$ north of Humboldt.

DRAINAGE AREA. $--46.0 \mathrm{mi}^{2}$.

PERIOD OF RECORD.--June 1959 to current year.

REVISED RECORDS.--WSP 1911: Drainage area.

GAGE.--Water-stage recorder. V-notch sharp-crested weir since Oct. 3, 1960. Datum of gage is $1,521.20$ ft above National Geodetic Vertical Datum of 1929 (Cleveland-Cliffs Iron Co. bench mark). Prior to Sept. 1 , 1960, nonrecording gage at same site and datum.

REMARKS.--Estimated daily discharges: Oct. 7-22, Mar. 30 to Apr. 5. Records good except for period of ice effect, Mar. 30 to Apr. 5, which is fair and period of indefinite stage-discharge relation, Oct. 722, which is poor. From July 1960 to June 1972, some diversion 100 ft upstream by industry for iron ore processing; figures of runoff adjusted. Several measurements of water temperature were made during the year.

AVERAGE DISCHARGE. - -28 years, $61.6 \mathrm{ft}^{3} / \mathrm{s}, 18.19 \mathrm{in} / \mathrm{yr}$, adjusted for diversion 1960 to 1972 .

EXTREMES FOR PERIOD OF RECORD.--Maximum discharge, 1,930 ft $3 / \mathrm{s}$, Apr. 20, 1985, gage height, $9.21 \mathrm{ft}$; minimum, $4.0 \mathrm{ft}^{3} / \mathrm{s}$, Sept. 12, 1976; minimum gage height, 1.07 ft, Aug. $24,1960$.

EXTREMES FOR CURRENT YEAR.--Maximum discharge, $228 \mathrm{ft}^{3} / \mathrm{s}$, Oct. 13, gage height, $4.24 \mathrm{ft} ; \mathrm{minimum,}$

$7.6 \mathrm{ft}^{3} / \mathrm{s}$, Sept. 10, 11; minimum gage height, $1.69 \mathrm{ft}$, July 1,2 .

DISCHARGE, IN CUBIC FEET PER SECOND, WATER YEAR OCTOBER 1986 TO SEPTEMBER 1987 MEAN VALUES

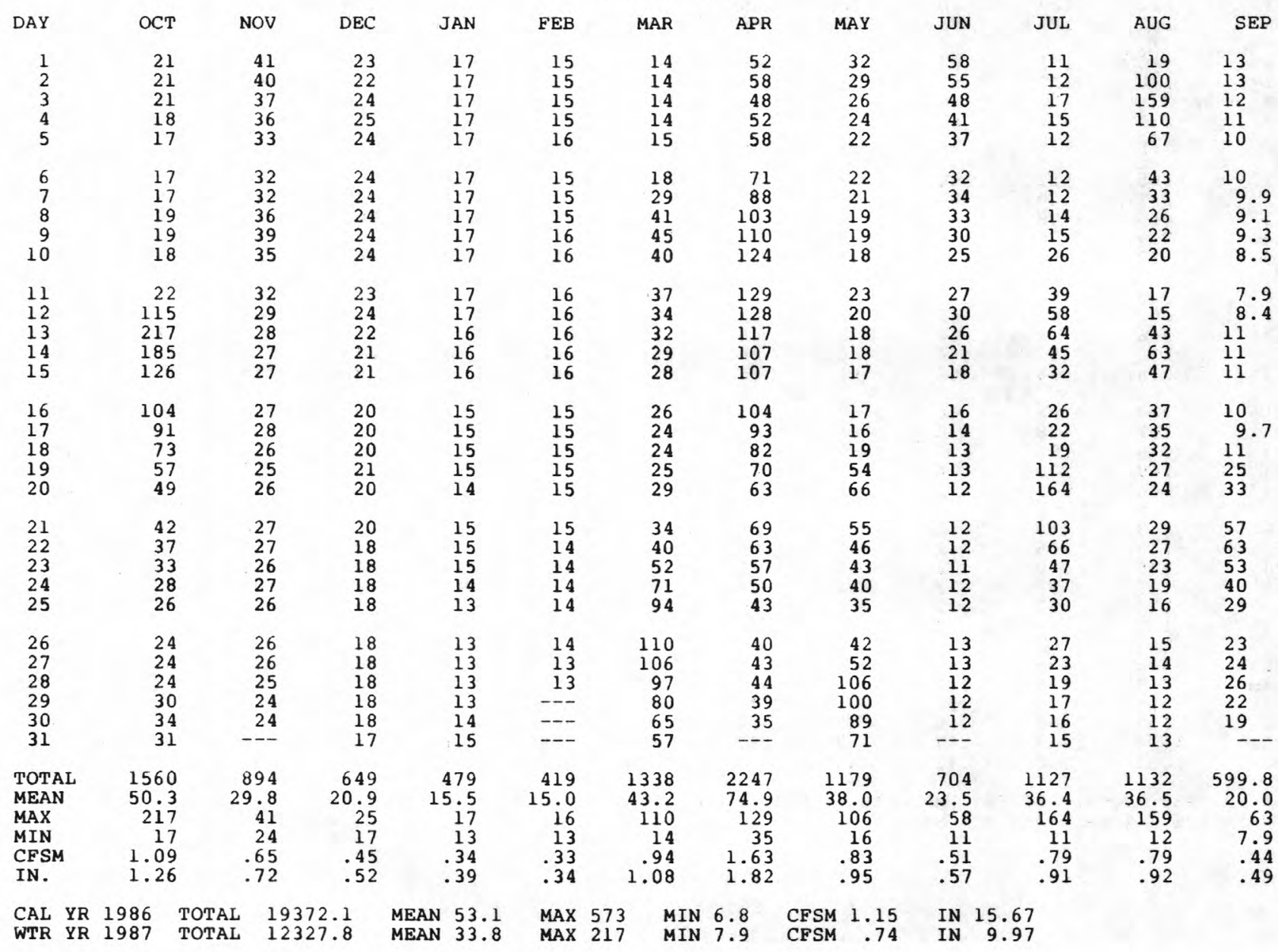




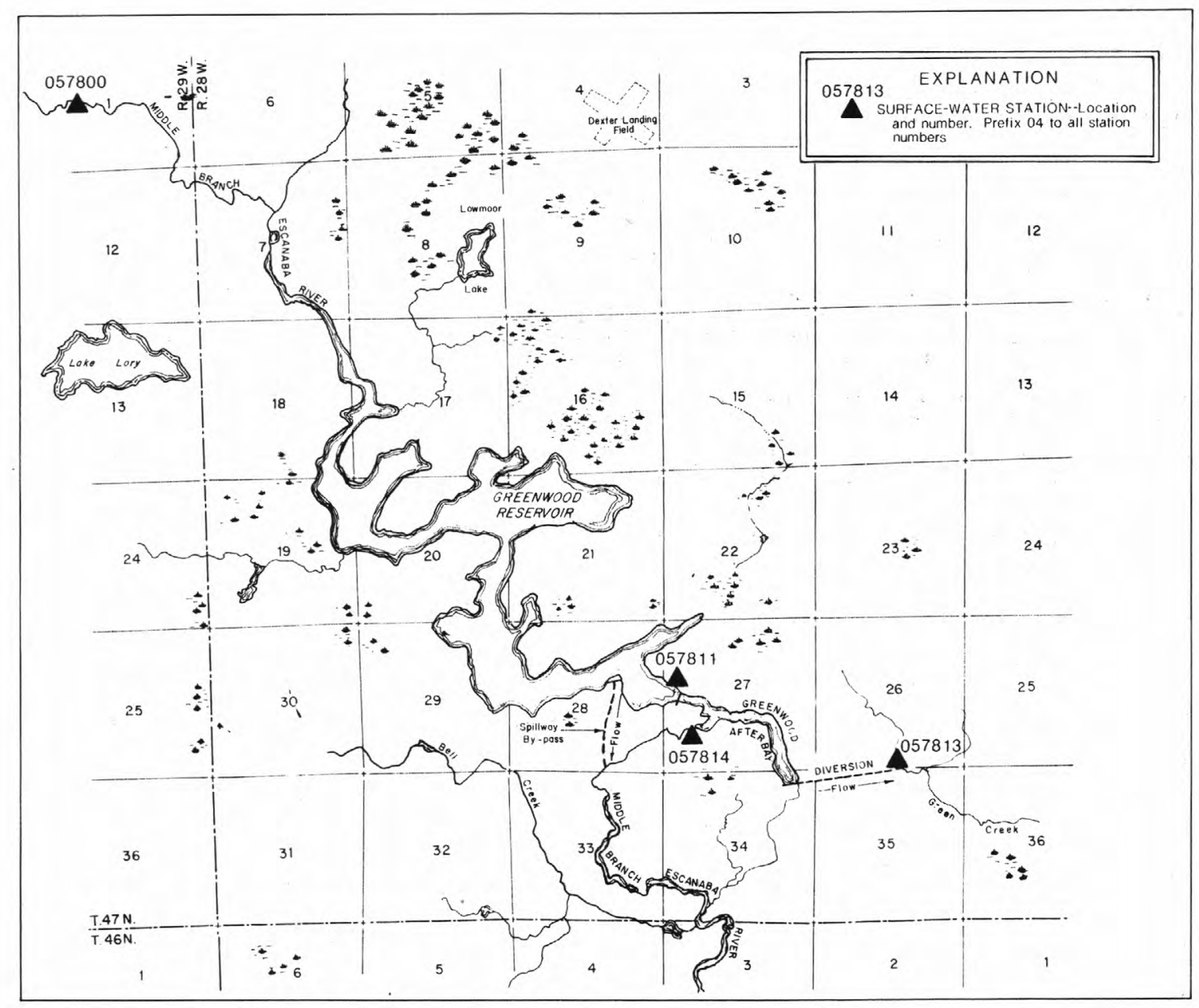

Figure 8.--Identification number and location of active surface-water gaging stations in and around the Greenwood Reservoir complex. 
LOCATION.--Lat $46^{\circ} 26^{\prime} 32^{\prime \prime}$, long $87^{\circ} 48^{\prime} 02^{\prime \prime}$, in NWl/4 SWl $/ 4$ sec. 27, T. 47 N., R. 28 W., Marquette County, Hydrologic Unit 04030110 , at downstream side of dam on Middle Branch Escanaba River, 3.7 mi southwest of Greenwood.

DRA INAGE AREA. $--67.4 \mathrm{mi}^{2}$.

PERIOD OF RECORD.--December 1972 to current year.

GAGE.--Water-stage recorder. Datum of gage is $1,400.00 \mathrm{ft}$ above National Geodetic Vertical Datum of 1929 (levels by Cleveland-Cliffs Iron Co.); gage readings have been converted to elevations NGVD. Prior to Feb. 20, 1973, nonrecording gage at same site and datum.

REMARKS. - The reservoir is formed by an earth/rockfill main dam and several earthfill dikes surrounding the storage area. Storage began Dec. 22, 1972. The fixed-crest concrete spillway was completed in September 1973. The usable capacity of the reservoir is 23,300 acre-ft at spillway elevation 1 , 515 ft. Above elevation $1,515 \mathrm{ft}$, water flows over concrete spillway into Middle Branch Escanaba River about 2,000 ft downstream from Greenwood Release (station 04057814). The main dam is equipped with an outlet structure with 4 valves to control flow to afterbay (conservation pool) which has a capacity of 420 acre-ft at elevation $1,480 \mathrm{ft}$. Two outlet systems from the afterbay provide for diversion and release flow. Diverted flow to Green Creek gaged at Greenwood Diversion (station 04057813 ); released flow to Middie Branch Escanaba River gaged at Greenwood Release (station 04057814). Reservoir impounds water for diversion to Schweitzer Reservoir (station 04058190), for use in iron ore processing.

EXTREMES FOR PERIOD OF RECORD.--Maximum contents, 26,520 acre-ft, Apr. 21, 22, 23, 1985, elevation, $1,517.3 \mathrm{ft}$; minimum since first filling, 3,240 acre-ft, Mar. 12, 1977, elevation, 1,491.1 ft.

EXTREMES FOR CURRENT YEAR.--Maximum contents, 21,090 acre-ft, June 12-16, elevation, 1,513.3 ft; minimum, 13,600 acre-ft, Mar. 6, 7, elevation, $1,506.6 \mathrm{ft}$.

MONTHEND ELEVATION, IN FEET NGVD, AND CONTENTS AT 2400, WATER YEAR OCTOBER 1986 TO SEPTEMBER 1987

Date

Sept. 30 . . . . . . . . . . . . . . . .

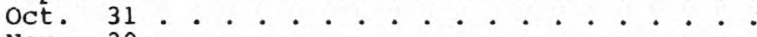

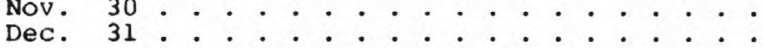

CAL YR 1986 . . . . . . . . . . . . . .

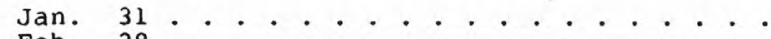

Feb. 28 . . . . . . . . . . • . .

Mar. $31 \cdot \cdot \cdot \cdot \cdot \cdot \cdot \cdot \cdot \cdot \cdot \cdot \cdot \cdot \cdot \cdot \cdot \cdot \cdot \cdot$

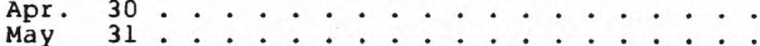

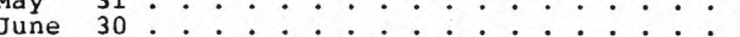

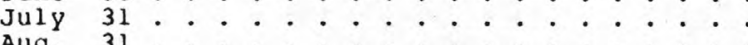

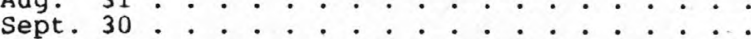

WTR YR 1987
Elevation
(feet)

$1,509.8$

$1,511.6$

$1,511.4$

$1,510.3$

-

$1,508.5$

$1,506.8$

$1,508.4$

$1,512.4$

$1,512.8$

$1,512.3$

$1,511.9$

$1,511.6$

$1,510.2$

Contents
(acre-feet
16,880
19,020
18,780
17,460
--
15,500
13,800
15,400
19,980
20,460
19,860
19,380
19,020
17,340

$--$
Change in contents (acre- (equivalent
feet)

-1,
$+2,140$
-240
$-1,320$
$-5,980$
$-1,960$
$-1,700$
$+1,600$
$+4,580$
+480
-600
-480
-360
$-1,680$
+460

$+34.8$

$-4.0$

$-21.5$

$-8.3$

$-31.9$

$-30.6$

$+26.0$

$+77.0$

$+7.8$

-10.1
-7.8

$-5.9$

$-28.2$

$+0.6$ 
04057813 GREENWOOD DIVERSION NEAR GREENWOOD, MI

LOCATION.--Lat $46^{\circ} 26^{\circ} 04^{\prime \prime}$, long $87^{\circ} 46^{\prime} 10^{\prime \prime}$, in NWl/4 NEl/4 sec.35, T. 47 N., R. 28 W. , Marquette County, Hydrologic Unit 04030110 , on left bank at downstream end of pipeline, $200 \mathrm{ft}$ upstream from Green Creek, $0.7 \mathrm{mi}$ downstream from Greenwood Afterbay, and $3.6 \mathrm{mi}$ south of Greenwood.

PERIOD OF RECORD.--December 1972 to current year.

GAGE.--Water-stage recorder and concrete flume. Datum of gage is $1,454.57$ ft above National Geodetic Vertical Datum of 1929 (Cleveland-Cliffs Iron Co. bench mark). Prior to Aug. 22, 1973 , nonrecording gage at same site and datum.

REMARKS.--No estimated daily discharges. Records excellent. Flow completely regulated. A pipeline, 0.7 $\mathrm{mi}$ long, diverts water from Greenwood Reservoir (station 04057811) into Green Creek, tributary to Schweitzer Reservoir (station 04058190). Water is used for iron ore processing: some returned to Middle Branch Escanaba River $27 \mathrm{mi}$ downstream via another Green Creek; some returned $31 \mathrm{mi}$ downstream via Goose Lake Outlet and East Branch Escanaba River. Several measurements of water temperature were made during the year.

EXTREMES FOR PERIOD OF RECORD.--Maximum daily discharge, $30 \mathrm{ft}^{3} / \mathrm{s}, \mathrm{June} 25-28,1977$, NOV. 9, 1979; no flow Dec. 27, 1972 to Jan. 6, 1973; minimum daily discharge since diversion began, 0.01 ft $3 / \mathrm{s}$, Apr. 16, 17, 1987 .

DISCHARGE, IN CUBIC FEET PER SECOND, WATER YEAR OCTOBER 1986 TO SEPTEMBER 1987 MEAN VALUES

\begin{tabular}{|c|c|c|c|c|c|c|c|c|c|c|c|c|}
\hline DAY & OCT & NOV & DEC & JAN & FEB & MAR & APR & MAY & JUN & JUL & AUG & SEP \\
\hline $\begin{array}{l}1 \\
2 \\
3 \\
4 \\
5\end{array}$ & $\begin{array}{l}24 \\
23 \\
23 \\
23 \\
23\end{array}$ & $\begin{array}{l}12 \\
12 \\
12 \\
12 \\
12\end{array}$ & $\begin{array}{ll}1 & 1 \\
1 & 1 \\
1 & 1 \\
14 \\
21\end{array}$ & $\begin{array}{l}23 \\
23 \\
23 \\
23 \\
23\end{array}$ & $\begin{array}{l}23 \\
23 \\
23 \\
23 \\
23\end{array}$ & $\begin{array}{c}16 \\
13 \\
9.1 \\
10 \\
10\end{array}$ & $\begin{array}{l}2.6 \\
2.6 \\
2.6 \\
2.6 \\
2.6\end{array}$ & $\begin{array}{l}16 \\
18 \\
19 \\
20 \\
22\end{array}$ & $\begin{array}{l}6.0 \\
2.9 \\
1.3 \\
.02 \\
.02\end{array}$ & $\begin{array}{l}23 \\
23 \\
23 \\
23 \\
23\end{array}$ & $\begin{array}{l}23 \\
24 \\
24 \\
23 \\
23\end{array}$ & $\begin{array}{l}24 \\
24 \\
24 \\
24 \\
23\end{array}$ \\
\hline $\begin{array}{r}6 \\
7 \\
8 \\
9 \\
10\end{array}$ & $\begin{array}{l}23 \\
24 \\
24 \\
23 \\
23\end{array}$ & $\begin{array}{l}12 \\
12 \\
12 \\
12 \\
12\end{array}$ & $\begin{array}{l}23 \\
23 \\
23 \\
23 \\
23\end{array}$ & $\begin{array}{l}23 \\
20 \\
22 \\
24 \\
24\end{array}$ & $\begin{array}{l}23 \\
23 \\
23 \\
23 \\
23\end{array}$ & $\begin{array}{r}10 \\
10 \\
11 \\
9.9 \\
8.9\end{array}$ & $\begin{array}{l}2.6 \\
2.6 \\
.83 \\
.02 \\
.02\end{array}$ & $\begin{array}{l}23 \\
23 \\
23 \\
23 \\
23\end{array}$ & $\begin{array}{l}.02 \\
.02 \\
.02 \\
.02 \\
3.3\end{array}$ & $\begin{array}{l}23 \\
23 \\
23 \\
23 \\
23\end{array}$ & $\begin{array}{l}23 \\
23 \\
23 \\
24 \\
24\end{array}$ & $\begin{array}{l}23 \\
23 \\
23 \\
23 \\
23\end{array}$ \\
\hline $\begin{array}{l}11 \\
12 \\
13 \\
14 \\
15\end{array}$ & $\begin{array}{l}23 \\
24 \\
24 \\
22 \\
20\end{array}$ & $\begin{array}{l}12 \\
12 \\
11 \\
11 \\
11\end{array}$ & $\begin{array}{l}23 \\
23 \\
23 \\
23 \\
23\end{array}$ & $\begin{array}{l}23 \\
23 \\
23 \\
23 \\
23\end{array}$ & $\begin{array}{l}23 \\
23 \\
23 \\
23 \\
23\end{array}$ & $\begin{array}{l}8.3 \\
7.5 \\
7.5 \\
7.5 \\
7.5\end{array}$ & $\begin{array}{l}.02 \\
.02 \\
.02 \\
.02 \\
.02\end{array}$ & $\begin{array}{l}23 \\
23 \\
23 \\
23 \\
23\end{array}$ & $\begin{array}{l}6.8 \\
8.3 \\
10 \\
10 \\
10\end{array}$ & $\begin{array}{l}23 \\
23 \\
23 \\
23 \\
23\end{array}$ & $\begin{array}{l}24 \\
24 \\
24 \\
23 \\
23\end{array}$ & $\begin{array}{l}23 \\
23 \\
23 \\
23 \\
23\end{array}$ \\
\hline $\begin{array}{l}16 \\
17 \\
18 \\
19 \\
20\end{array}$ & $\begin{array}{l}17 \\
12 \\
12 \\
12 \\
12\end{array}$ & $\begin{array}{l}11 \\
11 \\
11 \\
11 \\
11\end{array}$ & $\begin{array}{l}23 \\
23 \\
23 \\
23 \\
23\end{array}$ & $\begin{array}{l}23 \\
23 \\
23 \\
23 \\
23\end{array}$ & $\begin{array}{l}23 \\
23 \\
23 \\
23 \\
23\end{array}$ & $\begin{array}{l}7.5 \\
7.4 \\
7.4 \\
7.5 \\
7.5\end{array}$ & $\begin{array}{l}.01 \\
.01 \\
.02 \\
.02 \\
6.8\end{array}$ & $\begin{array}{l}23 \\
23 \\
23 \\
22 \\
20\end{array}$ & $\begin{array}{l}13 \\
15 \\
18 \\
20 \\
23\end{array}$ & $\begin{array}{l}23 \\
23 \\
23 \\
23 \\
23\end{array}$ & $\begin{array}{l}23 \\
23 \\
24 \\
23 \\
23\end{array}$ & $\begin{array}{l}23 \\
23 \\
23 \\
23 \\
23\end{array}$ \\
\hline $\begin{array}{l}21 \\
22 \\
23 \\
24 \\
25\end{array}$ & $\begin{array}{l}12 \\
12 \\
12 \\
12 \\
12\end{array}$ & $\begin{array}{l}11 \\
11 \\
11 \\
11 \\
11\end{array}$ & $\begin{array}{l}23 \\
23 \\
23 \\
23 \\
23\end{array}$ & $\begin{array}{l}23 \\
23 \\
23 \\
23 \\
23\end{array}$ & $\begin{array}{l}23 \\
23 \\
23 \\
23 \\
23\end{array}$ & $\begin{array}{l}7.5 \\
7.5 \\
5.9 \\
5.0 \\
2.7\end{array}$ & $\begin{array}{l}11 \\
11 \\
11 \\
11 \\
11\end{array}$ & $\begin{array}{l}17 \\
15 \\
13 \\
13 \\
13\end{array}$ & $\begin{array}{l}23 \\
23 \\
23 \\
23 \\
23\end{array}$ & $\begin{array}{l}23 \\
23 \\
23 \\
23 \\
23\end{array}$ & $\begin{array}{l}24 \\
23 \\
24 \\
24 \\
24\end{array}$ & $\begin{array}{l}23 \\
23 \\
23 \\
23 \\
23\end{array}$ \\
\hline $\begin{array}{l}26 \\
27 \\
28 \\
29 \\
30 \\
31\end{array}$ & $\begin{array}{l}12 \\
12 \\
12 \\
12 \\
12 \\
12\end{array}$ & $\begin{array}{l}11 \\
11 \\
11 \\
11 \\
11 \\
---\end{array}$ & $\begin{array}{l}23 \\
23 \\
23 \\
23 \\
23 \\
23\end{array}$ & $\begin{array}{l}23 \\
23 \\
23 \\
23 \\
23 \\
23\end{array}$ & $\begin{array}{r}19 \\
16 \\
16 \\
--- \\
---\end{array}$ & $\begin{array}{c}1.5 \\
.69 \\
.02 \\
.02 \\
.02 \\
1.0\end{array}$ & $\begin{array}{l}11 \\
11 \\
13 \\
15 \\
15\end{array}$ & $\begin{array}{r}13 \\
13 \\
14 \\
11 \\
8.7 \\
8.8\end{array}$ & $\begin{array}{l}23 \\
23 \\
23 \\
23 \\
23 \\
\end{array}$ & $\begin{array}{l}23 \\
23 \\
23 \\
23 \\
23 \\
23\end{array}$ & $\begin{array}{l}24 \\
24 \\
24 \\
24 \\
24 \\
24\end{array}$ & $\begin{array}{l}23 \\
23 \\
23 \\
23 \\
16 \\
-\end{array}$ \\
\hline $\begin{array}{l}\text { TOTAL } \\
\text { MEAN } \\
\text { MAX } \\
\text { MIN }\end{array}$ & $\begin{array}{r}543 \\
17.5 \\
24 \\
12\end{array}$ & $\begin{array}{r}342 \\
11.4 \\
12 \\
11\end{array}$ & $\begin{array}{r}666 \\
21.5 \\
23 \\
11\end{array}$ & $\begin{array}{r}711 \\
22.9 \\
24 \\
20\end{array}$ & $\begin{array}{r}626 \\
22.4 \\
23 \\
16\end{array}$ & $\begin{array}{r}215.35 \\
6.95 \\
16 \\
.02\end{array}$ & $\begin{array}{r}146.03 \\
4.87 \\
15 \\
.01\end{array}$ & $\begin{array}{r}575.5 \\
18.6 \\
23 \\
8.7\end{array}$ & $\begin{array}{r}377.72 \\
12.6 \\
23 \\
.02\end{array}$ & $\begin{array}{r}713 \\
23.0 \\
23 \\
23\end{array}$ & $\begin{array}{r}731 \\
23.6 \\
24 \\
23\end{array}$ & $\begin{array}{r}687 \\
22.9 \\
24 \\
16\end{array}$ \\
\hline
\end{tabular}

CAL YR 1986 TOTAL 5674.00 MEAN 15.5 MAX 25 MIN 2.5

WTR YR 1987 TOTAL 6333.60 MEAN 17.4 MAX 24 MIN .0I 
LOCATION.--Lat $46^{\circ} 26^{\prime} 22^{\prime \prime}$, long $87^{\circ} 47^{\prime} 52^{\prime \prime}$, in NW1/4 SWl/4 sec. 27, T. 47 N., R. 28 W., Marquette County, Hydrologic Unit 04030110 , on left bank at outlet of Greenwood Afterbay releasing to Middle Branch Escanaba River, $2.6 \mathrm{mi}$ upstream from Bell Creek and $3.8 \mathrm{mi}$ southwest of Greenwood.

DRAINAGE AREA. $--67.4 \mathrm{mi}^{2}$.

PERIOD OF RECORD,--October 1972 to current year.

GAGE. - Water-stage recorder and concrete flume. Datum of gage is $1,473.77 \mathrm{ft}$ above National Geodetic Vertical Datum of 1929 (Cleveland-Cliffs Iron Co. bench mark). Prior to Nov. 7, 1973, nonrecording gage at same site and different datum.

REMARKS.--No estimated daily discharges. Records excellent. Since December 1972, flow from Greenwood Reservoir (station 04057811) below spillway elevation $1,515 \mathrm{ft}$ is completely regulated by the afterbay release structure into the Middle Branch Escanaba River. Since January 1973, water diverted immediately upstream from station via Greenwood Diversion (station 04057813) to Green Creek for iron ore processing and some returned to Middle Branch Escanaba River 27 mi downstream via another Green Creek. Since October 1979, some of the diversion returned 31 mi downstream via Goose Lake Outlet and East Branch Escanaba River. Overflow from reservoir spillway bypasses and returns to the Middle Branch Escanaba River $0.5 \mathrm{mi}$ downstream from station. Several measurements of water temperature were made during the year.

EXTREMES FOR PERIOD OF RECORD.--Maximum daily discharge (prior to regulation), 290 ft $3 / 5$, Oct. 1, 1972; (since regulation began), $63 \mathrm{ft}^{3} / \mathrm{s}, \mathrm{July} 10,11,1974$; minimum daily, $10 \mathrm{ft} / \mathrm{s}, \mathrm{Dec}$. $29,30,1972$, result of construction.

DISCHARGE, IN CUBIC FEET PER SECOND, WATER YEAR OCTOBER 1986 TO SEPTEMBER 1987 MEAN VALUES

\begin{tabular}{|c|c|c|c|c|c|c|c|c|c|c|c|}
\hline DAY & OCT & NOV & DEC & JAN & FEB & MAR & APR & MAY & JUN & JUL & AUG \\
\hline $\begin{array}{l}1 \\
2 \\
3 \\
4 \\
5\end{array}$ & $\begin{array}{l}24 \\
24 \\
24 \\
24 \\
24\end{array}$ & $\begin{array}{l}26 \\
26 \\
26 \\
26 \\
26\end{array}$ & $\begin{array}{l}24 \\
24 \\
25 \\
25 \\
25\end{array}$ & $\begin{array}{l}25 \\
25 \\
25 \\
24 \\
24\end{array}$ & $\begin{array}{l}25 \\
25 \\
25 \\
25 \\
25\end{array}$ & $\begin{array}{l}23 \\
23 \\
24 \\
24 \\
25\end{array}$ & $\begin{array}{l}24 \\
24 \\
23 \\
23 \\
22\end{array}$ & $\begin{array}{l}25 \\
25 \\
25 \\
25 \\
25\end{array}$ & $\begin{array}{l}26 \\
27 \\
26 \\
26 \\
26\end{array}$ & $\begin{array}{l}25 \\
25 \\
25 \\
25 \\
25\end{array}$ & $\begin{array}{l}25 \\
26 \\
26 \\
26 \\
26\end{array}$ \\
\hline $\begin{array}{r}6 \\
7 \\
8 \\
9 \\
10\end{array}$ & $\begin{array}{l}24 \\
24 \\
24 \\
24 \\
24\end{array}$ & $\begin{array}{l}26 \\
26 \\
26 \\
26 \\
26\end{array}$ & $\begin{array}{l}25 \\
25 \\
25 \\
25 \\
25\end{array}$ & $\begin{array}{l}24 \\
24 \\
25 \\
25 \\
25\end{array}$ & $\begin{array}{l}25 \\
25 \\
25 \\
25 \\
25\end{array}$ & $\begin{array}{l}25 \\
26 \\
26 \\
26 \\
26\end{array}$ & $\begin{array}{l}22 \\
22 \\
22 \\
22 \\
22\end{array}$ & $\begin{array}{l}25 \\
25 \\
25 \\
25 \\
25\end{array}$ & $\begin{array}{l}26 \\
26 \\
26 \\
26 \\
26\end{array}$ & $\begin{array}{l}25 \\
25 \\
26 \\
26 \\
26\end{array}$ & $\begin{array}{l}26 \\
26 \\
26 \\
26 \\
26\end{array}$ \\
\hline $\begin{array}{l}11 \\
12 \\
13 \\
14 \\
15\end{array}$ & $\begin{array}{l}24 \\
24 \\
24 \\
24 \\
24\end{array}$ & $\begin{array}{l}26 \\
26 \\
26 \\
26 \\
26\end{array}$ & $\begin{array}{l}25 \\
25 \\
25 \\
25 \\
25\end{array}$ & $\begin{array}{l}25 \\
24 \\
24 \\
24 \\
24\end{array}$ & $\begin{array}{l}25 \\
25 \\
25 \\
25 \\
25\end{array}$ & $\begin{array}{l}26 \\
26 \\
26 \\
26 \\
26\end{array}$ & $\begin{array}{l}23 \\
24 \\
24 \\
24 \\
24\end{array}$ & $\begin{array}{l}25 \\
25 \\
25 \\
25 \\
25\end{array}$ & $\begin{array}{l}25 \\
25 \\
24 \\
22 \\
22\end{array}$ & $\begin{array}{l}26 \\
26 \\
26 \\
25 \\
25\end{array}$ & $\begin{array}{l}25 \\
25 \\
25 \\
25 \\
25\end{array}$ \\
\hline $\begin{array}{l}16 \\
17 \\
18 \\
19 \\
20\end{array}$ & $\begin{array}{l}24 \\
25 \\
25 \\
25 \\
26\end{array}$ & $\begin{array}{l}26 \\
26 \\
26 \\
25 \\
25\end{array}$ & $\begin{array}{l}25 \\
25 \\
25 \\
25 \\
25\end{array}$ & $\begin{array}{l}24 \\
24 \\
24 \\
24 \\
24\end{array}$ & $\begin{array}{l}25 \\
25 \\
25 \\
25 \\
25\end{array}$ & $\begin{array}{l}26 \\
26 \\
26 \\
26 \\
26\end{array}$ & $\begin{array}{l}25 \\
25 \\
25 \\
25 \\
25\end{array}$ & $\begin{array}{l}25 \\
25 \\
25 \\
25 \\
25\end{array}$ & $\begin{array}{l}21 \\
21 \\
24 \\
25 \\
25\end{array}$ & $\begin{array}{l}25 \\
25 \\
25 \\
25 \\
25\end{array}$ & $\begin{array}{l}25 \\
25 \\
25 \\
25 \\
25\end{array}$ \\
\hline $\begin{array}{l}21 \\
22 \\
23 \\
24 \\
25\end{array}$ & $\begin{array}{l}26 \\
26 \\
26 \\
26 \\
26\end{array}$ & $\begin{array}{l}25 \\
25 \\
25 \\
25 \\
25\end{array}$ & $\begin{array}{l}25 \\
25 \\
25 \\
25 \\
25\end{array}$ & $\begin{array}{l}24 \\
24 \\
24 \\
24 \\
24\end{array}$ & $\begin{array}{l}25 \\
25 \\
25 \\
24 \\
24\end{array}$ & $\begin{array}{l}26 \\
26 \\
26 \\
26 \\
26\end{array}$ & $\begin{array}{l}24 \\
22 \\
22 \\
21 \\
21\end{array}$ & $\begin{array}{l}25 \\
25 \\
25 \\
25 \\
25\end{array}$ & $\begin{array}{l}25 \\
25 \\
25 \\
25 \\
25\end{array}$ & $\begin{array}{l}25 \\
25 \\
25 \\
25 \\
25\end{array}$ & $\begin{array}{l}25 \\
25 \\
25 \\
25 \\
25\end{array}$ \\
\hline $\begin{array}{l}26 \\
27 \\
28 \\
29 \\
30 \\
31\end{array}$ & $\begin{array}{l}26 \\
26 \\
26 \\
26 \\
26 \\
26\end{array}$ & $\begin{array}{r}25 \\
25 \\
25 \\
25 \\
25 \\
--\end{array}$ & $\begin{array}{l}25 \\
25 \\
25 \\
25 \\
25 \\
25\end{array}$ & $\begin{array}{l}24 \\
24 \\
24 \\
24 \\
24 \\
24\end{array}$ & $\begin{array}{r}22 \\
22 \\
22 \\
--- \\
--\end{array}$ & $\begin{array}{l}25 \\
25 \\
25 \\
25 \\
25 \\
25\end{array}$ & $\begin{array}{r}21 \\
21 \\
24 \\
25 \\
25 \\
--\end{array}$ & $\begin{array}{l}26 \\
26 \\
26 \\
26 \\
26 \\
26\end{array}$ & $\begin{array}{r}25 \\
25 \\
25 \\
25 \\
25 \\
---\end{array}$ & $\begin{array}{l}25 \\
25 \\
25 \\
25 \\
25 \\
25\end{array}$ & $\begin{array}{l}25 \\
25 \\
25 \\
25 \\
25 \\
25\end{array}$ \\
\hline $\begin{array}{l}\text { TOTAL } \\
\text { MEAN } \\
\text { MAX } \\
\text { MIN }\end{array}$ & $\begin{array}{r}771 \\
24.9 \\
26 \\
24\end{array}$ & $\begin{array}{r}768 \\
25.6 \\
26 \\
25\end{array}$ & $\begin{array}{r}773 \\
24.9 \\
25 \\
24\end{array}$ & $\begin{array}{r}751 \\
24.2 \\
25 \\
24\end{array}$ & $\begin{array}{r}689 \\
24.6 \\
25 \\
22\end{array}$ & $\begin{array}{r}788 \\
25.4 \\
26 \\
23\end{array}$ & $\begin{array}{r}696 \\
23.2 \\
25 \\
21\end{array}$ & $\begin{array}{r}781 \\
25.2 \\
26 \\
25\end{array}$ & $\begin{array}{r}745 \\
24.8 \\
27 \\
21\end{array}$ & $\begin{array}{r}781 \\
25.2 \\
26 \\
25\end{array}$ & $\begin{array}{r}784 \\
25.3 \\
26 \\
25\end{array}$ \\
\hline
\end{tabular}

CAL YR 1986 TOTAL 10394 MEAN 28.5 MAX 55 MIN 18 WTR YR 1987 TOTAL 9049 MEAN 24.8 $\quad$ MAX 27 MIN 21 
04058190 SCHWEITZER RESERVOIR NEAR PALMER, MI

LOCATION, --Lat $46^{\circ} 25^{\prime} 00^{\prime \prime}$, long $87^{\circ} 38^{\prime} 48^{\prime \prime}$, in SEl/4 NWl/4 sec. 2, T.46 N., R.27 W., Marquette County, Hydrologic Unit 04030110 , on left bank $120 \mathrm{ft}$ upstream from dam on Schweitzer' Creek, 3.0 mi southwest of Palmer.

DRAINAGE AREA. $--23.1 \mathrm{mi}^{2}$.

PERIOD OF RECORD.--January 1963 to current year.

GAGE.--Water-stage recorder. Datum of gage is $1,300.00 \mathrm{ft}$ above National Geodetic Vertical Datum of 1929 (Cleveland-Cliffs Iron Co. reference mark); gage readings have been converted to elevations NGvD. Prior to Oct. 25, 1967, nonrecording gage at same site and datum.

REMARKS.--Reservoir is formed by an earthfill dam with fixed crest concrete spillway completed in 1963 . Usable capacity of reservoir is 5,300 acre-ft at spillway elevation, $1,338.00 \mathrm{ft}$. The dam includes a discharge pipe equipped with valve to control release flow to Schweitzer Creek (station 04058200). An average of $1.5 \mathrm{ft}^{3} / \mathrm{s}$ was diverted from the headwaters of basin by the City of Ishpeming for municipal supply and the effluent discharged to the Carp River basin. An average of 25 ft $3 / \mathrm{s}^{2}$ was municipal supply and the effluent discharged to the Carp River basin. An average of 25 ft $3 / 5$ was via Green Creek and some returned to the East Branch Escanaba River basin via Goose Lake Outlet. Since January 1973, controlled diversion from Greenwood Reservoir (station 04057811) via Greenwood Diversion (station 04057813) into Schweitzer Reservoir. Controlled inflow averaged 17.4 $\mathrm{ft}^{3 / 5} \mathrm{for}$ the year.

EXTREMES FOR PERIOD OF RECORD.--Maximum contents recorded, 5,900 acre-ft, May 31, 1970, Apr. 20, 1985, elevation, $1,339.5 \mathrm{ft}$; minimum recorded since first filling, 2,920 acre-ft, Apr. 10, 1974, elevation, $1,329.7 \mathrm{ft}$.

EXTREMES FOR CURRENT YEAR.--Maximum contents, 4,980 acre-ft, Oct. 16-20, June 2-5, elevation, 1,337.1 ft; minimum, 4, 140 acre-ft, Sept. 10-18, elevation, $1,334.3 \mathrm{ft}$.

MONTHEND ELEVATION, IN FEET NGVD, AND CONTENTS AT 2400, WATER YEAR OCTOBER 1986 TO SEPTEMBER 1987

Date

Sept. 30 . . . . . . . . . . . . .

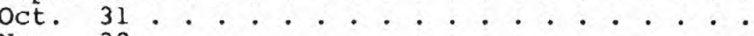

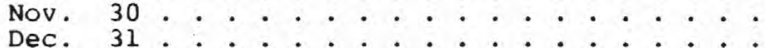

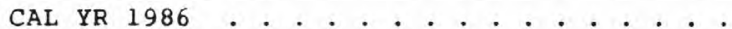

Jan. 31 . . . . . . . . . . . . .

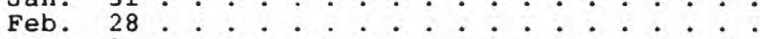

Mar. $31 \div \div \div \div \div$

Apr. 30 . . . . . . . . . . . .

June $31 \cdot \cdot \cdot \cdot \cdot \cdot \cdot \cdot \cdot \cdot \cdot \cdot \cdot \cdot \cdot \cdot \cdot \cdot \cdot \cdot$

July 31 . . . . . . . . . . . . . . :

Aug. $31 . . . . . . . . . . . . .0$

Sept. 30 . . . . . . . . . . . .

WTR YR 1987

\section{Elevation}

(feet)

$1,335.3$

$1,336.7$

$1,335.3$

$1,335.4$

--

$1,335.7$
$1,335.4$

$1,335.4$
$1,335.3$

$1,334.8$

$1,336.6$

$1,335.5$

$1,335.7$

$1,334.7$

$1,334.5$

$-$
Contents

(acre-feet)

4,440

4,860

4,440

4,470

--

4,560
4,470

4,470
4,440

4,440
4,290

4,830

4,500

560

4,56

4,260

$--$
Change in contents

feet) in $\mathrm{ft}^{3} / \mathrm{s}$ )

$+420$

+420
-420

-420
+30

$+\overline{+6} .8$

$-7.1$

$+0.5$

$-730$

$-1.0$

$+90$

$-90$

-30
-150

-150
+540

$-330$

$+60$

$-300$

$-60$

$-240$
$+1.5$

$-1.6$

$-0.5$

$-2.5$

$+8.8$

$-5.5$

$+1.0$

$-4.9$

$-1.0$

$-0.3$ 
LOCATION.--Lat $46^{\circ} 24^{\prime} 40^{\prime \prime}$, long $87^{\circ} 37^{\prime} 27^{\prime \prime}$, in SWl/4 sec.1, T.46 N., R.27 w., Marquette County, Hydrologic Unit 04030110 , on right bank $10 \mathrm{ft}$ upstream from highway bridge, $2.5 \mathrm{mi}$ ' southwest of Palmer.

DRAINAGE AREA. $--23.6 \mathrm{mi}^{2}$.

PERIOD OF RECORD.--October 1960 to current year.

GAGE.--Water-stage recorder. Concrete control since oct. 1, 1963. Elevation of gage is 1,270 ft above National Geodetic Vertical Datum of 1929, from topographic map. Prior to Aug. 21 , 1961 , nonrecording gage at same site and datum.

REMARKS.--Est imated daily discharges: Nov. 13, 14, Dec. 20, Jan. 17, 23-27, and Feb. 9, 28. Records good. Since August 1962, flow completely regulated by Schweitzer Reservoir (station 04058190 ) 1.0 mi upstream. An average of $1.5 \mathrm{ft}^{3} / \mathrm{s}$ was diverted from headwaters of basin by the City of Ishpeming for municipal supply and the effluent discharged to the Carp River basin. An average of 25 ft $3 / 5$ was diverted from Schweitzer Reservoir by industry for iron ore processing, some returned to the Middle Bas diverted from Schweitzer Reservoir by industry for iron ore processing, some returned to the Middle Branch Escanaba River via Green Creek and some returned via Goose Lake Outlet and East Branch Escanaba
River. Diversion into Schweitzer Reservoir from Greenwood Reservoir via Greenwood Diversion (station 04057813 ). Several measurements of water temperature were made during the year.

EXTREMES FOR PERIOD OF RECORD.--Maximum discharge, $860 \mathrm{ft}^{3} / \mathrm{s}$, May 31,1970 , gage height, $6.50 \mathrm{ft}$; minimum, $0.4 \mathrm{ft}^{3} / \mathrm{s}$, Sept. 6, 1962, gage height, $1.22 \mathrm{ft}$; minimum daily, $1.0 \mathrm{ft} / \mathrm{s}$, Apr.9-18, May $5,6,1963$.

EXTREMES FOR CURRENT YEAR.--Maximum discharge, $46 \mathrm{ft}^{3} / \mathrm{s}$, Oct. 15, gage height, $3.61 \mathrm{ft}$; minimum daily, 4.1 ft3/s, Aug. 16, 17, 23, 26, 29, 31, Sept. 4, 6, 7, 9, 10, $16,25$.

DISCHARGE, IN CUBIC FEET PER SECOND, WATER YEAR OCTOBER 1986 TO SEPTEMBER 1987

\begin{tabular}{|c|c|c|c|c|c|c|c|c|c|c|c|c|}
\hline \multirow[b]{2}{*}{ DAY } & \multirow[b]{2}{*}{ OCT } & \multirow[b]{2}{*}{ NOV } & \multirow[b]{2}{*}{ DEC } & \multicolumn{5}{|c|}{ MEAN VALUES } & \multirow[b]{2}{*}{ JUN } & \multirow[b]{2}{*}{ JUL } & \multirow[b]{2}{*}{ AUG } & \multirow[b]{2}{*}{ SEP } \\
\hline & & & & JAN & FEB & MAR & APR & MAY & & & & \\
\hline $\begin{array}{l}1 \\
2 \\
3 \\
4 \\
5\end{array}$ & $\begin{array}{l}4.7 \\
4.6 \\
4.6 \\
4.5 \\
4.6\end{array}$ & $\begin{array}{l}4.8 \\
4.7 \\
4.6 \\
4.6 \\
4.7\end{array}$ & $\begin{array}{l}4.5 \\
4.5 \\
4.6 \\
4.5 \\
4.5\end{array}$ & $\begin{array}{l}4.5 \\
4.5 \\
4.5 \\
4.5 \\
4.5\end{array}$ & $\begin{array}{l}4.4 \\
4.5 \\
4.5 \\
4.4 \\
4.5\end{array}$ & $\begin{array}{l}4.2 \\
4.7 \\
4.7 \\
4.7 \\
5.0\end{array}$ & $\begin{array}{l}4.8 \\
4.9 \\
4.7 \\
4.7 \\
5.0\end{array}$ & $\begin{array}{l}4.7 \\
4.6 \\
4.6 \\
4.6 \\
4.6\end{array}$ & $\begin{array}{l}5.1 \\
5.8 \\
5.0 \\
5.0 \\
5.0\end{array}$ & $\begin{array}{l}4.6 \\
4.8 \\
4.8 \\
4.6 \\
4.5\end{array}$ & $\begin{array}{l}4.8 \\
5.0 \\
4.5 \\
4.4 \\
4.4\end{array}$ & $\begin{array}{l}4.2 \\
4.2 \\
4.2 \\
4.1 \\
4.2\end{array}$ \\
\hline $\begin{array}{r}6 \\
7 \\
8 \\
9 \\
10\end{array}$ & $\begin{array}{l}4.7 \\
4.8 \\
4.7 \\
4.6 \\
4.6\end{array}$ & $\begin{array}{l}4.7 \\
4.7 \\
4.7 \\
4.7 \\
4.8\end{array}$ & $\begin{array}{l}4.5 \\
4.8 \\
4.2 \\
4.5 \\
4.5\end{array}$ & $\begin{array}{l}4.4 \\
4.5 \\
4.5 \\
4.5 \\
4.5\end{array}$ & $\begin{array}{l}4.5 \\
4.5 \\
4.5 \\
4.5 \\
4.5\end{array}$ & $\begin{array}{l}4.7 \\
5.2 \\
4.9 \\
4.5 \\
4.5\end{array}$ & $\begin{array}{l}5.2 \\
5.2 \\
5.0 \\
5.0 \\
5.0\end{array}$ & $\begin{array}{l}4.6 \\
4.6 \\
4.6 \\
4.6 \\
4.6\end{array}$ & $\begin{array}{l}5.1 \\
5.0 \\
5.0 \\
5.0 \\
5.0\end{array}$ & $\begin{array}{l}4.5 \\
4.5 \\
4.8 \\
4.8 \\
4.9\end{array}$ & $\begin{array}{l}4.4 \\
4.4 \\
4.4 \\
4.4 \\
4.3\end{array}$ & $\begin{array}{l}4.1 \\
4.1 \\
4.2 \\
4.1 \\
4.1\end{array}$ \\
\hline $\begin{array}{l}11 \\
12 \\
13 \\
14 \\
15\end{array}$ & $\begin{array}{l}5.0 \\
7.4 \\
5.3 \\
5.2 \\
7.8\end{array}$ & $\begin{array}{l}4.7 \\
4.8 \\
4.8 \\
4.8 \\
5.0\end{array}$ & $\begin{array}{l}4.5 \\
4.3 \\
4.2 \\
4.5 \\
4.5\end{array}$ & $\begin{array}{l}4.5 \\
4.5 \\
4.5 \\
4.5 \\
4.4\end{array}$ & $\begin{array}{l}4.5 \\
4.5 \\
4.5 \\
4.5 \\
4.4\end{array}$ & $\begin{array}{l}4.5 \\
4.5 \\
4.5 \\
4.5 \\
4.5\end{array}$ & $\begin{array}{l}5.0 \\
4.8 \\
4.9 \\
5.1 \\
5.1\end{array}$ & $\begin{array}{l}4.9 \\
4.6 \\
4.6 \\
4.8 \\
4.7\end{array}$ & $\begin{array}{l}5.3 \\
5.0 \\
4.9 \\
4.7 \\
4.8\end{array}$ & $\begin{array}{l}5.4 \\
5.0 \\
4.8 \\
4.8 \\
4.7\end{array}$ & $\begin{array}{l}4.3 \\
4.3 \\
4.3 \\
4.3 \\
4.5\end{array}$ & $\begin{array}{l}4.2 \\
4.3 \\
4.3 \\
4.2 \\
4.2\end{array}$ \\
\hline $\begin{array}{l}16 \\
17 \\
18 \\
19 \\
20\end{array}$ & $\begin{array}{l}5.1 \\
4.6 \\
4.7 \\
4.6 \\
4.7\end{array}$ & $\begin{array}{l}4.9 \\
4.8 \\
4.6 \\
4.8 \\
4.8\end{array}$ & $\begin{array}{l}4.5 \\
4.5 \\
4.5 \\
4.5 \\
4.5\end{array}$ & $\begin{array}{l}4.5 \\
4.4 \\
4.3 \\
4.4 \\
4.5\end{array}$ & $\begin{array}{l}4.4 \\
4.4 \\
4.4 \\
4.4 \\
4.4\end{array}$ & $\begin{array}{l}4.5 \\
4.5 \\
4.6 \\
4.6 \\
4.7\end{array}$ & $\begin{array}{l}5.0 \\
5.0 \\
4.8 \\
4.8 \\
4.7\end{array}$ & $\begin{array}{l}4.6 \\
4.7 \\
5.0 \\
5.9 \\
5.2\end{array}$ & $\begin{array}{l}4.7 \\
4.7 \\
4.7 \\
4.6 \\
4.7\end{array}$ & $\begin{array}{l}4.6 \\
4.5 \\
4.5 \\
4.9 \\
4.7\end{array}$ & $\begin{array}{l}4.1 \\
4.1 \\
4.2 \\
4.2 \\
4.3\end{array}$ & $\begin{array}{l}4.1 \\
4.3 \\
4.3 \\
4.8 \\
4.4\end{array}$ \\
\hline $\begin{array}{l}21 \\
22 \\
23 \\
24 \\
25\end{array}$ & $\begin{array}{l}4.6 \\
4.7 \\
4.6 \\
4.8 \\
4.8\end{array}$ & $\begin{array}{l}4.8 \\
4.7 \\
4.8 \\
4.8 \\
4.6\end{array}$ & $\begin{array}{l}4.5 \\
4.5 \\
4.5 \\
4.5 \\
4.5\end{array}$ & $\begin{array}{l}4.3 \\
4.5 \\
4.4 \\
4.4 \\
4.4\end{array}$ & $\begin{array}{l}4.4 \\
4.5 \\
4.4 \\
4.4 \\
4.4\end{array}$ & $\begin{array}{l}4.8 \\
4.8 \\
4.9 \\
4.9 \\
5.0\end{array}$ & $\begin{array}{l}5.0 \\
4.8 \\
4.8 \\
4.8 \\
4.7\end{array}$ & $\begin{array}{l}4.9 \\
4.9 \\
4.9 \\
4.9 \\
4.9\end{array}$ & $\begin{array}{l}4.8 \\
4.7 \\
4.7 \\
5.6 \\
5.1\end{array}$ & $\begin{array}{l}4.7 \\
4.5 \\
4.5 \\
4.5 \\
4.4\end{array}$ & $\begin{array}{l}4.3 \\
4.2 \\
4.1 \\
4.2 \\
4.2\end{array}$ & $\begin{array}{l}4.4 \\
4.3 \\
4.3 \\
4.2 \\
4.1\end{array}$ \\
\hline $\begin{array}{l}26 \\
27 \\
28 \\
29 \\
30 \\
31\end{array}$ & $\begin{array}{l}4.6 \\
5.1 \\
4.4 \\
4.7 \\
4.7 \\
4.8\end{array}$ & $\begin{array}{l}4.5 \\
4.5 \\
4.5 \\
4.5 \\
4.5 \\
---\end{array}$ & $\begin{array}{l}4.5 \\
4.5 \\
4.5 \\
4.5 \\
4.5 \\
4.5\end{array}$ & $\begin{array}{l}4.4 \\
4.3 \\
4.3 \\
4.4 \\
4.4 \\
4.3\end{array}$ & $\begin{array}{l}4.4 \\
4.5 \\
4.4 \\
--- \\
---\end{array}$ & $\begin{array}{l}5.0 \\
4.9 \\
4.8 \\
4.8 \\
4.8 \\
4.7\end{array}$ & $\begin{array}{l}4.8 \\
4.7 \\
4.8 \\
4.7 \\
4.7 \\
-.-\end{array}$ & $\begin{array}{l}4.9 \\
5.9 \\
5.9 \\
5.3 \\
6.3 \\
5.1\end{array}$ & $\begin{array}{l}4.8 \\
4.9 \\
4.7 \\
4.8 \\
4.8 \\
----\end{array}$ & $\begin{array}{l}4.4 \\
4.4 \\
4.4 \\
4.4 \\
4.4 \\
4.4\end{array}$ & $\begin{array}{l}4.1 \\
4.2 \\
4.2 \\
4.1 \\
4.2 \\
4.1\end{array}$ & $\begin{array}{l}4.2 \\
4.2 \\
4.2 \\
4.2 \\
4.2 \\
-\end{array}$ \\
\hline $\begin{array}{l}\text { TOTAL } \\
\text { MEAN } \\
\text { MAX } \\
\text { MIN }\end{array}$ & $\begin{array}{r}152.6 \\
4.92 \\
7.8 \\
4.4\end{array}$ & $\begin{array}{r}141.2 \\
4.71 \\
5.0 \\
4.5\end{array}$ & $\begin{array}{r}139.1 \\
4.49 \\
4.8 \\
4.2\end{array}$ & $\begin{array}{r}137.5 \\
4.44 \\
4.5 \\
4.3\end{array}$ & $\begin{array}{r}124.6 \\
4.45 \\
4.5 \\
4.4\end{array}$ & $\begin{array}{r}145.9 \\
4.71 \\
5.2 \\
4.2\end{array}$ & $\begin{array}{r}146.5 \\
4.88 \\
5.2 \\
4.7\end{array}$ & $\begin{array}{r}153.0 \\
4.94 \\
6.3 \\
4.6\end{array}$ & $\begin{array}{r}148.0 \\
4.93 \\
5.8 \\
4.6\end{array}$ & $\begin{array}{r}143.7 \\
4.64 \\
5.4 \\
4.4\end{array}$ & $\begin{array}{r}133.5 \\
4.31 \\
5.0 \\
4.1\end{array}$ & $\begin{array}{r}126.9 \\
4.23 \\
4.8 \\
4.1\end{array}$ \\
\hline $\begin{array}{ll}\text { CAL YR } \\
\text { WTR YR }\end{array}$ & $\begin{array}{l}1986 \\
1987\end{array}$ & $\begin{array}{ll}A L & 3 \\
A L & 1\end{array}$ & $\begin{array}{l}3 \\
5\end{array}$ & $\begin{array}{lc}\text { AN } & 10.5 \\
\text { AN } & 4.64\end{array}$ & $\begin{array}{l}\text { MAX } \\
\text { MAX }\end{array}$ & $\begin{array}{r}182 \\
7.8\end{array}$ & $\begin{array}{ll}\text { MIN } & 4.2 \\
\text { MIN } & 4.1\end{array}$ & & & & & \\
\hline
\end{tabular}


04059000 ESCANABA RIVER AT CORNELL, MI

(National stream quality accounting network station)

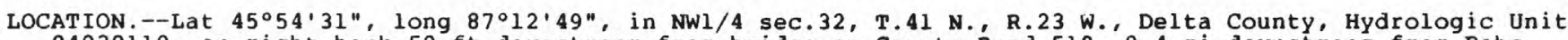
04030110 , on right bank 50 ft downstream from bridge on County Road $519,0.4$ mi downstream from Bobs creek, $0.7 \mathrm{mi}$ northeast of Cornell, and $16 \mathrm{mi}$ upstream from mouth.

DRA INAGE AREA. $--870 \mathrm{mi}^{2}$.

WATER-DISCHARGE RECORDS

PERIOD OF RECORD.--August 1903 to December 1912, January 1913 to November 1915 (gage heights only), October 1950 to current year. Monthly discharge only for some periods, published in wsp 1307 . Published as "near Escanaba" 1903-15.

REVISED RECORDS.--WSP 1387: 1904. WDR MI-85: 1970 (M).

GAGE.--Water-stage recorder. Datum of gage is $749.26 \mathrm{ft}$ above National Geodetic Vertical Datum of 1929 (levels by Michigan Department of Natural Resources). August 1903 to November 1915 , nonrecording gage at site $10 \mathrm{mi}$ downstream at different datum.

REMARKS.--Estimated daily discharges: Nov. 10 to Apr. 3. Water-discharge records good except for estimated daily discharges, which are fair. Since 1950, diurnal fluctuation and occasional slight regulation by Boney Falis powerplant $7 \mathrm{mi}$ upstream. Since August 1962, some regulation by Schweitzer Reservoir (station 04058190) about $50 \mathrm{mi}$ upstream. Since December 1972, some regulation by Greenwood Reservoir (station 04057811 ) about $60 \mathrm{mi}$ upstream. Gage-height telemeter at station.

AVERAGE DISCHARGE.--46 years (water years 1904-12, 1951-87), 888 $\mathrm{ft}^{3} / \mathrm{s}, 13.86 \mathrm{in} / \mathrm{y}^{\mathrm{r}}$.

EXTREMES FOR PERIOD OF RECORD,--Maximum discharge, $10,700 \mathrm{ft} 3 / \mathrm{s}, \mathrm{Apr} .26,1979$, gage height, 5.00 ft; maximum gage height, $6.40 \mathrm{ft}$, Apr. 9, 1971, backwater from lce; minimum discharge observed, 90 $\mathrm{ft}^{3} / \mathrm{s}$, July 5, 1910 , gage height, $1.5 \mathrm{ft}$, site and datum then in use, but may have been less during extended periods of no gage-height record during winter periods of 1903-12, or periods of ice effect in 1959 .

EXTREMES FOR CURRENT YEAR.--Maximum discharge, $2,360 \mathrm{ft}^{3} / \mathrm{s}$, Oct. 13, gage height, $2.83 \mathrm{ft}$; maximum gage height, $3.38 \mathrm{ft}$, Mar. 10, backwater from ice; minimum daily discharge, $183 \mathrm{ft} / \mathrm{s}^{3}$, Sept. 2 , but may have been less during period of ice effect.

DISCHARGE, IN CUBIC FEET PER SECOND, WATER YEAR OCTOBER 1986 TO SEPTEMBER 1987 MEAN VALUES

\begin{tabular}{|c|c|c|c|c|c|c|c|c|c|c|c|c|}
\hline DAY & OCT & NOV & DEC & JAN & FEB & MAR & APR & MAY & JUN & JUL & AUG & SEP \\
\hline $\begin{array}{l}1 \\
2 \\
3 \\
4 \\
5\end{array}$ & $\begin{array}{l}698 \\
630 \\
551 \\
513 \\
504\end{array}$ & $\begin{array}{l}507 \\
517 \\
514 \\
503 \\
503\end{array}$ & $\begin{array}{l}340 \\
330 \\
310 \\
300 \\
280\end{array}$ & $\begin{array}{l}320 \\
320 \\
320 \\
320 \\
320\end{array}$ & $\begin{array}{l}220 \\
230 \\
260 \\
260 \\
260\end{array}$ & $\begin{array}{l}270 \\
270 \\
280 \\
280 \\
310\end{array}$ & $\begin{array}{l}640 \\
600 \\
660 \\
691 \\
785\end{array}$ & $\begin{array}{l}606 \\
554 \\
521 \\
491 \\
457\end{array}$ & $\begin{array}{r}949 \\
1180 \\
1280 \\
1160 \\
821\end{array}$ & $\begin{array}{l}252 \\
264 \\
323 \\
350 \\
341\end{array}$ & $\begin{array}{l}349 \\
908 \\
972 \\
758 \\
629\end{array}$ & $\begin{array}{l}190 \\
183 \\
206 \\
231 \\
228\end{array}$ \\
\hline $\begin{array}{r}6 \\
7 \\
8 \\
9 \\
10\end{array}$ & $\begin{array}{l}477 \\
482 \\
514 \\
553 \\
552\end{array}$ & $\begin{array}{l}511 \\
498 \\
499 \\
464 \\
450\end{array}$ & $\begin{array}{l}260 \\
250 \\
240 \\
230 \\
220\end{array}$ & $\begin{array}{l}320 \\
320 \\
320 \\
320 \\
320\end{array}$ & $\begin{array}{l}260 \\
260 \\
260 \\
270 \\
290\end{array}$ & $\begin{array}{l}350 \\
410 \\
500 \\
580 \\
540\end{array}$ & $\begin{array}{r}926 \\
1140 \\
1300 \\
1420 \\
1360\end{array}$ & $\begin{array}{l}424 \\
390 \\
388 \\
369 \\
349\end{array}$ & $\begin{array}{l}700 \\
718 \\
773 \\
871 \\
747\end{array}$ & $\begin{array}{l}288 \\
271 \\
284 \\
293 \\
339\end{array}$ & $\begin{array}{l}538 \\
441 \\
404 \\
385 \\
409\end{array}$ & $\begin{array}{l}219 \\
223 \\
230 \\
230 \\
214\end{array}$ \\
\hline $\begin{array}{l}11 \\
12 \\
13 \\
14 \\
15\end{array}$ & $\begin{array}{r}519 \\
1270 \\
2050 \\
2180 \\
2130\end{array}$ & $\begin{array}{l}420 \\
410 \\
400 \\
385 \\
370\end{array}$ & $\begin{array}{l}210 \\
210 \\
210 \\
205 \\
200\end{array}$ & $\begin{array}{l}320 \\
320 \\
320 \\
300 \\
290\end{array}$ & $\begin{array}{l}290 \\
260 \\
260 \\
260 \\
260\end{array}$ & $\begin{array}{l}475 \\
430 \\
410 \\
410 \\
410\end{array}$ & $\begin{array}{l}1350 \\
1310 \\
1250 \\
1210 \\
1410\end{array}$ & $\begin{array}{l}358 \\
392 \\
393 \\
372 \\
355\end{array}$ & $\begin{array}{l}562 \\
533 \\
550 \\
523 \\
474\end{array}$ & $\begin{array}{r}431 \\
1230 \\
1620 \\
1730 \\
1240\end{array}$ & $\begin{array}{l}365 \\
330 \\
345 \\
371 \\
370\end{array}$ & $\begin{array}{l}200 \\
232 \\
260 \\
257 \\
240\end{array}$ \\
\hline $\begin{array}{l}16 \\
17 \\
18 \\
19 \\
20\end{array}$ & $\begin{array}{l}1950 \\
1640 \\
1410 \\
1240 \\
1110\end{array}$ & $\begin{array}{l}360 \\
360 \\
360 \\
360 \\
350\end{array}$ & $\begin{array}{l}200 \\
200 \\
200 \\
200 \\
200\end{array}$ & $\begin{array}{l}280 \\
270 \\
260 \\
260 \\
260\end{array}$ & $\begin{array}{l}260 \\
260 \\
260 \\
260 \\
260\end{array}$ & $\begin{array}{l}410 \\
410 \\
410 \\
420 \\
450\end{array}$ & $\begin{array}{l}1380 \\
1330 \\
1260 \\
1160 \\
1130\end{array}$ & $\begin{array}{l}349 \\
334 \\
332 \\
406 \\
528\end{array}$ & $\begin{array}{l}384 \\
314 \\
341 \\
334 \\
294\end{array}$ & $\begin{array}{l}994 \\
737 \\
603 \\
607 \\
663\end{array}$ & $\begin{array}{l}384 \\
462 \\
347 \\
316 \\
353\end{array}$ & $\begin{array}{l}236 \\
295 \\
317 \\
478 \\
666\end{array}$ \\
\hline $\begin{array}{l}21 \\
22 \\
23 \\
24 \\
25\end{array}$ & $\begin{array}{l}953 \\
822 \\
719 \\
711 \\
664\end{array}$ & $\begin{array}{l}350 \\
360 \\
380 \\
390 \\
390\end{array}$ & $\begin{array}{l}200 \\
215 \\
240 \\
290 \\
300\end{array}$ & $\begin{array}{l}260 \\
260 \\
260 \\
260 \\
260\end{array}$ & $\begin{array}{l}260 \\
260 \\
260 \\
260 \\
270\end{array}$ & $\begin{array}{l}500 \\
580 \\
650 \\
740 \\
800\end{array}$ & $\begin{array}{r}1100 \\
1070 \\
1040 \\
1050 \\
925\end{array}$ & $\begin{array}{r}636 \\
583 \\
-\quad 527 \\
524 \\
497\end{array}$ & $\begin{array}{l}279 \\
277 \\
275 \\
275 \\
290\end{array}$ & $\begin{array}{l}680 \\
640 \\
553 \\
514 \\
476\end{array}$ & $\begin{array}{l}425 \\
435 \\
394 \\
335 \\
308\end{array}$ & $\begin{array}{l}699 \\
650 \\
622 \\
604 \\
493\end{array}$ \\
\hline $\begin{array}{l}26 \\
27 \\
28 \\
29 \\
30 \\
31\end{array}$ & $\begin{array}{l}630 \\
611 \\
565 \\
532 \\
527 \\
522\end{array}$ & $\begin{array}{l}380 \\
380 \\
380 \\
370 \\
350 \\
---\end{array}$ & $\begin{array}{l}300 \\
300 \\
310 \\
320 \\
320 \\
320\end{array}$ & $\begin{array}{l}260 \\
260 \\
230 \\
220 \\
220 \\
220\end{array}$ & $\begin{array}{l}270 \\
270 \\
270 \\
--- \\
--- \\
---\end{array}$ & $\begin{array}{l}900 \\
960 \\
920 \\
840 \\
760 \\
700\end{array}$ & $\begin{array}{l}835 \\
814 \\
793 \\
749 \\
683 \\
---\end{array}$ & $\begin{array}{l}491 \\
449 \\
592 \\
895 \\
932 \\
999\end{array}$ & $\begin{array}{l}291 \\
277 \\
277 \\
273 \\
263 \\
---\end{array}$ & $\begin{array}{l}427 \\
396 \\
383 \\
336 \\
295 \\
298\end{array}$ & $\begin{array}{l}271 \\
255 \\
231 \\
237 \\
283 \\
223\end{array}$ & $\begin{array}{l}403 \\
369 \\
337 \\
334 \\
324 \\
\end{array}$ \\
\hline $\begin{array}{l}\text { TOTAL } \\
\text { MEAN } \\
\text { MAX } \\
\text { MIN } \\
\text { CFSM } \\
\text { IN. }\end{array}$ & $\begin{array}{r}28229 \\
911 \\
2180 \\
477 \\
1.05 \\
1.21\end{array}$ & $\begin{array}{r}12471 \\
416 \\
517 \\
350 \\
.48 \\
.53\end{array}$ & $\begin{array}{r}7910 \\
255 \\
340 \\
200 \\
.29 \\
.34\end{array}$ & $\begin{array}{r}8790 \\
284 \\
320 \\
220 \\
.33 \\
.38\end{array}$ & $\begin{array}{r}7320 \\
261 \\
290 \\
220 \\
.30 \\
.31\end{array}$ & $\begin{array}{r}16375 \\
528 \\
960 \\
270 \\
.61 \\
.70\end{array}$ & $\begin{array}{r}31371 \\
1046 \\
1420 \\
600 \\
1.20 \\
1.34\end{array}$ & $\begin{array}{r}15493 \\
500 \\
999 \\
332 \\
.58 \\
.66\end{array}$ & $\begin{array}{r}16285 \\
543 \\
1280 \\
263 \\
.62 \\
.70\end{array}$ & $\begin{array}{r}17858 \\
576 \\
1730 \\
252 \\
.66 \\
.76\end{array}$ & $\begin{array}{r}12833 \\
414 \\
972 \\
223 \\
.48 \\
.55\end{array}$ & $\begin{array}{r}10170 \\
339 \\
699 \\
183 \\
.39 \\
.43\end{array}$ \\
\hline
\end{tabular}

$\begin{array}{lllllllllll}\text { CAL YR } 1986 & \text { TOTAL } 278000 & \text { MEAN } 762 & \text { MAX } & 7260 & \text { MIN } 200 & \text { CFSM } & .88 & \text { IN } 11.89\end{array}$

WTR YR 1987 TOTAL 185105 MEAN 507 MAX 2180 MIN 183 CFSM .58 IN 7.91 
PERIOD OF RECORD.--Water years 1969-73, 1975 to current year.

PERIOD OF DAILY RECORD.--

SPECIFIC CONDUCTANCE: February 1975 to September 1981.

WATER TEMPERATURE: February 1975 to September 1981 .

INSTRUMENTATION. --Water-quality monitor from Oct. 15, 1975 to Sept. 30, 1981.

REMARKS.--Bimonthly cross-sectional samples were collected at or near bridge. From October 1975 to September 1981, instrument-recorded specific conductance below 200 microsiemens does not represent the conductance of the cross section. Results of a study of conductance in the cross section are available in the District files.

EXTREMES FOR PERIOD OF DAILY RECORD.--

SPECIFIC CONDUCTANCE (water years 1975, 1978-81): Maximum daily recorded (more than 20 percent missing record), $360 \mathrm{microsiemens,} \mathrm{Sept.} \mathrm{10,} \mathrm{1975;} \mathrm{minimum} \mathrm{measured,} \mathrm{114} \mathrm{microsiemens,} \mathrm{Apr.} \mathrm{15,} \mathrm{1981.}$

WATER TEMPERATURE (water years 1975, 1977-81): Maximum daily recorded (more than 20 percent missing

record), $35.0^{\circ} \mathrm{C}$, July 31 , 1975 ; minimum, $0.0^{\circ} \mathrm{C}$ on many days during winter.

EXTREMES OUTSIDE PERIOD OF DAILY RECORD.--A specific conductance of 72 microsiemens was measured Apr. 24 , 1985 .

WATER QUALITY DATA, WATER YEAR OCTOBER 1986 TO SEPTEMBER 1987

\begin{tabular}{|c|c|c|c|c|c|c|c|c|c|c|}
\hline DATE & TIME & $\begin{array}{l}\text { STREAM- } \\
\text { FLOW, } \\
\text { INSTAN- } \\
\text { TANEOUS } \\
\text { (CFS) }\end{array}$ & $\begin{array}{l}\text { SPE- } \\
\text { CIFIC } \\
\text { CON- } \\
\text { DUCT- } \\
\text { ANCE } \\
\text { (US/CM) }\end{array}$ & $\begin{array}{c}\text { PH } \\
\text { ( STAND- } \\
\text { ARD } \\
\text { UNITS) }\end{array}$ & $\begin{array}{l}\text { TEMPER- } \\
\text { ATURE } \\
\text { (DEG C) }\end{array}$ & $\begin{array}{l}\text { TUR- } \\
\text { BID- } \\
\text { ITY } \\
\text { (NTU) }\end{array}$ & $\begin{array}{c}\text { OXYGEN, } \\
\text { DIS- } \\
\text { SOLVED } \\
\text { (MG/L) }\end{array}$ & $\begin{array}{c}\text { OXYGEN, } \\
\text { DIS- } \\
\text { SOLVED } \\
\text { (PER- } \\
\text { CENT } \\
\text { SATUR- } \\
\text { ATION) }\end{array}$ & $\begin{array}{l}\text { COLI- } \\
\text { FORM, } \\
\text { FECAL, } \\
0.7 \\
\text { UM-MF } \\
\text { (COLS./ } \\
\text { IOO ML) }\end{array}$ & $\begin{array}{l}\text { STREP- } \\
\text { TOCOCCI } \\
\text { FECAL, } \\
\text { KF AGAR } \\
\text { (COLS. } \\
\text { PER } \\
100 \mathrm{ML} \text { ) }\end{array}$ \\
\hline $\begin{array}{l}\text { OCT } \\
28 \ldots \\
\text { DEC }\end{array}$ & 1430 & 524 & 173 & 8.4 & 9.0 & 1.5 & 11.1 & 104 & K3 & K9 \\
\hline$\underset{\text { MAR }}{22 \ldots}$ & 1250 & 216 & 268 & 7.9 & 0.0 & 3.4 & 14.0 & 99 & K2 & K10 \\
\hline$\underset{A P R}{04 \ldots}$ & 1330 & 280 & 276 & 8.2 & 0.0 & 2.0 & 13.2 & 92 & $<1$ & K4 \\
\hline JUL & 1115 & 804 & 184 & 7.8 & 11.0 & 1.2 & 11.9 & 111 & K4 & K2 \\
\hline AUG & 1315 & 276 & 212 & 8.8 & 22.5 & 1.4 & 9.6 & 114 & K6 & K9 \\
\hline $24 \ldots$ & 1315 & 359 & 231 & 8.6 & 18.5 & 2.3 & 10.2 & 112 & K1l & K13 \\
\hline DATE & $\begin{array}{l}\text { HARD- } \\
\text { NESS } \\
(M G / L \\
\text { AS } \\
\text { CACO3) }\end{array}$ & $\begin{array}{l}\text { HARD- } \\
\text { NESS } \\
\text { NONCARB } \\
\text { WH WAT } \\
\text { TOT FLD } \\
\text { MG/L AS } \\
\text { CACO3 }\end{array}$ & $\begin{array}{l}\text { CALCIUM } \\
\text { DIS- } \\
\text { SOLVED } \\
\text { (MG/L } \\
\text { AS CA) }\end{array}$ & $\begin{array}{l}\text { MAGNE- } \\
\text { SIUM, } \\
\text { DIS- } \\
\text { SOLVED } \\
\text { (MG/L } \\
\text { AS MG) }\end{array}$ & $\begin{array}{l}\text { SODIUM, } \\
\text { DIS- } \\
\text { SOLVED } \\
\text { (MG/L } \\
\text { AS NA) }\end{array}$ & $\begin{array}{l}\text { PERCENT } \\
\text { SODIUM }\end{array}$ & $\begin{array}{l}\text { SODIUM } \\
\text { AD- } \\
\text { SORP- } \\
\text { TION } \\
\text { RATIO }\end{array}$ & $\begin{array}{l}\text { POTAS- } \\
\text { SIUM, } \\
\text { DIS- } \\
\text { SOLVED } \\
\text { (MG/L } \\
\text { AS K) }\end{array}$ & $\begin{array}{l}\text { BICAR- } \\
\text { BONATE } \\
\text { WH WAT } \\
\text { TOTAL } \\
\text { FIELD } \\
\text { MG/I AS } \\
\text { HCO3 }\end{array}$ & $\begin{array}{l}\text { CAR- } \\
\text { BONATE } \\
\text { WH WAT } \\
\text { TOTAL } \\
\text { FIELD } \\
\text { MG } / L \text { AS } \\
\text { CO3 }\end{array}$ \\
\hline OCT & & & & & & & & & & \\
\hline $\mathrm{DEC}^{28 \ldots}$ & 88 & 21 & 21 & 8.6 & 3.5 & 8 & 0.2 & 0.8 & 79 & 2 \\
\hline$\underset{\operatorname{MAR}}{22 \ldots}$ & 100 & 0 & 25 & 10 & 19 & 28 & 0.8 & 1.0 & 150 & 0 \\
\hline $\begin{array}{c}04 \\
\mathrm{APR}\end{array}$ & 100 & 0 & 24 & 10 & 25 & 35 & 1 & 1.1 & 160 & 0 \\
\hline JuL $28 \cdots$ & 83 & 6 & 20 & 8.0 & 9.1 & 19 & 0.4 & 0.8 & 94 & 0 \\
\hline$\underset{\text { AUG }}{01 \ldots}$ & 100 & 9 & 25 & 9.9 & 5.6 & 10 & 0.2 & 0.8 & 110 & 5 \\
\hline $24 \ldots$ & 120 & 18 & 30 & 12 & 4.2 & 7 & 0.2 & 0.9 & 130 & 2 \\
\hline DATE & $\begin{array}{l}\text { ALKA- } \\
\text { LINITY } \\
\text { WH WAT } \\
\text { TOTAL } \\
\text { FIELD } \\
\text { MG/L AS } \\
\text { CACO3 }\end{array}$ & $\begin{array}{c}\text { CARBON } \\
\text { DIOXIDE } \\
\text { DIS- } \\
\text { SOLVED } \\
\text { (MG/L } \\
\text { AS CO2) }\end{array}$ & $\begin{array}{l}\text { SULFATE } \\
\text { DIS- } \\
\text { SOLVED } \\
\text { (MG/L } \\
\text { AS SO4) }\end{array}$ & $\begin{array}{l}\text { CHLO- } \\
\text { RIDE, } \\
\text { DIS- } \\
\text { SOLVED } \\
\text { (MG/L } \\
\text { AS CL) }\end{array}$ & $\begin{array}{l}\text { FLUO- } \\
\text { RIDE, } \\
\text { DIS- } \\
\text { SOLVED } \\
\text { (MG/L } \\
\text { AS F) }\end{array}$ & $\begin{array}{l}\text { SILICA, } \\
\text { DIS- } \\
\text { SOLVED } \\
\text { (MG/L } \\
\text { AS } \\
\text { SIO2) }\end{array}$ & $\begin{array}{l}\text { SOLIDS, } \\
\text { RESIDUE } \\
\text { AT } 180 \\
\text { DEG. C } \\
\text { DIS- } \\
\text { SOLVED } \\
\text { (MG/L) }\end{array}$ & $\begin{array}{l}\text { SOLIDS, } \\
\text { SUM OF } \\
\text { CONSTI- } \\
\text { TUENTS, } \\
\text { DIS- } \\
\text { SOLVED } \\
\text { (MG/L) }\end{array}$ & $\begin{array}{c}\text { SOLIDS, } \\
\text { DIS- } \\
\text { SOLVED } \\
\text { (TONS } \\
\text { PER } \\
\text { AC-FT) }\end{array}$ & $\begin{array}{c}\text { SOLIDS, } \\
\text { DIS- } \\
\text { SOLVED } \\
\text { (TONS } \\
\text { PER } \\
\text { DAY) }\end{array}$ \\
\hline OCT & & & & & & & & & & \\
\hline DEC & 67 & 0.5 & 13 & 3.3 & $<0.1$ & 7.3 & 112 & 100 & 0.15 & 158 \\
\hline MAR $22 \ldots$ & 119 & 2.9 & 18 & 6.5 & 0.1 & 11 & 16 & 160 & 0.22 & 96 \\
\hline $\begin{array}{l}04 \ldots \\
\text { APR }\end{array}$ & 133 & 1.6 & 18 & 6.4 & 0.2 & 11 & 168 & 180 & 0.23 & 127 \\
\hline JUL & 77 & 2.4 & 12 & 3.1 & 0.1 & 4.8 & 120 & 100 & 0.16 & 260 \\
\hline AUG & 94 & 0.3 & 10 & 3.9 & $<0.1$ & 6.0 & 125 & 130 & 0.17 & 93 \\
\hline $24 \ldots$ & 106 & 0.5 & 25 & 3.2 & 0.1 & 8.6 & 157 & 150 & 0.21 & 152 \\
\hline
\end{tabular}


04059000 ESCANABA RIVER AT CORNELL, MI--Continued

WÁTER QUALITY DATA, WATER YEAR OCTOBER 1986 TO SEPTEMBER 1987

\begin{tabular}{|c|c|c|c|c|c|c|c|c|c|c|}
\hline DATE & $\begin{array}{c}\text { NITRO- } \\
\text { GEN, } \\
\text { NITRITE } \\
\text { DIS- } \\
\text { SOLVED } \\
\text { (MG/L } \\
\text { AS N) }\end{array}$ & $\begin{array}{c}\text { NITRO- } \\
\text { GEN, } \\
\text { NO2+NO3 } \\
\text { DIS- } \\
\text { SOLVED } \\
\text { (MG/I } \\
\text { AS N) }\end{array}$ & $\begin{array}{c}\text { NITRO- } \\
\text { GEN, } \\
\text { AMMONIA } \\
\text { TOTAL } \\
\text { (MG/L } \\
\text { AS N) }\end{array}$ & $\begin{array}{c}\text { NITRO- } \\
\text { GEN, } \\
\text { AMMONIA } \\
\text { DIS- } \\
\text { SOLVED } \\
\text { (MG/L } \\
\text { AS N) }\end{array}$ & $\begin{array}{c}\text { NITRO- } \\
\text { GEN, } \\
\text { ORGANIC } \\
\text { TOTAL } \\
\text { (MG/L } \\
\text { AS N) }\end{array}$ & $\begin{array}{l}\text { NITRO- } \\
\text { GEN, AM- } \\
\text { MONIA + } \\
\text { ORGANIC } \\
\text { TOTAL } \\
\text { (MG/L } \\
\text { AS N) }\end{array}$ & $\begin{array}{c}\text { PHOS- } \\
\text { PHORUS, } \\
\text { TOTAL } \\
\text { (MG/L } \\
\text { AS P) }\end{array}$ & $\begin{array}{c}\text { PHOS- } \\
\text { PHORUS, } \\
\text { DIS- } \\
\text { SOLVED } \\
\text { (MG/L } \\
\text { AS P) }\end{array}$ & $\begin{array}{l}\text { PHOS- } \\
\text { PHORUS, } \\
\text { ORTHO, } \\
\text { DIS- } \\
\text { SOLVED } \\
\text { (MG/L } \\
\text { AS P) }\end{array}$ & $\begin{array}{l}\text { ALUM- } \\
\text { INUM, } \\
\text { DIS- } \\
\text { SOLVED } \\
\text { (UG/L } \\
\text { AS AL) }\end{array}$ \\
\hline${ }_{28}^{O C T}$ & $<0.01$ & 0.12 & 0.03 & -- & 1.5 & 1.5 & 0.01 & -- & $<0.01$ & 40 \\
\hline $\begin{array}{l}22 \ldots \\
\text { MAR }\end{array}$ & $<0.01$ & 0.20 & 0.07 & 0.04 & 0.23 & 0.3 & 0.01 & 0.01 & 0.01 & 10 \\
\hline $\begin{array}{c}04 \ldots \\
\text { APR }\end{array}$ & $<0.01$ & 0.15 & 0.01 & $<0.01$ & 0.19 & 0.2 & 0.01 & 0.01 & $<0.01$ & -- \\
\hline${ }_{\text {JUL }}^{28} \cdots$ & $<0.01$ & $<0.10$ & 0.01 & 0.01 & 0.99 & 1.0 & 0.01 & 0.01 & $<0.01$ & 20 \\
\hline AUG & $<0.01$ & $<0.10$ & 0.03 & 0.03 & 1.4 & 1.4 & 0.02 & -- & $<0.01$ & 20 \\
\hline $24 \ldots$ & $<0.01$ & $<0.10$ & $<0.01$ & 0.01 & 0.89 & 0.9 & 0.02 & 0.01 & $<0.01$ & - \\
\hline
\end{tabular}

DATE

$\begin{array}{cclc} & & \text { BERYL- } \\ \text { ARSENIC } & \text { BARIUM, } & \text { LIUM, } & \text { CADMIUM } \\ \text { DIS- } & \text { DIS- } & \text { DIS- } & \text { DIS- } \\ \text { SOLVED } & \text { SOLVED } & \text { SOLVED } & \text { SOLVED } \\ \text { (UG/L } & \text { (UG/L } & \text { (UG/L } & \text { (UG/L } \\ \text { AS AS) } & \text { AS BA) } & \text { AS BE) } & \text { AS CD) }\end{array}$

CHRO-

MIUM

DIS-

DIS- DIS-

SOLVED SOLVED

AS CR) AS CO)
COPPER,
DIS-
SOLVED
(UG/L

IRON,

DIS-
SOLVED

(UG/L

AS FE)

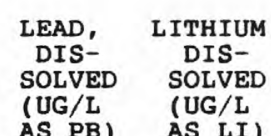

AS PB ) AS II)

OCT
$28 \ldots$
DEC
$22 \ldots$
MAR $\ldots$
$04 \ldots$
APR
$28 \ldots$
JUL
$01 \ldots$
AUG
$24 \ldots$

$\begin{array}{rrrr}<1 & 11 & 1 & <1 \\ <1 & 13 & <0.5 & <1 \\ -- & -- & -- & -- \\ <1 & 12 & <0.5 & 1 \\ <1 & 9 & <0.5 & <1 \\ -- & -- & -- & --\end{array}$

$\begin{array}{ll}<1 & <3 \\ <1 & <3 \\ -- & -- \\ <1 & <3 \\ <1 & <3 \\ -- & --\end{array}$

$<3$
$<3$
--
$<3$
$<3$
--

$\begin{array}{rrrr}1 & 490 & <5 & 4 \\ 1 & 220 & <5 & 5 \\ -- & -- & -- & -- \\ 7 & 230 & <5 & <4 \\ <1 & 150 & <5 & <4 \\ -- & -- & -- & --\end{array}$

DATE

MANGA-

$\begin{array}{lc}\text { MANGA- } & \\ \text { NESE, } & \text { MERCURY } \\ \text { DIS- } & \text { DIS- } \\ \text { SOLVED } & \text { SOLVED } \\ \text { (UG/L } & \text { (UG/L }\end{array}$

DENUM-

SELE- NIUM, SILVER,

STRON-
TIUM,

TIUM

DIS-

SOLVED

SOLVED

(UG/L

AS SR)

VANA-

DIUM,

DIS-

SOLVED

ZINC, SEDI-

(UG/L SOLVED

(UG $/ \mathrm{L}$

AS AG)

AS V)

(UG/L

SUS-

(MG/L)

OCT
$28 \ldots$
DEC
$22 \ldots$
MAR $\ldots$
$04 \ldots$
APR
$28 \ldots$
JUL $\ldots$
OI $1 \ldots$
AUG
$24 \ldots$

$\begin{array}{rrrr}14 & <0.1 & <10 & < \\ 3 & <0.1 & <10 & - \\ -- & -- & -- & <10 \\ 10 & <0.1 & <10 \\ 23 & <0.1 & <10 & < \\ -- & -- & --\end{array}$

\section{1}

$<1$

32

$<6$

$\begin{array}{rr}11 & 3 \\ <3 & 4 \\ -- & 14 \\ 17 & 6 \\ 45 & 4 \\ -- & 5\end{array}$

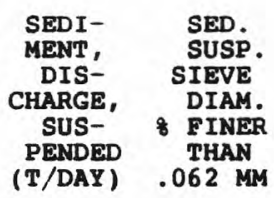

OCT

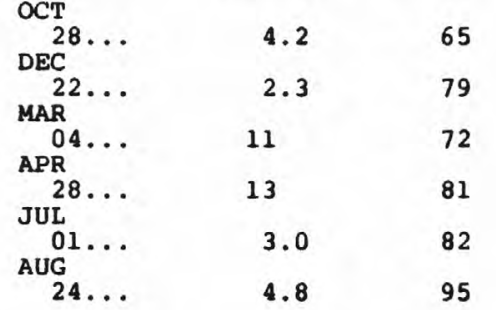


LOCATION.--Lat $45^{\circ} 45^{\prime} 20^{\prime \prime}$, long $87^{\circ} 12^{\prime} 05^{\prime \prime}$, in SWl/4 sec.19, T.39 N., R.23 W., Delta County, Hydrologic Unit 04030109 , on right bank $40 \mathrm{ft}$ downstream from bridge on County Road $533,1.4 \mathrm{mi}$ downstream from Tenmile Creek, and $1.5 \mathrm{mi}$ north of Hyde.

DRAINAGE AREA. $--450 \mathrm{mi}^{2}$.

WATER-DISCHARGE RECORDS

PERIOD OF RECORD.--October 1954 to current year.

GAGE.--Water-stage recorder. Datum of gage is $681.77 \mathrm{ft}$ above National Geodetic Vertical Datum of 1929 .

REMARKS.--Estimated daily discharges: Nov. 10 to Apr. 5. Water-discharge records good except for estimated daily discharges, which are fair.

AVERAGE DISCHARGE. --33 years, $387 \mathrm{ft}^{3} / \mathrm{s}, 11.68 \mathrm{in} / \mathrm{yr}^{\mathrm{r}}$.

EXTREMES FOR PERIOD OF RECORD, - Maximum discharge, 7,590 ft $3 / \mathrm{s}$, May 7,1960 , gage height, $8.27 \mathrm{ft}$; minimum, $18 \mathrm{ft}^{3} / \mathrm{s}$, Aug. 30, 1976, gage height, $1.33 \mathrm{ft}$.

EXTREMES FOR CURRENT YEAR.--Maximum discharge, $1,130 \mathrm{ft}^{3} / \mathrm{s}$, Oct. 16, 17, gage height, $3.95 \mathrm{ft}$; minimum, $50 \mathrm{ft}^{3} / \mathrm{s}$, Jan. 27, Sept. 10, 11, but may have been less during period of ice effect; minimum gage height, 1.62 ft, Juiy 2 .

DISCHARGE, IN CUBIC FEET PER SECOND, WATER YEAR OCTOBER 1986 TO SEPTEMBER 1987 MEAN VALUES

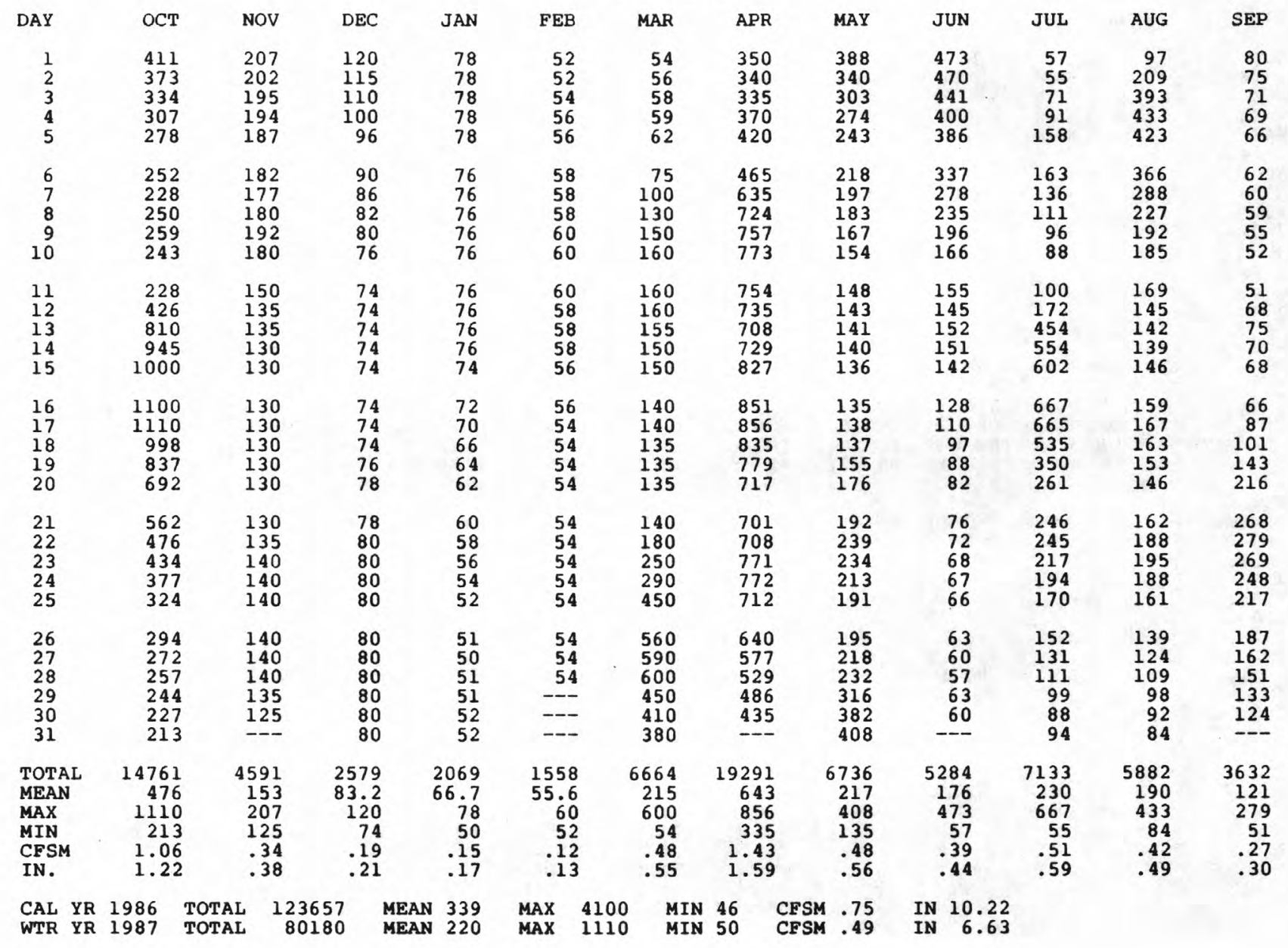


PERIOD OF RECORD.--Water years 1956 to current year.

PERIOD OF DAILY RECORD.--

SPECIFIC CONDUCTANCE: December 1974 to September 1981.

WATER TEMPERATURE: JulY 1956 to September 1981 .

INSTRUMENTATION. - Water-temperature recorder from July 20, 1956 to Sept. 30, 1975 . Water-quality monitor from Oct. 1, 1975 to Sept. 30, 1981 .

REMARKS.--Quarterly cross-sectional samples were collected at or near bridge. Daily record of specific conductance for water year 1975 is from once-daily observer samples.

EXTREMES FOR PERIOD OF DAILY RECORD.--

SPECIFIC CONDUCTANCE (water years 1975-77, 1979-81): Maximum, 482 microsiemens, Dec. 2, 1976; minimum recorded, 131 microsiemens, May 22, 1976, but may have been lower during instrument maifunction May 1821,1976 .

WATER TEMPERATURE (water years 1956-81): Maximum, $31.0^{\circ} \mathrm{C}$, July 31,$1975 ;$ minimum, $0.0^{\circ} \mathrm{C}$ on many days during winter.

\begin{tabular}{|c|c|c|c|c|c|c|c|c|c|c|}
\hline & & WATER Q & UALITY DA & TA, WATER & YEAR OCT & OBER 1986 & TO SEPTE & MBER 1987 & & \\
\hline DATE & TIME & $\begin{array}{l}\text { STREAM- } \\
\text { FLOW, } \\
\text { INSTAN- } \\
\text { TANEOUS } \\
\text { (CFS) }\end{array}$ & $\begin{array}{l}\text { SPE- } \\
\text { CIFIC } \\
\text { CON- } \\
\text { DUCT- } \\
\text { ANCE } \\
\text { (US/CM) }\end{array}$ & $\begin{array}{c}\text { PH } \\
\text { (STAND- } \\
\text { ARD } \\
\text { UNITS) }\end{array}$ & $\begin{array}{l}\text { TEMPER- } \\
\text { ATURE } \\
\text { (DEG C) }\end{array}$ & $\begin{array}{l}\text { TUR- } \\
\text { BID- } \\
\text { ITY } \\
\text { (NTU) }\end{array}$ & $\begin{array}{c}\text { OXYGEN, } \\
\text { DIS- } \\
\text { SOLVED } \\
\text { (MG/L) }\end{array}$ & $\begin{array}{c}\text { OXYGEN, } \\
\text { DIS- } \\
\text { SOLVED } \\
\text { (PER- } \\
\text { CENT } \\
\text { SATUR- } \\
\text { ATION) }\end{array}$ & $\begin{array}{l}\text { COLI- } \\
\text { FORM, } \\
\text { FECAL, } \\
0.7 \\
\text { UM-MF } \\
\text { (COLS.' } \\
100 \mathrm{ML} \text { ) }\end{array}$ & $\begin{array}{c}\text { STREP- } \\
\text { TOCOCCI } \\
\text { FECAL, } \\
\text { KF AGAR } \\
\text { (COLS. } \\
\text { PER } \\
100 \mathrm{ML} \text { ) }\end{array}$ \\
\hline \multirow{4}{*}{$\begin{array}{c}\text { OCT } \\
28 \ldots \\
\text { JAN } \\
27 \ldots \\
\text { APR } \\
28 \ldots \\
\text { JUL } \\
28 \ldots \\
\end{array}$} & 1030 & 260 & 282 & 8.1 & 6.5 & 0.6 & 12.3 & 104 & K10 & K9 \\
\hline & 1215 & 50 & 424 & 7.8 & 0.0 & 0.7 & 8.6 & 61 & $\mathrm{~K} 6$ & K5 \\
\hline & 1515 & 525 & 250 & 8.4 & 11.0 & 1.7 & 12.2 & 114 & K3 & K2 \\
\hline & 1400 & 109 & 284 & 8.6 & 24.0 & 7.0 & 9.2 & 113 & 35 & K17 \\
\hline DATE & $\begin{array}{l}\text { HARD- } \\
\text { NESS } \\
\text { (MG/L } \\
\text { AS } \\
\text { CACO3) }\end{array}$ & $\begin{array}{l}\text { HARD- } \\
\text { NESS } \\
\text { NONCARB } \\
\text { WH WAT } \\
\text { TOT FLD } \\
\text { MG/L AS } \\
\text { CACO3 }\end{array}$ & $\begin{array}{l}\text { CALCIUM } \\
\text { DIS- } \\
\text { SOLVED } \\
\text { (MG/L } \\
\text { AS CA) }\end{array}$ & $\begin{array}{l}\text { MAGNE- } \\
\text { SIUM, } \\
\text { DIS- } \\
\text { SOLVED } \\
\text { (MG/L } \\
\text { AS MG) }\end{array}$ & $\begin{array}{l}\text { SODIUM, } \\
\text { DIS- } \\
\text { SOLVED } \\
\text { (MG/L } \\
\text { AS NA) }\end{array}$ & $\begin{array}{l}\text { PERCENT } \\
\text { SODIUM }\end{array}$ & $\begin{array}{l}\text { SODIUM } \\
\text { AD- } \\
\text { SORP- } \\
\text { TION } \\
\text { RATIO }\end{array}$ & $\begin{array}{l}\text { POTAS- } \\
\text { SIUM, } \\
\text { DIS- } \\
\text { SOLVED } \\
\text { (MG/L } \\
\text { AS K) }\end{array}$ & $\begin{array}{l}\text { BICAR- } \\
\text { BONATE } \\
\text { WH WAT } \\
\text { TOTAL } \\
\text { FIELD } \\
\text { MG/L AS } \\
\text { HCO3 }\end{array}$ & $\begin{array}{l}\text { CAR- } \\
\text { BONATE } \\
\text { WH WAT } \\
\text { TOTAL } \\
\text { FIELD } \\
\text { MG } / L \text { AS } \\
\text { CO3 }\end{array}$ \\
\hline \multirow{5}{*}{$\begin{array}{c}\text { OCT } \\
28 \ldots \\
\text { JAN } \\
27 \ldots \\
\text { APR } \\
28 \ldots \\
\text { JUL } \\
28 \ldots \\
28\end{array}$} & & & & & & & & & & \\
\hline & 160 & 39 & 38 & 17 & 1.6 & 2 & 0.1 & 0.7 & 150 & 0 \\
\hline & 240 & 14 & 53 & 25 & 2.2 & 2 & 0.1 & 1.0 & 270 & 0 \\
\hline & 140 & 22 & 33 & 13 & 1.3 & 2 & 0 & 0.6 & 140 & 2 \\
\hline & 170 & 19 & 37 & 18 & 1.6 & 2 & 0.1 & 0.8 & 180 & 2 \\
\hline DATE & $\begin{array}{l}\text { ALKA- } \\
\text { LINITY } \\
\text { WH WAT } \\
\text { TOTAL } \\
\text { FIELD } \\
\text { MG/L AS } \\
\text { CACO3 }\end{array}$ & $\begin{array}{c}\text { CARBON } \\
\text { DIOXIDE } \\
\text { DIS- } \\
\text { SOLVED } \\
\text { (MG/L } \\
\text { AS CO2) }\end{array}$ & $\begin{array}{l}\text { SULFATE } \\
\text { DIS- } \\
\text { SOLVED } \\
\text { (MG/L } \\
\text { AS SO4) }\end{array}$ & $\begin{array}{l}\text { CHLO- } \\
\text { RIDE, } \\
\text { DIS- } \\
\text { SOLVED } \\
\text { (MG/L } \\
\text { AS CL) }\end{array}$ & $\begin{array}{l}\text { FLUO- } \\
\text { RIDE, } \\
\text { DIS- } \\
\text { SOLVED } \\
\text { (MG/L } \\
\text { AS F) }\end{array}$ & $\begin{array}{l}\text { SILICA, } \\
\text { DIS- } \\
\text { SOLVED } \\
\text { (MG/L } \\
\text { AS } \\
\text { SIO2) }\end{array}$ & $\begin{array}{l}\text { SOLIDS, } \\
\text { RESIDUE } \\
\text { AT } 180 \\
\text { DEG. C } \\
\text { DIS- } \\
\text { SOLVED } \\
\text { (MG/L) }\end{array}$ & $\begin{array}{c}\text { SOLIDS, } \\
\text { SUM OF } \\
\text { CONSTI- } \\
\text { TUENTS, } \\
\text { DIS- } \\
\text { SOLVED } \\
\text { (MG/L) }\end{array}$ & $\begin{array}{c}\text { SOLIDS, } \\
\text { DIS- } \\
\text { SOLVED } \\
\text { (TONS } \\
\text { PER } \\
\text { AC-FT) }\end{array}$ & $\begin{array}{c}\text { SOLIDS, } \\
\text { DIS- } \\
\text { SOLVED } \\
\text { (TONS } \\
\text { PER } \\
\text { DAY) }\end{array}$ \\
\hline \multicolumn{11}{|l|}{ OCT } \\
\hline $\operatorname{JAN}^{28} \cdots$ & 126 & 1.9 & 17 & 2.5 & $<0.1$ & 7.0 & 178 & 160 & 0.24 & 125 \\
\hline$\stackrel{27 \ldots}{A P R}$ & 221 & 6.8 & 14 & 3.3 & $<0.1$ & 11 & 242 & 240 & 0.33 & 33 \\
\hline${ }_{\text {JUL }}^{28} \cdots$ & 114 & 0.9 & 13 & 1.9 & $<0.1$ & 2.6 & 142 & 140 & 0.19 & 201 \\
\hline $28 \ldots$ & 148 & 0.7 & 19 & 2.3 & 0.2 & 8.2 & 209 & 180 & 0.28 & 62 \\
\hline
\end{tabular}


04059500 FORD RIVER NEAR HYDE, MI--Continued WATER QUALITY DATA, WATER YEAR OCTOBER 1986 TO SEPTEMBER 1987

\begin{tabular}{|c|c|c|c|c|c|c|c|c|c|c|}
\hline DATE & $\begin{array}{c}\text { NITRO- } \\
\text { GEN, } \\
\text { NITRITE } \\
\text { DIS- } \\
\text { SOLVED } \\
\text { (MG/L } \\
\text { AS N) }\end{array}$ & $\begin{array}{l}\text { NITRO- } \\
\text { GEN, } \\
\text { NO2+NO3 } \\
\text { DIS- } \\
\text { SOLVED } \\
\text { (MG/L } \\
\text { AS N) }\end{array}$ & $\begin{array}{l}\text { NITRO- } \\
\text { GEN, } \\
\text { AMMONIA } \\
\text { TOTAL } \\
\text { (MG/L } \\
\text { AS N) }\end{array}$ & $\begin{array}{c}\text { NITRO- } \\
\text { GEN, } \\
\text { AMMONIA } \\
\text { DIS- } \\
\text { SOLVED } \\
\text { (MG/L } \\
\text { AS N) }\end{array}$ & $\begin{array}{c}\text { NITRO- } \\
\text { GEN, } \\
\text { ORGANIC } \\
\text { TOTAL } \\
\text { (MG/L } \\
\text { AS N) }\end{array}$ & $\begin{array}{l}\text { NITRO- } \\
\text { GEN,AM- } \\
\text { MONIA + } \\
\text { ORGANIC } \\
\text { TOTAL } \\
\text { (MG/L } \\
\text { AS N) }\end{array}$ & $\begin{array}{c}\text { PHOS- } \\
\text { PHORUS, } \\
\text { TOTAL } \\
\text { (MG/L } \\
\text { AS P) }\end{array}$ & $\begin{array}{c}\text { PHOS- } \\
\text { PHORUS, } \\
\text { DIS- } \\
\text { SOLVED } \\
\text { (MG/L } \\
\text { AS P) }\end{array}$ & $\begin{array}{l}\text { PHOS- } \\
\text { PHORUS, } \\
\text { ORTHO, } \\
\text { DIS- } \\
\text { SOLVED } \\
\text { (MG/L } \\
\text { AS P) }\end{array}$ & $\begin{array}{l}\text { ALUM- } \\
\text { INUM, } \\
\text { DIS- } \\
\text { SOLVED } \\
\text { (UG/L } \\
\text { AS AL) }\end{array}$ \\
\hline $\begin{array}{l}T \\
28 \ldots\end{array}$ & $<0.01$ & $<0.10$ & 0.04 & $<0.01$ & 0.46 & 0.5 & $<0.01$ & -- & $<0.01$ & 10 \\
\hline $27 \ldots$ & $<0.01$ & 0.19 & 0.05 & 0.06 & 0.25 & 0.3 & 0.01 & 0.01 & $<0.01$ & $<10$ \\
\hline $28 \ldots$ & $<0.01$ & $<0.10$ & 0.02 & 0.01 & 0.78 & 0.8 & 0.02 & 0.01 & $<0.01$ & 30 \\
\hline & $<0.01$ & $<0.10$ & 0.02 & 0.02 & 0.98 & 1.0 & 0.01 & 0.01 & $<0.01$ & 10 \\
\hline
\end{tabular}

\begin{tabular}{|c|c|c|c|c|c|c|c|c|c|c|}
\hline DATE & $\begin{array}{c}\text { ARSENIC } \\
\text { DIS- } \\
\text { SOLVED } \\
\text { (UG/L } \\
\text { AS AS) }\end{array}$ & $\begin{array}{l}\text { BAR IUM, } \\
\text { DIS- } \\
\text { SOLVED } \\
\text { (UG/L } \\
\text { AS BA) }\end{array}$ & $\begin{array}{l}\text { BERYL- } \\
\text { LIUM, } \\
\text { DIS- } \\
\text { SOLVED } \\
\text { (UG/L } \\
\text { AS BE) }\end{array}$ & $\begin{array}{c}\text { CADMIUM } \\
\text { DIS- } \\
\text { SOLVED } \\
\text { (UG/L } \\
\text { AS CD) }\end{array}$ & $\begin{array}{l}\text { CHRO- } \\
\text { MIUM, } \\
\text { DIS- } \\
\text { SOLVED } \\
\text { (UG/L } \\
\text { AS CR) }\end{array}$ & $\begin{array}{l}\text { COBALT, } \\
\text { DIS- } \\
\text { SOLVED } \\
\text { (UG/L } \\
\text { AS CO) }\end{array}$ & $\begin{array}{l}\text { COPPER, } \\
\text { DIS- } \\
\text { SOLVED } \\
\text { (UG/L } \\
\text { AS CU) }\end{array}$ & $\begin{array}{l}\text { IRON, } \\
\text { DIS- } \\
\text { SOLVED } \\
\text { (UG/L } \\
\text { AS FE) }\end{array}$ & $\begin{array}{l}\text { LEAD, } \\
\text { DIS- } \\
\text { SOLVED } \\
\text { (UG/L } \\
\text { AS PB) }\end{array}$ & $\begin{array}{c}\text { LITHIUM } \\
\text { DIS- } \\
\text { SOLVED } \\
\text { (UG/L } \\
\text { AS LI) }\end{array}$ \\
\hline$\cdots$ & $<1$ & 13 & 1 & $<1$ & $<1$ & $<3$ & 3 & 200 & $<5$ & 4 \\
\hline$\cdots$ & $<1$ & 17 & $<0.5$ & $<1$ & $<1$ & $<3$ & 5 & 74 & $<5$ & 5 \\
\hline$\cdots$ & $<1$ & 9 & $<0.5$ & 1 & $<1$ & $<3$ & 7 & 85 & $<5$ & $<4$ \\
\hline$\cdots$ & $<1$ & 12 & $<0.5$ & $<1$ & $<1$ & $<3$ & 3 & 110 & $<5$ & $<4$ \\
\hline
\end{tabular}

$\begin{array}{cllllllllll} & \text { MANGA- } & & \text { MOLYB- } & & \text { SELE- } & & \text { STRON- } & \text { VANA- } \\ & \text { NESE, } & \text { MERCURY } & \text { DENUM, } & \text { NICKEL, } & \text { NIUM, } & \text { SILVER, } & \text { TIUM, } & \text { DIUM, } & \text { 2INC, } & \text { SEDI- } \\ & \text { DIS- } & \text { DIS- } & \text { DIS- } & \text { DIS- } & \text { DIS- } & \text { DIS- } & \text { DIS- } & \text { DIS- } & \text { DIS- } & \text { MENT, } \\ & \text { SOLVED } & \text { SOLVED } & \text { SOLVED } & \text { SOLVED } & \text { SOLVED } & \text { SOLVED } & \text { SOLVED } & \text { SOLVED } & \text { SOLVED } & \text { SUS- } \\ \text { DATE } & \text { (UG/L } & \text { (UG/L } & \text { (UG/L } & \text { (UG/L } & \text { (UG/L } & \text { (UG/L } & \text { (UG/L } & \text { (UG/L } & \text { (UG/L } & \text { PENDED } \\ & \text { AS MN) } & \text { AS HG) } & \text { AS MO) } & \text { AS NI) } & \text { AS SE) } & \text { AS AG) } & \text { AS SR) } & \text { AS V) } & \text { AS ZN) } & \text { (MG/L) }\end{array}$

$\begin{array}{lrrrrrrrrrr}\mathrm{OCT} \\ 28 \ldots & 8 & <0.1 & <10 & <1 & <1 & <1 & 44 & <6 & 19 & 3 \\ \underset{\mathrm{JAN}}{27 \ldots} & 7 & <0.1 & <10 & <1 & <1 & <1 & 67 & <6 & 5 & -- \\ \underset{\mathrm{APR}}{28} \ldots & 13 & <0.1 & <10 & <1 & <1 & <1 & 37 & <6 & 10 & 5 \\ \underset{\mathrm{JUL}}{28} \ldots & 22 & 0.6 & <10 & 2 & <1 & 1 & 54 & <6 & 11 & 2\end{array}$


04061000 BRULE RIVER NEAR FLORENCE, WI

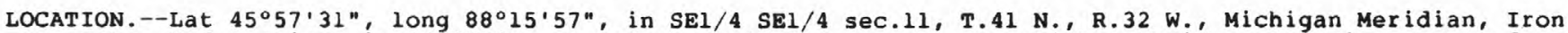
County, Hydrologic Unit 04030106 , on left bank 40 ft upstream from highway bridge, l.0 mi upstream from Paint River, $2.5 \mathrm{mi}$ north of Florence, WI, and $5.0 \mathrm{mi}$ upstream from confluence with Michigamme River.

DRAINAGE AREA. $--389 \mathrm{mi}^{2}$.

PERIOD OF RECORD.--January 1914 to February 1916, June 1944 to current year.

REVISED RECORDS.--WSP 1387: 1914-16. WSP 1911: Drainage area.

GAGE.--Water-stage recorder. Datum of gage is 1,200.55 ft above National Geodetic Vertical Datum of 1929 (levels by Owen Ayres Associates). Prior to Aug. 29, 1944, nonrecording gage at bridge 40 ft downstream at same datum.

REMARKS.--Estimated daily discharges: Nov. 11 to Mar. 20, Mar. 31, and Apr. 1. Records excellent except for estimated daily discharges, which are fair. Discharge includes some mine pumpage prior to August 1977. Several measurements of water temperature were made during the year.

AVERAGE DISCHARGE, - 44 years (water years $1915,1945-87$ ), $363 \mathrm{ft}^{3} / \mathrm{s}, 12.67 \mathrm{in} / \mathrm{yr}^{\mathrm{r}}$.

EXTREMES FOR PERIOD OF RECORD.--Maximum discharge, 4,700 ft $3 / \mathrm{s}$, July 2, 1953, gage height, 6.57 ft; maximum gage height, $8.60 \mathrm{ft}$, Dec. 20,1983 , backwater from ice; minimum discharge, $118 \mathrm{ft}^{3} / \mathrm{s}$, Dec. 2, 1963 (discharge measurement); minimum gage height, $1.79 \mathrm{ft}, \mathrm{Ju} 1 \mathrm{y} 24,1964$.

EXTREMES FOR CURRENT YEAR.--Maximum discharge, $953 \mathrm{ft}^{3} / \mathrm{s}$, Oct, 13, gage height, $3.29 \mathrm{ft}$; maximum gage height, $6.34 \mathrm{ft}$, Nov, 11, backwater from ice; minimum discharge, $183 \mathrm{ft} 3 / \mathrm{s}, \mathrm{Aug} .29$, 30 , gage height, $1.88 \mathrm{ft}$.

DISCHARGE, IN CUBIC FEET PER SECOND, WATER YEAR OCTOBER 1986 TO SEPTEMBER 1987 MEÁN VALUES

\begin{tabular}{|c|c|c|c|c|c|c|c|c|c|c|c|c|}
\hline DAY & OCT & NOV & DEC & JAN & FEB & MAR & APR & MAY & JUN & JUL & AUG & SEP \\
\hline $\begin{array}{l}1 \\
2 \\
3 \\
4 \\
5\end{array}$ & $\begin{array}{l}408 \\
359 \\
337 \\
323 \\
314\end{array}$ & $\begin{array}{l}328 \\
335 \\
313 \\
304 \\
304\end{array}$ & $\begin{array}{l}320 \\
325 \\
320 \\
310 \\
310\end{array}$ & $\begin{array}{l}300 \\
300 \\
300 \\
300 \\
305\end{array}$ & $\begin{array}{l}280 \\
290 \\
290 \\
280 \\
270\end{array}$ & $\begin{array}{l}290 \\
290 \\
290 \\
290 \\
280\end{array}$ & $\begin{array}{l}280 \\
299 \\
295 \\
297 \\
311\end{array}$ & $\begin{array}{l}277 \\
266 \\
260 \\
251 \\
249\end{array}$ & $\begin{array}{l}354 \\
358 \\
377 \\
325 \\
307\end{array}$ & $\begin{array}{l}206 \\
211 \\
265 \\
240 \\
218\end{array}$ & $\begin{array}{l}244 \\
580 \\
592 \\
435 \\
346\end{array}$ & $\begin{array}{l}191 \\
194 \\
199 \\
192 \\
193\end{array}$ \\
\hline $\begin{array}{r}6 \\
7 \\
8 \\
9 \\
10\end{array}$ & $\begin{array}{l}300 \\
293 \\
303 \\
314 \\
296\end{array}$ & $\begin{array}{l}308 \\
299 \\
321 \\
335 \\
304\end{array}$ & $\begin{array}{l}305 \\
290 \\
280 \\
280 \\
270\end{array}$ & $\begin{array}{l}300 \\
300 \\
290 \\
290 \\
280\end{array}$ & $\begin{array}{l}270 \\
260 \\
260 \\
270 \\
290\end{array}$ & $\begin{array}{l}300 \\
330 \\
370 \\
340 \\
320\end{array}$ & $\begin{array}{l}342 \\
361 \\
356 \\
342 \\
345\end{array}$ & $\begin{array}{l}255 \\
249 \\
236 \\
233 \\
233\end{array}$ & $\begin{array}{l}293 \\
273 \\
262 \\
253 \\
241\end{array}$ & $\begin{array}{l}208 \\
236 \\
233 \\
220 \\
223\end{array}$ & $\begin{array}{l}294 \\
283 \\
260 \\
249 \\
239\end{array}$ & $\begin{array}{l}190 \\
199 \\
196 \\
191 \\
186\end{array}$ \\
\hline $\begin{array}{l}11 \\
12 \\
13 \\
14 \\
15\end{array}$ & $\begin{array}{l}304 \\
730 \\
907 \\
714 \\
595\end{array}$ & $\begin{array}{l}300 \\
280 \\
250 \\
240 \\
300\end{array}$ & $\begin{array}{l}270 \\
260 \\
260 \\
270 \\
280\end{array}$ & $\begin{array}{l}280 \\
290 \\
290 \\
290 \\
290\end{array}$ & $\begin{array}{l}300 \\
290 \\
280 \\
270 \\
280\end{array}$ & $\begin{array}{l}310 \\
300 \\
300 \\
290 \\
290\end{array}$ & $\begin{array}{l}371 \\
357 \\
346 \\
355 \\
423\end{array}$ & $\begin{array}{l}235 \\
246 \\
240 \\
229 \\
225\end{array}$ & $\begin{array}{l}257 \\
291 \\
267 \\
248 \\
234\end{array}$ & $\begin{array}{l}296 \\
527 \\
503 \\
363 \\
297\end{array}$ & $\begin{array}{l}228 \\
221 \\
239 \\
249 \\
244\end{array}$ & $\begin{array}{l}191 \\
197 \\
197 \\
200 \\
192\end{array}$ \\
\hline $\begin{array}{l}16 \\
17 \\
18 \\
19 \\
20\end{array}$ & $\begin{array}{l}524 \\
468 \\
417 \\
385 \\
366\end{array}$ & $\begin{array}{l}310 \\
305 \\
270 \\
260 \\
270\end{array}$ & $\begin{array}{l}290 \\
290 \\
290 \\
290 \\
290\end{array}$ & $\begin{array}{l}260 \\
200 \\
230 \\
230 \\
240\end{array}$ & $\begin{array}{l}280 \\
280 \\
280 \\
280 \\
280\end{array}$ & $\begin{array}{l}285 \\
280 \\
275 \\
275 \\
275\end{array}$ & $\begin{array}{l}410 \\
381 \\
360 \\
346 \\
340\end{array}$ & $\begin{array}{l}231 \\
238 \\
243 \\
310 \\
394\end{array}$ & $\begin{array}{l}224 \\
214 \\
212 \\
213 \\
203\end{array}$ & $\begin{array}{l}265 \\
248 \\
239 \\
273 \\
267\end{array}$ & $\begin{array}{l}237 \\
226 \\
219 \\
214 \\
209\end{array}$ & $\begin{array}{l}186 \\
218 \\
243 \\
258 \\
270\end{array}$ \\
\hline $\begin{array}{l}21 \\
22 \\
23 \\
24 \\
25\end{array}$ & $\begin{array}{l}351 \\
335 \\
330 \\
326 \\
317\end{array}$ & $\begin{array}{l}290 \\
310 \\
320 \\
320 \\
320\end{array}$ & $\begin{array}{l}280 \\
270 \\
280 \\
290 \\
300\end{array}$ & $\begin{array}{l}250 \\
250 \\
240 \\
230 \\
230\end{array}$ & $\begin{array}{l}280 \\
280 \\
290 \\
290 \\
290\end{array}$ & $\begin{array}{l}281 \\
278 \\
294 \\
309 \\
317\end{array}$ & $\begin{array}{l}354 \\
340 \\
328 \\
318 \\
312\end{array}$ & $\begin{array}{l}355 \\
331 \\
328 \\
303 \\
286\end{array}$ & $\begin{array}{l}210 \\
210 \\
203 \\
198 \\
199\end{array}$ & $\begin{array}{l}287 \\
273 \\
245 \\
245 \\
263\end{array}$ & $\begin{array}{l}207 \\
209 \\
207 \\
195 \\
192\end{array}$ & $\begin{array}{l}260 \\
246 \\
243 \\
222 \\
210\end{array}$ \\
\hline $\begin{array}{l}26 \\
27 \\
28 \\
29 \\
30 \\
31\end{array}$ & $\begin{array}{l}313 \\
311 \\
308 \\
302 \\
296 \\
294\end{array}$ & $\begin{array}{l}310 \\
310 \\
320 \\
320 \\
320 \\
---\end{array}$ & $\begin{array}{l}300 \\
300 \\
300 \\
300 \\
300 \\
300\end{array}$ & $\begin{array}{l}230 \\
230 \\
230 \\
240 \\
260 \\
270\end{array}$ & $\begin{array}{l}290 \\
290 \\
280 \\
--- \\
--- \\
---\end{array}$ & $\begin{array}{l}314 \\
306 \\
294 \\
290 \\
283 \\
270\end{array}$ & $\begin{array}{l}317 \\
334 \\
311 \\
295 \\
284 \\
---\end{array}$ & $\begin{array}{l}298 \\
334 \\
385 \\
370 \\
427 \\
416\end{array}$ & $\begin{array}{l}208 \\
220 \\
221 \\
215 \\
220 \\
---\end{array}$ & $\begin{array}{l}240 \\
225 \\
218 \\
220 \\
215 \\
229\end{array}$ & $\begin{array}{l}190 \\
187 \\
187 \\
185 \\
192 \\
197\end{array}$ & $\begin{array}{l}202 \\
193 \\
189 \\
192 \\
194 \\
--\end{array}$ \\
\hline $\begin{array}{l}\text { TOTAL } \\
\text { MEAN } \\
\text { MAX } \\
\text { MIN } \\
\text { CESM } \\
\text { IN. }\end{array}$ & $\begin{array}{r}12140 \\
392 \\
907 \\
293 \\
1.01 \\
1.16\end{array}$ & $\begin{array}{r}9076 \\
303 \\
335 \\
240 \\
.78 \\
.87\end{array}$ & $\begin{array}{r}9020 \\
291 \\
325 \\
260 \\
.75 \\
.86\end{array}$ & $\begin{array}{r}8225 \\
265 \\
305 \\
200 \\
.68 \\
.79\end{array}$ & $\begin{array}{r}7870 \\
281 \\
300 \\
260 \\
.72 \\
.75\end{array}$ & $\begin{array}{r}9216 \\
297 \\
370 \\
270 \\
.76 \\
.88\end{array}$ & $\begin{array}{r}10110 \\
337 \\
423 \\
280 \\
.87 \\
.97\end{array}$ & $\begin{array}{r}8933 \\
288 \\
427 \\
225 \\
.74 \\
.85\end{array}$ & $\begin{array}{r}7510 \\
250 \\
377 \\
198 \\
.64 \\
.72\end{array}$ & $\begin{array}{r}8198 \\
264 \\
527 \\
206 \\
.68 \\
.78\end{array}$ & $\begin{array}{r}7956 \\
257 \\
592 \\
185 \\
.66 \\
.76\end{array}$ & $\begin{array}{r}6234 \\
208 \\
270 \\
186 \\
.54 \\
.60\end{array}$ \\
\hline
\end{tabular}

$\begin{array}{lllllllllll}\text { CAL YR } 1986 & \text { TOTAL } & 139188 & \text { MEAN } 381 & \text { MAX } & 2200 & \text { MIN } 236 & \text { CFSM } & .98 & \text { IN } 13.31 \\ \text { WTR } & \text { YR } 1987 & \text { TOTAL } & 104488 & \text { MEAN 286 } & \text { MAX } & 907 & \text { MIN } 185 & \text { CFSM } & 74 & \text { IN } 9.99\end{array}$ 
04061500 PAINT RIVER AT CRYSTAL FALLS, MI

LOCATION.--Lat $46^{\circ} 06^{\prime} 21^{\prime \prime}$, long $88^{\circ} 20^{\prime} 05^{\prime \prime}$, in SEl/4 sec.20, T.43 N., R.32 w., Iron County, Hydrologic Unit 04030106, on right bank $150 \mathrm{ft}$ downstream from municipal powerpiant at Crystal Falls, $14.5 \mathrm{mi}$ upstream
from mouth.

DRAINAGE AREA. $--597 \mathrm{mi}^{2}$.

PERIOD OF RECORD.--August 1944 to current year.

REVISED RECORDS.--WSP 1174: 1947-48(m). WSP 1911: Drainage area.

GAGE.--Water-stage recorder. Datum of gage is 1,306.1 ft above National Geodetic Vertical Datum of 1929 (wisconsin Electric Power Co. bench mark).

REMARKS.--Estimated daily discharges: Jan. 17 to Mar. 7. Records good except for estimated daily discharges, which are fair. Diurnal fluctuation caused by powerplant immediately upstream; since storage capacity is small, daily flows are not affected appreciably. Several measurements of water temperature were made during the year.

AVERAGE DISCHARGE. - -43 years, $604 \mathrm{ft}^{3} / \mathrm{s}, 13.74 \mathrm{in} / \mathrm{yr}^{\mathrm{r}}$

EXTREMES FOR PERIOD OF RECORD.--Maximum discharge, 10,900 $\mathrm{ft}^{3} / \mathrm{s}$, Apr. 25, 1960, gage height, 9.82

$\mathrm{ft}$; minimum, $7.7 \mathrm{ft} / \mathrm{s}$, Sept. 17,1950 , gage height, $0.89 \mathrm{ft}$; minimum daily, $81 \mathrm{ft} 3 / \mathrm{s}$, Nov. 1 , 1947 .

EXTREMES FOR CURRENT YEAR.--Maximum discharge, $1,650 \mathrm{ft}^{3} / \mathrm{s}$, Oct. 13, gage height, $4.02 \mathrm{ft}$; minimum,

$100 \mathrm{ft}^{3} / \mathrm{s}$, Sept. 9, 10, 11, 29, gage height, $1.60 \mathrm{ft} ; \mathrm{minimum}$ daily, $170 \mathrm{ft} / \mathrm{s}$, Sept. 13 .

DISCHARGE, IN CUBIC FEET PER SECOND, WATER YEAR OCTOBER 1986 TO SEPTEMBER 1987

MEAN VALUES

\begin{tabular}{|c|c|c|c|c|c|c|c|c|c|c|c|c|}
\hline DAY & OCT & NOV & DEC & JAN & FEB & MAR & APR & MAY & JUN & JUL & AUG & SEP \\
\hline $\begin{array}{l}1 \\
2 \\
3 \\
4 \\
5\end{array}$ & $\begin{array}{l}493 \\
434 \\
434 \\
409 \\
345\end{array}$ & $\begin{array}{l}473 \\
481 \\
482 \\
469 \\
468\end{array}$ & $\begin{array}{l}383 \\
392 \\
394 \\
371 \\
370\end{array}$ & $\begin{array}{l}342 \\
347 \\
346 \\
348 \\
335\end{array}$ & $\begin{array}{l}280 \\
300 \\
305 \\
300 \\
300\end{array}$ & $\begin{array}{l}285 \\
300 \\
290 \\
295 \\
315\end{array}$ & $\begin{array}{l}593 \\
520 \\
522 \\
497 \\
497\end{array}$ & $\begin{array}{l}391 \\
359 \\
317 \\
315 \\
307\end{array}$ & $\begin{array}{l}619 \\
652 \\
754 \\
686 \\
584\end{array}$ & $\begin{array}{l}220 \\
274 \\
433 \\
445 \\
340\end{array}$ & $\begin{array}{l}349 \\
525 \\
801 \\
938 \\
867\end{array}$ & $\begin{array}{l}237 \\
208 \\
250 \\
261 \\
236\end{array}$ \\
\hline $\begin{array}{r}6 \\
7 \\
8 \\
9 \\
10\end{array}$ & $\begin{array}{l}425 \\
373 \\
417 \\
429 \\
443\end{array}$ & $\begin{array}{l}451 \\
454 \\
463 \\
485 \\
473\end{array}$ & $\begin{array}{l}392 \\
373 \\
353 \\
362 \\
353\end{array}$ & $\begin{array}{l}349 \\
341 \\
342 \\
327 \\
329\end{array}$ & $\begin{array}{l}290 \\
295 \\
275 \\
300 \\
265\end{array}$ & $\begin{array}{l}325 \\
390 \\
516 \\
507 \\
458\end{array}$ & $\begin{array}{l}546 \\
591 \\
628 \\
626 \\
610\end{array}$ & $\begin{array}{l}295 \\
284 \\
286 \\
269 \\
217\end{array}$ & $\begin{array}{l}525 \\
429 \\
433 \\
373 \\
347\end{array}$ & $\begin{array}{l}373 \\
321 \\
321 \\
308 \\
327\end{array}$ & $\begin{array}{l}729 \\
647 \\
546 \\
418 \\
393\end{array}$ & $\begin{array}{l}180 \\
193 \\
305 \\
213 \\
208\end{array}$ \\
\hline $\begin{array}{l}11 \\
12 \\
13 \\
14 \\
15\end{array}$ & $\begin{array}{r}438 \\
940 \\
1550 \\
1470 \\
1300\end{array}$ & $\begin{array}{l}370 \\
389 \\
333 \\
336 \\
420\end{array}$ & $\begin{array}{l}336 \\
331 \\
333 \\
333 \\
338\end{array}$ & $\begin{array}{l}342 \\
344 \\
330 \\
339 \\
330\end{array}$ & $\begin{array}{l}285 \\
285 \\
295 \\
245 \\
285\end{array}$ & $\begin{array}{l}442 \\
431 \\
383 \\
380 \\
374\end{array}$ & $\begin{array}{l}683 \\
704 \\
707 \\
698 \\
707\end{array}$ & $\begin{array}{l}296 \\
315 \\
363 \\
357 \\
335\end{array}$ & $\begin{array}{l}337 \\
376 \\
377 \\
326 \\
349\end{array}$ & $\begin{array}{r}604 \\
963 \\
1090 \\
900 \\
762\end{array}$ & $\begin{array}{l}352 \\
322 \\
322 \\
333 \\
345\end{array}$ & $\begin{array}{l}219 \\
183 \\
170 \\
302 \\
235\end{array}$ \\
\hline $\begin{array}{l}16 \\
17 \\
18 \\
19 \\
20\end{array}$ & $\begin{array}{r}1180 \\
1070 \\
922 \\
810 \\
737\end{array}$ & $\begin{array}{l}418 \\
439 \\
393 \\
361 \\
375\end{array}$ & $\begin{array}{l}334 \\
338 \\
340 \\
327 \\
327\end{array}$ & $\begin{array}{l}311 \\
250 \\
255 \\
285 \\
265\end{array}$ & $\begin{array}{l}275 \\
280 \\
275 \\
270 \\
270\end{array}$ & $\begin{array}{l}363 \\
370 \\
374 \\
376 \\
403\end{array}$ & $\begin{array}{l}695 \\
696 \\
631 \\
578 \\
554\end{array}$ & $\begin{array}{l}287 \\
286 \\
354 \\
421 \\
552\end{array}$ & $\begin{array}{l}293 \\
270 \\
265 \\
267 \\
235\end{array}$ & $\begin{array}{l}660 \\
573 \\
468 \\
423 \\
392\end{array}$ & $\begin{array}{l}348 \\
388 \\
342 \\
315 \\
298\end{array}$ & $\begin{array}{l}240 \\
263 \\
275 \\
288 \\
288\end{array}$ \\
\hline $\begin{array}{l}21 \\
22 \\
23 \\
24 \\
25\end{array}$ & $\begin{array}{l}687 \\
618 \\
591 \\
578 \\
540\end{array}$ & $\begin{array}{l}405 \\
392 \\
417 \\
415 \\
409\end{array}$ & $\begin{array}{l}299 \\
282 \\
301 \\
310 \\
340\end{array}$ & $\begin{array}{l}285 \\
285 \\
285 \\
260 \\
265\end{array}$ & $\begin{array}{l}265 \\
270 \\
290 \\
280 \\
290\end{array}$ & $\begin{array}{l}420 \\
449 \\
480 \\
538 \\
592\end{array}$ & $\begin{array}{l}566 \\
551 \\
519 \\
491 \\
462\end{array}$ & $\begin{array}{l}578 \\
613 \\
658 \\
576 \\
547\end{array}$ & $\begin{array}{l}189 \\
269 \\
250 \\
222 \\
207\end{array}$ & $\begin{array}{l}477 \\
473 \\
432 \\
428 \\
432\end{array}$ & $\begin{array}{l}339 \\
279 \\
272 \\
343 \\
293\end{array}$ & $\begin{array}{l}412 \\
334 \\
324 \\
300 \\
314\end{array}$ \\
\hline $\begin{array}{l}26 \\
27 \\
28 \\
29 \\
30 \\
31\end{array}$ & $\begin{array}{l}477 \\
532 \\
515 \\
441 \\
451 \\
459\end{array}$ & $\begin{array}{l}426 \\
412 \\
417 \\
407 \\
400 \\
---\end{array}$ & $\begin{array}{l}346 \\
346 \\
345 \\
341 \\
339 \\
340\end{array}$ & $\begin{array}{l}265 \\
255 \\
260 \\
275 \\
265 \\
265\end{array}$ & $\begin{array}{l}280 \\
300 \\
275 \\
--- \\
--- \\
---\end{array}$ & $\begin{array}{l}650 \\
670 \\
661 \\
647 \\
543 \\
528\end{array}$ & $\begin{array}{l}440 \\
431 \\
436 \\
421 \\
389 \\
-\end{array}$ & $\begin{array}{l}533 \\
536 \\
582 \\
562 \\
618 \\
633\end{array}$ & $\begin{array}{l}255 \\
234 \\
197 \\
296 \\
253 \\
\end{array}$ & $\begin{array}{l}360 \\
372 \\
302 \\
312 \\
279 \\
319\end{array}$ & $\begin{array}{l}276 \\
249 \\
257 \\
245 \\
184 \\
280\end{array}$ & $\begin{array}{l}275 \\
253 \\
309 \\
232 \\
254 \\
---\end{array}$ \\
\hline $\begin{array}{l}\text { TOTAL } \\
\text { MEAN } \\
\text { MAX } \\
\text { MIN } \\
\text { CFSM } \\
\text { IN. }\end{array}$ & $\begin{array}{r}20508 \\
662 \\
1550 \\
345 \\
1.11 \\
1.28\end{array}$ & $\begin{array}{r}12633 \\
421 \\
485 \\
333 \\
.71 \\
.79\end{array}$ & $\begin{array}{r}10669 \\
344 \\
394 \\
282 \\
.58 \\
.66\end{array}$ & $\begin{array}{r}9422 \\
304 \\
349 \\
250 \\
.51 \\
.59\end{array}$ & $\begin{array}{r}7925 \\
283 \\
305 \\
245 \\
.47 \\
.49\end{array}$ & $\begin{array}{r}13755 \\
444 \\
670 \\
285 \\
.74 \\
.86\end{array}$ & $\begin{array}{r}16989 \\
566 \\
707 \\
389 \\
.95 \\
1.06\end{array}$ & $\begin{array}{r}13042 \\
421 \\
658 \\
217 \\
.71 \\
.81\end{array}$ & $\begin{array}{r}10869 \\
362 \\
754 \\
189 \\
.61 \\
.68\end{array}$ & $\begin{array}{r}14383 \\
464 \\
1090 \\
220 \\
.78 \\
.90\end{array}$ & $\begin{array}{r}12595 \\
406 \\
938 \\
184 \\
.68 \\
.78\end{array}$ & $\begin{array}{l}7761 \\
259 \\
412 \\
170 \\
.43 \\
.48\end{array}$ \\
\hline $\begin{array}{ll}\text { CAL } & \text { YR } \\
\text { WTR } & \text { YR }\end{array}$ & $\begin{array}{l}1986 \\
1987\end{array}$ & $\begin{array}{ll}\text { CAL } & 2 \\
\text { CAL } & 1\end{array}$ & $\begin{array}{l}10 \\
51\end{array}$ & $\begin{array}{l}613 \\
N \quad 412\end{array}$ & $\begin{array}{l}\text { MAX } \\
\text { MAX }\end{array}$ & $\begin{array}{l}\text { MIN } \\
\text { MIN }\end{array}$ & $\begin{array}{l}198 \\
170\end{array}$ & $\begin{array}{lr}\text { ESM } & 1.03 \\
\text { ESM } & .69\end{array}$ & $\begin{array}{l}\text { IN } \\
\text { IN }\end{array}$ & $\begin{array}{l}93 \\
38\end{array}$ & & \\
\hline
\end{tabular}


LOCATION, - Lat $46^{\circ} 00^{\prime} 40^{\prime \prime}$, long $88^{\circ} 15^{\prime} 30^{\prime \prime}$, in NWl/4 NWl/4 sec. 25, T.42 N., R. 32 W. , Iron County, Hydrologic Unit 04030106 , on right bank $0.6 \mathrm{mi}$ downstream from Lower Paint Dam, $5.5 \mathrm{mi}$ upstream from Brule River, and $6.0 \mathrm{mi}$ southeast of Alpha.

DRAINAGE AREA. $--631 \mathrm{mi}^{2}$.

PERIOD OF RECORD.--June 1952 to current year. Monthly discharge only for period October 1953 to September 1960, published in WSP 1727 .

REVISED RECORDS.--WSP 1727: Drainage area.

GAGE.--Water-stage recorder. Elevation of gage is 1,260 ft above National Geodetic Vertical Datum of 1929, from topographic map

REMARKS.--Estimated daily discharges: Nov. 9-11, 13, 18, 19, 25, 27, Dec. 3 to Mar. 17, Mar. 31 to Apr. 3. Records good. Flow completely regulated by powerplant and Lower Paint Dam, $0.6 \mathrm{mi}$ upstream. Records not adjusted for diversion to Michigamme River by Paint River Diversion Canal. Several measurements of water temperature were made during the year.

AVERAGE DISCHARGE.--35 years, $175 \mathrm{ft}^{3} / \mathrm{s}$.

EXTREMES FOR PERIOD OF RECORD.--Maximum discharge, 8,050 $\mathrm{ft}^{3} / \mathrm{s}$, July 2, 1953, gage height, 10.50 ft; minimum daily, $62 \mathrm{ft} 3 / \mathrm{s}$, Mar. 22,1963 .

EXTREMES FOR CURRENT YEAR.--Maximum discharge, $974 \mathrm{ft}^{3} / \mathrm{s}$, Aug. 19, gage height, 4.77 $\mathrm{ft}$; minimum daily, $78 \mathrm{ft}^{3} / \mathrm{s}, \mathrm{Mar} .30,31$.

DISCHARGE, IN CUBIC FEET PER SECOND, WATER YEAR OCTOBER 1986 TO SEPTEMBER 1987 MEAN VALUES

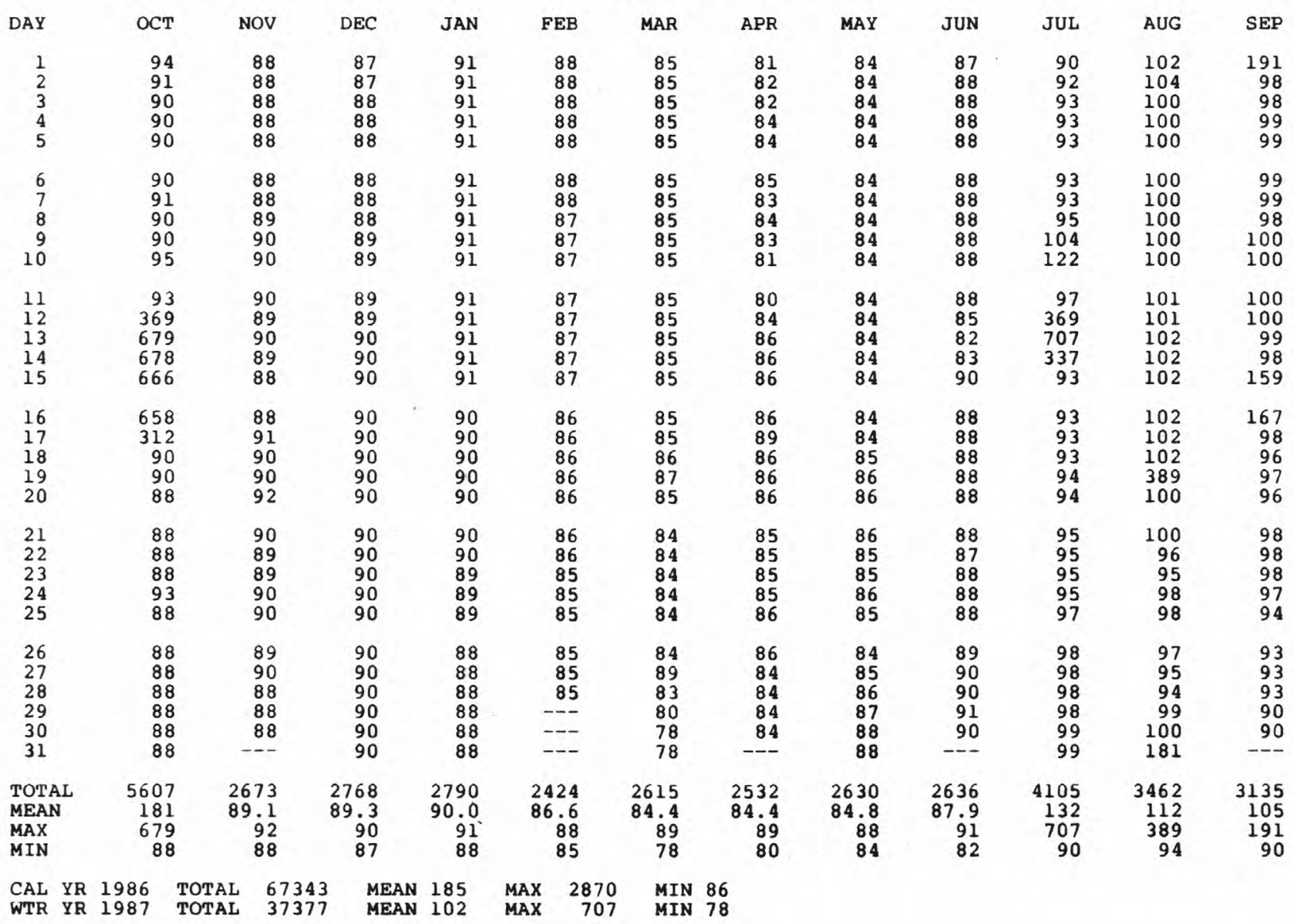




\section{LAKE MICHIGAMME NEAR CHAMPION, MI}

LOCATION.--Lat $46^{\circ} 31^{\prime} 39^{\prime \prime}$, long $88^{\circ} 00^{\prime} 1^{\prime \prime}$, in NE1/4 SWl/4 sec.25, T.48 N., R.30 W., Marquette County, Hydrologic Unit 04030107 , on left bank $60 \mathrm{ft}$ downstream from railroad bridge, at mouth of Peshekee River, $2.1 \mathrm{mi}$ northwest of Champion.

DRAINAGE AREA. $--193 \mathrm{mi}^{2}$.

PERIOD OF RECORD.--July 1942 to current year.

GAGE.--Water-stage recorder. Datum of gage is $1,548.83 \mathrm{ft}$ above National Geodetic Vertical Datum of 1929 (levels by Michigan Department of Natural Resources). Prior to Aug. 8, 1962, nonrecording gage at same site and datum.

REMARKS.--Major inlets to Lake Michigamme are Peshekee River and Spurr River. The outlet is Michigamme River. Streamflow records were collected for Michigamme River (station 04062230) from October 1968 to September 1982 and for Peshekee River (station 04062200) from July 1961 to September 1978. It has been determined that the gage records river stage rather than lake stage when the lake stage falls below a gage height of about $0.10 \mathrm{ft}$. This last occurred during the 1976 and 1977 water years. Lake stage for this period was determined on the basis of stage-discharge relation at the lake outlet using discharge figures from station 04062230 . Surface area of lake is 4,260 acres.

EXTREMES FOR PERIOD OF RECORD.--Maximum gage height, $8.49 \mathrm{ft}$, Apr. 21, 22 or 23, 1985, from floodmark; minimum, $-0.50 \mathrm{ft}$, Sept. 30, Oct. 1, 1976.

EXTREMES FOR CURRENT YEAR.--Maximum gage height, $3.24 \mathrm{ft}$, Aug. 6 ; minimum, $1.11 \mathrm{ft}$, Oct. 3, 4, 6, 7, July 6,7 .

GAGE HEIGHT (FEET ABOVE DATUM), WATER YEAR OCTOBER 1986 TO SEPTEMBER 1987 MEAN VALUES

\begin{tabular}{|c|c|c|c|c|c|c|c|c|c|c|c|c|}
\hline DAY & OCT & NOV & DEC & JAN & FEB & MAR & APR & MAY & JUN & JUL & AUG & SE \\
\hline $\begin{array}{l}1 \\
2 \\
3 \\
4 \\
5\end{array}$ & $\begin{array}{l}1.14 \\
1.13 \\
1.12 \\
1.12 \\
1.14\end{array}$ & $\begin{array}{l}2.02 \\
1.99 \\
1.95 \\
1.93 \\
1.91\end{array}$ & $\begin{array}{l}1.65 \\
1.64 \\
1.66 \\
1.68 \\
1.67\end{array}$ & $\begin{array}{l}1.48 \\
1.46 \\
1.45 \\
1.44 \\
1.41\end{array}$ & $\begin{array}{l}1.48 \\
1.48 \\
1.51 \\
1.52 \\
1.50\end{array}$ & $\begin{array}{l}1.31 \\
1.37 \\
1.38 \\
1.37 \\
1.36\end{array}$ & $\begin{array}{l}2.57 \\
2.61 \\
2.57 \\
2.53 \\
2.51\end{array}$ & $\begin{array}{l}2.32 \\
2.24 \\
2.17 \\
2.12 \\
2.07\end{array}$ & $\begin{array}{l}2.39 \\
2.43 \\
2.42 \\
2.35 \\
2.29\end{array}$ & $\begin{array}{l}1.18 \\
1.18 \\
1.19 \\
1.16 \\
1.14\end{array}$ & $\begin{array}{l}2.00 \\
2.40 \\
2.80 \\
3.08 \\
3.21\end{array}$ & $\begin{array}{l}2.17 \\
2.12 \\
2.08 \\
2.04 \\
2.00\end{array}$ \\
\hline $\begin{array}{r}6 \\
7 \\
8 \\
9 \\
10\end{array}$ & $\begin{array}{l}1.12 \\
1.12 \\
1.16 \\
1.20 \\
1.21\end{array}$ & $\begin{array}{l}1.87 \\
1.85 \\
1.94 \\
1.95 \\
1.87\end{array}$ & $\begin{array}{l}1.67 \\
1.67 \\
1.66 \\
1.66 \\
1.66\end{array}$ & $\begin{array}{l}1.40 \\
1.41 \\
1.42 \\
1.43 \\
1.42\end{array}$ & $\begin{array}{l}1.51 \\
1.49 \\
1.49 \\
1.46 \\
1.46\end{array}$ & $\begin{array}{l}1.37 \\
1.43 \\
1.58 \\
1.70 \\
1.73\end{array}$ & $\begin{array}{l}2.49 \\
2.51 \\
2.56 \\
2.63 \\
2.73\end{array}$ & $\begin{array}{l}2.01 \\
1.95 \\
1.91 \\
1.87 \\
1.82\end{array}$ & $\begin{array}{l}2.23 \\
2.18 \\
2.12 \\
2.05 \\
1.99\end{array}$ & $\begin{array}{l}1.12 \\
1.12 \\
1.14 \\
1.17 \\
1.21\end{array}$ & $\begin{array}{l}3.22 \\
3.14 \\
3.03 \\
2.92 \\
2.79\end{array}$ & $\begin{array}{l}1.86 \\
1.82\end{array}$ \\
\hline $\begin{array}{l}11 \\
12 \\
13 \\
14 \\
15\end{array}$ & $\begin{array}{l}1.21 \\
1.62 \\
1.91 \\
2.04 \\
2.17\end{array}$ & $\begin{array}{l}1.85 \\
1.85 \\
1.84 \\
1.81 \\
1.77\end{array}$ & $\begin{array}{l}1.66 \\
1.66 \\
1.66 \\
1.66 \\
1.65\end{array}$ & $\begin{array}{l}1.41 \\
1.40 \\
1.40 \\
1.39 \\
1.39\end{array}$ & $\begin{array}{l}1.46 \\
1.49 \\
1.48 \\
1.47 \\
1.46\end{array}$ & $\begin{array}{l}1.75 \\
1.73 \\
1.70 \\
1.67 \\
1.64\end{array}$ & $\begin{array}{l}2.84 \\
2.95 \\
3.03 \\
3.08 \\
3.11\end{array}$ & $\begin{array}{l}1.81 \\
1.76 \\
1.72 \\
1.67 \\
1.64\end{array}$ & $\begin{array}{l}1.98 \\
1.95 \\
1.90 \\
1.86 \\
1.82\end{array}$ & $\begin{array}{l}1.32 \\
1.47 \\
1.52 \\
1.53 \\
1.53\end{array}$ & $\begin{array}{l}2.68 \\
2.58 \\
2.66 \\
2.82 \\
3.00\end{array}$ & $\begin{array}{l}1.7 \\
1.7\end{array}$ \\
\hline $\begin{array}{l}16 \\
17 \\
18 \\
19 \\
20\end{array}$ & $\begin{array}{l}2.27 \\
2.36 \\
2.43 \\
2.45 \\
2.45\end{array}$ & $\begin{array}{l}1.76 \\
1.76 \\
1.74 \\
1.72 \\
1.73\end{array}$ & $\begin{array}{l}1.63 \\
1.62 \\
1.62 \\
1.61 \\
1.60\end{array}$ & $\begin{array}{l}1.40 \\
1.40 \\
1.41 \\
1.42 \\
1.43\end{array}$ & $\begin{array}{l}1.45 \\
1.43 \\
1.41 \\
1.40 \\
1.38\end{array}$ & $\begin{array}{l}1.63 \\
1.61 \\
1.60 \\
1.58 \\
1.58\end{array}$ & $\begin{array}{l}3.12 \\
3.11 \\
3.08 \\
3.08 \\
2.97\end{array}$ & $\begin{array}{l}1.61 \\
1.57 \\
1.54 \\
1.65 \\
1.72\end{array}$ & $\begin{array}{l}1.76 \\
1.71 \\
1.66 \\
1.60 \\
1.56\end{array}$ & $\begin{array}{l}1.54 \\
1.55 \\
1.55 \\
2.14 \\
2.47\end{array}$ & $\begin{array}{l}3.09 \\
3.11 \\
3.03 \\
2.97 \\
2.90\end{array}$ & $\begin{array}{l}1.6 \\
1.7 \\
1.7\end{array}$ \\
\hline $\begin{array}{l}21 \\
22 \\
23 \\
24 \\
25\end{array}$ & $\begin{array}{l}2.43 \\
2.41 \\
2.36 \\
2.31 \\
2.27\end{array}$ & $\begin{array}{l}1.73 \\
1.71 \\
1.72 \\
1.72 \\
1.71\end{array}$ & $\begin{array}{l}1.58 \\
1.57 \\
1.56 \\
1.56 \\
1.55\end{array}$ & $\begin{array}{l}1.42 \\
1.42 \\
1.43 \\
1.44 \\
1.46\end{array}$ & $\begin{array}{l}1.37 \\
1.37 \\
1.35 \\
1.34 \\
1.32\end{array}$ & $\begin{array}{l}1.59 \\
1.61 \\
1.68 \\
1.80 \\
1.93\end{array}$ & $\begin{array}{l}2.92 \\
2.87 \\
2.82 \\
2.76 \\
2.68\end{array}$ & $\begin{array}{l}1.79 \\
1.83 \\
1.91 \\
1.99 \\
2.05\end{array}$ & $\begin{array}{l}1.51 \\
1.48 \\
1.43 \\
1.40 \\
1.37\end{array}$ & $\begin{array}{l}2.56 \\
2.62 \\
2.62 \\
2.57 \\
2.50\end{array}$ & $\begin{array}{l}2.87 \\
2.82 \\
2.74 \\
2.67 \\
2.60\end{array}$ & $\begin{array}{l}1.9 \\
1.9\end{array}$ \\
\hline $\begin{array}{l}26 \\
27 \\
28 \\
29 \\
30 \\
31\end{array}$ & $\begin{array}{l}2.22 \\
2.17 \\
2.13 \\
2.11 \\
2.06 \\
2.05\end{array}$ & $\begin{array}{l}1.70 \\
1.69 \\
1.68 \\
1.67 \\
1.66\end{array}$ & $\begin{array}{l}1.54 \\
1.52 \\
1.51 \\
1.50 \\
1.49 \\
1.49\end{array}$ & $\begin{array}{l}1.47 \\
1.48 \\
1.47 \\
1.46 \\
1.48 \\
1.48\end{array}$ & \begin{tabular}{r}
1.31 \\
1.30 \\
1.29 \\
\hdashline-- \\
--
\end{tabular} & $\begin{array}{l}2.11 \\
2.24 \\
2.36 \\
2.50 \\
2.57 \\
2.53\end{array}$ & $\begin{array}{l}2.62 \\
2.59 \\
2.51 \\
2.44 \\
2.38\end{array}$ & $\begin{array}{l}2.13 \\
2.19 \\
2.26 \\
2.31 \\
2.36 \\
2.38\end{array}$ & $\begin{array}{l}1.35 \\
1.30 \\
1.26 \\
1.23 \\
1.21\end{array}$ & $\begin{array}{l}2.41 \\
2.32 \\
2.23 \\
2.15 \\
2.07 \\
2.00\end{array}$ & $\begin{array}{l}2.53 \\
2.46 \\
2.38 \\
2.32 \\
2.28 \\
2.23\end{array}$ & 1. \\
\hline $\begin{array}{l}\text { MEAN } \\
\text { MAX } \\
\text { MIN }\end{array}$ & $\begin{array}{l}1.84 \\
2.45 \\
1.12\end{array}$ & $\begin{array}{l}1.80 \\
2.02 \\
1.66\end{array}$ & $\begin{array}{l}1.61 \\
1.68 \\
1.49\end{array}$ & $\begin{array}{l}1.43 \\
1.48 \\
1.39\end{array}$ & $\begin{array}{l}1.43 \\
1.52 \\
1.29\end{array}$ & $\begin{array}{l}1.74 \\
2.57 \\
1.31\end{array}$ & $\begin{array}{l}2.76 \\
3.12 \\
2.38\end{array}$ & $\begin{array}{l}1.95 \\
2.38 \\
1.54\end{array}$ & $\begin{array}{l}1.79 \\
2.43 \\
1.21\end{array}$ & $\begin{array}{l}1.75 \\
2.62 \\
1.12\end{array}$ & $\begin{array}{l}2.75 \\
3.22 \\
2.00\end{array}$ & $\begin{array}{l}2.1 \\
1.6\end{array}$ \\
\hline
\end{tabular}

WTR YR 1987 MEAN 1.90 MAX 3.22 MIN 1.12 
04062500 MICHIGAMME RIVER NEAR CRYSTAL FALLS, MI

LOCATION.--Lat $46^{\circ} 06^{\prime} 50^{\prime \prime}$, long $88^{\circ} 12^{\prime} 57^{\prime \prime}$, in NW1/4 sec. 20 , T.43 N., R.31 W. Iron County, Hydrologic Unit 04030107, on right bank $400 \mathrm{ft}$ upstream from highway bridge, $5.0 \mathrm{mi}$ downstream from Michigamme Reservoir, $6.0 \mathrm{mi}$ east of Crystal Falls, and $15 \mathrm{mi}$ upstream from confluence with Brule River.

DRAINAGE AREA. $--656 \mathrm{mi}^{2}$.

PERIOD OF RECORD.--August 1944 to current year.

REVISED RECORDS.--WSP 1911: Drainage area.

GAGE.--Water-stage recorder. Elevation of gage is 1,300 ft above National Geodetic Vertical Datum of 1929 , from topographic map.

REMARKS. - No estimated daily discharges. Records good. Flow regulated by powerplant and by Michigamme Reservoir, capacity, 119,950 acre-ft, $5 \mathrm{mi}$ upstream. Several measurements of water temperature were made during the year.

AVERAGE DISCHARGE. --43 years, $714 \mathrm{ft}^{3} / \mathrm{s}$.

EXTREMES FOR PERIOD OF RECORD.--Maximum discharge, $7,260 \mathrm{ft}^{3} / \mathrm{s}$, Apr. 28, 1960, gage height, 10.73 ft; minimum daily, $71 \mathrm{ft}^{3} / \mathrm{s}$, Nov. 26,1950 .

EXTREMES FOR CURRENT YEAR.--Maximum discharge, 1,530 $\mathrm{ft}^{3} / \mathrm{s}, \mathrm{Mar} .17$, gage height, 5.40 ft; minimum daily, $116 \mathrm{ft}^{3} / \mathrm{s}$, May is.

DISCHARGE, IN CUBIC FEET PER SECOND, WATER YEAR OCTOBER 1986 TO SEPTEMBER 1987

MEAN VALUES

\begin{tabular}{|c|c|c|c|c|c|c|c|c|c|c|c|c|}
\hline DAY & OCT & NOV & DEC & JAN & FEB & MAR & APR & MAY & JUN & JUL & AUG & SEP \\
\hline $\begin{array}{l}1 \\
2 \\
3 \\
4 \\
5\end{array}$ & $\begin{array}{l}162 \\
161 \\
164 \\
162 \\
162\end{array}$ & $\begin{array}{l}161 \\
159 \\
160 \\
156 \\
142\end{array}$ & $\begin{array}{l}675 \\
717 \\
717 \\
712 \\
710\end{array}$ & $\begin{array}{l}902 \\
899 \\
768 \\
675 \\
675\end{array}$ & $\begin{array}{l}846 \\
843 \\
839 \\
837 \\
835\end{array}$ & $\begin{array}{l}922 \\
911 \\
903 \\
897 \\
889\end{array}$ & $\begin{array}{l}132 \\
131 \\
132 \\
133 \\
136\end{array}$ & $\begin{array}{l}140 \\
139 \\
133 \\
130 \\
130\end{array}$ & $\begin{array}{l}147 \\
340 \\
189 \\
174 \\
177\end{array}$ & $\begin{array}{l}604 \\
626 \\
366 \\
193 \\
189\end{array}$ & $\begin{array}{l}799 \\
189 \\
190 \\
504 \\
700\end{array}$ & $\begin{array}{r}1140 \\
1130 \\
714 \\
520 \\
520\end{array}$ \\
\hline $\begin{array}{r}6 \\
7 \\
8 \\
9 \\
10\end{array}$ & $\begin{array}{l}159 \\
161 \\
163 \\
162 \\
161\end{array}$ & $\begin{array}{l}141 \\
141 \\
144 \\
146 \\
145\end{array}$ & $\begin{array}{l}708 \\
708 \\
751 \\
794 \\
791\end{array}$ & $\begin{array}{l}675 \\
672 \\
672 \\
671 \\
669\end{array}$ & $\begin{array}{l}832 \\
831 \\
825 \\
825 \\
821\end{array}$ & $\begin{array}{l}884 \\
878 \\
874 \\
864 \\
838\end{array}$ & $\begin{array}{l}139 \\
142 \\
143 \\
139 \\
135\end{array}$ & $\begin{array}{l}130 \\
129 \\
126 \\
119 \\
119\end{array}$ & $\begin{array}{l}174 \\
173 \\
170 \\
168 \\
167\end{array}$ & $\begin{array}{l}479 \\
610 \\
406 \\
188 \\
188\end{array}$ & $\begin{array}{r}953 \\
1160 \\
1160 \\
1160 \\
1150\end{array}$ & $\begin{array}{l}520 \\
517 \\
518 \\
516 \\
517\end{array}$ \\
\hline $\begin{array}{l}11 \\
12 \\
13 \\
14 \\
15\end{array}$ & $\begin{array}{l}162 \\
205 \\
201 \\
195 \\
189\end{array}$ & $\begin{array}{l}143 \\
142 \\
143 \\
142 \\
144\end{array}$ & $\begin{array}{l}792 \\
788 \\
787 \\
787 \\
785\end{array}$ & $\begin{array}{l}762 \\
828 \\
827 \\
826 \\
823\end{array}$ & $\begin{array}{l}820 \\
816 \\
814 \\
810 \\
808\end{array}$ & $\begin{array}{r}757 \\
707 \\
856 \\
1090 \\
1120\end{array}$ & $\begin{array}{l}136 \\
137 \\
138 \\
143 \\
144\end{array}$ & $\begin{array}{l}122 \\
119 \\
119 \\
119 \\
116\end{array}$ & $\begin{array}{l}175 \\
172 \\
169 \\
168 \\
167\end{array}$ & $\begin{array}{l}232 \\
270 \\
267 \\
242 \\
508\end{array}$ & $\begin{array}{l}1150 \\
1140 \\
1150 \\
1140 \\
1120\end{array}$ & $\begin{array}{l}290 \\
417 \\
517 \\
300 \\
161\end{array}$ \\
\hline $\begin{array}{l}16 \\
17 \\
18 \\
19 \\
20\end{array}$ & $\begin{array}{l}189 \\
185 \\
182 \\
180 \\
180\end{array}$ & $\begin{array}{l}144 \\
144 \\
144 \\
144 \\
145\end{array}$ & $\begin{array}{l}784 \\
783 \\
781 \\
779 \\
777\end{array}$ & $\begin{array}{l}822 \\
820 \\
819 \\
816 \\
815\end{array}$ & $\begin{array}{l}805 \\
802 \\
799 \\
796 \\
792\end{array}$ & $\begin{array}{r}1140 \\
1020 \\
750 \\
545 \\
379\end{array}$ & $\begin{array}{l}152 \\
153 \\
152 \\
149 \\
149\end{array}$ & $\begin{array}{l}123 \\
122 \\
120 \\
134 \\
132\end{array}$ & $\begin{array}{l}167 \\
166 \\
166 \\
165 \\
162\end{array}$ & $\begin{array}{ll}6 & 30 \\
6 & 20 \\
6 & 13 \\
6 & 13 \\
6 & 12\end{array}$ & $\begin{array}{l}1140 \\
1130 \\
1130 \\
1130 \\
1160\end{array}$ & $\begin{array}{l}160 \\
166 \\
386 \\
522 \\
520\end{array}$ \\
\hline $\begin{array}{l}21 \\
22 \\
23 \\
24 \\
25\end{array}$ & $\begin{array}{l}179 \\
178 \\
176 \\
175 \\
175\end{array}$ & $\begin{array}{l}144 \\
144 \\
145 \\
144 \\
404\end{array}$ & $\begin{array}{l}777 \\
775 \\
775 \\
775 \\
774\end{array}$ & $\begin{array}{l}814 \\
812 \\
809 \\
806 \\
804\end{array}$ & $\begin{array}{l}790 \\
787 \\
783 \\
750 \\
855\end{array}$ & $\begin{array}{l}124 \\
128 \\
131 \\
133 \\
133\end{array}$ & $\begin{array}{l}148 \\
146 \\
148 \\
146 \\
146\end{array}$ & $\begin{array}{l}132 \\
133 \\
129 \\
128 \\
127\end{array}$ & $\begin{array}{l}162 \\
163 \\
162 \\
162 \\
353\end{array}$ & $\begin{array}{l}611 \\
608 \\
607 \\
774 \\
934\end{array}$ & $\begin{array}{l}1170 \\
1170 \\
1160 \\
1160 \\
1160\end{array}$ & $\begin{array}{l}323 \\
156 \\
156 \\
155 \\
155\end{array}$ \\
\hline $\begin{array}{l}26 \\
27 \\
28 \\
29 \\
30 \\
31\end{array}$ & $\begin{array}{l}178 \\
177 \\
178 \\
178 \\
177 \\
176\end{array}$ & $\begin{array}{l}622 \\
622 \\
621 \\
623 \\
622 \\
-\end{array}$ & $\begin{array}{l}772 \\
770 \\
768 \\
766 \\
842 \\
903\end{array}$ & $\begin{array}{l}835 \\
857 \\
853 \\
853 \\
851 \\
847\end{array}$ & $\begin{array}{l}940 \\
928 \\
926 \\
--- \\
--- \\
----\end{array}$ & $\begin{array}{l}132 \\
130 \\
132 \\
135 \\
134 \\
132\end{array}$ & $\begin{array}{l}150 \\
149 \\
141 \\
142 \\
138 \\
---\end{array}$ & $\begin{array}{l}132 \\
137 \\
148 \\
149 \\
152 \\
148\end{array}$ & $\begin{array}{l}678 \\
639 \\
609 \\
608 \\
606 \\
-\end{array}$ & $\begin{array}{l}932 \\
930 \\
928 \\
926 \\
928 \\
930\end{array}$ & $\begin{array}{l}1160 \\
1160 \\
1150 \\
1150 \\
1150 \\
1140\end{array}$ & $\begin{array}{l}155 \\
156 \\
156 \\
155 \\
154 \\
-\end{array}$ \\
\hline $\begin{array}{l}\text { TOTAL } \\
\text { MEAN } \\
\text { MAX } \\
\text { MIN }\end{array}$ & $\begin{array}{r}5432 \\
175 \\
205 \\
159\end{array}$ & $\begin{array}{r}7021 \\
234 \\
623 \\
141\end{array}$ & $\begin{array}{r}23823 \\
768 \\
903 \\
675\end{array}$ & $\begin{array}{r}24577 \\
793 \\
902 \\
669\end{array}$ & $\begin{array}{r}23155 \\
827 \\
940 \\
750\end{array}$ & $\begin{array}{r}18668 \\
602 \\
1140 \\
124\end{array}$ & $\begin{array}{r}4269 \\
142 \\
153 \\
131\end{array}$ & $\begin{array}{r}4036 \\
130 \\
152 \\
116\end{array}$ & $\begin{array}{r}7698 \\
257 \\
678 \\
147\end{array}$ & $\begin{array}{r}17564 \\
567 \\
934 \\
188\end{array}$ & $\begin{array}{r}32085 \\
1035 \\
1170 \\
189\end{array}$ & $\begin{array}{r}11772 \\
392 \\
1140 \\
154\end{array}$ \\
\hline
\end{tabular}

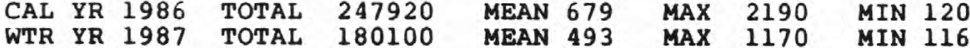


LOCATION.--Lat $45^{\circ} 57^{\prime} 04^{\prime \prime}$, long $88^{\circ} 11^{\prime} 13^{\prime \prime}$, in NEl/4 sec.16, T.41 N., R.31 W., Michigan Meridian, Iron County. Hydrologic Unit 04030108 , on left bank $0.5 \mathrm{mi}$ downstream from confluence of Brule and Michigamme Rivers, $3.5 \mathrm{mi}$ northeast of Florence, WI, and at mile 117.

DRA INAGE AREA. - - $1,780 \mathrm{mi}^{2}$.

PERIOD OF RECORD.--January 1914 to current year. Published as "at Twin Falls near Iron Mountain, MI"

1914-57. Records published for both sites July 1950 to September 1957.

REVISED RECORDS.--WSP 1707: 1953(M). WSP 1911: Drainage area of former site.

GAGE.--Water-stage recorder. Datum of gage is 1,119.23 ft above National Geodetic Vertical Datum of 1929 (levels by Owen Ayres Associates). Prior to July 1950, headwater and tailwater gages and generation data entered hourly in daily log sheets by company employees at the Twin Falls Powerplant of wisconsin Electric Power Co., $10.4 \mathrm{mi}$ downstream.

REMARKS. - No estimated daily discharges. Records excellent. Prior to July 1950, discharge determined from powerplant records computed on basis of load-discharge rating of hydroelectric units and rating for tailwater gage during periods of spill. Rating developed by U.S. Geological Survey. Flow regulated by powerplants, by Michigamme Reservoir, capacity, 119,950 acre-ft, by Peavy Pond, capacity, 33,860 acre-ft, on Michigamme River, and by many smaller reservoirs upstream from station. Several measurements of water temperature were made during the year.

AVERAGE DISCHARGE. - -73 years, $1,821 \mathrm{ft}^{3} / \mathrm{s}$.

EXTREMES FOR PERIOD OF RECORD.--Maximum discharge, 19,500 ft $3 / \mathrm{s}$, Apr. 26, 1960, gage height, 14.15 ft; minimum, $38 \mathrm{ft}^{3} / \mathrm{s}$, Aug. 21 , 1962, Sept. 26, 1975; minimum gage height, $1.18 \mathrm{ft}$, Aug. 21 , 1962, Nov. 4, 1965; minimum daily discharge, $57 \mathrm{ft}^{3} / \mathrm{s}$, Sept. 26, 1975.

EXTREMES FOR CURRENT YEAR.--Maximum discharge, 3,410 $\mathrm{ft}^{3} / \mathrm{s}$, Oct. 12, gage height, $5.79 \mathrm{ft}$; minimum, $217 \mathrm{ft} / \mathrm{s}$, June 26 , gage height, $1.91 \mathrm{ft} ; \mathrm{minimum}$ daily, $356 \mathrm{ft} / \mathrm{s}$, May 23 .

DISCHARGE, IN CUBIC FEET PER SECOND, WATER YEAR OCTOBER 1986 TO SEPTEMBER 1987 MEAN VALUES

\begin{tabular}{|c|c|c|c|c|c|c|c|c|c|c|c|c|}
\hline DAY & OCT & NOV & DEC & JAN & FEB & MAR & APR & MAY & JUN & JUL & AUG & SEP \\
\hline $\begin{array}{l}1 \\
2 \\
3 \\
4 \\
5\end{array}$ & $\begin{array}{r}1500 \\
1270 \\
1190 \\
1050 \\
693\end{array}$ & $\begin{array}{r}992 \\
880 \\
1060 \\
1090 \\
1060\end{array}$ & $\begin{array}{l}1500 \\
1490 \\
1450 \\
1410 \\
1560\end{array}$ & $\begin{array}{l}1460 \\
1440 \\
1470 \\
1360 \\
1560\end{array}$ & $\begin{array}{l}1510 \\
1550 \\
1510 \\
1450 \\
1460\end{array}$ & $\begin{array}{l}1480 \\
1460 \\
1440 \\
1490 \\
1360\end{array}$ & $\begin{array}{l}1770 \\
2060 \\
1920 \\
1880 \\
1890\end{array}$ & $\begin{array}{l}857 \\
711 \\
710 \\
659 \\
660\end{array}$ & $\begin{array}{r}962 \\
1100 \\
1440 \\
1510 \\
1370\end{array}$ & $\begin{array}{l}994 \\
988 \\
966 \\
926 \\
820\end{array}$ & $\begin{array}{l}1440 \\
2390 \\
2240 \\
1680 \\
1820\end{array}$ & $\begin{array}{r}1690 \\
1700 \\
1300 \\
803 \\
961\end{array}$ \\
\hline $\begin{array}{r}6 \\
7 \\
8 \\
9 \\
10\end{array}$ & $\begin{array}{r}763 \\
806 \\
966 \\
1000 \\
1000\end{array}$ & $\begin{array}{r}1150 \\
966 \\
718 \\
999 \\
804\end{array}$ & $\begin{array}{l}1450 \\
1440 \\
1350 \\
1580 \\
1370\end{array}$ & $\begin{array}{l}1570 \\
1260 \\
1310 \\
1320 \\
1320\end{array}$ & $\begin{array}{l}1390 \\
1430 \\
1450 \\
1490 \\
1500\end{array}$ & $\begin{array}{l}1490 \\
1490 \\
1650 \\
1720 \\
1350\end{array}$ & $\begin{array}{l}1690 \\
1400 \\
1220 \\
1190 \\
1110\end{array}$ & $\begin{array}{l}726 \\
630 \\
551 \\
547 \\
451\end{array}$ & $\begin{array}{r}815 \\
708 \\
930 \\
1120 \\
883\end{array}$ & $\begin{array}{r}1000 \\
993 \\
1190 \\
1220 \\
1060\end{array}$ & $\begin{array}{l}1720 \\
1850 \\
2050 \\
1910 \\
1710\end{array}$ & $\begin{array}{r}957 \\
953 \\
982 \\
986 \\
1030\end{array}$ \\
\hline $\begin{array}{l}11 \\
12 \\
13 \\
14 \\
15\end{array}$ & $\begin{array}{r}656 \\
2090 \\
2890 \\
2590 \\
2390\end{array}$ & $\begin{array}{r}928 \\
979 \\
1000 \\
872 \\
679\end{array}$ & $\begin{array}{l}1470 \\
1460 \\
1360 \\
1480 \\
1410\end{array}$ & $\begin{array}{l}1360 \\
1460 \\
1400 \\
1460 \\
1470\end{array}$ & $\begin{array}{l}1490 \\
1360 \\
1490 \\
1280 \\
1410\end{array}$ & $\begin{array}{l}1370 \\
1510 \\
1730 \\
1880 \\
2010\end{array}$ & $\begin{array}{l}1070 \\
1110 \\
1080 \\
1130 \\
1180\end{array}$ & $\begin{array}{l}587 \\
474 \\
601 \\
601 \\
503\end{array}$ & $\begin{array}{r}712 \\
1040 \\
658 \\
740 \\
906\end{array}$ & $\begin{array}{l}1090 \\
2260 \\
3140 \\
2540 \\
1630\end{array}$ & $\begin{array}{l}1600 \\
1680 \\
1790 \\
2100 \\
2230\end{array}$ & $\begin{array}{l}931 \\
874 \\
930 \\
922 \\
907\end{array}$ \\
\hline $\begin{array}{l}16 \\
17 \\
18 \\
19 \\
20\end{array}$ & $\begin{array}{l}2390 \\
2070 \\
1630 \\
1540 \\
1510\end{array}$ & $\begin{array}{r}487 \\
912 \\
924 \\
889 \\
1200\end{array}$ & $\begin{array}{l}1500 \\
1590 \\
1440 \\
1530 \\
1380\end{array}$ & $\begin{array}{l}1460 \\
1290 \\
1420 \\
1440 \\
1440\end{array}$ & $\begin{array}{l}1520 \\
1430 \\
1450 \\
1450 \\
1500\end{array}$ & $\begin{array}{l}1970 \\
2070 \\
2180 \\
1810 \\
1800\end{array}$ & $\begin{array}{l}1250 \\
1050 \\
1090 \\
1130 \\
1180\end{array}$ & $\begin{array}{l}553 \\
519 \\
544 \\
715 \\
733\end{array}$ & $\begin{array}{l}846 \\
919 \\
959 \\
844 \\
540\end{array}$ & $\begin{array}{l}1520 \\
1550 \\
1160 \\
1250 \\
1250\end{array}$ & $\begin{array}{l}2000 \\
1680 \\
1870 \\
1590 \\
1480\end{array}$ & $\begin{array}{l}913 \\
846 \\
921 \\
773 \\
804\end{array}$ \\
\hline $\begin{array}{l}21 \\
22 \\
23 \\
24 \\
25\end{array}$ & $\begin{array}{l}1360 \\
1320 \\
1320 \\
1420 \\
1090\end{array}$ & $\begin{array}{r}1130 \\
678 \\
615 \\
1140 \\
1120\end{array}$ & $\begin{array}{l}1540 \\
1380 \\
1430 \\
1470 \\
1520\end{array}$ & $\begin{array}{l}1650 \\
1240 \\
1470 \\
1270 \\
1410\end{array}$ & $\begin{array}{l}1310 \\
1410 \\
1530 \\
1430 \\
1360\end{array}$ & $\begin{array}{l}1980 \\
2150 \\
2350 \\
2180 \\
1840\end{array}$ & $\begin{array}{l}955 \\
896 \\
949 \\
900 \\
563\end{array}$ & $\begin{array}{l}554 \\
546 \\
356 \\
459 \\
453\end{array}$ & $\begin{array}{l}533 \\
818 \\
690 \\
607 \\
795\end{array}$ & $\begin{array}{l}1370 \\
1610 \\
1530 \\
1570 \\
1550\end{array}$ & $\begin{array}{l}1420 \\
1710 \\
1580 \\
1670 \\
1660\end{array}$ & $\begin{array}{l}837 \\
791 \\
804 \\
811 \\
860\end{array}$ \\
\hline $\begin{array}{l}26 \\
27 \\
28 \\
29 \\
30 \\
31\end{array}$ & $\begin{array}{l}939 \\
1040 \\
1100 \\
1160 \\
1060 \\
1090\end{array}$ & $\begin{array}{l}1510 \\
1440 \\
1490 \\
1560 \\
1530 \\
---\end{array}$ & $\begin{array}{l}1480 \\
1440 \\
1520 \\
1520 \\
1360 \\
1550\end{array}$ & $\begin{array}{l}1510 \\
1380 \\
1530 \\
1390 \\
1440 \\
1300\end{array}$ & $\begin{array}{r}1540 \\
1440 \\
1360 \\
--- \\
---\end{array}$ & $\begin{array}{l}2080 \\
1770 \\
1790 \\
1860 \\
1560 \\
1590\end{array}$ & $\begin{array}{l}450 \\
825 \\
769 \\
755 \\
856 \\
---\end{array}$ & $\begin{array}{l}557 \\
573 \\
630 \\
699 \\
608 \\
666\end{array}$ & $\begin{array}{r}876 \\
962 \\
879 \\
998 \\
1020 \\
---\end{array}$ & $\begin{array}{l}1560 \\
1540 \\
1570 \\
1650 \\
1540 \\
1510\end{array}$ & $\begin{array}{l}1620 \\
1680 \\
1630 \\
1660 \\
1640 \\
1840\end{array}$ & $\begin{array}{l}855 \\
783 \\
836 \\
810 \\
732\end{array}$ \\
\hline $\begin{array}{l}\text { TOTAL } \\
\text { MEAN } \\
\text { MAX } \\
\text { MIN }\end{array}$ & $\begin{array}{r}42893 \\
1384 \\
2890 \\
656\end{array}$ & $\begin{array}{r}30802 \\
1027 \\
1560 \\
487\end{array}$ & $\begin{array}{r}45430 \\
1465 \\
1590 \\
1350\end{array}$ & $\begin{array}{r}43860 \\
1415 \\
1650 \\
1240\end{array}$ & $\begin{array}{r}40500 \\
1446 \\
1550 \\
1280\end{array}$ & $\begin{array}{r}54410 \\
1755 \\
2350 \\
1350\end{array}$ & $\begin{array}{r}35318 \\
1177 \\
2060 \\
450\end{array}$ & $\begin{array}{r}18433 \\
595 \\
857 \\
356\end{array}$ & $\begin{array}{r}27180 \\
906 \\
1510 \\
533\end{array}$ & $\begin{array}{r}44547 \\
1437 \\
3140 \\
820\end{array}$ & $\begin{array}{r}54940 \\
1772 \\
2390 \\
1420\end{array}$ & $\begin{array}{r}28302 \\
943 \\
1700 \\
732\end{array}$ \\
\hline $\begin{array}{l}\text { CAL YR } \\
\text { WTR YR }\end{array}$ & $\begin{array}{l}1986 \\
1987\end{array}$ & $\begin{array}{ll}A L & 6 \\
A L & 4\end{array}$ & $\begin{array}{l}53 \\
15\end{array}$ & $\begin{array}{ll}\text { AN } & 1812 \\
\text { AN } & 1278\end{array}$ & $\begin{array}{l}\text { MAX } \\
\text { MAX }\end{array}$ & $\begin{array}{l}9930 \\
3140\end{array}$ & $\begin{array}{ll}\text { MIN } & 450 \\
\text { MIN } & 356\end{array}$ & & & & & \\
\hline
\end{tabular}


04066003 MENOMINEE RIVER BELOW PEMENE CREEK NEAR PEMBINE, WI

LOCATION.--Lat $45^{\circ} 34^{\prime} 46^{\prime \prime}$, long $87^{\circ} 47^{\prime} 13^{\prime \prime}$, in NEl/4 sec.29, T.37 N., R.28 W., Michigan Meridian, Menominee County, Hydrologic Unit 04030108 , on left bank $40 \mathrm{ft}$ downstream from County Trunk $z$ bridge, 0.9 mi downstream from Pemene creek, $3.9 \mathrm{mi}$ west of Nathan, $10.6 \mathrm{mi}$ southeast of Pembine, wI, and at mile 64.3.

DRAINAGE AREA. $--3,140 \mathrm{mi}^{2}$.

PERIOD OF RECORD.--October 1949 to current year. Published as "near Pembine, WI" prior to August 1982. Monthly discharge only for some periods, pubiished in WSP 1307 .

GAGE.--Water-stage recorder. Elevation of gage is $740 \mathrm{ft}$ above National Geodetic Vertical Datum of 1929, from topographic map. October 1949 to oct. 27 , 1972, water-stage recorder at site 1.0 mi upstream at different datum, and oct. 28, 1972, to August i 982 , water-stage recorder at site $1.5 \mathrm{mi}$ upstream at different datum.

REMARKS.--Estimated daily discharges: Nov. 14, 15, Dec. 4 to Mar. 7, and May 5-29. Records good except for estimated daily discharges, which are fair. Flow regulated by powerplants, by Michigamme Reservoir, capacity, 119,950 acre-ft, by Peavy Pond, capacity, 33,860 acre-ft, on michigamme River, and
by many smaller reservoirs upstream from station.

AVERAGE DISCHARGE.--38 years, $3,010 \mathrm{ft}^{3} / \mathrm{s}$.

EXTREMES FOR PERIOD OF RECORD.--Maximum discharge, 26,900 ft3/s, May 8, 1960, gage height, 13.90 ft, site and datum then in use; minimum, $694 \mathrm{ft}^{3} / \mathrm{s}$, Sept. 3, 1969, gage height, $1.66 \mathrm{ft}$, site and datum then in use.

EXTREMES FOR CURRENT YEAR.--Maximum discharge, $6,820 \mathrm{ft}^{3} / \mathrm{s}$, Oct. 13, gage height, $10.59 \mathrm{ft}$; maximum gage height, $13.22 \mathrm{ft}$, Jan. 30, backwater from ice; minimum daily discharge, $1,040 \mathrm{ft} 3 / \mathrm{s}, \mathrm{June} 22$, but may have been less during estimated period, May 5-29.

DISCHARGE, IN CUBIC FEET PER SECOND, WATER YEAR OCTOBER 1986 TO SEPTEMBER 1987

\begin{tabular}{|c|c|c|c|c|c|c|c|c|c|c|c|c|}
\hline DAY & OCT & NOV & DEC & JAN & FEB & MAR & APR & MAY & JUN & JUL & AUG & SEP \\
\hline $\begin{array}{l}1 \\
2 \\
3 \\
4 \\
5\end{array}$ & $\begin{array}{l}2940 \\
2660 \\
2400 \\
2220 \\
1930\end{array}$ & $\begin{array}{l}2080 \\
1590 \\
1800 \\
1980 \\
1790\end{array}$ & $\begin{array}{l}2120 \\
2220 \\
2030 \\
2000 \\
2200\end{array}$ & $\begin{array}{l}2000 \\
2100 \\
2200 \\
2200 \\
2000\end{array}$ & $\begin{array}{l}1700 \\
1800 \\
1900 \\
1900 \\
1800\end{array}$ & $\begin{array}{l}1800 \\
1800 \\
1900 \\
1900 \\
1800\end{array}$ & $\begin{array}{l}2340 \\
2500 \\
2720 \\
2490 \\
2670\end{array}$ & $\begin{array}{l}1930 \\
1780 \\
1460 \\
1550 \\
1450\end{array}$ & $\begin{array}{l}2320 \\
2620 \\
2550 \\
2360 \\
2160\end{array}$ & $\begin{array}{l}1360 \\
1310 \\
1510 \\
1480 \\
1130\end{array}$ & $\begin{array}{l}2410 \\
2950 \\
4200 \\
3630 \\
2730\end{array}$ & $\begin{array}{l}2250 \\
2080 \\
1830 \\
1450 \\
1240\end{array}$ \\
\hline $\begin{array}{r}6 \\
7 \\
8 \\
9 \\
10\end{array}$ & $\begin{array}{l}1880 \\
1800 \\
1670 \\
1680 \\
1790\end{array}$ & $\begin{array}{l}1870 \\
1910 \\
1920 \\
1780 \\
1680\end{array}$ & $\begin{array}{l}2100 \\
1900 \\
1800 \\
1800 \\
1700\end{array}$ & $\begin{array}{l}2200 \\
2000 \\
1800 \\
1800 \\
1800\end{array}$ & $\begin{array}{l}1800 \\
1800 \\
1700 \\
1700 \\
1800\end{array}$ & $\begin{array}{l}1900 \\
2000 \\
2430 \\
2540 \\
2270\end{array}$ & $\begin{array}{l}2770 \\
2760 \\
2750 \\
2640 \\
2380\end{array}$ & $\begin{array}{l}1340 \\
1300 \\
1300 \\
1200 \\
1200\end{array}$ & $\begin{array}{l}2040 \\
1570 \\
1510 \\
1530 \\
1450\end{array}$ & $\begin{array}{l}1300 \\
1410 \\
1590 \\
1400 \\
1450\end{array}$ & $\begin{array}{l}2760 \\
2590 \\
2700 \\
2630 \\
2700\end{array}$ & $\begin{array}{l}1320 \\
1290 \\
1350 \\
1430 \\
1250\end{array}$ \\
\hline $\begin{array}{l}11 \\
12 \\
13 \\
14 \\
15\end{array}$ & $\begin{array}{l}2110 \\
2250 \\
5930 \\
5950 \\
5370\end{array}$ & $\begin{array}{l}1770 \\
1790 \\
1950 \\
2000 \\
1600\end{array}$ & $\begin{array}{l}1700 \\
1700 \\
1600 \\
1600 \\
2000\end{array}$ & $\begin{array}{l}1900 \\
1900 \\
1900 \\
1800 \\
1900\end{array}$ & $\begin{array}{l}1900 \\
1900 \\
1800 \\
1800 \\
1700\end{array}$ & $\begin{array}{l}2010 \\
2030 \\
2160 \\
2570 \\
2530\end{array}$ & $\begin{array}{l}2370 \\
2360 \\
2470 \\
2230 \\
2750\end{array}$ & $\begin{array}{l}1100 \\
1100 \\
1100 \\
1200 \\
1200\end{array}$ & $\begin{array}{l}1500 \\
1510 \\
1470 \\
1340 \\
1330\end{array}$ & $\begin{array}{l}1790 \\
2330 \\
3560 \\
3990 \\
2890\end{array}$ & $\begin{array}{l}2260 \\
2100 \\
2460 \\
2830 \\
2840\end{array}$ & $\begin{array}{l}1160 \\
1450 \\
1280 \\
1340 \\
1320\end{array}$ \\
\hline $\begin{array}{l}16 \\
17 \\
18 \\
19 \\
20\end{array}$ & $\begin{array}{l}5290 \\
4850 \\
4080 \\
3200 \\
3170\end{array}$ & $\begin{array}{l}1290 \\
1320 \\
1530 \\
1720 \\
1690\end{array}$ & $\begin{array}{l}2000 \\
2200 \\
2200 \\
2000 \\
1800\end{array}$ & $\begin{array}{l}1700 \\
1600 \\
1600 \\
1600 \\
1700\end{array}$ & $\begin{array}{l}1700 \\
1800 \\
1800 \\
1700 \\
1700\end{array}$ & $\begin{array}{l}2440 \\
2600 \\
2700 \\
2570 \\
2230\end{array}$ & $\begin{array}{l}2950 \\
2930 \\
2820 \\
2670 \\
2750\end{array}$ & $\begin{array}{l}1100 \\
1100 \\
1100 \\
1100 \\
1100\end{array}$ & $\begin{array}{l}1300 \\
1330 \\
1300 \\
1320 \\
1240\end{array}$ & $\begin{array}{l}2290 \\
2310 \\
2050 \\
1820 \\
1900\end{array}$ & $\begin{array}{l}2470 \\
2600 \\
2450 \\
2200 \\
2240\end{array}$ & $\begin{array}{l}1270 \\
1370 \\
1370 \\
1470 \\
1580\end{array}$ \\
\hline $\begin{array}{l}21 \\
22 \\
23 \\
24 \\
25\end{array}$ & $\begin{array}{l}3140 \\
2770 \\
2550 \\
2550 \\
2490\end{array}$ & $\begin{array}{l}1850 \\
1860 \\
1330 \\
1490 \\
1780\end{array}$ & $\begin{array}{l}1800 \\
1700 \\
1700 \\
1800 \\
1900\end{array}$ & $\begin{array}{l}1600 \\
1800 \\
1700 \\
1600 \\
1500\end{array}$ & $\begin{array}{l}1700 \\
1700 \\
1700 \\
1800 \\
1800\end{array}$ & $\begin{array}{l}2480 \\
2630 \\
2780 \\
2930 \\
3080\end{array}$ & $\begin{array}{l}2520 \\
2300 \\
2420 \\
2530 \\
2340\end{array}$ & $\begin{array}{l}1200 \\
1300 \\
1100 \\
1100 \\
1100\end{array}$ & $\begin{array}{l}1060 \\
1040 \\
1070 \\
1070 \\
1070\end{array}$ & $\begin{array}{l}2150 \\
2050 \\
2090 \\
2180 \\
2130\end{array}$ & $\begin{array}{l}1890 \\
2020 \\
2050 \\
2070 \\
2200\end{array}$ & $\begin{array}{l}1380 \\
1680 \\
1440 \\
1370 \\
1360\end{array}$ \\
\hline $\begin{array}{l}26 \\
27 \\
28 \\
29 \\
30 \\
31\end{array}$ & $\begin{array}{l}2220 \\
2110 \\
2090 \\
2130 \\
2190 \\
2120\end{array}$ & $\begin{array}{l}1980 \\
2070 \\
2120 \\
2310 \\
2170 \\
---\end{array}$ & $\begin{array}{l}2000 \\
2000 \\
2000 \\
2000 \\
1800 \\
1900\end{array}$ & $\begin{array}{l}1500 \\
1500 \\
1600 \\
1700 \\
1700 \\
1600\end{array}$ & $\begin{array}{c}1900 \\
1900 \\
1800 \\
-0- \\
-\cdots\end{array}$ & $\begin{array}{l}2740 \\
2710 \\
2760 \\
2640 \\
2420 \\
2340\end{array}$ & $\begin{array}{l}2030 \\
2020 \\
2280 \\
2070 \\
1830 \\
---\end{array}$ & $\begin{array}{l}1140 \\
1200 \\
1600 \\
1800 \\
2070 \\
2250\end{array}$ & $\begin{array}{l}1190 \\
1240 \\
1310 \\
1150 \\
1240\end{array}$ & $\begin{array}{l}2070 \\
1970 \\
2070 \\
1850 \\
1880 \\
1970\end{array}$ & $\begin{array}{l}2050 \\
1870 \\
1880 \\
2040 \\
2110 \\
2010\end{array}$ & $\begin{array}{l}1330 \\
1410 \\
1220 \\
1200 \\
1140\end{array}$ \\
\hline $\begin{array}{l}\text { TOTAL } \\
\text { MEAN } \\
\text { MAX } \\
\text { MIN }\end{array}$ & $\begin{array}{r}89530 \\
2888 \\
5950 \\
1670\end{array}$ & $\begin{array}{r}54020 \\
1801 \\
2310 \\
1290\end{array}$ & $\begin{array}{r}59270 \\
1912 \\
2220 \\
1600\end{array}$ & $\begin{array}{r}55500 \\
1790 \\
2200 \\
1500\end{array}$ & $\begin{array}{r}50000 \\
1786 \\
1900 \\
1700\end{array}$ & $\begin{array}{r}73690 \\
2377 \\
3080 \\
1800\end{array}$ & $\begin{array}{r}74660 \\
2489 \\
2950 \\
1830\end{array}$ & $\begin{array}{r}41570 \\
1341 \\
2250 \\
1100\end{array}$ & $\begin{array}{r}45190 \\
1506 \\
2620 \\
1040\end{array}$ & $\begin{array}{r}61280 \\
1977 \\
3990 \\
1130\end{array}$ & $\begin{array}{r}75940 \\
2450 \\
4200 \\
1870\end{array}$ & $\begin{array}{r}42630 \\
1421 \\
2250 \\
1140\end{array}$ \\
\hline
\end{tabular}

CAL YR 1986 TOTAL 1099020 MEAN 3011 MAX 18200 MIN 1180 
04096400 ST. JOSEPH RIVER NEAR BURLINGTON, MI

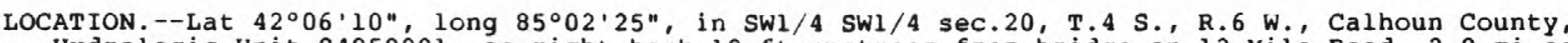
Hydrologic Unit 04050001 , on right bank $10 \mathrm{ft}$ upstream from bridge on $13 \mathrm{mile}$ Road, $2.0 \mathrm{mi}$ east of Burlington, $4.0 \mathrm{mi}$ downstream from Tekonsha Creek, and at mile 164.

DRAINAGE AREA. $--201 \mathrm{mi}^{2}$.

PERIOD OF RECORD.--October 1962 to current year.

GAGE.--Water-stage recorder. Datum of gage is $916.21 \mathrm{ft}$ above National Geodetic Vertical Datum of 1929.

REMARKS.--Estimated daily discharges: Dec. 14, Jan. 20 to Feb. 6, Feb. 17-20, July 22-24, and Aug. 1-9, 13-2i, 23-25. Records good except for periods of ice effect, Dec. 14, Jan. 20 to Feb. 6, and Feb. 1720, which are fair and those below $33 \mathrm{ft}^{3} / \mathrm{s}$, which are poor. Several measurements of water temperature were made during the year.

AVERAGE DISCHARGE. --25 years, $174 \mathrm{ft}^{3} / \mathrm{s}, 11.76 \mathrm{in} / \mathrm{yr}^{\circ}$

EXTREMES FOR PERIOD OF RECORD.--Maximum discharge, 1,340 ft3/s, Mar. 21, 1982, gage height, 5.78 ft; minimum, $8.0 \mathrm{ft}^{3} / \mathrm{s}$, Aug. 9, 10, 11, 1964 .

EXTREMES FOR CURRENT YEAR.--Maximum discharge, $734 \mathrm{ft} 3 / \mathrm{s}$, Oct. 4, gage height, $4.78 \mathrm{ft} ; \mathrm{minimum}$ daily, $25 \mathrm{ft}^{3} / \mathrm{s}$, Aug. $18,19$.

DISCHARGE, IN CUBIC FEET PER SECOND, WATER YEAR OCTOBER 1986 TO SEPTEMBER 1987 MEAN VALUES

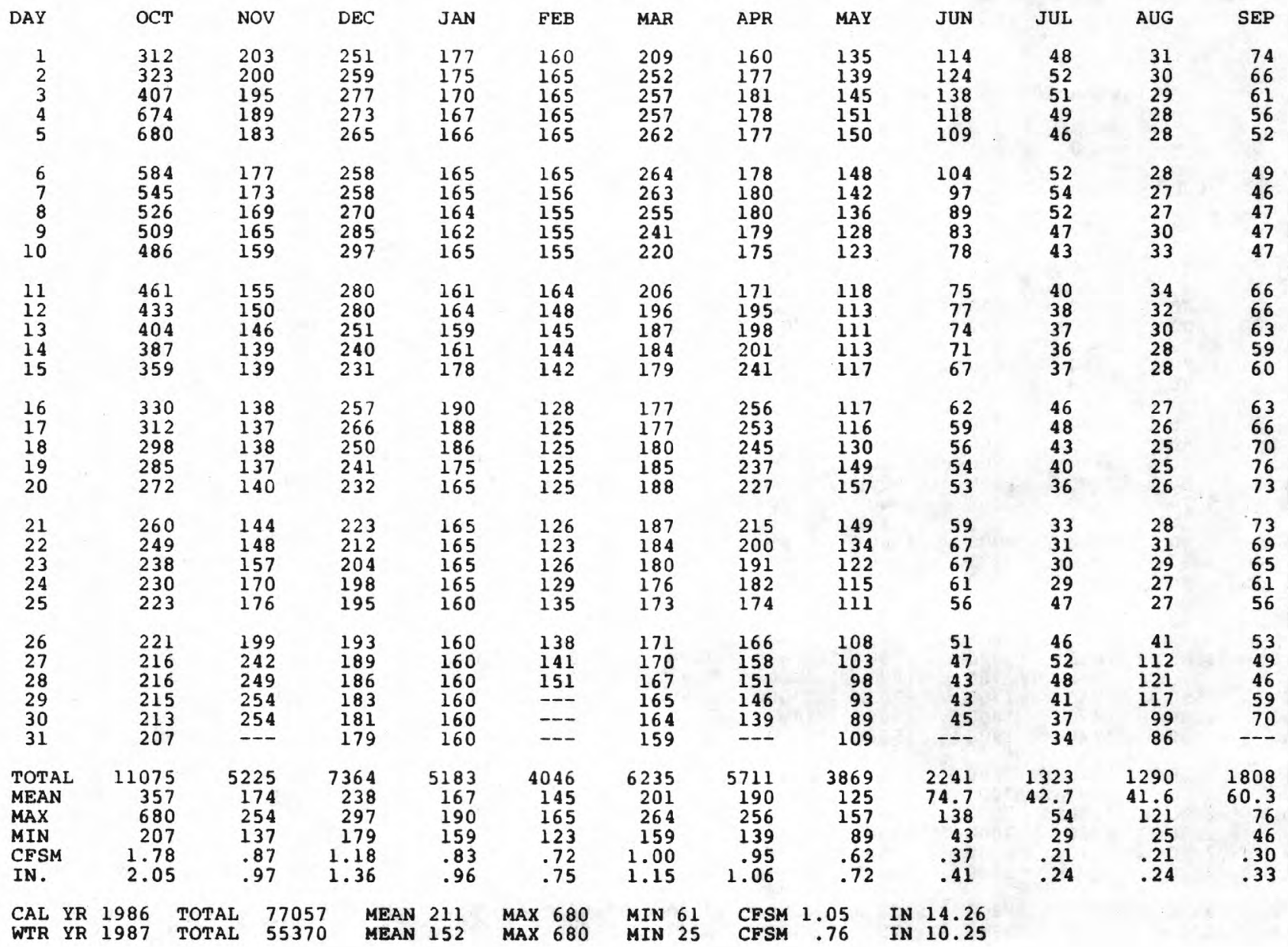


LOCATION.--Lat $41^{\circ} 56^{\prime} 55^{\prime \prime}$, long $84^{\circ} 49^{\prime} 40^{\prime \prime}$, in NEl/4 SEl/4 sec.13, T.6 S., R.5 W., Branch County, Hydrologic Unit 04050001 , on left bank $12 \mathrm{ft}$ downstream from bridge on U.S. Highway $12,1.0$ mi downstream from Little Hog Creek, and $3.1 \mathrm{mi}$ west of Allen.

DRAINAGE AREA. $--48.7 \mathrm{mi}^{2}$.

PERIOD OF RECORD.--October 1969 to current year.

GAGE.--Water-stage recorder. Elevation of gage is $1,010 \mathrm{ft}$ above National Geodetic Vertical Datum of 1929 , from topographic map. Prior to May 23, 1970, nonrecorjing gage at same site and datum.

REMARKS.--Estimated daily discharges: Dec. 14, 21-28, Jan. 10, 12, Jan. 17 to Feb. 10, and Feb. 15-19. Records good except for estimated daily discharges, which are fair. Several measurements of water temperature were made during the year.

AVERAGE DISCHARGE. - - 18 years, $42.8 \mathrm{ft}^{3} / \mathrm{s}, 11.93 \mathrm{in} / \mathrm{yr}^{\mathrm{r}}$.

EXTREMES FOR PERIOD OF RECORD.--Maximum discharge, $664 \mathrm{ft} 3 / \mathrm{s}$, Feb. 25,1985, gage height, $6.0 \mathrm{ft}$, from floodmarks; minimum, $1.2 \mathrm{ft} / \mathrm{s}$, Aug. 20, 21, 1971 ; minimum gage height, $1.28 \mathrm{ft}$, Aug. 15$18,21,24,25,1987$.

EXTREMES FOR CURRENT YEAR.--Maximum discharge, $184 \mathrm{ft}^{3} / \mathrm{s}$, Oct. 5 , gage height, $4.09 \mathrm{ft} ; \mathrm{minimum,} 2.0$ $\mathrm{ft}^{3} / \mathrm{s}$, Aug. 18, 21, 24, 25; minimum gage héight, 1.28 ft, Aug. 15-18, $21,24,25$.

DISCHARGE, IN CUBIC FEET PER SECOND, WATER YEAR OCTOBER 1986 TO SEPTEMBER 1987 MEAN VALUES

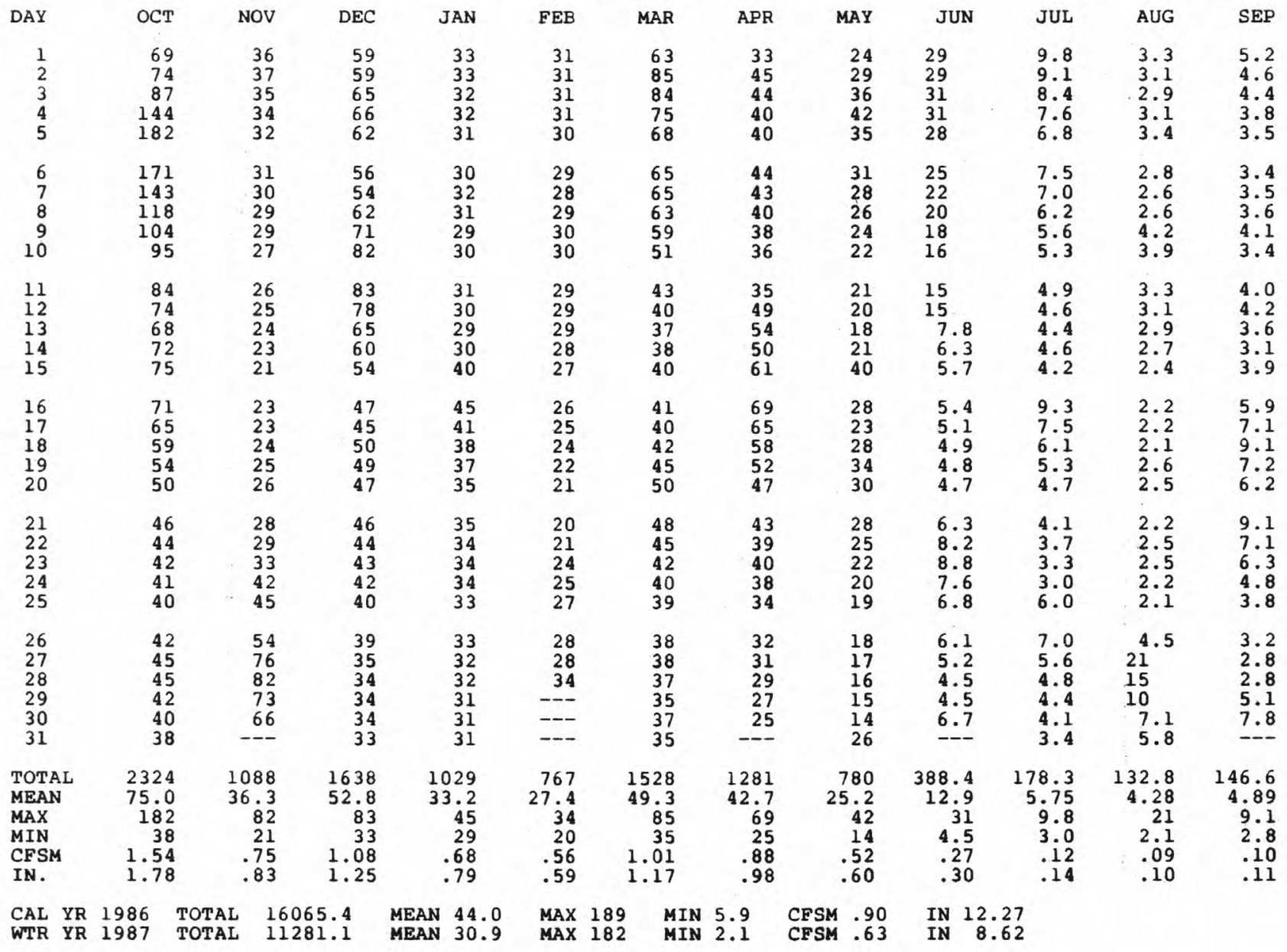




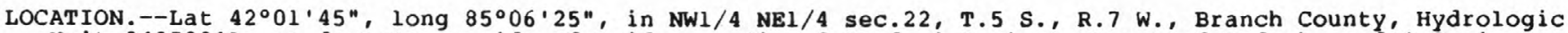
Unit 04050001 , on downstream side of bridge on Girard Road, 2.5 mi northwest of Hodunk, and 3.5 mi upstream from mouth.

DRAINAGE AREA. $--293 \mathrm{mi}^{2}$.

PERIOD OF RECORD.--October 1962 to current year.

REVISED RECORDS.--WDR MI-76-1: 1974.

GAGE.--Water-stage recorder. Elevation of gage is $900 \mathrm{ft}$ above National Geodetic Vertical Datum of 1929, from topographic map. Prior to July 26, 1963 , nonrecording gage and crest-stage gage at same site and datum.

REMARKS.--Estimated daily discharges: Jan. 2l-27. Records good. Diurnal fluctuation caused by mills upstream from station. Several measurements of water temperature were made during the year.

AVERAGE DISCHARGE.--25 years, $254 \mathrm{ft}^{3} / \mathrm{s}, 11.77 \mathrm{in} / \mathrm{yr}^{\mathrm{r}}$.

EXTREMES FOR PERIOD OF RECORD.--Maximum discharge, 2,280 $\mathrm{ft}^{3} / \mathrm{s}$, Feb. 26, 1985, gage height, $8.40 \mathrm{ft}$; minimum, $6.2 \mathrm{ft}^{3} / \mathrm{s}$, Sept. 26, 1964; minimum gage height, $2.28 \mathrm{ft}$, Oct. 4-14, 1964 .

EXTREMES FOR CURRENT YEAR.--Maximum discharge, 1,060 $\mathrm{ft}^{3} / \mathrm{s}$, Oct. 5, gage height, $6.17 \mathrm{ft}$; minimum, $22 \mathrm{ft} / \mathrm{s}$, July 12,$13 ;$ minimum gage height, $2.48 \mathrm{ft}$, July 13 .

DISCHARGE, IN CUBIC FEET PER SECOND, WATER YEAR OCTOBER 1986 TO SEPTEMBER 1987

\begin{tabular}{|c|c|c|c|c|c|c|c|c|c|c|c|c|}
\hline \multirow[b]{2}{*}{ DAY } & \multirow[b]{2}{*}{ OCT } & \multirow[b]{2}{*}{ NOV } & \multirow[b]{2}{*}{ DEC } & \multirow[b]{2}{*}{ JAN } & \multicolumn{4}{|c|}{ MEAN VALUES } & \multirow[b]{2}{*}{ JUN } & \multirow[b]{2}{*}{ JUL } & \multirow[b]{2}{*}{ AUG } & \multirow[b]{2}{*}{ SEP } \\
\hline & & & & & FEB & MAR & APR & MAY & & & & \\
\hline $\begin{array}{l}1 \\
2 \\
3 \\
4 \\
5\end{array}$ & $\begin{array}{l}401 \\
403 \\
565 \\
769 \\
996\end{array}$ & $\begin{array}{l}302 \\
294 \\
286 \\
277 \\
269\end{array}$ & $\begin{array}{l}290 \\
296 \\
349 \\
414 \\
395\end{array}$ & $\begin{array}{l}220 \\
219 \\
218 \\
217 \\
212\end{array}$ & $\begin{array}{l}199 \\
200 \\
200 \\
202 \\
196\end{array}$ & $\begin{array}{l}271 \\
343 \\
357 \\
344 \\
331\end{array}$ & $\begin{array}{l}226 \\
235 \\
246 \\
237 \\
232\end{array}$ & $\begin{array}{l}153 \\
160 \\
170 \\
181 \\
182\end{array}$ & $\begin{array}{l}132 \\
135 \\
136 \\
128 \\
122\end{array}$ & $\begin{array}{l}28 \\
31 \\
28 \\
26 \\
26\end{array}$ & $\begin{array}{l}50 \\
46 \\
40 \\
37 \\
34\end{array}$ & $\begin{array}{l}61 \\
56 \\
52 \\
50 \\
47\end{array}$ \\
\hline $\begin{array}{r}6 \\
7 \\
8 \\
9 \\
10\end{array}$ & $\begin{array}{l}991 \\
924 \\
853 \\
775 \\
702\end{array}$ & $\begin{array}{l}243 \\
200 \\
200 \\
198 \\
197\end{array}$ & $\begin{array}{l}370 \\
360 \\
370 \\
402 \\
427\end{array}$ & $\begin{array}{l}208 \\
207 \\
217 \\
232 \\
231\end{array}$ & $\begin{array}{l}195 \\
199 \\
198 \\
194 \\
205\end{array}$ & $\begin{array}{l}318 \\
310 \\
306 \\
297 \\
284\end{array}$ & $\begin{array}{l}236 \\
238 \\
213 \\
179 \\
160\end{array}$ & $\begin{array}{l}173 \\
156 \\
134 \\
132 \\
130\end{array}$ & $\begin{array}{r}116 \\
110 \\
104 \\
99 \\
95\end{array}$ & $\begin{array}{l}31 \\
32 \\
28 \\
28 \\
25\end{array}$ & $\begin{array}{l}33 \\
31 \\
32 \\
40 \\
41\end{array}$ & $\begin{array}{l}45 \\
42 \\
40 \\
41 \\
42\end{array}$ \\
\hline $\begin{array}{l}11 \\
12 \\
13 \\
14 \\
15\end{array}$ & $\begin{array}{l}645 \\
607 \\
580 \\
571 \\
558\end{array}$ & $\begin{array}{l}195 \\
194 \\
199 \\
209 \\
211\end{array}$ & $\begin{array}{l}415 \\
399 \\
377 \\
367 \\
342\end{array}$ & $\begin{array}{l}226 \\
220 \\
222 \\
220 \\
230\end{array}$ & $\begin{array}{l}208 \\
204 \\
205 \\
204 \\
193\end{array}$ & $\begin{array}{l}270 \\
259 \\
252 \\
255 \\
260\end{array}$ & $\begin{array}{l}107 \\
127 \\
145 \\
149 \\
299\end{array}$ & $\begin{array}{l}128 \\
123 \\
121 \\
122 \\
134\end{array}$ & $\begin{array}{l}93 \\
94 \\
92 \\
85 \\
80\end{array}$ & $\begin{array}{l}24 \\
24 \\
23 \\
24 \\
25\end{array}$ & $\begin{array}{l}40 \\
36 \\
30 \\
27 \\
26\end{array}$ & $\begin{array}{l}57 \\
59 \\
61 \\
57 \\
58\end{array}$ \\
\hline $\begin{array}{l}16 \\
17 \\
18 \\
19 \\
20\end{array}$ & $\begin{array}{l}536 \\
478 \\
321 \\
314 \\
310\end{array}$ & $\begin{array}{l}210 \\
208 \\
208 \\
207 \\
205\end{array}$ & $\begin{array}{l}336 \\
322 \\
319 \\
317 \\
310\end{array}$ & $\begin{array}{l}251 \\
248 \\
242 \\
222 \\
209\end{array}$ & $\begin{array}{l}178 \\
182 \\
185 \\
178 \\
176\end{array}$ & $\begin{array}{l}257 \\
256 \\
260 \\
269 \\
281\end{array}$ & $\begin{array}{l}405 \\
384 \\
349 \\
320 \\
282\end{array}$ & $\begin{array}{l}144 \\
135 \\
147 \\
192 \\
206\end{array}$ & $\begin{array}{l}76 \\
73 \\
69 \\
66 \\
67\end{array}$ & $\begin{array}{l}53 \\
59 \\
53 \\
50 \\
46\end{array}$ & $\begin{array}{l}25 \\
25 \\
23 \\
24 \\
28\end{array}$ & $\begin{array}{l}60 \\
64 \\
67 \\
68 \\
64\end{array}$ \\
\hline $\begin{array}{l}21 \\
22 \\
23 \\
24 \\
25\end{array}$ & $\begin{array}{l}308 \\
303 \\
298 \\
326 \\
384\end{array}$ & $\begin{array}{l}199 \\
186 \\
191 \\
201 \\
212\end{array}$ & $\begin{array}{l}298 \\
285 \\
274 \\
270 \\
266\end{array}$ & $\begin{array}{l}210 \\
210 \\
210 \\
210 \\
205\end{array}$ & $\begin{array}{l}177 \\
174 \\
174 \\
178 \\
183\end{array}$ & $\begin{array}{l}285 \\
275 \\
265 \\
256 \\
251\end{array}$ & $\begin{array}{l}231 \\
178 \\
178 \\
177 \\
175\end{array}$ & $\begin{array}{l}193 \\
177 \\
162 \\
153 \\
149\end{array}$ & $\begin{array}{l}72 \\
79 \\
78 \\
74 \\
71\end{array}$ & $\begin{array}{l}44 \\
43 \\
41 \\
38 \\
76\end{array}$ & $\begin{array}{r}35 \\
36 \\
35 \\
32 \\
24\end{array}$ & $\begin{array}{r}63 \\
64 \\
87 \\
106 \\
97\end{array}$ \\
\hline $\begin{array}{l}26 \\
27 \\
28 \\
29 \\
30 \\
31\end{array}$ & $\begin{array}{l}371 \\
359 \\
350 \\
338 \\
325 \\
314\end{array}$ & $\begin{array}{l}237 \\
288 \\
321 \\
316 \\
305 \\
-\end{array}$ & $\begin{array}{l}249 \\
222 \\
222 \\
222 \\
221 \\
222\end{array}$ & $\begin{array}{l}200 \\
195 \\
196 \\
195 \\
194 \\
197\end{array}$ & $\begin{array}{l}187 \\
189 \\
198 \\
--- \\
--- \\
---\end{array}$ & $\begin{array}{l}247 \\
244 \\
239 \\
234 \\
229 \\
224\end{array}$ & $\begin{array}{l}172 \\
167 \\
164 \\
160 \\
157 \\
-\end{array}$ & $\begin{array}{l}145 \\
139 \\
132 \\
125 \\
120 \\
128\end{array}$ & $\begin{array}{r}68 \\
65 \\
64 \\
53 \\
26 \\
-\end{array}$ & $\begin{array}{l}84 \\
72 \\
64 \\
61 \\
57 \\
54\end{array}$ & $\begin{array}{r}38 \\
91 \\
100 \\
92 \\
79 \\
68\end{array}$ & $\begin{array}{r}92 \\
87 \\
84 \\
94 \\
100 \\
--\end{array}$ \\
\hline $\begin{array}{l}\text { TOTAL } \\
\text { MEAN } \\
\text { MAX } \\
\text { MIN } \\
\text { CFSM } \\
\text { IN. }\end{array}$ & $\begin{array}{r}15975 \\
515 \\
996 \\
298 \\
1.76 \\
2.03\end{array}$ & $\begin{array}{r}6968 \\
232 \\
321 \\
186 \\
.79 \\
.88\end{array}$ & $\begin{array}{r}9928 \\
320 \\
427 \\
221 \\
1.09 \\
1.26\end{array}$ & $\begin{array}{r}6693 \\
216 \\
251 \\
194 \\
.74 \\
.85\end{array}$ & $\begin{array}{r}5361 \\
191 \\
208 \\
174 \\
.65 \\
.68\end{array}$ & $\begin{array}{r}8529 \\
275 \\
357 \\
224 \\
.94 \\
1.08\end{array}$ & $\begin{array}{r}6528 \\
218 \\
405 \\
107 \\
.74 \\
.83\end{array}$ & $\begin{array}{r}4646 \\
150 \\
206 \\
120 \\
.51 \\
.59\end{array}$ & $\begin{array}{r}2622 \\
87.4 \\
136 \\
26 \\
.30 \\
.33\end{array}$ & $\begin{array}{r}1298 \\
41.9 \\
84 \\
23 \\
.14 \\
.16\end{array}$ & $\begin{array}{r}1298 \\
41.9 \\
100 \\
23 \\
.14 \\
.16\end{array}$ & $\begin{array}{r}1965 \\
65.5 \\
106 \\
40 \\
.22 \\
.25\end{array}$ \\
\hline $\begin{array}{l}\text { CAL YR } \\
\text { WTR YR }\end{array}$ & $\begin{array}{l}1986 \\
1987\end{array}$ & $\begin{array}{l}\text { TOTAL } \\
\text { TOTAL }\end{array}$ & 18 & $\begin{array}{ll}\text { N } & 296 \\
\text { N } & 197\end{array}$ & $\begin{array}{l}\operatorname{MAX} 996 \\
\operatorname{MAX} 996\end{array}$ & $\begin{array}{l}\text { MIN } \\
\text { MIN }\end{array}$ & $\begin{array}{l}\text { CFSM } \\
\text { CFSM }\end{array}$ & $\begin{array}{r}1.01 \\
.67\end{array}$ & $\begin{array}{lr}\text { IN } & 13.72 \\
\text { IN } & 9.12\end{array}$ & & & \\
\hline
\end{tabular}


04096900 NOTTAWA CREEK NEAR ATHENS, MI

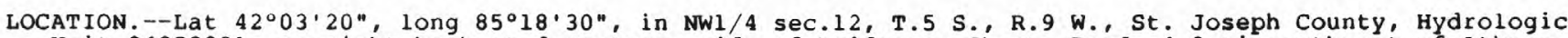
Unit 04050001 , on right bank at downstream side of bridge on Shorts Road, 4.2 mi southwest of Athens, and $5.0 \mathrm{mi}$ downstream from Pine Creek.

DRAINAGE AREA. $--162 \mathrm{mi}^{2}$.

PERIOD OF RECORD.--October 1966 to current year.

GAGE.--Water-stage recorder. Elevation of gage is $850 \mathrm{ft}$ above National Geodetic Vertical Datum of 1929 , from topographic map.

REMARKS.--Estimated daily discharges: Oct. 1, Dec. 13, 14, Jan. 19 to Feb. 2, Feb. 16-18, and July 1527. Records good except for estimated daily discharges, Oct. 1, Dec. 13, 14, Jan. 19 to Feb. 2, and Feb. 16-18, which are fair and estimated daily discharges, July 15-27, which are poor. Several measurements of water temperature were made during the year.

AVERAGE DISCHARGE. --21 years, $149 \mathrm{ft}^{3} / \mathrm{s}, 12.49 \mathrm{in} / \mathrm{yr}$.

EXTREMES FOR PERIOD OF RECORD.--Maximum discharge, 1, $340 \mathrm{ft} / \mathrm{s}$, Feb. 26, 1985, gage height, 6.03 ft; maximum gage height, $6.47 \mathrm{ft}$, June 29, 1978 ; minimum discharge, $21 \mathrm{ft} / \mathrm{s}^{3}, \mathrm{July} 28,29,30$, Aug.

4, 6, 1977; minimum gage height, $0.37 \mathrm{ft}$, Oct. 16, 18, 20, 21, Nov. 8, 1971.

EXTREMES FOR CURRENT YEAR.--Maximum discharge, $841 \mathrm{ft}^{3} / \mathrm{s}$, Oct. 5 , gage height, $4.67 \mathrm{ft}$; minimum daily, $35 \mathrm{ft}^{3} / \mathrm{s}$, July 24 .

DISCHARGE, IN CUBIC FEET PER SECOND, WATER YEAR OCTOBER 1986 TO SEPTEMBER 1987

MEAN VALUES

\begin{tabular}{|c|c|c|c|c|c|c|c|c|c|c|c|c|}
\hline DAY & OCT & NOV & DEC & JAN & FEB & MAR & APR & MAY & JUN & JUL & AUG & SEP \\
\hline $\begin{array}{l}1 \\
2 \\
3 \\
4 \\
5\end{array}$ & $\begin{array}{l}400 \\
501 \\
577 \\
763 \\
832\end{array}$ & $\begin{array}{l}158 \\
159 \\
160 \\
160 \\
156\end{array}$ & $\begin{array}{l}213 \\
204 \\
220 \\
250 \\
248\end{array}$ & $\begin{array}{l}146 \\
146 \\
147 \\
146 \\
143\end{array}$ & $\begin{array}{l}145 \\
145 \\
150 \\
151 \\
151\end{array}$ & $\begin{array}{l}232 \\
320 \\
339 \\
320 \\
286\end{array}$ & $\begin{array}{l}149 \\
164 \\
180 \\
180 \\
168\end{array}$ & $\begin{array}{l}110 \\
111 \\
126 \\
139 \\
142\end{array}$ & $\begin{array}{l}81 \\
81 \\
83 \\
82 \\
79\end{array}$ & $\begin{array}{l}59 \\
58 \\
56 \\
55 \\
57\end{array}$ & $\begin{array}{l}45 \\
42 \\
39 \\
38 \\
43\end{array}$ & $\begin{array}{r}138 \\
105 \\
82 \\
71 \\
66\end{array}$ \\
\hline $\begin{array}{r}6 \\
7 \\
8 \\
9 \\
10\end{array}$ & $\begin{array}{l}801 \\
712 \\
607 \\
510 \\
425\end{array}$ & $\begin{array}{l}152 \\
148 \\
147 \\
146 \\
142\end{array}$ & $\begin{array}{l}229 \\
218 \\
220 \\
235 \\
252\end{array}$ & $\begin{array}{l}141 \\
143 \\
143 \\
142 \\
134\end{array}$ & $\begin{array}{l}146 \\
148 \\
153 \\
140 \\
152\end{array}$ & $\begin{array}{l}257 \\
240 \\
229 \\
216 \\
189\end{array}$ & $\begin{array}{l}162 \\
157 \\
148 \\
140 \\
136\end{array}$ & $\begin{array}{l}129 \\
118 \\
110 \\
104 \\
100\end{array}$ & $\begin{array}{l}76 \\
73 \\
72 \\
70 \\
69\end{array}$ & $\begin{array}{l}63 \\
65 \\
64 \\
59 \\
52\end{array}$ & $\begin{array}{l}41 \\
36 \\
37 \\
43 \\
47\end{array}$ & $\begin{array}{l}62 \\
59 \\
60 \\
64 \\
62\end{array}$ \\
\hline $\begin{array}{l}11 \\
12 \\
13 \\
14 \\
15\end{array}$ & $\begin{array}{l}360 \\
313 \\
279 \\
266 \\
262\end{array}$ & $\begin{array}{l}138 \\
135 \\
132 \\
123 \\
129\end{array}$ & $\begin{array}{l}254 \\
218 \\
200 \\
180 \\
167\end{array}$ & $\begin{array}{l}141 \\
139 \\
144 \\
143 \\
156\end{array}$ & $\begin{array}{r}143 \\
143 \\
141 \\
140 \\
134\end{array}$ & $\begin{array}{l}174 \\
162 \\
154 \\
155 \\
160\end{array}$ & $\begin{array}{l}132 \\
146 \\
164 \\
166 \\
192\end{array}$ & $\begin{array}{r}95 \\
93 \\
90 \\
96 \\
116\end{array}$ & $\begin{array}{l}67 \\
66 \\
65 \\
64 \\
63\end{array}$ & $\begin{array}{l}47 \\
44 \\
43 \\
43 \\
45\end{array}$ & $\begin{array}{l}44 \\
39 \\
37 \\
36 \\
36\end{array}$ & $\begin{array}{r}79 \\
109 \\
104 \\
83 \\
74\end{array}$ \\
\hline $\begin{array}{l}16 \\
17 \\
18 \\
19 \\
20\end{array}$ & $\begin{array}{l}256 \\
243 \\
228 \\
216 \\
205\end{array}$ & $\begin{array}{l}130 \\
132 \\
135 \\
133 \\
135\end{array}$ & $\begin{array}{l}154 \\
157 \\
166 \\
171 \\
168\end{array}$ & $\begin{array}{l}174 \\
167 \\
154 \\
150 \\
145\end{array}$ & $\begin{array}{l}130 \\
125 \\
120 \\
118 \\
117\end{array}$ & $\begin{array}{l}162 \\
169 \\
178 \\
188 \\
193\end{array}$ & $\begin{array}{l}229 \\
236 \\
220 \\
194 \\
171\end{array}$ & $\begin{array}{l}118 \\
110 \\
111 \\
120 \\
122\end{array}$ & $\begin{array}{l}61 \\
60 \\
58 \\
58 \\
57\end{array}$ & $\begin{array}{l}50 \\
54 \\
56 \\
54 \\
49\end{array}$ & $\begin{array}{l}36 \\
40 \\
44 \\
43 \\
40\end{array}$ & $\begin{array}{r}81 \\
87 \\
96 \\
100 \\
92\end{array}$ \\
\hline $\begin{array}{l}21 \\
22 \\
23 \\
24 \\
25\end{array}$ & $\begin{array}{l}194 \\
187 \\
180 \\
175 \\
172\end{array}$ & $\begin{array}{l}138 \\
143 \\
151 \\
166 \\
177\end{array}$ & $\begin{array}{l}161 \\
152 \\
146 \\
144 \\
145\end{array}$ & $\begin{array}{l}140 \\
140 \\
135 \\
135 \\
135\end{array}$ & $\begin{array}{l}121 \\
121 \\
128 \\
133 \\
141\end{array}$ & $\begin{array}{l}189 \\
178 \\
168 \\
162 \\
159\end{array}$ & $\begin{array}{l}157 \\
144 \\
138 \\
136 \\
129\end{array}$ & $\begin{array}{r}121 \\
113 \\
100 \\
94 \\
92\end{array}$ & $\begin{array}{l}60 \\
69 \\
74 \\
73 \\
66\end{array}$ & $\begin{array}{l}43 \\
38 \\
36 \\
35 \\
50\end{array}$ & $\begin{array}{l}40 \\
41 \\
49 \\
45 \\
41\end{array}$ & $\begin{array}{r}92 \\
100 \\
94 \\
83 \\
72\end{array}$ \\
\hline $\begin{array}{l}26 \\
27 \\
28 \\
29 \\
30 \\
31\end{array}$ & $\begin{array}{l}171 \\
172 \\
171 \\
169 \\
165 \\
161\end{array}$ & $\begin{array}{l}200 \\
241 \\
265 \\
258 \\
238 \\
---\end{array}$ & $\begin{array}{l}145 \\
145 \\
145 \\
145 \\
144 \\
144\end{array}$ & $\begin{array}{l}135 \\
135 \\
135 \\
135 \\
140 \\
140\end{array}$ & $\begin{array}{l}148 \\
149 \\
162 \\
--- \\
--- \\
---\end{array}$ & $\begin{array}{l}161 \\
163 \\
164 \\
160 \\
157 \\
154\end{array}$ & $\begin{array}{l}125 \\
121 \\
119 \\
115 \\
113 \\
---\end{array}$ & $\begin{array}{l}90 \\
88 \\
86 \\
83 \\
81 \\
83\end{array}$ & $\begin{array}{r}64 \\
63 \\
62 \\
58 \\
58 \\
-\end{array}$ & $\begin{array}{l}60 \\
58 \\
52 \\
48 \\
50 \\
50\end{array}$ & $\begin{array}{l}57 \\
134 \\
167 \\
174 \\
174 \\
164\end{array}$ & $\begin{array}{r}65 \\
61 \\
57 \\
75 \\
101 \\
\end{array}$ \\
\hline $\begin{array}{l}\text { TOTAL } \\
\text { MEAN } \\
\text { MAX } \\
\text { MIN } \\
\text { CFSM } \\
\text { IN. }\end{array}$ & $\begin{array}{r}10673 \\
344 \\
832 \\
161 \\
2.12 \\
2.45\end{array}$ & $\begin{array}{r}4827 \\
161 \\
265 \\
123 \\
.99 \\
1.11\end{array}$ & $\begin{array}{r}5740 \\
185 \\
254 \\
144 \\
1.14 \\
1.32\end{array}$ & $\begin{array}{r}4449 \\
144 \\
174 \\
134 \\
.89 \\
1.02\end{array}$ & $\begin{array}{r}3895 \\
139 \\
162 \\
117 \\
.86 \\
.89\end{array}$ & $\begin{array}{r}6138 \\
198 \\
339 \\
154 \\
1.22 \\
1.41\end{array}$ & $\begin{array}{r}4731 \\
158 \\
236 \\
113 \\
.98 \\
1.09\end{array}$ & $\begin{array}{r}3291 \\
106 \\
142 \\
81 \\
.65 \\
.76\end{array}$ & $\begin{array}{r}2032 \\
67.7 \\
83 \\
57 \\
.42 \\
.47\end{array}$ & $\begin{array}{r}1593 \\
51.4 \\
65 \\
35 \\
.32 \\
.37\end{array}$ & $\begin{array}{r}1892 \\
61.0 \\
174 \\
36 \\
.38 \\
.43\end{array}$ & $\begin{array}{r}2474 \\
82.5 \\
138 \\
57 \\
.51 \\
.57\end{array}$ \\
\hline $\begin{array}{l}\text { CAL YR } \\
\text { WTR YR }\end{array}$ & $\begin{array}{l}1986 \\
1987\end{array}$ & $\begin{array}{l}7 \\
5\end{array}$ & $\begin{array}{l}\text { ME } \\
\text { ME }\end{array}$ & $\begin{array}{l}206 \\
142\end{array}$ & $\begin{array}{ll}\text { MAX } & 832 \\
\text { MAX } & 832\end{array}$ & $\begin{array}{ll}\text { MIN } & 70 \\
\text { MIN } & 35\end{array}$ & $\begin{array}{l}\text { CFSM } \\
\text { CFSM }\end{array}$ & $\begin{array}{r}1.27 \\
.88\end{array}$ & $\begin{array}{ll}N & 17.28 \\
N & 11.88\end{array}$ & & & \\
\hline
\end{tabular}




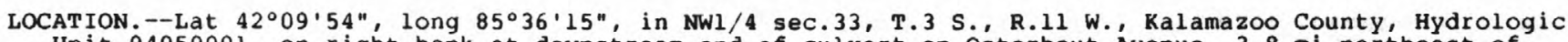
Unit 04050001 , on right bank at downstream end of culvert on Ósterhout Avenue, 3.8 mi northeast of Schoolcraft.

DRAINAGE AREA.--Indeterminate.

PERIOD OF RECORD.--October 1965 to December 1972, October 1982 to current year.

GAGE.--Water-stage recorder. Metal V-notch weir Aug. 4, 1969, to Dec. 31, 1972 . Datum of gage is 854.98

$f t$ above National Geodetic Vertical Datum of 1929 (levels by Michigan Department of Natural Resources).

REMARKS.--No estimated daily discharges. Records poor. Canal diverts water from Gourdneck Creek to West

Lake to sustain lake levels. Several measurements of water temperature were made during the year.

AVERAGE DISCHARGE.--12 years, $2.74 \mathrm{ft}^{3} / \mathrm{s}$.

EXTREMES FOR PERIOD OF RECORD.--Maximum daily discharge, $16 \mathrm{ft}^{3} / \mathrm{s}$, Dec. 10-12, 1966, Apr. 22-24,

1967; no flow on many days during November, December, 1970, January, February, 1971.

DISCHARGE, IN CUBIC FEET PER SECOND, WATER YEAR OCTOBER 1986 TO SEPTEMBER 1987 MEÁN VALUES

\begin{tabular}{|c|c|c|c|c|c|c|c|c|c|c|c|c|}
\hline DAY & OCT & NOV & DEC & JAN & FEB & MAR & APR & MAY & JUN & JUL & AUG & SEP \\
\hline $\begin{array}{l}1 \\
2 \\
3 \\
4 \\
5\end{array}$ & $\begin{array}{l}1.7 \\
1.6 \\
2.3 \\
2.7 \\
2.2\end{array}$ & $\begin{array}{r}.95 \\
.97 \\
.88 \\
.77 \\
.72\end{array}$ & $\begin{array}{l}.86 \\
.99 \\
.99 \\
.74 \\
.70\end{array}$ & $\begin{array}{l}.19 \\
.19 \\
.17 \\
.17 \\
.17\end{array}$ & $\begin{array}{l}.11 \\
.11 \\
.12 \\
.11 \\
.11\end{array}$ & $\begin{array}{r}.25 \\
.26 \\
.26 \\
.24 \\
.25\end{array}$ & $\begin{array}{r}.35 \\
.33 \\
.30 \\
.32 \\
.33\end{array}$ & $\begin{array}{l}.79 \\
.86 \\
.88 \\
.85 \\
.85\end{array}$ & $\begin{array}{l}.58 \\
.60 \\
.63 \\
.64 \\
.70\end{array}$ & $\begin{array}{l}.67 \\
.68 \\
.70 \\
.68 \\
.69\end{array}$ & $\begin{array}{l}.90 \\
.83 \\
.81 \\
.85 \\
.78\end{array}$ & $\begin{array}{l}.79 \\
.81 \\
.78 \\
.77 \\
.77\end{array}$ \\
\hline $\begin{array}{r}6 \\
7 \\
8 \\
9 \\
10\end{array}$ & $\begin{array}{c}1.8 \\
1.4 \\
1.2 \\
1.0 \\
.78\end{array}$ & $\begin{array}{r}.65 \\
.70 \\
.72 \\
.50 \\
.23\end{array}$ & $\begin{array}{r}.64 \\
.70 \\
.80 \\
.83 \\
.73\end{array}$ & $\begin{array}{l}.17 \\
.18 \\
.17 \\
.15 \\
.15\end{array}$ & $\begin{array}{r}.11 \\
.12 \\
.12 \\
.09 \\
.09\end{array}$ & $\begin{array}{r}.25 \\
.30 \\
.34 \\
.39 \\
.30\end{array}$ & $\begin{array}{r}.35 \\
.35 \\
.33 \\
.31 \\
.33\end{array}$ & $\begin{array}{l}.85 \\
.85 \\
.85 \\
.82 \\
.77\end{array}$ & $\begin{array}{l}.69 \\
.67 \\
.64 \\
.63 \\
.58\end{array}$ & $\begin{array}{l}.76 \\
.69 \\
.63 \\
.59 \\
.55\end{array}$ & $\begin{array}{l}.76 \\
.72 \\
.67 \\
.85 \\
.85\end{array}$ & $\begin{array}{l}.78 \\
.85 \\
.85 \\
.78 \\
.83\end{array}$ \\
\hline $\begin{array}{l}11 \\
12 \\
13 \\
14 \\
15\end{array}$ & $\begin{array}{l}.63 \\
.71 \\
.86 \\
.88 \\
.65\end{array}$ & $\begin{array}{r}.26 \\
.21 \\
.15 \\
.13 \\
.17\end{array}$ & $\begin{array}{r}.65 \\
.56 \\
.46 \\
.44 \\
.44\end{array}$ & $\begin{array}{r}.13 \\
.12 \\
.12 \\
.13 \\
.17\end{array}$ & $\begin{array}{r}.12 \\
.15 \\
.13 \\
.14 \\
.13\end{array}$ & $\begin{array}{r}.26 \\
.26 \\
.27 \\
.30 \\
.26\end{array}$ & $\begin{array}{r}.35 \\
.35 \\
.34 \\
.44 \\
.52\end{array}$ & $\begin{array}{r}.77 \\
.68 \\
.70 \\
.72 \\
.72\end{array}$ & $\begin{array}{l}.56 \\
.55 \\
.49 \\
.50 \\
.50\end{array}$ & $\begin{array}{r}.47 \\
.42 \\
.45 \\
.52 \\
.58\end{array}$ & $\begin{array}{r}.78 \\
.76 \\
.73 \\
.74 \\
.75\end{array}$ & $\begin{array}{l}.89 \\
.85 \\
.84 \\
.77 \\
.79\end{array}$ \\
\hline $\begin{array}{l}16 \\
17 \\
18 \\
19 \\
20\end{array}$ & $\begin{array}{l}.56 \\
.52 \\
.53 \\
.50 \\
.52\end{array}$ & $\begin{array}{r}.22 \\
.28 \\
.38 \\
.32 \\
.34\end{array}$ & $\begin{array}{r}.46 \\
.45 \\
.45 \\
.39 \\
.39\end{array}$ & $\begin{array}{r}.14 \\
.14 \\
.14 \\
.14 \\
.13\end{array}$ & $\begin{array}{l}.11 \\
.11 \\
.11 \\
.12 \\
.13\end{array}$ & $\begin{array}{r}.26 \\
.30 \\
.31 \\
.35 \\
.39\end{array}$ & $\begin{array}{r}.44 \\
.47 \\
.49 \\
.51 \\
.56\end{array}$ & $\begin{array}{l}.70 \\
.70 \\
.73 \\
.73 \\
.73\end{array}$ & $\begin{array}{l}.50 \\
.52 \\
.48 \\
.44 \\
.58\end{array}$ & $\begin{array}{r}1.0 \\
.84 \\
.80 \\
.85 \\
.83\end{array}$ & $\begin{array}{r}.73 \\
.77 \\
.77 \\
.83 \\
.82\end{array}$ & $\begin{array}{l}.77 \\
.81 \\
.79 \\
.75 \\
.77\end{array}$ \\
\hline $\begin{array}{l}21 \\
22 \\
23 \\
24 \\
25\end{array}$ & $\begin{array}{l}.51 \\
.50 \\
.52 \\
.56 \\
.66\end{array}$ & $\begin{array}{r}.31 \\
.31 \\
.45 \\
.45 \\
.41\end{array}$ & $\begin{array}{r}.36 \\
.34 \\
.35 \\
.32 \\
.34\end{array}$ & $\begin{array}{r}.14 \\
.14 \\
.13 \\
.12 \\
.12\end{array}$ & $\begin{array}{l}.15 \\
.16 \\
.14 \\
.14 \\
.15\end{array}$ & $\begin{array}{r}.39 \\
.40 \\
.44 \\
.50 \\
.53\end{array}$ & $\begin{array}{r}.63 \\
.63 \\
.70 \\
.69 \\
.71\end{array}$ & $\begin{array}{r}.75 \\
.71 \\
.70 \\
.70 \\
.70\end{array}$ & $\begin{array}{l}.61 \\
.59 \\
.58 \\
.58 \\
.56\end{array}$ & $\begin{array}{l}.85 \\
.81 \\
.73 \\
.72 \\
.94\end{array}$ & $\begin{array}{l}.77 \\
.75 \\
.71 \\
.70 \\
.70\end{array}$ & $\begin{array}{l}.86 \\
.75 \\
.70 \\
.70 \\
.70\end{array}$ \\
\hline $\begin{array}{l}26 \\
27 \\
28 \\
29 \\
30 \\
31\end{array}$ & $\begin{array}{l}.86 \\
.90 \\
.85 \\
.96 \\
.94 \\
.91\end{array}$ & $\begin{array}{l}.88 \\
.97 \\
.79 \\
.77 \\
.80 \\
.--\end{array}$ & $\begin{array}{l}.28 \\
.26 \\
.24 \\
.23 \\
.23 \\
.20\end{array}$ & $\begin{array}{l}.12 \\
.12 \\
.12 \\
.12 \\
.11 \\
.10\end{array}$ & $\begin{array}{l}.16 \\
.15 \\
.18 \\
--- \\
--- \\
---\end{array}$ & $\begin{array}{l}.53 \\
.46 \\
.44 \\
.40 \\
.41 \\
.35\end{array}$ & $\begin{array}{l}.77 \\
.77 \\
.77 \\
.77 \\
.77 \\
---\end{array}$ & $\begin{array}{l}.70 \\
.70 \\
.71 \\
.71 \\
.70 \\
.59\end{array}$ & $\begin{array}{r}.81 \\
1.1 \\
.95 \\
.77 \\
.70 \\
-.-\end{array}$ & $\begin{array}{l}.94 \\
.94 \\
.94 \\
.96 \\
.96 \\
.94\end{array}$ & $\begin{array}{r}1.0 \\
1.1 \\
.99 \\
.95 \\
.88 \\
.88\end{array}$ & $\begin{array}{l}.70 \\
.70 \\
.72 \\
.84 \\
.75\end{array}$ \\
\hline $\begin{array}{l}\text { TOTAL } \\
\text { MEAN } \\
\text { MAX } \\
\text { MIN }\end{array}$ & $\begin{array}{r}31.21 \\
1.01 \\
2.7 \\
.50\end{array}$ & $\begin{array}{r}15.69 \\
.52 \\
.97 \\
.13\end{array}$ & $\begin{array}{r}15.82 \\
.51 \\
.99 \\
.20\end{array}$ & $\begin{array}{r}4.41 \\
.14 \\
.19 \\
.10\end{array}$ & $\begin{array}{r}3.57 \\
.13 \\
.18 \\
.09\end{array}$ & $\begin{array}{r}10.65 \\
.34 \\
.53 \\
.24\end{array}$ & $\begin{array}{r}14.98 \\
.50 \\
.77 \\
.30\end{array}$ & $\begin{array}{r}23.22 \\
.75 \\
.88 \\
.59\end{array}$ & $\begin{array}{r}18.73 \\
.62 \\
1.1 \\
.44\end{array}$ & $\begin{array}{r}23.13 \\
.75 \\
1.0 \\
.42\end{array}$ & $\begin{array}{r}25.13 \\
.81 \\
1.11 \\
.67\end{array}$ & $\begin{array}{r}23.46 \\
.78 \\
.89 \\
.70\end{array}$ \\
\hline
\end{tabular}

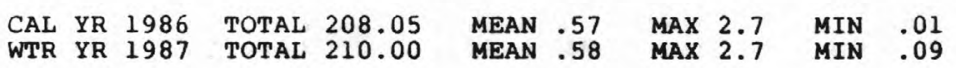




\section{PRAIRIE RIVER NEAR NOTTAWA, MI}

LOCATION. --Lat $41^{\circ} 53^{\prime} 18^{\prime \prime}$, long $85^{\circ} 24^{\prime} 34^{\prime \prime}$, in NWl/4 SWl/4 sec.6, T.7 S., R.9 W., St. Joseph County, Hydrologic Unit 04050001 , on left bank $10 \mathrm{ft}$ upstream from bridge on State Highway 66 , 3.0 mi upstream from unnamed tributary, and $3.0 \mathrm{mi}$ southeast of Nottawa.

DRAINAGE AREA. $--106 \mathrm{mi}^{2}$.

PERIOD OF RECORD.--October 1962 to current year.

GAGE.--Water-stage recorder. Elevation of gage is $850 \mathrm{ft}$ above National Geodetic Vertical Datum of 1929 , from topographic map.

REMARKS.--Estimated daily discharges: Dec. 13, and Jan. 19 to Feb. 4. Records good except for estimated daily discharges, which are fair. Since 1987, some diversion by pumping for sprinkler irrigation. Several measurements of water temperature were made during the year.

AVERAGE DISCHARGE.--25 years, $95.1 \mathrm{ft}^{3} / \mathrm{s}, 12.18 \mathrm{in} / \mathrm{yr}$.

EXTREMES FOR PERIOD OF RECORD.--Maximum discharge, $797 \mathrm{ft}^{3} / \mathrm{s}$, Feb. 26,1985, gage height, $6.30 \mathrm{ft}$; minimum, $11 \mathrm{ft} / \mathrm{s}$, Aug. 9, 10, Sept. 8, 9, 10, 1964; minimum gage height, 1.77 ft, Aug. 9, 10, 1964.

EXTREMES FOR CURRENT YEAR. --Maximum discharge, $254 \mathrm{ft}^{3} / \mathrm{s}$, Oct. 6 , gage height, $4.80 \mathrm{ft}$; maximum gage height, $4.83 \mathrm{ft}$, Dec. 13, backwater from ice; minimum discharge, $22 \mathrm{ft} 3 / \mathrm{s}, \mathrm{July} 25, \mathrm{Aug} .18$, 20,$21 ;$ minimum gage height, $1.99 \mathrm{ft}$, Aug. 18.

DISCHARGE, IN CUBIC FEET PER SECOND, WATER YEAR OCTOBER 1986 TO SEPTEMBER 1987

\begin{tabular}{|c|c|c|c|c|c|c|c|c|c|c|c|c|}
\hline DAY & OCT & NOV & DEC & JAN & FEB & MAR & APR & MAY & JUN & JUL & AUG & SEP \\
\hline $\begin{array}{l}1 \\
2 \\
3 \\
4 \\
5\end{array}$ & $\begin{array}{l}143 \\
148 \\
176 \\
220 \\
242\end{array}$ & $\begin{array}{l}105 \\
105 \\
103 \\
101 \\
100\end{array}$ & $\begin{array}{l}135 \\
135 \\
137 \\
138 \\
135\end{array}$ & $\begin{array}{l}94 \\
93 \\
93 \\
92 \\
90\end{array}$ & $\begin{array}{l}89 \\
91 \\
93 \\
94 \\
96\end{array}$ & $\begin{array}{l}119 \\
144 \\
153 \\
149 \\
143\end{array}$ & $\begin{array}{l}85 \\
90 \\
92 \\
90 \\
88\end{array}$ & $\begin{array}{r}89 \\
95 \\
105 \\
110 \\
107\end{array}$ & $\begin{array}{l}63 \\
67 \\
68 \\
66 \\
62\end{array}$ & $\begin{array}{l}42 \\
42 \\
41 \\
41 \\
39\end{array}$ & $\begin{array}{l}41 \\
38 \\
35 \\
33 \\
30\end{array}$ & $\begin{array}{l}39 \\
37 \\
35 \\
33 \\
31\end{array}$ \\
\hline $\begin{array}{r}6 \\
7 \\
8 \\
9 \\
10\end{array}$ & $\begin{array}{l}251 \\
250 \\
231 \\
209 \\
188\end{array}$ & $\begin{array}{l}98 \\
97 \\
96 \\
94 \\
92\end{array}$ & $\begin{array}{l}129 \\
128 \\
134 \\
144 \\
150\end{array}$ & $\begin{array}{l}89 \\
88 \\
87 \\
86 \\
89\end{array}$ & $\begin{array}{r}94 \\
94 \\
96 \\
100 \\
96\end{array}$ & $\begin{array}{l}139 \\
134 \\
130 \\
124 \\
116\end{array}$ & $\begin{array}{l}86 \\
85 \\
83 \\
81 \\
79\end{array}$ & $\begin{array}{r}101 \\
94 \\
88 \\
82 \\
79\end{array}$ & $\begin{array}{l}58 \\
55 \\
52 \\
49 \\
47\end{array}$ & $\begin{array}{l}39 \\
40 \\
37 \\
34 \\
31\end{array}$ & $\begin{array}{l}27 \\
26 \\
29 \\
34 \\
37\end{array}$ & $\begin{array}{l}30 \\
29 \\
29 \\
31 \\
31\end{array}$ \\
\hline $\begin{array}{l}11 \\
12 \\
13 \\
14 \\
15\end{array}$ & $\begin{array}{l}171 \\
159 \\
150 \\
146 \\
142\end{array}$ & $\begin{array}{l}90 \\
88 \\
87 \\
86 \\
85\end{array}$ & $\begin{array}{l}151 \\
144 \\
135 \\
129 \\
119\end{array}$ & $\begin{array}{l}88 \\
87 \\
86 \\
86 \\
91\end{array}$ & $\begin{array}{l}95 \\
94 \\
94 \\
93 \\
92\end{array}$ & $\begin{array}{l}109 \\
105 \\
101 \\
102 \\
105\end{array}$ & $\begin{array}{r}78 \\
89 \\
98 \\
105 \\
143\end{array}$ & $\begin{array}{l}76 \\
75 \\
72 \\
71 \\
75\end{array}$ & $\begin{array}{l}46 \\
48 \\
46 \\
46 \\
43\end{array}$ & $\begin{array}{l}29 \\
29 \\
27 \\
28 \\
31\end{array}$ & $\begin{array}{l}36 \\
34 \\
31 \\
30 \\
28\end{array}$ & $\begin{array}{l}36 \\
38 \\
37 \\
35 \\
34\end{array}$ \\
\hline $\begin{array}{l}16 \\
17 \\
18 \\
19 \\
20\end{array}$ & $\begin{array}{l}137 \\
131 \\
126 \\
121 \\
116\end{array}$ & $\begin{array}{l}85 \\
86 \\
87 \\
88 \\
89\end{array}$ & $\begin{array}{l}115 \\
115 \\
117 \\
116 \\
114\end{array}$ & $\begin{array}{l}97 \\
98 \\
98 \\
95 \\
92\end{array}$ & $\begin{array}{l}85 \\
83 \\
84 \\
82 \\
81\end{array}$ & $\begin{array}{r}105 \\
104 \\
103 \\
101 \\
99\end{array}$ & $\begin{array}{l}175 \\
182 \\
172 \\
156 \\
142\end{array}$ & $\begin{array}{l}73 \\
68 \\
76 \\
85 \\
87\end{array}$ & $\begin{array}{l}40 \\
37 \\
36 \\
34 \\
33\end{array}$ & $\begin{array}{l}39 \\
42 \\
41 \\
38 \\
35\end{array}$ & $\begin{array}{l}26 \\
25 \\
24 \\
24 \\
23\end{array}$ & $\begin{array}{l}35 \\
39 \\
42 \\
43 \\
42\end{array}$ \\
\hline $\begin{array}{l}21 \\
22 \\
23 \\
24 \\
25\end{array}$ & $\begin{array}{l}113 \\
110 \\
109 \\
107 \\
105\end{array}$ & $\begin{array}{r}92 \\
95 \\
97 \\
102 \\
105\end{array}$ & $\begin{array}{l}111 \\
108 \\
105 \\
103 \\
102\end{array}$ & $\begin{array}{l}89 \\
87 \\
86 \\
85 \\
84\end{array}$ & $\begin{array}{l}79 \\
80 \\
82 \\
83 \\
84\end{array}$ & $\begin{array}{l}96 \\
93 \\
92 \\
90 \\
90\end{array}$ & $\begin{array}{l}130 \\
123 \\
122 \\
116 \\
111\end{array}$ & $\begin{array}{l}84 \\
79 \\
75 \\
71 \\
69\end{array}$ & $\begin{array}{l}44 \\
51 \\
56 \\
57 \\
54\end{array}$ & $\begin{array}{l}35 \\
31 \\
29 \\
25 \\
23\end{array}$ & $\begin{array}{l}23 \\
24 \\
24 \\
24 \\
24\end{array}$ & $\begin{array}{l}41 \\
40 \\
39 \\
37 \\
35\end{array}$ \\
\hline $\begin{array}{l}26 \\
27 \\
28 \\
29 \\
30 \\
31\end{array}$ & $\begin{array}{l}107 \\
110 \\
113 \\
113 \\
110 \\
108\end{array}$ & $\begin{array}{l}121 \\
142 \\
150 \\
150 \\
144 \\
---\end{array}$ & $\begin{array}{r}101 \\
100 \\
99 \\
97 \\
97 \\
95\end{array}$ & $\begin{array}{l}84 \\
84 \\
85 \\
86 \\
86 \\
87\end{array}$ & $\begin{array}{r}86 \\
86 \\
90 \\
--- \\
-- \\
--\end{array}$ & $\begin{array}{l}90 \\
90 \\
88 \\
88 \\
87 \\
85\end{array}$ & $\begin{array}{r}104 \\
100 \\
96 \\
94 \\
91 \\
---\end{array}$ & $\begin{array}{l}67 \\
64 \\
61 \\
59 \\
58 \\
59\end{array}$ & $\begin{array}{r}49 \\
45 \\
43 \\
40 \\
40 \\
---\end{array}$ & $\begin{array}{l}25 \\
28 \\
29 \\
34 \\
42 \\
42\end{array}$ & $\begin{array}{l}31 \\
45 \\
52 \\
51 \\
47 \\
43\end{array}$ & $\begin{array}{r}33 \\
31 \\
30 \\
36 \\
43 \\
-\end{array}$ \\
\hline $\begin{array}{l}\text { TOTAL } \\
\text { MEAN } \\
\text { MAX } \\
\text { MIN } \\
\text { CFSM } \\
\text { IN. }\end{array}$ & $\begin{array}{r}4662 \\
150 \\
251 \\
105 \\
1.42 \\
1.64\end{array}$ & $\begin{array}{r}3060 \\
102 \\
150 \\
85 \\
.96 \\
1.07\end{array}$ & $\begin{array}{r}3738 \\
121 \\
151 \\
95 \\
1.14 \\
1.31\end{array}$ & $\begin{array}{r}2762 \\
89.1 \\
98 \\
84 \\
.84 \\
.97\end{array}$ & $\begin{array}{r}2496 \\
89.1 \\
100 \\
79 \\
.84 \\
.88\end{array}$ & $\begin{array}{r}3374 \\
109 \\
153 \\
85 \\
1.03 \\
1.18\end{array}$ & $\begin{array}{r}3286 \\
110 \\
182 \\
78 \\
1.04 \\
1.15\end{array}$ & $\begin{array}{r}2454 \\
79.2 \\
110 \\
58 \\
.75 \\
.86\end{array}$ & $\begin{array}{r}1475 \\
49.2 \\
68 \\
33 \\
.46 \\
.52\end{array}$ & $\begin{array}{r}1068 \\
34.5 \\
42 \\
23 \\
.33 \\
.37\end{array}$ & $\begin{array}{r}999 \\
32.2 \\
52 \\
23 \\
.30 \\
.35\end{array}$ & $\begin{array}{r}1071 \\
35.7 \\
43 \\
29 \\
.34 \\
.38\end{array}$ \\
\hline
\end{tabular}

$\begin{array}{llllllllll}\text { CAL YR } 1986 & \text { TOTAL } & 44085 & \text { MEAN } & 121 & \text { MAX } 387 & \text { MIN } 48 & \text { CFSM } 1.14 & \text { IN } 15.47\end{array}$

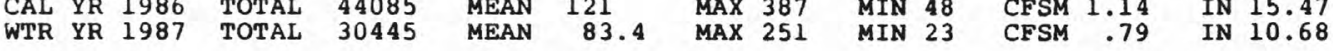


LOCATION. --Lat $41^{\circ} 48^{\circ} 03^{\prime \prime}$, long $85^{\circ} 45^{\prime} 22^{\prime \prime}$, in SWl/4 sec.6, T.8 S., R.12 W., Michigan Meridian, St. Joseph County, Hydrologic Unit 04050001, on right bank $500 \mathrm{ft}$ upstream from bridge on U.S. Highway 12 at Mottville, $0.4 \mathrm{mi}$ downstream from Michigan Power Co. hydroelectric plant, $4 \mathrm{mi}$ upstream from Pigeon River, and at mile 96 .

DRA INAGE AREA. $--1,866 \mathrm{mi}^{2}$.

PERIOD OF RECORD.--October 1923 to current year. Monthly discharge only for some periods, published in WSP 1307 .

REVISED RECORDS.--WSP 1387: 1930, 1932, 1938, 1940-42, 1945. WSP 1911: Drainage area.

GAGE.--Water-stage recorder. Datum of gage is $755.3 \mathrm{ft}$, Michigan Power Co. datum. Prior to Oct. 1, 1951, at site $0.4 \mathrm{mi}$ upstream at datum $4.2 \mathrm{ft}$ higher.

REMARKS.--No estimated daily discharges. Records good. Flow regulated by powerplants upstream from station. Several measurements of water temperature were made during the year.

AVERAGE DISCHARGE. -64 years, $1,602 \mathrm{ft}^{3} / \mathrm{s}, 11.66 \mathrm{in} / \mathrm{yr}^{\mathrm{r}}$.

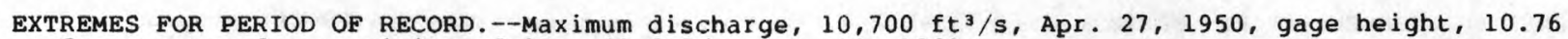
ft, present datum; minimum daily, $39 \mathrm{ft}^{3} / \mathrm{s}$, Oct. $19,1963$.

EXTREMES FOR CURRENT YEAR.--Maximum discharge, 5,430 ft3/s, Oct. 5, gage height, $6.99 \mathrm{ft}$; minimum daily, $369 \mathrm{ft}^{3} / \mathrm{s}$, July 26 .

DISCHARGE, IN CUBIC FEET PER SECOND, WATER YEAR OCTOBER 1986 TO SEPTEMBER 1987

\begin{tabular}{|c|c|c|c|c|c|c|c|c|c|c|c|c|}
\hline DAY & OCT & NOV & DEC & JAN & FEB & MAR & APR & MAY & JUN & JUL & AUG & SEP \\
\hline $\begin{array}{l}1 \\
2 \\
3 \\
4 \\
5\end{array}$ & $\begin{array}{l}2780 \\
3140 \\
3680 \\
4750 \\
5280\end{array}$ & $\begin{array}{l}2160 \\
2230 \\
1990 \\
1930 \\
2060\end{array}$ & $\begin{array}{l}2420 \\
2560 \\
2420 \\
2480 \\
2560\end{array}$ & $\begin{array}{l}1820 \\
1840 \\
1810 \\
1810 \\
1790\end{array}$ & $\begin{array}{l}1760 \\
1760 \\
1700 \\
1770 \\
1800\end{array}$ & $\begin{array}{l}1850 \\
2270 \\
2410 \\
2750 \\
2680\end{array}$ & $\begin{array}{l}1680 \\
1710 \\
1850 \\
1750 \\
1930\end{array}$ & $\begin{array}{l}1440 \\
1500 \\
1570 \\
1780 \\
1770\end{array}$ & $\begin{array}{l}1400 \\
1380 \\
1130 \\
1300 \\
1280\end{array}$ & $\begin{array}{l}736 \\
741 \\
673 \\
676 \\
624\end{array}$ & $\begin{array}{l}935 \\
562 \\
591 \\
780 \\
658\end{array}$ & $\begin{array}{r}1210 \\
1120 \\
821 \\
938 \\
980\end{array}$ \\
\hline $\begin{array}{r}6 \\
7 \\
8 \\
9 \\
10\end{array}$ & $\begin{array}{l}5400 \\
5240 \\
5080 \\
4730 \\
4410\end{array}$ & $\begin{array}{l}2100 \\
1970 \\
1620 \\
1900 \\
1990\end{array}$ & $\begin{array}{l}2700 \\
2580 \\
2570 \\
2700 \\
2720\end{array}$ & $\begin{array}{l}1810 \\
1730 \\
1780 \\
1720 \\
1700\end{array}$ & $\begin{array}{l}1770 \\
1740 \\
1740 \\
1650 \\
1680\end{array}$ & $\begin{array}{l}2540 \\
2450 \\
2540 \\
2420 \\
2240\end{array}$ & $\begin{array}{l}1770 \\
1740 \\
1670 \\
1660 \\
1620\end{array}$ & $\begin{array}{l}1670 \\
1540 \\
1600 \\
1590 \\
1370\end{array}$ & $\begin{array}{r}1060 \\
1070 \\
1120 \\
1110 \\
886\end{array}$ & $\begin{array}{l}579 \\
713 \\
793 \\
740 \\
701\end{array}$ & $\begin{array}{r}676 \\
613 \\
582 \\
613 \\
1010\end{array}$ & $\begin{array}{l}692 \\
602 \\
566 \\
752 \\
941\end{array}$ \\
\hline $\begin{array}{l}11 \\
12 \\
13 \\
14 \\
15\end{array}$ & $\begin{array}{l}3930 \\
4000 \\
3590 \\
2900 \\
3560\end{array}$ & $\begin{array}{l}1970 \\
1780 \\
1760 \\
1720 \\
1700\end{array}$ & $\begin{array}{l}2680 \\
2680 \\
2610 \\
2030 \\
2500\end{array}$ & $\begin{array}{l}1740 \\
1830 \\
1810 \\
1750 \\
1740\end{array}$ & $\begin{array}{l}1670 \\
1680 \\
1730 \\
1700 \\
1700\end{array}$ & $\begin{array}{l}2110 \\
2070 \\
1890 \\
1820 \\
1920\end{array}$ & $\begin{array}{l}1540 \\
1580 \\
1750 \\
1560 \\
2430\end{array}$ & $\begin{array}{l}1220 \\
1260 \\
1090 \\
1180 \\
1370\end{array}$ & $\begin{array}{r}797 \\
952 \\
715 \\
1010 \\
1040\end{array}$ & $\begin{array}{l}551 \\
533 \\
529 \\
718 \\
718\end{array}$ & $\begin{array}{l}749 \\
507 \\
509 \\
514 \\
553\end{array}$ & $\begin{array}{r}764 \\
1060 \\
1090 \\
914 \\
836\end{array}$ \\
\hline $\begin{array}{l}16 \\
17 \\
18 \\
19 \\
20\end{array}$ & $\begin{array}{l}2900 \\
3140 \\
3020 \\
2910 \\
2810\end{array}$ & $\begin{array}{l}1630 \\
1640 \\
1700 \\
1730 \\
1740\end{array}$ & $\begin{array}{l}2510 \\
2330 \\
2250 \\
2330 \\
2130\end{array}$ & $\begin{array}{l}1790 \\
1860 \\
1860 \\
1820 \\
1680\end{array}$ & $\begin{array}{l}1370 \\
1570 \\
1520 \\
1560 \\
1530\end{array}$ & $\begin{array}{l}1990 \\
1940 \\
1930 \\
1950 \\
1940\end{array}$ & $\begin{array}{l}2280 \\
2530 \\
2820 \\
2650 \\
2550\end{array}$ & $\begin{array}{l}1420 \\
1530 \\
1380 \\
1630 \\
1750\end{array}$ & $\begin{array}{l}936 \\
817 \\
733 \\
608 \\
527\end{array}$ & $\begin{array}{l}559 \\
785 \\
576 \\
580 \\
676\end{array}$ & $\begin{array}{l}554 \\
548 \\
673 \\
485 \\
481\end{array}$ & $\begin{array}{l}1080 \\
1190 \\
1150 \\
1360 \\
1030\end{array}$ \\
\hline $\begin{array}{l}21 \\
22 \\
23 \\
24 \\
25\end{array}$ & $\begin{array}{l}2580 \\
2100 \\
2250 \\
2380 \\
2290\end{array}$ & $\begin{array}{l}1770 \\
1750 \\
1780 \\
1850 \\
1860\end{array}$ & $\begin{array}{l}2280 \\
2230 \\
2080 \\
2100 \\
1970\end{array}$ & $\begin{array}{l}1650 \\
1770 \\
1850 \\
1600 \\
1060\end{array}$ & $\begin{array}{l}1520 \\
1350 \\
1580 \\
1490 \\
1550\end{array}$ & $\begin{array}{l}1850 \\
1870 \\
1960 \\
1900 \\
1780\end{array}$ & $\begin{array}{l}2260 \\
2370 \\
2160 \\
1950 \\
1870\end{array}$ & $\begin{array}{l}1710 \\
1810 \\
1710 \\
1560 \\
1420\end{array}$ & $\begin{array}{r}557 \\
1360 \\
1110 \\
849 \\
789\end{array}$ & $\begin{array}{l}571 \\
686 \\
658 \\
502 \\
428\end{array}$ & $\begin{array}{l}482 \\
482 \\
486 \\
634 \\
632\end{array}$ & $\begin{array}{r}660 \\
1290 \\
850 \\
649 \\
777\end{array}$ \\
\hline $\begin{array}{l}26 \\
27 \\
28 \\
29 \\
30 \\
31\end{array}$ & $\begin{array}{l}2100 \\
2140 \\
2290 \\
2310 \\
2220 \\
2090\end{array}$ & $\begin{array}{l}1930 \\
2260 \\
2290 \\
2510 \\
2520\end{array}$ & $\begin{array}{l}1870 \\
1900 \\
2030 \\
2020 \\
1900 \\
1870\end{array}$ & $\begin{array}{l}1900 \\
1810 \\
1640 \\
1630 \\
1720 \\
1730\end{array}$ & $\begin{array}{r}1480 \\
1550 \\
1620 \\
--- \\
--- \\
---\end{array}$ & $\begin{array}{l}1860 \\
1880 \\
1820 \\
1840 \\
1790 \\
1730\end{array}$ & $\begin{array}{l}1860 \\
1770 \\
1690 \\
1580 \\
1490 \\
---\end{array}$ & $\begin{array}{r}1360 \\
1320 \\
1350 \\
1310 \\
1110 \\
860\end{array}$ & $\begin{array}{l}756 \\
640 \\
762 \\
963 \\
785 \\
--\end{array}$ & $\begin{array}{r}369 \\
456 \\
712 \\
682 \\
943 \\
1020\end{array}$ & $\begin{array}{r}641 \\
1410 \\
1480 \\
1270 \\
935 \\
837\end{array}$ & $\begin{array}{r}1000 \\
822 \\
1000 \\
1270 \\
1100 \\
-\end{array}$ \\
\hline $\begin{array}{l}\text { TOTAL } \\
\text { MEAN } \\
\text { MAX } \\
\text { MIN } \\
\text { CFSM } \\
\text { IN. }\end{array}$ & $\begin{array}{r}102000 \\
3290 \\
5400 \\
2090 \\
1.76 \\
2.03\end{array}$ & $\begin{array}{r}57840 \\
1928 \\
2520 \\
1620 \\
1.03 \\
1.15\end{array}$ & $\begin{array}{r}72010 \\
2323 \\
2720 \\
1870 \\
1.25 \\
1.44\end{array}$ & $\begin{array}{r}54050 \\
1744 \\
1900 \\
1060 \\
.94 \\
1.08\end{array}$ & $\begin{array}{r}45540 \\
1626 \\
1800 \\
1350 \\
.87 \\
.91\end{array}$ & $\begin{array}{r}63990 \\
2064 \\
2750 \\
1730 \\
1.11 \\
1.28\end{array}$ & $\begin{array}{r}58070 \\
1936 \\
2820 \\
1490 \\
1.04 \\
1.16\end{array}$ & $\begin{array}{r}45180 \\
1457 \\
1810 \\
860 \\
.78 \\
.90\end{array}$ & $\begin{array}{r}28442 \\
948 \\
1400 \\
527 \\
.51 \\
.57\end{array}$ & $\begin{array}{r}20228 \\
653 \\
1020 \\
369 \\
.35 \\
.40\end{array}$ & $\begin{array}{r}21882 \\
706 \\
1480 \\
481 \\
.38 \\
.44\end{array}$ & $\begin{array}{r}28514 \\
950 \\
1360 \\
566 \\
.51 \\
.57\end{array}$ \\
\hline $\begin{array}{ll}\text { CAL YR } \\
\text { WTR }\end{array}$ & $\begin{array}{l}1986 \\
1987\end{array}$ & $\begin{array}{l}A L \\
A L\end{array}$ & $\begin{array}{l}29 \\
46\end{array}$ & $\begin{array}{ll}\mathbf{N} & 2191 \\
\mathbf{N} & 1638\end{array}$ & $\begin{array}{l}\text { MAX } \\
\text { MAX }\end{array}$ & $\begin{array}{l}5400 \\
5400\end{array}$ & $\begin{array}{ll}\text { MIN } & 596 \\
\text { MIN } & 369\end{array}$ & $\begin{array}{l}\text { CFSM } \\
\text { CFSM }\end{array}$ & $\begin{array}{l}7 \\
38\end{array}$ & $\begin{array}{l}15.94 \\
11.92\end{array}$ & & \\
\hline
\end{tabular}


04099750 PIGEON RIVER NEAR SCOTT, IN

LOCATION.--Lat $41^{\circ} 44^{\prime} 56^{\prime \prime}$, long $85^{\circ} 34^{\prime} 35^{\prime \prime}$, in SEl/4 NWI/4 sec.14, T.38 N., R.8 E., Lagrange County,

Hydrologic Unit 04050001 , on right bank $20 \mathrm{ft}$ downstream from bridge on County Road 750 North, 1,200 ft downstream from Page Ditch, $0.7 \mathrm{mi}$ south of Indiana-Michigan state line, and $1.2 \mathrm{mi}$ northwest of Scott, IN.

DRAINAGE AREA.--361 $\mathrm{mi}^{2}$, of which $53.9 \mathrm{mi}^{2}$ does not contribute directly to surface runoff.

PERIOD OF RECORD.--June 1968 to current year.

REVISED RECORDS.--WSP 2111: Drainage area.

GAGE.--Water-stage recorder. Datum of gage is $815.00 \mathrm{ft}$ above National Geodetic Vertical Datum of 1929 .

REMARKS.--Estimated daily discharges: Jan. 23 to Feb. 5, and Feb. 16, 17 . Records good except for estimated daily discharges, which are fair.

AVERAGE DISCHARGE. - - 19 years, $369 \mathrm{ft}^{3} / \mathrm{s}, 13.88 \mathrm{in} / \mathrm{yr}^{\mathrm{r}}$.

EXTREMES FOR PERIOD OF RECORD.--Maximum discharge, 2,370 ft $3 / \mathrm{s}$, Mar. 21, 1982, gage height, $7.85 \mathrm{ft}$; minimum daily, $42 \mathrm{ft}^{3} / \mathrm{s}$, Oct. 21,1971 .

EXTREMES FOR CURRENT YEAR.--Maximum discharge, 1,090 $\mathrm{ft}^{3} / \mathrm{s}$, Oct. 5, gage height, $5.40 \mathrm{ft}$; minimum daily, $101 \mathrm{ft}^{3} / \mathrm{s}$, Aug. 24 .

DISCHARGE, IN CUBIC FEET PER SECOND, WATER YEAR OCTOBER 1986 TO SEPTEMBER 1987

MEAN VALUES

\begin{tabular}{|c|c|c|c|c|c|c|c|c|c|c|c|c|}
\hline DAY & OCT & NOV & DEC & JAN & FEB & MAR & APR & MAY & JUN & JUL & AUG & SEP \\
\hline $\begin{array}{l}1 \\
2 \\
3 \\
4 \\
5\end{array}$ & $\begin{array}{r}432 \\
474 \\
591 \\
944 \\
1050\end{array}$ & $\begin{array}{l}308 \\
308 \\
284 \\
291 \\
291\end{array}$ & $\begin{array}{l}437 \\
453 \\
480 \\
459 \\
429\end{array}$ & $\begin{array}{l}297 \\
295 \\
291 \\
286 \\
282\end{array}$ & $\begin{array}{l}260 \\
270 \\
270 \\
265 \\
255\end{array}$ & $\begin{array}{l}415 \\
521 \\
536 \\
554 \\
593\end{array}$ & $\begin{array}{l}276 \\
301 \\
298 \\
283 \\
274\end{array}$ & $\begin{array}{l}288 \\
337 \\
427 \\
468 \\
431\end{array}$ & $\begin{array}{l}218 \\
224 \\
282 \\
247 \\
220\end{array}$ & $\begin{array}{l}310 \\
255 \\
226 \\
218 \\
219\end{array}$ & $\begin{array}{l}124 \\
122 \\
113 \\
113 \\
114\end{array}$ & $\begin{array}{l}123 \\
120 \\
117 \\
116 \\
118\end{array}$ \\
\hline $\begin{array}{r}6 \\
7 \\
8 \\
9 \\
10\end{array}$ & $\begin{array}{l}941 \\
900 \\
892 \\
891 \\
856\end{array}$ & $\begin{array}{l}283 \\
278 \\
275 \\
267 \\
258\end{array}$ & $\begin{array}{l}412 \\
423 \\
488 \\
521 \\
522\end{array}$ & $\begin{array}{l}278 \\
277 \\
276 \\
273 \\
286\end{array}$ & $\begin{array}{l}265 \\
265 \\
275 \\
281 \\
280\end{array}$ & $\begin{array}{l}630 \\
613 \\
598 \\
571 \\
526\end{array}$ & $\begin{array}{l}274 \\
271 \\
265 \\
260 \\
254\end{array}$ & $\begin{array}{l}413 \\
397 \\
376 \\
353 \\
331\end{array}$ & $\begin{array}{l}211 \\
204 \\
196 \\
188 \\
180\end{array}$ & $\begin{array}{l}221 \\
215 \\
216 \\
208 \\
183\end{array}$ & $\begin{array}{l}107 \\
104 \\
136 \\
160 \\
136\end{array}$ & $\begin{array}{l}121 \\
123 \\
133 \\
133 \\
141\end{array}$ \\
\hline $\begin{array}{l}11 \\
12 \\
13 \\
14 \\
15\end{array}$ & $\begin{array}{l}783 \\
717 \\
673 \\
653 \\
609\end{array}$ & $\begin{array}{l}249 \\
240 \\
244 \\
242 \\
239\end{array}$ & $\begin{array}{l}473 \\
480 \\
471 \\
497 \\
469\end{array}$ & $\begin{array}{l}284 \\
277 \\
273 \\
273 \\
299\end{array}$ & $\begin{array}{l}279 \\
283 \\
285 \\
287 \\
284\end{array}$ & $\begin{array}{l}492 \\
464 \\
439 \\
430 \\
435\end{array}$ & $\begin{array}{l}241 \\
310 \\
315 \\
306 \\
546\end{array}$ & $\begin{array}{l}316 \\
311 \\
292 \\
282 \\
319\end{array}$ & $\begin{array}{l}178 \\
192 \\
186 \\
176 \\
167\end{array}$ & $\begin{array}{l}171 \\
171 \\
163 \\
168 \\
168\end{array}$ & $\begin{array}{l}126 \\
118 \\
115 \\
114 \\
110\end{array}$ & $\begin{array}{l}189 \\
172 \\
155 \\
151 \\
154\end{array}$ \\
\hline $\begin{array}{l}16 \\
17 \\
18 \\
19 \\
20\end{array}$ & $\begin{array}{l}560 \\
524 \\
492 \\
463 \\
433\end{array}$ & $\begin{array}{l}241 \\
241 \\
246 \\
253 \\
256\end{array}$ & $\begin{array}{l}448 \\
436 \\
439 \\
417 \\
392\end{array}$ & $\begin{array}{l}315 \\
302 \\
307 \\
321 \\
367\end{array}$ & $\begin{array}{l}280 \\
280 \\
269 \\
254 \\
247\end{array}$ & $\begin{array}{l}415 \\
391 \\
370 \\
355 \\
339\end{array}$ & $\begin{array}{l}709 \\
705 \\
657 \\
629 \\
602\end{array}$ & $\begin{array}{l}293 \\
270 \\
303 \\
355 \\
337\end{array}$ & $\begin{array}{l}156 \\
148 \\
138 \\
133 \\
139\end{array}$ & $\begin{array}{l}218 \\
192 \\
176 \\
172 \\
154\end{array}$ & $\begin{array}{l}106 \\
110 \\
108 \\
108 \\
108\end{array}$ & $\begin{array}{l}171 \\
175 \\
169 \\
159 \\
143\end{array}$ \\
\hline $\begin{array}{l}21 \\
22 \\
23 \\
24 \\
25\end{array}$ & $\begin{array}{l}410 \\
390 \\
371 \\
359 \\
348\end{array}$ & $\begin{array}{l}272 \\
280 \\
290 \\
302 \\
303\end{array}$ & $\begin{array}{l}368 \\
351 \\
339 \\
333 \\
332\end{array}$ & $\begin{array}{l}361 \\
323 \\
305 \\
290 \\
275\end{array}$ & $\begin{array}{l}245 \\
246 \\
251 \\
256 \\
257\end{array}$ & $\begin{array}{l}329 \\
322 \\
317 \\
309 \\
305\end{array}$ & $\begin{array}{l}570 \\
523 \\
509 \\
473 \\
422\end{array}$ & $\begin{array}{l}320 \\
305 \\
288 \\
275 \\
267\end{array}$ & $\begin{array}{l}296 \\
295 \\
229 \\
195 \\
191\end{array}$ & $\begin{array}{l}142 \\
126 \\
124 \\
111 \\
116\end{array}$ & $\begin{array}{l}108 \\
113 \\
108 \\
101 \\
104\end{array}$ & $\begin{array}{l}138 \\
136 \\
132 \\
127 \\
125\end{array}$ \\
\hline $\begin{array}{l}26 \\
27 \\
28 \\
29 \\
30 \\
31\end{array}$ & $\begin{array}{l}363 \\
357 \\
358 \\
340 \\
327 \\
316\end{array}$ & $\begin{array}{l}397 \\
500 \\
466 \\
479 \\
451 \\
---\end{array}$ & $\begin{array}{l}326 \\
317 \\
310 \\
309 \\
304 \\
301\end{array}$ & $\begin{array}{l}265 \\
255 \\
250 \\
250 \\
250 \\
250\end{array}$ & $\begin{array}{l}260 \\
262 \\
278 \\
--- \\
--- \\
---\end{array}$ & $\begin{array}{l}304 \\
301 \\
295 \\
291 \\
288 \\
281\end{array}$ & $\begin{array}{l}389 \\
364 \\
341 \\
320 \\
300 \\
---\end{array}$ & $\begin{array}{l}262 \\
252 \\
239 \\
229 \\
220 \\
218\end{array}$ & $\begin{array}{l}183 \\
173 \\
165 \\
164 \\
217 \\
---\end{array}$ & $\begin{array}{l}144 \\
146 \\
128 \\
125 \\
133 \\
127\end{array}$ & $\begin{array}{l}165 \\
254 \\
207 \\
167 \\
143 \\
131\end{array}$ & $\begin{array}{l}122 \\
121 \\
122 \\
165 \\
187 \\
---\end{array}$ \\
\hline $\begin{array}{l}\text { TOTAL } \\
\text { MEAN } \\
\text { MAX } \\
\text { MIN } \\
\text { CFSM } \\
\text { IN. }\end{array}$ & $\begin{array}{r}17817 \\
575 \\
1050 \\
316 \\
1.59 \\
1.84\end{array}$ & $\begin{array}{r}9034 \\
301 \\
500 \\
239 \\
.83 \\
.93\end{array}$ & $\begin{array}{r}12736 \\
411 \\
522 \\
301 \\
1.14 \\
1.31\end{array}$ & $\begin{array}{r}8933 \\
288 \\
367 \\
250 \\
.80 \\
.92\end{array}$ & $\begin{array}{r}7489 \\
267 \\
287 \\
245 \\
.74 \\
.77\end{array}$ & $\begin{array}{r}13029 \\
420 \\
630 \\
281 \\
1.16 \\
1.34\end{array}$ & $\begin{array}{r}11987 \\
400 \\
709 \\
241 \\
1.11 \\
1.24\end{array}$ & $\begin{array}{r}9774 \\
315 \\
468 \\
218 \\
.87 \\
1.01\end{array}$ & $\begin{array}{r}5891 \\
196 \\
296 \\
133 \\
.54 \\
.61\end{array}$ & $\begin{array}{r}5446 \\
176 \\
310 \\
111 \\
.49 \\
.56\end{array}$ & $\begin{array}{r}3953 \\
128 \\
254 \\
101 \\
.35 \\
.41\end{array}$ & $\begin{array}{r}4258 \\
142 \\
189 \\
116 \\
.39 \\
.44\end{array}$ \\
\hline
\end{tabular}

$\begin{array}{lllllllll}\text { CAL YR } 1986 & \text { TOTAL } 154101 & \text { MEAN } 422 & \text { MAX } 1070 & \text { MIN } 133 & \text { CFSM } & 1.17 & \text { IN. } 15.88 \\ \text { WTR YR } 1987 & \text { TOTAL } 110347 & \text { MEAN } 302 & \text { MAX } & 1050 & \text { MIN } 101 & \text { CFSM } & .84 & \text { IN. } 11.37\end{array}$ 
04100222 NORTH BRANCH ELKHART RIVER AT COSPERVILLE, IN

LOCATION.--Lat $41^{\circ} 28^{\prime} 54^{\prime \prime}$, long $85^{\circ} 28^{\prime} 32^{\prime \prime}$, in NEl/4 NWl/4 sec. 22, T. 35 N., R.9 E., Noble County, Hydrologic Unit 04050001 , on right bank at downstream side of bridge on County Road 900 North at Cosperville, IN, $1,300 \mathrm{ft}$ downstream from Boyd Ditch, $1.7 \mathrm{mi}$ upstream from Hustin Ditch, and $3.1 \mathrm{mi}$ downstream from Waldron Lake.

DRAINAGE AREA.--142 $\mathrm{mi}^{2}$.

PERIOD OF RECORD.---October 1971 to current year.

GAGE.--Water-stage recorder. Datum of gage is $880.12 \mathrm{ft}$ above National Geodetic Vertical Datum of 1929 (levels by Indiana Department of Natural Resources).

REMARKS.--Estimated daily discharges: Jan. 16, 18, 19, 21-28. Records fair. Flow regulated at times by dam at Waldron Lake.

AVERAGE DISCHARGE.--16 years, $141 \mathrm{ft}^{3} / \mathrm{s}, 13.48 \mathrm{in} / \mathrm{yr}^{\mathrm{r}}$.

EXTREMES FOR PERIOD OF RECORD.--Maximum discharge, $919 \mathrm{ft}^{3} / \mathrm{s}$, Mar. 23, 1982, gage height, 8.12 ft; minimum daily, $2.4 \mathrm{ft}^{3} / \mathrm{s}$, Nov. $21,1971$.

EXTREMES FOR CURRENT YEAR.--Maximum discharge, $449 \mathrm{ft}^{3} / \mathrm{s}$, Oct. 6 , gage height, $5.95 \mathrm{ft}$; minimum daily, $4.1 \mathrm{ft}^{3} / \mathrm{s}$, Sept. 25 , caused by regulation.

DISCHARGE, IN CUBIC FEET PER SECOND, WATER YEAR OCTOBER 1986 TO SEPTEMBER 1987 MEAN VALUES

\begin{tabular}{|c|c|c|c|c|c|c|c|c|c|c|c|c|}
\hline DAY & OCT & NOV & DEC & JAN & FEB & MAR & APR & MAY & JUN & JUL & AUG & SEP \\
\hline $\begin{array}{l}1 \\
2 \\
3 \\
4 \\
5\end{array}$ & $\begin{array}{l}148 \\
157 \\
262 \\
382 \\
433\end{array}$ & $\begin{array}{l}135 \\
132 \\
128 \\
125 \\
121\end{array}$ & $\begin{array}{l}154 \\
159 \\
166 \\
169 \\
166\end{array}$ & $\begin{array}{l}124 \\
122 \\
120 \\
119 \\
117\end{array}$ & $\begin{array}{l}108 \\
109 \\
109 \\
111 \\
113\end{array}$ & $\begin{array}{l}153 \\
186 \\
197 \\
197 \\
202\end{array}$ & $\begin{array}{r}97 \\
98 \\
100 \\
98 \\
97\end{array}$ & $\begin{array}{r}98 \\
111 \\
144 \\
167 \\
169\end{array}$ & $\begin{array}{l}66 \\
68 \\
67 \\
61 \\
56\end{array}$ & $\begin{array}{l}80 \\
85 \\
83 \\
93 \\
90\end{array}$ & $\begin{array}{l}37 \\
36 \\
36 \\
34 \\
30\end{array}$ & $\begin{array}{l}36 \\
33 \\
31 \\
29 \\
25\end{array}$ \\
\hline $\begin{array}{r}6 \\
7 \\
8 \\
9 \\
10\end{array}$ & $\begin{array}{l}447 \\
443 \\
429 \\
424 \\
406\end{array}$ & $\begin{array}{l}117 \\
114 \\
110 \\
106 \\
104\end{array}$ & $\begin{array}{l}161 \\
161 \\
172 \\
184 \\
193\end{array}$ & $\begin{array}{l}115 \\
112 \\
112 \\
112 \\
114\end{array}$ & $\begin{array}{l}114 \\
115 \\
119 \\
124 \\
124\end{array}$ & $\begin{array}{l}209 \\
209 \\
205 \\
201 \\
190\end{array}$ & $\begin{array}{l}93 \\
91 \\
88 \\
85 \\
83\end{array}$ & $\begin{array}{l}164 \\
158 \\
149 \\
139 \\
131\end{array}$ & $\begin{array}{l}52 \\
47 \\
43 \\
40 \\
36\end{array}$ & $\begin{array}{l}84 \\
78 \\
70 \\
64 \\
57\end{array}$ & $\begin{array}{l}27 \\
24 \\
29 \\
22 \\
20\end{array}$ & $\begin{array}{l}22 \\
20 \\
21 \\
28 \\
31\end{array}$ \\
\hline $\begin{array}{l}11 \\
12 \\
13 \\
14 \\
15\end{array}$ & $\begin{array}{l}385 \\
364 \\
346 \\
332 \\
315\end{array}$ & $\begin{array}{r}101 \\
97 \\
93 \\
92 \\
90\end{array}$ & $\begin{array}{l}193 \\
185 \\
176 \\
168 \\
163\end{array}$ & $\begin{array}{l}112 \\
112 \\
111 \\
111 \\
118\end{array}$ & $\begin{array}{l}124 \\
126 \\
129 \\
132 \\
131\end{array}$ & $\begin{array}{l}179 \\
171 \\
164 \\
160 \\
159\end{array}$ & $\begin{array}{r}82 \\
90 \\
93 \\
101 \\
174\end{array}$ & $\begin{array}{l}122 \\
119 \\
112 \\
105 \\
101\end{array}$ & $\begin{array}{l}33 \\
39 \\
53 \\
44 \\
23\end{array}$ & $\begin{array}{l}52 \\
49 \\
51 \\
51 \\
50\end{array}$ & $\begin{array}{l}21 \\
20 \\
19 \\
18 \\
17\end{array}$ & $\begin{array}{l}38 \\
38 \\
35 \\
34 \\
52\end{array}$ \\
\hline $\begin{array}{l}16 \\
17 \\
18 \\
19 \\
20\end{array}$ & $\begin{array}{l}297 \\
279 \\
261 \\
242 \\
223\end{array}$ & $\begin{array}{l}89 \\
88 \\
92 \\
96 \\
99\end{array}$ & $\begin{array}{l}158 \\
155 \\
154 \\
152 \\
150\end{array}$ & $\begin{array}{l}122 \\
125 \\
123 \\
120 \\
121\end{array}$ & $\begin{array}{l}129 \\
122 \\
118 \\
113 \\
109\end{array}$ & $\begin{array}{l}154 \\
148 \\
144 \\
138 \\
132\end{array}$ & $\begin{array}{l}213 \\
221 \\
217 \\
209 \\
197\end{array}$ & $\begin{array}{r}94 \\
65 \\
56 \\
109 \\
122\end{array}$ & $\begin{array}{l}44 \\
41 \\
37 \\
37 \\
9.2\end{array}$ & $\begin{array}{l}52 \\
49 \\
45 \\
42 \\
38\end{array}$ & $\begin{array}{l}15 \\
17 \\
17 \\
14 \\
11\end{array}$ & $\begin{array}{l}80 \\
69 \\
62 \\
56 \\
52\end{array}$ \\
\hline $\begin{array}{l}21 \\
22 \\
23 \\
24 \\
25\end{array}$ & $\begin{array}{l}206 \\
192 \\
181 \\
173 \\
168\end{array}$ & $\begin{array}{l}104 \\
112 \\
118 \\
122 \\
125\end{array}$ & $\begin{array}{l}146 \\
141 \\
138 \\
136 \\
135\end{array}$ & $\begin{array}{l}123 \\
118 \\
112 \\
108 \\
106\end{array}$ & $\begin{array}{l}107 \\
106 \\
107 \\
109 \\
110\end{array}$ & $\begin{array}{l}127 \\
122 \\
119 \\
115 \\
112\end{array}$ & $\begin{array}{l}187 \\
178 \\
172 \\
164 \\
153\end{array}$ & $\begin{array}{r}118 \\
107 \\
98 \\
91 \\
87\end{array}$ & $\begin{array}{l}12 \\
46 \\
68 \\
65 \\
58\end{array}$ & $\begin{array}{l}35 \\
32 \\
30 \\
27 \\
25\end{array}$ & $\begin{array}{l}9.6 \\
9.4 \\
9.1 \\
8.5 \\
8.9\end{array}$ & $\begin{array}{r}49 \\
40 \\
7.1 \\
4.2 \\
4.1\end{array}$ \\
\hline $\begin{array}{l}26 \\
27 \\
28 \\
29 \\
30 \\
31\end{array}$ & $\begin{array}{l}165 \\
162 \\
158 \\
153 \\
147 \\
141\end{array}$ & $\begin{array}{l}138 \\
152 \\
157 \\
157 \\
156 \\
-\end{array}$ & $\begin{array}{l}135 \\
133 \\
130 \\
128 \\
127 \\
125\end{array}$ & $\begin{array}{l}105 \\
108 \\
110 \\
111 \\
110 \\
107\end{array}$ & \begin{tabular}{l}
111 \\
111 \\
115 \\
\hdashline- \\
---
\end{tabular} & $\begin{array}{r}109 \\
108 \\
106 \\
104 \\
101 \\
98\end{array}$ & $\begin{array}{l}142 \\
131 \\
121 \\
112 \\
105 \\
---\end{array}$ & $\begin{array}{l}81 \\
77 \\
73 \\
68 \\
63 \\
64\end{array}$ & $\begin{array}{l}51 \\
45 \\
39 \\
39 \\
53 \\
-\end{array}$ & $\begin{array}{l}31 \\
40 \\
39 \\
38 \\
39 \\
38\end{array}$ & $\begin{array}{l}27 \\
46 \\
51 \\
51 \\
46 \\
41\end{array}$ & $\begin{array}{r}4.6 \\
8.3 \\
11 \\
23 \\
30 \\
-\end{array}$ \\
\hline $\begin{array}{l}\text { TOTAL } \\
\text { MEAN } \\
\text { MAX } \\
\text { MIN } \\
\text { CFSM } \\
\text { IN. }\end{array}$ & $\begin{array}{r}8421 \\
272 \\
447 \\
141 \\
1.92 \\
2.21\end{array}$ & $\begin{array}{r}3470 \\
116 \\
157 \\
88 \\
.82 \\
.91\end{array}$ & $\begin{array}{r}4813 \\
155 \\
193 \\
125 \\
1.09 \\
1.26\end{array}$ & $\begin{array}{r}3560 \\
115 \\
125 \\
105 \\
.81 \\
.93\end{array}$ & $\begin{array}{l}3255 \\
116 \\
132 \\
106 \\
.82 \\
.85\end{array}$ & $\begin{array}{r}4719 \\
152 \\
209 \\
98 \\
1.07 \\
1.24\end{array}$ & $\begin{array}{r}3992 \\
133 \\
221 \\
82 \\
.94 \\
1.05\end{array}$ & $\begin{array}{r}3362 \\
108 \\
169 \\
56 \\
.76 \\
.88\end{array}$ & $\begin{array}{r}1372.2 \\
45.7 \\
68 \\
9.2 \\
.32 \\
.36\end{array}$ & $\begin{array}{r}1637 \\
52.8 \\
93 \\
25 \\
.37 \\
.43\end{array}$ & $\begin{array}{r}771.5 \\
24.9 \\
51 \\
8.5 \\
.18 \\
.20\end{array}$ & $\begin{array}{r}973.3 \\
32.4 \\
80 \\
4.1 \\
.23 \\
.25\end{array}$ \\
\hline
\end{tabular}

CAL YR 1986 TOTAL 56907.9 MEAN 156 MAX 447 MIN 7.3 CFSM 1.10 IN. 14.91 WTR YR 1987 TOTAL 40346.0 MEAN 111 MAX 447 MIN 4.1 CFSM .78 IN. 10.57 
04100500 ELKHART RIVER AT GOSHEN, IN

LOCATION. --Lat $41^{\circ} 35^{\prime} 36^{\prime \prime}$, long $85^{\circ} 50^{\prime} 55^{\prime \prime}$, in NEl/4 NEl/4 sec.8, T. 36 N., R.6 E., Elkhart County, Hydrologic Unit 04050001 , on right bank $20 \mathrm{ft}$ downstream from River Avenue bridge at Goshen,' IN, 0.4 mi upstream from Rock Run, and at mile 16.1.

DRAINAGE AREA. $--594 \mathrm{mi}^{2}$.

PERIOD OF RECORD.--April 1931 to current year.

REVISED RECORDS.--WSP 1337: 1939(M). WSP 1557: 1954. WSP 2111: Drainage area.

GAGE.--Water-stage recorder. Datum of gage is $769.43 \mathrm{ft}$ above National Geodetic Vertical Datum of 1929 . Prior to Nov. 20, 1931, nonrecording gage at same site and datum.

REMARKS.--Estimated daily discharges: Jan. 19-27 and Feb. 15-18. Records good except for estimated daily discharges, which are poor.

AVERAGE DISCHARGE. - -56 years, $524 \mathrm{ft}^{3} / \mathrm{s}, 11.98 \mathrm{in} / \mathrm{yr}$.

EXTREMES FOR PERIOD OF RECORD.--Maximum discharge, $6,360 \mathrm{ft}^{3} / \mathrm{s}$, Feb. 24, 1985; maximum gage height, $11.94 \mathrm{ft}$, Mar. 14, 1982; minimum daily discharge, $7.0 \mathrm{ft}^{3} / \mathrm{s}$, Aug. 11, 1964, result of extreme regulation.

EXTREMES FOR CURRENT YEAR.--Peak discharges greater than base discharge of $1,800 \mathrm{ft}^{3} / \mathrm{s}$ and maximum (*):

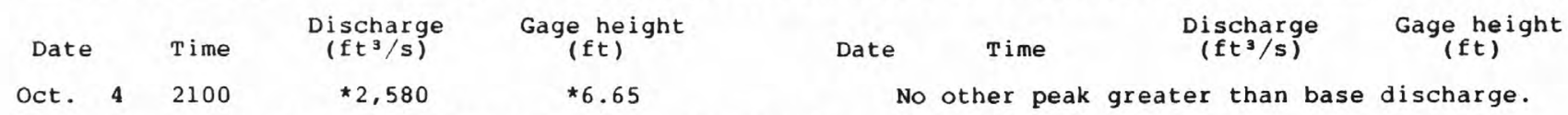

Minimum daily discharge, $115 \mathrm{ft}^{3} / \mathrm{s}$, Aug. 24, 25, Sept. 28.

DISCHARGE, IN CUBIC FEET PER SECOND, WATER YEAR OCTOBER 1986 TO SEPTEMBER 1987 MEAN VALUES

\begin{tabular}{|c|c|c|c|c|c|c|c|c|c|c|c|c|}
\hline DAY & OCT & NOV & DEC & JAN & FEB & MAR & APR & MAY & JUN & JUL & AUG & SEP \\
\hline $\begin{array}{l}1 \\
2 \\
3 \\
4 \\
5\end{array}$ & $\begin{array}{r}774 \\
835 \\
1120 \\
2160 \\
2320\end{array}$ & $\begin{array}{l}643 \\
628 \\
622 \\
600 \\
588\end{array}$ & $\begin{array}{l}741 \\
774 \\
903 \\
927 \\
837\end{array}$ & $\begin{array}{l}518 \\
517 \\
510 \\
503 \\
500\end{array}$ & $\begin{array}{l}538 \\
563 \\
600 \\
621 \\
627\end{array}$ & $\begin{array}{r}1050 \\
1410 \\
1200 \\
998 \\
971\end{array}$ & $\begin{array}{l}453 \\
471 \\
455 \\
436 \\
421\end{array}$ & $\begin{array}{l}480 \\
542 \\
695 \\
842 \\
740\end{array}$ & $\begin{array}{l}388 \\
384 \\
402 \\
379 \\
357\end{array}$ & $\begin{array}{l}295 \\
316 \\
321 \\
322 \\
329\end{array}$ & $\begin{array}{l}269 \\
254 \\
228 \\
217 \\
209\end{array}$ & $\begin{array}{l}179 \\
179 \\
164 \\
157 \\
149\end{array}$ \\
\hline $\begin{array}{r}6 \\
7 \\
8 \\
9 \\
10\end{array}$ & $\begin{array}{l}2020 \\
1870 \\
1740 \\
1680 \\
1630\end{array}$ & $\begin{array}{l}576 \\
563 \\
550 \\
535 \\
520\end{array}$ & $\begin{array}{r}784 \\
788 \\
872 \\
1000 \\
1040\end{array}$ & $\begin{array}{l}498 \\
500 \\
514 \\
515 \\
526\end{array}$ & $\begin{array}{l}610 \\
604 \\
644 \\
678 \\
672\end{array}$ & $\begin{array}{r}1110 \\
1070 \\
1000 \\
957 \\
917\end{array}$ & $\begin{array}{l}416 \\
406 \\
397 \\
381 \\
372\end{array}$ & $\begin{array}{l}681 \\
653 \\
628 \\
605 \\
583\end{array}$ & $\begin{array}{l}331 \\
296 \\
277 \\
262 \\
248\end{array}$ & $\begin{array}{l}325 \\
302 \\
283 \\
261 \\
235\end{array}$ & $\begin{array}{l}198 \\
187 \\
180 \\
183 \\
178\end{array}$ & $\begin{array}{l}141 \\
135 \\
137 \\
149 \\
149\end{array}$ \\
\hline $\begin{array}{l}11 \\
12 \\
13 \\
14 \\
15\end{array}$ & $\begin{array}{l}1540 \\
1450 \\
1370 \\
1320 \\
1260\end{array}$ & $\begin{array}{l}506 \\
467 \\
440 \\
424 \\
415\end{array}$ & $\begin{array}{l}944 \\
854 \\
808 \\
758 \\
777\end{array}$ & $\begin{array}{l}504 \\
481 \\
467 \\
477 \\
534\end{array}$ & $\begin{array}{l}648 \\
676 \\
740 \\
752 \\
700\end{array}$ & $\begin{array}{l}879 \\
849 \\
817 \\
793 \\
776\end{array}$ & $\begin{array}{l}380 \\
419 \\
428 \\
465 \\
935\end{array}$ & $\begin{array}{l}556 \\
545 \\
511 \\
487 \\
461\end{array}$ & $\begin{array}{l}236 \\
251 \\
239 \\
237 \\
230\end{array}$ & $\begin{array}{l}219 \\
204 \\
220 \\
239 \\
267\end{array}$ & $\begin{array}{l}166 \\
156 \\
148 \\
139 \\
135\end{array}$ & $\begin{array}{l}171 \\
164 \\
153 \\
150 \\
165\end{array}$ \\
\hline $\begin{array}{l}16 \\
17 \\
18 \\
19 \\
20\end{array}$ & $\begin{array}{r}1170 \\
1080 \\
1010 \\
954 \\
904\end{array}$ & $\begin{array}{l}414 \\
407 \\
416 \\
425 \\
436\end{array}$ & $\begin{array}{l}761 \\
752 \\
748 \\
724 \\
668\end{array}$ & $\begin{array}{l}705 \\
661 \\
631 \\
550 \\
460\end{array}$ & $\begin{array}{l}620 \\
600 \\
600 \\
591 \\
572\end{array}$ & $\begin{array}{l}744 \\
710 \\
680 \\
663 \\
634\end{array}$ & $\begin{array}{r}1250 \\
1070 \\
932 \\
912 \\
893\end{array}$ & $\begin{array}{l}430 \\
409 \\
435 \\
522 \\
650\end{array}$ & $\begin{array}{l}200 \\
186 \\
186 \\
179 \\
203\end{array}$ & $\begin{array}{l}282 \\
252 \\
234 \\
217 \\
206\end{array}$ & $\begin{array}{l}128 \\
132 \\
135 \\
128 \\
129\end{array}$ & $\begin{array}{l}170 \\
213 \\
223 \\
194 \\
196\end{array}$ \\
\hline $\begin{array}{l}21 \\
22 \\
23 \\
24 \\
25\end{array}$ & $\begin{array}{l}856 \\
807 \\
765 \\
738 \\
719\end{array}$ & $\begin{array}{l}528 \\
649 \\
652 \\
629 \\
604\end{array}$ & $\begin{array}{l}637 \\
605 \\
586 \\
574 \\
579\end{array}$ & $\begin{array}{l}510 \\
560 \\
540 \\
510 \\
490\end{array}$ & $\begin{array}{l}563 \\
563 \\
618 \\
674 \\
683\end{array}$ & $\begin{array}{l}600 \\
559 \\
535 \\
518 \\
518\end{array}$ & $\begin{array}{l}865 \\
834 \\
844 \\
791 \\
740\end{array}$ & $\begin{array}{l}608 \\
667 \\
606 \\
542 \\
525\end{array}$ & $\begin{array}{l}203 \\
200 \\
254 \\
253 \\
235\end{array}$ & $\begin{array}{l}183 \\
170 \\
157 \\
151 \\
145\end{array}$ & $\begin{array}{l}125 \\
122 \\
116 \\
115 \\
115\end{array}$ & $\begin{array}{l}189 \\
183 \\
186 \\
163 \\
136\end{array}$ \\
\hline $\begin{array}{l}26 \\
27 \\
28 \\
29 \\
30 \\
31\end{array}$ & $\begin{array}{l}728 \\
759 \\
759 \\
720 \\
683 \\
660\end{array}$ & $\begin{array}{r}767 \\
1050 \\
986 \\
831 \\
765 \\
-\end{array}$ & $\begin{array}{l}563 \\
549 \\
539 \\
531 \\
530 \\
523\end{array}$ & $\begin{array}{l}500 \\
510 \\
525 \\
531 \\
534 \\
538\end{array}$ & $\begin{array}{l}678 \\
628 \\
658 \\
--- \\
--- \\
---\end{array}$ & $\begin{array}{l}512 \\
495 \\
482 \\
472 \\
469 \\
454\end{array}$ & $\begin{array}{l}694 \\
652 \\
613 \\
570 \\
515 \\
---\end{array}$ & $\begin{array}{l}521 \\
496 \\
465 \\
437 \\
416 \\
396\end{array}$ & $\begin{array}{l}229 \\
214 \\
195 \\
189 \\
223 \\
---\end{array}$ & $\begin{array}{l}159 \\
175 \\
175 \\
199 \\
405 \\
328\end{array}$ & $\begin{array}{l}187 \\
248 \\
222 \\
214 \\
203 \\
190\end{array}$ & $\begin{array}{l}126 \\
120 \\
115 \\
160 \\
176 \\
\end{array}$ \\
\hline $\begin{array}{l}\text { TOTAL } \\
\text { MEAN } \\
\text { MAX } \\
\text { MIN } \\
\text { CFSM } \\
\text { IN. }\end{array}$ & $\begin{array}{r}36401 \\
1174 \\
2320 \\
660 \\
1.98 \\
2.28\end{array}$ & $\begin{array}{r}17636 \\
588 \\
1050 \\
407 \\
.99 \\
1.10\end{array}$ & $\begin{array}{r}22676 \\
731 \\
1040 \\
523 \\
1.23 \\
1.42\end{array}$ & $\begin{array}{r}16319 \\
526 \\
705 \\
460 \\
.89 \\
1.02\end{array}$ & $\begin{array}{r}17721 \\
633 \\
752 \\
538 \\
1.07 \\
1.11\end{array}$ & $\begin{array}{r}23842 \\
769 \\
1410 \\
454 \\
1.29 \\
1.49\end{array}$ & $\begin{array}{r}19010 \\
634 \\
1250 \\
372 \\
1.07 \\
1.19\end{array}$ & $\begin{array}{r}17134 \\
553 \\
842 \\
396 \\
.93 \\
1.07\end{array}$ & $\begin{array}{r}7666 \\
256 \\
402 \\
179 \\
.43 \\
.48\end{array}$ & $\begin{array}{r}7576 \\
244 \\
405 \\
145 \\
.41 \\
.47\end{array}$ & $\begin{array}{r}5356 \\
173 \\
269 \\
115 \\
.29 \\
.34\end{array}$ & $\begin{array}{r}4892 \\
163 \\
223 \\
115 \\
.27 \\
.31\end{array}$ \\
\hline
\end{tabular}

CAL YR 1986 TOTAL 258720 MEAN 709 MAX 2320 MIN 186 CFSM 1.19 IN. 16.20 WTR YR 1987 TOTAL 196229 MEAN 538 MAX 2320 MIN 115 CFSM $.91 \quad$ IN. 12.29 
LOCATION.--Lat 41.41'30", long $85^{\circ} 58^{\prime} 30^{\prime \prime}$, in SWl/4 NEl/4 sec.5, T. 37 N., R.5 E., Elkhart County,

Hydrologic Unit 04050001 , on left bank $200 \mathrm{ft}$ downstream from Elkhart River, 200 ft upstream from Main Street bridge in Elkhart, IN, 2,000 ft downstream from Christiana Creek, $0.5 \mathrm{mi}$ downstream from Elkhart Hydroelectric plant, and at mile 76.5 .

DRAINAGE AREA. $--3,370 \mathrm{mi}^{2}$.

PERIOD OF RECORD.--August 1947 to current year. Gage heights at site $0.8 \mathrm{mi}$ downstream at different datum from September 1924 to March 1926 are available in the Indiana District office.

REVISED RECORDS.--WSP 2111: Drainage area.

GAGE.--Water-stage recorder. Datum of gage is $700.00 \mathrm{ft}$ above National Geodetic Vertical Datum of 1929. REMARKS.--No estimated daily discharges. Records good. Flow regulated by Elkhart Hydroelectric plant. AVERAGE DISCHARGE. --40 years, $3,216 \mathrm{ft}^{3} / \mathrm{s}, 12.96 \mathrm{in} / \mathrm{yr}^{\mathrm{r}}$.

EXTREMES FOR PERIOD OF RECORD.--Maximum discharge, 18,800 $\mathrm{ft}^{3} / \mathrm{s}$, Feb. 27, 1985; maximum gage height, $27.91 \mathrm{ft}$, Mar. 21, 1982; minimum daily discharge, $336 \mathrm{ft} / \mathrm{s}$, Aug. 5,1964 .

EXTREMES FOR CURRENT YEAR.--Maximum discharge, 10,200 ft $3 / \mathrm{s}$, Oct. 6 , gage height, $23.53 \mathrm{ft}$; minimum daily, $1,140 \mathrm{ft}^{3} / \mathrm{s}$, Aug. 23 .

DISCHARGE, IN CUBIC FEET PER SECOND, WATER YEAR OCTOBER 1986 TO SEPTEMBER 1987 MEAN VALUES

\begin{tabular}{|c|c|c|c|c|c|c|c|c|c|c|c|c|}
\hline DAY & OCT & NOV & DEC & JAN & FEB & MAR & APR & MAY & JUN & JUL & AUG & SEP \\
\hline $\begin{array}{l}1 \\
2 \\
3 \\
4 \\
5\end{array}$ & $\begin{array}{l}4460 \\
4990 \\
6070 \\
8240 \\
9360\end{array}$ & $\begin{array}{l}3670 \\
3780 \\
3640 \\
3360 \\
3450\end{array}$ & $\begin{array}{l}4310 \\
4360 \\
4880 \\
4520 \\
4400\end{array}$ & $\begin{array}{l}3300 \\
3310 \\
3270 \\
3250 \\
3230\end{array}$ & $\begin{array}{l}3260 \\
3290 \\
3170 \\
3130 \\
3150\end{array}$ & $\begin{array}{l}3980 \\
4980 \\
5180 \\
4750 \\
5220\end{array}$ & $\begin{array}{l}2890 \\
2920 \\
3070 \\
2940 \\
3030\end{array}$ & $\begin{array}{l}2660 \\
2890 \\
3200 \\
3650 \\
3510\end{array}$ & $\begin{array}{l}2110 \\
2690 \\
2280 \\
2370 \\
2390\end{array}$ & $\begin{array}{l}1790 \\
1830 \\
1760 \\
1720 \\
1700\end{array}$ & $\begin{array}{l}1810 \\
1630 \\
1480 \\
1660 \\
1490\end{array}$ & $\begin{array}{l}1880 \\
2020 \\
1720 \\
1620 \\
1750\end{array}$ \\
\hline $\begin{array}{r}6 \\
7 \\
8 \\
9 \\
10\end{array}$ & $\begin{array}{l}9340 \\
9240 \\
8510 \\
8470 \\
7930\end{array}$ & $\begin{array}{l}3620 \\
3600 \\
2980 \\
3240 \\
3300\end{array}$ & $\begin{array}{l}4610 \\
4950 \\
4580 \\
5370 \\
5000\end{array}$ & $\begin{array}{l}3220 \\
3200 \\
3140 \\
3190 \\
3140\end{array}$ & $\begin{array}{l}3140 \\
3060 \\
3130 \\
3090 \\
3060\end{array}$ & $\begin{array}{l}5060 \\
4840 \\
4760 \\
4200 \\
4130\end{array}$ & $\begin{array}{l}3070 \\
2870 \\
2820 \\
2720 \\
2780\end{array}$ & $\begin{array}{l}3290 \\
3060 \\
2970 \\
2960 \\
2740\end{array}$ & $\begin{array}{l}2070 \\
2010 \\
2050 \\
1960 \\
1870\end{array}$ & $\begin{array}{l}1660 \\
1730 \\
1760 \\
1680 \\
1610\end{array}$ & $\begin{array}{l}1470 \\
1410 \\
1400 \\
1470 \\
1710\end{array}$ & $\begin{array}{l}1510 \\
1360 \\
1330 \\
1460 \\
1700\end{array}$ \\
\hline $\begin{array}{l}11 \\
12 \\
13 \\
14 \\
15\end{array}$ & $\begin{array}{l}7390 \\
7190 \\
6370 \\
5740 \\
5350\end{array}$ & $\begin{array}{l}3130 \\
3280 \\
2830 \\
3030 \\
2910\end{array}$ & $\begin{array}{l}5030 \\
4810 \\
4620 \\
4290 \\
3820\end{array}$ & $\begin{array}{l}3150 \\
3240 \\
3200 \\
3170 \\
3240\end{array}$ & $\begin{array}{l}3060 \\
3060 \\
3190 \\
3250 \\
3250\end{array}$ & $\begin{array}{l}4010 \\
3790 \\
3770 \\
3500 \\
3560\end{array}$ & $\begin{array}{l}2680 \\
2790 \\
3020 \\
3110 \\
4560\end{array}$ & $\begin{array}{l}2470 \\
2450 \\
2350 \\
2210 \\
2490\end{array}$ & $\begin{array}{l}1680 \\
1800 \\
1650 \\
1740 \\
1950\end{array}$ & $\begin{array}{l}1430 \\
1300 \\
1390 \\
1580 \\
1670\end{array}$ & $\begin{array}{l}1720 \\
1280 \\
1280 \\
1260 \\
1250\end{array}$ & $\begin{array}{l}1610 \\
1690 \\
1900 \\
1770 \\
1610\end{array}$ \\
\hline $\begin{array}{l}16 \\
17 \\
18 \\
19 \\
20\end{array}$ & $\begin{array}{l}5490 \\
4470 \\
5350 \\
5200 \\
4940\end{array}$ & $\begin{array}{l}2970 \\
2550 \\
3020 \\
2990 \\
2980\end{array}$ & $\begin{array}{l}4580 \\
4240 \\
3940 \\
4450 \\
3830\end{array}$ & $\begin{array}{l}3450 \\
3530 \\
3530 \\
3410 \\
3120\end{array}$ & $\begin{array}{l}2700 \\
2920 \\
2810 \\
2810 \\
2740\end{array}$ & $\begin{array}{l}3630 \\
3500 \\
3460 \\
3430 \\
3370\end{array}$ & $\begin{array}{l}5520 \\
5320 \\
5450 \\
5260 \\
4860\end{array}$ & $\begin{array}{l}2420 \\
2580 \\
2630 \\
2740 \\
3220\end{array}$ & $\begin{array}{l}1690 \\
1590 \\
1440 \\
1300 \\
1270\end{array}$ & $\begin{array}{l}1640 \\
1770 \\
1520 \\
1470 \\
1520\end{array}$ & $\begin{array}{l}1250 \\
1250 \\
1370 \\
1190 \\
1160\end{array}$ & $\begin{array}{l}1770 \\
2050 \\
1970 \\
2150 \\
2040\end{array}$ \\
\hline $\begin{array}{l}21 \\
22 \\
23 \\
24 \\
25\end{array}$ & $\begin{array}{l}4700 \\
4280 \\
3780 \\
4250 \\
3920\end{array}$ & $\begin{array}{l}3180 \\
3330 \\
3500 \\
3410 \\
3260\end{array}$ & $\begin{array}{l}4080 \\
3670 \\
4020 \\
3650 \\
3660\end{array}$ & $\begin{array}{l}3050 \\
3370 \\
3180 \\
3030 \\
2780\end{array}$ & $\begin{array}{l}2720 \\
2650 \\
2710 \\
2980 \\
2820\end{array}$ & $\begin{array}{l}3230 \\
3190 \\
3260 \\
3170 \\
3060\end{array}$ & $\begin{array}{l}4540 \\
4270 \\
4260 \\
3820 \\
3570\end{array}$ & $\begin{array}{l}3040 \\
3100 \\
2980 \\
2710 \\
2610\end{array}$ & $\begin{array}{l}1420 \\
2170 \\
2370 \\
1910 \\
1770\end{array}$ & $\begin{array}{l}1400 \\
1450 \\
1410 \\
1220 \\
1190\end{array}$ & $\begin{array}{l}1160 \\
1150 \\
1140 \\
1260 \\
1250\end{array}$ & $\begin{array}{l}1640 \\
1770 \\
1960 \\
1480 \\
1360\end{array}$ \\
\hline $\begin{array}{l}26 \\
27 \\
28 \\
29 \\
30 \\
31\end{array}$ & $\begin{array}{l}3890 \\
3720 \\
3870 \\
3940 \\
4060 \\
3800\end{array}$ & $\begin{array}{l}3830 \\
4680 \\
4730 \\
4510 \\
4810\end{array}$ & $\begin{array}{l}3440 \\
3430 \\
3470 \\
3530 \\
3490 \\
3380\end{array}$ & $\begin{array}{l}2960 \\
3500 \\
3320 \\
3150 \\
3180 \\
3270\end{array}$ & $\begin{array}{r}2980 \\
2770 \\
2980 \\
--- \\
---\end{array}$ & $\begin{array}{l}3160 \\
3130 \\
3080 \\
3070 \\
3080 \\
2940\end{array}$ & $\begin{array}{l}3440 \\
3310 \\
3140 \\
2980 \\
2680\end{array}$ & $\begin{array}{l}2500 \\
2340 \\
2310 \\
2200 \\
2030 \\
1860\end{array}$ & $\begin{array}{l}1710 \\
1530 \\
1600 \\
1860 \\
1760\end{array}$ & $\begin{array}{l}1180 \\
1240 \\
1430 \\
1600 \\
2270 \\
2070\end{array}$ & $\begin{array}{l}1660 \\
1980 \\
2700 \\
2190 \\
1990 \\
1630\end{array}$ & $\begin{array}{l}1720 \\
1690 \\
1520 \\
2170 \\
2080\end{array}$ \\
\hline $\begin{array}{l}\text { TOTAL } \\
\text { MEAN } \\
\text { MAX } \\
\text { MIN } \\
\text { CFSM } \\
\text { IN. }\end{array}$ & $\begin{array}{r}178310 \\
5752 \\
9360 \\
3720 \\
1.71 \\
1.97\end{array}$ & $\begin{array}{r}103570 \\
3452 \\
4810 \\
2550 \\
1.02 \\
1.14\end{array}$ & $\begin{array}{r}130410 \\
4207 \\
5370 \\
3380 \\
1.25 \\
1.44\end{array}$ & $\begin{array}{r}100080 \\
3228 \\
3530 \\
2780 \\
.96 \\
1.10\end{array}$ & $\begin{array}{r}83880 \\
2996 \\
3290 \\
2650 \\
.89 \\
.93\end{array}$ & $\begin{array}{r}117490 \\
3790 \\
5220 \\
2940 \\
1.12 \\
1.30\end{array}$ & $\begin{array}{r}107690 \\
3590 \\
5520 \\
2680 \\
1.07 \\
1.19\end{array}$ & $\begin{array}{r}84170 \\
2715 \\
3650 \\
1860 \\
.81 \\
.93\end{array}$ & $\begin{array}{r}56010 \\
1867 \\
2690 \\
1270 \\
.55 \\
.62\end{array}$ & $\begin{array}{r}48990 \\
1580 \\
2270 \\
1180 \\
.47 \\
.54\end{array}$ & $\begin{array}{r}46650 \\
1505 \\
2700 \\
1140 \\
.45 \\
.51\end{array}$ & $\begin{array}{r}52300 \\
1743 \\
2170 \\
1330 \\
.52 \\
.58\end{array}$ \\
\hline $\begin{array}{l}\text { CAL YR } \\
\text { WTR YR }\end{array}$ & $\begin{array}{l}1986 \\
1987\end{array}$ & $\begin{array}{l}\text { OTAL } \\
\text { OTAL }\end{array}$ & $\begin{array}{l}3790 \\
9550\end{array}$ & $\begin{array}{ll}\text { AN } & 3983 \\
\text { AN } & 3040\end{array}$ & $\begin{array}{l}\text { MAX } \\
\text { MAX }\end{array}$ & $\begin{array}{ll}9360 & \text { MIN } \\
9360 & \text { MIN }\end{array}$ & $\begin{array}{ll}N & 1540 \\
N & 1140\end{array}$ & $\begin{array}{l}\text { CFSM } \\
\text { CFSM }\end{array}$ & $\begin{aligned} 1.18 & \text { IN } \\
.90 & \text { IN }\end{aligned}$ & $\begin{array}{l}16.05 \\
12.25\end{array}$ & & \\
\hline
\end{tabular}


04101500 ST. JOSEPH RIVER AT NILES, MI

(National stream quality accounting network station)

LOCATION.--Lat $41^{\circ} 49^{\prime} 45^{\prime \prime}$, long $86^{\circ} 15^{\prime} 35^{\prime \prime}$, in SWl/4 sec.26, T.7 S., R.17 W., Berrien County, Hydrologic Unit 04050001 , on right bank $100 \mathrm{ft}$ upstream from Main street Bridge at' Niles, 0.6 mi downstream from dam at French' Paper Co., 1 mi upstream from Dowagiac River, and at mile 44.

DRAINAGE AREA. $--3,666 \mathrm{mi}^{2}$.

WATER-DISCHARGE RECORDS

PERIOD OF RECORD.--October 1930 to current year. Monthly discharge only for some periods, published in WSP 1307.

REVISED RECORDS.--WSP 1387: 1931, 1933-36, 1940-43, 1945-46(M). WSP 1911: Drainage area.

GAGE.-Water-stage recorder. Datum of gage is $633.02 \mathrm{ft}$ above National Geodetic Vertical Datum of 1929 . Prior to Oct. 1, 1968 , at datum 2.00 ft higher. Oct. 1, 1930, to Feb. 11, 1931, nonrecording gage on Main street Bridge, and Feb. 12 to June 30,1931 , nonrecording gage 50 ft upstream from present site (gage heights referred to NGVD). Since Apr. 13, 1970, auxiliary water-stage recorder at sewagetreatment plant, $1.1 \mathrm{mi}$ downstream from base gage at same datum. Oct. 1, 1943, to Apr. 12, 1970, auxiliary gage was headwater gage at hydroelectric plant at Buchanan Dam, 8 mi downstream from base gage at different datum.

REMARKS.--No estimated daily discharges, Water-discharge records good. Flow regulated by powerplants upstream from station.

AVERAGE DISCHARGE. -57 years, $3,307 \mathrm{ft}^{3} / \mathrm{s}, 12.25 \mathrm{in} / \mathrm{yr}$.

EXTREMES FOR PERIOD OF RECORD.--Maximum discharge, 20,200 ft ${ }^{3} / \mathrm{s}$, Apr. 5, 1950, gage height, 15.10 $\mathrm{ft}$, present datum; minimum daily, $420 \mathrm{ft}^{3} / \mathrm{s}$, Aug. 30, 1931 .

EXTREMES FOR CURRENT YEAR.--Maximum discharge, 10,700 $\mathrm{ft}^{3} / \mathrm{s}$, Oct. 5, gage height, $10.38 \mathrm{ft}$; minimum daily, $1,150 \mathrm{ft}^{3} / \mathrm{s}$, Aug. 22 .

DISCHARGE, IN CUBIC FEET PER SECOND, WATER YEAR OCTOBER 1986 TO SEPTEMBER 1987 MEAN VALUES

\begin{tabular}{|c|c|c|c|c|c|c|c|c|c|c|c|c|}
\hline DAY & OCT & NOV & DEC & JAN & FEB & MAR & APR & MAY & JUN & JUL & AUG & SEP \\
\hline $\begin{array}{l}1 \\
2 \\
3 \\
4 \\
5\end{array}$ & $\begin{array}{r}4730 \\
4940 \\
6890 \\
8660 \\
10100\end{array}$ & $\begin{array}{l}3860 \\
4010 \\
3940 \\
3760 \\
3610\end{array}$ & $\begin{array}{l}4640 \\
4960 \\
5110 \\
5010 \\
4890\end{array}$ & $\begin{array}{l}3600 \\
3530 \\
3520 \\
3510 \\
3450\end{array}$ & $\begin{array}{l}3670 \\
3780 \\
3880 \\
3590 \\
3730\end{array}$ & $\begin{array}{l}4640 \\
5780 \\
5960 \\
5440 \\
5420\end{array}$ & $\begin{array}{l}3290 \\
3330 \\
3450 \\
3450 \\
3290\end{array}$ & $\begin{array}{l}3140 \\
3510 \\
3640 \\
4090 \\
4280\end{array}$ & $\begin{array}{l}2530 \\
2820 \\
2970 \\
2540 \\
2670\end{array}$ & $\begin{array}{l}1990 \\
1920 \\
1940 \\
1840 \\
1800\end{array}$ & $\begin{array}{l}2120 \\
1950 \\
1420 \\
1650 \\
1690\end{array}$ & $\begin{array}{l}1560 \\
2110 \\
1950 \\
1530 \\
1810\end{array}$ \\
\hline $\begin{array}{r}6 \\
7 \\
8 \\
9 \\
10\end{array}$ & $\begin{array}{l}9800 \\
9660 \\
9010 \\
8880 \\
8770\end{array}$ & $\begin{array}{l}3760 \\
3800 \\
3520 \\
3190 \\
3690\end{array}$ & $\begin{array}{l}4770 \\
5070 \\
5270 \\
5490 \\
5810\end{array}$ & $\begin{array}{l}3370 \\
3430 \\
3440 \\
3480 \\
3470\end{array}$ & $\begin{array}{l}3680 \\
3660 \\
3600 \\
3790 \\
3630\end{array}$ & $\begin{array}{l}5650 \\
5400 \\
5240 \\
4970 \\
4370\end{array}$ & $\begin{array}{l}3490 \\
3230 \\
3200 \\
3100 \\
3080\end{array}$ & $\begin{array}{l}3890 \\
3740 \\
3420 \\
3540 \\
3380\end{array}$ & $\begin{array}{l}2650 \\
2300 \\
2220 \\
2290 \\
2210\end{array}$ & $\begin{array}{l}1760 \\
1730 \\
1780 \\
1820 \\
1740\end{array}$ & $\begin{array}{l}1570 \\
1500 \\
1480 \\
1480 \\
1530\end{array}$ & $\begin{array}{l}1820 \\
1500 \\
1510 \\
1390 \\
1660\end{array}$ \\
\hline $\begin{array}{l}11 \\
12 \\
13 \\
14 \\
15\end{array}$ & $\begin{array}{l}8400 \\
7580 \\
7150 \\
6630 \\
6020\end{array}$ & $\begin{array}{l}3570 \\
3410 \\
3150 \\
3120 \\
3120\end{array}$ & $\begin{array}{l}5530 \\
5220 \\
4980 \\
4760 \\
3980\end{array}$ & $\begin{array}{l}3370 \\
3350 \\
3490 \\
3470 \\
3480\end{array}$ & $\begin{array}{l}3690 \\
3560 \\
3620 \\
3760 \\
3790\end{array}$ & $\begin{array}{l}4600 \\
4330 \\
4240 \\
4130 \\
4060\end{array}$ & $\begin{array}{l}3070 \\
3010 \\
3110 \\
3390 \\
4120\end{array}$ & $\begin{array}{l}3060 \\
3020 \\
2890 \\
2530 \\
2840\end{array}$ & $\begin{array}{l}1900 \\
2060 \\
1840 \\
1800 \\
2330\end{array}$ & $\begin{array}{l}1650 \\
1520 \\
1450 \\
1510 \\
1920\end{array}$ & $\begin{array}{l}1880 \\
1560 \\
1380 \\
1330 \\
1340\end{array}$ & $\begin{array}{l}1860 \\
1730 \\
1890 \\
1910 \\
1790\end{array}$ \\
\hline $\begin{array}{l}16 \\
17 \\
18 \\
19 \\
20\end{array}$ & $\begin{array}{l}6470 \\
5530 \\
6080 \\
5460 \\
5100\end{array}$ & $\begin{array}{l}3120 \\
3090 \\
3010 \\
3210 \\
3240\end{array}$ & $\begin{array}{l}4910 \\
4630 \\
4390 \\
4490 \\
4350\end{array}$ & $\begin{array}{l}3720 \\
3850 \\
3870 \\
3830 \\
3440\end{array}$ & $\begin{array}{l}3710 \\
3270 \\
3380 \\
3410 \\
3320\end{array}$ & $\begin{array}{l}4030 \\
4050 \\
3920 \\
3960 \\
3880\end{array}$ & $\begin{array}{l}5980 \\
5490 \\
5470 \\
5490 \\
4960\end{array}$ & $\begin{array}{l}2830 \\
2990 \\
3610 \\
3050 \\
3610\end{array}$ & $\begin{array}{l}1980 \\
1780 \\
1730 \\
1640 \\
1510\end{array}$ & $\begin{array}{l}1800 \\
1700 \\
1790 \\
1540 \\
1470\end{array}$ & $\begin{array}{l}1310 \\
1340 \\
1340 \\
1410 \\
1290\end{array}$ & $\begin{array}{l}1910 \\
1910 \\
2180 \\
2070 \\
2180\end{array}$ \\
\hline $\begin{array}{l}21 \\
22 \\
23 \\
24 \\
25\end{array}$ & $\begin{array}{l}4490 \\
4600 \\
4250 \\
4260 \\
4470\end{array}$ & $\begin{array}{l}3300 \\
3520 \\
3630 \\
3930 \\
3630\end{array}$ & $\begin{array}{l}4320 \\
4060 \\
4000 \\
4170 \\
3840\end{array}$ & $\begin{array}{l}3140 \\
3570 \\
3300 \\
2890 \\
3050\end{array}$ & $\begin{array}{l}3220 \\
3250 \\
3150 \\
3550 \\
3440\end{array}$ & $\begin{array}{l}3840 \\
3680 \\
3640 \\
3700 \\
3620\end{array}$ & $\begin{array}{l}4970 \\
4600 \\
4730 \\
4270 \\
4090\end{array}$ & $\begin{array}{l}3850 \\
3510 \\
3830 \\
3370 \\
2980\end{array}$ & $\begin{array}{l}1710 \\
1860 \\
3000 \\
2010 \\
1890\end{array}$ & $\begin{array}{l}1600 \\
1420 \\
1490 \\
1430 \\
1260\end{array}$ & $\begin{array}{l}1240 \\
1150 \\
1210 \\
1170 \\
1420\end{array}$ & $\begin{array}{l}1960 \\
1690 \\
2010 \\
1850 \\
1540\end{array}$ \\
\hline $\begin{array}{l}26 \\
27 \\
28 \\
29 \\
30 \\
31\end{array}$ & $\begin{array}{l}4150 \\
4060 \\
4000 \\
4200 \\
4320 \\
4070\end{array}$ & $\begin{array}{l}4280 \\
5190 \\
5360 \\
5110 \\
5020\end{array}$ & $\begin{array}{l}3790 \\
3660 \\
3650 \\
3780 \\
3790 \\
3570\end{array}$ & $\begin{array}{l}2880 \\
3610 \\
3380 \\
3480 \\
3470 \\
3650\end{array}$ & $\begin{array}{c}3620 \\
3510 \\
3500 \\
--- \\
-- \\
---\end{array}$ & $\begin{array}{l}3430 \\
3600 \\
3580 \\
3470 \\
3510 \\
3370\end{array}$ & $\begin{array}{l}3900 \\
3700 \\
3620 \\
3530 \\
3240 \\
---\end{array}$ & $\begin{array}{l}3010 \\
2980 \\
2910 \\
2790 \\
2580 \\
2560\end{array}$ & $\begin{array}{l}1880 \\
1790 \\
1520 \\
1670 \\
2010 \\
---\end{array}$ & $\begin{array}{l}1350 \\
1310 \\
1340 \\
1590 \\
2020 \\
2500\end{array}$ & $\begin{array}{l}2040 \\
2050 \\
2540 \\
2730 \\
2250 \\
1760\end{array}$ & $\begin{array}{l}1490 \\
1730 \\
1620 \\
1970 \\
2270\end{array}$ \\
\hline $\begin{array}{l}\text { TOTAL } \\
\text { MEAN } \\
\text { MAX } \\
\text { MIN } \\
\text { CESM } \\
\text { IN. }\end{array}$ & $\begin{array}{r}192730 \\
6217 \\
10100 \\
4000 \\
1.70 \\
1.96\end{array}$ & $\begin{array}{r}112150 \\
3738 \\
5360 \\
3010 \\
1.02 \\
1.14\end{array}$ & $\begin{array}{r}140890 \\
4545 \\
5810 \\
3570 \\
1.24 \\
1.43\end{array}$ & $\begin{array}{r}107090 \\
3455 \\
3870 \\
2880 \\
.94 \\
1.09\end{array}$ & $\begin{array}{r}99760 \\
3563 \\
3880 \\
3150 \\
.97 \\
1.01\end{array}$ & $\begin{array}{r}133510 \\
4307 \\
5960 \\
3370 \\
1.18 \\
1.35\end{array}$ & $\begin{array}{r}117650 \\
3922 \\
5980 \\
3010 \\
1.07 \\
1.19\end{array}$ & $\begin{array}{r}101430 \\
3272 \\
4280 \\
2530 \\
.89 \\
1.03\end{array}$ & $\begin{array}{r}63110 \\
2104 \\
3000 \\
1510 \\
.57 \\
.64\end{array}$ & $\begin{array}{r}51980 \\
1677 \\
2500 \\
1260 \\
.46 \\
.53\end{array}$ & $\begin{array}{r}50130 \\
1617 \\
2730 \\
1150 \\
.44 \\
.51\end{array}$ & $\begin{array}{r}54400 \\
1813 \\
2270 \\
1390 \\
.50 \\
.55\end{array}$ \\
\hline $\begin{array}{ll}\text { CAL } & \text { YR } \\
\text { NTR } & \text { YR }\end{array}$ & $\begin{array}{l}1986 \\
1987\end{array}$ & $\mathrm{AL}$ & $\begin{array}{l}8000 \\
4830\end{array}$ & EAN & $M$ & $\begin{array}{l}10100 \\
10100\end{array}$ & $\begin{array}{l}\text { MIN } \\
\text { MIN }\end{array}$ & $\begin{array}{l}1800 \\
1150\end{array}$ & $\begin{array}{rr}M & 1.2 \\
\text { M } & .9\end{array}$ & $\begin{array}{l}\text { IN } \\
\text { IN }\end{array}$ & & \\
\hline
\end{tabular}


PERIOD OF RECORD.--Water years 1979 to current year.

PERIOD OF DAILY RECORD.--

SPECIFIC CONDUCTANCE: February 1979 to September 1984.

WATER TEMPERATURE: February 1979 to September 1984.

INSTRUMENTATION.--Water-quality monitor from Oct. 9, 1980 to Sept. 30, 1984.

REMARKS.--Bimonthly cross-sectional samples were collected at Grant street bridge 0.2 mi upstream from gage. Samples for the analyses of stable hydrogen and oxygen isotopes were also collected; analytical results were not published.

EXTREMES FOR PERIOD OF DAILY RECORD --

SPECIFIC CONDUCTANCE (water years 1982, 1984): Maximum, 678 microsiemens, Feb. 16, $1982 ;$ minimum, 278 microsiemens, Mar. 19, 1982.

WATER TEMPERATURE (water years 1980, 1982-84): Maximum daily recorded (more than 20 percent missing record), $29.0^{\circ} \mathrm{C}$, July $20^{2}, 21$, 1980 ; minimum, $0.0^{\circ} \mathrm{C}$ on many days during winter.

WATER QUALITY DATA, WATER YEAR OCTOBER 1986 TO SEPTEMBER 1987

\begin{tabular}{|c|c|c|c|c|c|c|c|c|c|c|}
\hline DATE & TIME & $\begin{array}{l}\text { STREAM- } \\
\text { FLOW, } \\
\text { INSTAN- } \\
\text { TANEOUS } \\
\text { (CFS) }\end{array}$ & $\begin{array}{l}\text { SPE- } \\
\text { CIFIC } \\
\text { CON- } \\
\text { DUCT- } \\
\text { ANCE } \\
\text { (US/CM) }\end{array}$ & $\begin{array}{c}\text { PH } \\
\text { (STAND- } \\
\text { ARD } \\
\text { UNITS) }\end{array}$ & $\begin{array}{l}\text { TEMPER- } \\
\text { ATURE } \\
\text { (DEG C) }\end{array}$ & $\begin{array}{l}\text { TUR- } \\
\text { BID- } \\
\text { ITY } \\
\text { (NTU) }\end{array}$ & $\begin{array}{c}\text { OXYGEN, } \\
\text { DIS- } \\
\text { SOLVED } \\
(\text { MG } / L)\end{array}$ & $\begin{array}{c}\text { OXYGEN, } \\
\text { DIS- } \\
\text { SOLVED } \\
\text { (PER- } \\
\text { CENT } \\
\text { SATUR- } \\
\text { ATION) }\end{array}$ & $\begin{array}{l}\text { COLI- } \\
\text { FORM, } \\
\text { FECAL, } \\
0.7 \\
\text { UM-MF } \\
\text { (COLS.' } \\
100 \mathrm{ML} \text { ) }\end{array}$ & $\begin{array}{l}\text { STREP- } \\
\text { TOCOCCI } \\
\text { FECAL, } \\
\text { KF AGAR } \\
\text { (COLS. } \\
\text { PER } \\
100 \mathrm{ML} \text { ) }\end{array}$ \\
\hline $\begin{array}{l}\text { NOV } \\
03 \ldots \\
\text { JAN }\end{array}$ & 1300 & 4460 & 559 & 8.2 & 10.0 & 3.2 & 11.2 & 101 & 980 & 240 \\
\hline${ }_{\text {MAR }}^{05} \cdots$ & 1330 & 3460 & 573 & 8.1 & 3.0 & 1.4 & 13.3 & 100 & 1100 & 550 \\
\hline$\underset{\text { MAY }}{25} \ldots$ & 1300 & 3640 & 552 & 8.3 & 10.5 & 3.5 & 11.0 & 102 & K 6000 & 890 \\
\hline${ }_{\text {JUL }}^{26} \cdots$ & 1430 & 3010 & -- & 8.5 & 21.0 & 5.4 & 7.9 & 91 & K330 & K47 \\
\hline $\operatorname{sep}^{15} \ldots$ & 1500 & 1950 & 516 & 7.9 & 22.5 & 2.1 & 7.2 & 86 & 4900 & 1100 \\
\hline $16 \ldots$ & 1330 & 1870 & 513 & 7.7 & 21.0 & 5.3 & 7.4 & 86 & 2600 & 520 \\
\hline DATE & $\begin{array}{l}\text { HARD- } \\
\text { NESS } \\
(\mathrm{MG} / \mathrm{L} \\
\text { AS } \\
\text { CACO3) }\end{array}$ & $\begin{array}{l}\text { HARD- } \\
\text { NESS } \\
\text { NONCARB } \\
\text { WH WAT } \\
\text { TOT FLD } \\
\text { MG/L AS } \\
\text { CACO3 }\end{array}$ & $\begin{array}{l}\text { CALCIUM } \\
\text { DIS- } \\
\text { SOLVED } \\
\text { (MG/L } \\
\text { AS CA) }\end{array}$ & $\begin{array}{l}\text { MAGNE- } \\
\text { SIUM, } \\
\text { DIS- } \\
\text { SOLVED } \\
\text { (MG/L } \\
\text { AS MG) }\end{array}$ & $\begin{array}{l}\text { SODIUM, } \\
\text { DIS- } \\
\text { SOLVED } \\
\text { (MG/L } \\
\text { AS NA) }\end{array}$ & $\begin{array}{l}\text { PERCENT } \\
\text { SODIUM }\end{array}$ & $\begin{array}{c}\text { SODIUM } \\
\text { AD- } \\
\text { SORP- } \\
\text { TION } \\
\text { RATIO }\end{array}$ & $\begin{array}{l}\text { POTAS- } \\
\text { SIUM, } \\
\text { DIS- } \\
\text { SOLVED } \\
\text { (MG/L } \\
\text { AS K) }\end{array}$ & $\begin{array}{l}\text { BICAR- } \\
\text { BONATE } \\
\text { WH WAT } \\
\text { TOTAL } \\
\text { FIELD } \\
\text { MG /L AS } \\
\text { HCO3 }\end{array}$ & $\begin{array}{l}\text { CAR- } \\
\text { BONATE } \\
\text { WH WAT } \\
\text { TOTAL } \\
\text { FIELD } \\
\text { MG } / L \text { AS } \\
\text { CO3 }\end{array}$ \\
\hline NOV & 280 & 71 & 78 & 21 & 12 & 8 & 0.3 & 2.3 & 260 & 0 \\
\hline $\begin{array}{l}\text { JAN } \\
05 \ldots \\
\text { MAR }\end{array}$ & 290 & 61 & 78 & 22 & 13 & 9 & 0.3 & 2.0 & 270 & 0 \\
\hline${ }_{M A Y}^{25} \cdots$ & 290 & 74 & 81 & 22 & 13 & 9 & 0.3 & 2.0 & - & -- \\
\hline JUL $26 \ldots$ & 280 & 66 & 75 & 22 & 12 & 9 & 0.3 & 1.8 & - & - \\
\hline $\operatorname{SEP}^{15 \ldots}$ & 240 & 52 & 63 & 21 & 17 & 13 & 0.5 & 2.2 & 230 & 0 \\
\hline $16 \ldots$ & 230 & 50 & 59 & 21 & 16 & 13 & 0.5 & 2.3 & 230 & 0 \\
\hline DATE & $\begin{array}{l}\text { ALKA- } \\
\text { LINITY } \\
\text { WH WAT } \\
\text { TOTAL } \\
\text { FIELD } \\
\text { MG/L AS } \\
\text { CACO3 }\end{array}$ & $\begin{array}{c}\text { CARBON } \\
\text { DIOXIDE } \\
\text { DIS- } \\
\text { SOLVED } \\
\text { (MG/L } \\
\text { AS CO2) }\end{array}$ & $\begin{array}{l}\text { SULFATE } \\
\text { DIS- } \\
\text { SOLVED } \\
\text { (MG/L } \\
\text { AS SO4) }\end{array}$ & $\begin{array}{l}\text { CHLO- } \\
\text { RIDE, } \\
\text { DIS- } \\
\text { SOLVED } \\
\text { (MG/L } \\
\text { AS CL) }\end{array}$ & $\begin{array}{l}\text { FLUO- } \\
\text { RIDE, } \\
\text { DIS- } \\
\text { SOLVED } \\
\text { (MG/L } \\
\text { AS F) }\end{array}$ & $\begin{array}{l}\text { SILICA, } \\
\text { DIS- } \\
\text { SOLVED } \\
\text { (MG/L } \\
\text { AS } \\
\text { SIO2) }\end{array}$ & $\begin{array}{l}\text { SOLIDS, } \\
\text { RESIDUE } \\
\text { AT } 180 \\
\text { DEG. C } \\
\text { DIS- } \\
\text { SOLVED } \\
(M G / L)\end{array}$ & $\begin{array}{l}\text { SOLIDS, } \\
\text { SUM OF } \\
\text { CONSTI- } \\
\text { TUENTS, } \\
\text { DIS- } \\
\text { SOLVED } \\
\text { (MG/L) }\end{array}$ & $\begin{array}{c}\text { SOLIDS, } \\
\text { DIS- } \\
\text { SOLVED } \\
\text { (TONS } \\
\text { PER } \\
\text { AC-FT) }\end{array}$ & $\begin{array}{c}\text { SOLIDS, } \\
\text { DIS- } \\
\text { SOLVED } \\
\text { (TONS } \\
\text { PER } \\
\text { DAY) }\end{array}$ \\
\hline NOV & & & & & & & & & & \\
\hline JAN & 210 & 2.6 & 47 & 18 & 0.1 & 9.7 & 351 & 320 & 0.48 & 4230 \\
\hline$\underset{M A R}{05} \ldots$ & 224 & 3.4 & 51 & 21 & 0.2 & 7.0 & 344 & 340 & 0.47 & 3210 \\
\hline${ }_{M A Y}^{25} \cdots$ & -- & 2.1 & 51 & 23 & 0.2 & 5.6 & 334 & 330 & 0.45 & 3280 \\
\hline$\stackrel{26 \ldots}{\text { JuL }}$ & -- & 1.3 & 46 & 26 & 0.2 & 4.0 & 326 & 310 & 0.44 & 2650 \\
\hline $\operatorname{SEP}^{15 \cdots}$ & 192 & 4.7 & 37 & 24 & 0.2 & 4.3 & 311 & 280 & 0.42 & 1640 \\
\hline $16 \ldots$ & 184 & 7.1 & 51 & 23 & 0.2 & 3.7 & 282 & 290 & 0.38 & 1420 \\
\hline
\end{tabular}


04101500 ST. JOSEPH RIVER AT NILES, MI--Continued

WATER QUALITY DATA, WATER YEAR OCTOBER 1986 TO SEPTEMBER 1987

\begin{tabular}{|c|c|c|c|c|c|c|c|c|c|c|}
\hline DATE & $\begin{array}{c}\text { NITRO- } \\
\text { GEN, } \\
\text { NITRITE } \\
\text { DIS- } \\
\text { SOLVED } \\
\text { (MG/L } \\
\text { AS N) }\end{array}$ & $\begin{array}{c}\text { NITRO- } \\
\text { GEN, } \\
\text { NO2+NO3 } \\
\text { DIS- } \\
\text { SOLVED } \\
\text { (MG/L } \\
\text { AS N) }\end{array}$ & $\begin{array}{l}\text { NITRO- } \\
\text { GEN, } \\
\text { AMMONIA } \\
\text { TOTAL } \\
\text { (MG/L } \\
\text { AS N) }\end{array}$ & $\begin{array}{c}\text { NITRO- } \\
\text { GEN, } \\
\text { AMMONIA } \\
\text { DIS- } \\
\text { SOLVED } \\
\text { (MG/L } \\
\text { AS N) }\end{array}$ & $\begin{array}{c}\text { NITRO- } \\
\text { GEN, } \\
\text { ORGANIC } \\
\text { TOTAL } \\
\text { (MG/L } \\
\text { AS N) }\end{array}$ & $\begin{array}{l}\text { NITRO- } \\
\text { GEN,AM- } \\
\text { MONIA + } \\
\text { ORGANIC } \\
\text { TOTAL } \\
\text { (MG/L } \\
\text { AS N) }\end{array}$ & $\begin{array}{l}\text { PHOS- } \\
\text { PHORUS, } \\
\text { TOTAL } \\
\text { (MG/L } \\
\text { AS P) }\end{array}$ & $\begin{array}{c}\text { PHOS- } \\
\text { PHORUS, } \\
\text { DIS- } \\
\text { SOLVED } \\
\text { (MG/L } \\
\text { AS P) }\end{array}$ & $\begin{array}{l}\text { PHOS- } \\
\text { PHORUS, } \\
\text { ORTHO, } \\
\text { DIS- } \\
\text { SOLVED } \\
\text { (MG/L } \\
\text { AS P) }\end{array}$ & $\begin{array}{l}\text { ALUM- } \\
\text { INUM, } \\
\text { DIS- } \\
\text { SOLVED } \\
\text { (UG/L } \\
\text { AS AL) }\end{array}$ \\
\hline ov $03 \ldots$ & 0.04 & 1.50 & 0.09 & 0.08 & 1.5 & 1.6 & 0.07 & 0.02 & $<0.01$ & $<10$ \\
\hline $\begin{array}{l}\mathrm{AN} \\
05 \ldots \\
\mathrm{AR}\end{array}$ & 0.02 & 1.90 & 0.20 & 0.20 & 0.8 & 1.0 & 0.02 & $<0.01$ & $<0.01$ & -- \\
\hline${ }_{\text {MAY }}^{25} \ldots$ & 0.03 & 1.70 & 0.19 & 0.20 & 0.91 & 1.1 & 0.10 & 0.03 & 0.04 & $<10$ \\
\hline $26 \ldots$ & 0.03 & 1.60 & 0.03 & 0.02 & 2.0 & 2.0 & 0.09 & 0.01 & $<0.01$ & $<10$ \\
\hline $15 \ldots$ & 0.03 & 0.80 & 0.09 & 0.10 & 0.91 & 1.0 & 0.10 & 0.01 & $<0.01$ & -- \\
\hline $16 \ldots$ & 0.02 & 0.76 & 0.14 & 0.14 & 0.86 & 1.0 & 0.02 & 0.02 & 0.01 & $<10$ \\
\hline
\end{tabular}

DATE

ARSENIC BARIUM, DIS- DISSOLVED SOLVED (UG/L (UG $/ L$ $\begin{array}{ll}\text { (UG } / L & \text { (UG } / L \\ \text { AS AS) } & \text { AS BA) }\end{array}$

NOV

$$
\begin{gathered}
\text { NO } \\
\text { JAN } \\
\text { J } . . \\
\text { MAR } \\
25 \ldots \\
\text { MAY } . . \\
26 \ldots \\
\text { JUL } \\
15 \ldots \\
\text { SEP } \ldots \\
16 \ldots \\
\end{gathered}
$$

$\begin{array}{cr}1 & 53 \\ -- & -- \\ <1 & 58 \\ 1 & 59 \\ -- & -- \\ 1 & 53\end{array}$

53
--
58
-
53

BERYL-

LIUM, CADMIUM

DIS-

SOLVED

(UG/L

AS BE)

\section{DIS-}

SOLVED

(UG/L

AS CD)

CHRO-

MIUM, COBALT, COPPER,

DIS- DIS- DIS-

SOLVED SOLVED SOLVED

UT $/$ SOL

AS CR) AS CO)
(UG/L AS CU)

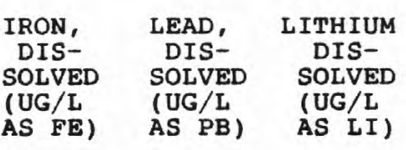

(UG/L AS PB) AS LI)
MANGA-

NESE,

DIS-

SOLVED

(UG/L (UG/L

AS MN) AS HG)

$$
\begin{array}{rr}
<0.5 & <1 \\
-- & -- \\
<0.5 & <1 \\
<0.5 & <1 \\
-- & -- \\
<0.5 & <1
\end{array}
$$

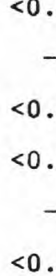

MOLYB-

DENUM, NICKEL,

DIS-

SOLVED

(UG/L (UG/L

AS MO) AS NI)

$$
\begin{aligned}
<1 & <3 \\
-- & -- \\
<1 & <3 \\
3 & <3 \\
-- & --
\end{aligned}
$$$$
<1
$$

SELE-

NIUM,$$
\text { DIS- SILVER, }
$$

SOLVED

(UG/L

(US SE)

DIS-
SOLVED

SOLVE

(US AG)

$\begin{array}{rrrr}4 & 14 & 7 & 12 \\ -- & -- & -- & -- \\ 3 & 6 & <5 & 9 \\ 3 & 6 & <5 & 10 \\ -- & -- & -- & -- \\ 3 & 11 & <5 & <4\end{array}$

STRON- VANA-

TIUM, DIUM, ZINC, SEDI-

\begin{tabular}{|c|c|c|}
\hline JAN $03 .$. & 434 & 81 \\
\hline MAR 05 & 243 & 77 \\
\hline $25 \ldots$ & 206 & 80 \\
\hline${ }_{\text {JUL }}^{26 \ldots}$ & 536 & 82 \\
\hline & 90 & 77 \\
\hline $16 \ldots$ & 96 & 95 \\
\hline
\end{tabular}
DIS-

DOLVED

(UG/L

AS SR )
DIS-
SOLVED

(UG/L

(UG V)
DIS- MENT,

SOLVED SUS-

(UG/L PENDED

AS $2 N) \quad(M G / L)$

\footnotetext{
NOV

NOV
$03 \ldots$
JAN $\ldots$
$05 \ldots$
MAR $\ldots$
$25 \ldots$
MAY
$26 \ldots$
JUL
$15 \ldots$
SEP
}

$\begin{array}{rrrr}6 & 0.1 & <10 & 3 \\ -- & -- & -- & -- \\ 15 & <0.1 & <10 & 2 \\ 1 & <0.1 & <10 & <1 \\ -- & -- & -- & -- \\ 10 & <0.1 & <10 & 1\end{array}$

$$
<1 \quad<1
$$

$\begin{array}{rrr}<6 & 22 & 36 \\ -- & -- & 26 \\ <6 & 4 & 21 \\ <6 & 13 & 66 \\ -- & -- & 17 \\ <6 & 22 & 19\end{array}$


LOCATION.--Lat $41^{\circ} 54^{\prime} 57^{\prime \prime}$, long $86^{\circ} 12^{\prime} 47^{\prime \prime}$, in SEl/4 sec.30, T.6 S., R.16 w., Cass County, Hydrologic Unit 04050001 , on right bank $30 \mathrm{ft}$ upstream from bridge on Indian Lake Road, $0.3 \mathrm{mi}$ west of Sumnerville. DRAINAGE AREA. $--255 \mathrm{mi}^{2}$.

PERIOD OF RECORD.--October 1960 to current year.

GAGE.--Water-stage recorder. Datum of gage is $692.62 \mathrm{ft}$ above National Geodetic Vertical Datum of 1929.

REMARKS.--No estimated daily discharges. Records good. Flow regulated by millpond and lake-level control dam upstream from station. Several measurements of water temperature were made during the year.

AVERAGE DISCHARGE. - 27 years, $289 \mathrm{ft}^{3} / \mathrm{s}, 15.39 \mathrm{in} / \mathrm{yr}$.

EXTREMES FOR PERIOD OF RECORD.--Maximum discharge, 1,590 ft $3 / \mathrm{s}$, Feb. 24, 1985, gage height, $9.26 \mathrm{ft}$; minimum, $86 \mathrm{ft} / \mathrm{s}$, Sept. 10,1964 ; minimum gage height, $2.57 \mathrm{ft}$, Aug. 8, 9, 1964.

EXTREMES FOR CURRENT YEAR.--Maximum discharge, 1,460 $\mathrm{ft}^{3} / \mathrm{s}$, Oct. 4, gage height, 8.84 $\mathrm{ft}$; minimum, $137 \mathrm{ft}^{3} / \mathrm{s}$, Aug. 8, gage height, $3.06 \mathrm{ft}$; minimum gage height, 3.01 ft, July 25.

DISCHARGE, IN CUBIC FEET PER SECOND, WATER YEAR OCTOBER 1986 TO SEPTEMBER 1987

\begin{tabular}{|c|c|c|c|c|c|c|c|c|c|c|c|c|}
\hline DAY & OCT & NOV & $\mathrm{DEC}$ & JAN & FEB & MAR & APR & MAY & JUN & JUL & AUG & SEP \\
\hline $\begin{array}{l}1 \\
2 \\
3 \\
4 \\
5\end{array}$ & $\begin{array}{r}966 \\
804 \\
987 \\
1410 \\
1170\end{array}$ & $\begin{array}{l}318 \\
320 \\
314 \\
310 \\
304\end{array}$ & $\begin{array}{l}374 \\
389 \\
401 \\
383 \\
360\end{array}$ & $\begin{array}{l}298 \\
295 \\
290 \\
286 \\
282\end{array}$ & $\begin{array}{l}279 \\
289 \\
294 \\
299 \\
291\end{array}$ & $\begin{array}{l}496 \\
504 \\
443 \\
392 \\
378\end{array}$ & $\begin{array}{l}270 \\
316 \\
318 \\
314 \\
299\end{array}$ & $\begin{array}{l}246 \\
324 \\
357 \\
338 \\
305\end{array}$ & $\begin{array}{l}241 \\
238 \\
251 \\
226 \\
212\end{array}$ & $\begin{array}{l}167 \\
166 \\
160 \\
156 \\
157\end{array}$ & $\begin{array}{l}163 \\
161 \\
157 \\
156 \\
154\end{array}$ & $\begin{array}{l}252 \\
225 \\
212 \\
199 \\
191\end{array}$ \\
\hline $\begin{array}{r}6 \\
7 \\
8 \\
9 \\
10\end{array}$ & $\begin{array}{l}847 \\
669 \\
569 \\
509 \\
465\end{array}$ & $\begin{array}{l}299 \\
297 \\
298 \\
295 \\
288\end{array}$ & $\begin{array}{l}346 \\
374 \\
454 \\
456 \\
434\end{array}$ & $\begin{array}{l}280 \\
281 \\
278 \\
276 \\
287\end{array}$ & $\begin{array}{l}284 \\
285 \\
307 \\
308 \\
306\end{array}$ & $\begin{array}{l}364 \\
348 \\
338 \\
325 \\
305\end{array}$ & $\begin{array}{l}288 \\
278 \\
267 \\
262 \\
257\end{array}$ & $\begin{array}{l}286 \\
268 \\
255 \\
242 \\
235\end{array}$ & $\begin{array}{l}202 \\
193 \\
187 \\
181 \\
175\end{array}$ & $\begin{array}{l}161 \\
156 \\
154 \\
149 \\
147\end{array}$ & $\begin{array}{l}149 \\
140 \\
146 \\
189 \\
173\end{array}$ & $\begin{array}{l}184 \\
179 \\
204 \\
206 \\
195\end{array}$ \\
\hline $\begin{array}{l}11 \\
12 \\
13 \\
14 \\
15\end{array}$ & $\begin{array}{l}438 \\
422 \\
436 \\
480 \\
476\end{array}$ & $\begin{array}{l}287 \\
286 \\
281 \\
277 \\
276\end{array}$ & $\begin{array}{l}391 \\
367 \\
349 \\
336 \\
331\end{array}$ & $\begin{array}{l}288 \\
285 \\
285 \\
288 \\
329\end{array}$ & $\begin{array}{l}302 \\
309 \\
308 \\
305 \\
294\end{array}$ & $\begin{array}{l}294 \\
286 \\
283 \\
300 \\
326\end{array}$ & $\begin{array}{l}261 \\
304 \\
285 \\
298 \\
543\end{array}$ & $\begin{array}{l}224 \\
226 \\
216 \\
215 \\
216\end{array}$ & $\begin{array}{l}174 \\
190 \\
183 \\
174 \\
167\end{array}$ & $\begin{array}{l}145 \\
143 \\
144 \\
145 \\
150\end{array}$ & $\begin{array}{l}162 \\
156 \\
153 \\
161 \\
182\end{array}$ & $\begin{array}{l}211 \\
206 \\
195 \\
190 \\
186\end{array}$ \\
\hline $\begin{array}{l}16 \\
17 \\
18 \\
19 \\
20\end{array}$ & $\begin{array}{l}436 \\
414 \\
394 \\
380 \\
366\end{array}$ & $\begin{array}{l}281 \\
289 \\
290 \\
292 \\
295\end{array}$ & $\begin{array}{l}331 \\
340 \\
353 \\
347 \\
335\end{array}$ & $\begin{array}{l}333 \\
306 \\
304 \\
298 \\
292\end{array}$ & $\begin{array}{l}269 \\
267 \\
259 \\
256 \\
255\end{array}$ & $\begin{array}{l}327 \\
320 \\
311 \\
306 \\
296\end{array}$ & $\begin{array}{l}527 \\
453 \\
399 \\
363 \\
339\end{array}$ & $\begin{array}{l}209 \\
205 \\
293 \\
348 \\
311\end{array}$ & $\begin{array}{l}163 \\
156 \\
155 \\
152 \\
153\end{array}$ & $\begin{array}{l}175 \\
164 \\
157 \\
153 \\
149\end{array}$ & $\begin{array}{l}169 \\
185 \\
177 \\
177 \\
167\end{array}$ & $\begin{array}{l}192 \\
210 \\
223 \\
220 \\
209\end{array}$ \\
\hline $\begin{array}{l}21 \\
22 \\
23 \\
24 \\
25\end{array}$ & $\begin{array}{l}358 \\
349 \\
345 \\
340 \\
337\end{array}$ & $\begin{array}{l}324 \\
336 \\
350 \\
365 \\
341\end{array}$ & $\begin{array}{l}324 \\
312 \\
308 \\
307 \\
305\end{array}$ & $\begin{array}{l}284 \\
283 \\
274 \\
267 \\
286\end{array}$ & $\begin{array}{l}260 \\
266 \\
279 \\
286 \\
286\end{array}$ & $\begin{array}{l}286 \\
281 \\
276 \\
272 \\
276\end{array}$ & $\begin{array}{l}317 \\
312 \\
351 \\
327 \\
304\end{array}$ & $\begin{array}{l}282 \\
259 \\
239 \\
231 \\
222\end{array}$ & $\begin{array}{l}180 \\
184 \\
182 \\
174 \\
178\end{array}$ & $\begin{array}{l}154 \\
151 \\
148 \\
145 \\
143\end{array}$ & $\begin{array}{l}162 \\
161 \\
157 \\
155 \\
154\end{array}$ & $\begin{array}{l}233 \\
294 \\
273 \\
248 \\
226\end{array}$ \\
\hline $\begin{array}{l}26 \\
27 \\
28 \\
29 \\
30 \\
31\end{array}$ & $\begin{array}{l}354 \\
357 \\
348 \\
341 \\
333 \\
324\end{array}$ & $\begin{array}{l}423 \\
571 \\
491 \\
432 \\
399 \\
---\end{array}$ & $\begin{array}{l}303 \\
300 \\
295 \\
294 \\
297 \\
298\end{array}$ & $\begin{array}{l}254 \\
269 \\
270 \\
272 \\
281 \\
277\end{array}$ & $\begin{array}{l}287 \\
285 \\
309 \\
--- \\
---\end{array}$ & $\begin{array}{l}286 \\
286 \\
279 \\
274 \\
278 \\
267\end{array}$ & $\begin{array}{l}291 \\
281 \\
266 \\
260 \\
245 \\
---\end{array}$ & $\begin{array}{l}219 \\
210 \\
202 \\
195 \\
200 \\
247\end{array}$ & $\begin{array}{l}182 \\
172 \\
167 \\
163 \\
164 \\
---\end{array}$ & $\begin{array}{l}171 \\
173 \\
163 \\
163 \\
176 \\
171\end{array}$ & $\begin{array}{l}217 \\
441 \\
395 \\
341 \\
298 \\
284\end{array}$ & $\begin{array}{l}211 \\
202 \\
194 \\
219 \\
230 \\
-\end{array}$ \\
\hline $\begin{array}{l}\text { TOTAL } \\
\text { MEAN } \\
\text { MAX } \\
\text { MIN } \\
\text { CFSM } \\
\text { IN. }\end{array}$ & $\begin{array}{r}16424 \\
530 \\
1410 \\
324 \\
2.08 \\
2.40\end{array}$ & $\begin{array}{r}9929 \\
331 \\
571 \\
276 \\
1.30 \\
1.45\end{array}$ & $\begin{array}{r}10794 \\
348 \\
456 \\
294 \\
1.37 \\
1.57\end{array}$ & $\begin{array}{r}8878 \\
286 \\
333 \\
254 \\
1.12 \\
1.30\end{array}$ & $\begin{array}{r}8024 \\
287 \\
309 \\
255 \\
1.13 \\
1.17\end{array}$ & $\begin{array}{r}10003 \\
323 \\
504 \\
267 \\
1.27 \\
1.46\end{array}$ & $\begin{array}{r}9595 \\
320 \\
543 \\
245 \\
1.26 \\
1.40\end{array}$ & $\begin{array}{r}7825 \\
252 \\
357 \\
195 \\
.99 \\
1.14\end{array}$ & $\begin{array}{r}5519 \\
184 \\
251 \\
152 \\
.72 \\
.81\end{array}$ & $\begin{array}{r}4856 \\
157 \\
176 \\
143 \\
.62 \\
.71\end{array}$ & $\begin{array}{r}6042 \\
195 \\
441 \\
140 \\
.77 \\
.88\end{array}$ & $\begin{array}{r}6419 \\
214 \\
294 \\
179 \\
.84 \\
.94\end{array}$ \\
\hline
\end{tabular}

$\begin{array}{lllllllllll}\text { CAL YR } 1986 & \text { TOTAL } & 125654 & \text { MEAN } 344 & \text { MAX } & 1410 & \text { MIN } 155 & \text { CFSM } & 1.35 & \text { IN } 18.33 \\ \text { WTR YR } 1987 & \text { TOTAL } & 104308 & \text { MEAN 286 } & \text { MAX } & 1410 & \text { MIN } 140 & \text { CFSM } & 1.12 & \text { IN } & 15.22\end{array}$ 
LOCATION.--Lat $42^{\circ} 11^{\prime} 10^{\prime \prime}$, long $86^{\circ} 22^{\prime} 06^{\prime \prime}$, in SWl/4 SEl/4 sec.23, T. 3 S., R.18 W., Berrien County, Hydrologic Unit 04050001 , on left bank $40 \mathrm{ft}$ upstream from bridge on Coloma Road, $0.8 \mathrm{mi}$ east of Riverside.

DRAINAGE AREA. $--390 \mathrm{mi}^{2}$.

PERIOD OF RECORD.--October 1951 to current year.

REVISED RECORDS.--WSP 1337: Drainage area.

GAGE.--Water-stage recorder. Datum of gage is $588.80 \mathrm{ft}$ above National Geodetic Vertical Datum of 1929. May 10, 1966, to July 11, 1967, nonrecording gage at same site and datum.

REMARKS.--Estimated daily discharges: Dec. 13, 14, and Jan, 24 to Feb. 2. Records good except for estimated daily discharges, which are fair. Diurnal fluctuation, principally during low flow, caused by paper mill upstream from station. Several measurements of water temperature were made during the year.

AVERAGE DISCHARGE. - -36 years, $450 \mathrm{ft}^{3} / \mathrm{s}, 15.67 \mathrm{in} / \mathrm{yr}^{\mathrm{r}}$

EXTREMES FOR PERIOD OF RECORD,--Maximum discharge, 3,580 $\mathrm{ft}^{3} / \mathrm{s}$, Oct. 4, 1986, gage height, $10.90 \mathrm{ft}$; minimum, $99 \mathrm{ft}^{3} / \mathrm{s}$, July 5, 1964, gage height, $2.66 \mathrm{ft}$.

EXTREMES FOR CURRENT YEAR.--Maximum discharge, 3,580 $\mathrm{ft}^{3} / \mathrm{s}$, Oct. 4, gage height, $10.90 \mathrm{ft}$ minimum, $220 \mathrm{ft}^{3} / \mathrm{s}$, July 13,15 , gage helght, $3.78 \mathrm{ft}$.

DISCHARGE, IN CUBIC FEET PER SECOND, WATER YEAR OCTOBER 1986 TO SEPTEMBER 1987 MEAN VALUES

\begin{tabular}{|c|c|c|c|c|c|c|c|c|c|c|c|c|}
\hline DAY & OCT & NOV & DEC & JAN & FEB & MAR & APR & MAY & JUN & JUL & AUG & SEP \\
\hline $\begin{array}{l}1 \\
2 \\
3 \\
4 \\
5\end{array}$ & $\begin{array}{l}2800 \\
2470 \\
2800 \\
3460 \\
2780\end{array}$ & $\begin{array}{l}518 \\
512 \\
502 \\
491 \\
481\end{array}$ & $\begin{array}{l}632 \\
650 \\
647 \\
628 \\
603\end{array}$ & $\begin{array}{l}439 \\
439 \\
436 \\
433 \\
433\end{array}$ & $\begin{array}{l}440 \\
450 \\
454 \\
455 \\
462\end{array}$ & $\begin{array}{l}485 \\
592 \\
656 \\
646 \\
642\end{array}$ & $\begin{array}{l}409 \\
422 \\
437 \\
446 \\
455\end{array}$ & $\begin{array}{l}397 \\
419 \\
452 \\
474 \\
487\end{array}$ & $\begin{array}{l}285 \\
288 \\
300 \\
297 \\
287\end{array}$ & $\begin{array}{l}251 \\
252 \\
254 \\
251 \\
248\end{array}$ & $\begin{array}{l}276 \\
264 \\
255 \\
249 \\
239\end{array}$ & $\begin{array}{l}545 \\
526 \\
451 \\
382 \\
340\end{array}$ \\
\hline $\begin{array}{r}6 \\
7 \\
8 \\
9 \\
10\end{array}$ & $\begin{array}{l}2350 \\
2300 \\
1970 \\
1560 \\
1260\end{array}$ & $\begin{array}{l}474 \\
466 \\
460 \\
456 \\
448\end{array}$ & $\begin{array}{l}574 \\
564 \\
577 \\
611 \\
620\end{array}$ & $\begin{array}{l}427 \\
419 \\
422 \\
424 \\
429\end{array}$ & $\begin{array}{l}463 \\
466 \\
483 \\
505 \\
503\end{array}$ & $\begin{array}{l}657 \\
648 \\
600 \\
552 \\
519\end{array}$ & $\begin{array}{l}463 \\
457 \\
436 \\
416 \\
398\end{array}$ & $\begin{array}{l}488 \\
487 \\
473 \\
437 \\
400\end{array}$ & $\begin{array}{l}277 \\
270 \\
262 \\
262 \\
259\end{array}$ & $\begin{array}{l}246 \\
242 \\
237 \\
235 \\
232\end{array}$ & $\begin{array}{l}241 \\
244 \\
240 \\
249 \\
249\end{array}$ & $\begin{array}{l}306 \\
293 \\
291 \\
295 \\
291\end{array}$ \\
\hline $\begin{array}{l}11 \\
12 \\
13 \\
14 \\
15\end{array}$ & $\begin{array}{r}1090 \\
939 \\
848 \\
813 \\
770\end{array}$ & $\begin{array}{l}441 \\
438 \\
433 \\
429 \\
427\end{array}$ & $\begin{array}{l}611 \\
601 \\
590 \\
575 \\
555\end{array}$ & $\begin{array}{l}427 \\
425 \\
430 \\
437 \\
448\end{array}$ & $\begin{array}{l}495 \\
492 \\
483 \\
477 \\
471\end{array}$ & $\begin{array}{l}492 \\
464 \\
441 \\
436 \\
447\end{array}$ & $\begin{array}{l}389 \\
400 \\
413 \\
427 \\
517\end{array}$ & $\begin{array}{l}377 \\
359 \\
347 \\
335 \\
330\end{array}$ & $\begin{array}{l}256 \\
263 \\
263 \\
263 \\
261\end{array}$ & $\begin{array}{l}227 \\
223 \\
221 \\
222 \\
229\end{array}$ & $\begin{array}{l}256 \\
256 \\
244 \\
309 \\
405\end{array}$ & $\begin{array}{l}296 \\
296 \\
291 \\
284 \\
279\end{array}$ \\
\hline $\begin{array}{l}16 \\
17 \\
18 \\
19 \\
20\end{array}$ & $\begin{array}{l}737 \\
699 \\
671 \\
658 \\
642\end{array}$ & $\begin{array}{l}427 \\
428 \\
432 \\
435 \\
439\end{array}$ & $\begin{array}{l}550 \\
540 \\
528 \\
522 \\
518\end{array}$ & $\begin{array}{l}470 \\
474 \\
471 \\
470 \\
461\end{array}$ & $\begin{array}{l}452 \\
428 \\
395 \\
392 \\
390\end{array}$ & $\begin{array}{l}460 \\
473 \\
483 \\
487 \\
484\end{array}$ & $\begin{array}{l}686 \\
707 \\
698 \\
731 \\
758\end{array}$ & $\begin{array}{l}329 \\
324 \\
325 \\
336 \\
356\end{array}$ & $\begin{array}{l}251 \\
246 \\
240 \\
233 \\
236\end{array}$ & $\begin{array}{l}263 \\
278 \\
285 \\
280 \\
273\end{array}$ & $\begin{array}{l}396 \\
382 \\
379 \\
375 \\
386\end{array}$ & $\begin{array}{l}279 \\
290 \\
339 \\
367 \\
379\end{array}$ \\
\hline $\begin{array}{l}21 \\
22 \\
23 \\
24 \\
25\end{array}$ & $\begin{array}{l}622 \\
599 \\
581 \\
568 \\
554\end{array}$ & $\begin{array}{l}450 \\
462 \\
474 \\
481 \\
487\end{array}$ & $\begin{array}{l}511 \\
503 \\
495 \\
487 \\
477\end{array}$ & $\begin{array}{l}446 \\
435 \\
422 \\
420 \\
415\end{array}$ & $\begin{array}{l}385 \\
383 \\
396 \\
414 \\
416\end{array}$ & $\begin{array}{l}474 \\
460 \\
446 \\
433 \\
418\end{array}$ & $\begin{array}{l}724 \\
653 \\
594 \\
558 \\
533\end{array}$ & $\begin{array}{l}371 \\
369 \\
349 \\
331 \\
321\end{array}$ & $\begin{array}{l}385 \\
398 \\
356 \\
336 \\
302\end{array}$ & $\begin{array}{l}266 \\
248 \\
254 \\
255 \\
254\end{array}$ & $\begin{array}{l}382 \\
357 \\
311 \\
289 \\
280\end{array}$ & $\begin{array}{l}430 \\
551 \\
646 \\
589 \\
547\end{array}$ \\
\hline $\begin{array}{l}26 \\
27 \\
28 \\
29 \\
30 \\
31\end{array}$ & $\begin{array}{l}544 \\
537 \\
535 \\
531 \\
525 \\
521\end{array}$ & $\begin{array}{l}504 \\
571 \\
687 \\
644 \\
626 \\
---\end{array}$ & $\begin{array}{l}466 \\
457 \\
452 \\
444 \\
440 \\
438\end{array}$ & $\begin{array}{l}410 \\
410 \\
415 \\
420 \\
430 \\
435\end{array}$ & $\begin{array}{l}420 \\
426 \\
432 \\
--- \\
--- \\
---\end{array}$ & $\begin{array}{l}406 \\
413 \\
420 \\
423 \\
424 \\
412\end{array}$ & $\begin{array}{l}515 \\
505 \\
479 \\
449 \\
422 \\
---\end{array}$ & $\begin{array}{l}316 \\
312 \\
306 \\
301 \\
293 \\
283\end{array}$ & $\begin{array}{l}278 \\
276 \\
269 \\
255 \\
251 \\
---\end{array}$ & $\begin{array}{l}285 \\
273 \\
269 \\
279 \\
266 \\
264\end{array}$ & $\begin{array}{l}287 \\
424 \\
525 \\
525 \\
513 \\
524\end{array}$ & $\begin{array}{l}513 \\
487 \\
434 \\
393 \\
397 \\
-\end{array}$ \\
\hline $\begin{array}{l}\text { TOTAL } \\
\text { MEAN } \\
\text { MAX } \\
\text { MIN } \\
\text { CFSM } \\
\text { IN. }\end{array}$ & $\begin{array}{r}37734 \\
1217 \\
3460 \\
521 \\
3.12 \\
3.60\end{array}$ & $\begin{array}{r}14523 \\
484 \\
687 \\
427 \\
1.24 \\
1.39\end{array}$ & $\begin{array}{r}16866 \\
544 \\
650 \\
438 \\
1.40 \\
1.61\end{array}$ & $\begin{array}{r}13472 \\
435 \\
474 \\
410 \\
1.12 \\
1.29\end{array}$ & $\begin{array}{r}12428 \\
444 \\
505 \\
383 \\
1.14 \\
1.19\end{array}$ & $\begin{array}{r}15393 \\
497 \\
657 \\
406 \\
1.27 \\
1.47\end{array}$ & $\begin{array}{r}15497 \\
517 \\
758 \\
389 \\
1.33 \\
1.48\end{array}$ & $\begin{array}{r}11484 \\
370 \\
488 \\
283 \\
.95 \\
1.10\end{array}$ & $\begin{array}{r}8405 \\
280 \\
398 \\
233 \\
.72 \\
.80\end{array}$ & $\begin{array}{r}7862 \\
254 \\
285 \\
221 \\
.65 \\
.75\end{array}$ & $\begin{array}{r}10311 \\
333 \\
525 \\
239 \\
.85 \\
.98\end{array}$ & $\begin{array}{r}11807 \\
394 \\
646 \\
279 \\
1.01 \\
1.13\end{array}$ \\
\hline $\begin{array}{l}\text { CAL YR } \\
\text { WTR YR }\end{array}$ & $\begin{array}{l}1986 \\
1987\end{array}$ & $\begin{array}{l}21 \\
17\end{array}$ & $\begin{array}{l}10 \\
82\end{array}$ & $\begin{array}{ll}\text { AN } & 581 \\
\text { AN } & 482\end{array}$ & $\begin{array}{l}\text { MAX } \\
\text { MAX }\end{array}$ & $\begin{array}{l}\text { MIN } \\
\text { MIN }\end{array}$ & $\begin{array}{l}259 \\
221\end{array}$ & $\begin{array}{ll}\text { SFSM } & 1.49 \\
\text { CFSM } & 1.24\end{array}$ & $\begin{array}{l}\text { IN } \\
\text { IN }\end{array}$ & & & \\
\hline
\end{tabular}


LOCATION.--Lat $42^{\circ} 21^{\prime} 15^{\prime \prime}$, long $86^{\circ} 11^{\prime} 15^{\prime \prime}$, in NWl/4 sec. 28 , T.1 S., R.16 w., Van Buren County, Hydrologic

Unit 04050002 , on left bank 50 ft upstream from bridge on 66 th street, $4.9 \mathrm{mi}$ northwest of Bangor.

DRAINAGE AREA. $--83.6 \mathrm{mi}^{2}$.

PERIOD OF RECORD.--June 1966 to current year. Prior to October 1981, published as Black River near Bangor.

REVISED RECORDS.--WDR MI-81: 1973-75(M), $1979(\mathrm{M})$.

GAGE.--Water-stage recorder. Elevation of gage is $610 \mathrm{ft}$ above National Geodetic Vertical Datum of 1929 , from topographic map.

REMARKS.--Estimated daily discharges: Jan. 23 to Feb. 17, and May 24 to June 25 . Records good except for estimated daily discharges, which are fair. Occasional regulation caused by mills upstream from

station. Several measurements of water temperature were made during the year.

AVERAGE DISCHARGE. --21 years, $107 \mathrm{ft}^{3} / \mathrm{s}, 17.38 \mathrm{in} / \mathrm{yr}$.

EXTREMES FOR PERIOD OF RECORD.--Maximum discharge, 1,860 ft $3 / \mathrm{s}$, Sept. 30, 1986, gage height, 13.63

$\mathrm{ft}$; minimum, $20 \mathrm{ft} / \mathrm{s}$, Sept. 28, 1966, Aug. 18, 19, 1984; minimum gage height, 1.79 ft, Aug. 18, $19,1984$.

EXTREMES FOR CURRENT YEAR.--Peak discharges greater than base discharge of $400 \mathrm{ft}^{3} / \mathrm{s}$ and maximum (*):

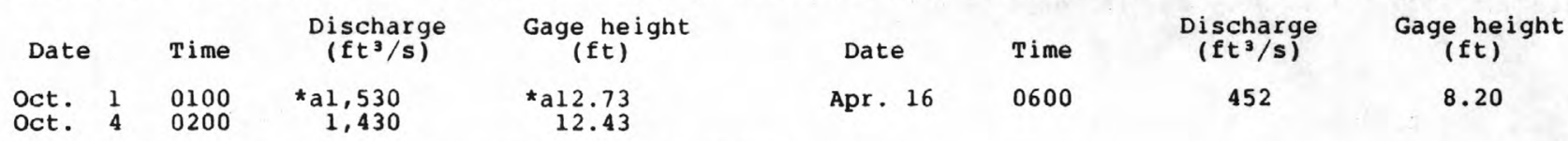

a Stage falling, peak occurred sept. 30, 1986.

Minimum discharge, $27 \mathrm{ft}^{3} / \mathrm{s}$, Aug. 8, gage height, $1.97 \mathrm{ft}$.

DISCHARGE, IN CUBIC FEET PER SECOND, WATER YEAR OCTOBER 1986 TO SEPTEMBER 1987

\begin{tabular}{|c|c|c|c|c|c|c|c|c|c|c|c|c|}
\hline \\
\hline DAY & OCT & NOV & $\mathrm{DEC}$ & JAN & FEB & MAR & APR & MAY & JUN & JUL & AUG & SEP \\
\hline $\begin{array}{l}1 \\
2 \\
3 \\
4 \\
5\end{array}$ & $\begin{array}{r}1340 \\
1160 \\
1100 \\
1300 \\
991\end{array}$ & $\begin{array}{l}96 \\
95 \\
92 \\
90 \\
88\end{array}$ & $\begin{array}{l}144 \\
144 \\
166 \\
166 \\
147\end{array}$ & $\begin{array}{l}84 \\
83 \\
81 \\
79 \\
77\end{array}$ & $\begin{array}{l}75 \\
75 \\
76 \\
78 \\
77\end{array}$ & $\begin{array}{l}179 \\
286 \\
257 \\
190 \\
152\end{array}$ & $\begin{array}{r}72 \\
93 \\
102 \\
95 \\
89\end{array}$ & $\begin{array}{r}63 \\
71 \\
91 \\
116 \\
98\end{array}$ & $\begin{array}{l}46 \\
48 \\
49 \\
49 \\
46\end{array}$ & $\begin{array}{l}34 \\
34 \\
34 \\
32 \\
32\end{array}$ & $\begin{array}{l}31 \\
31 \\
29 \\
31 \\
32\end{array}$ & $\begin{array}{l}72 \\
65 \\
60 \\
54 \\
51\end{array}$ \\
\hline $\begin{array}{r}6 \\
7 \\
8 \\
9 \\
10\end{array}$ & $\begin{array}{l}766 \\
595 \\
481 \\
392 \\
303\end{array}$ & $\begin{array}{l}86 \\
85 \\
85 \\
85 \\
83\end{array}$ & $\begin{array}{l}131 \\
135 \\
197 \\
228 \\
226\end{array}$ & $\begin{array}{l}76 \\
76 \\
76 \\
74 \\
76\end{array}$ & $\begin{array}{l}76 \\
77 \\
79 \\
80 \\
80\end{array}$ & $\begin{array}{r}137 \\
122 \\
112 \\
103 \\
91\end{array}$ & $\begin{array}{l}83 \\
78 \\
73 \\
70 \\
67\end{array}$ & $\begin{array}{l}83 \\
75 \\
70 \\
64 \\
61\end{array}$ & $\begin{array}{l}44 \\
41 \\
39 \\
38 \\
37\end{array}$ & $\begin{array}{l}33 \\
32 \\
31 \\
29 \\
32\end{array}$ & $\begin{array}{l}29 \\
28 \\
28 \\
41 \\
37\end{array}$ & $\begin{array}{l}48 \\
47 \\
59 \\
57 \\
53\end{array}$ \\
\hline $\begin{array}{l}11 \\
12 \\
13 \\
14 \\
15\end{array}$ & $\begin{array}{l}231 \\
183 \\
168 \\
170 \\
178\end{array}$ & $\begin{array}{l}82 \\
83 \\
82 \\
80 \\
80\end{array}$ & $\begin{array}{l}183 \\
150 \\
132 \\
123 \\
114\end{array}$ & $\begin{array}{l}78 \\
79 \\
80 \\
81 \\
95\end{array}$ & $\begin{array}{l}80 \\
80 \\
80 \\
80 \\
77\end{array}$ & $\begin{array}{l}84 \\
79 \\
77 \\
80 \\
87\end{array}$ & $\begin{array}{r}66 \\
81 \\
91 \\
97 \\
348\end{array}$ & $\begin{array}{l}58 \\
55 \\
53 \\
51 \\
51\end{array}$ & $\begin{array}{l}37 \\
38 \\
38 \\
37 \\
35\end{array}$ & $\begin{array}{l}32 \\
30 \\
29 \\
31 \\
33\end{array}$ & $\begin{array}{r}34 \\
32 \\
30 \\
89 \\
109\end{array}$ & $\begin{array}{l}50 \\
48 \\
49 \\
48 \\
50\end{array}$ \\
\hline $\begin{array}{l}16 \\
17 \\
18 \\
19 \\
20\end{array}$ & $\begin{array}{l}158 \\
145 \\
136 \\
125 \\
119\end{array}$ & $\begin{array}{l}83 \\
87 \\
92 \\
93 \\
92\end{array}$ & $\begin{array}{l}112 \\
122 \\
131 \\
128 \\
117\end{array}$ & $\begin{array}{r}108 \\
93 \\
85 \\
83 \\
81\end{array}$ & $\begin{array}{l}74 \\
70 \\
65 \\
63 \\
62\end{array}$ & $\begin{array}{r}96 \\
102 \\
102 \\
99 \\
92\end{array}$ & $\begin{array}{l}440 \\
328 \\
225 \\
162 \\
131\end{array}$ & $\begin{array}{l}50 \\
48 \\
50 \\
55 \\
57\end{array}$ & $\begin{array}{l}34 \\
32 \\
31 \\
31 \\
32\end{array}$ & $\begin{array}{l}50 \\
43 \\
38 \\
36 \\
34\end{array}$ & $\begin{array}{r}77 \\
144 \\
119 \\
116 \\
89\end{array}$ & $\begin{array}{r}57 \\
81 \\
200 \\
179 \\
139\end{array}$ \\
\hline $\begin{array}{l}21 \\
22 \\
23 \\
24 \\
25\end{array}$ & $\begin{array}{l}115 \\
111 \\
108 \\
106 \\
105\end{array}$ & $\begin{array}{l}100 \\
113 \\
122 \\
137 \\
128\end{array}$ & $\begin{array}{r}108 \\
99 \\
95 \\
95 \\
94\end{array}$ & $\begin{array}{l}77 \\
76 \\
73 \\
72 \\
70\end{array}$ & $\begin{array}{l}63 \\
65 \\
69 \\
72 \\
75\end{array}$ & $\begin{array}{l}84 \\
79 \\
76 \\
74 \\
74\end{array}$ & $\begin{array}{l}112 \\
101 \\
113 \\
117 \\
100\end{array}$ & $\begin{array}{l}53 \\
51 \\
50 \\
50 \\
48\end{array}$ & $\begin{array}{l}45 \\
60 \\
50 \\
45 \\
40\end{array}$ & $\begin{array}{l}33 \\
32 \\
31 \\
30 \\
30\end{array}$ & $\begin{array}{l}69 \\
59 \\
53 \\
47 \\
46\end{array}$ & $\begin{array}{l}188 \\
234 \\
189 \\
141 \\
117\end{array}$ \\
\hline $\begin{array}{l}26 \\
27 \\
28 \\
29 \\
30 \\
31\end{array}$ & $\begin{array}{r}106 \\
112 \\
110 \\
106 \\
103 \\
99\end{array}$ & $\begin{array}{l}145 \\
280 \\
291 \\
215 \\
169 \\
---\end{array}$ & $\begin{array}{l}91 \\
88 \\
86 \\
85 \\
85 \\
85\end{array}$ & $\begin{array}{l}70 \\
71 \\
71 \\
72 \\
72 \\
74\end{array}$ & $\begin{array}{r}77 \\
77 \\
82 \\
--- \\
--- \\
---\end{array}$ & $\begin{array}{l}78 \\
82 \\
78 \\
75 \\
77 \\
75\end{array}$ & $\begin{array}{r}89 \\
82 \\
77 \\
72 \\
68 \\
---\end{array}$ & $\begin{array}{l}48 \\
46 \\
45 \\
44 \\
43 \\
43\end{array}$ & $\begin{array}{r}36 \\
35 \\
34 \\
33 \\
33 \\
---\end{array}$ & $\begin{array}{l}32 \\
32 \\
30 \\
31 \\
31 \\
30\end{array}$ & $\begin{array}{r}59 \\
231 \\
207 \\
154 \\
113 \\
87\end{array}$ & $\begin{array}{r}93 \\
79 \\
71 \\
79 \\
87 \\
- \\
\end{array}$ \\
\hline $\begin{array}{l}\text { TOTAL } \\
\text { MEAN } \\
\text { MAX } \\
\text { MIN } \\
\text { CFSM } \\
\text { IN. }\end{array}$ & $\begin{array}{r}11222 \\
362 \\
1340 \\
99 \\
4.33 \\
4.99\end{array}$ & $\begin{array}{r}3439 \\
115 \\
291 \\
80 \\
1.38 \\
1.53\end{array}$ & $\begin{array}{r}4007 \\
129 \\
228 \\
85 \\
1.54 \\
1.78\end{array}$ & $\begin{array}{r}2443 \\
78.8 \\
108 \\
70 \\
.94 \\
1.09\end{array}$ & $\begin{array}{r}2084 \\
74.4 \\
82 \\
62 \\
.89 \\
.93\end{array}$ & $\begin{array}{r}3379 \\
109 \\
286 \\
74 \\
1.30 \\
1.50\end{array}$ & $\begin{array}{r}3722 \\
124 \\
440 \\
66 \\
1.48 \\
1.66\end{array}$ & $\begin{array}{r}1841 \\
59.4 \\
116 \\
43 \\
.71 \\
.82\end{array}$ & $\begin{array}{r}1193 \\
39.8 \\
60 \\
31 \\
.48 \\
.53\end{array}$ & $\begin{array}{r}1021 \\
32.9 \\
50 \\
29 \\
.39 \\
.45\end{array}$ & $\begin{array}{r}2281 \\
73.6 \\
231 \\
28 \\
.88 \\
1.01\end{array}$ & $\begin{array}{r}2745 \\
91.5 \\
234 \\
47 \\
1.09 \\
1.22\end{array}$ \\
\hline
\end{tabular}

$\begin{array}{llllllllllll}\text { CAL YR } 1986 & \text { TOTAL } 57596 & \text { MEAN } 158 & \text { MAX } & 1740 & \text { MIN } 37 & \text { CFSM } & 1.89 & \text { IN } 25.63\end{array}$

WTR YR 1987 TOTAL 39377 MEAN 108 MAX 1340 MIN 28 CFSM 1.29 IN 17.52 


\section{KALAMAZOO RIVER NEAR MARENGO, MI}

LOCATION.--Lat $42^{\circ} 15^{\prime} 42^{\prime \prime}$, long $84^{\circ} 51^{\prime} 21^{\prime \prime}$, in SWl/4 SEl/4 sec.26, T. 2 S., R.5 W. Calhoun County, Hydrologic Unit 04050003 , on right bank at upstream side of bridge on B Drive North, $0.8 \mathrm{mi}$ south of Marengo, and $5.0 \mathrm{mi}$ west of Albion.

DRAINAGE AREA. $--267 \mathrm{mi}^{2}$.

PERIOD OF RECORD.--October 1986 to September 1987.

GAGE.--Water-stage recorder. Elevation of gage is $910 \mathrm{ft}$ above National Geodetic Vertical Datum of 1929 , from topographic map.

REMARKS.--Estimated daily discharges: Oct. 23 to Nov, 23 and Jan. 21-31. Records good except for estimated daily discharges, which are fair. Several measurements of water temperature were made during the year.

EXTREMES FOR CURRENT YEAR.--Maximum discharge, $684 \mathrm{ft}^{3} / \mathrm{s}$, Oct. 5, gage height, $8.52 \mathrm{ft} ; \mathrm{minimum,} 88$ $\mathrm{ft}^{3} / \mathrm{s}$, Aug. 19, gage height, $5.90 \mathrm{ft}$.

DISCHARGE, IN CUBIC FEET PER SECOND, WATER YEAR OCTOBER 1986 TO SEPTEMBER 1987 MEAN VALUES

\begin{tabular}{|c|c|c|c|c|c|c|c|c|c|c|c|c|}
\hline DAY & OCT & NOV & DEC & JAN & FEB & MAR & APR & MAY & JUN & JUL & AUG & SEP \\
\hline $\begin{array}{l}1 \\
2 \\
3 \\
4 \\
5\end{array}$ & $\begin{array}{l}415 \\
392 \\
493 \\
644 \\
678\end{array}$ & $\begin{array}{l}235 \\
230 \\
230 \\
230 \\
225\end{array}$ & $\begin{array}{l}276 \\
282 \\
296 \\
298 \\
287\end{array}$ & $\begin{array}{l}210 \\
210 \\
209 \\
208 \\
206\end{array}$ & $\begin{array}{l}200 \\
200 \\
200 \\
197 \\
192\end{array}$ & $\begin{array}{l}244 \\
290 \\
291 \\
273 \\
258\end{array}$ & $\begin{array}{l}209 \\
223 \\
231 \\
224 \\
227\end{array}$ & $\begin{array}{l}177 \\
180 \\
198 \\
209 \\
206\end{array}$ & $\begin{array}{l}166 \\
174 \\
192 \\
178 \\
168\end{array}$ & $\begin{array}{l}122 \\
125 \\
128 \\
130 \\
124\end{array}$ & $\begin{array}{l}104 \\
105 \\
102 \\
109 \\
105\end{array}$ & $\begin{array}{l}173 \\
158 \\
146 \\
135 \\
131\end{array}$ \\
\hline $\begin{array}{r}6 \\
7 \\
8 \\
9 \\
10\end{array}$ & $\begin{array}{l}654 \\
586 \\
505 \\
430 \\
358\end{array}$ & $\begin{array}{l}225 \\
220 \\
220 \\
220 \\
220\end{array}$ & $\begin{array}{l}269 \\
263 \\
271 \\
294 \\
313\end{array}$ & $\begin{array}{l}205 \\
204 \\
205 \\
203 \\
210\end{array}$ & $\begin{array}{l}194 \\
192 \\
194 \\
185 \\
202\end{array}$ & $\begin{array}{l}250 \\
247 \\
248 \\
243 \\
233\end{array}$ & $\begin{array}{l}236 \\
241 \\
232 \\
220 \\
210\end{array}$ & $\begin{array}{l}196 \\
187 \\
181 \\
175 \\
169\end{array}$ & $\begin{array}{l}159 \\
152 \\
146 \\
142 \\
139\end{array}$ & $\begin{array}{l}142 \\
141 \\
133 \\
128 \\
123\end{array}$ & $\begin{array}{r}102 \\
99 \\
96 \\
115 \\
109\end{array}$ & $\begin{array}{l}127 \\
124 \\
131 \\
129 \\
128\end{array}$ \\
\hline $\begin{array}{l}11 \\
12 \\
13 \\
14 \\
15\end{array}$ & $\begin{array}{l}325 \\
304 \\
301 \\
312 \\
308\end{array}$ & $\begin{array}{l}215 \\
215 \\
210 \\
210 \\
205\end{array}$ & $\begin{array}{l}301 \\
281 \\
249 \\
233 \\
248\end{array}$ & $\begin{array}{l}207 \\
204 \\
206 \\
207 \\
222\end{array}$ & $\begin{array}{l}191 \\
190 \\
189 \\
186 \\
180\end{array}$ & $\begin{array}{l}217 \\
208 \\
201 \\
207 \\
208\end{array}$ & $\begin{array}{l}204 \\
228 \\
248 \\
244 \\
267\end{array}$ & $\begin{array}{l}167 \\
162 \\
162 \\
164 \\
165\end{array}$ & $\begin{array}{l}137 \\
137 \\
137 \\
135 \\
131\end{array}$ & $\begin{array}{l}120 \\
118 \\
116 \\
116 \\
116\end{array}$ & $\begin{array}{l}109 \\
105 \\
104 \\
101 \\
101\end{array}$ & $\begin{array}{l}175 \\
149 \\
141 \\
137 \\
155\end{array}$ \\
\hline $\begin{array}{l}16 \\
17 \\
18 \\
19 \\
20\end{array}$ & $\begin{array}{l}304 \\
293 \\
280 \\
267 \\
259\end{array}$ & $\begin{array}{l}205 \\
205 \\
205 \\
210 \\
215\end{array}$ & $\begin{array}{l}234 \\
230 \\
239 \\
240 \\
236\end{array}$ & $\begin{array}{l}238 \\
232 \\
225 \\
219 \\
201\end{array}$ & $\begin{array}{l}176 \\
178 \\
184 \\
177 \\
173\end{array}$ & $\begin{array}{l}209 \\
210 \\
213 \\
216 \\
217\end{array}$ & $\begin{array}{l}286 \\
290 \\
273 \\
250 \\
232\end{array}$ & $\begin{array}{l}167 \\
162 \\
176 \\
200 \\
206\end{array}$ & $\begin{array}{l}127 \\
125 \\
122 \\
120 \\
130\end{array}$ & $\begin{array}{l}126 \\
125 \\
120 \\
116 \\
114\end{array}$ & $\begin{array}{r}98 \\
103 \\
100 \\
101 \\
96\end{array}$ & $\begin{array}{l}158 \\
159 \\
171 \\
170 \\
157\end{array}$ \\
\hline $\begin{array}{l}21 \\
22 \\
23 \\
24 \\
25\end{array}$ & $\begin{array}{l}253 \\
249 \\
250 \\
250 \\
250\end{array}$ & $\begin{array}{l}220 \\
225 \\
230 \\
240 \\
245\end{array}$ & $\begin{array}{l}230 \\
224 \\
219 \\
217 \\
218\end{array}$ & $\begin{array}{l}210 \\
210 \\
190 \\
190 \\
190\end{array}$ & $\begin{array}{l}173 \\
173 \\
178 \\
181 \\
186\end{array}$ & $\begin{array}{l}213 \\
210 \\
206 \\
204 \\
207\end{array}$ & $\begin{array}{l}220 \\
211 \\
215 \\
208 \\
203\end{array}$ & $\begin{array}{l}201 \\
191 \\
179 \\
171 \\
167\end{array}$ & $\begin{array}{l}149 \\
158 \\
145 \\
129 \\
127\end{array}$ & $\begin{array}{l}111 \\
109 \\
107 \\
105 \\
118\end{array}$ & $\begin{array}{l}102 \\
138 \\
129 \\
126 \\
122\end{array}$ & $\begin{array}{l}153 \\
151 \\
148 \\
142 \\
138\end{array}$ \\
\hline $\begin{array}{l}26 \\
27 \\
28 \\
29 \\
30 \\
31\end{array}$ & $\begin{array}{l}250 \\
245 \\
245 \\
245 \\
240 \\
240\end{array}$ & $\begin{array}{l}277 \\
321 \\
334 \\
321 \\
295 \\
----\end{array}$ & $\begin{array}{l}217 \\
215 \\
214 \\
212 \\
211 \\
210\end{array}$ & $\begin{array}{l}190 \\
185 \\
185 \\
190 \\
190 \\
195\end{array}$ & $\begin{array}{l}189 \\
189 \\
195 \\
--- \\
--- \\
---\end{array}$ & $\begin{array}{l}207 \\
210 \\
210 \\
206 \\
208 \\
206\end{array}$ & $\begin{array}{l}195 \\
191 \\
182 \\
183 \\
178 \\
---\end{array}$ & $\begin{array}{l}163 \\
160 \\
155 \\
151 \\
152 \\
189\end{array}$ & $\begin{array}{l}122 \\
118 \\
116 \\
116 \\
123 \\
---\end{array}$ & $\begin{array}{l}121 \\
118 \\
115 \\
113 \\
110 \\
107\end{array}$ & $\begin{array}{l}157 \\
320 \\
275 \\
250 \\
223 \\
200\end{array}$ & $\begin{array}{l}134 \\
131 \\
133 \\
158 \\
160 \\
-\end{array}$ \\
\hline $\begin{array}{l}\text { TOTAL } \\
\text { MEAN } \\
\text { MAX } \\
\text { MIN } \\
\text { CFSM } \\
\text { IN. }\end{array}$ & $\begin{array}{r}10825 \\
349 \\
678 \\
240 \\
1.31 \\
1.51\end{array}$ & $\begin{array}{r}7058 \\
235 \\
334 \\
205 \\
.88 \\
.98\end{array}$ & $\begin{array}{r}7727 \\
249 \\
313 \\
210 \\
.93 \\
1.08\end{array}$ & $\begin{array}{r}6356 \\
205 \\
238 \\
185 \\
.77 \\
.89\end{array}$ & $\begin{array}{r}5244 \\
187 \\
202 \\
173 \\
.70 \\
.73\end{array}$ & $\begin{array}{r}6970 \\
225 \\
291 \\
201 \\
.84 \\
.97\end{array}$ & $\begin{array}{r}6761 \\
225 \\
290 \\
178 \\
.84 \\
.94\end{array}$ & $\begin{array}{r}5488 \\
177 \\
209 \\
151 \\
.66 \\
.76\end{array}$ & $\begin{array}{r}4220 \\
141 \\
192 \\
116 \\
.53 \\
.59\end{array}$ & $\begin{array}{r}3717 \\
120 \\
142 \\
105 \\
.45 \\
.52\end{array}$ & $\begin{array}{r}4106 \\
132 \\
320 \\
96 \\
.49 \\
.57\end{array}$ & $\begin{array}{r}4402 \\
147 \\
175 \\
124 \\
.55 \\
.61\end{array}$ \\
\hline WTR YR & 1987 & & IEAN & 200 & 678 & N 9 & CFSM . 75 & IN & & & & \\
\hline
\end{tabular}


LOCATION.--Lat $42^{\circ} 19^{\prime} 5^{\prime \prime}$, long $85^{\circ} 09^{\prime} 15^{\prime \prime}$, in NWl/4 sec.5, T.2 S., R.7 W., Calhoun County, Hydrologic Unit 04050003 , on right bank $350 \mathrm{ft}$ upstream from Emmett Street Bridge in Battle Creek, $3.0 \mathrm{mi}$ upstream from mouth.

DRAINAGE AREA. $--241 \mathrm{mi}^{2}$.

PERIOD OF RECORD.--October 1930 to September 1931, October 1932 to July 1933, January 1934 to current

year. Monthly discharge only for some periods, published in wSP 1307.

REVISED RECORDS.--WSP 1387: 1931, 1944. WSP 1507: 1956.

GAGE.--Water-stage recorder. Datum of gage is $823.24 \mathrm{ft}$ above National Geodetic Vertical Datum of 1929 (levels by Michigan Department of Natural Resources). Prior to May 14, 1951, nonrecording gage at same site and datum.

REMARKS.--Estimated daily discharges: Mar. 4-23. Records good except for estimated daily discharges, which are fair. Occasional slight regulation prior to November 1943 . Several measurements of water temperature were made during the year.

AVERAGE DISCHARGE.--54 years (water years 1931, 1935-87), $203 \mathrm{ft} 3 / \mathrm{s}, 11.44 \mathrm{in} / \mathrm{yr}^{\mathrm{r}}$.

EXTREMES FOR PERIOD OF RECORD.--Maximum discharge, 3,640 ft $3 / \mathrm{s}$, Apr. 7, 1947, gage height, 4.48 ft, from floodmark; minimum, $22 \mathrm{ft}^{3} / \mathrm{s}$. Aug. 14, 1934; minimum gage height, about $-0.5 \mathrm{ft}$ in July 1936 and on Aug. 31, 1939, due to opening of gates at dam forming control.

EXTREMES FOR CURRENT YEAR.--Maximum discharge, 1,650 $\mathrm{ft}^{3} / \mathrm{s}$, Oct. 6, gage height, $2.64 \mathrm{ft}$; minimum, $45 \mathrm{ft}^{3} / \mathrm{s}$, Aug. 7, 8; minimum gage height, $0.58 \mathrm{ft}$, Aug. 7, 8, 14, 15.

DISCHARGE, IN CUBIC FEET PER SECOND, WATER YEAR OCTOBER 1986 TO SEPTEMBER 1987

\begin{tabular}{|c|c|c|c|c|c|c|c|c|c|c|c|c|}
\hline DAY & OCT & NOV & DEC & JAN & FEB & MAR & APR & MAY & JUN & JUL & AUG & SEP \\
\hline $\begin{array}{l}1 \\
2 \\
3 \\
4 \\
5\end{array}$ & $\begin{array}{r}970 \\
1210 \\
1350 \\
1470 \\
1570\end{array}$ & $\begin{array}{l}208 \\
208 \\
205 \\
200 \\
198\end{array}$ & $\begin{array}{l}348 \\
344 \\
332 \\
326 \\
322\end{array}$ & $\begin{array}{l}185 \\
184 \\
176 \\
184 \\
185\end{array}$ & $\begin{array}{l}161 \\
175 \\
178 \\
165 \\
192\end{array}$ & $\begin{array}{l}240 \\
296 \\
347 \\
440 \\
440\end{array}$ & $\begin{array}{l}198 \\
207 \\
219 \\
223 \\
223\end{array}$ & $\begin{array}{l}136 \\
137 \\
143 \\
149 \\
157\end{array}$ & $\begin{array}{l}82 \\
77 \\
79 \\
78 \\
78\end{array}$ & $\begin{array}{l}74 \\
89 \\
77 \\
70 \\
64\end{array}$ & $\begin{array}{l}76 \\
70 \\
57 \\
55 \\
53\end{array}$ & $\begin{array}{r}104 \\
87 \\
83 \\
80 \\
78\end{array}$ \\
\hline $\begin{array}{r}6 \\
7 \\
8 \\
9 \\
10\end{array}$ & $\begin{array}{r}1640 \\
1540 \\
1330 \\
1130 \\
957\end{array}$ & $\begin{array}{l}192 \\
190 \\
183 \\
181 \\
181\end{array}$ & $\begin{array}{l}342 \\
359 \\
361 \\
359 \\
359\end{array}$ & $\begin{array}{l}181 \\
181 \\
183 \\
186 \\
185\end{array}$ & $\begin{array}{l}185 \\
169 \\
152 \\
195 \\
207\end{array}$ & $\begin{array}{l}420 \\
380 \\
350 \\
330 \\
320\end{array}$ & $\begin{array}{l}220 \\
208 \\
203 \\
199 \\
189\end{array}$ & $\begin{array}{l}143 \\
118 \\
122 \\
120 \\
116\end{array}$ & $\begin{array}{l}77 \\
76 \\
72 \\
73 \\
68\end{array}$ & $\begin{array}{l}67 \\
68 \\
72 \\
63 \\
67\end{array}$ & $\begin{array}{l}53 \\
48 \\
49 \\
58 \\
56\end{array}$ & $\begin{array}{l}71 \\
71 \\
71 \\
78 \\
81\end{array}$ \\
\hline $\begin{array}{l}11 \\
12 \\
13 \\
14 \\
15\end{array}$ & $\begin{array}{l}821 \\
693 \\
595 \\
525 \\
471\end{array}$ & $\begin{array}{l}178 \\
172 \\
164 \\
154 \\
154\end{array}$ & $\begin{array}{l}330 \\
391 \\
322 \\
327 \\
341\end{array}$ & $\begin{array}{l}173 \\
178 \\
182 \\
187 \\
193\end{array}$ & $\begin{array}{l}191 \\
190 \\
180 \\
176 \\
147\end{array}$ & $\begin{array}{l}280 \\
250 \\
230 \\
220 \\
215\end{array}$ & $\begin{array}{l}183 \\
185 \\
193 \\
195 \\
212\end{array}$ & $\begin{array}{l}107 \\
100 \\
100 \\
102 \\
102\end{array}$ & $\begin{array}{l}64 \\
68 \\
66 \\
65 \\
56\end{array}$ & $\begin{array}{l}77 \\
97 \\
97 \\
80 \\
69\end{array}$ & $\begin{array}{l}54 \\
52 \\
54 \\
50 \\
51\end{array}$ & $\begin{array}{r}91 \\
105 \\
116 \\
125 \\
149\end{array}$ \\
\hline $\begin{array}{l}16 \\
17 \\
18 \\
19 \\
20\end{array}$ & $\begin{array}{l}429 \\
402 \\
377 \\
357 \\
339\end{array}$ & $\begin{array}{l}152 \\
150 \\
153 \\
154 \\
154\end{array}$ & $\begin{array}{l}303 \\
283 \\
267 \\
250 \\
244\end{array}$ & $\begin{array}{l}216 \\
224 \\
228 \\
178 \\
183\end{array}$ & $\begin{array}{l}132 \\
146 \\
140 \\
134 \\
131\end{array}$ & $\begin{array}{l}210 \\
210 \\
220 \\
225 \\
230\end{array}$ & $\begin{array}{l}233 \\
261 \\
295 \\
318 \\
314\end{array}$ & $\begin{array}{r}101 \\
100 \\
96 \\
99 \\
114\end{array}$ & $\begin{array}{l}62 \\
58 \\
54 \\
53 \\
54\end{array}$ & $\begin{array}{l}76 \\
80 \\
70 \\
65 \\
58\end{array}$ & $\begin{array}{l}55 \\
75 \\
85 \\
76 \\
69\end{array}$ & $\begin{array}{l}154 \\
151 \\
166 \\
180 \\
182\end{array}$ \\
\hline $\begin{array}{l}21 \\
22 \\
23 \\
24 \\
25\end{array}$ & $\begin{array}{l}313 \\
292 \\
268 \\
249 \\
238\end{array}$ & $\begin{array}{l}154 \\
156 \\
165 \\
182 \\
193\end{array}$ & $\begin{array}{l}240 \\
228 \\
215 \\
198 \\
194\end{array}$ & $\begin{array}{l}221 \\
224 \\
191 \\
179 \\
147\end{array}$ & $\begin{array}{l}139 \\
140 \\
136 \\
141 \\
157\end{array}$ & $\begin{array}{l}220 \\
215 \\
205 \\
202 \\
208\end{array}$ & $\begin{array}{l}289 \\
251 \\
229 \\
203 \\
191\end{array}$ & $\begin{array}{r}114 \\
103 \\
89 \\
94 \\
90\end{array}$ & $\begin{array}{r}68 \\
107 \\
101 \\
83 \\
75\end{array}$ & $\begin{array}{r}73 \\
89 \\
102 \\
102 \\
82\end{array}$ & $\begin{array}{l}54 \\
67 \\
76 \\
83 \\
63\end{array}$ & $\begin{array}{l}185 \\
173 \\
157 \\
142 \\
128\end{array}$ \\
\hline $\begin{array}{l}26 \\
27 \\
28 \\
29 \\
30 \\
31\end{array}$ & $\begin{array}{l}231 \\
227 \\
225 \\
221 \\
213 \\
210\end{array}$ & $\begin{array}{l}219 \\
254 \\
284 \\
309 \\
344 \\
---\end{array}$ & $\begin{array}{l}190 \\
185 \\
187 \\
182 \\
184 \\
183\end{array}$ & $\begin{array}{l}137 \\
140 \\
133 \\
134 \\
144 \\
156\end{array}$ & $\begin{array}{l}156 \\
174 \\
184 \\
--- \\
--- \\
---\end{array}$ & $\begin{array}{l}208 \\
212 \\
213 \\
208 \\
194 \\
198\end{array}$ & $\begin{array}{l}180 \\
158 \\
139 \\
153 \\
148 \\
---\end{array}$ & $\begin{array}{l}77 \\
84 \\
84 \\
81 \\
79 \\
79\end{array}$ & $\begin{array}{r}70 \\
65 \\
61 \\
57 \\
58 \\
-\end{array}$ & $\begin{array}{l}71 \\
69 \\
58 \\
58 \\
56 \\
51\end{array}$ & $\begin{array}{l}71 \\
140 \\
165 \\
166 \\
149 \\
130\end{array}$ & $\begin{array}{l}118 \\
109 \\
101 \\
107 \\
118\end{array}$ \\
\hline $\begin{array}{l}\text { TOTAL } \\
\text { MEAN } \\
\text { MAX } \\
\text { MIN } \\
\text { CFSM } \\
\text { IN. }\end{array}$ & $\begin{array}{r}20863 \\
673 \\
1640 \\
210 \\
2.79 \\
3.22\end{array}$ & $\begin{array}{r}5791 \\
193 \\
344 \\
150 \\
.80 \\
.89\end{array}$ & $\begin{array}{r}8696 \\
281 \\
391 \\
182 \\
1.17 \\
1.34\end{array}$ & $\begin{array}{r}5578 \\
180 \\
228 \\
133 \\
.75 \\
.86\end{array}$ & $\begin{array}{r}4573 \\
163 \\
207 \\
131 \\
.68 \\
.71\end{array}$ & $\begin{array}{r}8136 \\
262 \\
440 \\
194 \\
1.09 \\
1.26\end{array}$ & $\begin{array}{r}6419 \\
214 \\
318 \\
139 \\
.89 \\
.99\end{array}$ & $\begin{array}{r}3336 \\
108 \\
157 \\
77 \\
.45 \\
.51\end{array}$ & $\begin{array}{r}2105 \\
70.2 \\
107 \\
53 \\
.29 \\
.32\end{array}$ & $\begin{array}{r}2291 \\
73.9 \\
102 \\
51 \\
.31 \\
.35\end{array}$ & $\begin{array}{r}2360 \\
76.1 \\
166 \\
48 \\
.32 \\
.36\end{array}$ & $\begin{array}{r}3561 \\
119 \\
185 \\
71 \\
.49 \\
.55\end{array}$ \\
\hline
\end{tabular}

$\begin{array}{lllllllllllll}\text { CAL YR } 1986 & \text { TOTAL } & 115562 & \text { MEAN } 317 & \text { MAX } & 1650 & \text { MIN } 81 & \text { CFSM } & 1.32 & \text { IN } 17.84\end{array}$

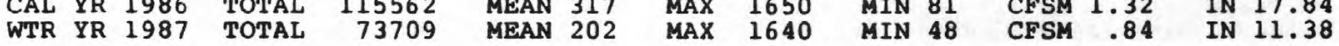


04105500 KALAMAZOO RIVER NEAR BATTLE CREEK, MI

LOCATION.--Lat $42^{\circ} 19^{\prime} 26^{\prime \prime}$, long $85^{\circ} 11^{\prime} 51^{\prime \prime}$, in SWl/4 sec.1, T.2 S., R.8 W., Calhoun County, Hydrologic Unit 04050003 , on left bank 20 ft upstream from bridge on Kendall Street in Battle Creek.

DRAINAGE AREA. $--824 \mathrm{mi}^{2}$.

PERIOD OF RECORD.--July 1937 to current year. Monthly discharge only for some periods, published in wSP 1307 .

REVISED RECORDS.--WSP 924: 1938-39. WSP 1387: 1938, 1945-46, 1948.

GAGE.--Water-stage recorder. Elevation of gage is $815 \mathrm{ft}$ above National Geodetic Vertical Datum of 1929 , from topographic map. Prior to Oct. 1, 1957, water-stage recorder at site $4.7 \mathrm{mi}$ downstream at

different datum. Oct. 1, 1957, to June 15, 1959, nonrecording gage at bridge 1,800 ft upstream at

different datum. June 16, 1959, to Oct. 13, 1960, nonrecording gage at same site and datum.

REMARKS.--Estimated daily discharges: Nov. 17, May 19, 20, and Sept. 29, 30. Records good. Diurnal fluctuation below $1,500 \mathrm{ft}^{3} / \mathrm{s}$ caused by powerplants upstream from station. Several measurements of water temperature were made during the year.

AVERAGE DISCHARGE. -50 years, $668 \mathrm{ft}^{3} / \mathrm{s}, 11.01 \mathrm{in} / \mathrm{yr}^{\circ}$

EXTREMES FOR PERIOD OF RECORD,--Maximum discharge, 7,290 ft $3 / \mathrm{s}$, Apr. 7, 1947, gage height, 9.13 ft, site and datum then in use; minimum, $50 \mathrm{ft} 3 / \mathrm{s}$, Sept. 22, 1939, site then in use; minimum daily, $86 \mathrm{ft}^{3} / \mathrm{s}$, Aug. 5,1964 .

EXTREMES FOR CURRENT YEAR.--Maximum daily discharge, 2,940 ft $3 / \mathrm{s}^{3}$ Oct. 5, 6; minimum discharge, $196 \mathrm{ft} / \mathrm{s}$, Aug. 14, gage height, $2.84 \mathrm{ft}$.

DISCHARGE，IN CUBIC FEET PER SECOND，WATER YEAR OCTOBER 1986 TO SEPTEMBER 1987

\begin{tabular}{|c|c|c|c|c|c|c|c|c|c|c|c|c|}
\hline DAY & OCT & NOV & DEC & JAN & FEB & MAR & APR & MAY & JUN & JUL & AUG & SEP \\
\hline $\begin{array}{l}1 \\
2 \\
3 \\
4 \\
5\end{array}$ & $\begin{array}{l}2090 \\
2280 \\
2550 \\
2810 \\
2940\end{array}$ & $\begin{array}{l}721 \\
712 \\
756 \\
714 \\
691\end{array}$ & $\begin{array}{l}933 \\
949 \\
979 \\
998 \\
965\end{array}$ & $\begin{array}{l}634 \\
596 \\
640 \\
648 \\
631\end{array}$ & $\begin{array}{l}677 \\
690 \\
697 \\
697 \\
668\end{array}$ & $\begin{array}{r}925 \\
1030 \\
1170 \\
1180 \\
1190\end{array}$ & $\begin{array}{l}684 \\
753 \\
774 \\
730 \\
747\end{array}$ & $\begin{array}{l}533 \\
518 \\
542 \\
574 \\
618\end{array}$ & $\begin{array}{l}492 \\
440 \\
389 \\
458 \\
425\end{array}$ & $\begin{array}{l}364 \\
358 \\
348 \\
348 \\
354\end{array}$ & $\begin{array}{l}343 \\
303 \\
284 \\
256 \\
254\end{array}$ & $\begin{array}{l}511 \\
469 \\
445 \\
411 \\
400\end{array}$ \\
\hline $\begin{array}{r}6 \\
7 \\
8 \\
9 \\
10\end{array}$ & $\begin{array}{l}2940 \\
2740 \\
2440 \\
2120 \\
1820\end{array}$ & $\begin{array}{l}684 \\
675 \\
661 \\
646 \\
659\end{array}$ & $\begin{array}{r}932 \\
942 \\
968 \\
1000 \\
1040\end{array}$ & $\begin{array}{l}622 \\
630 \\
650 \\
640 \\
642\end{array}$ & $\begin{array}{l}682 \\
675 \\
668 \\
622 \\
638\end{array}$ & $\begin{array}{r}1160 \\
1100 \\
1130 \\
975 \\
942\end{array}$ & $\begin{array}{l}713 \\
726 \\
735 \\
713 \\
644\end{array}$ & $\begin{array}{l}543 \\
487 \\
488 \\
483 \\
454\end{array}$ & $\begin{array}{l}409 \\
389 \\
379 \\
375 \\
357\end{array}$ & $\begin{array}{l}390 \\
417 \\
400 \\
400 \\
374\end{array}$ & $\begin{array}{l}285 \\
320 \\
221 \\
281 \\
318\end{array}$ & $\begin{array}{l}400 \\
384 \\
374 \\
365 \\
395\end{array}$ \\
\hline $\begin{array}{l}11 \\
12 \\
13 \\
14 \\
15\end{array}$ & $\begin{array}{l}1590 \\
1410 \\
1310 \\
1290 \\
1200\end{array}$ & $\begin{array}{l}642 \\
634 \\
622 \\
610 \\
600\end{array}$ & $\begin{array}{r}992 \\
1030 \\
984 \\
837 \\
808\end{array}$ & $\begin{array}{l}616 \\
625 \\
659 \\
650 \\
733\end{array}$ & $\begin{array}{l}647 \\
650 \\
637 \\
639 \\
582\end{array}$ & $\begin{array}{l}903 \\
814 \\
701 \\
794 \\
744\end{array}$ & $\begin{array}{l}660 \\
723 \\
681 \\
795 \\
811\end{array}$ & $\begin{array}{l}413 \\
438 \\
403 \\
388 \\
481\end{array}$ & $\begin{array}{l}363 \\
434 \\
324 \\
311 \\
316\end{array}$ & $\begin{array}{l}364 \\
384 \\
390 \\
364 \\
384\end{array}$ & $\begin{array}{l}358 \\
299 \\
242 \\
225 \\
301\end{array}$ & $\begin{array}{l}584 \\
516 \\
473 \\
452 \\
586\end{array}$ \\
\hline $\begin{array}{l}16 \\
17 \\
18 \\
19 \\
20\end{array}$ & $\begin{array}{r}1050 \\
1030 \\
855 \\
931 \\
901\end{array}$ & $\begin{array}{l}610 \\
614 \\
614 \\
603 \\
606\end{array}$ & $\begin{array}{l}845 \\
789 \\
753 \\
766 \\
767\end{array}$ & $\begin{array}{l}719 \\
752 \\
756 \\
661 \\
675\end{array}$ & $\begin{array}{l}470 \\
548 \\
483 \\
562 \\
548\end{array}$ & $\begin{array}{l}725 \\
722 \\
816 \\
733 \\
705\end{array}$ & $\begin{array}{l}855 \\
943 \\
884 \\
901 \\
839\end{array}$ & $\begin{array}{l}408 \\
401 \\
428 \\
460 \\
500\end{array}$ & $\begin{array}{l}315 \\
298 \\
316 \\
294 \\
287\end{array}$ & $\begin{array}{l}400 \\
384 \\
364 \\
364 \\
364\end{array}$ & $\begin{array}{l}316 \\
391 \\
411 \\
276 \\
326\end{array}$ & $\begin{array}{l}553 \\
611 \\
675 \\
562 \\
551\end{array}$ \\
\hline $\begin{array}{l}21 \\
22 \\
23 \\
24 \\
25\end{array}$ & $\begin{array}{l}873 \\
841 \\
809 \\
786 \\
761\end{array}$ & $\begin{array}{l}611 \\
622 \\
658 \\
698 \\
722\end{array}$ & $\begin{array}{l}750 \\
707 \\
671 \\
746 \\
649\end{array}$ & $\begin{array}{l}752 \\
747 \\
643 \\
602 \\
578\end{array}$ & $\begin{array}{l}523 \\
578 \\
532 \\
596 \\
628\end{array}$ & $\begin{array}{l}747 \\
749 \\
689 \\
727 \\
677\end{array}$ & $\begin{array}{l}856 \\
709 \\
752 \\
619 \\
611\end{array}$ & $\begin{array}{l}556 \\
463 \\
411 \\
434 \\
422\end{array}$ & $\begin{array}{l}349 \\
461 \\
435 \\
384 \\
353\end{array}$ & $\begin{array}{l}369 \\
400 \\
400 \\
324 \\
422\end{array}$ & $\begin{array}{l}279 \\
388 \\
443 \\
363 \\
361\end{array}$ & $\begin{array}{l}632 \\
582 \\
574 \\
516 \\
480\end{array}$ \\
\hline $\begin{array}{l}26 \\
27 \\
28 \\
29 \\
30 \\
31\end{array}$ & $\begin{array}{l}755 \\
743 \\
743 \\
741 \\
728 \\
744\end{array}$ & $\begin{array}{l}842 \\
946 \\
969 \\
972 \\
964 \\
----\end{array}$ & $\begin{array}{l}590 \\
660 \\
691 \\
628 \\
631 \\
676\end{array}$ & $\begin{array}{l}655 \\
640 \\
671 \\
667 \\
650 \\
659\end{array}$ & \begin{tabular}{l}
630 \\
608 \\
671 \\
\hdashline- \\
--- \\
-
\end{tabular} & $\begin{array}{l}687 \\
690 \\
674 \\
699 \\
662 \\
662\end{array}$ & $\begin{array}{l}591 \\
572 \\
550 \\
540 \\
478 \\
----\end{array}$ & $\begin{array}{l}390 \\
439 \\
395 \\
405 \\
380 \\
418\end{array}$ & $\begin{array}{l}319 \\
311 \\
305 \\
310 \\
352 \\
---\end{array}$ & $\begin{array}{l}411 \\
344 \\
301 \\
293 \\
291 \\
225\end{array}$ & $\begin{array}{r}522 \\
1080 \\
1060 \\
840 \\
791 \\
720\end{array}$ & $\begin{array}{l}437 \\
400 \\
404 \\
430 \\
470\end{array}$ \\
\hline $\begin{array}{l}\text { TOTAL } \\
\text { MEAN } \\
\text { MAX } \\
\text { MIN } \\
\text { CFSM } \\
\text { IN. }\end{array}$ & $\begin{array}{r}44821 \\
1446 \\
2940 \\
728 \\
1.76 \\
2.02\end{array}$ & $\begin{array}{r}21078 \\
703 \\
972 \\
600 \\
.85 \\
.95\end{array}$ & $\begin{array}{r}25676 \\
828 \\
1040 \\
590 \\
1.01 \\
1.16\end{array}$ & $\begin{array}{r}20443 \\
659 \\
756 \\
578 \\
.80 \\
.92\end{array}$ & $\begin{array}{r}17246 \\
616 \\
697 \\
470 \\
.75 \\
.78\end{array}$ & $\begin{array}{r}26122 \\
843 \\
1190 \\
662 \\
1.02 \\
1.18\end{array}$ & $\begin{array}{r}21589 \\
720 \\
943 \\
478 \\
.87 \\
.97\end{array}$ & $\begin{array}{r}14273 \\
460 \\
618 \\
380 \\
.56 \\
.64\end{array}$ & $\begin{array}{r}10950 \\
365 \\
492 \\
287 \\
.44 \\
.49\end{array}$ & $\begin{array}{r}11295 \\
364 \\
422 \\
225 \\
.44 \\
.51\end{array}$ & $\begin{array}{r}12857 \\
415 \\
1080 \\
221 \\
.50 \\
.58\end{array}$ & $\begin{array}{r}14642 \\
488 \\
675 \\
365 \\
.59 \\
.66\end{array}$ \\
\hline $\begin{array}{l}\text { CAL YR } \\
\text { WTR YR }\end{array}$ & $\begin{array}{l}1986 \\
1987\end{array}$ & $\begin{array}{ll}A L & 32 \\
A L & 24\end{array}$ & $\begin{array}{l}53 \\
92\end{array}$ & $\begin{array}{l}\text { N } 877 \\
\text { N } 660\end{array}$ & $\begin{array}{l}\text { MAX } \\
\text { MAX }\end{array}$ & $\begin{array}{l}\text { MIN } \\
\text { MIN }\end{array}$ & $\begin{array}{l}359 \\
221\end{array}$ & $\begin{array}{lr}\text { FSM } & 1.06 \\
\text { FSM } & .80\end{array}$ & $\begin{array}{l}\text { IN } \\
\text { IN }\end{array}$ & $\begin{array}{l}46 \\
88\end{array}$ & & \\
\hline
\end{tabular}


LOCATION.--Lat $42^{\circ} 21^{\prime} 12^{\prime \prime}$, long $85^{\circ} 21^{\prime} 14^{\prime \prime}$, in SWl/4 sec. 27 , T.1 S., R.9 W., Kalamazoo County, Hydrologic Unit 04050003 , on left bank $15 \mathrm{ft}$ downstream from bridge on EF Road, $1.3 \mathrm{mi}$ north of Augusta.

DRAINAGE AREA. $--38.9 \mathrm{mi}^{2}$.

\section{WATER-DISCHARGE RECORDS}

PERIOD OF RECORD.--October 1964 to current year.

GAGE.--Water-stage recorder. Elevation of gage is $815 \mathrm{ft}$ above National Geodetic Vertical Datum of 1929 , from topographic map. Prior to June 15, 1965, nonrecording gage at same site and datum.

REMARKS.--Estimated daily discharge: June 5. Water-discharge records good.

AVERAGE DISCHARGE. - -23 years, $44.1 \mathrm{ft}^{3} / \mathrm{s}, 15.40 \mathrm{in} / \mathrm{yr}^{\mathrm{r}}$.

EXTREMES FOR PERIOD OF RECORD.--Maximum discharge, $560 \mathrm{ft}^{3 / \mathrm{s}}$, June 27,1978 , gage height, $3.41 \mathrm{ft}$;

minimum, $8.9 \mathrm{ft}^{3} / \mathrm{s}$, Jan. 26,1978 , result of freezeup; minimum gage height, $0.65 \mathrm{ft}, \mathrm{Jan}$. 19 , i970.

EXTREMES FOR CURRENT YEAR.--Maximum discharge, $167 \mathrm{ft}^{3} / \mathrm{s}$, Oct. 3 , gage height, $2.65 \mathrm{ft}$; minimum,

$21 \mathrm{ft}^{3} / \mathrm{s}$, June 7,8 , Aug. 13, 14; minimum gage height, $0.82 \mathrm{ft}, \mathrm{June} 7,8$.

DISCHARGE, IN CUBIC FEET PER SECOND, WATER YEAR OCTOBER 1986 TO SEPTEMBER 1987 MEAN VALUES

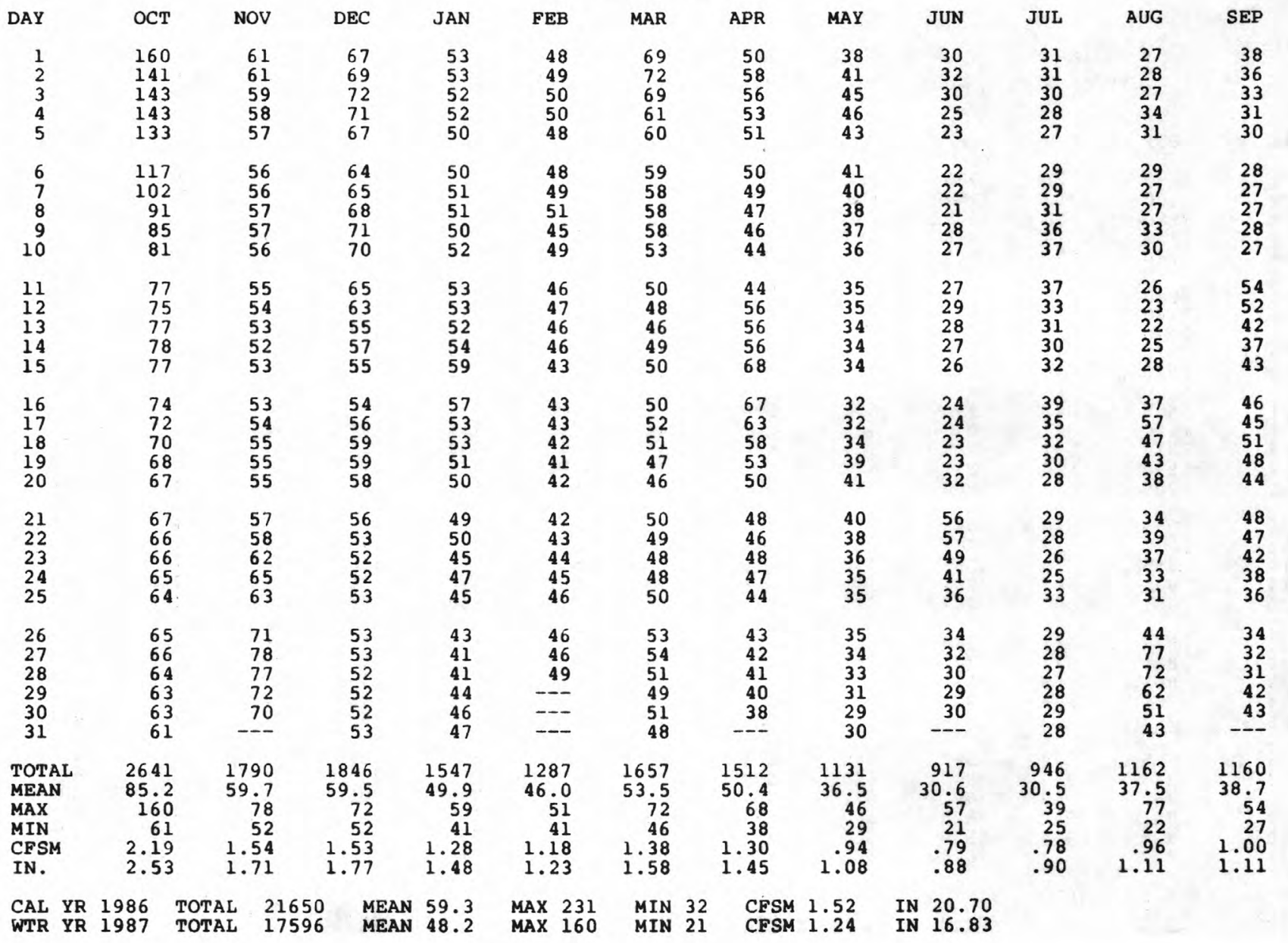


04105700 AUGUSTA CREEK NEAR AUGUSTA, MI--Continued

WATER-QUALITY RECORDS

PERIOD OF RECORD.--Water years 1965-66, 1986 to September 1987 (discontinued).

WATER QUALITY DATA, WATER YEAR OCTOBER 1986 TO SEPTEMBER 1987

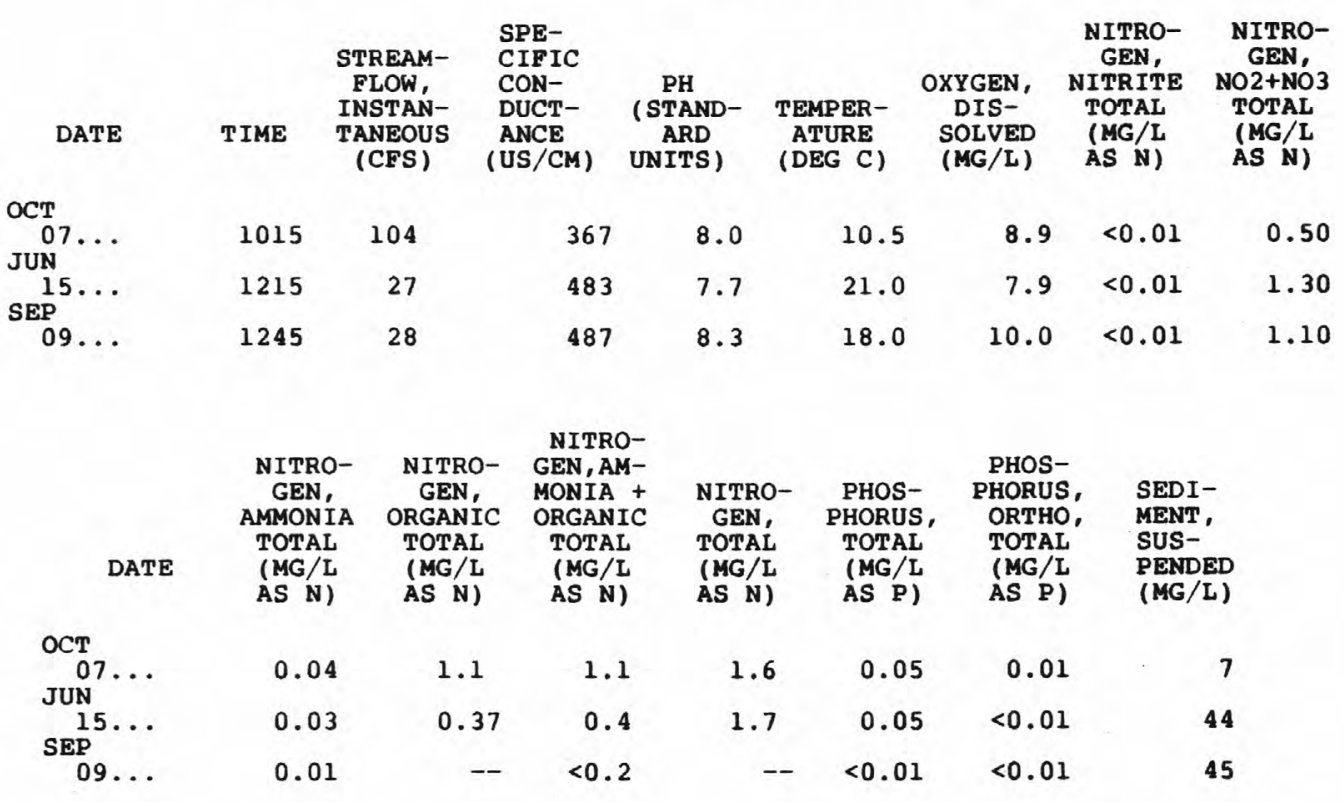




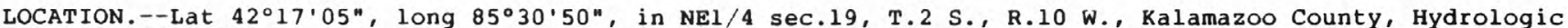
Unit 04050003 , on left bank at downstream side of bridge on River street in Comstock, 0.2 mi downstream from Comstock' Creek.

DRAINAGE AREA.--1,010 $\mathrm{mi}^{2}$, approximately.

\section{WATER-DISCHARGE RECORDS}

PERIOD OF RECORD.--April to August 1931, October 1932 to December 1979, October 1984 to current year. Monthly discharge only for some periods, published in WSP 1307 .

REVISED RECORDS.--WSP 824: 1933-36. WSP 1387: 1933, 1934(M), 1935, 1936(M), 1938(M), 1940(M), 1941.

GAGE.--Water-stage recorder. Datum of gage is 759.12 ft above National Geodetic Vertical Datum of 1929. Prior to November 1945, nonrecording gage at same site and datum.

REMARKS.--No estimated daily discharges. Water-discharge records good. Flow regulated by powerplants upstream from station. National Weather Service gage-height telemeter at station.

AVERAGE DISCHARGE. - -50 years (water years 1933-79, 1985-87), 861 $\mathrm{ft}^{3} / \mathrm{s}, 11.58 \mathrm{in} / \mathrm{y}^{\mathrm{r}}$.

EXTREMES FOR PERIOD OF RECORD.--Maximum discharge, 6,910 ft3/s, Apr. 8, 1947, gage height, 7.94 ft; minimum, $119 \mathrm{ft}^{3} / \mathrm{s}$, May 29, 1958; minimum gage height, $0.09 \mathrm{ft}$, May 29, 1958, May 23, 1987; minimum daily discharge, $185 \mathrm{ft}^{3} / \mathrm{s}$, Aug. 7, 1934 .

EXTREMES FOR CURRENT YEAR.--Maximum discharge, 3,780 $\mathrm{ft}^{3} / \mathrm{s}$, Oct. 6 , gage height, $5.20 \mathrm{ft}$; minimum, $129 \mathrm{ft}^{3} / \mathrm{s}$, May 23, gage height, $0.09 \mathrm{ft} ; \mathrm{minimum}$ daily, $413 \mathrm{ft} / \mathrm{s}$, Aug. 14 .

DISCHARGE, IN CUBIC FEET PER SECOND, WATER YEAR OCTOBER 1986 TO SEPTEMBER 1987

\begin{tabular}{|c|c|c|c|c|c|c|c|c|c|c|c|c|}
\hline DAY & OCT & NOV & DEC & JAN & FEB & MAR & APR & MAY & JUN & JUL & AUG & SEP \\
\hline $\begin{array}{l}1 \\
2 \\
3 \\
4 \\
5\end{array}$ & $\begin{array}{l}2720 \\
2650 \\
2870 \\
3200 \\
3430\end{array}$ & $\begin{array}{l}1110 \\
1080 \\
1100 \\
1100 \\
1080\end{array}$ & $\begin{array}{l}1350 \\
1330 \\
1350 \\
1380 \\
1390\end{array}$ & $\begin{array}{l}986 \\
986 \\
980 \\
978 \\
880\end{array}$ & $\begin{array}{l}971 \\
965 \\
962 \\
962 \\
962\end{array}$ & $\begin{array}{r}993 \\
1070 \\
1280 \\
1480 \\
1510\end{array}$ & $\begin{array}{r}984 \\
987 \\
996 \\
1010 \\
1000\end{array}$ & $\begin{array}{l}764 \\
771 \\
784 \\
798 \\
808\end{array}$ & $\begin{array}{l}515 \\
669 \\
693 \\
517 \\
628\end{array}$ & $\begin{array}{l}515 \\
509 \\
486 \\
517 \\
453\end{array}$ & $\begin{array}{l}440 \\
454 \\
582 \\
485 \\
451\end{array}$ & $\begin{array}{l}907 \\
762 \\
523 \\
681 \\
616\end{array}$ \\
\hline $\begin{array}{r}6 \\
7 \\
8 \\
9 \\
10\end{array}$ & $\begin{array}{l}3710 \\
3630 \\
3380 \\
3010 \\
2720\end{array}$ & $\begin{array}{l}1030 \\
1050 \\
1030 \\
1020 \\
1010\end{array}$ & $\begin{array}{l}1370 \\
1300 \\
1410 \\
1290 \\
1380\end{array}$ & $\begin{array}{l}890 \\
987 \\
985 \\
979 \\
980\end{array}$ & $\begin{array}{l}880 \\
744 \\
793 \\
938 \\
991\end{array}$ & $\begin{array}{l}1600 \\
1460 \\
1260 \\
1460 \\
1180\end{array}$ & $\begin{array}{r}1000 \\
989 \\
988 \\
983 \\
978\end{array}$ & $\begin{array}{l}864 \\
824 \\
777 \\
765 \\
742\end{array}$ & $\begin{array}{l}517 \\
519 \\
517 \\
517 \\
520\end{array}$ & $\begin{array}{l}487 \\
515 \\
517 \\
583 \\
616\end{array}$ & $\begin{array}{l}454 \\
431 \\
497 \\
495 \\
462\end{array}$ & $\begin{array}{l}524 \\
612 \\
478 \\
514 \\
738\end{array}$ \\
\hline $\begin{array}{l}11 \\
12 \\
13 \\
14 \\
15\end{array}$ & $\begin{array}{l}2470 \\
2010 \\
1710 \\
1920 \\
1800\end{array}$ & $\begin{array}{r}974 \\
881 \\
1010 \\
966 \\
870\end{array}$ & $\begin{array}{l}1460 \\
1450 \\
1390 \\
1290 \\
1210\end{array}$ & $\begin{array}{l}978 \\
913 \\
834 \\
986 \\
987\end{array}$ & $\begin{array}{l}974 \\
970 \\
964 \\
962 \\
843\end{array}$ & $\begin{array}{r}1210 \\
1180 \\
1040 \\
984 \\
1000\end{array}$ & $\begin{array}{r}867 \\
900 \\
999 \\
1000 \\
1040\end{array}$ & $\begin{array}{l}754 \\
653 \\
526 \\
675 \\
732\end{array}$ & $\begin{array}{l}518 \\
517 \\
605 \\
519 \\
493\end{array}$ & $\begin{array}{l}524 \\
500 \\
491 \\
524 \\
529\end{array}$ & $\begin{array}{l}500 \\
495 \\
489 \\
413 \\
470\end{array}$ & $\begin{array}{l}763 \\
762 \\
758 \\
683 \\
748\end{array}$ \\
\hline $\begin{array}{l}16 \\
17 \\
18 \\
19 \\
20\end{array}$ & $\begin{array}{l}1670 \\
1450 \\
1360 \\
1290 \\
1660\end{array}$ & $\begin{array}{r}780 \\
925 \\
1010 \\
997 \\
933\end{array}$ & $\begin{array}{l}1170 \\
1190 \\
1190 \\
1170 \\
1150\end{array}$ & $\begin{array}{r}998 \\
1010 \\
1020 \\
1030 \\
1010\end{array}$ & $\begin{array}{l}740 \\
742 \\
749 \\
753 \\
882\end{array}$ & $\begin{array}{r}997 \\
1010 \\
1000 \\
1000 \\
994\end{array}$ & $\begin{array}{l}1190 \\
1180 \\
1100 \\
1250 \\
1150\end{array}$ & $\begin{array}{l}614 \\
634 \\
659 \\
688 \\
675\end{array}$ & $\begin{array}{l}424 \\
512 \\
456 \\
474 \\
456\end{array}$ & $\begin{array}{l}553 \\
530 \\
526 \\
460 \\
495\end{array}$ & $\begin{array}{l}453 \\
684 \\
662 \\
514 \\
531\end{array}$ & $\begin{array}{l}912 \\
845 \\
827 \\
917 \\
917\end{array}$ \\
\hline $\begin{array}{l}21 \\
22 \\
23 \\
24 \\
25\end{array}$ & $\begin{array}{l}1290 \\
1180 \\
1260 \\
1270 \\
1240\end{array}$ & $\begin{array}{r}893 \\
1000 \\
998 \\
1010 \\
1030\end{array}$ & $\begin{array}{l}1140 \\
1080 \\
1080 \\
1040 \\
1060\end{array}$ & $\begin{array}{l}991 \\
995 \\
995 \\
902 \\
584\end{array}$ & $\begin{array}{l}959 \\
841 \\
734 \\
738 \\
742\end{array}$ & $\begin{array}{l}986 \\
986 \\
987 \\
951 \\
979\end{array}$ & $\begin{array}{r}1060 \\
1160 \\
951 \\
953 \\
909\end{array}$ & $\begin{array}{l}757 \\
737 \\
713 \\
737 \\
678\end{array}$ & $\begin{array}{l}574 \\
7.58 \\
714 \\
637 \\
578\end{array}$ & $\begin{array}{l}503 \\
472 \\
490 \\
522 \\
521\end{array}$ & $\begin{array}{l}525 \\
528 \\
626 \\
531 \\
530\end{array}$ & $\begin{array}{l}811 \\
956 \\
915 \\
762 \\
762\end{array}$ \\
\hline $\begin{array}{l}26 \\
27 \\
28 \\
29 \\
30 \\
31\end{array}$ & $\begin{array}{l}1160 \\
1030 \\
1140 \\
1210 \\
1130 \\
1120\end{array}$ & $\begin{array}{l}1060 \\
1150 \\
1370 \\
1440 \\
1390 \\
---\end{array}$ & $\begin{array}{r}1030 \\
1010 \\
1000 \\
1000 \\
997 \\
986\end{array}$ & $\begin{array}{r}530 \\
651 \\
908 \\
1060 \\
1010 \\
984\end{array}$ & $\begin{array}{l}750 \\
895 \\
974 \\
--- \\
--- \\
---\end{array}$ & $\begin{array}{l}973 \\
978 \\
978 \\
978 \\
880 \\
877\end{array}$ & $\begin{array}{l}813 \\
838 \\
795 \\
765 \\
774 \\
-\end{array}$ & $\begin{array}{l}604 \\
595 \\
650 \\
589 \\
511 \\
609\end{array}$ & $\begin{array}{l}471 \\
482 \\
493 \\
425 \\
489 \\
---\end{array}$ & $\begin{array}{l}517 \\
517 \\
492 \\
497 \\
525 \\
543\end{array}$ & $\begin{array}{r}692 \\
1030 \\
1260 \\
1170 \\
1090 \\
917\end{array}$ & $\begin{array}{l}624 \\
681 \\
705 \\
657 \\
742 \\
--\end{array}$ \\
\hline $\begin{array}{l}\text { TOTAL } \\
\text { MEAN } \\
\text { MAX } \\
\text { MIN } \\
\text { CFSM } \\
\text { IN. }\end{array}$ & $\begin{array}{r}61690 \\
1990 \\
3710 \\
1030 \\
1.97 \\
2.27\end{array}$ & $\begin{array}{r}31297 \\
1043 \\
1440 \\
780 \\
1.03 \\
1.15\end{array}$ & $\begin{array}{r}37643 \\
1214 \\
1460 \\
986 \\
1.20 \\
1.39\end{array}$ & $\begin{array}{r}29007 \\
936 \\
1060 \\
530 \\
.93 \\
1.07\end{array}$ & $\begin{array}{r}24380 \\
871 \\
991 \\
734 \\
.86 \\
.90\end{array}$ & $\begin{array}{r}34261 \\
1105 \\
1600 \\
877 \\
1.09 \\
1.26\end{array}$ & $\begin{array}{r}29609 \\
987 \\
1250 \\
765 \\
.98 \\
1.09\end{array}$ & $\begin{array}{r}21687 \\
700 \\
864 \\
511 \\
.69 \\
.80\end{array}$ & $\begin{array}{r}16207 \\
540 \\
758 \\
424 \\
.54 \\
.60\end{array}$ & $\begin{array}{r}15929 \\
514 \\
616 \\
453 \\
.51 \\
.59\end{array}$ & $\begin{array}{r}18861 \\
608 \\
1260 \\
413 \\
.60 \\
.69\end{array}$ & $\begin{array}{r}22102 \\
737 \\
956 \\
478 \\
.73 \\
.81\end{array}$ \\
\hline
\end{tabular}

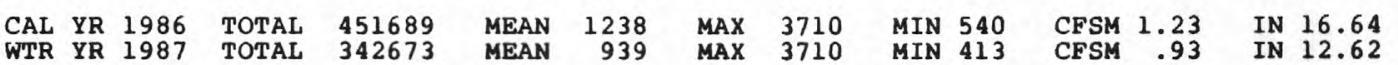


PERIOD OF RECORD.--Water years 1965-66, 1969-75, 1986 to September 1987 (discontinued).

PERIOD OF DAILY RECORD.--

WATER TEMPERATURE: December 1968 to September 1975.

EXTREMES FOR PERIOD OF DAILY RECORD.--

WATER TEMPERATURE: (water years 1969, 1972-73, 1975): Maximum, 33.0 $0^{\circ} \mathrm{C}$ July 30,31, Aug. 1, 1975; minimum, $0.0^{\circ} \mathrm{C}$ on many days during winter.

\section{WATER QUALITY DATA, WATER YEAR OCTOBER 1986 TO SEPTEMBER 1987}

\begin{tabular}{|c|c|c|c|c|c|c|c|c|c|c|}
\hline DATE & TIME & $\begin{array}{c}\text { STREAM- } \\
\text { FLOW, } \\
\text { INSTAN- } \\
\text { TANEOUS } \\
\text { (CFS) }\end{array}$ & $\begin{array}{l}\text { SPE- } \\
\text { CIFIC } \\
\text { CON- } \\
\text { DUCT- } \\
\text { ANCE } \\
\text { (US/CM) }\end{array}$ & $\begin{array}{c}\text { PH } \\
\text { ( STAND- } \\
\text { ARD } \\
\text { UNITS) }\end{array}$ & $\begin{array}{l}\text { TEMPER- } \\
\text { ATURE } \\
\text { (DEG C) }\end{array}$ & $\begin{array}{c}\text { OXYGEN, } \\
\text { DIS- } \\
\text { SOLVED } \\
\text { (MG/L) }\end{array}$ & $\begin{array}{c}\text { NITRO- } \\
\text { GEN, } \\
\text { NITRITE } \\
\text { TOTAL } \\
\text { (MG/L } \\
\text { AS N) }\end{array}$ & $\begin{array}{c}\text { NITRO- } \\
\text { GEN, } \\
\text { NO2+NO3 } \\
\text { TOTAL } \\
\text { (MG/L } \\
\text { AS N) }\end{array}$ & $\begin{array}{l}\text { NITRO- } \\
\text { GEN, } \\
\text { AMMONIA } \\
\text { TOTAL } \\
\text { (MG/L } \\
\text { AS N) }\end{array}$ & $\begin{array}{c}\text { NITRO- } \\
\text { GEN, } \\
\text { ORGANIC } \\
\text { TOTAL } \\
\text { (MG/L } \\
\text { AS N) }\end{array}$ \\
\hline $\begin{array}{l}\text { OCT } \\
\text { O9.... } \\
\text { JUN }\end{array}$ & 1000 & 3100 & 441 & 8.2 & 13.5 & 9.8 & 0.01 & 0.70 & 0.05 & 1.2 \\
\hline $17 \ldots$ & 1000 & 580 & 561 & 8.2 & 27.0 & 11.7 & 0.02 & 0.30 & 0.03 & 0.57 \\
\hline $11 \ldots$ & 0945 & 762 & 551 & 8.2 & 22.0 & 10.6 & 0.04 & 0.60 & 0.02 & 0.58 \\
\hline
\end{tabular}

\begin{tabular}{|c|c|c|c|c|c|c|c|c|c|c|}
\hline DATE & $\begin{array}{l}\text { NITRO- } \\
\text { GEN, AM- } \\
\text { MONIA + } \\
\text { ORGANIC } \\
\text { TOTAL } \\
\text { (MG/L } \\
\text { AS N) }\end{array}$ & $\begin{array}{l}\text { NITRO- } \\
\text { GEN, } \\
\text { TOTAL } \\
\text { (MG/L } \\
\text { AS N) }\end{array}$ & $\begin{array}{c}\text { PHOS- } \\
\text { PHORUS, } \\
\text { TOTAL } \\
\text { (MG/L } \\
\text { AS P) }\end{array}$ & $\begin{array}{c}\text { PHOS- } \\
\text { PHORUS, } \\
\text { ORTHO, } \\
\text { TOTAL } \\
\text { (MG/L } \\
\text { AS P) }\end{array}$ & $\begin{array}{l}\text { PHENOLS } \\
\text { TOTAL } \\
\text { (UG/L) }\end{array}$ & $\begin{array}{c}\text { ALA- } \\
\text { CHLOR } \\
\text { TOTAL } \\
\text { RECOVER } \\
\text { (UG/L) }\end{array}$ & $\begin{array}{l}\text { AME- } \\
\text { TRYNE } \\
\text { TOTAL }\end{array}$ & $\begin{array}{l}\text { ATRA- } \\
\text { ZINE, } \\
\text { TOTAL } \\
\text { (UG/L) }\end{array}$ & $\begin{array}{l}\text { CYAN- } \\
\text { AZ INE } \\
\text { TOTAL } \\
\text { (UG/L) }\end{array}$ & $\begin{array}{c}\text { DI- } \\
\text { AZINON, } \\
\text { TOTAL } \\
\text { (UG/L) }\end{array}$ \\
\hline $9 \ldots$ & 1.2 & 1.9 & 0.07 & 0.03 & -- & -- & -- & -- & -- & - \\
\hline $7 \ldots$ & 0.6 & 0.9 & 0.08 & $<0.01$ & 5 & $<0.1$ & $<0.1$ & 0.2 & $<0.1$ & 0.02 \\
\hline$\cdots$ & 0.6 & 1.2 & $<0.01$ & $<0.01$ & -- & -- & -- & -- & -- & - \\
\hline DATE & $\begin{array}{l}\text { ETHION, } \\
\text { TOTAL } \\
\text { (UG/L) }\end{array}$ & $\begin{array}{l}\text { MALA- } \\
\text { THION, } \\
\text { TOTAL } \\
\text { (UG/L) }\end{array}$ & $\begin{array}{l}\text { METHYL } \\
\text { PARA- } \\
\text { THION, } \\
\text { TOTAL } \\
\text { (UG/L) }\end{array}$ & $\begin{array}{l}\text { METHYL } \\
\text { TRI- } \\
\text { THION, } \\
\text { TOTAL } \\
\text { (UG/L) }\end{array}$ & $\begin{array}{l}\text { METOLA- } \\
\text { CHLOR } \\
\text { WATER } \\
\text { WHOLE } \\
\text { TOT.REC } \\
\text { (UG/L) }\end{array}$ & $\begin{array}{l}\text { METRI- } \\
\text { BUZIN } \\
\text { WATER } \\
\text { WHOLE } \\
\text { TOT.REC } \\
(\text { UG/L) }\end{array}$ & $\begin{array}{l}\text { PARA- } \\
\text { THION, } \\
\text { TOTAL } \\
\text { (UG/L) }\end{array}$ & $\begin{array}{l}\text { PROME- } \\
\text { TONE } \\
\text { TOTAL } \\
\text { (UG/L) }\end{array}$ & $\begin{array}{l}\text { PROME- } \\
\text { TRYNE } \\
\text { TOTAL } \\
\text { (UG/L) }\end{array}$ & $\begin{array}{l}\text { PRO- } \\
\text { PAZ INE } \\
\text { TOTAL } \\
\text { (UG/L) }\end{array}$ \\
\hline $9 \ldots$ & -- & -- & -- & -- & -- & -- & -- & -- & -- & -- \\
\hline $7 \ldots$ & $<0.01$ & $<0.01$ & $<0.01$ & $<0.01$ & $<0.1$ & $<0.1$ & $<0.01$ & $<0.1$ & $<0.1$ & $<0.1$ \\
\hline$\ldots$ & -- & -- & -- & -- & -- & -- & -- & -- & -- & - \\
\hline
\end{tabular}

\begin{tabular}{|c|c|c|c|c|c|c|c|c|c|}
\hline DATE & $\begin{array}{l}\text { SIME- } \\
\text { TRYNE } \\
\text { TOTAL } \\
\text { (UG/L) }\end{array}$ & $\begin{array}{l}\text { SIMA- } \\
\text { ZINE } \\
\text { TOTAL } \\
\text { (UG/L) }\end{array}$ & $\begin{array}{l}\text { TRI- } \\
\text { FLURA- } \\
\text { LIN } \\
\text { TOTAL } \\
\text { RECOVER } \\
\text { (UG/L) }\end{array}$ & $\begin{array}{l}\text { TOTAL } \\
\text { TRI- } \\
\text { THION } \\
\text { (UG/L) }\end{array}$ & $\begin{array}{l}2,4-D, \\
\text { TOTAL } \\
\text { (UG/L) }\end{array}$ & $\begin{array}{l}2, \quad 4-D P \\
\text { TOTAL } \\
\text { (UG/L) }\end{array}$ & $\begin{array}{c}2,4,5-T \\
\text { TOTAL } \\
\text { (UG/L) }\end{array}$ & $\begin{array}{l}\text { SILVEX, } \\
\text { TOTAL, } \\
\text { (UG/L) }\end{array}$ & $\begin{array}{l}\text { SEDI- } \\
\text { MENT, } \\
\text { SUS- } \\
\text { PENDED } \\
(M G / L)\end{array}$ \\
\hline 9. & -- & -- & -- & -- & -- & -- & -- & -- & 7 \\
\hline $7 \ldots$ & $<0.1$ & 0.1 & $<0.1$ & $<0.01$ & 0.04 & $<0.01$ & $<0.01$ & $<0.01$ & 11 \\
\hline$\ldots$ & -- & -- & -- & -- & -- & -- & -- & -- & $\begin{array}{l}39 \\
\end{array}$ \\
\hline
\end{tabular}


LOCATION.--Lat $42^{\circ} 12^{\prime} 21^{\prime \prime}$, long $85^{\circ} 35^{\prime} 23^{\prime \prime}$, in SEl/4 sec.16, T.3 S., R.11 W., Kalamazoo County, Hydrologic Unit 04050003, on right bank $750 \mathrm{ft}$ upstream from bridge on Westnedge Avenue in Portage.

DRAINAGE AREA. $--16.5 \mathrm{mi}^{2}$.

WATER-DISCHARGE RECORDS

PERIOD OF RECORD.--October 1982 to current year.

GAGE.--Water-stage recorder. Elevation of gage is $850 \mathrm{ft}$ above National Geodetic Vertical Datum of 1929 , from topographic map.

REMARKS.--No estimated daily discharges. Water-discharge records good.

AVERAGE DISCHARGE. --5 years, $18.8 \mathrm{ft}^{3} / \mathrm{s}, 15.47 \mathrm{in} / \mathrm{yr}^{\mathrm{r}}$.

EXTREMES FOR PERIOD OF RECORD.--Maximum discharge, $63 \mathrm{ft}^{3} / \mathrm{s}$, July 16,1986 , gage height, $3.41 \mathrm{ft}$; maximum gage height, $3.52 \mathrm{ft}$, Oct. 19,$1985 ;$ minimum discharge, $11 \mathrm{ft} / \mathrm{s}, \mathrm{Aug}$. 26 , $1984 ; \mathrm{minimum}$ gage height, $1.79 \mathrm{ft}$, June $8,9,10,16,17,18,19,1987$.

EXTREMES FOR CURRENT YEAR.--Maximum discharge, $58 \mathrm{ft}^{3} / \mathrm{s}$, Oct. 3 , gage height, $3.29 \mathrm{ft}$; maximum gage height, $3.35 \mathrm{ft}$, Aug. 26; minimum daily discharge, $12 \mathrm{ft}^{3} / \mathrm{s}$, July 12 ; minimum gage height,

$1.79 \mathrm{ft}$, June $8,9,10,16,17,18,19$.

DISCHARGE, IN CUBIC FEET PER SECOND, WATER YEAR OCTOBER 1986 TO SEPTEMBER 1987 MEAN VALUES

\begin{tabular}{|c|c|c|c|c|c|c|c|c|c|c|c|c|}
\hline DAY & OCT & NOV & DEC & JAN & FEB & MAR & APR & MAY & JUN & JUL & AUG & SEP \\
\hline $\begin{array}{l}1 \\
2 \\
3 \\
4 \\
5\end{array}$ & $\begin{array}{l}35 \\
30 \\
43 \\
42 \\
32\end{array}$ & $\begin{array}{l}20 \\
21 \\
20 \\
20 \\
20\end{array}$ & $\begin{array}{l}20 \\
22 \\
23 \\
21 \\
21\end{array}$ & $\begin{array}{l}18 \\
18 \\
18 \\
18 \\
18\end{array}$ & $\begin{array}{l}16 \\
17 \\
17 \\
17 \\
16\end{array}$ & $\begin{array}{l}29 \\
27 \\
23 \\
21 \\
21\end{array}$ & $\begin{array}{l}18 \\
20 \\
19 \\
19 \\
18\end{array}$ & $\begin{array}{l}16 \\
19 \\
19 \\
19 \\
18\end{array}$ & $\begin{array}{l}15 \\
15 \\
15 \\
14 \\
14\end{array}$ & $\begin{array}{l}14 \\
14 \\
14 \\
13 \\
13\end{array}$ & $\begin{array}{l}15 \\
15 \\
14 \\
15 \\
14\end{array}$ & $\begin{array}{l}16 \\
15 \\
15 \\
14 \\
14\end{array}$ \\
\hline $\begin{array}{r}6 \\
7 \\
8 \\
9 \\
10\end{array}$ & $\begin{array}{l}27 \\
25 \\
24 \\
23 \\
22\end{array}$ & $\begin{array}{l}20 \\
20 \\
20 \\
20 \\
20\end{array}$ & $\begin{array}{l}20 \\
21 \\
22 \\
23 \\
22\end{array}$ & $\begin{array}{l}18 \\
18 \\
17 \\
17 \\
18\end{array}$ & $\begin{array}{l}16 \\
16 \\
17 \\
17 \\
16\end{array}$ & $\begin{array}{l}21 \\
20 \\
20 \\
19 \\
19\end{array}$ & $\begin{array}{l}18 \\
17 \\
17 \\
17 \\
17\end{array}$ & $\begin{array}{l}17 \\
16 \\
16 \\
16 \\
16\end{array}$ & $\begin{array}{l}14 \\
14 \\
13 \\
13 \\
13\end{array}$ & $\begin{array}{l}14 \\
13 \\
13 \\
14 \\
13\end{array}$ & $\begin{array}{l}14 \\
13 \\
14 \\
17 \\
15\end{array}$ & $\begin{array}{l}14 \\
13 \\
14 \\
14 \\
13\end{array}$ \\
\hline $\begin{array}{l}11 \\
12 \\
13 \\
14 \\
15\end{array}$ & $\begin{array}{l}22 \\
23 \\
23 \\
24 \\
23\end{array}$ & $\begin{array}{l}19 \\
19 \\
19 \\
19 \\
19\end{array}$ & $\begin{array}{l}20 \\
20 \\
19 \\
19 \\
19\end{array}$ & $\begin{array}{l}18 \\
18 \\
18 \\
18 \\
19\end{array}$ & $\begin{array}{l}16 \\
16 \\
16 \\
16 \\
16\end{array}$ & $\begin{array}{l}18 \\
18 \\
18 \\
19 \\
19\end{array}$ & $\begin{array}{l}17 \\
19 \\
18 \\
20 \\
29\end{array}$ & $\begin{array}{l}16 \\
15 \\
15 \\
17 \\
17\end{array}$ & $\begin{array}{l}13 \\
14 \\
14 \\
14 \\
13\end{array}$ & $\begin{array}{l}13 \\
12 \\
13 \\
13 \\
15\end{array}$ & $\begin{array}{l}15 \\
14 \\
14 \\
14 \\
14\end{array}$ & $\begin{array}{l}18 \\
15 \\
14 \\
14 \\
15\end{array}$ \\
\hline $\begin{array}{l}16 \\
17 \\
18 \\
19 \\
20\end{array}$ & $\begin{array}{l}22 \\
22 \\
21 \\
21 \\
21\end{array}$ & $\begin{array}{l}20 \\
19 \\
19 \\
19 \\
19\end{array}$ & $\begin{array}{l}19 \\
19 \\
20 \\
19 \\
19\end{array}$ & $\begin{array}{l}18 \\
17 \\
18 \\
17 \\
17\end{array}$ & $\begin{array}{l}16 \\
16 \\
16 \\
15 \\
15\end{array}$ & $\begin{array}{l}19 \\
19 \\
19 \\
20 \\
19\end{array}$ & $\begin{array}{l}25 \\
21 \\
19 \\
19 \\
18\end{array}$ & $\begin{array}{l}16 \\
15 \\
18 \\
20 \\
18\end{array}$ & $\begin{array}{l}13 \\
13 \\
13 \\
13 \\
16\end{array}$ & $\begin{array}{l}16 \\
14 \\
14 \\
13 \\
13\end{array}$ & $\begin{array}{l}16 \\
18 \\
16 \\
15 \\
14\end{array}$ & $\begin{array}{l}15 \\
18 \\
21 \\
18 \\
16\end{array}$ \\
\hline $\begin{array}{l}21 \\
22 \\
23 \\
24 \\
25\end{array}$ & $\begin{array}{l}21 \\
20 \\
20 \\
20 \\
20\end{array}$ & $\begin{array}{l}20 \\
20 \\
22 \\
22 \\
21\end{array}$ & $\begin{array}{l}18 \\
18 \\
18 \\
18 \\
18\end{array}$ & $\begin{array}{l}17 \\
17 \\
17 \\
17 \\
17\end{array}$ & $\begin{array}{l}16 \\
16 \\
16 \\
16 \\
16\end{array}$ & $\begin{array}{l}19 \\
18 \\
18 \\
18 \\
18\end{array}$ & $\begin{array}{l}17 \\
17 \\
19 \\
18 \\
17\end{array}$ & $\begin{array}{l}17 \\
16 \\
16 \\
16 \\
15\end{array}$ & $\begin{array}{l}16 \\
14 \\
14 \\
14 \\
14\end{array}$ & $\begin{array}{l}14 \\
13 \\
13 \\
13 \\
23\end{array}$ & $\begin{array}{l}14 \\
14 \\
14 \\
13 \\
13\end{array}$ & $\begin{array}{l}22 \\
24 \\
19 \\
17 \\
16\end{array}$ \\
\hline $\begin{array}{l}26 \\
27 \\
28 \\
29 \\
30 \\
31\end{array}$ & $\begin{array}{l}21 \\
22 \\
21 \\
21 \\
20 \\
20\end{array}$ & $\begin{array}{r}26 \\
26 \\
23 \\
22 \\
21 \\
-\end{array}$ & $\begin{array}{l}18 \\
18 \\
18 \\
18 \\
18 \\
18\end{array}$ & $\begin{array}{l}18 \\
16 \\
16 \\
16 \\
17 \\
16\end{array}$ & $\begin{array}{r}16 \\
16 \\
18 \\
--- \\
--- \\
---\end{array}$ & $\begin{array}{l}19 \\
19 \\
18 \\
18 \\
18 \\
18\end{array}$ & $\begin{array}{l}17 \\
17 \\
17 \\
16 \\
16 \\
---\end{array}$ & $\begin{array}{l}15 \\
15 \\
14 \\
14 \\
14 \\
14\end{array}$ & $\begin{array}{r}14 \\
13 \\
13 \\
13 \\
14 \\
---\end{array}$ & $\begin{array}{l}18 \\
16 \\
15 \\
16 \\
16 \\
15\end{array}$ & $\begin{array}{l}24 \\
38 \\
25 \\
19 \\
17 \\
17\end{array}$ & $\begin{array}{l}15 \\
15 \\
15 \\
19 \\
18 \\
-\end{array}$ \\
\hline $\begin{array}{l}\text { TOTAL } \\
\text { MEAN } \\
\text { MAX } \\
\text { MIN } \\
\text { CESM } \\
\text { IN. }\end{array}$ & $\begin{array}{r}751 \\
24.2 \\
43 \\
20 \\
1.47 \\
1.69\end{array}$ & $\begin{array}{r}615 \\
20.5 \\
26 \\
19 \\
1.24 \\
1.39\end{array}$ & $\begin{array}{r}606 \\
19.5 \\
23 \\
18 \\
1.18 \\
1.37\end{array}$ & $\begin{array}{r}540 \\
17.4 \\
19 \\
16 \\
1.06 \\
1.22\end{array}$ & $\begin{array}{r}453 \\
16.2 \\
18 \\
15 \\
.98 \\
1.02\end{array}$ & $\begin{array}{r}609 \\
19.6 \\
29 \\
18 \\
1.19 \\
1.37\end{array}$ & $\begin{array}{r}556 \\
18.5 \\
29 \\
16 \\
1.12 \\
1.25\end{array}$ & $\begin{array}{r}505 \\
16.3 \\
20 \\
14 \\
.99 \\
1.14\end{array}$ & $\begin{array}{r}415 \\
13.8 \\
16 \\
13 \\
.84 \\
.94\end{array}$ & $\begin{array}{r}443 \\
14.3 \\
23 \\
12 \\
.87 \\
1.00\end{array}$ & $\begin{array}{r}504 \\
16.3 \\
38 \\
13 \\
.99 \\
1.14\end{array}$ & $\begin{array}{r}486 \\
16.2 \\
24 \\
13 \\
.98 \\
1.10\end{array}$ \\
\hline
\end{tabular}

$\begin{array}{lllllllllll}\text { CAL YR } 1986 & \text { TOTAL } & 7323 & \text { MEAN } 20.1 & \text { MAX } 51 & \text { MIN } 12 & \text { CFSM } 1.22 & \text { IN } 16.51\end{array}$ 
04106180 PORTAGE CREEK AT PORTAGE, MI--Continued

WATER-QUALITY RECORDS

PERIOD OF RECORD.--Water years 1964-66, 1986 to September 1987 (discontinued).

WATER QUALITY DATA, WATER YEAR OCTOBER 1986 TO SEPTEMBER 1987

\begin{tabular}{|c|c|c|c|c|c|c|c|c|c|c|}
\hline DATE & TIME & $\begin{array}{l}\text { STREAM- } \\
\text { FLOW, } \\
\text { INSTAN- } \\
\text { TANEOUS } \\
\text { (CFS) }\end{array}$ & $\begin{array}{l}\text { SPE- } \\
\text { CIFIC } \\
\text { CON- } \\
\text { DUCT- } \\
\text { ANCE } \\
\text { (US/CM) }\end{array}$ & $\begin{array}{c}\text { PH } \\
\text { (STAND- } \\
\text { ARD } \\
\text { UNITS) }\end{array}$ & $\begin{array}{l}\text { TEMPER- } \\
\text { ATURE } \\
\text { (DEG C) }\end{array}$ & $\begin{array}{c}\text { OXYGEN, } \\
\text { DIS- } \\
\text { SOLVED } \\
\text { (MG/L) }\end{array}$ & $\begin{array}{l}\text { NITRO- } \\
\text { GEN, } \\
\text { NITRITE } \\
\text { TOTAL } \\
\text { (MG /L } \\
\text { AS N) }\end{array}$ & $\begin{array}{c}\text { NITRO- } \\
\text { GEN, } \\
\text { NO2+NO3 } \\
\text { TOTAL } \\
\text { (MG/L } \\
\text { AS N) }\end{array}$ & $\begin{array}{l}\text { NITRO- } \\
\text { GEN, } \\
\text { AMMONIA } \\
\text { TOTAL } \\
\text { (MG/L } \\
\text { AS N) }\end{array}$ & $\begin{array}{c}\text { NITRO- } \\
\text { GEN, } \\
\text { ORGANIC } \\
\text { TOTAL } \\
\text { (MG/L } \\
\text { AS N) }\end{array}$ \\
\hline$C T$ & & & & & & & & & & \\
\hline$\underset{\mathrm{IN}}{07 \ldots}$ & 1315 & 25 & 421 & 7.9 & 12.0 & 8.2 & 0.02 & 0.80 & 0.14 & 0.86 \\
\hline $16 \ldots$ & 0830 & 13 & 437 & 7.8 & 15.0 & 8.2 & 0.02 & 0.80 & 0.10 & 1.1 \\
\hline $09 .$. & 1630 & 14 & 437 & 7.9 & 18.0 & 9.0 & 0.02 & 0.90 & 0.08 & -- \\
\hline
\end{tabular}

\begin{tabular}{|c|c|c|c|c|c|c|c|c|c|c|}
\hline DATE & $\begin{array}{l}\text { NITRO- } \\
\text { GEN, AM- } \\
\text { MONIA + } \\
\text { ORGANIC } \\
\text { TOTAL } \\
\text { (MG/L } \\
\text { AS N) }\end{array}$ & $\begin{array}{l}\text { NITRO- } \\
\text { GEN, } \\
\text { TOTAL } \\
\text { (MG/L } \\
\text { AS N) }\end{array}$ & $\begin{array}{c}\text { PHOS- } \\
\text { PHORUS, } \\
\text { TOTAL } \\
\text { (MG/L } \\
\text { AS P) }\end{array}$ & $\begin{array}{c}\text { PHOS- } \\
\text { PHORUS, } \\
\text { ORTHO, } \\
\text { TOTAL } \\
\text { (MG/L } \\
\text { AS P) }\end{array}$ & $\begin{array}{l}\text { PHENOLS } \\
\text { TOTAL } \\
\text { (UG/L) }\end{array}$ & $\begin{array}{c}\text { ALA- } \\
\text { CHLOR } \\
\text { TOTAL } \\
\text { RECOVER } \\
\text { (UG/L) }\end{array}$ & $\begin{array}{l}\text { AME- } \\
\text { TRYNE } \\
\text { TOTAL }\end{array}$ & $\begin{array}{l}\text { ATRA- } \\
\text { ZINE, } \\
\text { TOTAL } \\
\text { (UG/L) }\end{array}$ & $\begin{array}{l}\text { CYAN- } \\
\text { AZINE } \\
\text { TOTAL } \\
\text { (UG/L) }\end{array}$ & $\begin{array}{c}\text { DI- } \\
\text { AZINON, } \\
\text { TOTAL } \\
\text { (UG/L) }\end{array}$ \\
\hline $\begin{array}{l}\text { OCT } \\
07 \ldots \\
\text { JUN }\end{array}$ & 1.0 & 1.8 & 0.03 & $<0.01$ & -- & -- & -- & -- & - & - \\
\hline $\operatorname{SEP}^{16 \ldots}$ & 1.2 & 2.0 & 0.03 & $<0.01$ & 8 & $<0.1$ & $<0.1$ & $<0.1$ & $<0.1$ & 0.01 \\
\hline $09 \ldots$ & $<0.2$ & -- & $<0.01$ & $<0.01$ & -- & -- & -- & -- & -- & -- \\
\hline DATE & $\begin{array}{l}\text { ETHION, } \\
\text { TOTAL } \\
\text { (UG/L) }\end{array}$ & $\begin{array}{l}\text { MALA- } \\
\text { THION, } \\
\text { TOTAL } \\
\text { (UG/L) }\end{array}$ & $\begin{array}{l}\text { METHYL } \\
\text { PARA- } \\
\text { THION, } \\
\text { TOTAL } \\
\text { (UG/L) }\end{array}$ & $\begin{array}{l}\text { METHYL } \\
\text { TRI- } \\
\text { THION, } \\
\text { TOTAL } \\
\text { (UG/L) }\end{array}$ & $\begin{array}{l}\text { METOLA- } \\
\text { CHLOR } \\
\text { WATER } \\
\text { WHOLE } \\
\text { TOT.REC } \\
(\text { UG } / L)\end{array}$ & $\begin{array}{l}\text { METRI- } \\
\text { BUZIN } \\
\text { WATER } \\
\text { WHOLE } \\
\text { TOT.REC } \\
\text { (UG/L) }\end{array}$ & $\begin{array}{l}\text { PARA- } \\
\text { THION, } \\
\text { TOTAL } \\
\text { (UG/L) }\end{array}$ & $\begin{array}{l}\text { PROME- } \\
\text { TONE } \\
\text { TOTAL } \\
\text { (UG/L) }\end{array}$ & $\begin{array}{l}\text { PROME- } \\
\text { TRYNE } \\
\text { TOTAL } \\
\text { (UG/L) }\end{array}$ & $\begin{array}{l}\text { PRO- } \\
\text { PAZINE } \\
\text { TOTAL } \\
\text { (UG/L) }\end{array}$ \\
\hline OCT & & & & & & & & & & \\
\hline$\underset{\text { JUN }}{07 \ldots}$ & -- & -- & -- & -- & -- & -- & -- & -- & -- & -- \\
\hline $\operatorname{EP}^{16 \ldots}$ & $<0.01$ & $<0.01$ & $<0.01$ & $<0.01$ & $<0.1$ & $<0.1$ & $<0.01$ & $<0.1$ & $<0.1$ & $<0.1$ \\
\hline $09 \ldots$ & -- & -- & -- & -- & -- & -- & -- & -- & -- & - \\
\hline
\end{tabular}

\begin{tabular}{|c|c|c|c|c|c|c|c|c|c|}
\hline DATE & $\begin{array}{l}\text { SIME- } \\
\text { TRYNE } \\
\text { TOTAL } \\
\text { (UG/L) }\end{array}$ & $\begin{array}{l}\text { SIMA- } \\
\text { ZINE } \\
\text { TOTAL } \\
\text { (UG/L) }\end{array}$ & $\begin{array}{l}\text { TRI- } \\
\text { FLURA- } \\
\text { LIN } \\
\text { TOTAL } \\
\text { RECOVER } \\
\text { (UG/L) }\end{array}$ & $\begin{array}{l}\text { TOTAL } \\
\text { TRI- } \\
\text { THION } \\
\text { (UG/L) }\end{array}$ & $\begin{array}{l}2,4-D, \\
\text { TOTAL, } \\
\text { (UG/L) }\end{array}$ & $\begin{array}{c}2, \quad 4-D P \\
\text { TOTAL } \\
\text { (UG/L) }\end{array}$ & $\begin{array}{l}2,4,5-T \\
\text { TOTAL } \\
\text { (UG/L) }\end{array}$ & $\begin{array}{l}\text { SILVEX, } \\
\text { TOTAL, } \\
\text { (UG/L) }\end{array}$ & $\begin{array}{l}\text { SEDI- } \\
\text { MENT, } \\
\text { SUS- } \\
\text { PENDED } \\
\text { (MG/L) }\end{array}$ \\
\hline$T_{1} 7 \ldots$ & -- & -- & -- & -- & -- & -- & -- & - & 6 \\
\hline $6 \ldots$ & $<0.1$ & $<0.1$ & $<0.1$ & $<0.01$ & 0.08 & $<0.01$ & $<0.01$ & $<0.01$ & 11 \\
\hline $9 .$. & -- & -- & -- & -- & -- & -- & -- & -- & 20 \\
\hline
\end{tabular}


LOCATION.--Lat $42^{\circ} 14^{\prime} 46^{\prime \prime}$, long $85^{\circ} 34^{\prime} 33^{\prime \prime}$, in SEl/4 sec.34, T. 2 S., R.11 W., Kalamazoo County, Hydrologic Unit 04050003, on left bank $5 \mathrm{ft}$ upstream from bridge on Lovers Lane, $3.0 \mathrm{mi}$ south of Kalamazoo.

DRAINAGE AREA. $--22.4 \mathrm{mi}^{2}$.

PERIOD OF RECORD.--October 1964 to current year.

GAGE.--Water-stage recorder. Datum of gage is $814.88 \mathrm{ft}$ above National Geodetic Vertical Datum of 1929.

REMARKS.--No estimated daily discharges. Records fair. Flow includes water which is pumped from groundwater sources by industry and discharged into stream $2.0 \mathrm{mi}$ upstream from station. Several

measurements of water temperature were made during the year.

AVERAGE DISCHARGE. -23 years, $40.3 \mathrm{ft} 3 / \mathrm{s}, 24.43 \mathrm{in} / \mathrm{yr}$.

EXTREMES FOR PERIOD OF RECORD.--Maximum discharge, $290 \mathrm{ft}^{3} / \mathrm{s}$, June 26, 1978, gage height, $4.49 \mathrm{ft}$;

minimum, $8.0 \mathrm{ft}^{3} / \mathrm{s}$, Jan. 19,1965 , gage height, $0.88 \mathrm{ft}$, result of bridge construction upstream.

EXTREMES FOR CURRENT YEAR.--Peak discharges greater than base discharge of $120 \mathrm{ft} 3 / \mathrm{s}$ and maximum (*):

\begin{tabular}{|c|c|c|c|c|c|c|c|}
\hline Date & Time & $\begin{array}{c}\text { Discharge } \\
\left(\mathrm{ft}^{3} / \mathrm{s}\right)\end{array}$ & $\begin{array}{l}\text { Gage height } \\
\text { (ft) }\end{array}$ & Date & Time & $\begin{array}{l}\text { Discharge } \\
\left(\mathrm{ft}^{3} / \mathrm{s}\right)\end{array}$ & $\begin{array}{c}\text { Gage height } \\
\text { (ft) }\end{array}$ \\
\hline $\begin{array}{l}\text { ct. } \\
\text { pr. } 15\end{array}$ & $\begin{array}{l}1700 \\
0100\end{array}$ & $\begin{array}{r}\star 203 \\
144\end{array}$ & $\begin{array}{r}\star 2.20 \\
1.92\end{array}$ & $\begin{array}{ll}\text { Aug. } & 27 \\
\text { Sept. } & 18\end{array}$ & $\begin{array}{l}0200 \\
0200\end{array}$ & $\begin{array}{l}168 \\
128\end{array}$ & $\begin{array}{l}2.09 \\
1.90\end{array}$ \\
\hline
\end{tabular}

Minimum discharge, $20 \mathrm{ft}^{3} / \mathrm{s}$, June 28 , July 12; minimum gage height, 1.21 ft, June $27,28, \mathrm{July} 12$.

DISCHARGE, IN CUBIC FEET PER SECOND, WATER YEAR OCTOBER 1986 TO SEPTEMBER 1987 MEAN VALUES

\begin{tabular}{|c|c|c|c|c|c|c|c|c|c|c|c|c|}
\hline DAY & OCT & NOV & DEC & JAN & FEB & MAR & APR & MAY & JUN & JUL & AUG & SEP \\
\hline $\begin{array}{l}1 \\
2 \\
3 \\
4 \\
5\end{array}$ & $\begin{array}{r}77 \\
62 \\
128 \\
93 \\
61\end{array}$ & $\begin{array}{l}35 \\
35 \\
37 \\
37 \\
37\end{array}$ & $\begin{array}{l}37 \\
44 \\
44 \\
41 \\
39\end{array}$ & $\begin{array}{l}42 \\
43 \\
44 \\
44 \\
46\end{array}$ & $\begin{array}{l}45 \\
45 \\
46 \\
47 \\
46\end{array}$ & $\begin{array}{l}76 \\
64 \\
57 \\
53 \\
55\end{array}$ & $\begin{array}{l}55 \\
57 \\
51 \\
50 \\
49\end{array}$ & $\begin{array}{l}52 \\
60 \\
62 \\
56 \\
53\end{array}$ & $\begin{array}{l}34 \\
33 \\
33 \\
30 \\
28\end{array}$ & $\begin{array}{l}27 \\
26 \\
24 \\
23 \\
25\end{array}$ & $\begin{array}{l}31 \\
28 \\
28 \\
41 \\
28\end{array}$ & $\begin{array}{l}31 \\
30 \\
29 \\
28 \\
25\end{array}$ \\
\hline $\begin{array}{r}6 \\
7 \\
8 \\
9 \\
10\end{array}$ & $\begin{array}{l}56 \\
52 \\
51 \\
52 \\
48\end{array}$ & $\begin{array}{l}37 \\
36 \\
36 \\
34 \\
37\end{array}$ & $\begin{array}{l}38 \\
44 \\
49 \\
50 \\
46\end{array}$ & $\begin{array}{l}50 \\
52 \\
51 \\
52 \\
49\end{array}$ & $\begin{array}{l}45 \\
46 \\
45 \\
44 \\
45\end{array}$ & $\begin{array}{l}53 \\
54 \\
52 \\
49 \\
49\end{array}$ & $\begin{array}{l}52 \\
51 \\
50 \\
50 \\
49\end{array}$ & $\begin{array}{l}52 \\
53 \\
46 \\
32 \\
31\end{array}$ & $\begin{array}{l}28 \\
27 \\
27 \\
28 \\
28\end{array}$ & $\begin{array}{l}28 \\
26 \\
27 \\
35 \\
38\end{array}$ & $\begin{array}{l}25 \\
25 \\
25 \\
42 \\
30\end{array}$ & $\begin{array}{l}24 \\
24 \\
27 \\
27 \\
31\end{array}$ \\
\hline $\begin{array}{l}11 \\
12 \\
13 \\
14 \\
15\end{array}$ & $\begin{array}{l}43 \\
45 \\
50 \\
50 \\
46\end{array}$ & $\begin{array}{l}38 \\
36 \\
36 \\
36 \\
33\end{array}$ & $\begin{array}{l}43 \\
41 \\
36 \\
36 \\
39\end{array}$ & $\begin{array}{l}46 \\
49 \\
49 \\
52 \\
54\end{array}$ & $\begin{array}{l}48 \\
49 \\
49 \\
48 \\
44\end{array}$ & $\begin{array}{l}47 \\
46 \\
45 \\
50 \\
47\end{array}$ & $\begin{array}{l}54 \\
59 \\
55 \\
67 \\
94\end{array}$ & $\begin{array}{l}33 \\
32 \\
31 \\
41 \\
35\end{array}$ & $\begin{array}{l}29 \\
32 \\
29 \\
27 \\
27\end{array}$ & $\begin{array}{l}24 \\
22 \\
24 \\
24 \\
36\end{array}$ & $\begin{array}{l}27 \\
27 \\
25 \\
29 \\
26\end{array}$ & $\begin{array}{l}57 \\
34 \\
30 \\
31 \\
38\end{array}$ \\
\hline $\begin{array}{l}16 \\
17 \\
18 \\
19 \\
20\end{array}$ & $\begin{array}{l}43 \\
41 \\
36 \\
36 \\
39\end{array}$ & $\begin{array}{l}34 \\
37 \\
38 \\
39 \\
42\end{array}$ & $\begin{array}{l}41 \\
44 \\
43 \\
39 \\
36\end{array}$ & $\begin{array}{l}51 \\
48 \\
48 \\
49 \\
49\end{array}$ & $\begin{array}{l}45 \\
44 \\
44 \\
42 \\
42\end{array}$ & $\begin{array}{l}49 \\
51 \\
52 \\
51 \\
52\end{array}$ & $\begin{array}{l}68 \\
58 \\
53 \\
48 \\
52\end{array}$ & $\begin{array}{l}33 \\
32 \\
47 \\
49 \\
39\end{array}$ & $\begin{array}{l}26 \\
27 \\
26 \\
27 \\
39\end{array}$ & $\begin{array}{l}38 \\
27 \\
24 \\
22 \\
25\end{array}$ & $\begin{array}{l}34 \\
51 \\
31 \\
29 \\
28\end{array}$ & $\begin{array}{l}35 \\
46 \\
69 \\
37 \\
32\end{array}$ \\
\hline $\begin{array}{l}21 \\
22 \\
23 \\
24 \\
25\end{array}$ & $\begin{array}{l}39 \\
38 \\
38 \\
37 \\
37\end{array}$ & $\begin{array}{l}41 \\
39 \\
44 \\
44 \\
40\end{array}$ & $\begin{array}{l}36 \\
38 \\
38 \\
34 \\
32\end{array}$ & $\begin{array}{l}49 \\
45 \\
45 \\
42 \\
40\end{array}$ & $\begin{array}{l}41 \\
45 \\
44 \\
46 \\
46\end{array}$ & $\begin{array}{l}49 \\
47 \\
49 \\
48 \\
50\end{array}$ & $\begin{array}{l}50 \\
50 \\
59 \\
53 \\
51\end{array}$ & $\begin{array}{l}38 \\
37 \\
32 \\
31 \\
30\end{array}$ & $\begin{array}{l}45 \\
32 \\
29 \\
28 \\
28\end{array}$ & $\begin{array}{l}28 \\
24 \\
24 \\
24 \\
52\end{array}$ & $\begin{array}{l}28 \\
30 \\
26 \\
27 \\
24\end{array}$ & $\begin{array}{l}58 \\
49 \\
36 \\
32 \\
29\end{array}$ \\
\hline $\begin{array}{l}26 \\
27 \\
28 \\
29 \\
30 \\
31\end{array}$ & $\begin{array}{l}39 \\
40 \\
38 \\
40 \\
37 \\
37\end{array}$ & $\begin{array}{r}62 \\
47 \\
39 \\
36 \\
35 \\
\end{array}$ & $\begin{array}{l}33 \\
33 \\
33 \\
41 \\
45 \\
46\end{array}$ & $\begin{array}{l}44 \\
42 \\
44 \\
45 \\
46 \\
44\end{array}$ & $\begin{array}{r}47 \\
49 \\
50 \\
-- \\
-- \\
--\end{array}$ & $\begin{array}{l}51 \\
50 \\
49 \\
46 \\
48 \\
46\end{array}$ & $\begin{array}{r}49 \\
51 \\
50 \\
51 \\
52 \\
-\end{array}$ & $\begin{array}{l}34 \\
32 \\
29 \\
29 \\
30 \\
32\end{array}$ & $\begin{array}{r}28 \\
25 \\
21 \\
25 \\
27 \\
- \\
--\end{array}$ & $\begin{array}{l}33 \\
29 \\
28 \\
37 \\
42 \\
30\end{array}$ & $\begin{array}{r}65 \\
111 \\
51 \\
38 \\
32 \\
37\end{array}$ & $\begin{array}{l}28 \\
25 \\
26 \\
42 \\
32\end{array}$ \\
\hline $\begin{array}{l}\text { TOTAL } \\
\text { MEAN } \\
\text { MAX } \\
\text { MIN }\end{array}$ & $\begin{array}{r}1529 \\
49.3 \\
128 \\
36\end{array}$ & $\begin{array}{r}1157 \\
38.6 \\
62 \\
33\end{array}$ & $\begin{array}{r}1239 \\
40.0 \\
50 \\
32\end{array}$ & $\begin{array}{r}1454 \\
46.9 \\
54 \\
40\end{array}$ & $\begin{array}{r}1277 \\
45.6 \\
50 \\
41\end{array}$ & $\begin{array}{r}1585 \\
51.1 \\
76 \\
45\end{array}$ & $\begin{array}{r}1638 \\
54.6 \\
94 \\
48\end{array}$ & $\begin{array}{r}1223 \\
39.5 \\
62 \\
29\end{array}$ & $\begin{array}{r}873 \\
29.1 \\
45 \\
21\end{array}$ & $\begin{array}{r}896 \\
28.9 \\
52 \\
22\end{array}$ & $\begin{array}{r}1079 \\
34.8 \\
111 \\
24\end{array}$ & $\begin{array}{r}1042 \\
34.7 \\
69 \\
24\end{array}$ \\
\hline
\end{tabular}

CAL YR 1986 TOTAL 14518 MEAN 39.8 MAX 146 MIN 21 WTR YR 1987 TOTAL 14992 MEAN 41.1 MAX 128 MIN 21 
04106320 WEST FORK PORTAGE CREEK NEAR OSHTEMO, MI

LOCATION.--Lat $42^{\circ} 14^{\circ} 07^{\prime \prime}$, long $85^{\circ} 38^{\prime} 54^{\prime \prime}$, in SEl/4 sec.1, T.3 S., R.12 W., Kalamazoo County, Hydrologic Unit 04050003 , on right bank at upstream side of culvert on íth street, 2.1 mi southeast of Oshtemo. DRAINAGE AREA. $--13.0 \mathrm{mi}^{2}$.

PERIOD OF RECORD.--MaY 1972 to current year.

GAGE.--Water-stage recorder. Datum of gage is $868.86 \mathrm{ft}$, Kalamazoo County Road Commission datum.

REMARKS.--No estimated daily discharges. Records good. At $t$ imes, flow is affected by ground-water withdrawals. Several measurements of water temperature were made during the year.

AVERAGE DISCHARGE. - - 15 years, $6.75 \mathrm{ft}^{3} / \mathrm{s}, 7.05 \mathrm{in} / \mathrm{yr}^{\circ}$

EXTREMES. FOR PERIOD OF RECORD.--Maximum discharge, $26 \mathrm{ft}^{3} / \mathrm{s}$, Aug. 31, 1975, gage height, $2.15 \mathrm{ft}$; minimum, $1.3 \mathrm{ft}^{3} / \mathrm{s}$, June 18,1987 , gage height, $0.97 \mathrm{ft}$.

EXTREMES FOR CURRENT YEAR.--Maximum discharge, $15 \mathrm{ft}^{3} / \mathrm{s}$, Oct. 3 , gage height, $1.71 \mathrm{ft}$; minimum, $1.3 \mathrm{ft}^{3} / \mathrm{s}$, June 18 , gage height, $0.97 \mathrm{ft}$.

DISCHARGE, IN CUBIC FEET PER SECOND, WATER YEAR OCTOBER 1986 TO SEPTEMBER 1987 MEAN VALUES

\begin{tabular}{|c|c|c|c|c|c|c|c|c|c|c|c|c|}
\hline DAY & OCT & NOV & DEC & JAN & FEB & MAR & APR & MAY & JUN & JUL & AUG & SEP \\
\hline $\begin{array}{l}1 \\
2 \\
3 \\
4 \\
5\end{array}$ & $\begin{array}{l}14 \\
13 \\
13 \\
14 \\
13\end{array}$ & $\begin{array}{l}5.5 \\
5.5 \\
5.5 \\
5.4 \\
5.3\end{array}$ & $\begin{array}{l}6.2 \\
6.7 \\
7.3 \\
6.9 \\
6.4\end{array}$ & $\begin{array}{l}5.9 \\
5.9 \\
5.9 \\
5.7 \\
5.7\end{array}$ & $\begin{array}{l}6.6 \\
6.9 \\
6.8 \\
6.7 \\
6.4\end{array}$ & $\begin{array}{l}9.1 \\
9.9 \\
9.1 \\
8.2 \\
7.8\end{array}$ & $\begin{array}{l}6.6 \\
7.3 \\
7.2 \\
7.2 \\
7.3\end{array}$ & $\begin{array}{l}4.6 \\
5.3 \\
5.9 \\
5.9 \\
5.5\end{array}$ & $\begin{array}{l}2.4 \\
2.4 \\
2.4 \\
2.2 \\
2.1\end{array}$ & $\begin{array}{l}2.5 \\
2.4 \\
2.3 \\
2.2 \\
2.2\end{array}$ & $\begin{array}{l}3.0 \\
2.9 \\
2.8 \\
3.2 \\
3.0\end{array}$ & $\begin{array}{l}5.1 \\
4.6 \\
4.2 \\
3.8 \\
3.6\end{array}$ \\
\hline $\begin{array}{r}6 \\
7 \\
8 \\
9 \\
10\end{array}$ & $\begin{array}{r}11 \\
9.2 \\
7.9 \\
6.8 \\
6.1\end{array}$ & $\begin{array}{l}5.4 \\
5.4 \\
5.7 \\
5.6 \\
5.4\end{array}$ & $\begin{array}{l}6.2 \\
6.6 \\
7.3 \\
7.9 \\
7.7\end{array}$ & $\begin{array}{l}5.7 \\
5.5 \\
5.5 \\
5.7 \\
6.0\end{array}$ & $\begin{array}{l}6.5 \\
6.6 \\
6.6 \\
6.4 \\
6.4\end{array}$ & $\begin{array}{l}7.6 \\
7.3 \\
6.9 \\
6.5 \\
6.4\end{array}$ & $\begin{array}{l}7.1 \\
6.7 \\
6.3 \\
6.0 \\
5.6\end{array}$ & $\begin{array}{l}5.1 \\
4.7 \\
4.4 \\
4.2 \\
3.9\end{array}$ & $\begin{array}{l}2.0 \\
2.1 \\
2.0 \\
2.0 \\
1.8\end{array}$ & $\begin{array}{l}2.3 \\
2.2 \\
2.2 \\
2.1 \\
2.1\end{array}$ & $\begin{array}{l}2.8 \\
2.7 \\
2.7 \\
3.3 \\
3.1\end{array}$ & $\begin{array}{l}3.4 \\
3.3 \\
3.4 \\
3.4 \\
3.4\end{array}$ \\
\hline $\begin{array}{l}11 \\
12 \\
13 \\
14 \\
15\end{array}$ & $\begin{array}{l}5.7 \\
5.6 \\
6.2 \\
6.6 \\
6.4\end{array}$ & $\begin{array}{l}5.4 \\
5.5 \\
5.5 \\
5.7 \\
5.7\end{array}$ & $\begin{array}{l}7.5 \\
6.8 \\
6.8 \\
6.6 \\
6.3\end{array}$ & $\begin{array}{l}6.3 \\
6.1 \\
6.1 \\
6.2 \\
6.4\end{array}$ & $\begin{array}{l}6.4 \\
6.4 \\
6.3 \\
6.3 \\
6.1\end{array}$ & $\begin{array}{l}6.6 \\
6.7 \\
6.8 \\
7.3 \\
7.4\end{array}$ & $\begin{array}{l}5.6 \\
6.3 \\
6.3 \\
6.6 \\
9.2\end{array}$ & $\begin{array}{l}3.8 \\
3.6 \\
3.4 \\
3.3 \\
3.1\end{array}$ & $\begin{array}{l}1.8 \\
2.0 \\
1.9 \\
1.9 \\
1.8\end{array}$ & $\begin{array}{l}2.0 \\
2.0 \\
2.0 \\
1.9 \\
2.3\end{array}$ & $\begin{array}{l}3.0 \\
3.0 \\
2.8 \\
2.9 \\
2.9\end{array}$ & $\begin{array}{l}3.6 \\
3.6 \\
3.5 \\
3.4 \\
3.6\end{array}$ \\
\hline $\begin{array}{l}16 \\
17 \\
18 \\
19 \\
20\end{array}$ & $\begin{array}{l}6.1 \\
5.8 \\
5.5 \\
5.4 \\
5.8\end{array}$ & $\begin{array}{l}5.7 \\
5.7 \\
5.9 \\
5.9 \\
6.0\end{array}$ & $\begin{array}{l}6.3 \\
6.3 \\
6.4 \\
6.4 \\
6.2\end{array}$ & $\begin{array}{l}6.3 \\
6.1 \\
6.3 \\
6.0 \\
5.9\end{array}$ & $\begin{array}{l}6.1 \\
6.0 \\
5.9 \\
6.0 \\
6.1\end{array}$ & $\begin{array}{l}7.2 \\
7.0 \\
6.8 \\
6.8 \\
6.8\end{array}$ & $\begin{array}{l}9.5 \\
9.1 \\
8.8 \\
8.0 \\
7.4\end{array}$ & $\begin{array}{l}3.0 \\
3.0 \\
3.3 \\
3.7 \\
3.9\end{array}$ & $\begin{array}{l}1.7 \\
1.7 \\
1.6 \\
1.5 \\
1.8\end{array}$ & $\begin{array}{l}3.1 \\
3.3 \\
3.5 \\
3.4 \\
3.3\end{array}$ & $\begin{array}{l}3.1 \\
4.0 \\
4.0 \\
4.0 \\
3.6\end{array}$ & $\begin{array}{l}3.8 \\
4.5 \\
6.4 \\
6.8 \\
6.3\end{array}$ \\
\hline $\begin{array}{l}21 \\
22 \\
23 \\
24 \\
25\end{array}$ & $\begin{array}{l}5.9 \\
5.7 \\
5.9 \\
5.6 \\
5.4\end{array}$ & $\begin{array}{l}6.1 \\
6.2 \\
6.6 \\
6.8 \\
6.5\end{array}$ & $\begin{array}{l}6.0 \\
5.9 \\
5.8 \\
5.7 \\
5.7\end{array}$ & $\begin{array}{l}5.8 \\
5.9 \\
5.8 \\
5.7 \\
5.7\end{array}$ & $\begin{array}{l}6 \cdot 1 \\
6 \cdot 2 \\
6 \cdot 3 \\
6 \cdot 2 \\
6.2\end{array}$ & $\begin{array}{l}6.6 \\
6.5 \\
6.4 \\
6.2 \\
6.4\end{array}$ & $\begin{array}{l}6.7 \\
6.3 \\
6.9 \\
6.4 \\
6.3\end{array}$ & $\begin{array}{l}3.9 \\
3.7 \\
3.4 \\
3.1 \\
3.0\end{array}$ & $\begin{array}{l}2.2 \\
2.6 \\
2.6 \\
2.5 \\
2.6\end{array}$ & $\begin{array}{l}3.3 \\
3.0 \\
2.9 \\
2.7 \\
2.9\end{array}$ & $\begin{array}{l}3.3 \\
3.3 \\
3.0 \\
2.8 \\
2.6\end{array}$ & $\begin{array}{l}7.0 \\
7.4 \\
6.8 \\
6.1 \\
5.4\end{array}$ \\
\hline $\begin{array}{l}26 \\
27 \\
28 \\
29 \\
30 \\
31\end{array}$ & $\begin{array}{l}5.9 \\
6.3 \\
6.1 \\
5.8 \\
5.6 \\
5.5\end{array}$ & $\begin{array}{l}7.5 \\
8.8 \\
8.3 \\
7.4 \\
6.6 \\
---\end{array}$ & $\begin{array}{l}5.7 \\
5.7 \\
5.7 \\
5.7 \\
5.9 \\
5.9\end{array}$ & $\begin{array}{l}5.7 \\
5.7 \\
5.7 \\
5.8 \\
6.1 \\
6.2\end{array}$ & $\begin{array}{l}6.1 \\
6.1 \\
6.4 \\
--- \\
--- \\
---\end{array}$ & $\begin{array}{l}6.7 \\
6.8 \\
6.6 \\
6.5 \\
6.5 \\
6.4\end{array}$ & $\begin{array}{l}6.0 \\
5.6 \\
5.3 \\
5.1 \\
4.6 \\
-.--\end{array}$ & $\begin{array}{l}3.1 \\
3.0 \\
2.7 \\
2.5 \\
2.4 \\
2.4\end{array}$ & $\begin{array}{l}2.7 \\
2.6 \\
2.4 \\
2.3 \\
2.5 \\
---\end{array}$ & $\begin{array}{l}2.9 \\
2.8 \\
2.8 \\
2.9 \\
3.1 \\
3.1\end{array}$ & $\begin{array}{l}3.8 \\
6.9 \\
7.9 \\
7.5 \\
6.4 \\
5.8\end{array}$ & $\begin{array}{l}5.0 \\
4.7 \\
4.4 \\
4.9 \\
5.2 \\
\end{array}$ \\
\hline $\begin{array}{l}\text { TOTAL } \\
\text { MEAN } \\
\text { MAX } \\
\text { MIN } \\
\text { CFSM } \\
\text { IN. }\end{array}$ & $\begin{array}{r}230.8 \\
7.45 \\
14 \\
5.4 \\
.57 \\
.66\end{array}$ & $\begin{array}{r}182.5 \\
6.08 \\
8.8 \\
5.3 \\
.47 \\
.52\end{array}$ & $\begin{array}{r}198.5 \\
6.40 \\
7.9 \\
5.7 \\
.49 \\
.57\end{array}$ & $\begin{array}{r}183.3 \\
5.91 \\
6.4 \\
5.5 \\
.46 \\
.52\end{array}$ & $\begin{array}{r}177.1 \\
6.33 \\
6.9 \\
5.9 \\
.49 \\
.51\end{array}$ & $\begin{array}{r}219.8 \\
7.09 \\
9.9 \\
6.2 \\
.55 \\
.63\end{array}$ & $\begin{array}{r}203.3 \\
6.78 \\
9.5 \\
4.6 \\
.52 \\
.58\end{array}$ & $\begin{array}{r}116.8 \\
3.77 \\
5.9 \\
2.4 \\
.29 \\
.33\end{array}$ & $\begin{array}{r}64.1 \\
2.14 \\
2.7 \\
1.5 \\
.17 \\
.18\end{array}$ & $\begin{array}{r}81.7 \\
2.64 \\
3.5 \\
1.9 \\
.20 \\
.23\end{array}$ & $\begin{array}{r}116.1 \\
3.75 \\
7.9 \\
2.6 \\
.29 \\
.33\end{array}$ & $\begin{array}{r}140.6 \\
4.69 \\
7.4 \\
3.3 \\
.36 \\
.40\end{array}$ \\
\hline
\end{tabular}

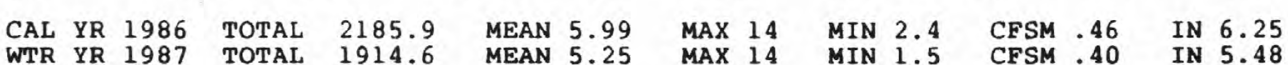


LOCATION. - Lat $42^{\circ} 14^{\prime} 40^{\prime \prime}$, long $85^{\circ} 36^{\prime} 50^{\prime \prime}$, in NEl/4 sec.5, T.3 S.. R.11 W. Kalamazoo County, Hydrologic Unit 04050003 , on right bank $30 \mathrm{ft}$ upstream from cuivert on Oáland Drive, $2.5 \mathrm{mi}$ upstream from mouth, and $3.7 \mathrm{mi}$ southwest of main business district of Kalamazoo.

DRAINAGE AREA. $--18.7 \mathrm{mi}^{2}$.

\section{WATER-DISCHARGE RECORDS}

PERIOD OF RECORD.--September 1959 to current year.

GAGE.--Water-stage recorder and V-notch sharp-crested weir. Datum of gage is $858.09 \mathrm{ft}$ above National Geodetic Vertical Datum of 1929 (levels by Michigan Department of Natural Resources).

REMARKS.--Estimated daily discharges: Oct. 1-16, Nov. 29 to Mar. 25, May 7 to June 16 , and Aug. 3 to Sept. 10. Water-discharge records poor. At times, flow is affected by ground-water withdrawals.

AVERAGE DISCHARGE. --28 years, $9.87 \mathrm{ft}^{3} / \mathrm{s}, 7.17 \mathrm{in} / \mathrm{yr}^{\circ}$

EXTREMES FOR PERIOD OF RECORD.--Maximum discharge, $41 \mathrm{ft}^{3} / \mathrm{s}$, Apr. 19, 1975, gage height, $3.32 \mathrm{ft}$; minimum, $1.0 \mathrm{ft}^{3} / \mathrm{s}$, Aug. 9, 1964; minimum gage height, 0.88 ft, July 30, 1963, caused by construction.

EXTREMES FOR CURRENT YEAR,--Maximum daily discharge, $28 \mathrm{ft}^{3} / \mathrm{s}$, Oct. 1,$4 ; \mathrm{minimum} \mathrm{daily,} 3.9 \mathrm{ft} 3 / \mathrm{s}$, June 16-19, July $12,13$.

DISCHARGE, IN CUBIC FEET PER SECOND, WATER YEAR OCTOBER 1986 TO SEPTEMBER 1987

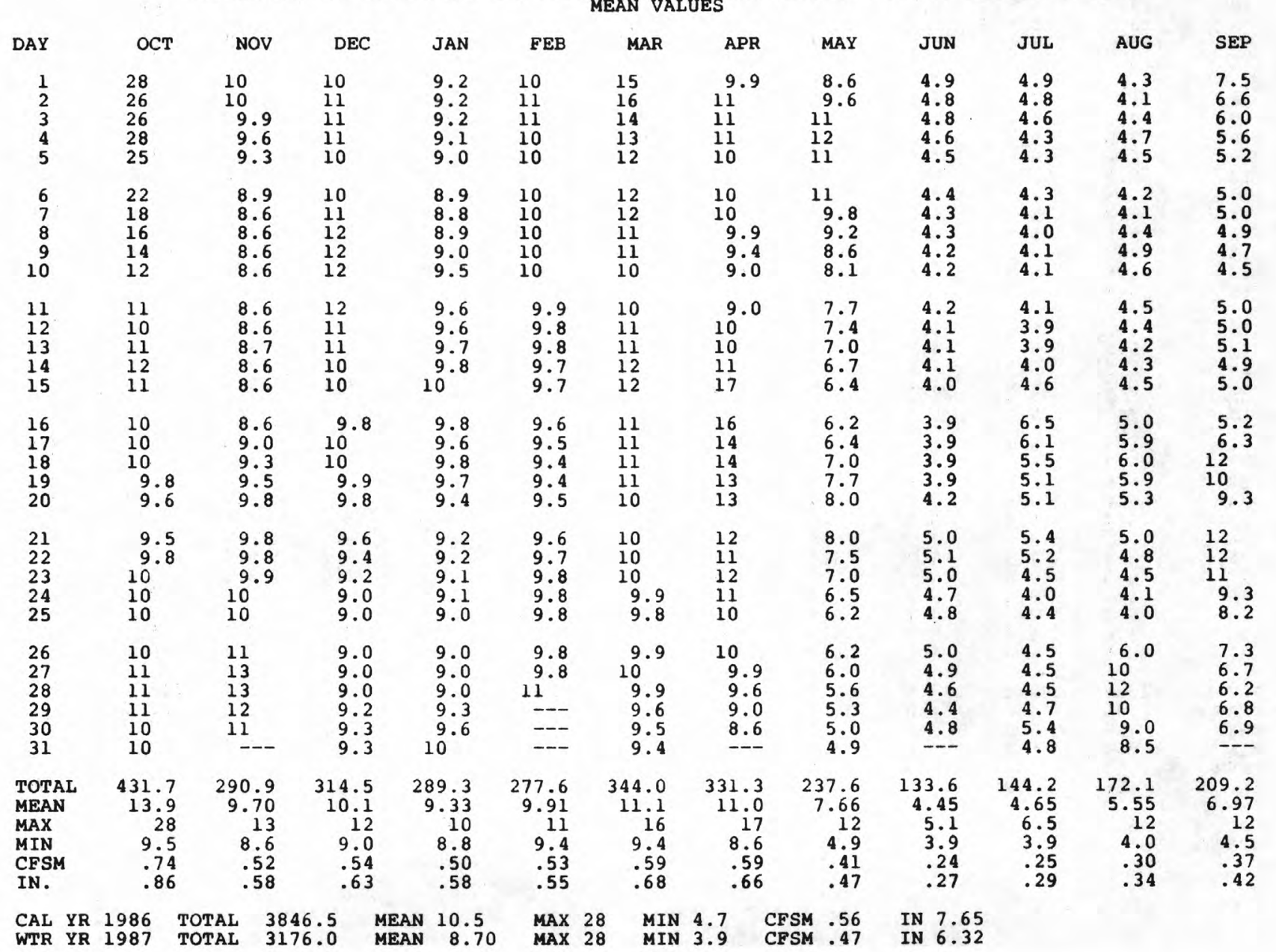


PERIOD OF RECORD.--Water years 1965, 1971-75, 1986 to September 1987 (discontinued).

PERIOD OF DAILY RECORD.--

SPECIFIC CONDUCTANCE: April to June 1971

WATER TEMPERATURE: April 1971 to April 1972.

EXTREMES FOR PERIOD OF DAILY RECORD - -

SPECIFIC CONDUCTANCE: Maximum recorded (more than 20 percent missing record), 410 microsiemens, June

22, 23, 1971; minimum recorded (more than 20 percent missing record), 310 microsiemens, kiay $24,1971$.

WATER TEMPERATURE (water year 1971): maximum, $34.0^{\circ} \mathrm{C}$, June 28, 1971 .

EXTREMES OUTSIDE PERIOD OF DAILY RECORD.--A specific conductance of 476 microsiemens was measured June 16, 1987 .

WATER QUALITY DATA, WATER YEAR OCTOBER 1986 TO SEPTEMBER 1987

\begin{tabular}{|c|c|c|c|c|c|c|c|c|c|c|}
\hline DATE & TIME & $\begin{array}{l}\text { STREAM- } \\
\text { FLOW, } \\
\text { INSTAN- } \\
\text { TANEOUS } \\
\text { (CFS) }\end{array}$ & $\begin{array}{l}\text { SPE- } \\
\text { CIFIC } \\
\text { CON- } \\
\text { DUCT- } \\
\text { ANCE } \\
\text { (US/CM) }\end{array}$ & $\begin{array}{c}\text { PH } \\
\text { (STAND- } \\
\text { ARD } \\
\text { UNITS ) }\end{array}$ & $\begin{array}{l}\text { TEMPER- } \\
\text { ATURE } \\
\text { (DEG C) }\end{array}$ & $\begin{array}{c}\text { OXYGEN, } \\
\text { DIS- } \\
\text { SOLVED } \\
\text { (MG/L) }\end{array}$ & $\begin{array}{l}\text { NITRO- } \\
\text { GEN, } \\
\text { NITRITE } \\
\text { TOTAL } \\
\text { (MG/L } \\
\text { AS N) }\end{array}$ & $\begin{array}{l}\text { NITRO- } \\
\text { GEN, } \\
\text { NO2+NO3 } \\
\text { TOTAL } \\
\text { (MG/L } \\
\text { AS N) }\end{array}$ & $\begin{array}{l}\text { NITRO- } \\
\text { GEN, } \\
\text { AMMONIA } \\
\text { TOTAL } \\
\text { (MG/L } \\
\text { AS N) }\end{array}$ & $\begin{array}{l}\text { NITRO- } \\
\text { GEN, } \\
\text { ORGANIC } \\
\text { TOTAL } \\
\text { (MG/L } \\
\text { AS N) }\end{array}$ \\
\hline $\begin{array}{l}\text { OCT } \\
07 \ldots \\
\text { JUN }\end{array}$ & 1050 & 17 & 429 & 7.8 & 13.5 & 6.1 & 0.02 & 0.10 & 0.07 & 0.83 \\
\hline $\operatorname{SEP}_{16 \ldots}$ & 1100 & 3.9 & 476 & 7.8 & 25.5 & 8.5 & $<0.01$ & $<0.10$ & 0.03 & 0.57 \\
\hline $10 \ldots$ & 0845 & 4.5 & 450 & 7.4 & 19.0 & 5.1 & $<0.01$ & $<0.10$ & 0.03 & 0.27 \\
\hline DATE & $\begin{array}{l}\text { NITRO- } \\
\text { GEN,AM- } \\
\text { MONIA + } \\
\text { ORGANIC } \\
\text { TOTAL } \\
\text { (MG/L } \\
\text { AS N) }\end{array}$ & $\begin{array}{l}\text { NITRO- } \\
\text { GEN, } \\
\text { TOTAL } \\
\text { (MG/L } \\
\text { AS N) }\end{array}$ & $\begin{array}{c}\text { PHOS- } \\
\text { PHORUS, } \\
\text { TOTAL } \\
\text { (MG/L } \\
\text { AS P) }\end{array}$ & $\begin{array}{l}\text { PHOS- } \\
\text { PHORUS, } \\
\text { ORTHO, } \\
\text { TOTAL } \\
\text { (MG/L } \\
\text { AS P) }\end{array}$ & $\begin{array}{l}\text { PHENOLS } \\
\text { TOTAL } \\
\text { (UG/L) }\end{array}$ & $\begin{array}{c}\text { ALA- } \\
\text { CHLOR } \\
\text { TOTAL } \\
\text { RECOVER } \\
\text { (UG/L) }\end{array}$ & $\begin{array}{l}\text { AME- } \\
\text { TRYNE } \\
\text { TOTAL }\end{array}$ & $\begin{array}{l}\text { ATRA- } \\
\text { ZINE, } \\
\text { TOTAL } \\
\text { (UG/L) }\end{array}$ & $\begin{array}{l}\text { CYAN- } \\
\text { AZINE } \\
\text { TOTAL } \\
\text { (UG/L) }\end{array}$ & $\begin{array}{c}\text { DI- } \\
\text { AZINON, } \\
\text { TOTAL } \\
\text { (UG/L) }\end{array}$ \\
\hline $\begin{array}{l}\text { OCT } \\
07 \ldots \\
\text { JUN }\end{array}$ & 0.9 & 1.0 & 0.02 & 0.01 & -- & -- & $\cdots$ & -- & -- & -- \\
\hline $\operatorname{SEP}^{16 \ldots}$ & 0.6 & -- & 0.04 & $<0.01$ & 4 & $<0.1$ & $<0.1$ & $<0.1$ & $<0.1$ & $<0.01$ \\
\hline $10 \ldots$ & 0.3 & -- & 0.02 & $<0.01$ & -- & -- & -- & -- & -- & -- \\
\hline DATE & $\begin{array}{l}\text { ETHION, } \\
\text { TOTAL } \\
\text { (UG/L) }\end{array}$ & $\begin{array}{l}\text { MALA- } \\
\text { THION, } \\
\text { TOTAL } \\
\text { (UG/L) }\end{array}$ & $\begin{array}{l}\text { METHYL } \\
\text { PARA- } \\
\text { THION, } \\
\text { TOTAL } \\
\text { (UG/L) }\end{array}$ & $\begin{array}{l}\text { METHYL } \\
\text { TRI- } \\
\text { THION, } \\
\text { TOTAL } \\
\text { (UG/L) }\end{array}$ & $\begin{array}{l}\text { METOLA- } \\
\text { CHLOR } \\
\text { WATER } \\
\text { WHOLE } \\
\text { TOT.REC } \\
\text { (UG/L) }\end{array}$ & $\begin{array}{l}\text { METRI- } \\
\text { BUZ IN } \\
\text { WATER } \\
\text { WHOLE } \\
\text { TOT.REC } \\
\text { (UG/L) }\end{array}$ & $\begin{array}{l}\text { PARA- } \\
\text { THION, } \\
\text { TOTAL } \\
\text { (UG/L) }\end{array}$ & $\begin{array}{l}\text { PROME- } \\
\text { TONE } \\
\text { TOTAL } \\
\text { (UG/L ) }\end{array}$ & $\begin{array}{l}\text { PROME- } \\
\text { TRYNE } \\
\text { TOTAL } \\
\text { (UG/L) }\end{array}$ & $\begin{array}{l}\text { PRO- } \\
\text { PAZ INE } \\
\text { TOTAL } \\
\text { (UG/L) }\end{array}$ \\
\hline $\begin{array}{l}\text { OCT } \\
07 \ldots \\
\text { JUN }\end{array}$ & -- & -- & -- & -- & -- & -- & -- & -- & -- & -- \\
\hline $\operatorname{seP}_{16} \ldots$ & $<0.01$ & $<0.01$ & $<0.01$ & $<0.01$ & $<0.1$ & $<0.1$ & $<0.01$ & $<0.1$ & $<0.1$ & $<0.1$ \\
\hline $10 \ldots$ & -- & -- & -- & -- & -- & -- & -- & - & -- & - \\
\hline
\end{tabular}

\begin{tabular}{|c|c|c|c|c|c|c|c|c|c|}
\hline DATE & $\begin{array}{l}\text { SIME- } \\
\text { TRYNE } \\
\text { TOTAL } \\
\text { (UG/L) }\end{array}$ & $\begin{array}{l}\text { SIMA- } \\
\text { ZINE } \\
\text { TOTAL } \\
\text { (UG/L) }\end{array}$ & $\begin{array}{l}\text { TRI- } \\
\text { FLURA- } \\
\text { LIN } \\
\text { TOTAL } \\
\text { RECOVER } \\
\text { (UG/L) }\end{array}$ & $\begin{array}{l}\text { TOTAL } \\
\text { TRI- } \\
\text { THION } \\
\text { (UG/L) }\end{array}$ & $\begin{array}{l}2,4-D, \\
\text { TOTAL } \\
\text { (UG/L) }\end{array}$ & $\begin{array}{l}2, \quad 4-D P \\
\text { TOTAL } \\
\text { (UG/L) }\end{array}$ & $\begin{array}{l}2,4,5-T \\
\text { TOTAL } \\
\text { (UG/L) }\end{array}$ & $\begin{array}{l}\text { SILVEX, } \\
\text { TOTAL } \\
\text { (UG/L) }\end{array}$ & $\begin{array}{l}\text { SEDI- } \\
\text { MENT, } \\
\text { SUS- } \\
\text { PENDED } \\
\text { (MG/L ) }\end{array}$ \\
\hline $\begin{array}{l}\text { OCT } \\
07 \ldots \\
\text { JUN }\end{array}$ & -- & -- & -- & -- & -- & -- & -- & -- & 1 \\
\hline $\begin{array}{l}16 \ldots \\
\operatorname{SEP} \\
10 \ldots\end{array}$ & $\begin{array}{r}<0.1 \\
\ldots\end{array}$ & $\begin{array}{r}<0.1 \\
--\end{array}$ & $\begin{array}{r}<0.1 \\
\quad--\end{array}$ & $\begin{array}{r}<0.01 \\
--\end{array}$ & $\begin{array}{r}0.19 \\
--\end{array}$ & $\begin{array}{r}<0.01 \\
--\end{array}$ & $\begin{array}{r}<0.01 \\
--\end{array}$ & $\begin{array}{r}<0.01 \\
--\end{array}$ & 3 \\
\hline
\end{tabular}


(National stream quality accounting network station)

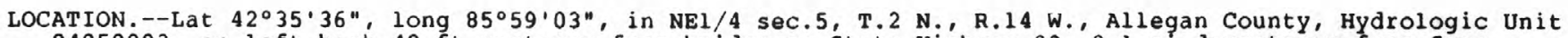
04050003 , on left bank $40 \mathrm{ft}$ upstream from bridge on State Highway 89, 2.1 mi downstream from Swan Creek, $4.0 \mathrm{mi}$ downstream from Calkins Dam, and $6.1 \mathrm{mi}$ east of Fennville.

DRAINAGE AREA.--1,600 $\mathrm{mi}^{2}$, approximately.

WATER-DISCHARGE RECORDS

PERIOD OF RECORD.--April 1929 to September 1936, October 1937 to current year. Monthly discharge only for some periods, published in WSP 1307. Published as "near Allegan" April 1929 to September 1932; as "at Calkins Bridge, near Allegan" October 1932 to September 1936, and October 1937 to September 1938; as "at Calkins Dam, near Allegan" October 1938 to September 1950.

REVISED RECORDS.--WSP 1387: 1929(M)，1930, 1933，1934-36(M)，1938(M)，1939-40, 1942 .

GAGE.--Water-stage recorder. Datum of gage is $586.51 \mathrm{ft}$ above National Geodetic Vertical Datum of 1929 (levels by Michigan Department of Natural Resources). April 1929 to September 1936 at bridge and october 1937 to September 1950 in powerplant, $4.0 \mathrm{mi}$ upstream at NGVD (1evels by City of Allegan).

REMARKS.--Estimated daily discharges: Jan. 23-27. Water-discharge records good. Flow regulated at low and medium stages by powerplants upstream from station and since June 1936 by Calkins Dam and powerplant, $4.0 \mathrm{mi}$ upstream from station.

AVERAGE DISCHARGE. --57 years, $1,442 \mathrm{ft}^{3} / \mathrm{s}, 12.24 \mathrm{in} / \mathrm{yr}$.

EXTREMES FOR PERIOD OF RECORD,--Maximum discharge, 17,500 ft $3 / \mathrm{s}$, Apr. 11, 1947, gage height, 606.76 $\mathrm{ft}$, site and datum then in use; minimum daily, $50 \mathrm{ft}^{3} / \mathrm{s}$, Aug. 19, 1976, caused by shutting off flow at Calkins Dam.

EXTREMES FOR CURRENT YEAR.--Maximum discharge, $7,370 \mathrm{ft}^{3} / \mathrm{s}$, Oct. 1, gage height, $13.37 \mathrm{ft}$; minimum daily, $585 \mathrm{ft}^{3} / \mathrm{s}$, July 24 .

DISCHARGE, IN CUBIC FEET PER SECOND, WATER YEAR OCTOBER 1986 TO SEPTEMBER 1987 MEAN VALUES

\begin{tabular}{|c|c|c|c|c|c|c|c|c|c|c|c|c|}
\hline DAY & OCT & NOV & DEC & JAN & FEB & MAR & APR & MAY & JUN & JUL & AUG & SEP \\
\hline $\begin{array}{l}1 \\
2 \\
3 \\
4 \\
5\end{array}$ & $\begin{array}{l}6360 \\
6760 \\
5980 \\
5900 \\
5980\end{array}$ & $\begin{array}{l}1840 \\
1740 \\
1770 \\
1830 \\
1760\end{array}$ & $\begin{array}{l}2290 \\
2280 \\
2210 \\
2230 \\
2280\end{array}$ & $\begin{array}{l}1750 \\
1750 \\
1730 \\
1680 \\
1660\end{array}$ & $\begin{array}{l}1770 \\
1720 \\
1720 \\
1720 \\
1710\end{array}$ & $\begin{array}{l}1770 \\
2110 \\
2260 \\
2060 \\
2110\end{array}$ & $\begin{array}{l}1530 \\
1540 \\
1550 \\
1550 \\
1540\end{array}$ & $\begin{array}{l}1560 \\
1080 \\
1470 \\
1580 \\
1120\end{array}$ & $\begin{array}{r}1010 \\
976 \\
924 \\
948 \\
1070\end{array}$ & $\begin{array}{l}837 \\
812 \\
730 \\
776 \\
832\end{array}$ & $\begin{array}{r}1040 \\
1020 \\
869 \\
725 \\
751\end{array}$ & $\begin{array}{r}1740 \\
1430 \\
1430 \\
1290 \\
872\end{array}$ \\
\hline $\begin{array}{r}6 \\
7 \\
8 \\
9 \\
10\end{array}$ & $\begin{array}{l}5760 \\
5130 \\
5020 \\
4780 \\
4490\end{array}$ & $\begin{array}{l}1800 \\
1790 \\
1750 \\
1750 \\
1750\end{array}$ & $\begin{array}{l}2240 \\
2320 \\
2340 \\
2350 \\
2360\end{array}$ & $\begin{array}{l}1630 \\
1270 \\
1320 \\
1780 \\
1730\end{array}$ & $\begin{array}{l}1630 \\
1570 \\
1540 \\
1580 \\
1570\end{array}$ & $\begin{array}{l}2210 \\
2290 \\
2280 \\
2190 \\
2060\end{array}$ & $\begin{array}{l}1610 \\
1590 \\
1540 \\
1530 \\
1530\end{array}$ & $\begin{array}{l}1130 \\
1470 \\
1370 \\
1410 \\
1320\end{array}$ & $\begin{array}{r}1040 \\
1010 \\
856 \\
787 \\
787\end{array}$ & $\begin{array}{l}829 \\
819 \\
821 \\
826 \\
823\end{array}$ & $\begin{array}{l}744 \\
757 \\
748 \\
687 \\
843\end{array}$ & $\begin{array}{l}1050 \\
1050 \\
1180 \\
1080 \\
1050\end{array}$ \\
\hline $\begin{array}{l}11 \\
12 \\
13 \\
14 \\
15\end{array}$ & $\begin{array}{l}4090 \\
3980 \\
3460 \\
3130 \\
2870\end{array}$ & $\begin{array}{l}1750 \\
1750 \\
1500 \\
1350 \\
1780\end{array}$ & $\begin{array}{l}2360 \\
2360 \\
2360 \\
2260 \\
2120\end{array}$ & $\begin{array}{l}1640 \\
1670 \\
1670 \\
1610 \\
1590\end{array}$ & $\begin{array}{l}1600 \\
1640 \\
1640 \\
1640 \\
1640\end{array}$ & $\begin{array}{l}2070 \\
1980 \\
1810 \\
1710 \\
1680\end{array}$ & $\begin{array}{l}1520 \\
1650 \\
1690 \\
1700 \\
2060\end{array}$ & $\begin{array}{r}1080 \\
1100 \\
1090 \\
1050 \\
969\end{array}$ & $\begin{array}{l}790 \\
861 \\
978 \\
720 \\
780\end{array}$ & $\begin{array}{r}1010 \\
1140 \\
877 \\
636 \\
735\end{array}$ & $\begin{array}{r}950 \\
844 \\
789 \\
1670 \\
1880\end{array}$ & $\begin{array}{l}1050 \\
1410 \\
1370 \\
1080 \\
1420\end{array}$ \\
\hline $\begin{array}{l}16 \\
17 \\
18 \\
19 \\
20\end{array}$ & $\begin{array}{l}2990 \\
2790 \\
2550 \\
2330 \\
2310\end{array}$ & $\begin{array}{l}1730 \\
1500 \\
1250 \\
1500 \\
2020\end{array}$ & $\begin{array}{l}2110 \\
2010 \\
1920 \\
1900 \\
1910\end{array}$ & $\begin{array}{l}1670 \\
1730 \\
1740 \\
1730 \\
1730\end{array}$ & $\begin{array}{l}1630 \\
1250 \\
1300 \\
1600 \\
1200\end{array}$ & $\begin{array}{l}1600 \\
1640 \\
1610 \\
1540 \\
1540\end{array}$ & $\begin{array}{l}2720 \\
2370 \\
2020 \\
1900 \\
1880\end{array}$ & $\begin{array}{r}989 \\
1080 \\
1090 \\
1290 \\
1210\end{array}$ & $\begin{array}{l}916 \\
716 \\
715 \\
715 \\
720\end{array}$ & $\begin{array}{l}855 \\
943 \\
996 \\
999 \\
949\end{array}$ & $\begin{array}{l}1220 \\
1570 \\
2070 \\
1820 \\
1400\end{array}$ & $\begin{array}{l}1450 \\
1380 \\
1560 \\
1540 \\
1500\end{array}$ \\
\hline $\begin{array}{l}21 \\
22 \\
23 \\
24 \\
25\end{array}$ & $\begin{array}{l}2200 \\
2290 \\
2060 \\
1840 \\
1980\end{array}$ & $\begin{array}{l}1920 \\
1740 \\
1700 \\
1780 \\
1830\end{array}$ & $\begin{array}{l}1930 \\
1860 \\
1850 \\
1840 \\
1750\end{array}$ & $\begin{array}{l}1730 \\
1670 \\
1600 \\
1500 \\
1300\end{array}$ & $\begin{array}{l}1260 \\
1560 \\
1560 \\
1560 \\
1220\end{array}$ & $\begin{array}{l}1530 \\
1520 \\
1520 \\
1520 \\
1580\end{array}$ & $\begin{array}{l}1870 \\
1820 \\
1780 \\
1770 \\
1760\end{array}$ & $\begin{array}{r}1260 \\
960 \\
1370 \\
1310 \\
1040\end{array}$ & $\begin{array}{r}858 \\
1020 \\
1020 \\
984 \\
1010\end{array}$ & $\begin{array}{l}902 \\
850 \\
634 \\
585 \\
761\end{array}$ & $\begin{array}{r}1130 \\
1350 \\
916 \\
1360 \\
1350\end{array}$ & $\begin{array}{l}1740 \\
1820 \\
1770 \\
1520 \\
1510\end{array}$ \\
\hline $\begin{array}{l}26 \\
27 \\
28 \\
29 \\
30 \\
31\end{array}$ & $\begin{array}{l}2220 \\
1970 \\
1920 \\
1720 \\
1800 \\
1920\end{array}$ & $\begin{array}{l}1810 \\
2010 \\
2020 \\
2320 \\
2560 \\
\end{array}$ & $\begin{array}{l}1690 \\
1730 \\
1680 \\
1640 \\
1640 \\
1690\end{array}$ & $\begin{array}{l}1200 \\
1240 \\
1210 \\
1410 \\
1810 \\
1830\end{array}$ & $\begin{array}{l}1250 \\
1550 \\
1560 \\
-\ldots \\
- \\
-\end{array}$ & $\begin{array}{l}1660 \\
1580 \\
1520 \\
1530 \\
1560 \\
1570\end{array}$ & $\begin{array}{l}1740 \\
1560 \\
1110 \\
1100 \\
1450\end{array}$ & $\begin{array}{r}1050 \\
1010 \\
945 \\
947 \\
816 \\
1010\end{array}$ & $\begin{array}{l}973 \\
898 \\
822 \\
835 \\
839 \\
---\end{array}$ & $\begin{array}{l}801 \\
827 \\
860 \\
936 \\
833 \\
880\end{array}$ & $\begin{array}{r}905 \\
1750 \\
2750 \\
2310 \\
2210 \\
1830\end{array}$ & $\begin{array}{r}1530 \\
907 \\
1150 \\
1350 \\
1310\end{array}$ \\
\hline $\begin{array}{l}\text { TOTAL } \\
\text { MEAN } \\
\text { MAX } \\
\text { MIN } \\
\text { CESM } \\
\text { IN. }\end{array}$ & $\begin{array}{r}108580 \\
3503 \\
6760 \\
1720 \\
2.19 \\
2.52\end{array}$ & $\begin{array}{r}53600 \\
1787 \\
2560 \\
1250 \\
1.12 \\
1.25\end{array}$ & $\begin{array}{r}63510 \\
2049 \\
2360 \\
1640 \\
1.28 \\
1.48\end{array}$ & $\begin{array}{r}49580 \\
1599 \\
1830 \\
1200 \\
1.00 \\
1.15\end{array}$ & $\begin{array}{r}43190 \\
1543 \\
1770 \\
1200 \\
1.96 \\
1.00\end{array}$ & $\begin{array}{r}55610 \\
1794 \\
2290 \\
1520 \\
1.12 \\
1.29\end{array}$ & $\begin{array}{r}50980 \\
1699 \\
2720 \\
1100 \\
1.06 \\
1.19\end{array}$ & $\begin{array}{r}36176 \\
1167 \\
1580 \\
816 \\
.73 \\
.84\end{array}$ & $\begin{array}{r}26578 \\
886 \\
1070 \\
715 \\
.55 \\
.62\end{array}$ & $\begin{array}{r}26114 \\
842 \\
1140 \\
585 \\
.53 \\
.61\end{array}$ & $\begin{array}{r}40258 \\
1299 \\
2750 \\
687 \\
.81 \\
.94\end{array}$ & $\begin{array}{r}40539 \\
1351 \\
1820 \\
872 \\
.84 \\
.94\end{array}$ \\
\hline $\begin{array}{ll}\text { CAL YR } \\
\text { WTR YR }\end{array}$ & $\begin{array}{l}1986 \\
1987\end{array}$ & $\begin{array}{ll}A L & 7 \\
A L & 5\end{array}$ & $\begin{array}{l}68 \\
15\end{array}$ & $\begin{array}{ll}\mathbf{N} & 2082 \\
\mathbf{N} & 1629\end{array}$ & $\begin{array}{l}\text { MAX } \\
\text { MAX }\end{array}$ & $\begin{array}{l}6760 \\
6760\end{array}$ & $\begin{array}{ll}\text { MIN } & 849 \\
\text { MIN } & 585\end{array}$ & $\begin{array}{l}\text { CFSM } \\
\text { CFSM }\end{array}$ & $\begin{array}{l}\text { IN } \\
\text { IN }\end{array}$ & $\begin{array}{l}17.67 \\
13.83\end{array}$ & & \\
\hline
\end{tabular}




\section{WATER-QUALITY RECORDS}

PERIOD OF RECORD. --Water years $1967,1987$.

REMARKS.--Bimonthly cross-sectional samples were collected at bridge.

WATER QUALITY DATA, WATER YEAR OCTOBER 1986 TO SEPTEMBER 1987

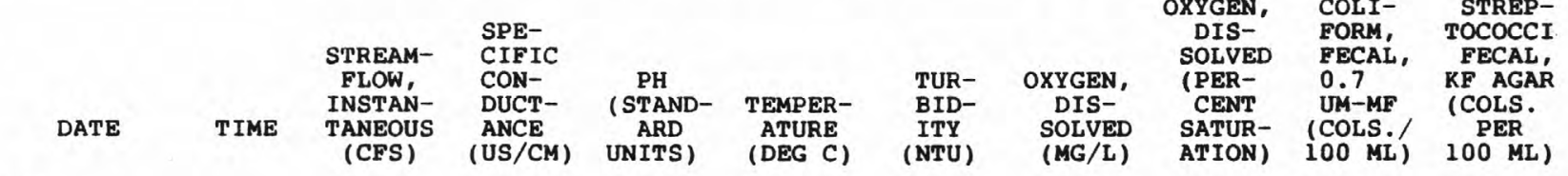

\begin{tabular}{|c|c|c|c|c|c|c|c|c|c|c|}
\hline $\begin{array}{l}\text { NOV } \\
04 \ldots \\
\text { JAN }\end{array}$ & 1030 & 1820 & 584 & 8.3 & 10.0 & 3.2 & 10.7 & 96 & K8 & $\mathrm{K} 6$ \\
\hline MAR & 1100 & 1630 & 592 & 8.2 & 4.0 & 1.9 & 13.1 & 103 & K530 & $\mathrm{K} 14$ \\
\hline${ }_{M A Y}^{26 \ldots}$ & 1000 & 1660 & 572 & 8.2 & 9.0 & 5.2 & 11.6 & 102 & K2 & K2 \\
\hline JUL $^{27 \ldots}$ & 1100 & 1040 & -- & 8.6 & 22.0 & 8.4 & 11.2 & 130 & -- & -- \\
\hline $\operatorname{SEP}^{16} \cdots$ & 1300 & 858 & 554 & 8.2 & 24.5 & 12 & 9.7 & 119 & K16 & E32 \\
\hline $17 \ldots$ & 1200 & 1560 & 583 & 8.0 & 21.5 & 4.5 & 10.6 & 125 & K5 & 59 \\
\hline
\end{tabular}

DATE

$\begin{array}{ccc} & \text { HARD- } \\ \text { NESS } & \\ \text { HARD- } & \text { NONCARB } & \text { CALCIUM } \\ \text { NESS } & \text { WH WAT } & \text { DIS- } \\ \text { (MG/L } & \text { TOT FLD } & \text { SOLVED } \\ \text { AS } & \text { MG/L AS } & \text { (MG/L } \\ \text { CACO3) } & \text { CACO3 } & \text { AS CA })\end{array}$

NOV
$04 \ldots$
JAN
$06 \ldots$

MAR $26 \ldots$

MAY

JUL

$16 \ldots$

SEP $17 \ldots$

$\begin{array}{lll}290 & 57 & 78 \\ 280 & 65 & 76 \\ 280 & 59 & 76 \\ 280 & 55 & 72 \\ 240 & 57 & 60 \\ 250 & 61 & 64\end{array}$

ALKA-

LINITY

WH WAT

TOTAL

DATE

MG $/ L$ AS

$\mathrm{CACO} 3$

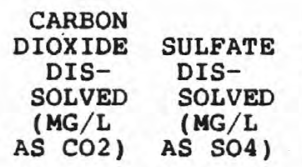

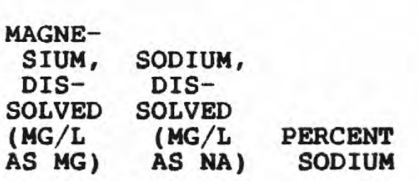

SODIUM
AD-
SORP-

TION

RATIO SODIUM
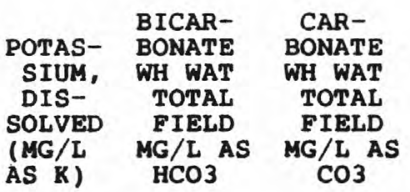

$\begin{array}{ll}22 & 18 \\ 23 & 18 \\ 22 & 20 \\ 24 & 24 \\ 23 & 29 \\ 23 & 24\end{array}$

12
12
13
16
20
17
0.5
0.5
0.6

2.4

0.5

1.9

2.1

2.1

0.82 .6

0.7

2.6

SOLIDS, SOLIDS,

RESIDUE SUM OF

AT 180 CONSTI-

DEG. C TUENTS

DIS

SOLVED
(MG/L)

TUENTS,

DIS-
SOLVED

SOLVED

SOLIDS, SOLIDS,

DIS- DIS-

SOLVED SOLVED

(TONS (TONS

(TONS (TONS

$\begin{array}{cl}\text { PER } & \text { PER } \\ \text { AC-FT) } & \text { DAY }\end{array}$

\begin{tabular}{|c|c|c|c|c|}
\hline $\begin{array}{l}\text { NOV } \\
04 \ldots\end{array}$ & -- & 2.2 & 45 & 28 \\
\hline JAN & & & & \\
\hline$\underset{M A R}{06} \ldots$ & 220 & 2.7 & 47 & 30 \\
\hline${ }_{\text {MAY }}^{26 \ldots}$ & 222 & 2.7 & 48 & 32 \\
\hline${ }_{\text {JUL }} 27 \ldots$ & 224 & 0.9 & 46 & 39 \\
\hline $\operatorname{SEP}_{16}$ & 188 & 2.3 & 40 & 40 \\
\hline $17 \ldots$ & 194 & 3.8 & 52 & 1 \\
\hline
\end{tabular}

$\begin{array}{rrrrrr}0.2 & 11 & 293 & 350 & 0.4 & 1440 \\ 0.1 & 8.1 & 356 & 340 & 0.48 & 1570 \\ 0.2 & 5.0 & 346 & 340 & 0.47 & 1550 \\ 0.2 & 1.3 & 352 & 370 & 0.48 & 988 \\ 0.2 & 0.7 & 325 & 310 & 0.44 & 753 \\ 0.2 & 2.3 & 324 & 320 & 0.44 & 1360\end{array}$


04108500 KALAMAZOO RIVER NEAR FENNVILLE, MI WATER QUALITY DATA, WATER YEAR OCTOBER 1986 TO SEPTEMBER 1987

\begin{tabular}{|c|c|c|c|c|c|c|c|c|c|c|}
\hline DATE & $\begin{array}{c}\text { NITRO- } \\
\text { GEN, } \\
\text { NITRITE } \\
\text { DIS- } \\
\text { SOLVED } \\
\text { (MG/L } \\
\text { AS N) }\end{array}$ & $\begin{array}{c}\text { NITRO- } \\
\text { GEN, } \\
\text { NO2+NO3 } \\
\text { DIS- } \\
\text { SOLVED } \\
\text { (MG/L } \\
\text { AS N) }\end{array}$ & $\begin{array}{l}\text { NITRO- } \\
\text { GEN, } \\
\text { AMMONIA } \\
\text { TOTAL } \\
\text { (MG/L } \\
\text { AS N) }\end{array}$ & $\begin{array}{l}\text { NITRO- } \\
\text { GEN, } \\
\text { AMMONIA } \\
\text { DIS- } \\
\text { SOLVED } \\
\text { (MG/L } \\
\text { AS N) }\end{array}$ & $\begin{array}{c}\text { NITRO- } \\
\text { GEN, } \\
\text { ORGANIC } \\
\text { TOTAL } \\
\text { (MG/L } \\
\text { AS N) }\end{array}$ & $\begin{array}{l}\text { NITRO- } \\
\text { GEN, AM- } \\
\text { MONIA + } \\
\text { ORGANIC } \\
\text { TOTAL } \\
\text { (MG/L } \\
\text { AS N) }\end{array}$ & $\begin{array}{c}\text { PHOS- } \\
\text { PHORUS, } \\
\text { TOTAL } \\
\text { (MG/L } \\
\text { AS P) }\end{array}$ & $\begin{array}{c}\text { PHOS- } \\
\text { PHORUS, } \\
\text { DIS- } \\
\text { SOLVED } \\
\text { (MG/L } \\
\text { AS P) }\end{array}$ & $\begin{array}{l}\text { PHOS- } \\
\text { PHORUS, } \\
\text { ORTHO, } \\
\text { DIS- } \\
\text { SOLVED } \\
\text { (MG/L } \\
\text { AS P) }\end{array}$ & $\begin{array}{l}\text { ALUM- } \\
\text { INUM, } \\
\text { DIS- } \\
\text { SOLVED } \\
\text { (UG/L } \\
\text { AS AL) }\end{array}$ \\
\hline & & & & & & & & & & \\
\hline$\ldots$ & 0.02 & 1.10 & 0.12 & 0.11 & 1.1 & 1.2 & 0.09 & 0.03 & 0.03 & $<10$ \\
\hline$\cdots$ & 0.02 & 1.50 & 0.05 & 0.05 & 0.45 & 0.5 & 0.03 & $<0.01$ & 0.01 & -- \\
\hline$\cdots$ & $\quad 0.01$ & 1.10 & 0.05 & 0.06 & 0.75 & 0.8 & 0.07 & 0.02 & 0.04 & 10 \\
\hline & 0.02 & 0.45 & 0.03 & 0.02 & 1.4 & 1.4 & 0.13 & 0.03 & $<0.01$ & $<10$ \\
\hline & 0.02 & 0.18 & 0.12 & 0.13 & 1.2 & 1.3 & 0.16 & 0.03 & 0.02 & - \\
\hline $7 \ldots$ & 0.07 & 4.60 & 0.37 & 0.38 & 2.0 & 2.4 & 0.70 & 0.32 & 0.30 & 20 \\
\hline
\end{tabular}

$\begin{array}{cc}\text { ARSENIC } & \text { BARIUM, } \\ \text { DIS- } & \text { DIS- } \\ \text { SOLVED } & \text { SOLVED } \\ \text { (UG/L } & \text { (UG/L } \\ \text { AS AS) } & \text { AS BA) }\end{array}$

BERYL-

CHRO-

SOLVED

(UG/L

AS BE)

CADMIUM
DIS-
SOLVED
(UG/L
AS CD)

MIUM,

DIS-

SOLVED

( US CR
COBALT, COPPER,

DIS- DIS-

SOLVED SOLVED

(UG/L (UG/L

AS CO) AS CU)

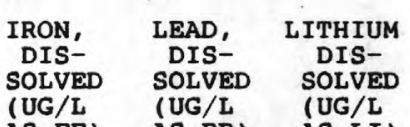
$\begin{array}{lll}\text { (UG/L } & \text { (UG/L } & \text { (UG } / L \\ \text { AS FE) } & \text { AS PB) } & \text { AS LI) }\end{array}$

$$
\begin{gathered}
\text { NOV } \\
04 \ldots \\
\text { JAN } \\
06 \ldots \\
\text { MAR } \ldots \\
26 \ldots \\
\text { MAY } \ldots \\
27 \ldots \\
\text { JUL } \\
16 \ldots \\
\text { SEP }
\end{gathered}
$$$$
17 \ldots
$$

$17 \ldots$

NOV

$04 \ldots$

JAN 06

MAR 06

$26 \ldots$

$27 \ldots$

JUL

$16 \ldots$

$17 \ldots$

$\begin{array}{rr}1 & 59 \\ -- & -- \\ <1 & 63 \\ 1 & 72 \\ -- & -- \\ 1 & 66\end{array}$

$\begin{array}{rr}<0.5 & <1 \\ -- & -- \\ <0.5 & <1 \\ <0.5 & <1 \\ -- & - \\ <0.5 & 3\end{array}$

MANGA-

NESE,

$$
\text { DIS- }
$$
SOLVET (UG/L

MERCURY
DIS-
SOLVED
(UG/L
AS HG)

DENUM, NICKEL,

DIS-

SOLVED

(UG/L

DIS-

DOLVED

SOLVED

(UG NI

1

$<3$
--
$<3$
$<3$
--
$<3$

SELE

NIUM, SILVER,

DIS-

SOLVED

(UG/L (UG/L

(UG/L

4
--
5
2
--
1

20
--
10
7
--
12


A-
M,
S-
VED
V)
V)

$\begin{array}{lr}<5 & 12 \\ -- & -- \\ <5 & 11 \\ <5 & 12 \\ -- & -- \\ <5 & 6\end{array}$

INC, SEDI-

DIS- MENT,

SOLVED SUS-

$\begin{array}{ll}\text { (UG/L } & \text { PENDED } \\ \text { AS ZN) } & \text { (MG/L) }\end{array}$

$\begin{array}{rrrrrrrrrr}24 & <0.1 & <10 & 3 & <1 & <1 & 130 & <6 & 12 & 11 \\ -- & -- & -- & -- & -- & - & -- & -- & -- & 37 \\ 54 & <0.1 & <10 & 4 & <1 & <1 & 130 & <6 & 7 & 18 \\ <1 & <0.1 & <10 & 1 & <1 & <1 & 140 & <6 & 7 & 30 \\ -- & -- & -- & -- & -- & -- & -- & -- & -- & 34 \\ 2 & 0.1 & <10 & 1 & <1 & <1 & 130 & <6 & 13 & 18\end{array}$

DATE

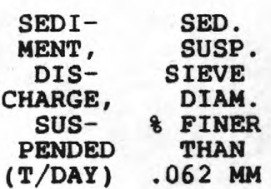

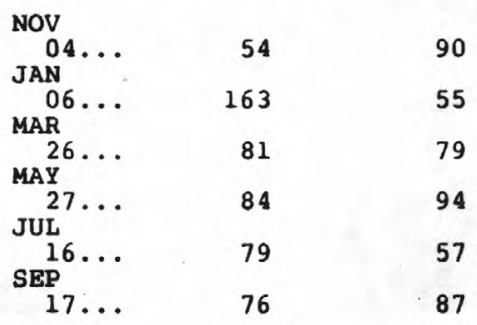


LOCATION. --Lat $42^{\circ} 38^{\prime} 32^{\prime \prime}$, long $85^{\circ} 43^{\prime} 19^{\prime \prime}$, in SEl/4 sec.16, T.3 N., R.12 W., Allegan County, Hydrologic Unit 04050003 , on left bank at downstream side of bridge on 18 th street, $2.5 \mathrm{mi}$ northeast of Hopkins.

DRAINAGE AREA. $--71.4 \mathrm{mi}^{2}$.

PERIOD OF RECORD.--October 1965 to current year.

GAGE.--Water-stage recorder. Elevation of gage is $700 \mathrm{ft}$ above National Geodetic Vertical Datum of 1929 , from topographic map.

REMARKS.--Estimated daily discharges: Dec. 14, and Jan. 21 to Feb. 19. Records good except for estimated daily discharges, which are fair. Several measurements of water temperature were made during the year.

AVERAGE DISCHARGE.--22 years, $57.4 \mathrm{ft}^{3} / \mathrm{s}, 10.92 \mathrm{in} / \mathrm{yr}^{2}$

EXTREMES FOR PERIOD OF RECORD.--Maximum discharge, 1,180 $\mathrm{ft}^{3} / \mathrm{s}$, June 26, 1978, gage height, 9.56 ft; minimum not determined; minimum daily, 9.2 ft3/s, Aug. 27, 28, 1970, Sept. 18, 1971, Aug. 7, 1987 ; minimum gage height, $1.68 \mathrm{ft}$, Aug. 8, 1987 .

EXTREMES FOR CURRENT YEAR.--Maximum discharge, $336 \mathrm{ft}^{3} / \mathrm{s}$, Oct. 1, gage height, $7.22 \mathrm{ft}$, stage falling, peak occurred Sept. 30,1986 ; maximum peak discharge, $277 \mathrm{ft} 3 / \mathrm{s}$. Aug. 15, gage height, $6.53 \mathrm{ft}$, no independent peak discharge above base discharge of $300 \mathrm{ft} / \mathrm{s}$; minimum discharge, $8.5 \mathrm{ft} / \mathrm{s}, \mathrm{Aug} .8, \mathrm{gage} \mathrm{height,}$

DISCHARGE, IN CUBIC FEET PER SECOND, WATER YEAR OCTOBER 1986 TO SEPTEMBER 1987 MEAN VALUES

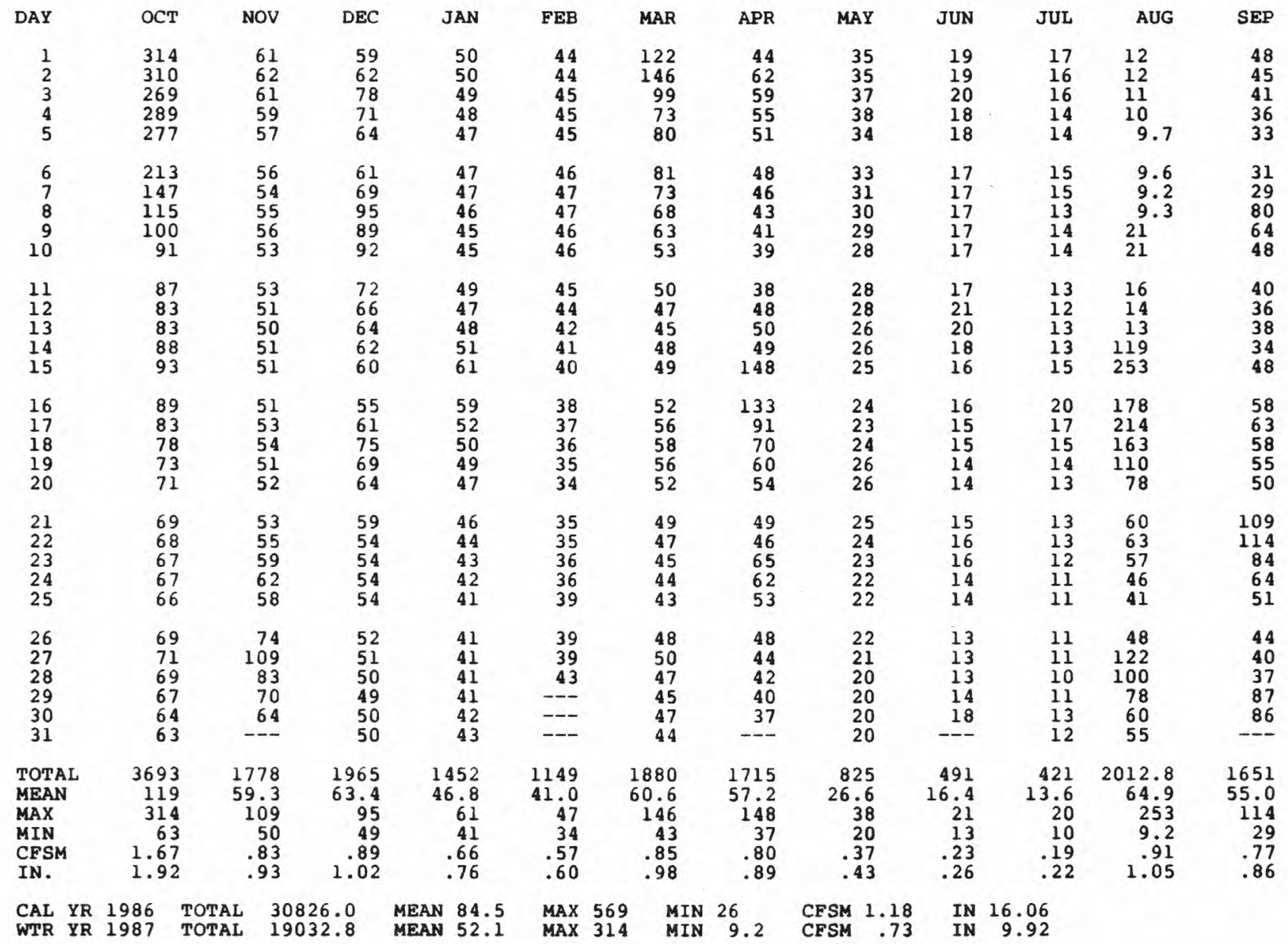




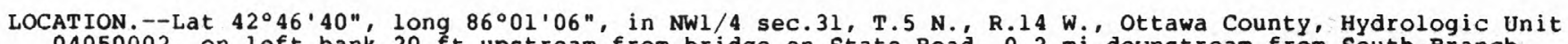
04050002 , on left bank 20 ft upstream from bridge on state Road, $0.2 \mathrm{mi}$ downstream from South Branch, and $2.5 \mathrm{mi}$ south of Zeeland.

DRAINAGE AREA. $--65.8 \mathrm{mi}^{2}$.

PERIOD OF RECORD.--October 1960 to current year. Prior to October 1978, published as Black River near Zeeland.

GAGE.--Water-stage recorder. Datum of gage is $585.7 \mathrm{ft}$ above National Geodetic Vertical Datum of 1929 (levels by Gove Associates, Inc.).

REMARKS.--Estimated daily discharges: Dec. 13, 14, and Jan. 19 to Feb. 26. Records good except for estimated daily discharges, which are poor. Several measurements of water temperature were made during the year.

AVERAGE DISCHARGE.--27 years, $67.3 \mathrm{ft}^{3} / \mathrm{s}, 13.89 \mathrm{in} / \mathrm{yr}$.

EXTREMES FOR PERIOD OF RECORD.--Maximum discharge, 7,220 ft $3 / \mathrm{s}$, May 11, 1981, gage height, $15.81 \mathrm{ft}$; minimum, $0.90 \mathrm{ft}^{3} / \mathrm{s}$, Aug. 24, 1962, Aug. 8, 1987; minimum gage height, 1.61 ft, Sept. 3, 1983.

EXTREMES FOR CURRENT YEAR.--Peak discharges greater than base discharge of $900 \mathrm{ft}^{3} / \mathrm{s}$ and maximum ( ${ }^{*}$ ):

\begin{tabular}{|c|c|c|c|c|c|c|c|}
\hline Date & Time & $\begin{array}{c}\text { Discharge } \\
\left(\mathrm{ft}^{3} / \mathrm{s}\right)\end{array}$ & $\begin{array}{l}\text { Gage height } \\
\text { (ft) }\end{array}$ & Date & Time & $\begin{array}{c}\text { Discharge } \\
\left(\mathrm{ft}^{3} / \mathrm{s}\right)\end{array}$ & $\begin{array}{c}\text { Gage height } \\
(f t)\end{array}$ \\
\hline Oct. 2 & 0400 & 1,130 & 10.48 & Sept. 22 & 0100 & $\star 1,240$ & $\star 10.76$ \\
\hline
\end{tabular}

Minimum discharge, $0.90 \mathrm{ft}^{3} / \mathrm{s}$, Aug. 8; minimum gage height, $1.70 \mathrm{ft}, \mathrm{July} 24$.

DISCHARGE, IN CUBIC FEET PER SECOND, WATER YEAR OCTOBER 1986 TO SEPTEMBER 1987

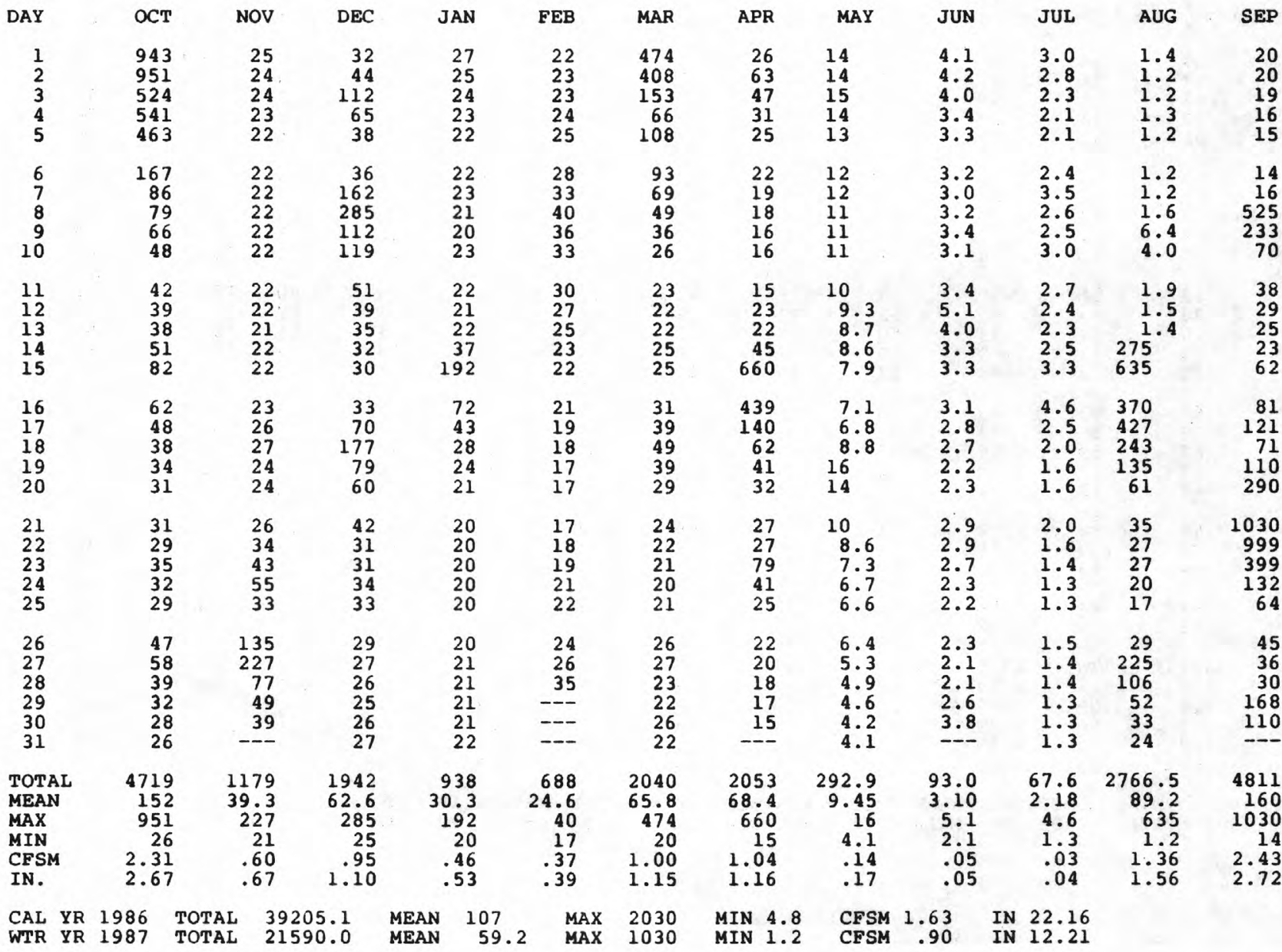


LOCATION.--Lat $42^{\circ} 17^{\prime} 05^{\prime \prime}$, long $84^{\circ} 24^{\prime} 30^{\prime \prime}$, in sec. 22, T.2 S., R.1 W., Jackson County, Hydrologic Unit 04050004 , on left bank on grounds of sewage-treatment plant, 1 mi north of Jackson, $2.2 \mathrm{mi}$ upstream from Portage River, and at mile 216 .

DRAINAGE AREA. $--174 \mathrm{mi}^{2}$.

PERIOD OF RECORD.--April 1935 to current year.

REVISED RECORDS.--WSP 974: 1937(M). WSP 1387: 1936. WSP 1727: 1950(M).

GAGE.--Water-stage recorder. Datum of gage is $900.00 \mathrm{ft}$, Fargo Engineering Co. datum. Prior to Sept. 24 , 1935, nonrecording gage at same site and datum.

REMARKS.--Estimated daily discharges: June 1-24. Records good except for estimated daily discharges, which are poor. Slight regulation by mills upstream from station. Flow includes about 17 ft $3 / 5$ as sewage effluent, which originates from ground-water sources, from the City of Jackson. Several measurements of water temperature were made during the year.

AVERAGE DISCHARGE. -52 years, $123 \mathrm{ft}^{3} / \mathrm{s}, 9.60 \mathrm{in} / \mathrm{yr}^{\mathrm{r}}$.

EXTREMES FOR PERIOD OF RECORD.--Maximum discharge, 1,070 $\mathrm{ft}^{3} / \mathrm{s}$, June 25, 1937, gage height, 13.50 ft; maximum gage height, $15.44 \mathrm{ft}$, June 25, 1968 ; minimum discharge, 9.2 ft3/s, Aug. 22 , 1936 .

EXTREMES FOR CURRENT YEAR.--Maximum discharge, $476 \mathrm{ft}^{3} / \mathrm{s}$, Oct. 3 , gage height, $12.36 \mathrm{ft}$, from graph based on gage readings; minimum, $13 \mathrm{ft}^{3} / \mathrm{s}$, Aug. 13, gage height, $8.13 \mathrm{ft}$, result of regulation.

DISCHARGE, IN CUBIC FEET PER SECOND, WATER YEAR OCTOBER 1986 TO SEPTEMBER 1987

\begin{tabular}{|c|c|c|c|c|c|c|c|c|c|c|c|c|}
\hline DAY & OCT & NOV & DEC & JAN & FEB & MAR & APR & MAY & JUN & JUL & AUG & SEP \\
\hline $\begin{array}{l}1 \\
2 \\
3 \\
4 \\
5\end{array}$ & $\begin{array}{l}272 \\
261 \\
319 \\
299 \\
300\end{array}$ & $\begin{array}{r}145 \\
144 \\
142 \\
98 \\
89\end{array}$ & $\begin{array}{l}163 \\
176 \\
175 \\
173 \\
168\end{array}$ & $\begin{array}{r}95 \\
98 \\
100 \\
97 \\
102\end{array}$ & $\begin{array}{l}83 \\
86 \\
88 \\
91 \\
94\end{array}$ & $\begin{array}{l}144 \\
151 \\
140 \\
131 \\
136\end{array}$ & $\begin{array}{l}154 \\
156 \\
154 \\
150 \\
161\end{array}$ & $\begin{array}{l}78 \\
79 \\
95 \\
92 \\
88\end{array}$ & $\begin{array}{l}130 \\
130 \\
130 \\
130 \\
130\end{array}$ & $\begin{array}{l}46 \\
43 \\
65 \\
43 \\
39\end{array}$ & $\begin{array}{l}34 \\
32 \\
33 \\
41 \\
36\end{array}$ & $\begin{array}{l}78 \\
78 \\
74 \\
70 \\
64\end{array}$ \\
\hline $\begin{array}{r}6 \\
7 \\
8 \\
9 \\
10\end{array}$ & $\begin{array}{l}292 \\
289 \\
283 \\
277 \\
246\end{array}$ & $\begin{array}{r}85 \\
120 \\
116 \\
110 \\
109\end{array}$ & $\begin{array}{l}163 \\
166 \\
169 \\
179 \\
179\end{array}$ & $\begin{array}{l}103 \\
112 \\
114 \\
113 \\
113\end{array}$ & $\begin{array}{r}113 \\
113 \\
116 \\
98 \\
121\end{array}$ & $\begin{array}{l}140 \\
171 \\
178 \\
176 \\
171\end{array}$ & $\begin{array}{l}166 \\
193 \\
197 \\
188 \\
185\end{array}$ & $\begin{array}{r}88 \\
87 \\
134 \\
137 \\
127\end{array}$ & $\begin{array}{r}110 \\
90 \\
75 \\
65 \\
60\end{array}$ & $\begin{array}{l}66 \\
45 \\
42 \\
40 \\
43\end{array}$ & $\begin{array}{l}35 \\
31 \\
28 \\
41 \\
31\end{array}$ & $\begin{array}{l}58 \\
55 \\
70 \\
66 \\
62\end{array}$ \\
\hline $\begin{array}{l}11 \\
12 \\
13 \\
14 \\
15\end{array}$ & $\begin{array}{l}240 \\
235 \\
237 \\
191 \\
168\end{array}$ & $\begin{array}{r}109 \\
108 \\
105 \\
103 \\
75\end{array}$ & $\begin{array}{l}171 \\
178 \\
154 \\
158 \\
167\end{array}$ & $\begin{array}{l}115 \\
115 \\
117 \\
117 \\
121\end{array}$ & $\begin{array}{r}113 \\
112 \\
110 \\
109 \\
97\end{array}$ & $\begin{array}{l}135 \\
124 \\
164 \\
169 \\
165\end{array}$ & $\begin{array}{l}159 \\
149 \\
145 \\
145 \\
150\end{array}$ & $\begin{array}{r}125 \\
78 \\
69 \\
79 \\
77\end{array}$ & $\begin{array}{l}65 \\
72 \\
60 \\
50 \\
47\end{array}$ & $\begin{array}{l}40 \\
34 \\
37 \\
37 \\
38\end{array}$ & $\begin{array}{l}32 \\
34 \\
27 \\
32 \\
33\end{array}$ & $\begin{array}{l}70 \\
63 \\
57 \\
58 \\
92\end{array}$ \\
\hline $\begin{array}{l}16 \\
17 \\
18 \\
19 \\
20\end{array}$ & $\begin{array}{l}180 \\
176 \\
167 \\
159 \\
158\end{array}$ & $\begin{array}{l}66 \\
70 \\
73 \\
74 \\
79\end{array}$ & $\begin{array}{l}157 \\
155 \\
156 \\
135 \\
128\end{array}$ & $\begin{array}{l}119 \\
115 \\
117 \\
106 \\
104\end{array}$ & $\begin{array}{l}101 \\
101 \\
101 \\
110 \\
109\end{array}$ & $\begin{array}{l}163 \\
160 \\
158 \\
156 \\
145\end{array}$ & $\begin{array}{l}153 \\
148 \\
144 \\
139 \\
140\end{array}$ & $\begin{array}{r}67 \\
60 \\
82 \\
85 \\
104\end{array}$ & $\begin{array}{r}45 \\
44 \\
43 \\
52 \\
100\end{array}$ & $\begin{array}{l}38 \\
38 \\
34 \\
30 \\
36\end{array}$ & $\begin{array}{l}26 \\
31 \\
33 \\
33 \\
31\end{array}$ & $\begin{array}{l}80 \\
93 \\
94 \\
96 \\
91\end{array}$ \\
\hline $\begin{array}{l}21 \\
22 \\
23 \\
24 \\
25\end{array}$ & $\begin{array}{r}155 \\
152 \\
157 \\
153 \\
98\end{array}$ & $\begin{array}{r}88 \\
135 \\
139 \\
144 \\
147\end{array}$ & $\begin{array}{l}124 \\
119 \\
121 \\
114 \\
111\end{array}$ & $\begin{array}{r}127 \\
128 \\
110 \\
92 \\
114\end{array}$ & $\begin{array}{l}107 \\
102 \\
109 \\
109 \\
111\end{array}$ & $\begin{array}{l}137 \\
134 \\
133 \\
104 \\
104\end{array}$ & $\begin{array}{r}119 \\
109 \\
112 \\
103 \\
94\end{array}$ & $\begin{array}{r}109 \\
108 \\
101 \\
97 \\
94\end{array}$ & $\begin{array}{l}80 \\
90 \\
70 \\
5.3 \\
48\end{array}$ & $\begin{array}{l}35 \\
36 \\
33 \\
35 \\
31\end{array}$ & $\begin{array}{r}54 \\
107 \\
50 \\
42 \\
42\end{array}$ & $\begin{array}{l}94 \\
96 \\
95 \\
91 \\
73\end{array}$ \\
\hline $\begin{array}{l}26 \\
27 \\
28 \\
29 \\
30 \\
31\end{array}$ & $\begin{array}{r}92 \\
101 \\
147 \\
156 \\
148 \\
147\end{array}$ & $\begin{array}{l}171 \\
166 \\
165 \\
162 \\
161 \\
---\end{array}$ & $\begin{array}{r}111 \\
101 \\
98 \\
101 \\
100 \\
97\end{array}$ & $\begin{array}{r}112 \\
106 \\
105 \\
103 \\
83 \\
80\end{array}$ & $\begin{array}{l}112 \\
115 \\
120 \\
---- \\
---\end{array}$ & $\begin{array}{l}109 \\
140 \\
141 \\
140 \\
151 \\
145\end{array}$ & $\begin{array}{r}86 \\
91 \\
89 \\
84 \\
80 \\
---\end{array}$ & $\begin{array}{r}95 \\
71 \\
67 \\
63 \\
93 \\
108\end{array}$ & $\begin{array}{r}49 \\
42 \\
37 \\
42 \\
46 \\
-\end{array}$ & $\begin{array}{l}31 \\
33 \\
32 \\
33 \\
32 \\
32\end{array}$ & $\begin{array}{r}126 \\
131 \\
101 \\
83 \\
75 \\
79\end{array}$ & $\begin{array}{r}67 \\
59 \\
62 \\
99 \\
114 \\
\end{array}$ \\
\hline $\begin{array}{l}\text { TOTAL } \\
\text { MEAN } \\
\text { MAX } \\
\text { MIN } \\
\text { CFSM } \\
\text { IN. }\end{array}$ & $\begin{array}{r}6255 \\
202 \\
319 \\
92 \\
1.16 \\
1.34\end{array}$ & $\begin{array}{r}3498 \\
117 \\
171 \\
66 \\
.67 \\
.75\end{array}$ & $\begin{array}{r}4467 \\
144 \\
179 \\
97 \\
.83 \\
.96\end{array}$ & $\begin{array}{r}3353 \\
108 \\
128 \\
80 \\
.62 \\
.72\end{array}$ & $\begin{array}{r}2951 \\
105 \\
121 \\
83 \\
.60 \\
.63\end{array}$ & $\begin{array}{r}4515 \\
146 \\
178 \\
104 \\
.84 \\
.97\end{array}$ & $\begin{array}{r}4143 \\
138 \\
197 \\
80 \\
.79 \\
.89\end{array}$ & $\begin{array}{r}2837 \\
91.5 \\
137 \\
60 \\
.53 \\
.61\end{array}$ & $\begin{array}{r}2185 \\
72.8 \\
130 \\
37 \\
.42 \\
.47\end{array}$ & $\begin{array}{r}1197 \\
38.6 \\
66 \\
30 \\
.22 \\
.26\end{array}$ & $\begin{array}{r}1544 \\
49.8 \\
131 \\
26 \\
.29 \\
.33\end{array}$ & $\begin{array}{r}2319 \\
77.3 \\
114 \\
55 \\
.44 \\
.50\end{array}$ \\
\hline $\begin{array}{l}\text { CAL YR } \\
\text { WTR YR }\end{array}$ & $\begin{array}{l}1986 \\
1987\end{array}$ & $\begin{array}{ll}A L & 5 \\
A L & 3\end{array}$ & $\begin{array}{l}\mathbf{M} \\
\mathbf{M}\end{array}$ & $\begin{array}{l}142 \\
108\end{array}$ & $\begin{array}{ll}\text { MAX } & 407 \\
\text { MAX } & 319\end{array}$ & $\begin{array}{ll}\text { MIN } & 40 \\
\text { MIN } & 26\end{array}$ & $\begin{array}{l}\text { CFSM } \\
\text { CFSM }\end{array}$ & $\begin{array}{l}.82 \\
.62\end{array}$ & $\begin{array}{r}11.07 \\
8.39\end{array}$ & & & \\
\hline
\end{tabular}


LOCATION.--Lat $42^{\circ} 40^{\prime} 59^{\prime \prime}$, long $84^{\circ} 13^{\prime} 09^{\prime \prime}$, in NEl/4 sec.4, T.3 N., R. 2 E. Ingham County, Hydrologic Unit 04050004 , on $r i g h t$ bank $20 \mathrm{ft}$ upstream from bridge on state Highway 52 , $1.5 \mathrm{mi}$ upstream from Squaw Creek, and $3.5 \mathrm{mi}$ east of Williamston.

DRAINAGE AREA. $--163 \mathrm{mi}^{2}$.

PERIOD OF RECORD.--July 1975 to current year.

GAGE.--Water-stage recorder. Elevation of gage is $870 \mathrm{ft}$ above National Geodetic Vertical Datum of 1929 , from topographic map.

REMARKS.--Estimated daily discharges: Dec. 12-15 and Jan. 19 to Feb. 21. Records good except for estimated daily discharges, which are fair. Several measurements of water temperature were made during the year. National Weather Service gage-height telemeter at station.

AVERAGE DISCHARGE. --12 years, $104 \mathrm{ft}^{3} / \mathrm{s}, 8.66 \mathrm{in} / \mathrm{yr}^{2}$

EXTREMES FOR PERIOD OF RECORD.--Maximum discharge, 1,790 ft $3 / \mathrm{s}$, Feb. 26, 1985, gage height, $9.07 \mathrm{ft}$; minimum, $2.6 \mathrm{fts} / \mathrm{s}$, Aug. $24,27,1984$, gage height, $1.96 \mathrm{ft}$.

EXTREMES OUTSIDE PERIOD OF RECORD.--Flood of April 1975, reached a stage of $10.41 \mathrm{ft}$, Apr. 19, and a discharge of $2,640 \mathrm{ft}^{3} / \mathrm{s}, \mathrm{Apr} .20$.

EXTREMES FOR CURRENT YEAR.--Maximum discharge, $589 \mathrm{ft}^{3} / \mathrm{s}$, Oct. 5, gage height, $6.60 \mathrm{ft}$; minimum, $3.8 \mathrm{ft}^{3} / \mathrm{s}$, Aug. 21 , gage height, $2.02 \mathrm{ft}$.

DISCHARGE, IN CUBIC FEET PER SECOND, WATER YEAR OCTOBER 1986 TO SEPTEMBER 1987

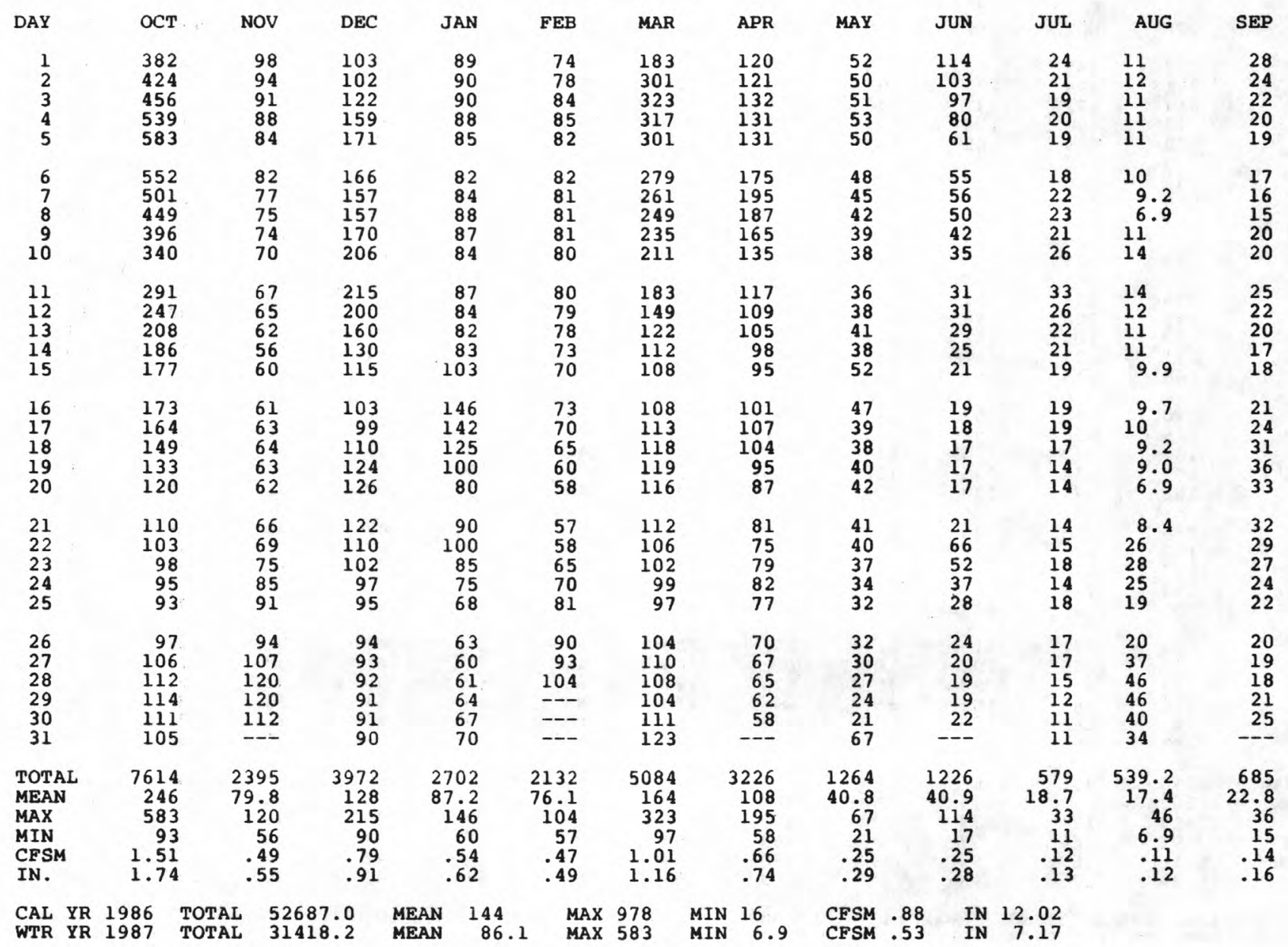




\section{DEER CREEK NEAR DANSVILLE, MI}

LOCATION.--Lat $42^{\circ} 36^{\prime} 30^{\prime \prime}$, long $84^{\circ} 19^{\prime} 15^{\prime \prime}$, in El/2 sec.33, T. 3 N., R. 1 E., Ingham County, Hydrologic Unit 04050004 , on right bank $15 \mathrm{ft}$ upstream from bridge on Clark Road, $3.5 \mathrm{mi}$ north of Dansville, and $7.2 \mathrm{mi}$ upstream from mouth.

DRAINAGE AREA.--16.3 $\mathrm{mi}^{2}$.

PERIOD OF RECORD.--May 1954 to current year.

REVISED RECORDS.--WSP 1727: $1954(\mathrm{M})$.

GAGE.--Water-stage recorder and concrete control. Datum of gage is $889.08 \mathrm{ft}$ above National Geodetic Vertical Datum of 1929 (levels by Michigan Department of Natural Resources).

REMARKS.--Estimated daily discharges: Jan. 19 to Feb. 6. Records good except for estimated daily discharges, which are fair. Several measurements of water temperature were made during the year.

AVERAGE DISCHARGE. -33 years, $10.9 \mathrm{ft}^{3} / \mathrm{s}, 9.08 \mathrm{in} / \mathrm{yr}$.

EXTREMES FOR PERIOD OF RECORD.--Maximum discharge, $962 \mathrm{ft}^{3} / \mathrm{s}$, Apr. 19, 1975, gage height, $12.18 \mathrm{ft}$, from floodmark, from rating curve extended above $610 \mathrm{ft} / \mathrm{s}$; minimum, $0.04 \mathrm{ft} / \mathrm{s}, \mathrm{Sept}$. 8 ,

9, 12, 1978, gage height, $2.58 \mathrm{ft}$.

EXTREMES FOR CURRENT YEAR.--Peak discharges greater than base discharge of $100 \mathrm{ft}^{3} / \mathrm{s}$ and maximum (*):

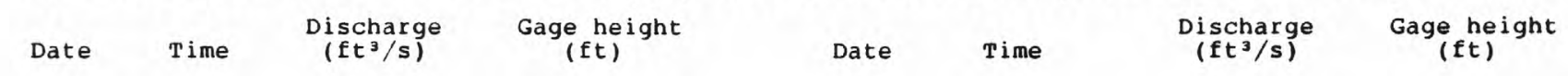

oct. $32200 \quad \star 161 \quad \star 5.81 \quad$ No other peak greater than base discharge.

Minimum discharge, $0.09 \mathrm{ft}^{3} / \mathrm{s}$, Aug. 20,21 , gage height, $2.61 \mathrm{ft}$.

DISCHARGE, IN CUBIC FEET PER SECOND, WATER YEAR OCTOBER 1986 TO SEPTEMBER 1987 MEAN VALUES

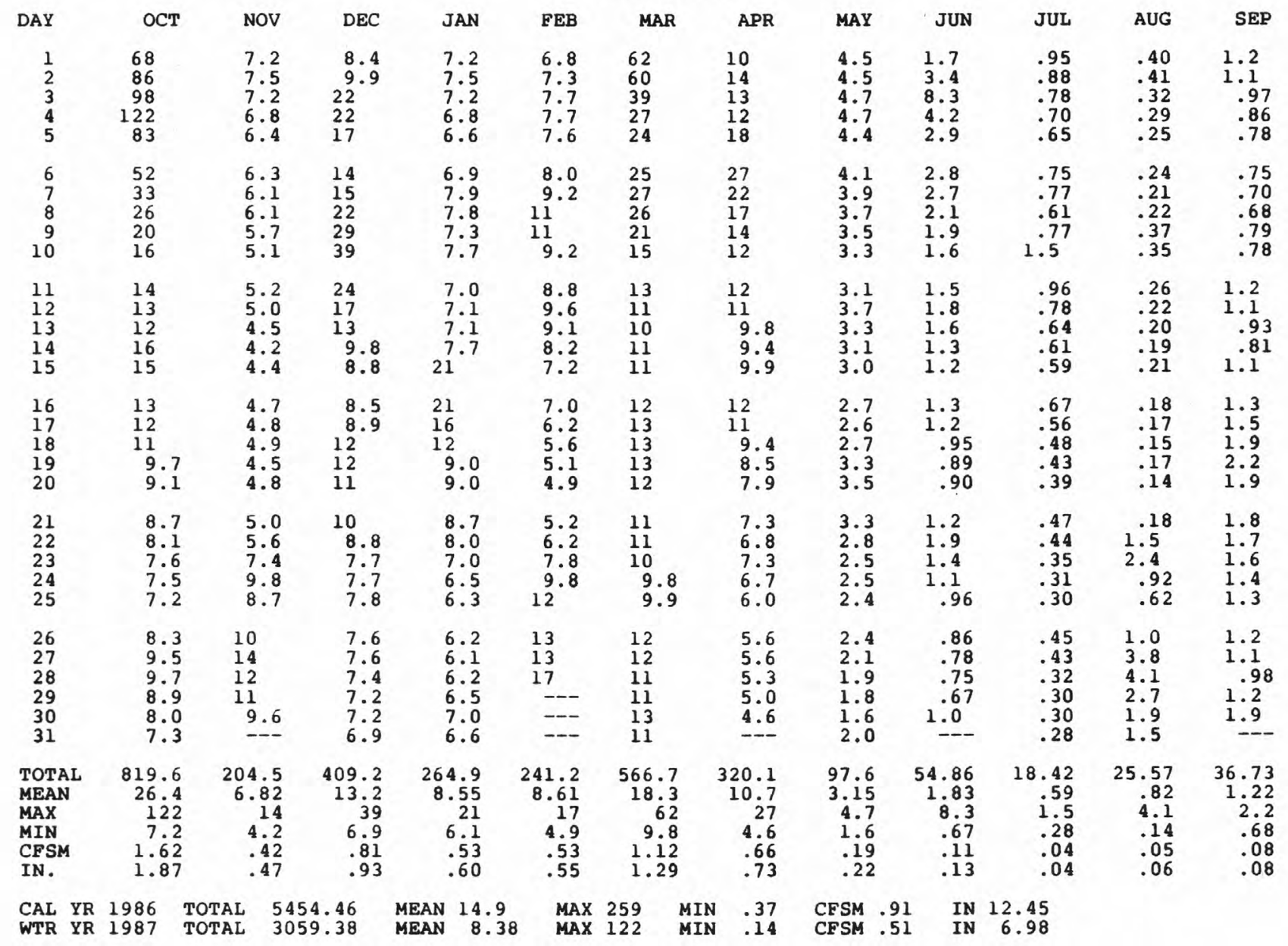




\section{SLOAN CREEK NEAR WILLIAMSTON, MI}

LOCATION.--Lat $42^{\circ} 40^{\prime} 33^{\prime \prime}$, long $84^{\circ} 21^{\prime} 50^{\prime \prime}$, in SE1/4 NEl/4 sec.1, T.3 N., R.1 W., Ingham County, Hydrologic Unit 04050004 , on left bank 30 ft downstream from culvert on Meridian Road, 2.1 mi upstream from mouth, and $4.2 \mathrm{mi}$ west of williamston.

DRAINAGE AREA. $--9.34 \mathrm{mi}^{2}$.

PERIOD OF RECORD.--June 1954 to current year.

GAGE.--Water-stage recorder and concrete control with V-notch sharp-crested weir. Datum of gage is 862.12 $f t$ above National Geodetic Vertical Datum of 1929 (levels by Michigan Department of Natural Resources).

REMARKS.--Estimated daily discharges: Jan. 17-27, June 26, 27, July 25-30, Aug. 6, 16-24, and Sept. 11, 20-24. Records good except for estimated daily discharges, which are poor. Several measurements of water temperature were made during the year.

AVERAGE DISCHARGE. --33 years, $5.77 \mathrm{ft}^{3} / \mathrm{s}, 8.39 \mathrm{in} / \mathrm{yr}^{\mathrm{r}}$.

EXTREMES FOR PERIOD OF RECORD.--Maximum discharge, 1,290 ft3/s, Apr. 18, 1975, gage height, $9.99 \mathrm{ft}$, from rating curve extended above $660 \mathrm{ft} / \mathrm{s}$ on basis of computation of peak flow through cuivert and over road embankment; minimum, $0.01 \mathrm{ft} / \mathrm{s}$, Sept. 11, 1954, Jan. 18, 1957, gage helght, $1.10 \mathrm{ft}$.

EXTREMES FOR CURRENT YEAR.--Maximum discharge, $112 \mathrm{ft}^{3} / \mathrm{s}$, Oct. 3 , gage height, $3.89 \mathrm{ft}$, no peak discharge above base discharge of $120 \mathrm{ft}^{3} / \mathrm{s} ;$ minimum daily, $0.04 \mathrm{ft}^{3} / \mathrm{s}$, July 30,31, Aug. $7,16,18,20$, minimum gage height, $1.20 \mathrm{ft}, J_{1} l_{Y} 31$, Aug. $3,4,6,7,16$.

DISCHARGE, IN CUBIC FEET PER SECOND, WATER YEAR OCTOBER 1986 TO SEPTEMBER 1987 MEAN VALUES

\begin{tabular}{|c|c|c|c|c|c|c|c|c|c|c|c|c|}
\hline DAY & OCT & NOV & DEC & JAN & FEB & MAR & APR & MAY & JUN & JUL & AUG & SEP \\
\hline $\begin{array}{l}1 \\
2 \\
3 \\
4 \\
5\end{array}$ & $\begin{array}{l}53 \\
57 \\
61 \\
64 \\
44\end{array}$ & $\begin{array}{l}2.4 \\
2.4 \\
2.4 \\
2.2 \\
2.2\end{array}$ & $\begin{array}{l}3.3 \\
4.1 \\
14 \\
11 \\
7.5\end{array}$ & $\begin{array}{l}2.9 \\
3.0 \\
2.8 \\
2.7 \\
2.6\end{array}$ & $\begin{array}{l}2.6 \\
2.9 \\
3.0 \\
3.1 \\
3.0\end{array}$ & $\begin{array}{l}44 \\
38 \\
25 \\
16 \\
15\end{array}$ & $\begin{array}{r}5.8 \\
7.7 \\
8.3 \\
7.3 \\
18\end{array}$ & $\begin{array}{l}1.7 \\
1.6 \\
1.6 \\
1.5 \\
1.4\end{array}$ & $\begin{array}{l}.44 \\
.54 \\
.73 \\
.53 \\
.45\end{array}$ & $\begin{array}{l}.32 \\
.27 \\
.20 \\
.16 \\
.16\end{array}$ & $\begin{array}{l}.06 \\
.07 \\
.05 \\
.06 \\
.06\end{array}$ & $\begin{array}{l}.12 \\
.12 \\
.11 \\
.10 \\
.09\end{array}$ \\
\hline $\begin{array}{r}6 \\
7 \\
8 \\
9 \\
10\end{array}$ & $\begin{array}{c}31 \\
23 \\
18 \\
14 \\
9.6\end{array}$ & $\begin{array}{l}2.1 \\
2.0 \\
1.9 \\
1.8 \\
1.7\end{array}$ & $\begin{array}{l}6.3 \\
6.6 \\
9.7 \\
19 \\
20\end{array}$ & $\begin{array}{l}2.8 \\
3.2 \\
3.1 \\
3.0 \\
3.0\end{array}$ & $\begin{array}{l}3.2 \\
3.9 \\
4.9 \\
4.7 \\
3.8\end{array}$ & $\begin{array}{r}16 \\
18 \\
15 \\
9.9 \\
6.8\end{array}$ & $\begin{array}{l}26 \\
16 \\
10 \\
7.9 \\
6.5\end{array}$ & $\begin{array}{l}1.4 \\
1.3 \\
1.2 \\
1.1 \\
1.1\end{array}$ & $\begin{array}{l}.57 \\
.55 \\
.46 \\
.42 \\
.39\end{array}$ & $\begin{array}{l}.18 \\
.16 \\
.16 \\
.16 \\
.17\end{array}$ & $\begin{array}{l}.05 \\
.04 \\
.05 \\
.11 \\
.08\end{array}$ & $\begin{array}{l}.09 \\
.08 \\
.10 \\
.13 \\
.15\end{array}$ \\
\hline $\begin{array}{l}11 \\
12 \\
13 \\
14 \\
15\end{array}$ & $\begin{array}{l}8.1 \\
7.0 \\
6.0 \\
7.9 \\
7.7\end{array}$ & $\begin{array}{l}1.7 \\
1.6 \\
1.4 \\
1.3 \\
1.4\end{array}$ & $\begin{array}{r}10 \\
6.8 \\
5.1 \\
4.4 \\
3.9\end{array}$ & $\begin{array}{r}2.9 \\
2.8 \\
2.7 \\
3.1 \\
12\end{array}$ & $\begin{array}{l}4.0 \\
4.7 \\
4.0 \\
3.5 \\
3.1\end{array}$ & $\begin{array}{l}5.5 \\
4.8 \\
4.4 \\
4.5 \\
4.3\end{array}$ & $\begin{array}{l}5.6 \\
5.1 \\
4.4 \\
4.2 \\
4.2\end{array}$ & $\begin{array}{l}1.0 \\
1.2 \\
1.0 \\
1.0 \\
.95\end{array}$ & $\begin{array}{l}.40 \\
.47 \\
.38 \\
.29 \\
.26\end{array}$ & $\begin{array}{l}.17 \\
.14 \\
.12 \\
.12 \\
.12\end{array}$ & $\begin{array}{l}.06 \\
.05 \\
.05 \\
.08 \\
.08\end{array}$ & $\begin{array}{l}.20 \\
.18 \\
.16 \\
.14 \\
.19\end{array}$ \\
\hline $\begin{array}{l}16 \\
17 \\
18 \\
19 \\
20\end{array}$ & $\begin{array}{l}6.7 \\
5.7 \\
4.9 \\
4.5 \\
4.2\end{array}$ & $\begin{array}{l}1.5 \\
1.5 \\
1.4 \\
1.3 \\
1.5\end{array}$ & $\begin{array}{l}3.7 \\
3.8 \\
4.8 \\
4.5 \\
4.3\end{array}$ & $\begin{array}{r}12 \\
7.0 \\
4.8 \\
3.7 \\
3.5\end{array}$ & $\begin{array}{l}2.9 \\
2.5 \\
2.2 \\
2.0 \\
2.0\end{array}$ & $\begin{array}{l}4.6 \\
5.2 \\
5.9 \\
5.7 \\
5.2\end{array}$ & $\begin{array}{l}6.1 \\
5.5 \\
4.7 \\
4.1 \\
3.8\end{array}$ & $\begin{array}{l}.85 \\
.80 \\
.83 \\
.97 \\
.99\end{array}$ & $\begin{array}{l}.24 \\
.23 \\
.22 \\
.20 \\
.21\end{array}$ & $\begin{array}{l}.14 \\
.13 \\
.11 \\
.12 \\
.12\end{array}$ & $\begin{array}{l}.04 \\
.05 \\
.04 \\
.05 \\
.04\end{array}$ & $\begin{array}{l}.19 \\
.28 \\
.35 \\
.32 \\
.30\end{array}$ \\
\hline $\begin{array}{l}21 \\
22 \\
23 \\
24 \\
25\end{array}$ & $\begin{array}{l}3.9 \\
3.6 \\
3.3 \\
3.1 \\
3.0\end{array}$ & $\begin{array}{l}1.5 \\
1.5 \\
1.9 \\
2.3 \\
2.2\end{array}$ & $\begin{array}{l}4.0 \\
3.6 \\
3.4 \\
3.3 \\
3.3\end{array}$ & $\begin{array}{l}3.4 \\
3.3 \\
3.0 \\
2.7 \\
2.5\end{array}$ & $\begin{array}{l}2.2 \\
2.8 \\
3.7 \\
3.9 \\
5.3\end{array}$ & $\begin{array}{l}4.8 \\
4.3 \\
4.1 \\
3.9 \\
3.9\end{array}$ & $\begin{array}{l}3.6 \\
3.3 \\
3.2 \\
2.8 \\
2.4\end{array}$ & $\begin{array}{l}.91 \\
.78 \\
.69 \\
.68 \\
.68\end{array}$ & $\begin{array}{l}.43 \\
.39 \\
.32 \\
.25 \\
.22\end{array}$ & $\begin{array}{l}.11 \\
.13 \\
.12 \\
.13 \\
.14\end{array}$ & $\begin{array}{l}.06 \\
.25 \\
.11 \\
.08 \\
.08\end{array}$ & $\begin{array}{l}.25 \\
.22 \\
.20 \\
.17 \\
.15\end{array}$ \\
\hline $\begin{array}{l}26 \\
27 \\
28 \\
29 \\
30 \\
31\end{array}$ & $\begin{array}{l}3.2 \\
3.3 \\
3.2 \\
3.0 \\
2.8 \\
2.5\end{array}$ & $\begin{array}{l}3.7 \\
6.0 \\
4.9 \\
4.2 \\
3.7\end{array}$ & $\begin{array}{l}3.0 \\
3.0 \\
3.0 \\
2.9 \\
2.9 \\
2.8\end{array}$ & $\begin{array}{l}2.3 \\
2.3 \\
2.5 \\
2.6 \\
2.8 \\
2.5\end{array}$ & $\begin{array}{l}5.5 \\
5.7 \\
8.0 \\
--- \\
--- \\
---\end{array}$ & $\begin{array}{l}4.3 \\
4.3 \\
4.4 \\
5.3 \\
6.5 \\
6.0\end{array}$ & $\begin{array}{l}2.3 \\
2.2 \\
2.1 \\
2.0 \\
1.8\end{array}$ & $\begin{array}{r}.69 \\
.62 \\
.53 \\
.47 \\
.42 \\
.44\end{array}$ & $\begin{array}{l}.24 \\
.24 \\
.25 \\
.27 \\
.32 \\
--\end{array}$ & $\begin{array}{l}.15 \\
.13 \\
.09 \\
.07 \\
.04 \\
.04\end{array}$ & $\begin{array}{l}.21 \\
.47 \\
.29 \\
.20 \\
.15 \\
.15\end{array}$ & $\begin{array}{l}.14 \\
.12 \\
.13 \\
.29 \\
.36 \\
-.-\end{array}$ \\
\hline $\begin{array}{l}\text { TOTAL } \\
\text { MEAN } \\
\text { MAX } \\
\text { MIN } \\
\text { CFSM } \\
\text { IN. }\end{array}$ & $\begin{array}{r}472.2 \\
15.2 \\
64 \\
2.5 \\
1.63 \\
1.88\end{array}$ & $\begin{array}{r}67.6 \\
2.25 \\
6.0 \\
1.3 \\
.24 \\
.27\end{array}$ & $\begin{array}{r}188.0 \\
6.06 \\
20 \\
2.8 \\
.65 \\
.75\end{array}$ & $\begin{array}{r}113.5 \\
3.66 \\
12 \\
2.3 \\
.39 \\
.45\end{array}$ & $\begin{array}{r}103.1 \\
3.68 \\
8.0 \\
2.0 \\
.39 \\
.41\end{array}$ & $\begin{array}{r}305.6 \\
9.86 \\
44 \\
3.9 \\
1.06 \\
1.22\end{array}$ & $\begin{array}{r}186.9 \\
6.23 \\
26 \\
1.8 \\
.67 \\
.74\end{array}$ & $\begin{array}{r}30.40 \\
.98 \\
1.7 \\
.42 \\
.11 \\
.12\end{array}$ & $\begin{array}{r}10.91 \\
.36 \\
.73 \\
.20 \\
.04 \\
.04\end{array}$ & $\begin{array}{r}4.38 \\
.14 \\
.32 \\
.04 \\
.02 \\
.02\end{array}$ & $\begin{array}{l}3.22 \\
.10 \\
.47 \\
.04 \\
.01 \\
.01\end{array}$ & $\begin{array}{r}5.43 \\
.18 \\
.36 \\
.08 \\
.02 \\
.02\end{array}$ \\
\hline $\begin{array}{l}\text { CAL YR } \\
\text { WTR YR }\end{array}$ & $\begin{array}{l}1986 \\
1987\end{array}$ & $\mathrm{~L}$ & $\begin{array}{l}.85 \\
.24\end{array}$ & $\begin{array}{l}\text { EAN } 7.99 \\
\text { EAN } 4.09\end{array}$ & $\begin{array}{l}\text { MAX } \\
\text { MAX }\end{array}$ & $\begin{array}{l}\text { MIN } \\
\text { MIN }\end{array}$ & $\begin{array}{l}.16 \\
.04\end{array}$ & $\begin{array}{l}\text { CFSM } .86 \\
\text { CFSM } .44\end{array}$ & $\begin{array}{l}\text { IN } \\
\text { IN }\end{array}$ & & & \\
\hline
\end{tabular}


04112500 RED CEDAR RIVER AT EAST LANSING, MI

LOCATION.--Lat $42^{\circ} 43^{\prime} 40^{\prime \prime}$, long $84^{\circ} 28^{\prime} 40^{\prime \prime}$, in SWl/4 sec.18, T.4 N., R.1 W. , Ingham County, Hydrologic Unit 04050004 , in left downstream bridge abutment of Farm Lane Bridge on Michigan State University Campus in East Lansing, $4.0 \mathrm{mi}$ upstream from sycamore Creek, and $5.6 \mathrm{mi}$ upstream from mouth.

DRAINAGE AREA. $--355 \mathrm{mi}^{2}$.

PERIOD OF RECORD.--August 1902 to December 1903, March 1931 to current year. Monthly discharge only for some periods, published in WSP 1307. Published as Red Cedar River at Agricultural College, August 1902 to December 1903 and as Cedar River at East Lansing, March 1931 to September 1965 . Gage-height records collected in this vicinity 1911-19, and for flood seasons only 1920-28, are contained in reports of the National Weather Service.

REVISED RECORDS.--WSP 1307: $1936(\mathrm{M})$.

GAGE.--Water-stage recorder and concrete control. Datum of gage is $824.39 \mathrm{ft}$ above National Geodetic Vertical Datum of 1929 . August 1902 to December 1903 nonrecording gage at site $0.8 \mathrm{mi}$ downstream at different datum. March 1931 to November 1940 water-stage recorder at site 250 ft upstream at present datum.

REMARKS.--Estimated daily discharges: Sept. 17-21. Records good. Prior to April 1975, occasional regulation at low flow by mill at williamston, 16 mi upstream from station. Several measurements of water temperature were made during the year. National Weather Service gage-height telemeter at station.

AVERAGE DISCHARGE. --57 years, $208 \mathrm{ft}^{3} / \mathrm{s}, 7.96 \mathrm{in} / \mathrm{yr}$.

EXTREMES FOR PERIOD OF RECORD.--Maximum discharge, 5,940 ft $3 / \mathrm{s}$, Apr. 20, 1975, gage height, 11.95 $\mathrm{ft}$; minimum, $3 \mathrm{ft} / \mathrm{s}$, July 31,1931 .

EXTREMES OUTSIDE PERIOD OF RECORD.--Flood of Mar. 24, 1904, reached a stage of 13.4 ft, discharge, 8,000 $\mathrm{ft}^{3} / \mathrm{s}$.

EXTREMES FOR CURRENT YEAR.--Maximum discharge, 1, $290 \mathrm{ft}^{3} / \mathrm{s}$, Oct. 5 , gage height, $5.98 \mathrm{ft}$; minimum, $15 \mathrm{ft} / \mathrm{s}$, Aug. $7,8,21$, gage height, $3.08 \mathrm{ft}$.

DISCHARGE, IN CUBIC FEET PER SECOND, WATER YEAR OCTOBER 1986 TO SEPTEMBER 1987

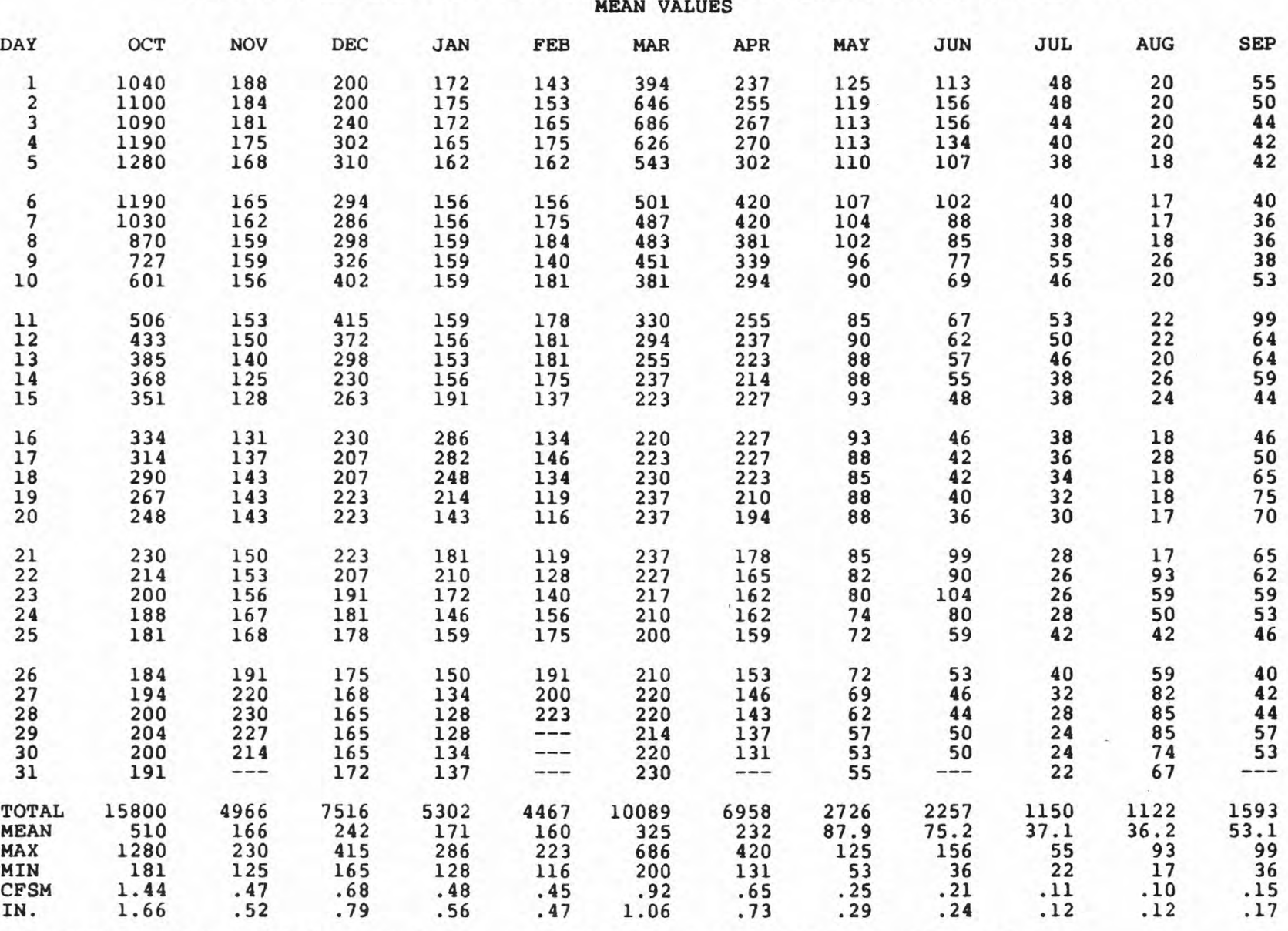

CAL YR 1986 TOTAL 109092 MEAN 299 MAX $2200 \quad$ MIN $32 \quad$ CFSM $.84 \quad$ IN 11.43

WTR YR 1987 TOTAL 63946 MEAN 175 MAX 1280 MIN 17 CFSM .49 IN 6.70 
LOCATION.--Lat $42^{\circ} 45^{\prime} 02^{\prime \prime}$, long $84^{\circ} 33^{\prime} 19^{\prime \prime}$, in NWl/4 sec.9, T.4 N., R.2 W., Ingham County, Hydrologic Unit 04050004 , on $\mathrm{right}$ bank $30 \mathrm{ft}$ upstream from bridge on North Grand River Avenue in Lansing, $2.0 \mathrm{mi}$ downstream from Red Cedar River, and at mile 152 .

DRAINAGE AREA. $--1,230 \mathrm{mi}^{2}$, approximately.

PERIOD OF RECORD.--March 1901 to September 1906, October 1934 to current year. Monthly discharge only for some periods, published in wSP 1307 . Published as "at North Lansing" 1901-6. Gage-helght records collected in this vicinity 1907-10 (flood seasons only), 1911-19, 1920-28 (flood seasons only), and since 1931 are contained in reports of the National Weather Service.

REVISED RECORDS.--WSP 1174: 1949. WSP 1387: 1901, 1903-4, 1935, 1937, 1942.

GAGE.--Water-stage recorder. Datum of gage is $805.53 \mathrm{ft}$ above National Geodetic Vertical Datum of 1929 (ievels by Michigan Department of Natural Resources). Prior to August 1906, nonrecording gage at same site at different datum. November 1934 to June 1949 water-stage recorder at site $1.8 \mathrm{mi}$ downstream at datum $2.42 \mathrm{ft}$ lower.

REMARKS. --No estimated daily discharges. Records good. Large diurnal fluctuation at low and medium flow caused by powerplants upstream from station. Several measurements of water temperature were made during the year. National Weather Service gage-height telemeter at station.

AVERAGE DISCHARGE. -58 years, $842 \mathrm{ft}^{3} / \mathrm{s}, 9.30 \mathrm{in} / \mathrm{yr}$.

EXTREMES FOR PERIOD OF RECORD.--Maximum discharge, 24,500 ft $3 / \mathrm{s}$, Mar. 26, 1904, gage height, 18.60 $\mathrm{ft}$, datum then in use, from rating curve extended above $15,000 \mathrm{ft}^{3} / \mathrm{s} ; \mathrm{minimum}, 2.8 \mathrm{ft}^{3} / \mathrm{s}$, Sept. 9, 1963, gage height, $0.85 \mathrm{ft}$; minimum daily, $20 \mathrm{ft}^{3} / \mathrm{s}$, Aug. 25, 1941 .

EXTREMES OUTSIDE PERIOD OF RECORD.--Maximum discharge since at least 1901, that of Mar. 26, 1904, EXTREMES FOR CURRENT YEAR.--Maximum discharge, 4,280 ft $3 / \mathrm{s}$, Oct. 4, gage height, $9.02 \mathrm{ft}$; minimum daily, $83 \mathrm{ft}^{3} / \mathrm{s}$, Aug. is.

DISCHARGE, IN CUBIC FEET PER SECOND, WATER YEAR OCTOBER 1986 TO SEPTEMBER 1987 MEAN VALUES

\begin{tabular}{|c|c|c|c|c|c|c|c|c|c|c|c|c|}
\hline DAY & OCT & NOV & DEC & JAN & FEB & MAR & APR & MAY & JUN & JUL & AUG & SEP \\
\hline $\begin{array}{l}1 \\
2 \\
3 \\
4 \\
5\end{array}$ & $\begin{array}{l}3180 \\
3310 \\
3390 \\
4000 \\
4070\end{array}$ & $\begin{array}{l}844 \\
763 \\
751 \\
792 \\
748\end{array}$ & $\begin{array}{r}1020 \\
997 \\
1030 \\
1230 \\
1200\end{array}$ & $\begin{array}{l}589 \\
747 \\
676 \\
692 \\
589\end{array}$ & $\begin{array}{l}617 \\
656 \\
644 \\
746 \\
665\end{array}$ & $\begin{array}{l}1120 \\
1660 \\
1770 \\
1690 \\
1590\end{array}$ & $\begin{array}{r}841 \\
1020 \\
916 \\
1020 \\
1040\end{array}$ & $\begin{array}{l}538 \\
460 \\
509 \\
499 \\
529\end{array}$ & $\begin{array}{l}432 \\
619 \\
489 \\
490 \\
407\end{array}$ & $\begin{array}{l}227 \\
219 \\
201 \\
217 \\
232\end{array}$ & $\begin{array}{l}173 \\
112 \\
107 \\
111 \\
107\end{array}$ & $\begin{array}{l}355 \\
335 \\
283 \\
253 \\
247\end{array}$ \\
\hline $\begin{array}{r}6 \\
7 \\
8 \\
9 \\
10\end{array}$ & $\begin{array}{l}3810 \\
3470 \\
2980 \\
2520 \\
2140\end{array}$ & $\begin{array}{l}698 \\
752 \\
715 \\
656 \\
567\end{array}$ & $\begin{array}{l}1170 \\
1170 \\
1200 \\
1320 \\
1450\end{array}$ & $\begin{array}{l}696 \\
557 \\
749 \\
642 \\
709\end{array}$ & $\begin{array}{l}734 \\
711 \\
694 \\
650 \\
758\end{array}$ & $\begin{array}{l}1440 \\
1470 \\
1440 \\
1310 \\
1360\end{array}$ & $\begin{array}{l}1270 \\
1270 \\
1240 \\
1160 \\
1100\end{array}$ & $\begin{array}{l}522 \\
496 \\
517 \\
410 \\
477\end{array}$ & $\begin{array}{l}533 \\
428 \\
470 \\
320 \\
280\end{array}$ & $\begin{array}{l}276 \\
207 \\
188 \\
430 \\
395\end{array}$ & $\begin{array}{l}109 \\
127 \\
100 \\
215 \\
100\end{array}$ & $\begin{array}{l}226 \\
209 \\
381 \\
371 \\
264\end{array}$ \\
\hline $\begin{array}{l}11 \\
12 \\
13 \\
14 \\
15\end{array}$ & $\begin{array}{l}1950 \\
1760 \\
1630 \\
1550 \\
1580\end{array}$ & $\begin{array}{l}683 \\
629 \\
566 \\
557 \\
586\end{array}$ & $\begin{array}{r}1450 \\
1360 \\
1010 \\
906 \\
1110\end{array}$ & $\begin{array}{l}675 \\
696 \\
617 \\
755 \\
691\end{array}$ & $\begin{array}{l}712 \\
734 \\
730 \\
725 \\
452\end{array}$ & $\begin{array}{l}1200 \\
1120 \\
1050 \\
1010 \\
1020\end{array}$ & $\begin{array}{r}1010 \\
1040 \\
966 \\
965 \\
1030\end{array}$ & $\begin{array}{l}480 \\
455 \\
495 \\
416 \\
343\end{array}$ & $\begin{array}{l}356 \\
359 \\
295 \\
241 \\
218\end{array}$ & $\begin{array}{l}283 \\
252 \\
224 \\
153 \\
139\end{array}$ & $\begin{array}{r}92 \\
128 \\
118 \\
153 \\
140\end{array}$ & $\begin{array}{l}783 \\
579 \\
514 \\
365 \\
312\end{array}$ \\
\hline $\begin{array}{l}16 \\
17 \\
18 \\
19 \\
20\end{array}$ & $\begin{array}{l}1470 \\
1420 \\
1370 \\
1180 \\
1210\end{array}$ & $\begin{array}{l}541 \\
589 \\
495 \\
593 \\
523\end{array}$ & $\begin{array}{r}1130 \\
1070 \\
1050 \\
988 \\
1030\end{array}$ & $\begin{array}{r}984 \\
1000 \\
957 \\
772 \\
607\end{array}$ & $\begin{array}{l}629 \\
545 \\
602 \\
557 \\
566\end{array}$ & $\begin{array}{l}960 \\
927 \\
974 \\
953 \\
978\end{array}$ & $\begin{array}{r}1040 \\
1070 \\
994 \\
994 \\
832\end{array}$ & $\begin{array}{l}415 \\
415 \\
400 \\
441 \\
438\end{array}$ & $\begin{array}{l}270 \\
179 \\
253 \\
193 \\
230\end{array}$ & $\begin{array}{l}201 \\
142 \\
215 \\
124 \\
169\end{array}$ & $\begin{array}{r}102 \\
234 \\
85 \\
83 \\
92\end{array}$ & $\begin{array}{l}329 \\
323 \\
415 \\
419 \\
354\end{array}$ \\
\hline $\begin{array}{l}21 \\
22 \\
23 \\
24 \\
25\end{array}$ & $\begin{array}{r}1110 \\
1070 \\
1000 \\
954 \\
991\end{array}$ & $\begin{array}{l}574 \\
597 \\
559 \\
768 \\
683\end{array}$ & $\begin{array}{l}985 \\
859 \\
860 \\
808 \\
730\end{array}$ & $\begin{array}{l}590 \\
774 \\
806 \\
627 \\
577\end{array}$ & $\begin{array}{l}534 \\
598 \\
565 \\
594 \\
732\end{array}$ & $\begin{array}{l}935 \\
950 \\
911 \\
861 \\
899\end{array}$ & $\begin{array}{l}868 \\
735 \\
859 \\
665 \\
725\end{array}$ & $\begin{array}{l}472 \\
427 \\
451 \\
402 \\
369\end{array}$ & $\begin{array}{l}467 \\
375 \\
440 \\
370 \\
230\end{array}$ & $\begin{array}{l}155 \\
148 \\
116 \\
173 \\
153\end{array}$ & $\begin{array}{r}99 \\
664 \\
269 \\
283 \\
244\end{array}$ & $\begin{array}{l}446 \\
351 \\
465 \\
246 \\
359\end{array}$ \\
\hline $\begin{array}{l}26 \\
27 \\
28 \\
29 \\
30 \\
31\end{array}$ & $\begin{array}{l}909 \\
849 \\
942 \\
879 \\
767 \\
815\end{array}$ & $\begin{array}{r}926 \\
1030 \\
1020 \\
986 \\
945\end{array}$ & $\begin{array}{l}771 \\
738 \\
722 \\
720 \\
684 \\
738\end{array}$ & $\begin{array}{l}533 \\
610 \\
590 \\
634 \\
660 \\
576\end{array}$ & $\begin{array}{l}644 \\
792 \\
808 \\
--- \\
---\end{array}$ & $\begin{array}{l}880 \\
878 \\
856 \\
856 \\
905 \\
924\end{array}$ & $\begin{array}{l}524 \\
791 \\
502 \\
515 \\
498\end{array}$ & $\begin{array}{l}417 \\
370 \\
349 \\
375 \\
294 \\
292\end{array}$ & $\begin{array}{l}275 \\
282 \\
152 \\
281 \\
217\end{array}$ & $\begin{array}{l}209 \\
133 \\
110 \\
175 \\
104 \\
126\end{array}$ & $\begin{array}{l}341 \\
505 \\
469 \\
560 \\
520 \\
457\end{array}$ & $\begin{array}{l}306 \\
267 \\
215 \\
199 \\
362\end{array}$ \\
\hline $\begin{array}{l}\text { TOTAL } \\
\text { MEAN } \\
\text { MAX } \\
\text { MIN } \\
\text { CFSM } \\
\text { IN. }\end{array}$ & $\begin{array}{r}58276 \\
1880 \\
4070 \\
767 \\
1.53 \\
1.76\end{array}$ & $\begin{array}{r}21136 \\
705 \\
1030 \\
495 \\
.57 \\
.64\end{array}$ & $\begin{array}{r}31506 \\
1016 \\
1450 \\
684 \\
.83 \\
.95\end{array}$ & $\begin{array}{r}21377 \\
690 \\
1000 \\
533 \\
.56 \\
.65\end{array}$ & $\begin{array}{r}18394 \\
657 \\
808 \\
452 \\
.53 \\
.56\end{array}$ & $\begin{array}{r}34897 \\
1126 \\
1770 \\
856 \\
.92 \\
1.06\end{array}$ & $\begin{array}{r}27500 \\
917 \\
1270 \\
498 \\
.75 \\
.83\end{array}$ & $\begin{array}{r}13473 \\
435 \\
538 \\
292 \\
.35 \\
.41\end{array}$ & $\begin{array}{r}10151 \\
338 \\
619 \\
152 \\
.28 \\
.31\end{array}$ & $\begin{array}{r}6096 \\
197 \\
430 \\
104 \\
.16 \\
.18\end{array}$ & $\begin{array}{r}6899 \\
223 \\
664 \\
83 \\
.18 \\
.21\end{array}$ & $\begin{array}{r}10533 \\
351 \\
783 \\
199 \\
.29 \\
.32\end{array}$ \\
\hline $\begin{array}{l}\text { CAL YR } \\
\text { WTR YR }\end{array}$ & $\begin{array}{l}1986 \\
1987\end{array}$ & $\begin{array}{ll}A L & 4 \\
A L & 2\end{array}$ & & $\begin{array}{r}1165 \\
713\end{array}$ & $\begin{array}{l}\text { MAX } \\
\text { MAX }\end{array}$ & $\begin{array}{l}5790 \\
4070\end{array}$ & $\begin{array}{lr}\text { MIN } & 155 \\
\text { MIN } & 83\end{array}$ & $\begin{array}{l}\text { CFSM } \\
\text { CFSM }\end{array}$ & $\begin{array}{l}\text { IN } \\
\text { IN }\end{array}$ & $\begin{array}{r}12.86 \\
7.87\end{array}$ & & \\
\hline
\end{tabular}


LOCATION.--Lat $42^{\circ} 49^{\prime} 45^{\prime \prime}$, long $84^{\circ} 46^{\prime} 40^{\prime \prime}$, in sec.10, T.5 N., R.4 W. , Clinton County, Hydrologic Unit 04050004 , on right bank at upstream side of former bridgé site, 1.5 mi northeast of Eagle, and 10 mi upstream from mouth.

DRAINAGE AREA. $--281 \mathrm{mi}^{2}$.

PERIOD OF RECORD.--August 1944 to current year.

REVISED RECORDS.--WSP 1387: 1946-47.

GAGE.--Water-stage recorder. Datum of gage is $747.09 \mathrm{ft}$ above National Geodetic Vertical Datum of 1929 (levels by Michigan Department of Natural Resources). Prior to June 2, 1962, nonrecording gage at same site and datum.

REMARKS.--Estimated daily discharges: Nov. 14, Dec. 11-16, 22, Jan, 12, 13, and Jan. 17 to Feb. 23. Records good except for estimated daily discharges, which are fair. Small intermittent diversion at times into Lake Geneva when discharge is above $50 \mathrm{ft}^{3} / \mathrm{s}$. Several measurements of water temperature were made during the year.

AVERAGE DISCHARGE. -43 years, $176 \mathrm{ft}^{3} / \mathrm{s}, 8.51 \mathrm{in} / \mathrm{yr}^{\circ}$

EXTREMES FOR PERIOD OF RECORD.--Maximum discharge, 2,860 ft 3/s, Apr. 5, 1947, gage height, 7.70 ft, from graph based on gage readings, from rating curve extended above $1,900 \mathrm{ft} 3 / \mathrm{s}$; maximum gage height, $9.9 \mathrm{ft}$, Mar. 7, 1956, from floodmark, backwater from ice; minimum discharge, $10 \mathrm{ft} 3 / \mathrm{s}$, July 28, 1965, gage height, 1.01 ft.

EXTREMES FOR CURRENT YEAR.--Maximum discharge, 1,060 $\mathrm{ft}^{3} / \mathrm{s}$, Oct. 4, gage height, $4.90 \mathrm{ft}$; minimum, $27 \mathrm{ft} / \mathrm{s}$, Aug. 8, gage height, $1.24 \mathrm{ft}$.

DISCHARGE, IN CUBIC FEET PER SECOND, WATER YEAR OCTOBER 1986 TO SEPTEMBER 1987

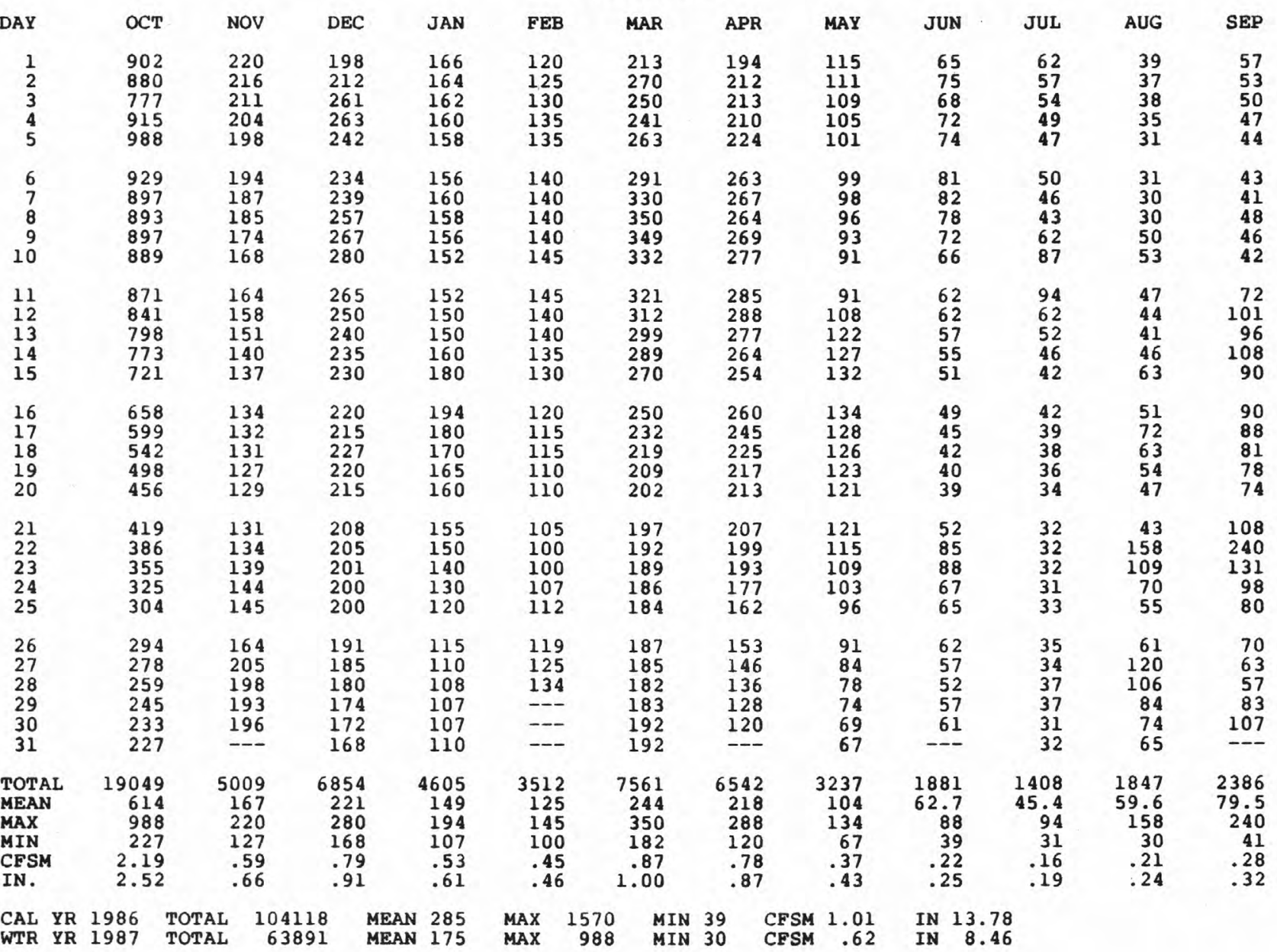




\section{MAPLE RIVER AT MAPLE RAPIDS, MI}

LOCATION.--Lat $43^{\circ} 06^{\prime} 35^{\prime \prime}$, long $84^{\circ} 41^{\prime} 35^{\prime \prime}$, in sec.5, T. 8 N., R. 3 w. , Clinton County, Hydrologic Unit

04050005 , on right bank at downstream side of bridge on Maple Road in Maple Rapids, 50 ft upstream from Pine Creek, and $0.8 \mathrm{mi}$ upstream from Hayworth Creek. Records include flow of Pine Creek.

DRAINAGE AREA. $--434 \mathrm{mi}^{2}$.

PERIOD OF RECORD.--August 1944 to current year.

REVISED RECORDS.--WSP 1707: 1956.

GAGE.--Water-stage recorder. Datum of gage is $642.58 \mathrm{ft}$ above National Geodetic Vertical Datum of 1929 (1evels by Michigan Department of Natural Resources). Prior to Oct. 4, 1968, nonrecording gage at same site and datum.

REMARKS.--Estimated daily discharges: Sept. 18, 19. Records good except those for period Oct. 1-10, which are poor. Several measurements of water temperature were made during the year.

AVERAGE DISCHARGE. --43 years, $267 \mathrm{ft}^{3} / \mathrm{s}, 8.35 \mathrm{in} / \mathrm{yr}^{\mathrm{r}}$.

EXTREMES FOR PERIOD OF RECORD.--Maximum discharge, 8,770 ft3/s, Sept. 12, 1986, gage height, 12.33

$\mathrm{ft}$, from floodmark, caused by dam failure on Rainbow Lake (Pine Creek); minimum, 4.4 ft $3 / \mathrm{s}^{2}$ Aug.

13,1965 , gage height, $1.62 \mathrm{ft}$

EXTREMES OUTSIDE PERIOD OF RECORD.--Flood in March 1904 reached a stage of 13.8 ft, from information by local resident.

EXTREMES FOR CURRENT YEAR.--Maximum discharge, 4,400 $\mathrm{ft}^{3} / \mathrm{s}$, Oct. 2, gage height, $11.27 \mathrm{ft}$; minimum, $14 \mathrm{ft}^{3} / \mathrm{s}$, Aug. 7, gage height, $1.74 \mathrm{ft}$.

DISCHARGE, IN CUBIC FEET PER SECOND, WATER YEAR OCTOBER 1986 TO SEPTEMBER 1987

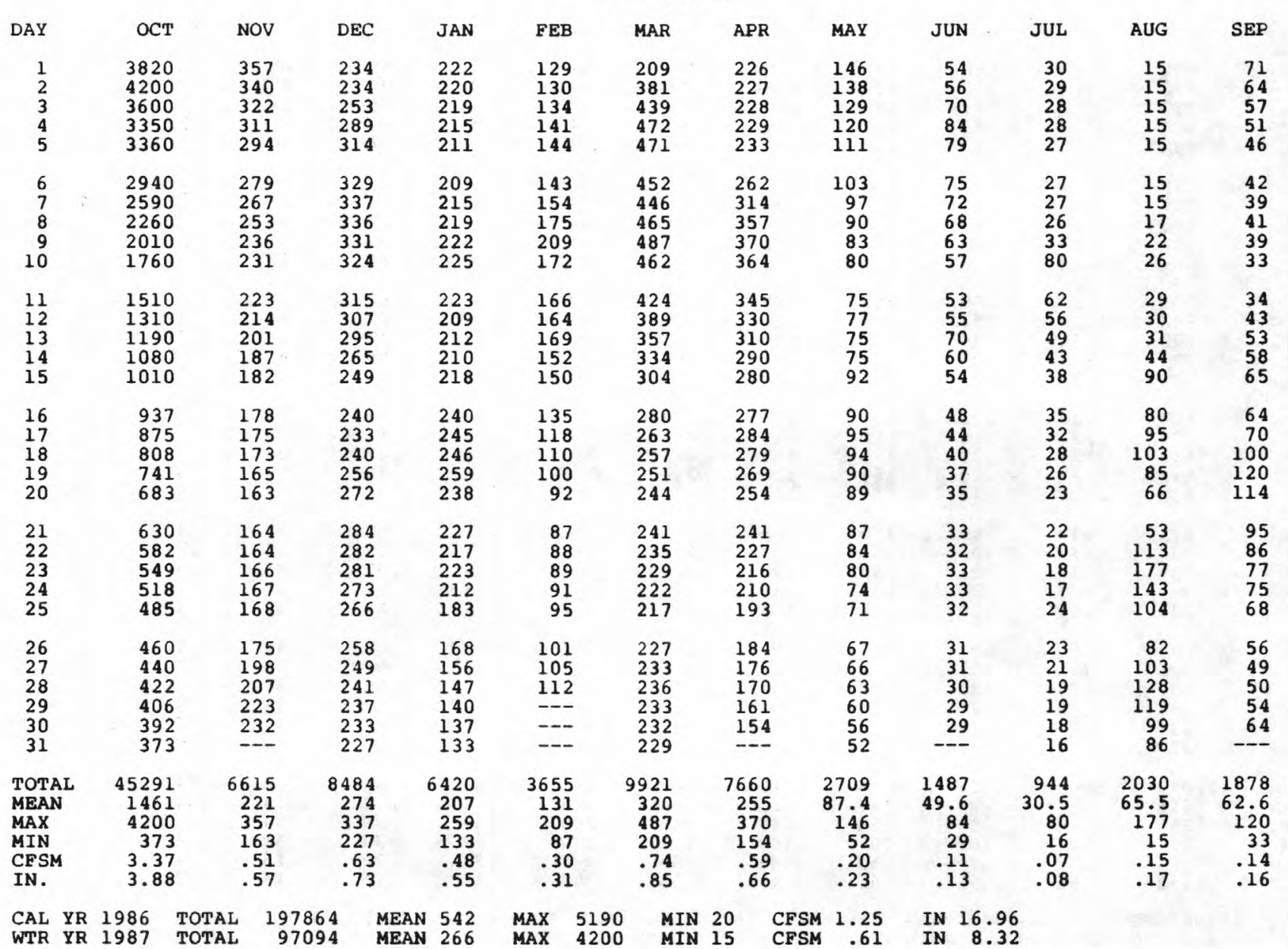


LOCATION. --Lat $42^{\circ} 58^{\prime} 20^{\prime \prime}$, long $85^{\circ} 04^{\prime} 13^{\prime \prime}$, in NWl/4 sec.30, T.7 N., R. 6 W. , Ionia County, Hydrologic Unit 04050006 , on left bank $15 \mathrm{ft}$ downstream from bridge on state Highway 66 in Ionia, 2.7 mi downstream from Prairie Creek, and at mile 87.

DRAINAGE AREA. $--2,840 \mathrm{mi}^{2}$, approximately.

PERIOD OF RECORD.--March to June 1931, July and September 1931 (fragmentary), July 1951 to current year. Gage-height records for flood seasons collected in this vicinity 1907-28 are contained in reports of the National Weather Service.

GAGE.--Water-stage recorder. Datum of gage is $615.38 \mathrm{ft}$ above National Geodetic Vertical Datum of 1929 . Mar. 19 to Sept. 24, 1931, nonrecording gage at site $1.5 \mathrm{mi}$ upstream at diferent datum.

REMARKS.--Estimated daily discharges: Jan. 23 to Feb. 6. Records good except for estimated daily discharges, which are fair. Diurnal fluctuation below about $5,000 \mathrm{ft}^{3} / \mathrm{s}$ caused by powerplants upstream from station. National Weather Service gage-height telemeter at station.

AVERAGE DISCHARGE.--36 years (water years 1952-87), 1,952 ft $3 / \mathrm{s}, 9.33 \mathrm{in} / \mathrm{yr}$.

EXTREMES FOR PERIOD OF RECORD.--Maximum discharge, 21,500 ft3/s, Apr. 1, 1960, gage height, 23.43 $\mathrm{ft}$; minimum, $40 \mathrm{ft} / \mathrm{s}$, May 13, 1968, gage height, $5.61 \mathrm{ft}$; minimum daily, $109 \mathrm{ft} / \mathrm{s}, \mathrm{Ju} 1 \mathrm{y}$, 16,1977 .

EXTREMES FOR CURRENT YEAR.--Maximum discharge, 17,700 ft $3 / \mathrm{s}$, Oct. 3, gage height, $23.01 \mathrm{ft}$; minimum, $207 \mathrm{ft}^{3} / \mathrm{s}$, July 31 , gage height, $6.68 \mathrm{ft}$; minimum daily, $319 \mathrm{ft} 3 / \mathrm{s}$, Aug. 6 .

DISCHARGE, IN CUBIC FEET PER SECOND, WATER YEAR OCTOBER 1986 TO SEPTEMBER 1987

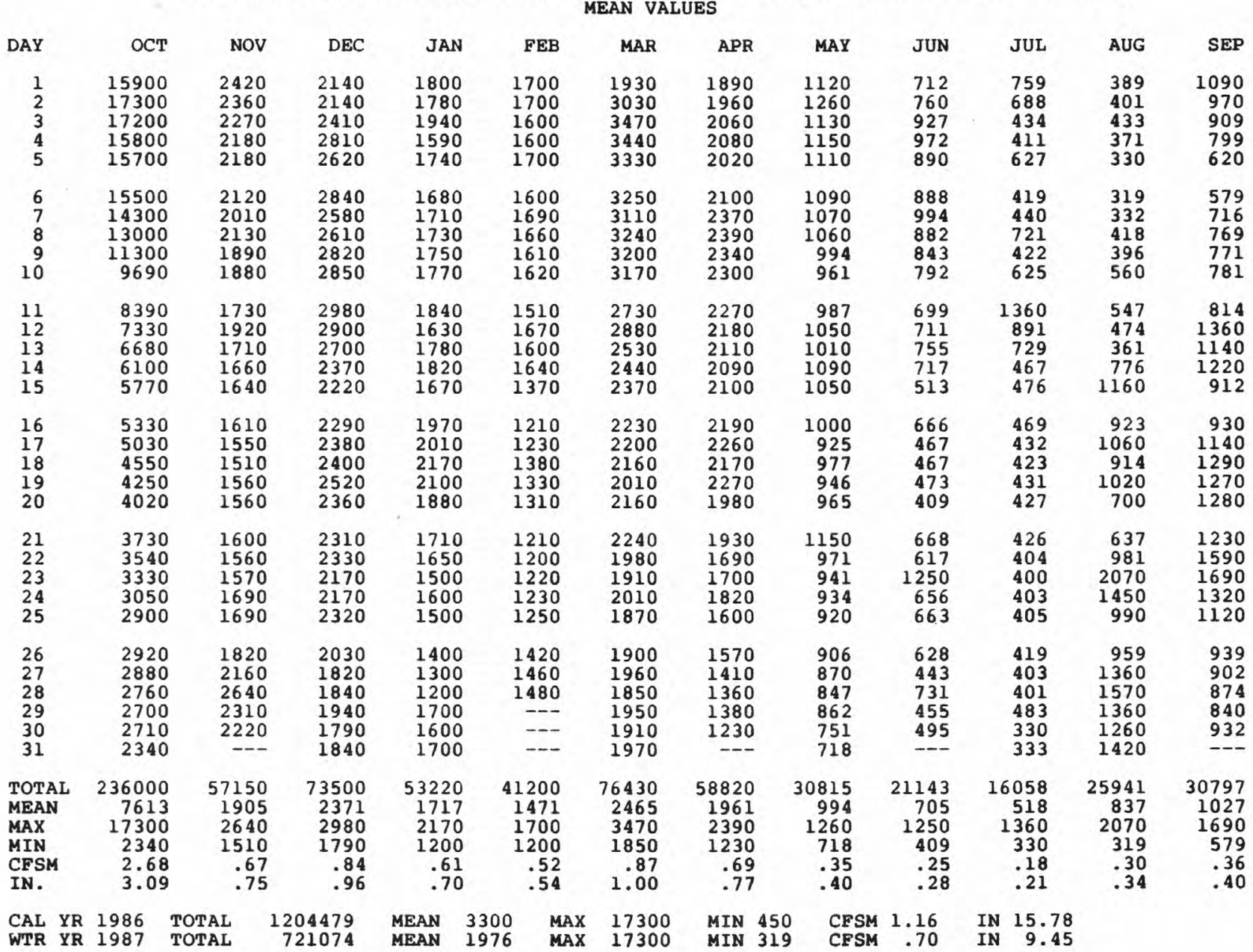


LOCATION.--Lat $42^{\circ} 36^{\prime} 57^{\prime \prime}$, long $85^{\circ} 14^{\prime} 11^{\prime \prime}$, in SEl/4 sec. 27, T. 3 N., R. 8 W., Barry County, Hydrologic Unit 04050007, on right bank at downstream side of bridge on Mckeown Road, $0.6 \mathrm{mi}$ downstream from Cedar Creek, $2.0 \mathrm{mi}$ downstream from Thornapple Lake, and $3.2 \mathrm{mi}$ southeast of Hastings.

DRAINAGE AREA. $--385 \mathrm{mi}^{2}$.

PERIOD OF RECORD.--October 1944 to current year.

GAGE.--Water-stage recorder. Datum of gage is $786.71 \mathrm{ft}$ above National Geodetic Vertical Datum of 1929 (levels by Michigan Department of Natural Resources). Prior to Oct. 1, 1965, nonrecording gage at same site and datum.

REMARKS.--No estimated daily discharges. Records good. Several measurements of water temperature were made during the year. National weather Service gage-height telemeter at station.

AVERAGE DISCHARGE. -43 years, $320 \mathrm{ft}^{3} / \mathrm{s}, 11.29 \mathrm{in} / \mathrm{yr}$.

EXTREMES FOR PERIOD OF RECORD.--Maximum discharge, 6,810 ft3/s, Apr. 7, 1947, gage height, 10.20 ft, from graph based on gage readings; minimum, $33 \mathrm{ft} / \mathrm{s}$, Aug. 10, 1964, gage height, $2.71 \mathrm{ft}$.

EXTREMES FOR CURRENT YEAR.--Maximum discharge, 2,830 $\mathrm{ft}^{3} / \mathrm{s}$, Oct. 5, gage height, $7.61 \mathrm{ft}$; minimum, $56 \mathrm{ft}^{3} / \mathrm{s}$, Aug. 7, gage height, $2.77 \mathrm{ft}$.

DISCHARGE，IN CUBIC FEET PER SECOND，WATER YEAR OCTOBER 1986 TO SEPTEMBER 1987 MEAN VALUES

\begin{tabular}{|c|c|c|c|c|c|c|c|c|c|c|c|c|}
\hline DAY & OCT & NOV & DEC & JAN & FEB & MAR & APR & MAY & JUN & JUL & AUG & SEP \\
\hline $\begin{array}{l}1 \\
2 \\
3 \\
4 \\
5\end{array}$ & $\begin{array}{l}1660 \\
2110 \\
2470 \\
2740 \\
2810\end{array}$ & $\begin{array}{l}306 \\
303 \\
296 \\
292 \\
284\end{array}$ & $\begin{array}{l}438 \\
410 \\
413 \\
453 \\
493\end{array}$ & $\begin{array}{l}278 \\
278 \\
278 \\
275 \\
270\end{array}$ & $\begin{array}{l}228 \\
235 \\
242 \\
251 \\
252\end{array}$ & $\begin{array}{l}315 \\
463 \\
563 \\
589 \\
563\end{array}$ & $\begin{array}{l}273 \\
293 \\
322 \\
322 \\
306\end{array}$ & $\begin{array}{l}185 \\
182 \\
188 \\
193 \\
190\end{array}$ & $\begin{array}{l}118 \\
118 \\
115 \\
111 \\
109\end{array}$ & $\begin{array}{l}146 \\
143 \\
133 \\
124 \\
115\end{array}$ & $\begin{array}{l}71 \\
73 \\
72 \\
70 \\
66\end{array}$ & $\begin{array}{l}181 \\
166 \\
150 \\
137 \\
127\end{array}$ \\
\hline $\begin{array}{r}6 \\
7 \\
8 \\
9 \\
10\end{array}$ & $\begin{array}{l}2670 \\
2400 \\
2060 \\
1720 \\
1420\end{array}$ & $\begin{array}{l}279 \\
275 \\
271 \\
269 \\
267\end{array}$ & $\begin{array}{l}496 \\
480 \\
479 \\
494 \\
535\end{array}$ & $\begin{array}{l}264 \\
269 \\
276 \\
278 \\
281\end{array}$ & $\begin{array}{l}249 \\
251 \\
268 \\
256 \\
271\end{array}$ & $\begin{array}{l}519 \\
485 \\
476 \\
473 \\
435\end{array}$ & $\begin{array}{l}295 \\
292 \\
287 \\
275 \\
262\end{array}$ & $\begin{array}{l}183 \\
178 \\
171 \\
164 \\
161\end{array}$ & $\begin{array}{r}107 \\
104 \\
106 \\
106 \\
99\end{array}$ & $\begin{array}{l}113 \\
114 \\
110 \\
110 \\
108\end{array}$ & $\begin{array}{r}62 \\
58 \\
61 \\
96 \\
110\end{array}$ & $\begin{array}{l}121 \\
118 \\
122 \\
134 \\
132\end{array}$ \\
\hline $\begin{array}{l}11 \\
12 \\
13 \\
14 \\
15\end{array}$ & $\begin{array}{r}1180 \\
988 \\
838 \\
740 \\
675\end{array}$ & $\begin{array}{l}259 \\
250 \\
246 \\
239 \\
235\end{array}$ & $\begin{array}{l}561 \\
565 \\
461 \\
405 \\
393\end{array}$ & $\begin{array}{l}276 \\
276 \\
272 \\
270 \\
288\end{array}$ & $\begin{array}{l}266 \\
258 \\
256 \\
252 \\
232\end{array}$ & $\begin{array}{l}382 \\
337 \\
307 \\
300 \\
292\end{array}$ & $\begin{array}{l}254 \\
254 \\
265 \\
262 \\
270\end{array}$ & $\begin{array}{l}157 \\
160 \\
158 \\
152 \\
150\end{array}$ & $\begin{array}{r}97 \\
106 \\
109 \\
106 \\
102\end{array}$ & $\begin{array}{l}109 \\
111 \\
109 \\
105 \\
105\end{array}$ & $\begin{array}{r}103 \\
93 \\
86 \\
99 \\
118\end{array}$ & $\begin{array}{l}167 \\
204 \\
200 \\
192 \\
200\end{array}$ \\
\hline $\begin{array}{l}16 \\
17 \\
18 \\
19 \\
20\end{array}$ & $\begin{array}{l}633 \\
596 \\
551 \\
508 \\
472\end{array}$ & $\begin{array}{l}237 \\
240 \\
244 \\
244 \\
242\end{array}$ & $\begin{array}{l}384 \\
355 \\
357 \\
377 \\
385\end{array}$ & $\begin{array}{l}331 \\
356 \\
352 \\
319 \\
300\end{array}$ & $\begin{array}{l}207 \\
210 \\
211 \\
205 \\
200\end{array}$ & $\begin{array}{l}290 \\
295 \\
307 \\
312 \\
319\end{array}$ & $\begin{array}{l}312 \\
365 \\
384 \\
366 \\
326\end{array}$ & $\begin{array}{l}144 \\
139 \\
142 \\
149 \\
163\end{array}$ & $\begin{array}{l}95 \\
90 \\
86 \\
83 \\
85\end{array}$ & $\begin{array}{r}118 \\
115 \\
109 \\
102 \\
97\end{array}$ & $\begin{array}{l}117 \\
134 \\
139 \\
134 \\
121\end{array}$ & $\begin{array}{l}211 \\
230 \\
313 \\
356 \\
343\end{array}$ \\
\hline $\begin{array}{l}21 \\
22 \\
23 \\
24 \\
25\end{array}$ & $\begin{array}{l}444 \\
419 \\
396 \\
375 \\
357\end{array}$ & $\begin{array}{l}243 \\
248 \\
260 \\
282 \\
298\end{array}$ & $\begin{array}{l}376 \\
351 \\
327 \\
314 \\
303\end{array}$ & $\begin{array}{l}294 \\
282 \\
255 \\
217 \\
208\end{array}$ & $\begin{array}{l}200 \\
200 \\
204 \\
210 \\
217\end{array}$ & $\begin{array}{l}308 \\
298 \\
287 \\
278 \\
275\end{array}$ & $\begin{array}{l}294 \\
270 \\
262 \\
255 \\
237\end{array}$ & $\begin{array}{l}166 \\
161 \\
152 \\
144 \\
140\end{array}$ & $\begin{array}{l}103 \\
148 \\
187 \\
181 \\
156\end{array}$ & $\begin{array}{l}98 \\
92 \\
85 \\
81 \\
82\end{array}$ & $\begin{array}{l}109 \\
122 \\
164 \\
201 \\
182\end{array}$ & $\begin{array}{l}301 \\
278 \\
282 \\
285 \\
264\end{array}$ \\
\hline $\begin{array}{l}26 \\
27 \\
28 \\
29 \\
30 \\
31\end{array}$ & $\begin{array}{l}344 \\
339 \\
337 \\
331 \\
324 \\
314\end{array}$ & $\begin{array}{l}321 \\
403 \\
467 \\
494 \\
479 \\
---\end{array}$ & $\begin{array}{l}300 \\
294 \\
286 \\
283 \\
280 \\
279\end{array}$ & $\begin{array}{l}216 \\
218 \\
213 \\
215 \\
215 \\
221\end{array}$ & $\begin{array}{l}224 \\
229 \\
240 \\
--- \\
--- \\
---\end{array}$ & $\begin{array}{l}291 \\
308 \\
305 \\
288 \\
284 \\
279\end{array}$ & $\begin{array}{l}224 \\
214 \\
200 \\
195 \\
190 \\
---\end{array}$ & $\begin{array}{l}137 \\
135 \\
132 \\
128 \\
124 \\
119\end{array}$ & $\begin{array}{l}137 \\
123 \\
114 \\
113 \\
136 \\
-\end{array}$ & $\begin{array}{l}82 \\
81 \\
77 \\
74 \\
73 \\
71\end{array}$ & $\begin{array}{l}171 \\
227 \\
270 \\
278 \\
246 \\
211\end{array}$ & $\begin{array}{l}230 \\
206 \\
185 \\
185 \\
203 \\
-\end{array}$ \\
\hline $\begin{array}{l}\text { TOTAL } \\
\text { MEAN } \\
\text { MAX } \\
\text { MIN } \\
\text { CFSM } \\
\text { IN. }\end{array}$ & $\begin{array}{r}33221 \\
1072 \\
2810 \\
314 \\
2.78 \\
3.21\end{array}$ & $\begin{array}{r}8773 \\
292 \\
494 \\
235 \\
.76 \\
.85\end{array}$ & $\begin{array}{r}12327 \\
398 \\
565 \\
279 \\
1.03 \\
1.19\end{array}$ & $\begin{array}{r}8341 \\
269 \\
356 \\
208 \\
.70 \\
.81\end{array}$ & $\begin{array}{r}6524 \\
233 \\
271 \\
200 \\
.61 \\
.63\end{array}$ & $\begin{array}{r}11223 \\
362 \\
589 \\
275 \\
.94 \\
1.08\end{array}$ & $\begin{array}{r}8326 \\
278 \\
384 \\
190 \\
.72 \\
.80\end{array}$ & $\begin{array}{r}4847 \\
156 \\
193 \\
119 \\
.41 \\
.47\end{array}$ & $\begin{array}{r}3450 \\
115 \\
187 \\
83 \\
.30 \\
.33\end{array}$ & $\begin{array}{r}3192 \\
103 \\
146 \\
71 \\
.27 \\
.31\end{array}$ & $\begin{array}{r}4064 \\
131 \\
278 \\
58 \\
.34 \\
.39\end{array}$ & $\begin{array}{r}6223 \\
207 \\
356 \\
118 \\
.54 \\
.60\end{array}$ \\
\hline $\begin{array}{l}\text { CAL YR } \\
\text { WTR YR }\end{array}$ & $\begin{array}{l}1986 \\
1987\end{array}$ & $\begin{array}{ll}A L & 1 \\
A L & 1\end{array}$ & $\begin{array}{l}33 \\
11\end{array}$ & $\begin{array}{l}\mathbf{N} 506 \\
\text { N } 303\end{array}$ & $\begin{array}{l}\text { MAX } \\
\text { MAX }\end{array}$ & $\begin{array}{l}\text { MIN } \\
\text { MIN }\end{array}$ & $\begin{array}{r}125 \\
58\end{array}$ & $\begin{array}{lr}\text { ESM } & 1.31 \\
\text { FSM } & .79\end{array}$ & $\begin{array}{l}\text { IN } \\
\text { IN }\end{array}$ & & & \\
\hline
\end{tabular}


04118000 THORNAPPLE RIVER NEAR CALEDONIA, MI

LOCATION.--Lat $42^{\circ} 48^{\prime} 40^{\prime \prime}$, long $85^{\circ} 29^{\circ} 00^{\prime \prime}$, in NWl/4 sec. 22, T.5 N., R.10 w., Kent County, Hydrologic Unit 04050007 , on right bank $200 \mathrm{ft}$ downstream from LaBarge powerplant, $2.3 \mathrm{mi}$ northeast of Caledonia, and $3.3 \mathrm{mi}$ downstream from Coldwater River.

DRAINAGE AREA. $--773 \mathrm{mi}^{2}$.

PERIOD OF RECORD.--October 1930 to September 1938, October 1951 to March 1982 , October 1983 to current year. Monthly discharge only for some periods, published in wSp 1307.

REVISED RECORDS.--WSP 824: 1931-36. WSP 1307: 1931-37.

GAGE.--Water-stage recorder. Datum of gage is $676.31 \mathrm{ft}$, Consumers Power Co. datum. Oct. i, 1930, to Sept. 30, 1938, nonrecording gage at same site and at National Geodetic Vertical Datum of 1929.

REMARKS. - No estimated daily discharges. Records good. Prior to Dec, 1, 1958 , and since Oct. 1 , 1983, large diurnal fluctuation at low and medium flow, and occasional regulation during high flow, caused by powerplant upstream from station; occasional fluctuation during the interim period. Several measurements of water temperature were made during the year. Gage-height telemeter at station.

AVERAGE DISCHARGE.--42 years (water years 1931-38, 1952-81, 1984-87), 593 ft3/s, $10.42 \mathrm{in} / \mathrm{yr}^{3}$.

EXTREMES FOR PERIOD OF RECORD,--Maximum discharge, 6,700 $\mathrm{ft}^{3} / \mathrm{s}$, Feb. 27, 1985, gage height, 11.43 ft; minimum, $1.0 \mathrm{ft} / \mathrm{s}$, May 28, 1968, gage height, $1.40 \mathrm{ft}$, result of regulation during bridge construction.

EXTREMES OUTSIDE PERIOD OF RECORD.--Flood of Apr. 7, 1947, reached a stage of 14.4 ft, from information by powerplant operator.

EXTREMES FOR CURRENT YeAR.--Maximum discharge, 4,830 ft ${ }^{3} / \mathrm{s}$, Oct. 5, gage height, $9.59 \mathrm{ft}$; minimum daily, $181 \mathrm{ft}^{3} / \mathrm{s}$, June 16 .

DISCHARGE, IN CUBIC FEET PER SECOND, WATER YEAR OCTOBER 1986 TO SEPTEMBER 1987 MEAN VALUES

\begin{tabular}{|c|c|c|c|c|c|c|c|c|c|c|c|c|}
\hline DAY & OCT & NOV & DEC & JAN & FEB & MAR & APR & MAY & JUN & JUL & AUG & SEP \\
\hline $\begin{array}{l}1 \\
2 \\
3 \\
4 \\
5\end{array}$ & $\begin{array}{l}3440 \\
4040 \\
4210 \\
4390 \\
4550\end{array}$ & $\begin{array}{l}705 \\
622 \\
642 \\
626 \\
605\end{array}$ & $\begin{array}{r}852 \\
667 \\
786 \\
841 \\
1020\end{array}$ & $\begin{array}{l}586 \\
598 \\
585 \\
579 \\
564\end{array}$ & $\begin{array}{l}486 \\
509 \\
515 \\
553 \\
544\end{array}$ & $\begin{array}{r}641 \\
908 \\
1030 \\
1040 \\
1030\end{array}$ & $\begin{array}{l}541 \\
589 \\
628 \\
615 \\
615\end{array}$ & $\begin{array}{l}408 \\
335 \\
454 \\
403 \\
451\end{array}$ & $\begin{array}{l}285 \\
242 \\
225 \\
264 \\
247\end{array}$ & $\begin{array}{l}351 \\
327 \\
322 \\
234 \\
301\end{array}$ & $\begin{array}{l}213 \\
243 \\
230 \\
245 \\
219\end{array}$ & $\begin{array}{l}523 \\
467 \\
455 \\
402 \\
356\end{array}$ \\
\hline $\begin{array}{r}6 \\
7 \\
8 \\
9 \\
10\end{array}$ & $\begin{array}{l}4350 \\
4070 \\
3590 \\
3450 \\
3040\end{array}$ & $\begin{array}{l}620 \\
587 \\
584 \\
565 \\
587\end{array}$ & $\begin{array}{r}953 \\
922 \\
965 \\
976 \\
1000\end{array}$ & $\begin{array}{l}524 \\
580 \\
580 \\
579 \\
573\end{array}$ & $\begin{array}{l}518 \\
518 \\
522 \\
523 \\
525\end{array}$ & $\begin{array}{r}1000 \\
956 \\
927 \\
891 \\
843\end{array}$ & $\begin{array}{l}589 \\
559 \\
559 \\
544 \\
525\end{array}$ & $\begin{array}{l}372 \\
392 \\
370 \\
380 \\
265\end{array}$ & $\begin{array}{l}266 \\
276 \\
259 \\
213 \\
225\end{array}$ & $\begin{array}{l}279 \\
245 \\
245 \\
266 \\
267\end{array}$ & $\begin{array}{l}204 \\
196 \\
195 \\
251 \\
311\end{array}$ & $\begin{array}{l}372 \\
356 \\
461 \\
445 \\
435\end{array}$ \\
\hline $\begin{array}{l}11 \\
12 \\
13 \\
14 \\
15\end{array}$ & $\begin{array}{l}2430 \\
2060 \\
1670 \\
1860 \\
1600\end{array}$ & $\begin{array}{l}549 \\
535 \\
535 \\
533 \\
501\end{array}$ & $\begin{array}{r}1010 \\
1020 \\
859 \\
829 \\
808\end{array}$ & $\begin{array}{l}578 \\
576 \\
573 \\
572 \\
575\end{array}$ & $\begin{array}{l}557 \\
554 \\
506 \\
506 \\
495\end{array}$ & $\begin{array}{l}765 \\
686 \\
618 \\
626 \\
582\end{array}$ & $\begin{array}{l}488 \\
519 \\
536 \\
529 \\
670\end{array}$ & $\begin{array}{l}369 \\
336 \\
358 \\
307 \\
353\end{array}$ & $\begin{array}{l}246 \\
273 \\
354 \\
283 \\
234\end{array}$ & $\begin{array}{l}245 \\
219 \\
268 \\
242 \\
243\end{array}$ & $\begin{array}{l}291 \\
281 \\
267 \\
638 \\
984\end{array}$ & $\begin{array}{l}378 \\
405 \\
439 \\
459 \\
440\end{array}$ \\
\hline $\begin{array}{l}16 \\
17 \\
18 \\
19 \\
20\end{array}$ & $\begin{array}{l}1290 \\
1320 \\
1260 \\
1160 \\
1080\end{array}$ & $\begin{array}{l}506 \\
563 \\
530 \\
522 \\
533\end{array}$ & $\begin{array}{l}725 \\
745 \\
772 \\
804 \\
811\end{array}$ & $\begin{array}{l}658 \\
656 \\
621 \\
647 \\
612\end{array}$ & $\begin{array}{l}380 \\
535 \\
404 \\
447 \\
439\end{array}$ & $\begin{array}{l}606 \\
597 \\
596 \\
629 \\
607\end{array}$ & $\begin{array}{l}653 \\
662 \\
703 \\
691 \\
647\end{array}$ & $\begin{array}{l}335 \\
262 \\
314 \\
358 \\
318\end{array}$ & $\begin{array}{l}181 \\
201 \\
215 \\
212 \\
254\end{array}$ & $\begin{array}{l}300 \\
288 \\
259 \\
258 \\
213\end{array}$ & $\begin{array}{l}722 \\
711 \\
606 \\
541 \\
435\end{array}$ & $\begin{array}{l}462 \\
477 \\
516 \\
597 \\
617\end{array}$ \\
\hline $\begin{array}{l}21 \\
22 \\
23 \\
24 \\
25\end{array}$ & $\begin{array}{r}1140 \\
879 \\
972 \\
863 \\
716\end{array}$ & $\begin{array}{l}532 \\
536 \\
570 \\
602 \\
588\end{array}$ & $\begin{array}{l}797 \\
753 \\
719 \\
699 \\
643\end{array}$ & $\begin{array}{l}571 \\
560 \\
534 \\
502 \\
494\end{array}$ & $\begin{array}{l}420 \\
418 \\
444 \\
426 \\
453\end{array}$ & $\begin{array}{l}630 \\
594 \\
579 \\
576 \\
560\end{array}$ & $\begin{array}{l}571 \\
493 \\
612 \\
540 \\
515\end{array}$ & $\begin{array}{l}331 \\
345 \\
367 \\
266 \\
345\end{array}$ & $\begin{array}{l}276 \\
473 \\
360 \\
292 \\
401\end{array}$ & $\begin{array}{l}258 \\
222 \\
251 \\
227 \\
208\end{array}$ & $\begin{array}{l}364 \\
490 \\
689 \\
677 \\
606\end{array}$ & $\begin{array}{l}638 \\
711 \\
637 \\
594 \\
574\end{array}$ \\
\hline $\begin{array}{l}26 \\
27 \\
28 \\
29 \\
30 \\
31\end{array}$ & $\begin{array}{l}803 \\
780 \\
718 \\
749 \\
741 \\
876\end{array}$ & $\begin{array}{l}641 \\
811 \\
888 \\
903 \\
897 \\
---\end{array}$ & $\begin{array}{l}647 \\
647 \\
624 \\
580 \\
609 \\
593\end{array}$ & $\begin{array}{l}373 \\
418 \\
497 \\
483 \\
482 \\
490\end{array}$ & $\begin{array}{l}459 \\
457 \\
477 \\
--- \\
--- \\
---\end{array}$ & $\begin{array}{l}571 \\
587 \\
587 \\
570 \\
604 \\
569\end{array}$ & $\begin{array}{l}484 \\
468 \\
450 \\
449 \\
361 \\
---\end{array}$ & $\begin{array}{l}328 \\
303 \\
305 \\
271 \\
307 \\
265\end{array}$ & $\begin{array}{l}329 \\
327 \\
325 \\
249 \\
274 \\
---\end{array}$ & $\begin{array}{l}218 \\
226 \\
218 \\
223 \\
221 \\
194\end{array}$ & $\begin{array}{l}562 \\
677 \\
761 \\
769 \\
730 \\
629\end{array}$ & $\begin{array}{l}542 \\
501 \\
467 \\
474 \\
499\end{array}$ \\
\hline $\begin{array}{l}\text { TOTAL } \\
\text { MEAN } \\
\text { MAX } \\
\text { MIN } \\
\text { CFSM } \\
\text { IN. }\end{array}$ & $\begin{array}{r}64097 \\
2068 \\
4550 \\
716 \\
2.68 \\
3.08\end{array}$ & $\begin{array}{r}18418 \\
614 \\
903 \\
501 \\
.79 \\
.89\end{array}$ & $\begin{array}{r}24676 \\
796 \\
1020 \\
580 \\
1.03 \\
1.19\end{array}$ & $\begin{array}{r}17220 \\
555 \\
658 \\
373 \\
.72 \\
.83\end{array}$ & $\begin{array}{r}13590 \\
485 \\
557 \\
380 \\
.63 \\
.65\end{array}$ & $\begin{array}{r}22005 \\
710 \\
1040 \\
560 \\
1.92 \\
1.06\end{array}$ & $\begin{array}{r}16805 \\
560 \\
703 \\
361 \\
.72 \\
.81\end{array}$ & $\begin{array}{r}10573 \\
341 \\
454 \\
262 \\
.44 \\
.51\end{array}$ & $\begin{array}{r}8261 \\
275 \\
473 \\
181 \\
.36 \\
.40\end{array}$ & $\begin{array}{r}7838 \\
253 \\
351 \\
194 \\
.33 \\
.38\end{array}$ & $\begin{array}{r}14737 \\
475 \\
984 \\
195 \\
.61 \\
.71\end{array}$ & $\begin{array}{r}14699 \\
490 \\
711 \\
356 \\
.63 \\
.71\end{array}$ \\
\hline
\end{tabular}

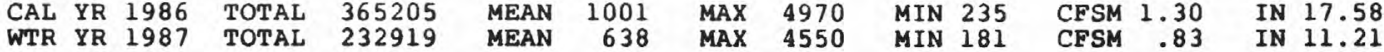


LOCATION.--Lat $42^{\circ} 57^{\prime} 52^{\prime \prime}$, long $85^{\circ} 40^{\prime} 35^{\prime \prime}$, in NEl/4 sec.25, T.7 N. , R.12 w., Kent County, Hydrologic Unit 04050006 , on $r i g h t$ bank 500 ft upstream from bridge on Fuiton street, i.7 mi upstream from plaster creek, and at mile 41 .

DRAINAGE AREA. - -4,900 $\mathrm{mi}^{2}$, approximately.

PERIOD OF RECORD.--March 1901 to December 1905, January 1906 to August 1918 (gage heights only), October 1930 to current year. Monthly discharge only for some periods, published in wsp l307. Gage-height records collected in this vicinity since 1907 are contained in reports of the National weather service.

REVISED RECORDS.--WSP 924: 1938(M). WSP 1387: 1901-5, 1940.

GAGE.--Water-stage recorder. Datum of gage is $585.70 \mathrm{ft}$ above National Geodetic vertical Datum of 1929 (levels by City of Grand Rapids). March 1901 to August 1918, nonrecording gage at Fulton Street Bridge $500 \mathrm{ft}$ downstream and Oct. 1, 1930, to Oct. 26, 1953, water-stage recorder at sewage pumping station $1 \mathrm{mi}$ downstream at datum 2.99 ft higher.

REMARKS.--Estimated daily discharges: Jan. 25-31. Records good except for estimated daily discharges, which are fair. Moderate diurnal fluctuation at low and medium flow caused by powerplants upstream from station. National Weather Service gage-height telemeter at station.

AVERAGE DISCHARGE. --61 years, 3,625 $\mathrm{ft}^{3} / \mathrm{s}, 10.05 \mathrm{in} / \mathrm{\gamma r}^{\mathrm{r}}$.

EXTREMES FOR PERIOD OF RECORD.--Maximum discharge, 54,000 ft $3 / \mathrm{s}$, Mar. 28, 1904, gage height, 19.5 ft, from graph based on gage readings, site then in use; maximum gage height, $19.64 \mathrm{ft}, \mathrm{Mar}$. 1 , i985; minimum daily discharge, $381 \mathrm{ft}^{3} / \mathrm{s}$, Aug. 9, 17,1936 .

EXTREMES OUTSIDE PERIOD OF RECORD.--Maximum discharge since at least 1901, that of Mar. 28 , 1904.

EXTREMES FOR CURRENT YEAR.--Maximum discharge, 28,300 $\mathrm{ft}^{3} / \mathrm{s}$, Oct. 4, gage height, 19.25 ft; minimum, $890 \mathrm{ft} / \mathrm{s}$, Aug. 8, gage height, $2.69 \mathrm{ft}$.

DISCHARGE, IN CUBIC FEET PER SECOND, WATER YEAR OCTOBER 1986 TO SEPTEMBER 1987

\begin{tabular}{|c|c|c|c|c|c|c|c|c|c|c|c|c|}
\hline DAY & ОСт & NOV & DEC & JAN & FEB & MAR & APR & MAY & JUN & JUL & AUG & SEP \\
\hline $\begin{array}{l}1 \\
2 \\
3 \\
4 \\
5\end{array}$ & $\begin{array}{l}20500 \\
23800 \\
26300 \\
27700 \\
28000\end{array}$ & $\begin{array}{l}5230 \\
5000 \\
4920 \\
4850 \\
4730\end{array}$ & $\begin{array}{l}4780 \\
4790 \\
4840 \\
5150 \\
5340\end{array}$ & $\begin{array}{l}4050 \\
3960 \\
4060 \\
4000 \\
3760\end{array}$ & $\begin{array}{l}3680 \\
3580 \\
3570 \\
3570 \\
3600\end{array}$ & $\begin{array}{l}3890 \\
5040 \\
5850 \\
6170 \\
6200\end{array}$ & $\begin{array}{l}3950 \\
3970 \\
4050 \\
4140 \\
4100\end{array}$ & $\begin{array}{l}3020 \\
2820 \\
2660 \\
2800 \\
2440\end{array}$ & $\begin{array}{l}1740 \\
1720 \\
1740 \\
1820 \\
1930\end{array}$ & $\begin{array}{l}1470 \\
1600 \\
1580 \\
1340 \\
1260\end{array}$ & $\begin{array}{l}1080 \\
1220 \\
1240 \\
1240 \\
1180\end{array}$ & $\begin{array}{l}3040 \\
2680 \\
2360 \\
2140 \\
1940\end{array}$ \\
\hline $\begin{array}{r}6 \\
7 \\
8 \\
9 \\
10\end{array}$ & $\begin{array}{l}27200 \\
26100 \\
24400 \\
21900 \\
19400\end{array}$ & $\begin{array}{l}4630 \\
4610 \\
4560 \\
4560 \\
4290\end{array}$ & $\begin{array}{l}5330 \\
5440 \\
5350 \\
5350 \\
5470\end{array}$ & $\begin{array}{l}3970 \\
3420 \\
3740 \\
3810 \\
3910\end{array}$ & $\begin{array}{l}3420 \\
3510 \\
3760 \\
3260 \\
3550\end{array}$ & $\begin{array}{l}6050 \\
5910 \\
5800 \\
5790 \\
5680\end{array}$ & $\begin{array}{l}4040 \\
4100 \\
4300 \\
4200 \\
4140\end{array}$ & $\begin{array}{l}2680 \\
2580 \\
2750 \\
2630 \\
2560\end{array}$ & $\begin{array}{l}1920 \\
1900 \\
2000 \\
1830 \\
1720\end{array}$ & $\begin{array}{l}1420 \\
1370 \\
1200 \\
1440 \\
1590\end{array}$ & $\begin{array}{r}1060 \\
1040 \\
986 \\
1340 \\
1450\end{array}$ & $\begin{array}{l}1940 \\
1760 \\
2590 \\
2510 \\
2080\end{array}$ \\
\hline $\begin{array}{l}11 \\
12 \\
13 \\
14 \\
15\end{array}$ & $\begin{array}{l}17100 \\
15100 \\
13400 \\
11900 \\
10800\end{array}$ & $\begin{array}{l}4240 \\
4020 \\
4140 \\
4090 \\
3910\end{array}$ & $\begin{array}{l}5490 \\
5520 \\
4860 \\
4380 \\
4370\end{array}$ & $\begin{array}{l}3860 \\
3950 \\
3830 \\
3950 \\
4010\end{array}$ & $\begin{array}{l}3650 \\
3570 \\
3440 \\
3350 \\
3160\end{array}$ & $\begin{array}{l}5500 \\
5150 \\
5030 \\
4770 \\
4650\end{array}$ & $\begin{array}{l}4070 \\
4020 \\
4000 \\
4020 \\
4810\end{array}$ & $\begin{array}{l}2380 \\
2380 \\
2460 \\
2380 \\
2280\end{array}$ & $\begin{array}{l}1730 \\
1730 \\
1770 \\
1800 \\
1630\end{array}$ & $\begin{array}{l}1780 \\
2060 \\
1710 \\
1520 \\
1360\end{array}$ & $\begin{array}{l}1470 \\
1460 \\
1400 \\
2620 \\
4340\end{array}$ & $\begin{array}{l}2100 \\
1940 \\
2440 \\
2400 \\
2460\end{array}$ \\
\hline $\begin{array}{l}16 \\
17 \\
18 \\
19 \\
20\end{array}$ & $\begin{array}{l}9940 \\
9140 \\
8530 \\
7840 \\
7430\end{array}$ & $\begin{array}{l}3870 \\
3700 \\
3720 \\
3650 \\
3730\end{array}$ & $\begin{array}{l}5120 \\
5410 \\
5180 \\
5060 \\
5100\end{array}$ & $\begin{array}{l}3920 \\
4150 \\
4190 \\
4210 \\
4020\end{array}$ & $\begin{array}{l}2370 \\
2160 \\
2770 \\
2880 \\
2830\end{array}$ & $\begin{array}{l}4440 \\
4380 \\
4250 \\
4270 \\
4180\end{array}$ & $\begin{array}{l}4820 \\
4720 \\
4630 \\
4460 \\
4370\end{array}$ & $\begin{array}{l}2260 \\
2260 \\
2210 \\
2310 \\
2460\end{array}$ & $\begin{array}{l}1370 \\
1420 \\
1330 \\
1230 \\
1290\end{array}$ & $\begin{array}{l}1290 \\
1270 \\
1190 \\
1130 \\
1110\end{array}$ & $\begin{array}{l}3880 \\
4080 \\
4110 \\
3570 \\
3130\end{array}$ & $\begin{array}{l}2220 \\
2360 \\
2580 \\
2870 \\
3050\end{array}$ \\
\hline $\begin{array}{l}21 \\
22 \\
23 \\
24 \\
25\end{array}$ & $\begin{array}{l}7040 \\
6680 \\
6450 \\
6440 \\
6330\end{array}$ & $\begin{array}{l}3810 \\
3790 \\
3820 \\
3960 \\
4010\end{array}$ & $\begin{array}{l}4990 \\
4930 \\
4790 \\
4640 \\
4540\end{array}$ & $\begin{array}{l}3870 \\
3930 \\
2890 \\
2790 \\
3400\end{array}$ & $\begin{array}{l}2690 \\
2540 \\
2410 \\
2470 \\
2550\end{array}$ & $\begin{array}{l}4250 \\
4310 \\
3940 \\
3900 \\
3940\end{array}$ & $\begin{array}{l}4140 \\
3900 \\
3660 \\
4120 \\
3810\end{array}$ & $\begin{array}{l}2410 \\
2510 \\
2280 \\
2280 \\
2060\end{array}$ & $\begin{array}{l}1710 \\
1780 \\
1790 \\
2090 \\
1580\end{array}$ & $\begin{array}{l}1170 \\
1220 \\
1110 \\
1130 \\
1150\end{array}$ & $\begin{array}{l}2500 \\
3230 \\
4240 \\
4620 \\
4020\end{array}$ & $\begin{array}{l}3150 \\
2960 \\
3340 \\
3380 \\
2740\end{array}$ \\
\hline $\begin{array}{l}26 \\
27 \\
28 \\
29 \\
30 \\
31\end{array}$ & $\begin{array}{l}5870 \\
5680 \\
5330 \\
5550 \\
5430 \\
5320\end{array}$ & $\begin{array}{l}4270 \\
4580 \\
4920 \\
5200 \\
4950\end{array}$ & $\begin{array}{l}4610 \\
4400 \\
4180 \\
4120 \\
4170 \\
4090\end{array}$ & $\begin{array}{l}3000 \\
2800 \\
3100 \\
3500 \\
3400 \\
3600\end{array}$ & $\begin{array}{r}2620 \\
2810 \\
2950 \\
--- \\
--- \\
---\end{array}$ & $\begin{array}{l}3880 \\
3900 \\
3920 \\
3800 \\
3940 \\
3860\end{array}$ & $\begin{array}{l}3510 \\
3000 \\
2820 \\
2800 \\
3020\end{array}$ & $\begin{array}{l}2210 \\
2060 \\
1980 \\
1980 \\
1880 \\
1880\end{array}$ & $\begin{array}{l}1620 \\
1620 \\
1330 \\
1660 \\
1490\end{array}$ & $\begin{array}{l}1240 \\
1070 \\
1080 \\
1120 \\
1230 \\
1070\end{array}$ & $\begin{array}{l}3450 \\
3640 \\
3830 \\
3940 \\
3610 \\
3300\end{array}$ & $\begin{array}{l}2450 \\
2240 \\
2150 \\
2320 \\
2260\end{array}$ \\
\hline $\begin{array}{l}\text { TOTAL } \\
\text { MEAN } \\
\text { MAX } \\
\text { MIN } \\
\text { CFSM } \\
\text { IN. }\end{array}$ & $\begin{array}{r}422600 \\
13630 \\
28000 \\
5320 \\
2.78 \\
3.21\end{array}$ & $\begin{array}{r}129760 \\
4325 \\
5230 \\
3650 \\
.88 \\
.99\end{array}$ & $\begin{array}{r}151790 \\
4896 \\
5520 \\
4090 \\
1.00 \\
1.15\end{array}$ & $\begin{array}{r}115050 \\
3711 \\
4210 \\
2790 \\
.76 \\
.87\end{array}$ & $\begin{array}{r}86720 \\
3097 \\
3760 \\
2160 \\
.63 \\
.66\end{array}$ & $\begin{array}{r}146640 \\
4730 \\
6200 \\
3800 \\
.97 \\
1.11\end{array}$ & $\begin{array}{r}119690 \\
3990 \\
4820 \\
2800 \\
.81 \\
.91\end{array}$ & $\begin{array}{r}73850 \\
2382 \\
3020 \\
1880 \\
.49 \\
.56\end{array}$ & $\begin{array}{r}50290 \\
1676 \\
2090 \\
1230 \\
.34 \\
.38\end{array}$ & $\begin{array}{r}41280 \\
1332 \\
2060 \\
1070 \\
.27 \\
.31\end{array}$ & $\begin{array}{r}82276 \\
2654 \\
4620 \\
986 \\
.54 \\
.62\end{array}$ & $\begin{array}{r}74450 \\
2482 \\
3380 \\
1760 \\
.51 \\
.57\end{array}$ \\
\hline $\begin{array}{ll}\text { CAL YR } \\
\text { WTR }\end{array}$ & $\begin{array}{l}1986 \\
1987\end{array}$ & $A L$ & $\begin{array}{l}6640 \\
4396\end{array}$ & $\begin{array}{l}\text { MEAN } \\
\text { MEAN }\end{array}$ & $\begin{array}{l}\text { MA } \\
\text { MA }\end{array}$ & $\begin{array}{l}2800 \\
2800\end{array}$ & $\begin{array}{l}\text { MIN } \\
\text { MIN }\end{array}$ & $\begin{array}{l}200 \\
986\end{array}$ & $\begin{array}{r}1.2 \\
1.8\end{array}$ & $\begin{array}{l}\text { IN } \\
\text { IN }\end{array}$ & $\frac{2}{5}$ & \\
\hline
\end{tabular}


LOCATION.--Lat $43^{\circ} 00^{\prime} 53^{\prime \prime}$, long $85^{\circ} 57^{\prime} 21^{\prime \prime}$, in NEl/4 NWl/4 sec.10, T. 7 N., R.14 W., Ottawa County, Hydrologic Unit 04050006, at bridge on 68 th Avenue in Eastmanville, $1.1 \mathrm{mi}$ downstream from Deer Creek, and at mile 19.3.

DRAINAGE AREA. $--5,230 \mathrm{mi}^{2}$, approximately.

PERIOD OF RECORD.--February 1979 to current year.

PERIOD OF DAILY RECORD.--

SPECIFIC CONDUCTANCE: February 1979 to September 1983.

WATER TEMPERATURE: February 1979 to September 1983.

INSTRUMENTATION. --Water-quality monitor from Oct. 7, 1980 to Sept. 30, 1983.

REMARKS.--Bimonthly cross-sectional samples were collected at bridge. A water-discharge measurement was made at time of sampling.

EXTREMES FOR PERIOD OF DAILY RECORD --

SPECIFIC CONDUCTANCE (water years 1979-82): Maximum daily recorded (more than 20 percent missing record), 1,100 microsiemens, Mar. 2, 1979; minimum measured, 324 microsiemens, Mar. 24, 1982.

WATER TEMPERATURE (water years 1980-81, 1983): Maximum, $28.5^{\circ} \mathrm{C}, \mathrm{Ju} 1 \mathrm{y} 21^{2}, 1983^{\prime}$ minimum, $0.0^{\circ} \mathrm{C}$ on many days during winter.

WATER QUALITY DATA, WATER YEAR OCTOBER 1986 TO SEPTEMBER 1987

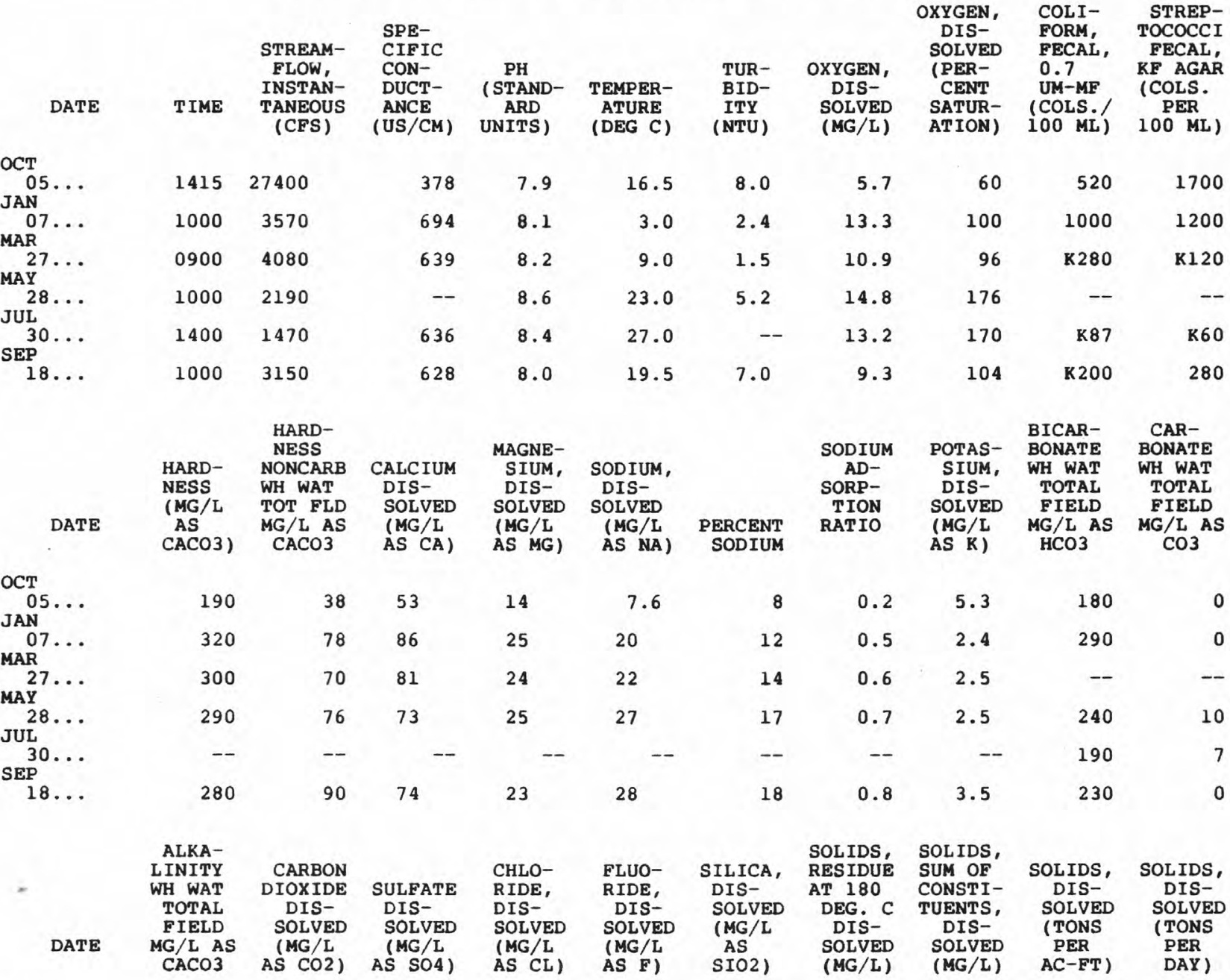

\begin{tabular}{|c|c|c|c|}
\hline OCT & & & \\
\hline JAN & 152 & 3.7 & 33 \\
\hline $\begin{array}{l}07 \ldots \\
\text { MAR }\end{array}$ & 240 & 3.7 & 59 \\
\hline${ }_{\text {MAY }}^{27} \cdots$ & -- & 2.8 & 54 \\
\hline JUL $^{28 \ldots}$ & 210 & 0.9 & 59 \\
\hline $\operatorname{SEP}^{30} \ldots$ & 166 & 1.2 & -- \\
\hline $18 \ldots$ & 190 & 3.7 & 74 \\
\hline
\end{tabular}

\begin{tabular}{|c|c|c|}
\hline 16 & 0.1 & 9.6 \\
\hline 44 & 0.2 & 7.2 \\
\hline 38 & 0.2 & 3.0 \\
\hline 51 & 0.2 & 1.0 \\
\hline-- & -- & -- \\
\hline 43 & 0.2 & 5.4 \\
\hline
\end{tabular}

$\begin{array}{rr}250 & 230 \\ 404 & 400 \\ 375 & 360 \\ 380 & 380 \\ -- & -- \\ 374 & 370\end{array}$

0.3418500

0.553890

0.514130

$0.52 \quad 2250$

$0.51 \quad 3180$ 
04119300 GRAND RIVER AT EASTMANVILLE, MI--Continued

WATER QUALITY DATA, WATER YEAR OCTOBER 1986 TO SEPTEMBER 1987

\begin{tabular}{|c|c|c|c|c|c|c|c|c|c|c|}
\hline DATE & $\begin{array}{c}\text { NITRO- } \\
\text { GEN, } \\
\text { NITRITE } \\
\text { DIS- } \\
\text { SOLVED } \\
\text { (MG/L } \\
\text { AS N) }\end{array}$ & $\begin{array}{c}\text { NITRO- } \\
\text { GEN, } \\
\text { NO2+NO3 } \\
\text { DIS- } \\
\text { SOLVED } \\
\text { (MG/L } \\
\text { AS N) }\end{array}$ & $\begin{array}{c}\text { NITRO- } \\
\text { GEN, } \\
\text { AMMONIA } \\
\text { TOTAL } \\
\text { (MG/L } \\
\text { AS N) }\end{array}$ & $\begin{array}{c}\text { NITRO- } \\
\text { GEN, } \\
\text { AMMONIA } \\
\text { DIS- } \\
\text { SOLVED } \\
\text { (MG/L } \\
\text { AS N) }\end{array}$ & $\begin{array}{l}\text { NITRO- } \\
\text { GEN, } \\
\text { ORGANIC } \\
\text { TOTAL } \\
\text { (MG/L } \\
\text { AS N) }\end{array}$ & $\begin{array}{l}\text { NITRO- } \\
\text { GEN, AM- } \\
\text { MONIA + } \\
\text { ORGANIC } \\
\text { TOTAL } \\
\text { (MG/L } \\
\text { AS N) }\end{array}$ & $\begin{array}{l}\text { PHOS- } \\
\text { PHORUS, } \\
\text { TOTAL } \\
\text { (MG/L } \\
\text { AS P) }\end{array}$ & $\begin{array}{c}\text { PHOS- } \\
\text { PHORUS, } \\
\text { DIS- } \\
\text { SOLVED } \\
\text { (MG/L } \\
\text { AS P) }\end{array}$ & $\begin{array}{l}\text { PHOS- } \\
\text { PHORUS, } \\
\text { ORTHO, } \\
\text { DIS- } \\
\text { SOLVED } \\
\text { (MG/L } \\
\text { AS P) }\end{array}$ & $\begin{array}{l}\text { ALUM- } \\
\text { INUM, } \\
\text { DIS- } \\
\text { SOLVED } \\
\text { (UG/L } \\
\text { AS AL) }\end{array}$ \\
\hline CT & & & & & & & & & & \\
\hline $05 \ldots$ & 0.04 & 0.93 & 0.10 & 0.05 & 1.7 & 1.8 & $<0.20$ & $<0.20$ & 0.08 & 10 \\
\hline$\underset{M A R}{07} \cdots$ & 0.01 & 1.60 & 0.37 & 0.36 & 0.93 & 1.3 & 0.03 & 0.01 & 0.01 & - \\
\hline$\underset{A Y}{27} \cdots$ & 0.02 & 0.94 & 0.32 & 0.33 & 0.88 & 1.2 & 0.07 & 0.01 & 0.02 & $<10$ \\
\hline${ }_{\text {JUL }}^{28 \ldots}$ & 0.05 & 0.46 & 0.02 & 0.02 & 2.0 & 2.0 & 0.10 & 0.01 & $<0.01$ & $<10$ \\
\hline $\mathrm{EP}^{30 \ldots}$ & 0.03 & 0.36 & $<0.01$ & $<0.01$ & -- & 2.0 & 0.13 & 0.01 & $<0.01$ & - \\
\hline $18 \ldots$ & 0.03 & 0.67 & 0.22 & 0.20 & 1.3 & 1.5 & 0.10 & $<0.01$ & $<0.01$ & $<10$ \\
\hline
\end{tabular}

DATE

$\begin{array}{cc}\text { ARSENIC } & \text { BARIUM, } \\ \text { DIS- } & \text { DIS- } \\ \text { SOLVED } & \text { SOLVED } \\ \text { (UG/L } & \text { (UG/L } \\ \text { AS AS) } & \text { AS BA) }\end{array}$

BERYL-

LIUM, CADMIUM

DIS-

SOLVED

SOLVED

(US $\mathrm{BE}$ )
DIS-

SOLVED

(UG/L
CHRO-

MIUM, COBALT, COPPER,

DIS- DIS- DIS-

SOLVED SOLVED SOLVED

(UG $/ I$ SOLVED

$\begin{array}{ll}\text { (UG/L } & \text { (UG/L } \\ \text { AS CR) } & \text { AS CO) }\end{array}$
SOLVED

(UG/L
IRON,
DIS-
SOLVED
(UG/L
AS FE)

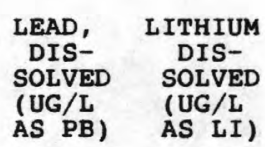

$\begin{array}{ll}\text { (UG/L } & \text { (UG/L } \\ \text { AS PB) } & \text { AS II) }\end{array}$
OCT
$05 \ldots$
JAN $\ldots$
$07 \ldots$
MAR $\ldots$
$27 \ldots$
MAY
$28 \ldots$
JUL $\ldots$
$30 \ldots$
SEP $\ldots$
$18 \ldots$

OC'

$$
\begin{gathered}
\text { OCT } \\
05 \ldots \\
\text { JAN } \\
07 \ldots \\
\text { MAR } \\
27 \ldots \\
\text { MAY } \\
28 \ldots \\
\text { JUL } \\
30 \ldots \\
\text { SEP }
\end{gathered}
$$$$
18 \ldots
$$

$$
\begin{array}{cc}
<0.5 & <1 \\
-- & -- \\
<0.5 & <1 \\
1 & <1 \\
-- & --
\end{array}
$$

$<0.5$

$$
\begin{array}{rr}
<1 & <3 \\
-- & -- \\
<1 & <3 \\
2 & <3 \\
-- & -- \\
<1 & <3
\end{array}
$$$$
<1
$$

MOLYB-

MANGA-

NESE,

$$
\text { DIS- }
$$

DIS-

SOLVED SOLVED

(UG/L (UG/L

AS MN) AS HG)
DENUM, NICKEL,

DIS-

SOLVED SOLVED

(UG/L SOLVED

$\begin{array}{ll}\text { (UG/L } & \text { (UG/L } \\ \text { AS MO) } & \text { AS NI) }\end{array}$
NIUM, SILVER,

OLVED

(UG/L

(UG/L
AS AG)

5
--
3
1
--
1

110
--
13
7
--
13


NA-
UM,
IS-
LVED
G/L
V)

$\begin{array}{ll}<5 & 10 \\ -- & -- \\ <5 & 14 \\ <5 & 14 \\ -- & -- \\ <5 & 6\end{array}$

ZINC, SEDIDIS- MENT, SOLVED SUS(UG / L PENDED AS $\mathrm{ZN}) \quad(\mathrm{MG} / \mathrm{L})$

$\begin{array}{rrrr}9 & <0.1 & <10 & 2 \\ -- & -- & -- & -- \\ 18 & <0.1 & <10 & 5 \\ <1 & <0.1 & <10 & 3 \\ -- & -- & -- & -- \\ 3 & <0.1 & <10 & 6\end{array}$

$$
\begin{array}{ll}
<1 \\
-- \\
<1 \\
-- \\
<1
\end{array}
$$

$\begin{array}{rrr}<6 & 11 & 25 \\ -- & -- & 29 \\ <6 & 4 & 22 \\ <6 & 9 & 31 \\ -- & -- & 31 \\ <6 & 8 & 22\end{array}$

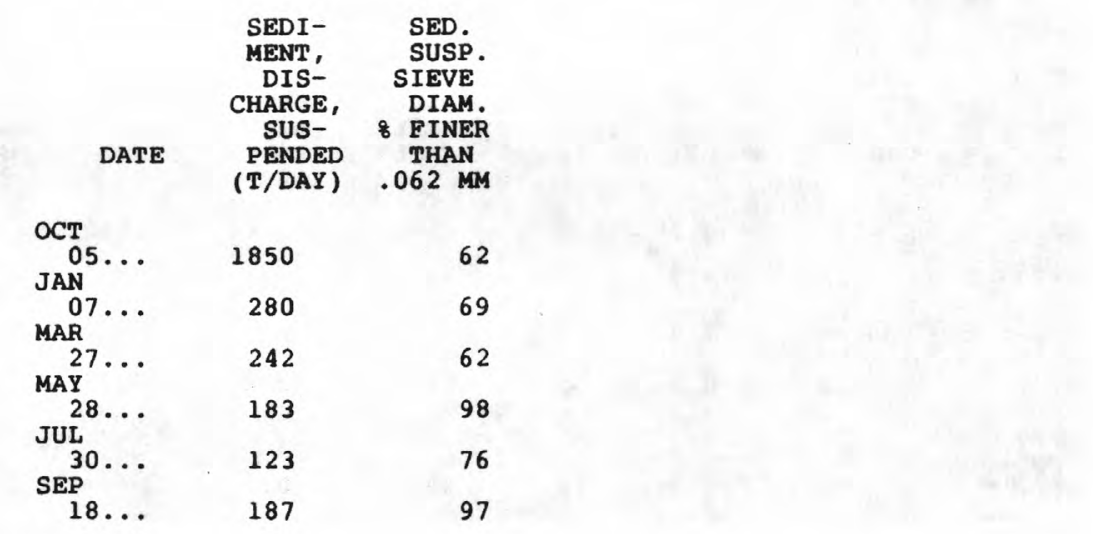




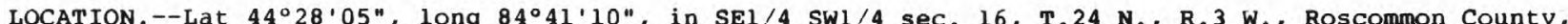
Hydrologic Unit 04060102 , at Flag Point Association, $0.3 \mathrm{mi}$ east of Fiag Point, and $5.2 \mathrm{mi}$ southwest of Roscommon.

DRAINAGE AREA. $--58 \mathrm{mi}^{2}$, approximately.

PERIOD OF RECORD.--September 1942 to current year.

GAGE.--Water-stage recorder. Datum of gage is $1,148.74 \mathrm{ft}$ above National Geodetic Vertical Datum of 1929 (levels by Michigan Department of Natural Resources). Prior to Nov. 27, 1942, nonrecording gage at same datum.

REMARKS.--Higgins Lake has two inlets, Big creek and Little Creek. The outlet is "The Cut" which flows into Marl Lake and then into Houghton Lake. Streamflow records for the outlet (station 04120500 ) were collected from July 1942 to July 1950. Lake elevation maintained by a three bay dam with stop logs. Maximum depth $141 \mathrm{ft,} \mathrm{surface} \mathrm{area} \mathrm{9,900} \mathrm{acres.} \mathrm{Established} \mathrm{legal} \mathrm{level;} \mathrm{summer,} \mathrm{1,154.11} \mathrm{ft,} \mathrm{winter,}$ $1,153.61 \mathrm{ft}$, above NGVD.

EXTREMES FOR PERIOD OF RECORD.--Maximum gage height, $6.23 \mathrm{ft}$, June 26, 1954; minimum, 4.32 ft, OCt. 3, 4, 1955 .

EXTREMES FOR CURRENT YeAR.--Maximum gage height, $5.97 \mathrm{ft}$, Oct. 4, 5; minimum, $5.07 \mathrm{ft}, \mathrm{July} 31, \mathrm{Aug}$. 1.

GAGE HEIGHT (FEET ABOVE DATUM), WATER YEAR OCTOBER 1986 TO SEPTEMBER 1987

\begin{tabular}{|c|c|c|c|c|c|c|c|c|c|c|c|c|}
\hline DAY & OCT & NOV & DEC & JAN & FEB & MAR & APR & MAY & JUN & JUL & AUG & SEP \\
\hline $\begin{array}{l}1 \\
2 \\
3 \\
4 \\
5\end{array}$ & $\begin{array}{l}5.92 \\
5.91 \\
5.93 \\
5.94 \\
5.95\end{array}$ & $\begin{array}{l}5.64 \\
5.63 \\
5.61 \\
5.59 \\
5.57\end{array}$ & $\begin{array}{l}5.33 \\
5.33 \\
5.34 \\
5.34 \\
5.32\end{array}$ & $\begin{array}{l}5.34 \\
5.35 \\
5.35 \\
5.35 \\
5.34\end{array}$ & $\begin{array}{l}5.38 \\
5.38 \\
5.38 \\
5.38 \\
5.37\end{array}$ & $\begin{array}{l}5.38 \\
5.40 \\
5.40 \\
5.39 \\
5.39\end{array}$ & $\begin{array}{l}5.36 \\
5.38 \\
5.38 \\
5.38 \\
5.37\end{array}$ & $\begin{array}{l}5.32 \\
5.32 \\
5.31 \\
5.30 \\
5.29\end{array}$ & $\begin{array}{l}5.36 \\
5.36 \\
5.36 \\
5.35 \\
5.33\end{array}$ & $\begin{array}{l}5.28 \\
5.27 \\
5.28 \\
5.26 \\
5.25\end{array}$ & $\begin{array}{l}5.10 \\
5.16 \\
5.16 \\
5.17 \\
5.14\end{array}$ & $\begin{array}{l}5.27 \\
5.26 \\
5.24 \\
5.24 \\
5.24\end{array}$ \\
\hline $\begin{array}{r}6 \\
7 \\
8 \\
9 \\
10\end{array}$ & $\begin{array}{l}5.94 \\
5.90 \\
5.89 \\
5.86 \\
5.83\end{array}$ & $\begin{array}{l}5.56 \\
5.55 \\
5.54 \\
5.53 \\
5.50\end{array}$ & $\begin{array}{l}5.32 \\
5.32 \\
5.32 \\
5.34 \\
5.34\end{array}$ & $\begin{array}{l}5.34 \\
5.36 \\
5.35 \\
5.34 \\
5.36\end{array}$ & $\begin{array}{l}5.37 \\
5.37 \\
5.38 \\
5.36 \\
5.36\end{array}$ & $\begin{array}{l}5.38 \\
5.37 \\
5.37 \\
5.37 \\
5.37\end{array}$ & $\begin{array}{l}5.37 \\
5.36 \\
5.36 \\
5.36 \\
5.35\end{array}$ & $\begin{array}{l}5.29 \\
5.28 \\
5.27 \\
5.27 \\
5.27\end{array}$ & $\begin{array}{l}5.31 \\
5.31 \\
5.31 \\
5.30 \\
5.27\end{array}$ & $\begin{array}{l}5.25 \\
5.25 \\
5.25 \\
5.27 \\
5.30\end{array}$ & $\begin{array}{l}5.13 \\
5.14 \\
5.13 \\
5.22 \\
5.29\end{array}$ & $\begin{array}{l}5.23 \\
5.23 \\
5.23 \\
5.23 \\
5.22\end{array}$ \\
\hline $\begin{array}{l}11 \\
12 \\
13 \\
14 \\
15\end{array}$ & $\begin{array}{l}5.81 \\
5.81 \\
5.81 \\
5.80 \\
5.78\end{array}$ & $\begin{array}{l}5.49 \\
5.47 \\
5.45 \\
5.41 \\
5.40\end{array}$ & $\begin{array}{l}5.32 \\
5.34 \\
5.34 \\
5.33 \\
5.34\end{array}$ & $\begin{array}{l}5.36 \\
5.36 \\
5.35 \\
5.35 \\
5.35\end{array}$ & $\begin{array}{l}5.36 \\
5.37 \\
5.36 \\
5.38 \\
5.37\end{array}$ & $\begin{array}{l}5.36 \\
5.36 \\
5.35 \\
5.35 \\
5.35\end{array}$ & $\begin{array}{l}5.35 \\
5.35 \\
5.35 \\
5.35 \\
5.38\end{array}$ & $\begin{array}{l}5.30 \\
5.29 \\
5.28 \\
5.29 \\
5.29\end{array}$ & $\begin{array}{l}5.27 \\
5.29 \\
5.29 \\
5.29 \\
5.28\end{array}$ & $\begin{array}{l}5.30 \\
5.30 \\
5.29 \\
5.27 \\
5.23\end{array}$ & $\begin{array}{l}5.27 \\
5.26 \\
5.25 \\
5.26 \\
5.41\end{array}$ & $\begin{array}{l}5.23 \\
5.25 \\
5.26 \\
5.25 \\
5.23\end{array}$ \\
\hline $\begin{array}{l}16 \\
17 \\
18 \\
19 \\
20\end{array}$ & $\begin{array}{l}5.76 \\
5.74 \\
5.73 \\
5.72 \\
5.71\end{array}$ & $\begin{array}{l}5.40 \\
5.39 \\
5.38 \\
5.36 \\
5.38\end{array}$ & $\begin{array}{l}5.33 \\
5.33 \\
5.35 \\
5.35 \\
5.34\end{array}$ & $\begin{array}{l}5.34 \\
5.34 \\
5.34 \\
5.34 \\
5.34\end{array}$ & $\begin{array}{l}5.37 \\
5.38 \\
5.38 \\
5.38 \\
5.37\end{array}$ & $\begin{array}{l}5.35 \\
5.34 \\
5.34 \\
5.33 \\
5.33\end{array}$ & $\begin{array}{l}5.38 \\
5.38 \\
5.38 \\
5.38 \\
5.38\end{array}$ & $\begin{array}{l}5.28 \\
5.28 \\
5.27 \\
5.28 \\
5.31\end{array}$ & $\begin{array}{l}5.27 \\
5.27 \\
5.26 \\
5.26 \\
5.26\end{array}$ & $\begin{array}{l}5.21 \\
5.21 \\
5.21 \\
5.20 \\
5.19\end{array}$ & $\begin{array}{l}5.48 \\
5.52 \\
5.51 \\
5.49 \\
5.47\end{array}$ & $\begin{array}{l}5.22 \\
5.28 \\
5.36 \\
5.38 \\
5.39\end{array}$ \\
\hline $\begin{array}{l}21 \\
22 \\
23 \\
24 \\
25\end{array}$ & $\begin{array}{l}5.70 \\
5.69 \\
5.74 \\
5.73 \\
5.71\end{array}$ & $\begin{array}{l}5.38 \\
5.37 \\
5.38 \\
5.38 \\
5.37\end{array}$ & $\begin{array}{l}5.34 \\
5.33 \\
5.34 \\
5.33 \\
5.34\end{array}$ & $\begin{array}{l}5.34 \\
5.34 \\
5.35 \\
5.35 \\
5.35\end{array}$ & $\begin{array}{l}5.37 \\
5.37 \\
5.37 \\
5.37 \\
5.36\end{array}$ & $\begin{array}{l}5.33 \\
5.33 \\
5.33 \\
5.33 \\
5.33\end{array}$ & $\begin{array}{l}5.38 \\
5.37 \\
5.39 \\
5.39 \\
5.37\end{array}$ & $\begin{array}{l}5 \cdot 32 \\
5.34 \\
5.34 \\
5.33 \\
5.33\end{array}$ & $\begin{array}{l}5.25 \\
5.27 \\
5.28 \\
5.27 \\
5.28\end{array}$ & $\begin{array}{l}5.17 \\
5.16 \\
5.16 \\
5.15 \\
5.14\end{array}$ & $\begin{array}{l}5.46 \\
5.45 \\
5.42 \\
5.39 \\
5.37\end{array}$ & $\begin{array}{l}5.39 \\
5.37 \\
5.38 \\
5.36 \\
5.33\end{array}$ \\
\hline $\begin{array}{l}26 \\
27 \\
28 \\
29 \\
30 \\
31\end{array}$ & $\begin{array}{l}5.70 \\
5.71 \\
5.70 \\
5.69 \\
5.67 \\
5.64\end{array}$ & $\begin{array}{r}5.37 \\
5.36 \\
5.35 \\
5.35 \\
5.34 \\
-\end{array}$ & $\begin{array}{l}5.33 \\
5.33 \\
5.32 \\
5.33 \\
5.34 \\
5.34\end{array}$ & $\begin{array}{l}5.34 \\
5.33 \\
5.34 \\
5.34 \\
5.38 \\
5.38\end{array}$ & $\begin{array}{r}5.36 \\
5.36 \\
5.36 \\
--- \\
- \\
-\end{array}$ & $\begin{array}{l}5.34 \\
5.35 \\
5.36 \\
5.37 \\
5.38 \\
5.37\end{array}$ & $\begin{array}{l}5.37 \\
5.38 \\
5.37 \\
5.36 \\
5.34 \\
-\end{array}$ & $\begin{array}{l}5 \cdot 34 \\
5 \cdot 35 \\
5.36 \\
5 \cdot 36 \\
5.36 \\
5.37\end{array}$ & $\begin{array}{r}5.30 \\
5.30 \\
5.28 \\
5.29 \\
5.29 \\
-\end{array}$ & $\begin{array}{l}5.13 \\
5.11 \\
5.09 \\
5.09 \\
5.08 \\
5.07\end{array}$ & $\begin{array}{l}5.34 \\
5.32 \\
5.30 \\
5.31 \\
5.30 \\
5.29\end{array}$ & $\begin{array}{l}5.33 \\
5.31 \\
5.32 \\
5.34 \\
5.37\end{array}$ \\
\hline $\begin{array}{l}\text { MEAN } \\
\text { MAX } \\
\text { MIN }\end{array}$ & $\begin{array}{l}5.79 \\
5.95 \\
5.64\end{array}$ & $\begin{array}{l}5.45 \\
5.64 \\
5.34\end{array}$ & $\begin{array}{l}5.33 \\
5.35 \\
5.32\end{array}$ & $\begin{array}{l}5.35 \\
5.38 \\
5.33\end{array}$ & $\begin{array}{l}5.37 \\
5.38 \\
5.36\end{array}$ & $\begin{array}{l}5.36 \\
5.40 \\
5.33\end{array}$ & $\begin{array}{l}5.37 \\
5.39 \\
5.34\end{array}$ & $\begin{array}{l}5.31 \\
5.37 \\
5.27\end{array}$ & $\begin{array}{l}5.29 \\
5.36 \\
5.25\end{array}$ & $\begin{array}{l}5.21 \\
5.30 \\
5.07\end{array}$ & $\begin{array}{l}5.31 \\
5.52 \\
5.10\end{array}$ & $\begin{array}{l}5.29 \\
5.39 \\
5.22\end{array}$ \\
\hline
\end{tabular}

WTR YR 1987 MEAN 5.37 MAX 5.95 MIN 5.07 
LOCATION.--Lat $44^{\circ} 24^{\prime} 16^{\prime \prime}$, long $84^{\circ} 47^{\prime} 28^{\prime \prime}$, in NWl/4 NWl/4 sec.10, T.23 N., R. 4 W., Roscommon CountY,

Hydrologic Unit 04060102 , on right bank of Muskegon River at upstream side of bridge on old U.S.

Highway 27, $0.4 \mathrm{mi}$ downstream from Houghton Lake, and $5.2 \mathrm{mi}$ north of Houghton Lake Heights.

DRAINAGE AREA. $--222 \mathrm{mi}^{2}$.

PERIOD OF RECORD.--June 1942 to current year, except winter period of 1942-43.

GAGE.--Water-stage recorder. Datum of gage is 1,130.00 ft above National Geodetic Vertical Datum of 1929 (levels by Michigan Department of Natural Resources). Prior to Sept. 28, 1960, nonrecording gage at same datum.

REMARKS.--Backus Creek and "The Cut" from Higgins Lake, join about 1 mi upstream from Houghton Lake and become the major inlet. There are also many small tributaries which feed the lake. The outlet is Muskegon River. Houghton Lake is the largest inland lake in Michigan covering 19,600 acres, with a maximum depth of $20 \mathrm{ft}$. Established legal level; summer, 1,138.1 ft, minimum winter, 1, 137.6 ft, above NGVD.

EXTREMES FOR PERIOD OF RECORD.--Maximum gage height, $10.18 \mathrm{ft}$, Apr. 23, 1985; minimum observed, 6.95 ft, Sept. 3, 5, Nov. 8, 1958.

EXTREMES FOR CURRENT YEAR.--Maximum gage height, $9.82 \mathrm{ft}$, Oct. 7; minimum, $7.05 \mathrm{ft}, \mathrm{July} 20$.

GAGE HEIGHT (FEET ABOVE DATUM), WATER YEAR OCTOBER 1986 TO SEPTEMBER 1987 MEAN VALUES

\begin{tabular}{|c|c|c|c|c|c|c|c|c|c|c|c|c|}
\hline DAY & OCT & NOV & DEC & JAN & FEB & MAR & APR & MAY & JUN & JUL & AUG & SEP \\
\hline $\begin{array}{l}1 \\
2 \\
3 \\
4 \\
5\end{array}$ & $\begin{array}{l}9.59 \\
9.61 \\
9.63 \\
9.65 \\
9.68\end{array}$ & $\begin{array}{l}9.54 \\
9.51 \\
9.52 \\
9.49 \\
9.51\end{array}$ & $\begin{array}{l}9.13 \\
9.13 \\
9.10 \\
9.08 \\
9.09\end{array}$ & $\begin{array}{l}8.91 \\
8.91 \\
8.91 \\
8.90 \\
8.90\end{array}$ & $\begin{array}{l}8.59 \\
8.58 \\
8.56 \\
8.54 \\
8.54\end{array}$ & $\begin{array}{l}8.26 \\
8.26 \\
8.26 \\
8.25 \\
8.25\end{array}$ & $\begin{array}{l}8.50 \\
8.34 \\
8.42 \\
8.35 \\
8.35\end{array}$ & $\begin{array}{l}8.41 \\
8.44 \\
8.44 \\
8.42 \\
8.40\end{array}$ & $\begin{array}{l}8.32 \\
8.28 \\
8.22 \\
8.20 \\
8.18\end{array}$ & $\begin{array}{l}7.98 \\
7.97 \\
7.90 \\
7.90 \\
7.96\end{array}$ & $\begin{array}{l}7.72 \\
7.67 \\
7.69 \\
7.62 \\
7.67\end{array}$ & $\begin{array}{l}7.87 \\
7.87 \\
7.90 \\
7.93 \\
7.91\end{array}$ \\
\hline $\begin{array}{r}6 \\
7 \\
8 \\
9 \\
10\end{array}$ & $\begin{array}{l}9.67 \\
9.76 \\
9.73 \\
9.71 \\
9.78\end{array}$ & $\begin{array}{l}9.48 \\
9.48 \\
9.53 \\
9.36 \\
9.39\end{array}$ & $\begin{array}{l}9.08 \\
9.08 \\
9.08 \\
9.08 \\
9.08\end{array}$ & $\begin{array}{l}8.89 \\
8.87 \\
8.87 \\
8.86 \\
8.86\end{array}$ & $\begin{array}{l}8.51 \\
8.50 \\
8.48 \\
8.47 \\
8.45\end{array}$ & $\begin{array}{l}8.25 \\
8.25 \\
8.25 \\
8.25 \\
8.25\end{array}$ & $\begin{array}{l}8.40 \\
8.42 \\
8.45 \\
8.46 \\
8.47\end{array}$ & $\begin{array}{l}8.33 \\
8.35 \\
8.35 \\
8.33 \\
8.41\end{array}$ & $\begin{array}{l}8.23 \\
8.18 \\
8.10 \\
8.08 \\
8.14\end{array}$ & $\begin{array}{l}7.90 \\
7.91 \\
7.91 \\
7.99 \\
7.96\end{array}$ & $\begin{array}{l}7.68 \\
7.60 \\
7.64 \\
7.80 \\
7.77\end{array}$ & $\begin{array}{l}7.90 \\
7.89 \\
7.92 \\
7.90 \\
7.93\end{array}$ \\
\hline $\begin{array}{l}11 \\
12 \\
13 \\
14 \\
15\end{array}$ & $\begin{array}{l}9.77 \\
9.78 \\
9.75 \\
9.73 \\
9.71\end{array}$ & $\begin{array}{l}9.35 \\
9.31 \\
9.29 \\
9.33 \\
9.31\end{array}$ & $\begin{array}{l}9.07 \\
9.05 \\
9.04 \\
9.03 \\
9.02\end{array}$ & $\begin{array}{l}8.87 \\
8.86 \\
8.85 \\
8.85 \\
8.84\end{array}$ & $\begin{array}{l}8.44 \\
8.43 \\
8.42 \\
8.41 \\
8.40\end{array}$ & $\begin{array}{l}8.25 \\
8.25 \\
8.25 \\
8.24 \\
8.24\end{array}$ & $\begin{array}{l}8.50 \\
8.45 \\
8.48 \\
8.52 \\
8.51\end{array}$ & $\begin{array}{l}8.35 \\
8.36 \\
8.42 \\
8.32 \\
8.32\end{array}$ & $\begin{array}{l}8.18 \\
8.11 \\
8.13 \\
8.10 \\
8.10\end{array}$ & $\begin{array}{l}7.95 \\
7.96 \\
7.86 \\
7.77 \\
7.85\end{array}$ & $\begin{array}{l}7.80 \\
7.81 \\
7.78 \\
7.83 \\
7.94\end{array}$ & $\begin{array}{l}7.94 \\
7.93 \\
7.91 \\
7.90 \\
7.92\end{array}$ \\
\hline $\begin{array}{l}16 \\
17 \\
18 \\
19 \\
20\end{array}$ & $\begin{array}{l}9.73 \\
9.72 \\
9.73 \\
9.72 \\
9.70\end{array}$ & $\begin{array}{l}9.29 \\
9.29 \\
9.27 \\
9.26 \\
9.26\end{array}$ & $\begin{array}{l}9.01 \\
9.00 \\
9.00 \\
8.99 \\
8.98\end{array}$ & $\begin{array}{l}8.81 \\
8.76 \\
8.75 \\
8.74 \\
8.73\end{array}$ & $\begin{array}{l}8.39 \\
8.36 \\
8.35 \\
8.34 \\
8.33\end{array}$ & $\begin{array}{l}8.24 \\
8.22 \\
8.22 \\
8.21 \\
8.21\end{array}$ & $\begin{array}{l}8.54 \\
8.52 \\
8.52 \\
8.53 \\
8.55\end{array}$ & $\begin{array}{l}8.34 \\
8.31 \\
8.33 \\
8.37 \\
8.33\end{array}$ & $\begin{array}{l}8.08 \\
8.12 \\
8.09 \\
8.05 \\
8.09\end{array}$ & $\begin{array}{l}7.86 \\
7.86 \\
7.82 \\
7.84 \\
7.78\end{array}$ & $\begin{array}{l}8.03 \\
8.02 \\
8.04 \\
7.99 \\
8.02\end{array}$ & $\begin{array}{l}7.93 \\
8.02 \\
8.07 \\
8.11 \\
8.15\end{array}$ \\
\hline $\begin{array}{l}21 \\
22 \\
23 \\
24 \\
25\end{array}$ & $\begin{array}{l}9.69 \\
9.68 \\
9.67 \\
9.69 \\
9.67\end{array}$ & $\begin{array}{l}9.26 \\
9.25 \\
9.24 \\
9.24 \\
9.24\end{array}$ & $\begin{array}{l}8.97 \\
8.96 \\
8.97 \\
8.96 \\
8.95\end{array}$ & $\begin{array}{l}8.72 \\
8.71 \\
8.69 \\
8.68 \\
8.66\end{array}$ & $\begin{array}{l}8.30 \\
8.30 \\
8.29 \\
8.28 \\
8.27\end{array}$ & $\begin{array}{l}8.24 \\
8.28 \\
8.27 \\
8.28 \\
8.32\end{array}$ & $\begin{array}{l}8.46 \\
8.57 \\
8.50 \\
8.51 \\
8.53\end{array}$ & $\begin{array}{l}8.35 \\
8.33 \\
8.30 \\
8.31 \\
8.35\end{array}$ & $\begin{array}{l}8.07 \\
8.04 \\
8.04 \\
8.03 \\
8.00\end{array}$ & $\begin{array}{l}7.80 \\
7.81 \\
7.78 \\
7.75 \\
7.75\end{array}$ & $\begin{array}{l}8.05 \\
7.91 \\
7.94 \\
7.95 \\
7.96\end{array}$ & $\begin{array}{l}8.12 \\
8.10 \\
8.08 \\
8.07 \\
8.08\end{array}$ \\
\hline $\begin{array}{l}26 \\
27 \\
28 \\
29 \\
30 \\
31\end{array}$ & $\begin{array}{l}9.65 \\
9.62 \\
9.62 \\
9.55 \\
9.57 \\
9.66\end{array}$ & $\begin{array}{r}9.21 \\
9.20 \\
9.18 \\
9.15 \\
9.14 \\
-\end{array}$ & $\begin{array}{l}8.95 \\
8.95 \\
8.94 \\
8.93 \\
8.93 \\
8.93\end{array}$ & $\begin{array}{l}8.66 \\
8.65 \\
8.64 \\
8.61 \\
8.62 \\
8.61\end{array}$ & $\begin{array}{r}8.26 \\
8.25 \\
8.24 \\
-\ldots \\
-.- \\
-\end{array}$ & $\begin{array}{l}8.34 \\
8.37 \\
8.36 \\
8.38 \\
8.27 \\
8.30\end{array}$ & $\begin{array}{l}8.52 \\
8.35 \\
8.33 \\
8.30 \\
8.36 \\
---\end{array}$ & $\begin{array}{l}8.37 \\
8.34 \\
8.34 \\
8.33 \\
8.32 \\
8.32\end{array}$ & $\begin{array}{l}7.97 \\
7.95 \\
7.97 \\
7.96 \\
7.95\end{array}$ & $\begin{array}{l}7.71 \\
7.70 \\
7.70 \\
7.69 \\
7.69 \\
7.71\end{array}$ & $\begin{array}{l}7.98 \\
7.94 \\
7.93 \\
7.94 \\
7.96 \\
7.86\end{array}$ & $\begin{array}{l}8.10 \\
8.12 \\
8.14 \\
8.14 \\
8.09\end{array}$ \\
\hline $\begin{array}{l}\text { MEAN } \\
\text { MAX } \\
\text { MIN }\end{array}$ & $\begin{array}{l}9.68 \\
9.78 \\
9.55\end{array}$ & $\begin{array}{l}9.33 \\
9.54 \\
9.14\end{array}$ & $\begin{array}{l}9.02 \\
9.13 \\
8.93\end{array}$ & $\begin{array}{l}8.78 \\
8.91 \\
8.61\end{array}$ & $\begin{array}{l}8.40 \\
8.59 \\
8.24\end{array}$ & $\begin{array}{l}8.27 \\
8.38 \\
8.21\end{array}$ & $\begin{array}{l}8.46 \\
8.57 \\
8.30\end{array}$ & $\begin{array}{l}8.35 \\
8.44 \\
8.30\end{array}$ & $\begin{array}{l}8.10 \\
8.32 \\
7.95\end{array}$ & $\begin{array}{l}7.84 \\
7.99 \\
7.69\end{array}$ & $\begin{array}{l}7.86 \\
8.05 \\
7.60\end{array}$ & $\begin{array}{l}8.00 \\
8.15 \\
7.87\end{array}$ \\
\hline
\end{tabular}

WTR YR 1987 MEAN 8.51 MAX 9.78 MIN 7.60 


\section{CLAM RIVER AT VOGEL CENTER, MI}

LOCATION.--Lat $44^{\circ} 12^{\prime} 02^{\prime \prime}$, long $85^{\circ} 03^{\prime} 10^{\prime \prime}$, in SWl/4 NWl/4 sec. 21, T. 21 N., R.6 W., Missaukee County, Hydrologic Unit 04060102 , on left bank 10 ft downstream from bridge on 8 Mile Road, $0.5 \mathrm{mi}$ north of vogel Center, and $3.5 \mathrm{mi}$ southeast of Falmouth.

DRA INAGE AREA. $--243 \mathrm{mi}^{2}$.

PERIOD OF RECORD.--June 1966 to current year.

GAGE.--Water-stage recorder. Elevation of gage is $1,130 \mathrm{ft}$ above National Geodetic Vertical Datum of 1929, from topographic map.

REMARKS.--Estimated daily discharges: Jan. 25, 26. Records good except for estimated daily discharges, which are fair. Some regulation at low flow by dams upstream from station. Several measurements of water temperature were made during the year.

AVERAGE DISCHARGE. --21 years, $128 \mathrm{ft}^{3} / \mathrm{s}, 7.15 \mathrm{in} / \mathrm{yr}^{2}$

EXTREMES FOR PERIOD OF RECORD.--Maximum discharge, 1,150 $\mathrm{ft}^{3} / \mathrm{s}$, Apr. 13, 1971, gage height, $6.33 \mathrm{ft}$; minimum, $29 \mathrm{ft}^{3} / \mathrm{s}$, Nov. 3, 1969, result of freezeup.

EXTREMES FOR CURRENT YEAR.--Peak discharges greater than base discharge of $350 \mathrm{ft}^{3} / \mathrm{s}$ and maximum (*):

$\begin{array}{cccccccc}\text { Date } & \text { Time } & \begin{array}{c}\text { Discharge } \\ \left(\mathrm{ft}^{3} / \mathrm{s}\right)\end{array} & \begin{array}{c}\text { Gage height } \\ \text { (ft) }\end{array} & \text { Date } & \text { Time } & \begin{array}{c}\text { Discharge } \\ \left.\text { (ft } / \mathrm{ft}^{3}\right)\end{array} \\ \text { Oct. } 1 & 1900 & * 389 & \star 4.38 & \text { Mar. } & 9 & 2200 & \begin{array}{c}\text { Gage height } \\ \text { (ft) }\end{array}\end{array}$

Minimum discharge, $48 \mathrm{ft}^{3} / \mathrm{s}, J u l y 31$, gage height, $2.41 \mathrm{ft}$.

DISCHARGE, IN CUBIC FEET PER SECOND, WATER YEAR OCTOBER 1986 TO SEPTEMBER 1987 MEAN VALUES

\begin{tabular}{|c|c|c|c|c|c|c|c|c|c|c|c|c|}
\hline DAY & OCT & NOV & $\mathrm{DEC}$ & JAN & FEB & MAR & APR & MAY & JUN & JUL & AUG & SEP \\
\hline $\begin{array}{l}1 \\
2 \\
3 \\
4 \\
5\end{array}$ & $\begin{array}{l}380 \\
365 \\
325 \\
313 \\
344\end{array}$ & $\begin{array}{l}207 \\
206 \\
204 \\
200 \\
197\end{array}$ & $\begin{array}{l}156 \\
161 \\
159 \\
157 \\
154\end{array}$ & $\begin{array}{l}138 \\
139 \\
138 \\
136 \\
136\end{array}$ & $\begin{array}{l}122 \\
127 \\
131 \\
133 \\
127\end{array}$ & $\begin{array}{l}113 \\
128 \\
125 \\
118 \\
118\end{array}$ & $\begin{array}{l}100 \\
108 \\
107 \\
106 \\
111\end{array}$ & $\begin{array}{r}109 \\
97 \\
88 \\
82 \\
92\end{array}$ & $\begin{array}{l}74 \\
72 \\
74 \\
68 \\
68\end{array}$ & $\begin{array}{l}61 \\
58 \\
59 \\
58 \\
58\end{array}$ & $\begin{array}{l}50 \\
60 \\
66 \\
66 \\
69\end{array}$ & $\begin{array}{l}62 \\
62 \\
63 \\
61 \\
60\end{array}$ \\
\hline $\begin{array}{r}6 \\
7 \\
8 \\
9 \\
10\end{array}$ & $\begin{array}{l}380 \\
374 \\
348 \\
315 \\
293\end{array}$ & $\begin{array}{l}194 \\
192 \\
192 \\
191 \\
186\end{array}$ & $\begin{array}{l}158 \\
150 \\
154 \\
152 \\
133\end{array}$ & $\begin{array}{l}136 \\
136 \\
135 \\
133 \\
135\end{array}$ & $\begin{array}{l}125 \\
125 \\
118 \\
102 \\
118\end{array}$ & $\begin{array}{l}125 \\
165 \\
246 \\
337 \\
301\end{array}$ & $\begin{array}{r}112 \\
109 \\
103 \\
99 \\
95\end{array}$ & $\begin{array}{l}83 \\
77 \\
77 \\
76 \\
79\end{array}$ & $\begin{array}{l}66 \\
68 \\
67 \\
65 \\
62\end{array}$ & $\begin{array}{l}58 \\
59 \\
59 \\
62 \\
64\end{array}$ & $\begin{array}{r}60 \\
56 \\
56 \\
84 \\
122\end{array}$ & $\begin{array}{l}60 \\
62 \\
67 \\
65 \\
62\end{array}$ \\
\hline $\begin{array}{l}11 \\
12 \\
13 \\
14 \\
15\end{array}$ & $\begin{array}{l}275 \\
266 \\
271 \\
275 \\
273\end{array}$ & $\begin{array}{l}183 \\
178 \\
159 \\
174 \\
171\end{array}$ & $\begin{array}{l}143 \\
149 \\
150 \\
154 \\
152\end{array}$ & $\begin{array}{l}135 \\
131 \\
131 \\
136 \\
134\end{array}$ & $\begin{array}{r}119 \\
116 \\
116 \\
110 \\
90\end{array}$ & $\begin{array}{l}225 \\
175 \\
148 \\
139 \\
132\end{array}$ & $\begin{array}{r}91 \\
91 \\
88 \\
95 \\
118\end{array}$ & $\begin{array}{l}90 \\
89 \\
84 \\
82 \\
81\end{array}$ & $\begin{array}{l}65 \\
70 \\
73 \\
72 \\
67\end{array}$ & $\begin{array}{l}62 \\
61 \\
60 \\
59 \\
59\end{array}$ & $\begin{array}{r}104 \\
78 \\
67 \\
70 \\
122\end{array}$ & $\begin{array}{l}63 \\
69 \\
69 \\
66 \\
66\end{array}$ \\
\hline $\begin{array}{l}16 \\
17 \\
18 \\
19 \\
20\end{array}$ & $\begin{array}{l}267 \\
261 \\
253 \\
245 \\
241\end{array}$ & $\begin{array}{l}170 \\
171 \\
171 \\
163 \\
162\end{array}$ & $\begin{array}{l}153 \\
154 \\
157 \\
155 \\
153\end{array}$ & $\begin{array}{l}125 \\
111 \\
126 \\
130 \\
125\end{array}$ & $\begin{array}{l}104 \\
111 \\
110 \\
103 \\
106\end{array}$ & $\begin{array}{l}127 \\
122 \\
119 \\
119 \\
124\end{array}$ & $\begin{array}{r}132 \\
120 \\
109 \\
100 \\
93\end{array}$ & $\begin{array}{l}81 \\
79 \\
78 \\
79 \\
87\end{array}$ & $\begin{array}{l}62 \\
60 \\
59 \\
59 \\
65\end{array}$ & $\begin{array}{l}59 \\
59 \\
67 \\
59 \\
55\end{array}$ & $\begin{array}{l}189 \\
209 \\
168 \\
132 \\
112\end{array}$ & $\begin{array}{r}70 \\
92 \\
142 \\
150 \\
133\end{array}$ \\
\hline $\begin{array}{l}21 \\
22 \\
23 \\
24 \\
25\end{array}$ & $\begin{array}{l}239 \\
235 \\
230 \\
225 \\
222\end{array}$ & $\begin{array}{l}165 \\
167 \\
168 \\
173 \\
174\end{array}$ & $\begin{array}{l}145 \\
135 \\
148 \\
142 \\
142\end{array}$ & $\begin{array}{l}126 \\
127 \\
104 \\
103 \\
110\end{array}$ & $\begin{array}{l}109 \\
109 \\
106 \\
104 \\
103\end{array}$ & $\begin{array}{l}127 \\
129 \\
131 \\
137 \\
140\end{array}$ & $\begin{array}{r}89 \\
95 \\
129 \\
140 \\
136\end{array}$ & $\begin{array}{r}87 \\
93 \\
104 \\
93 \\
86\end{array}$ & $\begin{array}{l}67 \\
68 \\
72 \\
66 \\
61\end{array}$ & $\begin{array}{l}55 \\
73 \\
63 \\
56 \\
55\end{array}$ & $\begin{array}{l}92 \\
80 \\
74 \\
71 \\
75\end{array}$ & $\begin{array}{r}119 \\
106 \\
99 \\
109 \\
105\end{array}$ \\
\hline $\begin{array}{l}26 \\
27 \\
28 \\
29 \\
30 \\
31\end{array}$ & $\begin{array}{l}221 \\
226 \\
224 \\
221 \\
215 \\
209\end{array}$ & $\begin{array}{l}174 \\
175 \\
173 \\
172 \\
168 \\
---\end{array}$ & $\begin{array}{l}140 \\
138 \\
137 \\
137 \\
137 \\
139\end{array}$ & $\begin{array}{l}118 \\
123 \\
122 \\
125 \\
119 \\
116\end{array}$ & $\begin{array}{l}103 \\
102 \\
102 \\
--- \\
--- \\
---\end{array}$ & $\begin{array}{l}141 \\
133 \\
122 \\
115 \\
116 \\
109\end{array}$ & $\begin{array}{l}127 \\
122 \\
118 \\
115 \\
112 \\
---\end{array}$ & $\begin{array}{l}85 \\
86 \\
81 \\
80 \\
76 \\
74\end{array}$ & $\begin{array}{r}61 \\
63 \\
65 \\
70 \\
71 \\
\end{array}$ & $\begin{array}{l}55 \\
54 \\
53 \\
51 \\
50 \\
50\end{array}$ & $\begin{array}{l}67 \\
66 \\
64 \\
63 \\
62 \\
61\end{array}$ & $\begin{array}{r}90 \\
85 \\
83 \\
86 \\
94 \\
- \\
\end{array}$ \\
\hline $\begin{array}{l}\text { TOTAL } \\
\text { MEAN } \\
\text { MAX } \\
\text { MIN } \\
\text { CFSM } \\
\text { IN. }\end{array}$ & $\begin{array}{r}8531 \\
275 \\
380 \\
209 \\
1.13 \\
1.31\end{array}$ & $\begin{array}{r}5380 \\
179 \\
207 \\
159 \\
.74 \\
.82\end{array}$ & $\begin{array}{r}4594 \\
148 \\
161 \\
133 \\
.61 \\
.70\end{array}$ & $\begin{array}{r}3939 \\
127 \\
139 \\
103 \\
.52 \\
.60\end{array}$ & $\begin{array}{r}3151 \\
113 \\
133 \\
90 \\
.47 \\
.48\end{array}$ & $\begin{array}{r}4606 \\
149 \\
337 \\
109 \\
.61 \\
.71\end{array}$ & $\begin{array}{r}3270 \\
109 \\
140 \\
88 \\
.45 \\
.50\end{array}$ & $\begin{array}{r}2635 \\
85.0 \\
109 \\
74 \\
.35 \\
.40\end{array}$ & $\begin{array}{r}2000 \\
66.7 \\
74 \\
59 \\
.27 \\
.31\end{array}$ & $\begin{array}{r}1811 \\
58.4 \\
73 \\
50 \\
.24 \\
.28\end{array}$ & $\begin{array}{r}2715 \\
87.6 \\
209 \\
50 \\
.36 \\
.42\end{array}$ & $\begin{array}{r}2520 \\
84.0 \\
150 \\
60 \\
.35 \\
.39\end{array}$ \\
\hline
\end{tabular}

$\begin{array}{lllllllllll}\text { CAL YR } 1986 & \text { TOTAL } & 64824 & \text { MEAN } 178 & \text { MAX 711 } & \text { MIN } 67 & \text { CFSM } & 73 & \text { IN } & 9.92 \\ \text { WTR YR } 1987 & \text { TOTAL } & 45152 & \text { MEAN } 124 & \text { MAX } 380 & \text { MIN } 50 & \text { CFSM } .51 & \text { IN } 6.91\end{array}$ 
LOCATION,--Lat $43^{\circ} 53^{\prime} 57^{\prime \prime}$, long $85^{\circ} 15^{\prime} 19^{\prime \prime}$, in NW1/4 NEl/4 sec.3, T.17 N., R.8 W., Osceola County, Hydrologic Unit 04060102 , on right bank $500 \mathrm{ft}$ downstream from bridge on U.S. Highway 10 in Evart, 0.4 mi upstream from Twin Creek, and at mile 123.9.

DRAINAGE AREA. $-1,450 \mathrm{mi}^{2}$, approximately.

PERIOD OF RECORD.--October 1930 to September 1931, October 1933 to current year. Monthly discharge only for some periods, published in WSP 1307.

REVISED RECORDS.--WSP 1437: 1934, $1947(\mathrm{M})$.

GAGE.--Water-stage recorder. Datum of gage is $977.72 \mathrm{ft}$ above National Geodetic Vertical Datum of 1929. Prior to Nov. 7, 1956, nonrecording gages at sites $400 \mathrm{ft}$ and 500 ft upstream at present datum.

REMARKS.--Estimated daily discharges: Jan. 18, 19, Jan. 21 to Feb. 3 and Feb. 5, 9, 11, 13, 15-20, 2426. Records good except for estimated daily discharges, which are poor. Some regulation at low flow by dams upstream from station. Several measurements of water temperature were made during the year.

AVERAGE DISCHARGE.--55 years, $1,013 \mathrm{ft}^{3} / \mathrm{s}, 9.49 \mathrm{in} / \mathrm{yr}$.

EXTREMES FOR PERIOD OF RECORD.--Maximum discharge, 7,790 ft $3 / \mathrm{s}$, Mar. 29, 1976; maximum gage height, $14.42 \mathrm{ft}$, Apr. 9, 1959; minimum discharge observed, $164 \mathrm{ft} / \mathrm{s}$, Dec. 20, 1947 , result of freezeup.

EXTREMES FOR CURRENT YEAR.--Maximum discharge, 4,210 $\mathrm{ft}^{3} / \mathrm{s}$, Oct. 1, gage height, $11.48 \mathrm{ft}$, stage falling, peak occurred Sept. 30, 1986; maximum independent peak discharge, 2,060 ft3/s, Mar. 9, gage height $9.03 \mathrm{ft}$; minimum discharge, $281 \mathrm{ft} / \mathrm{s}$, July 31 , Aug. 1, gage height, $6.43 \mathrm{ft}$.

DISCHARGE, IN CUBIC FEET PER SECOND, WATER YEAR OCTOBER 1986 TO SEPTEMBER 1987 MEAN VALUES

\begin{tabular}{|c|c|c|c|c|c|c|c|c|c|c|c|c|}
\hline DAY & OCT & NOV & DEC & JAN & FEB & MAR & APR & MAY & JUN & JUL & AUG & SEP \\
\hline $\begin{array}{l}1 \\
2 \\
3 \\
4 \\
5\end{array}$ & $\begin{array}{l}4020 \\
3620 \\
3390 \\
3440 \\
3690\end{array}$ & $\begin{array}{l}1430 \\
1420 \\
1410 \\
1400 \\
1380\end{array}$ & $\begin{array}{l}1210 \\
1190 \\
1230 \\
1230 \\
1190\end{array}$ & $\begin{array}{l}1040 \\
1050 \\
1040 \\
1030 \\
1030\end{array}$ & $\begin{array}{l}1040 \\
1060 \\
1070 \\
1070 \\
1000\end{array}$ & $\begin{array}{r}979 \\
1120 \\
1110 \\
1050 \\
1040\end{array}$ & $\begin{array}{l}1130 \\
1120 \\
1090 \\
1070 \\
1040\end{array}$ & $\begin{array}{l}863 \\
834 \\
805 \\
779 \\
761\end{array}$ & $\begin{array}{l}527 \\
514 \\
497 \\
485 \\
466\end{array}$ & $\begin{array}{l}395 \\
375 \\
365 \\
356 \\
351\end{array}$ & $\begin{array}{l}289 \\
369 \\
377 \\
383 \\
364\end{array}$ & $\begin{array}{l}433 \\
450 \\
442 \\
430 \\
419\end{array}$ \\
\hline $\begin{array}{r}6 \\
7 \\
8 \\
9 \\
10\end{array}$ & $\begin{array}{l}3680 \\
3660 \\
3480 \\
3230 \\
2940\end{array}$ & $\begin{array}{l}1360 \\
1340 \\
1340 \\
1350 \\
1320\end{array}$ & $\begin{array}{l}1170 \\
1160 \\
1140 \\
1130 \\
1110\end{array}$ & $\begin{array}{r}1010 \\
1020 \\
1010 \\
999 \\
998\end{array}$ & $\begin{array}{l}971 \\
966 \\
980 \\
940 \\
883\end{array}$ & $\begin{array}{l}1090 \\
1310 \\
1740 \\
2010 \\
2030\end{array}$ & $\begin{array}{r}1020 \\
1000 \\
983 \\
951 \\
922\end{array}$ & $\begin{array}{l}753 \\
735 \\
717 \\
712 \\
741\end{array}$ & $\begin{array}{l}462 \\
459 \\
458 \\
443 \\
434\end{array}$ & $\begin{array}{l}353 \\
378 \\
369 \\
372 \\
409\end{array}$ & $\begin{array}{l}350 \\
339 \\
327 \\
416 \\
514\end{array}$ & $\begin{array}{l}411 \\
406 \\
441 \\
443 \\
444\end{array}$ \\
\hline $\begin{array}{l}11 \\
12 \\
13 \\
14 \\
15\end{array}$ & $\begin{array}{l}2710 \\
2540 \\
2450 \\
2360 \\
2250\end{array}$ & $\begin{array}{l}1300 \\
1270 \\
1220 \\
1190 \\
1200\end{array}$ & $\begin{array}{l}1060 \\
1080 \\
1030 \\
1010 \\
1050\end{array}$ & $\begin{array}{l}998 \\
990 \\
973 \\
980 \\
994\end{array}$ & $\begin{array}{l}900 \\
908 \\
910 \\
908 \\
910\end{array}$ & $\begin{array}{l}1890 \\
1670 \\
1550 \\
1520 \\
1480\end{array}$ & $\begin{array}{r}900 \\
881 \\
860 \\
886 \\
1140\end{array}$ & $\begin{array}{l}761 \\
748 \\
748 \\
722 \\
709\end{array}$ & $\begin{array}{l}428 \\
442 \\
440 \\
438 \\
428\end{array}$ & $\begin{array}{l}416 \\
396 \\
372 \\
363 \\
356\end{array}$ & $\begin{array}{l}515 \\
504 \\
462 \\
464 \\
569\end{array}$ & $\begin{array}{l}436 \\
431 \\
432 \\
425 \\
422\end{array}$ \\
\hline $\begin{array}{l}16 \\
17 \\
18 \\
19 \\
20\end{array}$ & $\begin{array}{l}2160 \\
2050 \\
1960 \\
1870 \\
1800\end{array}$ & $\begin{array}{l}1190 \\
1190 \\
1190 \\
1130 \\
1140\end{array}$ & $\begin{array}{l}1120 \\
1170 \\
1210 \\
1260 \\
1230\end{array}$ & $\begin{array}{l}965 \\
870 \\
840 \\
810 \\
780\end{array}$ & $\begin{array}{l}910 \\
910 \\
900 \\
880 \\
890\end{array}$ & $\begin{array}{l}1420 \\
1310 \\
1220 \\
1170 \\
1160\end{array}$ & $\begin{array}{l}1240 \\
1230 \\
1160 \\
1100 \\
1060\end{array}$ & $\begin{array}{l}675 \\
645 \\
631 \\
607 \\
611\end{array}$ & $\begin{array}{l}409 \\
392 \\
378 \\
371 \\
393\end{array}$ & $\begin{array}{l}355 \\
348 \\
340 \\
339 \\
337\end{array}$ & $\begin{array}{l}714 \\
865 \\
885 \\
828 \\
745\end{array}$ & $\begin{array}{l}415 \\
590 \\
808 \\
780 \\
796\end{array}$ \\
\hline $\begin{array}{l}21 \\
22 \\
23 \\
24 \\
25\end{array}$ & $\begin{array}{l}1730 \\
1670 \\
1620 \\
1590 \\
1560\end{array}$ & $\begin{array}{l}1140 \\
1160 \\
1190 \\
1230 \\
1240\end{array}$ & $\begin{array}{l}1160 \\
1060 \\
1160 \\
1110 \\
1110\end{array}$ & $\begin{array}{l}800 \\
840 \\
860 \\
890 \\
900\end{array}$ & $\begin{array}{l}897 \\
843 \\
836 \\
860 \\
860\end{array}$ & $\begin{array}{l}1150 \\
1150 \\
1170 \\
1180 \\
1210\end{array}$ & $\begin{array}{l}1000 \\
1000 \\
1150 \\
1210 \\
1170\end{array}$ & $\begin{array}{l}618 \\
639 \\
654 \\
655 \\
635\end{array}$ & $\begin{array}{l}394 \\
405 \\
398 \\
394 \\
388\end{array}$ & $\begin{array}{l}328 \\
321 \\
321 \\
319 \\
309\end{array}$ & $\begin{array}{l}688 \\
649 \\
609 \\
566 \\
524\end{array}$ & $\begin{array}{l}766 \\
748 \\
700 \\
664 \\
636\end{array}$ \\
\hline $\begin{array}{l}26 \\
27 \\
28 \\
29 \\
30 \\
31\end{array}$ & $\begin{array}{l}1520 \\
1530 \\
1510 \\
1500 \\
1470 \\
1450\end{array}$ & $\begin{array}{l}1250 \\
1260 \\
1250 \\
1250 \\
1240 \\
---\end{array}$ & $\begin{array}{l}1100 \\
1070 \\
1050 \\
1040 \\
1050 \\
1040\end{array}$ & $\begin{array}{r}980 \\
1000 \\
1020 \\
1030 \\
1000 \\
990\end{array}$ & $\begin{array}{l}860 \\
854 \\
874 \\
--- \\
--- \\
---\end{array}$ & $\begin{array}{l}1230 \\
1230 \\
1210 \\
1190 \\
1200 \\
1170\end{array}$ & $\begin{array}{r}1100 \\
1050 \\
1020 \\
963 \\
910 \\
-\end{array}$ & $\begin{array}{l}648 \\
645 \\
614 \\
585 \\
556 \\
538\end{array}$ & $\begin{array}{l}379 \\
373 \\
375 \\
391 \\
422 \\
-\end{array}$ & $\begin{array}{l}300 \\
292 \\
291 \\
287 \\
291 \\
285\end{array}$ & $\begin{array}{l}504 \\
501 \\
482 \\
477 \\
459 \\
441\end{array}$ & $\begin{array}{l}624 \\
592 \\
568 \\
605 \\
618\end{array}$ \\
\hline $\begin{array}{l}\text { TOTAL } \\
\text { MEAN } \\
\text { MAX } \\
\text { MIN } \\
\text { CFSM } \\
\text { IN. }\end{array}$ & $\begin{array}{r}74450 \\
2402 \\
4020 \\
1450 \\
1.66 \\
1.91\end{array}$ & $\begin{array}{r}37980 \\
1266 \\
1430 \\
1130 \\
.87 \\
.97\end{array}$ & $\begin{array}{r}34930 \\
1127 \\
1260 \\
1010 \\
.78 \\
.90\end{array}$ & $\begin{array}{r}29737 \\
959 \\
1050 \\
780 \\
.66 \\
.76\end{array}$ & $\begin{array}{r}25890 \\
925 \\
1070 \\
836 \\
.64 \\
.66\end{array}$ & $\begin{array}{r}40959 \\
1321 \\
2030 \\
979 \\
.91 \\
1.05\end{array}$ & $\begin{array}{r}31356 \\
1045 \\
1240 \\
860 \\
.72 \\
.80\end{array}$ & $\begin{array}{r}21344 \\
689 \\
863 \\
538 \\
.48 \\
.55\end{array}$ & $\begin{array}{r}12783 \\
426 \\
527 \\
371 \\
.29 \\
.33\end{array}$ & $\begin{array}{r}10689 \\
345 \\
416 \\
285 \\
.24 \\
.27\end{array}$ & $\begin{array}{r}16179 \\
522 \\
885 \\
289 \\
.36 \\
.42\end{array}$ & $\begin{array}{r}16375 \\
546 \\
808 \\
406 \\
.38 \\
.42\end{array}$ \\
\hline
\end{tabular}

CAL YR 1986 TOTAL 536831 MEAN 1471 MAX 5380 MIN $395 \quad$ CFSM $1.01 \quad$ IN 13.77 
04121900 LITTLE MUSKEGON RIVER NEAR MORLEY, MI

LOCATION.--Lat $43^{\circ} 30^{\prime} 09^{\prime \prime}$, long $85^{\circ} 20^{\prime} 33^{\prime \prime}$, in SWl/4 SWl/4 sec.24, T.13 N., R.9 W., Mecosta County Hydrologic Unit 04060102 , on right bank at upstream side of highway bridge on' 130 th Avenue, 0.5 mi downstream from Rustford Dam, and $5.2 \mathrm{mi}$ east of Morley.

DRAINAGE AREA. $--138 \mathrm{mi}^{2}$.

PERIOD OF RECORD.--October 1966 to current year.

GAGE.--Water-stage recorder. Elevation of gage is $920 \mathrm{ft}$ above National Geodetic Vertical Datum of 1929 , from topographic map.

REMARKS.--Estimated daily discharges: Dec. 13, 14, Jan. 17, 19, 20, 23-31, and Feb. 9, 16, 17. Records good except for estimated daily discharges, which are fair. Some regulation by dams upstream from station. Several measurements of water temperature were made during the year.

AVERAGE DISCHARGE. --21 years, $130 \mathrm{ft}^{3} / \mathrm{s}, 12.79 \mathrm{in} / \mathrm{yr}$.

EXTREMES FOR PERIOD OF RECORD.--Maximum discharge, 2,300 $\mathrm{ft}^{3} / \mathrm{s}$, Sept. 12, 1986, gage height, 8.57 $\mathrm{ft}$; minimum, $22 \mathrm{ft}^{3} / \mathrm{s}$, July 21, 1979; minimum gage height, i.51 ft, July 28 , 1987.

EXTREMES FOR CURRENT YEAR.--Peak discharges greater than base discharge of $400 \mathrm{ft}^{3} / \mathrm{s}^{\mathrm{and}}$ maximum (*):

$\begin{array}{ccccccc}\text { Date } & \text { Time } & \begin{array}{c}\text { Discharge } \\ \left(\mathrm{ft}^{3} / \mathrm{s}\right)\end{array} & \begin{array}{c}\text { Gage height } \\ (\mathrm{ft})\end{array} & \text { Date } & \text { Time } & \begin{array}{c}\text { Discharge } \\ \left(\mathrm{ft} / \mathrm{s}^{3}\right)\end{array} \\ \text { Oct. } 1 & 0230 & * a 876 & \star \mathrm{a} 5.34 & \text { Oct. } 5 & 0200 & \begin{array}{c}\text { Gage height } \\ (\mathrm{ft})\end{array}\end{array}$

a Stage falling, peak occurred sept. 30, 1986.

Minimum discharge, $24 \mathrm{ft}^{3} / \mathrm{s}$, July 28 , gage height, $1.51 \mathrm{ft}$.

DISCHARGE, IN CUBIC FEET PER SECOND, WATER YEAR OCTOBER 1986 TO SEPTEMBER 1987 MEAN VALUES

\begin{tabular}{|c|c|c|c|c|c|c|c|c|c|c|c|c|}
\hline DAY & OCT & NOV & DEC & JAN & FEB & MAR & APR & MAY & JUN & JUL & AUG & SEP \\
\hline $\begin{array}{l}1 \\
2 \\
3 \\
4 \\
5\end{array}$ & $\begin{array}{l}841 \\
694 \\
550 \\
578 \\
735\end{array}$ & $\begin{array}{l}200 \\
200 \\
194 \\
188 \\
183\end{array}$ & $\begin{array}{l}164 \\
163 \\
180 \\
184 \\
177\end{array}$ & $\begin{array}{l}152 \\
152 \\
152 \\
150 \\
147\end{array}$ & $\begin{array}{l}147 \\
146 \\
148 \\
147 \\
144\end{array}$ & $\begin{array}{l}197 \\
230 \\
198 \\
175 \\
173\end{array}$ & $\begin{array}{l}145 \\
153 \\
149 \\
147 \\
142\end{array}$ & $\begin{array}{r}106 \\
105 \\
106 \\
90 \\
89\end{array}$ & $\begin{array}{l}76 \\
79 \\
80 \\
74 \\
72\end{array}$ & $\begin{array}{l}65 \\
63 \\
62 \\
64 \\
62\end{array}$ & $\begin{array}{r}121 \\
175 \\
113 \\
98 \\
77\end{array}$ & $\begin{array}{l}93 \\
96 \\
92 \\
85 \\
80\end{array}$ \\
\hline $\begin{array}{r}6 \\
7 \\
8 \\
9 \\
10\end{array}$ & $\begin{array}{l}689 \\
563 \\
483 \\
439 \\
385\end{array}$ & $\begin{array}{l}181 \\
179 \\
182 \\
182 \\
175\end{array}$ & $\begin{array}{l}174 \\
172 \\
173 \\
171 \\
170\end{array}$ & $\begin{array}{l}147 \\
152 \\
149 \\
146 \\
147\end{array}$ & $\begin{array}{l}144 \\
143 \\
143 \\
140 \\
139\end{array}$ & $\begin{array}{l}186 \\
220 \\
252 \\
265 \\
229\end{array}$ & $\begin{array}{l}140 \\
137 \\
131 \\
127 \\
125\end{array}$ & $\begin{array}{l}89 \\
88 \\
88 \\
86 \\
85\end{array}$ & $\begin{array}{l}82 \\
91 \\
81 \\
75 \\
70\end{array}$ & $\begin{array}{l}60 \\
65 \\
65 \\
62 \\
63\end{array}$ & $\begin{array}{r}66 \\
62 \\
62 \\
115 \\
127\end{array}$ & $\begin{array}{l}72 \\
72 \\
83 \\
84 \\
78\end{array}$ \\
\hline $\begin{array}{l}11 \\
12 \\
13 \\
14 \\
15\end{array}$ & $\begin{array}{l}348 \\
323 \\
311 \\
304 \\
293\end{array}$ & $\begin{array}{l}168 \\
162 \\
156 \\
151 \\
152\end{array}$ & $\begin{array}{l}170 \\
166 \\
165 \\
160 \\
156\end{array}$ & $\begin{array}{l}152 \\
151 \\
148 \\
150 \\
154\end{array}$ & $\begin{array}{l}134 \\
138 \\
136 \\
135 \\
136\end{array}$ & $\begin{array}{l}188 \\
166 \\
157 \\
157 \\
153\end{array}$ & $\begin{array}{l}110 \\
101 \\
102 \\
109 \\
198\end{array}$ & $\begin{array}{l}86 \\
86 \\
84 \\
83 \\
89\end{array}$ & $\begin{array}{l}73 \\
82 \\
76 \\
70 \\
68\end{array}$ & $\begin{array}{l}65 \\
66 \\
60 \\
59 \\
57\end{array}$ & $\begin{array}{r}98 \\
87 \\
81 \\
105 \\
133\end{array}$ & $\begin{array}{l}76 \\
74 \\
75 \\
75 \\
74\end{array}$ \\
\hline $\begin{array}{l}16 \\
17 \\
18 \\
19 \\
20\end{array}$ & $\begin{array}{l}279 \\
266 \\
253 \\
246 \\
240\end{array}$ & $\begin{array}{l}159 \\
165 \\
167 \\
157 \\
155\end{array}$ & $\begin{array}{l}155 \\
160 \\
179 \\
180 \\
174\end{array}$ & $\begin{array}{l}146 \\
140 \\
137 \\
135 \\
135\end{array}$ & $\begin{array}{l}132 \\
128 \\
125 \\
123 \\
123\end{array}$ & $\begin{array}{l}155 \\
153 \\
152 \\
153 \\
155\end{array}$ & $\begin{array}{l}216 \\
190 \\
156 \\
139 \\
124\end{array}$ & $\begin{array}{r}86 \\
84 \\
92 \\
98 \\
105\end{array}$ & $\begin{array}{l}65 \\
64 \\
63 \\
61 \\
60\end{array}$ & $\begin{array}{l}59 \\
56 \\
55 \\
55 \\
53\end{array}$ & $\begin{array}{l}149 \\
269 \\
212 \\
153 \\
108\end{array}$ & $\begin{array}{r}77 \\
87 \\
129 \\
120 \\
119\end{array}$ \\
\hline $\begin{array}{l}21 \\
22 \\
23 \\
24 \\
25\end{array}$ & $\begin{array}{l}236 \\
236 \\
230 \\
224 \\
219\end{array}$ & $\begin{array}{l}160 \\
165 \\
176 \\
192 \\
185\end{array}$ & $\begin{array}{l}166 \\
155 \\
156 \\
158 \\
159\end{array}$ & $\begin{array}{l}136 \\
138 \\
135 \\
130 \\
130\end{array}$ & $\begin{array}{l}123 \\
126 \\
129 \\
129 \\
130\end{array}$ & $\begin{array}{l}154 \\
154 \\
152 \\
155 \\
161\end{array}$ & $\begin{array}{l}120 \\
135 \\
187 \\
175 \\
136\end{array}$ & $\begin{array}{l}102 \\
128 \\
127 \\
110 \\
102\end{array}$ & $\begin{array}{l}66 \\
66 \\
64 \\
62 \\
60\end{array}$ & $\begin{array}{l}56 \\
54 \\
52 \\
52 \\
51\end{array}$ & $\begin{array}{l}89 \\
87 \\
81 \\
78 \\
74\end{array}$ & $\begin{array}{r}122 \\
110 \\
101 \\
95 \\
88\end{array}$ \\
\hline $\begin{array}{l}26 \\
27 \\
28 \\
29 \\
30 \\
31\end{array}$ & $\begin{array}{l}219 \\
228 \\
222 \\
216 \\
207 \\
200\end{array}$ & $\begin{array}{l}189 \\
197 \\
188 \\
182 \\
175 \\
---\end{array}$ & $\begin{array}{l}155 \\
151 \\
150 \\
150 \\
152 \\
152\end{array}$ & $\begin{array}{l}128 \\
128 \\
128 \\
130 \\
135 \\
140\end{array}$ & $\begin{array}{l}132 \\
133 \\
136 \\
--- \\
--- \\
---\end{array}$ & $\begin{array}{l}167 \\
163 \\
158 \\
159 \\
164 \\
152\end{array}$ & $\begin{array}{l}122 \\
118 \\
116 \\
111 \\
107 \\
---\end{array}$ & $\begin{array}{l}91 \\
87 \\
86 \\
80 \\
76 \\
75\end{array}$ & $\begin{array}{r}61 \\
64 \\
63 \\
62 \\
69 \\
-\end{array}$ & $\begin{array}{l}53 \\
50 \\
45 \\
46 \\
44 \\
42\end{array}$ & $\begin{array}{l}80 \\
99 \\
89 \\
84 \\
84 \\
93\end{array}$ & $\begin{array}{r}86 \\
87 \\
75 \\
88 \\
100 \\
---\end{array}$ \\
\hline $\begin{array}{l}\text { TOTAL } \\
\text { MEAN } \\
\text { MAX } \\
\text { MIN } \\
\text { CFSM } \\
\text { IN. }\end{array}$ & $\begin{array}{r}11257 \\
363 \\
841 \\
200 \\
2.63 \\
3.03\end{array}$ & $\begin{array}{r}5265 \\
176 \\
200 \\
151 \\
1.28 \\
1.42\end{array}$ & $\begin{array}{r}5097 \\
164 \\
184 \\
150 \\
1.19 \\
1.37\end{array}$ & $\begin{array}{r}4400 \\
142 \\
154 \\
128 \\
1.03 \\
1.19\end{array}$ & $\begin{array}{r}3789 \\
135 \\
148 \\
123 \\
.98 \\
1.02\end{array}$ & $\begin{array}{r}5453 \\
176 \\
265 \\
152 \\
1.28 \\
1.47\end{array}$ & $\begin{array}{r}4168 \\
139 \\
216 \\
101 \\
1.01 \\
1.12\end{array}$ & $\begin{array}{r}2889 \\
93.2 \\
128 \\
75 \\
.68 \\
.78\end{array}$ & $\begin{array}{r}2099 \\
70.0 \\
91 \\
60 \\
.51 \\
.57\end{array}$ & $\begin{array}{r}1761 \\
56.8 \\
66 \\
42 \\
.41 \\
.47\end{array}$ & $\begin{array}{r}3349 \\
108 \\
269 \\
62 \\
.78 \\
.90\end{array}$ & $\begin{array}{r}2693 \\
89.8 \\
129 \\
72 \\
.65 \\
.73\end{array}$ \\
\hline
\end{tabular}

$\begin{array}{lllllllllll}\text { CAL YR } 1986 & \text { TOTAL } & 73313 & \text { MEAN } 201 & \text { MAX } & 2190 & \text { MIN } 54 & \text { CFSM } & 1.46 & \text { IN } 19.76\end{array}$ WTR YR 1987 TOTAL 52220 MEAN 143 MAX 841 MIN 42 CFSM 1.04 IN 14.08 
LOCATION.--Lat $43^{\circ} 25^{\prime} 20^{\prime \prime}$, long $85^{\circ} 48^{\prime} 04^{\prime \prime}$, in NE1/4 NEl/4 sec.24, T.12 N., R.13 W., Newaygo County, Hydrologic Unit 04060102 , on left bank near nonoperative powerpiant in Newaygo, 600 ft downstream from Penoyer Creek, and at mile 39.1 .

DRAINAGE AREA. $--2,350 \mathrm{mi}^{2}$, approximately.

PERIOD OF RECORD.--July to December 1908, July 1909 to July 1915, January 1916 to December 1919, October 1930 to current year. Monthly discharge only for some periods, published in wSP 1307 . Records for June 1901 to December 1906, published in WSP 129, 170, and 206, are unreliable and should not be used.

REVISED RECORDS.--WSP 974: 1933, 1935, 1937-38. WSP 1307: 1940(M). See also PERIOD OF RECORD.

GAGE.--Water-stage recorder. Datum of gage is $625.83 \mathrm{ft}$ above National Geodetic Vertical Datum of 1929. October 1930 to January 1939, nonrecording gage, and Jan. 31, 1939 to Sept. 30, 1963, water-stage recorder at present site at datum $40.0 \mathrm{ft}$ lower.

REMARKS.--Estimated daily discharges: Dec. 17 to Mar. 10. Records good except for estimated daily discharges, which are fair. Flow regulated by powerplants upstream from station, the largest of which are Croton Dam, Hardy Dam (since 1931), and Rogers Dam. Since Dec. 27, 1965, powerplant at Newaygo nonoperative, and in January 1969, dam at Newaygo was removed. Several measurements of water temperature were made during the year. National Weather Service gage-height telemeter at station.

AVERAGE DISCHARGE.--65 years (water years 1910-14, 1917-19, 1931-87), 2,001 $\mathrm{ft}^{3} / \mathrm{s}, 11.56 \mathrm{in} / \mathrm{yr}^{\mathrm{r}}$.

EXTREMES FOR PERIOD OF RECORD.--Maximum discharge, 23, $200 \mathrm{ft}^{3} / \mathrm{s}$, Sept. 12, 1986, gage height, 19.54 ft, from floodmark; minimum, $52 \mathrm{ft}^{3} / \mathrm{s}$, Oct. 2 , 1965, gage height, 5.31 ft, result of regulation during pipeline repair; minimum daily, $330 \mathrm{ft}^{3} / \mathrm{s}, \mathrm{Feb} .15,1914$

EXTREMES FOR CURRENT YEAR.--Maximum discharge, $9,940 \mathrm{ft}^{3} / \mathrm{s}$, Oct. 1 , gage height, $12.88 \mathrm{ft}$; minimum, $823 \mathrm{ft}^{3} / \mathrm{s}$, July 30,31 , Aug. 2, 3, gage height, $6.36 \mathrm{ft} ;$ minimum daily, $828 \mathrm{ft} / \mathrm{s}, \mathrm{Aug}$. 2 .

DISCHARGE, IN CUBIC FEET PER SECOND, WATER YEAR OCTOBER 1986 TO SEPTEMBER 1987 MEAN VALUES

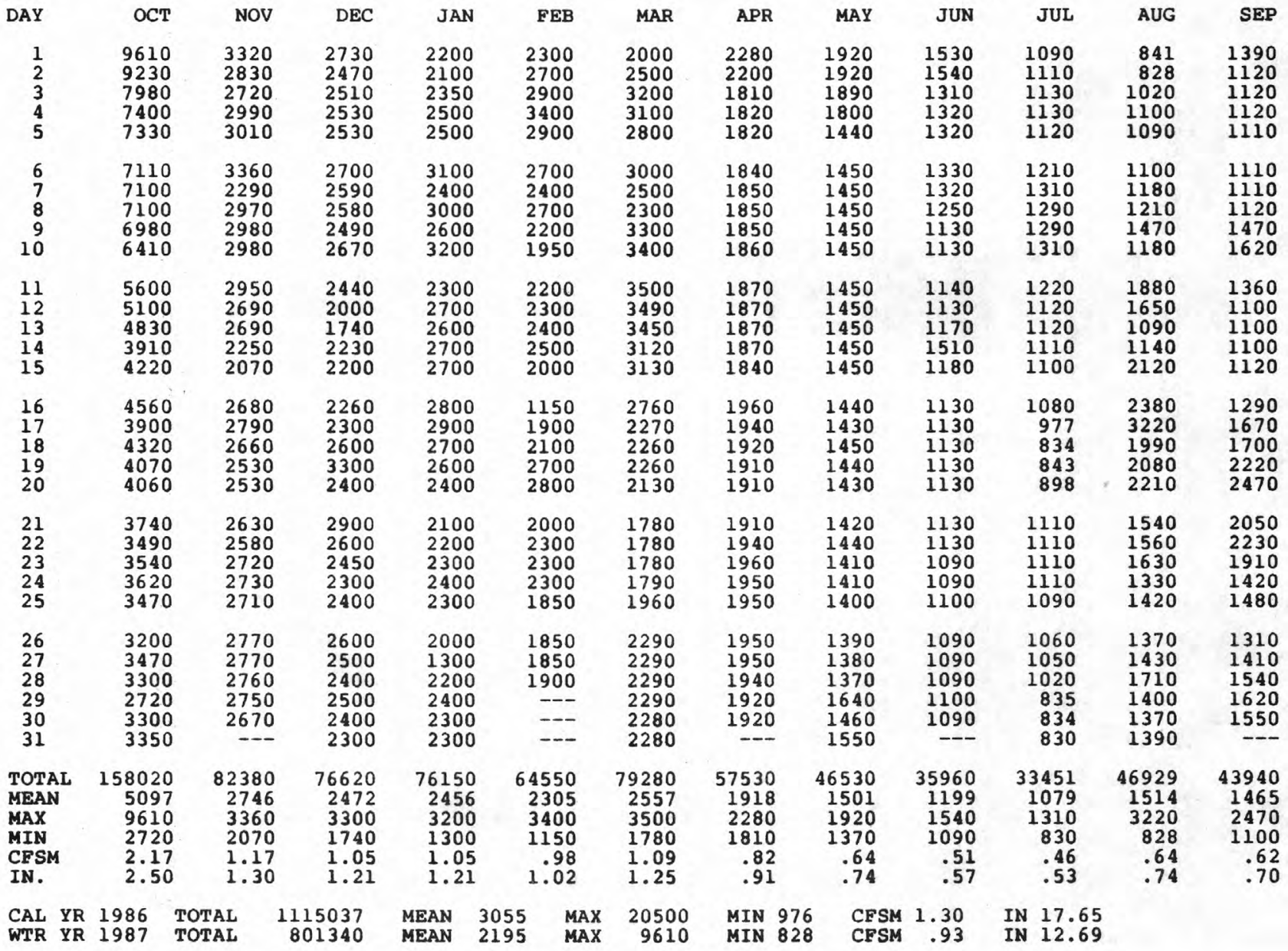


LOCATION. --Lat $43^{\circ} 19^{\prime} 05^{\prime \prime}$, long $86^{\circ} 02^{\prime} 11^{\prime \prime}$, in SWl/4 Nw1/4 sec.30, T.11 N., R.14 W. Newaygo County, Hydrologic Unit 04060102 , at bridge on Maple Island Road, 5 mi southwest of Bridgeton, 13 mi upstream from Muskegon Lake, and $20 \mathrm{mi}$ downstream from gaging station at Newaygo.

DRAINAGE AREA. $--2,420 \mathrm{mi}^{2}$, approximately.

PERIOD OF RECORD.--Water years 1974 to current year.

PERIOD OF DAILY RECORD.--

SPECIFIC CONDUCTANCE: November 1974 to September 1981.

WATER TEMPERATURE: November 1974 to September 1981 .

INSTRUMENTATION.--Water-quality monitor from Nov. 12, 1975 to Sept. $24,1981$.

REMARKS.--Cross-sectional samples were collected at or near Maple Island Road bridge. Water-discharge measurements were made at time of sampling. Some regulation by upstream dams.

EXTREMES FOR PERIOD OF DAILY RECORD.--

SPECIFIC CONDUCTANCE (water years 1975, 1978-81): Maximum, 1,550 microsiemens, Sept. 24, 1979; minimum, 69 microsiemens, May 3, 1979.

WATER TEMPERATURE (water years 1975, 1977-81): Maximum, $33.0^{\circ} \mathrm{C}$, July 19, 1977; minimum, $0.0^{\circ} \mathrm{C}$ on many days during winter.

\begin{tabular}{|c|c|c|c|c|c|c|c|c|c|c|}
\hline & & WATER QU & ALITY DATA & A, WATER & YEAR OCTO & BER 1986 & TO SEPTEM & BER 1987 & & \\
\hline DATE & TIME & $\begin{array}{l}\text { STREAM- } \\
\text { FLOW, } \\
\text { INSTAN- } \\
\text { TANEOUS } \\
\text { (CFS) }\end{array}$ & $\begin{array}{l}\text { SPE- } \\
\text { CIFIC } \\
\text { CON- } \\
\text { DUCT- } \\
\text { ANCE } \\
\text { (US/CM) }\end{array}$ & $\begin{array}{c}\text { PH } \\
\text { (STAND- } \\
\text { ARD } \\
\text { UNITS) }\end{array}$ & $\begin{array}{l}\text { TEMPER- } \\
\text { ATURE } \\
\text { (DEG C) }\end{array}$ & $\begin{array}{l}\text { TUR- } \\
\text { BID- } \\
\text { ITY } \\
\text { (NTU) }\end{array}$ & $\begin{array}{c}\text { OXYGEN, } \\
\text { DIS- } \\
\text { SOLVED } \\
(M G / L)\end{array}$ & $\begin{array}{c}\text { OXYGEN, } \\
\text { DIS- } \\
\text { SOLVED } \\
\text { (PER- } \\
\text { CENT } \\
\text { SATUR- } \\
\text { ATION) }\end{array}$ & $\begin{array}{l}\text { COLI- } \\
\text { FORM, } \\
\text { FECAL, } \\
0.7 \\
\text { UM-MF } \\
\text { (COLS./ } \\
100 \mathrm{ML} \text { ) }\end{array}$ & $\begin{array}{l}\text { STREP- } \\
\text { TOCOCCI } \\
\text { FECAL, } \\
\text { KF AGAR } \\
\text { (COLS. } \\
\text { PER } \\
100 \mathrm{ML} \text { ) }\end{array}$ \\
\hline \multirow{4}{*}{$\begin{array}{c}\text { NOV } \\
13 \ldots \\
\text { MAR } \\
11 \ldots \\
\text { MAY } \\
27 \ldots \\
\text { AUG } \\
26 \ldots\end{array}$} & 1000 & 2510 & 322 & 8.13 & 4.5 & 1.9 & 11.3 & 87 & K10 & K24 \\
\hline & 1030 & 3460 & 416 & 8.18 & 2.0 & 3.0 & 14.1 & 103 & K1 & K 2 \\
\hline & 1000 & 1270 & 408 & 8.48 & 20.0 & 1.7 & 9.2 & 103 & $\mathrm{~K} 25$ & K88 \\
\hline & 1300 & 1140 & 383 & 8.27 & 18.5 & 1.3 & 8.9 & 97 & -- & 62 \\
\hline DATE & $\begin{array}{l}\text { HARD- } \\
\text { NESS } \\
\text { (MG/L } \\
\text { AS } \\
\text { CACO3) }\end{array}$ & $\begin{array}{l}\text { HARD- } \\
\text { NESS } \\
\text { NONCARB } \\
\text { WH WAT } \\
\text { TOT FLD } \\
\text { MG/L AS } \\
\text { CACO3 }\end{array}$ & $\begin{array}{l}\text { CALCIUM } \\
\text { DIS- } \\
\text { SOLVED } \\
\text { (MG/L } \\
\text { AS CA) }\end{array}$ & $\begin{array}{l}\text { MAGNE- } \\
\text { SIUM, } \\
\text { DIS- } \\
\text { SOLVED } \\
\text { (MG/L } \\
\text { AS MG) }\end{array}$ & $\begin{array}{l}\text { SODIUM, } \\
\text { DIS- } \\
\text { SOLVED } \\
\text { (MG/L } \\
\text { AS NA) }\end{array}$ & $\begin{array}{l}\text { PERCENT } \\
\text { SODIUM }\end{array}$ & $\begin{array}{c}\text { SODIUM } \\
\text { AD- } \\
\text { SORP- } \\
\text { TION } \\
\text { RATIO }\end{array}$ & $\begin{array}{l}\text { POTAS- } \\
\text { SIUM, } \\
\text { DIS- } \\
\text { SOLVED } \\
\text { (MG/L } \\
\text { AS R) }\end{array}$ & $\begin{array}{l}\text { BICAR- } \\
\text { BONATE } \\
\text { WH WAT } \\
\text { TOTAL } \\
\text { FIELD } \\
\text { MG/L AS } \\
\text { HCO3 }\end{array}$ & $\begin{array}{l}\text { CAR- } \\
\text { BONATE } \\
\text { WH WAT } \\
\text { TOTAL } \\
\text { EIELD } \\
\text { MG/L AS } \\
\mathrm{CO}^{3}\end{array}$ \\
\hline \multirow{5}{*}{$\begin{array}{l}\text { NOV } \\
13 \ldots \\
\text { MAR } \\
11 \ldots \\
\text { MAY } \\
27 \ldots \\
\text { AUG } \\
26 \ldots\end{array}$} & & & & & & & & & & 0 \\
\hline & 150 & 29 & 42 & 12 & 7.1 & 9 & 0.3 & 1.6 & 150 & 0 \\
\hline & 180 & 31 & 47 & 14 & 11 & 12 & 0.4 & 1.4 & 180 & 0 \\
\hline & 180 & 43 & 49 & 15 & 11 & 11 & 0.4 & 1.2 & 160 & 5 \\
\hline & 180 & 31 & 48 & 15 & 11 & 12 & 0.4 & 1.2 & 180 & 0 \\
\hline DATE & $\begin{array}{l}\text { ALKA- } \\
\text { LINITY } \\
\text { WH WAT } \\
\text { TOTAL } \\
\text { FIELD } \\
\text { MG/L AS } \\
\text { CACO3 }\end{array}$ & $\begin{array}{c}\text { CARBON } \\
\text { DIOXIDE } \\
\text { DIS- } \\
\text { SOLVED } \\
\text { (MG/L } \\
\text { AS CO2) }\end{array}$ & $\begin{array}{l}\text { SULFATE } \\
\text { DIS- } \\
\text { SOLVED } \\
\text { (MG/L } \\
\text { AS SO4) }\end{array}$ & $\begin{array}{l}\text { CHLO- } \\
\text { RIDE, } \\
\text { DIS- } \\
\text { SOLVED } \\
\text { (MG/L } \\
\text { AS CL) }\end{array}$ & $\begin{array}{l}\text { FLUO- } \\
\text { RIDE, } \\
\text { DIS- } \\
\text { SOLVED } \\
\text { (MG/L } \\
\text { AS F) }\end{array}$ & $\begin{array}{l}\text { SILICA, } \\
\text { DIS- } \\
\text { SOLVED } \\
\text { (MG/L } \\
\text { AS } \\
\text { SIO2) }\end{array}$ & $\begin{array}{l}\text { SOLIDS, } \\
\text { RESIDUE } \\
\text { AT } 180 \\
\text { DEG. C } \\
\text { DIS- } \\
\text { SOLVED } \\
\text { (MG/L) }\end{array}$ & $\begin{array}{l}\text { SOLIDS, } \\
\text { SUM OF } \\
\text { CONSTI- } \\
\text { TUENTS, } \\
\text { DIS- } \\
\text { SOLVED } \\
\text { (MG/L) }\end{array}$ & $\begin{array}{c}\text { SOLIDS, } \\
\text { DIS- } \\
\text { SOLVED } \\
\text { (TONS } \\
\text { PER } \\
\text { AC-FT) }\end{array}$ & $\begin{array}{c}\text { SOLIDS, } \\
\text { DIS- } \\
\text { SOLVED } \\
\text { (TONS } \\
\text { PER } \\
\text { DAY) }\end{array}$ \\
\hline \multirow{4}{*}{$\begin{array}{l}\text { NOV } \\
13 \ldots \\
\text { MAR } \\
11 \ldots \\
\text { MAY } \\
27 \ldots \\
\text { AUG } \\
26 \ldots\end{array}$} & 125 & 1.8 & 19 & 14 & $<0.1$ & 8.6 & 179 & 180 & 0.24 & 1210 \\
\hline & 144 & 1.8 & 22 & 18 & $<0.1$ & 8.0 & 207 & 210 & 0.28 & 1930 \\
\hline & 141 & 0.9 & 21 & 22 & 0.1 & 4.4 & 242 & 210 & 0.33 & 830 \\
\hline & 151 & 1.6 & 24 & 18 & 0.1 & 4.1 & 220 & 210 & 0.3 & 677 \\
\hline
\end{tabular}


WATER QUALITY DATA, WATER YEAR OCTOBER 1986 TO SEPTEMBER 1987

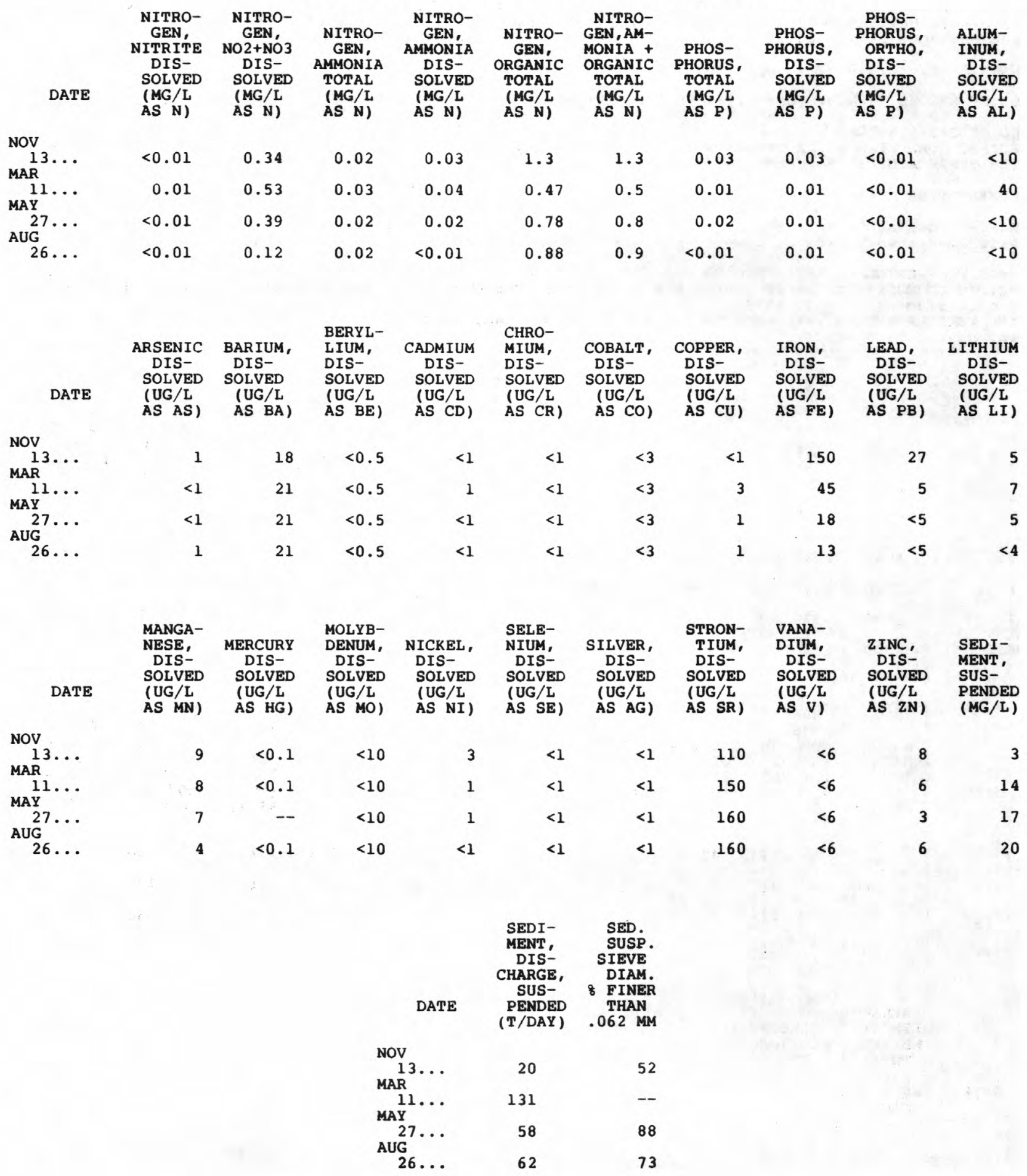


04122100 BEAR CREEK NEAR MUSKEGON, MI

LOCATION.--Lat $43^{\circ} 17^{\prime} 19^{\prime \prime}$, long $86^{\circ} 13^{\prime} 22^{\prime \prime}$, in SWl $/ 4$ NWl $/ 4$ sec.4, T.10 N., R.16 W., Muskegon County, Hydrologic Unit 04060i02, on left bank at upstream side of bridge on' North Getty street, $1.5 \mathrm{mi}$ upstream from Little Bear Creek, and $3.9 \mathrm{mi}$ northeast of Muskegon.

DRAINAGE AREA.--14.8 $\mathrm{mi}^{2}$.

PERIOD OF RECORD.--October 1965 to current year.

REVISED RECORDS.--WDR MI-80-1: 1976(M), 1978(M), 1979(P).

GAGE.--Water-stage recorder. Datum of gage is $590.00 \mathrm{ft}$ above National Geodetic Vertical Datum of 1929 (Michigan Department of Natural Resources benchmark). Prior to Mar. 17, 1978, at different datum.

REMARKS.--Estimated daily discharges: Dec. 13, 14, Jan. 17, 19, 20, 22-31, and Feb. 15-17. Records good except for estimated daily discharges, which are poor. Some regulation during low flow by dams and

irrigation upstream from station. Several measurements of water temperature were made during the year.

AVERAGE DISCHARGE. --22 years, $17.1 \mathrm{ft}^{3} / \mathrm{s}, 15.69 \mathrm{in} / \mathrm{yr}^{\circ}$

EXTREMES FOR PERIOD OF RECORD.--Maximum discharge, $930 \mathrm{ft}^{3} / \mathrm{s}$, Mar. 5, 1976, gage height, $11.00 \mathrm{ft}$, datum then in use; minimum, $1.0 \mathrm{ft} 3 / \mathrm{s}$, Aug. 5, 17, 22, 1971 .

EXTREMES FOR CURRENT YEAR.--Peak discharges greater than base discharge of $100 \mathrm{ft}{ }^{3} / \mathrm{s}$ and maximum (*):

\begin{tabular}{|c|c|c|c|c|c|c|c|}
\hline Date & Time & $\begin{array}{c}\text { Discharge } \\
\left(\mathrm{ft}^{3} / \mathrm{s}\right)\end{array}$ & $\begin{array}{c}\text { Gage height } \\
\text { (ft) }\end{array}$ & Date & Time & $\begin{array}{c}\text { Discharge } \\
\left(\mathrm{ft}^{3} / \mathrm{s}\right)\end{array}$ & $\begin{array}{l}\text { Gage height } \\
(f t)\end{array}$ \\
\hline $\begin{array}{l}\text { Oct. } 4 \\
\text { Aug. } 17\end{array}$ & $\begin{array}{l}2330 \\
1300\end{array}$ & $\begin{array}{r}\star 184 \\
152\end{array}$ & $\begin{array}{r}* 14.70 \\
14.39\end{array}$ & Aug. & 1630 & 107 & 13.86 \\
\hline
\end{tabular}

Minimum discharge, $2.3 \mathrm{ft}^{3} / \mathrm{s}$, Aug. 7,8 , gage height, $10.23 \mathrm{ft}$.

DISCHARGE, IN CUBIC FEET PER SECOND, WATER YEAR OCTOBER 1986 TO SEPTEMBER 1987 MEAN VALUES

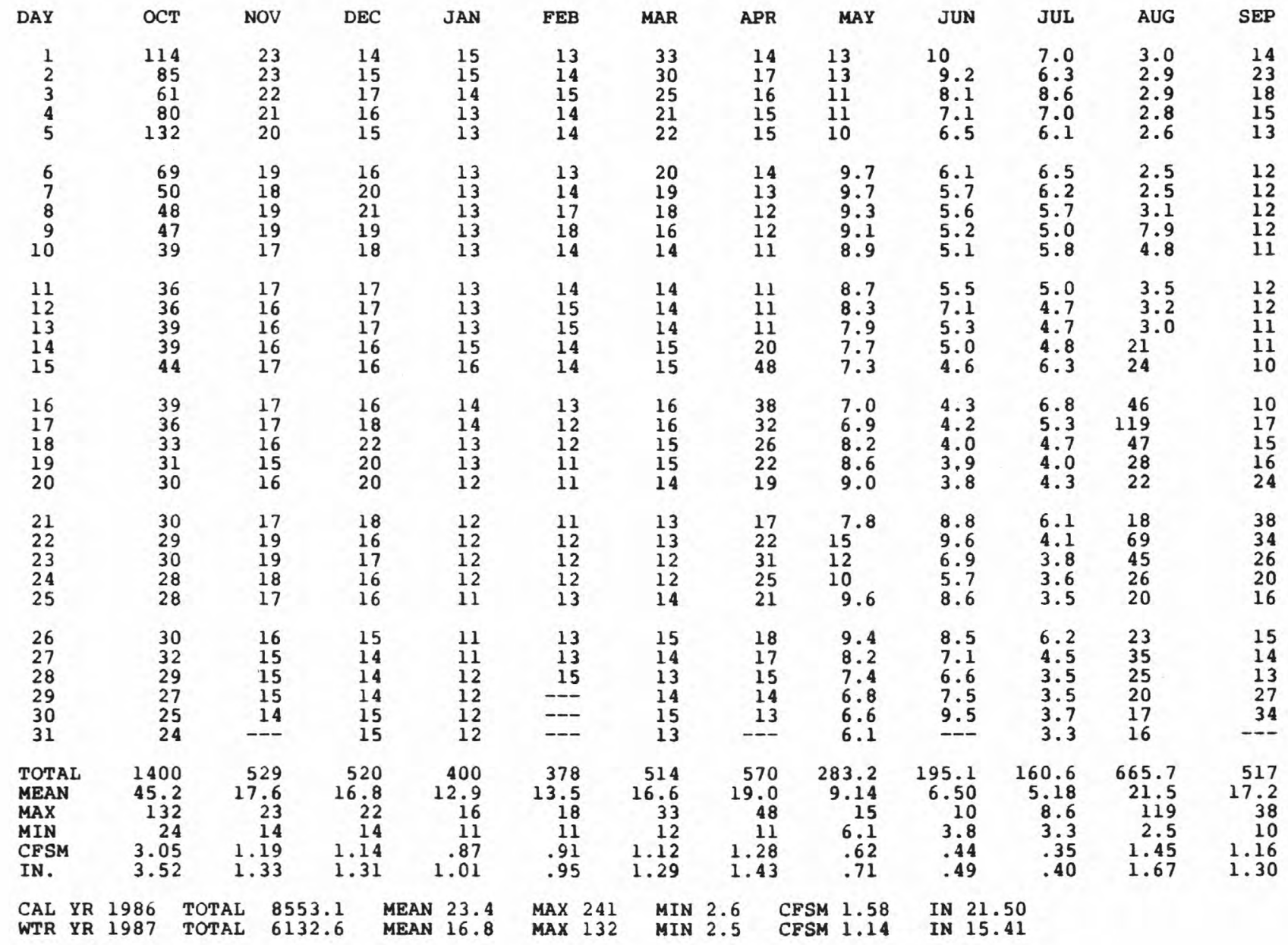


LOCATION.--Lat $43^{\circ} 27^{\prime} 51^{\prime \prime}$, long $86^{\circ} 13^{\prime} 57^{\prime \prime}$, in SEl/4 NWl/4 sec.4, T.12 N., R. 16 W., Muskegon County, Hydrologic Unit 04060101 , on right bank $30 \mathrm{ft}$ downstream from bridge on Fruitvale Road, 6.3 mi downstream from North Branch, and $6.9 \mathrm{mi}$ northeast of Whitehall.

DRAINAGE AREA. $--406 \mathrm{mi}^{2}$.

PERIOD OF RECORD.--August 1957 to current year.

REVISED RECORDS.--WDR MI-83: Drainage area.

GAGE.- Water-stage recorder. Datum of gage is $594.1 \mathrm{ft}$ above National Geodetic Vertical Datum of 1929. Nov. 18, 1957, to Oct. 22, 1958, nonrecording gage at same site and datum.

REMARKS.--Estimated daily discharges: Dec. 15 to Feb. 15, and Feb. 17-20. Records good except for estimated daily discharges, which are poor. Some regulation during low flow by dams upstream from station. Several measurements of water temperature were made during the year.

AVERAGE DISCHARGE. --30 years, $445 \mathrm{ft}^{3} / \mathrm{s}, 14.88 \mathrm{in} / \mathrm{yr}$.

EXTREMES FOR PERIOD OF RECORD.--Maximum discharge, 5,400 ft $3 / \mathrm{s}$, Sept. 1, 1975, gage height, 7.46 ft; minimum, $163 \mathrm{ft}^{3} / \mathrm{s}$, Aug. 18, 19, 1958.

EXTREMES FOR CURRENT YEAR.--Maximum discharge, 1,720 $\mathrm{ft}^{3} / \mathrm{s}$, Oct. 5, gage height, $5.80 \mathrm{ft}$; minimum, $208 \mathrm{ft}^{3} / \mathrm{s}$, Aug. 8, gage height, $1.28 \mathrm{ft}$.

DISCHARGE, IN CUBIC FEET PER SECOND, WATER YEAR OCTOBER 1986 TO SEPTEMBER 1987 MEAN VALUES

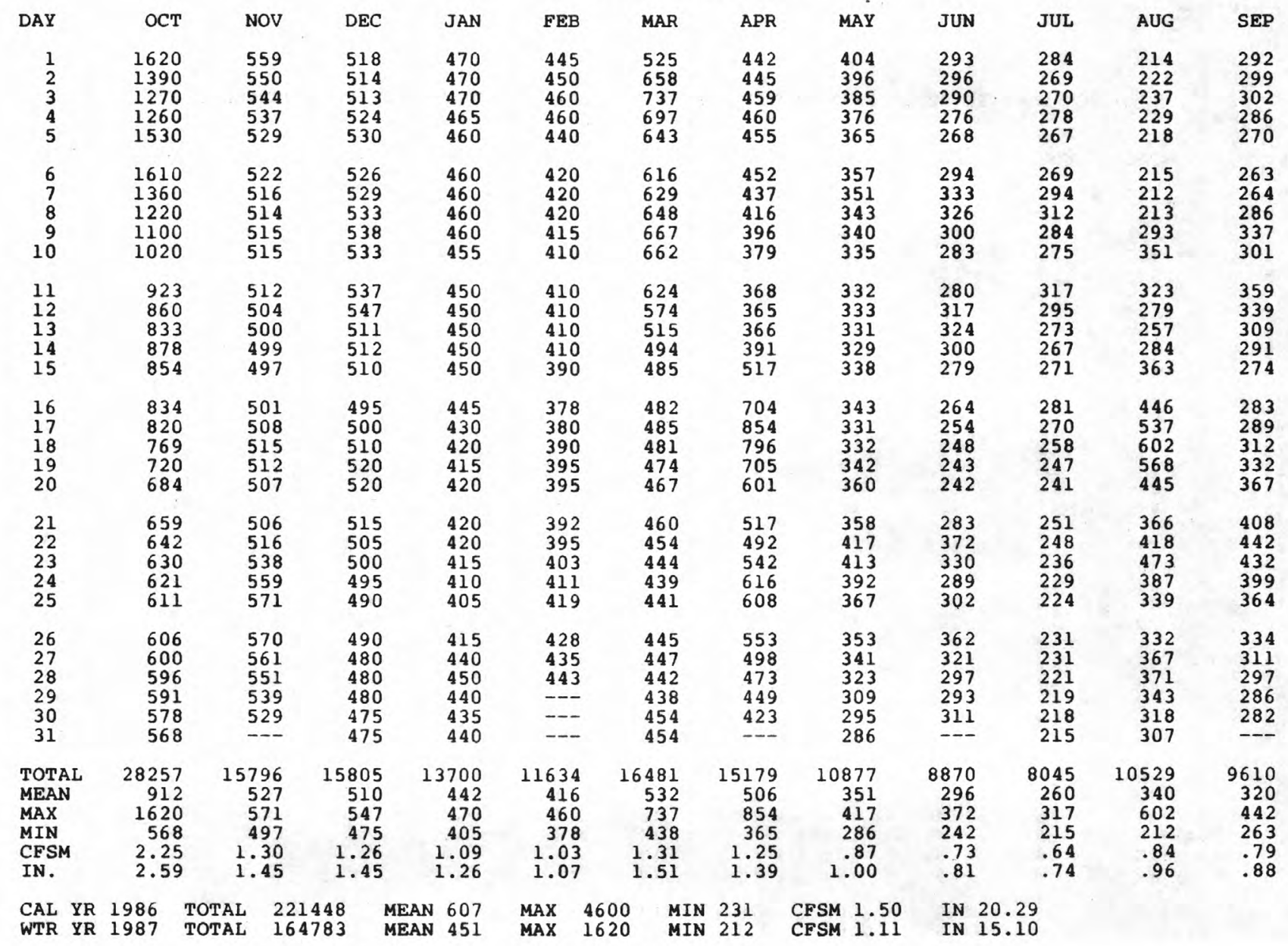


04122500 PERE MARQUETTE RIVER AT SCOTTVILLE, MI

LOCATION. -- Lat $43^{\circ} 56^{\prime} 42^{\prime \prime}$, long $86^{\circ} 16^{\prime} 43^{\prime \prime}$, in NWl/4 NWl/4 sec.19, T.18 N., R.16 W., Mason County, Hydrologic Unit 04060101 , on right bank $20 \mathrm{ft}$ upstream from highway bridge at south edge of Scottville, $1.4 \mathrm{mi}$ upstream from India Creek, and $5.6 \mathrm{mi}$ downstream from Big South Branch.

DRAINAGE AREA. $--681 \mathrm{mi}^{2}$.

PERIOD OF RECORD.--August 1939 to current year. Prior to October 1942, published as "at Custer" .

REVISED RECORDS.--WSP 1437: 1941(M)，1943(M)，1949(M)，1950. WDR MI-81: Drainage area.

GAGE.--Water-stage recorder. Datum of gage is $597.66 \mathrm{ft}$ above National Geodetic Vertical Datum of 1929. Prior to June 12, 1943, nonrecording gage at bridge $4.5 \mathrm{mi}$ upstream at different datum.

REMARKS.--Estimated daily discharges: Dec. 13-16, Jan. 25 to Feb. 3, and Feb. 17, 18. Records good except for estimated daily discharges, which are fair. Some regulation at low flow. Several measurements of water temperature were made during the year.

AVERAGE DISCHARGE, -48 years, $688 \mathrm{ft} / \mathrm{s}, 13.72 \mathrm{in} / \mathrm{yr}^{3}$.

EXTREMES FOR PERIOD OF RECORD.--Maximum discharge, 6,440 ft $3 / \mathrm{s}$, Sept. 13, 1986, gage height, 8.07 $\mathrm{ft}$; minimum, $209 \mathrm{ft} / \mathrm{s}$, Dec. Il, 1962, discharge measurement; minimum daily, $310 \mathrm{ft} / \mathrm{s}$, Aug. $9,10,1941$.

EXTREMES FOR CURRENT YEAR.--Maximum discharge, 1,880 $\mathrm{ft}^{3} / \mathrm{s}$, Oct. 8, gage height, $4.80 \mathrm{ft}$; minimum, $380 \mathrm{ft}^{3} / \mathrm{s}$, Aug. 1, gage height, $1.47 \mathrm{ft}$.

DISCHARGE, IN CUBIC FEET PER SECOND, WATER YEAR OCTOBER 1986 TO SEPTEMBER 1987 MEAN VALUES

\begin{tabular}{|c|c|c|c|c|c|c|c|c|c|c|c|c|}
\hline DAY & OCT & NOV & DEC & JAN & FEB & MAR & APR & MAY & JUN & JUL & AUG & SEP \\
\hline $\begin{array}{l}1 \\
2 \\
3 \\
4 \\
5\end{array}$ & $\begin{array}{l}1710 \\
1720 \\
1760 \\
1780 \\
1790\end{array}$ & $\begin{array}{l}1140 \\
1120 \\
1120 \\
1100 \\
1090\end{array}$ & $\begin{array}{l}1020 \\
1010 \\
1010 \\
1020 \\
1030\end{array}$ & $\begin{array}{l}924 \\
924 \\
919 \\
912 \\
901\end{array}$ & $\begin{array}{l}880 \\
890 \\
890 \\
889 \\
856\end{array}$ & $\begin{array}{r}882 \\
1010 \\
1080 \\
1100 \\
1080\end{array}$ & $\begin{array}{l}808 \\
810 \\
816 \\
824 \\
820\end{array}$ & $\begin{array}{l}743 \\
724 \\
702 \\
687 \\
672\end{array}$ & $\begin{array}{l}565 \\
559 \\
557 \\
546 \\
532\end{array}$ & $\begin{array}{l}480 \\
471 \\
460 \\
453 \\
452\end{array}$ & $\begin{array}{l}384 \\
407 \\
445 \\
461 \\
437\end{array}$ & $\begin{array}{l}444 \\
442 \\
443 \\
441 \\
432\end{array}$ \\
\hline $\begin{array}{r}6 \\
7 \\
8 \\
9 \\
10\end{array}$ & $\begin{array}{l}1820 \\
1830 \\
1860 \\
1770 \\
1670\end{array}$ & $\begin{array}{l}1070 \\
1060 \\
1060 \\
1060 \\
1060\end{array}$ & $\begin{array}{l}1020 \\
1010 \\
1010 \\
1010 \\
1010\end{array}$ & $\begin{array}{l}894 \\
891 \\
896 \\
899 \\
899\end{array}$ & $\begin{array}{l}826 \\
824 \\
826 \\
820 \\
797\end{array}$ & $\begin{array}{l}1060 \\
1090 \\
1140 \\
1190 \\
1240\end{array}$ & $\begin{array}{l}816 \\
800 \\
779 \\
758 \\
737\end{array}$ & $\begin{array}{l}656 \\
645 \\
638 \\
634 \\
627\end{array}$ & $\begin{array}{l}564 \\
588 \\
600 \\
569 \\
541\end{array}$ & $\begin{array}{l}451 \\
468 \\
486 \\
506 \\
479\end{array}$ & $\begin{array}{l}420 \\
408 \\
404 \\
490 \\
526\end{array}$ & $\begin{array}{l}427 \\
428 \\
446 \\
457 \\
473\end{array}$ \\
\hline $\begin{array}{l}11 \\
12 \\
13 \\
14 \\
15\end{array}$ & $\begin{array}{l}1580 \\
1540 \\
1510 \\
1530 \\
1560\end{array}$ & $\begin{array}{l}1050 \\
1040 \\
1020 \\
1020 \\
1010\end{array}$ & $\begin{array}{l}1010 \\
1010 \\
1010 \\
1000 \\
1000\end{array}$ & $\begin{array}{l}894 \\
886 \\
885 \\
876 \\
876\end{array}$ & $\begin{array}{l}798 \\
806 \\
804 \\
798 \\
776\end{array}$ & $\begin{array}{r}1230 \\
1140 \\
1030 \\
959 \\
913\end{array}$ & $\begin{array}{l}723 \\
713 \\
703 \\
724 \\
842\end{array}$ & $\begin{array}{l}633 \\
673 \\
669 \\
639 \\
626\end{array}$ & $\begin{array}{l}531 \\
541 \\
545 \\
533 \\
513\end{array}$ & $\begin{array}{l}468 \\
463 \\
451 \\
444 \\
441\end{array}$ & $\begin{array}{l}549 \\
499 \\
460 \\
450 \\
549\end{array}$ & $\begin{array}{l}472 \\
523 \\
575 \\
527 \\
501\end{array}$ \\
\hline $\begin{array}{l}16 \\
17 \\
18 \\
19 \\
20\end{array}$ & $\begin{array}{l}1590 \\
1560 \\
1520 \\
1460 \\
1410\end{array}$ & $\begin{array}{l}1010 \\
1030 \\
1040 \\
1030 \\
1030\end{array}$ & $\begin{array}{r}990 \\
984 \\
981 \\
1000 \\
1020\end{array}$ & $\begin{array}{l}875 \\
845 \\
804 \\
797 \\
811\end{array}$ & $\begin{array}{l}720 \\
730 \\
740 \\
747 \\
739\end{array}$ & $\begin{array}{l}885 \\
865 \\
853 \\
839 \\
830\end{array}$ & $\begin{array}{r}962 \\
1100 \\
1180 \\
1130 \\
1030\end{array}$ & $\begin{array}{l}639 \\
634 \\
618 \\
625 \\
635\end{array}$ & $\begin{array}{l}499 \\
487 \\
483 \\
474 \\
482\end{array}$ & $\begin{array}{l}439 \\
438 \\
429 \\
422 \\
418\end{array}$ & $\begin{array}{l}627 \\
691 \\
720 \\
726 \\
662\end{array}$ & $\begin{array}{l}486 \\
524 \\
625 \\
742 \\
814\end{array}$ \\
\hline $\begin{array}{l}21 \\
22 \\
23 \\
24 \\
25\end{array}$ & $\begin{array}{l}1370 \\
1330 \\
1310 \\
1280 \\
1250\end{array}$ & $\begin{array}{l}1010 \\
1020 \\
1040 \\
1070 \\
1100\end{array}$ & $\begin{array}{r}1010 \\
999 \\
972 \\
957 \\
955\end{array}$ & $\begin{array}{l}820 \\
825 \\
815 \\
581 \\
780\end{array}$ & $\begin{array}{l}736 \\
743 \\
752 \\
755 \\
761\end{array}$ & $\begin{array}{l}825 \\
817 \\
811 \\
804 \\
800\end{array}$ & $\begin{array}{r}938 \\
894 \\
905 \\
961 \\
1020\end{array}$ & $\begin{array}{l}638 \\
664 \\
668 \\
691 \\
674\end{array}$ & $\begin{array}{l}512 \\
531 \\
513 \\
500 \\
495\end{array}$ & $\begin{array}{l}458 \\
439 \\
422 \\
411 \\
403\end{array}$ & $\begin{array}{l}582 \\
532 \\
507 \\
495 \\
478\end{array}$ & $\begin{array}{l}849 \\
825 \\
765 \\
691 \\
627\end{array}$ \\
\hline $\begin{array}{l}26 \\
27 \\
28 \\
29 \\
30 \\
31\end{array}$ & $\begin{array}{l}1240 \\
1220 \\
1210 \\
1190 \\
1180 \\
1160\end{array}$ & $\begin{array}{l}1120 \\
1110 \\
1080 \\
1060 \\
1040 \\
---\end{array}$ & $\begin{array}{l}954 \\
945 \\
934 \\
925 \\
925 \\
926\end{array}$ & $\begin{array}{l}820 \\
870 \\
880 \\
870 \\
850 \\
850\end{array}$ & $\begin{array}{l}768 \\
770 \\
784 \\
--- \\
--- \\
---\end{array}$ & $\begin{array}{l}796 \\
796 \\
789 \\
790 \\
794 \\
809\end{array}$ & $\begin{array}{r}1010 \\
942 \\
869 \\
813 \\
770 \\
-\end{array}$ & $\begin{array}{l}659 \\
643 \\
629 \\
608 \\
587 \\
573\end{array}$ & $\begin{array}{l}517 \\
514 \\
503 \\
498 \\
486 \\
----\end{array}$ & $\begin{array}{l}401 \\
394 \\
389 \\
386 \\
386 \\
384\end{array}$ & $\begin{array}{l}469 \\
469 \\
472 \\
470 \\
458 \\
451\end{array}$ & $\begin{array}{l}587 \\
563 \\
546 \\
549 \\
556 \\
-\end{array}$ \\
\hline $\begin{array}{l}\text { TOTAL } \\
\text { MEAN } \\
\text { MAX } \\
\text { MIN } \\
\text { CFSM } \\
\text { IN. }\end{array}$ & $\begin{array}{r}46710 \\
1507 \\
1860 \\
1160 \\
2.21 \\
2.55\end{array}$ & $\begin{array}{r}31810 \\
1060 \\
1140 \\
1010 \\
1.56 \\
1.74\end{array}$ & $\begin{array}{r}30657 \\
989 \\
1030 \\
925 \\
1.45 \\
1.67\end{array}$ & $\begin{array}{r}26569 \\
857 \\
924 \\
581 \\
1.26 \\
1.45\end{array}$ & $\begin{array}{r}22225 \\
794 \\
890 \\
720 \\
1.17 \\
1.21\end{array}$ & $\begin{array}{r}29247 \\
943 \\
1240 \\
789 \\
1.39 \\
1.60\end{array}$ & $\begin{array}{r}26197 \\
873 \\
1180 \\
703 \\
1.28 \\
1.43\end{array}$ & $\begin{array}{r}20153 \\
650 \\
743 \\
573 \\
.95 \\
1.10\end{array}$ & $\begin{array}{r}15778 \\
526 \\
600 \\
474 \\
.77 \\
.86\end{array}$ & $\begin{array}{r}13592 \\
438 \\
506 \\
384 \\
.64 \\
.74\end{array}$ & $\begin{array}{r}15698 \\
506 \\
726 \\
384 \\
.74 \\
.86\end{array}$ & $\begin{array}{r}16780 \\
559 \\
849 \\
427 \\
.82 \\
.92\end{array}$ \\
\hline $\begin{array}{l}\text { CAL YR } \\
\text { WTR YR }\end{array}$ & $\begin{array}{l}1986 \\
1987\end{array}$ & AL & $\begin{array}{l}0 \\
6\end{array}$ & $\begin{array}{lr}\text { AN } & 1070 \\
\text { AN } & 809\end{array}$ & $\begin{array}{l}\text { MAXX } \\
\text { MAX }\end{array}$ & $\begin{array}{l}6020 \\
1860\end{array}$ & $\begin{array}{ll}\text { MIN } & 485 \\
\text { MIN } & 384\end{array}$ & $\begin{array}{l}\text { CFSM } \\
\text { CFSM }\end{array}$ & $\begin{array}{l}\text { IN } \\
\text { IN }\end{array}$ & $\begin{array}{l}21.34 \\
16.14\end{array}$ & & \\
\hline
\end{tabular}


LOCATION.--Lat $44^{\circ} 26^{\prime} 1^{\prime \prime}$, long $85^{\circ} 41^{\prime} 55^{\prime \prime}$, in NEl/4 NEl/4 sec.36, T. 24 N., R.12 W., Wexford County, Hydrologic Unit 04060103 , on downstream side of bridge near right piér on staté Highway $37,250 \mathrm{ft}$ upstream from wheeler creek, $0.9 \mathrm{mi}$ north of Sherman, and at mile 60.8 .

DRAINAGE AREA. $--900 \mathrm{mi}^{2}$.

PERIOD OF RECORD.--July 1903 to May 1916, October 1930 to September 1931, October 1933 to current year. Monthly discharge only for some periods, published in WSP 1307.

REVISED RECORDS.--WSP 1004: 1936(M). WSP 1307: 1911, 1913-14(M), 1934(M), 1936(M), 1937, 1939-40(M). WSP 1437: 1911, 1913(M), 1937.

GAGE.--Nonrecording gage. Elevation of gage is $804 \mathrm{ft}$, from river profile map. Prior to Apr. 13, 1934, at various datums.

REMARKS.--Estimated daily discharges: Nov. 20-26, Nov. 28 to Dec. 16, Dec. 18, 25, Jan. 24-31, and Mar. 23-26. Records fair except for estimated daily discharges, which are poor. Several measurements of water temperature were made during the year.

AVERAGE DISCHARGE.--67 years (water years 1904-15, 1931, 1934-87), 1,059 ft $3 / \mathrm{s}, 15.98 \mathrm{in} / \mathrm{y}^{\mathrm{r}}$.

EXTREMES FOR PERIOD OF RECORD.--Maximum discharge, 3,570 $\mathrm{ft}^{3} / \mathrm{s}$, Mar. 25, 1913, gage height, $7.1 \mathrm{ft}$, from graph based on gage readings, datum then in use; minimum daily, $540 \mathrm{ft} 3 / \mathrm{s}, \mathrm{Feb}$. $21-23$, 1936 .

EXTREMES FOR CURRENT YEAR.--Maximum discharge observed, 2,600 $\mathrm{ft}^{3} / \mathrm{s}$, Oct. 1, gage height, $15.01 \mathrm{ft}$; minimum observed, $738 \mathrm{ft}^{3} / \mathrm{s}, \mathrm{July} 31$, Aug. 1, gage height, $10.69 \mathrm{ft}$.

DISCHARGE, IN CUBIC FEET PER SECOND, WATER YEAR OCTOBER 1986 TO SEPTEMBER 1987 MEAN VALUES

\begin{tabular}{|c|c|c|c|c|c|c|c|c|c|c|c|c|}
\hline DAY & OCT & NOV & $\mathrm{DEC}$ & JAN & FEB & MAR & APR & MAY & JUN & JUL & AUG & SEP \\
\hline $\begin{array}{l}1 \\
2 \\
3 \\
4 \\
5\end{array}$ & $\begin{array}{l}2600 \\
2560 \\
2440 \\
2400 \\
2360\end{array}$ & $\begin{array}{l}1370 \\
1360 \\
1350 \\
1340 \\
1340\end{array}$ & $\begin{array}{l}1280 \\
1250 \\
1230 \\
1200 \\
1190\end{array}$ & $\begin{array}{l}1110 \\
1120 \\
1120 \\
1110 \\
1110\end{array}$ & $\begin{array}{l}1190 \\
1210 \\
1290 \\
1200 \\
1050\end{array}$ & $\begin{array}{l}1040 \\
1080 \\
1110 \\
1100 \\
1120\end{array}$ & $\begin{array}{l}1230 \\
1190 \\
1160 \\
1120 \\
1150\end{array}$ & $\begin{array}{l}906 \\
894 \\
887 \\
884 \\
878\end{array}$ & $\begin{array}{l}863 \\
854 \\
839 \\
830 \\
821\end{array}$ & $\begin{array}{l}854 \\
803 \\
798 \\
794 \\
790\end{array}$ & $\begin{array}{l}738 \\
794 \\
766 \\
794 \\
872\end{array}$ & $\begin{array}{l}910 \\
898 \\
890 \\
884 \\
875\end{array}$ \\
\hline $\begin{array}{r}6 \\
7 \\
8 \\
9 \\
10\end{array}$ & $\begin{array}{l}2330 \\
2240 \\
2170 \\
2080 \\
1910\end{array}$ & $\begin{array}{l}1330 \\
1320 \\
1310 \\
1310 \\
1290\end{array}$ & $\begin{array}{l}1170 \\
1120 \\
1130 \\
1140 \\
1150\end{array}$ & $\begin{array}{l}1110 \\
1110 \\
1110 \\
1110 \\
1110\end{array}$ & $\begin{array}{l}1050 \\
1050 \\
1040 \\
1030 \\
1030\end{array}$ & $\begin{array}{l}1190 \\
1280 \\
1640 \\
1610 \\
1450\end{array}$ & $\begin{array}{l}1130 \\
1120 \\
1110 \\
1100 \\
1090\end{array}$ & $\begin{array}{l}872 \\
869 \\
869 \\
869 \\
869\end{array}$ & $\begin{array}{l}815 \\
812 \\
818 \\
812 \\
806\end{array}$ & $\begin{array}{l}784 \\
782 \\
776 \\
774 \\
776\end{array}$ & $\begin{array}{r}827 \\
800 \\
884 \\
1010 \\
1040\end{array}$ & $\begin{array}{l}869 \\
863 \\
857 \\
857 \\
854\end{array}$ \\
\hline $\begin{array}{l}11 \\
12 \\
13 \\
14 \\
15\end{array}$ & $\begin{array}{l}1760 \\
1730 \\
1720 \\
1700 \\
1690\end{array}$ & $\begin{array}{l}1270 \\
1240 \\
1220 \\
1210 \\
1190\end{array}$ & $\begin{array}{l}1140 \\
1160 \\
1200 \\
1210 \\
1220\end{array}$ & $\begin{array}{l}1100 \\
1090 \\
1090 \\
1090 \\
1090\end{array}$ & $\begin{array}{l}1050 \\
1080 \\
1060 \\
1030 \\
1010\end{array}$ & $\begin{array}{l}1350 \\
1300 \\
1250 \\
1220 \\
1180\end{array}$ & $\begin{array}{l}1070 \\
1050 \\
1040 \\
1030 \\
1060\end{array}$ & $\begin{array}{l}998 \\
978 \\
930 \\
906 \\
884\end{array}$ & $\begin{array}{l}806 \\
821 \\
851 \\
833 \\
806\end{array}$ & $\begin{array}{l}780 \\
833 \\
839 \\
803 \\
784\end{array}$ & $\begin{array}{r}1030 \\
1010 \\
872 \\
1000 \\
1310\end{array}$ & $\begin{array}{l}851 \\
863 \\
906 \\
910 \\
890\end{array}$ \\
\hline $\begin{array}{l}16 \\
17 \\
18 \\
19 \\
20\end{array}$ & $\begin{array}{l}1680 \\
1600 \\
1560 \\
1510 \\
1460\end{array}$ & $\begin{array}{l}1170 \\
1190 \\
1250 \\
1230 \\
1250\end{array}$ & $\begin{array}{l}1220 \\
1180 \\
1210 \\
1210 \\
1190\end{array}$ & $\begin{array}{l}1080 \\
1080 \\
1070 \\
1060 \\
1060\end{array}$ & $\begin{array}{l}1090 \\
1110 \\
1110 \\
1100 \\
1100\end{array}$ & $\begin{array}{l}1160 \\
1150 \\
1140 \\
1150 \\
1160\end{array}$ & $\begin{array}{l}1100 \\
1090 \\
1060 \\
1040 \\
1010\end{array}$ & $\begin{array}{l}878 \\
869 \\
863 \\
930 \\
906\end{array}$ & $\begin{array}{l}798 \\
794 \\
786 \\
782 \\
800\end{array}$ & $\begin{array}{l}768 \\
766 \\
764 \\
762 \\
766\end{array}$ & $\begin{array}{l}1460 \\
2160 \\
2120 \\
2120 \\
1880\end{array}$ & $\begin{array}{r}881 \\
902 \\
1000 \\
1140 \\
1150\end{array}$ \\
\hline $\begin{array}{l}21 \\
22 \\
23 \\
24 \\
25\end{array}$ & $\begin{array}{l}1420 \\
1390 \\
1660 \\
1770 \\
1520\end{array}$ & $\begin{array}{l}1300 \\
1330 \\
1360 \\
1380 \\
1390\end{array}$ & $\begin{array}{l}1170 \\
1150 \\
1150 \\
1150 \\
1140\end{array}$ & $\begin{array}{l}1050 \\
1040 \\
1030 \\
1020 \\
1020\end{array}$ & $\begin{array}{l}1090 \\
1070 \\
1040 \\
1040 \\
1030\end{array}$ & $\begin{array}{l}1170 \\
1190 \\
1220 \\
1290 \\
1370\end{array}$ & $\begin{array}{r}990 \\
982 \\
1050 \\
1030 \\
1010\end{array}$ & $\begin{array}{l}942 \\
962 \\
950 \\
946 \\
914\end{array}$ & $\begin{array}{l}812 \\
830 \\
803 \\
792 \\
794\end{array}$ & $\begin{array}{l}818 \\
824 \\
788 \\
770 \\
756\end{array}$ & $\begin{array}{r}1590 \\
1240 \\
1040 \\
854 \\
998\end{array}$ & $\begin{array}{r}1140 \\
1090 \\
1040 \\
990 \\
942\end{array}$ \\
\hline $\begin{array}{l}26 \\
27 \\
28 \\
29 \\
30 \\
31\end{array}$ & $\begin{array}{l}1490 \\
1480 \\
1450 \\
1430 \\
1410 \\
1370\end{array}$ & $\begin{array}{l}1360 \\
1290 \\
1290 \\
1290 \\
1290 \\
---\end{array}$ & $\begin{array}{l}1130 \\
1120 \\
1120 \\
1120 \\
1120 \\
1110\end{array}$ & $\begin{array}{l}1050 \\
1080 \\
1090 \\
1100 \\
1100 \\
1130\end{array}$ & $\begin{array}{r}1030 \\
1030 \\
1030 \\
--- \\
--- \\
---\end{array}$ & $\begin{array}{l}1400 \\
1370 \\
1330 \\
1300 \\
1270 \\
1250\end{array}$ & $\begin{array}{l}962 \\
966 \\
954 \\
942 \\
918 \\
---\end{array}$ & $\begin{array}{l}906 \\
898 \\
898 \\
887 \\
881 \\
842\end{array}$ & $\begin{array}{l}827 \\
854 \\
845 \\
848 \\
836 \\
---\end{array}$ & $\begin{array}{l}750 \\
746 \\
742 \\
740 \\
740 \\
738\end{array}$ & $\begin{array}{l}974 \\
958 \\
946 \\
930 \\
926 \\
918\end{array}$ & $\begin{array}{l}898 \\
884 \\
866 \\
887 \\
910 \\
---\end{array}$ \\
\hline $\begin{array}{l}\text { TOTAL } \\
\text { MEAN } \\
\text { MAX } \\
\text { MIN } \\
\text { CFSM } \\
\text { IN. }\end{array}$ & $\begin{array}{r}55890 \\
1803 \\
2600 \\
1370 \\
2.00 \\
2.31\end{array}$ & $\begin{array}{r}38820 \\
1294 \\
1390 \\
1170 \\
1.44 \\
1.60\end{array}$ & $\begin{array}{r}36280 \\
1170 \\
1280 \\
1110 \\
1.30 \\
1.50\end{array}$ & $\begin{array}{r}33640 \\
1085 \\
1130 \\
1020 \\
1.21 \\
1.39\end{array}$ & $\begin{array}{r}30240 \\
1080 \\
1290 \\
1010 \\
1.20 \\
1.25\end{array}$ & $\begin{array}{r}38840 \\
1253 \\
1640 \\
1040 \\
1.39 \\
1.61\end{array}$ & $\begin{array}{r}31754 \\
1058 \\
1230 \\
918 \\
1.18 \\
1.31\end{array}$ & $\begin{array}{r}27965 \\
902 \\
998 \\
842 \\
1.00 \\
1.16\end{array}$ & $\begin{array}{r}24588 \\
820 \\
863 \\
782 \\
.91 \\
1.02\end{array}$ & $\begin{array}{r}24208 \\
781 \\
854 \\
738 \\
.87 \\
1.00\end{array}$ & $\begin{array}{r}34861 \\
1125 \\
2160 \\
738 \\
1.25 \\
1.44\end{array}$ & $\begin{array}{r}27897 \\
930 \\
1150 \\
851 \\
1.03 \\
1.15\end{array}$ \\
\hline
\end{tabular}

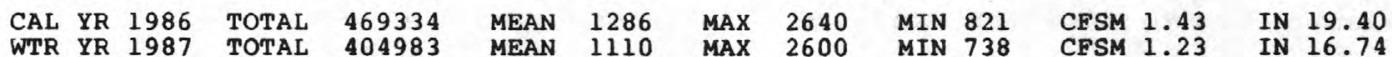


04126000 MANISTEE RIVER NEAR MANISTEE, MI

LOCATION. - Lat $44^{\circ} 16^{\prime} 14^{\prime \prime}$, long $86^{\circ} 11^{\prime} 56^{\prime \prime}$, in NWl/4 NWl/4 sec. 36 , T. 22 N., R.16 W., Manistee County, Hydrologic Unit 04060103 , on right bank $6.4 \mathrm{mi}$ northeast of Manistee, $7.8 \mathrm{mi}$ upstream from Manistee Lake, and at mile 10.8 .

DRAINAGE AREA. $--1,780 \mathrm{mi}^{2}$, approximately.

PERIOD OF RECORD.--October 1951 to current year. Monthly discharge only for October, November, 1951, published in WSP 1727.

GAGE.--Water-stage recorder. Elevation of gage is $585 \mathrm{ft}$, from river-profile map.

REMARKS.--Estimated daily discharges: Jan. 23-29. Records good except for estimated daily discharges, which are fair. Flow regulated at all stages by Tippy Hydroelectric Powerplant 21 mi upstream. Several measurements of water temperature were made during the year.

AVERAGE DISCHARGE.--36 years, $2,034 \mathrm{ft}^{3} / \mathrm{s}, 15.52 \mathrm{in} / \mathrm{yr}$.

EXTREMES FOR PERIOD OF RECORD.--Maximum discharge, $7,280 \mathrm{ft}^{3} / \mathrm{s}$, Oct. 5,1986, gage height, $8.44 \mathrm{ft}$; maximum gage height, $9.25 \mathrm{ft}$, Dec. 28, 1985, backwater from ice; minimum daily discharge, 570 $\mathrm{ft}^{3} / \mathrm{s}$, June 18,1980 .

EXTREMES FOR CURRENT YEAR.--Maximum discharge, $7,280 \mathrm{ft}^{3} / \mathrm{s}$, Oct. 5 , gage height, $8.44 \mathrm{ft}$; maximum gage height, $8.95 \mathrm{ft}$, Jan. 24, backwater from ice; minimum discharge, $880 \mathrm{ft}^{3} / \mathrm{s}, \mathrm{July} 28, \mathrm{gage}$ height, $4.20 \mathrm{ft}$.

DISCHARGE, IN CUBIC FEET PER SECOND, WATER YEAR OCTOBER 1986 TO SEPTEMBER 1987 MEAN VALUES

\begin{tabular}{|c|c|c|c|c|c|c|c|c|c|c|c|c|}
\hline DAY & OCT & NOV & $\mathrm{DEC}$ & JAN & FEB & MAR & APR & MAY & JUN & JUL & AUG & SEP \\
\hline $\begin{array}{l}1 \\
2 \\
3 \\
4 \\
5\end{array}$ & $\begin{array}{l}4700 \\
5160 \\
5730 \\
6290 \\
6160\end{array}$ & $\begin{array}{l}2720 \\
2660 \\
2040 \\
2550 \\
2800\end{array}$ & $\begin{array}{l}2140 \\
2300 \\
2410 \\
2490 \\
2510\end{array}$ & $\begin{array}{l}2670 \\
2120 \\
2240 \\
1930 \\
1890\end{array}$ & $\begin{array}{l}2030 \\
1860 \\
2140 \\
2420 \\
2420\end{array}$ & $\begin{array}{l}1970 \\
1890 \\
2220 \\
2220 \\
2210\end{array}$ & $\begin{array}{l}2300 \\
2380 \\
2240 \\
2280 \\
1970\end{array}$ & $\begin{array}{l}2050 \\
1870 \\
1500 \\
1490 \\
1760\end{array}$ & $\begin{array}{l}1620 \\
1710 \\
1610 \\
1820 \\
1540\end{array}$ & $\begin{array}{l}1560 \\
1610 \\
1790 \\
1410 \\
1550\end{array}$ & $\begin{array}{l}1150 \\
1690 \\
1910 \\
1260 \\
2120\end{array}$ & $\begin{array}{l}1790 \\
1700 \\
1780 \\
1830 \\
1780\end{array}$ \\
\hline $\begin{array}{r}6 \\
7 \\
8 \\
9 \\
10\end{array}$ & $\begin{array}{l}4630 \\
5070 \\
4870 \\
4760 \\
4680\end{array}$ & $\begin{array}{l}2580 \\
2380 \\
2590 \\
2460 \\
1910\end{array}$ & $\begin{array}{l}2540 \\
2520 \\
2250 \\
2120 \\
2360\end{array}$ & $\begin{array}{l}2450 \\
2300 \\
2150 \\
2270 \\
2200\end{array}$ & $\begin{array}{l}2380 \\
1890 \\
1790 \\
1770 \\
2170\end{array}$ & $\begin{array}{l}2250 \\
2260 \\
2210 \\
2740 \\
2910\end{array}$ & $\begin{array}{l}1630 \\
2140 \\
2470 \\
2100 \\
2150\end{array}$ & $\begin{array}{l}1840 \\
1930 \\
1690 \\
1630 \\
1480\end{array}$ & $\begin{array}{l}1190 \\
1400 \\
1300 \\
1560 \\
1460\end{array}$ & $\begin{array}{l}1680 \\
1050 \\
1310 \\
1270 \\
1580\end{array}$ & $\begin{array}{l}1610 \\
1610 \\
1390 \\
1650 \\
2340\end{array}$ & $\begin{array}{l}1350 \\
1360 \\
1610 \\
1670 \\
1960\end{array}$ \\
\hline $\begin{array}{l}11 \\
12 \\
13 \\
14 \\
15\end{array}$ & $\begin{array}{l}4080 \\
3660 \\
3900 \\
3870 \\
4000\end{array}$ & $\begin{array}{l}2340 \\
2350 \\
2370 \\
2390 \\
2260\end{array}$ & $\begin{array}{l}2410 \\
2510 \\
2200 \\
2030 \\
2060\end{array}$ & $\begin{array}{l}2200 \\
2020 \\
2280 \\
2230 \\
2200\end{array}$ & $\begin{array}{l}2130 \\
1920 \\
2050 \\
1990 \\
1830\end{array}$ & $\begin{array}{l}3120 \\
2950 \\
2620 \\
2070 \\
1940\end{array}$ & $\begin{array}{l}1790 \\
1940 \\
1690 \\
2100 \\
2070\end{array}$ & $\begin{array}{l}1640 \\
1860 \\
2020 \\
1680 \\
1950\end{array}$ & $\begin{array}{l}1490 \\
1540 \\
1890 \\
1320 \\
1240\end{array}$ & $\begin{array}{l}1430 \\
1280 \\
1350 \\
1610 \\
1540\end{array}$ & $\begin{array}{l}2250 \\
1860 \\
1880 \\
1760 \\
1990\end{array}$ & $\begin{array}{l}1560 \\
1790 \\
1500 \\
1880 \\
1770\end{array}$ \\
\hline $\begin{array}{l}16 \\
17 \\
18 \\
19 \\
20\end{array}$ & $\begin{array}{l}4000 \\
3840 \\
3660 \\
3650 \\
3240\end{array}$ & $\begin{array}{l}2160 \\
1960 \\
2290 \\
2390 \\
2380\end{array}$ & $\begin{array}{l}2310 \\
2430 \\
2720 \\
2620 \\
2320\end{array}$ & $\begin{array}{l}2290 \\
2010 \\
1770 \\
1600 \\
2220\end{array}$ & $\begin{array}{l}1720 \\
1800 \\
1810 \\
1940 \\
2040\end{array}$ & $\begin{array}{l}2010 \\
2010 \\
2200 \\
2150 \\
2080\end{array}$ & $\begin{array}{l}2670 \\
2730 \\
2030 \\
2030 \\
1700\end{array}$ & $\begin{array}{l}1680 \\
1390 \\
1380 \\
1650 \\
1800\end{array}$ & $\begin{array}{l}1610 \\
1400 \\
1590 \\
1470 \\
1480\end{array}$ & $\begin{array}{l}1490 \\
1480 \\
1240 \\
1080 \\
1160\end{array}$ & $\begin{array}{l}2900 \\
3460 \\
4040 \\
5210 \\
4450\end{array}$ & $\begin{array}{l}1770 \\
1970 \\
1910 \\
2590 \\
2620\end{array}$ \\
\hline $\begin{array}{l}21 \\
22 \\
23 \\
24 \\
25\end{array}$ & $\begin{array}{l}2830 \\
2700 \\
2880 \\
2870 \\
3010\end{array}$ & $\begin{array}{l}2300 \\
2300 \\
2190 \\
2350 \\
2370\end{array}$ & $\begin{array}{l}2330 \\
2170 \\
2320 \\
2500 \\
2380\end{array}$ & $\begin{array}{l}1960 \\
2300 \\
2200 \\
2150 \\
1180\end{array}$ & $\begin{array}{l}2120 \\
1790 \\
1460 \\
2260 \\
1860\end{array}$ & $\begin{array}{l}2090 \\
1860 \\
2200 \\
2590 \\
2110\end{array}$ & $\begin{array}{l}2050 \\
2430 \\
2380 \\
2460 \\
2190\end{array}$ & $\begin{array}{l}1900 \\
2120 \\
2180 \\
1630 \\
1650\end{array}$ & $\begin{array}{l}1390 \\
1320 \\
1520 \\
1560 \\
1560\end{array}$ & $\begin{array}{l}1390 \\
1580 \\
1670 \\
1370 \\
1500\end{array}$ & $\begin{array}{l}4370 \\
3070 \\
2160 \\
1690 \\
1780\end{array}$ & $\begin{array}{l}2130 \\
2500 \\
2270 \\
2110 \\
1960\end{array}$ \\
\hline $\begin{array}{l}26 \\
27 \\
28 \\
29 \\
30 \\
31\end{array}$ & $\begin{array}{l}3170 \\
2870 \\
2950 \\
3080 \\
2940 \\
2580\end{array}$ & $\begin{array}{l}2750 \\
2670 \\
2540 \\
2510 \\
2270 \\
-\end{array}$ & $\begin{array}{l}2460 \\
2480 \\
1900 \\
2010 \\
2320 \\
2350\end{array}$ & $\begin{array}{l}1200 \\
1600 \\
2150 \\
2250 \\
2880 \\
2470\end{array}$ & $\begin{array}{r}1700 \\
1960 \\
1950 \\
--- \\
--- \\
---\end{array}$ & $\begin{array}{l}2500 \\
2400 \\
2090 \\
2410 \\
1930 \\
2390\end{array}$ & $\begin{array}{l}1720 \\
1770 \\
1980 \\
2250 \\
1820 \\
---\end{array}$ & $\begin{array}{l}1970 \\
1880 \\
1800 \\
2240 \\
1260 \\
1220\end{array}$ & $\begin{array}{l}1640 \\
1570 \\
1380 \\
1450 \\
1580 \\
--\end{array}$ & $\begin{array}{l}1130 \\
1190 \\
1270 \\
1200 \\
1410 \\
1400\end{array}$ & $\begin{array}{l}1700 \\
2000 \\
1820 \\
1600 \\
1610 \\
1580\end{array}$ & $\begin{array}{l}1800 \\
1590 \\
1490 \\
1870 \\
2060\end{array}$ \\
\hline $\begin{array}{l}\text { TOTAL } \\
\text { MEAN } \\
\text { MAX } \\
\text { MIN } \\
\text { CFSM } \\
\text { IN. }\end{array}$ & $\begin{array}{r}121830 \\
3930 \\
6290 \\
2580 \\
2.21 \\
2.55\end{array}$ & $\begin{array}{r}71830 \\
2394 \\
2800 \\
1910 \\
1.35 \\
1.50\end{array}$ & $\begin{array}{r}72470 \\
2338 \\
2720 \\
1900 \\
1.31 \\
1.51\end{array}$ & $\begin{array}{r}65380 \\
2109 \\
2880 \\
1180 \\
1.19 \\
1.37\end{array}$ & $\begin{array}{r}55200 \\
1971 \\
2420 \\
1460 \\
1.11 \\
1.15\end{array}$ & $\begin{array}{r}70600 \\
2277 \\
3120 \\
1860 \\
1.28 \\
1.48\end{array}$ & $\begin{array}{r}63460 \\
2115 \\
2730 \\
1630 \\
1.19 \\
1.33\end{array}$ & $\begin{array}{r}54140 \\
1746 \\
2240 \\
1220 \\
.98 \\
1.13\end{array}$ & $\begin{array}{r}45210 \\
1507 \\
1890 \\
1190 \\
.85 \\
.94\end{array}$ & $\begin{array}{r}43580 \\
1406 \\
1790 \\
1050 \\
.79 \\
.91\end{array}$ & $\begin{array}{r}69910 \\
2255 \\
5210 \\
1150 \\
1.27 \\
1.46\end{array}$ & $\begin{array}{r}55970 \\
1866 \\
2620 \\
1350 \\
1.05 \\
1.17\end{array}$ \\
\hline $\begin{array}{ll}\text { CAL } & \text { YR } \\
\text { WTR } & \text { YR }\end{array}$ & $\begin{array}{l}1986 \\
1987\end{array}$ & $\begin{array}{l}A L \\
A L\end{array}$ & & $\begin{array}{l}266 \\
\text { AN } \\
216\end{array}$ & $\begin{array}{l}\text { MAX } \\
\text { MAX }\end{array}$ & $\begin{array}{l}6660 \\
6290\end{array}$ & $\begin{array}{ll}\text { MIN } & 1240 \\
\text { MIN } & 1050\end{array}$ & $\begin{array}{l}\text { CFSM } \\
\text { CFSM }\end{array}$ & $\begin{array}{l}1.50 \\
1.22\end{array}$ & $\begin{array}{ll}\text { IN } 20.34 \\
\text { IN } 16.50\end{array}$ & & \\
\hline
\end{tabular}




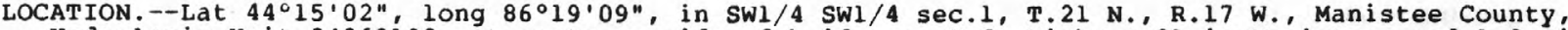
Hydrologic Unit 04060103 , at upstream side of bridge on U.S. Highway 31 in Manistee, and 1.3 mi upstream from mouth.

DRAINAGE AREA. $--2,000 \mathrm{mi}^{2}$, approximately.

PERIOD OF RECORD.--Water years 1974 to current year.

PERIOD OF DAILY RECORD.--

SPECIFIC CONDUCTANCE: November 1974 to September 1981

WATER TEMPERATURE: November 1974 to September 1981.

INSTRUMENTATION.--Water-quality monitor from Mar. 18, 1977 to Sept. 30, 1981.

REMARKS. --Bimonthly cross-sectional samples were collected at Washington Street bridge. Samples for the analyses of stable hydrogen and oxygen isotopes were also collected; analytical results from these samples were not published. Water-discharge measurements were made at time of sampling.

EXTREMES FOR PERIOD OF DAILY RECORD -

SPECIFIC CONDUCTANCE (water years 1975-81): Maximum daily, 1,680 microsiemens, Nov. 18, 1974; minimum, 226 microsiemens, Apr. 22, 1980.

WATER TEMPERATURE (water years 1975-81): Maximum, $26.5^{\circ} \mathrm{C}$, July 8,1981, minimum, $0.0^{\circ} \mathrm{C}$ on many days during winter.

WATER QUALITY DATA, WATER YEAR OCTOBER 1986 TO SEPTEMBER 1987

\begin{tabular}{|c|c|c|c|c|c|c|c|c|c|c|}
\hline DATE & TIME & $\begin{array}{l}\text { STREAM- } \\
\text { FLOW, } \\
\text { INSTAN- } \\
\text { TANEOUS } \\
\text { (CFS) }\end{array}$ & $\begin{array}{l}\text { SPE- } \\
\text { CIFIC } \\
\text { CON- } \\
\text { DUCT- } \\
\text { ANCE } \\
\text { (US/CM) }\end{array}$ & $\begin{array}{c}\text { PH } \\
\text { ( STAND- } \\
\text { ARD } \\
\text { UNITS) }\end{array}$ & $\begin{array}{l}\text { TEMPER- } \\
\text { ATURE } \\
\text { (DEG C) }\end{array}$ & $\begin{array}{l}\text { TUR- } \\
\text { BID- } \\
\text { ITY } \\
\text { (NTU) }\end{array}$ & $\begin{array}{c}\text { OXYGEN, } \\
\text { DIS- } \\
\text { SOLVED } \\
\text { (MG/L) }\end{array}$ & $\begin{array}{l}\text { OXYGEN, } \\
\text { DIS- } \\
\text { SOLVED } \\
\text { (PER- } \\
\text { CENT } \\
\text { SATUR- } \\
\text { ATION) }\end{array}$ & $\begin{array}{l}\text { COLI- } \\
\text { FORM, } \\
\text { FECAL, } \\
0.7 \\
\text { UM-MF } \\
\text { (COLS.' } \\
\text { 100 ML) }\end{array}$ & $\begin{array}{l}\text { STREP- } \\
\text { TOCOCCI } \\
\text { FECAL, } \\
\text { KF AGAR } \\
\text { (COLS. } \\
\text { PER } \\
100 \mathrm{ML} \text { ) }\end{array}$ \\
\hline $\begin{array}{l}\text { NOV } \\
14 \ldots \\
\text { JAN }\end{array}$ & 0930 & 1930 & 465 & 8.05 & 2.5 & 2.4 & 11.2 & 83 & 55 & 22 \\
\hline $\operatorname{MAR}^{16} \cdots$ & 0900 & 1830 & 431 & 8.14 & 1.0 & -- & 14.1 & 101 & K 27 & K35 \\
\hline${ }_{\mathrm{MAY}}^{12 \ldots}$ & 1000 & 3530 & 457 & 8.12 & 2.0 & 3.2 & 13.5 & 98 & 4 & K 8 \\
\hline$\underset{\text { JUN }}{28 \ldots}$ & 0830 & 1920 & 395 & 8.30 & 20.0 & 2.4 & 7.8 & 87 & K63 & K16 \\
\hline UG 30. & 1200 & 2320 & 459 & 8.23 & 22.5 & 1.8 & 8.1 & 95 & 120 & K28 \\
\hline $27 \ldots$ & 0930 & 2790 & 448 & 8.31 & 19.0 & 4.2 & 7.8 & 85 & -- & 47 \\
\hline DATE & $\begin{array}{l}\text { HARD- } \\
\text { NESS } \\
\text { (MG/L } \\
\text { AS } \\
\text { CACO3) }\end{array}$ & $\begin{array}{l}\text { HARD- } \\
\text { NESS } \\
\text { NONCARB } \\
\text { WH WAT } \\
\text { TOT ELD } \\
\text { MG/L AS } \\
\text { CACO3 }\end{array}$ & $\begin{array}{l}\text { CALCIUM } \\
\text { DIS- } \\
\text { SOLVED } \\
\text { (MG/L } \\
\text { AS CA) }\end{array}$ & $\begin{array}{l}\text { MAGNE- } \\
\text { SIUM, } \\
\text { DIS- } \\
\text { SOLVED } \\
\text { (MG/L } \\
\text { AS MG) }\end{array}$ & $\begin{array}{l}\text { SODIUM, } \\
\text { DIS- } \\
\text { SOLVED } \\
\text { (MG/I } \\
\text { AS NA) }\end{array}$ & $\begin{array}{l}\text { PERCENT } \\
\text { SODIUM }\end{array}$ & $\begin{array}{c}\text { SODIUM } \\
\text { AD- } \\
\text { SORP- } \\
\text { TION } \\
\text { RATIO }\end{array}$ & $\begin{array}{l}\text { POTAS- } \\
\text { SIUM, } \\
\text { DIS- } \\
\text { SOLVED } \\
\text { (MG/L } \\
\text { AS K) }\end{array}$ & $\begin{array}{l}\text { BICAR- } \\
\text { BONATE } \\
\text { WH WAT } \\
\text { TOTAL } \\
\text { FIELD } \\
\text { MG/L AS } \\
\text { HCO3 }\end{array}$ & $\begin{array}{l}\text { CAR- } \\
\text { BONATE } \\
\text { WH WAT } \\
\text { TOTAL } \\
\text { FIELD } \\
\text { MG } / L \text { AS } \\
\text { CO3 }\end{array}$ \\
\hline $\begin{array}{l}\text { NOV } \\
14 \ldots \\
\text { JAN }\end{array}$ & 200 & 58 & 57 & 13 & 13 & 13 & 0.4 & 1.5 & 170 & 0 \\
\hline $\operatorname{MAR}^{16} \ldots$ & 170 & 28 & 47 & 12 & 14 & 15 & 0.5 & 1.0 & 170 & 0 \\
\hline$\underset{\operatorname{MAY}}{12} \cdots$ & 190 & 47 & 55 & 13 & 14 & 14 & 0.5 & 1.6 & 180 & 0 \\
\hline$\underset{\text { JUN }}{28}$ & 170 & 30 & 48 & 13 & 10 & 11 & 0.3 & 1.0 & 180 & 0 \\
\hline${ }_{A U G}^{30} \ldots$ & 200 & 32 & 57 & 13 & 14 & 13 & 0.5 & 1.2 & 200 & 0 \\
\hline $27 \ldots$ & 190 & 50 & 55 & 13 & 14 & 14 & 0.5 & 1.4 & 170 & 0 \\
\hline DATE & $\begin{array}{l}\text { ALKA- } \\
\text { LINITY } \\
\text { WH WAT } \\
\text { TOTAL } \\
\text { FIELD } \\
\text { MG/L AS } \\
\text { CACO3 }\end{array}$ & $\begin{array}{c}\text { CARBON } \\
\text { DIOXIDE } \\
\text { DIS- } \\
\text { SOLVED } \\
\text { (MG/L } \\
\text { AS CO2) }\end{array}$ & $\begin{array}{l}\text { SULFATE } \\
\text { DIS- } \\
\text { SOLVED } \\
\text { (MG/I } \\
\text { AS SO4) }\end{array}$ & $\begin{array}{l}\text { CHLO- } \\
\text { RIDE, } \\
\text { DIS- } \\
\text { SOLVED } \\
\text { (MG/L } \\
\text { AS CL) }\end{array}$ & $\begin{array}{l}\text { FLUO- } \\
\text { RIDE, } \\
\text { DIS- } \\
\text { SOLVED } \\
\text { (MG/L } \\
\text { AS F) }\end{array}$ & $\begin{array}{l}\text { SILICA, } \\
\text { DIS- } \\
\text { SOLVED } \\
\text { (MG/L } \\
\text { AS } \\
\text { SIO2) }\end{array}$ & $\begin{array}{l}\text { SOLIDS, } \\
\text { RESIDUE } \\
\text { AT } 180 \\
\text { DEG. C } \\
\text { DIS- } \\
\text { SOLVED } \\
\text { (MG/L) }\end{array}$ & $\begin{array}{l}\text { SOL IDS, } \\
\text { SUM OF } \\
\text { CONSTI- } \\
\text { TUENTS, } \\
\text { DIS- } \\
\text { SOLVED } \\
(M G / L)\end{array}$ & $\begin{array}{c}\text { SOLIDS, } \\
\text { DIS- } \\
\text { SOLVED } \\
\text { (TONS } \\
\text { PER } \\
\text { AC-FT) }\end{array}$ & $\begin{array}{c}\text { SOLIDS, } \\
\text { DIS- } \\
\text { SOLVED } \\
\text { (TONS } \\
\text { PER } \\
\text { DAY) }\end{array}$ \\
\hline $\begin{array}{l}\text { NOV } \\
14 \ldots \\
\text { JAN }\end{array}$ & 138 & 2.4 & 16 & 45 & 0.1 & 8.6 & 232 & 240 & 0.32 & 1210 \\
\hline$\underset{\text { MAR }}{16} \ldots$ & 139 & 2.0 & 14 & 32 & 0.1 & 8.0 & 231 & 210 & 0.31 & 1140 \\
\hline$\underset{\operatorname{MAY}}{12} \cdots$ & 144 & 2.1 & 14 & 38 & 0.1 & 8.1 & 225 & 230 & 0.31 & 2140 \\
\hline JUN & 144 & 1.4 & 11 & 22 & 0.1 & 6.7 & 225 & 200 & 0.31 & 1170 \\
\hline AUG $30 \ldots$ & 164 & 1.9 & 16 & 37 & 0.2 & 7.1 & 234 & 240 & 0.32 & 1470 \\
\hline $27 \ldots$ & 141 & 1.3 & 18 & 44 & 0.1 & 6.6 & 247 & 240 & 0.34 & 1860 \\
\hline
\end{tabular}


04126520 MANISTEE RIVER AT MANISTEE, MI--Continued

WATER QUALITY DATA, WATER YEAR OCTOBER 1986 TO SEPTEMBER 1987

\begin{tabular}{|c|c|c|c|c|c|c|c|c|c|c|}
\hline DATE & $\begin{array}{l}\text { NITRO- } \\
\text { GEN, } \\
\text { NITRITE } \\
\text { DIS- } \\
\text { SOLVED } \\
\text { (MG/L } \\
\text { AS N) }\end{array}$ & $\begin{array}{c}\text { NITRO- } \\
\text { GEN, } \\
\text { NO2+NO3 } \\
\text { DIS- } \\
\text { SOLVED } \\
\text { (MG / } \\
\text { AS N) }\end{array}$ & $\begin{array}{c}\text { NITRO- } \\
\text { GEN, } \\
\text { AMMONIA } \\
\text { TOTAL } \\
\text { (MG/L } \\
\text { AS N) }\end{array}$ & $\begin{array}{l}\text { NITRO- } \\
\text { GEN, } \\
\text { AMMONIA } \\
\text { DIS- } \\
\text { SOLVED } \\
\text { (MG/L } \\
\text { AS N) }\end{array}$ & $\begin{array}{c}\text { NITRO- } \\
\text { GEN, } \\
\text { ORGANIC } \\
\text { TOTAL } \\
\text { (MG/L } \\
\text { AS N) }\end{array}$ & $\begin{array}{l}\text { NITRO- } \\
\text { GEN, AM- } \\
\text { MONIA + } \\
\text { ORGANIC } \\
\text { TOTAL } \\
\text { (MG/L } \\
\text { AS N) }\end{array}$ & $\begin{array}{c}\text { PHOS- } \\
\text { PHORUS, } \\
\text { TOTAL } \\
\text { (MG/L } \\
\text { AS P) }\end{array}$ & $\begin{array}{c}\text { PHOS- } \\
\text { PHORUS, } \\
\text { DIS- } \\
\text { SOLVED } \\
\text { (MG/L } \\
\text { AS P) }\end{array}$ & $\begin{array}{l}\text { PHOS- } \\
\text { PHORUS, } \\
\text { ORTHO, } \\
\text { DIS- } \\
\text { SOLVED } \\
\text { (MG/L } \\
\text { AS P) }\end{array}$ & $\begin{array}{l}\text { ALUM- } \\
\text { INUM, } \\
\text { DIS- } \\
\text { SOLVED } \\
\text { (UG/L } \\
\text { AS AL) }\end{array}$ \\
\hline OV $14 \ldots$ & $<0.01$ & 0.97 & 0.07 & 0.06 & 0.83 & 0.9 & 0.02 & 0.02 & $<0.01$ & $<10$ \\
\hline $\begin{array}{l}\text { JAN } \\
16 \ldots \\
\text { MAR }\end{array}$ & $<0.01$ & 0.31 & 0.07 & 0.06 & 0.43 & 0.5 & 0.02 & 0.01 & $<0.01$ & -- \\
\hline${ }_{\mathrm{MAY}}^{12 \ldots}$ & $<0.01$ & 0.55 & 0.07 & 0.07 & 0.33 & 0.4 & 0.01 & 0.01 & $<0.01$ & 50 \\
\hline${ }_{\text {JUN }}^{28 \ldots}$ & $<0.01$ & 0.14 & 0.01 & $<0.01$ & 0.49 & 0.5 & 0.02 & 0.01 & $<0.01$ & $<10$ \\
\hline UG & $<0.01$ & $<0.10$ & 0.06 & 0.05 & 0.14 & 0.2 & 0.02 & 0.01 & $<0.01$ & -- \\
\hline $27 \ldots$ & $<0.01$ & $<0.10$ & 0.03 & 0.01 & 1.2 & 1.2 & 0.04 & 0.01 & $<0.01$ & $<10$ \\
\hline
\end{tabular}

BERYL-

CHRO-

LIUM,

DIS-

AS BE)

AS $(D)$

MIUM,

DIS-

(UG/L

$\begin{array}{llll}\text { (UG/L } & \text { (UG/L } & \text { (UG/L } & \text { (UG/L } \\ \text { AS AS) } & \text { AS BA) } & \text { AS BE) } & \text { AS CD) }\end{array}$

SOLVED

AS CR)

COBALT, SOLVED

(UG/L

AS CO)

COPPER,
DIS-
SOLVED
(UG/L

IRON,
DIS-
SOLVED
(UG/L

LEAD, LITHIUM

SOLVED SOLVED

UG $/ \mathrm{L}$ (UG/I

AS CU) AS FE) AS PB) AS LI)

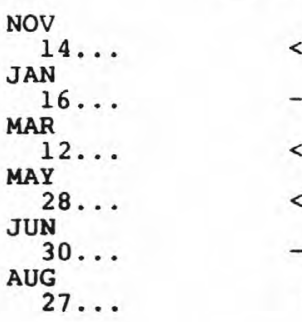

$$
\begin{array}{ll}
<1 & 17 \\
-- & - \\
<1 & 18 \\
<1 & 19 \\
-- & -- \\
1 & 19
\end{array}
$$

$\begin{array}{rr}<0.5 & <1 \\ -- & -- \\ <0.5 & <1 \\ <0.5 & <1 \\ -- & -- \\ <0.5 & <1\end{array}$

MANGA-

$$
\text { NESE, }
$$

NESE，

SOLVED

(UG, L

AS MN)

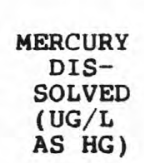

MOLYB-

DENUM, NICKEL,

DIS-

SOLVED SIS-

(UG/L (UG/L

AS MO)

AS NI)

$\begin{array}{ll}<1 & <3 \\ -- & -- \\ <1 & <3 \\ <1 & <3 \\ -- & - \\ <1 & <3\end{array}$

$\begin{array}{rr}<3 & <1 \\ -- & -- \\ <3 & 2 \\ <3 & 1 \\ -- & -- \\ <3 & 11\end{array}$

SELE-

NIUM, SILVER,

DIS-

SOLVED

(UG/L SOLVED

AS SE)

SILVER,

SOLVED

(UG/L

STRON-

TIUM,

DIS-

SOLVED

(UG/L

AS SR)

VANA-

DIUM,

DIS-

SOLVED

AS V)

$84<5$

17

NOV 14.

JAN 14.

$16 \ldots$

MAR ..

MAY 12

JUN $28 \ldots$

JUN $30 .$.

AUG 27 .

$\begin{array}{rrrr}8 & <0.1 & <10 & <1 \\ -- & -- & -- & - \\ 20 & 0.5 & <10 & <1 \\ 3 & 0.2 & <10 & < \\ -- & -- & -- & - \\ 2 & 0.1 & <10 & <1\end{array}$

$\begin{array}{ll}<1 & <1 \\ -- & - \\ <1 & <1 \\ <1 & <1 \\ -- & - \\ <1 & <1\end{array}$

\begin{tabular}{cr}
$<1$ & $<1$ \\
-- & -- \\
$<1$ & $<1$ \\
$<1$ & $<1$ \\
-- & -- \\
$<1$ & $<1$ \\
& \\
& \\
- & SED. \\
\hline SUSP. \\
SIEVE \\
DIAM. \\
O FINER \\
THAN \\
THA \\
.062 MM
\end{tabular}

DATE

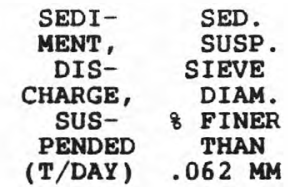

NOV

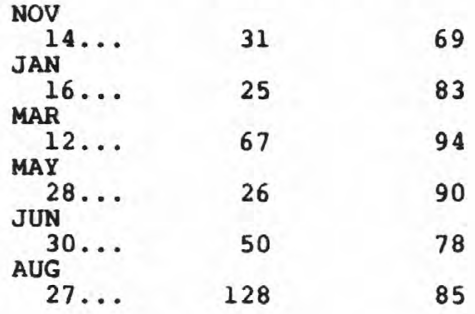




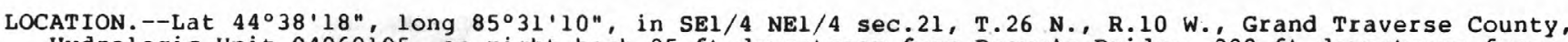
Hydrologic Unit 04060105 , on right bank $25 \mathrm{ft}$ downstream from Brown's Bridge, $300 \mathrm{ft}$ downstream from East Creek, $0.9 \mathrm{mi}$ downstream from Brown's Bridge Dam, $1.0 \mathrm{mi}$ northeast of Mayfield, and $9.6 \mathrm{mi}$ southeast of Traverse City.

DRAINAGE AREA. $--182 \mathrm{mi}^{2}$.

PERIOD OF RECORD.--June 1952 to current year.

REVISED RECORDS.--WDR MI-83: Drainage area.

GAGE.--Water-stage recorder. Elevation of gage is $760 \mathrm{ft}$, by barometer.

REMARKS.--No estimated daily discharges. Records good. Flow regulated by hydroelectric

powerplant $0.9 \mathrm{mi}$ upstream. Several measurements of water temperature were made during the year.

AVERAGE DISCHARGE. --35 years, $196 \mathrm{ft}^{3} / \mathrm{s}, 14.62 \mathrm{in} / \mathrm{yr}$.

EXTREMES FOR PERIOD OF RECORD.--Maximum discharge, 1,220 ft $3 / \mathrm{s}$, Sept. 14, 1961, gage height,

$6.90 \mathrm{ft} ; \mathrm{minimum}, 30 \mathrm{ft} / \mathrm{s}$, Jan. 15 , 1965 , gage height, $2.53 \mathrm{ft} ; \mathrm{minimum}$ daily, $47 \mathrm{ft} / \mathrm{s}$,

Nov. 2, 3, 1963

EXTREMES FOR CURRENT YEAR.--Maximum discharge, 1,100 $\mathrm{ft}^{3} / \mathrm{s}$, Aug. 16, gage height, $6.70 \mathrm{ft} ; \mathrm{minimum,}$

$67 \mathrm{ft}^{3} / \mathrm{s}$, Sept. 1, gage height, $2.81 \mathrm{ft} ;$ minimum daily, $125 \mathrm{ft}^{3} / \mathrm{s}, \mathrm{July} 18,19$.

DISCHARGE, IN CUBIC FEET PER SECOND, WATER YEAR OCTOBER 1986 TO SEPTEMBER 1987 MEÁN VALUES

\begin{tabular}{|c|c|c|c|c|c|c|c|c|c|c|c|c|}
\hline DAY & OCT & NOV & $\mathrm{DEC}$ & JAN & FEB & MAR & APR & MAY & JUN & JUL & AUG & SEP \\
\hline $\begin{array}{l}1 \\
2 \\
3 \\
4 \\
5\end{array}$ & $\begin{array}{l}527 \\
514 \\
493 \\
446 \\
445\end{array}$ & $\begin{array}{l}306 \\
303 \\
298 \\
296 \\
250\end{array}$ & $\begin{array}{l}270 \\
264 \\
265 \\
259 \\
252\end{array}$ & $\begin{array}{l}252 \\
247 \\
248 \\
232 \\
220\end{array}$ & $\begin{array}{l}225 \\
235 \\
217 \\
201 \\
242\end{array}$ & $\begin{array}{l}235 \\
218 \\
222 \\
221 \\
213\end{array}$ & $\begin{array}{l}230 \\
223 \\
223 \\
228 \\
233\end{array}$ & $\begin{array}{l}179 \\
185 \\
188 \\
181 \\
177\end{array}$ & $\begin{array}{l}148 \\
129 \\
158 \\
173 \\
172\end{array}$ & $\begin{array}{l}192 \\
200 \\
188 \\
170 \\
148\end{array}$ & $\begin{array}{l}145 \\
176 \\
165 \\
165 \\
179\end{array}$ & $\begin{array}{l}157 \\
194 \\
227 \\
188 \\
168\end{array}$ \\
\hline $\begin{array}{r}6 \\
7 \\
8 \\
9 \\
10\end{array}$ & $\begin{array}{l}478 \\
460 \\
404 \\
426 \\
363\end{array}$ & $\begin{array}{l}276 \\
295 \\
295 \\
295 \\
271\end{array}$ & $\begin{array}{l}257 \\
262 \\
262 \\
259 \\
265\end{array}$ & $\begin{array}{l}247 \\
272 \\
238 \\
222 \\
214\end{array}$ & $\begin{array}{l}251 \\
209 \\
193 \\
199 \\
203\end{array}$ & $\begin{array}{l}232 \\
266 \\
306 \\
317 \\
287\end{array}$ & $\begin{array}{l}231 \\
233 \\
237 \\
223 \\
208\end{array}$ & $\begin{array}{l}178 \\
178 \\
177 \\
178 \\
179\end{array}$ & $\begin{array}{l}176 \\
144 \\
144 \\
156 \\
131\end{array}$ & $\begin{array}{l}135 \\
142 \\
167 \\
169 \\
160\end{array}$ & $\begin{array}{l}163 \\
138 \\
146 \\
245 \\
249\end{array}$ & $\begin{array}{l}168 \\
169 \\
170 \\
176 \\
179\end{array}$ \\
\hline $\begin{array}{l}11 \\
12 \\
13 \\
14 \\
15\end{array}$ & $\begin{array}{l}332 \\
382 \\
400 \\
353 \\
368\end{array}$ & $\begin{array}{l}257 \\
263 \\
273 \\
250 \\
231\end{array}$ & $\begin{array}{l}252 \\
243 \\
244 \\
247 \\
243\end{array}$ & $\begin{array}{l}243 \\
266 \\
246 \\
228 \\
228\end{array}$ & $\begin{array}{l}214 \\
215 \\
208 \\
217 \\
223\end{array}$ & $\begin{array}{l}270 \\
252 \\
238 \\
222 \\
211\end{array}$ & $\begin{array}{l}208 \\
208 \\
219 \\
218 \\
237\end{array}$ & $\begin{array}{l}191 \\
187 \\
181 \\
180 \\
179\end{array}$ & $\begin{array}{l}142 \\
177 \\
181 \\
179 \\
166\end{array}$ & $\begin{array}{l}142 \\
142 \\
151 \\
162 \\
163\end{array}$ & $\begin{array}{l}162 \\
174 \\
174 \\
180 \\
470\end{array}$ & $\begin{array}{l}196 \\
207 \\
175 \\
178 \\
169\end{array}$ \\
\hline $\begin{array}{l}16 \\
17 \\
18 \\
19 \\
20\end{array}$ & $\begin{array}{l}355 \\
340 \\
339 \\
321 \\
307\end{array}$ & $\begin{array}{l}266 \\
294 \\
293 \\
269 \\
257\end{array}$ & $\begin{array}{l}241 \\
253 \\
263 \\
265 \\
261\end{array}$ & $\begin{array}{l}236 \\
233 \\
225 \\
216 \\
208\end{array}$ & $\begin{array}{l}197 \\
203 \\
201 \\
206 \\
205\end{array}$ & $\begin{array}{l}225 \\
232 \\
232 \\
230 \\
229\end{array}$ & $\begin{array}{l}239 \\
225 \\
212 \\
214 \\
200\end{array}$ & $\begin{array}{l}179 \\
178 \\
178 \\
154 \\
170\end{array}$ & $\begin{array}{l}146 \\
142 \\
139 \\
132 \\
145\end{array}$ & $\begin{array}{l}162 \\
151 \\
125 \\
125 \\
148\end{array}$ & $\begin{array}{l}857 \\
758 \\
532 \\
404 \\
341\end{array}$ & $\begin{array}{l}161 \\
242 \\
221 \\
237 \\
254\end{array}$ \\
\hline $\begin{array}{l}21 \\
22 \\
23 \\
24 \\
25\end{array}$ & $\begin{array}{l}308 \\
306 \\
308 \\
306 \\
301\end{array}$ & $\begin{array}{l}277 \\
267 \\
266 \\
291 \\
297\end{array}$ & $\begin{array}{l}256 \\
260 \\
236 \\
231 \\
240\end{array}$ & $\begin{array}{l}202 \\
208 \\
211 \\
202 \\
207\end{array}$ & $\begin{array}{l}205 \\
204 \\
211 \\
205 \\
192\end{array}$ & $\begin{array}{l}234 \\
236 \\
247 \\
275 \\
284\end{array}$ & $\begin{array}{l}190 \\
193 \\
205 \\
203 \\
200\end{array}$ & $\begin{array}{l}182 \\
198 \\
189 \\
180 \\
179\end{array}$ & $\begin{array}{l}144 \\
165 \\
176 \\
154 \\
157\end{array}$ & $\begin{array}{l}211 \\
179 \\
152 \\
138 \\
137\end{array}$ & $\begin{array}{l}217 \\
299 \\
170 \\
204 \\
226\end{array}$ & $\begin{array}{l}176 \\
190 \\
207 \\
193 \\
166\end{array}$ \\
\hline $\begin{array}{l}26 \\
27 \\
28 \\
29 \\
30 \\
31\end{array}$ & $\begin{array}{l}298 \\
311 \\
303 \\
299 \\
320 \\
316\end{array}$ & $\begin{array}{l}271 \\
269 \\
291 \\
291 \\
288 \\
---\end{array}$ & $\begin{array}{l}236 \\
240 \\
250 \\
235 \\
237 \\
247\end{array}$ & $\begin{array}{l}235 \\
230 \\
227 \\
209 \\
211 \\
226\end{array}$ & $\begin{array}{l}194 \\
217 \\
238 \\
--- \\
--- \\
---\end{array}$ & $\begin{array}{l}268 \\
267 \\
265 \\
263 \\
221 \\
210\end{array}$ & $\begin{array}{l}198 \\
200 \\
199 \\
187 \\
180 \\
---\end{array}$ & $\begin{array}{l}181 \\
180 \\
178 \\
177 \\
176 \\
176\end{array}$ & $\begin{array}{l}188 \\
188 \\
184 \\
188 \\
186 \\
---\end{array}$ & $\begin{array}{l}141 \\
148 \\
145 \\
145 \\
145 \\
144\end{array}$ & $\begin{array}{l}229 \\
177 \\
182 \\
192 \\
195 \\
194\end{array}$ & $\begin{array}{l}172 \\
173 \\
172 \\
178 \\
178 \\
-\end{array}$ \\
\hline $\begin{array}{l}\text { TOTAL } \\
\text { MEAN } \\
\text { MAX } \\
\text { MIN } \\
\text { CFSM } \\
\text { IN. }\end{array}$ & $\begin{array}{r}11429 \\
369 \\
527 \\
298 \\
2.03 \\
2.34\end{array}$ & $\begin{array}{r}8346 \\
278 \\
306 \\
231 \\
1.53 \\
1.71\end{array}$ & $\begin{array}{r}7795 \\
251 \\
270 \\
231 \\
1.38 \\
1.59\end{array}$ & $\begin{array}{r}7089 \\
229 \\
272 \\
202 \\
1.26 \\
1.45\end{array}$ & $\begin{array}{r}5930 \\
212 \\
251 \\
192 \\
1.17 \\
1.21\end{array}$ & $\begin{array}{r}7628 \\
246 \\
317 \\
210 \\
1.35 \\
1.56\end{array}$ & $\begin{array}{r}6404 \\
213 \\
239 \\
180 \\
1.17 \\
1.31\end{array}$ & $\begin{array}{r}5573 \\
180 \\
198 \\
154 \\
.99 \\
1.14\end{array}$ & $\begin{array}{r}4810 \\
160 \\
188 \\
129 \\
.88 \\
.98\end{array}$ & $\begin{array}{r}4827 \\
156 \\
211 \\
125 \\
.86 \\
.99\end{array}$ & $\begin{array}{r}8108 \\
262 \\
857 \\
138 \\
1.44 \\
1.66\end{array}$ & $\begin{array}{r}5641 \\
188 \\
254 \\
157 \\
1.03 \\
1.15\end{array}$ \\
\hline
\end{tabular}

$\begin{array}{lllrlllllll}\text { CAL YR } 1986 & \text { TOTAL } & 102542 & \text { MEAN } 281 & \text { MAX } 751 & \text { MIN } 132 & \text { CFSM } 1.54 & \text { IN } 20.96 \\ \text { WTR YR } 1987 & \text { TOTAL } & 83580 & \text { MEAN } 229 & \text { MAX } 857 & \text { MIN } 125 & \text { CFSM } 1.26 & \text { IN } 17.08\end{array}$ 
LOCATION.--Lat $44^{\circ} 50^{\prime} 43^{\prime \prime}$, long $85^{\circ} 23^{\prime} 33^{\prime \prime}$, in SWl/4 SWl/4 sec.3, T. 28 N., R.9 W., Grand Traverse County, Hydrologic Unit 04060105, at Gay Road, $3.5 \mathrm{mi}$ south of Elk Rapids.

DRAINAGE AREA. $-410 \mathrm{mi}^{2}$, approximately.

PERIOD OF RECORD.--October 1951 to current year.

GAGE.--Water-stage recorder. Datum of gage is $586.25 \mathrm{ft}$ above National Geodetic Vertical Datum of 1929 (levels by Michigan Department of Natural Resources). Prior to June 20, 1952, nonrecording gage at same datum.

REMARKS.--Elk Lake is at the end of a long chain of interconnected lakes and is contiguous with Lake Skegemog. The major inlet to these lakes is Torch River. Smaller inlets include williamsburg, Battle, Barker, and Desmond Creeks. The outlet of Elk Lake is Elk River. Lake elevation controlled by dam at Elk Rapids. Maximum depth $192 \mathrm{ft}$, surface area 7,930 acres. Established legal level; summer, 589.50 $\mathrm{ft}$, winter, $588.90 \mathrm{ft}$, above NGVD.

EXTREMES FOR PERIOD OF RECORD.--Maximum gage height, $3.88 \mathrm{ft}$, Oct. 6,$1986 ; \mathrm{minimum,} 2.08 \mathrm{ft}$, Dec. 30 , 31, 1981 .

EXTREMES FOR CURRENT YEAR.--Maximum gage height, $3.88 \mathrm{ft}$, Oct. 6 ; minimum, $2.52 \mathrm{ft}, \mathrm{Jan} .5$.

GAGE HEIGHT (FEET ABOVE DATUM), WATER YEAR OCTOBER 1986 TO SEPTEMBER 1987

\begin{tabular}{|c|c|c|c|c|c|c|c|c|c|c|c|c|}
\hline DAY & OCT & NOV & DEC & JAN & FEB & MAR & APR & MAY & JUN & JUL & AUG & SEP \\
\hline $\begin{array}{l}1 \\
2 \\
3 \\
4 \\
5\end{array}$ & $\begin{array}{l}3.77 \\
3.76 \\
3.79 \\
3.84 \\
3.84\end{array}$ & $\begin{array}{l}3.02 \\
2.96 \\
2.92 \\
2.90 \\
2.87\end{array}$ & $\begin{array}{l}2.72 \\
2.69 \\
2.67 \\
2.65 \\
2.64\end{array}$ & $\begin{array}{l}2.56 \\
2.56 \\
2.55 \\
2.55 \\
2.55\end{array}$ & $\begin{array}{l}2.81 \\
2.81 \\
2.82 \\
2.83 \\
2.85\end{array}$ & $\begin{array}{l}2.75 \\
2.75 \\
2.75 \\
2.75 \\
2.73\end{array}$ & $\begin{array}{l}3.14 \\
3.14 \\
3.18 \\
3.19 \\
3.18\end{array}$ & $\begin{array}{l}3.16 \\
3.16 \\
3.16 \\
3.15 \\
3.18\end{array}$ & $\begin{array}{l}3.18 \\
3.17 \\
3.15 \\
3.13 \\
3.12\end{array}$ & $\begin{array}{l}3.19 \\
3.19 \\
3.19 \\
3.19 \\
3.18\end{array}$ & $\begin{array}{l}3.12 \\
3.28 \\
3.23 \\
3.22 \\
3.21\end{array}$ & $\begin{array}{l}3.13 \\
3.14 \\
3.13 \\
3.13 \\
3.12\end{array}$ \\
\hline $\begin{array}{r}6 \\
7 \\
8 \\
9 \\
10\end{array}$ & $\begin{array}{l}3.85 \\
3.83 \\
3.83 \\
3.81 \\
3.80\end{array}$ & $\begin{array}{l}2.84 \\
2.82 \\
2.78 \\
2.75 \\
2.78\end{array}$ & $\begin{array}{l}2.64 \\
2.70 \\
2.73 \\
2.71 \\
2.68\end{array}$ & \begin{tabular}{c}
2.56 \\
-- \\
\hdashline- \\
$-\ldots$ \\
-
\end{tabular} & $\begin{array}{l}2.85 \\
2.85 \\
2.85 \\
2.84 \\
2.84\end{array}$ & $\begin{array}{l}2.74 \\
2.73 \\
2.74 \\
2.70 \\
2.67\end{array}$ & $\begin{array}{l}3.19 \\
3.20 \\
3.21 \\
3.21 \\
3.22\end{array}$ & $\begin{array}{l}3.21 \\
3.24 \\
3.25 \\
3.24 \\
3.26\end{array}$ & $\begin{array}{l}3.11 \\
3.10 \\
3.12 \\
3.11 \\
3.11\end{array}$ & $\begin{array}{l}3.17 \\
3.16 \\
3.16 \\
3.18 \\
3.17\end{array}$ & $\begin{array}{l}3.19 \\
3.20 \\
3.17 \\
3.19 \\
3.20\end{array}$ & $\begin{array}{l}3.11 \\
3.13 \\
3.15 \\
3.11 \\
3.08\end{array}$ \\
\hline $\begin{array}{l}11 \\
12 \\
13 \\
14 \\
15\end{array}$ & $\begin{array}{l}3.77 \\
3.80 \\
3.83 \\
3.82 \\
3.77\end{array}$ & $\begin{array}{l}2.76 \\
2.75 \\
2.77 \\
2.75 \\
2.74\end{array}$ & $\begin{array}{l}2.67 \\
2.67 \\
2.67 \\
2.65 \\
2.63\end{array}$ & $\begin{array}{r}--- \\
--- \\
--- \\
-\overline{2.65}\end{array}$ & $\begin{array}{l}2.84 \\
2.83 \\
2.82 \\
2.81 \\
2.80\end{array}$ & $\begin{array}{l}2.62 \\
2.60 \\
2.60 \\
2.61 \\
2.61\end{array}$ & $\begin{array}{l}3.23 \\
3.22 \\
3.21 \\
3.19 \\
3.18\end{array}$ & $\begin{array}{l}3.27 \\
3.27 \\
3.24 \\
3.23 \\
3.23\end{array}$ & $\begin{array}{l}3.12 \\
3.14 \\
3.16 \\
3.17 \\
3.17\end{array}$ & $\begin{array}{l}3.16 \\
3.18 \\
3.16 \\
3.13 \\
3.11\end{array}$ & $\begin{array}{l}3.19 \\
3.14 \\
3.09 \\
3.10 \\
3.17\end{array}$ & $\begin{array}{l}3.11 \\
3.12 \\
3.09 \\
3.06 \\
3.03\end{array}$ \\
\hline $\begin{array}{l}16 \\
17 \\
18 \\
19 \\
20\end{array}$ & $\begin{array}{l}3.70 \\
3.64 \\
3.57 \\
3.50 \\
3.45\end{array}$ & $\begin{array}{l}2.73 \\
2.73 \\
2.73 \\
2.73 \\
2.73\end{array}$ & $\begin{array}{l}2.62 \\
2.60 \\
2.60 \\
2.62 \\
2.60\end{array}$ & $\begin{array}{l}2.63 \\
2.61 \\
2.63 \\
2.65 \\
2.67\end{array}$ & $\begin{array}{l}2.80 \\
2.81 \\
2.83 \\
2.83 \\
\end{array}$ & $\begin{array}{l}2.61 \\
2.64 \\
2.66 \\
2.69 \\
2.74\end{array}$ & $\begin{array}{l}3.15 \\
3.13 \\
3.14 \\
3.17 \\
3.19\end{array}$ & $\begin{array}{l}3.22 \\
3.21 \\
3.22 \\
3.22 \\
3.22\end{array}$ & $\begin{array}{l}3.16 \\
3.16 \\
3.16 \\
3.16 \\
3.17\end{array}$ & $\begin{array}{l}3.11 \\
3.10 \\
3.09 \\
3.09 \\
3.10\end{array}$ & $\begin{array}{l}3.32 \\
3.44 \\
3.38 \\
3.30 \\
3.23\end{array}$ & $\begin{array}{l}3.04 \\
3.12 \\
3.12 \\
3.14 \\
3.13\end{array}$ \\
\hline $\begin{array}{l}21 \\
22 \\
23 \\
24 \\
25\end{array}$ & $\begin{array}{l}3.39 \\
3.35 \\
3.31 \\
3.27 \\
3.22\end{array}$ & $\begin{array}{l}2.72 \\
2.71 \\
2.70 \\
2.70 \\
2.69\end{array}$ & $\begin{array}{l}2.58 \\
2.56 \\
2.59 \\
2.59 \\
2.58\end{array}$ & $\begin{array}{l}2.69 \\
2.67 \\
2.67 \\
2.67 \\
2.67\end{array}$ & $\begin{array}{r}--- \\
--- \\
--- \\
.72\end{array}$ & $\begin{array}{l}2.78 \\
2.82 \\
2.85 \\
2.89 \\
2.93\end{array}$ & $\begin{array}{l}3.19 \\
3.19 \\
3.19 \\
3.18 \\
3.17\end{array}$ & $\begin{array}{l}3.21 \\
3.22 \\
3.22 \\
3.21 \\
3.20\end{array}$ & $\begin{array}{l}3.16 \\
3.15 \\
3.14 \\
3.13 \\
3.17\end{array}$ & $\begin{array}{l}3.15 \\
3.17 \\
3.16 \\
3.15 \\
3.16\end{array}$ & $\begin{array}{l}3.16 \\
3.11 \\
3.11 \\
3.10 \\
3.10\end{array}$ & $\begin{array}{l}3.11 \\
3.10 \\
3.10 \\
3.12 \\
3.13\end{array}$ \\
\hline $\begin{array}{l}26 \\
27 \\
28 \\
29 \\
30 \\
31\end{array}$ & $\begin{array}{l}3.18 \\
3.15 \\
3.11 \\
3.09 \\
3.09 \\
3.05\end{array}$ & $\begin{array}{l}2.68 \\
2.66 \\
2.67 \\
2.72 \\
2.73 \\
-\end{array}$ & $\begin{array}{l}2.58 \\
2.57 \\
2.56 \\
2.56 \\
2.56 \\
2.56\end{array}$ & $\begin{array}{l}2.68 \\
2.72 \\
2.73 \\
2.75 \\
2.80 \\
2.81\end{array}$ & $\begin{array}{r}2.73 \\
2.73 \\
2.73 \\
---- \\
-- \\
---\end{array}$ & $\begin{array}{l}2.97 \\
3.00 \\
3.03 \\
3.07 \\
3.10 \\
3.12\end{array}$ & $\begin{array}{l}3.15 \\
3.14 \\
3.15 \\
3.16 \\
3.16 \\
-\end{array}$ & $\begin{array}{l}3.22 \\
3.22 \\
3.22 \\
3.22 \\
3.21 \\
3.19\end{array}$ & $\begin{array}{l}3.20 \\
3.18 \\
3.16 \\
3.20 \\
3.20 \\
-\end{array}$ & $\begin{array}{l}3.15 \\
3.14 \\
3.14 \\
3.13 \\
3.13 \\
3.12\end{array}$ & $\begin{array}{l}3.12 \\
3.12 \\
3.13 \\
3.12 \\
3.14 \\
3.14\end{array}$ & $\begin{array}{l}3.12 \\
3.12 \\
3.10 \\
3.11 \\
3.12 \\
-\end{array}$ \\
\hline $\begin{array}{l}\text { MEAN } \\
\text { MAX } \\
\text { MIN }\end{array}$ & $\begin{array}{l}3.55 \\
3.85 \\
3.05\end{array}$ & $\begin{array}{l}2.77 \\
3.02 \\
2.66\end{array}$ & $\begin{array}{l}2.63 \\
2.73 \\
2.56\end{array}$ & $\begin{array}{l}--- \\
--- \\
---\end{array}$ & $\begin{array}{l}--- \\
--- \\
---\end{array}$ & $\begin{array}{l}2.78 \\
3.12 \\
2.60\end{array}$ & $\begin{array}{l}3.18 \\
3.23 \\
3.13\end{array}$ & $\begin{array}{l}3.22 \\
3.27 \\
3.15\end{array}$ & $\begin{array}{l}3.15 \\
3.20 \\
3.10\end{array}$ & $\begin{array}{l}3.15 \\
3.19 \\
3.09\end{array}$ & $\begin{array}{l}3.18 \\
3.44 \\
3.09\end{array}$ & $\begin{array}{l}3.11 \\
3.15 \\
3.03\end{array}$ \\
\hline
\end{tabular}




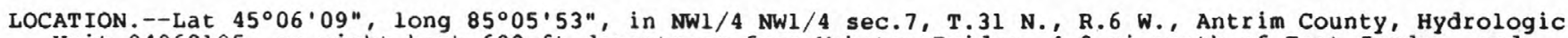
Unit 04060105 , on right bank $600 \mathrm{ft}$ downstream from Webster Bridge, $4.2 \mathrm{mi}$ south of East Jordan, and $4.5 \mathrm{mi}$ upstream from mouth.

DRAINAGE AREA. $--67.9 \mathrm{mi}^{2}$.

PERIOD OF RECORD.--Occasional low-flow measurements, water years 1960-65. October 1966 to current year. REVISED RECORDS.--WDR MI-83: Drainage area.

GAGE.--Water-stage recorder. Elevation of gage is $610 \mathrm{ft}$ above National Geodetic Vertical Datum of 1929 , from topographic map. Nov. 19, 1959 to Sept. 30, 1966, nonrecording gage at present site and at site $600 \mathrm{ft}$ upstream at same datum.

REMARKS.--Estimated daily discharges: Jan. 24-28 and Feb. 16-18. Records good except for estimated daily discharges, which are fair. Some regulation at low flow by fish hatchery upstream from station. Several measurements of water temperature were made during the year.

AVERAGE DISCHARGE.--21 years, $188 \mathrm{ft}^{3} / \mathrm{s}, 37.60 \mathrm{in} / \mathrm{yr}^{\circ}$

EXTREMES FOR PERIOD OF RECORD.--Maximum discharge, 1, $360 \mathrm{ft}^{3} / \mathrm{s}$, July 19, 1975, gage height, 6.51 ft; minimum, $91 \mathrm{ft} / \mathrm{s}$, Mar. 8, 1982, result of freezeup.

EXTREMES FOR CURRENT YEAR.--Peak discharges greater than base discharge of $400 \mathrm{ft} 3 / \mathrm{s}$ and maximum (*):

\begin{tabular}{|c|c|c|c|c|c|c|c|c|}
\hline Date & Time & $\begin{array}{c}\text { Discharge } \\
\left(\mathrm{ft}^{3} / \mathrm{s}\right)\end{array}$ & $\begin{array}{l}\text { Gage height } \\
\text { (ft) }\end{array}$ & Date & & Time & $\begin{array}{c}\text { Discharge } \\
\left(\mathrm{ft}^{3} / \mathrm{s}\right)\end{array}$ & $\begin{array}{c}\text { Gage height } \\
(\mathrm{ft})\end{array}$ \\
\hline $\begin{array}{lr}\text { Oct. } & 3 \\
\text { Oct. } & 12\end{array}$ & $\begin{array}{l}1600 \\
2200\end{array}$ & $\begin{array}{r}* 785 \\
420\end{array}$ & $\begin{array}{r}\star 5.53 \\
4.66\end{array}$ & July & 10 & 0500 & 611 & 5.09 \\
\hline
\end{tabular}

Minimum discharge, $123 \mathrm{ft}^{3} / \mathrm{s}, \mathrm{Feb} .15$, gage height, $2.86 \mathrm{ft}$, result of freezeup.

DISCHARGE, IN CUBIC FEET PER SECOND, WATER YEAR OCTOBER 1986 TO SEPTEMBER 1987 MEAN VALUES

\begin{tabular}{|c|c|c|c|c|c|c|c|c|c|c|c|c|}
\hline DAY & OCT & NOV & DEC & JAN & FEB & MAR & APR & MAY & JUN & JUL & AUG & SEP \\
\hline $\begin{array}{l}1 \\
2 \\
3 \\
4 \\
5\end{array}$ & $\begin{array}{l}209 \\
197 \\
524 \\
373 \\
307\end{array}$ & $\begin{array}{l}225 \\
210 \\
194 \\
195 \\
189\end{array}$ & $\begin{array}{l}182 \\
186 \\
198 \\
198 \\
193\end{array}$ & $\begin{array}{l}187 \\
189 \\
185 \\
183 \\
183\end{array}$ & $\begin{array}{l}180 \\
182 \\
183 \\
180 \\
175\end{array}$ & $\begin{array}{l}187 \\
196 \\
183 \\
178 \\
182\end{array}$ & $\begin{array}{l}181 \\
188 \\
187 \\
189 \\
199\end{array}$ & $\begin{array}{l}171 \\
170 \\
169 \\
168 \\
169\end{array}$ & $\begin{array}{l}159 \\
159 \\
159 \\
157 \\
164\end{array}$ & $\begin{array}{l}168 \\
165 \\
167 \\
167 \\
166\end{array}$ & $\begin{array}{l}158 \\
218 \\
170 \\
181 \\
165\end{array}$ & $\begin{array}{l}162 \\
164 \\
161 \\
157 \\
155\end{array}$ \\
\hline $\begin{array}{r}6 \\
7 \\
8 \\
9 \\
10\end{array}$ & $\begin{array}{l}292 \\
222 \\
250 \\
221 \\
202\end{array}$ & $\begin{array}{l}189 \\
188 \\
189 \\
191 \\
188\end{array}$ & $\begin{array}{l}192 \\
188 \\
187 \\
188 \\
189\end{array}$ & $\begin{array}{l}184 \\
188 \\
184 \\
183 \\
183\end{array}$ & $\begin{array}{l}180 \\
179 \\
181 \\
178 \\
178\end{array}$ & $\begin{array}{l}192 \\
241 \\
286 \\
249 \\
185\end{array}$ & $\begin{array}{l}201 \\
194 \\
186 \\
182 \\
181\end{array}$ & $\begin{array}{l}169 \\
169 \\
168 \\
170 \\
172\end{array}$ & $\begin{array}{l}162 \\
164 \\
164 \\
163 \\
161\end{array}$ & $\begin{array}{l}166 \\
166 \\
165 \\
222 \\
376\end{array}$ & $\begin{array}{l}159 \\
158 \\
157 \\
167 \\
163\end{array}$ & $\begin{array}{l}153 \\
156 \\
164 \\
160 \\
156\end{array}$ \\
\hline $\begin{array}{l}11 \\
12 \\
13 \\
14 \\
15\end{array}$ & $\begin{array}{l}199 \\
282 \\
291 \\
243 \\
306\end{array}$ & $\begin{array}{l}190 \\
189 \\
191 \\
189 \\
191\end{array}$ & $\begin{array}{l}187 \\
188 \\
185 \\
185 \\
187\end{array}$ & $\begin{array}{l}182 \\
181 \\
180 \\
181 \\
180\end{array}$ & $\begin{array}{l}176 \\
179 \\
176 \\
176 \\
159\end{array}$ & $\begin{array}{l}179 \\
175 \\
174 \\
177 \\
177\end{array}$ & $\begin{array}{l}182 \\
179 \\
178 \\
178 \\
185\end{array}$ & $\begin{array}{l}170 \\
166 \\
165 \\
168 \\
172\end{array}$ & $\begin{array}{l}167 \\
195 \\
167 \\
162 \\
160\end{array}$ & $\begin{array}{l}184 \\
181 \\
172 \\
170 \\
168\end{array}$ & $\begin{array}{l}157 \\
156 \\
155 \\
161 \\
207\end{array}$ & $\begin{array}{l}169 \\
186 \\
171 \\
172 \\
160\end{array}$ \\
\hline $\begin{array}{l}16 \\
17 \\
18 \\
19 \\
20\end{array}$ & $\begin{array}{l}240 \\
218 \\
204 \\
200 \\
198\end{array}$ & $\begin{array}{l}193 \\
194 \\
191 \\
184 \\
188\end{array}$ & $\begin{array}{l}189 \\
193 \\
208 \\
205 \\
194\end{array}$ & $\begin{array}{l}175 \\
168 \\
175 \\
174 \\
175\end{array}$ & $\begin{array}{l}162 \\
168 \\
170 \\
172 \\
173\end{array}$ & $\begin{array}{l}177 \\
178 \\
181 \\
186 \\
192\end{array}$ & $\begin{array}{l}184 \\
180 \\
175 \\
174 \\
172\end{array}$ & $\begin{array}{l}168 \\
165 \\
167 \\
182 \\
179\end{array}$ & $\begin{array}{l}158 \\
157 \\
157 \\
157 \\
157\end{array}$ & $\begin{array}{l}166 \\
165 \\
161 \\
161 \\
166\end{array}$ & $\begin{array}{l}222 \\
242 \\
173 \\
167 \\
159\end{array}$ & $\begin{array}{l}158 \\
167 \\
177 \\
199 \\
184\end{array}$ \\
\hline $\begin{array}{l}21 \\
22 \\
23 \\
24 \\
25\end{array}$ & $\begin{array}{l}196 \\
194 \\
193 \\
190 \\
190\end{array}$ & $\begin{array}{l}190 \\
195 \\
212 \\
224 \\
199\end{array}$ & $\begin{array}{l}188 \\
185 \\
188 \\
187 \\
187\end{array}$ & $\begin{array}{l}176 \\
177 \\
166 \\
170 \\
175\end{array}$ & $\begin{array}{l}175 \\
177 \\
180 \\
178 \\
176\end{array}$ & $\begin{array}{l}192 \\
196 \\
202 \\
209 \\
215\end{array}$ & $\begin{array}{l}171 \\
177 \\
181 \\
174 \\
170\end{array}$ & $\begin{array}{l}173 \\
178 \\
173 \\
172 \\
169\end{array}$ & $\begin{array}{l}157 \\
160 \\
158 \\
156 \\
202\end{array}$ & $\begin{array}{l}184 \\
166 \\
161 \\
164 \\
162\end{array}$ & $\begin{array}{l}156 \\
155 \\
156 \\
154 \\
154\end{array}$ & $\begin{array}{l}187 \\
179 \\
167 \\
162 \\
160\end{array}$ \\
\hline $\begin{array}{l}26 \\
27 \\
28 \\
29 \\
30 \\
31\end{array}$ & $\begin{array}{l}192 \\
200 \\
194 \\
191 \\
188 \\
187\end{array}$ & $\begin{array}{l}196 \\
192 \\
191 \\
191 \\
186 \\
---\end{array}$ & $\begin{array}{l}186 \\
184 \\
184 \\
185 \\
188 \\
187\end{array}$ & $\begin{array}{l}178 \\
178 \\
178 \\
178 \\
183 \\
180\end{array}$ & $\begin{array}{l}176 \\
177 \\
179 \\
--- \\
---\end{array}$ & $\begin{array}{l}209 \\
197 \\
192 \\
192 \\
201 \\
185\end{array}$ & $\begin{array}{l}170 \\
183 \\
180 \\
174 \\
172 \\
-\end{array}$ & $\begin{array}{l}192 \\
177 \\
166 \\
165 \\
162 \\
161\end{array}$ & $\begin{array}{l}202 \\
191 \\
176 \\
197 \\
174 \\
-\end{array}$ & $\begin{array}{l}160 \\
157 \\
156 \\
156 \\
156 \\
155\end{array}$ & $\begin{array}{l}154 \\
155 \\
155 \\
157 \\
170 \\
172\end{array}$ & $\begin{array}{l}160 \\
160 \\
158 \\
178 \\
182 \\
--\end{array}$ \\
\hline $\begin{array}{l}\text { TOTAL } \\
\text { MEAN } \\
\text { MAX } \\
\text { MIN } \\
\text { CFSM } \\
\text { IN. }\end{array}$ & $\begin{array}{r}7293 \\
235 \\
524 \\
187 \\
3.46 \\
4.00\end{array}$ & $\begin{array}{r}5834 \\
194 \\
225 \\
184 \\
2.86 \\
3.20\end{array}$ & $\begin{array}{r}5871 \\
189 \\
208 \\
182 \\
2.78 \\
3.22\end{array}$ & $\begin{array}{r}5559 \\
179 \\
189 \\
166 \\
2.64 \\
3.05\end{array}$ & $\begin{array}{r}4925 \\
176 \\
183 \\
159 \\
2.59 \\
2.70\end{array}$ & $\begin{array}{r}6065 \\
196 \\
286 \\
174 \\
2.89 \\
3.32\end{array}$ & $\begin{array}{r}5427 \\
181 \\
201 \\
170 \\
2.67 \\
2.97\end{array}$ & $\begin{array}{r}5285 \\
170 \\
192 \\
161 \\
2.50 \\
2.90\end{array}$ & $\begin{array}{r}5022 \\
167 \\
202 \\
156 \\
2.46 \\
2.75\end{array}$ & $\begin{array}{r}5399 \\
174 \\
376 \\
155 \\
2.56 \\
2.96\end{array}$ & $\begin{array}{r}5233 \\
169 \\
242 \\
154 \\
2.49 \\
2.87\end{array}$ & $\begin{array}{r}5024 \\
167 \\
199 \\
153 \\
2.46 \\
2.75\end{array}$ \\
\hline
\end{tabular}

$\begin{array}{lllllllllll}\text { CAL YR } 1986 & \text { TOTAL } & 73695 & \text { MEAN } 202 & \text { MAX } 726 & \text { MIN 150 } & \text { CFSM } 2.98 & \text { IN } 40.37 \\ \text { WTR YR } 1987 & \text { TOTAL } & 66937 & \text { MEAN } 183 & \text { MAX 524 } & \text { MIN 153 } & \text { CFSM } 2.70 & \text { IN } 36.67\end{array}$ 


\section{PINE RIVER NEAR RUDYARD, MI}

LOCATION,--Lat $46^{\circ} 11^{\prime} 09^{\prime \prime}$, long $84^{\circ} 35^{\prime} 52^{\prime \prime}$, in NWl/4 NEl/4 sec. $30, T .44$ N., R. 2 W. Chippewa County, Hydrologic Unit 04070002 , on right bank $15 \mathrm{ft}$ upstream from county highway bridge, $3.2 \mathrm{mi}$ south of Rudyard.

DRAINAGE AREA. $--184 \mathrm{mi}^{2}$.

PERIOD OF RECORD.--April 1972 to current year.

GAGE.--Water-stage recorder. Elevation of gage is $600 \mathrm{ft}$ above National Geodetic Vertical Datum of 1929. from topographic map. Prior to Aug. 4, 1972, nonrecording gage at same site and datum.

REMARKS.--Estimated daily discharges: Nov. 11-19, Nov. 30 to Dec. 21, Jan. 3-5, 9-11, Jan. 16 to Mar. 6, Mar. 9-18, and Mar. 29 to Apr. 4. Records good except for estimated daily discharges, which are fair. Several measurements of water temperature were made during the year.

AVERAGE DISCHARGE.--15 years, $235 \mathrm{ft}^{3} / \mathrm{s}, 17.34 \mathrm{in} / \mathrm{yr}^{\circ}$

EXTREMES FOR PERIOD OF RECORD.--Maximum discharge, 4,500 ft $3 / \mathrm{s}$, Mar. 30, 1986, gage height, $18.44 \mathrm{ft}$; minimum, $51 \mathrm{ft} / \mathrm{s}$, July 29, Aug. 14, 1987; minimum gage height, $1.83 \mathrm{ft}, \mathrm{July} 29,30,1982$.

EXTREMES OUTSIDE PERIOD OF RECORD.--A discharge of $50.3 \mathrm{ft}^{3} / \mathrm{s}$ was measured Aug. 6 , 1963 .

EXTREMES FOR CURRENT YEAR,--Peak discharges greater than base discharge of $1,200 \mathrm{ft}^{3} / \mathrm{s}^{2}$ and maximum (*):

\begin{tabular}{|c|c|c|c|c|c|c|c|}
\hline Date & Time & $\begin{array}{c}\text { Discharge } \\
\left(\mathrm{ft}^{3} / \mathrm{s}\right)\end{array}$ & $\begin{array}{c}\text { Gage height } \\
(f t)\end{array}$ & Date & Time & $\begin{array}{c}\text { Discharge } \\
\left(\mathrm{ft}^{3} / \mathrm{s}\right)\end{array}$ & $\begin{array}{c}\text { Gage height } \\
(f t)\end{array}$ \\
\hline
\end{tabular}

Mar. $242400 \quad \star 1,580 \quad \star 8.37 \quad$ No other peak greater than base discharge.

Minimum discharge, $51 \mathrm{ft}^{3} / \mathrm{s}$, July 29 , Aug. 14, gage height, $1.95 \mathrm{ft}$.

DISCHARGE, IN CUBIC FEET PER SECOND, WATER YEAR OCTOBER 1986 TO SEPTEMBER 1987 MEAN VALUES

\begin{tabular}{|c|c|c|c|c|c|c|c|c|c|c|c|c|}
\hline DAY & OCT & NOV & DEC & JAN & FEB & MAR & APR & MAY & JUN & JUL & AUG & SEP \\
\hline $\begin{array}{l}1 \\
2 \\
3 \\
4 \\
5\end{array}$ & $\begin{array}{l}155 \\
138 \\
127 \\
135 \\
130\end{array}$ & $\begin{array}{l}151 \\
157 \\
149 \\
145 \\
136\end{array}$ & $\begin{array}{l}205 \\
190 \\
165 \\
160 \\
155\end{array}$ & $\begin{array}{l}120 \\
122 \\
120 \\
115 \\
115\end{array}$ & $\begin{array}{l}86 \\
86 \\
86 \\
85 \\
84\end{array}$ & $\begin{array}{l}82 \\
82 \\
80 \\
78 \\
88\end{array}$ & $\begin{array}{l}300 \\
250 \\
270 \\
250 \\
381\end{array}$ & $\begin{array}{l}146 \\
135 \\
125 \\
118 \\
113\end{array}$ & $\begin{array}{l}98 \\
95 \\
99 \\
88 \\
83\end{array}$ & $\begin{array}{l}74 \\
68 \\
66 \\
66 \\
65\end{array}$ & $\begin{array}{r}61 \\
85 \\
114 \\
93 \\
76\end{array}$ & $\begin{array}{r}108 \\
91 \\
85 \\
77 \\
72\end{array}$ \\
\hline $\begin{array}{r}6 \\
7 \\
8 \\
9 \\
10\end{array}$ & $\begin{array}{l}174 \\
164 \\
246 \\
240 \\
192\end{array}$ & $\begin{array}{l}133 \\
135 \\
133 \\
137 \\
132\end{array}$ & $\begin{array}{l}150 \\
145 \\
140 \\
135 \\
130\end{array}$ & $\begin{array}{l}111 \\
111 \\
111 \\
110 \\
110\end{array}$ & $\begin{array}{l}88 \\
87 \\
84 \\
76 \\
84\end{array}$ & $\begin{array}{l}105 \\
125 \\
222 \\
240 \\
195\end{array}$ & $\begin{array}{l}547 \\
483 \\
427 \\
371 \\
341\end{array}$ & $\begin{array}{r}108 \\
103 \\
100 \\
95 \\
93\end{array}$ & $\begin{array}{r}81 \\
124 \\
161 \\
141 \\
120\end{array}$ & $\begin{array}{l}61 \\
59 \\
58 \\
64 \\
86\end{array}$ & $\begin{array}{l}67 \\
61 \\
58 \\
54 \\
57\end{array}$ & $\begin{array}{l}66 \\
62 \\
61 \\
59 \\
59\end{array}$ \\
\hline $\begin{array}{l}11 \\
12 \\
13 \\
14 \\
15\end{array}$ & $\begin{array}{l}163 \\
462 \\
759 \\
501 \\
394\end{array}$ & $\begin{array}{l}115 \\
115 \\
115 \\
115 \\
115\end{array}$ & $\begin{array}{l}125 \\
125 \\
120 \\
120 \\
125\end{array}$ & $\begin{array}{l}105 \\
106 \\
105 \\
105 \\
105\end{array}$ & $\begin{array}{l}83 \\
82 \\
80 \\
78 \\
76\end{array}$ & $\begin{array}{l}170 \\
150 \\
135 \\
125 \\
120\end{array}$ & $\begin{array}{l}329 \\
307 \\
280 \\
260 \\
317\end{array}$ & $\begin{array}{r}99 \\
105 \\
97 \\
93 \\
102\end{array}$ & $\begin{array}{l}120 \\
227 \\
192 \\
151 \\
120\end{array}$ & $\begin{array}{r}110 \\
107 \\
108 \\
79 \\
68\end{array}$ & $\begin{array}{l}62 \\
57 \\
54 \\
53 \\
58\end{array}$ & $\begin{array}{l}58 \\
59 \\
60 \\
65 \\
63\end{array}$ \\
\hline $\begin{array}{l}16 \\
17 \\
18 \\
19 \\
20\end{array}$ & $\begin{array}{l}320 \\
278 \\
237 \\
212 \\
198\end{array}$ & $\begin{array}{l}115 \\
115 \\
115 \\
115 \\
118\end{array}$ & $\begin{array}{l}125 \\
130 \\
130 \\
125 \\
120\end{array}$ & $\begin{array}{r}100 \\
98 \\
96 \\
94 \\
92\end{array}$ & $\begin{array}{l}70 \\
80 \\
80 \\
80 \\
82\end{array}$ & $\begin{array}{l}115 \\
110 \\
115 \\
131 \\
184\end{array}$ & $\begin{array}{l}326 \\
287 \\
256 \\
229 \\
206\end{array}$ & $\begin{array}{r}98 \\
93 \\
94 \\
115 \\
126\end{array}$ & $\begin{array}{r}100 \\
88 \\
79 \\
74 \\
72\end{array}$ & $\begin{array}{l}62 \\
58 \\
56 \\
56 \\
75\end{array}$ & $\begin{array}{r}77 \\
87 \\
89 \\
105 \\
103\end{array}$ & $\begin{array}{l}60 \\
59 \\
57 \\
58 \\
88\end{array}$ \\
\hline $\begin{array}{l}21 \\
22 \\
23 \\
24 \\
25\end{array}$ & $\begin{array}{l}186 \\
176 \\
170 \\
162 \\
153\end{array}$ & $\begin{array}{l}120 \\
124 \\
156 \\
263 \\
256\end{array}$ & $\begin{array}{l}118 \\
115 \\
120 \\
117 \\
117\end{array}$ & $\begin{array}{l}88 \\
84 \\
76 \\
70 \\
80\end{array}$ & $\begin{array}{l}82 \\
82 \\
82 \\
82 \\
82\end{array}$ & $\begin{array}{r}368 \\
656 \\
938 \\
1270 \\
1370\end{array}$ & $\begin{array}{l}191 \\
190 \\
256 \\
255 \\
211\end{array}$ & $\begin{array}{l}121 \\
167 \\
178 \\
160 \\
137\end{array}$ & $\begin{array}{l}68 \\
65 \\
65 \\
62 \\
71\end{array}$ & $\begin{array}{l}71 \\
62 \\
57 \\
56 \\
74\end{array}$ & $\begin{array}{l}88 \\
81 \\
73 \\
67 \\
62\end{array}$ & $\begin{array}{l}219 \\
227 \\
174 \\
138 \\
114\end{array}$ \\
\hline $\begin{array}{l}26 \\
27 \\
28 \\
29 \\
30 \\
31\end{array}$ & $\begin{array}{l}148 \\
150 \\
161 \\
158 \\
154 \\
146\end{array}$ & $\begin{array}{l}271 \\
256 \\
247 \\
240 \\
225 \\
---\end{array}$ & $\begin{array}{l}117 \\
116 \\
115 \\
115 \\
117 \\
119\end{array}$ & $\begin{array}{l}82 \\
82 \\
82 \\
82 \\
82 \\
84\end{array}$ & $\begin{array}{r}82 \\
82 \\
82 \\
--- \\
--- \\
---\end{array}$ & $\begin{array}{l}904 \\
663 \\
565 \\
500 \\
430 \\
350\end{array}$ & $\begin{array}{l}184 \\
185 \\
205 \\
185 \\
162 \\
-\end{array}$ & $\begin{array}{l}145 \\
202 \\
178 \\
147 \\
124 \\
108\end{array}$ & $\begin{array}{r}136 \\
114 \\
92 \\
81 \\
78 \\
---\end{array}$ & $\begin{array}{l}74 \\
63 \\
56 \\
53 \\
57 \\
65\end{array}$ & $\begin{array}{r}59 \\
57 \\
56 \\
54 \\
62 \\
119\end{array}$ & $\begin{array}{r}101 \\
91 \\
86 \\
95 \\
113 \\
\end{array}$ \\
\hline $\begin{array}{l}\text { TOTAL } \\
\text { MEAN } \\
\text { MAX } \\
\text { MIN } \\
\text { CFSM } \\
\text { IN. }\end{array}$ & $\begin{array}{r}6989 \\
225 \\
759 \\
127 \\
1.22 \\
1.41\end{array}$ & $\begin{array}{r}4719 \\
157 \\
271 \\
115 \\
.85 \\
.95\end{array}$ & $\begin{array}{r}4106 \\
132 \\
205 \\
115 \\
.72 \\
.83\end{array}$ & $\begin{array}{r}3043 \\
98.2 \\
122 \\
70 \\
.53 \\
.62\end{array}$ & $\begin{array}{r}2293 \\
81.9 \\
88 \\
70 \\
.45 \\
.46\end{array}$ & $\begin{array}{r}10666 \\
344 \\
1370 \\
78 \\
1.87 \\
2.16\end{array}$ & $\begin{array}{r}8441 \\
281 \\
547 \\
162 \\
1.53 \\
1.71\end{array}$ & $\begin{array}{r}3825 \\
123 \\
202 \\
93 \\
.67 \\
.77\end{array}$ & $\begin{array}{r}3145 \\
105 \\
227 \\
62 \\
.57 \\
.64\end{array}$ & $\begin{array}{r}2134 \\
68.8 \\
110 \\
53 \\
.37 \\
.43\end{array}$ & $\begin{array}{r}2249 \\
72.5 \\
119 \\
53 \\
.39 \\
.45\end{array}$ & $\begin{array}{r}2725 \\
90.8 \\
227 \\
57 \\
.49 \\
.55\end{array}$ \\
\hline
\end{tabular}

CAL YR 1986 TOTAL 87617 MEAN 240 MAX $3920 \quad$ MIN $59 \quad$ CFSM $1.30 \quad$ IN 17.71

WTR YR 1987 TOTAL 54335 MEAN 149 MAX 1370 MIN 53 CFSM .81 IN 10.99 
LOCATION.--Lat $45^{\circ} 23^{\prime} 52^{\prime \prime}$, long $84^{\circ} 49^{\prime} 22^{\prime \prime}$, in NEl/4 SWl/4 sec. 29, T.35 N., R.4 W. Emmet County, Hydrologic Unit 04070004 , at Minnehaha Creek Inlét on Channel Road, $2.5 \mathrm{mi}$ southeast of Conway.

DRAINAGE AREA. - - $101 \mathrm{mi}^{2}$.

PERIOD OF RECORD.--June 1942 to July 1945 (summer months only), August 1945 to current year.

GAGE.--Water-stage recorder. Datum of gage is $593.38 \mathrm{ft}$ above National Geodetic Vertical Datum of 1929 . Prior to June 13, 1960 , nonrecording gage at datum $1.00 \mathrm{ft}$ higher. June 13 , 1960 to June 29 , 1964 , nonrecording gage at same datum.

REMARKS.--Crooked Lake is the upstream end of the navigable inland water route. Major inlets are Minnehaha Creek, Round Lake Outlet, and Pickerel Lake outlet. The outlet is Crooked River. Lake elevation controlled by dam and boat lock at Alanson. Maximum depth $68 \mathrm{ft}$, surface area 2,400 acres. EXTREMES FOR PERIOD OF RECORD.--Maximum gage height, $3.60 \mathrm{ft}$, Apr. 12, 1948 (present datum); minimum, $0.54 \mathrm{ft}, \operatorname{Mar} .30,1982$.

EXTREMES FOR CURRENT YEAR,--Maximum gage height, $2.79 \mathrm{ft}$, Oct. 5; minimum, $0.91 \mathrm{ft}, \mathrm{Feb}$. 28.

GAGE HEIGHT (FEET ABOVE DATUM), WATER YEAR OCTOBER 1986 TO SEPTEMBER 1987

\begin{tabular}{|c|c|c|c|c|c|c|c|c|c|c|c|c|}
\hline DAY & OCT & NOV & $\mathrm{DEC}$ & JAN & FEB & MAR & APR & MAY & JUN & JUL & AUG & SEP \\
\hline $\begin{array}{l}1 \\
2 \\
3 \\
4 \\
5\end{array}$ & $\begin{array}{l}2.59 \\
2.57 \\
2.59 \\
2.63 \\
2.64\end{array}$ & $\begin{array}{l}2.47 \\
2.47 \\
2.46 \\
2.46 \\
2.45\end{array}$ & $\begin{array}{l}1.61 \\
1.58 \\
1.60 \\
1.62 \\
1.59\end{array}$ & $\begin{array}{l}1.31 \\
1.31 \\
1.30 \\
1.29 \\
1.28\end{array}$ & $\begin{array}{l}1.05 \\
1.05 \\
1.06 \\
1.06 \\
1.06\end{array}$ & $\begin{array}{r}.94 \\
.97 \\
.95 \\
.95 \\
.94\end{array}$ & $\begin{array}{l}1.11 \\
1.14 \\
1.13 \\
1.13 \\
1.14\end{array}$ & $\begin{array}{l}2.03 \\
2.05 \\
2.07 \\
2.08 \\
2.09\end{array}$ & $\begin{array}{l}2.39 \\
2.37 \\
2.34 \\
2.30 \\
2.30\end{array}$ & $\begin{array}{l}2.37 \\
2.35 \\
2.33 \\
2.31 \\
2.30\end{array}$ & $\begin{array}{l}2.14 \\
2.21 \\
2.22 \\
2.21 \\
2.20\end{array}$ & $\begin{array}{l}2.21 \\
2.22 \\
2.22 \\
2.21 \\
2.21\end{array}$ \\
\hline $\begin{array}{r}6 \\
7 \\
8 \\
9 \\
10\end{array}$ & $\begin{array}{l}2.65 \\
2.62 \\
2.65 \\
2.68 \\
2.66\end{array}$ & $\begin{array}{l}2.44 \\
2.44 \\
2.42 \\
2.34 \\
2.39\end{array}$ & $\begin{array}{l}1.58 \\
1.57 \\
1.55 \\
1.54 \\
1.54\end{array}$ & $\begin{array}{l}1.27 \\
1.26 \\
1.25 \\
1.24 \\
1.23\end{array}$ & $\begin{array}{l}1.04 \\
1.02 \\
1.10 \\
1.22 \\
1.03\end{array}$ & $\begin{array}{r}.94 \\
.98 \\
1.06 \\
1.12 \\
1.13\end{array}$ & $\begin{array}{l}1.15 \\
1.16 \\
1.16 \\
1.15 \\
1.15\end{array}$ & $\begin{array}{l}2.10 \\
2.11 \\
2.12 \\
2.11 \\
2.14\end{array}$ & $\begin{array}{l}2.29 \\
2.32 \\
2.33 \\
2.33 \\
2.31\end{array}$ & $\begin{array}{l}2.29 \\
2.29 \\
2.28 \\
2.29 \\
2.36\end{array}$ & $\begin{array}{l}2.19 \\
2.18 \\
2.17 \\
2.20 \\
2.20\end{array}$ & $\begin{array}{l}2.21 \\
2.23 \\
2.26 \\
2.27 \\
2.27\end{array}$ \\
\hline $\begin{array}{l}11 \\
12 \\
13 \\
14 \\
15\end{array}$ & $\begin{array}{l}2.64 \\
2.65 \\
2.69 \\
2.71 \\
2.74\end{array}$ & $\begin{array}{l}2.39 \\
2.29 \\
2.22 \\
2.13 \\
2.07\end{array}$ & $\begin{array}{l}1.54 \\
1.53 \\
1.52 \\
1.50 \\
1.48\end{array}$ & $\begin{array}{l}1.22 \\
1.20 \\
1.18 \\
1.17 \\
1.17\end{array}$ & $\begin{array}{l}1.02 \\
1.02 \\
1.01 \\
1.05 \\
1.08\end{array}$ & $\begin{array}{l}1.11 \\
1.10 \\
1.08 \\
1.07 \\
1.05\end{array}$ & $\begin{array}{l}1.20 \\
1.27 \\
1.32 \\
1.37 \\
1.44\end{array}$ & $\begin{array}{l}2.14 \\
2.15 \\
2.15 \\
2.17 \\
2.18\end{array}$ & $\begin{array}{l}2.30 \\
2.31 \\
2.31 \\
2.29 \\
2.28\end{array}$ & $\begin{array}{l}2.35 \\
2.35 \\
2.35 \\
2.32 \\
2.29\end{array}$ & $\begin{array}{l}2.20 \\
2.19 \\
2.19 \\
2.20 \\
2.23\end{array}$ & $\begin{array}{l}2.29 \\
2.31 \\
2.30 \\
2.29 \\
2.29\end{array}$ \\
\hline $\begin{array}{l}16 \\
17 \\
18 \\
19 \\
20\end{array}$ & $\begin{array}{l}2.74 \\
2.73 \\
2.68 \\
2.66 \\
2.63\end{array}$ & $\begin{array}{l}2.03 \\
1.98 \\
1.93 \\
1.87 \\
1.84\end{array}$ & $\begin{array}{l}1.47 \\
1.46 \\
1.45 \\
1.45 \\
1.44\end{array}$ & $\begin{array}{l}1.15 \\
1.13 \\
1.12 \\
1.10 \\
1.09\end{array}$ & $\begin{array}{r}1.10 \\
1.04 \\
1.04 \\
1.01 \\
.97\end{array}$ & $\begin{array}{l}1.04 \\
1.03 \\
1.02 \\
1.01 \\
1.01\end{array}$ & $\begin{array}{l}1.50 \\
1.56 \\
1.62 \\
1.67 \\
1.70\end{array}$ & $\begin{array}{l}2.18 \\
2.20 \\
2.23 \\
2.23 \\
2.24\end{array}$ & $\begin{array}{l}2.26 \\
2.26 \\
2.24 \\
2.24 \\
2.24\end{array}$ & $\begin{array}{l}2.28 \\
2.25 \\
2.24 \\
2.24 \\
2.23\end{array}$ & $\begin{array}{l}2.25 \\
2.28 \\
2.28 \\
2.30 \\
2.30\end{array}$ & $\begin{array}{l}2.28 \\
2.31 \\
2.30 \\
2.34 \\
2.37\end{array}$ \\
\hline $\begin{array}{l}21 \\
22 \\
23 \\
24 \\
25\end{array}$ & $\begin{array}{l}2.61 \\
2.57 \\
2.56 \\
2.54 \\
2.52\end{array}$ & $\begin{array}{l}1.80 \\
1.77 \\
1.76 \\
1.77 \\
1.75\end{array}$ & $\begin{array}{l}1.43 \\
1.42 \\
1.40 \\
1.39 \\
1.38\end{array}$ & $\begin{array}{l}1.10 \\
1.10 \\
1.25 \\
1.15 \\
1.18\end{array}$ & $\begin{array}{r}.95 \\
.94 \\
.94 \\
.94 \\
.93\end{array}$ & $\begin{array}{l}1.01 \\
1.01 \\
1.02 \\
1.03 \\
1.05\end{array}$ & $\begin{array}{l}1.74 \\
1.78 \\
1.83 \\
1.87 \\
1.89\end{array}$ & $\begin{array}{l}2.25 \\
2.26 \\
2.28 \\
2.28 \\
2.29\end{array}$ & $\begin{array}{l}2.22 \\
2.21 \\
2.20 \\
2.19 \\
2.26\end{array}$ & $\begin{array}{l}2.22 \\
2.22 \\
2.20 \\
2.19 \\
2.19\end{array}$ & $\begin{array}{l}2.29 \\
2.28 \\
2.23 \\
2.19 \\
2.18\end{array}$ & $\begin{array}{l}2.43 \\
2.48 \\
2.45 \\
2.44 \\
2.40\end{array}$ \\
\hline $\begin{array}{l}26 \\
27 \\
28 \\
29 \\
30 \\
31\end{array}$ & $\begin{array}{l}2.51 \\
2.50 \\
2.48 \\
2.49 \\
2.47 \\
2.45\end{array}$ & $\begin{array}{l}1.73 \\
1.71 \\
1.67 \\
1.65 \\
1.63 \\
-\end{array}$ & $\begin{array}{l}1.37 \\
1.36 \\
1.35 \\
1.34 \\
1.33 \\
1.32\end{array}$ & $\begin{array}{l}1.16 \\
1.17 \\
1.13 \\
1.06 \\
1.07 \\
1.06\end{array}$ & $\begin{array}{l}.93 \\
.92 \\
.92 \\
--- \\
---\end{array}$ & $\begin{array}{l}1.07 \\
1.08 \\
1.09 \\
1.11 \\
1.13 \\
1.12\end{array}$ & $\begin{array}{l}1.92 \\
1.96 \\
2.00 \\
2.03 \\
2.03 \\
\end{array}$ & $\begin{array}{l}2.34 \\
2.45 \\
2.49 \\
2.47 \\
2.44 \\
2.42\end{array}$ & $\begin{array}{l}2.38 \\
2.40 \\
2.39 \\
2.39 \\
2.39\end{array}$ & $\begin{array}{l}2.18 \\
2.16 \\
2.16 \\
2.15 \\
2.15 \\
2.15\end{array}$ & $\begin{array}{l}2.19 \\
2.19 \\
2.19 \\
2.20 \\
2.21 \\
2.22\end{array}$ & $\begin{array}{l}2.38 \\
2.37 \\
2.35 \\
2.36 \\
2.41\end{array}$ \\
\hline $\begin{array}{l}\text { MEAN } \\
\text { MAX } \\
\text { MIN }\end{array}$ & $\begin{array}{l}2.61 \\
2.74 \\
2.45\end{array}$ & $\begin{array}{l}2.08 \\
2.47 \\
1.63\end{array}$ & $\begin{array}{l}1.47 \\
1.62 \\
1.32\end{array}$ & $\begin{array}{l}1.18 \\
1.31 \\
1.06\end{array}$ & $\begin{array}{r}1.02 \\
1.22 \\
.92\end{array}$ & $\begin{array}{r}1.04 \\
1.13 \\
.94\end{array}$ & $\begin{array}{l}1.50 \\
2.03 \\
1.11\end{array}$ & $\begin{array}{l}2.22 \\
2.49 \\
2.03\end{array}$ & $\begin{array}{l}2.30 \\
2.40 \\
2.19\end{array}$ & $\begin{array}{l}2.26 \\
2.37 \\
2.15\end{array}$ & $\begin{array}{l}2.22 \\
2.30 \\
2.14\end{array}$ & $\begin{array}{l}2.32 \\
2.48 \\
2.21\end{array}$ \\
\hline
\end{tabular}

WTR YR 1987 MEAN 1.86 MAX $2.74 \quad$ MIN .92 
04128000 STURGEON RIVER NEAR WOLVERINE, MI

LOCATION.--Lat $45^{\circ} 17^{\prime} 56^{\prime \prime}$, long $84^{\circ} 36^{\prime} 40^{\prime \prime}$, in SEl/4 NEl/4 sec.36, T. 34 N., R. 3 W., Cheboygan County, Hydrologic Unit 04070004 , on left bank $1.8 \mathrm{mi}$ north of Wolverine, 2.8 mi downstream from West Branch, and $9 \mathrm{mi}$ upstream from mouth.

DRAINAGE AREA. $--198 \mathrm{mi}^{2}$.

PERIOD OF RECORD.--April 1942 to current year.

REVISED RECORDS.--WSP 1307: 1944(M), 1948(M). WSP 1727: 1951(M). WDR MI-83: Drainage area.

GAGE.--Water-stage recorder. Elevation of gage is $740 \mathrm{ft}$ above National Geodetic Vertical Datum of 1929, from topographic map. Prior to June 15, 1942, nonrecording gage at site $1.0 \mathrm{mi}$ upstream, and June 16, 1942, to Sept. 30, 1958, at site $0.7 \mathrm{mi}$ upstream at different datums.

REMARKS.--Estimated daily discharges: Dec, 13, 14, Jan. 18, 20, 21, 25-31, Feb. 9, 10, 16-21 and Mar. 14 to June 3. Records good except for estimated daily discharges, which are poor. Prior to July ig75, intermittent regulation at low flows by ponds $2.4 \mathrm{mi}$ upstream. Several measurements of water temperature were made during the year.

AVERAGE DISCHARGE. --45 years, $220 \mathrm{ft}^{3} / \mathrm{s}, 15.09 \mathrm{in} / \mathrm{yr}^{2}$

EXTREMES FOR PERIOD OF RECORD.--Maximum discharge, 1,290 ft $3 / \mathrm{s}$, Sept. 29, 1972, gage height, 3.72 $\mathrm{ft}$; maximum gage height, $4.48 \mathrm{ft}$, Sept. 14, 1961; minimum discharge, $94 \mathrm{ft} 3 / \mathrm{s}, \mathrm{Jan}$. 19,1971 , result of freezeup; minimum daily, $113 \mathrm{ft} / \mathrm{s}, \mathrm{Aug} .6,1958$.

EXTREMES FOR CURRENT YEAR.--Maximum discharge, $570 \mathrm{ft}^{3} / \mathrm{s}$, Oct. 3, gage height, $2.69 \mathrm{ft}$; minimum, $119 \mathrm{ft}^{3} / \mathrm{s}, \mathrm{Jan} .23,24$, gage height, $1.31 \mathrm{ft}$, result of freezeup.

DISCHARGE, IN CUBIC FEET PER SECOND, WATER YEAR OCTOBER 1986 TO SEPTEMBER 1987

\begin{tabular}{|c|c|c|c|c|c|c|c|c|c|c|c|c|}
\hline DAY & OCT & NOV & DEC & JAN & FEB & MAR & APR & MAY & JUN & JUL & AUG & SEP \\
\hline $\begin{array}{l}1 \\
2 \\
3 \\
4 \\
5\end{array}$ & $\begin{array}{l}271 \\
246 \\
427 \\
518 \\
448\end{array}$ & $\begin{array}{l}249 \\
254 \\
239 \\
238 \\
233\end{array}$ & $\begin{array}{l}233 \\
234 \\
248 \\
255 \\
247\end{array}$ & $\begin{array}{l}230 \\
232 \\
229 \\
227 \\
225\end{array}$ & $\begin{array}{l}237 \\
237 \\
237 \\
230 \\
227\end{array}$ & $\begin{array}{l}224 \\
240 \\
227 \\
221 \\
224\end{array}$ & $\begin{array}{l}230 \\
240 \\
240 \\
240 \\
250\end{array}$ & $\begin{array}{l}200 \\
200 \\
195 \\
195 \\
190\end{array}$ & $\begin{array}{l}175 \\
175 \\
175 \\
172 \\
172\end{array}$ & $\begin{array}{l}177 \\
170 \\
168 \\
170 \\
169\end{array}$ & $\begin{array}{l}146 \\
233 \\
226 \\
177 \\
167\end{array}$ & $\begin{array}{l}185 \\
173 \\
175 \\
167 \\
163\end{array}$ \\
\hline $\begin{array}{r}6 \\
7 \\
8 \\
9 \\
10\end{array}$ & $\begin{array}{l}432 \\
346 \\
321 \\
311 \\
276\end{array}$ & $\begin{array}{l}233 \\
233 \\
235 \\
232 \\
231\end{array}$ & $\begin{array}{l}245 \\
238 \\
238 \\
238 \\
240\end{array}$ & $\begin{array}{l}224 \\
227 \\
224 \\
224 \\
224\end{array}$ & $\begin{array}{l}237 \\
224 \\
227 \\
225 \\
225\end{array}$ & $\begin{array}{l}234 \\
332 \\
389 \\
344 \\
268\end{array}$ & $\begin{array}{l}255 \\
250 \\
240 \\
235 \\
230\end{array}$ & $\begin{array}{l}185 \\
185 \\
185 \\
190 \\
190\end{array}$ & $\begin{array}{l}174 \\
185 \\
183 \\
182 \\
178\end{array}$ & $\begin{array}{l}167 \\
173 \\
185 \\
182 \\
349\end{array}$ & $\begin{array}{l}157 \\
162 \\
161 \\
164 \\
170\end{array}$ & $\begin{array}{l}160 \\
160 \\
162 \\
167 \\
164\end{array}$ \\
\hline $\begin{array}{l}11 \\
12 \\
13 \\
14 \\
15\end{array}$ & $\begin{array}{l}263 \\
288 \\
325 \\
293 \\
304\end{array}$ & $\begin{array}{l}236 \\
233 \\
234 \\
237 \\
238\end{array}$ & $\begin{array}{l}236 \\
237 \\
238 \\
240 \\
241\end{array}$ & $\begin{array}{l}225 \\
224 \\
224 \\
227 \\
229\end{array}$ & $\begin{array}{l}227 \\
224 \\
224 \\
221 \\
169\end{array}$ & $\begin{array}{l}262 \\
237 \\
230 \\
225 \\
220\end{array}$ & $\begin{array}{l}230 \\
230 \\
230 \\
230 \\
235\end{array}$ & $\begin{array}{l}185 \\
180 \\
180 \\
185 \\
190\end{array}$ & $\begin{array}{l}180 \\
200 \\
191 \\
178 \\
170\end{array}$ & $\begin{array}{l}266 \\
199 \\
187 \\
183 \\
180\end{array}$ & $\begin{array}{l}160 \\
154 \\
160 \\
162 \\
199\end{array}$ & $\begin{array}{l}170 \\
179 \\
174 \\
170 \\
166\end{array}$ \\
\hline $\begin{array}{l}16 \\
17 \\
18 \\
19 \\
20\end{array}$ & $\begin{array}{l}289 \\
273 \\
263 \\
254 \\
250\end{array}$ & $\begin{array}{l}240 \\
241 \\
240 \\
231 \\
234\end{array}$ & $\begin{array}{l}237 \\
241 \\
248 \\
252 \\
242\end{array}$ & $\begin{array}{l}227 \\
210 \\
215 \\
219 \\
220\end{array}$ & $\begin{array}{l}210 \\
210 \\
215 \\
220 \\
220\end{array}$ & $\begin{array}{l}225 \\
230 \\
230 \\
235 \\
240\end{array}$ & $\begin{array}{l}235 \\
230 \\
225 \\
220 \\
220\end{array}$ & $\begin{array}{l}185 \\
180 \\
185 \\
200 \\
195\end{array}$ & $\begin{array}{l}167 \\
166 \\
164 \\
163 \\
162\end{array}$ & $\begin{array}{l}173 \\
171 \\
165 \\
158 \\
159\end{array}$ & $\begin{array}{l}258 \\
310 \\
249 \\
231 \\
194\end{array}$ & $\begin{array}{l}163 \\
171 \\
205 \\
214 \\
207\end{array}$ \\
\hline $\begin{array}{l}21 \\
22 \\
23 \\
24 \\
25\end{array}$ & $\begin{array}{l}241 \\
237 \\
238 \\
234 \\
232\end{array}$ & $\begin{array}{l}239 \\
243 \\
260 \\
287 \\
269\end{array}$ & $\begin{array}{l}231 \\
228 \\
229 \\
228 \\
229\end{array}$ & $\begin{array}{l}220 \\
223 \\
180 \\
165 \\
220\end{array}$ & $\begin{array}{l}220 \\
224 \\
224 \\
218 \\
214\end{array}$ & $\begin{array}{l}245 \\
250 \\
255 \\
260 \\
275\end{array}$ & $\begin{array}{l}215 \\
220 \\
230 \\
225 \\
220\end{array}$ & $\begin{array}{l}190 \\
195 \\
190 \\
190 \\
190\end{array}$ & $\begin{array}{l}160 \\
165 \\
164 \\
159 \\
184\end{array}$ & $\begin{array}{l}180 \\
170 \\
160 \\
164 \\
174\end{array}$ & $\begin{array}{l}176 \\
175 \\
163 \\
158 \\
156\end{array}$ & $\begin{array}{l}214 \\
258 \\
211 \\
190 \\
183\end{array}$ \\
\hline $\begin{array}{l}26 \\
27 \\
28 \\
29 \\
30 \\
31\end{array}$ & $\begin{array}{l}233 \\
242 \\
249 \\
237 \\
231 \\
228\end{array}$ & $\begin{array}{l}263 \\
259 \\
253 \\
259 \\
245 \\
-\end{array}$ & $\begin{array}{l}228 \\
227 \\
227 \\
227 \\
228 \\
230\end{array}$ & $\begin{array}{l}225 \\
225 \\
230 \\
230 \\
230 \\
230\end{array}$ & $\begin{array}{l}214 \\
214 \\
214 \\
--- \\
--- \\
---\end{array}$ & $\begin{array}{l}270 \\
260 \\
245 \\
245 \\
250 \\
240\end{array}$ & $\begin{array}{l}210 \\
215 \\
210 \\
205 \\
205 \\
---\end{array}$ & $\begin{array}{l}205 \\
195 \\
185 \\
180 \\
180 \\
175\end{array}$ & $\begin{array}{l}223 \\
194 \\
196 \\
191 \\
191 \\
-\end{array}$ & $\begin{array}{l}158 \\
152 \\
149 \\
150 \\
148 \\
145\end{array}$ & $\begin{array}{l}158 \\
158 \\
159 \\
185 \\
177 \\
194\end{array}$ & $\begin{array}{l}177 \\
178 \\
181 \\
180 \\
211 \\
-\end{array}$ \\
\hline $\begin{array}{l}\text { TOTAL } \\
\text { MEAN } \\
\text { MAX } \\
\text { MIN } \\
\text { CFSM } \\
\text { IN. }\end{array}$ & $\begin{array}{r}9000 \\
290 \\
518 \\
228 \\
1.47 \\
1.69\end{array}$ & $\begin{array}{r}7318 \\
244 \\
287 \\
231 \\
1.23 \\
1.37\end{array}$ & $\begin{array}{r}7340 \\
237 \\
255 \\
227 \\
1.20 \\
1.38\end{array}$ & $\begin{array}{r}6864 \\
221 \\
232 \\
165 \\
1.12 \\
1.29\end{array}$ & $\begin{array}{r}6188 \\
221 \\
237 \\
169 \\
1.12 \\
1.16\end{array}$ & $\begin{array}{r}7832 \\
253 \\
389 \\
220 \\
1.28 \\
1.47\end{array}$ & $\begin{array}{r}6850 \\
228 \\
255 \\
205 \\
1.15 \\
1.29\end{array}$ & $\begin{array}{r}5855 \\
189 \\
205 \\
175 \\
.96 \\
1.10\end{array}$ & $\begin{array}{r}5339 \\
178 \\
223 \\
159 \\
.90 \\
1.00\end{array}$ & $\begin{array}{r}5501 \\
177 \\
349 \\
145 \\
.89 \\
1.03\end{array}$ & $\begin{array}{r}5699 \\
184 \\
310 \\
146 \\
.93 \\
1.07\end{array}$ & $\begin{array}{r}5478 \\
183 \\
258 \\
160 \\
.92 \\
1.03\end{array}$ \\
\hline
\end{tabular}

$\begin{array}{lllllllllll}\text { CAL YR } 1986 & \text { TOTAL } & 92721 & \text { MEAN 254 } & \text { MAX } 670 & \text { MIN } 169 & \text { CFSM } 1.28 & \text { IN } 17.42 \\ \text { WTR YR } 1987 & \text { TOTAL } & 79264 & \text { MEAN 217 } & \text { MAX } 518 & \text { MIN } 145 & \text { CFSM } 1.10 & \text { IN } 14.89\end{array}$ 
LOCATION.--Lat $45^{\circ} 24^{\prime} 38^{\prime \prime}$, long $84^{\circ} 37^{\prime} 12^{\prime \prime}$, in NEl/4 SWl/4 sec.24, T.35 N., R.3 W., Cheboygan County, Hydrologic Unit 04070004 , on left bank of Indian River $500 \mathrm{ft}$ downstream from Burt Lake, $2.3 \mathrm{ml}$ upstream From Mullett Lake.

DRAINAGE AREA. $--598 \mathrm{mi}^{2}$.

PERIOD OF RECORD.--April 1942 to current year.

GAGE.--Water stage recorder. Datum of gage is $590.21 \mathrm{ft}$ above National Geodetic Vertical Datum of 1929 (ievels by Michigan Department of Natural Resources). Prior to Nov. 12, 1942, nonrecording gage at same datum.

REMARKS.--Burt Lake is part of the navigable inland water route. The major inlet to Burt Lake is Crooked River and the outlet is Indian River. Maple River, Sturgeon River, and Little Carp River also flow into Burt Lake. Streamflow records are currently collected for sturgeon River (station 04128000) at a site $9 \mathrm{mi}$ upstream from Burt Lake. Streamflow records for Indian River (station 04128500) were collected from April 1942 to September 1982. Lake elevation affected by regulation from dam at Cheboygan. Maximum depth $73 \mathrm{ft}$, surface area 16,700 acres.

EXTREMES FOR PERIOD OF RECORD.--Maximum daily gage height, $5.58 \mathrm{ft}$, May 13, 14, 1960; minimum daily, $3.16 \mathrm{ft}, \operatorname{Mar} .12,1982$.

EXTREMES FOR CURRENT YEAR.--Maximum daily gage height, $4.66 \mathrm{ft}$, Oct. 15, 16; minimum daily, $3.43 \mathrm{ft}$, Feb. 26-28, Mar. 4-6.

GAGE HEIGHT (FEET ABOVE DATUM), WATER YEAR OCTOBER 1986 TO SEPTEMBER 1987 MEAN VALUES

\begin{tabular}{|c|c|c|c|c|c|c|c|c|c|c|c|c|}
\hline DAY & OCT & NOV & DEC & JAN & FEB & MAR & APR & MAY & JUN & JUL & AUG & SEP \\
\hline $\begin{array}{l}1 \\
2 \\
3 \\
4 \\
5\end{array}$ & $\begin{array}{l}4.44 \\
4.43 \\
4.48 \\
4.51 \\
4.53\end{array}$ & $\begin{array}{l}4.39 \\
4.35 \\
4.32 \\
4.30 \\
4.26\end{array}$ & $\begin{array}{l}4.00 \\
3.99 \\
4.00 \\
4.01 \\
3.99\end{array}$ & $\begin{array}{l}3.80 \\
3.80 \\
3.78 \\
3.77 \\
3.75\end{array}$ & $\begin{array}{l}3.53 \\
3.52 \\
3.55 \\
3.54 \\
3.53\end{array}$ & $\begin{array}{l}3.45 \\
3.45 \\
3.44 \\
3.43 \\
3.43\end{array}$ & $\begin{array}{l}3.60 \\
3.67 \\
3.64 \\
3.64 \\
3.64\end{array}$ & $\begin{array}{l}3.60 \\
3.60 \\
3.60 \\
3.60 \\
3.60\end{array}$ & $\begin{array}{l}3.92 \\
3.93 \\
3.93 \\
3.90 \\
3.87\end{array}$ & $\begin{array}{l}3.87 \\
3.86 \\
3.86 \\
3.84 \\
3.83\end{array}$ & $\begin{array}{l}3.68 \\
3.75 \\
3.76 \\
3.77 \\
3.74\end{array}$ & $\begin{array}{l}3.76 \\
3.75 \\
3.73 \\
3.72 \\
3.72\end{array}$ \\
\hline $\begin{array}{r}6 \\
7 \\
8 \\
9 \\
10\end{array}$ & $\begin{array}{l}4.55 \\
4.51 \\
4.59 \\
4.59 \\
4.56\end{array}$ & $\begin{array}{l}4.24 \\
4.22 \\
4.17 \\
4.17 \\
4.15\end{array}$ & $\begin{array}{l}4.00 \\
3.99 \\
3.96 \\
3.96 \\
3.96\end{array}$ & $\begin{array}{l}3.75 \\
3.74 \\
3.72 \\
3.70 \\
3.71\end{array}$ & $\begin{array}{l}3.53 \\
3.52 \\
3.54 \\
3.52 \\
3.51\end{array}$ & $\begin{array}{l}3.43 \\
3.47 \\
3.48 \\
3.51 \\
3.50\end{array}$ & $\begin{array}{l}3.63 \\
3.63 \\
3.63 \\
3.63 \\
3.63\end{array}$ & $\begin{array}{l}3.60 \\
3.60 \\
3.59 \\
3.57 \\
3.58\end{array}$ & $\begin{array}{l}3.85 \\
3.87 \\
3.90 \\
3.89 \\
3.86\end{array}$ & $\begin{array}{l}3.82 \\
3.83 \\
3.85 \\
3.86 \\
3.94\end{array}$ & $\begin{array}{l}3.71 \\
3.71 \\
3.69 \\
3.70 \\
3.71\end{array}$ & $\begin{array}{l}3.71 \\
3.74 \\
3.76 \\
3.76 \\
3.75\end{array}$ \\
\hline $\begin{array}{l}11 \\
12 \\
13 \\
14 \\
15\end{array}$ & $\begin{array}{l}4.54 \\
4.58 \\
4.61 \\
4.63 \\
4.66\end{array}$ & $\begin{array}{l}4.14 \\
4.14 \\
4.13 \\
4.09 \\
4.10\end{array}$ & $\begin{array}{l}3.98 \\
4.00 \\
4.02 \\
4.02 \\
3.99\end{array}$ & $\begin{array}{l}3.70 \\
3.68 \\
3.67 \\
3.66 \\
3.65\end{array}$ & $\begin{array}{l}3.51 \\
3.51 \\
3.50 \\
3.51 \\
3.49\end{array}$ & $\begin{array}{l}3.50 \\
3.50 \\
3.49 \\
3.49 \\
3.48\end{array}$ & $\begin{array}{l}3.61 \\
3.60 \\
3.58 \\
3.57 \\
3.57\end{array}$ & $\begin{array}{l}3.59 \\
3.58 \\
3.56 \\
3.59 \\
3.60\end{array}$ & $\begin{array}{l}3.85 \\
3.88 \\
3.88 \\
3.88 \\
3.87\end{array}$ & $\begin{array}{l}3.95 \\
3.95 \\
3.98 \\
3.95 \\
3.90\end{array}$ & $\begin{array}{l}3.70 \\
3.69 \\
3.69 \\
3.70 \\
3.72\end{array}$ & $\begin{array}{l}3.78 \\
3.78 \\
3.79 \\
3.78 \\
3.77\end{array}$ \\
\hline $\begin{array}{l}16 \\
17 \\
18 \\
19 \\
20\end{array}$ & $\begin{array}{l}4.66 \\
4.65 \\
4.63 \\
4.62 \\
4.60\end{array}$ & $\begin{array}{l}4.11 \\
4.12 \\
4.11 \\
4.07 \\
4.08\end{array}$ & $\begin{array}{l}3.97 \\
3.96 \\
3.95 \\
3.94 \\
3.93\end{array}$ & $\begin{array}{l}3.64 \\
3.62 \\
3.61 \\
3.60 \\
3.58\end{array}$ & $\begin{array}{l}3.48 \\
3.47 \\
3.47 \\
3.46 \\
3.45\end{array}$ & $\begin{array}{l}3.47 \\
3.46 \\
3.46 \\
3.45 \\
3.45\end{array}$ & $\begin{array}{l}3.56 \\
3.56 \\
3.56 \\
3.56 \\
3.56\end{array}$ & $\begin{array}{l}3.59 \\
3.60 \\
3.61 \\
3.61 \\
3.62\end{array}$ & $\begin{array}{l}3.86 \\
3.84 \\
3.83 \\
3.83 \\
3.81\end{array}$ & $\begin{array}{l}3.88 \\
3.86 \\
3.86 \\
3.85 \\
3.86\end{array}$ & $\begin{array}{l}3.75 \\
3.80 \\
3.83 \\
3.87 \\
3.88\end{array}$ & $\begin{array}{l}3.77 \\
3.81 \\
3.80 \\
3.82 \\
3.89\end{array}$ \\
\hline $\begin{array}{l}21 \\
22 \\
23 \\
24 \\
25\end{array}$ & $\begin{array}{l}4.60 \\
4.58 \\
4.57 \\
4.54 \\
4.51\end{array}$ & $\begin{array}{l}4.07 \\
4.06 \\
4.07 \\
4.07 \\
4.06\end{array}$ & $\begin{array}{l}3.91 \\
3.90 \\
3.89 \\
3.88 \\
3.87\end{array}$ & $\begin{array}{l}3.59 \\
3.58 \\
3.58 \\
3.55 \\
3.54\end{array}$ & $\begin{array}{l}3.44 \\
3.44 \\
3.45 \\
3.45 \\
3.44\end{array}$ & $\begin{array}{l}3.45 \\
3.45 \\
3.45 \\
3.47 \\
3.48\end{array}$ & $\begin{array}{l}3.59 \\
3.58 \\
3.61 \\
3.61 \\
3.61\end{array}$ & $\begin{array}{l}3.63 \\
3.67 \\
3.69 \\
3.69 \\
3.70\end{array}$ & $\begin{array}{l}3.80 \\
3.78 \\
3.77 \\
3.77 \\
3.82\end{array}$ & $\begin{array}{l}3.84 \\
3.83 \\
3.82 \\
3.80 \\
3.80\end{array}$ & $\begin{array}{l}3.88 \\
3.90 \\
3.86 \\
3.81 \\
3.79\end{array}$ & $\begin{array}{l}3.95 \\
3.98 \\
3.97 \\
3.97 \\
3.93\end{array}$ \\
\hline $\begin{array}{l}26 \\
27 \\
28 \\
29 \\
30 \\
31\end{array}$ & $\begin{array}{l}4.50 \\
4.48 \\
4.45 \\
4.45 \\
4.41 \\
4.35\end{array}$ & $\begin{array}{r}4.06 \\
4.04 \\
4.04 \\
4.04 \\
4.02 \\
---\end{array}$ & $\begin{array}{l}3.86 \\
3.85 \\
3.83 \\
3.82 \\
3.82 \\
3.80\end{array}$ & $\begin{array}{l}3.52 \\
3.51 \\
3.51 \\
3.51 \\
3.53 \\
3.53\end{array}$ & $\begin{array}{r}3.43 \\
3.43 \\
3.43 \\
- \\
--- \\
---\end{array}$ & $\begin{array}{l}3.52 \\
3.54 \\
3.55 \\
3.58 \\
3.61 \\
3.60\end{array}$ & $\begin{array}{l}3.61 \\
3.65 \\
3.65 \\
3.65 \\
3.63 \\
-\end{array}$ & $\begin{array}{l}3.76 \\
3.88 \\
3.91 \\
3.93 \\
3.93 \\
3.93\end{array}$ & $\begin{array}{l}3.90 \\
3.90 \\
3.88 \\
3.88 \\
3.89 \\
\end{array}$ & $\begin{array}{l}3.79 \\
3.76 \\
3.74 \\
3.72 \\
3.72 \\
3.70\end{array}$ & $\begin{array}{l}3.79 \\
3.78 \\
3.77 \\
3.77 \\
3.78 \\
3.79\end{array}$ & $\begin{array}{l}3.92 \\
3.91 \\
3.90 \\
3.92 \\
3.97\end{array}$ \\
\hline $\begin{array}{l}\text { MEAN } \\
\text { MAX } \\
\text { MIN }\end{array}$ & $\begin{array}{l}4.54 \\
4.66 \\
4.35\end{array}$ & $\begin{array}{l}4.14 \\
4.39 \\
4.02\end{array}$ & $\begin{array}{l}3.94 \\
4.02 \\
3.80\end{array}$ & $\begin{array}{l}3.64 \\
3.80 \\
3.51\end{array}$ & $\begin{array}{l}3.49 \\
3.55 \\
3.43\end{array}$ & $\begin{array}{l}3.49 \\
3.61 \\
3.43\end{array}$ & $\begin{array}{l}3.61 \\
3.67 \\
3.56\end{array}$ & $\begin{array}{l}3.66 \\
3.93 \\
3.56\end{array}$ & $\begin{array}{l}3.86 \\
3.93 \\
3.77\end{array}$ & $\begin{array}{l}3.84 \\
3.98 \\
3.70\end{array}$ & $\begin{array}{l}3.77 \\
3.90 \\
3.68\end{array}$ & $\begin{array}{l}3.83 \\
3.98 \\
3.71\end{array}$ \\
\hline
\end{tabular}

WTR YR 1987 MEAN 3.82 MAX 4.66 MIN 3.43 
04129000 PIGEON RIVER NEAR VANDERBILT, MI

LOCATION.--Lat $45^{\circ} 10^{\prime} 15^{\prime \prime}$, long $84^{\circ} 26^{\prime} 18^{\prime \prime}$, in SEl/4 Swl/4 sec.9, T.32 N., R.1 W., Otsego County, Hydrologic Unit 04070004 , on right bank at Pigeon River Headquarters, 11.1 mi east of Vanderbilt, and 26 mi upstream from Mullett Lake.

DRAINAGE AREA. $--62.6 \mathrm{mi}^{2}$.

PERIOD OF RECORD.--September 1950 to current year.

REVISED RECORDS.--WDR MI-83: Drainage area.

GAGE.--Water-stage recorder. Datum of gage is $886.24 \mathrm{ft}$ above National Geodetic Vertical Datum of 1929 .

REMARKS.--Estimated daily discharges: Jan. 23, 24, 26-31 and Feb. 14-16. Records good except for estimated daily discharges, which are poor. Prior to May 16, 1957, and since Apr. 22, 1958, occasional regulation by Lansing Club Dam $3.5 \mathrm{mi}$ upstream. Several measurements of water temperature were made during the year.

AVERAGE DISCHARGE. --37 years, $78.5 \mathrm{ft}^{3} / \mathrm{s}, 17.03 \mathrm{in} / \mathrm{yr}$.

EXTREMES FOR PERIOD OF RECORD,--Maximum discharge, 1,500 ft $3 / \mathrm{s}$, May 15, 1957, gage height, $6.80 \mathrm{ft}$, from floodmark, from rating curve extended above $500 \mathrm{ft}^{3} / \mathrm{s}$, result of failure of lansing club Dam; minimum, $13 \mathrm{ft}^{3} / \mathrm{s}, \mathrm{Jan} .8,1957$.

EXTREMES FOR CURRENT YEAR.--Maximum discharge, $454 \mathrm{ft}^{3} / \mathrm{s}$, Oct. 4, gage height, $5.13 \mathrm{ft}$; minimum, $30 \mathrm{ft}^{3} / \mathrm{s}$, Feb. 3, gage height, $1.78 \mathrm{ft}$.

DISCHARGE, IN CUBIC FEET PER SECOND, WATER YEAR OCTOBER 1986 TO SEPTEMBER 1987

\begin{tabular}{|c|c|c|c|c|c|c|c|c|c|c|c|c|}
\hline DAY & OCT & NOV & DEC & JAN & FEB & MAR & APR & MAY & JUN & JUL & AUG & SEP \\
\hline $\begin{array}{l}1 \\
2 \\
3 \\
4 \\
5\end{array}$ & $\begin{array}{r}112 \\
90 \\
179 \\
242 \\
234\end{array}$ & $\begin{array}{l}87 \\
97 \\
85 \\
92 \\
78\end{array}$ & $\begin{array}{l}79 \\
84 \\
83 \\
86 \\
78\end{array}$ & $\begin{array}{l}81 \\
79 \\
77 \\
75 \\
76\end{array}$ & $\begin{array}{l}96 \\
69 \\
83 \\
76 \\
77\end{array}$ & $\begin{array}{l}58 \\
94 \\
71 \\
80 \\
69\end{array}$ & $\begin{array}{l}87 \\
79 \\
86 \\
77 \\
86\end{array}$ & $\begin{array}{l}73 \\
69 \\
66 \\
60 \\
65\end{array}$ & $\begin{array}{l}65 \\
60 \\
59 \\
49 \\
53\end{array}$ & $\begin{array}{l}58 \\
57 \\
58 \\
51 \\
51\end{array}$ & $\begin{array}{r}49 \\
110 \\
95 \\
69 \\
67\end{array}$ & $\begin{array}{l}61 \\
59 \\
67 \\
64 \\
60\end{array}$ \\
\hline $\begin{array}{r}6 \\
7 \\
8 \\
9 \\
10\end{array}$ & $\begin{array}{r}179 \\
139 \\
127 \\
116 \\
94\end{array}$ & $\begin{array}{l}85 \\
85 \\
84 \\
84 \\
81\end{array}$ & $\begin{array}{l}83 \\
78 \\
78 \\
76 \\
79\end{array}$ & $\begin{array}{l}76 \\
78 \\
77 \\
74 \\
77\end{array}$ & $\begin{array}{l}79 \\
76 \\
72 \\
79 \\
75\end{array}$ & $\begin{array}{r}78 \\
95 \\
138 \\
134 \\
99\end{array}$ & $\begin{array}{r}89 \\
105 \\
95 \\
101 \\
77\end{array}$ & $\begin{array}{l}69 \\
53 \\
80 \\
53 \\
53\end{array}$ & $\begin{array}{l}56 \\
65 \\
55 \\
63 \\
58\end{array}$ & $\begin{array}{r}52 \\
54 \\
68 \\
63 \\
208\end{array}$ & $\begin{array}{l}58 \\
66 \\
56 \\
65 \\
67\end{array}$ & $\begin{array}{l}54 \\
55 \\
65 \\
61 \\
62\end{array}$ \\
\hline $\begin{array}{l}11 \\
12 \\
13 \\
14 \\
15\end{array}$ & $\begin{array}{r}98 \\
98 \\
101 \\
96 \\
99\end{array}$ & $\begin{array}{l}88 \\
85 \\
89 \\
90 \\
56\end{array}$ & $\begin{array}{l}79 \\
76 \\
84 \\
80 \\
77\end{array}$ & $\begin{array}{l}74 \\
75 \\
76 \\
77 \\
79\end{array}$ & $\begin{array}{l}83 \\
76 \\
70 \\
68 \\
66\end{array}$ & $\begin{array}{l}87 \\
80 \\
77 \\
77 \\
73\end{array}$ & $\begin{array}{l}91 \\
80 \\
82 \\
91 \\
82\end{array}$ & $\begin{array}{l}62 \\
65 \\
56 \\
68 \\
63\end{array}$ & $\begin{array}{l}54 \\
81 \\
53 \\
69 \\
49\end{array}$ & $\begin{array}{l}97 \\
75 \\
60 \\
61 \\
57\end{array}$ & $\begin{array}{l}57 \\
57 \\
58 \\
61 \\
82\end{array}$ & $\begin{array}{l}68 \\
88 \\
66 \\
68 \\
64\end{array}$ \\
\hline $\begin{array}{l}16 \\
17 \\
18 \\
19 \\
20\end{array}$ & $\begin{array}{r}102 \\
86 \\
93 \\
86 \\
94\end{array}$ & $\begin{array}{l}85 \\
84 \\
87 \\
80 \\
76\end{array}$ & $\begin{array}{l}79 \\
81 \\
81 \\
86 \\
85\end{array}$ & $\begin{array}{l}68 \\
79 \\
75 \\
73 \\
69\end{array}$ & $\begin{array}{r}64 \\
63 \\
74 \\
105 \\
66\end{array}$ & $\begin{array}{l}70 \\
65 \\
67 \\
82 \\
80\end{array}$ & $\begin{array}{l}83 \\
87 \\
94 \\
62 \\
75\end{array}$ & $\begin{array}{l}52 \\
62 \\
58 \\
84 \\
68\end{array}$ & $\begin{array}{l}52 \\
52 \\
53 \\
53 \\
52\end{array}$ & $\begin{array}{l}58 \\
60 \\
60 \\
55 \\
55\end{array}$ & $\begin{array}{r}129 \\
162 \\
115 \\
83 \\
71\end{array}$ & $\begin{array}{l}68 \\
63 \\
80 \\
81 \\
81\end{array}$ \\
\hline $\begin{array}{l}21 \\
22 \\
23 \\
24 \\
25\end{array}$ & $\begin{array}{l}85 \\
82 \\
91 \\
89 \\
83\end{array}$ & $\begin{array}{l}91 \\
84 \\
86 \\
98 \\
94\end{array}$ & $\begin{array}{l}90 \\
70 \\
71 \\
78 \\
76\end{array}$ & $\begin{array}{l}74 \\
71 \\
71 \\
71 \\
71\end{array}$ & $\begin{array}{l}62 \\
73 \\
83 \\
76 \\
62\end{array}$ & $\begin{array}{r}82 \\
82 \\
98 \\
115 \\
128\end{array}$ & $\begin{array}{l}76 \\
71 \\
82 \\
72 \\
69\end{array}$ & $\begin{array}{l}80 \\
69 \\
53 \\
65 \\
73\end{array}$ & $\begin{array}{l}50 \\
51 \\
50 \\
57 \\
61\end{array}$ & $\begin{array}{l}60 \\
62 \\
60 \\
61 \\
56\end{array}$ & $\begin{array}{l}65 \\
57 \\
62 \\
55 \\
63\end{array}$ & $\begin{array}{r}93 \\
104 \\
76 \\
75 \\
67\end{array}$ \\
\hline $\begin{array}{l}26 \\
27 \\
28 \\
29 \\
30 \\
31\end{array}$ & $\begin{array}{r}82 \\
108 \\
110 \\
99 \\
80 \\
89\end{array}$ & $\begin{array}{r}88 \\
90 \\
92 \\
84 \\
86 \\
---\end{array}$ & $\begin{array}{l}79 \\
79 \\
75 \\
77 \\
82 \\
78\end{array}$ & $\begin{array}{l}72 \\
72 \\
73 \\
73 \\
74 \\
74\end{array}$ & $\begin{array}{r}67 \\
87 \\
72 \\
--- \\
-- \\
---\end{array}$ & $\begin{array}{r}171 \\
137 \\
113 \\
102 \\
117 \\
93\end{array}$ & $\begin{array}{r}72 \\
75 \\
75 \\
74 \\
65 \\
-\end{array}$ & $\begin{array}{l}66 \\
79 \\
66 \\
89 \\
49 \\
53\end{array}$ & $\begin{array}{r}56 \\
70 \\
56 \\
64 \\
58 \\
---\end{array}$ & $\begin{array}{l}50 \\
47 \\
48 \\
51 \\
50 \\
48\end{array}$ & $\begin{array}{l}56 \\
57 \\
59 \\
63 \\
59 \\
87\end{array}$ & $\begin{array}{r}59 \\
67 \\
78 \\
73 \\
102\end{array}$ \\
\hline $\begin{array}{l}\text { TOTAL } \\
\text { MEAN } \\
\text { MAX } \\
\text { MIN } \\
\text { CFSM } \\
\text { IN. }\end{array}$ & $\begin{array}{r}3463 \\
112 \\
242 \\
80 \\
1.79 \\
2.06\end{array}$ & $\begin{array}{r}2571 \\
85.7 \\
98 \\
56 \\
1.37 \\
1.53\end{array}$ & $\begin{array}{r}2467 \\
79.6 \\
90 \\
70 \\
1.27 \\
1.47\end{array}$ & $\begin{array}{r}2311 \\
74.5 \\
81 \\
68 \\
1.19 \\
1.37\end{array}$ & $\begin{array}{r}2099 \\
75.0 \\
105 \\
62 \\
1.20 \\
1.25\end{array}$ & $\begin{array}{r}2912 \\
93.9 \\
171 \\
58 \\
1.50 \\
1.73\end{array}$ & $\begin{array}{r}2440 \\
81.3 \\
105 \\
62 \\
1.30 \\
1.45\end{array}$ & $\begin{array}{r}2021 \\
65.2 \\
89 \\
49 \\
1.04 \\
1.20\end{array}$ & $\begin{array}{r}1724 \\
57.5 \\
81 \\
49 \\
.92 \\
1.02\end{array}$ & $\begin{array}{r}1951 \\
62.9 \\
208 \\
47 \\
1.01 \\
1.16\end{array}$ & $\begin{array}{r}2260 \\
72.9 \\
162 \\
49 \\
1.17 \\
1.34\end{array}$ & $\begin{array}{r}2129 \\
71.0 \\
104 \\
54 \\
1.13 \\
1.27\end{array}$ \\
\hline
\end{tabular}

$\begin{array}{lllllllll}\text { CAL YR } 1986 & \text { TOTAL } 32432 & \text { MEAN } 88.9 & \text { MAX } 320 & \text { MIN } 52 & \text { CFSM } 1.42 & \text { IN } 19.27\end{array}$

WTR YR 1987 TOTAL 28348 MEAN 77.7 MAX 242 MIN 47 CFSM 1.24 IN 16.85 
LOCATION.--Lat $45^{\circ} 34^{\prime} 38^{\prime \prime}$, long $84^{\circ} 29^{\prime} 15^{\prime \prime}$, in SWl/4 SWl/4 sec.19, T.37 N., R.1 W., Cheboygan County, Hydrologic Unit 04070004 , on right bank of Cheboygan River, 300 ft downstream from Mullett Lake, 2.4 mi upstream from Black River, and $4.8 \mathrm{mi}$ south of Cheboygan.

DRAINAGE AREA. $--889 \mathrm{mi}^{2}$.

PERIOD OF RECORD.--November 1942 to current year.

GAGE.--Water-stage recorder. Datum of gage is $591.21 \mathrm{ft}$ above National Geodetic Vertical Datum of 1929.

REMARKS.--Mullett Lake is part of the navigable inland water route. The major inlet is Indian River. other inlets are Pigeon, Little Pigeon, and Little sturgeon Rivers and Negro and Scott Creeks. The outlet is Cheboygan River. Streamflow records were collected for cheboygan River (station 04130000 ) from October 1942 to September 1982 and for Indian River (station 04128500 ) from April 1942 to

September 1982. Lake level regulated by hydroelectric dam and spillway in Cheboygan. Maximum depth $147 \mathrm{ft}$, surface area 17,100 acres.

EXTREMES FOR PERIOD OF RECORD.--Maximum daily gage height, 3.27 ft, May 13, 14, 1960; minimum daily, 0.88 ft, Mar. 19, 1984 .

EXTREMES FOR CURRENT YEAR.--Maximum daily gage height, $2.63 \mathrm{ft}$, Oct. 7,$13 ; \mathrm{minimum}$ daily, $1.47 \mathrm{ft}$, Mar. 23 .

GAGE HEIGHT (FEET ABOVE DATUM), WATER YEAR OCTOBER 1986 TO SEPTEMBER 1987 MEAN VALUES

\begin{tabular}{|c|c|c|c|c|c|c|c|c|c|c|c|c|}
\hline DAY & OCT & NOV & DEC & JAN & FEB & MAR & APR & MAY & JUN & JUL & AUG & SEP \\
\hline $\begin{array}{l}1 \\
2 \\
3 \\
4 \\
5\end{array}$ & $\begin{array}{l}2.54 \\
2.52 \\
2.53 \\
2.54 \\
2.56\end{array}$ & $\begin{array}{l}2.25 \\
2.25 \\
2.24 \\
2.18 \\
2.18\end{array}$ & $\begin{array}{l}1.74 \\
1.72 \\
1.73 \\
1.73 \\
1.74\end{array}$ & $\begin{array}{l}1.69 \\
1.68 \\
1.68 \\
1.66 \\
1.66\end{array}$ & $\begin{array}{l}1.56 \\
1.57 \\
1.57 \\
1.59 \\
1.59\end{array}$ & $\begin{array}{l}1.56 \\
1.57 \\
1.57 \\
1.56 \\
1.54\end{array}$ & $\begin{array}{l}1.62 \\
1.66 \\
1.67 \\
1.67 \\
1.66\end{array}$ & $\begin{array}{l}2.37 \\
2.36 \\
2.38 \\
2.40 \\
2.41\end{array}$ & $\begin{array}{l}2.54 \\
2.53 \\
2.51 \\
2.46 \\
2.45\end{array}$ & $\begin{array}{l}2.42 \\
2.40 \\
2.42 \\
2.41 \\
2.42\end{array}$ & $\begin{array}{l}2.36 \\
2.44 \\
2.45 \\
2.42 \\
2.40\end{array}$ & $\begin{array}{l}2.37 \\
2.34 \\
2.34 \\
2.32 \\
2.29\end{array}$ \\
\hline $\begin{array}{r}6 \\
7 \\
8 \\
9 \\
10\end{array}$ & $\begin{array}{l}2.57 \\
2.63 \\
2.60 \\
2.61 \\
2.61\end{array}$ & $\begin{array}{l}2.15 \\
2.13 \\
2.17 \\
2.11 \\
2.04\end{array}$ & $\begin{array}{l}1.73 \\
1.73 \\
1.72 \\
1.74 \\
1.79\end{array}$ & $\begin{array}{l}1.64 \\
1.63 \\
1.62 \\
1.61 \\
1.59\end{array}$ & $\begin{array}{l}1.59 \\
1.59 \\
1.61 \\
1.60 \\
1.59\end{array}$ & $\begin{array}{l}1.54 \\
1.55 \\
1.57 \\
1.59 \\
1.60\end{array}$ & $\begin{array}{l}1.67 \\
1.68 \\
1.68 \\
1.66 \\
1.65\end{array}$ & $\begin{array}{l}2.43 \\
2.43 \\
2.41 \\
2.43 \\
2.38\end{array}$ & $\begin{array}{l}2.47 \\
2.49 \\
2.50 \\
2.46 \\
2.46\end{array}$ & $\begin{array}{l}2.43 \\
2.44 \\
2.46 \\
2.48 \\
2.51\end{array}$ & $\begin{array}{l}2.42 \\
2.41 \\
2.39 \\
2.40 \\
2.41\end{array}$ & $\begin{array}{l}2.31 \\
2.31 \\
2.32 \\
2.32 \\
2.29\end{array}$ \\
\hline $\begin{array}{l}11 \\
12 \\
13 \\
14 \\
15\end{array}$ & $\begin{array}{l}2.59 \\
2.62 \\
2.63 \\
2.62 \\
2.60\end{array}$ & $\begin{array}{l}2.01 \\
2.01 \\
1.98 \\
2.02 \\
1.92\end{array}$ & $\begin{array}{l}1.75 \\
1.78 \\
1.86 \\
1.89 \\
1.88\end{array}$ & $\begin{array}{l}1.60 \\
1.59 \\
1.58 \\
1.58 \\
1.56\end{array}$ & $\begin{array}{l}1.59 \\
1.60 \\
1.59 \\
1.60 \\
1.59\end{array}$ & $\begin{array}{l}1.60 \\
1.60 \\
1.59 \\
1.57 \\
1.56\end{array}$ & $\begin{array}{l}1.65 \\
1.66 \\
1.67 \\
1.68 \\
1.73\end{array}$ & $\begin{array}{l}2.40 \\
2.38 \\
2.40 \\
2.41 \\
2.43\end{array}$ & $\begin{array}{l}2.47 \\
2.47 \\
2.46 \\
2.50 \\
2.49\end{array}$ & $\begin{array}{l}2.50 \\
2.51 \\
2.48 \\
2.47 \\
2.46\end{array}$ & $\begin{array}{l}2.43 \\
2.41 \\
2.40 \\
2.41 \\
2.43\end{array}$ & $\begin{array}{l}2.31 \\
2.34 \\
2.33 \\
2.30 \\
2.28\end{array}$ \\
\hline $\begin{array}{l}16 \\
17 \\
18 \\
19 \\
20\end{array}$ & $\begin{array}{l}2.59 \\
2.57 \\
2.55 \\
2.53 \\
2.50\end{array}$ & $\begin{array}{l}1.91 \\
1.87 \\
1.84 \\
1.83 \\
1.82\end{array}$ & $\begin{array}{l}1.88 \\
1.89 \\
1.92 \\
1.91 \\
1.88\end{array}$ & $\begin{array}{l}1.55 \\
1.54 \\
1.53 \\
1.51 \\
1.51\end{array}$ & $\begin{array}{l}1.60 \\
1.59 \\
1.59 \\
1.58 \\
1.59\end{array}$ & $\begin{array}{l}1.54 \\
1.53 \\
1.51 \\
1.50 \\
1.49\end{array}$ & $\begin{array}{l}1.81 \\
1.87 \\
1.97 \\
2.07 \\
2.16\end{array}$ & $\begin{array}{l}2.44 \\
2.41 \\
2.41 \\
2.42 \\
2.40\end{array}$ & $\begin{array}{l}2.43 \\
2.40 \\
2.39 \\
2.40 \\
2.38\end{array}$ & $\begin{array}{l}2.45 \\
2.47 \\
2.43 \\
2.41 \\
2.43\end{array}$ & $\begin{array}{l}2.43 \\
2.48 \\
2.49 \\
2.51 \\
2.49\end{array}$ & $\begin{array}{l}2.30 \\
2.31 \\
2.29 \\
2.34 \\
2.36\end{array}$ \\
\hline $\begin{array}{l}21 \\
22 \\
23 \\
24 \\
25\end{array}$ & $\begin{array}{l}2.49 \\
2.47 \\
2.42 \\
2.40 \\
2.37\end{array}$ & $\begin{array}{l}1.81 \\
1.79 \\
1.78 \\
1.79 \\
1.79\end{array}$ & $\begin{array}{l}1.85 \\
1.83 \\
1.80 \\
1.77 \\
1.77\end{array}$ & $\begin{array}{l}1.51 \\
1.51 \\
1.51 \\
1.51 \\
1.50\end{array}$ & $\begin{array}{l}1.57 \\
1.57 \\
1.58 \\
1.57 \\
1.57\end{array}$ & $\begin{array}{l}1.48 \\
1.48 \\
1.47 \\
1.48 \\
1.49\end{array}$ & $\begin{array}{l}2.22 \\
2.30 \\
2.36 \\
2.36 \\
2.37\end{array}$ & $\begin{array}{l}2.41 \\
2.43 \\
2.46 \\
2.47 \\
2.45\end{array}$ & $\begin{array}{l}2.38 \\
2.38 \\
2.41 \\
2.40 \\
2.40\end{array}$ & $\begin{array}{l}2.45 \\
2.42 \\
2.44 \\
2.43 \\
2.41\end{array}$ & $\begin{array}{l}2.47 \\
2.42 \\
2.40 \\
2.40 \\
2.40\end{array}$ & $\begin{array}{l}2.39 \\
2.41 \\
2.42 \\
2.37 \\
2.37\end{array}$ \\
\hline $\begin{array}{l}26 \\
27 \\
28 \\
29 \\
30 \\
31\end{array}$ & $\begin{array}{l}2.35 \\
2.34 \\
2.33 \\
2.30 \\
2.29 \\
2.29\end{array}$ & $\begin{array}{l}1.76 \\
1.82 \\
1.81 \\
1.75 \\
1.76 \\
----\end{array}$ & $\begin{array}{l}1.76 \\
1.75 \\
1.74 \\
1.72 \\
1.71 \\
1.70\end{array}$ & $\begin{array}{l}1.49 \\
1.49 \\
1.50 \\
1.50 \\
1.54 \\
1.56\end{array}$ & $\begin{array}{r}1.56 \\
1.55 \\
1.54 \\
---- \\
--- \\
---\end{array}$ & $\begin{array}{l}1.54 \\
1.55 \\
1.57 \\
1.59 \\
1.60 \\
1.60\end{array}$ & $\begin{array}{l}2.35 \\
2.38 \\
2.38 \\
2.38 \\
2.36 \\
----\end{array}$ & $\begin{array}{l}2.48 \\
2.56 \\
2.60 \\
2.61 \\
2.59 \\
2.57\end{array}$ & $\begin{array}{l}2.47 \\
2.45 \\
2.45 \\
2.45 \\
2.45 \\
-.--\end{array}$ & $\begin{array}{l}2.39 \\
2.39 \\
2.37 \\
2.38 \\
2.38 \\
2.36\end{array}$ & $\begin{array}{l}2.38 \\
2.36 \\
2.38 \\
2.38 \\
2.41 \\
2.38\end{array}$ & $\begin{array}{l}2.35 \\
2.33 \\
2.34 \\
2.35 \\
2.33 \\
----\end{array}$ \\
\hline $\begin{array}{l}\text { MEAN } \\
\text { MAX } \\
\text { MIN }\end{array}$ & $\begin{array}{l}2.50 \\
2.63 \\
2.29\end{array}$ & $\begin{array}{l}1.96 \\
2.25 \\
1.75\end{array}$ & $\begin{array}{l}1.79 \\
1.92 \\
1.70\end{array}$ & $\begin{array}{l}1.57 \\
1.69 \\
1.49\end{array}$ & $\begin{array}{l}1.58 \\
1.61 \\
1.54\end{array}$ & $\begin{array}{l}1.55 \\
1.60 \\
1.47\end{array}$ & $\begin{array}{l}1.95 \\
2.38 \\
1.62\end{array}$ & $\begin{array}{l}2.44 \\
2.61 \\
2.36\end{array}$ & $\begin{array}{l}2.45 \\
2.54 \\
2.38\end{array}$ & $\begin{array}{l}2.43 \\
2.51 \\
2.36\end{array}$ & $\begin{array}{l}2.42 \\
2.51 \\
2.36\end{array}$ & $\begin{array}{l}2.33 \\
2.42 \\
2.28\end{array}$ \\
\hline
\end{tabular}

WTR YR 1987 MEAN 2.08 MAX $2.63 \quad$ MIN 1.47 
04130500 BLACK RIVER NEAR TOWER, MI

LOCATION. - Lat $45^{\circ} 23^{\prime} 33^{\prime \prime}$, long $84^{\circ} 20^{\prime} 00^{\prime \prime}$, in SEl/4 NEl/4 sec. 29, T. 35 N. R. I E. Cheboygan COunty, Hydrologic Unit 04070005 , on right bank $400 \mathrm{ft}$ downstream from Kleber' Dam, 1,000 ft upstream from Miligan Creek, $3.0 \mathrm{mi}$ northwest of Tower, and $10.8 \mathrm{mi}$ upstream from Black Lake.

DRAINAGE AREA. $--311 \mathrm{mi}^{2}$.

PERIOD OF RECORD.--October 1942 to current year. Monthly discharge only for October 1942 , published in WSP 1307.

REVISED RECORDS.--WSP 1307: 1942. WDR MI-83: Drainage area.

GAGE.--Water-stage recorder. Datum of gage is $658.00 \mathrm{ft}$, Stanley Engineering Co. datum. Prior to Aug. 1, 1949, at site $1 \mathrm{mi}$ upstream at different datum.

REMARKS.--No estimated daily discharges. Records good. Flow completely regulated by $\mathrm{kleber}$ Dam $400 \mathrm{ft}$ upstream. Several measurements of water temperature were made during the year.

AVERAGE DISCHARGE. -45 years, $273 \mathrm{ft}^{3} / \mathrm{s}, 11.92 \mathrm{in} / \mathrm{yr}$.

EXTREMES FOR PERIOD OF RECORD.--Maximum discharge, 2,340 $\mathrm{ft}^{3} / \mathrm{s}$, Apr. 17, 1960, gage height, $7.13 \mathrm{ft}$; minimum, $0.60 \mathrm{ft}^{3} / \mathrm{s}$, Mar. 11, 1950; minimum daily, $4.0 \mathrm{ft}^{3} / \mathrm{s}$, Nov. $27,1949$.

EXTREMES FOR CURRENT YEAR.--Maximum discharge, $718 \mathrm{ft}^{3} / \mathrm{s}$, Oct. 6 , gage height, 4.07 $\mathrm{ft}$; minimum, $9.0 \mathrm{ft}^{3} / \mathrm{s}, \mathrm{Apr}$. 15, gage height, $1.20 \mathrm{ft} ; \mathrm{minimum} \mathrm{daily,} 1 \mathrm{il} \mathrm{ft} / \mathrm{s}, \mathrm{July} 22$.

DISCHARGE, IN CUBIC FEET PER SECOND, WATER YEAR OCTOBER 1986 TO SEPTEMBER 1987 MEAN VALUES

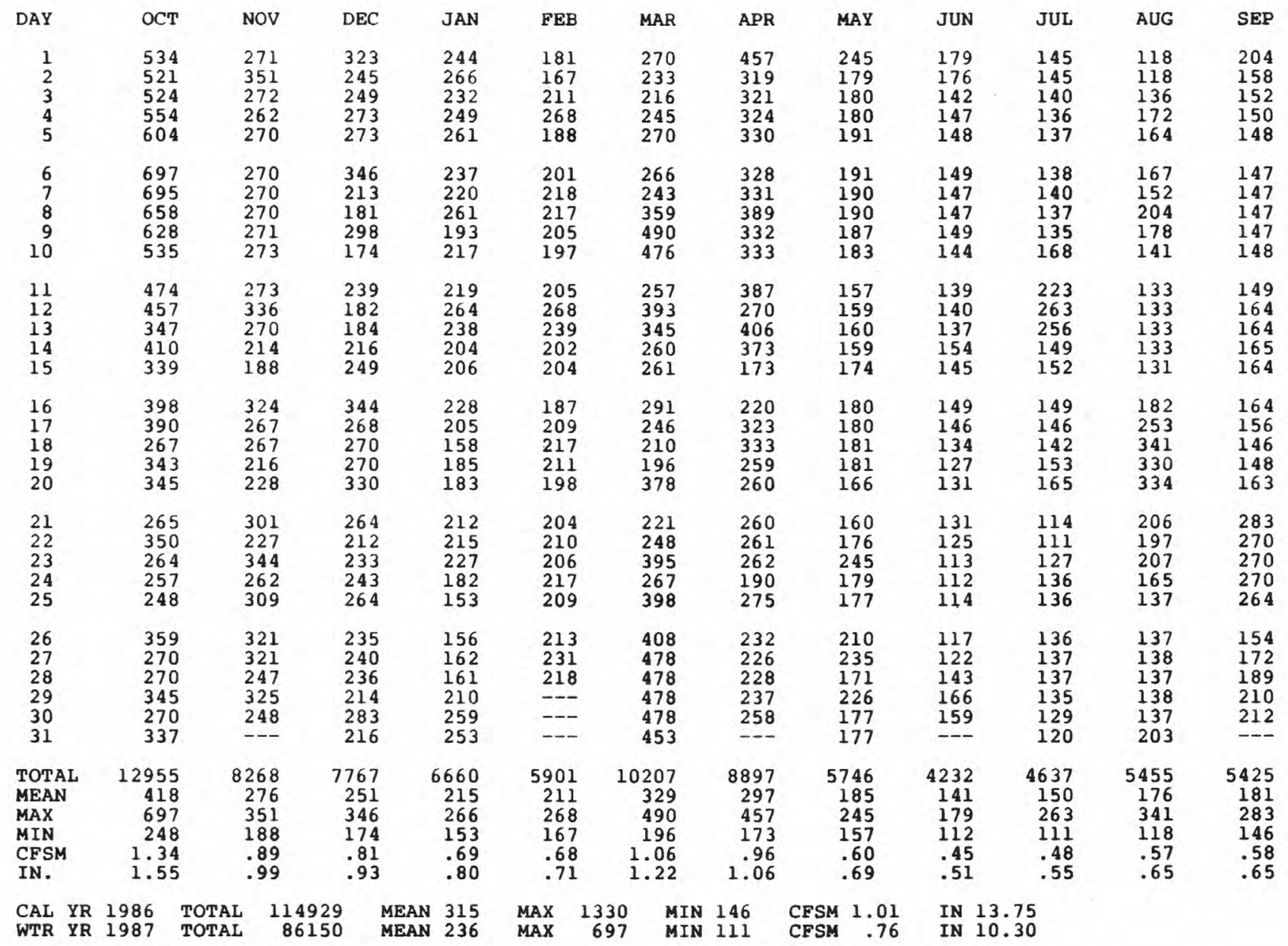


LOCATION. --Lat $45^{\circ} 38^{\prime} 09^{\prime \prime}$, long $84^{\circ} 28^{\prime} 50^{\prime \prime}$, in SWl/4 SEl/4 sec.31, T. 38 N., R.1 W., Cheboygan County, Hydrologic Unit 04070004 , on right bank $660 \mathrm{ft}$ downstream from Iincoln Avenue' in Cheboygan, 1.8 mi upstream from mouth of Cheboygan River.

DRAINAGE AREA. $--1,500 \mathrm{mi}^{2}$, approximately.

PERIOD OF RECORD.--November 1942 to current year.

GAGE. - Water-stage recorder. Datum of gage is $590.00 \mathrm{ft}$ above National Geodetic Vertical Datum of 1929. Prior to Aug. 30,1967 , nonrecording gage at same datum.

REMARKS.--Cheboygan Pond is formed by an earthfill dam, hydro-electric dam, boat lock and concrete spiliway which contains 6 vertical lift gates. Cheboygan Pond is part of the navigable inland water route. The inlet and outlet of Cheboygan Pond is the Cheboygan River. Other inlets are Black River and Tannery Gulley. Streamflow records for Cheboygan River (station 04130000 ) were collected from October 1942 to September 1982. Pond elevation regulated by hydroelectric dam and spillway.

EXTREMES FOR PERIOD OF RECORD.--Maximum gage height, $3.83 \mathrm{ft}$, Oct. 19, 1984; minimum, $-0.27 \mathrm{ft}, \mathrm{Mar}$. 11, 12,1984 .

EXTREMES FOR CURRENT YEAR.--Maximum gage height, $3.71 \mathrm{ft}$, May $30 ;$ minimum, $1.60 \mathrm{ft}$, Feb. 3 .

GAGE HEIGHT (FEET ABOVE DATUM), WATER YEAR OCTOBER 1986 TO SEPTEMBER 1987 MEAN VALUES

\begin{tabular}{|c|c|c|c|c|c|c|c|c|c|c|c|c|}
\hline DAY & OCT & NOV & DEC & JAN & FEB & MAR & APR & MAY & JUN & JUL & AUG & SEP \\
\hline $\begin{array}{l}1 \\
2 \\
3 \\
4 \\
5\end{array}$ & $\begin{array}{l}2.92 \\
2.94 \\
2.93 \\
2.95 \\
2.95\end{array}$ & $\begin{array}{l}2.59 \\
2.58 \\
2.57 \\
2.50 \\
2.49\end{array}$ & $\begin{array}{l}1.97 \\
1.94 \\
1.95 \\
1.94 \\
1.99\end{array}$ & $\begin{array}{l}2.00 \\
1.98 \\
2.03 \\
1.99 \\
2.00\end{array}$ & $\begin{array}{l}2.18 \\
2.15 \\
2.04 \\
2.17 \\
2.18\end{array}$ & $\begin{array}{l}2.11 \\
2.10 \\
2.10 \\
2.10 \\
2.08\end{array}$ & $\begin{array}{l}1.99 \\
1.99 \\
2.02 \\
2.01 \\
1.99\end{array}$ & $\begin{array}{l}3.21 \\
3.28 \\
3.31 \\
3.35 \\
3.37\end{array}$ & $\begin{array}{l}3.26 \\
3.25 \\
3.25 \\
3.23 \\
3.36\end{array}$ & $\begin{array}{l}3.21 \\
3.22 \\
3.35 \\
3.34 \\
3.35\end{array}$ & $\begin{array}{l}3.29 \\
3.36 \\
3.37 \\
3.25 \\
3.27\end{array}$ & $\begin{array}{l}3.24 \\
3.16 \\
3.17 \\
3.09 \\
3.11\end{array}$ \\
\hline $\begin{array}{r}6 \\
7 \\
8 \\
9 \\
10\end{array}$ & $\begin{array}{l}2.94 \\
2.96 \\
2.94 \\
2.94 \\
2.95\end{array}$ & $\begin{array}{l}2.48 \\
2.45 \\
2.41 \\
2.38 \\
2.36\end{array}$ & $\begin{array}{l}2.11 \\
2.12 \\
2.12 \\
2.12 \\
2.10\end{array}$ & $\begin{array}{l}2.00 \\
1.98 \\
1.98 \\
1.98 \\
1.95\end{array}$ & $\begin{array}{l}2.17 \\
2.18 \\
2.16 \\
2.17 \\
2.17\end{array}$ & $\begin{array}{l}2.08 \\
2.10 \\
2.09 \\
2.08 \\
2.09\end{array}$ & $\begin{array}{l}2.05 \\
2.01 \\
1.96 \\
1.94 \\
1.96\end{array}$ & $\begin{array}{l}3.39 \\
3.36 \\
3.23 \\
3.27 \\
3.34\end{array}$ & $\begin{array}{l}3.42 \\
3.37 \\
3.27 \\
3.25 \\
3.26\end{array}$ & $\begin{array}{l}3.36 \\
3.37 \\
3.35 \\
3.36 \\
3.26\end{array}$ & $\begin{array}{l}3.34 \\
3.33 \\
3.33 \\
3.31 \\
3.38\end{array}$ & $\begin{array}{l}3.22 \\
3.16 \\
3.18 \\
3.14 \\
3.10\end{array}$ \\
\hline $\begin{array}{l}11 \\
12 \\
13 \\
14 \\
15\end{array}$ & $\begin{array}{l}2.95 \\
2.96 \\
2.85 \\
2.73 \\
2.73\end{array}$ & $\begin{array}{l}2.28 \\
2.32 \\
2.28 \\
2.27 \\
2.16\end{array}$ & $\begin{array}{l}2.02 \\
2.05 \\
2.09 \\
2.12 \\
2.13\end{array}$ & $\begin{array}{l}1.99 \\
1.99 \\
1.99 \\
2.00 \\
1.96\end{array}$ & $\begin{array}{l}2.17 \\
2.18 \\
2.17 \\
2.18 \\
2.16\end{array}$ & $\begin{array}{l}2.09 \\
2.07 \\
2.04 \\
1.97 \\
1.99\end{array}$ & $\begin{array}{l}2.04 \\
2.10 \\
2.21 \\
2.26 \\
2.42\end{array}$ & $\begin{array}{l}3.33 \\
3.34 \\
3.36 \\
3.37 \\
3.38\end{array}$ & $\begin{array}{l}3.26 \\
3.27 \\
3.31 \\
3.45 \\
3.34\end{array}$ & $\begin{array}{l}3.24 \\
3.24 \\
3.27 \\
3.30 \\
3.33\end{array}$ & $\begin{array}{l}3.35 \\
3.27 \\
3.33 \\
3.31 \\
3.30\end{array}$ & $\begin{array}{l}3.11 \\
3.09 \\
3.18 \\
3.07 \\
3.08\end{array}$ \\
\hline $\begin{array}{l}16 \\
17 \\
18 \\
19 \\
20\end{array}$ & $\begin{array}{l}2.85 \\
2.79 \\
2.72 \\
2.71 \\
2.70\end{array}$ & $\begin{array}{l}2.18 \\
2.11 \\
2.03 \\
2.02 \\
2.03\end{array}$ & $\begin{array}{l}2.14 \\
2.33 \\
2.41 \\
2.31 \\
2.07\end{array}$ & $\begin{array}{l}1.97 \\
1.97 \\
1.97 \\
1.95 \\
1.97\end{array}$ & $\begin{array}{l}2.18 \\
2.18 \\
2.19 \\
2.17 \\
2.21\end{array}$ & $\begin{array}{l}1.95 \\
1.93 \\
1.92 \\
1.91 \\
1.89\end{array}$ & $\begin{array}{l}2.67 \\
2.82 \\
3.00 \\
3.10 \\
3.19\end{array}$ & $\begin{array}{l}3.33 \\
3.34 \\
3.35 \\
3.31 \\
3.24\end{array}$ & $\begin{array}{l}3.14 \\
3.14 \\
3.21 \\
3.29 \\
3.25\end{array}$ & $\begin{array}{l}3.31 \\
3.34 \\
3.22 \\
3.24 \\
3.31\end{array}$ & $\begin{array}{l}3.30 \\
3.41 \\
3.32 \\
3.24 \\
3.24\end{array}$ & $\begin{array}{l}3.25 \\
3.13 \\
3.11 \\
3.17 \\
3.17\end{array}$ \\
\hline $\begin{array}{l}21 \\
22 \\
23 \\
24 \\
25\end{array}$ & $\begin{array}{l}2.71 \\
2.67 \\
2.64 \\
2.64 \\
2.62\end{array}$ & $\begin{array}{l}1.99 \\
1.93 \\
1.94 \\
1.96 \\
2.02\end{array}$ & $\begin{array}{l}2.04 \\
2.05 \\
2.00 \\
1.97 \\
2.01\end{array}$ & $\begin{array}{l}1.99 \\
2.00 \\
2.01 \\
1.98 \\
1.99\end{array}$ & $\begin{array}{l}2.15 \\
2.16 \\
2.17 \\
2.14 \\
2.15\end{array}$ & $\begin{array}{l}1.90 \\
1.90 \\
1.88 \\
1.89 \\
1.90\end{array}$ & $\begin{array}{l}3.24 \\
3.31 \\
3.31 \\
3.22 \\
3.22\end{array}$ & $\begin{array}{l}3.34 \\
3.34 \\
3.41 \\
3.42 \\
3.30\end{array}$ & $\begin{array}{l}3.33 \\
3.32 \\
3.38 \\
3.24 \\
3.19\end{array}$ & $\begin{array}{l}3.36 \\
3.25 \\
3.31 \\
3.33 \\
3.34\end{array}$ & $\begin{array}{l}3.22 \\
3.19 \\
3.25 \\
3.35 \\
3.33\end{array}$ & $\begin{array}{l}3.15 \\
3.15 \\
3.15 \\
3.12 \\
3.13\end{array}$ \\
\hline $\begin{array}{l}26 \\
27 \\
28 \\
29 \\
30 \\
31\end{array}$ & $\begin{array}{l}2.65 \\
2.63 \\
2.65 \\
2.63 \\
2.63 \\
2.62\end{array}$ & $\begin{array}{r}2.02 \\
2.19 \\
2.17 \\
1.97 \\
2.12 \\
-\end{array}$ & $\begin{array}{l}2.05 \\
2.04 \\
2.07 \\
2.02 \\
2.03 \\
2.02\end{array}$ & $\begin{array}{l}1.99 \\
2.03 \\
2.09 \\
2.12 \\
2.16 \\
2.17\end{array}$ & $\begin{array}{r}2.14 \\
2.12 \\
2.12 \\
- \\
-.-- \\
-\end{array}$ & $\begin{array}{l}1.90 \\
1.92 \\
1.93 \\
1.92 \\
1.92 \\
1.95\end{array}$ & $\begin{array}{c}3.19 \\
3.25 \\
3.22 \\
3.24 \\
3.21 \\
-\end{array}$ & $\begin{array}{l}3.26 \\
3.28 \\
3.32 \\
3.33 \\
3.28 \\
3.26\end{array}$ & $\begin{array}{r}3.21 \\
3.30 \\
3.30 \\
3.27 \\
3.30 \\
-\end{array}$ & $\begin{array}{l}3.31 \\
3.31 \\
3.30 \\
3.36 \\
3.31 \\
3.29\end{array}$ & $\begin{array}{l}3.25 \\
3.22 \\
3.30 \\
3.25 \\
3.27 \\
3.31\end{array}$ & $\begin{array}{l}3.15 \\
3.09 \\
3.12 \\
3.12 \\
3.10 \\
\end{array}$ \\
\hline $\begin{array}{l}\text { MEAN } \\
\text { MAX } \\
\text { MIN }\end{array}$ & $\begin{array}{l}2.79 \\
2.96 \\
2.62\end{array}$ & $\begin{array}{l}2.23 \\
2.59 \\
1.93\end{array}$ & $\begin{array}{l}2.08 \\
2.41 \\
1.94\end{array}$ & $\begin{array}{l}2.01 \\
2.17 \\
1.95\end{array}$ & $\begin{array}{l}2.16 \\
2.21 \\
2.04\end{array}$ & $\begin{array}{l}1.99 \\
2.11 \\
1.88\end{array}$ & $\begin{array}{l}2.60 \\
3.31 \\
1.94\end{array}$ & $\begin{array}{l}3.32 \\
3.42 \\
3.21\end{array}$ & $\begin{array}{l}3.28 \\
3.45 \\
3.14\end{array}$ & $\begin{array}{l}3.30 \\
3.37 \\
3.21\end{array}$ & $\begin{array}{l}3.30 \\
3.41 \\
3.19\end{array}$ & $\begin{array}{l}3.14 \\
3.25 \\
3.07\end{array}$ \\
\hline
\end{tabular}

WTR YR 1987 MEAN 2.69 MAX $3.45 \quad$ MIN 1.88 
04135000 THUNDER BAY RIVER NEAR ALPENA, MI

(National stream quality accounting network station)

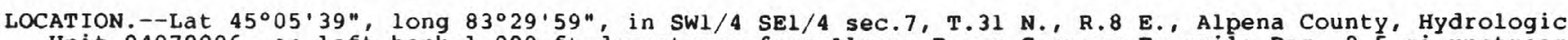
Unit 04070006 , on left bank $1,000 \mathrm{ft}$ downstream from Alpena' Power Company Fourmile Dam, 2.5 mi upstream from Bagley street in Alpena, and $6.0 \mathrm{mi}$ upstream from mouth.

DRAINAGE AREA.--1,238 $\mathrm{mi}^{2}$.

\section{WATER-DISCHARGE RECORDS}

PERIOD OF RECORD.--April 1901 to December 1908, October 1979 to current year. Occasional discharge measurements, water years $1945-50$.

REVISED RECORDS.--WSP 1307: 1901-09. WDR MI-80: Drainage area.

GAGE.--Two water-stage recorders. Elevation of gage on main (north) channel and secondary gage on (south) channel is $615 \mathrm{ft}$ above National Geodetic Vertical Datum of 1929, from topographic map.

REMARKS.--Estimated daily discharges: Dec. 5 to Mar. 5, Mar. 9-16, June 14, 15, 24, 29, July 10, 18, and Aug. 4 to Sept. 30. Water-discharge records good except for estimated daily discharges, which are poor. Flow regulated at all stages by hydroelectric plant 1,000 ft upstream.

AVERAGE DISCHARGE.--15 years (water years 1902-08, 1980-87), 915 ft $3 / \mathrm{s}, 10.04 \mathrm{in} / \mathrm{yr}^{\mathrm{s}}$

EXTREMES FOR PERIOD OF RECORD.--Maximum daily discharge, 12,100 ft $3 / \mathrm{s}, \mathrm{Mar} .28,1986$; minimum daily, $31 \mathrm{ft}^{3} / \mathrm{s}, \mathrm{May} 9,1987$.

EXTREMES FOR CURRENT YEAR.--Maximum daily discharge, $2,760 \mathrm{ft}^{3} / \mathrm{s}$, Oct. 6 ; minimum daily, $31 \mathrm{ft} 3 / \mathrm{s}$, May 9.

DISCHARGE, IN CUBIC FEET PER SECOND, WATER YEAR OCTOBER 1986 TO SEPTEMBER 1987

\begin{tabular}{|c|c|c|c|c|c|c|c|c|c|c|c|c|}
\hline DAY & OCT & NOV & DEC & JAN & FEB & MAR & APR & MAY & JUN & JUL & AUG & SEP \\
\hline $\begin{array}{l}1 \\
2 \\
3 \\
4 \\
5\end{array}$ & $\begin{array}{l}2080 \\
1680 \\
2310 \\
2480 \\
2690\end{array}$ & $\begin{array}{l}1290 \\
1340 \\
1340 \\
1340 \\
1340\end{array}$ & $\begin{array}{l}1240 \\
1170 \\
1240 \\
1500 \\
1210\end{array}$ & $\begin{array}{r}895 \\
1090 \\
928 \\
823 \\
961\end{array}$ & $\begin{array}{l}631 \\
611 \\
631 \\
812 \\
812\end{array}$ & $\begin{array}{r}664 \\
903 \\
842 \\
1010 \\
1030\end{array}$ & $\begin{array}{r}1530 \\
1480 \\
1500 \\
1360 \\
652\end{array}$ & $\begin{array}{l}645 \\
236 \\
226 \\
619 \\
670\end{array}$ & $\begin{array}{l}503 \\
527 \\
602 \\
594 \\
505\end{array}$ & $\begin{array}{r}458 \\
431 \\
437 \\
226 \\
52\end{array}$ & $\begin{array}{r}81 \\
120 \\
599 \\
449 \\
469\end{array}$ & $\begin{array}{l}510 \\
472 \\
493 \\
454 \\
492\end{array}$ \\
\hline $\begin{array}{r}6 \\
7 \\
8 \\
9 \\
10\end{array}$ & $\begin{array}{l}2760 \\
2700 \\
2510 \\
2260 \\
2000\end{array}$ & $\begin{array}{l}1330 \\
1330 \\
1320 \\
1330 \\
1330\end{array}$ & $\begin{array}{l}1180 \\
1010 \\
1040 \\
1100 \\
1110\end{array}$ & $\begin{array}{r}969 \\
968 \\
961 \\
1030 \\
492\end{array}$ & $\begin{array}{l}722 \\
472 \\
592 \\
731 \\
680\end{array}$ & $\begin{array}{r}984 \\
1220 \\
1230 \\
1600 \\
2130\end{array}$ & $\begin{array}{r}930 \\
1030 \\
1050 \\
1130 \\
1040\end{array}$ & $\begin{array}{r}642 \\
651 \\
456 \\
31 \\
53\end{array}$ & $\begin{array}{l}429 \\
451 \\
526 \\
452 \\
428\end{array}$ & $\begin{array}{l}444 \\
485 \\
501 \\
446 \\
424\end{array}$ & $\begin{array}{l}484 \\
453 \\
422 \\
514 \\
500\end{array}$ & $\begin{array}{l}534 \\
502 \\
514 \\
478 \\
540\end{array}$ \\
\hline $\begin{array}{l}11 \\
12 \\
13 \\
14 \\
15\end{array}$ & $\begin{array}{l}1940 \\
1530 \\
1310 \\
1310 \\
1320\end{array}$ & $\begin{array}{r}1290 \\
1080 \\
1240 \\
1180 \\
951\end{array}$ & $\begin{array}{r}1110 \\
1030 \\
686 \\
489 \\
787\end{array}$ & $\begin{array}{l}492 \\
712 \\
932 \\
932 \\
932\end{array}$ & $\begin{array}{l}741 \\
762 \\
801 \\
490 \\
489\end{array}$ & $\begin{array}{r}1730 \\
1580 \\
1460 \\
1220 \\
825\end{array}$ & $\begin{array}{l}933 \\
827 \\
956 \\
987 \\
931\end{array}$ & $\begin{array}{r}302 \\
293 \\
130 \\
112 \\
82\end{array}$ & $\begin{array}{l}381 \\
482 \\
427 \\
442 \\
452\end{array}$ & $\begin{array}{l}379 \\
449 \\
495 \\
421 \\
415\end{array}$ & $\begin{array}{l}306 \\
284 \\
355 \\
464 \\
433\end{array}$ & $\begin{array}{l}378 \\
455 \\
435 \\
438 \\
308\end{array}$ \\
\hline $\begin{array}{l}16 \\
17 \\
18 \\
19 \\
20\end{array}$ & $\begin{array}{l}1370 \\
1360 \\
1330 \\
1320 \\
1280\end{array}$ & $\begin{array}{r}865 \\
1150 \\
1100 \\
1180 \\
1120\end{array}$ & $\begin{array}{r}941 \\
1090 \\
1140 \\
1220 \\
1190\end{array}$ & $\begin{array}{l}912 \\
461 \\
350 \\
610 \\
610\end{array}$ & $\begin{array}{l}769 \\
800 \\
801 \\
792 \\
613\end{array}$ & $\begin{array}{l}880 \\
868 \\
935 \\
847 \\
901\end{array}$ & $\begin{array}{l}970 \\
912 \\
617 \\
472 \\
835\end{array}$ & $\begin{array}{l}268 \\
361 \\
262 \\
386 \\
415\end{array}$ & $\begin{array}{l}424 \\
445 \\
405 \\
403 \\
410\end{array}$ & $\begin{array}{l}289 \\
284 \\
452 \\
219 \\
219\end{array}$ & $\begin{array}{l}449 \\
485 \\
532 \\
833 \\
834\end{array}$ & $\begin{array}{l}531 \\
449 \\
441 \\
418 \\
451\end{array}$ \\
\hline $\begin{array}{l}21 \\
22 \\
23 \\
24 \\
25\end{array}$ & $\begin{array}{l}1240 \\
1230 \\
1240 \\
1240 \\
1250\end{array}$ & $\begin{array}{l}1100 \\
1010 \\
1150 \\
1180 \\
1210\end{array}$ & $\begin{array}{l}1000 \\
1050 \\
1180 \\
1210 \\
1100\end{array}$ & $\begin{array}{l}460 \\
460 \\
460 \\
450 \\
440\end{array}$ & $\begin{array}{l}443 \\
434 \\
674 \\
874 \\
814\end{array}$ & $\begin{array}{r}889 \\
838 \\
1070 \\
1250 \\
1550\end{array}$ & $\begin{array}{l}859 \\
776 \\
770 \\
719 \\
512\end{array}$ & $\begin{array}{l}409 \\
440 \\
358 \\
402 \\
403\end{array}$ & $\begin{array}{l}426 \\
430 \\
303 \\
297 \\
260\end{array}$ & $\begin{array}{l}284 \\
151 \\
316 \\
362 \\
260\end{array}$ & $\begin{array}{l}849 \\
792 \\
626 \\
629 \\
541\end{array}$ & $\begin{array}{l}789 \\
681 \\
751 \\
796 \\
835\end{array}$ \\
\hline $\begin{array}{l}26 \\
27 \\
28 \\
29 \\
30 \\
31\end{array}$ & $\begin{array}{l}1240 \\
1240 \\
1240 \\
1250 \\
1250 \\
1250\end{array}$ & $\begin{array}{l}1240 \\
1240 \\
1240 \\
1240 \\
1230 \\
-\end{array}$ & $\begin{array}{r}1040 \\
899 \\
847 \\
1050 \\
1080 \\
1120\end{array}$ & $\begin{array}{r}490 \\
440 \\
710 \\
1230 \\
1230 \\
1230\end{array}$ & $\begin{array}{l}705 \\
845 \\
715 \\
--- \\
--- \\
---\end{array}$ & $\begin{array}{l}1540 \\
1550 \\
1640 \\
1720 \\
1700 \\
1580\end{array}$ & $\begin{array}{l}425 \\
763 \\
657 \\
782 \\
690 \\
---\end{array}$ & $\begin{array}{l}455 \\
410 \\
433 \\
448 \\
577 \\
597\end{array}$ & $\begin{array}{r}247 \\
62 \\
51 \\
339 \\
454 \\
--\end{array}$ & $\begin{array}{r}44 \\
264 \\
306 \\
531 \\
369 \\
337\end{array}$ & $\begin{array}{l}467 \\
471 \\
475 \\
196 \\
318 \\
547\end{array}$ & $\begin{array}{l}762 \\
673 \\
726 \\
636 \\
693 \\
-\end{array}$ \\
\hline $\begin{array}{l}\text { TOTAL } \\
\text { MEAN } \\
\text { MAX } \\
\text { MIN } \\
\text { CFSM } \\
\text { IN. }\end{array}$ & $\begin{array}{r}51210 \\
1652 \\
2760 \\
1230 \\
1.33 \\
1.54\end{array}$ & $\begin{array}{r}36286 \\
1210 \\
1340 \\
865 \\
.98 \\
1.09\end{array}$ & $\begin{array}{r}33059 \\
1066 \\
1500 \\
489 \\
.86 \\
.99\end{array}$ & $\begin{array}{r}23660 \\
763 \\
1230 \\
350 \\
.62 \\
.71\end{array}$ & $\begin{array}{r}19256 \\
688 \\
874 \\
434 \\
.56 \\
.58\end{array}$ & $\begin{array}{r}38186 \\
1232 \\
2130 \\
664 \\
1.00 \\
1.15\end{array}$ & $\begin{array}{r}27095 \\
903 \\
1530 \\
425 \\
.73 \\
.81\end{array}$ & $\begin{array}{r}11772 \\
380 \\
670 \\
31 \\
.31 \\
.35\end{array}$ & $\begin{array}{r}12157 \\
405 \\
602 \\
51 \\
.33 \\
.37\end{array}$ & $\begin{array}{r}10750 \\
347 \\
531 \\
44 \\
.28 \\
.32\end{array}$ & $\begin{array}{r}14977 \\
483 \\
849 \\
81 \\
.39 \\
.45\end{array}$ & $\begin{array}{r}16635 \\
555 \\
835 \\
308 \\
.45 \\
.50\end{array}$ \\
\hline $\begin{array}{l}\text { CAL YR } \\
\text { WTR YR }\end{array}$ & $\begin{array}{l}1986 \\
1987\end{array}$ & $\begin{array}{l}A L \\
A L\end{array}$ & $\begin{array}{l}53 \\
13\end{array}$ & $\begin{array}{rr}\mathrm{N} & 1210 \\
\mathrm{~N} & 808\end{array}$ & $\begin{array}{l}\text { MAX } \\
\text { MAX }\end{array}$ & $\begin{array}{r}12100 \\
2760\end{array}$ & $\begin{array}{lr}\text { MIN } & 214 \\
\text { MIN } & 31\end{array}$ & $\begin{array}{l}\text { CFSM } \\
\text { CFSM }\end{array}$ & $\begin{array}{l}.98 \\
.65\end{array}$ & $\begin{array}{r}13.27 \\
8.87\end{array}$ & & \\
\hline
\end{tabular}


PERIOD OF RECORD.--October 1979 to current year.

PERIOD OF DAILY RECORD.--

SPECIFIC CONDUCTANCE: October 1979 to September 1985.

WATER TEMPERATURE: October 1979 to September 1985.

INSTRUMENTATION.--Water-quality monitor from Oct. 9, 1980 to sept. 30, 1985.

REMARKS.--Bimonthly cross-sectional samples were collected near the gage. From February 1979 to September 1979, samples were collected $6.9 \mathrm{mi}$ downstream from gage (station 04135020).

EXTREMES FOR PERIOD OF DAILY RECORD.--

SPECIFIC CONDUCTANCE (water years 1980-83): Maximum, 511 microsiemens, Jan. 2, 1982; minimum measured, 120 microsiemens, Dec. $19,1981$.

WATER TEMPERATURE (water years 1980-83): Maximum, $31.0^{\circ} \mathrm{C}$, July 11, 12, 1981; minimum, $0.0^{\circ} \mathrm{C}$ on many days during winter.

WATER QUALITY DATA， WATER YEAR OCTOBER 1986 TO SEPTEMBER 1987

\begin{tabular}{|c|c|c|c|c|c|c|c|c|c|c|}
\hline DATE & TIME & $\begin{array}{l}\text { STREAM- } \\
\text { FLOW, } \\
\text { INSTAN- } \\
\text { TANEOUS } \\
\text { (CFS) }\end{array}$ & $\begin{array}{l}\text { SPE- } \\
\text { CIFIC } \\
\text { CON- } \\
\text { DUCT- } \\
\text { ANCE } \\
\text { (US/CM) }\end{array}$ & $\begin{array}{c}\text { PH } \\
\text { ( STAND- } \\
\text { ARD } \\
\text { UNITS) }\end{array}$ & $\begin{array}{l}\text { TEMPER- } \\
\text { ATURE } \\
\text { (DEG C) }\end{array}$ & $\begin{array}{l}\text { TUR- } \\
\text { BID- } \\
\text { ITY } \\
\text { (NTU) }\end{array}$ & $\begin{array}{c}\text { OXYGEN, } \\
\text { DIS- } \\
\text { SOLVED } \\
\text { (MG/L) }\end{array}$ & $\begin{array}{l}\text { OXYGEN, } \\
\text { DIS- } \\
\text { SOLVED } \\
\text { (PER- } \\
\text { CENT } \\
\text { SATUR- } \\
\text { ATION) }\end{array}$ & $\begin{array}{l}\text { COLI- } \\
\text { FORM, } \\
\text { FECAL, } \\
0.7 \\
\text { UM-MF } \\
\text { (COLS./ } \\
\text { 100 ML) }\end{array}$ & $\begin{array}{c}\text { STREP- } \\
\text { TOCOCCI } \\
\text { FECAL, } \\
\text { KF AGAR } \\
\text { (COLS. } \\
\text { PER } \\
100 \mathrm{ML} \text { ) }\end{array}$ \\
\hline & & & & & & & & & & \\
\hline $05 \ldots$ & 1030 & 1270 & 393 & 8.19 & 5.0 & 9.7 & 12.2 & 97 & K3 & K15 \\
\hline${ }_{A R}^{09} \cdots$ & 1400 & 1230 & 396 & 8.15 & 0.5 & 1.1 & 15.0 & 107 & $<1$ & K3 \\
\hline $17 \ldots$ & 1330 & 1510 & 403 & 7.96 & 1.5 & 3.0 & 13.9 & 100 & $<1$ & K2 \\
\hline$\underset{\text { JUL }}{12 \ldots}$ & 1300 & 644 & 402 & 8.09 & 16.0 & 2.0 & 9.8 & 101 & $<1$ & $<1$ \\
\hline $\begin{array}{l}08 \\
\operatorname{SEP}\end{array}$ & 0900 & 441 & 344 & 8.44 & 24.0 & 2.5 & 8.0 & 97 & K6 & K17 \\
\hline $15 \ldots$ & 1130 & 765 & 341 & 8.45 & 20.0 & 1.7 & 8.4 & 94 & K4 & K5 \\
\hline DATE & $\begin{array}{l}\text { HARD- } \\
\text { NESS } \\
\text { (MG/L } \\
\text { AS } \\
\text { CACO3) }\end{array}$ & $\begin{array}{l}\text { HARD- } \\
\text { NESS } \\
\text { NONCARB } \\
\text { WH WAT } \\
\text { TOT FLD } \\
\text { MG/L AS } \\
\text { CACO3 }\end{array}$ & $\begin{array}{l}\text { CALCIUM } \\
\text { DIS- } \\
\text { SOLVED } \\
\text { (MG/L } \\
\text { AS CA) }\end{array}$ & $\begin{array}{l}\text { MAGNE- } \\
\text { SIUM, } \\
\text { DIS- } \\
\text { SOLVED } \\
\text { (MG/L } \\
\text { AS MG) }\end{array}$ & $\begin{array}{l}\text { SODIUM, } \\
\text { DIS- } \\
\text { SOLVED } \\
\text { (MG/L } \\
\text { AS NA) }\end{array}$ & $\begin{array}{l}\text { PERCENT } \\
\text { SODIUM }\end{array}$ & $\begin{array}{c}\text { SODIUM } \\
\text { AD- } \\
\text { SORP- } \\
\text { TION } \\
\text { RATIO }\end{array}$ & $\begin{array}{l}\text { POTAS- } \\
\text { SIUM, } \\
\text { DIS- } \\
\text { SOLVED } \\
\text { (MG/L } \\
\text { AS K) }\end{array}$ & $\begin{array}{c}\text { BICAR- } \\
\text { BONATE } \\
\text { WH WAT } \\
\text { TOTAL } \\
\text { FIELD } \\
\text { MG/L AS } \\
\mathrm{HCO}_{3}\end{array}$ & $\begin{array}{l}\text { CAR- } \\
\text { BONATE } \\
\text { WH WAT } \\
\text { TOTAL } \\
\text { FIELD } \\
\text { MG } / \mathrm{L} \text { AS } \\
\text { CO3 }\end{array}$ \\
\hline ov & & & & & & & & & & \\
\hline${ }_{\mathrm{DEC}} 05 \cdots$ & 190 & 21 & 54 & 14 & 4.7 & 5 & 0.2 & 1.0 & 210 & 0 \\
\hline$\underset{\text { MAR }}{09} \ldots$ & 200 & 19 & 56 & 15 & 5.1 & 5 & 0.2 & 0.9 & 220 & 0 \\
\hline $\operatorname{MAY}_{17}$ & 200 & 26 & 57 & 15 & 4.4 & 4 & 0.1 & 1.7 & 220 & 0 \\
\hline $12 \ldots$ & 200 & 2 & 57 & 15 & 5.3 & 5 & 0.2 & 1.0 & 250 & 0 \\
\hline $08 \ldots$ & 180 & 5 & 46 & 15 & 4.9 & 6 & 0.2 & 0.4 & 210 & 1 \\
\hline $15 \ldots$ & 170 & 4 & 43 & 15 & 5.6 & 7 & 0.2 & 0.7 & -- & -- \\
\hline DATE & $\begin{array}{c}\text { ALKA- } \\
\text { LINITY } \\
\text { WH WAT } \\
\text { TOTAL } \\
\text { FIELD } \\
\text { MG/L AS } \\
\text { CACO3 }\end{array}$ & $\begin{array}{c}\text { CARBON } \\
\text { DIOXIDE } \\
\text { DIS- } \\
\text { SOLVED } \\
\text { (MG/L } \\
\text { AS CO2) }\end{array}$ & $\begin{array}{l}\text { SULFATE } \\
\text { DIS- } \\
\text { SOLVED } \\
\text { (MG/L } \\
\text { AS SO4) }\end{array}$ & $\begin{array}{l}\text { CHLO- } \\
\text { RIDE, } \\
\text { DIS- } \\
\text { SOLVED } \\
\text { (MG/L } \\
\text { AS CL) }\end{array}$ & $\begin{array}{l}\text { FLUO- } \\
\text { RIDE, } \\
\text { DIS- } \\
\text { SOLVED } \\
\text { (MG/L } \\
\text { AS F) }\end{array}$ & $\begin{array}{l}\text { SILICA, } \\
\text { DIS- } \\
\text { SOLVED } \\
\text { (MG/L } \\
\text { AS } \\
\text { SIO2) }\end{array}$ & $\begin{array}{l}\text { SOLIDS, } \\
\text { RESIDUE } \\
\text { AT } 180 \\
\text { DEG.C } \\
\text { DIS- } \\
\text { SOLVED } \\
\text { (MG/L) }\end{array}$ & $\begin{array}{c}\text { SOLIDS, } \\
\text { SUM OF } \\
\text { CONSTI- } \\
\text { TUENTS, } \\
\text { DIS- } \\
\text { SOLVED } \\
\text { (MG/L) }\end{array}$ & $\begin{array}{c}\text { SOLIDS, } \\
\text { DIS- } \\
\text { SOLVED } \\
\text { (TONS } \\
\text { PER } \\
\text { AC-FT) }\end{array}$ & $\begin{array}{c}\text { SOLIDS, } \\
\text { DIS- } \\
\text { SOLVED } \\
\text { (TONS } \\
\text { PER } \\
\text { DAY) }\end{array}$ \\
\hline $\begin{array}{l}\text { OV } \\
05 \ldots \\
\text { EC }\end{array}$ & 172 & 2.2 & 15 & 5.3 & 0.1 & 8.0 & 231 & 210 & 0.31 & 792 \\
\hline $\begin{array}{l}09 \\
\text { MAR }\end{array}$ & 183 & 2.5 & 12 & 7.0 & 0.1 & 8.7 & 223 & 210 & 0.3 & 741 \\
\hline${ }_{\operatorname{MAY}}^{17} \cdots$ & 178 & 3.8 & 12 & 6.1 & 0.1 & 9.1 & 214 & 210 & 0.29 & 872 \\
\hline $12 \ldots$ & 202 & 3.2 & 10 & 6.0 & 0.1 & 4.8 & 216 & 220 & 0.29 & 376 \\
\hline $08 \cdots$ & 172 & 1.2 & 16 & 4.3 & 0.1 & 10 & 193 & 200 & 0.26 & 230 \\
\hline b... & -- & 1.1 & 11 & 5.1 & 0.2 & 8.7 & 190 & 190 & 0.26 & 392 \\
\hline
\end{tabular}


04135000 THUNDER BAY RIVER NEAR ALPENA, MI--Continued WATER QUALITY DATA, WATER YEAR OCTOBER 1986 TO SEPTEMBER 1987

\begin{tabular}{|c|c|c|c|c|c|c|c|c|c|c|}
\hline DATE & $\begin{array}{c}\text { NITRO- } \\
\text { GEN, } \\
\text { NITRITE } \\
\text { DIS- } \\
\text { SOLVED } \\
\text { (MG/L } \\
\text { AS N) }\end{array}$ & $\begin{array}{c}\text { NITRO- } \\
\text { GEN, } \\
\text { NO2+NO3 } \\
\text { DIS- } \\
\text { SOLVED } \\
\text { (MG/L } \\
\text { AS N) }\end{array}$ & $\begin{array}{l}\text { NITRO- } \\
\text { GEN, } \\
\text { AMMONIA } \\
\text { TOTAL } \\
\text { (MG/L } \\
\text { AS N) }\end{array}$ & $\begin{array}{c}\text { NITRO- } \\
\text { GEN, } \\
\text { AMMONIA } \\
\text { DIS- } \\
\text { SOLVED } \\
\text { (MG/L } \\
\text { AS N) }\end{array}$ & $\begin{array}{c}\text { NITRO- } \\
\text { GEN, } \\
\text { ORGANIC } \\
\text { TOTAL } \\
\text { (MG/L } \\
\text { AS N) }\end{array}$ & $\begin{array}{l}\text { NITRO- } \\
\text { GEN,AM- } \\
\text { MONIA + } \\
\text { ORGANIC } \\
\text { TOTAL } \\
\text { (MG/L } \\
\text { AS N) }\end{array}$ & $\begin{array}{c}\text { PHOS- } \\
\text { PHORUS, } \\
\text { TOTAL } \\
\text { (MG/L } \\
\text { AS P) }\end{array}$ & $\begin{array}{l}\text { PHOS- } \\
\text { PHORUS, } \\
\text { DIS- } \\
\text { SOLVED } \\
\text { (MG/L } \\
\text { AS P) }\end{array}$ & $\begin{array}{l}\text { PHOS- } \\
\text { PHORUS, } \\
\text { ORTHO, } \\
\text { DIS- } \\
\text { SOLVED } \\
\text { (MG/L } \\
\text { AS P) }\end{array}$ & $\begin{array}{l}\text { ALUM- } \\
\text { INUM, } \\
\text { DIS- } \\
\text { SOLVED } \\
\text { (UG/L } \\
\text { AS AL) }\end{array}$ \\
\hline$\underset{\mathrm{EC}}{\mathrm{OOV}}$ & $<0.01$ & $<0.10$ & 0.04 & 0.02 & 0.86 & 0.9 & 0.02 & 0.01 & 0.01 & $<10$ \\
\hline${ }_{\mathrm{AR}}^{09} \ldots$ & 0.01 & $<0.10$ & 0.04 & 0.04 & 1.1 & 1.1 & $<0.01$ & 0.01 & $<0.01$ & $<10$ \\
\hline $17 \ldots$ & $<0.01$ & 0.35 & 0.03 & 0.03 & 0.87 & 0.9 & 0.02 & 0.02 & $<0.01$ & $<10$ \\
\hline $12 \ldots$ & 0.02 & $<0.10$ & -- & 0.04 & -- & 0.9 & 0.02 & 0.01 & 0.01 & -- \\
\hline SEP & $<0.01$ & $<0.10$ & 0.04 & 0.02 & 0.56 & 0.6 & 0.05 & 0.01 & 0.02 & $<10$ \\
\hline $15 \ldots$ & $<0.01$ & $<0.10$ & 0.01 & 0.02 & 0.39 & 0.4 & $<0.01$ & -- & $<0.01$ & -- \\
\hline
\end{tabular}

DATE

$\begin{array}{cclc} & & \text { BERYL- } & \\ \text { ARSENIC } & \text { BARIUM, } & \text { LIUM, } & \text { CADMIUM } \\ \text { DIS- } & \text { DIS- } & \text { DIS- } & \text { DIS- } \\ \text { SOLVED } & \text { SOLVED } & \text { SOLVED } & \text { SOLVED } \\ \text { (UG/L } & \text { (UG/L } & \text { (UG/L } & \text { (UG/L } \\ \text { AS AS) } & \text { AS BA) } & \text { AS BE) } & \text { AS CD) }\end{array}$

CHRO-

MIUM, COBALT, COPPER,

DIS-

DIS-

$\begin{array}{lll}\text { (UG } / L & \text { (UG } / L & \text { (UG/L } \\ \text { AS CR } & \text { AS CO) } & \text { AS CU) }\end{array}$

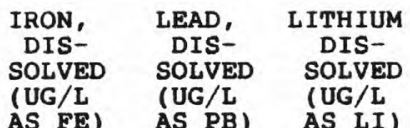
$\begin{array}{lll}\text { (UG/L } & \text { (UG/L } & \text { (UG/L } \\ \text { AS FE) } & \text { AS PB) } & \text { AS LI) }\end{array}$
NOV

DEC 05

O9...

MAR

$17 \ldots$

$12 \ldots$

JUL

SEP

$15 \ldots$

\section{$<0.5,<1$}

$<0.5$

$<0.5$

--

\section{$<1<3$}

$<1$

$<3$
$<3$

$<1$

$--$

$<1$

$--$

$<3$

--

$<3$

$<1$

\section{7}

27

66

--
MANGA-

NESE,

DISSOLVED (UG/L

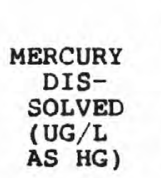

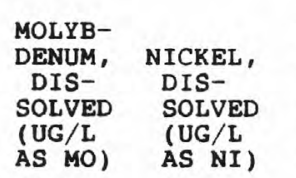

SELE-

SELE

NIUM,

SOLVED

(UG/L

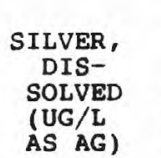

STRON-
TIUM,
DIS-
SOLVED
(UG/L AS SR)
VANA-

DIUM,

DISSOLVED (UG/L AS V)
NOV
O5 ....
DEC

DEC 09.

MAR
$17 .$.

$17 \ldots$

$12 \ldots$

08 ...

SEP

$$
\begin{aligned}
& <0.1<10 \\
& 0.1<10 \\
& \begin{array}{cc}
\text { SUS- } & \text { FINER } \\
\text { PENDED } & \text { THAN } \\
\text { (T/DAY) } & .062 \mathrm{MM}
\end{array}
\end{aligned}
$$

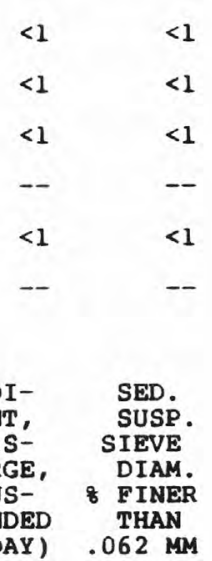

NOV

05 ..

DEC 09

21

17

65

MAR

$17 \ldots$

JUL 12 .

$08 \ldots$

SEP $15 .$.
$<1 \quad 100$

100

$<1 \quad 110$

-

93

$-$
$<6$

$<6$

$<6$

$--$

$<6$

$--$

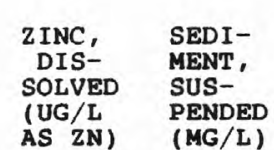

AS $\mathrm{ZN}$ )

$\begin{array}{rr}<5 & 7 \\ <5 & 9 \\ -- & 4 \\ -- & -- \\ <5 & <4 \\ -- & --\end{array}$


LOCATION.--Lat $44^{\circ} 39^{\prime} 35^{\prime \prime}$, long $84^{\circ} 42^{\prime} 45^{\prime \prime}$, in SEl/4 SEl/4 sec. 7, T.26 N., R.3 W., Crawford County, Hydrologic Unit 04070007 , on right bank $65 \mathrm{ft}$ upstream from bridge on Interstate Highway 75 (Business Loop) in Grayling, $0.7 \mathrm{mi}$ upstream from East Branch, and $114 \mathrm{mi}$ upstream from mouth.

DRAINAGE AREA, $--110 \mathrm{mi}^{2}$.

PERIOD OF RECORD.--October 1942 to current year. Monthly discharge only for some periods, published in WSP 1307. Prior to October 1954, published as Middle Branch Au Sable River at Grayling.

GAGE.--Water-stage recorder and steel-crested dam. Datum of gage is $1,123.49 \mathrm{ft}$ above National Geodetic Vertical Datum of 1929.

REMARKS.--Estimated daily discharges: Jan, 16 and Feb. 6-8, 11, 12, 14, 17, 18 . Records good except for estimated daily discharges, which are fair. Prior to Dec. 31, 1952 , diurnal fluctuation caused by powerplant $2.5 \mathrm{mi}$ upstream. Several measurements of water temperature were made during the year.

AVERAGE DISCHARGE. - -45 years, $75.7 \mathrm{ft}^{3} / \mathrm{s}, 9.35 \mathrm{in} / \mathrm{yr}^{\circ}$

EXTREMES FOR PERIOD OF RECORD.--Maximum discharge, $274 \mathrm{ft}^{3} / \mathrm{s}$, June 2, 1943, gage height, $3.00 \mathrm{ft}^{\circ}$ minimum, $28 \mathrm{ft}^{3} / \mathrm{s}, \mathrm{Apr} .21,1946$, gage height, $0.80 \mathrm{ft}$.

EXTREMES FOR CURRENT YEAR.--Maximum discharge, $212 \mathrm{ft}^{3} / \mathrm{s}$, Oct. 1, gage height, $2.54 \mathrm{ft} ; \mathrm{minimum,}$ $55 \mathrm{ft} / \mathrm{s}$, July 31, Aug. 1, gage height, $1.19 \mathrm{ft}$.

DISCHARGE, IN CUBIC FEET PER SECOND, WATER YEAR OCTOBER 1986 TO SEPTEMBER 1987 MEAN VALUES

\begin{tabular}{|c|c|c|c|c|c|c|c|c|c|c|c|c|}
\hline DAY & OCT & NOV & DEC & JAN & FEB & MAR & APR & MAY & JUN & JUL & AUG & SEP \\
\hline $\begin{array}{l}1 \\
2 \\
3 \\
4 \\
5\end{array}$ & $\begin{array}{l}210 \\
194 \\
178 \\
181 \\
192\end{array}$ & $\begin{array}{l}109 \\
109 \\
109 \\
107 \\
107\end{array}$ & $\begin{array}{r}104 \\
103 \\
100 \\
97 \\
98\end{array}$ & $\begin{array}{l}87 \\
90 \\
92 \\
93 \\
93\end{array}$ & $\begin{array}{l}90 \\
91 \\
94 \\
95 \\
91\end{array}$ & $\begin{array}{r}96 \\
102 \\
102 \\
97 \\
97\end{array}$ & $\begin{array}{r}100 \\
97 \\
95 \\
94 \\
94\end{array}$ & $\begin{array}{l}81 \\
79 \\
78 \\
78 \\
77\end{array}$ & $\begin{array}{l}71 \\
70 \\
69 \\
67 \\
66\end{array}$ & $\begin{array}{l}79 \\
73 \\
72 \\
71 \\
69\end{array}$ & $\begin{array}{l}56 \\
73 \\
86 \\
92 \\
88\end{array}$ & $\begin{array}{l}77 \\
76 \\
75 \\
73 \\
72\end{array}$ \\
\hline $\begin{array}{r}6 \\
7 \\
8 \\
9 \\
10\end{array}$ & $\begin{array}{l}193 \\
182 \\
167 \\
154 \\
147\end{array}$ & $\begin{array}{l}107 \\
107 \\
108 \\
105 \\
101\end{array}$ & $\begin{array}{l}95 \\
90 \\
92 \\
93 \\
93\end{array}$ & $\begin{array}{l}92 \\
92 \\
93 \\
92 \\
93\end{array}$ & $\begin{array}{l}91 \\
91 \\
91 \\
76 \\
85\end{array}$ & $\begin{array}{r}97 \\
102 \\
115 \\
125 \\
116\end{array}$ & $\begin{array}{l}96 \\
98 \\
98 \\
96 \\
94\end{array}$ & $\begin{array}{l}76 \\
75 \\
75 \\
76 \\
75\end{array}$ & $\begin{array}{l}67 \\
67 \\
67 \\
67 \\
66\end{array}$ & $\begin{array}{l}68 \\
66 \\
65 \\
65 \\
71\end{array}$ & $\begin{array}{r}81 \\
79 \\
76 \\
87 \\
100\end{array}$ & $\begin{array}{l}72 \\
72 \\
71 \\
71 \\
70\end{array}$ \\
\hline $\begin{array}{l}11 \\
12 \\
13 \\
14 \\
15\end{array}$ & $\begin{array}{l}141 \\
140 \\
143 \\
143 \\
140\end{array}$ & $\begin{array}{l}99 \\
99 \\
96 \\
94 \\
99\end{array}$ & $\begin{array}{r}92 \\
94 \\
98 \\
100 \\
102\end{array}$ & $\begin{array}{l}93 \\
91 \\
88 \\
87 \\
88\end{array}$ & $\begin{array}{l}91 \\
91 \\
86 \\
84 \\
76\end{array}$ & $\begin{array}{r}106 \\
101 \\
94 \\
92 \\
91\end{array}$ & $\begin{array}{l}92 \\
91 \\
90 \\
89 \\
92\end{array}$ & $\begin{array}{l}78 \\
78 \\
77 \\
78 \\
77\end{array}$ & $\begin{array}{l}68 \\
70 \\
68 \\
68 \\
66\end{array}$ & $\begin{array}{r}93 \\
100 \\
88 \\
80 \\
74\end{array}$ & $\begin{array}{r}92 \\
80 \\
72 \\
72 \\
105\end{array}$ & $\begin{array}{l}72 \\
75 \\
78 \\
80 \\
79\end{array}$ \\
\hline $\begin{array}{l}16 \\
17 \\
18 \\
19 \\
20\end{array}$ & $\begin{array}{l}140 \\
143 \\
141 \\
135 \\
125\end{array}$ & $\begin{array}{r}99 \\
99 \\
97 \\
97 \\
101\end{array}$ & $\begin{array}{l}105 \\
103 \\
103 \\
102 \\
101\end{array}$ & $\begin{array}{l}88 \\
79 \\
82 \\
89 \\
87\end{array}$ & $\begin{array}{l}77 \\
86 \\
86 \\
85 \\
85\end{array}$ & $\begin{array}{l}89 \\
88 \\
88 \\
88 \\
90\end{array}$ & $\begin{array}{l}95 \\
94 \\
92 \\
90 \\
87\end{array}$ & $\begin{array}{l}76 \\
74 \\
72 \\
75 \\
79\end{array}$ & $\begin{array}{l}67 \\
67 \\
66 \\
67 \\
70\end{array}$ & $\begin{array}{l}70 \\
68 \\
66 \\
64 \\
64\end{array}$ & $\begin{array}{l}155 \\
181 \\
172 \\
144 \\
119\end{array}$ & $\begin{array}{l}75 \\
78 \\
82 \\
85 \\
87\end{array}$ \\
\hline $\begin{array}{l}21 \\
22 \\
23 \\
24 \\
25\end{array}$ & $\begin{array}{l}118 \\
115 \\
114 \\
113 \\
111\end{array}$ & $\begin{array}{l}106 \\
109 \\
110 \\
113 \\
113\end{array}$ & $\begin{array}{l}97 \\
93 \\
96 \\
93 \\
92\end{array}$ & $\begin{array}{l}86 \\
87 \\
80 \\
71 \\
76\end{array}$ & $\begin{array}{l}86 \\
90 \\
95 \\
93 \\
87\end{array}$ & $\begin{array}{r}93 \\
96 \\
100 \\
104 \\
112\end{array}$ & $\begin{array}{l}85 \\
84 \\
87 \\
89 \\
90\end{array}$ & $\begin{array}{l}84 \\
90 \\
87 \\
85 \\
82\end{array}$ & $\begin{array}{l}66 \\
65 \\
63 \\
62 \\
63\end{array}$ & $\begin{array}{l}68 \\
67 \\
67 \\
67 \\
65\end{array}$ & $\begin{array}{r}104 \\
94 \\
87 \\
81 \\
77\end{array}$ & $\begin{array}{l}90 \\
93 \\
94 \\
89 \\
83\end{array}$ \\
\hline $\begin{array}{l}26 \\
27 \\
28 \\
29 \\
30 \\
31\end{array}$ & $\begin{array}{l}112 \\
115 \\
118 \\
117 \\
114 \\
110\end{array}$ & $\begin{array}{l}110 \\
108 \\
107 \\
107 \\
107 \\
----\end{array}$ & $\begin{array}{l}92 \\
92 \\
91 \\
90 \\
88 \\
87\end{array}$ & $\begin{array}{l}83 \\
86 \\
87 \\
87 \\
87 \\
87\end{array}$ & $\begin{array}{r}85 \\
84 \\
86 \\
--- \\
--- \\
---\end{array}$ & $\begin{array}{l}118 \\
117 \\
111 \\
106 \\
104 \\
103\end{array}$ & $\begin{array}{r}88 \\
86 \\
85 \\
84 \\
82 \\
--\end{array}$ & $\begin{array}{l}81 \\
80 \\
77 \\
75 \\
75 \\
73\end{array}$ & $\begin{array}{r}68 \\
71 \\
70 \\
81 \\
81 \\
\end{array}$ & $\begin{array}{l}62 \\
59 \\
59 \\
58 \\
57 \\
56\end{array}$ & $\begin{array}{l}75 \\
75 \\
75 \\
74 \\
76 \\
77\end{array}$ & $\begin{array}{r}79 \\
76 \\
75 \\
76 \\
78 \\
- \\
-\end{array}$ \\
\hline $\begin{array}{l}\text { TOTAL } \\
\text { MEAN } \\
\text { MAX } \\
\text { MIN } \\
\text { CFSM } \\
\text { IN. }\end{array}$ & $\begin{array}{r}4446 \\
143 \\
210 \\
110 \\
1.30 \\
1.50\end{array}$ & $\begin{array}{r}3139 \\
105 \\
113 \\
94 \\
.96 \\
1.06\end{array}$ & $\begin{array}{r}2976 \\
96.0 \\
105 \\
87 \\
.87 \\
1.01\end{array}$ & $\begin{array}{r}2706 \\
87.3 \\
93 \\
71 \\
.79 \\
.92\end{array}$ & $\begin{array}{r}2448 \\
87.4 \\
95 \\
76 \\
.80 \\
.83\end{array}$ & $\begin{array}{r}3140 \\
101 \\
125 \\
88 \\
.92 \\
1.06\end{array}$ & $\begin{array}{r}2734 \\
91.1 \\
100 \\
82 \\
.83 \\
.92\end{array}$ & $\begin{array}{r}2423 \\
78.2 \\
90 \\
72 \\
.71 \\
.82\end{array}$ & $\begin{array}{r}2044 \\
68.1 \\
81 \\
62 \\
.62 \\
.69\end{array}$ & $\begin{array}{r}2151 \\
69.4 \\
100 \\
56 \\
.63 \\
.73\end{array}$ & $\begin{array}{r}2905 \\
93.7 \\
181 \\
56 \\
.85 \\
.98\end{array}$ & $\begin{array}{r}2353 \\
78.4 \\
94 \\
70 \\
.71 \\
.80\end{array}$ \\
\hline
\end{tabular}

CAL YR 1986 TOTAL 38566 MEAN $106 \quad$ MAX $210 \quad$ MIN $69 \quad$ CFSM $.96 \quad$ IN 13.04

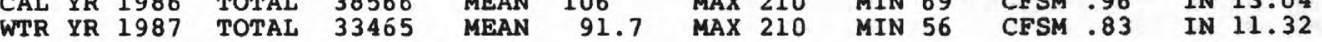


04135700 SOUTH BRANCH AU SABLE RIVER NEAR LUZERNE, MI

LOCATION.--Lat $44^{\circ} 36^{\prime} 5^{\prime \prime}$, long $84^{\circ} 27^{\prime} 20^{\prime \prime}$, in SEl/4 SEl/4 sec.29, T.26 N., R.1 W., Crawford County, Hydrologic Unit 04070007, on right bank $10 \mathrm{ft}$ upstream from Smith Bridge, $400 \mathrm{ft}$ downstream from bridge on State Highway $72,4.6 \mathrm{mi}$ upstream from mouth, and $9.1 \mathrm{mi}$ west of Luzerne.

DRAINAGE AREA. $--401 \mathrm{mi}^{2}$.

PERIOD OF RECORD.--Occasional low-flow measurements, water years 1951-66. October 1966 to current year.

REVISED RECORDS.--WSP 2111: Drainage area.

GAGE.--Water-stage recorder. Elevation of gage is $1,070 \mathrm{ft}$ above National Geodetic Vertical Datum of 1929, from topographic map. Apr. 19, 1951, to Nov. 14, 1966, nonrecording gage at same site and datum.

REMARKS.--Estimated daily discharges: Jan, 24-27, Feb, 6, 8, 10, 12, 14, 16, 22, 23, and Feb. 25-27. Records good except for estimated daily discharges, which are fair. Occasional regulation by dams upstream from station. Several measurements of water temperature were made during the year.

AVERAGE DISCHARGE. --21 years, $225 \mathrm{ft}^{3} / \mathrm{s}, 7.62 \mathrm{in} / \mathrm{yr}$.

EXTREMES FOR PERIOD OF RECORD.--Maximum discharge, 1,120 ft ${ }^{3} / \mathrm{s}$, Mar, 28, 1976, gage height, $7.30 \mathrm{ft}$ maximum gage height, $7.75 \mathrm{ft}, \mathrm{Jan} .28$, 1986, backwater from ice; minimum discharge, 78 ft ${ }^{3} / \mathrm{s}$ Feb. 12, 1981, gage height, $3.98 \mathrm{ft}$, result of freezeup.

EXTREMES FOR CURRENT YEAR.--Maximum discharge, $662 \mathrm{ft}^{3} / \mathrm{s}$, Oct. 1 , gage height, $6.10 \mathrm{ft}$, stage falling, peak occurred Sept. 30, 1986; maximum independent peak discharge, $306 \mathrm{ft}^{3} / \mathrm{s}$, Aug. 17, gage height, $5.03 \mathrm{ft}$; minimum discharge, $116 \mathrm{ft}^{3} / \mathrm{s}$, July $28,29,30,31$, Aug. 1, gage height $4.21 \mathrm{ft}$.

DISCHARGE, IN CUBIC FEET PER SECOND, WATER YEAR OCTOBER 1986 TO SEPTEMBER 1987 MEAN VALUES

\begin{tabular}{|c|c|c|c|c|c|c|c|c|c|c|c|c|}
\hline DAY & OCT & NOV & DEC & JAN & FEB & MAR & APR & MAY & JUN & JUL & AUG & SEP \\
\hline $\begin{array}{l}1 \\
2 \\
3 \\
4 \\
5\end{array}$ & $\begin{array}{l}645 \\
616 \\
607 \\
599 \\
607\end{array}$ & $\begin{array}{l}343 \\
337 \\
329 \\
328 \\
323\end{array}$ & $\begin{array}{l}259 \\
257 \\
259 \\
255 \\
244\end{array}$ & $\begin{array}{l}216 \\
215 \\
214 \\
213 \\
210\end{array}$ & $\begin{array}{l}174 \\
176 \\
179 \\
181 \\
177\end{array}$ & $\begin{array}{l}164 \\
176 \\
174 \\
162 \\
174\end{array}$ & $\begin{array}{l}229 \\
217 \\
211 \\
209 \\
210\end{array}$ & $\begin{array}{l}171 \\
170 \\
166 \\
162 \\
160\end{array}$ & $\begin{array}{l}136 \\
136 \\
134 \\
132 \\
130\end{array}$ & $\begin{array}{l}136 \\
128 \\
125 \\
123 \\
122\end{array}$ & $\begin{array}{l}118 \\
135 \\
134 \\
133 \\
126\end{array}$ & $\begin{array}{l}130 \\
128 \\
127 \\
126 \\
125\end{array}$ \\
\hline $\begin{array}{r}6 \\
7 \\
8 \\
9 \\
10\end{array}$ & $\begin{array}{l}602 \\
587 \\
571 \\
542 \\
506\end{array}$ & $\begin{array}{l}320 \\
312 \\
310 \\
308 \\
301\end{array}$ & $\begin{array}{l}244 \\
229 \\
233 \\
236 \\
233\end{array}$ & $\begin{array}{l}210 \\
209 \\
208 \\
205 \\
204\end{array}$ & $\begin{array}{l}180 \\
182 \\
180 \\
179 \\
180\end{array}$ & $\begin{array}{l}171 \\
190 \\
241 \\
284 \\
266\end{array}$ & $\begin{array}{l}209 \\
209 \\
212 \\
209 \\
205\end{array}$ & $\begin{array}{l}158 \\
156 \\
154 \\
152 \\
151\end{array}$ & $\begin{array}{l}129 \\
129 \\
128 \\
125 \\
124\end{array}$ & $\begin{array}{l}122 \\
123 \\
123 \\
125 \\
145\end{array}$ & $\begin{array}{l}123 \\
148 \\
139 \\
151 \\
175\end{array}$ & $\begin{array}{l}124 \\
124 \\
131 \\
134 \\
132\end{array}$ \\
\hline $\begin{array}{l}11 \\
12 \\
13 \\
14 \\
15\end{array}$ & $\begin{array}{l}480 \\
460 \\
447 \\
448 \\
434\end{array}$ & $\begin{array}{l}298 \\
291 \\
271 \\
266 \\
271\end{array}$ & $\begin{array}{l}226 \\
229 \\
223 \\
231 \\
229\end{array}$ & $\begin{array}{l}203 \\
199 \\
193 \\
203 \\
202\end{array}$ & $\begin{array}{l}177 \\
175 \\
176 \\
170 \\
166\end{array}$ & $\begin{array}{l}245 \\
219 \\
202 \\
197 \\
189\end{array}$ & $\begin{array}{l}206 \\
204 \\
202 \\
201 \\
219\end{array}$ & $\begin{array}{l}157 \\
156 \\
152 \\
146 \\
146\end{array}$ & $\begin{array}{l}125 \\
130 \\
129 \\
127 \\
124\end{array}$ & $\begin{array}{l}143 \\
133 \\
126 \\
124 \\
123\end{array}$ & $\begin{array}{l}162 \\
144 \\
133 \\
132 \\
209\end{array}$ & $\begin{array}{l}132 \\
130 \\
129 \\
130 \\
128\end{array}$ \\
\hline $\begin{array}{l}16 \\
17 \\
18 \\
19 \\
20\end{array}$ & $\begin{array}{l}424 \\
412 \\
399 \\
386 \\
374\end{array}$ & $\begin{array}{l}276 \\
275 \\
275 \\
252 \\
264\end{array}$ & $\begin{array}{l}227 \\
230 \\
235 \\
239 \\
240\end{array}$ & $\begin{array}{l}194 \\
172 \\
191 \\
191 \\
191\end{array}$ & $\begin{array}{l}160 \\
155 \\
153 \\
152 \\
151\end{array}$ & $\begin{array}{l}187 \\
185 \\
183 \\
186 \\
193\end{array}$ & $\begin{array}{l}237 \\
246 \\
236 \\
226 \\
217\end{array}$ & $\begin{array}{l}145 \\
143 \\
139 \\
139 \\
149\end{array}$ & $\begin{array}{l}122 \\
120 \\
121 \\
119 \\
124\end{array}$ & $\begin{array}{l}122 \\
120 \\
118 \\
118 \\
125\end{array}$ & $\begin{array}{l}284 \\
302 \\
294 \\
272 \\
220\end{array}$ & $\begin{array}{l}125 \\
130 \\
166 \\
192 \\
189\end{array}$ \\
\hline $\begin{array}{l}21 \\
22 \\
23 \\
24 \\
25\end{array}$ & $\begin{array}{l}364 \\
360 \\
360 \\
371 \\
367\end{array}$ & $\begin{array}{l}263 \\
265 \\
269 \\
276 \\
277\end{array}$ & $\begin{array}{l}219 \\
227 \\
225 \\
224 \\
227\end{array}$ & $\begin{array}{l}185 \\
186 \\
175 \\
175 \\
175\end{array}$ & $\begin{array}{l}151 \\
150 \\
150 \\
149 \\
150\end{array}$ & $\begin{array}{l}201 \\
210 \\
221 \\
234 \\
253\end{array}$ & $\begin{array}{l}211 \\
203 \\
201 \\
202 \\
199\end{array}$ & $\begin{array}{l}153 \\
151 \\
147 \\
146 \\
144\end{array}$ & $\begin{array}{l}126 \\
137 \\
131 \\
124 \\
126\end{array}$ & $\begin{array}{l}142 \\
135 \\
127 \\
124 \\
122\end{array}$ & $\begin{array}{l}181 \\
165 \\
154 \\
148 \\
143\end{array}$ & $\begin{array}{l}183 \\
181 \\
179 \\
171 \\
164\end{array}$ \\
\hline $\begin{array}{l}26 \\
27 \\
28 \\
29 \\
30 \\
31\end{array}$ & $\begin{array}{l}367 \\
376 \\
371 \\
361 \\
355 \\
346\end{array}$ & $\begin{array}{l}279 \\
276 \\
273 \\
271 \\
267 \\
---\end{array}$ & $\begin{array}{l}224 \\
221 \\
218 \\
217 \\
217 \\
217\end{array}$ & $\begin{array}{l}175 \\
172 \\
172 \\
171 \\
173 \\
172\end{array}$ & $\begin{array}{l}150 \\
150 \\
159 \\
--- \\
--- \\
---\end{array}$ & $\begin{array}{l}274 \\
280 \\
275 \\
262 \\
256 \\
245\end{array}$ & $\begin{array}{l}191 \\
189 \\
188 \\
184 \\
175 \\
-\end{array}$ & $\begin{array}{l}151 \\
157 \\
153 \\
145 \\
141 \\
138\end{array}$ & $\begin{array}{l}131 \\
139 \\
132 \\
138 \\
141 \\
--\end{array}$ & $\begin{array}{l}120 \\
117 \\
117 \\
117 \\
117 \\
116\end{array}$ & $\begin{array}{l}140 \\
138 \\
137 \\
134 \\
136 \\
133\end{array}$ & $\begin{array}{l}160 \\
157 \\
156 \\
162 \\
181 \\
-\end{array}$ \\
\hline $\begin{array}{l}\text { TOTAL } \\
\text { MEAN } \\
\text { MAX } \\
\text { MIN } \\
\text { CFSM } \\
\text { IN. }\end{array}$ & $\begin{array}{r}14144 \\
456 \\
645 \\
346 \\
1.14 \\
1.31\end{array}$ & $\begin{array}{r}8666 \\
289 \\
343 \\
252 \\
.72 \\
.80\end{array}$ & $\begin{array}{r}7194 \\
232 \\
259 \\
217 \\
.58 \\
.67\end{array}$ & $\begin{array}{r}5974 \\
193 \\
216 \\
171 \\
.48 \\
.55\end{array}$ & $\begin{array}{r}4632 \\
165 \\
182 \\
149 \\
.41 \\
.43\end{array}$ & $\begin{array}{r}6699 \\
216 \\
284 \\
162 \\
.54 \\
.62\end{array}$ & $\begin{array}{r}6257 \\
209 \\
246 \\
175 \\
.52 \\
.58\end{array}$ & $\begin{array}{r}4698 \\
152 \\
171 \\
138 \\
.38 \\
.44\end{array}$ & $\begin{array}{r}3869 \\
129 \\
141 \\
119 \\
.32 \\
.36\end{array}$ & $\begin{array}{r}3878 \\
125 \\
145 \\
116 \\
.31 \\
.36\end{array}$ & $\begin{array}{r}5143 \\
166 \\
302 \\
118 \\
.41 \\
.48\end{array}$ & $\begin{array}{r}4426 \\
148 \\
192 \\
124 \\
.37 \\
.41\end{array}$ \\
\hline
\end{tabular}

$\begin{array}{lllrlllllll}\text { CAL YR } 1986 & \text { TOTAL } & 100654 & \text { MEAN } 276 & \text { MAX } 735 & \text { MIN } 139 & \text { CFSM } & .69 & \text { IN } 9.34 \\ \text { WTR YR } 1987 & \text { TOTAL } & 75580 & \text { MEAN } 207 & \text { MAX } 645 & \text { MIN } 116 & \text { CFSM } & .52 & \text { IN } 7.01\end{array}$ 
LOCATION. - Lat $44^{\circ} 55^{\prime} 52^{\prime \prime}$, long $84^{\circ} 41^{\prime} 33^{\prime \prime}$, in SWl/4 SEl/4 sec.5, T. 29 N., R. 3 W. Otsego County, Hydrologic Unit 04070007 , at Otsego lake state Park, $200 \mathrm{ft}$ northwest of boat ramp, $7.5 \mathrm{mi}$ south of Gaylord.

DRAINAGE AREA.--Not determined.

PERIOD OF RECORD.--August 1942 to current year, except for winter months 1942-43, 1943-44, 1977-78.

GAGE.--Water-stage recorder. Datum of gage is $1,270.03$ ft above National Geodetic Vertical Datum of 1929 (levels by Michigan Department of Natural Resources). prior to Aug. 18, 1958, nonrecording gage at datum $2.0 \mathrm{ft}$ higher.

REMARKS.--Otsego Lake has no natural inlets or outlets. In December 1972 an outlet tube and pump system was installed connecting the lake with the North Branch Au Sable River to lower lake levels. Maximum depth $23 \mathrm{ft}$, surface area 1,970 acres. Established legal level; maximum, 1,273.5 ft, minimum, 1,272.0 ft, above NGVD.

EXTREMES FOR PERIOD OF RECORD.--Maximum gage height, $5.10 \mathrm{ft}$, May 6, 7, 1972; minimum, $0.96 \mathrm{ft}$, Aug. 14, 1959.

EXTREMES FOR CURRENT YEAR.--Maximum gage height, $4.10 \mathrm{ft}$, Oct. 5 ; minimum, $2.47 \mathrm{ft}, \mathrm{Aug}$. 2 .

GAGE HEIGHT (FEET ABOVE DATUM), WATER YEAR OCTOBER 1986 TO SEPTEMBER 1987

\begin{tabular}{|c|c|c|c|c|c|c|c|c|c|c|c|c|}
\hline DAY & OCT & NOV & DEC & JAN & FEB & MAR & APR & MAY & JUN & JUL & AUG & SEP \\
\hline $\begin{array}{l}1 \\
2 \\
3 \\
4 \\
5\end{array}$ & $\begin{array}{l}3.88 \\
3.87 \\
3.93 \\
3.98 \\
4.00\end{array}$ & $\begin{array}{l}3.94 \\
3.93 \\
3.93 \\
3.93 \\
3.90\end{array}$ & $\begin{array}{l}3.65 \\
3.64 \\
3.64 \\
3.65 \\
3.65\end{array}$ & $\begin{array}{l}3.41 \\
3.40 \\
3.39 \\
3.38 \\
3.37\end{array}$ & $\begin{array}{l}3.26 \\
3.26 \\
3.26 \\
3.25 \\
3.24\end{array}$ & $\begin{array}{l}3.17 \\
3.19 \\
3.19 \\
3.18 \\
3.17\end{array}$ & $\begin{array}{l}3.27 \\
3.28 \\
3.29 \\
3.30 \\
3.30\end{array}$ & $\begin{array}{l}3.17 \\
3.16 \\
3.15 \\
3.14 \\
3.12\end{array}$ & $\begin{array}{l}2.94 \\
2.93 \\
2.92 \\
2.89 \\
2.88\end{array}$ & $\begin{array}{l}2.61 \\
2.59 \\
2.59 \\
2.57 \\
2.54\end{array}$ & $\begin{array}{l}2.50 \\
2.66 \\
2.82 \\
2.75 \\
2.74\end{array}$ & $\begin{array}{l}--- \\
2.63 \\
2.62 \\
2.60 \\
2.59\end{array}$ \\
\hline $\begin{array}{r}6 \\
7 \\
8 \\
9 \\
10\end{array}$ & $\begin{array}{l}4.02 \\
3.99 \\
4.01 \\
4.01 \\
3.99\end{array}$ & $\begin{array}{l}3.88 \\
3.86 \\
3.83 \\
3.83 \\
3.84\end{array}$ & $\begin{array}{l}3.64 \\
3.63 \\
3.63 \\
3.63 \\
---\end{array}$ & $\begin{array}{l}3.36 \\
3.35 \\
3.34 \\
3.33 \\
3.33\end{array}$ & $\begin{array}{l}3.23 \\
3.23 \\
3.24 \\
3.23 \\
3.23\end{array}$ & $\begin{array}{l}3.17 \\
3.17 \\
3.17 \\
3.18 \\
3.17\end{array}$ & $\begin{array}{l}3.29 \\
3.29 \\
3.29 \\
3.28 \\
3.28\end{array}$ & $\begin{array}{l}3.11 \\
3.10 \\
3.07 \\
3.05 \\
3.06\end{array}$ & $\begin{array}{l}2.85 \\
2.85 \\
2.85 \\
2.83 \\
2.81\end{array}$ & $\begin{array}{l}2.54 \\
2.53 \\
2.53 \\
2.68 \\
3.20\end{array}$ & $\begin{array}{l}2.92 \\
2.96 \\
2.95 \\
2.96 \\
2.96\end{array}$ & $\begin{array}{l}2.59 \\
2.60 \\
2.59 \\
2.59 \\
2.59\end{array}$ \\
\hline $\begin{array}{l}11 \\
12 \\
13 \\
14 \\
15\end{array}$ & $\begin{array}{l}3.97 \\
3.98 \\
4.00 \\
4.01 \\
4.03\end{array}$ & $\begin{array}{l}3.83 \\
3.83 \\
3.84 \\
3.83 \\
3.81\end{array}$ & $\begin{array}{l}--- \\
--- \\
--- \\
--- \\
---\end{array}$ & $\begin{array}{l}3.32 \\
3.32 \\
3.30 \\
3.29 \\
3.28\end{array}$ & $\begin{array}{l}3.23 \\
3.23 \\
3.22 \\
3.22 \\
3.22\end{array}$ & $\begin{array}{l}3.17 \\
3.17 \\
3.17 \\
3.17 \\
3.17\end{array}$ & $\begin{array}{l}3.27 \\
3.27 \\
3.27 \\
3.27 \\
3.28\end{array}$ & $\begin{array}{l}3.06 \\
3.06 \\
3.03 \\
3.02 \\
3.03\end{array}$ & $\begin{array}{l}2.79 \\
2.80 \\
2.81 \\
2.80 \\
2.79\end{array}$ & $\begin{array}{l}3.01 \\
2.90 \\
2.83 \\
2.78 \\
2.72\end{array}$ & $\begin{array}{l}2.94 \\
2.98 \\
3.05 \\
3.05 \\
3.00\end{array}$ & $\begin{array}{l}2.60 \\
2.64 \\
2.63 \\
2.64 \\
2.63\end{array}$ \\
\hline $\begin{array}{l}16 \\
17 \\
18 \\
19 \\
20\end{array}$ & $\begin{array}{l}4.03 \\
4.03 \\
4.01 \\
4.00 \\
3.98\end{array}$ & $\begin{array}{l}3.80 \\
3.78 \\
3.77 \\
3.76 \\
3.77\end{array}$ & $\begin{array}{l}--- \\
--- \\
--- \\
--- \\
---\end{array}$ & $\begin{array}{l}3.27 \\
3.27 \\
3.26 \\
3.26 \\
3.25\end{array}$ & $\begin{array}{l}3.21 \\
3.20 \\
3.20 \\
3.19 \\
3.18\end{array}$ & $\begin{array}{l}3.17 \\
3.17 \\
3.17 \\
3.17 \\
3.17\end{array}$ & $\begin{array}{l}3.29 \\
3.29 \\
3.28 \\
3.28 \\
3.27\end{array}$ & $\begin{array}{l}2.98 \\
2.98 \\
2.98 \\
2.99 \\
3.00\end{array}$ & $\begin{array}{l}2.76 \\
2.74 \\
2.73 \\
2.73 \\
2.71\end{array}$ & $\begin{array}{l}2.69 \\
2.66 \\
2.64 \\
2.63 \\
2.62\end{array}$ & $\begin{array}{l}2.92 \\
2.89 \\
2.87 \\
2.84 \\
-\end{array}$ & $\begin{array}{l}2.62 \\
2.65 \\
2.68 \\
2.68 \\
2.69\end{array}$ \\
\hline $\begin{array}{l}21 \\
22 \\
23 \\
24 \\
25\end{array}$ & $\begin{array}{l}3.97 \\
3.97 \\
3.97 \\
3.96 \\
3.96\end{array}$ & $\begin{array}{l}3.76 \\
3.75 \\
3.74 \\
3.73 \\
3.72\end{array}$ & $\begin{array}{l}--- \\
--- \\
--- \\
--- \\
---\end{array}$ & $\begin{array}{l}3.25 \\
3.24 \\
3.25 \\
3.25 \\
3.25\end{array}$ & $\begin{array}{l}3.17 \\
3.17 \\
3.18 \\
3.18 \\
3.17\end{array}$ & $\begin{array}{l}3.17 \\
3.17 \\
3.17 \\
3.18 \\
3.20\end{array}$ & $\begin{array}{l}3.27 \\
3.26 \\
3.26 \\
3.25 \\
3.23\end{array}$ & $\begin{array}{l}3.00 \\
3.00 \\
3.01 \\
3.00 \\
2.99\end{array}$ & $\begin{array}{l}2.69 \\
2.68 \\
2.66 \\
2.65 \\
2.64\end{array}$ & $\begin{array}{l}2.65 \\
2.64 \\
2.63 \\
2.62 \\
2.61\end{array}$ & $\begin{array}{l}--- \\
--- \\
--- \\
--- \\
---\end{array}$ & $\begin{array}{l}2.70 \\
2.71 \\
2.69 \\
2.69 \\
2.66\end{array}$ \\
\hline $\begin{array}{l}26 \\
27 \\
28 \\
29 \\
30 \\
31\end{array}$ & $\begin{array}{l}3.95 \\
3.97 \\
3.96 \\
3.96 \\
3.94 \\
3.92\end{array}$ & $\begin{array}{l}3.71 \\
3.69 \\
3.67 \\
3.67 \\
3.66 \\
\end{array}$ & $\begin{array}{r}--- \\
--- \\
--- \\
3.43 \\
3.43 \\
3.42\end{array}$ & $\begin{array}{l}3.24 \\
3.24 \\
3.23 \\
3.24 \\
3.27 \\
3.27\end{array}$ & $\begin{array}{r}3.17 \\
3.16 \\
3.16 \\
-\ldots \\
\ldots-\end{array}$ & $\begin{array}{l}3.21 \\
3.22 \\
3.23 \\
3.25 \\
3.26 \\
3.26\end{array}$ & $\begin{array}{l}3.22 \\
3.23 \\
3.23 \\
3.23 \\
3.20 \\
-\end{array}$ & $\begin{array}{l}2.99 \\
2.99 \\
3.00 \\
2.99 \\
2.97 \\
2.95\end{array}$ & $\begin{array}{l}2.65 \\
2.64 \\
2.62 \\
2.63 \\
2.63 \\
\end{array}$ & $\begin{array}{l}2.61 \\
2.59 \\
2.57 \\
2.55 \\
2.54 \\
2.52\end{array}$ & $\begin{array}{l}--- \\
-- \\
--- \\
--- \\
-- \\
---\end{array}$ & $\begin{array}{l}2.65 \\
2.64 \\
2.63 \\
2.65 \\
2.68 \\
-\end{array}$ \\
\hline $\begin{array}{l}\text { MEAN } \\
\text { MAX } \\
\text { MIN }\end{array}$ & $\begin{array}{l}3.98 \\
4.03 \\
3.87\end{array}$ & $\begin{array}{l}3.80 \\
3.94 \\
3.66\end{array}$ & $\begin{array}{l}--- \\
--- \\
---\end{array}$ & $\begin{array}{l}3.30 \\
3.41 \\
3.23\end{array}$ & $\begin{array}{l}3.21 \\
3.26 \\
3.16\end{array}$ & $\begin{array}{l}3.19 \\
3.26 \\
3.17\end{array}$ & $\begin{array}{l}3.27 \\
3.30 \\
3.20\end{array}$ & $\begin{array}{l}3.04 \\
3.17 \\
2.95\end{array}$ & $\begin{array}{l}2.76 \\
2.94 \\
2.62\end{array}$ & $\begin{array}{l}2.66 \\
3.20 \\
2.52\end{array}$ & $\begin{array}{l}-- \\
--- \\
---\end{array}$ & $\begin{array}{l}--- \\
--- \\
---\end{array}$ \\
\hline
\end{tabular}


04136500 AU SABLE RIVER AT MIO, MI

LOCATION. --Lat $44^{\circ} 39^{\prime} 36^{\prime \prime}$, long $84^{\circ} 07^{\prime} 52^{\prime \prime}$, in SEl/4 NEl/4 sec.12, T.26 N., R.2 E. Oscoda County, Hydrologic Unit 04070007 , on right bank $150 \mathrm{ft}$ upstream from bridge on State Highway 33 in Mio, 500 ft downstream from Mio hydroelectric plant, $9.5 \mathrm{mi}$ downstream from Big Creek, and $73.0 \mathrm{mi}$ upstream from mouth.

DRAINAGE AREA.--1,100 $\mathrm{mi}^{2}$, approximately.

PERIOD OF RECORD.--July 1952 to current year.

GAGE.--Water-stage recorder. Datum of gage is $929.60 \mathrm{ft}$ above National Geodetic Vertical Datum of 1929.

REMARKS. - No estimated daily discharges. Records good. Flow regulated by Mio Dam 500 ft upstream. Several measurements of water temperature were made during the year.

AVERAGE DISCHARGE. --35 years, $998 \mathrm{ft} / \mathrm{s}, 12.32 \mathrm{in} / \mathrm{yr}^{3}$

EXTREMES FOR PERIOD OF RECORD.--Maximum discharge, 4,380 ft $3 / \mathrm{s}$, Sept. 30, 1986, gage height, 6.16 $\mathrm{ft}$; minimum, $7.0 \mathrm{ft} / \mathrm{s}$, Aug. 4, 1977, gage height, $-0.09 \mathrm{ft}$; minimum daily, $21 \mathrm{ft} / \mathrm{s}, \mathrm{Aug}$. 9 , 1977.

EXTREMES FOR CURRENT YEAR.--Maximum discharge, $2,770 \mathrm{ft}^{3} / \mathrm{s}$, Oct. 1, gage height, 4.96 ft, stage falling, peak occurred Sept. 30, 1986; maximum independent peak discharge, 2,670 ft $3 / \mathrm{s}$, Aug. 16, gage height, $4.99 \mathrm{ft}$; minimum discharge, $94 \mathrm{ft}^{3} / \mathrm{s}$, July 8 , gage height, $0.81 \mathrm{ft} ; \mathrm{minimum}$ daily, $682 \mathrm{ft}^{3} / \mathrm{s}$, Aug. 1 .

DISCHARGE, IN CUBIC FEET PER SECOND, WATER YEAR OCTOBER 1986 TO SEPTEMBER 1987 MEAN VALUES

\begin{tabular}{|c|c|c|c|c|c|c|c|c|c|c|c|c|}
\hline DAY & OCT & NOV & DEC & JAN & FEB & MAR & APR & MAY & JUN & JUL & AUG & SEP \\
\hline $\begin{array}{l}1 \\
2 \\
3 \\
4 \\
5\end{array}$ & $\begin{array}{l}2660 \\
2360 \\
2420 \\
2550 \\
2700\end{array}$ & $\begin{array}{l}1400 \\
1320 \\
1320 \\
1280 \\
1280\end{array}$ & $\begin{array}{l}1180 \\
1160 \\
1150 \\
1150 \\
1150\end{array}$ & $\begin{array}{l}1050 \\
1050 \\
1070 \\
1050 \\
1020\end{array}$ & $\begin{array}{r}1000 \\
1070 \\
1020 \\
968 \\
943\end{array}$ & $\begin{array}{r}952 \\
988 \\
1030 \\
1010 \\
971\end{array}$ & $\begin{array}{l}1150 \\
1100 \\
1070 \\
1070 \\
1070\end{array}$ & $\begin{array}{l}895 \\
881 \\
877 \\
858 \\
851\end{array}$ & $\begin{array}{l}817 \\
810 \\
822 \\
787 \\
771\end{array}$ & $\begin{array}{l}844 \\
783 \\
771 \\
765 \\
751\end{array}$ & $\begin{array}{l}682 \\
816 \\
963 \\
957 \\
838\end{array}$ & $\begin{array}{l}824 \\
813 \\
783 \\
777 \\
783\end{array}$ \\
\hline $\begin{array}{r}6 \\
7 \\
8 \\
9 \\
10\end{array}$ & $\begin{array}{l}2540 \\
2290 \\
2150 \\
1930 \\
1820\end{array}$ & $\begin{array}{l}1320 \\
1250 \\
1280 \\
1320 \\
1240\end{array}$ & $\begin{array}{l}1110 \\
1090 \\
1090 \\
1120 \\
1130\end{array}$ & $\begin{array}{l}1040 \\
1040 \\
1020 \\
1030 \\
1030\end{array}$ & $\begin{array}{l}955 \\
974 \\
974 \\
880 \\
954\end{array}$ & $\begin{array}{r}961 \\
1060 \\
1350 \\
1380 \\
1360\end{array}$ & $\begin{array}{l}1100 \\
1110 \\
1070 \\
1060 \\
1030\end{array}$ & $\begin{array}{l}863 \\
859 \\
835 \\
840 \\
829\end{array}$ & $\begin{array}{l}777 \\
793 \\
791 \\
778 \\
765\end{array}$ & $\begin{array}{l}746 \\
743 \\
757 \\
779 \\
892\end{array}$ & $\begin{array}{r}782 \\
806 \\
877 \\
929 \\
1090\end{array}$ & $\begin{array}{l}766 \\
778 \\
826 \\
795 \\
794\end{array}$ \\
\hline $\begin{array}{l}11 \\
12 \\
13 \\
14 \\
15\end{array}$ & $\begin{array}{l}1760 \\
1700 \\
1710 \\
1740 \\
1670\end{array}$ & $\begin{array}{l}1220 \\
1200 \\
1180 \\
1130 \\
1130\end{array}$ & $\begin{array}{l}1080 \\
1040 \\
1040 \\
1010 \\
1120\end{array}$ & $\begin{array}{l}1050 \\
1040 \\
1010 \\
1010 \\
1010\end{array}$ & $\begin{array}{r}1020 \\
970 \\
956 \\
916 \\
790\end{array}$ & $\begin{array}{r}1200 \\
1120 \\
1060 \\
1040 \\
998\end{array}$ & $\begin{array}{r}1000 \\
976 \\
949 \\
991 \\
1130\end{array}$ & $\begin{array}{l}855 \\
906 \\
856 \\
850 \\
851\end{array}$ & $\begin{array}{l}768 \\
827 \\
805 \\
781 \\
767\end{array}$ & $\begin{array}{l}917 \\
917 \\
857 \\
837 \\
770\end{array}$ & $\begin{array}{r}932 \\
875 \\
810 \\
801 \\
1140\end{array}$ & $\begin{array}{l}772 \\
764 \\
812 \\
830 \\
828\end{array}$ \\
\hline $\begin{array}{l}16 \\
17 \\
18 \\
19 \\
20\end{array}$ & $\begin{array}{l}1640 \\
1570 \\
1530 \\
1530 \\
1510\end{array}$ & $\begin{array}{l}1180 \\
1230 \\
1190 \\
1150 \\
1110\end{array}$ & $\begin{array}{l}1160 \\
1110 \\
1110 \\
1110 \\
1110\end{array}$ & $\begin{array}{r}1010 \\
880 \\
934 \\
1010 \\
951\end{array}$ & $\begin{array}{r}736 \\
977 \\
1050 \\
964 \\
905\end{array}$ & $\begin{array}{r}986 \\
993 \\
984 \\
986 \\
1050\end{array}$ & $\begin{array}{l}1150 \\
1110 \\
1090 \\
1030 \\
1030\end{array}$ & $\begin{array}{l}839 \\
830 \\
816 \\
810 \\
874\end{array}$ & $\begin{array}{l}757 \\
739 \\
727 \\
735 \\
773\end{array}$ & $\begin{array}{l}763 \\
776 \\
746 \\
713 \\
726\end{array}$ & $\begin{array}{l}1970 \\
1800 \\
1530 \\
1310 \\
1170\end{array}$ & $\begin{array}{l}786 \\
830 \\
978 \\
951 \\
962\end{array}$ \\
\hline $\begin{array}{l}21 \\
22 \\
23 \\
24 \\
25\end{array}$ & $\begin{array}{l}1390 \\
1410 \\
1400 \\
1330 \\
1510\end{array}$ & $\begin{array}{l}1190 \\
1200 \\
1180 \\
1230 \\
1210\end{array}$ & $\begin{array}{l}1110 \\
1090 \\
1040 \\
1030 \\
1060\end{array}$ & $\begin{array}{l}973 \\
997 \\
897 \\
703 \\
708\end{array}$ & $\begin{array}{l}890 \\
926 \\
933 \\
922 \\
901\end{array}$ & $\begin{array}{l}1090 \\
1090 \\
1150 \\
1220 \\
1260\end{array}$ & $\begin{array}{r}1020 \\
947 \\
959 \\
980 \\
956\end{array}$ & $\begin{array}{r}897 \\
1090 \\
1020 \\
888 \\
857\end{array}$ & $\begin{array}{l}768 \\
748 \\
772 \\
763 \\
762\end{array}$ & $\begin{array}{l}810 \\
785 \\
758 \\
753 \\
700\end{array}$ & $\begin{array}{r}1050 \\
937 \\
897 \\
838 \\
838\end{array}$ & $\begin{array}{r}1050 \\
961 \\
972 \\
949 \\
858\end{array}$ \\
\hline $\begin{array}{l}26 \\
27 \\
28 \\
29 \\
30 \\
31\end{array}$ & $\begin{array}{l}1320 \\
1440 \\
1480 \\
1410 \\
1360 \\
1320\end{array}$ & $\begin{array}{l}1240 \\
1240 \\
1170 \\
1170 \\
1190 \\
---\end{array}$ & $\begin{array}{l}1080 \\
1060 \\
1060 \\
1060 \\
1050 \\
1050\end{array}$ & $\begin{array}{r}859 \\
962 \\
1100 \\
1010 \\
989 \\
983\end{array}$ & $\begin{array}{l}893 \\
914 \\
924 \\
--- \\
--- \\
---\end{array}$ & $\begin{array}{l}1410 \\
1460 \\
1350 \\
1300 \\
1270 \\
1190\end{array}$ & $\begin{array}{l}942 \\
938 \\
944 \\
936 \\
924 \\
-\end{array}$ & $\begin{array}{l}930 \\
981 \\
919 \\
907 \\
807 \\
812\end{array}$ & $\begin{array}{l}841 \\
807 \\
784 \\
843 \\
889 \\
---\end{array}$ & $\begin{array}{l}733 \\
735 \\
707 \\
683 \\
703 \\
705\end{array}$ & $\begin{array}{l}828 \\
810 \\
829 \\
839 \\
833 \\
827\end{array}$ & $\begin{array}{l}853 \\
853 \\
845 \\
845 \\
946 \\
---\end{array}$ \\
\hline $\begin{array}{l}\text { TOTAL } \\
\text { MEAN } \\
\text { MAX } \\
\text { MIN } \\
\text { CFSM } \\
\text { IN. }\end{array}$ & $\begin{array}{r}55150 \\
1779 \\
2700 \\
1320 \\
1.62 \\
1.87\end{array}$ & $\begin{array}{r}36750 \\
1225 \\
1400 \\
1110 \\
1.11 \\
1.24\end{array}$ & $\begin{array}{r}33910 \\
1094 \\
1180 \\
1010 \\
1.00 \\
1.15\end{array}$ & $\begin{array}{r}30486 \\
983 \\
1100 \\
703 \\
.89 \\
1.03\end{array}$ & $\begin{array}{r}26325 \\
940 \\
1070 \\
736 \\
.86 \\
.89\end{array}$ & $\begin{array}{r}35269 \\
1138 \\
1460 \\
952 \\
1.04 \\
1.19\end{array}$ & $\begin{array}{r}30832 \\
1028 \\
1150 \\
924 \\
.94 \\
1.04\end{array}$ & $\begin{array}{r}27183 \\
877 \\
1090 \\
807 \\
.80 \\
.92\end{array}$ & $\begin{array}{r}23567 \\
786 \\
889 \\
727 \\
.72 \\
.80\end{array}$ & $\begin{array}{r}23925 \\
772 \\
917 \\
683 \\
.70 \\
.81\end{array}$ & $\begin{array}{r}30604 \\
987 \\
1970 \\
682 \\
.90 \\
1.03\end{array}$ & $\begin{array}{r}25584 \\
853 \\
1050 \\
764 \\
.78 \\
.87\end{array}$ \\
\hline $\begin{array}{l}\text { CAL YR } \\
\text { WTR YR }\end{array}$ & $\begin{array}{l}1986 \\
1987\end{array}$ & $\mathrm{AL}$ & & $\begin{array}{ll}\mathrm{N} & 1253 \\
\mathrm{~N} & 1040\end{array}$ & $\begin{array}{l}\text { MAX } \\
\text { MAX }\end{array}$ & $\begin{array}{l}3170 \\
2700\end{array}$ & $\begin{array}{l}\text { MIN } 586 \\
\text { MIN } 682\end{array}$ & $\begin{array}{l}\text { CFSM } \\
\text { CFSM }\end{array}$ & $\begin{array}{l}\text { IN } \\
\text { IN }\end{array}$ & $\begin{array}{l}15.47 \\
12.84\end{array}$ & & \\
\hline
\end{tabular}


LOCATION.--Lat $44^{\circ} 26^{\prime} 09^{\prime \prime}$, long $8^{\circ} 26^{\prime} 28^{\prime \prime}$, in NEl/4 NW1/4 sec.35, T.24 N., R.8 E., Iosco County, Hydrologic Unit 04070007 , at bridge on Rea Road, $5.5 \mathrm{mi}$ northwest of Au Sable and $10.4 \mathrm{mi}$ upstream from mouth.

DRAINAGE AREA.--1,540 $\mathrm{mi}^{2}$, approximately.

PERIOD OF RECORD.--Water years 1978 to current year.

PERIOD OF DAILY RECORD.--

SPECIFIC CONDUCTANCE: April 1978 to September 1981.

WATER TEMPERATURE: April 1978 to September 1981.

REMARKS. - Discharge regulated by Foote Dam $0.6 \mathrm{mi}$ upstream, operated by Consumers Power Company.

EXTREMES FOR PERIOD OF DAILY RECORD.--

SPECIFIC CONDUCTANCE (water years 1978-79): Maximum daily, 346 microsiemens, Nov. 21, 1978; minimum daily, 229 microsiemens, Apr. 19, $21,1979$.

WATER TEMPERATURE (water years 1979-80): Maximum measured, 28. $0^{\circ} \mathrm{C}$, Aug. 8, $1979 ;$ minimum daily, $0.0^{\circ} \mathrm{C}$ on many days during winter.

WATER QUALITY DATA, WATER YEAR OCTOBER 1986 TO SEPTEMBER 1987

\begin{tabular}{|c|c|c|c|c|c|c|c|c|c|c|}
\hline DATE & TIME & $\begin{array}{l}\text { STREAM- } \\
\text { FLOW, } \\
\text { INSTAN- } \\
\text { TANEOUS } \\
\text { (CFS ) }\end{array}$ & $\begin{array}{l}\text { SPE- } \\
\text { CIFIC } \\
\text { CON- } \\
\text { DUCT- } \\
\text { ANCE } \\
\text { (US/CM) }\end{array}$ & $\begin{array}{c}\text { PH } \\
\text { (STAND- } \\
\text { ARD } \\
\text { UNITS ) }\end{array}$ & $\begin{array}{l}\text { TEMPER- } \\
\text { ATURE } \\
\text { (DEG C ) }\end{array}$ & $\begin{array}{l}\text { TUR- } \\
\text { BID- } \\
\text { ITY } \\
\text { (NTU) }\end{array}$ & $\begin{array}{c}\text { OXYGEN, } \\
\text { DIS- } \\
\text { SOLVED } \\
\text { (MG/L) }\end{array}$ & $\begin{array}{c}\text { OXYGEN, } \\
\text { DIS- } \\
\text { SOLVED } \\
\text { (PER- } \\
\text { CENT } \\
\text { SATUR- } \\
\text { ATION) }\end{array}$ & $\begin{array}{l}\text { COLI- } \\
\text { FORM, } \\
\text { FECAL, } \\
0.7 \\
\text { UM-MF } \\
\text { (COLS./ } \\
100 \mathrm{ML} \text { ) }\end{array}$ & $\begin{array}{l}\text { STREP- } \\
\text { TOCOCCI } \\
\text { FECAL, } \\
\text { KF AGAR } \\
\text { (COLS. } \\
\text { PER } \\
100 \mathrm{ML} \text { ) }\end{array}$ \\
\hline $\begin{array}{l}\text { NOV } \\
04 \ldots \\
\text { DEC }\end{array}$ & 1600 & 2900 & 272 & 7.84 & 8.5 & 2.2 & 9.8 & 84 & K3 & 56 \\
\hline $10 \ldots$ & 1030 & 2270 & 342 & 8.27 & 1.0 & 1.3 & 13.7 & 99 & $<1$ & K 3 \\
\hline${ }_{M A Y}^{18} \ldots$ & 1015 & 2850 & 328 & 8.18 & 1.5 & 2.0 & 14.0 & 101 & $<1$ & K 1 \\
\hline${ }_{\text {JUL }}^{13} \ldots$ & 1030 & 2130 & 305 & 8.25 & 14.0 & 1.0 & 9.9 & 97 & $<1$ & K4 \\
\hline$\underset{\text { AUG }}{07} \ldots$ & 1330 & 2060 & 310 & 8.20 & 24.0 & 0.7 & 7.6 & 92 & K5 & 92 \\
\hline $12 \ldots$ & 1115 & 647 & 327 & 7.98 & 24.5 & 0.6 & 6.8 & 83 & K5 & K21 \\
\hline DATE & $\begin{array}{l}\text { HARD- } \\
\text { NESS } \\
\text { (MG/L } \\
\text { AS } \\
\text { CACO3) }\end{array}$ & $\begin{array}{l}\text { HARD- } \\
\text { NESS } \\
\text { NONCARB } \\
\text { WH WAT } \\
\text { TOT FLD } \\
\text { MG/L AS } \\
\text { CACO3 }\end{array}$ & $\begin{array}{l}\text { CALCIUM } \\
\text { DIS- } \\
\text { SOLVED } \\
\text { (MG/L } \\
\text { AS CA) }\end{array}$ & $\begin{array}{l}\text { MAGNE- } \\
\text { SIUM, } \\
\text { DIS- } \\
\text { SOLVED } \\
\text { (MG/L } \\
\text { AS MG) }\end{array}$ & $\begin{array}{l}\text { SODIUM, } \\
\text { DIS- } \\
\text { SOLVED } \\
\text { (MG/L } \\
\text { AS NA) }\end{array}$ & $\begin{array}{l}\text { PERCENT } \\
\text { SODIUM }\end{array}$ & $\begin{array}{l}\text { SODIUM } \\
\text { AD- } \\
\text { SORP- } \\
\text { TION } \\
\text { RATIO }\end{array}$ & $\begin{array}{l}\text { POTAS- } \\
\text { SIUM, } \\
\text { DIS- } \\
\text { SOLVED } \\
\text { (MG/L } \\
\text { AS K) }\end{array}$ & $\begin{array}{l}\text { BICAR- } \\
\text { BONATE } \\
\text { WH WAT } \\
\text { TOTAL } \\
\text { FIELD } \\
\text { MG/L AS } \\
\text { HCO3 }\end{array}$ & $\begin{array}{l}\text { CAR- } \\
\text { BONATE } \\
\text { WH WAT } \\
\text { TOTAL } \\
\text { FIELD } \\
\text { MG/L AS } \\
\text { CO3 }\end{array}$ \\
\hline $\begin{array}{l}\text { NOV } \\
04 \ldots \\
\text { DEC }\end{array}$ & 140 & 18 & 41 & 9.2 & 3.6 & 5 & 0.1 & 0.9 & 150 & 0 \\
\hline$\underset{M A R}{10} \cdots$ & 150 & 16 & 45 & 10 & 4.1 & 5 & 0.1 & 0.6 & 170 & 0 \\
\hline$\underset{M A Y}{18} \ldots$ & 170 & 23 & 48 & 11 & 4.4 & 5 & 0.2 & 0.6 & 170 & 0 \\
\hline JUL $13 \ldots$ & 160 & 16 & 46 & 11 & 4.4 & 6 & 0.2 & 0.7 & 180 & 0 \\
\hline$\underset{\text { AUG }}{07 \ldots}$ & 160 & 13 & 46 & 12 & 4.4 & 5 & 0.2 & 0.4 & 180 & 0 \\
\hline $12 \ldots$ & 150 & 7 & 41 & 11 & 4.5 & 6 & 0.2 & 0.4 & 170 & 0 \\
\hline DATE & $\begin{array}{l}\text { ALKA- } \\
\text { LINITY } \\
\text { WH WAT } \\
\text { TOTAL } \\
\text { FIELD } \\
\text { MG/L AS } \\
\text { CACO3 }\end{array}$ & $\begin{array}{c}\text { CARBON } \\
\text { DIOXIDE } \\
\text { DIS- } \\
\text { SOLVED } \\
\text { (MG/L } \\
\text { AS CO2) }\end{array}$ & $\begin{array}{l}\text { SULFATE } \\
\text { DIS- } \\
\text { SOLVED } \\
\text { (MG/L } \\
\text { AS SO4) }\end{array}$ & $\begin{array}{l}\text { CHLO- } \\
\text { RIDE, } \\
\text { DIS- } \\
\text { SOLVED } \\
\text { (MG/L } \\
\text { AS CL) }\end{array}$ & $\begin{array}{l}\text { FLUO- } \\
\text { RIDE, } \\
\text { DIS- } \\
\text { SOLVED } \\
\text { (MG/L } \\
\text { AS F) }\end{array}$ & $\begin{array}{l}\text { SILICA, } \\
\text { DIS- } \\
\text { SOLVED } \\
\text { (MG/L } \\
\text { AS } \\
\text { SIO2) }\end{array}$ & $\begin{array}{l}\text { SOLIDS, } \\
\text { RESIDUE } \\
\text { AT } 180 \\
\text { DEG.C } \\
\text { DIS- } \\
\text { SOLVED } \\
\text { (MG/L) }\end{array}$ & $\begin{array}{l}\text { SOLIDS, } \\
\text { SUM OF } \\
\text { CONSTI- } \\
\text { TUENTS, } \\
\text { DIS- } \\
\text { SOLVED } \\
\text { (MG/L) }\end{array}$ & $\begin{array}{c}\text { SOLIDS, } \\
\text { DIS- } \\
\text { SOLVED } \\
\text { (TONS } \\
\text { PER } \\
\text { AC-FT) }\end{array}$ & $\begin{array}{c}\text { SOLIDS, } \\
\text { DIS- } \\
\text { SOLVED } \\
\text { (TONS } \\
\text { PER } \\
\text { DAY) }\end{array}$ \\
\hline $\begin{array}{l}\text { NOV } \\
04 \ldots \\
\text { DEC }\end{array}$ & 122 & 3.4 & 15 & 4.9 & $<0.1$ & 9.2 & 172 & 160 & 0.23 & 1350 \\
\hline$\underset{\operatorname{MAR}}{10} \cdot \cdots$ & 138 & 1.4 & 13 & 12 & $<0.1$ & 8.6 & 170 & 180 & 0.23 & 1040 \\
\hline${ }_{M A Y}^{18} \ldots$ & 142 & 1.8 & 10 & 4.9 & 0.1 & 8.8 & 163 & 170 & 0.22 & 1250 \\
\hline JuL $13 \ldots$ & 144 & 1.6 & 11 & 5.2 & $<0.1$ & 7.3 & 168 & 170 & 0.23 & 966 \\
\hline$\stackrel{07}{A U G}$ & 151 & 1.8 & 13 & 4.9 & $<0.1$ & 9.0 & 177 & 180 & 0.24 & 984 \\
\hline $12 \ldots$ & 141 & 2.9 & 11 & 5.0 & 0.1 & 9.9 & 163 & 170 & 0.22 & 285 \\
\hline
\end{tabular}


04137500 AU SABLE RIVER NEAR AU SABLE, MI--Continued

WATER QUALITY DATA, WATER YEAR OCTOBER 1986 TO SEPTEMBER 1987

\begin{tabular}{|c|c|c|c|c|c|c|c|c|c|c|}
\hline DATE & $\begin{array}{c}\text { NITRO- } \\
\text { GEN, } \\
\text { NITRITE } \\
\text { DIS- } \\
\text { SOLVED } \\
\text { (MG/L } \\
\text { AS N) }\end{array}$ & $\begin{array}{c}\text { NITRO- } \\
\text { GEN, } \\
\text { NO2+NO3 } \\
\text { DIS- } \\
\text { SOLVED } \\
\text { (MG/L } \\
\text { AS N) }\end{array}$ & $\begin{array}{c}\text { NITRO- } \\
\text { GEN, } \\
\text { AMMONIA } \\
\text { TOTAL } \\
\text { (MG/L } \\
\text { AS N) }\end{array}$ & $\begin{array}{c}\text { NITRO- } \\
\text { GEN, } \\
\text { AMMONIA } \\
\text { DIS- } \\
\text { SOLVED } \\
\text { (MG/L } \\
\text { AS N) }\end{array}$ & $\begin{array}{c}\text { NITRO- } \\
\text { GEN, } \\
\text { ORGANIC } \\
\text { TOTAL } \\
\text { (MG/L } \\
\text { AS N) }\end{array}$ & $\begin{array}{l}\text { NITRO- } \\
\text { GEN,AM- } \\
\text { MONIA + } \\
\text { ORGANIC } \\
\text { TOTAL } \\
\text { (MG/L } \\
\text { AS N) }\end{array}$ & $\begin{array}{l}\text { PHOS- } \\
\text { PHORUS, } \\
\text { TOTAL } \\
\text { (MG/L } \\
\text { AS P) }\end{array}$ & $\begin{array}{c}\text { PHOS- } \\
\text { PHORUS, } \\
\text { DIS- } \\
\text { SOLVED } \\
\text { (MG/L } \\
\text { AS P) }\end{array}$ & $\begin{array}{l}\text { PHOS- } \\
\text { PHORUS, } \\
\text { ORTHO, } \\
\text { DIS- } \\
\text { SOLVED } \\
\text { (MG/L } \\
\text { AS P) }\end{array}$ & $\begin{array}{l}\text { ALUM- } \\
\text { INUM, } \\
\text { DIS- } \\
\text { SOLVED } \\
\text { (UG/L } \\
\text { AS AL) }\end{array}$ \\
\hline $\begin{array}{l}\text { NOV } \\
04 \ldots \\
\text { DEC }\end{array}$ & $<0.01$ & $<0.10$ & 0.05 & 0.03 & 0.75 & 0.8 & 0.03 & $<0.01$ & 0.01 & 20 \\
\hline $10 \ldots$ & 0.01 & $<0.10$ & 0.01 & 0.01 & 0.19 & 0.2 & $<0.01$ & 0.01 & $<0.01$ & $<10$ \\
\hline $\operatorname{MAY}^{18} \ldots$ & $<0.01$ & 0.12 & 0.02 & $<0.01$ & 0.78 & 0.8 & 0.01 & 0.01 & $<0.01$ & $<10$ \\
\hline JUL $13 \ldots$ & 0.02 & $<0.10$ & 0.02 & -- & 0.68 & 0.7 & 0.02 & 0.02 & 0.03 & - \\
\hline AUG $07 \ldots$ & $<0.01$ & $<0.10$ & 0.04 & 0.01 & 0.36 & 0.4 & 0.05 & 0.02 & 0.02 & $<10$ \\
\hline $12 \ldots$ & $<0.01$ & $<0.10$ & 0.03 & 0.02 & 0.57 & 0.6 & 0.02 & 0.02 & $<0.01$ & - \\
\hline
\end{tabular}

$\begin{array}{ll} & \\ \text { BRSENIC BARIU- } & \\ \text { LIUM, }\end{array}$

DIS-

SOLVED SOLVED

(UG/L (UG/L

AS AS) AS BA)
DIS-

SOLVED

(UG/L

AS BE)
CADMIUM

DIS-

SOLVED

(UG/L

AS CD)
CHRO-

MIUM, COBALT, COPPER, DIS- DIS- DISDOIVED SOLVED (UG/L (UG/L U IUG/L $\begin{array}{lll}\text { AS } C R \text { ) } & \text { AS CO) } & \text { AS CU) }\end{array}$

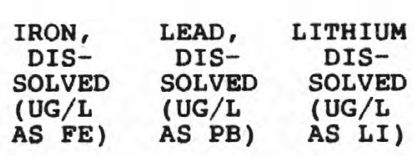

NOV $04 \ldots$

DEC $10 .$.

MAR

$18 \ldots$

$13 \ldots$

JUL 7 ...

AUG

$12 \ldots$

DATE

MANGA-

NESE, MERCURY

SOLVED

SOLVED

(UG /L

\begin{abstract}
$<0.5$

$<1$
\end{abstract}

$<1<3$

$<3$
$<3$

$<0.5$

$<1$

$<0.5$

$<1$

$<1$

$<1$

79

$\begin{array}{rr}<5 & 6 \\ <5 & 7 \\ 31 & 5 \\ -- & -- \\ <5 & <4 \\ -- & --\end{array}$

DENUM, NICKEL,

DIS-

SOLVED

SOLVED

(UG/L (UG/L

AS MO) AS NI)

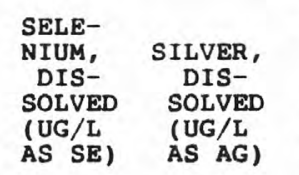

STRONTIUM, DISSOLVED (UT) (US SR)
VANA-

DIUM, ZINC, SEDIDIS- DIS- MENT, SOLVED SOLVED SUS(UG /L (UG $/ \mathrm{L}$ PENDED AS $V$ ) AS $\mathrm{ZN}) \quad$ (MG/L)

\begin{tabular}{|c|c|c|c|c|c|c|c|c|c|c|}
\hline $\begin{array}{l}\text { NOV } \\
04 \ldots \\
\text { DEC }\end{array}$ & 8 & 0.1 & $<10$ & 3 & $<1$ & $<1$ & 59 & $<6$ & 12 & 11 \\
\hline MAR $10 \ldots$ & 10 & $<0.1$ & $<10$ & $<1$ & $<1$ & $<1$ & 64 & $<6$ & 3 & 5 \\
\hline${ }_{M A Y}^{18} \ldots$ & 14 & 0.6 & $<10$ & 1 & $<1$ & $<1$ & 69 & $<6$ & 7 & - \\
\hline JUL $13 \ldots$ & -- & -- & -- & - & -- & -- & -- & -- & -- & 5 \\
\hline$\underset{\text { AUG }}{07 \ldots}$ & $<1$ & 0.1 & $<10$ & $<1$ & $<1$ & $<1$ & 74 & $<6$ & 9 & 4 \\
\hline $12 \ldots$ & -- & -- & -- & -- & -- & -- & - & - & -- & 12 \\
\hline
\end{tabular}

12

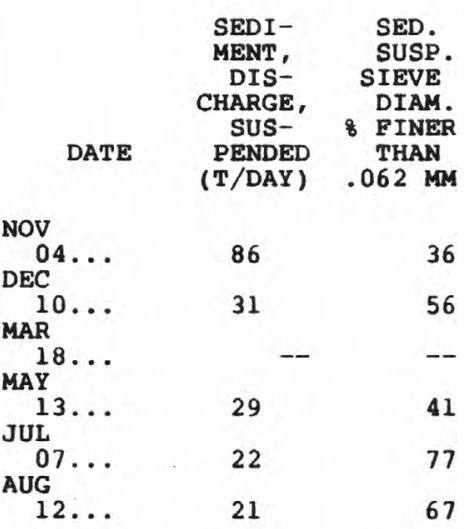


LOCATION. - Lat $44^{\circ} 04^{\prime} 21^{\prime \prime}$, long $84^{\circ} 01^{\prime} 12^{\prime \prime}$, in NEl/4 SWl/4 sec.5, T.19 N., R.4 E., Arenac County, Hydrologic Unit 04080101 , on left bank $30 \mathrm{ft}$ downstream from bridge on old $\mathrm{M}-70,2.8 \mathrm{mi}$ north of Ster ing, and 20 mi upstream from mouth.

DRAINAGE AREA. $--320 \mathrm{mi}^{2}$, approximately.

WATER-DISCHARGE RECORDS

PERIOD OF RECORD.--November 1905 to December 1908 (gage heights and discharge measurements only), October 1936 to current year. Monthly discharge only for some periods, published in wSP 1307. Published as Rifle River at Michigan Highway 70 near sterling 1936-61.

REVISED RECORDS,--WSP 1437: $1937(M), 1939-40(M)$.

GAGE.--Water-stage recorder. Datum of gage is $649.48 \mathrm{ft}$ above National Geodetic Vertical Datum of 1929. November 1905 to December 1908, nonrecording gage at site $400 \mathrm{ft}$ downstream at different datum. Jan. 13, 1937, to Jan. 10, 1939, nonrecording gage at same site and datum.

REMARKS.--Estimated daily discharges: Jan. 18 to Mar. 5. Water-discharge records good except for estimated daily discharges, which are poor. Occasional regulation by dams upstream from station.

AVERAGE DISCHARGE. -51 years, $314 \mathrm{ft}^{3} / \mathrm{s}, 13.32 \mathrm{in} / \mathrm{yr}$.

EXTREMES FOR PERIOD OF RECORD.--Maximum discharge, 5,340 ft $3 / \mathrm{s}$, Mar. 28, 1950, gage height, 13.74 ft, from rating curve extended above $3,800 \mathrm{ft}^{3} / \mathrm{s}$; minimum, $75 \mathrm{ft} / \mathrm{s}$, Nov. 22, 1964, result of freezeup.

EXTREMES FOR CURRENT YEAR.--Peak discharges greater than base discharge of $1,600 \mathrm{ft} 3 / \mathrm{s}$ and maximum (*):

\begin{tabular}{|c|c|c|c|c|c|c|c|}
\hline Date & Time & $\begin{array}{c}\text { Discharge } \\
\left(\mathrm{ft}^{3} / \mathrm{s}\right)\end{array}$ & $\begin{array}{l}\text { Gage height } \\
\text { (ft) }\end{array}$ & Date & Time & $\begin{array}{c}\text { Discharge } \\
\left(\mathrm{ft}^{3} / \mathrm{s}\right)\end{array}$ & $\begin{array}{l}\text { Gage height } \\
\text { (ft) }\end{array}$ \\
\hline Oct. & 0100 & $\star a 3,120$ & *a9.73 & Oct. 5 & 0600 & 1,720 & 6.56 \\
\hline
\end{tabular}

a Stage falling, peak occurred sept. $30,1986$.

Minimum discharge, $120 \mathrm{ft}^{3} / \mathrm{s}, \mathrm{July} 31$, gage height, $1.19 \mathrm{ft}$.

DISCHARGE, IN CUBIC FEET PER SECOND, WATER YEAR OCTOBER 1986 TO SEPTEMBER 1987 MEAN VALUES

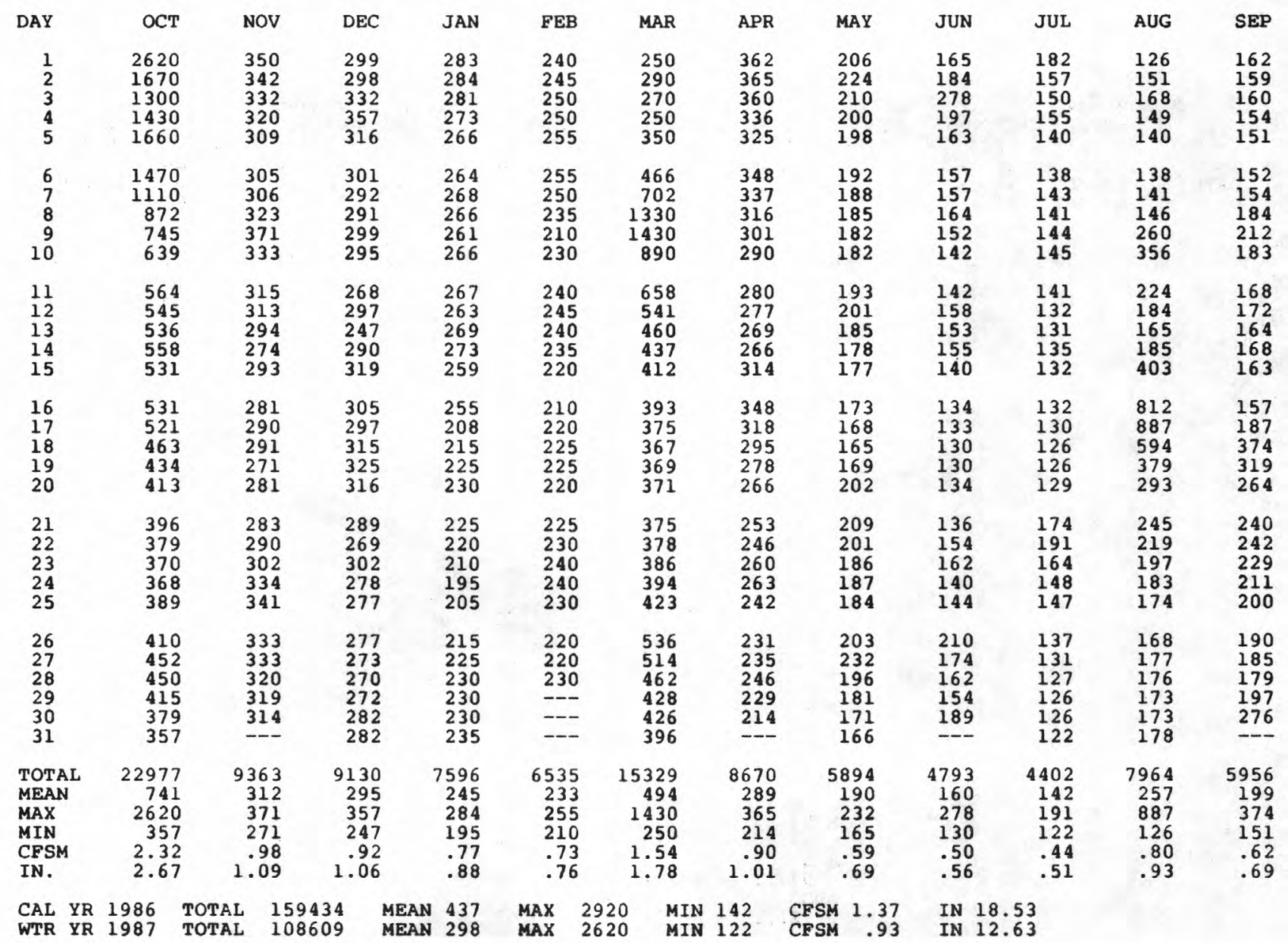


PERIOD OF RECORD.--Water years 1966-72, 1974 to current year.

PERIOD OF DAILY RECORD.--

SPECIFIC CONDUCTANCE: November 1974 to September 1981

WATER TEMPERATURE: November 1974 to September 1981.

SUSPENDED-SEDIMENT DISCHARGE: April to September 1966, October 1969 to September 1970 , April to September 1972

INSTRUMENTATION.--Water-quality monitor from Aug. 28, 1975 to Sept. 30, 1981.

REMARKS.--Quarterly cross-sectional samples were collected at or near bridge. Samples for the analyses of stable hydrogen and oxygen isotopes were also collected; analytical results from these samples were not published.

EXTREMES FOR PERIOD OF DAILY RECORD.--

SPECIFIC CONDUCTANCE (water years 1975-77, 1979-80): Maximum recorded (more than 20 percent missing record), 567 microsiemens, Sept. 6, 1979; minimum recorded (more than 20 percent missing record), 157 microsiemens, Aug. 31, 1975.

WATER TEMPERATURE (water years 1976-77, 1980): Maximum, $30.5^{\circ} \mathrm{C}, \mathrm{July} 20,1977 ; \mathrm{minimum,} 0.0^{\circ} \mathrm{C}$

on many days during winter.

SEDIMENT CONCENTRATION (water years 1970, 1972): Maximum daily mean, 304 mg/L, Apr. 13, 1972; minimum daily, $0 \mathrm{mg} / \mathrm{L}$ on several days in water year 1972.

SEDIMENT LOAD (water years 1970, 1972): Maximum daily, 1,760 tons, Apr. 13, 1972; minimum daily, 0 ton on several days during 1972 .

EXTREMES OUTSIDE PERIOD OF DAILY RECORD.--A suspended-sediment concentration of $647 \mathrm{mg} / \mathrm{L}$ was measured Mar, 27, 1967, and a sediment load of 3,270 tons was calculated Mar. 27, 1967.

WATER QUALITY DATA, WATER YEAR OCTOBER 1986 TO SEPTEMBER 1987

\begin{tabular}{|c|c|c|c|c|c|c|c|c|c|c|}
\hline DATE & TIME & $\begin{array}{l}\text { STREAM- } \\
\text { FLOW, } \\
\text { INSTAN- } \\
\text { TANEOUS } \\
\text { (CFS) }\end{array}$ & $\begin{array}{l}\text { SPE- } \\
\text { CIFIC } \\
\text { CON- } \\
\text { DUCT- } \\
\text { ANCE } \\
\text { (US/CM) }\end{array}$ & $\begin{array}{c}\text { PH } \\
\text { ( STAND- } \\
\text { ARD } \\
\text { UNITS ) }\end{array}$ & $\begin{array}{l}\text { TEMPER- } \\
\text { ATURE } \\
\text { (DEG C) }\end{array}$ & $\begin{array}{l}\text { TUR- } \\
\text { BID- } \\
\text { ITY } \\
\text { (NTU) }\end{array}$ & $\begin{array}{c}\text { OXYGEN, } \\
\text { DIS- } \\
\text { SOLVED } \\
\text { (MG/L) }\end{array}$ & $\begin{array}{c}\text { OXYGEN, } \\
\text { DIS- } \\
\text { SOLVED } \\
\text { (PER- } \\
\text { CENT } \\
\text { SATUR- } \\
\text { ATION) }\end{array}$ & $\begin{array}{l}\text { COLI- } \\
\text { FORM, } \\
\text { FECAL, } \\
0.7 \\
\text { UM-MF } \\
\text { (COLS. , } \\
\text { IOO ML) }\end{array}$ & $\begin{array}{l}\text { STREP- } \\
\text { TOCOCCI } \\
\text { FECAL, } \\
\text { KF AGAR } \\
\text { (COLS. } \\
\text { PER } \\
100 \mathrm{ML} \text { ) }\end{array}$ \\
\hline OCT & & & & & & & & & & \\
\hline $10 \ldots$ & 1000 & 626 & 380 & 8.19 & 8.5 & 2.9 & 11.5 & 98 & K31 & K110 \\
\hline $\begin{array}{l}20 \ldots \\
A P R\end{array}$ & 1100 & 222 & 470 & 8.29 & 0.0 & 0.6 & 16.0 & 111 & $\mathrm{~K} 6$ & K12 \\
\hline $\begin{array}{l}09 \\
\text { AUG }\end{array}$ & 1030 & 303 & 434 & 8.01 & 7.5 & 3.0 & 10.1 & 86 & $<1$ & $<1$ \\
\hline $05 \ldots$ & 1415 & 142 & 451 & 8.18 & 23.0 & 1.0 & 9.9 & 118 & 48 & 43 \\
\hline
\end{tabular}

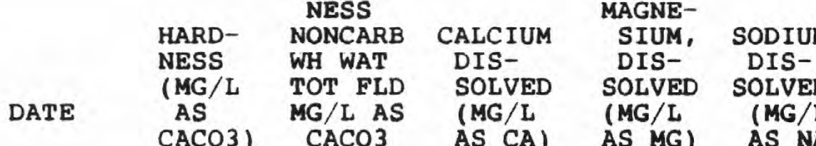

OCT $10 \ldots \quad 190$

20.

APR

$09 .$.

AUG

$05 .$.

$$
220
$$

210

$\begin{array}{ll}36 & 53 \\ 43 & 63 \\ 46 & 60 \\ 36 & 58\end{array}$

AS MG)

MG /L PERCENT
AS NA) SODIUM

13
16
15
17

7.1
9.2
8.6
9.7

8
8
8
9

\section{2}

0.3

0.3

0.3

9.7

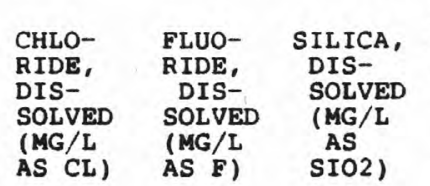

SOLIDS, SOLIDS,

RESIDUE SUM OF

AT 180 CONSTI-

DEG. C TUENTS

SOLVED

(MG/L)

DIS-

(MG/L)

BONATE

TOTAL

FIELD

MG $/ L$ AS

$\mathrm{HCO}_{3}$

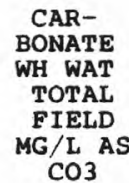

$\mathrm{CO}_{3}$

$\begin{array}{ll}0.2 & 9.1 \\ 0.2 & 9.7 \\ 0.2 & 6.2 \\ 0.2 & 8.0\end{array}$

SOLIDS,

DIS-

SOLVED

(TONS

(TONS

AC-FT

SOLIDS,

SOLVED

(TONS

PER

DAY)

$\begin{array}{lllll}\begin{array}{l}\text { OCT } \\ 10 \ldots\end{array} & 150 & 1.9 & 25 & 11 \\ \begin{array}{c}\text { FEB } \\ 20 \ldots\end{array} & 181 & 1.8 & 28 & 17 \\ \begin{array}{c}\text { APR } \\ \text { O9... }\end{array} & 166 & 3.1 & 26 & 13 \\ \text { AUG } & 179 & 2.3 & 27 & 12 \\ 05 \ldots & & & \end{array}$

\begin{abstract}
250
\end{abstract}
210
.7

253

250

230

240
$0.34 \quad 423$

$0.34 \quad 152$

$0.33 \quad 196$

$0.33 \quad 94$ 
04142000 RIFLE RIVER NEAR STERLING, MI--Continued

WATER QUALITY DATA, WATER YEAR OCTOBER 1986 TO SEPTEMBER 1987

\begin{tabular}{|c|c|c|c|c|c|c|c|c|c|c|}
\hline DATE & $\begin{array}{c}\text { NITRO- } \\
\text { GEN, } \\
\text { NITRITE } \\
\text { DIS- } \\
\text { SOLVED } \\
\text { (MG/L } \\
\text { AS N) }\end{array}$ & $\begin{array}{c}\text { NITRO- } \\
\text { GEN, } \\
\text { NO2+NO3 } \\
\text { DIS- } \\
\text { SOLVED } \\
\text { (MG/L } \\
\text { AS N) }\end{array}$ & $\begin{array}{c}\text { NITRO- } \\
\text { GEN, } \\
\text { AMMONIA } \\
\text { TOTAL } \\
\text { (MG/L } \\
\text { AS N) }\end{array}$ & $\begin{array}{c}\text { NITRO- } \\
\text { GEN, } \\
\text { AMMONIA } \\
\text { DIS- } \\
\text { SOLVED } \\
\text { (MG/L } \\
\text { AS N) }\end{array}$ & $\begin{array}{c}\text { NITRO- } \\
\text { GEN, } \\
\text { ORGANIC } \\
\text { TOTAL } \\
\text { (MG/L } \\
\text { AS N) }\end{array}$ & $\begin{array}{l}\text { NITRO- } \\
\text { GEN, AM- } \\
\text { MONIA + } \\
\text { ORGANIC } \\
\text { TOTAL } \\
\text { (MG/L } \\
\text { AS N) }\end{array}$ & $\begin{array}{c}\text { PHOS- } \\
\text { PHORUS, } \\
\text { TOTAL } \\
\text { (MG/L } \\
\text { AS P) }\end{array}$ & $\begin{array}{c}\text { PHOS- } \\
\text { PHORUS, } \\
\text { DIS- } \\
\text { SOLVED } \\
\text { (MG/L } \\
\text { AS P) }\end{array}$ & $\begin{array}{l}\text { PHOS- } \\
\text { PHORUS, } \\
\text { ORTHO, } \\
\text { DIS- } \\
\text { SOLVED } \\
\text { (MG/L } \\
\text { AS P) }\end{array}$ & $\begin{array}{l}\text { ALUM- } \\
\text { INUM, } \\
\text { DIS- } \\
\text { SOLVED } \\
\text { (UG/L } \\
\text { AS AL) }\end{array}$ \\
\hline $0 \ldots$ & $<0.01$ & 0.21 & 0.09 & 0.03 & 0.81 & 0.9 & $<0.20$ & $<0.20$ & $<0.01$ & 30 \\
\hline $0 .$. & $<0.01$ & 0.30 & 0.03 & 0.03 & 0.57 & 0.6 & 0.01 & 0.01 & 0.01 & $<10$ \\
\hline & $<0.01$ & 0.16 & 0.18 & 0.19 & 0.92 & 1.1 & 0.05 & 0.03 & 0.01 & $<10$ \\
\hline 5 & $<0.01$ & $<0.10$ & -- & 0.02 & -- & 0.8 & 0.04 & 0.03 & $<0.01$ & 20 \\
\hline DATE & $\begin{array}{c}\text { ARSENIC } \\
\text { DIS- } \\
\text { SOLVED } \\
\text { (UG/L } \\
\text { AS AS) }\end{array}$ & $\begin{array}{l}\text { BARIUM, } \\
\text { DIS- } \\
\text { SOLVED } \\
\text { (UG/L } \\
\text { AS BA) }\end{array}$ & $\begin{array}{l}\text { BERYL- } \\
\text { LIUM, } \\
\text { DIS- } \\
\text { SOLVED } \\
\text { (UG/L } \\
\text { AS BE) }\end{array}$ & $\begin{array}{c}\text { CADMIUM } \\
\text { DIS- } \\
\text { SOLVED } \\
\text { (UG/L } \\
\text { AS CD) }\end{array}$ & $\begin{array}{l}\text { CHRO- } \\
\text { MIUM, } \\
\text { DIS- } \\
\text { SOLVED } \\
\text { (UG/L } \\
\text { AS CR) }\end{array}$ & $\begin{array}{l}\text { COBALT, } \\
\text { DIS- } \\
\text { SOLVED } \\
\text { (UG/L } \\
\text { AS CO) }\end{array}$ & $\begin{array}{l}\text { COPPER, } \\
\text { DIS- } \\
\text { SOLVED } \\
\text { (UG/L } \\
\text { AS CU) }\end{array}$ & $\begin{array}{l}\text { IRON, } \\
\text { DIS- } \\
\text { SOLVED } \\
\text { (UG/L } \\
\text { AS FE) }\end{array}$ & $\begin{array}{l}\text { LEAD, } \\
\text { DIS- } \\
\text { SOLVED } \\
\text { (UG/L } \\
\text { AS PB) }\end{array}$ & $\begin{array}{c}\text { LITHIUM } \\
\text { DIS- } \\
\text { SOLVED } \\
\text { (UG/L } \\
\text { AS LI) }\end{array}$ \\
\hline & $?$ & & $5=$ & 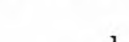 & 4 & & ? & 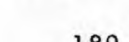 & $=$ & 0 \\
\hline & 1 & 47 & 1 & $<1$ & $<1$ & $<3$ & 1 & $\begin{array}{r}100 \\
48\end{array}$ & $<5$ & 10 \\
\hline$\cdots$ & 1 & 46 & $<0.5$ & $<1$ & $<1$ & $<3$ & 2 & 31 & $<5$ & 7 \\
\hline 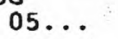 & 4 & 56 & $<0.5$ & $<1$ & $<1$ & $<3$ & $<1$ & 23 & $<5$ & $<4$ \\
\hline
\end{tabular}

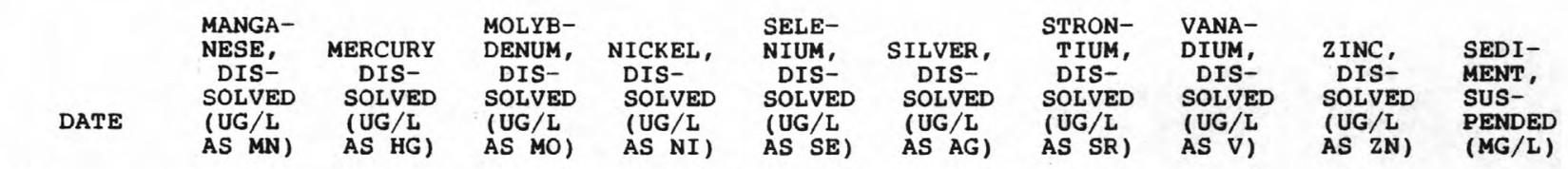

\begin{tabular}{|c|c|c|c|c|c|c|c|c|c|c|}
\hline${ }_{10}^{\text {OCT }}$ & 21 & 0.1 & $<10$ & $<1$ & $<1$ & $<1$ & 170 & $<6$ & 28 & 48 \\
\hline $\begin{array}{l}\text { FEB } \\
20 \ldots\end{array}$ & 16 & 0.2 & $<10$ & 2 & $<1$ & $<1$ & 230 & $<6$ & 7 & 15 \\
\hline AUG 0 & 16 & $<0.1$ & $<10$ & 1 & $<1$ & $<1$ & 210 & $<6$ & 9 & 19 \\
\hline $05 \ldots$ & 9 & $<0.1$ & $<10$ & $<1$ & $<1$ & $<1$ & 240 & $<6$ & 6 & 12 \\
\hline
\end{tabular}

DATE

$$
\begin{array}{cc}
\text { SEDI- } & \text { SED. } \\
\text { MENT, } & \text { SUSP. } \\
\text { DIS- } & \text { SIEVE } \\
\text { CHARGE, } & \text { DIAM. } \\
\text { SUS- } & \text { F FINER } \\
\text { PENDED } & \text { THAN } \\
\text { (T/DAY) } & .062 \text { MM }
\end{array}
$$

$\begin{array}{lcc}\underset{10}{\text { OCT }} \ldots & 81 & 46 \\ \underset{\text { FEB }}{20 \ldots} & 9.0 & 67 \\ \begin{array}{l}\text { APR } \\ \text { 09... }\end{array} & 16 & 52 \\ \begin{array}{c}\text { AUG } \\ \text { 05... }\end{array} & 4.6 & 77\end{array}$


04143900 SHIAWASSEE RIVER AT LINDEN, MI

LOCATION. - Lat $42^{\circ} 48^{\prime} 56^{\prime \prime}$, long $83^{\circ} 48^{\prime} 08^{\prime \prime}$, in SWl/4 sec.19, T.5 N., R.6 E., Genesee County, Hydrologic Unit 04080203 , on right bank at upstream side of bridge on Hogan Road, 1.0 mi west of Linden.

DRAINAGE AREA. $--83.7 \mathrm{mi}^{2}$, revised.

PERIOD OF RECORD,--October 1967 to current year.

GAGE.--Water-stage recorder. Datum of gage is $844.96 \mathrm{ft}$ above National Geodetic Vertical Datum of 1929 .

REMARKS.--Estimated daily discharges: Dec. 13,14, Jan. 20 to Feb. 3, and Feb. 5, 9, 10, 15-21. Records good except for estimated daily discharges, which are poor. Flow regulated by dam at Linden since 1967. Several measurements of water temperature were made during the year.

AVERAGE DISCHARGE. --20 years, $60.7 \mathrm{ft}^{3} / \mathrm{s}, 9.85 \mathrm{in} / \mathrm{yr}^{\mathrm{r}}$.

EXTREMES FOR PERIOD OF RECORD.--Maximum discharge, $476 \mathrm{ft}^{3} / \mathrm{s}$, Apr, 22, 1975, gage height, $7.43 \mathrm{ft}$; minimum, $0.74 \mathrm{ft}^{3} / \mathrm{s}$, May 22, 23, 1971; minimum gage height, 2.82 ft, Aug. 2, 1971.

EXTREMES FOR CURRENT YEAR.--Maximum discharge, $216 \mathrm{ft}^{3} / \mathrm{s}$, Oct. 4, gage height, $6.22 \mathrm{ft}$; minimum, $2.8 \mathrm{ft}^{3} / \mathrm{s}$, Aug. 8, gage height, $2.94 \mathrm{ft}$

DISCHARGE, IN CUBIC FEET PER SECOND, WATER YEAR OCTOBER 1986 TO SEPTEMBER 1987 MEAN VALUES

\begin{tabular}{|c|c|c|c|c|c|c|c|c|c|c|c|c|}
\hline DAY & OCT & NOV & $\mathrm{DEC}$ & JAN & FEB & MAR & APR & MAY & JUN & JUL & AUG & SEP \\
\hline $\begin{array}{l}1 \\
2 \\
3 \\
4 \\
5\end{array}$ & $\begin{array}{l}154 \\
176 \\
203 \\
212 \\
210\end{array}$ & $\begin{array}{l}71 \\
79 \\
80 \\
72 \\
74\end{array}$ & $\begin{array}{l}61 \\
61 \\
65 \\
66 \\
66\end{array}$ & $\begin{array}{l}69 \\
73 \\
68 \\
67 \\
67\end{array}$ & $\begin{array}{l}18 \\
20 \\
34 \\
43 \\
45\end{array}$ & $\begin{array}{l}65 \\
67 \\
70 \\
74 \\
79\end{array}$ & $\begin{array}{l}72 \\
73 \\
74 \\
82 \\
88\end{array}$ & $\begin{array}{l}40 \\
40 \\
42 \\
55 \\
58\end{array}$ & $\begin{array}{l}48 \\
51 \\
48 \\
36 \\
32\end{array}$ & $\begin{array}{l}26 \\
25 \\
24 \\
27 \\
30\end{array}$ & $\begin{array}{l}20 \\
18 \\
17 \\
17 \\
10\end{array}$ & $\begin{array}{l}34 \\
31 \\
32 \\
31 \\
28\end{array}$ \\
\hline $\begin{array}{r}6 \\
7 \\
8 \\
9 \\
10\end{array}$ & $\begin{array}{l}190 \\
164 \\
166 \\
173 \\
164\end{array}$ & $\begin{array}{l}74 \\
73 \\
73 \\
68 \\
61\end{array}$ & $\begin{array}{r}71 \\
90 \\
103 \\
110 \\
106\end{array}$ & $\begin{array}{l}65 \\
69 \\
64 \\
67 \\
63\end{array}$ & $\begin{array}{l}46 \\
47 \\
49 \\
50 \\
50\end{array}$ & $\begin{array}{r}92 \\
116 \\
134 \\
135 \\
123\end{array}$ & $\begin{array}{r}93 \\
109 \\
124 \\
131 \\
137\end{array}$ & $\begin{array}{r}52 \\
8.3 \\
5.9 \\
5.0 \\
5.8\end{array}$ & $\begin{array}{l}30 \\
26 \\
25 \\
24 \\
24\end{array}$ & $\begin{array}{l}35 \\
37 \\
36 \\
43 \\
51\end{array}$ & $\begin{array}{l}3.7 \\
3.3 \\
3.1 \\
6.4 \\
7.7\end{array}$ & $\begin{array}{l}26 \\
25 \\
28 \\
27 \\
28\end{array}$ \\
\hline $\begin{array}{l}11 \\
12 \\
13 \\
14 \\
15\end{array}$ & $\begin{array}{l}152 \\
137 \\
125 \\
119 \\
110\end{array}$ & $\begin{array}{l}57 \\
60 \\
53 \\
54 \\
47\end{array}$ & $\begin{array}{l}106 \\
100 \\
100 \\
100 \\
102\end{array}$ & $\begin{array}{l}75 \\
62 \\
69 \\
62 \\
70\end{array}$ & $\begin{array}{l}50 \\
51 \\
51 \\
52 \\
52\end{array}$ & $\begin{array}{l}111 \\
106 \\
109 \\
109 \\
106\end{array}$ & $\begin{array}{r}132 \\
120 \\
111 \\
104 \\
98\end{array}$ & $\begin{array}{l}9.8 \\
16 \\
18 \\
24 \\
50\end{array}$ & $\begin{array}{l}22 \\
18 \\
20 \\
26 \\
26\end{array}$ & $\begin{array}{l}52 \\
51 \\
46 \\
41 \\
35\end{array}$ & $\begin{array}{l}9.1 \\
17 \\
13 \\
12 \\
16\end{array}$ & $\begin{array}{l}32 \\
27 \\
27 \\
27 \\
26\end{array}$ \\
\hline $\begin{array}{l}16 \\
17 \\
18 \\
19 \\
20\end{array}$ & $\begin{array}{r}99 \\
100 \\
86 \\
84 \\
95\end{array}$ & $\begin{array}{l}37 \\
61 \\
54 \\
36 \\
34\end{array}$ & $\begin{array}{l}96 \\
90 \\
88 \\
84 \\
82\end{array}$ & $\begin{array}{l}70 \\
72 \\
73 \\
73 \\
73\end{array}$ & $\begin{array}{l}51 \\
51 \\
50 \\
50 \\
60\end{array}$ & $\begin{array}{r}100 \\
82 \\
79 \\
78 \\
78\end{array}$ & $\begin{array}{l}94 \\
90 \\
86 \\
83 \\
80\end{array}$ & $\begin{array}{l}62 \\
71 \\
75 \\
74 \\
70\end{array}$ & $\begin{array}{l}24 \\
22 \\
18 \\
18 \\
18\end{array}$ & $\begin{array}{l}31 \\
30 \\
30 \\
31 \\
29\end{array}$ & $\begin{array}{l}14 \\
20 \\
20 \\
18 \\
15\end{array}$ & $\begin{array}{l}29 \\
31 \\
39 \\
40 \\
39\end{array}$ \\
\hline $\begin{array}{l}21 \\
22 \\
23 \\
24 \\
25\end{array}$ & $\begin{array}{l}96 \\
82 \\
76 \\
71 \\
70\end{array}$ & $\begin{array}{l}38 \\
51 \\
63 \\
73 \\
86\end{array}$ & $\begin{array}{l}83 \\
82 \\
78 \\
79 \\
77\end{array}$ & $\begin{array}{l}73 \\
72 \\
71 \\
70 \\
68\end{array}$ & $\begin{array}{l}59 \\
59 \\
58 \\
57 \\
56\end{array}$ & $\begin{array}{l}78 \\
77 \\
76 \\
74 \\
74\end{array}$ & $\begin{array}{l}77 \\
58 \\
48 \\
46 \\
68\end{array}$ & $\begin{array}{l}71 \\
74 \\
68 \\
57 \\
45\end{array}$ & $\begin{array}{l}19 \\
21 \\
24 \\
30 \\
32\end{array}$ & $\begin{array}{l}29 \\
22 \\
24 \\
23 \\
24\end{array}$ & $\begin{array}{l}15 \\
20 \\
24 \\
22 \\
18\end{array}$ & $\begin{array}{l}41 \\
40 \\
39 \\
40 \\
38\end{array}$ \\
\hline $\begin{array}{l}26 \\
27 \\
28 \\
29 \\
30 \\
31\end{array}$ & $\begin{array}{l}81 \\
78 \\
70 \\
72 \\
67 \\
63\end{array}$ & $\begin{array}{r}88 \\
80 \\
75 \\
72 \\
66 \\
---\end{array}$ & $\begin{array}{l}75 \\
76 \\
74 \\
73 \\
72 \\
72\end{array}$ & $\begin{array}{l}66 \\
60 \\
42 \\
34 \\
31 \\
27\end{array}$ & $\begin{array}{r}56 \\
56 \\
56 \\
--- \\
--- \\
---\end{array}$ & $\begin{array}{l}74 \\
73 \\
73 \\
72 \\
74 \\
73\end{array}$ & $\begin{array}{r}82 \\
68 \\
54 \\
43 \\
41 \\
---\end{array}$ & $\begin{array}{l}46 \\
46 \\
45 \\
42 \\
35 \\
43\end{array}$ & $\begin{array}{r}28 \\
30 \\
24 \\
20 \\
23 \\
---\end{array}$ & $\begin{array}{l}28 \\
24 \\
21 \\
19 \\
12 \\
18\end{array}$ & $\begin{array}{l}20 \\
31 \\
30 \\
32 \\
32 \\
33\end{array}$ & $\begin{array}{r}36 \\
33 \\
32 \\
39 \\
41 \\
-\end{array}$ \\
\hline $\begin{array}{l}\text { TOTAL } \\
\text { MEAN } \\
\text { MAX } \\
\text { MIN } \\
\text { CFSM } \\
\text { IN. }\end{array}$ & $\begin{array}{r}3745 \\
121 \\
212 \\
63 \\
1.45 \\
1.66\end{array}$ & $\begin{array}{r}1910 \\
63.7 \\
88 \\
34 \\
.76 \\
.85\end{array}$ & $\begin{array}{r}2588 \\
83.5 \\
110 \\
61 \\
1.00 \\
1.15\end{array}$ & $\begin{array}{r}1985 \\
64.0 \\
75 \\
27 \\
.77 \\
.88\end{array}$ & $\begin{array}{r}1377 \\
49.2 \\
60 \\
18 \\
.59 \\
.61\end{array}$ & $\begin{array}{r}2731 \\
88.1 \\
135 \\
65 \\
1.05 \\
1.21\end{array}$ & $\begin{array}{r}2566 \\
85.5 \\
137 \\
41 \\
1.02 \\
1.14\end{array}$ & $\begin{array}{r}1353.8 \\
43.7 \\
75 \\
5.0 \\
.52 \\
.60\end{array}$ & $\begin{array}{r}807 \\
26.9 \\
51 \\
18 \\
.32 \\
.36\end{array}$ & $\begin{array}{r}954 \\
30.8 \\
52 \\
12 \\
.37 \\
.42\end{array}$ & $\begin{array}{r}537.3 \\
17.3 \\
33 \\
3.1 \\
.21 \\
.24\end{array}$ & $\begin{array}{r}986 \\
32.9 \\
41 \\
25 \\
.39 \\
.44\end{array}$ \\
\hline
\end{tabular}

$\begin{array}{llllllllll}\text { CAL YR } 1986 & \text { TOTAL } & 27232.9 & \text { MEAN 74.6 } & \text { MAX 212 } & \text { MIN } & \text { 2.9 } & \text { CFSM } & .89 & \text { IN } 12.10 \\ \text { WTR YR } 1987 & \text { TOTAL } & 21540.1 & \text { MEAN } 59.0 & \text { MAX } 212 & \text { MIN 3.1 } & \text { CFSM } .71 & \text { IN } 9.57\end{array}$ 


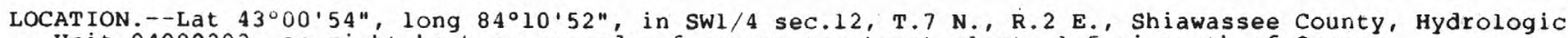
Unit 04080203 , on right bank on grounds of sewage-treatment plant, 1.5 mi north of Owosso.

DRAINAGE AREA. $--538 \mathrm{mi}^{2}$.

PERIOD OF RECORD. --March 1931 to current year. Monthly discharge only for some periods, published in wSP 1307. Gage-height record for flood seasons collected in this vicinity 1904, 1910-30 are contained in reports of the National Weather Service.

REVISED RECORDS.--WSP 1307: 1949(M). WSP 1337: 1932, 1934, 1936-38, 1944.

GAGE.--Water-stage recorder. Datum of gage is $707.25 \mathrm{ft}$ above National Geodetic Vertical Datum of 1929 . Prior to Oct. 15, 1933, at site $1.5 \mathrm{mi}$ upstream at datum $5.46 \mathrm{ft}$ higher.

REMARKS.--Estimated daily discharges: Jan. 22, 23, 25-28, and June 6 to July 16 . Records good except for estimated daily discharges, which are fair. Flow regulated below about $800 \mathrm{ft} 3 / \mathrm{s}$ by powerplant at Shiawasseetown prior to February 1953; occasional regulation at low stages since. Several measurements of water temperature were made during the year. National Weather Service gage-height telemeter at station.

AVERAGE DISCHARGE.--56 years, $338 \mathrm{ft}^{3} / \mathrm{s}, 8.53 \mathrm{in} / \mathrm{yr}$.

EXTREMES FOR PERIOD OF RECORD.--Maximum discharge, $6,240 \mathrm{ft} 3 / \mathrm{s}$, Apr. 6,1947 , gage height, 10.35 ft, minimum, $0.2 \mathrm{ft}^{3} / \mathrm{s}$, July 27 , 1934, gage height, 1.12 ft; minimum daily, $2.0 \mathrm{ft} / \mathrm{s}, \mathrm{July} 28,1934$.

EXTREMES FOR CURRENT YEAR,--Maximum discharge, 2,900 $\mathrm{ft}^{3} / \mathrm{s}$, Oct. 1, gage height, $7.45 \mathrm{ft}$, stage falling, peak occurred Sept. 30, 1986; maximum peak discharge, $755 \mathrm{ft} / \mathrm{s}$, Apr. 6, gage height, 4.22 ft, no independent peak discharge above base discharge of $1,500 \mathrm{ft}^{3} / \mathrm{s} ; \mathrm{minimum}$ discharge, $29 \mathrm{ft} / \mathrm{s}$, Aug. 6 , 7 ; minimum gage height, $2.10 \mathrm{ft}$, Aug. 7 .

DISCHARGE, IN CUBIC FEET PER SECOND, WATER YEAR OCTOBER 1986 TO SEPTEMBER 1987

\begin{tabular}{|c|c|c|c|c|c|c|c|c|c|c|c|c|}
\hline DAY & OCT & NOV & $\mathrm{DEC}$ & JAN & FEB & MAR & APR & MAY & JUN & JUL & AUG & SEP \\
\hline $\begin{array}{l}1 \\
2 \\
3 \\
4 \\
5\end{array}$ & $\begin{array}{l}2570 \\
2340 \\
2170 \\
2300 \\
2430\end{array}$ & $\begin{array}{l}386 \\
375 \\
361 \\
313 \\
353\end{array}$ & $\begin{array}{l}402 \\
402 \\
446 \\
527 \\
531\end{array}$ & $\begin{array}{l}352 \\
355 \\
352 \\
342 \\
327\end{array}$ & $\begin{array}{l}253 \\
262 \\
265 \\
266 \\
275\end{array}$ & $\begin{array}{l}502 \\
728 \\
709 \\
710 \\
718\end{array}$ & $\begin{array}{l}454 \\
495 \\
514 \\
506 \\
573\end{array}$ & $\begin{array}{l}260 \\
245 \\
223 \\
208 \\
182\end{array}$ & $\begin{array}{l}220 \\
268 \\
318 \\
324 \\
301\end{array}$ & $\begin{array}{l}125 \\
130 \\
130 \\
130 \\
122\end{array}$ & $\begin{array}{l}72 \\
68 \\
60 \\
52 \\
39\end{array}$ & $\begin{array}{l}125 \\
117 \\
108 \\
105 \\
102\end{array}$ \\
\hline $\begin{array}{r}6 \\
7 \\
8 \\
9 \\
10\end{array}$ & $\begin{array}{l}2020 \\
1720 \\
1560 \\
1380 \\
1230\end{array}$ & $\begin{array}{l}360 \\
344 \\
328 \\
329 \\
330\end{array}$ & $\begin{array}{l}456 \\
533 \\
516 \\
481 \\
568\end{array}$ & $\begin{array}{l}306 \\
309 \\
337 \\
341 \\
339\end{array}$ & $\begin{array}{l}262 \\
248 \\
263 \\
250 \\
238\end{array}$ & $\begin{array}{l}725 \\
734 \\
746 \\
739 \\
731\end{array}$ & $\begin{array}{l}730 \\
716 \\
678 \\
648 \\
611\end{array}$ & $\begin{array}{l}173 \\
184 \\
208 \\
181 \\
134\end{array}$ & $\begin{array}{l}274 \\
250 \\
225 \\
206 \\
189\end{array}$ & $\begin{array}{l}115 \\
103 \\
103 \\
110 \\
125\end{array}$ & $\begin{array}{l}31 \\
30 \\
39 \\
73 \\
71\end{array}$ & $\begin{array}{r}97 \\
94 \\
91 \\
110 \\
128\end{array}$ \\
\hline $\begin{array}{l}11 \\
12 \\
13 \\
14 \\
15\end{array}$ & $\begin{array}{r}1080 \\
929 \\
802 \\
721 \\
704\end{array}$ & $\begin{array}{l}332 \\
322 \\
310 \\
278 \\
302\end{array}$ & $\begin{array}{l}590 \\
611 \\
501 \\
438 \\
461\end{array}$ & $\begin{array}{l}343 \\
329 \\
319 \\
318 \\
366\end{array}$ & $\begin{array}{l}261 \\
272 \\
269 \\
254 \\
231\end{array}$ & $\begin{array}{l}687 \\
636 \\
555 \\
499 \\
456\end{array}$ & $\begin{array}{l}572 \\
539 \\
516 \\
509 \\
494\end{array}$ & $\begin{array}{l}129 \\
140 \\
139 \\
167 \\
249\end{array}$ & $\begin{array}{l}175 \\
175 \\
164 \\
155 \\
135\end{array}$ & $\begin{array}{l}140 \\
155 \\
170 \\
160 \\
150\end{array}$ & $\begin{array}{l}63 \\
54 \\
48 \\
61 \\
50\end{array}$ & $\begin{array}{l}169 \\
170 \\
160 \\
137 \\
132\end{array}$ \\
\hline $\begin{array}{l}16 \\
17 \\
18 \\
19 \\
20\end{array}$ & $\begin{array}{l}675 \\
651 \\
615 \\
572 \\
535\end{array}$ & $\begin{array}{l}281 \\
275 \\
276 \\
272 \\
270\end{array}$ & $\begin{array}{l}486 \\
462 \\
474 \\
484 \\
484\end{array}$ & $\begin{array}{l}451 \\
423 \\
416 \\
386 \\
347\end{array}$ & $\begin{array}{l}201 \\
204 \\
224 \\
214 \\
202\end{array}$ & $\begin{array}{l}434 \\
384 \\
434 \\
423 \\
407\end{array}$ & $\begin{array}{l}497 \\
492 \\
491 \\
472 \\
451\end{array}$ & $\begin{array}{l}260 \\
278 \\
283 \\
258 \\
268\end{array}$ & $\begin{array}{l}120 \\
113 \\
115 \\
113 \\
110\end{array}$ & $\begin{array}{l}140 \\
130 \\
118 \\
109 \\
104\end{array}$ & $\begin{array}{l}60 \\
80 \\
54 \\
47 \\
59\end{array}$ & $\begin{array}{l}136 \\
169 \\
157 \\
161 \\
174\end{array}$ \\
\hline $\begin{array}{l}21 \\
22 \\
23 \\
24 \\
25\end{array}$ & $\begin{array}{l}493 \\
462 \\
438 \\
420 \\
402\end{array}$ & $\begin{array}{l}268 \\
262 \\
265 \\
277 \\
277\end{array}$ & $\begin{array}{l}476 \\
439 \\
436 \\
387 \\
404\end{array}$ & $\begin{array}{l}324 \\
300 \\
270 \\
269 \\
260\end{array}$ & $\begin{array}{l}205 \\
215 \\
222 \\
225 \\
239\end{array}$ & $\begin{array}{l}393 \\
385 \\
378 \\
367 \\
372\end{array}$ & $\begin{array}{l}430 \\
404 \\
387 \\
348 \\
329\end{array}$ & $\begin{array}{l}286 \\
283 \\
273 \\
267 \\
253\end{array}$ & $\begin{array}{l}103 \\
113 \\
145 \\
142 \\
140\end{array}$ & $\begin{array}{r}98 \\
92 \\
86 \\
82 \\
123\end{array}$ & $\begin{array}{r}77 \\
115 \\
93 \\
86 \\
90\end{array}$ & $\begin{array}{l}177 \\
168 \\
158 \\
153 \\
147\end{array}$ \\
\hline $\begin{array}{l}26 \\
27 \\
28 \\
29 \\
30 \\
31\end{array}$ & $\begin{array}{l}408 \\
416 \\
407 \\
404 \\
402 \\
395\end{array}$ & $\begin{array}{l}319 \\
374 \\
396 \\
424 \\
420 \\
---\end{array}$ & $\begin{array}{l}390 \\
364 \\
357 \\
361 \\
356 \\
355\end{array}$ & $\begin{array}{l}260 \\
280 \\
290 \\
303 \\
279 \\
259\end{array}$ & $\begin{array}{l}247 \\
264 \\
279 \\
--- \\
--- \\
---\end{array}$ & $\begin{array}{l}393 \\
412 \\
424 \\
419 \\
441 \\
449\end{array}$ & $\begin{array}{l}314 \\
298 \\
283 \\
287 \\
269 \\
---\end{array}$ & $\begin{array}{l}232 \\
216 \\
205 \\
188 \\
176 \\
181\end{array}$ & $\begin{array}{l}132 \\
120 \\
122 \\
120 \\
122 \\
---\end{array}$ & $\begin{array}{r}102 \\
88 \\
78 \\
83 \\
82 \\
76\end{array}$ & $\begin{array}{r}90 \\
113 \\
121 \\
140 \\
142 \\
139\end{array}$ & $\begin{array}{l}138 \\
134 \\
131 \\
147 \\
141 \\
-\end{array}$ \\
\hline $\begin{array}{l}\text { TOTAL } \\
\text { MEAN } \\
\text { MAX } \\
\text { MIN } \\
\text { CESM } \\
\text { IN. }\end{array}$ & $\begin{array}{r}31651 \\
1021 \\
2570 \\
395 \\
1.90 \\
2.19\end{array}$ & $\begin{array}{r}9679 \\
323 \\
424 \\
262 \\
.60 \\
.67\end{array}$ & $\begin{array}{r}14178 \\
457 \\
611 \\
355 \\
.85 \\
.98\end{array}$ & $\begin{array}{r}10152 \\
327 \\
451 \\
259 \\
.61 \\
.70\end{array}$ & $\begin{array}{r}6810 \\
243 \\
279 \\
201 \\
.45 \\
.47\end{array}$ & $\begin{array}{r}16390 \\
529 \\
746 \\
367 \\
.98 \\
1.13\end{array}$ & $\begin{array}{r}14307 \\
477 \\
730 \\
269 \\
.89 \\
.99\end{array}$ & $\begin{array}{r}6729 \\
217 \\
286 \\
129 \\
.40 \\
.47\end{array}$ & $\begin{array}{r}5209 \\
174 \\
324 \\
103 \\
.32 \\
.36\end{array}$ & $\begin{array}{r}3559 \\
115 \\
170 \\
76 \\
.21 \\
.25\end{array}$ & $\begin{array}{r}2317 \\
74.7 \\
142 \\
30 \\
.14 \\
.16\end{array}$ & $\begin{array}{r}4136 \\
138 \\
177 \\
91 \\
.26 \\
.29\end{array}$ \\
\hline
\end{tabular}

$\begin{array}{llllllllllll}\text { CAL YR } 1986 & \text { TOTAL } 192117 & \text { MEAN } 526 & \text { MAX } & 2910 & \text { MIN } 72 & \text { CFSM } & .98 & \text { IN } 13.28\end{array}$

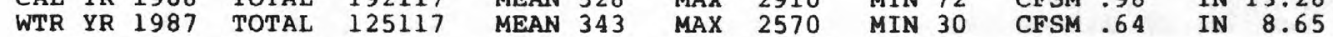


04146000 FARMERS CREEK NEAR LAPEER, MI

LOCATION.--Lat $43^{\circ} 02^{\prime} 41^{\prime \prime}$, long $83^{\circ} 20^{\prime} 14^{\prime \prime}$, in sec.6, T.7 N., R.10 E., Lapeer County, Hydrologic Unit 04080204 , on left bank on grounds of sewage-treatment plant at Michigan Home and Training School, 2.0 mi west of Lapeer.

DRAINAGE AREA. $--55.3 \mathrm{mi}^{2}$.

PERIOD OF RECORD.--October 1932 to current year. Monthly discharge only for some periods, published in WSP 1307.

REVISED RECORDS.--WSP 924: 1940. WSP 1084: 1942(M), 1943. WSP 1337: 1934-38, 1940(M), 1944(M), 1945, $1946(M), 1948-51(M)$. WSP 1727: 1952 (M). WDR MI-78: Drainage area.

GAGE.--Water-stage recorder and concrete control. Datum of gage is $805.79 \mathrm{ft}$ above National Geodetic Vertical Datum of 1929. Prior to May 25, 1954, nonrecording gage at same site and datum.

REMARKS.--Estimated daily discharges: Dec. 6, 10-14, 21, 22, Jan. 4-6, Jan. 17 to Feb. 11, and Feb. 1518. Records good except for estimated daily discharges, which are fair. Prior to ig4l, occasional regulation by dam upstream from station. Several measurements of water temperature were made during the year.

AVERAGE DISCHARGE. - -55 years, $31.6 \mathrm{ft}^{3} / \mathrm{s}, 7.76 \mathrm{in} / \mathrm{yr}$.

EXTREMES FOR PERIOD OF RECORD.--Maximum discharge, 1,380 ft3/s, Sept. 9, 1985, gage height, 20.95 ft, from floodmark; minimum not determined.

EXTREMES FOR CURRENT YEAR.--Peak discharges greater than base discharge of $160 \mathrm{ft}{ }^{3} / \mathrm{s}$ and maximum (*):

\begin{tabular}{|c|c|c|}
\hline Dat & Time & $\begin{array}{c}\text { Discharge } \\
\left(f t^{3} / \mathrm{s}\right)\end{array}$ \\
\hline
\end{tabular}

oct. $20500 \quad$ *26 $\$ 18.35$ No other peak greater than base discharge.

Minimum discharge, $2.2 \mathrm{ft}^{3} / \mathrm{s}$, June $16-19,20$, gage height, $15.05 \mathrm{ft}$.

DISCHARGE, IN CUBIC FEET PER SECOND, WATER YEAR OCTOBER 1986 TO SEPTEMBER 1987 MEAN VALUES

\begin{tabular}{|c|c|c|c|c|c|c|c|c|c|c|c|c|}
\hline DAY & OCT & NOV & DEC & JAN & FEB & MAR & APR & MAY & JUN & JUL & AUG & SEP \\
\hline $\begin{array}{l}1 \\
2 \\
3 \\
4 \\
5\end{array}$ & $\begin{array}{l}335 \\
416 \\
367 \\
330 \\
290\end{array}$ & $\begin{array}{l}49 \\
47 \\
45 \\
43 \\
41\end{array}$ & $\begin{array}{l}43 \\
43 \\
47 \\
47 \\
52\end{array}$ & $\begin{array}{l}38 \\
38 \\
37 \\
35 \\
34\end{array}$ & $\begin{array}{l}25 \\
26 \\
26 \\
26 \\
27\end{array}$ & $\begin{array}{r}51 \\
66 \\
79 \\
102 \\
104\end{array}$ & $\begin{array}{l}56 \\
60 \\
62 \\
62 \\
83\end{array}$ & $\begin{array}{l}8 \cdot 3 \\
7 \cdot 9 \\
7 \cdot 1 \\
6 \cdot 3 \\
6.2\end{array}$ & $\begin{array}{l}15 \\
15 \\
17 \\
18 \\
18\end{array}$ & $\begin{array}{r}9.1 \\
13 \\
12 \\
4.8 \\
4.4\end{array}$ & $\begin{array}{l}4.2 \\
4.7 \\
5.0 \\
4.7 \\
4.3\end{array}$ & $\begin{array}{r}13 \\
12 \\
10 \\
8.7 \\
7.7\end{array}$ \\
\hline $\begin{array}{r}6 \\
7 \\
8 \\
9 \\
10\end{array}$ & $\begin{array}{l}251 \\
224 \\
196 \\
166 \\
138\end{array}$ & $\begin{array}{l}40 \\
38 \\
37 \\
35 \\
34\end{array}$ & $\begin{array}{l}53 \\
55 \\
56 \\
56 \\
58\end{array}$ & $\begin{array}{l}34 \\
34 \\
34 \\
34 \\
34\end{array}$ & $\begin{array}{l}27 \\
28 \\
28 \\
28 \\
28\end{array}$ & $\begin{array}{l}96 \\
91 \\
92 \\
95 \\
99\end{array}$ & $\begin{array}{r}92 \\
111 \\
130 \\
130 \\
116\end{array}$ & $\begin{array}{l}6 \cdot 1 \\
5 \cdot 4 \\
5 \cdot 3 \\
5 \cdot 1 \\
5 \cdot 1\end{array}$ & $\begin{array}{l}15 \\
10 \\
10 \\
13 \\
13\end{array}$ & $\begin{array}{r}5.6 \\
8.2 \\
9.7 \\
11 \\
15\end{array}$ & $\begin{array}{l}3.5 \\
3.2 \\
3.0 \\
4.4 \\
5.1\end{array}$ & $\begin{array}{l}7.1 \\
6.6 \\
8.5 \\
13 \\
14\end{array}$ \\
\hline $\begin{array}{l}11 \\
12 \\
13 \\
14 \\
15\end{array}$ & $\begin{array}{r}118 \\
102 \\
86 \\
64 \\
46\end{array}$ & $\begin{array}{l}34 \\
32 \\
29 \\
28 \\
26\end{array}$ & $\begin{array}{l}56 \\
52 \\
46 \\
42 \\
41\end{array}$ & $\begin{array}{l}34 \\
35 \\
35 \\
35 \\
41\end{array}$ & $\begin{array}{l}28 \\
29 \\
29 \\
29 \\
26\end{array}$ & $\begin{array}{r}100 \\
86 \\
77 \\
68 \\
62\end{array}$ & $\begin{array}{l}98 \\
84 \\
74 \\
67 \\
63\end{array}$ & $\begin{array}{l}7.2 \\
13 \\
8.4 \\
13 \\
16\end{array}$ & $\begin{array}{r}12 \\
15 \\
7.5 \\
3.3 \\
2.8\end{array}$ & $\begin{array}{l}20 \\
22 \\
21 \\
18 \\
13\end{array}$ & $\begin{array}{l}5.5 \\
5.4 \\
5.1 \\
8.7 \\
9.0\end{array}$ & $\begin{array}{l}16 \\
16 \\
16 \\
15 \\
14\end{array}$ \\
\hline $\begin{array}{l}16 \\
17 \\
18 \\
19 \\
20\end{array}$ & $\begin{array}{l}47 \\
84 \\
97 \\
88 \\
78\end{array}$ & $\begin{array}{l}26 \\
26 \\
26 \\
26 \\
26\end{array}$ & $\begin{array}{l}39 \\
38 \\
43 \\
44 \\
47\end{array}$ & $\begin{array}{l}41 \\
41 \\
40 \\
39 \\
38\end{array}$ & $\begin{array}{l}25 \\
24 \\
23 \\
23 \\
23\end{array}$ & $\begin{array}{l}58 \\
55 \\
53 \\
50 \\
48\end{array}$ & $\begin{array}{l}59 \\
56 \\
54 \\
52 \\
49\end{array}$ & $\begin{array}{l}11 \\
14 \\
17 \\
19 \\
20\end{array}$ & $\begin{array}{l}2.3 \\
2.2 \\
2.2 \\
2.2 \\
2.2\end{array}$ & $\begin{array}{r}10 \\
8.6 \\
7.4 \\
6.5 \\
7.2\end{array}$ & $\begin{array}{l}7.9 \\
7.8 \\
6.8 \\
5.6 \\
4.8\end{array}$ & $\begin{array}{l}15 \\
20 \\
22 \\
22 \\
22\end{array}$ \\
\hline $\begin{array}{l}21 \\
22 \\
23 \\
24 \\
25\end{array}$ & $\begin{array}{l}67 \\
59 \\
54 \\
57 \\
63\end{array}$ & $\begin{array}{l}28 \\
30 \\
33 \\
34 \\
35\end{array}$ & $\begin{array}{l}50 \\
47 \\
47 \\
45 \\
44\end{array}$ & $\begin{array}{l}36 \\
35 \\
32 \\
30 \\
29\end{array}$ & $\begin{array}{l}22 \\
23 \\
24 \\
25 \\
26\end{array}$ & $\begin{array}{l}46 \\
45 \\
45 \\
44 \\
44\end{array}$ & $\begin{array}{l}47 \\
44 \\
41 \\
38 \\
35\end{array}$ & $\begin{array}{l}20 \\
20 \\
18 \\
17 \\
15\end{array}$ & $\begin{array}{l}4.1 \\
9.1 \\
12 \\
11 \\
10\end{array}$ & $\begin{array}{l}11 \\
15 \\
11 \\
4.2 \\
3.7\end{array}$ & $\begin{array}{l}4.0 \\
7.8 \\
11 \\
12 \\
10\end{array}$ & $\begin{array}{l}23 \\
23 \\
24 \\
24 \\
23\end{array}$ \\
\hline $\begin{array}{l}26 \\
27 \\
28 \\
29 \\
30 \\
31\end{array}$ & $\begin{array}{l}60 \\
57 \\
54 \\
53 \\
52 \\
51\end{array}$ & $\begin{array}{r}37 \\
41 \\
43 \\
45 \\
45 \\
---\end{array}$ & $\begin{array}{l}43 \\
42 \\
42 \\
41 \\
40 \\
39\end{array}$ & $\begin{array}{l}28 \\
28 \\
27 \\
26 \\
25 \\
25\end{array}$ & $\begin{array}{r}26 \\
28 \\
30 \\
--- \\
--- \\
---\end{array}$ & $\begin{array}{l}46 \\
47 \\
47 \\
47 \\
54 \\
54\end{array}$ & $\begin{array}{l}33 \\
31 \\
19 \\
12 \\
9.5 \\
-\end{array}$ & $\begin{array}{l}16 \\
16 \\
15 \\
13 \\
12 \\
15\end{array}$ & $\begin{array}{l}9.2 \\
9.3 \\
8.9 \\
8.5 \\
9.4 \\
----\end{array}$ & $\begin{array}{l}3.7 \\
5.1 \\
5.3 \\
5.2 \\
4.8 \\
4.5\end{array}$ & $\begin{array}{l}11 \\
16 \\
17 \\
17 \\
16 \\
15\end{array}$ & $\begin{array}{l}19 \\
16 \\
14 \\
14 \\
15 \\
-\end{array}$ \\
\hline $\begin{array}{l}\text { TOTAL } \\
\text { MEAN } \\
\text { MAX } \\
\text { MIN } \\
\text { CFSM } \\
\text { IN. }\end{array}$ & $\begin{array}{r}4150 \\
134 \\
416 \\
46 \\
2.42 \\
2.79\end{array}$ & $\begin{array}{r}1059 \\
35.3 \\
49 \\
26 \\
.64 \\
.71\end{array}$ & $\begin{array}{r}1438 \\
46.4 \\
58 \\
38 \\
.84 \\
.97\end{array}$ & $\begin{array}{r}1052 \\
33.9 \\
41 \\
25 \\
.61 \\
.71\end{array}$ & $\begin{array}{r}732 \\
26.1 \\
30 \\
22 \\
.47 \\
.49\end{array}$ & $\begin{array}{r}2051 \\
66.2 \\
104 \\
44 \\
1.20 \\
1.38\end{array}$ & $\begin{array}{r}1867.5 \\
62.3 \\
130 \\
9.5 \\
1.13 \\
1.26\end{array}$ & $\begin{array}{r}378.4 \\
12.2 \\
20 \\
5.1 \\
.22 \\
.25\end{array}$ & $\begin{array}{r}287.2 \\
9.57 \\
18 \\
2.2 \\
.17 \\
.19\end{array}$ & $\begin{array}{r}300.0 \\
9.68 \\
22 \\
3.7 \\
.18 \\
.20\end{array}$ & $\begin{array}{r}245.5 \\
7.92 \\
17 \\
3.0 \\
.14 \\
.17\end{array}$ & $\begin{array}{r}473.6 \\
15.8 \\
24 \\
6.6 \\
.29 \\
.32\end{array}$ \\
\hline $\begin{array}{l}\text { CAL YR } \\
\text { WTR YR }\end{array}$ & $\begin{array}{l}1986 \\
1987\end{array}$ & $\begin{array}{l}1 \\
1\end{array}$ & $\begin{array}{r}5 \\
.2\end{array}$ & $\begin{array}{ll}\text { EAN } & 52.4 \\
\text { EAN } & 38.4\end{array}$ & $\begin{array}{l}\text { MAX } \\
\text { MAX }\end{array}$ & $\begin{array}{l}6 \\
6\end{array}$ & $\begin{array}{l}5.2 \\
2.2\end{array}$ & $\begin{array}{l}\text { SM } \\
\text { SM } .95 \\
.69\end{array}$ & IN 1 & 7 & & \\
\hline
\end{tabular}




\section{SOUTH BRANCH FLINT RIVER NEAR COLUMBIAVILLE, MI}

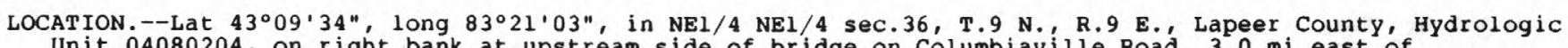
Unit 04080204 , on right bank at upstream side of bridge on Columbiavilie Road, $3.0 \mathrm{mi}$ east of

Columbiaville, and 3.2 mi upstream from confluence of North and South Branches.

DRAINAGE AREA. $--221 \mathrm{mi}^{2}$.

PERIOD OF RECORD.--March 1980 to current year.

GAGE.--Water-stage recorder. Elevation of gage is $765 \mathrm{ft}$ above National Geodetic Vertical Datum of 1929 , from topographic map.

REMARKS.--Estimated daily discharges: Jan. 17 to Feb. 23 and July 5-14. Records good except for

estimated daily discharges, which are fair. Several measurements of water temperature were made during the year. Gage-height telemeter at station.

AVERAGE DISCHARGE. -7 years, $202 \mathrm{ft}^{3} / \mathrm{s}, 12.41 \mathrm{in} / \mathrm{yr}$.

EXTREMES FOR PERIOD OF RECORD.--Maximum discharge, 3,090 ft $3 / \mathrm{s}$, Sept. 9, 1985, gage height, 9.60 ft; maximum gage height, $9.61 \mathrm{ft}$, Feb. 26, 1985, backwater from ice; minimum daily discharge, i4 ft3/s, Aug. 27, 1984 .

EXTREMES FOR CURRENT YEAR.--Maximum discharge, $1,870 \mathrm{ft}^{3} / \mathrm{s}$, Oct. 1 , gage height, $7.21 \mathrm{ft}$; minimum, $35 \mathrm{ft}^{3} / \mathrm{s}$, Aug. 5, 6, 7-9, gage height, $1.42 \mathrm{ft}$.

DISCHARGE, IN CUBIC FEET PER SECOND, WATER YEAR OCTOBER 1986 TO SEPTEMBER 1987 MEAN VALUES

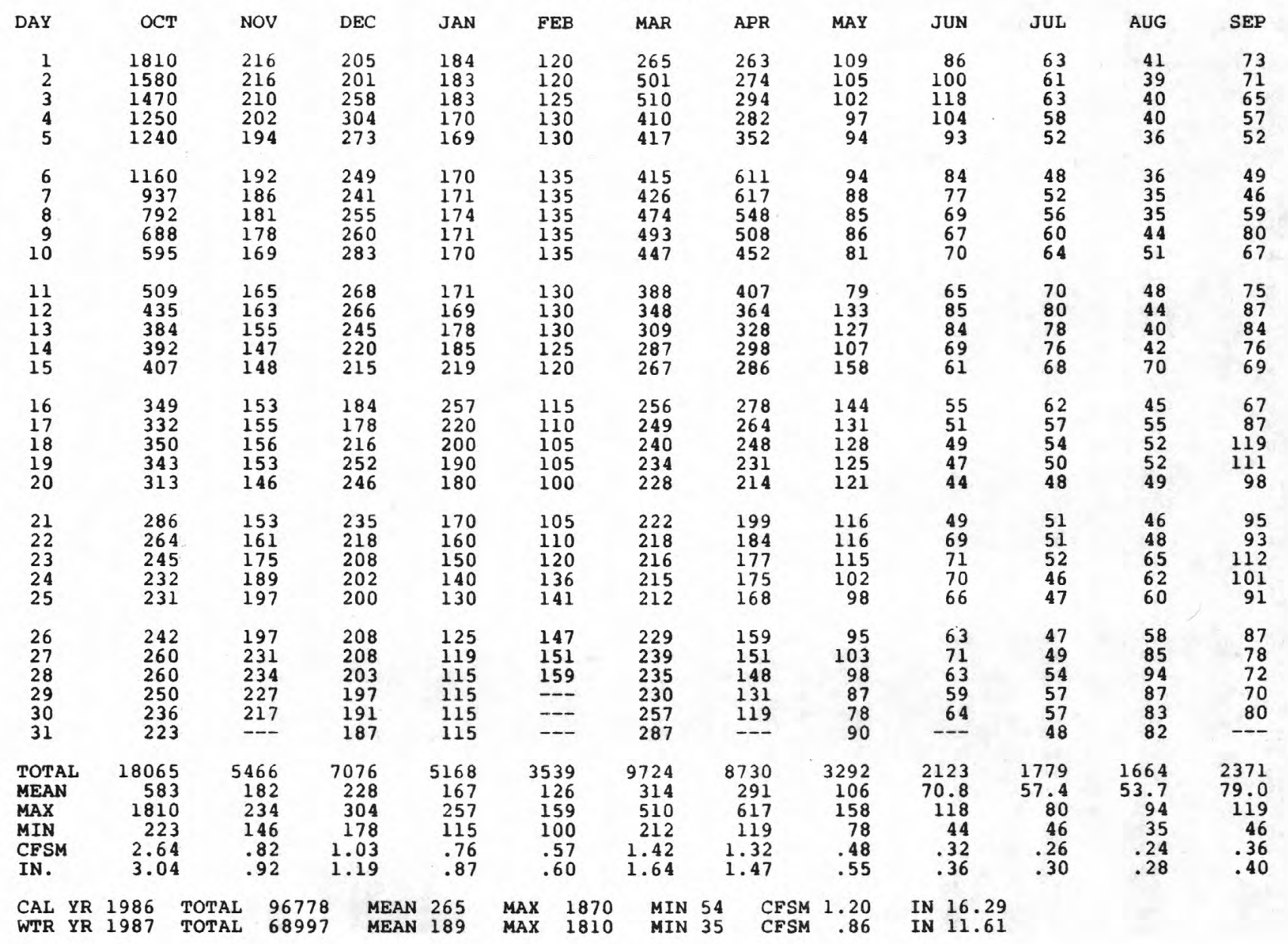


LOCATION.--Lat $43^{\circ} 07^{\prime} 1^{\prime \prime}$, long $83^{\circ} 29^{\prime} 45^{\prime \prime}$, in NWl/4 sec.11, T.8 N., R.8 E., Genesee County, Hydrologic Unit 04080204 , in gatehouse on right side of Holloway Dam on Flint River, $3.5 \mathrm{mi}$ southeast of Otisville,

DRAINAGE AREA. $--526 \mathrm{mi}^{2}$.

PERIOD OF RECORD.--March 1954 to current year.

REVISED RECORDS.--WSP 2111: Drainage area.

GAGE.--Water-stage recorder. Datum of gage is National Geodetic Vertical Datum of 1929 (levels by City of Flint).

REMARKS. --Reservoir is formed by an earth-fill dam with concrete spillway completed in 1953 . Capacity of

reservoir, 1,256,000,000 ft $\mathrm{ft}^{3}$ at elevation $760,00 \mathrm{ft}$. The spiliway section includes two $90-\mathrm{foot}$

drum gates with minimum crest elevation of $75 \mathrm{i} \mathrm{ft}$, maximum at $755 \mathrm{ft}$, three 20 -foot radial gates with

sill elevation of $745 \mathrm{ft}$, and 2 sluices (each 4 by $6 \mathrm{ft}$ ), one on each side with valve controls.

Entrance elevation of sluiceways is $724 \mathrm{ft}$. Reservoir is used to regulate flow for sewage dilution for

City of Flint.

COOPERATION. --Reservoir elevations furnished by city of Flint.

EXTREMES FOR PERIOD OF RECORD.--Maximum contents, 996,000,000 ft3, Mar. 8, 1956, elevation, 757.4 ft;

minimum, reservoir empty at times during October, November, 1954, January, February, 1955, October, 1971.

EXTREMES FOR CURRENT YEAR.--Maximum contents, 895,000,000 ft 3 , Oct. 2, elevation, $756.39 \mathrm{ft}$;

minimum, 433,000,000 $\mathrm{ft}^{3}$, Oct. 31, elevation, $750.33 \mathrm{ft}$.

MONTHEND ELEVATION, IN FEET NGVD, AND CONTENTS, WATER YEAR OCTOBER 1986 TO SEPTEMBER 1987

\begin{tabular}{|c|c|c|c|c|c|c|c|c|c|c|c|c|c|c|c|c|c|c|}
\hline & & $\mathrm{Dat}$ & & & & & & & & & & & & & $\begin{array}{c}\text { Elevation } \\
\text { (feet) }\end{array}$ & $\begin{array}{l}\text { Contents } \\
\text { (millions of } \\
\text { cubic feet) }\end{array}$ & $\begin{array}{l}\text { Change in } \\
\text { (millions of } \\
\text { cubic feet) }\end{array}$ & $\begin{array}{l}\text { contents } \\
\text { (equivalent } \\
\text { in } \mathrm{ft}^{3} / \mathrm{s} \text { ) }\end{array}$ \\
\hline $\begin{array}{ll}\text { Sept. } & 30 \\
\text { Oct. } & 31 \\
\text { Nov. } & 30 \\
\text { Dec. } & 31\end{array}$ & 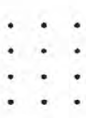 & : : & $\dot{.}$ & $\dot{.}$ & $\dot{:}$ & $\dot{:}$ & $\dot{:}$ & $\dot{:}$ & $\dot{:}$ & $\dot{:}$ & $\dot{:}$ & $\dot{0}$ & 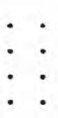 & $\dot{:}$ & $\begin{array}{l}755.65 \\
750.33 \\
751.54 \\
751.54\end{array}$ & $\begin{array}{l}828 \\
433 \\
505 \\
505\end{array}$ & $\begin{array}{r}-- \\
-395 \\
+72 \\
0\end{array}$ & $\begin{array}{l}-147 \\
+27.8 \\
0\end{array}$ \\
\hline CAL YR & 1986 & 6. & . & . & . & . & . & . & - & . & - & . & . . & . & -- & -- & +16 & +0.5 \\
\hline $\begin{array}{ll}\text { Jan. } & 31 \\
\text { Feb: } & 28 \\
\text { Mar: } & 31 \\
\text { Apr: } & 30 \\
\text { May } & 31 \\
\text { June } & 30 \\
\text { July } & 31 \\
\text { Aug. } & 31 \\
\text { Sept. } & 30\end{array}$ & 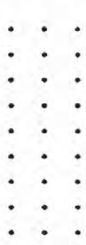 & : & $\begin{array}{l}\dot{5} \\
\dot{5} \\
\dot{5} \\
\dot{.}\end{array}$ & $\begin{array}{l}\dot{:} \\
\dot{5} \\
\dot{5} \\
\dot{.}\end{array}$ & $\begin{array}{l}\dot{:} \\
\dot{:} \\
\dot{:} \\
\dot{:}\end{array}$ & $\begin{array}{l}\dot{:} \\
\dot{.} \\
\dot{.}\end{array}$ & $\begin{array}{l}\dot{:} \\
\dot{:} \\
\dot{.} \\
\dot{.}\end{array}$ & $\begin{array}{l}\dot{:} \\
\dot{5} \\
\dot{:} \\
\dot{0}\end{array}$ & $\dot{:}$ & $\dot{:}:$ & $\begin{array}{l}\dot{:} \\
\dot{:} \\
\dot{:} \\
\dot{.}\end{array}$ & $\begin{array}{l}: \\
: \\
: \\
: \\
: \\
: \\
\end{array}$ & 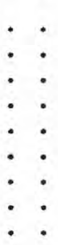 & $\dot{ }:$ & $\begin{array}{l}751.30 \\
751.40 \\
751.57 \\
754.97 \\
755.05 \\
754.96 \\
754.80 \\
755.01 \\
755.08\end{array}$ & $\begin{array}{l}491 \\
497 \\
507 \\
767 \\
774 \\
766 \\
752 \\
771 \\
777\end{array}$ & $\begin{array}{r}-14 \\
+6 \\
+10 \\
+260 \\
+7 \\
-8 \\
-14 \\
+19 \\
+6\end{array}$ & $\begin{array}{r}-5.2 \\
+2.5 \\
+3.7 \\
+100 \\
+2.6 \\
-3.1 \\
-5.2 \\
+7.1 \\
+2.3\end{array}$ \\
\hline WTR YR & 1987 & 7 . & - & . & - & - & - & - & . & - & - & $\cdot$ & . . & $\cdot$ & -- & -- & -51 & -1.6 \\
\hline
\end{tabular}


LOCATION. --Lat $43^{\circ} 06^{\circ} 40^{\prime \prime}$, long $83^{\circ} 31^{\prime} 10^{\prime \prime}$, in SEl/4 sec.9, T.8 N., R. 8 E. , Genesee County, Hydrologic Unit 04080204 , on left bank $20 \mathrm{ft}$ downstream from bridge on State Highway $15,1.5 \mathrm{mi}$ downstream from Holloway Reservoir, $3.5 \mathrm{mi}$ upstream from Powers-Cullen Drain, and $3.8 \mathrm{mi}$ south of Otisville.

DRA INAGE AREA. $--530 \mathrm{mi}^{2}$.

PERIOD OF RECORD.--October 1952 to current year.

REVISED RECORDS.--WDR MI-78: Drainage area.

GAGE.--Water-stage recorder. Datum of gage is $721.39 \mathrm{ft}$ above National Geodetic Vertical Datum of 1929 .

REMARKS.--No estimated daily discharges. Records good. Flow regulated by Holloway Reservoir, 1.5 mi

upstream from station (see preceding page). Several measurements of water temperature were made during

the year. City of Flint gage-height telemeter at station.

AVERAGE DISCHARGE.--35 years, $324 \mathrm{ft}^{3} / \mathrm{s}, 8.30 \mathrm{in} / \mathrm{yr}^{\mathrm{r}}$, adjusted for storage since 1954 .

EXTREMES FOR PERIOD OF RECORD.--Maximum discharge, 6,150 ft3/s, Apr. 1, 1960, gage height, 14.97 ft; minimum, $2.1 \mathrm{ft}^{3} / \mathrm{s}$, Oct. $11,12,1971$, gage height, $1.57 \mathrm{ft}$.

EXTREMES FOR CURRENT YEAR.--Maximum discharge, 4,580 $\mathrm{ft}^{3} / \mathrm{s}$, Oct. 2, gage height, $13.93 \mathrm{ft}$; minimum, $42 \mathrm{ft}^{3} / \mathrm{s}$, Aug. 7, gage height, $2.38 \mathrm{ft}$.

DISCHARGE, IN CUBIC FEET PER SECOND, WATER YEAR OCTOBER 1986 TO SEPTEMBER 1987

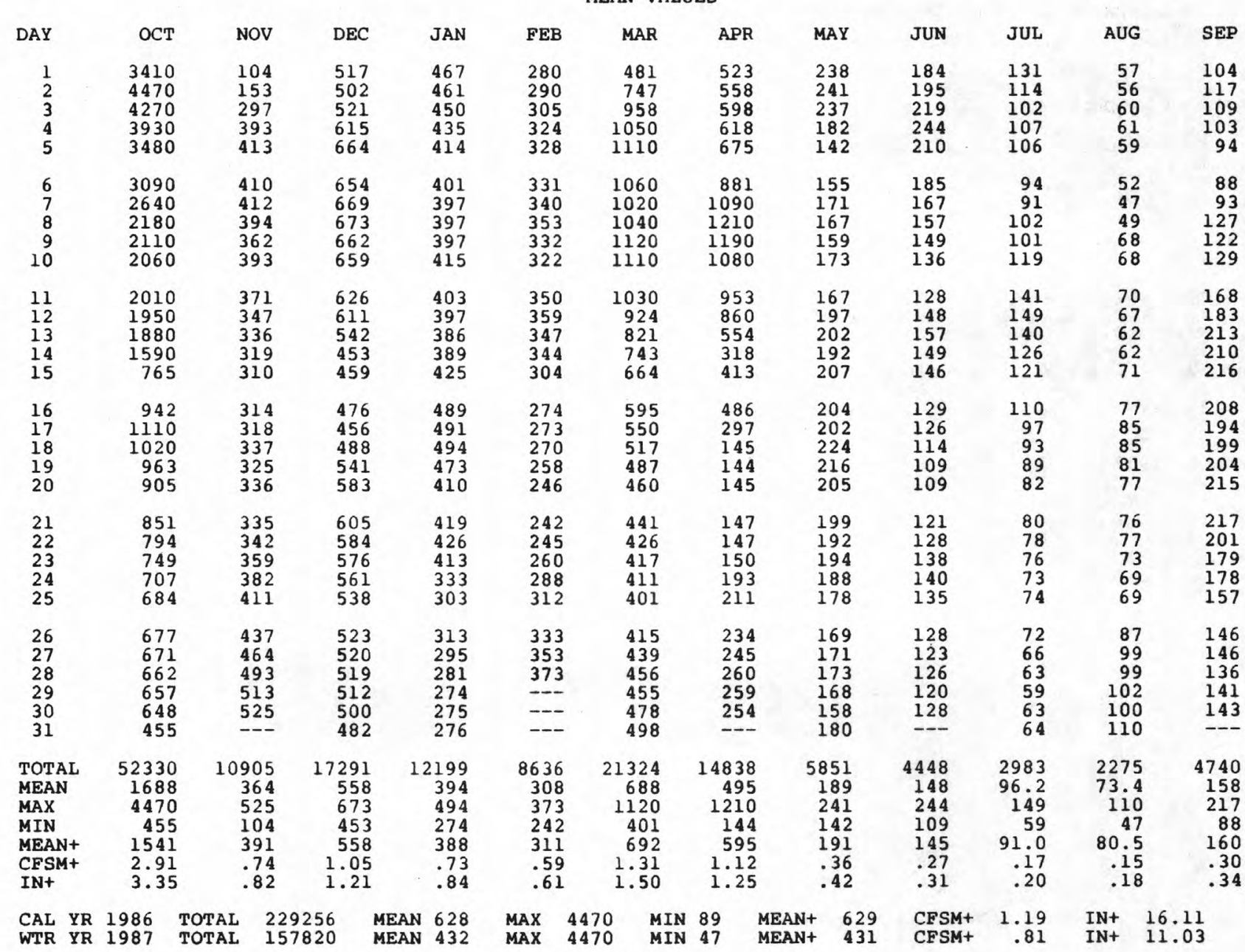

+ Adjusted for change in contents in Holloway Reservoir. 


\section{KEARSLEY CREEK NEAR DAVISON, MI}

LOCATION. - Lat $43^{\circ} 02^{\prime} 01^{\prime \prime}$, long $83^{\circ} 34^{\prime} 53^{\prime \prime}$, in NEl/4 sec.12, T.7 N., R. 7 E., Genesee County, Hydrologic Unit 04080204 , on right bank $10 \mathrm{ft}$ upstream from bridge on Davison Road, $1.4 \mathrm{mi}$ downstream from Black Creek, and $3.3 \mathrm{mi}$ west of Davison.

DRAINAGE AREA. $--99.4 \mathrm{mi}^{2}$.

PERIOD OF RECORD.--October 1965 to current year.

REVISED RECORDS. --WDR MI-78: Drainage area. WDR MI-85: 1968(M), 1973(M), 1975, 1982(P).

GAGE.--Water-stage recorder. Datum of gage is $747.39 \mathrm{ft}$ above National Geodetic Vertical Datum of 1929.

REMARKS.--Estimated daily discharges: Nov. 14-16, Dec. 11-15, 22, 23, Jan. 4, 5, and Jan. 16 to Mar. 4. Records good except for estimated daily discharges, which are fair. Some diurnal fluctuation caused by small dams, and occasional diversion for sprinkler irrigation upstream from station. Several measurements of water temperature were made during the year. Gage-height telemeter at station.

AVERAGE DISCHARGE. --22 years, $73.3 \mathrm{ft} / \mathrm{s}, 10.01 \mathrm{in} / \mathrm{yr}$.

EXTREMES FOR PERIOD OF RECORD.--Maximum discharge, 1,500 ft $3 / \mathrm{s}$, Sept. 9, 1985, gage height, 11.85 ft, from floodmark; minimum, $2.5 \mathrm{ft}^{3} / \mathrm{s}$, Sept. 10, 1978; minimum gage height, 2.69 ft, Sept. 12 , 1969, Aug. 7, 1987 .

EXTREMES FOR CURRENT YEAR.--Maximum discharge, $732 \mathrm{ft}^{3} / \mathrm{s}$, Oct. l, gage height, 9.89 ft, stage falling, peak occurred Sept. 30, 1986 ; maximum peak discharge, $321 \mathrm{ft} / \mathrm{s}$, Apr. 5, gage height, $7.02 \mathrm{ft}$, no independent peak discharge above base discharge of $350 \mathrm{ft} / \mathrm{s}$; minimum discharge, $3.8 \mathrm{ft} 3 / \mathrm{s}^{3}$ Aug. 7 , gage height, $2.69 \mathrm{ft}$.

DISCHARGE, IN CUBIC FEET PER SECOND, WATER YEAR OCTOBER 1986 TO SEPTEMBER 1987

\begin{tabular}{|c|c|c|c|c|c|c|c|c|c|c|c|c|}
\hline DAY & OCT & NOV & DEC & JAN & FEB & MAR & APR & MAY & JUN & JUL & AUG & SEP \\
\hline $\begin{array}{l}1 \\
2 \\
3 \\
4 \\
5\end{array}$ & $\begin{array}{l}640 \\
634 \\
571 \\
530 \\
520\end{array}$ & $\begin{array}{l}69 \\
66 \\
63 \\
64 \\
62\end{array}$ & $\begin{array}{r}59 \\
66 \\
121 \\
112 \\
102\end{array}$ & $\begin{array}{l}87 \\
80 \\
77 \\
68 \\
67\end{array}$ & $\begin{array}{l}38 \\
39 \\
41 \\
42 \\
43\end{array}$ & $\begin{array}{l}150 \\
220 \\
185 \\
180 \\
190\end{array}$ & $\begin{array}{l}106 \\
143 \\
136 \\
128 \\
227\end{array}$ & $\begin{array}{l}43 \\
41 \\
39 \\
37 \\
28\end{array}$ & $\begin{array}{l}31 \\
39 \\
44 \\
31 \\
24\end{array}$ & $\begin{array}{l}9.0 \\
9.8 \\
9.6 \\
9.0 \\
9.0\end{array}$ & $\begin{array}{l}8.5 \\
6.8 \\
5.8 \\
5.4 \\
5.2\end{array}$ & $\begin{array}{l}15 \\
15 \\
11 \\
10 \\
9.5\end{array}$ \\
\hline $\begin{array}{r}6 \\
7 \\
8 \\
9 \\
10\end{array}$ & $\begin{array}{l}392 \\
285 \\
229 \\
198 \\
165\end{array}$ & $\begin{array}{l}59 \\
57 \\
57 \\
54 \\
51\end{array}$ & $\begin{array}{r}95 \\
89 \\
93 \\
100 \\
120\end{array}$ & $\begin{array}{l}67 \\
67 \\
67 \\
63 \\
60\end{array}$ & $\begin{array}{l}44 \\
45 \\
45 \\
45 \\
45\end{array}$ & $\begin{array}{l}153 \\
169 \\
185 \\
178 \\
159\end{array}$ & $\begin{array}{l}303 \\
261 \\
259 \\
227 \\
166\end{array}$ & $\begin{array}{l}17 \\
16 \\
22 \\
24 \\
24\end{array}$ & $\begin{array}{l}20 \\
17 \\
16 \\
14 \\
13\end{array}$ & $\begin{array}{l}8.9 \\
9.2 \\
14 \\
17 \\
17\end{array}$ & $\begin{array}{r}5.0 \\
4.8 \\
4.7 \\
12.1 \\
7.1\end{array}$ & $\begin{array}{l}8.7 \\
8.2 \\
10 \\
20 \\
36\end{array}$ \\
\hline $\begin{array}{l}11 \\
12 \\
13 \\
14 \\
15\end{array}$ & $\begin{array}{l}136 \\
135 \\
137 \\
170 \\
169\end{array}$ & $\begin{array}{l}44 \\
41 \\
39 \\
37 \\
35\end{array}$ & $\begin{array}{l}95 \\
85 \\
74 \\
72 \\
66\end{array}$ & $\begin{array}{r}63 \\
62 \\
66 \\
73 \\
117\end{array}$ & $\begin{array}{l}45 \\
45 \\
45 \\
44 \\
42\end{array}$ & $\begin{array}{r}141 \\
122 \\
105 \\
97 \\
90\end{array}$ & $\begin{array}{l}141 \\
126 \\
113 \\
105 \\
101\end{array}$ & $\begin{array}{l}25 \\
40 \\
40 \\
42 \\
44\end{array}$ & $\begin{array}{l}12 \\
17 \\
13 \\
11 \\
10\end{array}$ & $\begin{array}{l}27 \\
41 \\
37 \\
27 \\
20\end{array}$ & $\begin{array}{l}6.3 \\
6.7 \\
6 \cdot 1 \\
6 \cdot 2 \\
6.2\end{array}$ & $\begin{array}{l}54 \\
54 \\
44 \\
29 \\
29\end{array}$ \\
\hline $\begin{array}{l}16 \\
17 \\
18 \\
19 \\
20\end{array}$ & $\begin{array}{r}163 \\
161 \\
144 \\
103 \\
94\end{array}$ & $\begin{array}{l}36 \\
37 \\
37 \\
36 \\
37\end{array}$ & $\begin{array}{r}64 \\
61 \\
117 \\
162 \\
118\end{array}$ & $\begin{array}{r}105 \\
100 \\
74 \\
66 \\
62\end{array}$ & $\begin{array}{l}39 \\
37 \\
35 \\
35 \\
34\end{array}$ & $\begin{array}{l}87 \\
85 \\
84 \\
81 \\
80\end{array}$ & $\begin{array}{r}109 \\
103 \\
99 \\
94 \\
87\end{array}$ & $\begin{array}{l}45 \\
50 \\
53 \\
44 \\
41\end{array}$ & $\begin{array}{l}8.9 \\
7.9 \\
7.4 \\
7.0 \\
6.9\end{array}$ & $\begin{array}{r}17 \\
14 \\
13 \\
12 \\
9.9\end{array}$ & $\begin{array}{c}5.6 \\
10 \\
6.9 \\
6.7 \\
6.3\end{array}$ & $\begin{array}{l}25 \\
32 \\
35 \\
40 \\
38\end{array}$ \\
\hline $\begin{array}{l}21 \\
22 \\
23 \\
24 \\
25\end{array}$ & $\begin{array}{l}86 \\
78 \\
68 \\
61 \\
57\end{array}$ & $\begin{array}{l}40 \\
41 \\
47 \\
53 \\
53\end{array}$ & $\begin{array}{l}96 \\
87 \\
82 \\
76 \\
81\end{array}$ & $\begin{array}{l}60 \\
55 \\
52 \\
46 \\
43\end{array}$ & $\begin{array}{l}34 \\
35 \\
37 \\
39 \\
41\end{array}$ & $\begin{array}{l}78 \\
74 \\
73 \\
72 \\
74\end{array}$ & $\begin{array}{l}75 \\
60 \\
66 \\
62 \\
57\end{array}$ & $\begin{array}{l}38 \\
36 \\
33 \\
28 \\
25\end{array}$ & $\begin{array}{l}12 \\
14 \\
12 \\
12 \\
11\end{array}$ & $\begin{array}{l}9.2 \\
17 \\
11 \\
8.4 \\
15\end{array}$ & $\begin{array}{l}5.9 \\
29 \\
11 \\
15 \\
13\end{array}$ & $\begin{array}{l}38 \\
33 \\
29 \\
16 \\
12\end{array}$ \\
\hline $\begin{array}{l}26 \\
27 \\
28 \\
29 \\
30 \\
31\end{array}$ & $\begin{array}{l}65 \\
69 \\
69 \\
73 \\
75 \\
72\end{array}$ & $\begin{array}{r}64 \\
73 \\
68 \\
69 \\
65 \\
-\end{array}$ & $\begin{array}{r}80 \\
80 \\
79 \\
83 \\
107 \\
94\end{array}$ & $\begin{array}{l}40 \\
39 \\
38 \\
37 \\
37 \\
37\end{array}$ & $\begin{array}{r}43 \\
46 \\
48 \\
--- \\
--- \\
---\end{array}$ & $\begin{array}{r}81 \\
84 \\
85 \\
83 \\
114 \\
107\end{array}$ & $\begin{array}{r}54 \\
53 \\
52 \\
49 \\
45 \\
---\end{array}$ & $\begin{array}{l}31 \\
43 \\
26 \\
22 \\
19 \\
49\end{array}$ & $\begin{array}{r}9.6 \\
9.2 \\
9.1 \\
11 \\
11 \\
-\end{array}$ & $\begin{array}{l}12 \\
11 \\
10 \\
8.5 \\
7.3 \\
6.4\end{array}$ & $\begin{array}{l}18 \\
25 \\
18 \\
20 \\
18 \\
20\end{array}$ & $\begin{array}{l}14 \\
17 \\
16 \\
23 \\
20 \\
-\end{array}$ \\
\hline $\begin{array}{l}\text { TOTAL } \\
\text { MEAN } \\
\text { MAX } \\
\text { MIN } \\
\text { CFSM } \\
\text { IN. }\end{array}$ & $\begin{array}{r}6349 \\
205 \\
640 \\
57 \\
2.06 \\
2.38\end{array}$ & $\begin{array}{r}1554 \\
51.8 \\
73 \\
35 \\
.52 \\
.58\end{array}$ & $\begin{array}{r}2816 \\
90.8 \\
162 \\
59 \\
.91 \\
1.05\end{array}$ & $\begin{array}{r}1975 \\
63.7 \\
117 \\
37 \\
.64 \\
.74\end{array}$ & $\begin{array}{r}1151 \\
41.1 \\
48 \\
34 \\
.41 \\
.43\end{array}$ & $\begin{array}{r}3666 \\
118 \\
220 \\
72 \\
1.19 \\
1.37\end{array}$ & $\begin{array}{r}3607 \\
120 \\
303 \\
45 \\
1.21 \\
1.35\end{array}$ & $\begin{array}{r}1065 \\
34.4 \\
53 \\
16 \\
.35 \\
.40\end{array}$ & $\begin{array}{r}461.0 \\
15.4 \\
44 \\
6.9 \\
.16 \\
.17\end{array}$ & $\begin{array}{r}446.2 \\
14.4 \\
41 \\
6.4 \\
.15 \\
.17\end{array}$ & $\begin{array}{r}325.2 \\
10.5 \\
29 \\
4.7 \\
.11 \\
.12\end{array}$ & $\begin{array}{r}741.4 \\
24.7 \\
54 \\
8.2 \\
.25 \\
.28\end{array}$ \\
\hline
\end{tabular}

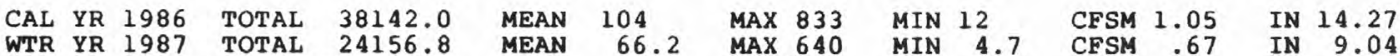


LOCATION.--Lat $43^{\circ} 02^{\prime} 2^{\prime \prime}$, long $83^{\circ} 46^{\prime} 10^{\prime \prime}$, in SWl/4 sec.4, T.7 N., R.6 E., Genesee County, Hydrologic Unit 04080204 , on left bank on grounds of sewage-treatment plant, $1.2 \mathrm{mi}$ upstream from Pirnie Creek, and 5.0 mi downstream from Swartz Creek.

DRAINAGE AREA. $--956 \mathrm{mi}^{2}$.

PERIOD OF RECORD.--September 1903 to March 1904 (gage heights only), August 1932 to current year. Gageheight records for flood seasons collected in this vicinity 1911-32, are contained in reports of the National weather Service.

REVISED RECORDS.--WSP 954: 1941. WSP 1337: 1933-34(M), 1935-37. WDR MI-78: Drainage area.

GAGE.--Water-stage recorder. Datum of gage is $678.80 \mathrm{ft}$ above National Geodetic Vertical Datum of 1929 (levels by the National Weather Service and City of Flint).

REMARKS.--No estimated daily discharges. Records good. Some regulation by reservoirs upstream from station (station 04147000). Occasional diversion for industrial use. Since Dec. 17, 1967, flow contains up to $50 \mathrm{ft} / \mathrm{s}$ as sewage effluent which originates outside the basin. Several measurements of water temperature were made during the year. National Weather service gage-height telemeter at station.

AVERAGE DISCHARGE.--55 years, $614 \mathrm{ft}^{3} / \mathrm{s}, 8.72 \mathrm{in} / \mathrm{yr}^{2}$ adjusted for storage since 1954 .

EXTREMES FOR PERIOD OF RECORD.--Maximum discharge, 14,900 ft $3 / \mathrm{s}$, Apr. 6, 1947, gage height, 16.35 ft; maximum gage height, $16.95 \mathrm{ft}$. Sept. 6, 1985; minimum discharge, 9.0 ft3/s, Aug. 7, 1934.

EXTREMES FOR CURRENT YEAR.--Maximum discharge, $7,810 \mathrm{ft}^{3} / \mathrm{s}$, Oct. 2 , gage height, $13.61 \mathrm{ft}$, was not independent of the peak discharge that occurred Sept. 30, 1986; maximum independent peak discharge, $2,960 \mathrm{ft}^{3} / \mathrm{s}$, Oct. 14, gage height, $8.22 \mathrm{ft} ; \mathrm{minimum}$ daily, $94 \mathrm{ft} / \mathrm{s}, \mathrm{Aug}$. 8 .

DISCHARGE, IN CUBIC FEET PER SECOND, WATER YEAR OCTOBER 1986 TO SEPTEMBER 1987 MEAN VALUES

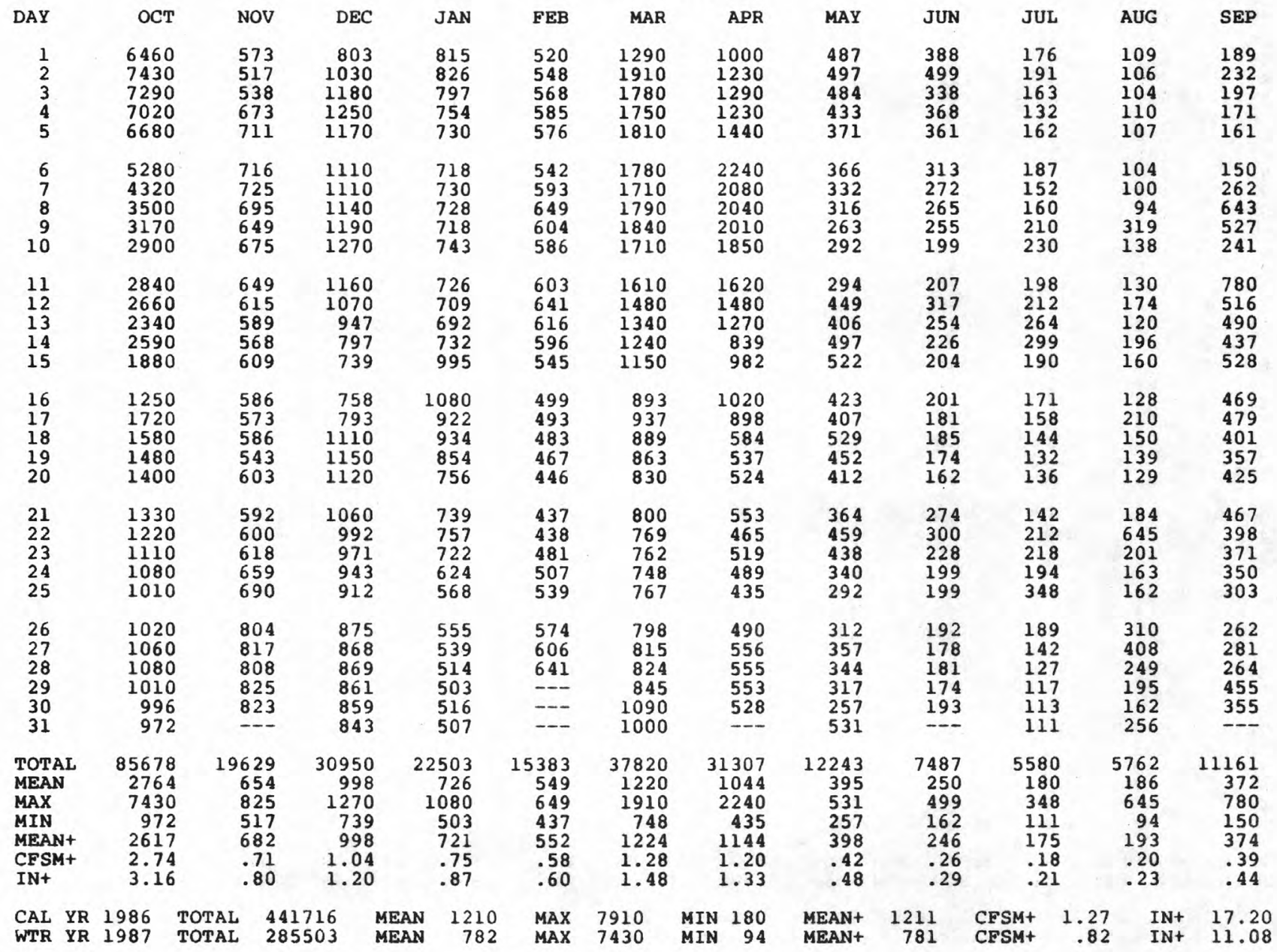

+ Adjusted for change in contents in Holloway Reservoir. 
04150500 CASS RIVER AT CASS CITY, MI

LOCATION.--Lat $43^{\circ} 35^{\prime} 03^{\prime \prime}$, long $83^{\circ} 10^{\prime} 34^{\prime \prime}$, in NE1/4 NEl/4 sec.4, T.13 N., R.11 E., Tuscola County Hydrologic Unit 04080205 , on left bank $600 \mathrm{ft}$ downstream from bridgé on Cemetéry Road, $0.3 \mathrm{mI}$

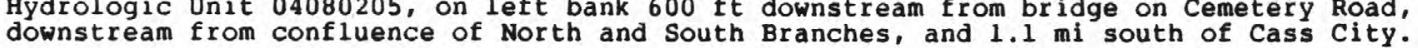

DRAINAGE AREA. $--359 \mathrm{mi}^{2}$.

PERIOD OF RECORD.--October 1947 to current year. Monthly discharge only for some periods, published in WSP 1307.

REVISED RECORDS.--WSP 1337: 1949-50. WSP 1727: 1948(M), 1950. WDR MI-78: Drainage area.

GAGE.--Water-stage recorder. Datum of gage is $697.92 \mathrm{ft}$ above National Geodetic Vertical Datum of 1929. Prior to Nov. 14, 1952, nonrecording gage at site $600 \mathrm{ft}$ upstream at present datum.

REMARKS.--Estimated daily discharges: Nov. 14, 19, Dec. 5-7, 10-15, 21-23, Jan. 4-6, 9, 11-13, Jan. 16 to Feb. 21 and Feb. 23-27. Records good except for estimated daily discharges, which are poor.

Several measurements of water temperature were made during the year.

AVERAGE DISCHARGE. - -40 years, $220 \mathrm{ft}^{3} / \mathrm{s}, 8.32 \mathrm{in} / \mathrm{yr}$.

EXTREMES FOR PERIOD OF RECORD.--Maximum discharge, 12,500 $\mathrm{ft}^{3} / \mathrm{s}$, Sept. 12, 1986, gage height, 19.82 ft, from floodmarks; minimum, $0.50 \mathrm{ft}^{3} / \mathrm{s}$, Sept. 26, 1948.

EXTREMES FOR CURRENT YEAR.--Peak discharges greater than base discharge of $1,400 \mathrm{ft}^{3} / \mathrm{s}$ and maximum (*):

\begin{tabular}{|c|c|c|c|c|c|c|c|c|c|}
\hline Date & & Time & $\begin{array}{c}\text { Discharge } \\
\left.\text { ( } \mathrm{ft}^{3} / \mathrm{s}\right)\end{array}$ & $\begin{array}{c}\text { Gage height } \\
(f t)\end{array}$ & Date & & Time & $\begin{array}{c}\text { Discharge } \\
\left(\mathrm{ft}^{3} / \mathrm{s}\right)\end{array}$ & $\begin{array}{l}\text { Gage height } \\
(\mathrm{ft})\end{array}$ \\
\hline $\begin{array}{l}\text { Oct. } \\
\text { Oct. } \\
\text { Mar. }\end{array}$ & $\begin{array}{l}1 \\
5 \\
2\end{array}$ & $\begin{array}{l}0100 \\
1200 \\
1300\end{array}$ & $\begin{array}{r}\star a 4,720 \\
2,940 \\
3,120\end{array}$ & $\begin{array}{r}\star a 12.99 \\
10.89 \\
10.99\end{array}$ & $\begin{array}{l}\text { Mar. } \\
\text { Apr. }\end{array}$ & $\begin{array}{l}8 \\
6\end{array}$ & $\begin{array}{l}1000 \\
1200\end{array}$ & $\begin{array}{l}2,390 \\
1,720\end{array}$ & $\begin{array}{l}9.97 \\
8.95\end{array}$ \\
\hline
\end{tabular}

a Stage falling, peak occurred sept. 30, 1986.

Minimum discharge, $3.4 \mathrm{ft}^{3} / \mathrm{s}$, July 27 , gage height, $4.44 \mathrm{ft}$.

DISCHARGE, IN CUBIC FEET PER SECOND, WATER YEAR OCTOBER 1986 TO SEPTEMBER 1987

MEAN VALUES

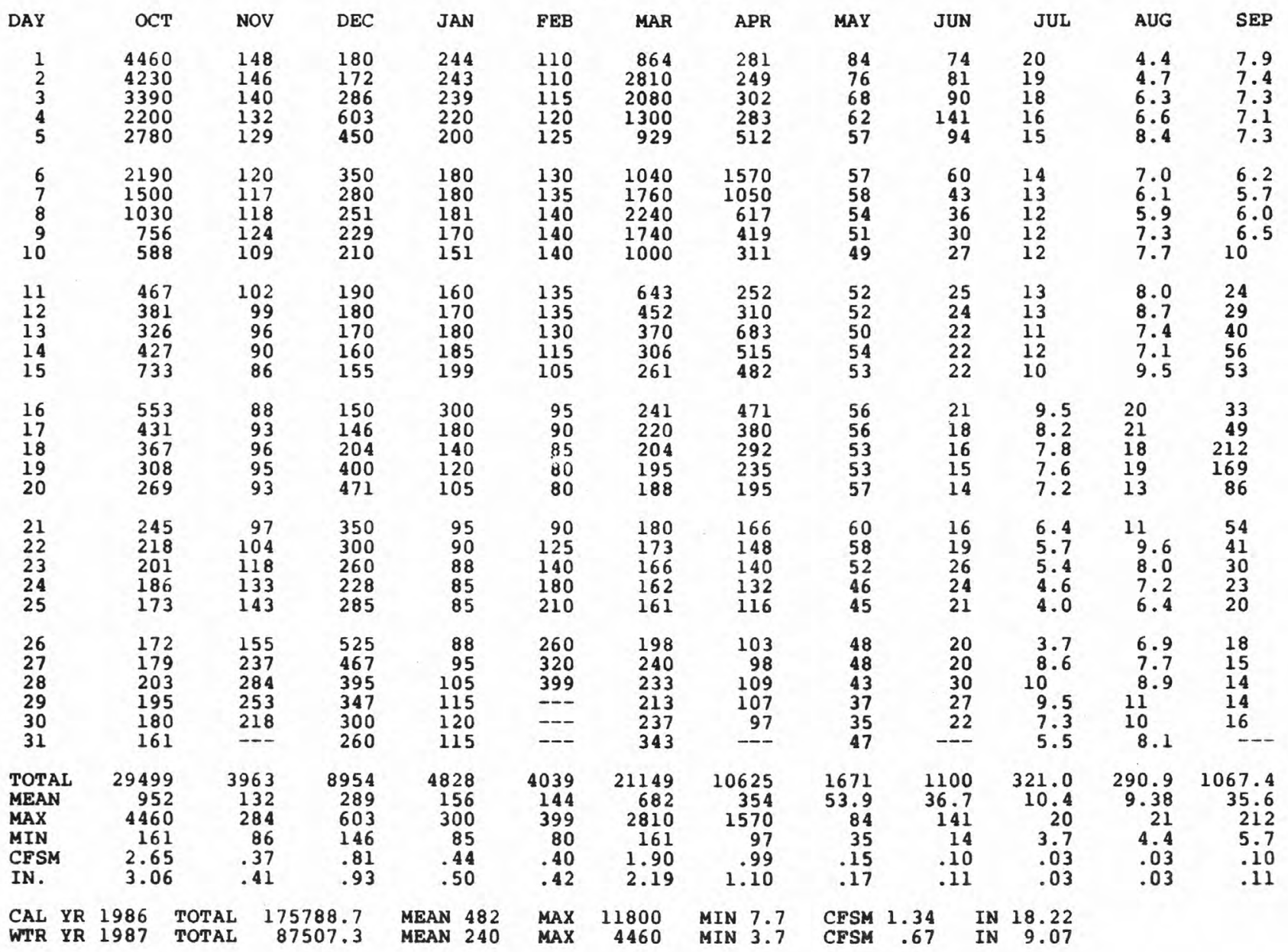




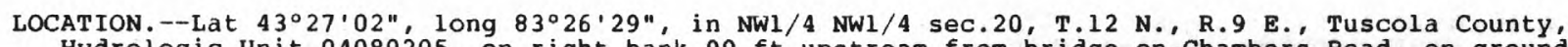
Hydrologic Unit 04080205 , on right bank $90 \mathrm{ft}$ upstream from bridge on Chambers Road, on grounds of Caro Regional Center at wahjamega, $1.9 \mathrm{mi}$ downstream from Michigan Sugar Co. dam, and $40 \mathrm{mi}$ upstream from mouth.

DRAINAGE AREA. $--645 \mathrm{mi}^{2}$.

PERIOD OF RECORD.--October 1968 to current year.

REVISED RECORDS.--WDR MI-78: Drainage area.

GAGE.--Water-stage recorder. Elevation of gage is $650 \mathrm{ft}$ above National Geodetic Vertical Datum of 1929 , from topographic map. Prior to June 19, 1969, nonrecording gage at bridge 90 ft downstream at present datum.

REMARKS.--Estimated daily discharges: Dec. 10-15, Jan. 16-29, and Feb. 5, 9, 13-21, 23-27. Records good except for estimated daily discharges, which are poor. Some regulation by dam at Michigan Sugar Co., $1.9 \mathrm{mi}$ upstream from station. Several measurements of water temperature were made during the year. National Weather Service gage-height telemeter at station.

AVERAGE DISCHARGE.--19 years, $461 \mathrm{ft}^{3} / \mathrm{s}, 9.71 \mathrm{in} / \mathrm{yr}$.

EXTREMES FOR PERIOD OF RECORD.--Maximum discharge, 20,000 ft $\mathrm{ft}^{3} \mathrm{~s}$, Sept. 12, 1986, gage height, $26.66 \mathrm{ft}$, from floodmarks; minimum, $20 \mathrm{ft}^{3} / \mathrm{s}$, Oct. 2, 3, 1979, July 31, Aug. 1, 2, 1987.

EXTREMES FOR CURRENT YEAR.--Peak discharges greater than base discharge of $2,400 \mathrm{ft}^{3} / \mathrm{s}$ and maximum (*):

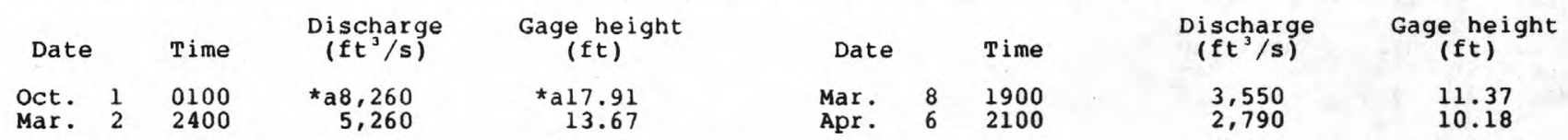

a Stage falling, peak occurred Sept. 30, 1986.

Minimum discharge, $20 \mathrm{ft}^{3} / \mathrm{s}$, July 31 , Aug. 1, 2; minimum gage height, $2.84 \mathrm{ft}, \mathrm{July} 31$, Aug. 1, $2,4-8$. DISCHARGE, IN CUBIC FEET PER SECOND, WATER YEAR OCTOBER 1986 TO SEPTEMBER 1987 MEÁN VALUES

\begin{tabular}{|c|c|c|c|c|c|c|c|c|c|c|c|c|}
\hline DAY & OCT & NOV & DEC & JAN & FEB & MAR & APR & MAY & JUN & JUL & AUG & SEP \\
\hline $\begin{array}{l}1 \\
2 \\
3 \\
4 \\
5\end{array}$ & $\begin{array}{l}7580 \\
6570 \\
5760 \\
4140 \\
4370\end{array}$ & $\begin{array}{l}386 \\
375 \\
364 \\
350 \\
335\end{array}$ & $\begin{array}{l}374 \\
364 \\
546 \\
952 \\
917\end{array}$ & $\begin{array}{l}451 \\
447 \\
443 \\
392 \\
380\end{array}$ & $\begin{array}{l}235 \\
234 \\
248 \\
267 \\
265\end{array}$ & $\begin{array}{r}983 \\
3630 \\
4160 \\
2300 \\
1600\end{array}$ & $\begin{array}{l}544 \\
504 \\
569 \\
579 \\
730\end{array}$ & $\begin{array}{l}251 \\
233 \\
214 \\
199 \\
187\end{array}$ & $\begin{array}{l}107 \\
130 \\
150 \\
155 \\
182\end{array}$ & $\begin{array}{l}53 \\
48 \\
43 \\
41 \\
39\end{array}$ & $\begin{array}{l}20 \\
22 \\
21 \\
21 \\
21\end{array}$ & $\begin{array}{l}35 \\
37 \\
35 \\
33 \\
32\end{array}$ \\
\hline $\begin{array}{r}6 \\
7 \\
8 \\
9 \\
10\end{array}$ & $\begin{array}{l}4050 \\
2750 \\
1930 \\
1480 \\
1210\end{array}$ & $\begin{array}{l}322 \\
311 \\
316 \\
313 \\
293\end{array}$ & $\begin{array}{l}669 \\
568 \\
505 \\
463 \\
430\end{array}$ & $\begin{array}{l}360 \\
372 \\
365 \\
360 \\
334\end{array}$ & $\begin{array}{l}265 \\
267 \\
298 \\
290 \\
264\end{array}$ & $\begin{array}{l}1490 \\
2350 \\
3290 \\
2970 \\
1800\end{array}$ & $\begin{array}{r}2370 \\
2170 \\
1250 \\
858 \\
659\end{array}$ & $\begin{array}{l}179 \\
179 \\
170 \\
156 \\
156\end{array}$ & $\begin{array}{r}133 \\
104 \\
91 \\
81 \\
73\end{array}$ & $\begin{array}{l}38 \\
37 \\
37 \\
37 \\
37\end{array}$ & $\begin{array}{l}21 \\
21 \\
22 \\
23 \\
24\end{array}$ & $\begin{array}{l}31 \\
30 \\
31 \\
40 \\
45\end{array}$ \\
\hline $\begin{array}{l}11 \\
12 \\
13 \\
14 \\
15\end{array}$ & $\begin{array}{r}1000 \\
871 \\
784 \\
835 \\
1210\end{array}$ & $\begin{array}{l}273 \\
261 \\
250 \\
204 \\
241\end{array}$ & $\begin{array}{l}390 \\
370 \\
350 \\
330 \\
320\end{array}$ & $\begin{array}{l}337 \\
336 \\
340 \\
357 \\
397\end{array}$ & $\begin{array}{l}273 \\
282 \\
270 \\
250 \\
230\end{array}$ & $\begin{array}{r}1060 \\
813 \\
668 \\
575 \\
516\end{array}$ & $\begin{array}{l}545 \\
529 \\
938 \\
919 \\
864\end{array}$ & $\begin{array}{l}142 \\
138 \\
125 \\
121 \\
120\end{array}$ & $\begin{array}{l}69 \\
70 \\
76 \\
76 \\
67\end{array}$ & $\begin{array}{l}37 \\
36 \\
36 \\
36 \\
36\end{array}$ & $\begin{array}{l}24 \\
24 \\
24 \\
27 \\
29\end{array}$ & $\begin{array}{r}89 \\
134 \\
148 \\
99 \\
104\end{array}$ \\
\hline $\begin{array}{l}16 \\
17 \\
18 \\
19 \\
20\end{array}$ & $\begin{array}{r}1130 \\
906 \\
779 \\
691 \\
621\end{array}$ & $\begin{array}{l}230 \\
236 \\
243 \\
231 \\
229\end{array}$ & $\begin{array}{l}320 \\
323 \\
429 \\
663 \\
824\end{array}$ & $\begin{array}{l}470 \\
380 \\
310 \\
250 \\
230\end{array}$ & $\begin{array}{l}210 \\
195 \\
185 \\
175 \\
170\end{array}$ & $\begin{array}{l}475 \\
442 \\
415 \\
395 \\
383\end{array}$ & $\begin{array}{l}884 \\
770 \\
624 \\
522 \\
445\end{array}$ & $\begin{array}{l}107 \\
105 \\
108 \\
114 \\
121\end{array}$ & $\begin{array}{l}57 \\
53 \\
49 \\
46 \\
43\end{array}$ & $\begin{array}{l}34 \\
32 \\
30 \\
29 \\
28\end{array}$ & $\begin{array}{l}31 \\
35 \\
40 \\
40 \\
40\end{array}$ & $\begin{array}{l}101 \\
138 \\
405 \\
459 \\
275\end{array}$ \\
\hline $\begin{array}{l}21 \\
22 \\
23 \\
24 \\
25\end{array}$ & $\begin{array}{l}578 \\
536 \\
502 \\
476 \\
447\end{array}$ & $\begin{array}{l}234 \\
248 \\
268 \\
296 \\
306\end{array}$ & $\begin{array}{l}695 \\
560 \\
538 \\
463 \\
486\end{array}$ & $\begin{array}{l}210 \\
200 \\
190 \\
180 \\
180\end{array}$ & $\begin{array}{l}175 \\
199 \\
220 \\
250 \\
310\end{array}$ & $\begin{array}{l}373 \\
363 \\
351 \\
343 \\
339\end{array}$ & $\begin{array}{l}391 \\
355 \\
353 \\
355 \\
324\end{array}$ & $\begin{array}{r}118 \\
115 \\
106 \\
98 \\
95\end{array}$ & $\begin{array}{r}57 \\
104 \\
107 \\
93 \\
81\end{array}$ & $\begin{array}{l}27 \\
26 \\
24 \\
23 \\
23\end{array}$ & $\begin{array}{l}38 \\
36 \\
33 \\
31 \\
29\end{array}$ & $\begin{array}{r}195 \\
147 \\
120 \\
99 \\
81\end{array}$ \\
\hline $\begin{array}{l}26 \\
27 \\
28 \\
29 \\
30 \\
31\end{array}$ & $\begin{array}{l}435 \\
447 \\
468 \\
464 \\
440 \\
403\end{array}$ & $\begin{array}{l}324 \\
452 \\
528 \\
489 \\
431\end{array}$ & $\begin{array}{l}712 \\
779 \\
666 \\
593 \\
543 \\
481\end{array}$ & $\begin{array}{l}185 \\
210 \\
260 \\
260 \\
257 \\
247\end{array}$ & $\begin{array}{l}360 \\
420 \\
537 \\
-- \\
--\end{array}$ & $\begin{array}{l}374 \\
438 \\
445 \\
423 \\
461 \\
546\end{array}$ & $\begin{array}{l}293 \\
282 \\
301 \\
302 \\
275\end{array}$ & $\begin{array}{r}102 \\
103 \\
97 \\
89 \\
81 \\
81\end{array}$ & $\begin{array}{r}68 \\
62 \\
59 \\
62 \\
61 \\
\end{array}$ & $\begin{array}{l}22 \\
21 \\
21 \\
21 \\
21 \\
21\end{array}$ & $\begin{array}{l}30 \\
31 \\
32 \\
33 \\
35 \\
36\end{array}$ & $\begin{array}{l}73 \\
71 \\
67 \\
80 \\
92\end{array}$ \\
\hline $\begin{array}{l}\text { TOTALL } \\
\text { MEAN } \\
\text { MAX } \\
\text { MIN } \\
\text { CFSM } \\
\text { IN. }\end{array}$ & $\begin{array}{r}53863 \\
1738 \\
7580 \\
403 \\
2.70 \\
3.11\end{array}$ & $\begin{array}{r}9339 \\
311 \\
528 \\
204 \\
.48 \\
.54\end{array}$ & $\begin{array}{r}16623 \\
536 \\
952 \\
320 \\
.83 \\
.96\end{array}$ & $\begin{array}{r}9690 \\
313 \\
470 \\
180 \\
.49 \\
.56\end{array}$ & $\begin{array}{r}7344 \\
262 \\
537 \\
170 \\
.41 \\
.42\end{array}$ & $\begin{array}{r}34771 \\
1122 \\
4160 \\
339 \\
1.74 \\
2.01\end{array}$ & $\begin{array}{r}20504 \\
683 \\
2370 \\
275 \\
1.06 \\
1.18\end{array}$ & $\begin{array}{r}4210 \\
136 \\
251 \\
81 \\
.21 \\
.24\end{array}$ & $\begin{array}{r}2566 \\
85.5 \\
182 \\
43 \\
.13 \\
.15\end{array}$ & $\begin{array}{r}994 \\
32.1 \\
53 \\
21 \\
.05 \\
.06\end{array}$ & $\begin{array}{r}894 \\
28.8 \\
40 \\
20 \\
.05 \\
.05\end{array}$ & $\begin{array}{r}3326 \\
111 \\
459 \\
30 \\
.17 \\
.19\end{array}$ \\
\hline $\begin{array}{l}\text { CAL YR } \\
\text { WTR YR }\end{array}$ & $\begin{array}{l}1986 \\
1987\end{array}$ & 3 & & $\begin{array}{l}\text { AN } 852 \\
\text { AN } 450\end{array}$ & $\begin{array}{l}\text { MAXX } \\
\text { MAX }\end{array}$ & $\begin{array}{l}00 \\
80\end{array}$ & $\begin{array}{l}36 \\
20\end{array}$ & $\begin{array}{lr}\text { FSM } & 1.32 \\
\text { FSM } & .70\end{array}$ & $\begin{array}{l}\text { IN } \\
\text { IN }\end{array}$ & & & \\
\hline
\end{tabular}


04151500 CASS RIVER AT FRANKENMUTH, MI

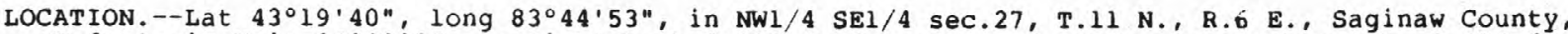
Hydrologic Unit 04080205 , on right bank 2,000 ft downstream from dam in Frankenmuth, 3,600 ft upstream from highway bridge on Dehmel Road, $3.4 \mathrm{mi}$ upstream from Dead Creek, and $17 \mathrm{mi}$ upstream from mouth.

DRAINAGE AREA. $--841 \mathrm{mi}^{2}$.

PERIOD OF RECORD.--February 1908 to March 1909, July 1935 to September 1936 , June 1939 to current year.

REVISED RECORDS.--WSP 1307: 1936(M), 1940(M). WSP 1727: 1952. WSP 1911: 1952. WDR MI-78: Drainage area.

GAGE--Water-stage recorder. Datum of gage is $583.96 \mathrm{ft}$ above National Geodetic Vertical Datum of 1929 (levels by Michigan Department of Natural Resources). February 1908 to March 1909, nonrecording gage at site 2,000 ft upstream at datum $1.81 \mathrm{ft}$ lower. July 18 to september 11, 1935, nonrecording gage, Sept. 12, 1935, to Sept. 30, 1936, June 20, 1939, to Sept. 30, 1949, water-stage recorder, at site $3,600 \mathrm{ft}$ downstream at datum $0.04 \mathrm{ft}$ higher.

REMARKS.--Estimated daily discharges: Nov. 14, Dec. 9-16, Jan. 12, 17-28 and Feb. 8-21. Records good except for estimated daily discharges, which are poor. Occasional regulation by dams upstream from station. Prior to 1950, regulation at low and medium flows by mill upstream from station. Several measurements of water temperature were made during the year.

AVERAGE DISCHARGE. -49 years, $516 \mathrm{ft}^{3} / \mathrm{s}, 8.33 \mathrm{in} / \mathrm{yr}^{\mathrm{r}}$.

EXTREMES FOR PERIOD OF RECORD.--Maximum discharge, $22.200 \mathrm{ft}^{3} / \mathrm{s}$, Sept. 12, 1986 , gage height, 27.52 $\mathrm{ft}$; minimum daily, about $1.5 \mathrm{ft} / \mathrm{s}$, Aug. 6,1944 .

EXTREMES FOR CURRENT YEAR.--Peak discharges greater than base discharge of $3,500 \mathrm{ft}^{3} / \mathrm{s}$ and maximum (*):

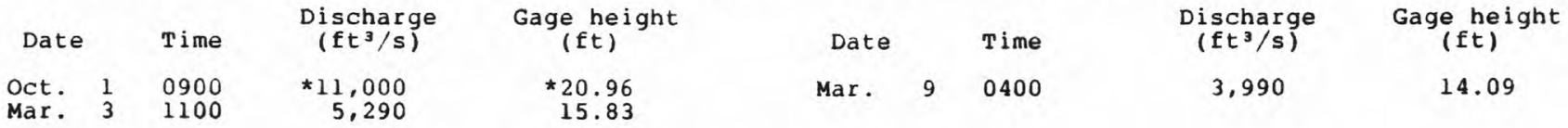

Minimum discharge, $32 \mathrm{ft}^{3} / \mathrm{s}$, July 29,30 , gage height, $3.24 \mathrm{ft}$.

DISCHARGE, IN CUBIC FEET PER SECOND, WATER YEAR OCTOBER 1986 TO SEPTEMBER 1987 MEAN VALUES

\begin{tabular}{|c|c|c|c|c|c|c|c|c|c|c|c|c|}
\hline DAY & OCT & NOV & $\mathrm{DEC}$ & JAN & FEB & MAR & APR & MAY & JUN & JUL & AUG & SEP \\
\hline $\begin{array}{l}1 \\
2 \\
3 \\
4 \\
5\end{array}$ & $\begin{array}{r}10900 \\
10600 \\
9180 \\
7290 \\
6420\end{array}$ & $\begin{array}{l}552 \\
537 \\
525 \\
513 \\
493\end{array}$ & $\begin{array}{r}588 \\
568 \\
884 \\
1320 \\
1380\end{array}$ & $\begin{array}{l}656 \\
644 \\
641 \\
595 \\
556\end{array}$ & $\begin{array}{l}402 \\
419 \\
432 \\
458 \\
450\end{array}$ & $\begin{array}{l}1080 \\
3090 \\
5020 \\
3210 \\
2170\end{array}$ & $\begin{array}{r}782 \\
815 \\
875 \\
869 \\
1010\end{array}$ & $\begin{array}{l}352 \\
325 \\
294 \\
269 \\
251\end{array}$ & $\begin{array}{l}127 \\
171 \\
204 \\
189 \\
198\end{array}$ & $\begin{array}{l}90 \\
81 \\
74 \\
69 \\
64\end{array}$ & $\begin{array}{l}36 \\
44 \\
54 \\
45 \\
40\end{array}$ & $\begin{array}{l}57 \\
76 \\
76 \\
69 \\
62\end{array}$ \\
\hline $\begin{array}{r}6 \\
7 \\
8 \\
9 \\
10\end{array}$ & $\begin{array}{l}6260 \\
4510 \\
2950 \\
2260 \\
1800\end{array}$ & $\begin{array}{l}482 \\
464 \\
457 \\
455 \\
444\end{array}$ & $\begin{array}{r}1070 \\
873 \\
794 \\
700 \\
640\end{array}$ & $\begin{array}{l}543 \\
550 \\
559 \\
538 \\
518\end{array}$ & $\begin{array}{l}450 \\
452 \\
450 \\
450 \\
440\end{array}$ & $\begin{array}{l}1830 \\
2310 \\
3380 \\
3730 \\
2600\end{array}$ & $\begin{array}{l}2430 \\
3030 \\
1990 \\
1340 \\
1000\end{array}$ & $\begin{array}{l}241 \\
230 \\
226 \\
208 \\
197\end{array}$ & $\begin{array}{l}195 \\
154 \\
133 \\
119 \\
110\end{array}$ & $\begin{array}{r}61 \\
65 \\
65 \\
77 \\
109\end{array}$ & $\begin{array}{l}37 \\
37 \\
41 \\
51 \\
54\end{array}$ & $\begin{array}{l}56 \\
52 \\
52 \\
66 \\
81\end{array}$ \\
\hline $\begin{array}{l}11 \\
12 \\
13 \\
14 \\
15\end{array}$ & $\begin{array}{l}1480 \\
1260 \\
1130 \\
1160 \\
1390\end{array}$ & $\begin{array}{l}418 \\
399 \\
385 \\
310 \\
340\end{array}$ & $\begin{array}{l}590 \\
560 \\
530 \\
500 \\
520\end{array}$ & $\begin{array}{l}501 \\
500 \\
503 \\
514 \\
576\end{array}$ & $\begin{array}{l}430 \\
410 \\
390 \\
370 \\
350\end{array}$ & $\begin{array}{r}1620 \\
1190 \\
962 \\
851 \\
770\end{array}$ & $\begin{array}{r}812 \\
748 \\
968 \\
1260 \\
1150\end{array}$ & $\begin{array}{l}189 \\
181 \\
170 \\
161 \\
161\end{array}$ & $\begin{array}{l}101 \\
111 \\
109 \\
120 \\
107\end{array}$ & $\begin{array}{l}91 \\
76 \\
71 \\
86 \\
74\end{array}$ & $\begin{array}{l}49 \\
44 \\
42 \\
50 \\
61\end{array}$ & $\begin{array}{l}107 \\
164 \\
223 \\
180 \\
147\end{array}$ \\
\hline $\begin{array}{l}16 \\
17 \\
18 \\
19 \\
20\end{array}$ & $\begin{array}{r}1560 \\
1300 \\
1110 \\
971 \\
881\end{array}$ & $\begin{array}{l}362 \\
368 \\
384 \\
374 \\
360\end{array}$ & $\begin{array}{r}530 \\
524 \\
688 \\
953 \\
1140\end{array}$ & $\begin{array}{l}693 \\
560 \\
460 \\
400 \\
360\end{array}$ & $\begin{array}{l}330 \\
300 \\
280 \\
270 \\
260\end{array}$ & $\begin{array}{l}720 \\
676 \\
637 \\
610 \\
587\end{array}$ & $\begin{array}{r}1200 \\
1120 \\
909 \\
748 \\
641\end{array}$ & $\begin{array}{l}152 \\
143 \\
145 \\
155 \\
162\end{array}$ & $\begin{array}{l}94 \\
83 \\
76 \\
72 \\
67\end{array}$ & $\begin{array}{l}64 \\
59 \\
54 \\
50 \\
48\end{array}$ & $\begin{array}{l}58 \\
63 \\
63 \\
64 \\
63\end{array}$ & $\begin{array}{l}154 \\
196 \\
282 \\
574 \\
423\end{array}$ \\
\hline $\begin{array}{l}21 \\
22 \\
23 \\
24 \\
25\end{array}$ & $\begin{array}{l}812 \\
754 \\
710 \\
669 \\
634\end{array}$ & $\begin{array}{l}377 \\
398 \\
431 \\
473 \\
490\end{array}$ & $\begin{array}{r}1070 \\
874 \\
799 \\
712 \\
694\end{array}$ & $\begin{array}{l}330 \\
310 \\
300 \\
290 \\
280\end{array}$ & $\begin{array}{l}270 \\
303 \\
344 \\
400 \\
474\end{array}$ & $\begin{array}{l}572 \\
555 \\
539 \\
531 \\
522\end{array}$ & $\begin{array}{l}571 \\
505 \\
514 \\
537 \\
486\end{array}$ & $\begin{array}{l}168 \\
188 \\
172 \\
152 \\
142\end{array}$ & $\begin{array}{l}121 \\
194 \\
189 \\
158 \\
135\end{array}$ & $\begin{array}{l}45 \\
43 \\
41 \\
40 \\
40\end{array}$ & $\begin{array}{l}64 \\
59 \\
54 \\
50 \\
46\end{array}$ & $\begin{array}{l}294 \\
221 \\
175 \\
150 \\
127\end{array}$ \\
\hline $\begin{array}{l}26 \\
27 \\
28 \\
29 \\
30 \\
31\end{array}$ & $\begin{array}{l}612 \\
635 \\
650 \\
655 \\
627 \\
587\end{array}$ & $\begin{array}{l}501 \\
689 \\
781 \\
756 \\
671 \\
---\end{array}$ & $\begin{array}{r}821 \\
1020 \\
933 \\
834 \\
766 \\
703\end{array}$ & $\begin{array}{l}290 \\
330 \\
360 \\
394 \\
397 \\
401\end{array}$ & $\begin{array}{l}545 \\
590 \\
654 \\
--- \\
--- \\
---\end{array}$ & $\begin{array}{l}555 \\
620 \\
650 \\
622 \\
686 \\
753\end{array}$ & $\begin{array}{l}437 \\
401 \\
420 \\
418 \\
391 \\
---\end{array}$ & $\begin{array}{l}144 \\
151 \\
141 \\
132 \\
123 \\
116\end{array}$ & $\begin{array}{r}118 \\
107 \\
99 \\
92 \\
92 \\
---\end{array}$ & $\begin{array}{l}38 \\
37 \\
35 \\
34 \\
34 \\
35\end{array}$ & $\begin{array}{l}52 \\
71 \\
66 \\
60 \\
58 \\
58\end{array}$ & $\begin{array}{l}110 \\
103 \\
100 \\
109 \\
132\end{array}$ \\
\hline $\begin{array}{l}\text { TOTAL } \\
\text { MEAN } \\
\text { MAX } \\
\text { MIN } \\
\text { CFSM } \\
\text { IN. }\end{array}$ & $\begin{array}{r}81757 \\
2637 \\
10900 \\
587 \\
3.14 \\
3.62\end{array}$ & $\begin{array}{r}14189 \\
473 \\
781 \\
310 \\
.56 \\
.63\end{array}$ & $\begin{array}{r}24578 \\
793 \\
1380 \\
500 \\
.94 \\
1.09\end{array}$ & $\begin{array}{r}14549 \\
469 \\
693 \\
280 \\
.56 \\
.64\end{array}$ & $\begin{array}{r}11373 \\
406 \\
654 \\
260 \\
.48 \\
.50\end{array}$ & $\begin{array}{r}43648 \\
1408 \\
5020 \\
522 \\
1.67 \\
1.93\end{array}$ & $\begin{array}{r}28377 \\
946 \\
3030 \\
391 \\
1.13 \\
1.26\end{array}$ & $\begin{array}{r}5841 \\
188 \\
352 \\
116 \\
.22 \\
.26\end{array}$ & $\begin{array}{r}3845 \\
128 \\
204 \\
67 \\
.15 \\
.17\end{array}$ & $\begin{array}{r}1850 \\
59.7 \\
109 \\
34 \\
.07 \\
.08\end{array}$ & $\begin{array}{r}1634 \\
52.7 \\
71 \\
36 \\
.06 \\
.07\end{array}$ & $\begin{array}{r}4618 \\
154 \\
574 \\
52 \\
.18 \\
.20\end{array}$ \\
\hline
\end{tabular}

$\begin{array}{llllllllllll}\text { CAL YR } 1986 & \text { TOTAL } & 427806 & \text { MEAN } & 1172 & \text { MAX } & 21700 & \text { MIN } 57 & \text { CFSM } & 1.39 & \text { IN } 18.92 \\ \text { WTR YR } 1987 & \text { TOTAL } & 236259 & \text { MEAN } & 647 & \text { MAX } & 10900 & \text { MIN } 34 & \text { CFSM } & .77 & \text { IN } 10.45\end{array}$ 
LOCATION.--Lat $43^{\circ} 52^{\prime} 01^{\prime \prime}$, long $84^{\circ} 32^{\prime} 43^{\prime \prime}$, in SEl/4 NEl/4 sec.16, T.17 N., R.2 W., Gladwin County,

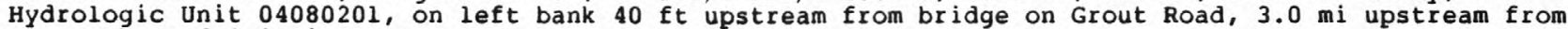
Ross Lake and $3.2 \mathrm{mi}$ southwest of Beaverton.

DRAINAGE AREA, $--160 \mathrm{mi}^{2}$.

PERIOD OF RECORD.--January to September 1987.

GAGE.--Water stage recorder. Datum of gage is $709.92 \mathrm{ft}$ above National Geodetic Vertical Datum of 1929.

REMARKS.--Estimated daily discharges: Jan. 17 to Mar. 5, June 11 to July 9, and July 16 to Aug. 8.

Records good except for estimated daily discharges, which are poor. Several measurements of water temperature were made during the year.

EXTREMES FOR CURRENT YEAR.--Maximum discharge, $366 \mathrm{ft}^{3} / \mathrm{s}$, Mar. 8 , gage height $6.19 \mathrm{ft} ;$ maximum gage

height, $6.91 \mathrm{ft}$, Mar. 2, backwater from ice; minimum discharge, $54 \mathrm{ft}^{3} / \mathrm{s}^{,} \mathrm{Aug}$. $21, \mathrm{gage}$ height,

$3.53 \mathrm{ft}$

DISCHARGE, IN CUBIC FEET PER SECOND, WATER YEAR OCTOBER 1986 TO SEPTEMBER 1987 MEAN VALUES

\begin{tabular}{|c|c|c|c|c|c|c|c|c|c|c|c|c|}
\hline DAY & OCT & NOV & DEC & JAN & FEB & MAR & APR & MAY & JUN & JUL & AUG & SEP \\
\hline $\begin{array}{l}1 \\
2 \\
3 \\
4 \\
5\end{array}$ & & & & $\begin{array}{l}141 \\
141 \\
142 \\
138 \\
135\end{array}$ & $\begin{array}{l}105 \\
110 \\
115 \\
115 \\
110\end{array}$ & $\begin{array}{l}110 \\
120 \\
115 \\
110 \\
130\end{array}$ & $\begin{array}{l}119 \\
122 \\
124 \\
117 \\
115\end{array}$ & $\begin{array}{l}90 \\
88 \\
85 \\
86 \\
85\end{array}$ & $\begin{array}{l}78 \\
89 \\
85 \\
77 \\
73\end{array}$ & $\begin{array}{l}90 \\
70 \\
68 \\
68 \\
68\end{array}$ & $\begin{array}{l}68 \\
74 \\
84 \\
96 \\
80\end{array}$ & $\begin{array}{l}62 \\
66 \\
75 \\
70 \\
66\end{array}$ \\
\hline $\begin{array}{r}6 \\
7 \\
8 \\
9 \\
10\end{array}$ & & & & $\begin{array}{l}134 \\
136 \\
137 \\
132 \\
132\end{array}$ & $\begin{array}{r}105 \\
100 \\
95 \\
90 \\
90\end{array}$ & $\begin{array}{l}179 \\
240 \\
335 \\
341 \\
235\end{array}$ & $\begin{array}{l}117 \\
118 \\
113 \\
110 \\
106\end{array}$ & $\begin{array}{l}78 \\
83 \\
82 \\
82 \\
81\end{array}$ & $\begin{array}{l}72 \\
72 \\
72 \\
71 \\
69\end{array}$ & $\begin{array}{l}66 \\
66 \\
66 \\
66 \\
97\end{array}$ & $\begin{array}{r}68 \\
66 \\
66 \\
81 \\
123\end{array}$ & $\begin{array}{l}64 \\
61 \\
69 \\
85 \\
77\end{array}$ \\
\hline $\begin{array}{l}11 \\
12 \\
13 \\
14 \\
15\end{array}$ & & & & $\begin{array}{l}136 \\
135 \\
136 \\
129 \\
131\end{array}$ & $\begin{array}{r}95 \\
100 \\
100 \\
100 \\
95\end{array}$ & $\begin{array}{l}170 \\
147 \\
131 \\
128 \\
130\end{array}$ & $\begin{array}{l}102 \\
100 \\
100 \\
100 \\
124\end{array}$ & $\begin{array}{l}86 \\
95 \\
89 \\
85 \\
94\end{array}$ & $\begin{array}{l}74 \\
76 \\
74 \\
72 \\
70\end{array}$ & $\begin{array}{r}167 \\
115 \\
97 \\
79 \\
72\end{array}$ & $\begin{array}{r}112 \\
80 \\
79 \\
78 \\
116\end{array}$ & $\begin{array}{l}71 \\
68 \\
69 \\
68 \\
68\end{array}$ \\
\hline $\begin{array}{l}16 \\
17 \\
18 \\
19 \\
20\end{array}$ & & & & $\begin{array}{l}130 \\
110 \\
100 \\
105 \\
110\end{array}$ & $\begin{array}{r}90 \\
90 \\
95 \\
100 \\
100\end{array}$ & $\begin{array}{l}128 \\
125 \\
122 \\
120 \\
121\end{array}$ & $\begin{array}{l}161 \\
155 \\
132 \\
118 \\
110\end{array}$ & $\begin{array}{l}96 \\
89 \\
85 \\
85 \\
92\end{array}$ & $\begin{array}{l}68 \\
66 \\
66 \\
66 \\
68\end{array}$ & $\begin{array}{l}72 \\
70 \\
68 \\
68 \\
68\end{array}$ & $\begin{array}{r}141 \\
145 \\
135 \\
96 \\
87\end{array}$ & $\begin{array}{r}69 \\
85 \\
304 \\
231 \\
152\end{array}$ \\
\hline $\begin{array}{l}21 \\
22 \\
23 \\
24 \\
25\end{array}$ & & & & $\begin{array}{r}105 \\
100 \\
95 \\
90 \\
95\end{array}$ & $\begin{array}{l}100 \\
105 \\
105 \\
105 \\
100\end{array}$ & $\begin{array}{l}124 \\
126 \\
119 \\
129 \\
138\end{array}$ & $\begin{array}{l}104 \\
101 \\
126 \\
140 \\
121\end{array}$ & $\begin{array}{r}95 \\
99 \\
104 \\
94 \\
89\end{array}$ & $\begin{array}{l}70 \\
74 \\
84 \\
80 \\
72\end{array}$ & $\begin{array}{l}68 \\
68 \\
68 \\
68 \\
66\end{array}$ & $\begin{array}{l}68 \\
72 \\
68 \\
63 \\
61\end{array}$ & $\begin{array}{r}119 \\
108 \\
100 \\
92 \\
77\end{array}$ \\
\hline $\begin{array}{l}26 \\
27 \\
28 \\
29 \\
30 \\
31\end{array}$ & & & & $\begin{array}{l}100 \\
105 \\
105 \\
105 \\
100 \\
100\end{array}$ & $\begin{array}{r}100 \\
95 \\
100 \\
--- \\
---\end{array}$ & $\begin{array}{l}152 \\
150 \\
144 \\
132 \\
138 \\
131\end{array}$ & $\begin{array}{r}109 \\
104 \\
103 \\
98 \\
95 \\
---\end{array}$ & $\begin{array}{l}89 \\
95 \\
90 \\
85 \\
80 \\
76\end{array}$ & $\begin{array}{r}90 \\
82 \\
74 \\
66 \\
110 \\
---\end{array}$ & $\begin{array}{l}66 \\
66 \\
64 \\
64 \\
64 \\
66\end{array}$ & $\begin{array}{l}58 \\
62 \\
70 \\
69 \\
64 \\
63\end{array}$ & $\begin{array}{r}81 \\
81 \\
80 \\
81 \\
91 \\
\end{array}$ \\
\hline $\begin{array}{l}\text { TOTAL } \\
\text { MEAN } \\
\text { MAX } \\
\text { MIN } \\
\text { CFSM } \\
\text { IN. }\end{array}$ & & & & $\begin{array}{r}3690 \\
119 \\
142 \\
90 \\
.74 \\
.86\end{array}$ & $\begin{array}{r}2810 \\
100 \\
115 \\
90 \\
.63 \\
.65\end{array}$ & $\begin{array}{r}4720 \\
152 \\
341 \\
110 \\
.95 \\
1.10\end{array}$ & $\begin{array}{r}3464 \\
115 \\
161 \\
95 \\
.72 \\
.81\end{array}$ & $\begin{array}{r}2732 \\
88.1 \\
104 \\
76 \\
.55 \\
.64\end{array}$ & $\begin{array}{r}2260 \\
75.3 \\
110 \\
66 \\
.47 \\
.53\end{array}$ & $\begin{array}{r}2329 \\
75.1 \\
167 \\
64 \\
.47 \\
.54\end{array}$ & $\begin{array}{r}2593 \\
83.6 \\
145 \\
58 \\
.52 \\
.60\end{array}$ & $\begin{array}{r}2790 \\
93.0 \\
304 \\
61 \\
.58 \\
.65\end{array}$ \\
\hline
\end{tabular}


04154000 CHIPPEWA RIVER NEAR MOUNT PLEASANT, MI

LOCATION. --Lat $43^{\circ} 37^{\prime} 32^{\prime \prime}$, long $84^{\circ} 42^{\prime} 28^{\prime \prime}$, in NWl/4 NWl/4 sec.8, T.14 N., R. 3 W. , Isabella County Hydrologic Unit 04080202 , on right bank $12 \mathrm{ft}$ downstream from bridge on South Leaton Road, 3.8 mi northeast of Mount Pleasant, and $36 \mathrm{mi}$ upstream from mouth.

DRAINAGE AREA. $--416 \mathrm{mi}^{2}$.

PERIOD OF RECORD.--October 1930 to September 1931, October 1932 to current year. Monthly discharge only for some periods, published in WSP 1307. Gage-height records for flood seasons collected in this vicinity 1910-27, are contained in reports of National Weather Service.

REVISED RECORDS.--WSP 744: Drainage area. WSP 1337: 1931, 1933-40, 1945, $1948-49$.

GAGE.--Water-stage recorder. Datum of gage is $710.38 \mathrm{ft}$ above National Geodetic Vertical Datum of 1929 (levels by Michigan Department of Natural Resources). Prior to Oct. 21, 1938, nonrecording gage at site $30 \mathrm{ft}$ upstream at present datum.

REMARKS.--Estimated daily discharges: Dec. 13-16, Jan. 17 to Feb. 2, and Feb. 9, 10, 15-19. Records good except for estimated daily discharges, which are poor. Diurnal fluctuation below $750 \mathrm{ft} / \mathrm{s}$ caused by powerplant at Mount pleasant prior to 1962 , occasional regulation at low flow since. Since July 30,1968 , occasional regulation by control structures on lake outlets. Several measurements of water temperature were made during the year. National Weather Service gage-height telemeter at station.

AVERAGE DISCHARGE. - -56 years, $316 \mathrm{ft}^{3} / \mathrm{s}, 10.32 \mathrm{in} / \mathrm{yr}$

EXTREMES FOR PERIOD OF RECORD.--Maximum discharge, $6,660 \mathrm{ft}^{3} / \mathrm{s}$, Sept. 12, 1986 , gage height, 15.58 ft, from floodmarks; minimum, $12 \mathrm{ft} / \mathrm{s}$, Aug. 18, 1945; minimum gage height, 2.70 ft, Oct. 8, 1966 ; minimum daily discharge, $19 \mathrm{ft}^{3} / \mathrm{s}$, Aug. 16, 1936.

EXTREMES FOR CURRENT YEAR.--Maximum discharge, $2,300 \mathrm{ft}^{3} / \mathrm{s}$, Oct. 1, gage height, $9.39 \mathrm{ft}$, stage falling, peak occurred Sept. 30, 1986; maximum peak discharge, $739 \mathrm{ft}^{3} / \mathrm{s}, \mathrm{Mar}$. 2, gage height, $4.89 \mathrm{ft}$; no independent peak discharge above base of $1,000 \mathrm{ft} / \mathrm{s}$; minimum discharge, 104 $\mathrm{ft}^{3} / \mathrm{s}$, July 29, Aug. 1; minimum gage height, $2.88 \mathrm{ft}$, July 28, 29, Aug. 1 .

DISCHARGE, IN CUBIC FEET PER SECOND, WATER YEAR OCTOBER 1986 TO SEPTEMBER 1987

\begin{tabular}{|c|c|c|c|c|c|c|c|c|c|c|c|c|}
\hline DAY & OCT & NOV & DEC & JAN & FEB & MAR & APR & MAY & JUN & JUL & AUG & SEP \\
\hline $\begin{array}{l}1 \\
2 \\
3 \\
4 \\
5\end{array}$ & $\begin{array}{l}2230 \\
2170 \\
1940 \\
1830 \\
2220\end{array}$ & $\begin{array}{l}506 \\
493 \\
486 \\
476 \\
464\end{array}$ & $\begin{array}{l}442 \\
446 \\
461 \\
463 \\
447\end{array}$ & $\begin{array}{l}405 \\
408 \\
410 \\
408 \\
405\end{array}$ & $\begin{array}{l}370 \\
380 \\
388 \\
358 \\
333\end{array}$ & $\begin{array}{l}513 \\
656 \\
502 \\
447 \\
429\end{array}$ & $\begin{array}{l}344 \\
354 \\
351 \\
346 \\
331\end{array}$ & $\begin{array}{l}284 \\
277 \\
265 \\
255 \\
248\end{array}$ & $\begin{array}{l}210 \\
220 \\
213 \\
203 \\
192\end{array}$ & $\begin{array}{l}134 \\
132 \\
133 \\
134 \\
127\end{array}$ & $\begin{array}{l}109 \\
116 \\
123 \\
125 \\
124\end{array}$ & $\begin{array}{l}189 \\
196 \\
195 \\
195 \\
189\end{array}$ \\
\hline $\begin{array}{r}6 \\
7 \\
8 \\
9 \\
10\end{array}$ & $\begin{array}{l}1960 \\
1690 \\
1500 \\
1340 \\
1200\end{array}$ & $\begin{array}{l}459 \\
453 \\
454 \\
461 \\
455\end{array}$ & $\begin{array}{l}442 \\
439 \\
441 \\
441 \\
439\end{array}$ & $\begin{array}{l}402 \\
402 \\
400 \\
397 \\
403\end{array}$ & $\begin{array}{l}339 \\
340 \\
349 \\
340 \\
330\end{array}$ & $\begin{array}{l}428 \\
464 \\
514 \\
526 \\
482\end{array}$ & $\begin{array}{l}332 \\
330 \\
325 \\
316 \\
309\end{array}$ & $\begin{array}{l}245 \\
238 \\
234 \\
231 \\
229\end{array}$ & $\begin{array}{l}191 \\
193 \\
188 \\
180 \\
171\end{array}$ & $\begin{array}{l}127 \\
129 \\
131 \\
150 \\
158\end{array}$ & $\begin{array}{l}122 \\
117 \\
117 \\
177 \\
182\end{array}$ & $\begin{array}{l}187 \\
183 \\
210 \\
217 \\
210\end{array}$ \\
\hline $\begin{array}{l}11 \\
12 \\
13 \\
14 \\
15\end{array}$ & $\begin{array}{r}1090 \\
995 \\
925 \\
897 \\
858\end{array}$ & $\begin{array}{l}442 \\
439 \\
429 \\
420 \\
423\end{array}$ & $\begin{array}{l}458 \\
438 \\
420 \\
410 \\
400\end{array}$ & $\begin{array}{l}402 \\
397 \\
396 \\
395 \\
397\end{array}$ & $\begin{array}{l}331 \\
332 \\
325 \\
327 \\
320\end{array}$ & $\begin{array}{l}446 \\
425 \\
407 \\
405 \\
396\end{array}$ & $\begin{array}{l}303 \\
298 \\
290 \\
288 \\
330\end{array}$ & $\begin{array}{l}222 \\
233 \\
231 \\
231 \\
228\end{array}$ & $\begin{array}{l}168 \\
171 \\
170 \\
166 \\
163\end{array}$ & $\begin{array}{l}180 \\
195 \\
183 \\
168 \\
154\end{array}$ & $\begin{array}{l}182 \\
173 \\
164 \\
184 \\
246\end{array}$ & $\begin{array}{l}204 \\
198 \\
195 \\
196 \\
198\end{array}$ \\
\hline $\begin{array}{l}16 \\
17 \\
18 \\
19 \\
20\end{array}$ & $\begin{array}{l}833 \\
792 \\
724 \\
684 \\
655\end{array}$ & $\begin{array}{l}427 \\
432 \\
430 \\
425 \\
426\end{array}$ & $\begin{array}{l}400 \\
412 \\
428 \\
435 \\
435\end{array}$ & $\begin{array}{l}394 \\
370 \\
360 \\
350 \\
350\end{array}$ & $\begin{array}{l}320 \\
310 \\
310 \\
300 \\
298\end{array}$ & $\begin{array}{l}358 \\
252 \\
284 \\
285 \\
326\end{array}$ & $\begin{array}{l}395 \\
428 \\
420 \\
396 \\
371\end{array}$ & $\begin{array}{l}222 \\
220 \\
224 \\
226 \\
224\end{array}$ & $\begin{array}{l}155 \\
152 \\
148 \\
146 \\
144\end{array}$ & $\begin{array}{l}150 \\
144 \\
141 \\
137 \\
134\end{array}$ & $\begin{array}{l}281 \\
370 \\
390 \\
337 \\
289\end{array}$ & $\begin{array}{l}193 \\
266 \\
479 \\
477 \\
487\end{array}$ \\
\hline $\begin{array}{l}21 \\
22 \\
23 \\
24 \\
25\end{array}$ & $\begin{array}{l}633 \\
610 \\
592 \\
575 \\
558\end{array}$ & $\begin{array}{l}428 \\
429 \\
435 \\
446 \\
442\end{array}$ & $\begin{array}{l}430 \\
418 \\
418 \\
417 \\
417\end{array}$ & $\begin{array}{l}350 \\
350 \\
350 \\
340 \\
330\end{array}$ & $\begin{array}{l}297 \\
296 \\
297 \\
296 \\
300\end{array}$ & $\begin{array}{l}394 \\
396 \\
396 \\
397 \\
369\end{array}$ & $\begin{array}{l}343 \\
335 \\
370 \\
389 \\
377\end{array}$ & $\begin{array}{l}227 \\
250 \\
263 \\
253 \\
239\end{array}$ & $\begin{array}{l}144 \\
143 \\
143 \\
143 \\
143\end{array}$ & $\begin{array}{l}130 \\
126 \\
123 \\
120 \\
116\end{array}$ & $\begin{array}{l}251 \\
230 \\
213 \\
200 \\
192\end{array}$ & $\begin{array}{l}442 \\
387 \\
343 \\
311 \\
282\end{array}$ \\
\hline $\begin{array}{l}26 \\
27 \\
28 \\
29 \\
30 \\
31\end{array}$ & $\begin{array}{l}549 \\
567 \\
565 \\
558 \\
537 \\
519\end{array}$ & $\begin{array}{l}448 \\
458 \\
454 \\
451 \\
449 \\
---\end{array}$ & $\begin{array}{l}412 \\
411 \\
409 \\
408 \\
408 \\
406\end{array}$ & $\begin{array}{l}330 \\
330 \\
330 \\
330 \\
340 \\
350\end{array}$ & $\begin{array}{l}303 \\
303 \\
307 \\
--- \\
--- \\
---\end{array}$ & $\begin{array}{l}252 \\
244 \\
234 \\
230 \\
274 \\
326\end{array}$ & $\begin{array}{l}361 \\
346 \\
331 \\
311 \\
295 \\
--\end{array}$ & $\begin{array}{l}235 \\
231 \\
225 \\
216 \\
206 \\
201\end{array}$ & $\begin{array}{l}147 \\
137 \\
133 \\
132 \\
135 \\
---\end{array}$ & $\begin{array}{l}113 \\
111 \\
108 \\
106 \\
107 \\
106\end{array}$ & $\begin{array}{l}194 \\
205 \\
199 \\
193 \\
189 \\
191\end{array}$ & $\begin{array}{l}266 \\
254 \\
245 \\
262 \\
285 \\
\end{array}$ \\
\hline $\begin{array}{l}\text { TOTAL } \\
\text { MEAN } \\
\text { MAX } \\
\text { MIN } \\
\text { CFSM } \\
\text { IN. }\end{array}$ & $\begin{array}{r}32796 \\
1058 \\
2230 \\
519 \\
2.54 \\
2.93\end{array}$ & $\begin{array}{r}13440 \\
448 \\
506 \\
420 \\
1.08 \\
1.20\end{array}$ & $\begin{array}{r}13251 \\
427 \\
463 \\
400 \\
1.03 \\
1.18\end{array}$ & $\begin{array}{r}11581 \\
374 \\
410 \\
330 \\
.90 \\
1.04\end{array}$ & $\begin{array}{r}9099 \\
325 \\
388 \\
296 \\
.78 \\
.81\end{array}$ & $\begin{array}{r}12057 \\
389 \\
656 \\
230 \\
.94 \\
1.08\end{array}$ & $\begin{array}{r}10315 \\
344 \\
428 \\
288 \\
.83 \\
.92\end{array}$ & $\begin{array}{r}7313 \\
236 \\
284 \\
201 \\
.57 \\
.65\end{array}$ & $\begin{array}{r}4944 \\
165 \\
220 \\
132 \\
.40 \\
.44\end{array}$ & $\begin{array}{r}4207 \\
136 \\
195 \\
106 \\
.33 \\
.38\end{array}$ & $\begin{array}{r}6185 \\
200 \\
390 \\
109 \\
.48 \\
.55\end{array}$ & $\begin{array}{r}7941 \\
265 \\
487 \\
183 \\
.64 \\
.71\end{array}$ \\
\hline
\end{tabular}

CAL YR 1986 TOTAL 213936 MEAN 586 MAX 6210 MIN $195 \quad$ CFSM $1.41 \quad$ IN 19.13 WTR YR 1987 TOTAL 133129 MEAN 365 MAX 2230 MIN 106 CFSM .88 IN 11.90 
LOCATION.--Lat $43^{\circ} 22^{\prime} 46^{\prime \prime}$, long $84^{\circ} 39^{\prime} 20^{\prime \prime}$, in SWl/4 SEl/4 sec. 34, T. 12 N., R. 3 W., Gratiot County, Hydrologic Unit 04080202 , on right bank $270 \mathrm{ft}$ downstream from Superior Street Bridge in Alma, 0.6 mi downstream from municipal reservoir, and $38 \mathrm{mi}$ upstream from mouth.

DRAINAGE AREA. $--288 \mathrm{mi}^{2}$.

PERIOD OF RECORD.--October 1930 to current year. Gage-height records for flood seasons collected in this vicinity 1910-28 are contained in reports of National Weather Service.

REVISED RECORDS.--WSP 744: Drainage area. WSP 1307: 1945(M). WSP 1337: 1931, 1932-34(M), 1936, $1939,1945,1949$.

GAGE.--Water-stage recorder. Datum of gage is $718.37 \mathrm{ft}$ above National Geodetic Vertical Datum of 1929 . Prior to Dec. 10,1930, nonrecording gage at Superior street Bridge at different datum. Dec. 10, 1930, to June 15, 1938, nonrecording gage at site 70 ft downstream from bridge, and June 16 to Oct. 25 , 1938 , nonrecording gage at bridge at present datum.

REMARKS.--Estimated daily discharges: Nov. 13-17, Jan. 21-31 and Feb. 1, 15, 18, 19. Records fair except for estimated daily discharges, which are poor. Flow regulated by dam $0.6 \mathrm{mi}$ upstream from station, and by variable backwater from powerplant at St. Louis, $5.2 \mathrm{mi}$ downstream. About $3.2 \mathrm{ft} 3 / \mathrm{s}$ diverted upstream from station for municipal and industrial use; sewage effluent is returned downstream from station. Several measurements of water temperature were made during the year.

AVERAGE DISCHARGE.--57 years, $221 \mathrm{ft}^{3} / \mathrm{s}, 10.42 \mathrm{in} / \mathrm{yr}^{\mathrm{r}}$.

EXTREMES FOR PERIOD OF RECORD.--Maximum discharge, 5,160 ft $3 / \mathrm{s}$, Sept. 12, 1986, gage height, 12.82 ft, from floodmarks; minimum daily, $0.40 \mathrm{ft}^{3} / \mathrm{s}$, Sept. 6, 1964, caused by closing dam during construction of waterworks.

EXTREMES FOR CURRENT YEAR.--Maximum discharge, 2,190 $\mathrm{ft}^{3} / \mathrm{s}$, Oct. 4, gage height, $8.27 \mathrm{ft}$; minimum, $39 \mathrm{ft}^{3} / \mathrm{s}$, July 30,31 , gage height, $0.45 \mathrm{ft}$.

DISCHARGE, IN CUBIC FEET PER SECOND, WATER YEAR OCTOBER 1986 TO SEPTEMBER 1987 MEAN VALUES

\begin{tabular}{|c|c|c|c|c|c|c|c|c|c|c|c|c|}
\hline DAY & OCT & NOV & DEC & JAN & FEB & MAR & APR & MAY & JUN & JUL & AUG & SEP \\
\hline $\begin{array}{l}1 \\
2 \\
3 \\
4 \\
5\end{array}$ & $\begin{array}{l}1920 \\
1950 \\
1790 \\
1860 \\
1980\end{array}$ & $\begin{array}{l}381 \\
371 \\
369 \\
350 \\
347\end{array}$ & $\begin{array}{l}295 \\
295 \\
304 \\
283 \\
303\end{array}$ & $\begin{array}{l}230 \\
242 \\
234 \\
229 \\
247\end{array}$ & $\begin{array}{l}201 \\
249 \\
247 \\
242 \\
244\end{array}$ & $\begin{array}{l}421 \\
536 \\
512 \\
507 \\
636\end{array}$ & $\begin{array}{l}282 \\
278 \\
272 \\
274 \\
271\end{array}$ & $\begin{array}{l}176 \\
173 \\
199 \\
188 \\
155\end{array}$ & $\begin{array}{l}154 \\
146 \\
133 \\
122 \\
114\end{array}$ & $\begin{array}{l}92 \\
93 \\
98 \\
97 \\
98\end{array}$ & $\begin{array}{l}44 \\
51 \\
62 \\
86 \\
96\end{array}$ & $\begin{array}{l}125 \\
124 \\
113 \\
127 \\
128\end{array}$ \\
\hline $\begin{array}{r}6 \\
7 \\
8 \\
9 \\
10\end{array}$ & $\begin{array}{l}1620 \\
1420 \\
1300 \\
1170 \\
1010\end{array}$ & $\begin{array}{l}339 \\
313 \\
325 \\
304 \\
320\end{array}$ & $\begin{array}{l}285 \\
283 \\
281 \\
285 \\
288\end{array}$ & $\begin{array}{l}252 \\
250 \\
248 \\
249 \\
258\end{array}$ & $\begin{array}{l}251 \\
270 \\
276 \\
250 \\
217\end{array}$ & $\begin{array}{l}532 \\
461 \\
450 \\
463 \\
479\end{array}$ & $\begin{array}{l}258 \\
239 \\
225 \\
221 \\
215\end{array}$ & $\begin{array}{l}147 \\
143 \\
150 \\
135 \\
124\end{array}$ & $\begin{array}{l}120 \\
151 \\
139 \\
116 \\
114\end{array}$ & $\begin{array}{r}99 \\
98 \\
96 \\
94 \\
103\end{array}$ & $\begin{array}{r}81 \\
88 \\
100 \\
113 \\
108\end{array}$ & $\begin{array}{r}111 \\
96 \\
123 \\
126 \\
139\end{array}$ \\
\hline $\begin{array}{l}11 \\
12 \\
13 \\
14 \\
15\end{array}$ & $\begin{array}{l}885 \\
796 \\
747 \\
725 \\
682\end{array}$ & $\begin{array}{l}304 \\
307 \\
295 \\
290 \\
285\end{array}$ & $\begin{array}{l}271 \\
267 \\
223 \\
187 \\
197\end{array}$ & $\begin{array}{l}252 \\
235 \\
235 \\
241 \\
248\end{array}$ & $\begin{array}{l}228 \\
248 \\
228 \\
225 \\
210\end{array}$ & $\begin{array}{l}471 \\
423 \\
330 \\
292 \\
287\end{array}$ & $\begin{array}{l}197 \\
189 \\
197 \\
215 \\
240\end{array}$ & $\begin{array}{l}140 \\
126 \\
139 \\
151 \\
126\end{array}$ & $\begin{array}{l}130 \\
149 \\
127 \\
141 \\
142\end{array}$ & $\begin{array}{l}101 \\
119 \\
124 \\
124 \\
121\end{array}$ & $\begin{array}{l}137 \\
117 \\
111 \\
150 \\
146\end{array}$ & $\begin{array}{l}153 \\
121 \\
123 \\
118 \\
101\end{array}$ \\
\hline $\begin{array}{l}16 \\
17 \\
18 \\
19 \\
20\end{array}$ & $\begin{array}{l}644 \\
604 \\
567 \\
538 \\
508\end{array}$ & $\begin{array}{l}285 \\
290 \\
290 \\
292 \\
295\end{array}$ & $\begin{array}{l}277 \\
301 \\
288 \\
282 \\
289\end{array}$ & $\begin{array}{l}256 \\
233 \\
210 \\
187 \\
183\end{array}$ & $\begin{array}{l}168 \\
171 \\
175 \\
180 \\
184\end{array}$ & $\begin{array}{l}285 \\
266 \\
291 \\
294 \\
285\end{array}$ & $\begin{array}{l}262 \\
288 \\
304 \\
288 \\
264\end{array}$ & $\begin{array}{l}119 \\
131 \\
147 \\
138 \\
150\end{array}$ & $\begin{array}{r}123 \\
112 \\
93 \\
84 \\
85\end{array}$ & $\begin{array}{r}116 \\
110 \\
104 \\
97 \\
86\end{array}$ & $\begin{array}{l}162 \\
214 \\
185 \\
210 \\
205\end{array}$ & $\begin{array}{r}97 \\
143 \\
164 \\
175 \\
177\end{array}$ \\
\hline $\begin{array}{l}21 \\
22 \\
23 \\
24 \\
25\end{array}$ & $\begin{array}{l}499 \\
479 \\
464 \\
451 \\
460\end{array}$ & $\begin{array}{l}291 \\
291 \\
301 \\
304 \\
307\end{array}$ & $\begin{array}{l}299 \\
294 \\
276 \\
262 \\
259\end{array}$ & $\begin{array}{l}180 \\
180 \\
180 \\
175 \\
175\end{array}$ & $\begin{array}{l}181 \\
199 \\
214 \\
198 \\
195\end{array}$ & $\begin{array}{l}291 \\
291 \\
282 \\
270 \\
268\end{array}$ & $\begin{array}{l}245 \\
223 \\
249 \\
248 \\
261\end{array}$ & $\begin{array}{l}165 \\
167 \\
158 \\
194 \\
210\end{array}$ & $\begin{array}{r}98 \\
111 \\
115 \\
96 \\
96\end{array}$ & $\begin{array}{l}75 \\
63 \\
57 \\
50 \\
46\end{array}$ & $\begin{array}{l}157 \\
139 \\
146 \\
126 \\
110\end{array}$ & $\begin{array}{l}164 \\
162 \\
195 \\
162 \\
130\end{array}$ \\
\hline $\begin{array}{l}26 \\
27 \\
28 \\
29 \\
30 \\
31\end{array}$ & $\begin{array}{l}441 \\
460 \\
447 \\
418 \\
432 \\
440\end{array}$ & $\begin{array}{l}320 \\
319 \\
311 \\
326 \\
314 \\
--\end{array}$ & $\begin{array}{l}270 \\
267 \\
254 \\
242 \\
237 \\
233\end{array}$ & $\begin{array}{l}170 \\
170 \\
175 \\
175 \\
180 \\
185\end{array}$ & $\begin{array}{l}197 \\
201 \\
211 \\
--- \\
---\end{array}$ & $\begin{array}{l}274 \\
281 \\
292 \\
297 \\
294 \\
287\end{array}$ & $\begin{array}{l}257 \\
239 \\
218 \\
199 \\
187 \\
---\end{array}$ & $\begin{array}{l}196 \\
172 \\
155 \\
137 \\
132 \\
154\end{array}$ & $\begin{array}{l}103 \\
114 \\
124 \\
128 \\
113 \\
---\end{array}$ & $\begin{array}{l}46 \\
45 \\
44 \\
43 \\
41 \\
40\end{array}$ & $\begin{array}{l}119 \\
131 \\
153 \\
161 \\
139 \\
120\end{array}$ & $\begin{array}{l}121 \\
133 \\
121 \\
116 \\
111 \\
-\end{array}$ \\
\hline $\begin{array}{l}\text { TOTAL } \\
\text { MEAN } \\
\text { MAX } \\
\text { MIN } \\
\text { CFSM } \\
\text { IN. }\end{array}$ & $\begin{array}{r}27707 \\
894 \\
1980 \\
418 \\
3.10 \\
3.58\end{array}$ & $\begin{array}{r}9436 \\
315 \\
381 \\
285 \\
1.09 \\
1.22\end{array}$ & $\begin{array}{r}8377 \\
270 \\
304 \\
187 \\
.94 \\
1.08\end{array}$ & $\begin{array}{r}6664 \\
215 \\
258 \\
170 \\
.75 \\
.86\end{array}$ & $\begin{array}{r}6060 \\
216 \\
276 \\
168 \\
.75 \\
.78\end{array}$ & $\begin{array}{r}11348 \\
366 \\
636 \\
266 \\
1.27 \\
1.47\end{array}$ & $\begin{array}{r}7305 \\
244 \\
304 \\
187 \\
.85 \\
.94\end{array}$ & $\begin{array}{r}4797 \\
155 \\
210 \\
119 \\
.54 \\
.62\end{array}$ & $\begin{array}{r}3593 \\
120 \\
154 \\
84 \\
.42 \\
.46\end{array}$ & $\begin{array}{r}2620 \\
84.5 \\
124 \\
40 \\
.29 \\
.34\end{array}$ & $\begin{array}{r}3967 \\
128 \\
214 \\
44 \\
.44 \\
.51\end{array}$ & $\begin{array}{r}3999 \\
133 \\
195 \\
96 \\
.46 \\
.52\end{array}$ \\
\hline $\begin{array}{l}\text { CAL YR } \\
\text { WTR YR }\end{array}$ & $\begin{array}{l}1986 \\
1987\end{array}$ & $\begin{array}{ll}A L & 1 \\
A L & \end{array}$ & & $\begin{array}{ll}N & 428 \\
N & 263\end{array}$ & $\begin{array}{l}\text { MAX } \\
\text { MAX }\end{array}$ & $\begin{array}{l}\text { MIN } \\
\text { MIN }\end{array}$ & $\begin{array}{l}49 \\
40\end{array}$ & $\begin{array}{r}1.49 \\
\text { SM }\end{array}$ & $\begin{array}{ll}\text { IN } 20 \\
\text { IN } 12\end{array}$ & & & \\
\hline
\end{tabular}


04155500 PINE RIVER NEAR MIDLAND, MI

LOCATION.--Lat $43^{\circ} 33^{\prime} 52^{\prime \prime}$, long $84^{\circ} 22^{\prime} 09^{\prime \prime}$, in SWl/4 NW1/4 sec.4, T.13 N., R.1 E., Midland County,

Hydrologic Unit 04080202 , on left bank at downstream side of bridge on Meridian Road, 7.2 mi southwest of Midland, and $7.8 \mathrm{mi}$ upstream from Chippewa River.

DRAINAGE AREA. $--390 \mathrm{mi}^{2}$, approximately.

PERIOD OF RECORD.--May 1934 to September 1938, February 1948 to current year.

REVISED RECORDS.--WSP 1207: Drainage area. WSP 1307: 1935(M). WSP 1337: 1936-38, 1948-49.

GAGE.--Water-stage recorder. Datum of gage is $623.94 \mathrm{ft}$ above National Geodetic Vertical Datum of 1929 .

Prior to Sept. 30, 1938, nonrecording gage at same site at datum 5.55 ft lower. Feb. 3 , 1948, to Dec. 13,1951 , nonrecording gage at present site and datum.

REMARKS.--Estimated daily discharges: Dec. 13-23, Jan. 16-19 and Jan. 21 to Mar. 5. Records good except for estimated daily discharges, which are poor. Regulation at low and medium flows by hydroelectric powerplant at St. Louis. Some diversion upstream from station for irrigation. Several measurements of water temperature were made during the year.

AVERAGE DISCHARGE. -43 years, $307 \mathrm{ft}^{3} / \mathrm{s}, 10.69 \mathrm{in} / \mathrm{yr}^{\circ}$

EXTREMES FOR PERIOD OF RECORD.--Maximum discharge, 9,360 $\mathrm{ft}^{3} / \mathrm{s}$, Sept. 12, 1986, gage height, $11.74 \mathrm{ft}$; maximum gage height, $12.08 \mathrm{ft}$, Feb. 2, 1968 , backwater from ice; minimum daily discharge, 11 ft , s $^{\prime}$ Aug. 19, 1980 .

EXTREMES FOR CURRENT YEAR.--Peak discharges greater than base discharge of $1,200 \mathrm{ft}^{3} / \mathrm{s}^{\mathrm{and}} \mathrm{maximum} \mathrm{(*):}$

\begin{tabular}{|c|c|c|c|c|c|c|c|}
\hline Date & Time & $\begin{array}{c}\text { Discharge } \\
\left(\mathrm{ft}^{3} / \mathrm{s}\right)\end{array}$ & $\begin{array}{l}\text { Gage height } \\
(\mathrm{ft})\end{array}$ & Date & Time & $\begin{array}{c}\text { Discharge } \\
\left(\mathrm{ft}^{3} / \mathrm{s}\right)\end{array}$ & $\begin{array}{c}\text { Gage height } \\
(\mathrm{ft})\end{array}$ \\
\hline $\begin{array}{l}\text { Oct. } \\
\text { Oct. }\end{array}$ & $\begin{array}{l}0100 \\
1000\end{array}$ & $\begin{array}{r}\star a 3,460 \\
3,400\end{array}$ & $\begin{array}{r}\star a 7.25 \\
7.16\end{array}$ & $\begin{array}{l}\text { Oct. } \\
\text { Mar. }\end{array}$ & 0800 & $\begin{array}{l}1,310 \\
1,310\end{array}$ & $\begin{array}{l}4.79 \\
\text { ice jam }\end{array}$ \\
\hline
\end{tabular}

a stage falling, peak occurred sept. 30, 1986.

Minimum discharge, $11 \mathrm{ft}^{3} / \mathrm{s}$, Aug. 6 , gage height, $1.71 \mathrm{ft}$.

DISCHARGE, IN CUBIC FEET PER SECOND, WATER YEAR OCTOBER 1986 TO SEPTEMBER 1987 MEAN VALUES

\begin{tabular}{|c|c|c|c|c|c|c|c|c|c|c|c|c|}
\hline DAY & OCT & NOV & DEC & JAN & FEB & MAR & APR & MAY & JUN & JUL & AUG & SEP \\
\hline $\begin{array}{l}1 \\
2 \\
3 \\
4 \\
5\end{array}$ & $\begin{array}{l}3180 \\
2940 \\
2680 \\
2450 \\
3190\end{array}$ & $\begin{array}{l}686 \\
443 \\
423 \\
467 \\
471\end{array}$ & $\begin{array}{l}453 \\
323 \\
332 \\
488 \\
241\end{array}$ & $\begin{array}{l}329 \\
248 \\
337 \\
311 \\
204\end{array}$ & $\begin{array}{l}230 \\
250 \\
270 \\
290 \\
300\end{array}$ & $\begin{array}{l}270 \\
350 \\
600 \\
760 \\
840\end{array}$ & $\begin{array}{l}320 \\
330 \\
322 \\
315 \\
317\end{array}$ & $\begin{array}{l}205 \\
204 \\
102 \\
160 \\
252\end{array}$ & $\begin{array}{l}101 \\
178 \\
167 \\
130 \\
114\end{array}$ & $\begin{array}{r}141 \\
69 \\
68 \\
68 \\
67\end{array}$ & $\begin{array}{l}20 \\
17 \\
16 \\
14 \\
13\end{array}$ & $\begin{array}{l}110 \\
120 \\
155 \\
109 \\
113\end{array}$ \\
\hline $\begin{array}{r}6 \\
7 \\
8 \\
9 \\
10\end{array}$ & $\begin{array}{l}2560 \\
1920 \\
1790 \\
1550 \\
1370\end{array}$ & $\begin{array}{l}393 \\
508 \\
315 \\
536 \\
236\end{array}$ & $\begin{array}{l}598 \\
357 \\
347 \\
334 \\
320\end{array}$ & $\begin{array}{l}275 \\
313 \\
311 \\
303 \\
315\end{array}$ & $\begin{array}{l}310 \\
320 \\
310 \\
300 \\
280\end{array}$ & $\begin{array}{l}686 \\
550 \\
559 \\
547 \\
520\end{array}$ & $\begin{array}{l}323 \\
325 \\
317 \\
242 \\
231\end{array}$ & $\begin{array}{l}183 \\
153 \\
118 \\
217 \\
155\end{array}$ & $\begin{array}{r}120 \\
65 \\
122 \\
180 \\
106\end{array}$ & $\begin{array}{l}68 \\
63 \\
64 \\
72 \\
85\end{array}$ & $\begin{array}{l}31 \\
49 \\
24 \\
42 \\
99\end{array}$ & $\begin{array}{r}155 \\
149 \\
92 \\
134 \\
193\end{array}$ \\
\hline $\begin{array}{l}11 \\
12 \\
13 \\
14 \\
15\end{array}$ & $\begin{array}{r}1130 \\
1080 \\
880 \\
1060 \\
781\end{array}$ & $\begin{array}{l}479 \\
355 \\
345 \\
354 \\
355\end{array}$ & $\begin{array}{l}323 \\
333 \\
300 \\
260 \\
240\end{array}$ & $\begin{array}{l}351 \\
345 \\
342 \\
301 \\
273\end{array}$ & $\begin{array}{l}270 \\
280 \\
290 \\
280 \\
250\end{array}$ & $\begin{array}{l}507 \\
496 \\
482 \\
405 \\
269\end{array}$ & $\begin{array}{l}284 \\
276 \\
178 \\
181 \\
198\end{array}$ & $\begin{array}{r}86 \\
153 \\
112 \\
73 \\
187\end{array}$ & $\begin{array}{r}65 \\
69 \\
162 \\
113 \\
64\end{array}$ & $\begin{array}{l}87 \\
74 \\
72 \\
72 \\
72\end{array}$ & $\begin{array}{r}61 \\
126 \\
76 \\
91 \\
246\end{array}$ & $\begin{array}{r}94 \\
268 \\
121 \\
120 \\
213\end{array}$ \\
\hline $\begin{array}{l}16 \\
17 \\
18 \\
19 \\
20\end{array}$ & $\begin{array}{l}843 \\
825 \\
737 \\
684 \\
660\end{array}$ & $\begin{array}{l}340 \\
337 \\
336 \\
355 \\
358\end{array}$ & $\begin{array}{l}280 \\
320 \\
350 \\
370 \\
380\end{array}$ & $\begin{array}{l}270 \\
260 \\
250 \\
200 \\
131\end{array}$ & $\begin{array}{l}220 \\
200 \\
200 \\
210 \\
220\end{array}$ & $\begin{array}{l}298 \\
429 \\
196 \\
301 \\
338\end{array}$ & $\begin{array}{l}307 \\
305 \\
323 \\
365 \\
328\end{array}$ & $\begin{array}{r}169 \\
87 \\
77 \\
160 \\
151\end{array}$ & $\begin{array}{r}143 \\
79 \\
114 \\
95 \\
87\end{array}$ & $\begin{array}{l}72 \\
70 \\
68 \\
65 \\
66\end{array}$ & $\begin{array}{l}197 \\
133 \\
373 \\
155 \\
231\end{array}$ & $\begin{array}{l}231 \\
208 \\
505 \\
299 \\
376\end{array}$ \\
\hline $\begin{array}{l}21 \\
22 \\
23 \\
24 \\
25\end{array}$ & $\begin{array}{l}531 \\
603 \\
609 \\
598 \\
483\end{array}$ & $\begin{array}{l}335 \\
331 \\
335 \\
355 \\
368\end{array}$ & $\begin{array}{l}380 \\
380 \\
370 \\
374 \\
334\end{array}$ & $\begin{array}{l}170 \\
190 \\
210 \\
210 \\
200\end{array}$ & $\begin{array}{l}230 \\
230 \\
230 \\
230 \\
230\end{array}$ & $\begin{array}{l}276 \\
304 \\
315 \\
315 \\
318\end{array}$ & $\begin{array}{l}252 \\
314 \\
213 \\
319 \\
304\end{array}$ & $\begin{array}{l}135 \\
164 \\
210 \\
173 \\
175\end{array}$ & $\begin{array}{r}57 \\
63 \\
106 \\
138 \\
85\end{array}$ & $\begin{array}{l}64 \\
61 \\
62 \\
60 \\
59\end{array}$ & $\begin{array}{l}256 \\
168 \\
129 \\
136 \\
132\end{array}$ & $\begin{array}{r}352 \\
146 \\
87 \\
297 \\
305\end{array}$ \\
\hline $\begin{array}{l}26 \\
27 \\
28 \\
29 \\
30 \\
31\end{array}$ & $\begin{array}{l}677 \\
471 \\
569 \\
613 \\
442 \\
460\end{array}$ & $\begin{array}{l}380 \\
421 \\
416 \\
342 \\
451 \\
---\end{array}$ & $\begin{array}{l}276 \\
331 \\
348 \\
337 \\
334 \\
313\end{array}$ & $\begin{array}{l}190 \\
190 \\
200 \\
200 \\
210 \\
220\end{array}$ & $\begin{array}{l}240 \\
240 \\
250 \\
--- \\
--- \\
---\end{array}$ & $\begin{array}{l}327 \\
323 \\
323 \\
324 \\
329 \\
322\end{array}$ & $\begin{array}{l}298 \\
276 \\
260 \\
253 \\
219 \\
---\end{array}$ & $\begin{array}{r}181 \\
205 \\
161 \\
187 \\
161 \\
65\end{array}$ & $\begin{array}{r}74 \\
73 \\
75 \\
74 \\
73 \\
---\end{array}$ & $\begin{array}{l}63 \\
53 \\
50 \\
48 \\
48 \\
39\end{array}$ & $\begin{array}{r}90 \\
131 \\
138 \\
140 \\
193 \\
160\end{array}$ & $\begin{array}{r}203 \\
88 \\
170 \\
203 \\
196 \\
-\end{array}$ \\
\hline $\begin{array}{l}\text { TOTAL } \\
\text { MEAN } \\
\text { MAX } \\
\text { MIN } \\
\text { CFSM } \\
\text { IN. }\end{array}$ & $\begin{array}{r}38366 \\
1238 \\
3190 \\
442 \\
3.17 \\
3.66\end{array}$ & $\begin{array}{r}11826 \\
394 \\
686 \\
236 \\
1.01 \\
1.13\end{array}$ & $\begin{array}{r}10726 \\
346 \\
598 \\
240 \\
.89 \\
1.02\end{array}$ & $\begin{array}{r}7859 \\
254 \\
351 \\
131 \\
.65 \\
.75\end{array}$ & $\begin{array}{l}7160 \\
256 \\
320 \\
200 \\
.66 \\
.68\end{array}$ & $\begin{array}{r}12879 \\
415 \\
840 \\
196 \\
1.06 \\
1.23\end{array}$ & $\begin{array}{r}8495 \\
283 \\
365 \\
178 \\
.73 \\
.81\end{array}$ & $\begin{array}{r}4821 \\
156 \\
252 \\
65 \\
.40 \\
.46\end{array}$ & $\begin{array}{r}3092 \\
103 \\
180 \\
57 \\
.26 \\
.29\end{array}$ & $\begin{array}{r}2090 \\
67.4 \\
141 \\
39 \\
.17 \\
.20\end{array}$ & $\begin{array}{r}3687 \\
119 \\
373 \\
13 \\
.31 \\
.35\end{array}$ & $\begin{array}{r}5812 \\
194 \\
505 \\
87 \\
.50 \\
.55\end{array}$ \\
\hline $\begin{array}{l}\text { CAL YR } \\
\text { WTR YR }\end{array}$ & $\begin{array}{l}1986 \\
1987\end{array}$ & $\begin{array}{ll}A L & 21 \\
A L & 11\end{array}$ & $\begin{array}{l}06 \\
13\end{array}$ & $\begin{array}{l}587 \\
320\end{array}$ & $\begin{array}{l}\text { MAX } \\
\text { MAX }\end{array}$ & $\begin{array}{l}\text { MIN } \\
\text { MIN }\end{array}$ & $\begin{array}{l}29 \\
13\end{array}$ & $\begin{array}{lr}M & 1.51 \\
M & .82\end{array}$ & $\begin{array}{ll}\text { IN } & 2 \\
\text { IN } 1\end{array}$ & & & \\
\hline
\end{tabular}




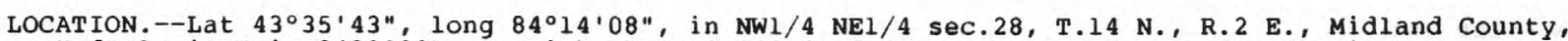
Hydrologic Unit 04080201 , on $r i g h t$ bank $2,000 \mathrm{ft}$ downstream from dam at Dow Chemical Co. powerplant in Midland, $0.7 \mathrm{mi}$ upstream from Bullock Creek, $1.4 \mathrm{mi}$ downstream from Chippewa River, and $23 \mathrm{mi}$ upstream from mouth.

DRAINAGE AREA. $--2,400 \mathrm{mi}^{2}$, approximately.

PERIOD OF RECORD.--March 1936 to current year. Gage-height records for flood seasons collected in this vicinity 1910-26, 1928, and since 1946 are contained in reports of National Weather Service.

REVISED RECORDS.--WSP 1045: 1945. WSP 1144: 1948.

GAGE.--Water-stage recorder. Datum of gage is $580.28 \mathrm{ft}$ above National Geodetic vertical Datum of 1929. Prior to sept. 30, 1955, at datum $10.00 \mathrm{ft}$ higher.

REMARKS.--Estimated daily discharges: Jan. 24 to Feb. 7. Records good except for estimated daily discharges, which are poor. Water is diverted from river a short distance upstream from station for industrial use. Small part returned to river $0.25 \mathrm{mi}$ downstream from station, remainder returned $1 \mathrm{mi}$ downstream. Extremes and daily discharges not adjusted for diversion. Prior to May 20, 1970,

discharge below 4,000 $\mathrm{ft}^{3} / \mathrm{s}$ regulated by dam 2,000 $\mathrm{ft}$ upstream from station; fixed crest dam

since. Several measurements of water temperature were made during the year. National Weather service gage-height telemeter at station.

AVERAGE DISCHARGE. - -51 years, $1,734 \mathrm{ft}^{3} / \mathrm{s}, 9.81 \mathrm{in} / \mathrm{yr}^{\mathrm{r}}$.

EXTREMES FOR PERIOD OF RECORD.--Maximum discharge, 38,700 ft3/s, Sept. 13, 1986, gage height,

$33.89 \mathrm{ft}$, from floodmarks; minimum, $39 \mathrm{ft}^{3} / \mathrm{s}$, Oct. 1,1942 ; minimum gage height, $8.92 \mathrm{ft}$, Aug.

2. 9, 1987; minimum daily discharge, $111 \mathrm{ft}^{3} / \mathrm{s}$, Aug. 21,1949 .

EXTREMES FOR CURRENT YEAR.--Peak discharges greater than base discharge of $7,000 \mathrm{ft}^{3} / \mathrm{s}$ and maximum (*):

\begin{tabular}{|c|c|c|c|c|c|c|c|}
\hline Date & Time & $\begin{array}{c}\text { Discharge } \\
\left(\mathrm{ft}^{3 / \mathrm{s}}\right)\end{array}$ & $\begin{array}{c}\text { Gage height } \\
(f t)\end{array}$ & Date & Time & $\begin{array}{c}\text { Discharge } \\
\left(\mathrm{ft}^{3} / \mathrm{s}\right)\end{array}$ & $\begin{array}{l}\text { Gage height } \\
(f t)\end{array}$ \\
\hline ct. & 1800 & $\star 19,500$ & $\star 26.29$ & oct. & 0130 & 15,800 & 23.98 \\
\hline
\end{tabular}

Minimum discharge, $164 \mathrm{ft}^{3} / \mathrm{s}$, Aug. 2; minimum gage height, $8.92 \mathrm{ft}$, Aug. 2, 9; minimum daily, $207 \mathrm{ft}^{3} / \mathrm{s}$, Aug. 2 .

DISCHARGE, IN CUBIC FEET PER SECOND, WATER YEAR OCTOBER 1986 TO SEPTEMBER 1987 MEAN VALUES

\begin{tabular}{|c|c|c|c|c|c|c|c|c|c|c|c|c|}
\hline DAY & OCT & NOV & DEC & JAN & FEB & MAR & APR & MAY & JUN & JUL & AUG & SEP \\
\hline $\begin{array}{l}1 \\
2 \\
3 \\
4 \\
5\end{array}$ & $\begin{array}{l}19200 \\
17800 \\
14200 \\
12500 \\
15200\end{array}$ & $\begin{array}{l}2660 \\
1970 \\
1970 \\
2140 \\
2150\end{array}$ & $\begin{array}{l}1790 \\
1990 \\
2180 \\
2340 \\
1960\end{array}$ & $\begin{array}{l}1100 \\
1570 \\
1290 \\
1000 \\
1520\end{array}$ & $\begin{array}{r}800 \\
1200 \\
1400 \\
1600 \\
1800\end{array}$ & $\begin{array}{l}1150 \\
3510 \\
4590 \\
4010 \\
3580\end{array}$ & $\begin{array}{l}1960 \\
1740 \\
1900 \\
1330 \\
1010\end{array}$ & $\begin{array}{r}1120 \\
849 \\
624 \\
992 \\
996\end{array}$ & $\begin{array}{l}516 \\
814 \\
730 \\
780 \\
625\end{array}$ & $\begin{array}{l}653 \\
603 \\
345 \\
256 \\
257\end{array}$ & $\begin{array}{l}241 \\
207 \\
257 \\
335 \\
330\end{array}$ & $\begin{array}{l}574 \\
670 \\
733 \\
714 \\
394\end{array}$ \\
\hline $\begin{array}{r}6 \\
7 \\
8 \\
9 \\
10\end{array}$ & $\begin{array}{r}15000 \\
11000 \\
8370 \\
7310 \\
6140\end{array}$ & $\begin{array}{l}2000 \\
1780 \\
1400 \\
1350 \\
1750\end{array}$ & $\begin{array}{l}1570 \\
1120 \\
1670 \\
2090 \\
2050\end{array}$ & $\begin{array}{l}1790 \\
1780 \\
1930 \\
1450 \\
1060\end{array}$ & $\begin{array}{r}1600 \\
840 \\
754 \\
1840 \\
1240\end{array}$ & $\begin{array}{l}3630 \\
2440 \\
2380 \\
3830 \\
3540\end{array}$ & $\begin{array}{l}1480 \\
1940 \\
1960 \\
1540 \\
1310\end{array}$ & $\begin{array}{l}799 \\
715 \\
770 \\
591 \\
563\end{array}$ & $\begin{array}{l}485 \\
409 \\
618 \\
783 \\
610\end{array}$ & $\begin{array}{l}494 \\
563 \\
390 \\
432 \\
520\end{array}$ & $\begin{array}{l}325 \\
356 \\
279 \\
242 \\
627\end{array}$ & $\begin{array}{l}420 \\
426 \\
645 \\
684 \\
782\end{array}$ \\
\hline $\begin{array}{l}11 \\
12 \\
13 \\
14 \\
15\end{array}$ & $\begin{array}{l}5530 \\
5070 \\
4540 \\
4220 \\
3880\end{array}$ & $\begin{array}{l}2180 \\
2140 \\
2060 \\
1950 \\
1500\end{array}$ & $\begin{array}{l}1620 \\
1460 \\
1110 \\
1030 \\
1450\end{array}$ & $\begin{array}{r}987 \\
1350 \\
1580 \\
1810 \\
1780\end{array}$ & $\begin{array}{r}1160 \\
1430 \\
1770 \\
1130 \\
819\end{array}$ & $\begin{array}{l}3170 \\
3080 \\
3000 \\
2930 \\
1490\end{array}$ & $\begin{array}{r}888 \\
848 \\
1390 \\
1380 \\
1470\end{array}$ & $\begin{array}{l}884 \\
815 \\
930 \\
621 \\
930\end{array}$ & $\begin{array}{l}494 \\
488 \\
423 \\
423 \\
372\end{array}$ & $\begin{array}{l}479 \\
436 \\
635 \\
542 \\
583\end{array}$ & $\begin{array}{r}822 \\
678 \\
641 \\
1110 \\
1660\end{array}$ & $\begin{array}{l}883 \\
500 \\
455 \\
599 \\
589\end{array}$ \\
\hline $\begin{array}{l}16 \\
17 \\
18 \\
19 \\
20\end{array}$ & $\begin{array}{l}3910 \\
3720 \\
3590 \\
2920 \\
2950\end{array}$ & $\begin{array}{l}1130 \\
1670 \\
2030 \\
1980 \\
1880\end{array}$ & $\begin{array}{l}1640 \\
1460 \\
1860 \\
2190 \\
1840\end{array}$ & $\begin{array}{r}1560 \\
870 \\
843 \\
1150 \\
1780\end{array}$ & $\begin{array}{r}709 \\
1310 \\
1820 \\
1570 \\
1140\end{array}$ & $\begin{array}{l}2240 \\
2650 \\
1440 \\
1760 \\
1390\end{array}$ & $\begin{array}{r}1500 \\
1820 \\
1900 \\
1410 \\
976\end{array}$ & $\begin{array}{l}583 \\
472 \\
840 \\
841 \\
857\end{array}$ & $\begin{array}{l}500 \\
616 \\
541 \\
475 \\
363\end{array}$ & $\begin{array}{l}500 \\
447 \\
347 \\
289 \\
385\end{array}$ & $\begin{array}{r}720 \\
1280 \\
1790 \\
1580 \\
981\end{array}$ & $\begin{array}{r}782 \\
1290 \\
2280 \\
2840 \\
1210\end{array}$ \\
\hline $\begin{array}{l}21 \\
22 \\
23 \\
24 \\
25\end{array}$ & $\begin{array}{l}2810 \\
2910 \\
2850 \\
2820 \\
2270\end{array}$ & $\begin{array}{l}1590 \\
1180 \\
1110 \\
1550 \\
1830\end{array}$ & $\begin{array}{l}1220 \\
1780 \\
2130 \\
2190 \\
1350\end{array}$ & $\begin{array}{r}1450 \\
1540 \\
1840 \\
900 \\
820\end{array}$ & $\begin{array}{r}691 \\
649 \\
889 \\
1080 \\
1420\end{array}$ & $\begin{array}{l}1070 \\
1030 \\
1320 \\
1510 \\
1720\end{array}$ & $\begin{array}{l}1540 \\
1650 \\
1390 \\
1640 \\
1710\end{array}$ & $\begin{array}{r}1000 \\
1440 \\
911 \\
600 \\
583\end{array}$ & $\begin{array}{l}399 \\
572 \\
639 \\
515 \\
533\end{array}$ & $\begin{array}{l}539 \\
438 \\
440 \\
442 \\
325\end{array}$ & $\begin{array}{l}873 \\
568 \\
465 \\
547 \\
573\end{array}$ & $\begin{array}{r}1550 \\
1360 \\
1050 \\
959 \\
865\end{array}$ \\
\hline $\begin{array}{l}26 \\
27 \\
28 \\
29 \\
30 \\
31\end{array}$ & $\begin{array}{l}1830 \\
2340 \\
2840 \\
2870 \\
2670 \\
2590\end{array}$ & $\begin{array}{l}2090 \\
1720 \\
1720 \\
2170 \\
1470\end{array}$ & $\begin{array}{l}1720 \\
1930 \\
1380 \\
1650 \\
1950 \\
1830\end{array}$ & $\begin{array}{r}1400 \\
1500 \\
1300 \\
1400 \\
1500 \\
820\end{array}$ & $\begin{array}{r}1600 \\
1700 \\
1080 \\
--- \\
---\end{array}$ & $\begin{array}{l}1950 \\
1880 \\
1790 \\
1330 \\
1560 \\
1980\end{array}$ & $\begin{array}{r}1460 \\
1340 \\
1270 \\
1120 \\
947\end{array}$ & $\begin{array}{l}988 \\
932 \\
838 \\
744 \\
532 \\
397\end{array}$ & $\begin{array}{l}596 \\
368 \\
288 \\
519 \\
595\end{array}$ & $\begin{array}{l}276 \\
311 \\
360 \\
313 \\
291 \\
298\end{array}$ & $\begin{array}{l}564 \\
689 \\
738 \\
473 \\
437 \\
688\end{array}$ & $\begin{array}{l}636 \\
523 \\
706 \\
859 \\
999\end{array}$ \\
\hline $\begin{array}{l}\text { TOTAL } \\
\text { MEAN } \\
\text { MAX } \\
\text { MIN } \\
\text { MEAN+ } \\
\text { CFSM+ } \\
\text { IN }+\end{array}$ & $\begin{array}{r}195850 \\
6318 \\
19200 \\
1830 \\
6335 \\
2.64 \\
3.04\end{array}$ & $\begin{array}{r}54120 \\
1804 \\
2660 \\
1110 \\
1815 \\
.76 \\
.84\end{array}$ & $\begin{array}{r}53550 \\
1727 \\
2340 \\
1030 \\
1738 \\
.72 \\
.83\end{array}$ & $\begin{array}{r}42670 \\
1376 \\
1930 \\
820 \\
1390 \\
.58 \\
.67\end{array}$ & $\begin{array}{r}35041 \\
1251 \\
1840 \\
649 \\
1268 \\
.53 \\
.55\end{array}$ & $\begin{array}{r}72950 \\
2353 \\
4590 \\
1030 \\
2368 \\
.99 \\
1.14\end{array}$ & $\begin{array}{r}43819 \\
1461 \\
1960 \\
848 \\
1475 \\
.61 \\
.69\end{array}$ & $\begin{array}{r}24757 \\
799 \\
1440 \\
397 \\
814 \\
.34 \\
.39\end{array}$ & $\begin{array}{r}16089 \\
536 \\
814 \\
288 \\
549 \\
.23 \\
.26\end{array}$ & $\begin{array}{r}13189 \\
425 \\
653 \\
256 \\
430 \\
.18 \\
.21\end{array}$ & $\begin{array}{r}21076 \\
680 \\
1790 \\
207 \\
688 \\
.29 \\
.33\end{array}$ & $\begin{array}{r}26977 \\
899 \\
2840 \\
394 \\
909 \\
.38 \\
.42\end{array}$ \\
\hline $\begin{array}{l}\text { CAL YR } \\
\text { WTR YR }\end{array}$ & $\begin{array}{l}1986 \\
1987\end{array}$ & AL & $\begin{array}{l}421 \\
088\end{array}$ & $\begin{array}{ll}\text { EAN } & 3160 \\
\text { EAN } & 1644\end{array}$ & $\begin{array}{l}\text { MAX } \\
\text { MAX }\end{array}$ & $\begin{array}{l}36200 \\
19200\end{array}$ & $\begin{array}{l}\text { MIN } 348 \\
\text { MIN } 207\end{array}$ & $\begin{array}{l}\text { MEAN+ } \\
\text { MEAN+ }\end{array}$ & $\begin{array}{l}3173 \\
1656\end{array}$ & $\begin{array}{l}\text { CFSM+ } \\
\text { CFSM+ }\end{array}$ & $\begin{aligned} 1.32 & \text { IN }+ \\
.69 & \text { IN }\end{aligned}$ & $\begin{array}{r}17.92 \\
9.37\end{array}$ \\
\hline
\end{tabular}

+ Adjusted for diversion; records furnished by Dow Chemical Co. 
04156100 TITTABAWASSEE RIVER NEAR MIDLAND, MI

(National stream quality accounting network station)

LOCATION. --Lat $43^{\circ} 34^{\prime} 07^{\prime \prime}$, long $84^{\circ} 11^{\prime} 37^{\prime \prime}$, in SWl/4 SEl/4 sec.35, T.14 N., R.2 E., Midland County, Hydrologic Unit 04080201 ; at bridge on Gordonville Road, $3.0 \mathrm{mi}$ downstream from gaging station 04156000 , and $20 \mathrm{mi}$ upstream from mouth.

DRAINAGE AREA. $--2,450 \mathrm{mi}^{2}$.

PERIOD OF RECORD.--October 1986 to August 1987.

REMARKS.--Cross-sectional samples were collected at or near bridge. Water-discharge measurements were made at time of sampling. All flow except for high-water is regulated by powerplant at Sanford.

\begin{tabular}{|c|c|c|c|c|c|c|c|c|c|c|}
\hline DATE & TIME & $\begin{array}{c}\text { STREAM- } \\
\text { FLOW, } \\
\text { INSTAN- } \\
\text { TANEOUS } \\
\text { (CFS) }\end{array}$ & $\begin{array}{l}\text { SPE- } \\
\text { CIFIC } \\
\text { CON- } \\
\text { DUCT- } \\
\text { ANCE } \\
\text { (US/CM) }\end{array}$ & $\begin{array}{c}\text { PH } \\
\text { ( STAND- } \\
\text { ARD } \\
\text { UNITS) }\end{array}$ & $\begin{array}{l}\text { TEMPER- } \\
\text { ATURE } \\
\text { (DEG C) }\end{array}$ & $\begin{array}{l}\text { TUR- } \\
\text { BID- } \\
\text { ITY } \\
\text { (NTU) }\end{array}$ & $\begin{array}{c}\text { OXYGEN, } \\
\text { DIS- } \\
\text { SOLVED } \\
\text { (MG/L) }\end{array}$ & $\begin{array}{c}\text { OXYGEN, } \\
\text { DIS- } \\
\text { SOLVED } \\
\text { (PER- } \\
\text { CENT } \\
\text { SATUR- } \\
\text { ATION) }\end{array}$ & $\begin{array}{l}\text { COLI- } \\
\text { FORM, } \\
\text { FECAL, } \\
0.7 \\
\text { UM-MF } \\
\text { (COLS. } \\
100 \mathrm{ML} \text { ) }\end{array}$ & $\begin{array}{c}\text { STREP- } \\
\text { TOCOCCI } \\
\text { FECAL, } \\
\text { KF AGAR } \\
\text { (COLS. } \\
\text { PER } \\
100 \mathrm{ML} \text { ) }\end{array}$ \\
\hline OCT & & & & & & & & & & \\
\hline $\begin{array}{l}07 \ldots \\
\text { DEC }\end{array}$ & 1430 & 9590 & 389 & 8.00 & 10.5 & 4.5 & 8.7 & 79 & $\mathrm{~K} 870$ & 90 \\
\hline FEB & 1430 & 2150 & 681 & 8.33 & 2.0 & 2.1 & 13.5 & 100 & E12000 & 120 \\
\hline $\mathrm{APR}^{18 \ldots}$ & 1400 & 1600 & 844 & 8.29 & 0.5 & 1.2 & 14.9 & 105 & 970 & 490 \\
\hline$\underset{\text { JUN }}{07 \cdots}$ & 1430 & 2560 & 637 & 8.36 & 9.0 & 2.5 & 12.4 & 110 & 210 & 87 \\
\hline${ }_{\text {AUG }}^{16} \ldots$ & 1200 & 439 & 940 & 8.45 & 26.0 & 2.9 & 8.0 & 101 & 130 & K31 \\
\hline $04 \ldots$ & 1330 & 230 & 661 & 8.34 & 28.5 & 12 & 9.2 & 121 & 1500 & K35 \\
\hline DATE & $\begin{array}{l}\text { HARD- } \\
\text { NESS } \\
\text { (MG/L } \\
\text { AS } \\
\text { CACO3) }\end{array}$ & $\begin{array}{l}\text { HARD- } \\
\text { NESS } \\
\text { NONCARB } \\
\text { WH WAT } \\
\text { TOT FLD } \\
\text { MG/L AS } \\
\text { CACO3 }\end{array}$ & $\begin{array}{l}\text { CALCIUM } \\
\text { DIS- } \\
\text { SOLVED } \\
\text { (MG/L } \\
\text { AS CA) }\end{array}$ & $\begin{array}{l}\text { MAGNE- } \\
\text { SIUM, } \\
\text { DIS- } \\
\text { SOLVED } \\
\text { (MG/L } \\
\text { AS MG) }\end{array}$ & $\begin{array}{l}\text { SODIUM, } \\
\text { DIS- } \\
\text { SOLVED } \\
\text { (MG/L } \\
\text { AS NA) }\end{array}$ & $\begin{array}{l}\text { PERCENT } \\
\text { SODIUM }\end{array}$ & $\begin{array}{c}\text { SODIUM } \\
\text { AD- } \\
\text { SORP- } \\
\text { TION } \\
\text { RATIO }\end{array}$ & $\begin{array}{l}\text { POTAS- } \\
\text { SIUM, } \\
\text { DIS- } \\
\text { SOLVED } \\
\text { (MG/L } \\
\text { AS K) }\end{array}$ & $\begin{array}{l}\text { BICAR- } \\
\text { BONATE } \\
\text { WH WAT } \\
\text { TOTAL } \\
\text { FIELD } \\
\text { MG } / L \text { AS } \\
\text { HCO3 }\end{array}$ & $\begin{array}{c}\text { CAR- } \\
\text { BONATE } \\
\text { WH WAT } \\
\text { TOTAL } \\
\text { FIELD } \\
\text { MG } / L \text { AS } \\
\mathrm{CO}^{3}\end{array}$ \\
\hline \multicolumn{11}{|l|}{ OCT } \\
\hline${ }_{\mathrm{DEC}}^{07} \cdots$ & 180 & 43 & 52 & 12 & 12 & 12 & 0.4 & 3.5 & 170 & 0 \\
\hline$\underset{\text { FEB }}{02} \ldots$ & 250 & 64 & 69 & 18 & 40 & 26 & 1 & 2.3 & 220 & 0 \\
\hline$\underset{A P R}{18 \ldots}$ & 280 & 80 & 78 & 20 & 51 & 28 & 1 & 2.6 & 240 & 0 \\
\hline$\underset{\text { JUN }}{07 \cdots}$ & 240 & 80 & 67 & 18 & 35 & 24 & 1 & 2.2 & 200 & 1 \\
\hline$\underset{A U G}{16} \ldots$ & 280 & 120 & 78 & 21 & 82 & 38 & 2 & 3.7 & 200 & 1 \\
\hline $04 \ldots$ & 220 & 61 & 54 & 20 & 46 & 31 & 1 & 2.2 & 190 & 1 \\
\hline DATE & $\begin{array}{l}\text { ALKA- } \\
\text { LINITY } \\
\text { WH WAT } \\
\text { TOTAL } \\
\text { FIELD } \\
\text { MG/L AS } \\
\text { CACO3 }\end{array}$ & $\begin{array}{c}\text { CARBON } \\
\text { DIOXIDE } \\
\text { DIS- } \\
\text { SOLVED } \\
\text { (MG/L } \\
\text { AS CO2) }\end{array}$ & $\begin{array}{l}\text { SULFATE } \\
\text { DIS- } \\
\text { SOLVED } \\
\text { (MG/L } \\
\text { AS SO4) }\end{array}$ & $\begin{array}{l}\text { CHLO- } \\
\text { RIDE, } \\
\text { DIS- } \\
\text { SOLVED } \\
\text { (MG/L } \\
\text { AS CL) }\end{array}$ & $\begin{array}{l}\text { FLUO- } \\
\text { RIDE, } \\
\text { DIS- } \\
\text { SOLVED } \\
\text { (MG/L } \\
\text { AS E) }\end{array}$ & $\begin{array}{l}\text { SILICA, } \\
\text { DIS- } \\
\text { SOLVED } \\
\text { (MG/L } \\
\text { AS } \\
\text { SIO2) }\end{array}$ & $\begin{array}{l}\text { SOLIDS, } \\
\text { RESIDUE } \\
\text { AT } 180 \\
\text { DEG. C } \\
\text { DIS- } \\
\text { SOLVED } \\
\text { (MG/L) }\end{array}$ & $\begin{array}{l}\text { SOL IDS, } \\
\text { SUM OF } \\
\text { CONSTI- } \\
\text { TUENTS, } \\
\text { DIS- } \\
\text { SOLVED } \\
\text { (MG/L) }\end{array}$ & $\begin{array}{c}\text { SOLIDS, } \\
\text { DIS- } \\
\text { SOLVED } \\
\text { (TONS } \\
\text { PER } \\
\text { AC-FT) }\end{array}$ & $\begin{array}{c}\text { SOLIDS, } \\
\text { DIS- } \\
\text { SOLVED } \\
\text { (TONS } \\
\text { PER } \\
\text { DAY) }\end{array}$ \\
\hline \multicolumn{11}{|l|}{ OCT } \\
\hline${ }_{\mathrm{DEC}}^{07 \cdots}$ & 137 & 2.7 & 24 & 23 & 0.2 & 9.5 & 276 & 220 & 0.38 & 7150 \\
\hline$\underset{\text { FEB }}{02} \cdots$ & 183 & 1.7 & 35 & 75 & 0.2 & 7.6 & 380 & 360 & 0.52 & 2210 \\
\hline$\underset{A P R}{18 \ldots}$ & 197 & 2.0 & 41 & 110 & 0.2 & 8.8 & 437 & 430 & 0.59 & 1890 \\
\hline$\underset{\text { JUN }}{07} \ldots$ & 162 & 1.4 & 34 & 74 & 0.2 & 4.2 & 356 & 330 & 0.48 & 2460 \\
\hline${ }_{\text {AUG }}^{16} \cdots$ & 163 & 1.1 & 50 & 180 & 0.2 & 5.6 & 562 & 520 & 0.76 & 666 \\
\hline $04 \ldots$ & 157 & 1.4 & 47 & 79 & 0.3 & 5.5 & 341 & 350 & 0.46 & 212 \\
\hline
\end{tabular}


04156100 TITTABAWASSEE RIVER NEAR MIDLAND, MI--Cont inued WATER QUALITY DATA, WATER YEAR OCTOBER 1986 TO SEPTEMBER 1987

\begin{tabular}{|c|c|c|c|c|c|c|c|c|c|c|}
\hline DATE & $\begin{array}{c}\text { NITRO- } \\
\text { GEN, } \\
\text { NITRITE } \\
\text { DIS- } \\
\text { SOLVED } \\
\text { (MG/L } \\
\text { AS N) }\end{array}$ & $\begin{array}{c}\text { NITRO- } \\
\text { GEN, } \\
\text { NO2+NO3 } \\
\text { DIS- } \\
\text { SOLVED } \\
\text { (MG/L } \\
\text { AS N) }\end{array}$ & $\begin{array}{c}\text { NITRO- } \\
\text { GEN, } \\
\text { AMMONIA } \\
\text { TOTAL } \\
\text { (MG/L } \\
\text { AS N) }\end{array}$ & $\begin{array}{c}\text { NITRO- } \\
\text { GEN, } \\
\text { AMMONIA } \\
\text { DIS- } \\
\text { SOLVED } \\
\text { (MG/L } \\
\text { AS N) }\end{array}$ & $\begin{array}{l}\text { NITRO- } \\
\text { GEN, } \\
\text { ORGANIC } \\
\text { TOTAL } \\
\text { (MG/L } \\
\text { AS N) }\end{array}$ & $\begin{array}{c}\text { NITRO- } \\
\text { GEN,AM- } \\
\text { MONIA + } \\
\text { ORGANIC } \\
\text { TOTAL } \\
\text { (MG/L } \\
\text { AS N) }\end{array}$ & $\begin{array}{c}\text { PHOS- } \\
\text { PHORUS, } \\
\text { TOTAL } \\
\text { (MG/L } \\
\text { AS P) }\end{array}$ & $\begin{array}{c}\text { PHOS- } \\
\text { PHORUS, } \\
\text { DIS- } \\
\text { SOLVED } \\
\text { (MG/L } \\
\text { AS P) }\end{array}$ & $\begin{array}{l}\text { PHOS- } \\
\text { PHORUS, } \\
\text { ORTHO, } \\
\text { DIS- } \\
\text { SOLVED } \\
\text { (MG/L } \\
\text { AS P) }\end{array}$ & $\begin{array}{l}\text { ALUM- } \\
\text { INUM, } \\
\text { DIS- } \\
\text { SOLVED } \\
\text { (UG/L } \\
\text { AS AL) }\end{array}$ \\
\hline . & 0.01 & 0.65 & 0.05 & 0.04 & 1.5 & 1.6 & 0.09 & 0.05 & 0.05 & 50 \\
\hline & $<0.01$ & 0.58 & 0.20 & 0.19 & 0.8 & 1.0 & 0.03 & 0.02 & 0.01 & $<10$ \\
\hline & $<0.01$ & 0.68 & 0.21 & 0.21 & 1.1 & 1.3 & 0.03 & 0.03 & 0.03 & -- \\
\hline$\cdots$ & $<0.01$ & 0.38 & 0.11 & 0.08 & 0.49 & 0.6 & 0.05 & 0.01 & $<0.01$ & 20 \\
\hline 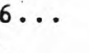 & 0.02 & 0.13 & 0.48 & 0.51 & 1.1 & 1.6 & 0.08 & 0.02 & $<0.01$ & -- \\
\hline & 0.01 & 0.12 & -- & 0.50 & 1.2 & 1.6 & 0.08 & 0.02 & 0.01 & 20 \\
\hline
\end{tabular}

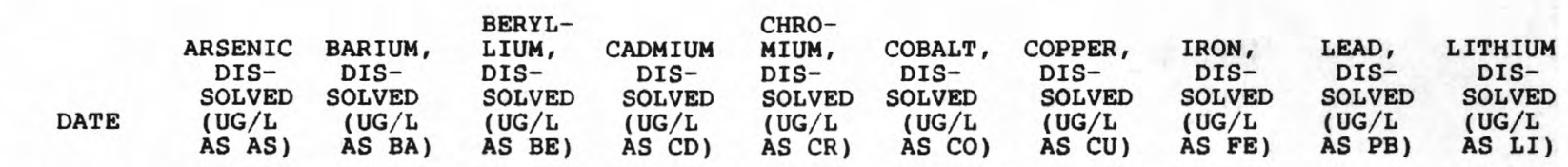

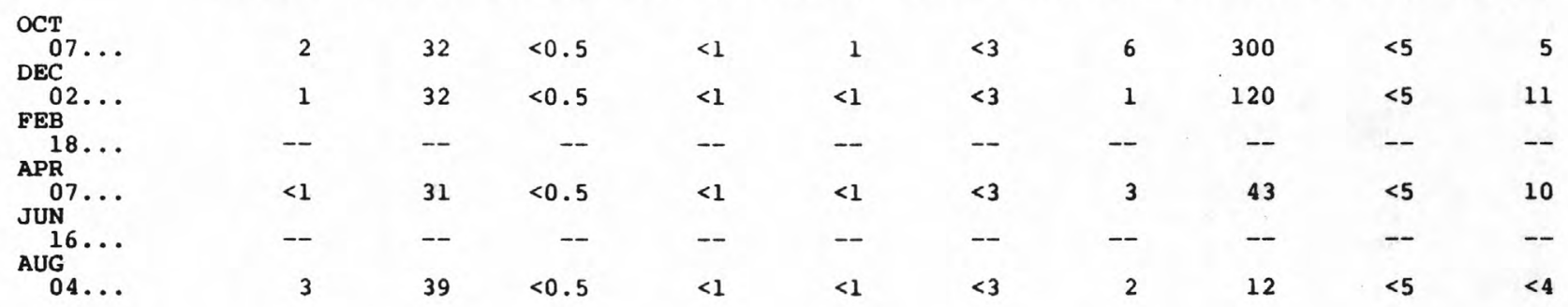

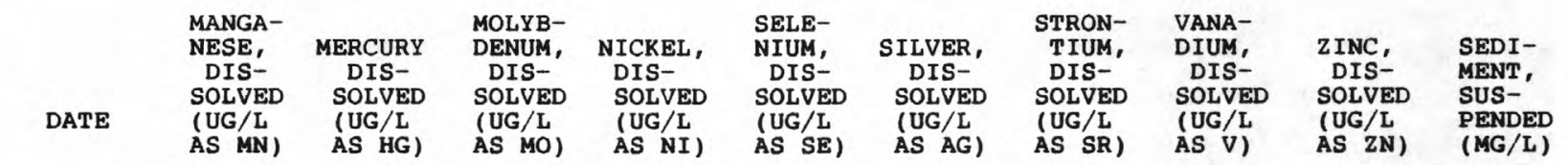

\begin{tabular}{|c|c|c|c|c|c|c|c|c|c|c|}
\hline \multicolumn{11}{|l|}{ ОСт } \\
\hline DEC $07 .$. & 22 & 0.2 & $<10$ & 2 & $<1$ & $<1$ & 180 & $<6$ & 260 & 19 \\
\hline $02 \ldots$ & 18 & 0.3 & $<10$ & 1 & $<1$ & $<1$ & 280 & $<6$ & 6 & 6 \\
\hline${ }_{A P R}^{18} \ldots$ & -- & -- & -- & -- & -- & -- & -- & -- & -- & 13 \\
\hline JUN $07 .$. & 19 & $<0.1$ & $<10$ & 1 & $<1$ & $<1$ & 360 & $<6$ & 3 & 1 \\
\hline${ }_{\text {AUG }}^{16} \ldots$ & -- & -- & -- & -- & -- & -- & -- & -- & -- & 18 \\
\hline $04 \ldots$ & 8 & $<0.1$ & $<10$ & $<1$ & $<1$ & $<1$ & 390 & $<6$ & 30 & 47 \\
\hline
\end{tabular}




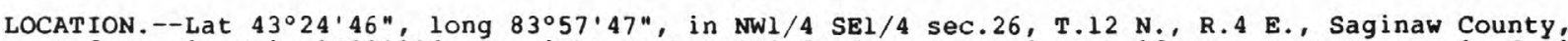
Hydrologic Unit 04080206 , on right bank $1,000 \mathrm{ft}$ downstream from bridge on Rust Avenue in Saginaw, 1.9 mi downstream from Tittabawasee River, and $20.3 \mathrm{mi}$ upstream from mouth.

DRAINAGE AREA. $--6,060 \mathrm{mi}^{2}$, approximately.

PERIOD OF RECORD.--1904, 1908-9, 1912-13, 1916, 1918-19, 1929-30, and 1942 (flood discharge for certain

periods only) in WSP 1084; December 1942 to current year (high-water periods only): no high water 1944, $1949,1953,1955,1958,1961,1963,1964,1966$. Gage-height records for flood seasons collected in this vicinity 1910-20, and for entire years since 1921 are contained in reports of National Weather Service.

GAGE,--Water-stage recorder. Datum of gage is $565.11 \mathrm{ft}$. International Great Lakes datum. Prior to Oct. 1 , 1972, nonrecording gage at site $1.9 \mathrm{mi}$ downstream at same datum. Auxiliary water-stage recorder on right bank near Aplin Beach, $19.9 \mathrm{mi}$ downstream.

REMARKS.--No estimated daily discharges. Water-discharge records fair; only daily discharges greater than $10,000 \mathrm{ft}^{3} / \mathrm{s}$ are published. Considerable diversion through metropolitan area of Saginaw. National weather Service gage-height telemeter at station.

COOPERATION. --Auxiliary gage-height record furnished by National Oceanic and Atmospheric Administration.

EXTREMES FOR PERIOD OF RECORD.--Maximum discharge, $68,000 \mathrm{ft}^{3} / \mathrm{s}$, Mar. 30, 1904, gage height, 24.9 $f t$, site then in use.

EXTREMES FOR CURRENT YEAR.--Maximum daily discharge, 47,000 ft $3 / \mathrm{s}$, Oct. 3; maximum daily gage height, $22.76 \mathrm{ft}$, Oct. 3 .

REVISIONS.--Revised daily discharges, in cubic feet per second, for period Sept. 17-30, 1986 are given below. These figures supercede those published in the report MI-86-1.

$\begin{array}{rrrrr}\text { Sept. } 17--45,800 & \text { Sept. } 21--27,400 & \text { Sept. } 25--34,300 & \text { Sept. } 29--33,100 \\ 18--39,500 & 22--25,900 & 26-33,900 & 30-3,500 \\ 19--34,500 & 23--27,100 & 27-33,600 & \\ 20--31,700 & 24--32,500 & 28--33,500 & \end{array}$

DISCHARGE, IN CUBIC FEET PER SECOND, WATER YEAR OCTOBER 1986 TO SEPTEMBER 1987 MEÁN VALUES

\begin{tabular}{|c|c|c|c|c|c|c|c|c|c|c|c|c|}
\hline DAY & OCT & NOV & DEC & JAN & FEB & MAR & APR & MAY & JUN & JUL & AUG & SEP \\
\hline $\begin{array}{l}1 \\
2 \\
3 \\
4 \\
5\end{array}$ & $\begin{array}{l}36400 \\
43200 \\
47000 \\
45400 \\
46500\end{array}$ & & $\begin{array}{r}10700 \\
10100 \\
11200 \\
11600\end{array}$ & & & $\begin{array}{l}11000 \\
12400 \\
16600 \\
18600 \\
17300\end{array}$ & $\begin{array}{r}10400 \\
- \\
-- \\
14700\end{array}$ & & & & & $\begin{array}{l}--- \\
--- \\
--- \\
---\end{array}$ \\
\hline $\begin{array}{r}6 \\
7 \\
8 \\
9 \\
10\end{array}$ & $\begin{array}{l}43700 \\
44200 \\
37700 \\
33500 \\
32600\end{array}$ & & $\begin{array}{r}--- \\
--- \\
11600 \\
10700\end{array}$ & & & $\begin{array}{r}15600 \\
14200 \\
24000 \\
12500\end{array}$ & $\begin{array}{l}14800 \\
14000 \\
14500 \\
12500 \\
10600\end{array}$ & & & & & $\begin{array}{l}--- \\
--- \\
--- \\
--- \\
---\end{array}$ \\
\hline $\begin{array}{l}11 \\
12 \\
13 \\
14 \\
15\end{array}$ & $\begin{array}{l}29200 \\
26000 \\
21000 \\
20200 \\
15200\end{array}$ & & $\begin{array}{r}12200 \\
--- \\
-- \\
- \\
--\end{array}$ & & & $\begin{array}{r}13400 \\
13300 \\
11700 \\
12300 \\
\end{array}$ & $\begin{array}{r}10400 \\
10500\end{array}$ & & & & & $\begin{array}{l}--- \\
--- \\
--- \\
---\end{array}$ \\
\hline $\begin{array}{l}16 \\
17 \\
18 \\
19 \\
20\end{array}$ & $\begin{array}{l}14300 \\
13600 \\
13600 \\
12400 \\
10800\end{array}$ & & $\begin{array}{l}--- \\
--- \\
--- \\
---\end{array}$ & & & $\begin{array}{r}10400 \\
10900 \\
10500 \\
\end{array}$ & $\begin{array}{r}10100 \\
--- \\
--- \\
--\end{array}$ & & & & & 11200 \\
\hline $\begin{array}{l}21 \\
22 \\
23 \\
24 \\
25\end{array}$ & $\begin{array}{r}10300 \\
10500 \\
---\end{array}$ & & $\begin{array}{l}--- \\
--- \\
--- \\
---\end{array}$ & & & $\begin{array}{l}--- \\
--- \\
--- \\
--- \\
---\end{array}$ & $\begin{array}{r}12300 \\
11100 \\
---\end{array}$ & & & & & $\begin{array}{l}--- \\
--- \\
--- \\
--- \\
---\end{array}$ \\
\hline $\begin{array}{l}26 \\
27 \\
28 \\
29 \\
30 \\
31\end{array}$ & $\begin{array}{r}--- \\
---- \\
10000 \\
10600\end{array}$ & & $\begin{array}{l}--- \\
--- \\
--- \\
--- \\
--- \\
---\end{array}$ & & & 10300 & $\begin{array}{l}--- \\
--- \\
--- \\
--- \\
--- \\
---\end{array}$ & & & & & $\begin{array}{l}--- \\
--- \\
--- \\
--- \\
--- \\
---\end{array}$ \\
\hline
\end{tabular}


04159010 PIGEON RIVER NEAR CASEVILLE, MI

(National stream quality accounting network station)

LOCATION.--Lat $43^{\circ} 56^{\prime} 22^{\prime \prime}$, long $83^{\circ} 14^{\prime} 30^{\prime \prime}$, in SWl/4 NW1/4 sec.31, T.18 N., R.11 E., Huron County,

Hydrologic Unit 04080103 , on left bank at upstream side of kinde Road, $1.5 \mathrm{mi}$ east of Caseville, and $3.1 \mathrm{mi}$ upstream from mouth.

DRAINAGE AREA. $--125 \mathrm{mi}^{2}$.

\section{WATER-DISCHARGE RECORDS}

PERIOD OF RECORD.--October 1986 to September 1987.

GAGE.--Nonrecording gage october 1 to June 10. Water-stage recorder June 11 to September 30 . Datum of gage $578.43 \mathrm{ft}$ above National Geodetic Vertical Datum of 1929.

REMARKS. --Estimated daily discharges: Oct. 1-8, Nov. 5, 10, 11, 14, 18-20, 25-29, Dec. 5-14, 21-25, Dec. 28 to Feb. 25, Mar. 4-7, 11, 16, 20-25, 27, 28, Apr. 11, 17, 20-26, May 2, 3, 6-11, 15, 19, 21, 22, 24, May 30 to June 10. Water discharge records poor Oct. 1 to June 10 , records good June 11 to Sept. 30. Some regulation at low flows.

EXTREMES OUTSIDE PERIOD OF RECORD.--Flood in September 1986 reached a stage of 18.2 ft, present datum, from floodmarks, discharge $2,900 \mathrm{ft} 3 / \mathrm{s}$ from indirect computation of discharge.

EXTREMES FOR CURRENT YEAR.--Maximum daily discharge, $1,800 \mathrm{ft} 3 / \mathrm{s}$, Oct. 1; maximum independent discharge observed, 1,200 ft $3 / \mathrm{s}$ Mar. 3, but may have been greater during period of no gage-height record Mar. 4-7; no flow July 12 to Aug. 1 , Aug. 3-8, Sept. 8, 10 .

DISCHARGE, IN CUBIC FEET PER SECOND, WATER YEAR OCTOBER 1986 TO SEPTEMBER 1987 MEAN VALUES

\begin{tabular}{|c|c|c|c|c|c|c|c|c|c|c|c|c|}
\hline DAY & OCT & NOV & DEC & JAN & FEB & MAR & APR & MAY & JUN & JUL & AUG & SEP \\
\hline $\begin{array}{l}1 \\
2 \\
3 \\
4 \\
5\end{array}$ & $\begin{array}{r}1800 \\
1600 \\
1300 \\
900 \\
1100\end{array}$ & $\begin{array}{l}59 \\
52 \\
52 \\
50 \\
47\end{array}$ & $\begin{array}{r}39 \\
34 \\
50 \\
134 \\
120\end{array}$ & $\begin{array}{l}68 \\
64 \\
60 \\
56 \\
53\end{array}$ & $\begin{array}{l}29 \\
29 \\
30 \\
32 \\
34\end{array}$ & $\begin{array}{r}528 \\
829 \\
1140 \\
1200 \\
500\end{array}$ & $\begin{array}{l}63 \\
47 \\
48 \\
54 \\
54\end{array}$ & $\begin{array}{l}31 \\
26 \\
23 \\
22 \\
26\end{array}$ & $\begin{array}{l}20 \\
22 \\
30 \\
66 \\
66\end{array}$ & $\begin{array}{l}.94 \\
.68 \\
.48 \\
.36 \\
.66\end{array}$ & $\begin{array}{l}.00 \\
.07 \\
.00 \\
.00 \\
.00\end{array}$ & $\begin{array}{l}.21 \\
.24 \\
.73 \\
.64 \\
.26\end{array}$ \\
\hline $\begin{array}{r}6 \\
7 \\
8 \\
9 \\
10\end{array}$ & $\begin{array}{l}800 \\
500 \\
300 \\
239 \\
189\end{array}$ & $\begin{array}{l}44 \\
34 \\
30 \\
26 \\
24\end{array}$ & $\begin{array}{r}100 \\
88 \\
78 \\
70 \\
60\end{array}$ & $\begin{array}{l}51 \\
49 \\
47 \\
45 \\
44\end{array}$ & $\begin{array}{l}35 \\
36 \\
37 \\
37 \\
37\end{array}$ & $\begin{array}{l}650 \\
800 \\
539 \\
454 \\
280\end{array}$ & $\begin{array}{r}139 \\
236 \\
256 \\
198 \\
90\end{array}$ & $\begin{array}{l}32 \\
34 \\
31 \\
27 \\
23\end{array}$ & $\begin{array}{l}62 \\
35 \\
20 \\
10 \\
6.0\end{array}$ & $\begin{array}{l}.77 \\
.71 \\
.54 \\
.33 \\
.20\end{array}$ & $\begin{array}{r}.00 \\
.00 \\
.00 \\
13^{4.4}\end{array}$ & $\begin{array}{l}.19 \\
.02 \\
.00 \\
.09 \\
.00\end{array}$ \\
\hline $\begin{array}{l}11 \\
12 \\
13 \\
14 \\
15\end{array}$ & $\begin{array}{l}165 \\
147 \\
132 \\
145 \\
173\end{array}$ & $\begin{array}{l}23 \\
23 \\
22 \\
21 \\
20\end{array}$ & $\begin{array}{l}52 \\
45 \\
40 \\
36 \\
48\end{array}$ & $\begin{array}{l}43 \\
44 \\
46 \\
49 \\
54\end{array}$ & $\begin{array}{l}37 \\
36 \\
34 \\
31 \\
28\end{array}$ & $\begin{array}{l}190 \\
165 \\
148 \\
142 \\
136\end{array}$ & $\begin{array}{r}54 \\
126 \\
101 \\
105 \\
170\end{array}$ & $\begin{array}{l}20 \\
17 \\
14 \\
13 \\
13\end{array}$ & $\begin{array}{l}4.0 \\
3.1 \\
3.8 \\
5.3 \\
4.9\end{array}$ & $\begin{array}{l}.07 \\
.00 \\
.00 \\
.00 \\
.00\end{array}$ & $\begin{array}{l}17 \\
11 \\
6.1 \\
4.8 \\
26\end{array}$ & $\begin{array}{l}2.9 \\
14 \\
23 \\
69 \\
52\end{array}$ \\
\hline $\begin{array}{l}16 \\
17 \\
18 \\
19 \\
20\end{array}$ & $\begin{array}{l}199 \\
167 \\
137 \\
117 \\
105\end{array}$ & $\begin{array}{l}22 \\
19 \\
19 \\
19 \\
18\end{array}$ & $\begin{array}{r}50 \\
48 \\
76 \\
126 \\
150\end{array}$ & $\begin{array}{l}60 \\
50 \\
40 \\
32 \\
28\end{array}$ & $\begin{array}{l}25 \\
23 \\
22 \\
21 \\
22\end{array}$ & $\begin{array}{r}120 \\
112 \\
84 \\
52 \\
48\end{array}$ & $\begin{array}{l}232 \\
190 \\
149 \\
124 \\
105\end{array}$ & $\begin{array}{l}14 \\
13 \\
11 \\
11 \\
11\end{array}$ & $\begin{array}{l}4.3 \\
3.9 \\
3.2 \\
2.7 \\
2.2\end{array}$ & $\begin{array}{l}.00 \\
.00 \\
.00 \\
.00 \\
.00\end{array}$ & $\begin{array}{l}36 \\
20 \\
11 \\
7.4 \\
5.1\end{array}$ & $\begin{array}{r}23 \\
18 \\
52 \\
171 \\
276\end{array}$ \\
\hline $\begin{array}{l}21 \\
22 \\
23 \\
24 \\
25\end{array}$ & $\begin{array}{r}100 \\
108 \\
111 \\
115 \\
96\end{array}$ & $\begin{array}{l}18 \\
24 \\
27 \\
27 \\
30\end{array}$ & $\begin{array}{r}110 \\
90 \\
80 \\
72 \\
90\end{array}$ & $\begin{array}{l}25 \\
23 \\
22 \\
22 \\
23\end{array}$ & $\begin{array}{l}24 \\
30 \\
40 \\
50 \\
65\end{array}$ & $\begin{array}{l}45 \\
43 \\
42 \\
42 \\
44\end{array}$ & $\begin{array}{l}90 \\
80 \\
70 \\
60 \\
50\end{array}$ & $\begin{array}{l}13 \\
14 \\
12 \\
12 \\
17\end{array}$ & $\begin{array}{l}1.5 \\
1.4 \\
1.8 \\
2.9 \\
4.4\end{array}$ & $\begin{array}{l}.00 \\
.00 \\
.00 \\
.00 \\
.00\end{array}$ & $\begin{array}{l}3.6 \\
2.6 \\
2.0 \\
1.5 \\
1.2\end{array}$ & $\begin{array}{r}168 \\
109 \\
78 \\
58 \\
45\end{array}$ \\
\hline $\begin{array}{l}26 \\
27 \\
28 \\
29 \\
30 \\
31\end{array}$ & $\begin{array}{l}91 \\
80 \\
93 \\
93 \\
84 \\
80\end{array}$ & $\begin{array}{r}40 \\
60 \\
90 \\
65 \\
39 \\
---\end{array}$ & $\begin{array}{r}126 \\
130 \\
110 \\
92 \\
82 \\
74\end{array}$ & $\begin{array}{l}24 \\
26 \\
29 \\
32 \\
32 \\
30\end{array}$ & $\begin{array}{r}83 \\
103 \\
186 \\
--- \\
--- \\
---\end{array}$ & $\begin{array}{l}50 \\
56 \\
52 \\
47 \\
52 \\
63\end{array}$ & $\begin{array}{r}43 \\
36 \\
38 \\
38 \\
40 \\
---\end{array}$ & $\begin{array}{l}16 \\
16 \\
16 \\
16 \\
15 \\
16\end{array}$ & $\begin{array}{l}4.1 \\
3.6 \\
2.4 \\
1.6 \\
1.4 \\
---\end{array}$ & $\begin{array}{l}.00 \\
.00 \\
.00 \\
.00 \\
.00 \\
.00\end{array}$ & $\begin{array}{l}.97 \\
1.0 \\
1.0 \\
1.1 \\
.92 \\
.64\end{array}$ & $\begin{array}{l}36 \\
29 \\
25 \\
25 \\
43\end{array}$ \\
\hline $\begin{array}{l}\text { TOTAL } \\
\text { MEAN } \\
\text { MAX } \\
\text { MIN } \\
\text { CFSM } \\
\text { IN. }\end{array}$ & $\begin{array}{r}11266 \\
363 \\
1800 \\
80 \\
2.90 \\
3.35\end{array}$ & $\begin{array}{r}1044 \\
34.8 \\
90 \\
18 \\
.28 \\
.31\end{array}$ & $\begin{array}{r}2500 \\
80.6 \\
150 \\
34 \\
.65 \\
.74\end{array}$ & $\begin{array}{r}1271 \\
41.0 \\
68 \\
22 \\
.33 \\
.38\end{array}$ & $\begin{array}{r}1196 \\
42.7 \\
186 \\
21 \\
.34 \\
.36\end{array}$ & $\begin{array}{r}8653 \\
279 \\
1200 \\
42 \\
2.23 \\
2.58\end{array}$ & $\begin{array}{r}3086 \\
103 \\
256 \\
36 \\
.82 \\
.92\end{array}$ & $\begin{array}{r}575 \\
18.5 \\
34 \\
11 \\
.15 \\
.17\end{array}$ & $\begin{array}{r}399.5 \\
13.3 \\
66 \\
1.4 \\
.11 \\
.12\end{array}$ & $\begin{array}{r}5.74 \\
.19 \\
.94 \\
.00 \\
.002 \\
.00\end{array}$ & $\begin{array}{r}178.40 \\
5.75 \\
36 \\
.00 \\
.05 \\
.05\end{array}$ & $\begin{array}{r}1319.28 \\
44.0 \\
276 \\
.00 \\
.35 \\
.39\end{array}$ \\
\hline
\end{tabular}

$\begin{array}{llllllllllll}\text { WTR YR } 1987 \text { TOTAL } & 31493.92 & \text { MEAN } 86.3 & \text { MAX } & 1800 & \text { MIN } & .00 & \text { CFSM } & .69 & \text { IN } & 9.37\end{array}$ 
PERIOD OF RECORD.--January 1978 to current year.

PERIOD OF DAILY RECORD.--

SPECIFIC CONDUCTANCE: April 1978 to September 1981.

WATER TEMPERATURE: April 1978 to September 1981 .

REMARKS.--Cross-sectional samples were collected at or near bridge. Samples for the analyses of stable hydrogen and oxygen isotopes were also collected; analytical results from these samples were not published. Some regulation at low flows.

EXTREMES FOR PERIOD OF DAILY RECORD.--

SPECIFIC CONDUCTANCE (water year 1980): Maximum daily recorded (more than 20 percent missing record) 2,000 microsiemens, Oct. 20, 1979; minimum daily recorded (more than 20 percent missing record), 175 microsiemens, Mar. 6, 1979.

WATER TEMPERATURE (water year 1978): Maximum daily recorded (more than 20 percent missing record) $27.5^{\circ} \mathrm{C}$, July 7, 1978; minimun daily recorded (more than 20 percent missing record). $0.0^{\circ} \mathrm{C}$ on many days during winter.

WATER QUALITY DATA, WATER YEAR OCTOBER 1986 TO SEPTEMBER 1987

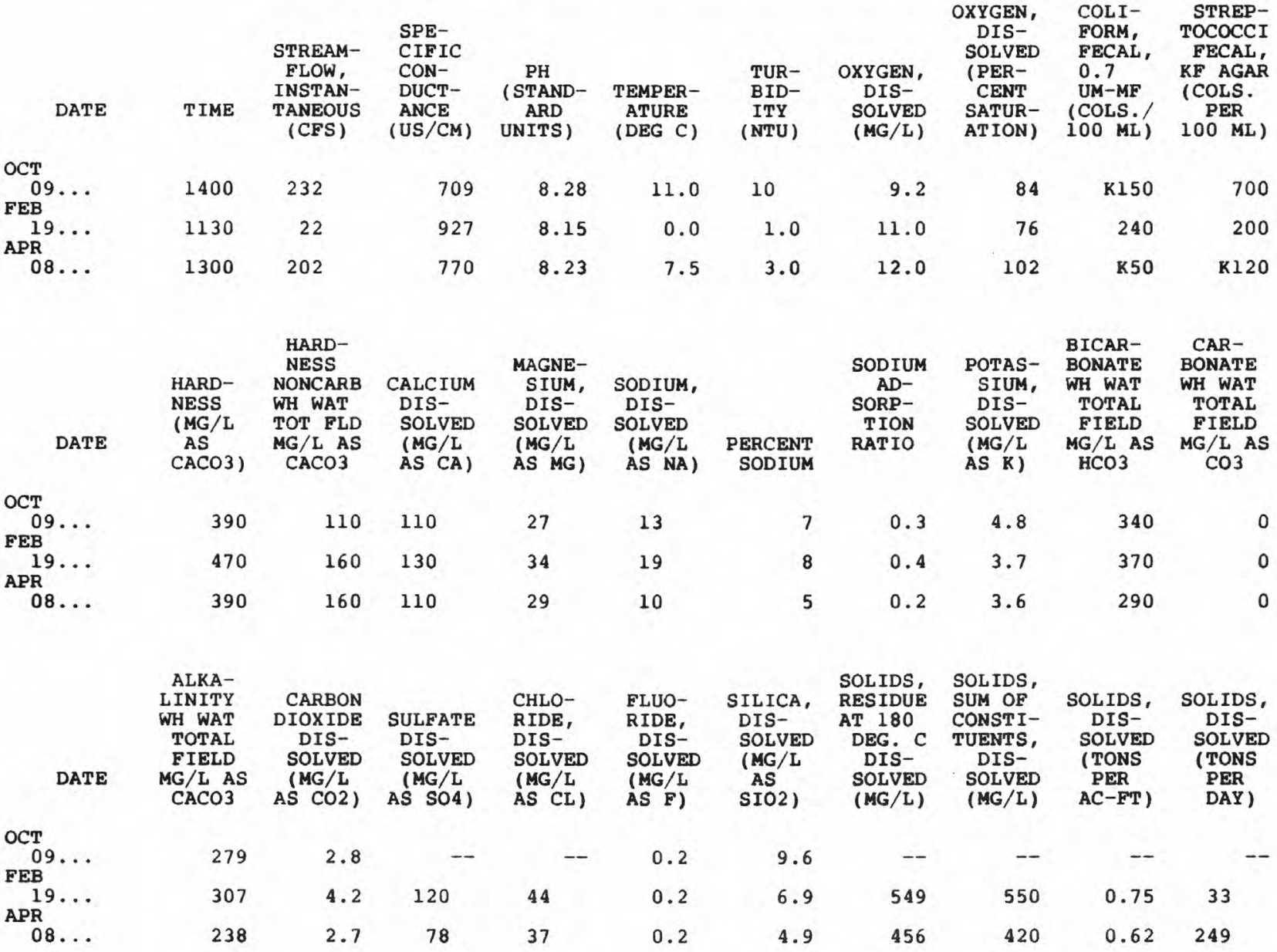

\section{DATE}

NITRO-
GEN,
NITRITE
DIS-
SOLVED
(MG/L
AS N)

NITROGEN, $\mathrm{NO} 2+\mathrm{NO}$ DISSOLVED
(MG/L (MG/L

OCT

$\begin{array}{cc}\text { OCT } \\ \text { O9... } & 0.04 \\ \begin{array}{c}\text { FEB } \\ 19 . . .\end{array} & 0.02 \\ \begin{array}{c}\text { APR } \\ 08 \ldots\end{array} & 0.02\end{array}$

4.50

2.50

5.20
NITRO-

GEN, AMMONIA (MG/L AS N)

\subsection{9}

0.19

0.05
NITROGEN, AMMONIA DISSOLVED (MG/L

0.04

0.18

0.05

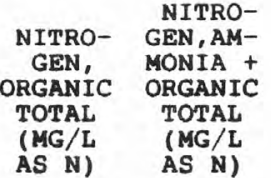

PHOSPHORUS, TOTAL' (MG/L AS P)

1.7
1.0
1.4

$<0.20$

1.20 .04

1.4

1.4

0.10

$<0.20$

0.09

20

0.03

0.03

$<10$

0.03

0.02

$<10$ 
04159010 PIGEON RIVER NEAR CASEVILLE, MI--Continued

WATER QUALITY DATA, WATER YEAR OCTOBER 1986 TO SEPTEMBER 1987

\begin{tabular}{|c|c|c|c|c|c|c|c|c|c|c|}
\hline DATE & $\begin{array}{c}\text { ARSENIC } \\
\text { DIS- } \\
\text { SOLVED } \\
\text { (UG/L } \\
\text { AS AS) }\end{array}$ & $\begin{array}{l}\text { BAR IUM, } \\
\text { DIS- } \\
\text { SOLVED } \\
\text { (UG/L } \\
\text { AS BA) }\end{array}$ & $\begin{array}{l}\text { BERYL- } \\
\text { LIUM, } \\
\text { DIS- } \\
\text { SOLVED } \\
\text { (UG/L } \\
\text { AS BE) }\end{array}$ & $\begin{array}{c}\text { CADMIUM } \\
\text { DIS- } \\
\text { SOLVED } \\
\text { (UG/L } \\
\text { AS CD) }\end{array}$ & $\begin{array}{l}\text { CHRO- } \\
\text { MIUM, } \\
\text { DIS- } \\
\text { SOLVED } \\
\text { (UG/L } \\
\text { AS CR) }\end{array}$ & $\begin{array}{l}\text { COBALT, } \\
\text { DIS- } \\
\text { SOLVED } \\
\text { (UG/L } \\
\text { AS CO) }\end{array}$ & $\begin{array}{l}\text { COPPER, } \\
\text { DIS- } \\
\text { SOLVED } \\
\text { (UG/L } \\
\text { AS CU) }\end{array}$ & $\begin{array}{l}\text { IRON, } \\
\text { DIS- } \\
\text { SOLVED } \\
\text { (UG/L } \\
\text { AS FE) }\end{array}$ & $\begin{array}{l}\text { LEAD, } \\
\text { DIS- } \\
\text { SOLVED } \\
\text { (UG/L } \\
\text { AS PB) }\end{array}$ & $\begin{array}{c}\text { LITHIUM } \\
\text { DIS- } \\
\text { SOLVED } \\
\text { (UG/L } \\
\text { AS LI) }\end{array}$ \\
\hline \multirow{3}{*}{ 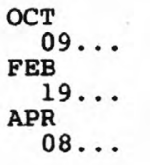 } & 1 & 43 & $<0.5$ & 1 & $<1$ & $<3$ & 5 & 34 & $<5$ & 16 \\
\hline & 1 & 54 & 1 & $<1$ & $<1$ & $<3$ & 2 & 27 & $<5$ & 13 \\
\hline & $<1$ & 41 & $<0.5$ & $<1$ & $<1$ & $<3$ & 3 & 12 & $<5$ & 10 \\
\hline DATE & $\begin{array}{l}\text { MANGA- } \\
\text { NESE, } \\
\text { DIS- } \\
\text { SOLVED } \\
\text { (UG/L } \\
\text { AS MN) }\end{array}$ & $\begin{array}{c}\text { MERCURY } \\
\text { DIS- } \\
\text { SOLVED } \\
\text { (UG/L } \\
\text { AS HG) }\end{array}$ & $\begin{array}{l}\text { MOLYB- } \\
\text { DENUM, } \\
\text { DIS- } \\
\text { SOLVED } \\
\text { (UG/L } \\
\text { AS MO) }\end{array}$ & $\begin{array}{l}\text { NICKEL, } \\
\text { DIS- } \\
\text { SOLVED } \\
\text { (UG/L } \\
\text { AS NI) }\end{array}$ & $\begin{array}{l}\text { SELE- } \\
\text { NIUM, } \\
\text { DIS- } \\
\text { SOLVED } \\
\text { (UG/L } \\
\text { AS SE) }\end{array}$ & $\begin{array}{c}\text { SILVER, } \\
\text { DIS- } \\
\text { SOLVED } \\
\text { (UG/L } \\
\text { AS AG) }\end{array}$ & $\begin{array}{l}\text { STRON- } \\
\text { TIUM, } \\
\text { DIS- } \\
\text { SOLVED } \\
\text { (UG/L } \\
\text { AS SR) }\end{array}$ & $\begin{array}{l}\text { VANA- } \\
\text { DIUM, } \\
\text { DIS- } \\
\text { SOLVED } \\
\text { (UG/L } \\
\text { AS V) }\end{array}$ & $\begin{array}{l}\text { ZINC, } \\
\text { DIS- } \\
\text { SOLVED } \\
\text { (UG/L } \\
\text { AS ZN) }\end{array}$ & $\begin{array}{l}\text { SEDI- } \\
\text { MENT, } \\
\text { SUS- } \\
\text { PENDED } \\
\text { (MG/L) }\end{array}$ \\
\hline${ }_{\mathrm{BB}}^{\mathrm{CT}} .$. & 24 & $<0.1$ & $<10$ & 1 & 1 & $<1$ & 220 & $<6$ & 10 & 73 \\
\hline & 26 & $<0.1$ & $<10$ & 2 & $<1$ & $<1$ & 330 & $<6$ & 12 & 41 \\
\hline & 12 & $<0.1$ & $<10$ & 1 & 1 & $<1$ & 220 & $<6$ & 9 & 79 \\
\hline
\end{tabular}

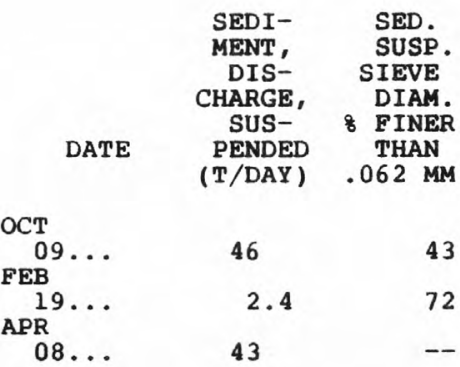


04159130 ST. CLAIR RIVER AT PORT HURON, MI

(National stream quality accounting network station)

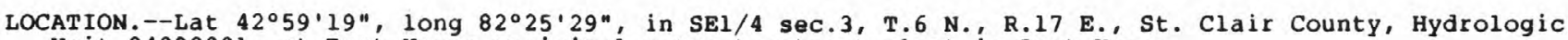
Unit 04090001 , at Port Huron municipal water-treatment plant in Port Huron.

DRAINAGE AREA.--222,400 $\mathrm{mi}^{2}$, approximately.

PERIOD OF RECORD.--Water years 1970-73, January 1978 to current year.

PERIOD OF DAILY RECORD.--

SPECIFIC CONDUCTANCE: April 1978 to September 1981.

WATER TEMPERATURE: April 1978 to September 1981 .

REMARKS.--Bimonthly samples were collected near the Port Huron municipal water-treatment plant. Dailymean water discharge is reported at sample time.

COOPERATION. --Water discharges were provided by the National Oceanic and Atmospheric Administration.

EXTREMES FOR PERIOD OF DAILY RECORD.--

SPECIFIC CONDUCTANCE (water years 1979-81): Maximum daily, 260 microsiemens, Dec. 18, 1980; minimum

daily, 194 microsiemens, Jan. $27,28,1980$.

WATER TEMPERATURE (water years 1979-81): Maximum daily, $24.0^{\circ} \mathrm{C}$, Aug. 14-16, $1980 ; \mathrm{minimum}$ daily, 0.0 ${ }^{\circ} \mathrm{C}$ on many days during winter.

EXTREMES OUTSIDE PERIOD OF DAILY RECORD.--A specific conductance of 265 microsiemens was measured Mar. 18, 1982. A specific conductance of 164 microsiemens was measured July 3,1972 .

WATER QUALITY DATA, WATER YEAR OCTOBER 1986 TO SEPTEMBER 1987

\begin{tabular}{|c|c|c|c|c|c|c|c|c|c|c|}
\hline DATE & TIME & $\begin{array}{c}\text { DIS- } \\
\text { CHARGE, } \\
\text { IN } \\
\text { CUBIC } \\
\text { FEET } \\
\text { PER } \\
\text { SECOND }\end{array}$ & $\begin{array}{l}\text { SPE- } \\
\text { CIFIC } \\
\text { CON- } \\
\text { DUCT- } \\
\text { ANCE } \\
\text { (US/CM) }\end{array}$ & $\begin{array}{c}\text { PH } \\
\text { (STAND- } \\
\text { ARD } \\
\text { UNITS) }\end{array}$ & $\begin{array}{l}\text { TEMPER- } \\
\text { ATURE } \\
\text { (DEG C) }\end{array}$ & $\begin{array}{l}\text { TUR- } \\
\text { BID- } \\
\text { ITY } \\
\text { (NTU) }\end{array}$ & $\begin{array}{c}\text { OXYGEN, } \\
\text { DIS- } \\
\text { SOLVED } \\
(M G / L)\end{array}$ & $\begin{array}{c}\text { OXYGEN, } \\
\text { DIS- } \\
\text { SOLVED } \\
\text { (PER- } \\
\text { CENT } \\
\text { SATUR- } \\
\text { ATION) }\end{array}$ & $\begin{array}{l}\text { COLI- } \\
\text { FORM, } \\
\text { FECAL, } \\
0.7 \\
\text { UM-MF } \\
\text { (COLS.' } \\
100 \mathrm{ML} \text { ) }\end{array}$ & $\begin{array}{c}\text { STREP- } \\
\text { TOCOCCI } \\
\text { FECAL, } \\
\text { KF AGAR } \\
\text { (COLS. } \\
\text { PER } \\
100 \mathrm{ML} \text { ) }\end{array}$ \\
\hline $\begin{array}{l}\text { NOV } \\
19 . . . \\
\text { DEC }\end{array}$ & 1100 & 237000 & 198 & -- & 7.0 & 8.9 & 11.4 & 94 & K2 & K4 \\
\hline $11 \ldots$ & 1500 & 218000 & 205 & 7.9 & 4.0 & 0.4 & 13.0 & 99 & KI & -- \\
\hline${ }_{\mathrm{AY}}^{31} \ldots$ & 1130 & 234000 & 213 & 8.0 & 4.0 & 50 & 12.8 & 98 & -- & 130 \\
\hline$\underset{U N}{29} \ldots$ & 1045 & 219000 & 211 & 8.4 & 15.0 & 0.4 & 6.3 & 64 & $<1$ & $<1$ \\
\hline $23 \ldots$ & 1230 & 222000 & 207 & 8.1 & 19.0 & 1.0 & 9.8 & 108 & K1 & $<1$ \\
\hline $22 \ldots$ & 1130 & 213000 & 215 & 7.9 & 18.0 & 0.3 & 9.5 & 102 & K2 & K6 \\
\hline DATE & $\begin{array}{l}\text { HARD- } \\
\text { NESS } \\
\text { (MG/L } \\
\text { AS } \\
\text { CACO3) }\end{array}$ & $\begin{array}{l}\text { HARD- } \\
\text { NESS } \\
\text { NONCARB } \\
\text { WH WAT } \\
\text { TOT FLD } \\
\text { MG/L AS } \\
\text { CACO3 }\end{array}$ & $\begin{array}{l}\text { CALCIUM } \\
\text { DIS- } \\
\text { SOLVED } \\
\text { (MG/L } \\
\text { AS CA) }\end{array}$ & $\begin{array}{l}\text { MAGNE- } \\
\text { SIUM, } \\
\text { DIS- } \\
\text { SOLVED } \\
\text { (MG/L } \\
\text { AS MG) }\end{array}$ & $\begin{array}{l}\text { SODIUM, } \\
\text { DIS- } \\
\text { SOLVED } \\
\text { (MG/L } \\
\text { AS NA) }\end{array}$ & $\begin{array}{l}\text { PERCENT } \\
\text { SODIUM }\end{array}$ & $\begin{array}{c}\text { SODIUM } \\
\text { AD- } \\
\text { SORP- } \\
\text { TION } \\
\text { RATIO }\end{array}$ & $\begin{array}{l}\text { POTAS- } \\
\text { SIUM, } \\
\text { DIS- } \\
\text { SOLVED } \\
\text { (MG/L } \\
\text { AS K) }\end{array}$ & $\begin{array}{l}\text { BICAR- } \\
\text { BONATE } \\
\text { WH WAT } \\
\text { TOTAL } \\
\text { FIELD } \\
\text { MG/L AS } \\
\text { HCO3 }\end{array}$ & $\begin{array}{l}\text { CAR- } \\
\text { BONATE } \\
\text { WH WAT } \\
\text { TOTAL } \\
\text { FIELD } \\
\text { MG } / \mathrm{L} \text { AS } \\
\mathrm{CO}_{3}\end{array}$ \\
\hline${ }_{\mathrm{EC}} 19 \ldots$ & 98 & 18 & 27 & 7.4 & 3.4 & 7 & 0.2 & 0.9 & -- & -- \\
\hline $\operatorname{MAR}_{11}^{11}$ & 97 & 21 & 27 & 7.1 & 3.4 & 7 & 0.2 & 1.0 & 93 & C \\
\hline${ }_{M A Y}^{31} \ldots$ & 100 & 22 & 28 & 7.7 & 3.6 & 7 & 0.2 & 1.0 & 98 & C \\
\hline${ }_{\text {JUN }}^{29} \ldots$ & 100 & 18 & 28 & 7.8 & 3.6 & 7 & 0.2 & 0.9 & 98 & 2 \\
\hline${ }_{E P}^{23} \cdots$ & 97 & 13 & 27 & 7.2 & 3.7 & 8 & 0.2 & 0.9 & -- & - \\
\hline $22 \ldots$ & 100 & 19 & 28 & 7.5 & 3.8 & 7 & 0.2 & 1.0 & -- & -- \\
\hline DATE & $\begin{array}{l}\text { ALKA- } \\
\text { LINITY } \\
\text { WH WAT } \\
\text { TOTAL } \\
\text { FIELD } \\
\text { MG/I AS } \\
\text { CACO3 }\end{array}$ & $\begin{array}{c}\text { CARBON } \\
\text { DIOXIDE } \\
\text { DIS- } \\
\text { SOLVED } \\
\text { (MG/L } \\
\text { AS CO2) }\end{array}$ & $\begin{array}{l}\text { SULFATE } \\
\text { DIS- } \\
\text { SOLVED } \\
\text { (MG/L } \\
\text { AS SO4) }\end{array}$ & $\begin{array}{l}\text { CHLO- } \\
\text { RIDE, } \\
\text { DIS- } \\
\text { SOLVED } \\
\text { (MG/L } \\
\text { AS CL) }\end{array}$ & $\begin{array}{l}\text { FLUO- } \\
\text { RIDE, } \\
\text { DIS- } \\
\text { SOLVED } \\
\text { (MG/L } \\
\text { AS F) }\end{array}$ & $\begin{array}{l}\text { SILICA, } \\
\text { DIS- } \\
\text { SOLVED } \\
\text { (MG/L } \\
\text { AS } \\
\text { SIO2) }\end{array}$ & $\begin{array}{l}\text { SOLIDS, } \\
\text { RESIDUE } \\
\text { AT } 180 \\
\text { DEG. C } \\
\text { DIS- } \\
\text { SOLVED } \\
(\text { MG/L) }\end{array}$ & $\begin{array}{c}\text { SOLIDS, } \\
\text { SUM OE } \\
\text { CONSTI- } \\
\text { TUENTS, } \\
\text { DIS- } \\
\text { SOLVED } \\
\text { (MG/L) }\end{array}$ & $\begin{array}{c}\text { SOLIDS, } \\
\text { DIS- } \\
\text { SOLVED } \\
\text { (TONS } \\
\text { PER } \\
\text { AC-FT) }\end{array}$ & $\begin{array}{c}\text { SOLIDS, } \\
\text { DIS- } \\
\text { SOLVED } \\
\text { (TONS } \\
\text { PER } \\
\text { DAY) }\end{array}$ \\
\hline
\end{tabular}

\begin{tabular}{|c|c|c|}
\hline NOV $19 . .$. & -- & -- \\
\hline $\begin{array}{l}\mathrm{DEC} \\
11 \ldots \\
\operatorname{MAR}\end{array}$ & 76 & 1.9 \\
\hline $\begin{array}{l}31 \ldots \\
\text { MAY }\end{array}$ & 80 & 1.6 \\
\hline$\underset{\text { JUN }}{29 \ldots}$ & 84 & 0.6 \\
\hline & -- & 1.3 \\
\hline $22 \ldots$ & -- & 2.0 \\
\hline
\end{tabular}

$\begin{array}{lllllll}5.8 & <0.1 & 1.1 & 105 & 110 & 0.1467200 \\ 6.0 & <0.1 & 1.4 & 114 & 110 & 0.1667100 \\ 6.1 & 0.1 & 1.5 & 121 & 110 & 0.1676400 \\ 11 & 0.1 & 1.1 & 113 & 120 & 0.1566800 \\ 6.7 & 0.2 & 0.7 & 112 & 110 & 0.1567100 \\ 6.2 & 0.1 & 1.1 & 116 & 110 & 0.1666700\end{array}$


04159130 ST. CLAIR RIVER AT PORT HURON, MI--Continued WATER QUALITY DATA, WATER YEAR OCTOBER 1986 TO SEPTEMBER 1987

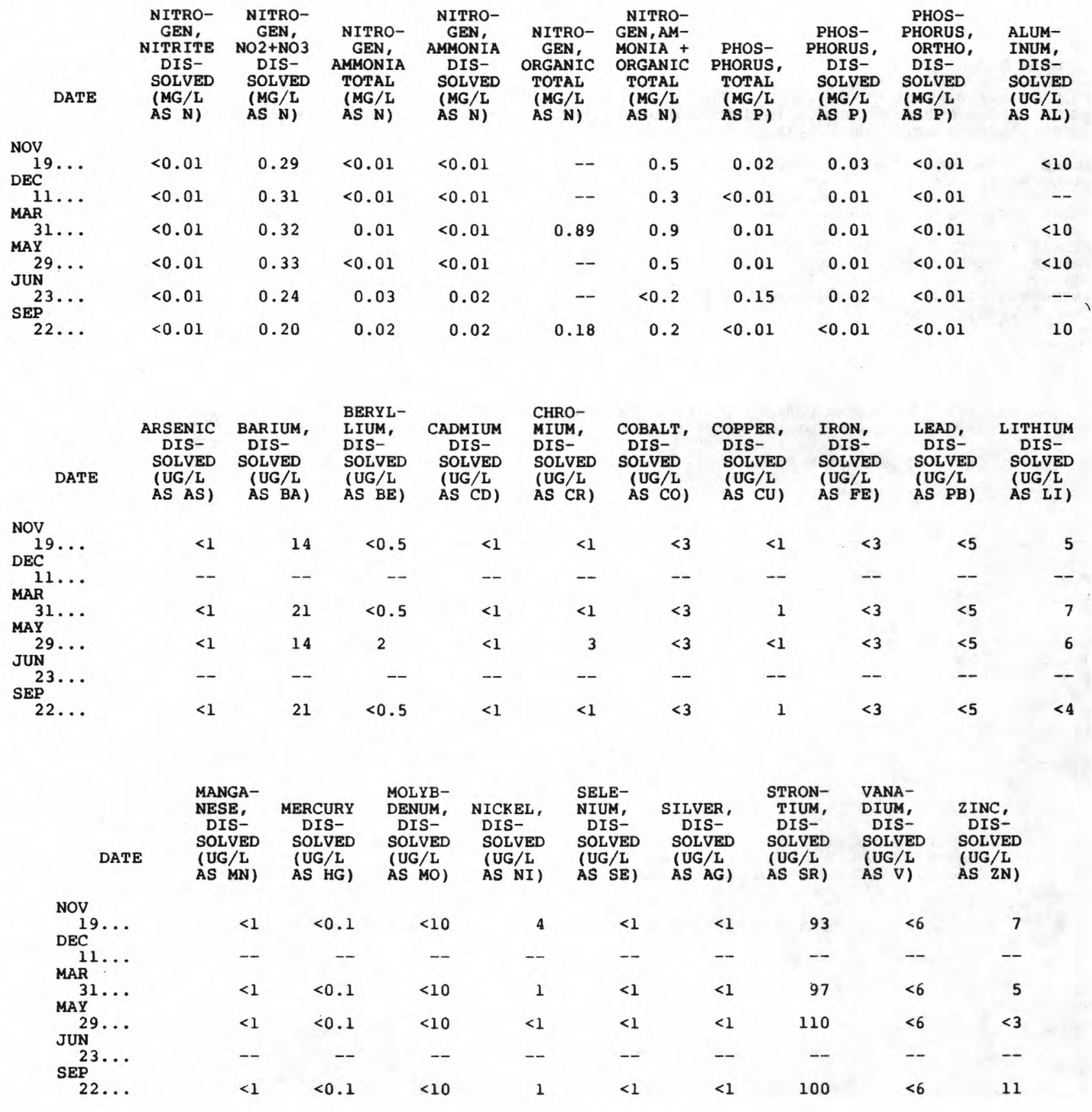




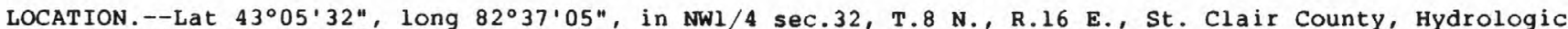
Unit 04090001 , on left bank $20 \mathrm{ft}$ downstream from bridge on Norman Road, $2.1 \mathrm{mi}$ east of Fargo, $5.3 \mathrm{mi}$ upstream from Mill Creek, and $12 \mathrm{mi}$ northwest of Port Huron.

DRAINAGE AREA. $-480 \mathrm{mi}^{2}$.

PERIOD OF RECORD.--February 1944 to current year.

REVISED RECORDS.--WSP 1307: 1950(M). WSP 1627: 1956-58. WSP 2112: Drainage area.

GAGE.--Water-stage recorder. Datum of gage is $613.75 \mathrm{ft}$ above National Geodetic Vertical Datum of 1929 (levels by Michigan Department of Natural Resources). Prior to July 9, 1954, nonrecording gage at same site and datum.

REMARKS.--Estimated daily discharges: Dec. 11-18, 21-23, Jan. 12, 13, and Jan. 19 to Mar. 1. Records good except for estimated daily discharges, which are fair. Several measurements of water temperature were made during the year.

AVERAGE DISCHARGE. -43 years, $301 \mathrm{ft}^{3} / \mathrm{s}, 8.52 \mathrm{in} / \mathrm{yr}$.

EXTREMES FOR PERIOD OF RECORD.--Maximum discharge, 14,400 ft $3 / \mathrm{s}$, Apr. 5, 1947, gage height, 16.06

ft, from floodmark, from rating curve extended above $9,500 \mathrm{ft}^{3} / \mathrm{s}$; maximum gage height observed,

$18.05 \mathrm{ft}$, Feb. 20, 1951, backwater from ice; minimum discharge observed, $1.8 \mathrm{ft} / \mathrm{s}, \mathrm{Sept}$. 18 , 19, 1946 .

EXTREMES FOR CURRENT YEAR.--Peak discharges greater than base discharge of $3,500 \mathrm{ft} 3 / \mathrm{s}$ and maximum (*):

\begin{tabular}{|c|c|c|c|c|c|c|c|}
\hline Date & Time & $\begin{array}{c}\text { Discharge } \\
\left(\mathrm{ft}^{3} / \mathrm{s}\right)\end{array}$ & $\begin{array}{l}\text { Gage height } \\
\text { (ft) }\end{array}$ & Date & Time & $\begin{array}{c}\text { Discharge } \\
\left(\mathrm{ft}^{3} / \mathrm{s}\right)\end{array}$ & $\begin{array}{c}\text { Gage height } \\
\text { (ft) }\end{array}$ \\
\hline Oct. & 1800 & $\star 5,660$ & $\star 12.66$ & Mar. & 1500 & 4,240 & 10.57 \\
\hline
\end{tabular}

Minimum discharge, $16 \mathrm{ft}^{3} / \mathrm{s}$, Aug. $25,26,27,28$, Sept. 11; minimum gage height, 1.81 ft, Aug. 25, 27, 28, Sept. 11 .

DISCHARGE, IN CUBIC FEET PER SECOND, WATER YEAR OCTOBER 1986 TO SEPTEMBER 1987 MEAN VALUES

\begin{tabular}{|c|c|c|c|c|c|c|c|c|c|c|c|c|}
\hline DAY & OCT & NOV & DEC & JAN & FEB & MAR & APR & MAY & JUN & JUL & AUG & SEP \\
\hline $\begin{array}{l}1 \\
2 \\
3 \\
4 \\
5\end{array}$ & $\begin{array}{l}5380 \\
5400 \\
4920 \\
4120 \\
4150\end{array}$ & $\begin{array}{l}203 \\
192 \\
188 \\
180 \\
165\end{array}$ & $\begin{array}{r}203 \\
188 \\
542 \\
1230 \\
868\end{array}$ & $\begin{array}{l}351 \\
355 \\
361 \\
310 \\
267\end{array}$ & $\begin{array}{r}96 \\
98 \\
100 \\
105 \\
110\end{array}$ & $\begin{array}{r}1000 \\
3990 \\
3790 \\
1890 \\
970\end{array}$ & $\begin{array}{r}649 \\
499 \\
536 \\
477 \\
1280\end{array}$ & $\begin{array}{r}119 \\
108 \\
98 \\
91 \\
86\end{array}$ & $\begin{array}{l}43 \\
56 \\
54 \\
72 \\
94\end{array}$ & $\begin{array}{l}27 \\
25 \\
24 \\
23 \\
24\end{array}$ & $\begin{array}{l}20 \\
25 \\
30 \\
25 \\
24\end{array}$ & $\begin{array}{l}23 \\
25 \\
23 \\
21 \\
21\end{array}$ \\
\hline $\begin{array}{r}6 \\
7 \\
8 \\
9 \\
10\end{array}$ & $\begin{array}{r}3390 \\
2460 \\
1210 \\
709 \\
539\end{array}$ & $\begin{array}{l}154 \\
147 \\
116 \\
134 \\
127\end{array}$ & $\begin{array}{l}468 \\
338 \\
290 \\
293 \\
413\end{array}$ & $\begin{array}{l}258 \\
243 \\
257 \\
253 \\
233\end{array}$ & $\begin{array}{l}110 \\
115 \\
115 \\
115 \\
115\end{array}$ & $\begin{array}{l}1110 \\
2300 \\
3210 \\
2700 \\
1310\end{array}$ & $\begin{array}{r}3110 \\
2480 \\
1080 \\
581 \\
424\end{array}$ & $\begin{array}{l}83 \\
80 \\
79 \\
78 \\
76\end{array}$ & $\begin{array}{l}74 \\
60 \\
50 \\
45 \\
49\end{array}$ & $\begin{array}{l}25 \\
27 \\
29 \\
31 \\
41\end{array}$ & $\begin{array}{l}25 \\
25 \\
24 \\
26 \\
26\end{array}$ & $\begin{array}{l}21 \\
22 \\
20 \\
19 \\
18\end{array}$ \\
\hline $\begin{array}{l}11 \\
12 \\
13 \\
14 \\
15\end{array}$ & $\begin{array}{r}428 \\
366 \\
323 \\
495 \\
1140\end{array}$ & $\begin{array}{r}129 \\
120 \\
109 \\
99 \\
93\end{array}$ & $\begin{array}{l}410 \\
370 \\
290 \\
260 \\
250\end{array}$ & $\begin{array}{l}211 \\
210 \\
200 \\
205 \\
280\end{array}$ & $\begin{array}{l}115 \\
115 \\
110 \\
105 \\
100\end{array}$ & $\begin{array}{l}620 \\
477 \\
381 \\
336 \\
310\end{array}$ & $\begin{array}{l}345 \\
313 \\
782 \\
818 \\
569\end{array}$ & $\begin{array}{l}73 \\
77 \\
75 \\
77 \\
81\end{array}$ & $\begin{array}{l}49 \\
48 \\
40 \\
38 \\
36\end{array}$ & $\begin{array}{l}49 \\
43 \\
40 \\
32 \\
27\end{array}$ & $\begin{array}{l}24 \\
26 \\
25 \\
28 \\
25\end{array}$ & $\begin{array}{l}28 \\
41 \\
37 \\
39 \\
42\end{array}$ \\
\hline $\begin{array}{l}16 \\
17 \\
18 \\
19 \\
20\end{array}$ & $\begin{array}{l}832 \\
563 \\
578 \\
472 \\
371\end{array}$ & $\begin{array}{l}94 \\
93 \\
83 \\
94 \\
95\end{array}$ & $\begin{array}{l}230 \\
200 \\
300 \\
585 \\
714\end{array}$ & $\begin{array}{l}563 \\
583 \\
443 \\
270 \\
250\end{array}$ & $\begin{array}{l}96 \\
92 \\
88 \\
84 \\
82\end{array}$ & $\begin{array}{l}289 \\
273 \\
256 \\
257 \\
246\end{array}$ & $\begin{array}{l}628 \\
521 \\
394 \\
319 \\
265\end{array}$ & $\begin{array}{l}79 \\
72 \\
66 \\
63 \\
68\end{array}$ & $\begin{array}{l}34 \\
32 \\
30 \\
28 \\
27\end{array}$ & $\begin{array}{l}26 \\
23 \\
21 \\
20 \\
20\end{array}$ & $\begin{array}{l}22 \\
39 \\
40 \\
36 \\
32\end{array}$ & $\begin{array}{l}39 \\
43 \\
71 \\
87 \\
73\end{array}$ \\
\hline $\begin{array}{l}21 \\
22 \\
23 \\
24 \\
25\end{array}$ & $\begin{array}{l}318 \\
279 \\
246 \\
219 \\
201\end{array}$ & $\begin{array}{l}102 \\
104 \\
119 \\
138 \\
161\end{array}$ & $\begin{array}{l}560 \\
410 \\
340 \\
294 \\
515\end{array}$ & $\begin{array}{l}210 \\
170 \\
140 \\
130 \\
115\end{array}$ & $\begin{array}{l}82 \\
82 \\
84 \\
90 \\
98\end{array}$ & $\begin{array}{l}232 \\
224 \\
217 \\
212 \\
217\end{array}$ & $\begin{array}{l}234 \\
211 \\
188 \\
160 \\
170\end{array}$ & $\begin{array}{l}67 \\
64 \\
59 \\
55 \\
52\end{array}$ & $\begin{array}{l}28 \\
30 \\
32 \\
35 \\
32\end{array}$ & $\begin{array}{l}21 \\
32 \\
30 \\
23 \\
23\end{array}$ & $\begin{array}{l}26 \\
23 \\
22 \\
19 \\
16\end{array}$ & $\begin{array}{l}56 \\
48 \\
42 \\
37 \\
32\end{array}$ \\
\hline $\begin{array}{l}26 \\
27 \\
28 \\
29 \\
30 \\
31\end{array}$ & $\begin{array}{l}195 \\
228 \\
374 \\
359 \\
292 \\
238\end{array}$ & $\begin{array}{l}170 \\
276 \\
358 \\
307 \\
248 \\
--\end{array}$ & $\begin{array}{r}1350 \\
1030 \\
680 \\
539 \\
439 \\
383\end{array}$ & $\begin{array}{r}105 \\
100 \\
99 \\
96 \\
94 \\
94\end{array}$ & $\begin{array}{l}110 \\
180 \\
350 \\
--- \\
--- \\
---\end{array}$ & $\begin{array}{l}231 \\
266 \\
275 \\
247 \\
451 \\
974\end{array}$ & $\begin{array}{l}148 \\
104 \\
107 \\
134 \\
128 \\
---\end{array}$ & $\begin{array}{l}50 \\
49 \\
48 \\
46 \\
44 \\
43\end{array}$ & $\begin{array}{r}36 \\
32 \\
30 \\
30 \\
29 \\
---\end{array}$ & $\begin{array}{l}29 \\
25 \\
30 \\
33 \\
27 \\
24\end{array}$ & $\begin{array}{l}17 \\
17 \\
19 \\
22 \\
26 \\
25\end{array}$ & $\begin{array}{l}28 \\
29 \\
30 \\
30 \\
28 \\
\end{array}$ \\
\hline $\begin{array}{l}\text { TOTAL } \\
\text { MEAN } \\
\text { MAX } \\
\text { MIN } \\
\text { CFSM } \\
\text { IN. }\end{array}$ & $\begin{array}{r}40795 \\
1316 \\
5400 \\
195 \\
2.74 \\
3.16\end{array}$ & $\begin{array}{r}4598 \\
153 \\
358 \\
83 \\
.32 \\
.36\end{array}$ & $\begin{array}{r}14982 \\
483 \\
1350 \\
188 \\
1.01 \\
1.16\end{array}$ & $\begin{array}{r}7456 \\
241 \\
583 \\
94 \\
.50 \\
.58\end{array}$ & $\begin{array}{r}3142 \\
112 \\
350 \\
82 \\
.23 \\
.24\end{array}$ & $\begin{array}{r}29261 \\
944 \\
3990 \\
212 \\
1.97 \\
2.27\end{array}$ & $\begin{array}{r}17654 \\
588 \\
3110 \\
104 \\
1.23 \\
1.37\end{array}$ & $\begin{array}{r}2206 \\
71.2 \\
119 \\
43 \\
.15 \\
.17\end{array}$ & $\begin{array}{r}1273 \\
42.4 \\
94 \\
27 \\
.09 \\
.10\end{array}$ & $\begin{array}{r}874 \\
28.2 \\
49 \\
20 \\
.06 \\
.07\end{array}$ & $\begin{array}{r}779 \\
25.1 \\
40 \\
16 \\
.05 \\
.06\end{array}$ & $\begin{array}{r}1073 \\
35.8 \\
87 \\
18 \\
.08 \\
.08\end{array}$ \\
\hline
\end{tabular}

$\begin{array}{lllllllllll}\text { CAL YR } 1986 & \text { TOTAL } & 212210 & \text { MEAN } 581 & \text { MAX } & 6120 & \text { MIN } 18 & \text { CFSM } & 1.21 & \text { IN } 16.45 \\ \text { WTR YR } 1987 & \text { TOTAL } & 124093 & \text { MEAN } 340 & \text { MAX } & 5400 & \text { MIN } 16 & \text { CFSM } & .71 & \text { IN } & 9.62\end{array}$ 
LOCATION.--Lat $43^{\circ} 01^{\prime} 49^{\prime \prime}$, long $83^{\circ} 04^{\prime} 02^{\prime \prime}$, in SW1/4 NW1/4 sec.16, T.7 N., R.12 E., Lapeer County, Hydrologic Unit 04090001 , on left bank 12 ft upstream from bridge on state Highway 21 , 0.6 mi northeast of Imlay City.

DRA INAGE AREA. $--18.0 \mathrm{mi}^{2}$.

PERIOD OF RECORD.--August 1965 to current year.

GAGE.--Water-stage recorder. Concrete weir Aug. 20, 1965, to Nov. 2, 1981 . Datum of gage is 789.69 ft above National Geodetic Vertical Datum of 1929 (levels by Boldt, McLeod, and Johnson, Inc.). Prior to Feb. 24, 1985, at datum $2.00 \mathrm{ft}$ higher.

REMARKS.--Estimated daily discharges: Nov. 13, 14, Dec. 13, 14, Jan. 19 to Feb. 28, Mar. 2-6, 9-11, and June 16 to July 11. Records good except for estimated daily discharges, which are poor. Some diversion by pumping for sprinkler irrigation. Several measurements of water temperature were made during the year.

AVERAGE DISCHARGE. --22 years, $12.2 \mathrm{ft}^{3} / \mathrm{s}, 9.20 \mathrm{in} / \mathrm{yr}^{\mathrm{r}}$

EXTREMES FOR PERIOD OF RECORD.--Maximum discharge, $354 \mathrm{ft}^{3} / \mathrm{s}$, June 12, 1986, gage height, $6.66 \mathrm{ft}$, from rating curve extended above $100 \mathrm{ft}^{3} / \mathrm{s}$; maximum gage height, $9.33 \mathrm{ft}$, Apr. 19, 1975, datum then in use; no flow part of each day June $27,28,1977$, June 26-28, 1979, caused by irrigation pumpage.

EXTREMES FOR CURRENT YEAR.--Peak discharges greater than base discharge of $60 \mathrm{ft} 3 / \mathrm{s}$ and maximum (*):

\begin{tabular}{|c|c|c|c|c|c|c|c|}
\hline Date & Time & $\begin{array}{c}\text { Discharge } \\
\left(\mathrm{ft}^{3} / \mathrm{s}\right)\end{array}$ & $\begin{array}{c}\text { Gage height } \\
(\mathrm{ft})\end{array}$ & Date & Time & $\begin{array}{c}\text { Discharge } \\
\left(\mathrm{ft}^{3} / \mathrm{s}\right)\end{array}$ & $\begin{array}{c}\text { Gage height } \\
\text { (ft) }\end{array}$ \\
\hline $\begin{array}{l}\text { ct. } \\
\text { ct. }\end{array}$ & $\begin{array}{l}0100 \\
2100\end{array}$ & $\begin{array}{r}\star a 189 \\
112\end{array}$ & $\begin{array}{r}\star a 5.01 \\
4.04\end{array}$ & $\begin{array}{l}\text { Mar. } \\
\text { Apr. }\end{array}$ & $\begin{array}{l}0100 \\
1400\end{array}$ & $\begin{array}{l}90 \\
96\end{array}$ & $\begin{array}{l}3.72 \\
3.81\end{array}$ \\
\hline
\end{tabular}

a Stage falling, peak occurred Sept. $29,1986$.

Minimum daily discharge, $0.97 \mathrm{ft}^{3} / \mathrm{s}$, Aug. 5 .

DISCHARGE, IN CUBIC FEET PER SECOND, WATER YEAR OCTOBER 1986 TO SEPTEMBER 1987 MEAN VALUES

\begin{tabular}{|c|c|c|c|c|c|c|c|c|c|c|c|c|}
\hline DAY & OCT & NOV & DEC & JAN & FEB & MAR & APR & MAY & JUN & JUL & AUG & SEP \\
\hline $\begin{array}{l}1 \\
2 \\
3 \\
4 \\
5\end{array}$ & $\begin{array}{r}148 \\
106 \\
74 \\
87 \\
85\end{array}$ & $\begin{array}{l}11 \\
12 \\
12 \\
12 \\
11\end{array}$ & $\begin{array}{l}9.5 \\
13 \\
29 \\
30 \\
23\end{array}$ & $\begin{array}{l}14 \\
14 \\
14 \\
12 \\
12\end{array}$ & $\begin{array}{l}7.1 \\
7.2 \\
7.4 \\
7.8 \\
8.0\end{array}$ & $\begin{array}{l}60 \\
65 \\
40 \\
30 \\
30\end{array}$ & $\begin{array}{l}19 \\
25 \\
25 \\
20 \\
70\end{array}$ & $\begin{array}{l}7.1 \\
6.9 \\
6.5 \\
7.0 \\
5.1\end{array}$ & $\begin{array}{l}4.6 \\
9.5 \\
7.0 \\
5.0 \\
4.0\end{array}$ & $\begin{array}{l}3.4 \\
3.4 \\
7.0 \\
5.0 \\
4.0\end{array}$ & $\begin{array}{l}1.2 \\
1.3 \\
1.0 \\
.99 \\
.97\end{array}$ & $\begin{array}{l}2.0 \\
4.8 \\
2.9 \\
2.3 \\
2.2\end{array}$ \\
\hline $\begin{array}{r}6 \\
7 \\
8 \\
9 \\
10\end{array}$ & $\begin{array}{l}59 \\
46 \\
39 \\
33 \\
28\end{array}$ & $\begin{array}{l}11 \\
11 \\
11 \\
10 \\
9.1\end{array}$ & $\begin{array}{l}19 \\
16 \\
20 \\
22 \\
30\end{array}$ & $\begin{array}{l}12 \\
12 \\
13 \\
12 \\
11\end{array}$ & $\begin{array}{l}8.1 \\
8.2 \\
8.3 \\
8.4 \\
8.3\end{array}$ & $\begin{array}{l}36 \\
46 \\
48 \\
40 \\
27\end{array}$ & $\begin{array}{l}65 \\
49 \\
39 \\
32 \\
27\end{array}$ & $\begin{array}{l}3.9 \\
3.8 \\
3.9 \\
3.8 \\
3.6\end{array}$ & $\begin{array}{l}3.2 \\
3.4 \\
2.8 \\
2.5 \\
2.5\end{array}$ & $\begin{array}{l}7.7 \\
6.5 \\
5.5 \\
10 \\
15\end{array}$ & $\begin{array}{l}1.0 \\
2.0 \\
1.6 \\
5.7 \\
4.4\end{array}$ & $\begin{array}{l}2.0 \\
2.2 \\
2.6 \\
3.1 \\
3.3\end{array}$ \\
\hline $\begin{array}{l}11 \\
12 \\
13 \\
14 \\
15\end{array}$ & $\begin{array}{l}25 \\
22 \\
22 \\
49 \\
37\end{array}$ & $\begin{array}{l}9.0 \\
8.2 \\
7.0 \\
5.8 \\
6.0\end{array}$ & $\begin{array}{l}23 \\
16 \\
14 \\
11 \\
9.6\end{array}$ & $\begin{array}{l}13 \\
12 \\
11 \\
12 \\
29\end{array}$ & $\begin{array}{l}8.3 \\
8.2 \\
8.1 \\
8.0 \\
7.5\end{array}$ & $\begin{array}{l}20 \\
16 \\
14 \\
14 \\
14\end{array}$ & $\begin{array}{l}22 \\
22 \\
23 \\
20 \\
23\end{array}$ & $\begin{array}{r}4.5 \\
16 \\
8.0 \\
6.6 \\
7.9\end{array}$ & $\begin{array}{l}2.3 \\
9.1 \\
5.8 \\
4.1 \\
3.4\end{array}$ & $\begin{array}{r}10 \\
8.5 \\
6.1 \\
5.1 \\
6.1\end{array}$ & $\begin{array}{l}2.7 \\
1.6 \\
1.4 \\
1.6 \\
1.6\end{array}$ & $\begin{array}{l}6.9 \\
6.8 \\
7.9 \\
5.9 \\
6.2\end{array}$ \\
\hline $\begin{array}{l}16 \\
17 \\
18 \\
19 \\
20\end{array}$ & $\begin{array}{l}30 \\
27 \\
23 \\
21 \\
18\end{array}$ & $\begin{array}{l}6.6 \\
7.2 \\
7.5 \\
7.1 \\
7.2\end{array}$ & $\begin{array}{l}10 \\
11 \\
24 \\
25 \\
23\end{array}$ & $\begin{array}{l}29 \\
23 \\
15 \\
13 \\
12\end{array}$ & $\begin{array}{l}7.0 \\
6.7 \\
6.5 \\
6.3 \\
6.2\end{array}$ & $\begin{array}{l}14 \\
13 \\
12 \\
12 \\
12\end{array}$ & $\begin{array}{l}23 \\
20 \\
17 \\
14 \\
13\end{array}$ & $\begin{array}{r}6.3 \\
5.0 \\
10 \\
9.8 \\
7.5\end{array}$ & $\begin{array}{l}3.0 \\
2.7 \\
2.4 \\
2.2 \\
2.3\end{array}$ & $\begin{array}{l}4.8 \\
2.8 \\
1.8 \\
1.4 \\
2.0\end{array}$ & $\begin{array}{l}3.2 \\
6.0 \\
4.5 \\
3.4 \\
2.7\end{array}$ & $\begin{array}{l}7.0 \\
8.4 \\
9.4 \\
8.8 \\
7.3\end{array}$ \\
\hline $\begin{array}{l}21 \\
22 \\
23 \\
24 \\
25\end{array}$ & $\begin{array}{l}16 \\
15 \\
14 \\
13 \\
12\end{array}$ & $\begin{array}{r}7.8 \\
8.8 \\
9.6 \\
12 \\
11\end{array}$ & $\begin{array}{l}20 \\
16 \\
14 \\
13 \\
22\end{array}$ & $\begin{array}{r}11 \\
10 \\
9.6 \\
9.0 \\
8.4\end{array}$ & $\begin{array}{l}6.1 \\
6.1 \\
6.4 \\
7.0 \\
7.5\end{array}$ & $\begin{array}{l}11 \\
12 \\
12 \\
12 \\
13\end{array}$ & $\begin{array}{l}12 \\
11 \\
12 \\
10 \\
9.9\end{array}$ & $\begin{array}{r}3.9 \\
8.6 \\
6.9 \\
12.7 \\
9.7\end{array}$ & $\begin{array}{l}3.0 \\
5.0 \\
7.7 \\
3.5 \\
4.0\end{array}$ & $\begin{array}{l}3.2 \\
2.7 \\
2.4 \\
2.6 \\
3.3\end{array}$ & $\begin{array}{l}2.3 \\
3.5 \\
2.6 \\
2.0 \\
1.9\end{array}$ & $\begin{array}{l}7.1 \\
9.7 \\
9.9 \\
7.6 \\
6.3\end{array}$ \\
\hline $\begin{array}{l}26 \\
27 \\
28 \\
29 \\
30 \\
31\end{array}$ & $\begin{array}{l}15 \\
18 \\
18 \\
16 \\
14 \\
12\end{array}$ & $\begin{array}{l}14 \\
20 \\
16 \\
14 \\
11 \\
---\end{array}$ & $\begin{array}{l}23 \\
20 \\
19 \\
16 \\
15 \\
14\end{array}$ & $\begin{array}{l}7.8 \\
7.3 \\
7.1 \\
7.0 \\
7.0 \\
7.0\end{array}$ & $\begin{array}{l}8.0 \\
9.0 \\
14 \\
--- \\
--- \\
---\end{array}$ & $\begin{array}{l}18 \\
16 \\
15 \\
13 \\
33 \\
25\end{array}$ & $\begin{array}{r}8.6 \\
8.7 \\
11 \\
9.5 \\
7.7 \\
---\end{array}$ & $\begin{array}{l}7.3 \\
7.5 \\
6.1 \\
5.1 \\
4.2 \\
4.6\end{array}$ & $\begin{array}{r}10 \\
8.0 \\
6.0 \\
4.5 \\
3.5 \\
\end{array}$ & $\begin{array}{l}2.4 \\
1.9 \\
1.8 \\
1.6 \\
1.3 \\
1.1\end{array}$ & $\begin{array}{l}4.7 \\
7.8 \\
3.7 \\
3.2 \\
2.6 \\
2.5\end{array}$ & $\begin{array}{l}5.6 \\
5.2 \\
5.4 \\
5.5 \\
5.9 \\
\end{array}$ \\
\hline $\begin{array}{l}\text { TOTAL } \\
\text { MEAN } \\
\text { MAX } \\
\text { MIN } \\
\text { CFSM } \\
\text { IN. }\end{array}$ & $\begin{array}{r}1142 \\
36.8 \\
148 \\
12 \\
2.04 \\
2.36\end{array}$ & $\begin{array}{r}305.9 \\
10.2 \\
20 \\
5.8 \\
.57 \\
.63\end{array}$ & $\begin{array}{r}570.1 \\
18.4 \\
30 \\
9.5 \\
1.02 \\
1.18\end{array}$ & $\begin{array}{r}386.2 \\
12.5 \\
29 \\
7.0 \\
.69 \\
.80\end{array}$ & $\begin{array}{r}215.7 \\
7.70 \\
14 \\
6.11 \\
.43 \\
.45\end{array}$ & $\begin{array}{r}743 \\
24.0 \\
65 \\
11 \\
1.33 \\
1.54\end{array}$ & $\begin{array}{r}668.4 \\
22.3 \\
70 \\
7.7 \\
1.24 \\
1.38\end{array}$ & $\begin{array}{r}209.1 \\
6.75 \\
16 \\
3.6 \\
.38 \\
.43\end{array}$ & $\begin{array}{r}137.0 \\
4.57 \\
10 \\
2.2 \\
.25 \\
.28\end{array}$ & $\begin{array}{r}140.4 \\
4.53 \\
15 \\
1.1 \\
.25 \\
.29\end{array}$ & $\begin{array}{r}85.66 \\
2.76 \\
7.8 \\
.97 \\
.15 \\
.18\end{array}$ & $\begin{array}{r}170.2 \\
5.67 \\
9.9 \\
2.0 \\
.32 \\
.35\end{array}$ \\
\hline
\end{tabular}

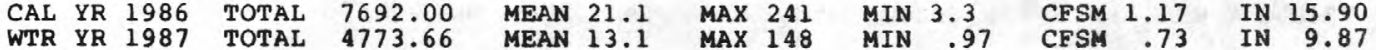




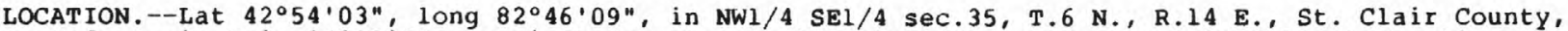

Hydrologic Unit 04090001 , on right downstream side of bridge on State Highway 19 at Memphis.

DRAINAGE AREA. $-151 \mathrm{mi}^{2}$.

PERIOD OF RECORD.--October 1962 to current year.

REVISED RECORDS. --WSP 2112: Drainage area.

GAGE.--Water-stage recorder. Datum of gage is $705.41 \mathrm{ft}$ above National Geodetic Vertical Datum of 1929 (Michigan Department of Transportation benchmark).

REMARKS.--Estimated daily discharges: Nov. 14, 15, and Jan. 19 to Mar. 4. Records good except for estimated daily discharges, which are fair. Several measurements of water temperature were made during the year.

AVERAGE DISCHARGE, --25 years, $92.5 \mathrm{ft}^{3} / \mathrm{s}, 8.32 \mathrm{in} / \mathrm{yr}^{\mathrm{r}}$.

EXTREMES FOR PERIOD OF RECORD.--Maximum discharge, 4,520 ft $3 / \mathrm{s}$, Apr. 19, 1975, gage height, 8.96 ft; minimum, $2.3 \mathrm{ft}^{3} / \mathrm{s}$, Sept. $6,10,1978$; minimum gage height,' $1.17 \mathrm{ft}$, Sept.' 6 , 1978.

EXTREMES OUTSIDE PERIOD OF RECORD.--Flood of April 1947, reached a stage of about 9 ft, from information by local residents.

EXTREMES FOR CURRENT YEAR.--Peak discharges greater than base discharge of $600 \mathrm{ft} 3 / \mathrm{s}$ and maximum (*):

\begin{tabular}{|c|c|c|c|c|c|c|c|}
\hline Date & Time & $\begin{array}{c}\text { Discharge } \\
\left(\mathrm{ft}^{3} / \mathrm{s}\right)\end{array}$ & $\begin{array}{c}\text { Gage height } \\
(f t)\end{array}$ & Date & Time & $\begin{array}{c}\text { Discharge } \\
\left(\mathrm{ft}^{3} / \mathrm{s}\right)\end{array}$ & $\begin{array}{c}\text { Gage height } \\
\text { (ft) }\end{array}$ \\
\hline $\begin{array}{ll}\text { ct. } & 1 \\
\text { ct. } & 5\end{array}$ & $\begin{array}{l}0100 \\
1500\end{array}$ & $\begin{array}{r}\star a 1,240 \\
785\end{array}$ & $\begin{array}{r}\star \mathrm{a} 6.47 \\
5.20\end{array}$ & $\begin{array}{l}\text { Mar. } \\
\text { Apr. }\end{array}$ & $\begin{array}{l}1200 \\
1000\end{array}$ & $\begin{array}{l}1,030 \\
1,090\end{array}$ & $\begin{array}{l}5.93 \\
6.11\end{array}$ \\
\hline
\end{tabular}

a Stage falling, peak occurred Sept. 30, 1986.

Minimum discharge, $9.0 \mathrm{ft}^{3} / \mathrm{s}$, Aug. 6, 7, gage height, $1.40 \mathrm{ft}$.

DISCHARGE, IN CUBIC FEET PER SECOND, WATER YEAR OCTOBER 1986 TO SEPTEMBER 1987 MEAN VALUES

\begin{tabular}{|c|c|c|c|c|c|c|c|c|c|c|c|c|}
\hline DAY & OCT & NOV & DEC & JAN & FEB & MAR & APR & MAY & JUN & JUL & AUG & SEP \\
\hline $\begin{array}{l}1 \\
2 \\
3 \\
4 \\
5\end{array}$ & $\begin{array}{r}1110 \\
798 \\
614 \\
574 \\
729\end{array}$ & $\begin{array}{l}79 \\
85 \\
90 \\
79 \\
70\end{array}$ & $\begin{array}{r}82 \\
78 \\
200 \\
314 \\
238\end{array}$ & $\begin{array}{r}102 \\
107 \\
108 \\
99 \\
86\end{array}$ & $\begin{array}{l}36 \\
37 \\
39 \\
40 \\
41\end{array}$ & $\begin{array}{l}260 \\
800 \\
550 \\
300 \\
233\end{array}$ & $\begin{array}{l}197 \\
178 \\
223 \\
176 \\
546\end{array}$ & $\begin{array}{l}47 \\
46 \\
46 \\
45 \\
44\end{array}$ & $\begin{array}{l}29 \\
36 \\
45 \\
42 \\
32\end{array}$ & $\begin{array}{l}21 \\
19 \\
22 \\
22 \\
20\end{array}$ & $\begin{array}{l}11 \\
13 \\
13 \\
12 \\
11\end{array}$ & $\begin{array}{l}18 \\
17 \\
17 \\
18 \\
16\end{array}$ \\
\hline $\begin{array}{r}6 \\
7 \\
8 \\
9 \\
10\end{array}$ & $\begin{array}{l}595 \\
400 \\
292 \\
234 \\
193\end{array}$ & $\begin{array}{l}66 \\
59 \\
60 \\
58 \\
49\end{array}$ & $\begin{array}{l}160 \\
122 \\
123 \\
161 \\
280\end{array}$ & $\begin{array}{l}88 \\
75 \\
85 \\
80 \\
73\end{array}$ & $\begin{array}{l}42 \\
43 \\
44 \\
44 \\
44\end{array}$ & $\begin{array}{l}267 \\
372 \\
438 \\
387 \\
234\end{array}$ & $\begin{array}{r}1010 \\
695 \\
393 \\
249 \\
185\end{array}$ & $\begin{array}{l}44 \\
43 \\
43 \\
44 \\
43\end{array}$ & $\begin{array}{l}27 \\
24 \\
22 \\
20 \\
19\end{array}$ & $\begin{array}{l}22 \\
47 \\
66 \\
49 \\
36\end{array}$ & $\begin{array}{l}10 \\
10 \\
11 \\
16 \\
17\end{array}$ & $\begin{array}{l}15 \\
14 \\
14 \\
13 \\
14\end{array}$ \\
\hline $\begin{array}{l}11 \\
12 \\
13 \\
14 \\
15\end{array}$ & $\begin{array}{l}158 \\
134 \\
115 \\
214 \\
337\end{array}$ & $\begin{array}{l}48 \\
50 \\
48 \\
45 \\
42\end{array}$ & $\begin{array}{r}259 \\
182 \\
100 \\
90 \\
92\end{array}$ & $\begin{array}{r}75 \\
74 \\
71 \\
68 \\
124\end{array}$ & $\begin{array}{l}44 \\
44 \\
43 \\
41 \\
39\end{array}$ & $\begin{array}{r}159 \\
117 \\
99 \\
89 \\
84\end{array}$ & $\begin{array}{l}142 \\
125 \\
141 \\
123 \\
143\end{array}$ & $\begin{array}{l}41 \\
45 \\
57 \\
49 \\
45\end{array}$ & $\begin{array}{l}17 \\
20 \\
22 \\
23 \\
21\end{array}$ & $\begin{array}{l}42 \\
32 \\
27 \\
25 \\
21\end{array}$ & $\begin{array}{l}19 \\
16 \\
13 \\
13 \\
14\end{array}$ & $\begin{array}{l}15 \\
17 \\
20 \\
20 \\
19\end{array}$ \\
\hline $\begin{array}{l}16 \\
17 \\
18 \\
19 \\
20\end{array}$ & $\begin{array}{l}245 \\
191 \\
158 \\
129 \\
110\end{array}$ & $\begin{array}{l}45 \\
47 \\
48 \\
49 \\
48\end{array}$ & $\begin{array}{r}80 \\
69 \\
91 \\
179 \\
178\end{array}$ & $\begin{array}{r}225 \\
169 \\
125 \\
110 \\
95\end{array}$ & $\begin{array}{l}37 \\
35 \\
34 \\
33 \\
32\end{array}$ & $\begin{array}{l}87 \\
90 \\
86 \\
81 \\
76\end{array}$ & $\begin{array}{r}175 \\
144 \\
113 \\
91 \\
79\end{array}$ & $\begin{array}{l}49 \\
43 \\
38 \\
38 \\
39\end{array}$ & $\begin{array}{l}19 \\
17 \\
15 \\
15 \\
14\end{array}$ & $\begin{array}{l}19 \\
19 \\
17 \\
15 \\
14\end{array}$ & $\begin{array}{l}14 \\
28 \\
28 \\
22 \\
17\end{array}$ & $\begin{array}{r}18 \\
34 \\
132 \\
47 \\
34\end{array}$ \\
\hline $\begin{array}{l}21 \\
22 \\
23 \\
24 \\
25\end{array}$ & $\begin{array}{l}96 \\
89 \\
83 \\
78 \\
73\end{array}$ & $\begin{array}{l}49 \\
52 \\
57 \\
68 \\
75\end{array}$ & $\begin{array}{r}153 \\
124 \\
108 \\
85 \\
142\end{array}$ & $\begin{array}{l}80 \\
60 \\
52 \\
46 \\
43\end{array}$ & $\begin{array}{l}31 \\
31 \\
32 \\
35 \\
37\end{array}$ & $\begin{array}{l}73 \\
71 \\
68 \\
68 \\
69\end{array}$ & $\begin{array}{l}75 \\
69 \\
66 \\
66 \\
61\end{array}$ & $\begin{array}{l}35 \\
32 \\
31 \\
34 \\
33\end{array}$ & $\begin{array}{l}16 \\
21 \\
23 \\
20 \\
20\end{array}$ & $\begin{array}{l}13 \\
15 \\
15 \\
14 \\
16\end{array}$ & $\begin{array}{l}14 \\
16 \\
27 \\
28 \\
19\end{array}$ & $\begin{array}{l}27 \\
24 \\
21 \\
21 \\
20\end{array}$ \\
\hline $\begin{array}{l}26 \\
27 \\
28 \\
29 \\
30 \\
31\end{array}$ & $\begin{array}{r}71 \\
81 \\
127 \\
123 \\
103 \\
87\end{array}$ & $\begin{array}{r}101 \\
163 \\
151 \\
116 \\
98 \\
---\end{array}$ & $\begin{array}{l}241 \\
196 \\
167 \\
143 \\
122 \\
109\end{array}$ & $\begin{array}{l}40 \\
37 \\
36 \\
36 \\
36 \\
36\end{array}$ & $\begin{array}{r}40 \\
48 \\
90 \\
--- \\
--- \\
---\end{array}$ & $\begin{array}{r}78 \\
89 \\
83 \\
76 \\
172 \\
301\end{array}$ & $\begin{array}{r}54 \\
51 \\
53 \\
54 \\
51 \\
-\end{array}$ & $\begin{array}{l}33 \\
29 \\
27 \\
26 \\
24 \\
28\end{array}$ & $\begin{array}{r}26 \\
27 \\
25 \\
22 \\
21 \\
-\end{array}$ & $\begin{array}{l}19 \\
19 \\
17 \\
14 \\
13 \\
11\end{array}$ & $\begin{array}{l}17 \\
19 \\
34 \\
30 \\
24 \\
20\end{array}$ & $\begin{array}{l}19 \\
17 \\
17 \\
17 \\
17 \\
-\end{array}$ \\
\hline $\begin{array}{l}\text { TOTAL } \\
\text { MEAN } \\
\text { MAX } \\
\text { MIN } \\
\text { CFSM } \\
\text { IN. }\end{array}$ & $\begin{array}{r}8341 \\
269 \\
1110 \\
71 \\
1.78 \\
2.05\end{array}$ & $\begin{array}{r}2095 \\
69.8 \\
163 \\
42 \\
.46 \\
.52\end{array}$ & $\begin{array}{r}4668 \\
151 \\
314 \\
69 \\
1.00 \\
1.15\end{array}$ & $\begin{array}{r}2541 \\
82.0 \\
225 \\
36 \\
.54 \\
.63\end{array}$ & $\begin{array}{r}1136 \\
40.6 \\
90 \\
31 \\
.27 \\
.28\end{array}$ & $\begin{array}{r}5957 \\
192 \\
800 \\
68 \\
1.27 \\
1.47\end{array}$ & $\begin{array}{r}5728 \\
191 \\
1010 \\
51 \\
1.27 \\
1.41\end{array}$ & $\begin{array}{r}1221 \\
39.4 \\
57 \\
24 \\
.26 \\
.30\end{array}$ & $\begin{array}{r}700 \\
23.3 \\
45 \\
14 \\
.15 \\
.17\end{array}$ & $\begin{array}{r}721 \\
23.3 \\
66 \\
11 \\
.15 \\
.18\end{array}$ & $\begin{array}{r}556 \\
17.9 \\
34 \\
10 \\
.12 \\
.14\end{array}$ & $\begin{array}{r}712 \\
23.7 \\
132 \\
13 \\
.16 \\
.18\end{array}$ \\
\hline $\begin{array}{l}\text { CAL YR } \\
\text { WTR YR }\end{array}$ & $\begin{array}{l}1986 \\
1987\end{array}$ & $\begin{array}{ll}L & 5 \\
L & 3\end{array}$ & ME & $\begin{array}{r}142 \\
94.2\end{array}$ & $\begin{array}{l}\text { MAX } \\
\text { MAX }\end{array}$ & $\begin{array}{l}1820 \\
1110\end{array}$ & IN 16 & 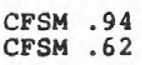 & $\begin{array}{l}\text { IN } \\
\text { IN }\end{array}$ & $\begin{array}{l}81 \\
47\end{array}$ & & \\
\hline
\end{tabular}


LOCATION.--Lat $42^{\circ} 43^{\prime} 12^{\prime \prime}$, long $83^{\circ} 21^{\prime} 13^{\prime \prime}$, in SEl/4 sec.26, T.4 N., R.9 E., Oakland County, Hydrologic Unit

04090003 , on right bank at upstream side of culverts on Maybee Road, í. mi upstream from mouth, and $2.5 \mathrm{mi}$ northeast of Drayton Plains.

DRAINAGE AREA. $--20.9 \mathrm{mi}^{2}$.

PERIOD OF RECORD.--October 1959 to current year.

REVISED RECORDS.--WSP 2112: Drainage area.

GAGE.--Water-stage recorder. Metal V-notch weir Aug. 30, 1961, to Mar. 6, 1968. Elevation of gage is $970 \mathrm{ft}$ above National Geodetic Vertical Datum of 1929, from topographic map.

REMARKS. --Estimated daily discharges: Nov. 14, Dec, 11-14, 22, Jan. 4, 5, 12, 13, 16, 17, Jan. 19 to Feb. 3, Feb. 5, 6, 8, 9, 13-16, 18-21, and Mar. 4, 10, 11. Records good except for estimated daily discharges, which are fair. Several measurements of water temperature were made during the year.

AVERAGE DISCHARGE. - -28 years, $12.7 \mathrm{ft}^{3} / \mathrm{s}, 8.25 \mathrm{in} / \mathrm{yr}$.

EXTREMES FOR PERIOD OF RECORD,--Maximum discharge, $181 \mathrm{ft}^{3} / \mathrm{s}$, Oct, 1, 1981, gage height, $4.53 \mathrm{ft}$; minimum, $0.05 \mathrm{ft}^{3} / \mathrm{s}$, Aug. $21,24,27,1984$; minimum gage height, 1.59 ft, Aug. 1, 2,1960 .

EXTREMES FOR CURRENT YEAR.--Maximum discharge, $49 \mathrm{ft}^{3} / \mathrm{s}$, Oct. l, gage height, $3.17 \mathrm{ft}$, stage falling, peak occurred Sept. 30, 1986; maximum peak discharge, $48 \mathrm{ft}^{3} / \mathrm{s}$, Apr. 5, gage height, $3.10 \mathrm{ft}$, no independent peak discharge above base discharge of $55 \mathrm{ft}^{3} / \mathrm{s}$; minimum discharge, $0.33 \mathrm{ft} / \mathrm{s}$, Aug. 8, gage height, $1.74 \mathrm{ft}$.

DISCHARGE, IN CUBIC FEET PER SECOND, WATER YEAR OCTOBER 1986 TO SEPTEMBER 1987

\begin{tabular}{|c|c|c|c|c|c|c|c|c|c|c|c|c|}
\hline \multirow[b]{2}{*}{ DAY } & \multirow[b]{2}{*}{ OCT } & \multirow[b]{2}{*}{ NOV } & \multicolumn{10}{|c|}{ MLAN V } \\
\hline & & & $\mathrm{DEC}$ & JAN & FEB & MAR & APR & MAY & JUN & JUL & AUG & SEP \\
\hline $\begin{array}{l}1 \\
2 \\
3 \\
4 \\
5\end{array}$ & $\begin{array}{l}46 \\
45 \\
43 \\
47 \\
45\end{array}$ & $\begin{array}{l}18 \\
18 \\
17 \\
16 \\
16\end{array}$ & $\begin{array}{l}14 \\
16 \\
23 \\
24 \\
21\end{array}$ & $\begin{array}{l}14 \\
14 \\
14 \\
14 \\
14\end{array}$ & $\begin{array}{l}11 \\
12 \\
12 \\
12 \\
11\end{array}$ & $\begin{array}{l}27 \\
34 \\
27 \\
23 \\
23\end{array}$ & $\begin{array}{l}24 \\
27 \\
25 \\
23 \\
38\end{array}$ & $\begin{array}{r}9.8 \\
9.7 \\
10 \\
9.3 \\
8.8\end{array}$ & $\begin{array}{r}7.7 \\
8.6 \\
11 \\
7.8 \\
6.9\end{array}$ & $\begin{array}{l}5.8 \\
4.8 \\
5.2 \\
6.2 \\
5.1\end{array}$ & $\begin{array}{r}1.1 \\
1.2 \\
.95 \\
.72 \\
.53\end{array}$ & $\begin{array}{l}3.6 \\
3.4 \\
3.1 \\
3.0 \\
2.9\end{array}$ \\
\hline $\begin{array}{r}6 \\
7 \\
8 \\
9 \\
10\end{array}$ & $\begin{array}{l}40 \\
36 \\
33 \\
30 \\
29\end{array}$ & $\begin{array}{l}16 \\
15 \\
14 \\
14 \\
13\end{array}$ & $\begin{array}{l}20 \\
20 \\
21 \\
23 \\
28\end{array}$ & $\begin{array}{l}14 \\
14 \\
14 \\
13 \\
14\end{array}$ & $\begin{array}{l}11 \\
11 \\
11 \\
11 \\
11\end{array}$ & $\begin{array}{l}23 \\
30 \\
37 \\
36 \\
31\end{array}$ & $\begin{array}{l}45 \\
39 \\
34 \\
29 \\
26\end{array}$ & $\begin{array}{l}8.4 \\
7.4 \\
7.4 \\
7.0 \\
6.9\end{array}$ & $\begin{array}{l}6.4 \\
6.0 \\
5.5 \\
5.3 \\
5.2\end{array}$ & $\begin{array}{l}6.9 \\
6.6 \\
4.8 \\
5.2 \\
8.5\end{array}$ & $\begin{array}{r}.46 \\
.43 \\
.39 \\
1.8 \\
2.3\end{array}$ & $\begin{array}{l}2.9 \\
2.8 \\
3.2 \\
4.9 \\
4.0\end{array}$ \\
\hline $\begin{array}{l}11 \\
12 \\
13 \\
14 \\
15\end{array}$ & $\begin{array}{l}27 \\
26 \\
26 \\
34 \\
32\end{array}$ & $\begin{array}{c}13 \\
12 \\
11 \\
10 \\
9.8\end{array}$ & $\begin{array}{l}24 \\
20 \\
18 \\
16 \\
15\end{array}$ & $\begin{array}{l}15 \\
14 \\
14 \\
14 \\
18\end{array}$ & $\begin{array}{r}11 \\
9.9 \\
9.5 \\
9.0 \\
8.6\end{array}$ & $\begin{array}{l}24 \\
20 \\
19 \\
19 \\
19\end{array}$ & $\begin{array}{l}24 \\
25 \\
24 \\
23 \\
23\end{array}$ & $\begin{array}{r}9.2 \\
8.2 \\
7.2 \\
11 \\
37\end{array}$ & $\begin{array}{l}3.2 \\
3.2 \\
3.0 \\
2.8 \\
3.0\end{array}$ & $\begin{array}{l}6.9 \\
6.0 \\
5.4 \\
4.9 \\
4.2\end{array}$ & $\begin{array}{l}1.6 \\
1.3 \\
1.2 \\
1.1 \\
1.3\end{array}$ & $\begin{array}{l}4.1 \\
4.5 \\
4.1 \\
3.7 \\
4.2\end{array}$ \\
\hline $\begin{array}{l}16 \\
17 \\
18 \\
19 \\
20\end{array}$ & $\begin{array}{l}30 \\
28 \\
26 \\
25 \\
23\end{array}$ & $\begin{array}{l}11 \\
11 \\
10 \\
9.4 \\
9.9\end{array}$ & $\begin{array}{l}14 \\
16 \\
22 \\
22 \\
20\end{array}$ & $\begin{array}{l}17 \\
15 \\
14 \\
13 \\
12\end{array}$ & $\begin{array}{l}8.2 \\
8.0 \\
7.8 \\
7.6 \\
7.4\end{array}$ & $\begin{array}{l}20 \\
20 \\
20 \\
20 \\
20\end{array}$ & $\begin{array}{l}29 \\
27 \\
25 \\
23 \\
21\end{array}$ & $\begin{array}{l}24 \\
19 \\
17 \\
16 \\
14\end{array}$ & $\begin{array}{l}2.7 \\
3.0 \\
2.8 \\
2.4 \\
2.1\end{array}$ & $\begin{array}{l}3.9 \\
3.5 \\
3.2 \\
2.6 \\
2.6\end{array}$ & $\begin{array}{l}1.1 \\
3.6 \\
2.6 \\
2.0 \\
1.6\end{array}$ & $\begin{array}{l}4.9 \\
6.5 \\
6.6 \\
5.8 \\
5.2\end{array}$ \\
\hline $\begin{array}{l}21 \\
22 \\
23 \\
24 \\
25\end{array}$ & $\begin{array}{l}23 \\
22 \\
21 \\
21 \\
19\end{array}$ & $\begin{array}{l}11 \\
11 \\
12 \\
14 \\
13\end{array}$ & $\begin{array}{l}18 \\
17 \\
15 \\
15 \\
18\end{array}$ & $\begin{array}{l}12 \\
11 \\
11 \\
11 \\
11\end{array}$ & $\begin{array}{l}7.2 \\
7.2 \\
8.2 \\
8.6 \\
8.9\end{array}$ & $\begin{array}{l}19 \\
18 \\
18 \\
20 \\
20\end{array}$ & $\begin{array}{l}19 \\
18 \\
18 \\
16 \\
15\end{array}$ & $\begin{array}{l}13 \\
14 \\
13 \\
12 \\
11\end{array}$ & $\begin{array}{l}2.5 \\
3.6 \\
3.2 \\
2.7 \\
2.5\end{array}$ & $\begin{array}{l}2.7 \\
2.3 \\
2.1 \\
1.8 \\
1.9\end{array}$ & $\begin{array}{l}1.9 \\
9.4 \\
6.0 \\
3.8 \\
3.1\end{array}$ & $\begin{array}{l}5.8 \\
5.8 \\
5.3 \\
4.7 \\
4.4\end{array}$ \\
\hline $\begin{array}{l}26 \\
27 \\
28 \\
29 \\
30 \\
31\end{array}$ & $\begin{array}{l}20 \\
23 \\
24 \\
22 \\
20 \\
18\end{array}$ & $\begin{array}{l}17 \\
20 \\
18 \\
17 \\
15 \\
-\end{array}$ & $\begin{array}{l}18 \\
17 \\
16 \\
15 \\
15 \\
14\end{array}$ & $\begin{array}{l}11 \\
11 \\
11 \\
11 \\
11 \\
11\end{array}$ & $\begin{array}{l}10 \\
11 \\
12 \\
--- \\
--\end{array}$ & $\begin{array}{l}21 \\
20 \\
19 \\
19 \\
26 \\
26\end{array}$ & $\begin{array}{r}14 \\
13 \\
13 \\
12 \\
9.9 \\
\end{array}$ & $\begin{array}{l}9.7 \\
9.0 \\
8.1 \\
7.9 \\
7.2 \\
8.6\end{array}$ & $\begin{array}{l}4.2 \\
3.5 \\
2.9 \\
3.5 \\
8.1 \\
\end{array}$ & $\begin{array}{l}2.2 \\
1.9 \\
1.6 \\
1.3 \\
1.2 \\
1.1\end{array}$ & $\begin{array}{l}3.5 \\
7.8 \\
6.0 \\
5.2 \\
4.3 \\
3.9\end{array}$ & $\begin{array}{l}3.9 \\
3.6 \\
3.4 \\
3.5 \\
3.8 \\
\end{array}$ \\
\hline $\begin{array}{l}\text { TOTAL } \\
\text { MEAN } \\
\text { MAX } \\
\text { MIN } \\
\text { CFSM } \\
\text { IN. }\end{array}$ & $\begin{array}{r}904 \\
29.2 \\
47 \\
18 \\
1.40 \\
1.61\end{array}$ & $\begin{array}{r}412.1 \\
13.7 \\
20 \\
9.4 \\
.66 \\
.73\end{array}$ & $\begin{array}{r}575 \\
18.5 \\
28 \\
14 \\
.89 \\
1.02\end{array}$ & $\begin{array}{r}407 \\
13.1 \\
18 \\
11 \\
.63 \\
.72\end{array}$ & $\begin{array}{r}273.1 \\
9.75 \\
12 \\
7.2 \\
.47 \\
.49\end{array}$ & $\begin{array}{r}718 \\
23.2 \\
37 \\
18 \\
1.11 \\
1.28\end{array}$ & $\begin{array}{r}701.9 \\
23.4 \\
45 \\
9.9 \\
1.12 \\
1.25\end{array}$ & $\begin{array}{r}360.8 \\
11.6 \\
37 \\
6.9 \\
.56 \\
.64\end{array}$ & $\begin{array}{r}135.3 \\
4.51 \\
11 \\
2.1 \\
.22 \\
.24\end{array}$ & $\begin{array}{r}122.4 \\
3.95 \\
8.5 \\
1.1 \\
.19 \\
.22\end{array}$ & $\begin{array}{r}82.18 \\
2.65 \\
9.4 \\
.39 \\
.13 \\
.15\end{array}$ & $\begin{array}{r}127.6 \\
4.25 \\
6.6 \\
2.8 \\
.20 \\
.23\end{array}$ \\
\hline
\end{tabular}

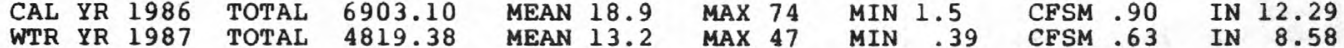


04160900 CLINTON RIVER NEAR DRAYTON PLAINS, MI

LOCATION. --Lat $42^{\circ} 39^{\prime} 37^{\prime \prime}$, long $83^{\circ} 23^{\prime} 25^{\prime \prime}$, in NEl/4 sec.21, T.3 N., R.9 E., Oakland County, Hydrologic Unit 04090003 , on left bank at downstream side of bridge on state Highway 59 , 1.0 mi downstream from State fish hatchery, and $2.0 \mathrm{mi}$ south of Drayton Plains.

DRAINAGE AREA. $--79.2 \mathrm{mi}^{2}$.

PERIOD OF RECORD.--October 1959 to current year.

REVISED RECORDS.--WSP 2112: Drainage area.

GAGE.--Water-stage recorder. Elevation of gage is $940 \mathrm{ft}$ above National Geodetic Vertical Datum of 1929 , from topographic map. Jan. 29 to July 9, 1964, nonrecording gage at same site and datum.

REMARKS.--Estimated daily discharges: Jan. 18-28 and Feb. 7, 8. Records good except for estimated daily discharges, which are fair. Some regulation and occasional diversion for lake-level control at many lakes upstream from station. Several measurements of water temperature were made during the year.

AVERAGE DISCHARGE. -28 years, $50.9 \mathrm{ft}^{3} / \mathrm{s}, 8.73 \mathrm{in} / \mathrm{yr}^{\circ}$

EXTREMES FOR PERIOD OF RECORD.--Maximum discharge, $276 \mathrm{ft}^{3} / \mathrm{s}$, Mar. 12, 1974, gage height, 4.95 ft; minimum, 2.4 $\mathrm{ft}^{3} / \mathrm{s}$, May 31, 1961; minimum gage height, $1.23 \mathrm{ft}$, Jan. 4, 1961.

EXTREMES FOR CURRENT YEAR.--Maximum discharge, $149 \mathrm{ft}^{3} / \mathrm{s}$, Oct. 3 , gage height, $3.98 \mathrm{ft}$; minimum, $8.2 \mathrm{ft}^{3} / \mathrm{s}, \mathrm{Apr} .24,25$, gage height, $2.08 \mathrm{ft}$.

DISCHARGE, IN CUBIC FEET PER SECOND, WATER YEAR OCTOBER 1986 TO SEPTEMBER 1987 MEAN VALUES

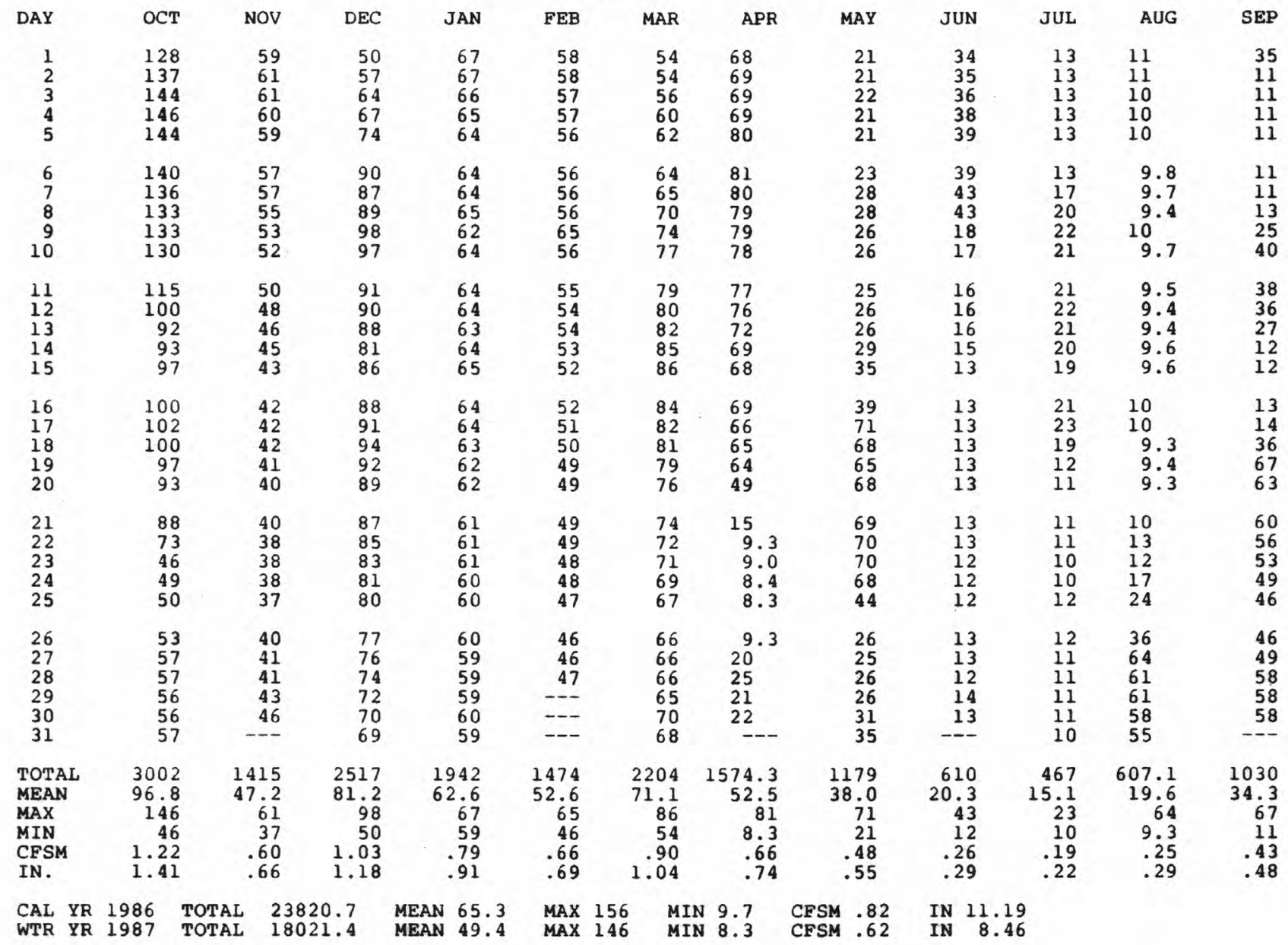


04161100 GALLOWAY CREEK NEAR AUBURN HEIGHTS, MI

LOCATION.--Lat $42^{\circ} 40^{\prime} 02^{\prime \prime}$, long $83^{\circ} 12^{\prime} 02^{\prime \prime}$, in SEl/4 sec.18, T.3 N., R.11 E., Oakland County, Hydrologic Unit 04090003 , on $\mathrm{right}$ bank $12 \mathrm{ft}$ downstream from wooden bridge on Oakland University property,
$2.7 \mathrm{mi}$ northeast of Auburn Heights.

DRAINAGE AREA.-- $-17.9 \mathrm{mi}^{2}$.

PERIOD OF RECORD.--October 1959 to current year.

REVISED RECORDS.--WSP 2112: Drainage area.

GAGE.--Water-stage recorder and concrete control. Datum of gage is $820.78 \mathrm{ft}$ above National Geodetic Vertical Datum of 1929 (levels by Johnson and Anderson, Inc.).

REMARKS.--Estimated daily discharges: Dec. 11-14, Jan. 22, and Jan. 24 to Mar. 3. Records good except for estimated daily discharges, which are fair. Several measurements of water temperature were made during the year.

AVERAGE DISCHARGE. - -28 years, $10.6 \mathrm{ft}^{3} / \mathrm{s}, 8.04 \mathrm{in} / \mathrm{yr}^{\mathrm{r}}$.

EXTREMES FOR PERIOD OF RECORD.--Maximum discharge, $536 \mathrm{ft}^{3} / \mathrm{s}$, Aug. 24, 1985; gage height, $5.62 \mathrm{ft}$;

maximum gage height, $6.27 \mathrm{ft}$, June 25, 1968; minimum discharge, $0.01 \mathrm{ft}^{3} / \mathrm{s}$, on many days during

July and August, 1964; minimum gage height, $0.82 \mathrm{ft}$, Aug. 1, 1960 .

EXTREMES FOR CURRENT YEAR.--Peak discharges greater than base discharge of $90 \mathrm{ft}^{3} / \mathrm{s}^{2}$ and maximum (*):

\begin{tabular}{|c|c|c|c|c|c|c|c|}
\hline Date & Time & $\begin{array}{c}\text { Discharge } \\
\left(\mathrm{ft}^{3} / \mathrm{s}\right)\end{array}$ & $\begin{array}{c}\text { Gage height } \\
\text { (ft) }\end{array}$ & Date & Time & $\begin{array}{l}\text { Discharge } \\
\left.\text { (ft } \mathrm{ft}^{3} / \mathrm{s}\right)\end{array}$ & $\begin{array}{c}\text { Gage height } \\
\text { (ft) }\end{array}$ \\
\hline $\begin{array}{lr}\text { Oct. } & 3 \\
\text { Mar. } & 1 \\
\text { Apr. } & 5 \\
\text { May } & 14\end{array}$ & $\begin{array}{l}1900 \\
\text { unknown } \\
1000 \\
2330\end{array}$ & $\begin{array}{r}124 \\
120 \\
120 \\
\star 127\end{array}$ & $\begin{array}{c}3.96 \\
\text { unknown } \\
3.87 \\
\star \mathrm{a} 4.0\end{array}$ & $\begin{array}{l}\text { June } 21 \\
\text { Aug. } \\
\text { Sept. } 17\end{array}$ & $\begin{array}{l}2300 \\
0600 \\
2300\end{array}$ & $\begin{array}{l}114 \\
121 \\
115\end{array}$ & $\begin{array}{l}3.76 \\
3.89 \\
3.77\end{array}$ \\
\hline
\end{tabular}

a From graph based on gage readings.

Minimum discharge, $0.73 \mathrm{ft}^{3} / \mathrm{s}$, Aug. $5,6,7$, gage height, $1.43 \mathrm{ft}$.

DISCHARGE, IN CUBIC FEET PER SECOND, WATER YEAR OCTOBER 1986 TO SEPTEMBER 1987

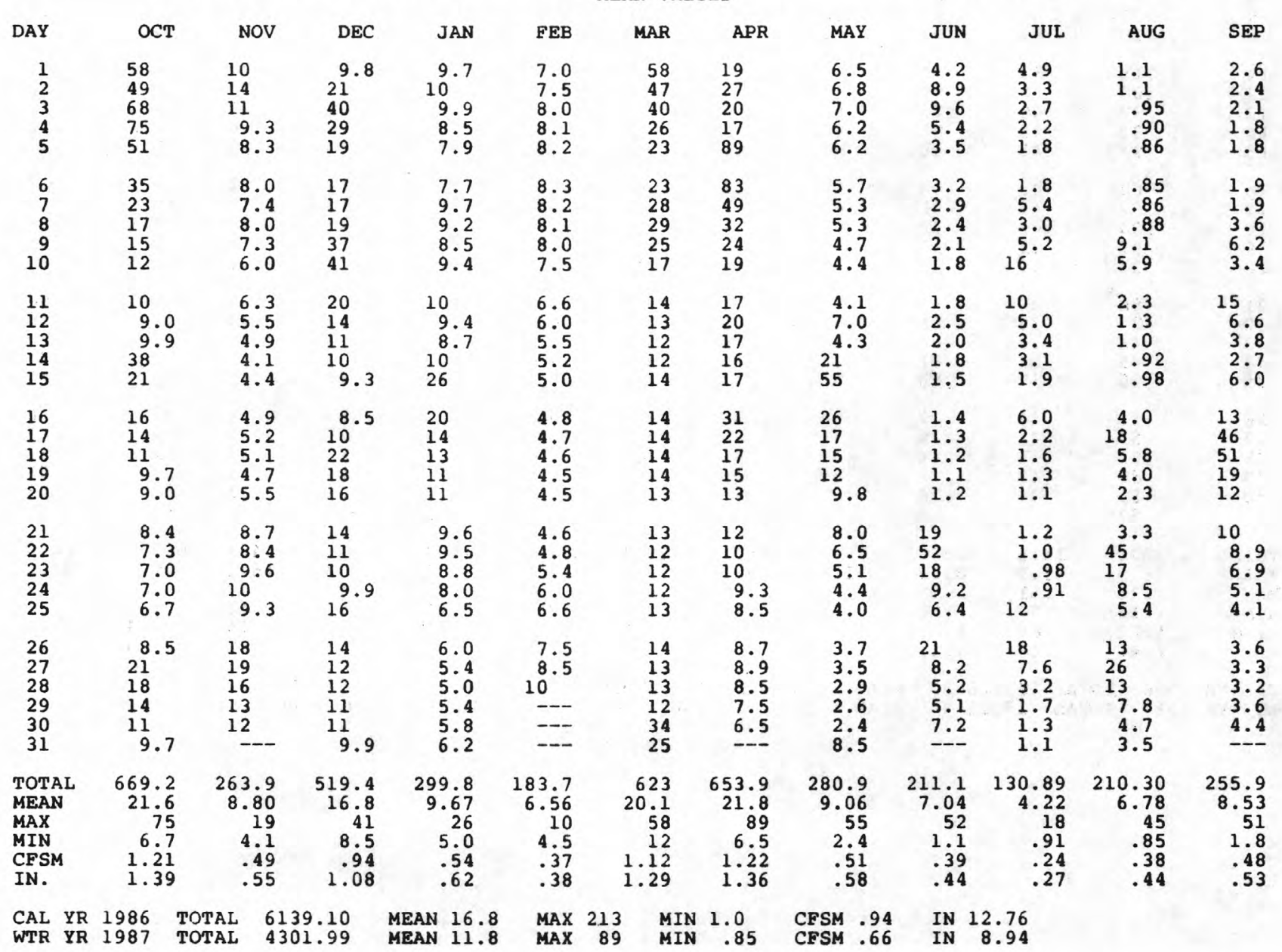


LOCATION.--Lat $42^{\circ} 41^{\prime} 18^{\prime \prime}$, long $83^{\circ} 08^{\prime} 35^{\prime \prime}$, in NW1/4 SEl/4 sec.10, T.3 N., R.11 E., Oakland County, Hydrologic Unit 04090003 , on right bank at upstream side of bridge on Ludlow Street in Rochester, $1.5 \mathrm{mi}$ upstream from mouth.

DRAINAGE AREA. $--70.9 \mathrm{mi}^{2}$.

PERIOD OF RECORD.--October 1959 to current year.

REVISED RECORDS.--WSP 2112: Drainage area.

GAGE.--Water-stage recorder. Datum of gage is $755.11 \mathrm{ft}$ above National Geodetic Vertical Datum of 1929.

REMARKS,--Estimated daily discharges: Dec. 13, 14, Jan. 23 to Feb. 1, Feb. 8, 9, 15-20, and Mar. 1. Records good except for estimated daily discharges, which are fair. Occasional regulation by Lake Orion. Several measurements of water temperature were made during the year.

AVERAGE DISCHARGE. --28 years, $52.4 \mathrm{ft}^{3} / \mathrm{s}, 10.04 \mathrm{in} / \mathrm{yr}$.

EXTREMES FOR PERIOD OF RECORD.--Maximum discharge, $918 \mathrm{ft}^{3} / \mathrm{s}$, Feb. 1, 1968; maximum gage height, $5.95 \mathrm{ft}$, Feb. 10, 1965, backwater from ice; minimum dischárge, $1.2 \mathrm{ft} / \mathrm{s}, \mathrm{Aug}$. 19, 1974, caused by regulation due to bridge construction; minimum gage height, $1.26 \mathrm{ft}$, Sept. 16, 1960 .

EXTREMES FOR CURRENT YEAR.--Maximum discharge, $264 \mathrm{ft}^{3} / \mathrm{s}$, Sept. 10 , gage height, $3.12 \mathrm{ft}$, no peak discharge above base discharge of $300 \mathrm{ft}^{3} / \mathrm{s}$; minimum, $11 \mathrm{ft} / \mathrm{s}$, Aug. i6, 21 , gage height, $1.47 \mathrm{ft}$.

DISCHARGE, IN CUBIC FEET PER SECOND, WATER YEAR OCTOBER 1986 TO SEPTEMBER 1987 MEAN VALUES

\begin{tabular}{|c|c|c|c|c|c|c|c|c|c|c|c|c|}
\hline DAY & OCT & NOV & DEC & JAN & FEB & MAR & APR & MAY & JUN & JUL & AUG & SEP \\
\hline $\begin{array}{l}1 \\
2 \\
3 \\
4 \\
5\end{array}$ & $\begin{array}{l}142 \\
134 \\
150 \\
160 \\
144\end{array}$ & $\begin{array}{l}59 \\
64 \\
58 \\
51 \\
47\end{array}$ & $\begin{array}{r}57 \\
81 \\
102 \\
90 \\
80\end{array}$ & $\begin{array}{l}55 \\
56 \\
54 \\
52 \\
51\end{array}$ & $\begin{array}{l}45 \\
46 \\
46 \\
45 \\
43\end{array}$ & $\begin{array}{r}100 \\
107 \\
71 \\
59 \\
61\end{array}$ & $\begin{array}{r}62 \\
72 \\
65 \\
60 \\
156\end{array}$ & $\begin{array}{l}34 \\
32 \\
32 \\
31 \\
31\end{array}$ & $\begin{array}{l}29 \\
34 \\
42 \\
33 \\
29\end{array}$ & $\begin{array}{l}31 \\
28 \\
28 \\
35 \\
29\end{array}$ & $\begin{array}{l}15 \\
15 \\
13 \\
13 \\
13\end{array}$ & $\begin{array}{l}19 \\
19 \\
18 \\
17 \\
16\end{array}$ \\
\hline $\begin{array}{r}6 \\
7 \\
8 \\
9 \\
10\end{array}$ & $\begin{array}{r}116 \\
97 \\
89 \\
83 \\
75\end{array}$ & $\begin{array}{l}45 \\
45 \\
48 \\
46 \\
44\end{array}$ & $\begin{array}{r}76 \\
80 \\
84 \\
100 \\
109\end{array}$ & $\begin{array}{l}51 \\
52 \\
50 \\
49 \\
51\end{array}$ & $\begin{array}{l}42 \\
43 \\
43 \\
43 \\
43\end{array}$ & $\begin{array}{l}65 \\
81 \\
90 \\
83 \\
72\end{array}$ & $\begin{array}{l}166 \\
127 \\
118 \\
110 \\
101\end{array}$ & $\begin{array}{l}32 \\
31 \\
33 \\
30 \\
33\end{array}$ & $\begin{array}{l}28 \\
27 \\
25 \\
24 \\
23\end{array}$ & $\begin{array}{l}30 \\
32 \\
30 \\
32 \\
43\end{array}$ & $\begin{array}{l}12 \\
12 \\
12 \\
41 \\
28\end{array}$ & $\begin{array}{l}16 \\
16 \\
18 \\
21 \\
24\end{array}$ \\
\hline $\begin{array}{l}11 \\
12 \\
13 \\
14 \\
15\end{array}$ & $\begin{array}{r}68 \\
64 \\
65 \\
103 \\
79\end{array}$ & $\begin{array}{l}42 \\
41 \\
40 \\
38 \\
38\end{array}$ & $\begin{array}{l}87 \\
82 \\
70 \\
65 \\
70\end{array}$ & $\begin{array}{l}52 \\
51 \\
48 \\
50 \\
65\end{array}$ & $\begin{array}{l}42 \\
42 \\
41 \\
41 \\
41\end{array}$ & $\begin{array}{l}71 \\
71 \\
70 \\
71 \\
71\end{array}$ & $\begin{array}{r}96 \\
101 \\
94 \\
87 \\
87\end{array}$ & $\begin{array}{l}35 \\
30 \\
25 \\
46 \\
64\end{array}$ & $\begin{array}{l}21 \\
23 \\
20 \\
19 \\
18\end{array}$ & $\begin{array}{l}36 \\
30 \\
29 \\
27 \\
25\end{array}$ & $\begin{array}{l}19 \\
15 \\
15 \\
15 \\
14\end{array}$ & $\begin{array}{l}44 \\
25 \\
22 \\
21 \\
26\end{array}$ \\
\hline $\begin{array}{l}16 \\
17 \\
18 \\
19 \\
20\end{array}$ & $\begin{array}{l}72 \\
86 \\
65 \\
61 \\
58\end{array}$ & $\begin{array}{l}38 \\
38 \\
38 \\
37 \\
39\end{array}$ & $\begin{array}{l}65 \\
67 \\
81 \\
70 \\
65\end{array}$ & $\begin{array}{l}58 \\
54 \\
50 \\
49 \\
53\end{array}$ & $\begin{array}{l}40 \\
40 \\
39 \\
38 \\
37\end{array}$ & $\begin{array}{l}69 \\
65 \\
63 \\
60 \\
58\end{array}$ & $\begin{array}{r}100 \\
85 \\
80 \\
76 \\
72\end{array}$ & $\begin{array}{l}36 \\
31 \\
33 \\
37 \\
39\end{array}$ & $\begin{array}{l}16 \\
16 \\
16 \\
15 \\
15\end{array}$ & $\begin{array}{l}25 \\
22 \\
20 \\
19 \\
18\end{array}$ & $\begin{array}{l}20 \\
35 \\
19 \\
16 \\
13\end{array}$ & $\begin{array}{l}37 \\
67 \\
68 \\
44 \\
40\end{array}$ \\
\hline $\begin{array}{l}21 \\
22 \\
23 \\
24 \\
25\end{array}$ & $\begin{array}{l}56 \\
55 \\
55 \\
53 \\
51\end{array}$ & $\begin{array}{l}44 \\
44 \\
45 \\
48 \\
50\end{array}$ & $\begin{array}{l}62 \\
59 \\
57 \\
57 \\
67\end{array}$ & $\begin{array}{l}51 \\
49 \\
49 \\
47 \\
46\end{array}$ & $\begin{array}{l}36 \\
37 \\
40 \\
40 \\
40\end{array}$ & $\begin{array}{l}56 \\
54 \\
53 \\
52 \\
54\end{array}$ & $\begin{array}{l}69 \\
64 \\
59 \\
45 \\
41\end{array}$ & $\begin{array}{l}38 \\
38 \\
36 \\
34 \\
33\end{array}$ & $\begin{array}{l}37 \\
46 \\
25 \\
21 \\
21\end{array}$ & $\begin{array}{l}22 \\
19 \\
18 \\
17 \\
26\end{array}$ & $\begin{array}{l}12 \\
74 \\
27 \\
18 \\
16\end{array}$ & $\begin{array}{l}39 \\
36 \\
35 \\
30 \\
27\end{array}$ \\
\hline $\begin{array}{l}26 \\
27 \\
28 \\
29 \\
30 \\
31\end{array}$ & $\begin{array}{l}55 \\
64 \\
64 \\
59 \\
58 \\
57\end{array}$ & $\begin{array}{r}67 \\
67 \\
59 \\
57 \\
57 \\
---\end{array}$ & $\begin{array}{l}61 \\
57 \\
57 \\
56 \\
55 \\
54\end{array}$ & $\begin{array}{l}45 \\
43 \\
42 \\
42 \\
43 \\
44\end{array}$ & $\begin{array}{r}40 \\
40 \\
43 \\
--- \\
--- \\
---\end{array}$ & $\begin{array}{l}57 \\
54 \\
51 \\
51 \\
83 \\
71\end{array}$ & $\begin{array}{r}40 \\
40 \\
39 \\
36 \\
34 \\
-\end{array}$ & $\begin{array}{l}32 \\
32 \\
30 \\
27 \\
27 \\
30\end{array}$ & $\begin{array}{r}46 \\
27 \\
24 \\
26 \\
41 \\
---\end{array}$ & $\begin{array}{l}22 \\
19 \\
16 \\
15 \\
15 \\
15\end{array}$ & $\begin{array}{l}26 \\
45 \\
28 \\
24 \\
21 \\
19\end{array}$ & $\begin{array}{l}25 \\
25 \\
25 \\
26 \\
29 \\
\end{array}$ \\
\hline $\begin{array}{l}\text { TOTAL } \\
\text { MEAN } \\
\text { MAX } \\
\text { MIN } \\
\text { CFSM } \\
\text { IN. }\end{array}$ & $\begin{array}{r}2538 \\
81.9 \\
160 \\
51 \\
1.16 \\
1.33\end{array}$ & $\begin{array}{r}1434 \\
47.8 \\
67 \\
37 \\
.67 \\
.75\end{array}$ & $\begin{array}{r}2223 \\
71.7 \\
109 \\
54 \\
1.01 \\
1.17\end{array}$ & $\begin{array}{r}1552 \\
50.1 \\
65 \\
42 \\
.71 \\
.81\end{array}$ & $\begin{array}{r}1156 \\
41.3 \\
46 \\
36 \\
.58 \\
.61\end{array}$ & $\begin{array}{r}2094 \\
67.5 \\
107 \\
51 \\
.95 \\
1.10\end{array}$ & $\begin{array}{r}2382 \\
79.4 \\
166 \\
34 \\
1.12 \\
1.25\end{array}$ & $\begin{array}{r}1052 \\
33.9 \\
64 \\
25 \\
.48 \\
.55\end{array}$ & $\begin{array}{r}787 \\
26.2 \\
46 \\
15 \\
.37 \\
.41\end{array}$ & $\begin{array}{r}773 \\
24.9 \\
43 \\
15 \\
.35 \\
.41\end{array}$ & $\begin{array}{r}665 \\
21.5 \\
74 \\
12 \\
.30 \\
.35\end{array}$ & $\begin{array}{r}875 \\
29.2 \\
68 \\
16 \\
.41 \\
.46\end{array}$ \\
\hline
\end{tabular}

$\begin{array}{lllllllllll}\text { CAL YR } 1986 & \text { TOTAL } 24729 & \text { MEAN } 67.8 & \text { MAX } 344 & \text { MIN } 22 & \text { CFSM } & .96 & \text { IN } 12.97\end{array}$ WTR YR 1987 TOTAL 17531 MEAN 48.0 MAX 166 MIN 12 CFSM .68 IN 9.20 


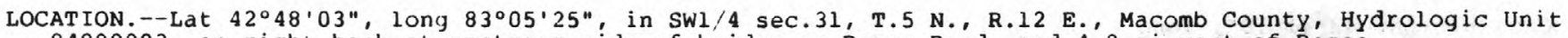
04090003 , on right bank at upstream side of bridge on Romeo Road, and $4.0 \mathrm{mi}$ west of Romeo.

DRA INAGE AREA. $--25.6 \mathrm{mi}^{2}$.

PERIOD OF RECORD.--October 1964 to current year.

GAGE.--Water-stage recorder. Datum of gage is $861.64 \mathrm{ft}$ above National Geodetic vertical Datum of 1929 .

REMARKS.--Estimated daily discharges: Dec. 11-14, Jan. 17 to Feb. 3, Feb. 5, 6, 9, 15, 16, 19, 20, and Mar. 3, 4, 10, 11. Records good except for estimated daily discharges, which are fair. Several measurements of water temperature were made during the year.

AVERAGE DISCHARGE. --23 years, $17.6 \mathrm{ft}^{3} / \mathrm{s}, 9.34 \mathrm{in} / \mathrm{yr}^{2}$

EXTREMES FOR PERIOD OF RECORD,--Maximum discharge, $290 \mathrm{ft}^{3} / \mathrm{s}$, Apr. 19, 1975, gage height, 5.19 ft; minimum, $0.92 \mathrm{ft} / \mathrm{s}$, Oct. 5, 9, 1967; minimum gage height, $1.28 \mathrm{ft}, \mathrm{July} 27,28,1965$.

EXTREMES FOR CURRENT YEAR.--Maximum discharge, $77 \mathrm{ft}^{3} / \mathrm{s}$, July 25 , gage height, $3.2 \mathrm{ft}$, from graph based on gage readings, no peak discharge above base discharge of $100 \mathrm{ft} / \mathrm{s}^{3} \mathrm{minimum,} 2.1 \mathrm{ft} 3 / \mathrm{s}^{2} \mathrm{Aug}$. 8 , gage height, 1.46 ft.

DISCHARGE, IN CUBIC FEET PER SECOND, WATER YEAR OCTOBER 1986 TO SEPTEMBER 1987 MEAN VALUES

\begin{tabular}{|c|c|c|c|c|c|c|c|c|c|c|c|c|}
\hline DAY & OCT & NOV & DEC & JAN & FEB & MAR & APR & MAY & JUN & JUL & AUG & SEP \\
\hline $\begin{array}{l}1 \\
2 \\
3 \\
4 \\
5\end{array}$ & $\begin{array}{l}33 \\
32 \\
31 \\
40 \\
41\end{array}$ & $\begin{array}{r}12 \\
14 \\
12 \\
11 \\
9.9\end{array}$ & $\begin{array}{l}12 \\
15 \\
23 \\
21 \\
19\end{array}$ & $\begin{array}{l}18 \\
18 \\
18 \\
16 \\
16\end{array}$ & $\begin{array}{l}12 \\
13 \\
13 \\
13 \\
13\end{array}$ & $\begin{array}{l}34 \\
39 \\
36 \\
33 \\
32\end{array}$ & $\begin{array}{l}29 \\
32 \\
31 \\
28 \\
43\end{array}$ & $\begin{array}{l}9.1 \\
8.9 \\
8.3 \\
7.9 \\
7.6\end{array}$ & $\begin{array}{l}6.1 \\
6.8 \\
8.8 \\
5.9 \\
5.0\end{array}$ & $\begin{array}{l}4.3 \\
4.0 \\
4.4 \\
5.0 \\
3.7\end{array}$ & $\begin{array}{l}6.4 \\
3.7 \\
3.2 \\
2.8 \\
2.6\end{array}$ & $\begin{array}{r}16 \\
17 \\
13 \\
4.2 \\
3.4\end{array}$ \\
\hline $\begin{array}{r}6 \\
7 \\
8 \\
9 \\
10\end{array}$ & $\begin{array}{l}34 \\
32 \\
30 \\
28 \\
24\end{array}$ & $\begin{array}{c}10 \\
14 \\
14 \\
12 \\
9.8\end{array}$ & $\begin{array}{l}17 \\
18 \\
22 \\
30 \\
44\end{array}$ & $\begin{array}{l}15 \\
16 \\
16 \\
15 \\
15\end{array}$ & $\begin{array}{l}12 \\
12 \\
12 \\
12 \\
12\end{array}$ & $\begin{array}{l}33 \\
41 \\
50 \\
48 \\
26\end{array}$ & $\begin{array}{l}53 \\
47 \\
40 \\
45 \\
46\end{array}$ & $\begin{array}{l}7.5 \\
7.2 \\
7.1 \\
6.8 \\
6.7\end{array}$ & $\begin{array}{r}4.8 \\
4.7 \\
11 \\
9.9 \\
6.5\end{array}$ & $\begin{array}{l}4.3 \\
4.2 \\
3.5 \\
3.5 \\
5.4\end{array}$ & $\begin{array}{l}2.4 \\
2.4 \\
2.4 \\
4.6 \\
3.8\end{array}$ & $\begin{array}{l}3.1 \\
2.8 \\
2.8 \\
3.2 \\
3.1\end{array}$ \\
\hline $\begin{array}{l}11 \\
12 \\
13 \\
14 \\
15\end{array}$ & $\begin{array}{l}24 \\
23 \\
22 \\
30 \\
27\end{array}$ & $\begin{array}{l}9.5 \\
9.3 \\
8.1 \\
7.7 \\
7.7\end{array}$ & $\begin{array}{l}45 \\
36 \\
31 \\
28 \\
26\end{array}$ & $\begin{array}{l}17 \\
16 \\
16 \\
16 \\
20\end{array}$ & $\begin{array}{l}11 \\
11 \\
11 \\
11 \\
11\end{array}$ & $\begin{array}{l}25 \\
24 \\
23 \\
32 \\
32\end{array}$ & $\begin{array}{l}42 \\
41 \\
40 \\
36 \\
36\end{array}$ & $\begin{array}{r}6.6 \\
6.7 \\
6.3 \\
8.8 \\
18\end{array}$ & $\begin{array}{l}5.9 \\
6.1 \\
5.5 \\
4.6 \\
4.5\end{array}$ & $\begin{array}{l}6.3 \\
4.3 \\
3.6 \\
3.8 \\
3.4\end{array}$ & $\begin{array}{l}2.9 \\
2.7 \\
2.6 \\
2.7 \\
3.3\end{array}$ & $\begin{array}{l}4.9 \\
4.5 \\
3.9 \\
4.0 \\
5.2\end{array}$ \\
\hline $\begin{array}{l}16 \\
17 \\
18 \\
19 \\
20\end{array}$ & $\begin{array}{l}25 \\
24 \\
20 \\
17 \\
16\end{array}$ & $\begin{array}{r}8.3 \\
9.3 \\
12 \\
9.3 \\
8.6\end{array}$ & $\begin{array}{l}23 \\
22 \\
27 \\
26 \\
24\end{array}$ & $\begin{array}{l}19 \\
15 \\
15 \\
14 \\
14\end{array}$ & $\begin{array}{r}10 \\
9.9 \\
9.6 \\
9.4 \\
9.2\end{array}$ & $\begin{array}{l}32 \\
30 \\
26 \\
25 \\
24\end{array}$ & $\begin{array}{l}39 \\
37 \\
33 \\
29 \\
26\end{array}$ & $\begin{array}{r}10 \\
8.2 \\
8.0 \\
12 \\
19\end{array}$ & $\begin{array}{l}3.6 \\
3.5 \\
3.5 \\
6.2 \\
3.8\end{array}$ & $\begin{array}{l}3.4 \\
3.1 \\
2.9 \\
2.9 \\
2.8\end{array}$ & $\begin{array}{l}3.1 \\
6.6 \\
3.8 \\
3.2 \\
3.3\end{array}$ & $\begin{array}{l}5.7 \\
16 \\
56 \\
40 \\
31\end{array}$ \\
\hline $\begin{array}{l}21 \\
22 \\
23 \\
24 \\
25\end{array}$ & $\begin{array}{l}15 \\
15 \\
15 \\
14 \\
16\end{array}$ & $\begin{array}{l}9.8 \\
11 \\
12 \\
14 \\
16\end{array}$ & $\begin{array}{l}23 \\
20 \\
19 \\
19 \\
24\end{array}$ & $\begin{array}{l}14 \\
14 \\
14 \\
13 \\
13\end{array}$ & $\begin{array}{l}9.0 \\
9.4 \\
10 \\
11 \\
11\end{array}$ & $\begin{array}{l}27 \\
25 \\
23 \\
27 \\
28\end{array}$ & $\begin{array}{l}22 \\
15 \\
14 \\
14 \\
12\end{array}$ & $\begin{array}{l}17 \\
17 \\
14 \\
10 \\
7.6\end{array}$ & $\begin{array}{l}4.4 \\
6.4 \\
4.5 \\
3.8 \\
4.3\end{array}$ & $\begin{array}{r}2.9 \\
2.7 \\
2.7 \\
2.7 \\
32\end{array}$ & $\begin{array}{l}3.2 \\
9.8 \\
5.2 \\
3.7 \\
4.1\end{array}$ & $\begin{array}{l}26 \\
23 \\
24 \\
22 \\
19\end{array}$ \\
\hline $\begin{array}{l}26 \\
27 \\
28 \\
29 \\
30 \\
31\end{array}$ & $\begin{array}{l}18 \\
19 \\
19 \\
16 \\
15 \\
13\end{array}$ & $\begin{array}{l}21 \\
21 \\
18 \\
16 \\
16 \\
---\end{array}$ & $\begin{array}{l}23 \\
21 \\
20 \\
19 \\
19 \\
18\end{array}$ & $\begin{array}{l}13 \\
13 \\
12 \\
12 \\
12 \\
12\end{array}$ & $\begin{array}{l}11 \\
11 \\
12 \\
--- \\
--- \\
--\end{array}$ & $\begin{array}{l}29 \\
27 \\
26 \\
24 \\
34 \\
32\end{array}$ & $\begin{array}{r}12 \\
11 \\
12 \\
11 \\
9.6 \\
-\end{array}$ & $\begin{array}{r}12 \\
9.4 \\
8.4 \\
9.3 \\
5.2 \\
9.1\end{array}$ & $\begin{array}{r}11 \\
4.8 \\
4.0 \\
4.1 \\
4.8 \\
-\end{array}$ & $\begin{array}{l}21 \\
24 \\
24 \\
22 \\
21 \\
19\end{array}$ & $\begin{array}{l}9.1 \\
20 \\
18 \\
21 \\
17 \\
13\end{array}$ & $\begin{array}{c}17 \\
17 \\
16 \\
15 \\
8.3\end{array}$ \\
\hline $\begin{array}{l}\text { TOTAL } \\
\text { MEAN } \\
\text { MAX } \\
\text { MIN } \\
\text { CFSM } \\
\text { IN. }\end{array}$ & $\begin{array}{r}728 \\
23.5 \\
41 \\
13 \\
.92 \\
1.06\end{array}$ & $\begin{array}{r}363.3 \\
12.1 \\
21 \\
7.7 \\
.47 \\
.53\end{array}$ & $\begin{array}{r}734 \\
23.7 \\
45 \\
12 \\
.93 \\
1.07\end{array}$ & $\begin{array}{r}467 \\
15.1 \\
20 \\
12 \\
.59 \\
.68\end{array}$ & $\begin{array}{r}311.5 \\
11.1 \\
13 \\
9.0 \\
.43 \\
.45\end{array}$ & $\begin{array}{r}947 \\
30.5 \\
50 \\
23 \\
1.19 \\
1.38\end{array}$ & $\begin{array}{r}885.6 \\
29.5 \\
53 \\
9.6 \\
1.15 \\
1.29\end{array}$ & $\begin{array}{r}299.7 \\
9.67 \\
19 \\
5.2 \\
.38 \\
.44\end{array}$ & $\begin{array}{r}168.8 \\
5.63 \\
11 \\
3.5 \\
.22 \\
.25\end{array}$ & $\begin{array}{r}252.8 \\
8.15 \\
32 \\
2.7 \\
.32 \\
.37\end{array}$ & $\begin{array}{r}192.6 \\
6.21 \\
21 \\
2.4 \\
.24 \\
.28\end{array}$ & $\begin{array}{r}427.1 \\
14.2 \\
56 \\
2.8 \\
.56 \\
.62\end{array}$ \\
\hline
\end{tabular}

$\begin{array}{lllllllllll}\text { CAL YR } 1986 & \text { TOTAL } & 7862.3 & \text { MEAN 21.5 } & \text { MAX } 100 & \text { MIN } 4.0 & \text { CFSM } & .84 & \text { IN } 11.42 \\ \text { WTR YR } 1987 & \text { TOTAL } & 5777.4 & \text { MEAN } 15.8 & \text { MAX } & 56 & \text { MIN } 2.4 & \text { CFSM } & .62 & \text { IN } & 8.39\end{array}$ 
04161790 STONY LAKE NEAR WASHINGTON, MI

LOCATION.--Lat $42^{\circ} 42^{\circ} 58^{\prime \prime}$, long $83^{\circ} 05^{\circ} 58^{\prime \prime}$, in SEl/4 sec.31, T.4 N., R.12 E., Macomb County, Hydrologic Unit 04090003 , on left bank $1,000 \mathrm{ft}$ east of bridge over dam on stony Creek, 2.7 mi west of washington.

DRAINAGE AREA, $--68.0 \mathrm{mi}^{2}$.

PERIOD OF RECORD. --February 1963 to current year.

REVISED RECORDS.--WDR MI-77-1: 1976.

GAGE.--Water-stage recorder. Datum of gage is $790.00 \mathrm{ft}$ above National Geodetic Vertical Datum of 1929

(levels by Huron-Clinton Metropolitan Authority); gage readings have been converted to elevations NGVD.

REMARKS.--Reservoir is formed by an earthfill dam with concrete spillway completed in 1962 . The spillway

section includes a drum gate with minimum crest elevation of $796 \mathrm{ft}$, maximum of $802 \mathrm{ft}$; and 2 sluices,

one on each side, with valve controls capable of draining lake. Total capacity (new capacity table put

into use Oct. 1, 1973), 4,649 acre-ft at elevation of $802 \mathrm{ft}$. The reservoir began filling February

1963. Lake is used for recreational purposes.

EXTREMES FOR PERIOD OF RECORD.--Maximum contents, 5,495 acre-ft, May 17, 18, 1974, Apr. 20, 1975,

elevation, $803.6 \mathrm{ft}$; minimum recorded, 1,758 acre-ft, Nov. 21, 1967 , elevation, $794.7 \mathrm{ft}$.

EXTREMES FOR CURRENT YEAR.--Maximum contents, 4,956 acre-ft, Oct, 4, 5, elevation, 802.59 ft; minimum,

3,844 acre-ft, Feb. 19-22, elevation, $800.35 \mathrm{ft}$.

MONTHEND ELEVATION, IN FEET NGVD, AND CONTENTS AT 2400, WATER YEAR OCTOBER 1986 TO SEPTEMBER 1987

Date

Sept. 30 . . . . . . . . . . . . . .

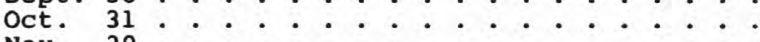

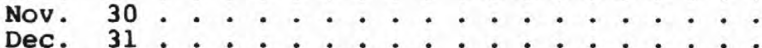

CAL YR $1986 \ldots \ldots$

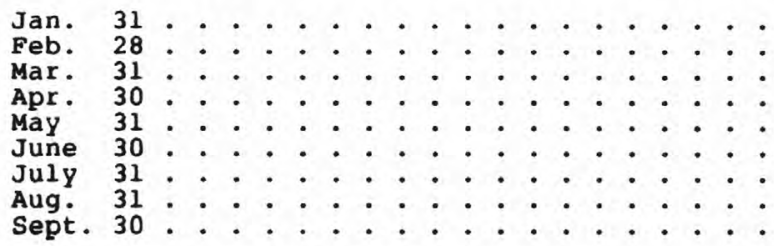

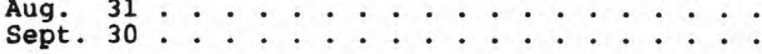

WTR YR 1987 . . . . . . . . . . . . . .

$\begin{array}{cc}\begin{array}{c}\text { Elevation } \\ \text { (feet) }\end{array} & \begin{array}{c}\text { Contents } \\ \text { (acre-feet) }\end{array} \\ 802.58 & 4,951 \\ 802.34 & 4,826 \\ 802.35 & 4,831 \\ 800.63 & 3,975\end{array}$

$--$

800.42

800.43

801.34

802.22

802.18

802.18

802.16

802.21

802.23

3,876

3,881

4,319

4,763

4,743

4,743

4,732

4,758

4,769
Change in contents

(acre-
feet)
in $\mathrm{ft}^{3} / \mathrm{s}$ )

$-$
--
-125
+5

+5
-856

$-2.0$

+.1
-13.9

$-5$

$-99$
0

$-1.6$

+.1
+7.1
+7.5

$+7.5$

$-.3$

-.2
+.4

$+.2$

$-.2$ 
LOCATION.--Lat $42^{\circ} 42^{\prime} 5^{\prime \prime}$, long $83^{\circ} 05^{\prime} 31^{\prime \prime}$, in SWl/4 sec.31, T.4 N., R.12 E., Macomb County, Hydrologic Unit 04090003, on left bank at downstream side of bridge on Mt. Vernon Road, 500 ft downstream from Stony Lake Dam, and $2.9 \mathrm{mi}$ west of Washington.

DRAINAGE AREA. $--68.2 \mathrm{mi}^{2}$.

PERIOD OF RECORD.--July 1958 to current year.

REVISED RECORDS.--WSP 2112: Drainage area.

GAGE.--Water-stage recorder. Datum of gage is $772.59 \mathrm{ft}$ above National Geodetic Vertical Datum of 1929 (levels by Huron-Clinton Metropolitan Authority).

REMARKS.--No estimated daily discharges. Records good. Occasional diurnal fluctuation caused by mills upstream from station prior to February 1963; occasional regulation by Stony Lake since (station $04161790)$. Several measurements of water temperature were made during the year.

AVERAGE DISCHARGE.--29 years, $43.0 \mathrm{ft} / \mathrm{s}, 8.56 \mathrm{in} / \mathrm{yr}$, adjusted for storage since 1963.

EXTREMES FOR PERIOD OF RECORD.--Maximum discharge, $427 \mathrm{ft} 3 / \mathrm{s}$, Feb. 2, 1968, gage height, 5.86 ft; maximum gage height, $6.71 \mathrm{ft}, \operatorname{Mar} .6,1959$, backwater from ice; minimum discharge, $0.9 \mathrm{ft}{ }^{3} / \mathrm{s}^{\prime}$ July 10, 1963; minimum gage height, 1.79 ft, Apr.6, 1979; minimum daily discharge, i.3 ft3/s, July 31, Aug. 1, 1964 .

EXTREMES FOR CURRENT YEAR.--Maximum discharge, $364 \mathrm{ft}^{3} / \mathrm{s}$, Dec. 31 , gage height, $5.42 \mathrm{ft} ; \mathrm{minimum,}$ $2.9 \mathrm{ft}^{3} / \mathrm{s}$, Nov. 14, gage height, $1.96 \mathrm{ft}$.

DISCHARGE, IN CUBIC FEET PER SECOND, WATER YEAR OCTOBER 1986 TO SEPTEMBER 1987 MEAN VALUES

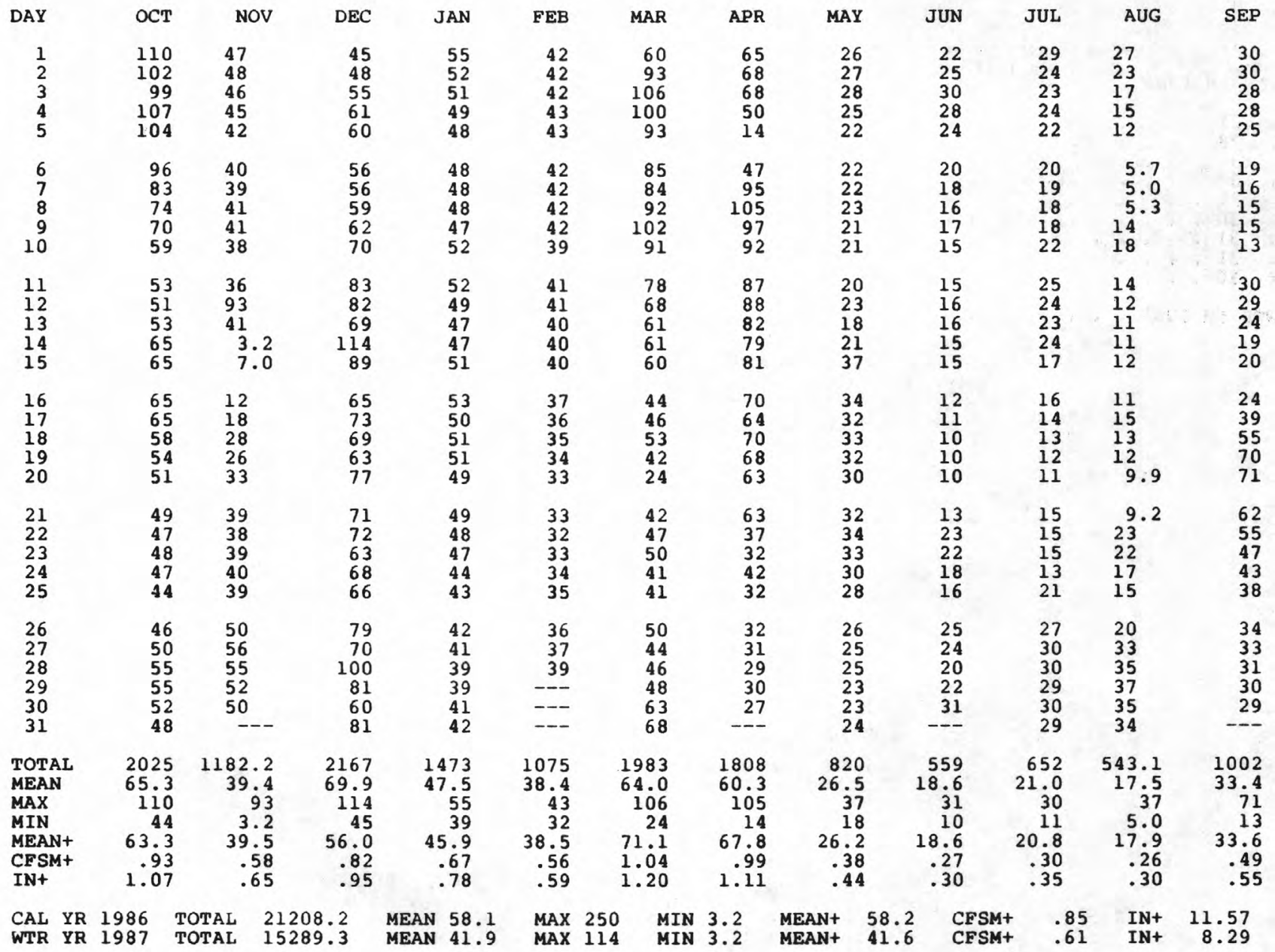

+ Adjusted for change in contents in Stony Lake. 
04162010 RED RUN NEAR WARREN, MI

LOCATION. - Lat $42^{\circ} 31^{\prime} 46^{\prime \prime}$, long $83^{\circ} 04^{\prime} 07^{\prime \prime}$, in SEl/4 NEl/4 sec.6, T.1 N., R.12 E., Macomb County, Hydrologic Unit 04090003 , on left bank at upstream side of bridge on Ryan Road, $1.0 \mathrm{mi}$ northwest of Warren.

DRA INAGE AREA.--Indeterminate.

PERIOD OF RECORD,--October 1979 to current year.

GAGE.--Water-stage recorder. Elevation of gage is $620 \mathrm{ft}$ above National Geodetic Vertical Datum of 1929 , from topographic map.

REMARKS.--Estimated daily discharges: Jan. 18 to Feb. 27. Records fair. Diversion from Big Beaver Creek basin via Henry-Graham Drain started in 1976, is ongoing and increasing with further development of new drains. Several measurements of water temperature were made during the year.

AVERAGE DISCHARGE. --8 years, $30.1 \mathrm{ft}^{3} / \mathrm{s}$.

EXTREMES FOR PERIOD OF RECORD.--Maximum discharge, $2,940 \mathrm{ft}^{3} / \mathrm{s}$, Oct. 1, 1981, gage height, $30.2 \mathrm{ft}$, from floodmark, from rating curve extended above $1,500 \mathrm{ft} / \mathrm{s} ; \mathrm{minimum} \mathrm{daily,} 0.30 \mathrm{ft} 3 / \mathrm{s}$,

Sept, 11, 1983.

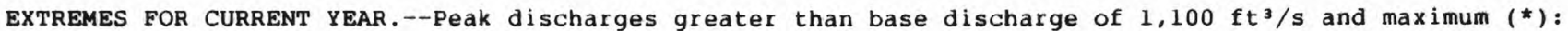

$\begin{array}{ccccccc}\text { Date } & \text { Time } & \begin{array}{c}\text { Discharge } \\ \left(\mathrm{ft}^{3} / \mathrm{s}\right)\end{array} & \begin{array}{c}\text { Gage height } \\ (\mathrm{ft})\end{array} & \text { Date } & \text { Time } & \begin{array}{c}\text { Discharge } \\ \left(\mathrm{ft} / \mathrm{s}^{3}\right)\end{array} \\ \text { Oct. } 3 & 1530 & 1,290 & 16.47 & \text { June } 21 & 2115 & \begin{array}{c}\text { Gage height } \\ (\mathrm{ft})\end{array}\end{array}$

Minimum daily discharge, $3.2 \mathrm{ft}^{3} / \mathrm{s}$, Feb. 18-20.

DISCHARGE, IN CUBIC FEET PER SECOND, WATER YEAR OCTOBER 1986 TO SEPTEMBER 1987

\begin{tabular}{|c|c|c|c|c|c|c|c|c|c|c|c|c|}
\hline DAY & OCT & NOV & DEC & JAN & FEB & MAR & APR & MAY & JUN & JUL & AUG & SEP \\
\hline $\begin{array}{l}1 \\
2 \\
3 \\
4 \\
5\end{array}$ & $\begin{array}{r}72 \\
34 \\
348 \\
106 \\
37\end{array}$ & $\begin{array}{r}20 \\
22 \\
7.5 \\
6.6 \\
6.0\end{array}$ & $\begin{array}{c}5.4 \\
168 \\
57 \\
22 \\
12\end{array}$ & $\begin{array}{r}7.1 \\
16 \\
8.9 \\
6.8 \\
6.4\end{array}$ & $\begin{array}{r}4.7 \\
6.0 \\
11 \\
7.0 \\
4.5\end{array}$ & $\begin{array}{r}164 \\
50 \\
20 \\
12 \\
29\end{array}$ & $\begin{array}{r}28 \\
49 \\
16 \\
14 \\
399\end{array}$ & $\begin{array}{r}4.9 \\
4.8 \\
15 \\
6.0 \\
5.0\end{array}$ & $\begin{array}{l}10 \\
66 \\
30 \\
8.6 \\
5.4\end{array}$ & $\begin{array}{l}16 \\
6.6 \\
53 \\
15 \\
6.9\end{array}$ & $\begin{array}{r}12 \\
15 \\
7.4 \\
4.3 \\
3.8\end{array}$ & $\begin{array}{l}4.9 \\
7.6 \\
5.1 \\
4.8 \\
4.4\end{array}$ \\
\hline $\begin{array}{r}6 \\
7 \\
8 \\
9 \\
10\end{array}$ & $\begin{array}{l}20 \\
12 \\
12 \\
15 \\
6.4\end{array}$ & $\begin{array}{l}6.0 \\
5.3 \\
8.7 \\
4.8 \\
4.3\end{array}$ & $\begin{aligned} & 9.4 \\
& 50 \\
& 35 \\
& 122 \\
& 55\end{aligned}$ & $\begin{array}{r}6.9 \\
8.5 \\
7.9 \\
6.7 \\
12\end{array}$ & $\begin{array}{r}6.0 \\
8.0 \\
11 \\
8.0 \\
6.0\end{array}$ & $\begin{array}{l}25 \\
21 \\
15 \\
11 \\
8.2\end{array}$ & $\begin{array}{r}135 \\
45 \\
25 \\
16 \\
14\end{array}$ & $\begin{array}{l}4.6 \\
4.5 \\
4.8 \\
4.4 \\
4.7\end{array}$ & $\begin{array}{l}7.0 \\
4.8 \\
4.6 \\
4.9 \\
5.1\end{array}$ & $\begin{array}{r}5.7 \\
5.5 \\
5.6 \\
49 \\
166\end{array}$ & $\begin{array}{r}3.7 \\
3.9 \\
3.8 \\
262 \\
37\end{array}$ & $\begin{array}{r}4.2 \\
4.2 \\
17 \\
17 \\
5.2\end{array}$ \\
\hline $\begin{array}{l}11 \\
12 \\
13 \\
14 \\
15\end{array}$ & $\begin{array}{l}5.5 \\
6.4 \\
24 \\
82 \\
12\end{array}$ & $\begin{array}{l}4.2 \\
4.1 \\
3.9 \\
3.9 \\
3.8\end{array}$ & $\begin{array}{r}17 \\
11 \\
8.2 \\
7.2 \\
6.5\end{array}$ & $\begin{array}{l}14 \\
10 \\
11 \\
36 \\
90\end{array}$ & $\begin{array}{l}5.0 \\
4.2 \\
3.9 \\
3.7 \\
3.5\end{array}$ & $\begin{array}{l}7.2 \\
7.5 \\
7.2 \\
17 \\
19\end{array}$ & $\begin{array}{l}10 \\
16 \\
9.5 \\
10 \\
39\end{array}$ & $\begin{array}{r}5.3 \\
8.1 \\
4.9 \\
127 \\
76\end{array}$ & $\begin{array}{l}5.2 \\
7.2 \\
5.7 \\
5.3 \\
5.4\end{array}$ & $\begin{array}{l}9.1 \\
5.3 \\
7.3 \\
29 \\
26\end{array}$ & $\begin{array}{l}7.7 \\
5.8 \\
4.8 \\
9.6 \\
7.3\end{array}$ & $\begin{array}{r}116 \\
11 \\
5.9 \\
5.0 \\
41\end{array}$ \\
\hline $\begin{array}{l}16 \\
17 \\
18 \\
19 \\
20\end{array}$ & $\begin{array}{l}8.5 \\
7.5 \\
5.9 \\
5.1 \\
5.4\end{array}$ & $\begin{array}{r}3.7 \\
3.7 \\
3.7 \\
3.8 \\
20\end{array}$ & $\begin{array}{l}6.9 \\
12 \\
37 \\
12 \\
10\end{array}$ & $\begin{array}{r}25 \\
12 \\
9.0 \\
7.5 \\
6.5\end{array}$ & $\begin{array}{l}3.4 \\
3.3 \\
3.2 \\
3.2 \\
3.2\end{array}$ & $\begin{array}{l}14 \\
11 \\
10 \\
8.9 \\
7.9\end{array}$ & $\begin{array}{r}56 \\
13 \\
9.5 \\
8.0 \\
7.2\end{array}$ & $\begin{array}{r}9.9 \\
5.9 \\
21 \\
8.4 \\
6.0\end{array}$ & $\begin{array}{l}5.9 \\
6.0 \\
6.9 \\
6.2 \\
6.7\end{array}$ & $\begin{array}{r}38 \\
7.0 \\
5.8 \\
5.5 \\
43\end{array}$ & $\begin{array}{r}9.5 \\
10 \\
5.7 \\
5.7 \\
4.7\end{array}$ & $\begin{array}{r}9.3 \\
91 \\
127 \\
13 \\
11\end{array}$ \\
\hline $\begin{array}{l}21 \\
22 \\
23 \\
24 \\
25\end{array}$ & $\begin{array}{r}5.6 \\
5.1 \\
4.7 \\
15 \\
5.3\end{array}$ & $\begin{array}{r}26 \\
9.3 \\
7.1 \\
6.2 \\
5.1\end{array}$ & $\begin{array}{l}8.6 \\
7.8 \\
7.1 \\
11 \\
44\end{array}$ & $\begin{array}{l}5.2 \\
4.7 \\
4.3 \\
4.0 \\
3.8\end{array}$ & $\begin{array}{l}3.3 \\
3.5 \\
3.8 \\
4.2 \\
4.5\end{array}$ & $\begin{array}{r}7.9 \\
6.8 \\
7.2 \\
7.6 \\
11\end{array}$ & $\begin{array}{l}6.6 \\
6.1 \\
6.4 \\
5.9 \\
5.2\end{array}$ & $\begin{array}{l}6.7 \\
5.3 \\
4.8 \\
4.7 \\
4.7\end{array}$ & $\begin{array}{c}282 \\
180 \\
11 \\
6.9 \\
19\end{array}$ & $\begin{array}{c}59 \\
6.1 \\
6.6 \\
77 \\
216\end{array}$ & $\begin{array}{r}24 \\
209 \\
9.8 \\
5.8 \\
4.8\end{array}$ & $\begin{array}{l}9.7 \\
7.4 \\
5.4 \\
5.6 \\
4.6\end{array}$ \\
\hline $\begin{array}{l}26 \\
27 \\
28 \\
29 \\
30 \\
31\end{array}$ & $\begin{array}{r}25 \\
28 \\
13 \\
7.6 \\
5.7 \\
5.2\end{array}$ & $\begin{array}{r}47 \\
14 \\
8.0 \\
6.5 \\
5.6 \\
---\end{array}$ & $\begin{array}{l}13 \\
11 \\
9.4 \\
8.5 \\
8.8 \\
7.5\end{array}$ & $\begin{array}{l}3.6 \\
3.5 \\
3.5 \\
3.5 \\
3.7 \\
4.0\end{array}$ & $\begin{array}{l}5.0 \\
5.8 \\
13 \\
-- \\
-- \\
--\end{array}$ & $\begin{array}{r}8.0 \\
6.8 \\
6.3 \\
10 \\
180 \\
39\end{array}$ & $\begin{array}{r}5.0 \\
13 \\
7.6 \\
5.4 \\
4.9 \\
\end{array}$ & $\begin{array}{r}5.9 \\
5.1 \\
5.3 \\
5.0 \\
23 \\
9.6\end{array}$ & $\begin{array}{c}121 \\
11 \\
6.0 \\
24 \\
53 \\
- \\
--\end{array}$ & $\begin{array}{r}26 \\
9.8 \\
5.9 \\
5.0 \\
4.6 \\
43\end{array}$ & $\begin{array}{r}298 \\
250 \\
29 \\
9.8 \\
6.5 \\
5.7\end{array}$ & $\begin{array}{r}4.3 \\
5.7 \\
4.5 \\
20 \\
21 \\
-\end{array}$ \\
\hline $\begin{array}{l}\text { TOTAL } \\
\text { MEAN } \\
\text { MAX } \\
\text { MIN }\end{array}$ & $\begin{array}{r}944.9 \\
30.5 \\
348 \\
4.7\end{array}$ & $\begin{array}{r}280.8 \\
9.36 \\
47 \\
3.7\end{array}$ & $\begin{array}{r}800.3 \\
25.8 \\
168 \\
5.4\end{array}$ & $\begin{array}{r}352.0 \\
11.4 \\
90 \\
3.5\end{array}$ & $\begin{array}{r}151.9 \\
5.43 \\
13 \\
3.2\end{array}$ & $\begin{array}{r}755.5 \\
24.4 \\
180 \\
6.3\end{array}$ & $\begin{array}{r}985.3 \\
32.8 \\
399 \\
4.9\end{array}$ & $\begin{array}{r}411.3 \\
13.3 \\
127 \\
4.4\end{array}$ & $\begin{array}{r}920.8 \\
30.7 \\
282 \\
4.6\end{array}$ & $\begin{array}{r}964.3 \\
31.1 \\
216 \\
4.6\end{array}$ & $\begin{array}{r}1276.1 \\
41.2 \\
298 \\
3.7\end{array}$ & $\begin{array}{r}592.8 \\
19.8 \\
127 \\
4.2\end{array}$ \\
\hline $\begin{array}{l}\text { CAL YR } \\
\text { WTR YR }\end{array}$ & $\begin{array}{l}1986 \\
1987\end{array}$ & $\begin{array}{l}\text { TOTAL } \\
\text { TOTAL }\end{array}$ & $\begin{array}{l}6.5 \\
6.0\end{array}$ & $\begin{array}{ll}\text { MEAN } & 31.5 \\
\text { MEAN } & 23.1\end{array}$ & $\begin{array}{l}\text { MAX } \\
\text { MAX }\end{array}$ & $\begin{array}{l}780 \\
399\end{array}$ & $\begin{array}{l}2.7 \\
3.2\end{array}$ & & & & & \\
\hline
\end{tabular}


LOCATION.--Lat $42^{\circ} 32^{\prime} 31^{\prime \prime}$, long $83^{\circ} 02^{\prime} 52^{\prime \prime}$, in NWl/4 SWl/4 sec.33, T.2 N., R.12 E., Macomb County, Hydrologic Unit 04090003 , on left bank between bridges on Mound Road, $1.0 \mathrm{mi}$ north of Warren, and 2.0 mi upstream from mouth.

DRAINAGE AREA.--Indeterminate since 1976. Prior to $1976,23.5 \mathrm{mi}^{2}$.

PERIOD OF RECORD.--OCtober 1958 to current year.

GAGE.--Water-stage recorder. Datum of gage is $598.80 \mathrm{ft}$, Macomb County datum. Prior to Aug. 26, 1960 , nonrecording gage and crest-stage gage at same site and datum.

REMARKS.--Estimated daily discharges: Jan. 18 to Feb. 28 . Records fair except those below 1.0 $\mathrm{ft}^{3} / \mathrm{s}$, which are poor. Diversion from the basin via Henry-Graham Drain started in 1976 , is ongoing and increasing with further development of new drains. Several measurements of water temperature were made during the year.

AVERAGE DISCHARGE. --18 years (water years $1959-76$ ), $13.9 \mathrm{ft} 3 / \mathrm{s}$; 11 years (water years $1977-87$ ), $4.54 \mathrm{ft}^{3} / \mathrm{s}$.

EXTREMES FOR PERIOD OF RECORD.--Maximum discharge, 1,240 $\mathrm{ft}^{3} / \mathrm{s}$, June 26, 1968, gage height, 14.45 ft; no flow on several days in June and July 1962, caused by unusual regulation upstream from gage; minimum discharge affected by diversion since 1976.

EXTREMES FOR CURRENT YEAR.--Maximum discharge, $118 \mathrm{ft} 3 / \mathrm{s}$, Oct. 3 , gage height, $7.01 \mathrm{ft} ; \mathrm{minimum,}$ $0.02 \mathrm{ft} / \mathrm{s}$, June $14,16,18 ;$ minimum gage height, $4.69 \mathrm{ft}$, June 16 .

DISCHARGE, IN CUBIC FEET PER SECOND, WATER YEAR OCTOBER 1986 TO SEPTEMBER 1987

\begin{tabular}{|c|c|c|c|c|c|c|c|c|c|c|c|c|}
\hline \multirow[b]{2}{*}{ DAY } & \multirow[b]{2}{*}{ OCT } & \multirow[b]{2}{*}{ NOV } & \multirow[b]{2}{*}{ DEC } & \multirow[b]{2}{*}{ JAN } & \multirow[b]{2}{*}{ FEB } & \multirow[b]{2}{*}{ MAR } & \multirow[b]{2}{*}{ APR } & \multirow[b]{2}{*}{ MAY } & \multirow[b]{2}{*}{ JUN } & \multirow[b]{2}{*}{ JUL } & & \\
\hline & & & & & & & & & & & AUG & SEP \\
\hline $\begin{array}{l}1 \\
2 \\
3 \\
4 \\
5\end{array}$ & $\begin{array}{r}7.6 \\
4.4 \\
38 \\
15 \\
5.5\end{array}$ & $\begin{array}{l}1.2 \\
3.1 \\
.92 \\
.95 \\
.87\end{array}$ & $\begin{array}{r}1.2 \\
18 \\
9.1 \\
3.6 \\
2.6\end{array}$ & $\begin{array}{l}.88 \\
1.4 \\
1.6 \\
.94 \\
.76\end{array}$ & $\begin{array}{l}.60 \\
.80 \\
1.6 \\
1.2 \\
1.0\end{array}$ & $\begin{array}{r}16 \\
7.8 \\
3.4 \\
2.3 \\
3.2\end{array}$ & $\begin{array}{r}4.0 \\
6.2 \\
3.4 \\
2.5 \\
45\end{array}$ & $\begin{array}{r}.60 \\
.60 \\
1.2 \\
1.1 \\
.74\end{array}$ & $\begin{array}{r}.78 \\
.99 \\
1.9 \\
.49 \\
.24\end{array}$ & $\begin{array}{l}2.7 \\
.92 \\
1.8 \\
1.4 \\
.64\end{array}$ & $\begin{array}{r}3.6 \\
1.0 \\
.95 \\
.64 \\
.41\end{array}$ & $\begin{array}{l}.47 \\
.58 \\
.45 \\
.33 \\
.30\end{array}$ \\
\hline $\begin{array}{r}6 \\
7 \\
8 \\
9 \\
10\end{array}$ & $\begin{array}{l}2.5 \\
1.4 \\
1.2 \\
1.5 \\
.73\end{array}$ & $\begin{aligned} .80 \\
.80 \\
1.1 \\
1.0 \\
.87\end{aligned}$ & $\begin{array}{r}2.0 \\
5.4 \\
5.4 \\
15 \\
9.0\end{array}$ & $\begin{array}{l}.78 \\
.92 \\
.78 \\
.66 \\
1.0\end{array}$ & $\begin{array}{l}.75 \\
1.0 \\
1.6 \\
1.0 \\
.60\end{array}$ & $\begin{array}{l}3.8 \\
3.2 \\
2.8 \\
2.1 \\
1.4\end{array}$ & $\begin{array}{r}19 \\
9.2 \\
3.7 \\
2.3 \\
1.8\end{array}$ & $\begin{array}{l}.54 \\
.61 \\
.71 \\
.59 \\
.49\end{array}$ & $\begin{array}{l}.31 \\
.33 \\
.23 \\
.16 \\
.11\end{array}$ & $\begin{array}{r}.50 \\
.62 \\
.77 \\
3.3 \\
10\end{array}$ & $\begin{array}{r}.32 \\
.29 \\
.27 \\
6.6\end{array}$ & $\begin{array}{l}.31 \\
.32 \\
.34 \\
.68 \\
.40\end{array}$ \\
\hline $\begin{array}{l}11 \\
12 \\
13 \\
14 \\
15\end{array}$ & $\begin{array}{l}.59 \\
.61 \\
1.7 \\
9.8 \\
1.9\end{array}$ & $\begin{array}{l}.92 \\
.91 \\
.81 \\
.82 \\
.93\end{array}$ & $\begin{array}{l}3.0 \\
2.4 \\
1.5 \\
1.3 \\
1.5\end{array}$ & $\begin{array}{r}2.0 \\
1.5 \\
1.7 \\
3.6 \\
11\end{array}$ & $\begin{array}{r}.40 \\
.35 \\
.32 \\
.30 \\
.29\end{array}$ & $\begin{array}{l}1 \cdot 3 \\
1 \cdot 3 \\
1 \cdot 5 \\
1 \cdot 7 \\
3.3\end{array}$ & $\begin{array}{l}1.6 \\
2.2 \\
1.7 \\
1.3 \\
3.7\end{array}$ & $\begin{array}{l}.42 \\
.67 \\
.59 \\
6.9 \\
8.8\end{array}$ & $\begin{array}{l}.15 \\
.22 \\
.13 \\
.08 \\
.07\end{array}$ & $\begin{array}{c}2.2 \\
.70 \\
.65 \\
3.6 \\
1.1\end{array}$ & $\begin{array}{r}2.2 \\
.66 \\
.42 \\
.66 \\
.66\end{array}$ & $\begin{array}{l}7.0 \\
1.6 \\
.74 \\
2.9 \\
1.3\end{array}$ \\
\hline $\begin{array}{l}16 \\
17 \\
18 \\
19 \\
20\end{array}$ & $\begin{array}{l}.92 \\
.70 \\
.60 \\
.56 \\
.52\end{array}$ & $\begin{array}{r}1.1 \\
1.0 \\
.98 \\
.95 \\
2.7\end{array}$ & $\begin{array}{l}1.5 \\
1.9 \\
4.6 \\
2.7 \\
2.0\end{array}$ & $\begin{array}{l}3.9 \\
1.9 \\
1.3 \\
1.0 \\
.75\end{array}$ & $\begin{array}{l}.28 \\
.27 \\
.27 \\
.27 \\
.27\end{array}$ & $\begin{array}{l}2.7 \\
1.9 \\
1.6 \\
1.5 \\
1.3\end{array}$ & $\begin{array}{l}7.8 \\
3.2 \\
1.9 \\
1.5 \\
1.2\end{array}$ & $\begin{array}{l}1.3 \\
.51 \\
1.8 \\
1.1 \\
.49\end{array}$ & $\begin{array}{l}.07 \\
.06 \\
.07 \\
.09 \\
.14\end{array}$ & $\begin{array}{r}2.3 \\
.78 \\
.35 \\
.26 \\
4.8\end{array}$ & $\begin{array}{r}.41 \\
1.5 \\
.58 \\
.55 \\
.32\end{array}$ & $\begin{array}{r}19 \\
3.7 \\
1.2 \\
1.1 \\
1.3\end{array}$ \\
\hline $\begin{array}{l}21 \\
22 \\
23 \\
24 \\
25\end{array}$ & $\begin{array}{r}.55 \\
.42 \\
.47 \\
1.8 \\
.59\end{array}$ & $\begin{array}{l}4.4 \\
2.1 \\
1.5 \\
1.2 \\
1.1\end{array}$ & $\begin{array}{l}1.7 \\
1.4 \\
1.4 \\
1.4 \\
5.3\end{array}$ & $\begin{array}{l}.60 \\
.50 \\
.40 \\
.35 \\
.32\end{array}$ & $\begin{array}{r}.28 \\
.29 \\
.31 \\
.35 \\
.38\end{array}$ & $\begin{array}{c}1.1 \\
1.0 \\
.96 \\
.93 \\
1.2\end{array}$ & $\begin{array}{l}1.0 \\
.88 \\
.89 \\
.75 \\
.70\end{array}$ & $\begin{array}{l}.34 \\
.28 \\
.30 \\
.28 \\
.21\end{array}$ & $\begin{array}{r}7.6 \\
12 \\
1.2 \\
.43 \\
.63\end{array}$ & $\begin{array}{l}11 \\
1.2 \\
13^{.51} \\
25\end{array}$ & $\begin{array}{rl}26 & .70 \\
2.6 \\
.83 \\
.70\end{array}$ & $\begin{array}{l}.86 \\
.39 \\
.31 \\
.27 \\
.25\end{array}$ \\
\hline $\begin{array}{l}26 \\
27 \\
28 \\
29 \\
30 \\
31\end{array}$ & $\begin{array}{r}2.0 \\
1.9 \\
1.4 \\
.67 \\
.54 \\
.49\end{array}$ & $\begin{array}{l}6.2 \\
4.2 \\
2.0 \\
1.5 \\
1.3 \\
-\end{array}$ & $\begin{array}{l}2.4 \\
1.6 \\
1.3 \\
1.1 \\
1.1 \\
.94\end{array}$ & $\begin{array}{l}.30 \\
.31 \\
.33 \\
.35 \\
.40 \\
.50\end{array}$ & $\begin{array}{l}.43 \\
.50 \\
.70 \\
--- \\
--. \\
---\end{array}$ & $\begin{array}{c}1.4 \\
1.1 \\
.86 \\
.97 \\
25.9 \\
8.2\end{array}$ & $\begin{array}{r}.65 \\
.93 \\
1.1 \\
.79 \\
.62 \\
-.-\end{array}$ & $\begin{array}{r}.19 \\
.25 \\
.21 \\
.22 \\
8.3 \\
6.2\end{array}$ & $\begin{array}{l}5.7 \\
1.3 \\
.51 \\
1.5 \\
4.6 \\
-.-\end{array}$ & $\begin{array}{l}2.8 \\
1.3 \\
1.3 \\
.70 \\
.46 \\
5.9\end{array}$ & $\begin{array}{l}20 \\
26 \\
3.7 \\
1.5 \\
.67 \\
.50\end{array}$ & $\begin{array}{r}.45 \\
.34 \\
1.0 \\
1.6 \\
.80 \\
-\end{array}$ \\
\hline $\begin{array}{l}\text { TOTAL } \\
\text { MEAN } \\
\text { MAX } \\
\text { MIN }\end{array}$ & $\begin{array}{r}106.56 \\
3.44 \\
38 \\
.42\end{array}$ & $\begin{array}{r}48.23 \\
1.61 \\
6.2 \\
.80\end{array}$ & $\begin{array}{r}113.34 \\
3.66 \\
18 \\
.94\end{array}$ & $\begin{array}{r}42.73 \\
1.38 \\
11 \\
.30\end{array}$ & $\begin{array}{r}16.41 \\
.59 \\
1.6 \\
.27\end{array}$ & $\begin{array}{r}106.82 \\
3.45 \\
25 \\
.86\end{array}$ & $\begin{array}{r}131.51 \\
4.38 \\
45 \\
.62\end{array}$ & $\begin{array}{r}46.54 \\
1.50 \\
8.8 \\
.19\end{array}$ & $\begin{array}{r}42.09 \\
1.40 \\
12 \\
.06\end{array}$ & $\begin{array}{r}102.56 \\
3.31 \\
25 \\
.26\end{array}$ & $\begin{array}{r}125.24 \\
4.04 \\
26 \\
.27\end{array}$ & $\begin{array}{r}50.29 \\
1.68 \\
19 \\
.25\end{array}$ \\
\hline $\begin{array}{l}\text { CAL YR } \\
\text { WTR YR }\end{array}$ & $\begin{array}{l}1986 \\
1987\end{array}$ & $\begin{array}{rr}\text { AAL } & 14 \\
\text { AAL } & 9\end{array}$ & $\begin{array}{l}2.65 \\
2.32\end{array}$ & $\begin{array}{ll}\text { MEAN } & 4.03 \\
\text { MEAN } 2.55\end{array}$ & $\begin{array}{l}\text { MAX } \\
\text { MAX }\end{array}$ & $\begin{array}{l}\text { MIN } \\
\text { MIN }\end{array}$ & $\begin{array}{l}.06 \\
.06\end{array}$ & & & & & \\
\hline
\end{tabular}


LOCATION.--Lat $42^{\circ} 36^{\prime} 05^{\prime \prime}$, long $83^{\circ} 04^{\prime} 27^{\prime \prime}$, in SEl/4 NEl,4 sec.7, T. 2 N., R.12 E., Macomb County, Hydrologic Unit 04090003 , on left bank at upstream side of bridge on Ryan Road, 1.0 mi southwest of Utica.

DRAINAGE AREA. $--16.5 \mathrm{mi}^{2}$.

PERIOD OF RECORD.--July 1965 to current year.

REVISED RECORDS.--WSP 2112: Drainage area.

GAGE.--Water-stage recorder. Datum of gage is $619.79 \mathrm{ft}$ above National Geodetic Vertical Datum of 1929 (levels by Johnson and Anderson, Inc.).

REMARKS.--Estimated daily discharges: Nov. 13-15, Dec. 11-13, Jan. 12, and Jan. 18 to Mar. 1. Records good except for estimated daily discharges, which are fair. Occasional diversion for sprinkler irrigation. Several measurements of water temperature were made during the year.

AVERAGE DISCHARGE.--22 years, $13.4 \mathrm{ft} / \mathrm{s}, 11.03 \mathrm{in} / \mathrm{yr}$.

EXTREMES FOR PERIOD OF RECORD.--Maximum discharge, 1,160 $\mathrm{ft}^{3} / \mathrm{s}$, June $26,1968, \mathrm{gage}$ height, $10.36 \mathrm{ft}$; no flow part of each day July 19, 28, 1966, Aug. 22-28, Sept. 3, 11, 1969.

EXTREMES FOR CURRENT YEAR.--Maximum discharge, $164 \mathrm{ft} 3 / \mathrm{s}$, Apr. 5 , gage height, $5.87 \mathrm{ft}$, no peak discharge above base discharge of $200 \mathrm{ft} / \mathrm{s}$; minimum, $0.42 \mathrm{ft} / \mathrm{s}$, June 18, 19, gage height, $1.66 \mathrm{ft}$.

DISCHARGE, IN CUBIC FEET PER SECOND, WATER YEAR OCTOBER 1986 TO SEPTEMBER 1987 MEAN VALUES

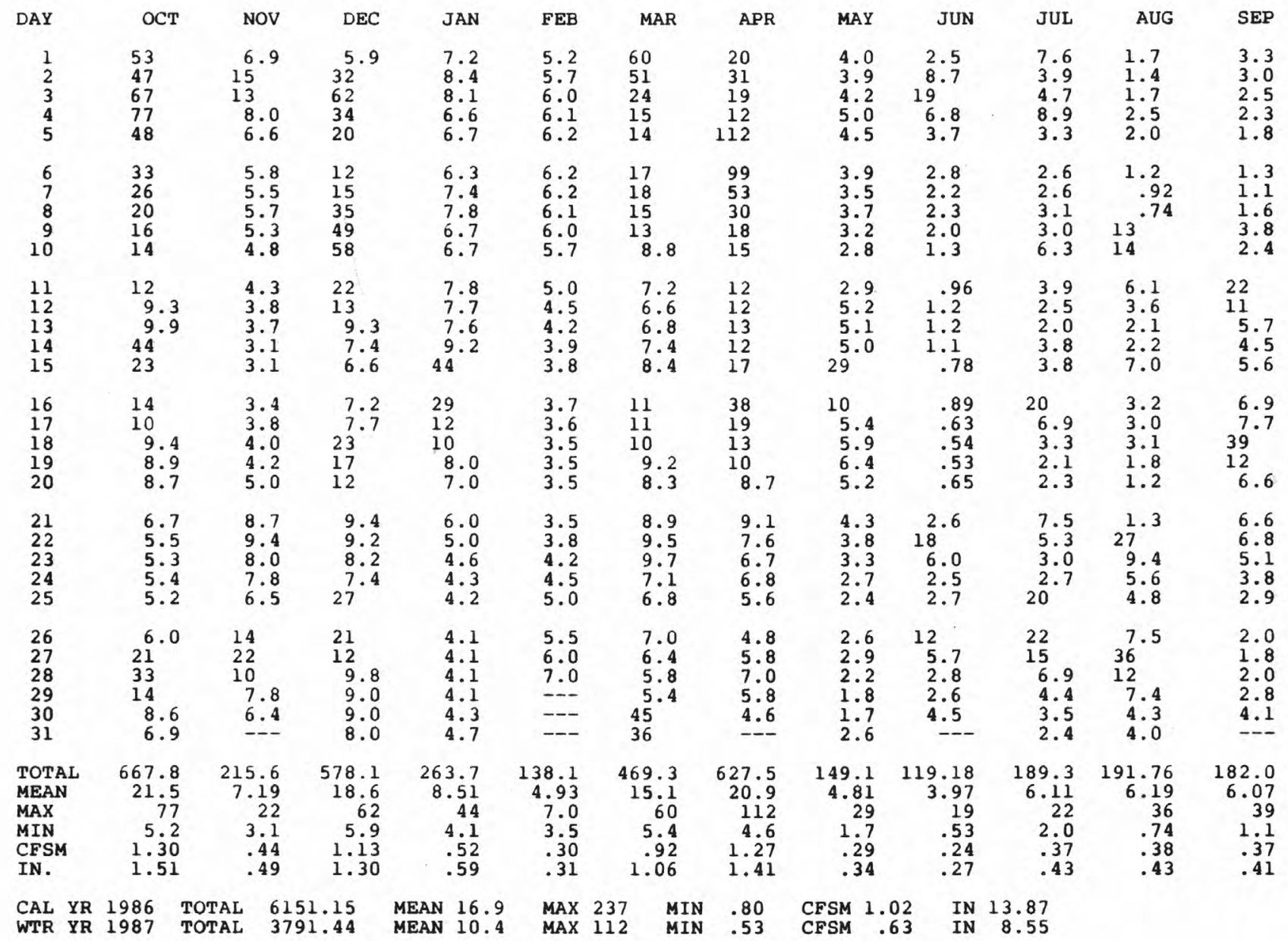


LOCATION.--Lat $42^{\circ} 34^{\prime} 40^{\prime \prime}$, long $82^{\circ} 57^{\prime} 00^{\prime \prime}$, in NWl/4 sec. 20, T. 2 N., R. 13 E., Macomb County, Hydrologic Unit 04090003 , on left bank $800 \mathrm{ft}$ downstream from bridge on Garfield Road, $2.8 \mathrm{mi}$ north of Fraser, and $4.0 \mathrm{mi}$ upstream from North Branch.

DRAINAGE AREA. $--444 \mathrm{mi}^{2}$.

PERIOD OF RECORD.--May 1947 to current year.

REVISED RECORDS.--WSP 2112: Drainage area.

GAGE.--Water-stage recorder. Datum of gage is $577.71 \mathrm{ft}$ above National Geodetic Vertical Datum of 1929 .

Prior to Nov. 17, 1949, nonrecording gage at site 800 ft upstream at same datum.

REMARKS.--No estimated daily discharges. Records good. National weather Service gage-height telemeter at station.

AVERAGE DISCHARGE. -40 years, $381 \mathrm{ft}^{3} / \mathrm{s}, 11.65 \mathrm{in} / \mathrm{yr}^{\circ}$

EXTREMES FOR PERIOD OF RECORD,--Maximum discharge, $8,840 \mathrm{ft}^{3} / \mathrm{s}$, Oct. 1, 1981 , gage height, $19.56 \mathrm{ft}$;

minimum, $47 \mathrm{ft}^{3} / \mathrm{s}$, Sept. 6, 1955; minimum gage height, 4.29 ft, Sept. 7, 1954.

EXTREMES OUTSIDE PERIOD OF RECORD.--Flood of Apr. 5 or 6,1947 , reached a stage of $20 \mathrm{ft}$, from floodmarks, discharge, $9,000 \mathrm{ft}^{3} / \mathrm{s}$.

EXTREMES FOR CURRENT YEAR.--Peak discharges greater than base discharge of $2,000 \mathrm{ft} 3 / \mathrm{s}$ and maximum (*):

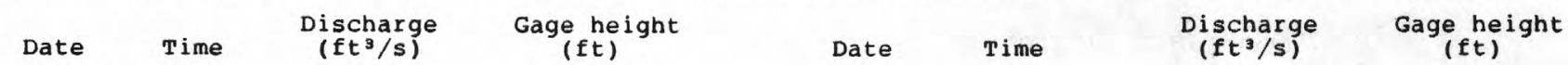

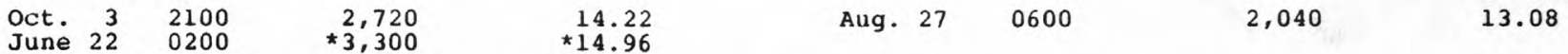

Minimum discharge, $109 \mathrm{ft}^{3} / \mathrm{s}$, Aug. 8, 21, gage height, $5.15 \mathrm{ft}$.

DISCHARGE, IN CUBIC FEET PER SECOND, WATER YEAR OCTOBER 1986 TO SEPTEMBER 1987

\begin{tabular}{|c|c|c|c|c|c|c|c|c|c|c|c|c|}
\hline DAY & OCT & NOV & DEC & JAN & FEB & MAR & APR & MAY & JUN & JUL & AUG & SEP \\
\hline $\begin{array}{l}1 \\
2 \\
3 \\
4 \\
5\end{array}$ & $\begin{array}{r}1180 \\
993 \\
1430 \\
1690 \\
1160\end{array}$ & $\begin{array}{l}345 \\
481 \\
344 \\
336 \\
331\end{array}$ & $\begin{array}{l}332 \\
772 \\
869 \\
621 \\
537\end{array}$ & $\begin{array}{l}392 \\
393 \\
395 \\
351 \\
334\end{array}$ & $\begin{array}{l}344 \\
372 \\
404 \\
389 \\
329\end{array}$ & $\begin{array}{l}886 \\
883 \\
615 \\
504 \\
497\end{array}$ & $\begin{array}{r}520 \\
605 \\
514 \\
445 \\
1390\end{array}$ & $\begin{array}{l}196 \\
190 \\
217 \\
195 \\
183\end{array}$ & $\begin{array}{l}215 \\
278 \\
598 \\
326 \\
262\end{array}$ & $\begin{array}{l}312 \\
216 \\
326 \\
303 \\
185\end{array}$ & $\begin{array}{l}265 \\
163 \\
159 \\
140 \\
130\end{array}$ & $\begin{array}{l}312 \\
269 \\
179 \\
144 \\
136\end{array}$ \\
\hline $\begin{array}{r}6 \\
7 \\
8 \\
9 \\
10\end{array}$ & $\begin{array}{l}865 \\
733 \\
655 \\
641 \\
580\end{array}$ & $\begin{array}{l}313 \\
303 \\
327 \\
313 \\
291\end{array}$ & $\begin{array}{l}470 \\
492 \\
620 \\
782 \\
949\end{array}$ & $\begin{array}{l}350 \\
368 \\
357 \\
331 \\
361\end{array}$ & $\begin{array}{l}322 \\
361 \\
407 \\
314 \\
300\end{array}$ & $\begin{array}{l}506 \\
495 \\
501 \\
484 \\
451\end{array}$ & $\begin{array}{r}1450 \\
943 \\
721 \\
647 \\
602\end{array}$ & $\begin{array}{l}179 \\
178 \\
183 \\
178 \\
164\end{array}$ & $\begin{array}{l}204 \\
192 \\
172 \\
165 \\
153\end{array}$ & $\begin{array}{l}176 \\
187 \\
192 \\
179 \\
637\end{array}$ & $\begin{array}{l}121 \\
116 \\
114 \\
596 \\
608\end{array}$ & $\begin{array}{l}128 \\
121 \\
120 \\
204 \\
148\end{array}$ \\
\hline $\begin{array}{l}11 \\
12 \\
13 \\
14 \\
15\end{array}$ & $\begin{array}{l}532 \\
508 \\
550 \\
893 \\
711\end{array}$ & $\begin{array}{l}287 \\
286 \\
351 \\
254 \\
234\end{array}$ & $\begin{array}{l}599 \\
560 \\
470 \\
435 \\
489\end{array}$ & $\begin{array}{l}409 \\
374 \\
369 \\
397 \\
720\end{array}$ & $\begin{array}{l}302 \\
308 \\
293 \\
275 \\
258\end{array}$ & $\begin{array}{l}407 \\
385 \\
371 \\
382 \\
393\end{array}$ & $\begin{array}{l}566 \\
552 \\
544 \\
506 \\
579\end{array}$ & $\begin{array}{r}171 \\
213 \\
176 \\
266 \\
1040\end{array}$ & $\begin{array}{l}148 \\
179 \\
155 \\
141 \\
134\end{array}$ & $\begin{array}{l}450 \\
244 \\
231 \\
523 \\
224\end{array}$ & $\begin{array}{l}183 \\
147 \\
135 \\
208 \\
291\end{array}$ & $\begin{array}{l}601 \\
316 \\
252 \\
208 \\
294\end{array}$ \\
\hline $\begin{array}{l}16 \\
17 \\
18 \\
19 \\
20\end{array}$ & $\begin{array}{l}572 \\
531 \\
474 \\
433 \\
421\end{array}$ & $\begin{array}{l}235 \\
243 \\
254 \\
258 \\
321\end{array}$ & $\begin{array}{l}486 \\
440 \\
624 \\
537 \\
476\end{array}$ & $\begin{array}{l}567 \\
412 \\
381 \\
371 \\
365\end{array}$ & $\begin{array}{l}252 \\
259 \\
260 \\
251 \\
246\end{array}$ & $\begin{array}{l}398 \\
366 \\
361 \\
361 \\
322\end{array}$ & $\begin{array}{l}743 \\
567 \\
489 \\
453 \\
426\end{array}$ & $\begin{array}{l}367 \\
233 \\
378 \\
359 \\
310\end{array}$ & $\begin{array}{l}138 \\
136 \\
134 \\
132 \\
132\end{array}$ & $\begin{array}{l}395 \\
201 \\
170 \\
151 \\
162\end{array}$ & $\begin{array}{l}128 \\
226 \\
156 \\
139 \\
121\end{array}$ & $\begin{array}{l}236 \\
388 \\
876 \\
401 \\
348\end{array}$ \\
\hline $\begin{array}{l}21 \\
22 \\
23 \\
24 \\
25\end{array}$ & $\begin{array}{l}417 \\
402 \\
404 \\
447 \\
397\end{array}$ & $\begin{array}{l}441 \\
355 \\
323 \\
319 \\
311\end{array}$ & $\begin{array}{l}467 \\
427 \\
431 \\
411 \\
624\end{array}$ & $\begin{array}{l}355 \\
381 \\
333 \\
300 \\
320\end{array}$ & $\begin{array}{l}246 \\
245 \\
281 \\
273 \\
272\end{array}$ & $\begin{array}{l}314 \\
316 \\
316 \\
326 \\
324\end{array}$ & $\begin{array}{l}411 \\
392 \\
344 \\
320 \\
278\end{array}$ & $\begin{array}{l}293 \\
236 \\
248 \\
248 \\
237\end{array}$ & $\begin{array}{r}311 \\
1950 \\
490 \\
263 \\
265\end{array}$ & $\begin{array}{r}484 \\
197 \\
186 \\
203 \\
1170\end{array}$ & $\begin{array}{r}174 \\
1030 \\
368 \\
204 \\
161\end{array}$ & $\begin{array}{l}459 \\
444 \\
281 \\
264 \\
261\end{array}$ \\
\hline $\begin{array}{l}26 \\
27 \\
28 \\
29 \\
30 \\
31\end{array}$ & $\begin{array}{l}473 \\
504 \\
624 \\
477 \\
436 \\
400\end{array}$ & $\begin{array}{l}470 \\
565 \\
412 \\
375 \\
319 \\
-\end{array}$ & $\begin{array}{l}493 \\
466 \\
428 \\
456 \\
405 \\
389\end{array}$ & $\begin{array}{l}320 \\
319 \\
302 \\
304 \\
316 \\
326\end{array}$ & $\begin{array}{l}269 \\
270 \\
283 \\
--- \\
--- \\
---\end{array}$ & $\begin{array}{l}356 \\
336 \\
308 \\
303 \\
988 \\
726\end{array}$ & $\begin{array}{l}243 \\
232 \\
255 \\
214 \\
203 \\
-\end{array}$ & $\begin{array}{l}257 \\
394 \\
194 \\
182 \\
207 \\
593\end{array}$ & $\begin{array}{l}650 \\
298 \\
227 \\
208 \\
492 \\
-\end{array}$ & $\begin{array}{l}438 \\
313 \\
202 \\
192 \\
173 \\
167\end{array}$ & $\begin{array}{r}484 \\
1440 \\
435 \\
371 \\
393 \\
242\end{array}$ & $\begin{array}{l}246 \\
209 \\
208 \\
212 \\
221 \\
-\end{array}$ \\
\hline $\begin{array}{l}\text { TOTAL } \\
\text { MEAN } \\
\text { MAX } \\
\text { MIN } \\
\text { CFSM } \\
\text { IN. }\end{array}$ & $\begin{array}{r}20533 \\
662 \\
1690 \\
397 \\
1.49 \\
1.72\end{array}$ & $\begin{array}{r}9997 \\
333 \\
565 \\
234 \\
.75 \\
.84\end{array}$ & $\begin{array}{r}16557 \\
534 \\
949 \\
332 \\
1.20 \\
1.39\end{array}$ & $\begin{array}{r}11573 \\
373 \\
720 \\
300 \\
.84 \\
.97\end{array}$ & $\begin{array}{r}8385 \\
299 \\
407 \\
245 \\
.67 \\
.70\end{array}$ & $\begin{array}{r}14181 \\
457 \\
988 \\
303 \\
1.03 \\
1.19\end{array}$ & $\begin{array}{r}16154 \\
538 \\
1450 \\
203 \\
1.21 \\
1.35\end{array}$ & $\begin{array}{r}8465 \\
273 \\
1040 \\
164 \\
.62 \\
.71\end{array}$ & $\begin{array}{r}9148 \\
305 \\
1950 \\
132 \\
.69 \\
.77\end{array}$ & $\begin{array}{r}9189 \\
296 \\
1170 \\
151 \\
.67 \\
.77\end{array}$ & $\begin{array}{r}9448 \\
305 \\
1440 \\
114 \\
.69 \\
.79\end{array}$ & $\begin{array}{r}8486 \\
283 \\
876 \\
120 \\
.64 \\
.71\end{array}$ \\
\hline $\begin{array}{ll}\text { CAL YR } \\
\text { WTR YR }\end{array}$ & $\begin{array}{l}1986 \\
1987\end{array}$ & $\begin{array}{ll}\mathrm{L} & 1 \\
\mathrm{~L} & 1\end{array}$ & $\begin{array}{l}90 \\
16\end{array}$ & $\begin{array}{ll}\text { AN } & 509 \\
\text { AN } & 389\end{array}$ & $\begin{array}{l}\text { MAX } \\
\text { MAX }\end{array}$ & 30 & $\begin{array}{l}139 \\
114\end{array}$ & $\begin{array}{lr}\text { CFSM } & 1.1 \\
\text { CFSM } & .8\end{array}$ & $\begin{array}{l}\text { IN } \\
\text { IN }\end{array}$ & $\begin{array}{l}57 \\
91\end{array}$ & & \\
\hline
\end{tabular}


LOCATION. --Lat $42^{\circ} 49^{\prime} 21^{\prime \prime}$, long $83^{\circ} 01^{\prime} 13^{\prime \prime}$, in NEl/4 SEl/4 sec.27, T.5 N., R.12 E., Macomb County, Hydrologic Unit 04090003, on right bank at upstream side of bridge on State Highway 53 , $1.4 \mathrm{mi}$ north of
Romeo.

DRAINAGE AREA. $--21.8 \mathrm{mi}^{2}$.

PERIOD OF RECORD.--September 1958 to current year.

GAGE.--Water-stage recorder. Elevation of gage is $780 \mathrm{ft}$ above National Geodetic Vertical Datum of 1929 , from topographic map.

REMARKS.--Estimated daily discharges: Nov, 14, Dec. 12-14, and Jan. 16 to Feb. 28 . Records good except for estimated daily discharges, which are fair. Occasional regulation by lakes upstream from station. Several measurements of water temperature were made during the year.

AVERAGE DISCHARGE. --29 years, $16.2 \mathrm{ft}^{3} / \mathrm{s}, 10.09 \mathrm{in} / \mathrm{yr}$.

EXTREMES FOR PERIOD OF RECORD.--Maximum discharge, $358 \mathrm{ft}^{3} / \mathrm{s}$, Feb. 10, 1965, gage height, 4.48 ft;

maximum gage height, $4.56 \mathrm{ft}, \operatorname{Mar} .12,1962$, backwater from ice; minimum discharge, 0.8 ft ${ }^{3} / \mathrm{s}^{\prime}$,

July 30, 31, 1964, Aug. 6, 7, 1965; minimum gage height, 0.71 ft, July $21,1959$.

EXTREMES FOR CURRENT YEAR.--Peak discharges greater than base discharge of $80 \mathrm{ft}^{3} / \mathrm{s}$ and maximum (*):

$\begin{array}{ccccccc}\text { Date } & \text { Time } & \begin{array}{c}\text { Discharge } \\ \left(\mathrm{ft}^{3} / \mathrm{s}\right)\end{array} & \begin{array}{c}\text { Gage height } \\ (\mathrm{ft})\end{array} & \text { Date } & \text { Time } & \begin{array}{c}\text { Discharge } \\ \left.(\mathrm{ft})^{3} / \mathrm{s}^{2}\right)\end{array} \\ \text { July } 25 & 0800 & * 327 & * 4.26 & \text { Sept. } 18 & 0800 & \begin{array}{c}\text { Gage height } \\ (\mathrm{ft})\end{array}\end{array}$

Minimum discharge, $3.0 \mathrm{ft}^{3} / \mathrm{s}, \mathrm{July} 17,18$, gage height, $0.92 \mathrm{ft}$.

DISCHARGE, IN CUBIC FEET PER SECOND, WATER YEAR OCTOBER 1986 TO SEPTEMBER 1987 MEAN VALUES

\begin{tabular}{|c|c|c|c|c|c|c|c|c|c|c|c|c|}
\hline DAY & OCT & NOV & DEC & JAN & FEB & MAR & APR & MAY & JUN & JUL & AUG & SEP \\
\hline $\begin{array}{l}1 \\
2 \\
3 \\
4 \\
5\end{array}$ & $\begin{array}{l}57 \\
57 \\
58 \\
65 \\
62\end{array}$ & $\begin{array}{l}18 \\
19 \\
17 \\
16 \\
16\end{array}$ & $\begin{array}{l}20 \\
22 \\
28 \\
26 \\
24\end{array}$ & $\begin{array}{l}20 \\
20 \\
20 \\
18 \\
17\end{array}$ & $\begin{array}{l}14 \\
15 \\
15 \\
15 \\
14\end{array}$ & $\begin{array}{l}44 \\
40 \\
35 \\
33 \\
33\end{array}$ & $\begin{array}{l}26 \\
28 \\
27 \\
26 \\
44\end{array}$ & $\begin{array}{r}14 \\
13 \\
13 \\
12 \\
9.5\end{array}$ & $\begin{array}{l}10 \\
11 \\
11 \\
9.7 \\
8.8\end{array}$ & $\begin{array}{r}16 \\
4.7 \\
6.3 \\
9.7 \\
7.7\end{array}$ & $\begin{array}{l}9.6 \\
9.2 \\
6.9 \\
6.6 \\
6.2\end{array}$ & $\begin{array}{l}9.3 \\
8.8 \\
6.4 \\
6.4 \\
5.4\end{array}$ \\
\hline $\begin{array}{r}6 \\
7 \\
8 \\
9 \\
10\end{array}$ & $\begin{array}{l}56 \\
51 \\
45 \\
42 \\
38\end{array}$ & $\begin{array}{l}16 \\
16 \\
9.9 \\
13 \\
13\end{array}$ & $\begin{array}{l}23 \\
23 \\
24 \\
27 \\
30\end{array}$ & $\begin{array}{l}17 \\
18 \\
17 \\
17 \\
18\end{array}$ & $\begin{array}{l}14 \\
14 \\
14 \\
14 \\
14\end{array}$ & $\begin{array}{l}34 \\
37 \\
38 \\
39 \\
33\end{array}$ & $\begin{array}{l}51 \\
45 \\
41 \\
38 \\
35\end{array}$ & $\begin{array}{r}6.0 \\
6.0 \\
6.5 \\
6.9 \\
11\end{array}$ & $\begin{array}{l}8.1 \\
8.0 \\
6.7 \\
6.4 \\
6.1\end{array}$ & $\begin{array}{r}7.0 \\
6.7 \\
6.8 \\
7.0 \\
11\end{array}$ & $\begin{array}{r}5.8 \\
5.4 \\
5.4 \\
8.6 \\
10\end{array}$ & $\begin{array}{l}5.2 \\
5.4 \\
5.7 \\
6.6 \\
6.4\end{array}$ \\
\hline $\begin{array}{l}11 \\
12 \\
13 \\
14 \\
15\end{array}$ & $\begin{array}{l}34 \\
30 \\
29 \\
36 \\
33\end{array}$ & $\begin{array}{l}13 \\
13 \\
13 \\
12 \\
12\end{array}$ & $\begin{array}{l}26 \\
22 \\
20 \\
18 \\
18\end{array}$ & $\begin{array}{l}18 \\
18 \\
18 \\
17 \\
21\end{array}$ & $\begin{array}{l}13 \\
12 \\
12 \\
11 \\
11\end{array}$ & $\begin{array}{l}31 \\
29 \\
29 \\
28 \\
27\end{array}$ & $\begin{array}{l}33 \\
33 \\
31 \\
29 \\
30\end{array}$ & $\begin{array}{l}12 \\
11 \\
11 \\
12 \\
19\end{array}$ & $\begin{array}{l}6.4 \\
5.0 \\
4.6 \\
4.5 \\
4.3\end{array}$ & $\begin{array}{r}13 \\
14 \\
10 \\
9.9 \\
8.2\end{array}$ & $\begin{array}{l}8.4 \\
7.3 \\
6.5 \\
5.5 \\
6.0\end{array}$ & $\begin{array}{l}8.9 \\
8.8 \\
8.5 \\
7.9 \\
8.7\end{array}$ \\
\hline $\begin{array}{l}16 \\
17 \\
18 \\
19 \\
20\end{array}$ & $\begin{array}{l}30 \\
30 \\
29 \\
29 \\
27\end{array}$ & $\begin{array}{l}12 \\
13 \\
13 \\
13 \\
14\end{array}$ & $\begin{array}{l}18 \\
18 \\
23 \\
23 \\
23\end{array}$ & $\begin{array}{l}18 \\
17 \\
16 \\
15 \\
15\end{array}$ & $\begin{array}{l}11 \\
10 \\
10 \\
10 \\
10\end{array}$ & $\begin{array}{l}27 \\
26 \\
26 \\
26 \\
24\end{array}$ & $\begin{array}{l}31 \\
29 \\
27 \\
26 \\
24\end{array}$ & $\begin{array}{l}17 \\
15 \\
16 \\
18 \\
18\end{array}$ & $\begin{array}{l}4.1 \\
4.3 \\
4.8 \\
4.2 \\
3.9\end{array}$ & $\begin{array}{l}3.7 \\
3.2 \\
3.2 \\
4.2 \\
5.1\end{array}$ & $\begin{array}{r}6.6 \\
11 \\
9.1 \\
8.1 \\
7.0\end{array}$ & $\begin{array}{l}12 \\
21 \\
76 \\
63 \\
38\end{array}$ \\
\hline $\begin{array}{l}21 \\
22 \\
23 \\
24 \\
25\end{array}$ & $\begin{array}{l}26 \\
25 \\
24 \\
24 \\
23\end{array}$ & $\begin{array}{l}16 \\
17 \\
17 \\
18 \\
17\end{array}$ & $\begin{array}{l}22 \\
21 \\
20 \\
20 \\
26\end{array}$ & $\begin{array}{l}15 \\
14 \\
14 \\
14 \\
14\end{array}$ & $\begin{array}{l}10 \\
10 \\
11 \\
12 \\
13\end{array}$ & $\begin{array}{l}23 \\
23 \\
22 \\
21 \\
22\end{array}$ & $\begin{array}{l}23 \\
21 \\
20 \\
16 \\
20\end{array}$ & $\begin{array}{l}20 \\
17 \\
14 \\
13 \\
11\end{array}$ & $\begin{array}{l}4.8 \\
7.8 \\
7.0 \\
6.2 \\
6.4\end{array}$ & $\begin{array}{r}5.9 \\
4.9 \\
4.3 \\
5.8 \\
201\end{array}$ & $\begin{array}{l}6.4 \\
14 \\
12 \\
11 \\
12\end{array}$ & $\begin{array}{l}27 \\
21 \\
12 \\
12 \\
15\end{array}$ \\
\hline $\begin{array}{l}26 \\
27 \\
28 \\
29 \\
30 \\
31\end{array}$ & $\begin{array}{l}23 \\
24 \\
22 \\
21 \\
19 \\
18\end{array}$ & $\begin{array}{l}22 \\
24 \\
22 \\
21 \\
22 \\
---\end{array}$ & $\begin{array}{l}24 \\
23 \\
23 \\
22 \\
21 \\
21\end{array}$ & $\begin{array}{l}14 \\
14 \\
14 \\
14 \\
14 \\
14\end{array}$ & $\begin{array}{r}15 \\
17 \\
19 \\
--- \\
--- \\
---\end{array}$ & $\begin{array}{l}23 \\
22 \\
21 \\
21 \\
29 \\
28\end{array}$ & $\begin{array}{l}21 \\
18 \\
18 \\
16 \\
15 \\
-\end{array}$ & $\begin{array}{l}9.0 \\
13 \\
12 \\
10 \\
9.1 \\
11\end{array}$ & $\begin{array}{l}20 \\
21 \\
12 \\
6.0 \\
12 \\
---\end{array}$ & $\begin{array}{l}85 \\
38 \\
17 \\
16 \\
12 \\
11\end{array}$ & $\begin{array}{l}12 \\
18 \\
15 \\
13 \\
11 \\
10\end{array}$ & $\begin{array}{l}4.9 \\
7.4 \\
12 \\
13 \\
13 \\
-\end{array}$ \\
\hline $\begin{array}{l}\text { TOTAL } \\
\text { MEAN } \\
\text { MAX } \\
\text { MIN } \\
\text { CESM } \\
\text { IN. }\end{array}$ & $\begin{array}{r}1087 \\
35.1 \\
65 \\
18 \\
1.61 \\
1.85\end{array}$ & $\begin{array}{r}477.9 \\
15.9 \\
24 \\
9.9 \\
.73 \\
.82\end{array}$ & $\begin{array}{r}699 \\
22.5 \\
30 \\
18 \\
1.03 \\
1.19\end{array}$ & $\begin{array}{r}510 \\
16.5 \\
21 \\
14 \\
.76 \\
.87\end{array}$ & $\begin{array}{r}360 \\
12.9 \\
19 \\
10 \\
.59 \\
.61\end{array}$ & $\begin{array}{r}894 \\
28.8 \\
44 \\
21 \\
1.32 \\
1.53\end{array}$ & $\begin{array}{r}842 \\
28.1 \\
51 \\
15 \\
1.29 \\
1.44\end{array}$ & $\begin{array}{r}386.0 \\
12.5 \\
20 \\
6.0 \\
.57 \\
.66\end{array}$ & $\begin{array}{r}235.1 \\
7.84 \\
21 \\
3.9 \\
.36 \\
.40\end{array}$ & $\begin{array}{r}558.3 \\
18.0 \\
201 \\
3.2 \\
.83 \\
.95\end{array}$ & $\begin{array}{r}283.6 \\
9.15 \\
18 \\
5.4 \\
.42 \\
.48\end{array}$ & $\begin{array}{r}455.7 \\
15.2 \\
76 \\
4.9 \\
.70 \\
.78\end{array}$ \\
\hline
\end{tabular}

$\begin{array}{llllllllll}\text { CAL YR } 1986 & \text { TOTAL } & 8937.3 & \text { MEAN } 24.5 & \text { MAX } 125 & \text { MIN } 6.3 & \text { CFSM } 1.12 & \text { IN } 15.25 \\ \text { WTR YR } 1987 & \text { TOTAL } & 6788.6 & \text { MEAN } 18.6 & \text { MAX } 201 & \text { MIN } 3.2 & \text { CFSM } & .85 & \text { IN } 11.58\end{array}$ 
LOCATION.--Lat $42^{\circ} 50^{\prime} 45^{\prime \prime}$, long $82^{\circ} 53^{\prime} 06^{\prime \prime}$, in NEl/4 sec.23, T.5 N., R. 13 E., Macomb County, Hydrologic Unit 04090003 , on right bank at downstream' side of bridge on prospect Street in Armada.

DRAINAGE AREA. $--13.0 \mathrm{mi}^{2}$.

PERIOD OF RECORD.--October 1958 to current year.

REVISED RECORDS.--WDR MI-83: 1982.

GAGE.--Water-stage recorder and concrete control. Elevation of gage is $735 \mathrm{ft}$ above National Geodetic Vertical Datum of 1929 , from topographic map.

REMARKS.--Estimated daily discharges: Dec. 10, 11, Jan. 15-27, and Feb. 7-10, 15-18. Records good except those for the winter period, which are poor. Severai measurements of water temperature were made during the year.

AVERAGE DISCHARGE.--29 years, $7.27 \mathrm{ft}^{3} / \mathrm{s}, 7.59 \mathrm{in} / \mathrm{yr}^{\mathrm{r}}$.

EXTREMES FOR PERIOD OF RECORD.--Maximum discharge, $910 \mathrm{ft}^{3} / \mathrm{s}$, Apr. 19, 1975, gage height, $6.69 \mathrm{ft}$; no flow Jan. 25 to Feb. 9, 1961, result of freezeup.

EXTREMES FOR CURRENT YEAR.--Peak discharges greater than base discharge of $100 \mathrm{ft} 3 / \mathrm{s}$ and maximum (*):

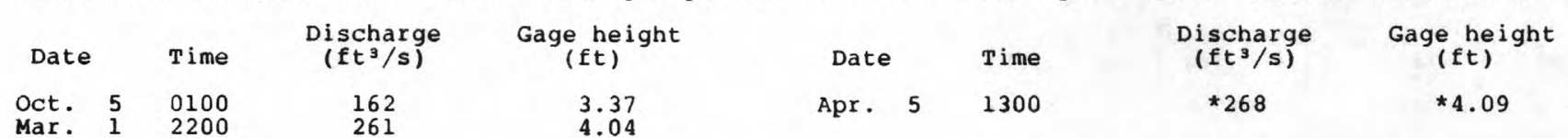

Minimum discharge, $0.08 \mathrm{ft} 3 / \mathrm{s}, \mathrm{July} 21,22,24,30,31$, Aug. 5, 6, 7, Sept. 9, 10; minimum gage height, $1.60 \mathrm{ft}, \mathrm{Jan} .29$, Juil $21,22,24,30,31$, Aug. 5, 6, 7 .

DISCHARGE, IN CUBIC FEET PER SECOND, WATER YEAR OCTOBER 1986 TO SEPTEMBER 1987 MEAN VALUES

\begin{tabular}{|c|c|c|c|c|c|c|c|c|c|c|c|c|}
\hline DAY & OCT & NOV & $\mathrm{DEC}$ & JAN & FEB & MAR & APR & MAY & JUN & JUL & AUG & SEP \\
\hline $\begin{array}{l}1 \\
2 \\
3 \\
4 \\
5\end{array}$ & $\begin{array}{l}58 \\
43 \\
36 \\
82 \\
96\end{array}$ & $\begin{array}{l}3.0 \\
5.2 \\
4.7 \\
4.3 \\
3.5\end{array}$ & $\begin{array}{l}3.9 \\
6.6 \\
40 \\
39 \\
17\end{array}$ & $\begin{array}{l}7.9 \\
9.5 \\
9.1 \\
6.3 \\
5.0\end{array}$ & $\begin{array}{r}.32 \\
.34 \\
.53 \\
.83 \\
1.8\end{array}$ & $\begin{array}{r}130 \\
132 \\
48 \\
24 \\
18\end{array}$ & $\begin{array}{c}11 \\
13 \\
11 \\
7.5 \\
159\end{array}$ & $\begin{array}{l}1.6 \\
1.4 \\
1.4 \\
1.4 \\
1.3\end{array}$ & $\begin{array}{l}3.2 \\
4.6 \\
4.6 \\
1.6 \\
1.0\end{array}$ & $\begin{array}{l}.53 \\
.45 \\
.44 \\
3.8 \\
1.4\end{array}$ & $\begin{array}{l}.12 \\
.16 \\
.16 \\
.15 \\
.14\end{array}$ & $\begin{array}{l}.29 \\
.31 \\
.24 \\
.22 \\
.21\end{array}$ \\
\hline $\begin{array}{r}6 \\
7 \\
8 \\
9 \\
10\end{array}$ & $\begin{array}{r}34 \\
21 \\
13 \\
8.0 \\
5.6\end{array}$ & $\begin{array}{l}2.9 \\
2.5 \\
2.3 \\
2.3 \\
2.4\end{array}$ & $\begin{array}{l}8.9 \\
6.9 \\
8.1 \\
18 \\
34\end{array}$ & $\begin{array}{l}4.4 \\
5.6 \\
5.9 \\
4.9 \\
4.4\end{array}$ & $\begin{array}{l}2.0 \\
2.0 \\
2.0 \\
2.5 \\
3.0\end{array}$ & $\begin{array}{l}28 \\
49 \\
47 \\
27 \\
9.4\end{array}$ & $\begin{array}{r}125 \\
56 \\
25 \\
11 \\
7.5\end{array}$ & $\begin{array}{l}1.3 \\
1.3 \\
1.3 \\
1.0 \\
.85\end{array}$ & $\begin{array}{l}.80 \\
.66 \\
.52 \\
.43 \\
.36\end{array}$ & $\begin{array}{l}.60 \\
.43 \\
.37 \\
.30 \\
.36\end{array}$ & $\begin{array}{l}.09 \\
.18 \\
.19 \\
.88 \\
.19\end{array}$ & $\begin{array}{l}.18 \\
.17 \\
.32 \\
.31 \\
.12\end{array}$ \\
\hline $\begin{array}{l}11 \\
12 \\
13 \\
14 \\
15\end{array}$ & $\begin{array}{r}4.7 \\
3.9 \\
3.9 \\
26 \\
25\end{array}$ & $\begin{array}{l}2.2 \\
2.1 \\
1.8 \\
1.6 \\
1.5\end{array}$ & $\begin{array}{l}24 \\
10 \\
5.3 \\
3.9 \\
3.2\end{array}$ & $\begin{array}{r}4.6 \\
4.2 \\
4.2 \\
4.6 \\
14\end{array}$ & $\begin{array}{l}3.3 \\
4.2 \\
4.6 \\
3.5 \\
2.5\end{array}$ & $\begin{array}{l}5.2 \\
4.2 \\
3.6 \\
3.4 \\
3.5\end{array}$ & $\begin{array}{r}5.5 \\
8.4 \\
8.6 \\
6.2 \\
19\end{array}$ & $\begin{array}{l}.85 \\
1.0 \\
.85 \\
2.5 \\
7.2\end{array}$ & $\begin{array}{l}.29 \\
.34 \\
.31 \\
.30 \\
.24\end{array}$ & $\begin{array}{l}.29 \\
.22 \\
.22 \\
.39 \\
.18\end{array}$ & $\begin{array}{r}.18 \\
.16 \\
.18 \\
.39 \\
.27\end{array}$ & $\begin{array}{r}.43 \\
.18 \\
.31 \\
.31 \\
.42\end{array}$ \\
\hline $\begin{array}{l}16 \\
17 \\
18 \\
19 \\
20\end{array}$ & $\begin{array}{r}14 \\
9.1 \\
6.1 \\
4.7 \\
4.1\end{array}$ & $\begin{array}{l}1.7 \\
1.7 \\
1.8 \\
1.8 \\
1.8\end{array}$ & $\begin{array}{l}3.0 \\
3.0 \\
5.9 \\
7.3 \\
7.4\end{array}$ & $\begin{array}{r}12 \\
9.0 \\
6.0 \\
4.1 \\
3.8\end{array}$ & $\begin{array}{l}1.8 \\
1.4 \\
1.3 \\
1.3 \\
1.1\end{array}$ & $\begin{array}{l}3.9 \\
3.9 \\
3.6 \\
3.6 \\
3.3\end{array}$ & $\begin{array}{l}18 \\
11 \\
7.7 \\
5.4 \\
4.4\end{array}$ & $\begin{array}{l}1.6 \\
1.2 \\
1.2 \\
1.0 \\
1.2\end{array}$ & $\begin{array}{l}.19 \\
.18 \\
.18 \\
.18 \\
.20\end{array}$ & $\begin{array}{l}.23 \\
.22 \\
.20 \\
.19 \\
.27\end{array}$ & $\begin{array}{r}.39 \\
.80 \\
.92 \\
.58 \\
.28\end{array}$ & $\begin{array}{l}14^{.70} \\
43 \\
10 \\
3.4\end{array}$ \\
\hline $\begin{array}{l}21 \\
22 \\
23 \\
24 \\
25\end{array}$ & $\begin{array}{l}3.7 \\
3.4 \\
2.8 \\
2.4 \\
2.2\end{array}$ & $\begin{array}{l}2.1 \\
2.2 \\
2.9 \\
4.4 \\
3.9\end{array}$ & $\begin{array}{l}6.7 \\
5.5 \\
4.7 \\
4.3 \\
15\end{array}$ & $\begin{array}{l}3.8 \\
3.4 \\
3.0 \\
1.8 \\
1.2\end{array}$ & $\begin{array}{l}1.2 \\
2.2 \\
5.4 \\
5.6 \\
7.4\end{array}$ & $\begin{array}{l}3.0 \\
2.8 \\
2.6 \\
2.5 \\
2.7\end{array}$ & $\begin{array}{l}3.4 \\
3.1 \\
3.1 \\
2.8 \\
2.2\end{array}$ & $\begin{array}{l}1.2 \\
1.0 \\
.85 \\
.70 \\
.70\end{array}$ & $\begin{array}{l}.61 \\
.40 \\
.22 \\
.29 \\
.42\end{array}$ & $\begin{array}{l}.15 \\
.53 \\
.21 \\
.48 \\
2.1\end{array}$ & $\begin{array}{l}.17 \\
4.0 \\
3.1 \\
.1 \\
.51\end{array}$ & $\begin{array}{r}2.1 \\
1.5 \\
1.2 \\
1.0 \\
.80\end{array}$ \\
\hline $\begin{array}{l}26 \\
27 \\
28 \\
29 \\
30 \\
31\end{array}$ & $\begin{array}{l}2.3 \\
3.5 \\
5.1 \\
4.8 \\
4.1 \\
3.2\end{array}$ & $\begin{array}{r}14 \\
18 \\
10 \\
6.9 \\
5.2 \\
\end{array}$ & $\begin{array}{r}18 \\
15 \\
13 \\
11 \\
9.3 \\
8.1\end{array}$ & $\begin{array}{l}.50 \\
.30 \\
.26 \\
.14 \\
.18 \\
.25\end{array}$ & $\begin{array}{l}8.8 \\
10 \\
14 \\
--- \\
--- \\
--\end{array}$ & $\begin{array}{l}3.3 \\
3.1 \\
2.7 \\
2.4 \\
23 \\
23\end{array}$ & $\begin{array}{l}2.0 \\
1.8 \\
2.0 \\
1.8 \\
1.6 \\
--\end{array}$ & $\begin{array}{l}.85 \\
.57 \\
.45 \\
.37 \\
.84 \\
6.3\end{array}$ & $\begin{array}{l}3.0 \\
2.0 \\
.98 \\
.91 \\
.64 \\
---\end{array}$ & $\begin{array}{l}.70 \\
.59 \\
.32 \\
.19 \\
.11 \\
.12\end{array}$ & $\begin{array}{l}.73 \\
1.3 \\
1.3 \\
.96 \\
.60 \\
.43\end{array}$ & $\begin{array}{l}.70 \\
.70 \\
.59 \\
.74 \\
.54 \\
. .-\end{array}$ \\
\hline $\begin{array}{l}\text { TOTAL } \\
\text { MEAN } \\
\text { MAX } \\
\text { MIN } \\
\text { CFSM } \\
\text { IN. }\end{array}$ & $\begin{array}{r}535.6 \\
17.3 \\
96 \\
2.2 \\
1.33 \\
1.53\end{array}$ & $\begin{array}{r}120.7 \\
4.02 \\
18 \\
1.5 \\
.31 \\
.35\end{array}$ & $\begin{array}{r}366.0 \\
11.8 \\
40 \\
3.0 \\
.91 \\
1.05\end{array}$ & $\begin{array}{r}144.33 \\
4.66 \\
14 \\
.14 \\
.36 \\
.41\end{array}$ & $\begin{array}{r}94.92 \\
3.39 \\
14 \\
.32 \\
.26 \\
.27\end{array}$ & $\begin{array}{r}621.7 \\
20.1 \\
132 \\
2.4 \\
1.55 \\
1.78\end{array}$ & $\begin{array}{r}544.0 \\
18.1 \\
159 \\
1.6 \\
1.39 \\
1.56\end{array}$ & $\begin{array}{r}45.28 \\
1.46 \\
7.2 \\
.37 \\
.11 \\
.13\end{array}$ & $\begin{array}{r}29.65 \\
.99 \\
4.6 \\
.18 \\
.08 \\
.08\end{array}$ & $\begin{array}{r}16.59 \\
.54 \\
3.8 \\
.11 \\
.04 \\
.05\end{array}$ & $\begin{array}{r}20.61 \\
.66 \\
4.0 \\
.09 \\
.05 \\
.06\end{array}$ & $\begin{array}{r}84.99 \\
2.83 \\
43 \\
.12 \\
.22 \\
.24\end{array}$ \\
\hline $\begin{array}{ll}\text { CAL YR } \\
\text { WTR } \\
\text { YR }\end{array}$ & $\begin{array}{l}1986 \\
1987\end{array}$ & $\begin{array}{l}A L \\
A L\end{array}$ & $\begin{array}{l}.63 \\
.37\end{array}$ & $\begin{array}{l}\text { MEAN } 11.1 \\
\text { MEAN } 7.19\end{array}$ & $\begin{array}{l}\text { MAX } \\
\text { MAX }\end{array}$ & $\begin{array}{l}257 \\
159\end{array}$ & $\begin{array}{l}.09 \\
.09\end{array}$ & $\begin{array}{l}\text { CFSM } \\
\text { CFSM }\end{array}$ & $\begin{array}{l}\text { IN } \\
\text { IN }\end{array}$ & $\begin{array}{l}1.64 \\
7.51\end{array}$ & & \\
\hline
\end{tabular}


04164500 NORTH BRANCH CLINTON RIVER NEAR MOUNT CLEMENS, MI

LOCATION.--Lat $42^{\circ} 37^{\prime} 45^{\prime \prime}$, long $82^{\circ} 53^{\prime} 25^{\prime \prime}$, in swl/4 sec.35, T.3 N., R.13 E., Macomb County, Hydrologic Unit 04090003 , on left bank $30 \mathrm{ft}$ upstream from bridge on State Highway 59 , 2 mi north of Mount Clemens, and $3.6 \mathrm{mi}$ upstream from mouth.

DRAINAGE AREA. --199 $\mathrm{mi}^{2}$.

PERIOD OF RECORD.--May 1947 to current year.

REVISED RECORDS.--WSP 1437: 1948. WSP 1557: Drainage area.

GAGE.--Water-stage recorder. Concrete control since september 1961 . Datum of gage is 576.38 ft above National Geodetic Vertical Datum of 1929 (levels by Michigan Department of Natural Resources). Prior to Nov. 15, 1949, nonrecording gage at same site and datum.

REMARKS.--Estimated daily discharges: Jan. 18 to Mar. 3. Records good except for estimated daily discharges, which are fair. Some regulation at times by mill upstream from station. Several measurements of water temperature were made during the year. National Weather Service gage-height telemeter at station.

AVERAGE DISCHARGE. --40 years, $127 \mathrm{ft} / \mathrm{s}, 8.67 \mathrm{in} / \mathrm{yr}$.

EXTREMES FOR PERIOD OF RECORD.--Maximum discharge, 6,700 ft $3 / \mathrm{s}$, Feb. 2, 1968, gage height, 18.62 ft; minimum, $0.2 \mathrm{ft}^{3} / \mathrm{s}$, Sept. 13, 14, 1954, July 30, 1965; minimum gage height, $3.12 \mathrm{ft}$, Sept. 13, 14,1954

EXTREMES OUTSIDE PERIOD OF RECORD.--Flood of Apr. 5 or 6,1947 , reached a stage of $20.0 \mathrm{ft}$, from floodmark.

EXTREMES FOR CURRENT YEAR.--Peak discharges greater than base discharge of $1,200 \mathrm{ft}^{3} / \mathrm{s}^{\mathrm{and}}$ maximum (*):

$\begin{array}{ccccccc}\text { Date } & \text { Time } & \begin{array}{c}\text { Discharge } \\ \left(\mathrm{ft}^{3} / \mathrm{s}\right)\end{array} & \begin{array}{c}\text { Gage height } \\ (\mathrm{ft})\end{array} & \text { Date } & \text { Time } & \begin{array}{c}\text { Discharge } \\ \left(\mathrm{ft} \mathrm{t}^{3} / \mathrm{s}\right)\end{array} \\ \text { Mar. } 3 & 0500 & \star 1,570 & \star 12.86 & \text { Apr. } 7 & 0100 & \begin{array}{c}\text { Gage height } \\ (\mathrm{ft})\end{array}\end{array}$

Minimum discharge, $5.0 \mathrm{ft}^{3} / \mathrm{s}$, June 19,20 , gage height, $4.06 \mathrm{ft}$.

DISCHARGE, IN CUBIC FEET PER SECOND, WATER YEAR OCTOBER 1986 TO SEPTEMBER 1987

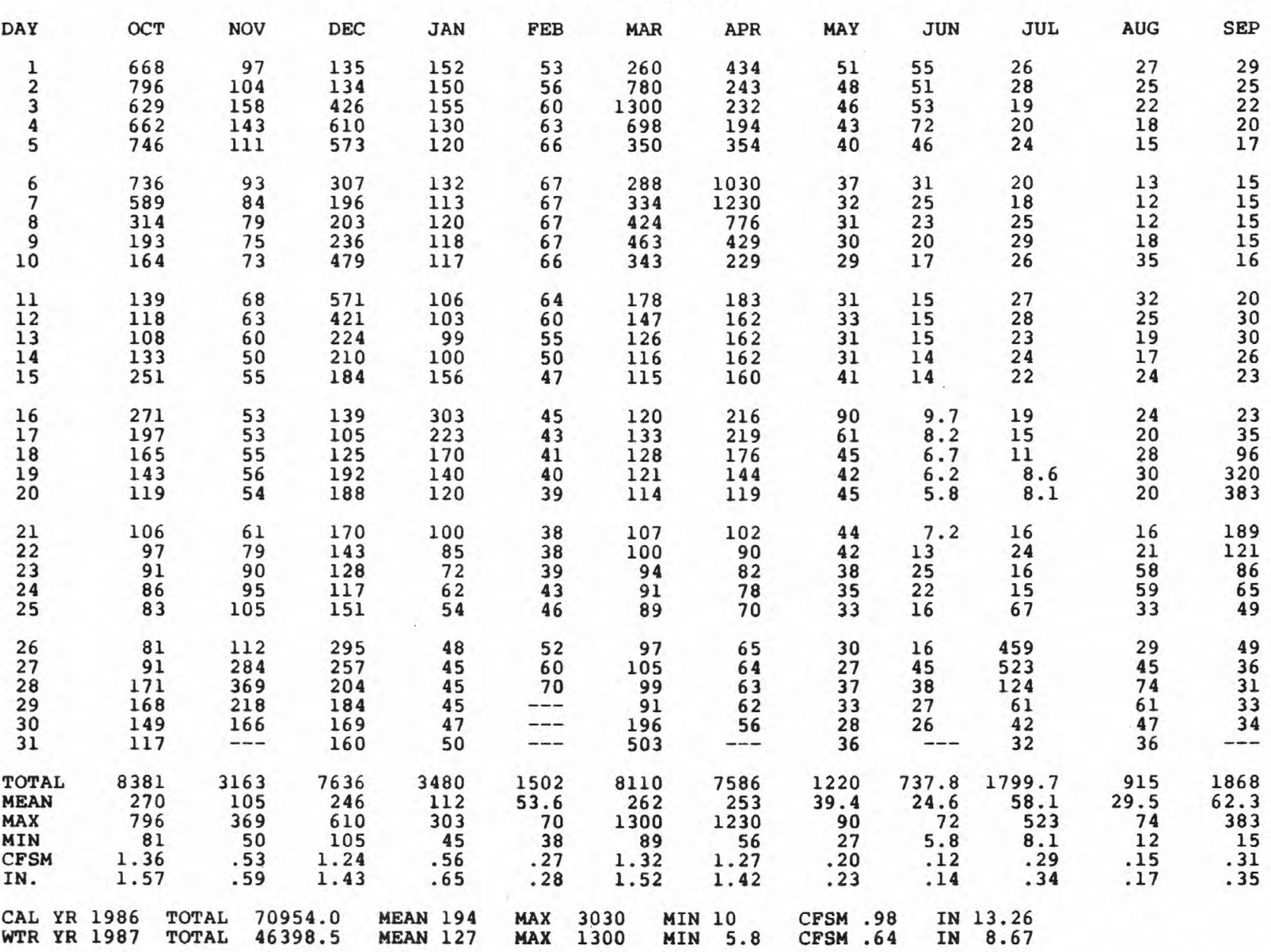




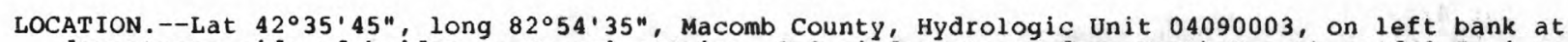
downstream side of bridge on Moravian'Drive, $0.2 \mathrm{mi}$ downstream from North Branch, and $0.5 \mathrm{mi}$ west of Mount clemens.

DRAINAGE AREA. $--734 \mathrm{mi}^{2}$.

WATER-DISCHARGE RECORDS

PERIOD OF RECORD.--May 1934 to current year.

REVISED RECORDS.--WSP 1084: 1943, 1945-46, WSP 1937: 1935, 1936(M), 1937-39, 1949(M), 1950. WSP 1557: Drainage area. WSP 1727: 1952(M), 1954(M).

GAGE.--Water-stage recorder. Datum of gage is $570.43 \mathrm{ft}$ above National Geodetic Vertical Datum of 1929 . May 10, 1934, to Jan. 11, 1939, nonrecording gage at same site and datum. Auxiliary gage is a waterstage recorder on right bank $2.0 \mathrm{mi}$ downstream from base gage at same datum. Mar. 15, 1938, to Jan. 3, 1952, auxiliary nonrecording gage $1.6 \mathrm{mi}$ downstream from base gage at same datum.

REMARKS.--Estimated daily discharges: Oct. 1-3, 6-13, Oct. 16 to Nov. 20, Nov. 23, 25, 30, Dec. 1, 13-17, 24, Jan. 5-7, 10, 19, 20, 24, Jan. 26 to Mar. 2, Mar. 5, 11, 12, 16, 18-22, 24, Mar. 29 to Aug. 21, Aug. 24-26, Aug. 30 to Sept. 10, and Sept. 13-16, 25-30. Water-discharge records fair. National Weather Service gage-height telemeter at station.

AVERAGE DISCHARGE. - -53 years, $542 \mathrm{ft}^{3} / \mathrm{s}, 10.03 \mathrm{in} / \mathrm{yr}^{\mathrm{r}}$.

EXTREMES FOR PERIOD OF RECORD,--Maximum discharge, 21, $200 \mathrm{ft}$ /s, Apr. 6, 1947, gage height, $23.55 \mathrm{ft}$, from floodmark; minimum not determined; minimum gage height, $2.72 \mathrm{ft}, \mathrm{Nov}$. 29 , 1963 .

EXTREMES FOR CURRENT YEAR.--Peak discharges greater than base discharge of $3,000 \mathrm{ft}^{3} / \mathrm{s}^{\mathrm{and}} \mathrm{maximum}\left({ }^{*}\right.$ ):

$\begin{array}{ccccccc}\text { Date } & \text { Time } & \begin{array}{c}\text { Discharge } \\ \left(\mathrm{ft}^{3} / \mathrm{s}\right)\end{array} & \begin{array}{c}\text { Gage height } \\ (\mathrm{ft})\end{array} & \text { Date } & \text { Time } & \begin{array}{c}\text { Discharge } \\ (\mathrm{ft} / \mathrm{s})\end{array} \\ \text { Oct. } 4 & 0200 & 3,060 & 10.28 & \text { Apr. } 6 & \begin{array}{c}\text { Gage height } \\ (\mathrm{ft})\end{array}\end{array}$

Minimum daily discharge, $140 \mathrm{ft}^{3} / \mathrm{s}, \mathrm{Aug}, 7,8$.

DISCHARGE, IN CUBIC FEET PER SECOND, WATER YEAR OCTOBER 1986 TO SEPTEMBER 1987 MEAN VALUES

\begin{tabular}{|c|c|c|c|c|c|c|c|c|c|c|c|c|}
\hline DAY & OCT & NOV & DEC & JAN & FEB & MAR & APR & MAY & JUN & JUL & AUG & SEP \\
\hline $\begin{array}{l}1 \\
2 \\
3 \\
4 \\
5\end{array}$ & $\begin{array}{l}2000 \\
1900 \\
2300 \\
2540 \\
1960\end{array}$ & $\begin{array}{l}480 \\
620 \\
540 \\
520 \\
480\end{array}$ & $\begin{array}{r}500 \\
973 \\
1530 \\
1310 \\
1140\end{array}$ & $\begin{array}{l}563 \\
558 \\
582 \\
486 \\
480\end{array}$ & $\begin{array}{l}410 \\
440 \\
480 \\
470 \\
450\end{array}$ & $\begin{array}{r}1300 \\
1900 \\
2130 \\
1340 \\
950\end{array}$ & $\begin{array}{r}1050 \\
930 \\
820 \\
700 \\
2000\end{array}$ & $\begin{array}{l}280 \\
270 \\
290 \\
270 \\
240\end{array}$ & $\begin{array}{l}310 \\
370 \\
730 \\
450 \\
350\end{array}$ & $\begin{array}{l}370 \\
370 \\
370 \\
360 \\
240\end{array}$ & $\begin{array}{l}320 \\
220 \\
200 \\
180 \\
160\end{array}$ & $\begin{array}{l}360 \\
330 \\
230 \\
190 \\
180\end{array}$ \\
\hline $\begin{array}{r}6 \\
7 \\
8 \\
9 \\
10\end{array}$ & $\begin{array}{r}1700 \\
1500 \\
1000 \\
900 \\
800\end{array}$ & $\begin{array}{l}440 \\
420 \\
440 \\
420 \\
400\end{array}$ & $\begin{array}{r}839 \\
747 \\
947 \\
1150 \\
1710\end{array}$ & $\begin{array}{l}520 \\
520 \\
495 \\
478 \\
530\end{array}$ & $\begin{array}{l}440 \\
470 \\
510 \\
410 \\
400\end{array}$ & $\begin{array}{r}895 \\
937 \\
993 \\
1030 \\
821\end{array}$ & $\begin{array}{r}2700 \\
2400 \\
1700 \\
1200 \\
920\end{array}$ & $\begin{array}{l}230 \\
230 \\
230 \\
230 \\
220\end{array}$ & $\begin{array}{l}260 \\
250 \\
230 \\
210 \\
200\end{array}$ & $\begin{array}{l}230 \\
225 \\
240 \\
230 \\
760\end{array}$ & $\begin{array}{l}150 \\
140 \\
140 \\
670 \\
700\end{array}$ & $\begin{array}{l}170 \\
160 \\
160 \\
250 \\
190\end{array}$ \\
\hline $\begin{array}{l}11 \\
12 \\
13 \\
14 \\
15\end{array}$ & $\begin{array}{r}720 \\
680 \\
700 \\
1050 \\
999\end{array}$ & $\begin{array}{l}380 \\
370 \\
440 \\
340 \\
320\end{array}$ & $\begin{array}{r}1230 \\
990 \\
740 \\
710 \\
740\end{array}$ & $\begin{array}{r}550 \\
510 \\
489 \\
523 \\
1050\end{array}$ & $\begin{array}{l}400 \\
400 \\
390 \\
360 \\
350\end{array}$ & $\begin{array}{l}640 \\
600 \\
523 \\
516 \\
519\end{array}$ & $\begin{array}{l}820 \\
770 \\
760 \\
720 \\
820\end{array}$ & $\begin{array}{r}230 \\
270 \\
230 \\
340 \\
1200\end{array}$ & $\begin{array}{l}190 \\
230 \\
200 \\
190 \\
190\end{array}$ & $\begin{array}{l}540 \\
330 \\
280 \\
620 \\
290\end{array}$ & $\begin{array}{l}240 \\
190 \\
170 \\
250 \\
340\end{array}$ & $\begin{array}{l}652 \\
402 \\
330 \\
260 \\
350\end{array}$ \\
\hline $\begin{array}{l}16 \\
17 \\
18 \\
19 \\
20\end{array}$ & $\begin{array}{l}880 \\
780 \\
700 \\
630 \\
600\end{array}$ & $\begin{array}{l}320 \\
330 \\
340 \\
350 \\
420\end{array}$ & $\begin{array}{l}680 \\
600 \\
819 \\
808 \\
719\end{array}$ & $\begin{array}{r}1020 \\
667 \\
590 \\
540 \\
520\end{array}$ & $\begin{array}{l}330 \\
340 \\
340 \\
330 \\
320\end{array}$ & $\begin{array}{l}570 \\
552 \\
540 \\
540 \\
500\end{array}$ & $\begin{array}{r}1100 \\
880 \\
720 \\
660 \\
600\end{array}$ & $\begin{array}{l}500 \\
330 \\
470 \\
450 \\
380\end{array}$ & $\begin{array}{l}190 \\
180 \\
180 \\
180 \\
180\end{array}$ & $\begin{array}{l}460 \\
250 \\
210 \\
180 \\
190\end{array}$ & $\begin{array}{l}170 \\
270 \\
210 \\
190 \\
160\end{array}$ & $\begin{array}{r}290 \\
433 \\
1130 \\
780 \\
758\end{array}$ \\
\hline $\begin{array}{l}21 \\
22 \\
23 \\
24 \\
25\end{array}$ & $\begin{array}{l}570 \\
540 \\
540 \\
550 \\
560\end{array}$ & $\begin{array}{l}521 \\
438 \\
420 \\
420 \\
430\end{array}$ & $\begin{array}{l}670 \\
593 \\
575 \\
560 \\
885\end{array}$ & $\begin{array}{l}476 \\
502 \\
436 \\
400 \\
376\end{array}$ & $\begin{array}{l}320 \\
320 \\
350 \\
350 \\
350\end{array}$ & $\begin{array}{l}470 \\
460 \\
537 \\
450 \\
458\end{array}$ & $\begin{array}{l}560 \\
520 \\
460 \\
440 \\
380\end{array}$ & $\begin{array}{l}370 \\
310 \\
320 \\
320 \\
310\end{array}$ & $\begin{array}{r}360 \\
2200 \\
560 \\
320 \\
320\end{array}$ & $\begin{array}{r}560 \\
250 \\
230 \\
250 \\
1400\end{array}$ & $\begin{array}{r}210 \\
1180 \\
491 \\
290 \\
220\end{array}$ & $\begin{array}{l}723 \\
659 \\
398 \\
359 \\
350\end{array}$ \\
\hline $\begin{array}{l}26 \\
27 \\
28 \\
29 \\
30 \\
31\end{array}$ & $\begin{array}{l}600 \\
640 \\
860 \\
700 \\
620 \\
550\end{array}$ & $\begin{array}{l}594 \\
926 \\
791 \\
616 \\
520 \\
-\end{array}$ & $\begin{array}{l}886 \\
795 \\
693 \\
678 \\
609 \\
572\end{array}$ & $\begin{array}{l}370 \\
370 \\
360 \\
360 \\
380 \\
400\end{array}$ & $\begin{array}{l}360 \\
370 \\
400 \\
--- \\
--- \\
---\end{array}$ & $\begin{array}{r}491 \\
477 \\
427 \\
440 \\
1300 \\
1380\end{array}$ & $\begin{array}{l}360 \\
440 \\
350 \\
310 \\
290 \\
\end{array}$ & $\begin{array}{l}330 \\
470 \\
260 \\
240 \\
260 \\
700\end{array}$ & $\begin{array}{l}720 \\
390 \\
300 \\
260 \\
600 \\
--\end{array}$ & $\begin{array}{r}1000 \\
940 \\
360 \\
280 \\
240 \\
220\end{array}$ & $\begin{array}{r}570 \\
1700 \\
565 \\
460 \\
480 \\
320\end{array}$ & $\begin{array}{l}330 \\
280 \\
280 \\
280 \\
290\end{array}$ \\
\hline $\begin{array}{l}\text { TOTAL } \\
\text { MEAN } \\
\text { MAX } \\
\text { MIN } \\
\text { CFSM } \\
\text { IN. }\end{array}$ & $\begin{array}{r}31069 \\
1002 \\
2540 \\
540 \\
1.37 \\
1.57\end{array}$ & $\begin{array}{r}14046 \\
468 \\
926 \\
320 \\
.64 \\
.71\end{array}$ & $\begin{array}{r}26398 \\
852 \\
1710 \\
500 \\
1.16 \\
1.34\end{array}$ & $\begin{array}{r}16101 \\
519 \\
1050 \\
360 \\
.71 \\
.82\end{array}$ & $\begin{array}{r}10860 \\
388 \\
510 \\
320 \\
.53 \\
.55\end{array}$ & $\begin{array}{r}24686 \\
796 \\
2130 \\
427 \\
1.08 \\
1.25\end{array}$ & $\begin{array}{r}26380 \\
879 \\
2700 \\
290 \\
1.20 \\
1.34\end{array}$ & $\begin{array}{r}10780 \\
348 \\
1200 \\
220 \\
.47 \\
.55\end{array}$ & $\begin{array}{r}11300 \\
377 \\
2200 \\
180 \\
.51 \\
.57\end{array}$ & $\begin{array}{r}12475 \\
402 \\
1400 \\
180 \\
.55 \\
.63\end{array}$ & $\begin{array}{r}11556 \\
373 \\
1700 \\
140 \\
.51 \\
.59\end{array}$ & $\begin{array}{r}11554 \\
385 \\
1130 \\
160 \\
.53 \\
.59\end{array}$ \\
\hline
\end{tabular}

$\begin{array}{lllllllllll}\text { CAL YR } 1986 & \text { TOTAL } & 273215 & \text { MEAN } 749 & \text { MAX } & 5030 & \text { MIN } 170 & \text { CFSM } 1.02 & \text { IN } 13.85 \\ \text { WTR YR } 1987 & \text { TOTAL } & 207205 & \text { MEAN } 568 & \text { MAX } & 2700 & \text { MIN } 140 & \text { CFSM } & .77 & \text { IN } 10.50\end{array}$ 
PERIOD OF RECORD.--Water years 1969,1972 to current year.

PERIOD OF DAILY RECORD.--

SPECIFIC CONDUCTANCE: October 1974 to September 1981.

WATER TEMPERATURE: October 1974 to September 1981 .

INSTRUMENTATION.--Water-quality monitor from Aug. 13, 1975 to Sept. 6, 1981.

REMARKS.--Quarterly cross-sectional samples were collected at bridge. Daily-mean discharge is reported at sample time.

EXTREMES FOR PERIOD OF DAILY RECORD.--

SPECIFIC CONDUCTANCE (water years 1975-76, 1978-81): Maximum, 3,580 microsiemens, Jan. 26, 1978;

minimum, 126 microsiemens, July $29,1976$.

WATER TEMPERATURE (water years 1975-81): Maximum, $29.5^{\circ} \mathrm{C}$, Sept. 20,1978 ; minimum, $0.0^{\circ} \mathrm{C}$ on many days during winter.

WATER QUALITY DATA, WATER YEAR OCTOBER 1986 TO SEPTEMBER 1987

\begin{tabular}{|c|c|c|c|c|c|c|c|c|c|c|}
\hline DATE & TIME & $\begin{array}{l}\text { DIS- } \\
\text { CHARGE, } \\
\text { IN } \\
\text { CUBIC } \\
\text { FEET } \\
\text { PER } \\
\text { SECOND }\end{array}$ & $\begin{array}{l}\text { SPE- } \\
\text { CIFIC } \\
\text { CON- } \\
\text { DUCT- } \\
\text { ANCE } \\
\text { (US/CM) }\end{array}$ & $\begin{array}{c}\text { PH } \\
\text { (STAND- } \\
\text { ARD } \\
\text { UNITS) }\end{array}$ & $\begin{array}{l}\text { TEMPER- } \\
\text { ATURE } \\
\text { (DEG C) }\end{array}$ & $\begin{array}{l}\text { TUR- } \\
\text { BID- } \\
\text { ITY } \\
\text { (NTU) }\end{array}$ & $\begin{array}{c}\text { OXYGEN, } \\
\text { DIS- } \\
\text { SOLVED } \\
\text { (MG/L) }\end{array}$ & $\begin{array}{l}\text { OXYGEN, } \\
\text { DIS- } \\
\text { SOLVED } \\
\text { (PER- } \\
\text { CENT } \\
\text { SATUR- } \\
\text { ATION) }\end{array}$ & $\begin{array}{l}\text { COLI- } \\
\text { FORM, } \\
\text { FECAL, } \\
0.7 \\
\text { UM-MF } \\
\text { (COLS./ } \\
100 \mathrm{ML} \text { ) }\end{array}$ & $\begin{array}{c}\text { STREP- } \\
\text { TOCOCCI } \\
\text { FECAL, } \\
\text { KF AGAR } \\
\text { (COLS. } \\
\text { PER } \\
100 \mathrm{ML} \text { ) }\end{array}$ \\
\hline $\begin{array}{l}\text { DEC } \\
10 \ldots \\
\text { MAR }\end{array}$ & 1130 & 1710 & 952 & 7.9 & 1.5 & 31 & 12.6 & 92 & K700 & -- \\
\hline${ }_{\text {JUN }}^{24 \ldots}$ & 1100 & 450 & 886 & 8.2 & 9.0 & 4.3 & 12.8 & 112 & K580 & 96 \\
\hline $\operatorname{SEP}^{24} \cdots$ & 1100 & 320 & 838 & 7.9 & 22.5 & 88 & 5.4 & 64 & K1300 & 620 \\
\hline $15 \ldots$ & 1115 & 350 & 735 & 7.8 & 18.0 & 23 & 7.3 & 79 & 4600 & E4300 \\
\hline DATE & $\begin{array}{l}\text { HARD- } \\
\text { NESS } \\
\text { (MG/L } \\
\text { AS } \\
\text { CACO3) }\end{array}$ & $\begin{array}{l}\text { HARD- } \\
\text { NESS } \\
\text { NONCARB } \\
\text { WH WAT } \\
\text { TOT FLD } \\
\text { MG/L AS } \\
\text { CACO3 }\end{array}$ & $\begin{array}{l}\text { CALCIUM } \\
\text { DIS- } \\
\text { SOLVED } \\
\text { (MG/L } \\
\text { AS CA) }\end{array}$ & $\begin{array}{l}\text { MAGNE- } \\
\text { SIUM, } \\
\text { DIS- } \\
\text { SOLVED } \\
\text { (MG/L } \\
\text { AS MG) }\end{array}$ & $\begin{array}{l}\text { SODIUM, } \\
\text { DIS- } \\
\text { SOLVED } \\
\text { (MG/L } \\
\text { AS NA) }\end{array}$ & $\begin{array}{l}\text { PERCENT } \\
\text { SODIUM }\end{array}$ & $\begin{array}{c}\text { SODIUM } \\
\text { AD- } \\
\text { SORP- } \\
\text { TION } \\
\text { RATIO }\end{array}$ & $\begin{array}{l}\text { POTAS- } \\
\text { SIUM, } \\
\text { DIS- } \\
\text { SOLVED } \\
\text { (MG/L } \\
\text { AS K) }\end{array}$ & $\begin{array}{l}\text { BICAR- } \\
\text { BONATE } \\
\text { WH WAT } \\
\text { TOTAL } \\
\text { FIELD } \\
\text { MG/L AS } \\
\text { HCO3 }\end{array}$ & $\begin{array}{l}\text { CAR- } \\
\text { BONATE } \\
\text { WH WAT } \\
\text { TOTAL } \\
\text { FIELD } \\
\text { MG } / L \text { AS } \\
\mathrm{CO} 3^{\text {CON }}\end{array}$ \\
\hline DEC & & & & & & & & & & \\
\hline $\operatorname{MAR} 10 \ldots$ & 240 & 88 & 68 & 18 & 100 & 47 & 3 & 3.8 & 190 & 0 \\
\hline$\underset{\text { JUN }}{24 \ldots}$ & 310 & 93 & 83 & 25 & 71 & 33 & 2 & 3.6 & -- & -- \\
\hline SEP $24 \ldots$ & 260 & 72 & 72 & 20 & 72 & 37 & 2 & 5.3 & 230 & 0 \\
\hline $15 \ldots$ & 250 & 68 & 67 & 21 & 54 & 31 & 2 & 5.0 & 230 & 0 \\
\hline DATE & $\begin{array}{l}\text { ALKA- } \\
\text { LINITY } \\
\text { WH WAT } \\
\text { TOTAL } \\
\text { FIELD } \\
\text { MG/L AS } \\
\text { CACO3 }\end{array}$ & $\begin{array}{c}\text { CARBON } \\
\text { DIOXIDE } \\
\text { DIS- } \\
\text { SOLVED } \\
\text { (MG/L } \\
\text { AS CO2) }\end{array}$ & $\begin{array}{l}\text { SULFATE } \\
\text { DIS- } \\
\text { SOLVED } \\
\text { (MG/L } \\
\text { AS SO4) }\end{array}$ & $\begin{array}{l}\text { CHLO- } \\
\text { RIDE, } \\
\text { DIS- } \\
\text { SOLVED } \\
\text { (MG/L } \\
\text { AS CL) }\end{array}$ & $\begin{array}{l}\text { FLUO- } \\
\text { RIDE, } \\
\text { DIS- } \\
\text { SOLVED } \\
\text { (MG/L } \\
\text { AS F) }\end{array}$ & $\begin{array}{l}\text { SILICA, } \\
\text { DIS- } \\
\text { SOLVED } \\
\text { (MG/L } \\
\text { AS } \\
\text { SIO2) }\end{array}$ & $\begin{array}{l}\text { SOLIDS, } \\
\text { RESIDUE } \\
\text { AT } 180 \\
\text { DEG. C } \\
\text { DIS- } \\
\text { SOLVED } \\
\text { (MG/L) }\end{array}$ & $\begin{array}{l}\text { SOLIDS, } \\
\text { SUM OF } \\
\text { CONSTI- } \\
\text { TUENTS, } \\
\text { DIS- } \\
\text { SOLVED } \\
(M G / L)\end{array}$ & $\begin{array}{c}\text { SOLIDS, } \\
\text { DIS- } \\
\text { SOLVED } \\
\text { (TONS } \\
\text { PER } \\
\text { AC-FT) }\end{array}$ & $\begin{array}{c}\text { SOLIDS, } \\
\text { DIS- } \\
\text { SOLVED } \\
\text { (TONS } \\
\text { PER } \\
\text { DAY) }\end{array}$ \\
\hline $\begin{array}{l}\text { DEC } \\
10 \ldots \\
\text { MAR }\end{array}$ & 156 & 3.8 & 51 & 190 & 0.2 & 6.0 & 529 & 540 & 0.72 & 2440 \\
\hline${ }_{\text {JUN }}^{24 \ldots}$ & -- & 2.6 & 58 & 130 & 0.3 & 2.0 & 515 & 500 & 0.7 & 626 \\
\hline$\underset{S E P}{24 \ldots}$ & 190 & 4.6 & 61 & 130 & 0.4 & 7.8 & 495 & 480 & 0.67 & 428 \\
\hline $15 \ldots$ & 186 & 5.7 & 46 & 81 & 0.4 & 6.0 & 418 & 390 & 0.57 & 395 \\
\hline
\end{tabular}




\begin{tabular}{|c|c|c|c|c|c|c|c|c|c|c|}
\hline DATE & $\begin{array}{c}\text { NITRO- } \\
\text { GEN, } \\
\text { NITRITE } \\
\text { DIS- } \\
\text { SOLVED } \\
\text { (MG/L } \\
\text { AS N) }\end{array}$ & $\begin{array}{c}\text { NITRO- } \\
\text { GEN, } \\
\text { NO2+NO3 } \\
\text { DIS- } \\
\text { SOLVED } \\
\text { (MG/L } \\
\text { AS N ) }\end{array}$ & $\begin{array}{c}\text { NITRO- } \\
\text { GEN, } \\
\text { AMMONIA } \\
\text { TOTAL } \\
\text { (MG/L } \\
\text { AS N) }\end{array}$ & $\begin{array}{l}\text { NITRO- } \\
\text { GEN, } \\
\text { AMMONIA } \\
\text { DIS- } \\
\text { SOLVED } \\
\text { (MG/L } \\
\text { AS N) }\end{array}$ & $\begin{array}{c}\text { NITRO- } \\
\text { GEN, } \\
\text { ORGANIC } \\
\text { TOTAL } \\
\text { (MG/L } \\
\text { AS N) }\end{array}$ & $\begin{array}{l}\text { NITRO- } \\
\text { GEN, AM- } \\
\text { MONIA + } \\
\text { ORGANIC } \\
\text { TOTAL } \\
\text { (MG/L } \\
\text { AS N) }\end{array}$ & $\begin{array}{c}\text { PHOS- } \\
\text { PHORUS, } \\
\text { TOTAL } \\
\text { (MG/L } \\
\text { AS P) }\end{array}$ & $\begin{array}{c}\text { PHOS- } \\
\text { PHORUS, } \\
\text { DIS- } \\
\text { SOLVED } \\
\text { (MG/L } \\
\text { AS P) }\end{array}$ & $\begin{array}{l}\text { PHOS- } \\
\text { PHORUS, } \\
\text { ORTHO, } \\
\text { DIS- } \\
\text { SOLVED } \\
\text { (MG/L } \\
\text { AS P) }\end{array}$ & $\begin{array}{l}\text { ALUM- } \\
\text { INUM, } \\
\text { DIS- } \\
\text { SOLVED } \\
\text { (UG/L } \\
\text { AS AL) }\end{array}$ \\
\hline${ }_{12}^{C C}$ & 0.02 & 1.60 & 0.14 & 0.12 & 1.4 & 1.5 & 0.07 & 0.04 & 0.03 & $<10$ \\
\hline$\underset{\mathrm{JN}}{24} \ldots$ & 0.02 & 1.90 & 0.07 & 0.07 & 1.0 & 1.1 & 0.09 & 0.04 & 0.03 & 10 \\
\hline $24 \ldots$ & 0.06 & 2.70 & 0.24 & 0.27 & 0.46 & 0.7 & 0.15 & 0.08 & 0.06 & $<10$ \\
\hline $15 \ldots$ & 0.02 & 2.40 & 0.09 & 0.09 & 0.91 & 1.0 & 0.26 & 0.17 & 0.13 & 10 \\
\hline
\end{tabular}

\begin{tabular}{|c|c|c|c|c|c|c|c|c|c|c|}
\hline & $\begin{array}{c}\text { ARSENIC } \\
\text { DIS- } \\
\text { SOLVED } \\
\text { (UG/L } \\
\text { AS AS) }\end{array}$ & $\begin{array}{l}\text { BARIUM, } \\
\text { DIS- } \\
\text { SOLVED } \\
\text { (UG/L }\end{array}$ & $\begin{array}{l}\text { BERYL- } \\
\text { LIUM, } \\
\text { DIS- } \\
\text { SOLVED } \\
\text { (UG/L }\end{array}$ & $\begin{array}{l}\text { CADMIUM } \\
\text { DIS- } \\
\text { SOLVED } \\
\text { (UG/L }\end{array}$ & $\begin{array}{l}\text { MIUM, } \\
\text { DIS- } \\
\text { SOLVED } \\
\text { (UG/L }\end{array}$ & $\begin{array}{l}\text { COBALT, } \\
\text { DIS- } \\
\text { SOLVED } \\
\text { (UG/L }\end{array}$ & $\begin{array}{l}\text { COPPER, } \\
\text { DIS- } \\
\text { SOLVED } \\
\text { (UG/L }\end{array}$ & $\begin{array}{l}\text { IRON, } \\
\text { DIS- } \\
\text { SOLVED } \\
\text { (UG/L } \\
\text { AS FE) }\end{array}$ & $\begin{array}{l}\text { LEAD, } \\
\text { DIS- } \\
\text { SOLVED } \\
\text { (UG/L } \\
\text { AS PB) }\end{array}$ & $\begin{array}{c}\text { LITHIUM } \\
\text { DIS- } \\
\text { SOLVED } \\
\text { (UG/L } \\
\text { (UG L }\end{array}$ \\
\hline
\end{tabular}

$$
<0.5<1<1<3
$$$$
\text { MAR } 24 \ldots
$$$$
\text { JUN }
$$$$
24 \ldots
$$$$
\text { SEP }
$$

$\begin{array}{rr}<1 & 39 \\ <1 & 52 \\ 2 & 56 \\ 2 & 51\end{array}$

$\begin{array}{rr}<0.5 & <1 \\ <0.5 & 1 \\ <0.5 & <1 \\ <0.5 & 2\end{array}$

$<1$
$<1$
$<1$
$<1$

$$
\begin{aligned}
& <3 \\
& <3
\end{aligned}
$$

4

21

PB) AS LI)

MANGA-

$\begin{array}{lc}\text { MANGA- } & \\ \text { NESE, } & \text { MERCURY } \\ \text { DIS- } & \text { DIS- } \\ \text { SOLVED } & \text { SOLVED } \\ \text { (UG/L } & \text { (UG/L }\end{array}$

DATE

AS MN) AS HG)

$\begin{array}{ll}\text { MOLYB- } & \\ \text { DENUM, } & \text { NICKEL, } \\ \text { DIS- } & \text { DIS- } \\ \text { SOLVED } & \text { SOLVED } \\ \text { (UG/L } & \text { (UG } / L \\ \text { AS MO) } & \text { AS NI) }\end{array}$

$\begin{array}{cc}\text { SELE- } & \\ \text { NIUM, } & \text { SILVER, } \\ \text { DIS- } & \text { DIS- } \\ \text { SOLVED } & \text { SOLVED } \\ \text { (UG/L } & \text { (UG/L } \\ \text { AS SE) } & \text { AS AG) }\end{array}$

STRON-
TIUM,
DIS-
SOLVED
(UG/L
AS SR)

VANA-
DIUM,
DIS-
SOLVED
(UG/L
AS V)

$\begin{array}{rr}<5 & 11 \\ <5 & 14 \\ <5 & 9 \\ <5 & 8\end{array}$

$$
\begin{gathered}
\text { DEC } \\
10 \ldots \\
\text { MAR } \\
24 \ldots \\
\text { JUN } \\
24 \ldots \\
\text { SEP } \\
15 \ldots
\end{gathered}
$$

$\begin{array}{rlr}36 & <0.1 & <10 \\ 52 & <0.1 & <10 \\ 99 & <0.1 & 10 \\ 33 & <0.1 & <10\end{array}$

\begin{tabular}{|c|c|c|}
\hline DATE & $\begin{array}{c}\text { SEDI- } \\
\text { MENT, } \\
\text { DIS- } \\
\text { CHARGE, } \\
\text { SUS- } \\
\text { PENDED } \\
\text { (T/DAY) }\end{array}$ & $\begin{array}{l}\text { SED. } \\
\text { SUSP. } \\
\text { SIEVE } \\
\text { DIAM. } \\
\text { \&INER } \\
\text { THAN } \\
.062 \text { MM }\end{array}$ \\
\hline DEC & & \\
\hline${ }_{\operatorname{MAR}}^{10} \cdots$ & 300 & 96 \\
\hline$\underset{\text { JUN }}{24} \ldots$ & 22 & 87 \\
\hline SEP $24 \ldots$ & -- & -- \\
\hline $15 \ldots$ & 42 & 99 \\
\hline
\end{tabular}

2
5
9
4

$\begin{array}{lll}<1 & <1 & 200 \\ <1 & <1 & 220 \\ <1 & <1 & 260 \\ <1 & <1 & 210\end{array}$

$\begin{array}{rrr}<6 & 11 & 65 \\ <6 & 3 & 18 \\ <6 & 39 & - \\ <6 & 58 & 44\end{array}$


LOCATION.--Lat $42^{\circ} 32^{\prime} 45^{\prime \prime}$, long $83^{\circ} 13^{\prime} 25^{\prime \prime}$, in NWl/4 sec.36, T. 2 N., R. 10 E., Oakland County, Hydrologic Unit 04090004 , on left bank 25 ft downstream from mouth of quarton Lake outlet, and 100 ft upstream from bridge on Maple Road at Birmingham.

DRAINAGE AREA.--33.3 $\mathrm{mi}^{2}$. Prior to water year 1971 , drainage area was $36.9 \mathrm{mi} 2$ An area of $3.6 \mathrm{mi}^{2}$ noncontributing since then.

PERIOD OF RECORD.--June 1950 to current year.

REVISED RECORDS.--WSP 1387: 1951-52(M). WSP 1557: Drainage area.

GAGE.--Water-stage recorder. Concrete control since July 27, 1962. Datum of gage is $715.94 \mathrm{ft}$ above National Geodetic Vertical Datum of 1929.

REMARKS.--Estimated daily discharges: Oct. 17 to Nov. 20, Jan. 18-28, and Sept. 18-30. Records good except for estimated daily discharges, which are fair. Occasional regulation by Quarton lake upstream from station. Several measurements of water temperature were made during the year.

AVERAGE DISCHARGE. -20 years (water years 1951-70), $15.3 \mathrm{ft} / \mathrm{s}, 5.63$ in/yr; 17 years (water years $1971-87), 23.1 \mathrm{ft} / \mathrm{s}, 9.42 \mathrm{in} / \mathrm{Yr}$.

EXTREMES FOR PERIOD OF RECORD.--Maximum discharge, 1,390 $\mathrm{ft}^{3} / \mathrm{s}$, June 26, 1968, gage height, $8.70 \mathrm{ft}$; minimum, $0.10 \mathrm{ft} / \mathrm{s}$, Aug. $8,9,1963$; minimum gage height, $1.02 \mathrm{ft}$, Oct. 12, 1961.

EXTREMES FOR CURRENT YEAR.--Peak discharges greater than base discharge of $180 \mathrm{ft} 3 / \mathrm{s}$ and maximum ( ${ }^{*}$ ):

\begin{tabular}{|c|c|c|c|c|c|c|c|}
\hline Date & Time & $\begin{array}{c}\text { Discharge } \\
\left(f t^{3} / \mathrm{s}\right)\end{array}$ & $\begin{array}{c}\text { Gage height } \\
(\mathrm{ft})\end{array}$ & Date & Time & $\begin{array}{c}\text { Discharge } \\
\left(\mathrm{ft}^{3} / \mathrm{s}\right)\end{array}$ & $\begin{array}{c}\text { Gage height } \\
(\mathrm{ft})\end{array}$ \\
\hline Oct. 3 & 1900 & 189 & 3.27 & June 21 & 2000 & $\star 192$ & $\star a 3.29$ \\
\hline
\end{tabular}

a From graph based on gage readings.

Minimum discharge, $4.4 \mathrm{ft}^{3} / \mathrm{s}$, June 20 , gage height, $1.63 \mathrm{ft}$.

DISCHARGE, IN CUBIC FEET PER SECOND, WATER YEAR OCTOBER 1986 TO SEPTEMBER 1987 MEAN VALUES

\begin{tabular}{|c|c|c|c|c|c|c|c|c|c|c|c|c|c|}
\hline DAY & OCT & NOV & DEC & JAN & FEB & & MAR & APR & MAY & JUN & JUL & AUG & SEP \\
\hline $\begin{array}{l}1 \\
2 \\
3 \\
4 \\
5\end{array}$ & $\begin{array}{r}75 \\
63 \\
105 \\
110 \\
74\end{array}$ & $\begin{array}{l}23 \\
32 \\
25 \\
22 \\
21\end{array}$ & $\begin{array}{l}20 \\
44 \\
59 \\
38 \\
30\end{array}$ & $\begin{array}{l}22 \\
24 \\
24 \\
22 \\
21\end{array}$ & $\begin{array}{l}18 \\
20 \\
22 \\
21 \\
18\end{array}$ & & $\begin{array}{l}89 \\
64 \\
38 \\
28 \\
29\end{array}$ & $\begin{array}{r}31 \\
46 \\
31 \\
27 \\
120\end{array}$ & $\begin{array}{l}13 \\
13 \\
16 \\
15 \\
13\end{array}$ & $\begin{array}{l}11 \\
41 \\
44 \\
18 \\
13\end{array}$ & $\begin{array}{r}13 \\
11 \\
18 \\
14 \\
9.9\end{array}$ & $\begin{array}{l}8.9 \\
8.9 \\
7.3 \\
6.2 \\
5.4\end{array}$ & $\begin{array}{l}8.3 \\
8.2 \\
7.6 \\
6.9 \\
7.0\end{array}$ \\
\hline $\begin{array}{r}6 \\
7 \\
8 \\
9 \\
10\end{array}$ & $\begin{array}{l}50 \\
40 \\
35 \\
34 \\
30\end{array}$ & $\begin{array}{l}20 \\
21 \\
21 \\
20 \\
18\end{array}$ & $\begin{array}{l}26 \\
29 \\
36 \\
55 \\
65\end{array}$ & $\begin{array}{l}22 \\
23 \\
22 \\
21 \\
23\end{array}$ & $\begin{array}{l}19 \\
21 \\
23 \\
20 \\
19\end{array}$ & & $\begin{array}{l}31 \\
33 \\
32 \\
27 \\
20\end{array}$ & $\begin{array}{l}97 \\
60 \\
45 \\
39 \\
35\end{array}$ & $\begin{array}{l}13 \\
11 \\
11 \\
11 \\
10\end{array}$ & $\begin{array}{r}12 \\
12 \\
9.8 \\
8.8 \\
7.8\end{array}$ & $\begin{array}{l}9.7 \\
10 \\
8.8 \\
12 \\
23\end{array}$ & $\begin{array}{l}5.2 \\
5.0 \\
5.0 \\
51 \\
41\end{array}$ & $\begin{array}{l}6.6 \\
6.4 \\
32 \\
56 \\
19\end{array}$ \\
\hline $\begin{array}{l}11 \\
12 \\
13 \\
14 \\
15\end{array}$ & $\begin{array}{l}27 \\
26 \\
29 \\
68 \\
40\end{array}$ & $\begin{array}{l}16 \\
15 \\
14 \\
13 \\
14\end{array}$ & $\begin{array}{l}37 \\
30 \\
25 \\
23 \\
22\end{array}$ & $\begin{array}{l}22 \\
20 \\
20 \\
21 \\
45\end{array}$ & $\begin{array}{l}19 \\
20 \\
18 \\
18 \\
16\end{array}$ & & $\begin{array}{l}17 \\
17 \\
16 \\
19 \\
21\end{array}$ & $\begin{array}{l}32 \\
37 \\
34 \\
31 \\
34\end{array}$ & $\begin{array}{l}9.6 \\
9.7 \\
8.5 \\
26 \\
50\end{array}$ & $\begin{array}{l}7.4 \\
7.9 \\
8.0 \\
6.6 \\
6.1\end{array}$ & $\begin{array}{l}12 \\
9.1 \\
8.1 \\
10 \\
11\end{array}$ & $\begin{array}{r}14 \\
9.2 \\
8.2 \\
9.7 \\
11\end{array}$ & $\begin{array}{l}77 \\
31 \\
18 \\
13 \\
21\end{array}$ \\
\hline $\begin{array}{l}16 \\
17 \\
18 \\
19 \\
20\end{array}$ & $\begin{array}{l}32 \\
29 \\
28 \\
27 \\
25\end{array}$ & $\begin{array}{l}14 \\
14 \\
14 \\
15 \\
19\end{array}$ & $\begin{array}{l}22 \\
23 \\
39 \\
31 \\
27\end{array}$ & $\begin{array}{l}33 \\
24 \\
22 \\
21 \\
20\end{array}$ & $\begin{array}{l}15 \\
15 \\
15 \\
14 \\
14\end{array}$ & & $\begin{array}{l}20 \\
20 \\
19 \\
18 \\
17\end{array}$ & $\begin{array}{l}48 \\
36 \\
31 \\
29 \\
26\end{array}$ & $\begin{array}{l}19 \\
14 \\
20 \\
21 \\
16\end{array}$ & $\begin{array}{l}5.4 \\
5.5 \\
5.5 \\
5.1 \\
4.5\end{array}$ & $\begin{array}{r}14 \\
9.0 \\
7.6 \\
7.1 \\
7.9\end{array}$ & $\begin{array}{r}8.7 \\
13 \\
9.3 \\
6.9 \\
5.4\end{array}$ & $\begin{array}{l}20 \\
33 \\
75 \\
40 \\
23\end{array}$ \\
\hline $\begin{array}{l}21 \\
22 \\
23 \\
24 \\
25\end{array}$ & $\begin{array}{l}24 \\
24 \\
24 \\
26 \\
24\end{array}$ & $\begin{array}{l}25 \\
24 \\
22 \\
22 \\
21\end{array}$ & $\begin{array}{l}25 \\
24 \\
25 \\
25 \\
34\end{array}$ & $\begin{array}{l}19 \\
18 \\
17 \\
16 \\
15\end{array}$ & $\begin{array}{l}14 \\
16 \\
17 \\
17 \\
18\end{array}$ & & $\begin{array}{l}20 \\
19 \\
18 \\
20 \\
20\end{array}$ & $\begin{array}{l}23 \\
20 \\
19 \\
17 \\
16\end{array}$ & $\begin{array}{l}14 \\
13 \\
12 \\
12 \\
11\end{array}$ & $\begin{array}{l}26 \\
54 \\
14 \\
8.6 \\
12\end{array}$ & $\begin{array}{r}15 \\
8.3 \\
6.7 \\
9.2 \\
77\end{array}$ & $\begin{array}{l}9.1 \\
56 \\
18 \\
11 \\
8.1\end{array}$ & $\begin{array}{l}22 \\
17 \\
14 \\
13 \\
11\end{array}$ \\
\hline $\begin{array}{l}26 \\
27 \\
28 \\
29 \\
30 \\
31\end{array}$ & $\begin{array}{l}29 \\
41 \\
43 \\
30 \\
25 \\
23\end{array}$ & $\begin{array}{r}30 \\
32 \\
24 \\
22 \\
20 \\
-\end{array}$ & $\begin{array}{l}29 \\
26 \\
25 \\
25 \\
25 \\
24\end{array}$ & $\begin{array}{l}15 \\
15 \\
15 \\
16 \\
18 \\
17\end{array}$ & $\begin{array}{r}17 \\
17 \\
19 \\
--- \\
---\end{array}$ & & $\begin{array}{l}20 \\
19 \\
18 \\
18 \\
58 \\
41\end{array}$ & $\begin{array}{l}16 \\
17 \\
18 \\
15 \\
13 \\
\end{array}$ & $\begin{array}{l}9.9 \\
9.8 \\
9.5 \\
8.5 \\
8.1 \\
14\end{array}$ & $\begin{array}{l}29 \\
11 \\
8.8 \\
9.6 \\
12 \\
-\end{array}$ & $\begin{array}{r}35 \\
23 \\
12 \\
9.8 \\
9.1 \\
9.8\end{array}$ & $\begin{array}{r}28 \\
65 \\
23 \\
15 \\
11 \\
9.4\end{array}$ & $\begin{array}{r}10 \\
9.5 \\
9.0 \\
12 \\
16 \\
-\end{array}$ \\
\hline $\begin{array}{l}\text { TOTAL } \\
\text { MEAN } \\
\text { MAX } \\
\text { MIN } \\
\text { CFSM } \\
\text { IN. }\end{array}$ & $\begin{array}{r}1260 \\
40.6 \\
110 \\
23 \\
1.22 \\
1.41\end{array}$ & $\begin{array}{r}613 \\
20.4 \\
32 \\
13 \\
.61 \\
.68\end{array}$ & $\begin{array}{r}968 \\
31.2 \\
65 \\
20 \\
.94 \\
1.08\end{array}$ & $\begin{array}{r}653 \\
21.1 \\
45 \\
15 \\
.63 \\
.73\end{array}$ & $\begin{array}{r}500 \\
17.9 \\
23 \\
14 \\
.54 \\
.56\end{array}$ & & $\begin{array}{r}846 \\
27.3 \\
89 \\
16 \\
.82 \\
.95\end{array}$ & $\begin{array}{r}1043 \\
34.8 \\
120 \\
13 \\
1.05 \\
1.17\end{array}$ & $\begin{array}{r}441.6 \\
14.2 \\
50 \\
8.1 \\
.43 \\
.49\end{array}$ & $\begin{array}{r}424.4 \\
14.1 \\
54 \\
4.5 \\
.42 \\
.47\end{array}$ & $\begin{array}{r}440.1 \\
14.2 \\
77 \\
6.7 \\
.43 \\
.49\end{array}$ & $\begin{array}{r}492.9 \\
15.9 \\
65 \\
5.0 \\
.48 \\
.55\end{array}$ & $\begin{array}{r}642.5 \\
21.4 \\
77 \\
6.4 \\
.64 \\
.72\end{array}$ \\
\hline $\begin{array}{l}\text { CAL YR } \\
\text { WTR YR }\end{array}$ & $\begin{array}{l}1986 \\
1987\end{array}$ & L & $\begin{array}{l}0 \\
5\end{array}$ & $\begin{array}{ll}\text { SAN } & 32.2 \\
\text { SAN } & 22.8\end{array}$ & $\begin{array}{l}\text { MAX } \\
\text { MAX }\end{array}$ & $\begin{array}{l}347 \\
120\end{array}$ & $\begin{array}{l}\text { MIN } \\
\text { MIN }\end{array}$ & $\begin{array}{l}5.6 \\
4.5\end{array}$ & $\begin{array}{ll}\text { CFSM } & .97 \\
\text { CFSM } & .69\end{array}$ & IN 13 & $\begin{array}{l}12 \\
30\end{array}$ & & \\
\hline
\end{tabular}


LOCATION.--Lat $42^{\circ} 26^{\prime} 52^{\prime \prime}$, long $83^{\circ} 17^{\prime} 52^{\prime \prime}$, in SWl/4 sec.32, T.1 N., R.10 E., Oakland County, Hydrologic Unit 04090004, on right bank at downstream side of bridge on Beech Road at Southfield, $4.2 \mathrm{mi}$ east of Farmington.

DRAINAGE AREA. $--87.9 \mathrm{mi}^{2}$.

PERIOD OF RECORD.--April 1958 to current year.

REVISED RECORDS.--WSP 2112: Drainage area.

GAGE.--Water-stage recorder. Datum of gage is $609.62 \mathrm{ft}$, City of Southfield datum. Prior to Sept. 30, 1958, nonrecording gage at same site and datum.

REMARKS.--Estimated daily discharges: Nov. 5-21, Dec. 13-15, Jan. 6, and Jan. 17 to Feb. 28 . Records good except for estimated daily discharges, which are fair. Several measurements of water temperature were made during the year.

AVERAGE DISCHARGE. -29 years, $62.7 \mathrm{ft}^{3} / \mathrm{s}, 9.69 \mathrm{in} / \mathrm{yr}$.

EXTREMES FOR PERIOD OF RECORD.--Maximum discharge, 4,900 ft $\mathrm{ft}^{3} / \mathrm{s}$, June 26, 1968, gage height, $19.04 \mathrm{ft}$; minimum, $0.1 \mathrm{ft}^{3} / \mathrm{s}$, Aug. 2, 1964 , gage height, $1.15 \mathrm{ft}$.

EXTREMES FOR CURRENT YEAR.--Peak discharges greater than base discharge of $700 \mathrm{ft}^{3} / \mathrm{s}$ and maximum (*):

$\begin{array}{cccccccc}\text { Date } & \text { Time } & \begin{array}{c}\text { Discharge } \\ \left(\mathrm{ft}^{3} / \mathrm{s}\right)\end{array} & \begin{array}{c}\text { Gage height } \\ (\mathrm{ft})\end{array} & \text { Date } & \text { Time } & \begin{array}{c}\text { Discharge } \\ \left(\mathrm{ft}^{3} / \mathrm{s}^{\mathrm{f}}\right)\end{array} & \begin{array}{c}\text { Gage height } \\ (\mathrm{ft})\end{array} \\ \text { Oct. } 3 & 2200 & \star 984 & * 10.32 & \text { Apr. } 5 & 1500 & 759 & 9.45\end{array}$

Minimum discharge, $14 \mathrm{ft}^{3} / \mathrm{s}$, June 18, 20, Aug. 6, 7, 8, 20, 21; minimum gage height, 2.71 ft, June 18 .

DISCHARGE, IN CUBIC FEET PER SECOND, WATER YEAR OCTOBER 1986 TO SEPTEMBER 1987 MEAN VALUES

\begin{tabular}{|c|c|c|c|c|c|c|c|c|c|c|c|c|}
\hline DAY & OCT & NOV & DEC & JAN & FEB & MAR & APR & MAY & JUN & JUL & AUG & SEP \\
\hline $\begin{array}{l}1 \\
2 \\
3 \\
4 \\
5\end{array}$ & $\begin{array}{l}247 \\
185 \\
417 \\
562 \\
248\end{array}$ & $\begin{array}{l}65 \\
96 \\
72 \\
65 \\
60\end{array}$ & $\begin{array}{r}46 \\
141 \\
192 \\
111 \\
85\end{array}$ & $\begin{array}{l}56 \\
65 \\
57 \\
53 \\
51\end{array}$ & $\begin{array}{l}48 \\
52 \\
58 \\
53 \\
51\end{array}$ & $\begin{array}{r}315 \\
197 \\
112 \\
81 \\
87\end{array}$ & $\begin{array}{r}82 \\
154 \\
93 \\
73 \\
508\end{array}$ & $\begin{array}{l}35 \\
36 \\
48 \\
41 \\
36\end{array}$ & $\begin{array}{r}42 \\
93 \\
155 \\
59 \\
41\end{array}$ & $\begin{array}{l}49 \\
37 \\
78 \\
63 \\
32\end{array}$ & $\begin{array}{r}134 \\
36 \\
27 \\
21 \\
17\end{array}$ & $\begin{array}{l}31 \\
31 \\
27 \\
26 \\
24\end{array}$ \\
\hline $\begin{array}{r}6 \\
7 \\
8 \\
9 \\
10\end{array}$ & $\begin{array}{r}148 \\
112 \\
96 \\
97 \\
81\end{array}$ & $\begin{array}{l}57 \\
55 \\
54 \\
53 \\
48\end{array}$ & $\begin{array}{r}73 \\
86 \\
115 \\
204 \\
230\end{array}$ & $\begin{array}{l}51 \\
56 \\
54 \\
51 \\
57\end{array}$ & $\begin{array}{l}52 \\
55 \\
60 \\
56 \\
53\end{array}$ & $\begin{array}{l}88 \\
92 \\
85 \\
75 \\
58\end{array}$ & $\begin{array}{r}368 \\
178 \\
121 \\
100 \\
87\end{array}$ & $\begin{array}{l}34 \\
32 \\
31 \\
29 \\
28\end{array}$ & $\begin{array}{l}39 \\
36 \\
29 \\
26 \\
23\end{array}$ & $\begin{array}{l}30 \\
29 \\
26 \\
30 \\
77\end{array}$ & $\begin{array}{r}15 \\
15 \\
14 \\
131 \\
146\end{array}$ & $\begin{array}{r}24 \\
24 \\
46 \\
151 \\
47\end{array}$ \\
\hline $\begin{array}{l}11 \\
12 \\
13 \\
14 \\
15\end{array}$ & $\begin{array}{r}73 \\
69 \\
78 \\
239 \\
116\end{array}$ & $\begin{array}{l}43 \\
40 \\
38 \\
37 \\
37\end{array}$ & $\begin{array}{r}107 \\
85 \\
66 \\
62 \\
59\end{array}$ & $\begin{array}{r}62 \\
56 \\
54 \\
57 \\
148\end{array}$ & $\begin{array}{l}52 \\
53 \\
50 \\
45 \\
42\end{array}$ & $\begin{array}{l}58 \\
52 \\
50 \\
57 \\
64\end{array}$ & $\begin{array}{r}80 \\
101 \\
81 \\
74 \\
81\end{array}$ & $\begin{array}{r}27 \\
36 \\
26 \\
44 \\
200\end{array}$ & $\begin{array}{l}21 \\
32 \\
23 \\
20 \\
18\end{array}$ & $\begin{array}{l}53 \\
33 \\
28 \\
35 \\
26\end{array}$ & $\begin{array}{l}41 \\
28 \\
23 \\
21 \\
29\end{array}$ & $\begin{array}{r}188 \\
84 \\
50 \\
38 \\
64\end{array}$ \\
\hline $\begin{array}{l}16 \\
17 \\
18 \\
19 \\
20\end{array}$ & $\begin{array}{l}89 \\
78 \\
72 \\
69 \\
65\end{array}$ & $\begin{array}{l}37 \\
36 \\
37 \\
41 \\
54\end{array}$ & $\begin{array}{r}58 \\
83 \\
110 \\
81 \\
72\end{array}$ & $\begin{array}{r}102 \\
62 \\
57 \\
54 \\
52\end{array}$ & $\begin{array}{l}40 \\
39 \\
38 \\
37 \\
37\end{array}$ & $\begin{array}{l}65 \\
61 \\
58 \\
56 \\
52\end{array}$ & $\begin{array}{r}124 \\
87 \\
73 \\
66 \\
62\end{array}$ & $\begin{array}{l}58 \\
41 \\
45 \\
51 \\
40\end{array}$ & $\begin{array}{l}16 \\
15 \\
15 \\
15 \\
16\end{array}$ & $\begin{array}{l}71 \\
31 \\
24 \\
21 \\
20\end{array}$ & $\begin{array}{l}21 \\
39 \\
24 \\
21 \\
16\end{array}$ & $\begin{array}{r}55 \\
76 \\
222 \\
111 \\
66\end{array}$ \\
\hline $\begin{array}{l}21 \\
22 \\
23 \\
24 \\
25\end{array}$ & $\begin{array}{l}65 \\
63 \\
63 \\
70 \\
64\end{array}$ & $\begin{array}{l}73 \\
62 \\
58 \\
57 \\
51\end{array}$ & $\begin{array}{l}65 \\
61 \\
60 \\
75 \\
90\end{array}$ & $\begin{array}{l}50 \\
47 \\
44 \\
42 \\
41\end{array}$ & $\begin{array}{l}38 \\
43 \\
44 \\
45 \\
47\end{array}$ & $\begin{array}{l}50 \\
49 \\
48 \\
49 \\
56\end{array}$ & $\begin{array}{l}56 \\
51 \\
50 \\
46 \\
42\end{array}$ & $\begin{array}{l}37 \\
34 \\
30 \\
29 \\
28\end{array}$ & $\begin{array}{r}37 \\
372 \\
96 \\
58 \\
44\end{array}$ & $\begin{array}{r}35 \\
24 \\
31 \\
20 \\
163\end{array}$ & $\begin{array}{r}24 \\
188 \\
56 \\
29 \\
24\end{array}$ & $\begin{array}{l}65 \\
59 \\
49 \\
44 \\
34\end{array}$ \\
\hline $\begin{array}{l}26 \\
27 \\
28 \\
29 \\
30 \\
31\end{array}$ & $\begin{array}{r}91 \\
104 \\
117 \\
82 \\
72 \\
66\end{array}$ & $\begin{array}{r}89 \\
97 \\
63 \\
55 \\
50 \\
---\end{array}$ & $\begin{array}{l}71 \\
65 \\
62 \\
60 \\
59 \\
57\end{array}$ & $\begin{array}{l}40 \\
40 \\
41 \\
44 \\
47 \\
45\end{array}$ & $\begin{array}{r}45 \\
44 \\
54 \\
--- \\
-- \\
--\end{array}$ & $\begin{array}{r}56 \\
52 \\
50 \\
48 \\
196 \\
120\end{array}$ & $\begin{array}{r}40 \\
45 \\
50 \\
41 \\
37 \\
--\end{array}$ & $\begin{array}{l}27 \\
26 \\
25 \\
23 \\
23 \\
35\end{array}$ & $\begin{array}{r}162 \\
55 \\
39 \\
37 \\
96 \\
-\end{array}$ & $\begin{array}{l}73 \\
47 \\
29 \\
22 \\
20 \\
20\end{array}$ & $\begin{array}{r}143 \\
414 \\
94 \\
60 \\
43 \\
36\end{array}$ & $\begin{array}{r}31 \\
29 \\
27 \\
43 \\
45 \\
---\end{array}$ \\
\hline $\begin{array}{l}\text { TOTAL } \\
\text { MEAN } \\
\text { MAX } \\
\text { MIN } \\
\text { CFSM } \\
\text { IN. }\end{array}$ & $\begin{array}{r}3998 \\
129 \\
562 \\
63 \\
1.47 \\
1.69\end{array}$ & $\begin{array}{r}1680 \\
56.0 \\
97 \\
36 \\
.64 \\
.71\end{array}$ & $\begin{array}{r}2791 \\
90.0 \\
230 \\
46 \\
1.02 \\
1.18\end{array}$ & $\begin{array}{r}1736 \\
56.0 \\
148 \\
40 \\
.64 \\
.73\end{array}$ & $\begin{array}{r}1331 \\
47.5 \\
60 \\
37 \\
.54 \\
.56\end{array}$ & $\begin{array}{r}2537 \\
81.8 \\
315 \\
48 \\
.93 \\
1.07\end{array}$ & $\begin{array}{r}3051 \\
102 \\
508 \\
37 \\
1.16 \\
1.29\end{array}$ & $\begin{array}{r}1235 \\
39.8 \\
200 \\
23 \\
.45 \\
.52\end{array}$ & $\begin{array}{r}1730 \\
57.7 \\
372 \\
15 \\
.66 \\
.73\end{array}$ & $\begin{array}{r}1277 \\
41.2 \\
163 \\
20 \\
.47 \\
.54\end{array}$ & $\begin{array}{r}1930 \\
62.3 \\
414 \\
14 \\
.71 \\
.82\end{array}$ & $\begin{array}{r}1811 \\
60.4 \\
222 \\
24 \\
.69 \\
.77\end{array}$ \\
\hline $\begin{array}{l}\text { CAL YR } \\
\text { WTR YR }\end{array}$ & $\begin{array}{l}1986 \\
1987\end{array}$ & $\mathrm{AL}$ & & $\begin{array}{l}93.3 \\
68.8\end{array}$ & $\begin{array}{l}\text { MAX } \\
\text { MAX }\end{array}$ & $\begin{array}{l}\text { MIN } \\
\text { MIN }\end{array}$ & $\begin{array}{l}16 \\
14\end{array}$ & $\begin{array}{ll}\text { SM } & 1.06 \\
\text { SM } & .78\end{array}$ & $\begin{array}{ll}\text { IN } 1 \\
\text { IN } 1\end{array}$ & & & \\
\hline
\end{tabular}


LOCATION, --Lat $42^{\circ} 27^{\prime} 28^{\prime \prime}$, long $83^{\circ} 16^{\prime} 03^{\prime \prime}$, in SEl/4 sec.28, T.1 N., R.10 E., Oakland County, Hydrologic Unit 04090004 , on right bank $70 \mathrm{ft}$ upstream from bridge on Nine Mile Road at Southfield, $1.6 \mathrm{mi}$ upstream from mouth, and $5.5 \mathrm{mi}$ east of Farmington.

DRAINAGE AREA. $--9.49 \mathrm{mi}^{2}$.

PERIOD OF RECORD.--September 1958 to current year.

GAGE.--Water-stage recorder. Datum of gage is $615.07 \mathrm{ft}$, City of Southfield datum.

REMARKS.--Estimated daily discharges: Jan. 17 to Feb. 16. Records good except for estimated daily discharges, which are fair. Several measurements of water temperature were made during the year.

AVERAGE DISCHARGE.--29 years, $8.49 \mathrm{ft}^{3} / \mathrm{s}, 12.15 \mathrm{in} / \mathrm{yr}$.

EXTREMES FOR PERIOD OF RECORD.--Maximum discharge, 1, $200 \mathrm{ft}^{3} / \mathrm{s}$, Oct. 1, 1981, gage height, 15.03 ft, from floodmarks, from rating curve extended above $410 \mathrm{ft}^{3} / \mathrm{s}$; no flow June 13-15, 1986 , caused by unnatural regulation of unknown source.

EXTREMES FOR CURRENT YEAR.--Peak discharges greater than base discharge of $330 \mathrm{ft}^{3} / \mathrm{s}$ and maximum (*):

\begin{tabular}{|c|c|c|c|c|c|c|c|}
\hline Date & Time & $\begin{array}{c}\text { Discharge } \\
\left(\mathrm{ft}^{3} / \mathrm{s}\right)\end{array}$ & $\begin{array}{l}\text { Gage height } \\
\text { (ft) }\end{array}$ & Date & Time & $\begin{array}{c}\text { Discharge } \\
\left(\mathrm{ft}^{3} / \mathrm{s}\right)\end{array}$ & $\begin{array}{l}\text { Gage height } \\
\text { (ft) }\end{array}$ \\
\hline $\begin{array}{lr}\text { Oct. } & 3 \\
\text { June } & 21 \\
\text { June } & 26 \\
\text { Aug. } & 9\end{array}$ & $\begin{array}{l}1830 \\
2315 \\
0145 \\
2015\end{array}$ & $\begin{array}{r}374 \\
\star 480 \\
360 \\
412\end{array}$ & $\begin{array}{r}9.28 \\
\star \mathrm{a} 9.98 \\
\mathrm{a} 9.18 \\
\mathrm{a} 9.56\end{array}$ & $\begin{array}{l}\text { Aug. } 22 \\
\text { Aug. } 26 \\
\text { Sept. } 8 \\
\text { Sept. } 11\end{array}$ & $\begin{array}{l}0845 \\
1745 \\
2045 \\
0215\end{array}$ & $\begin{array}{l}372 \\
407 \\
341 \\
407\end{array}$ & $\begin{array}{l}\mathrm{a} 9.28 \\
\mathrm{a} 9.54 \\
\mathrm{a} 9.07 \\
\mathrm{a} 9.54\end{array}$ \\
\hline
\end{tabular}

a From graph based on gage readings.

Minimum daily discharge, $1.4 \mathrm{ft}^{3} / \mathrm{s}$, June 14, Aug. 7, 20.

DISCHARGE, IN CUBIC FEET PER SECOND, WATER YEAR OCTOBER 1986 TO SEPTEMBER 1987 MEAN VALUES

\begin{tabular}{|c|c|c|c|c|c|c|c|c|c|c|c|c|}
\hline DAY & OCT & NOV & DEC & JAN & FEB & MAR & APR & MAY & JUN & JUL & AUG & SEP \\
\hline $\begin{array}{l}1 \\
2 \\
3 \\
4 \\
5\end{array}$ & $\begin{array}{r}23 \\
11 \\
121 \\
37 \\
15\end{array}$ & $\begin{array}{r}5.2 \\
12 \\
4.6 \\
4.0 \\
3.6\end{array}$ & $\begin{array}{r}3.2 \\
42 \\
17 \\
8.3 \\
6.2\end{array}$ & $\begin{array}{l}4.0 \\
6.9 \\
4.7 \\
3.8 \\
3.7\end{array}$ & $\begin{array}{l}3.7 \\
3.9 \\
4.1 \\
4.0 \\
3.8\end{array}$ & $\begin{array}{l}49 \\
13 \\
7.1 \\
5.5 \\
10\end{array}$ & $\begin{array}{l}9.3 \\
18 \\
6.8 \\
5.7 \\
95\end{array}$ & $\begin{array}{l}2.6 \\
2.5 \\
6.6 \\
2.8 \\
2.6\end{array}$ & $\begin{array}{r}7.9 \\
13 \\
5.2 \\
2.1 \\
1.6\end{array}$ & $\begin{array}{r}3.6 \\
2.7 \\
41 \\
4.1 \\
2.6\end{array}$ & $\begin{array}{r}35 \\
3.2 \\
2.0 \\
1.7 \\
1.5\end{array}$ & $\begin{array}{l}2.5 \\
2.9 \\
2.2 \\
2.0 \\
2.1\end{array}$ \\
\hline $\begin{array}{r}6 \\
7 \\
8 \\
9 \\
10\end{array}$ & $\begin{array}{r}10 \\
7.6 \\
6.0 \\
6.0 \\
4.9\end{array}$ & $\begin{array}{l}3.6 \\
3.3 \\
4.9 \\
3.3 \\
3.1\end{array}$ & $\begin{array}{l}5.3 \\
17 \\
12 \\
41 \\
15\end{array}$ & $\begin{array}{l}3.7 \\
4.3 \\
3.7 \\
3.7 \\
5.6\end{array}$ & $\begin{array}{l}3.9 \\
4.1 \\
4.5 \\
4.3 \\
4.1\end{array}$ & $\begin{array}{l}7.3 \\
6.7 \\
5.9 \\
4.8 \\
4.0\end{array}$ & $\begin{array}{r}31 \\
14 \\
9.5 \\
7.7 \\
6.7\end{array}$ & $\begin{array}{l}2.5 \\
2.5 \\
2.2 \\
2.0 \\
2.0\end{array}$ & $\begin{array}{l}4.3 \\
2.1 \\
1.7 \\
1.6 \\
1.6\end{array}$ & $\begin{array}{r}2.4 \\
2.7 \\
2.2 \\
27 \\
31\end{array}$ & $\begin{array}{r}1.6 \\
1.4 \\
1.5 \\
100 \\
17\end{array}$ & $\begin{array}{r}2.0 \\
1.8 \\
54 \\
9.9 \\
5.1\end{array}$ \\
\hline $\begin{array}{l}11 \\
12 \\
13 \\
14 \\
15\end{array}$ & $\begin{array}{r}4.3 \\
4.3 \\
9.0 \\
39 \\
6.5\end{array}$ & $\begin{array}{l}3.3 \\
3.2 \\
2.7 \\
2.5 \\
2.7\end{array}$ & $\begin{array}{l}7.3 \\
6.0 \\
4.8 \\
4.4 \\
4.1\end{array}$ & $\begin{array}{r}6.0 \\
4.8 \\
4.8 \\
9.5 \\
24\end{array}$ & $\begin{array}{l}4.0 \\
3.9 \\
3.7 \\
3.5 \\
3.2\end{array}$ & $\begin{array}{l}3.7 \\
3.7 \\
3.7 \\
7.1 \\
6.9\end{array}$ & $\begin{array}{l}6.5 \\
9.5 \\
6.0 \\
5.9 \\
8.9\end{array}$ & $\begin{array}{l}2.1 \\
5.2 \\
1.8 \\
39 \\
17\end{array}$ & $\begin{array}{l}2.2 \\
8.5 \\
1.7 \\
1.4 \\
1.7\end{array}$ & $\begin{array}{l}5.3 \\
2.8 \\
2.5 \\
7.3 \\
4.6\end{array}$ & $\begin{array}{l}3.1 \\
2.3 \\
2.4 \\
2.4 \\
2.3\end{array}$ & $\begin{array}{r}91 \\
6.5 \\
4.2 \\
3.2 \\
16\end{array}$ \\
\hline $\begin{array}{l}16 \\
17 \\
18 \\
19 \\
20\end{array}$ & $\begin{array}{l}5.0 \\
4.4 \\
3.9 \\
3.6 \\
3.6\end{array}$ & $\begin{array}{l}2.8 \\
2.9 \\
2.6 \\
2.6 \\
7.8\end{array}$ & $\begin{array}{r}4.1 \\
4.9 \\
15 \\
6.1 \\
5.3\end{array}$ & $\begin{array}{l}8.0 \\
5.0 \\
4.5 \\
4.1 \\
3.8\end{array}$ & $\begin{array}{l}3.1 \\
3.1 \\
3.0 \\
2.8 \\
2.8\end{array}$ & $\begin{array}{l}5.5 \\
5.0 \\
4.7 \\
4.4 \\
4.0\end{array}$ & $\begin{array}{r}14 \\
5.9 \\
4.8 \\
4.4 \\
4.1\end{array}$ & $\begin{array}{l}2.8 \\
2.4 \\
6.5 \\
2.9 \\
2.5\end{array}$ & $\begin{array}{l}1.7 \\
1.7 \\
1.6 \\
1.5 \\
1.8\end{array}$ & $\begin{array}{l}9.4 \\
2.1 \\
1.9 \\
1.8 \\
2.1\end{array}$ & $\begin{array}{l}2.6 \\
6.9 \\
2.1 \\
3.3 \\
1.4\end{array}$ & $\begin{array}{r}4.3 \\
45 \\
47 \\
8.8 \\
5.9\end{array}$ \\
\hline $\begin{array}{l}21 \\
22 \\
23 \\
24 \\
25\end{array}$ & $\begin{array}{l}3.8 \\
3.6 \\
3.9 \\
5.4 \\
3.7\end{array}$ & $\begin{array}{r}11 \\
4.8 \\
4.1 \\
3.6 \\
3.3\end{array}$ & $\begin{array}{r}4.7 \\
4.4 \\
4.4 \\
4.8 \\
14\end{array}$ & $\begin{array}{l}3.6 \\
3.4 \\
3.2 \\
3.0 \\
2.8\end{array}$ & $\begin{array}{l}3.0 \\
3.6 \\
4.2 \\
3.9 \\
3.8\end{array}$ & $\begin{array}{l}3.7 \\
3.5 \\
3.4 \\
3.5 \\
5.4\end{array}$ & $\begin{array}{l}4.0 \\
3.7 \\
4.1 \\
3.4 \\
3.4\end{array}$ & $\begin{array}{l}2.5 \\
2.3 \\
2.1 \\
2.1 \\
2.2\end{array}$ & $\begin{array}{l}57 \\
40 \\
3.9 \\
3.5 \\
7.8\end{array}$ & $\begin{array}{l}3.7 \\
1.7 \\
1.6 \\
11 \\
80\end{array}$ & $\begin{array}{r}13 \\
74 \\
3.4 \\
2.3 \\
2.0\end{array}$ & $\begin{array}{l}5.6 \\
4.4 \\
3.8 \\
3.2 \\
2.7\end{array}$ \\
\hline $\begin{array}{l}26 \\
27 \\
28 \\
29 \\
30 \\
31\end{array}$ & $\begin{array}{r}13 \\
14 \\
6.9 \\
4.6 \\
3.9 \\
3.6\end{array}$ & $\begin{array}{r}16 \\
6.1 \\
4.1 \\
3.6 \\
3.3 \\
\end{array}$ & $\begin{array}{l}5.6 \\
5.0 \\
4.7 \\
4.4 \\
4.4 \\
4.2\end{array}$ & $\begin{array}{l}2.8 \\
2.9 \\
3.0 \\
3.0 \\
3.3 \\
3.5\end{array}$ & $\begin{array}{l}3.6 \\
3.7 \\
5.5 \\
--- \\
--- \\
---\end{array}$ & $\begin{array}{r}4.5 \\
3.5 \\
3.3 \\
3.6 \\
47 \\
9.9\end{array}$ & $\begin{array}{l}3.2 \\
5.6 \\
3.5 \\
2.8 \\
2.7 \\
---\end{array}$ & $\begin{array}{l}2.4 \\
2.3 \\
3.3 \\
2.3 \\
3.4 \\
6.0\end{array}$ & $\begin{array}{r}56 \\
3.9 \\
3.3 \\
4.5 \\
22 \\
\end{array}$ & $\begin{array}{l}3.7 \\
2.1 \\
1.8 \\
1.7 \\
1.7 \\
30\end{array}$ & $\begin{array}{r}103 \\
91 \\
11 \\
5.0 \\
3.5 \\
2.9\end{array}$ & $\begin{array}{l}2.4 \\
2.4 \\
2.4 \\
7.2 \\
7.9\end{array}$ \\
\hline $\begin{array}{l}\text { TOTAL } \\
\text { MEAN } \\
\text { MAX } \\
\text { MIN } \\
\text { CFSM } \\
\text { IN. }\end{array}$ & $\begin{array}{r}391.5 \\
12.6 \\
121 \\
3.6 \\
1.33 \\
1.53\end{array}$ & $\begin{array}{r}140.6 \\
4.69 \\
16 \\
2.5 \\
.49 \\
.55\end{array}$ & $\begin{array}{r}289.6 \\
9.34 \\
42 \\
3.2 \\
.98 \\
1.14\end{array}$ & $\begin{array}{r}153.1 \\
4.94 \\
24 \\
2.8 \\
.52 \\
.60\end{array}$ & $\begin{array}{r}104.8 \\
3.74 \\
5.5 \\
2.8 \\
.39 \\
.41\end{array}$ & $\begin{array}{r}253.3 \\
8.17 \\
49 \\
3.3 \\
.86 \\
.99\end{array}$ & $\begin{array}{r}310.1 \\
10.3 \\
95 \\
2.7 \\
1.09 \\
1.22\end{array}$ & $\begin{array}{r}141.4 \\
4.56 \\
39 \\
1.8 \\
.48 \\
.55\end{array}$ & $\begin{array}{r}266.8 \\
8.89 \\
57 \\
1.4 \\
.94 \\
1.05\end{array}$ & $\begin{array}{r}298.1 \\
9.62 \\
80 \\
1.6 \\
1.01 \\
1.17\end{array}$ & $\begin{array}{r}504.8 \\
16.3 \\
103 \\
1.4 \\
1.72 \\
1.98\end{array}$ & $\begin{array}{r}358.4 \\
11.9 \\
91 \\
1.8 \\
1.25 \\
1.40\end{array}$ \\
\hline
\end{tabular}

CAL YR 1986 TOTAL $3694.50 \quad$ MEAN 10.1 $\quad$ MAX 121 MIN .00 
LOCATION.--Lat $42^{\circ} 27^{\prime} 52^{\prime \prime}$, long $83^{\circ} 22^{\prime} 11^{\prime \prime}$, in NWl/4 sec.27, T. I N., R.9 E., Oakland County, Hydrologic Unit 04090004 , on left bank $800^{\mathrm{ft}}$ downstrém from bridge on shiawassee Road at Farmington.

DRAINAGE AREA. $--17.5 \mathrm{mi}^{2}$.

PERIOD OF RECORD.--March 1958 to current year.

REVISED RECORDS.--WSP 1912: $1959(\mathrm{M}), 1960(\mathrm{M})$.

GAGE.--Water-stage recorder and concrete control. Datum of gage is $690.4 \mathrm{ft}$ above National Geodetic Vertical Datum of 1929.

REMARKS.--Estimated daily discharges: Dec. 12-16 and Jan. 20 to Feb. 17 . Records good except for

estimated daily discharges, which are fair. Several measurements of water temperature were made during the year.

AVERAGE DISCHARGE. --29 years, $12.2 \mathrm{ft}^{3} / \mathrm{s}, 9.47 \mathrm{in} / \mathrm{yr}$.

EXTREMES FOR PERIOD OF RECORD.--Maximum discharge, 1,500 $\mathrm{ft}^{3} / \mathrm{s}$, June 25, 1968, gage height, 8.70 ft;

minimum, $0.07 \mathrm{ft}^{3} / \mathrm{s}$, Aug. 30,1966 , result of regulation; minimum daily, $0.32 \mathrm{ft} / \mathrm{s}, \mathrm{Aug}$. io,

1964, Aug. 29, 1966 .

EXTREMES FOR CURRENT YEAR.--Peak discharges greater than base discharge of $120 \mathrm{ft}^{3} / \mathrm{s}^{\mathrm{and}}$ maximum (*):

\begin{tabular}{|c|c|c|c|c|c|c|c|}
\hline Date & Time & $\begin{array}{c}\text { Discharge } \\
\left(\mathrm{ft}^{3} / \mathrm{s}\right)\end{array}$ & $\begin{array}{c}\text { Gage height } \\
(\mathrm{ft})\end{array}$ & Date & Time & $\begin{array}{c}\text { Discharge } \\
\left(\mathrm{ft}^{3} / \mathrm{s}\right)\end{array}$ & $\begin{array}{l}\text { Gage height } \\
(f t)\end{array}$ \\
\hline $\begin{array}{l}\text { Apr. } \\
\text { June } 22\end{array}$ & $\begin{array}{l}1100 \\
0100\end{array}$ & $\begin{array}{r}125 \\
\star 166\end{array}$ & $\begin{array}{r}4.07 \\
\times 4.31\end{array}$ & Aug. 27 & 0600 & 125 & 4.07 \\
\hline
\end{tabular}

Minimum discharge, $2.3 \mathrm{ft}^{3} / \mathrm{s}$, June 19 , gage height, $2.83 \mathrm{ft}$.

DISCHARGE, IN CUBIC FEET PER SECOND, WATER YEAR OCTOBER 1986 TO SEPTEMBER 1987 MEAN VALUES

\begin{tabular}{|c|c|c|c|c|c|c|c|c|c|c|c|c|}
\hline DAY & OCT & NOV & DEC & JAN & FEB & MAR & APR & MAY & JUN & JUL & AUG & SEP \\
\hline $\begin{array}{l}1 \\
2 \\
3 \\
4 \\
5\end{array}$ & $\begin{array}{l}43 \\
32 \\
61 \\
73 \\
44\end{array}$ & $\begin{array}{r}8.1 \\
12 \\
8.8 \\
7.6 \\
7.2\end{array}$ & $\begin{array}{l}8 \cdot 3 \\
23 \\
37 \\
24 \\
16\end{array}$ & $\begin{array}{l}9.4 \\
10 \\
10 \\
8.9 \\
8.5\end{array}$ & $\begin{array}{l}9.0 \\
9.9 \\
10 \\
10 \\
9.5\end{array}$ & $\begin{array}{l}72 \\
57 \\
33 \\
21 \\
21\end{array}$ & $\begin{array}{l}19 \\
32 \\
22 \\
16 \\
94\end{array}$ & $\begin{array}{l}7.4 \\
7.6 \\
9.5 \\
8.8 \\
7.5\end{array}$ & $\begin{array}{l}10 \\
43 \\
50 \\
20 \\
11\end{array}$ & $\begin{array}{l}15 \\
9.0 \\
20 \\
13 \\
7.6\end{array}$ & $\begin{array}{l}54 \\
18 \\
8.5 \\
6.4 \\
5.9\end{array}$ & $\begin{array}{l}6.3 \\
5.0 \\
4.6 \\
5.0 \\
5.3\end{array}$ \\
\hline $\begin{array}{r}6 \\
7 \\
8 \\
9 \\
10\end{array}$ & $\begin{array}{l}27 \\
19 \\
15 \\
14 \\
12\end{array}$ & $\begin{array}{l}6.8 \\
6.7 \\
7.4 \\
7.0 \\
6.3\end{array}$ & $\begin{array}{l}13 \\
15 \\
20 \\
38 \\
45\end{array}$ & $\begin{array}{l}8.7 \\
9.9 \\
9.7 \\
9.1 \\
9.9\end{array}$ & $\begin{array}{l}8.8 \\
10 \\
11 \\
9.8 \\
9.3\end{array}$ & $\begin{array}{l}20 \\
24 \\
23 \\
19 \\
14\end{array}$ & $\begin{array}{l}78 \\
45 \\
29 \\
21 \\
18\end{array}$ & $\begin{array}{l}7.2 \\
6.8 \\
6.7 \\
6.1 \\
6.0\end{array}$ & $\begin{array}{l}7.9 \\
7.1 \\
6.0 \\
5.6 \\
4.5\end{array}$ & $\begin{array}{l}6.7 \\
6.0 \\
5.1 \\
5.1 \\
8.5\end{array}$ & $\begin{array}{l}5.2 \\
4.7 \\
5.2 \\
29 \\
29\end{array}$ & $\begin{array}{l}4.8 \\
4.8 \\
4.9 \\
5.5 \\
4.2\end{array}$ \\
\hline $\begin{array}{l}11 \\
12 \\
13 \\
14 \\
15\end{array}$ & $\begin{array}{l}11 \\
9.9 \\
12 \\
41 \\
21\end{array}$ & $\begin{array}{l}6.1 \\
6.1 \\
6.0 \\
5.4 \\
5.6\end{array}$ & $\begin{array}{l}27 \\
17 \\
13 \\
11 \\
10\end{array}$ & $\begin{array}{l}10 \\
9.7 \\
9.5 \\
11 \\
29\end{array}$ & $\begin{array}{l}9.3 \\
9.4 \\
9.4 \\
9.1 \\
8.8\end{array}$ & $\begin{array}{l}12 \\
11 \\
11 \\
12 \\
13\end{array}$ & $\begin{array}{l}16 \\
20 \\
16 \\
15 \\
15\end{array}$ & $\begin{array}{l}5 \cdot 2 \\
7 \cdot 3 \\
6 \cdot 2 \\
16 \\
37\end{array}$ & $\begin{array}{l}4.0 \\
5.9 \\
4.2 \\
3.6 \\
3.3\end{array}$ & $\begin{array}{r}13 \\
8.6 \\
6.8 \\
6.5 \\
11\end{array}$ & $\begin{array}{r}11 \\
7.7 \\
5.9 \\
5.1 \\
4.7\end{array}$ & $\begin{array}{r}16 \\
9.4 \\
6.2 \\
4.7 \\
7.9\end{array}$ \\
\hline $\begin{array}{l}16 \\
17 \\
18 \\
19 \\
20\end{array}$ & $\begin{array}{r}16 \\
14 \\
11 \\
9.8 \\
9.2\end{array}$ & $\begin{array}{l}6 \cdot 0 \\
6 \cdot 1 \\
6 \cdot 2 \\
5 \cdot 7 \\
6 \cdot 3\end{array}$ & $\begin{array}{l}10 \\
11 \\
24 \\
18 \\
14\end{array}$ & $\begin{array}{l}21 \\
18 \\
13 \\
10 \\
9.6\end{array}$ & $\begin{array}{l}8.4 \\
8.2 \\
7.9 \\
8.1 \\
8.6\end{array}$ & $\begin{array}{l}14 \\
13 \\
13 \\
12 \\
12\end{array}$ & $\begin{array}{l}20 \\
16 \\
13 \\
12 \\
11\end{array}$ & $\begin{array}{r}12 \\
8.1 \\
9.3 \\
7.9 \\
6.9\end{array}$ & $\begin{array}{l}3.0 \\
2.7 \\
2.6 \\
2.6 \\
2.9\end{array}$ & $\begin{array}{l}20 \\
9.3 \\
6.5 \\
5.1 \\
4.4\end{array}$ & $\begin{array}{l}5.2 \\
6.9 \\
4.8 \\
4.8 \\
3.8\end{array}$ & $\begin{array}{r}8.0 \\
8.2 \\
16 \\
11 \\
8.2\end{array}$ \\
\hline $\begin{array}{l}21 \\
22 \\
23 \\
24 \\
25\end{array}$ & $\begin{array}{l}8.4 \\
7.3 \\
7.0 \\
6.7 \\
6.6\end{array}$ & $\begin{array}{l}9.0 \\
9.4 \\
9.5 \\
11 \\
10\end{array}$ & $\begin{array}{l}12 \\
11 \\
9.7 \\
11 \\
15\end{array}$ & $\begin{array}{l}9.2 \\
9.0 \\
8.4 \\
7.7 \\
7.3\end{array}$ & $\begin{array}{l}8.8 \\
10 \\
10 \\
11 \\
11\end{array}$ & $\begin{array}{l}11 \\
11 \\
10 \\
9.8 \\
10\end{array}$ & $\begin{array}{l}11 \\
10 \\
11 \\
10 \\
9.0\end{array}$ & $\begin{array}{l}6.3 \\
5.8 \\
5.1 \\
4.8 \\
4.8\end{array}$ & $\begin{array}{r}26 \\
118 \\
45 \\
17 \\
16\end{array}$ & $\begin{array}{r}5.5 \\
6.0 \\
8.3 \\
5.3 \\
16\end{array}$ & $\begin{array}{l}3.7 \\
33 \\
18 \\
8.5 \\
6.0\end{array}$ & $\begin{array}{l}8.1 \\
6.5 \\
5.9 \\
4.8 \\
4.4\end{array}$ \\
\hline $\begin{array}{l}26 \\
27 \\
28 \\
29 \\
30 \\
31\end{array}$ & $\begin{array}{r}11 \\
14 \\
12 \\
9.8 \\
8.6 \\
7.9\end{array}$ & $\begin{array}{c}18 \\
20 \\
13 \\
10 \\
9.4 \\
----\end{array}$ & $\begin{array}{l}13 \\
12 \\
11 \\
10 \\
10 \\
9.9\end{array}$ & $\begin{array}{l}7.2 \\
7.1 \\
7.2 \\
7.5 \\
8.2 \\
8.5\end{array}$ & $\begin{array}{l}10 \\
10 \\
12 \\
--- \\
--- \\
---\end{array}$ & $\begin{array}{l}11 \\
10 \\
9.9 \\
9.7 \\
36 \\
24\end{array}$ & $\begin{array}{r}8.5 \\
9.6 \\
10 \\
8.9 \\
7.6 \\
-\end{array}$ & $\begin{array}{l}4.7 \\
4.3 \\
4.9 \\
4.7 \\
4.6 \\
5.8\end{array}$ & $\begin{array}{c}29 \\
14 \\
9.4 \\
8.0 \\
20 \\
---\end{array}$ & $\begin{array}{r}13 \\
6.8 \\
5.4 \\
4.6 \\
4.3 \\
11\end{array}$ & $\begin{array}{r}32 \\
86 \\
29 \\
15 \\
9.3 \\
7.1\end{array}$ & $\begin{array}{l}3.9 \\
3.4 \\
4.0 \\
6.4 \\
5.8 \\
-\end{array}$ \\
\hline $\begin{array}{l}\text { TOTAL } \\
\text { MEAN } \\
\text { MAX } \\
\text { MIN } \\
\text { CFSM } \\
\text { IN. }\end{array}$ & $\begin{array}{r}594.2 \\
19.2 \\
73 \\
6.6 \\
1.10 \\
1.26\end{array}$ & $\begin{array}{r}256.7 \\
8.56 \\
20 \\
5.4 \\
.49 \\
.55\end{array}$ & $\begin{array}{r}518.9 \\
16.7 \\
45 \\
8.3 \\
.95 \\
1.10\end{array}$ & $\begin{array}{r}322.2 \\
10.4 \\
29 \\
7.1 \\
.59 \\
.68\end{array}$ & $\begin{array}{r}267.3 \\
9.55 \\
12 \\
7.99 \\
.55 \\
.57\end{array}$ & $\begin{array}{r}579.4 \\
18.7 \\
72 \\
9.7 \\
1.07 \\
1.23\end{array}$ & $\begin{array}{r}623.6 \\
20.8 \\
94 \\
7.6 \\
1.19 \\
1.33\end{array}$ & $\begin{array}{r}245.3 \\
7.91 \\
37 \\
4.3 \\
.45 \\
.52\end{array}$ & $\begin{array}{r}502.3 \\
16.7 \\
118 \\
2.6 \\
.95 \\
1.07\end{array}$ & $\begin{array}{r}273.4 \\
8.82 \\
20 \\
4.3 \\
.50 \\
.58\end{array}$ & $\begin{array}{r}473.4 \\
15.3 \\
86 \\
3.7 \\
.87 \\
1.01\end{array}$ & $\begin{array}{r}199.2 \\
6.64 \\
16 \\
3.4 \\
.38 \\
.42\end{array}$ \\
\hline
\end{tabular}

$\begin{array}{llllllllll}\text { CAL YR } 1986 & \text { TOTAL } & 6119.4 & \text { MEAN } 16.8 & \text { MAX } 182 & \text { MIN 2.3 } & \text { CFSM } & .96 & \text { IN } 13.01 \\ \text { WTR YR } 1987 & \text { TOTAL } & 4855.9 & \text { MEAN } 13.3 & \text { MAX } 118 & \text { MIN } 2.6 & \text { CFSM } & .76 & \text { IN } 10.32\end{array}$ 
04166500 RIVER ROUGE AT DETROIT, MI

LOCATION, --Lat $42^{\circ} 22^{\prime} 20^{\prime \prime}$, long $83^{\circ} 15^{\prime} 20^{\prime \prime}$, in SWl/4 sec. 21 , T.I S. R.10 E. Wayne County, Hydrologic Unit 04090004 , on right bank $500 \mathrm{ft}$ upstream from bridge on plymouth Road at Detroit, and 4 mi ustream from Middle River Rouge.

DRAINAGE AREA. $--187 \mathrm{mi}^{2}$.

PERIOD OF RECORD.--October 1930 to current year. Monthly discharge only for some periods, published in WSP 1307.

REVISED RECORDS.--WSP 1034: 1933(M). WSP 1054: 1939, 1943, 1945(M). WSP 1437: 1931-32, 1934, 1936(M), $1937-38,1944(M), 1945$. WSP 2112: Drainage area.

GAGE.--Water-stage recorder. Datum of gage is $584.00 \mathrm{ft}$ above National Geodetic Vertical Datum of 1929 . Prior to Oct. 16, 1948, nonrecording gage at site 1 mi downstream at datum $4.6 \mathrm{ft} 10 w e r$.

REMARKS. --Estimated daily discharges: Dec, 2 to Jan, 6 and Jan. 17 to Feb. 17 . Records good except for estimated daily discharges, which are fair. Several measurements of water temperature were made during the year. National Weather Service gage-height telemeter at station.

AVERAGE DISCHARGE. -57 years, $117 \mathrm{ft}^{3} / \mathrm{s}, 8.50 \mathrm{in} / \mathrm{yr}^{2}$

EXTREMES FOR PERIOD OF RECORD.--Maximum discharge, 13,000 ft $3 / \mathrm{s}$, Apr. 5, 1947; maximum gage height, $23.0 \mathrm{ft}, \mathrm{Apr} .6,1947$, from floodmark, site and datum then in use; minimum discharge, $1.8 \mathrm{ft} 3 / \mathrm{s}$,

Aug. 1, 2, 1964 , gage height, $3.00 \mathrm{ft}$.

EXTREMES FOR CURRENT YEAR.--Peak discharges greater than base discharge of $1,200 \mathrm{ft}^{3} / \mathrm{s}$ and maximum (*):

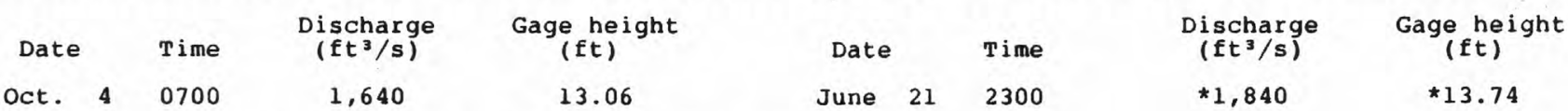

Minimum discharge, $20 \mathrm{ft}^{3} / \mathrm{s}$, June 18,19 , gage height, $4.13 \mathrm{ft}$.

DISCHARGE, IN CUBIC FEET PER SECOND, WATER YEAR OCTOBER 1986 TO SEPTEMBER 1987

MEAN VALUES

\begin{tabular}{|c|c|c|c|c|c|c|c|c|c|c|c|c|}
\hline DAY & OCT & NOV & DEC & JAN & FEB & MAR & APR & MAY & JUN & JUL & AUG & SEP \\
\hline $\begin{array}{l}1 \\
2 \\
3 \\
4 \\
5\end{array}$ & $\begin{array}{r}509 \\
335 \\
629 \\
1330 \\
537\end{array}$ & $\begin{array}{l}108 \\
183 \\
131 \\
109 \\
101\end{array}$ & $\begin{array}{r}84 \\
250 \\
330 \\
180 \\
145\end{array}$ & $\begin{array}{r}98 \\
110 \\
98 \\
87 \\
83\end{array}$ & $\begin{array}{l}83 \\
90 \\
96 \\
92 \\
90\end{array}$ & $\begin{array}{l}464 \\
454 \\
228 \\
153 \\
149\end{array}$ & $\begin{array}{l}178 \\
337 \\
213 \\
157 \\
629\end{array}$ & $\begin{array}{r}65 \\
67 \\
101 \\
92 \\
69\end{array}$ & $\begin{array}{r}56 \\
101 \\
219 \\
123 \\
70\end{array}$ & $\begin{array}{r}137 \\
66 \\
111 \\
187 \\
62\end{array}$ & $\begin{array}{r}258 \\
105 \\
54 \\
38 \\
32\end{array}$ & $\begin{array}{l}51 \\
59 \\
46 \\
40 \\
36\end{array}$ \\
\hline $\begin{array}{r}6 \\
7 \\
8 \\
9 \\
10\end{array}$ & $\begin{array}{l}300 \\
218 \\
183 \\
182 \\
152\end{array}$ & $\begin{array}{r}97 \\
93 \\
100 \\
100 \\
87\end{array}$ & $\begin{array}{l}130 \\
160 \\
230 \\
350 \\
400\end{array}$ & $\begin{array}{l}81 \\
86 \\
85 \\
82 \\
90\end{array}$ & $\begin{array}{r}89 \\
94 \\
100 \\
96 \\
90\end{array}$ & $\begin{array}{l}165 \\
160 \\
150 \\
132 \\
104\end{array}$ & $\begin{array}{l}911 \\
391 \\
250 \\
197 \\
168\end{array}$ & $\begin{array}{l}63 \\
61 \\
58 \\
56 \\
53\end{array}$ & $\begin{array}{l}57 \\
64 \\
49 \\
41 \\
36\end{array}$ & $\begin{array}{r}49 \\
49 \\
43 \\
46 \\
349\end{array}$ & $\begin{array}{r}27 \\
26 \\
24 \\
215 \\
375\end{array}$ & $\begin{array}{r}37 \\
36 \\
139 \\
301 \\
76\end{array}$ \\
\hline $\begin{array}{l}11 \\
12 \\
13 \\
14 \\
15\end{array}$ & $\begin{array}{l}137 \\
129 \\
162 \\
473 \\
252\end{array}$ & $\begin{array}{l}82 \\
76 \\
68 \\
64 \\
67\end{array}$ & $\begin{array}{l}180 \\
140 \\
115 \\
105 \\
100\end{array}$ & $\begin{array}{r}107 \\
98 \\
93 \\
94 \\
254\end{array}$ & $\begin{array}{l}88 \\
86 \\
83 \\
79 \\
73\end{array}$ & $\begin{array}{r}88 \\
89 \\
84 \\
98 \\
119\end{array}$ & $\begin{array}{l}152 \\
196 \\
162 \\
136 \\
156\end{array}$ & $\begin{array}{r}50 \\
67 \\
53 \\
58 \\
317\end{array}$ & $\begin{array}{l}32 \\
52 \\
42 \\
31 \\
27\end{array}$ & $\begin{array}{r}302 \\
71 \\
53 \\
87 \\
49\end{array}$ & $\begin{array}{l}92 \\
52 \\
41 \\
42 \\
38\end{array}$ & $\begin{array}{r}320 \\
194 \\
83 \\
58 \\
123\end{array}$ \\
\hline $\begin{array}{l}16 \\
17 \\
18 \\
19 \\
20\end{array}$ & $\begin{array}{l}171 \\
147 \\
135 \\
123 \\
115\end{array}$ & $\begin{array}{l}67 \\
66 \\
66 \\
69 \\
85\end{array}$ & $\begin{array}{l}100 \\
150 \\
190 \\
140 \\
120\end{array}$ & $\begin{array}{r}218 \\
110 \\
98 \\
92 \\
88\end{array}$ & $\begin{array}{l}69 \\
68 \\
69 \\
65 \\
63\end{array}$ & $\begin{array}{r}119 \\
106 \\
99 \\
99 \\
88\end{array}$ & $\begin{array}{l}259 \\
210 \\
136 \\
118 \\
113\end{array}$ & $\begin{array}{r}107 \\
60 \\
69 \\
85 \\
60\end{array}$ & $\begin{array}{l}25 \\
22 \\
23 \\
22 \\
24\end{array}$ & $\begin{array}{r}133 \\
63 \\
46 \\
38 \\
35\end{array}$ & $\begin{array}{l}34 \\
80 \\
45 \\
39 \\
30\end{array}$ & $\begin{array}{l}108 \\
122 \\
354 \\
221 \\
119\end{array}$ \\
\hline $\begin{array}{l}21 \\
22 \\
23 \\
24 \\
25\end{array}$ & $\begin{array}{l}114 \\
109 \\
104 \\
110 \\
111\end{array}$ & $\begin{array}{r}145 \\
125 \\
100 \\
97 \\
91\end{array}$ & $\begin{array}{l}110 \\
105 \\
100 \\
135 \\
155\end{array}$ & $\begin{array}{l}83 \\
79 \\
76 \\
73 \\
72\end{array}$ & $\begin{array}{l}67 \\
66 \\
85 \\
84 \\
85\end{array}$ & $\begin{array}{l}82 \\
82 \\
78 \\
77 \\
88\end{array}$ & $\begin{array}{r}104 \\
95 \\
95 \\
89 \\
82\end{array}$ & $\begin{array}{l}53 \\
48 \\
43 \\
41 \\
38\end{array}$ & $\begin{array}{r}404 \\
1200 \\
255 \\
109 \\
73\end{array}$ & $\begin{array}{r}45 \\
43 \\
45 \\
40 \\
192\end{array}$ & $\begin{array}{r}34 \\
375 \\
165 \\
59 \\
41\end{array}$ & $\begin{array}{r}127 \\
95 \\
81 \\
73 \\
62\end{array}$ \\
\hline $\begin{array}{l}26 \\
27 \\
28 \\
29 \\
30 \\
31\end{array}$ & $\begin{array}{l}153 \\
202 \\
213 \\
148 \\
121 \\
109\end{array}$ & $\begin{array}{r}156 \\
244 \\
130 \\
102 \\
92 \\
---\end{array}$ & $\begin{array}{r}125 \\
110 \\
105 \\
100 \\
100 \\
98\end{array}$ & $\begin{array}{l}70 \\
69 \\
69 \\
76 \\
81 \\
78\end{array}$ & $\begin{array}{r}82 \\
77 \\
86 \\
--- \\
--- \\
---\end{array}$ & $\begin{array}{r}98 \\
88 \\
80 \\
79 \\
398 \\
298\end{array}$ & $\begin{array}{r}76 \\
82 \\
104 \\
79 \\
72 \\
--\end{array}$ & $\begin{array}{l}40 \\
36 \\
34 \\
39 \\
32 \\
56\end{array}$ & $\begin{array}{r}305 \\
110 \\
67 \\
69 \\
189 \\
---\end{array}$ & $\begin{array}{r}150 \\
74 \\
48 \\
37 \\
32 \\
32\end{array}$ & $\begin{array}{r}180 \\
1020 \\
272 \\
134 \\
87 \\
61\end{array}$ & $\begin{array}{r}56 \\
53 \\
50 \\
64 \\
125\end{array}$ \\
\hline $\begin{array}{l}\text { TOTAL } \\
\text { MEAN } \\
\text { MAX } \\
\text { MIN } \\
\text { CFSM } \\
\text { IN. }\end{array}$ & $\begin{array}{r}7713 \\
249 \\
1330 \\
104 \\
1.33 \\
1.53\end{array}$ & $\begin{array}{r}3101 \\
103 \\
244 \\
64 \\
.55 \\
.62\end{array}$ & $\begin{array}{r}4842 \\
156 \\
400 \\
84 \\
.83 \\
.96\end{array}$ & $\begin{array}{r}2978 \\
96.1 \\
254 \\
69 \\
.51 \\
.59\end{array}$ & $\begin{array}{r}2295 \\
82.0 \\
100 \\
63 \\
.44 \\
.46\end{array}$ & $\begin{array}{r}4596 \\
148 \\
464 \\
77 \\
.79 \\
.91\end{array}$ & $\begin{array}{r}5947 \\
198 \\
911 \\
72 \\
1.06 \\
1.18\end{array}$ & $\begin{array}{r}2071 \\
66.8 \\
317 \\
32 \\
.36 \\
.41\end{array}$ & $\begin{array}{r}3897 \\
130 \\
1200 \\
22 \\
.70 \\
.78\end{array}$ & $\begin{array}{r}2714 \\
87.5 \\
349 \\
32 \\
.47 \\
.54\end{array}$ & $\begin{array}{r}4075 \\
131 \\
1020 \\
24 \\
.70 \\
.81\end{array}$ & $\begin{array}{r}3309 \\
110 \\
354 \\
36 \\
.59 \\
.66\end{array}$ \\
\hline
\end{tabular}

CAL YR 1986 TOTAL 62066 MEAN 170 MAX 1550 MIN 25 CFSM .91 IN 12.35 WTR YR 1987 TOTAL 47538 MEAN 130 MAX 1330 MIN 22 CFSM .70 IN 9.46 
LOCATION.--Lat $42^{\circ} 20^{\prime} 55^{\prime \prime}$, long $83^{\circ} 18^{\prime} 45^{\prime \prime}$, in SWl/4 NWl/4 sec.6, T. 2 S., R.10 E., Wayne County, Hydrologic Unit 04090004 , on right bank $200 \mathrm{ft}$ downstream from bridge on Inkster Road, i. 8 mi northeast of Garden city, and $6.0 \mathrm{mi}$ upstream from mouth.

DRAINAGE AREA. $--99.9 \mathrm{mi}^{2}$.

PERIOD OF RECORD. --October 1930 to September 1933 (published as "at Detroit"), June 1947 to September

1977, October 1977 to September 1983 (operated as a crest-stage partial-record station only), October

$1983^{3}$ to current year. Monthly discharge only for October, November, 1930, published in wsp i307.

REVISED RECORDS.--WSP 2112: Drainage area.

GAGE.--Water-stage recorder. Datum of gage is $600.95 \mathrm{ft}$ above National Geodetic Vertical Datum of 1929.

Nov. 21,1930 to Sept. 30, 1933, nonrecording gage at site $4.8 \mathrm{mi}$ downstream at datum 17.48 ft 10 ewer.

June 6, 1947 to oct. 18, 1948, nonrecording gage at site $200 \mathrm{ft}$ upstream at present datum.

REMARKS.--Estimated daily discharges: Jan. 18-28, Feb. 8-17, Mar. 30 to Apr. 1, June 2, 21-24, 28, 29, July 3, 15, 16, and Sept. 30. Records good except for estimated daily discharges, which are fair. Occasional regulation by reservoirs upstream from station since 1956. Several measurements of water temperature were made during the year. National Weather Service gage-height telemeter at station.

AVERAGE DISCHARGE.--37 years (water years 1931-33, 1948-77, 1984-87), 71.4 $\mathrm{ft} 3 / \mathrm{s}, 9.71 \mathrm{in} / \mathrm{yr}^{3}$.

EXTREMES FOR PERIOD OF RECORD.--Maximum discharge, 2,330 $\mathrm{ft}^{3} / \mathrm{s}$, June 26, 1968; maximum gage height, $10.50 \mathrm{ft}$, May 10, 1948; minimum discharge, $0.9 \mathrm{ft} / \mathrm{s}$, Aug. 16, 1956.

EXTREMES FOR CURRENT YEAR.--Peak discharges greater than base discharge of $700 \mathrm{ft}^{3} / \mathrm{s}$ and maximum (*):

$\begin{array}{cccccrr}\text { Date } & \text { Time } & \begin{array}{c}\text { Discharge } \\ \left(\mathrm{ft}^{3} / \mathrm{s}\right)\end{array} & \begin{array}{c}\text { Gage height } \\ (\mathrm{ft})\end{array} & \text { Date } & \text { Time } & \begin{array}{c}\text { Discharge } \\ (\mathrm{ft} / \mathrm{s})\end{array} \\ \text { June } 21 & \text { unknown } & * 1,000 & \text { unknown } & \text { July } 10 & 1800 & \begin{array}{c}\text { Gage height } \\ (\mathrm{ft})\end{array}\end{array}$

Minimum discharge, $17 \mathrm{ft}^{3} / \mathrm{s}$, June 18 , gage height, $1.76 \mathrm{ft}$.

DISCHARGE, IN CUBIC FEET PER SECOND, WATER YEAR OCTOBER 1986 TO SEPTEMBER 1987

\begin{tabular}{|c|c|c|c|c|c|c|c|c|c|c|c|c|}
\hline DAY & OCT & NOV & DEC & JAN & FEB & MAR & APR & MAY & JUN & JUL & AUG & SEP \\
\hline $\begin{array}{l}1 \\
2 \\
3 \\
4 \\
5\end{array}$ & $\begin{array}{l}247 \\
177 \\
369 \\
554 \\
273\end{array}$ & $\begin{array}{l}48 \\
81 \\
53 \\
46 \\
42\end{array}$ & $\begin{array}{r}46 \\
169 \\
184 \\
138 \\
104\end{array}$ & $\begin{array}{l}62 \\
71 \\
69 \\
60 \\
56\end{array}$ & $\begin{array}{l}61 \\
69 \\
71 \\
70 \\
64\end{array}$ & $\begin{array}{l}276 \\
294 \\
223 \\
150 \\
134\end{array}$ & $\begin{array}{l}118 \\
197 \\
127 \\
103 \\
325\end{array}$ & $\begin{array}{l}41 \\
39 \\
76 \\
58 \\
46\end{array}$ & $\begin{array}{l}35 \\
68 \\
80 \\
49 \\
31\end{array}$ & $\begin{array}{r}95 \\
57 \\
157 \\
142 \\
48\end{array}$ & $\begin{array}{r}258 \\
141 \\
61 \\
40 \\
32\end{array}$ & $\begin{array}{l}40 \\
39 \\
34 \\
30 \\
28\end{array}$ \\
\hline $\begin{array}{r}6 \\
7 \\
8 \\
9 \\
10\end{array}$ & $\begin{array}{r}177 \\
122 \\
94 \\
94 \\
70\end{array}$ & $\begin{array}{l}40 \\
37 \\
44 \\
41 \\
35\end{array}$ & $\begin{array}{r}82 \\
100 \\
126 \\
219 \\
264\end{array}$ & $\begin{array}{l}55 \\
56 \\
56 \\
56 \\
65\end{array}$ & $\begin{array}{l}60 \\
68 \\
72 \\
67 \\
62\end{array}$ & $\begin{array}{r}125 \\
119 \\
121 \\
114 \\
95\end{array}$ & $\begin{array}{r}342 \\
271 \\
174 \\
125 \\
99\end{array}$ & $\begin{array}{l}42 \\
39 \\
42 \\
38 \\
35\end{array}$ & $\begin{array}{l}32 \\
32 \\
27 \\
25 \\
23\end{array}$ & $\begin{array}{r}39 \\
35 \\
31 \\
34 \\
337\end{array}$ & $\begin{array}{l}27 \\
25 \\
24 \\
87 \\
72\end{array}$ & $\begin{array}{l}27 \\
26 \\
48 \\
54 \\
31\end{array}$ \\
\hline $\begin{array}{l}11 \\
12 \\
13 \\
14 \\
15\end{array}$ & $\begin{array}{r}61 \\
59 \\
97 \\
232 \\
117\end{array}$ & $\begin{array}{l}34 \\
33 \\
32 \\
30 \\
29\end{array}$ & $\begin{array}{r}192 \\
132 \\
96 \\
77 \\
68\end{array}$ & $\begin{array}{r}71 \\
64 \\
63 \\
73 \\
143\end{array}$ & $\begin{array}{l}61 \\
61 \\
60 \\
55 \\
52\end{array}$ & $\begin{array}{l}76 \\
67 \\
64 \\
77 \\
86\end{array}$ & $\begin{array}{r}87 \\
104 \\
84 \\
74 \\
82\end{array}$ & $\begin{array}{l}36 \\
43 \\
34 \\
51 \\
83\end{array}$ & $\begin{array}{l}22 \\
24 \\
24 \\
22 \\
21\end{array}$ & $\begin{array}{r}234 \\
64 \\
43 \\
71 \\
46\end{array}$ & $\begin{array}{l}52 \\
35 \\
29 \\
27 \\
25\end{array}$ & $\begin{array}{r}118 \\
69 \\
44 \\
31 \\
94\end{array}$ \\
\hline $\begin{array}{l}16 \\
17 \\
18 \\
19 \\
20\end{array}$ & $\begin{array}{l}84 \\
70 \\
61 \\
54 \\
50\end{array}$ & $\begin{array}{l}30 \\
31 \\
33 \\
35 \\
55\end{array}$ & $\begin{array}{r}64 \\
70 \\
135 \\
108 \\
94\end{array}$ & $\begin{array}{r}132 \\
96 \\
75 \\
66 \\
63\end{array}$ & $\begin{array}{l}48 \\
46 \\
45 \\
44 \\
43\end{array}$ & $\begin{array}{l}83 \\
79 \\
76 \\
74 \\
69\end{array}$ & $\begin{array}{l}89 \\
76 \\
67 \\
61 \\
56\end{array}$ & $\begin{array}{l}65 \\
44 \\
82 \\
71 \\
50\end{array}$ & $\begin{array}{l}20 \\
19 \\
19 \\
19 \\
19\end{array}$ & $\begin{array}{l}73 \\
41 \\
32 \\
28 \\
36\end{array}$ & $\begin{array}{l}25 \\
58 \\
31 \\
27 \\
22\end{array}$ & $\begin{array}{l}60 \\
74 \\
76 \\
64 \\
60\end{array}$ \\
\hline $\begin{array}{l}21 \\
22 \\
23 \\
24 \\
25\end{array}$ & $\begin{array}{l}49 \\
47 \\
45 \\
44 \\
41\end{array}$ & $\begin{array}{l}84 \\
61 \\
52 \\
52 \\
53\end{array}$ & $\begin{array}{l}84 \\
75 \\
69 \\
67 \\
95\end{array}$ & $\begin{array}{l}60 \\
57 \\
54 \\
52 \\
50\end{array}$ & $\begin{array}{l}43 \\
45 \\
57 \\
60 \\
65\end{array}$ & $\begin{array}{l}65 \\
62 \\
60 \\
59 \\
70\end{array}$ & $\begin{array}{l}54 \\
49 \\
51 \\
49 \\
44\end{array}$ & $\begin{array}{l}41 \\
38 \\
33 \\
30 \\
30\end{array}$ & $\begin{array}{r}130 \\
600 \\
300 \\
150 \\
72\end{array}$ & $\begin{array}{l}28 \\
24 \\
27 \\
30 \\
38\end{array}$ & $\begin{array}{r}23 \\
243 \\
86 \\
43 \\
31\end{array}$ & $\begin{array}{l}79 \\
47 \\
41 \\
40 \\
37\end{array}$ \\
\hline $\begin{array}{l}26 \\
27 \\
28 \\
29 \\
30 \\
31\end{array}$ & $\begin{array}{l}82 \\
79 \\
75 \\
62 \\
52 \\
46\end{array}$ & $\begin{array}{r}127 \\
140 \\
87 \\
66 \\
53 \\
---\end{array}$ & $\begin{array}{l}81 \\
75 \\
70 \\
67 \\
65 \\
63\end{array}$ & $\begin{array}{l}49 \\
48 \\
48 \\
50 \\
59 \\
57\end{array}$ & $\begin{array}{r}67 \\
66 \\
74 \\
--- \\
--- \\
---\end{array}$ & $\begin{array}{r}67 \\
63 \\
60 \\
61 \\
276 \\
191\end{array}$ & $\begin{array}{r}43 \\
52 \\
55 \\
48 \\
43 \\
---\end{array}$ & $\begin{array}{l}32 \\
30 \\
28 \\
26 \\
26 \\
25\end{array}$ & $\begin{array}{r}121 \\
65 \\
63 \\
68 \\
169 \\
--\end{array}$ & $\begin{array}{l}54 \\
39 \\
26 \\
23 \\
22 \\
22\end{array}$ & $\begin{array}{r}178 \\
405 \\
213 \\
124 \\
67 \\
50\end{array}$ & $\begin{array}{r}35 \\
37 \\
39 \\
46 \\
68 \\
-\end{array}$ \\
\hline $\begin{array}{l}\text { TOTAL } \\
\text { MEAN } \\
\text { MAX } \\
\text { MIN } \\
\text { CFSM } \\
\text { IN. }\end{array}$ & $\begin{array}{r}3684 \\
119 \\
554 \\
41 \\
1.19 \\
1.37\end{array}$ & $\begin{array}{r}1584 \\
52.8 \\
140 \\
29 \\
.53 \\
.59\end{array}$ & $\begin{array}{r}3279 \\
106 \\
264 \\
46 \\
1.06 \\
1.22\end{array}$ & $\begin{array}{r}2036 \\
65.7 \\
143 \\
48 \\
.66 \\
.76\end{array}$ & $\begin{array}{r}1656 \\
59.1 \\
74 \\
43 \\
.59 \\
.62\end{array}$ & $\begin{array}{r}3436 \\
111 \\
294 \\
59 \\
1.11 \\
1.28\end{array}$ & $\begin{array}{r}3149 \\
105 \\
342 \\
43 \\
1.05 \\
1.17\end{array}$ & $\begin{array}{r}1354 \\
43.7 \\
83 \\
25 \\
.44 \\
.50\end{array}$ & $\begin{array}{r}2349 \\
78.3 \\
600 \\
19 \\
.78 \\
.87\end{array}$ & $\begin{array}{r}1976 \\
63.7 \\
337 \\
22 \\
.64 \\
.74\end{array}$ & $\begin{array}{r}2561 \\
82.6 \\
405 \\
22 \\
.83 \\
.95\end{array}$ & $\begin{array}{r}1516 \\
50.5 \\
118 \\
26 \\
.51 \\
.56\end{array}$ \\
\hline
\end{tabular}

$\begin{array}{lllllllllll}\text { CAL YR } 1986 & \text { TOTAL } & 35002 & \text { MEAN } 95.9 & \text { MAX } 800 & \text { MIN 20 } & \text { CFSM } & .96 & \text { IN } 13.03 \\ \text { WTR YR } 1987 & \text { TOTAL } & 28580 & \text { MEAN 78.3 } & \text { MAX 600 } & \text { MIN 19 } & \text { CFSM } .78 & \text { IN } 10.64\end{array}$ 


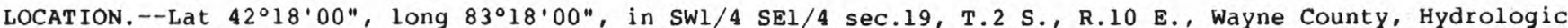
Unit 04090004 , on right bank $10 \mathrm{ft}$ downstream from bridge on John Daly Road, $0.6 \mathrm{mi}$ northeast of Inkster, and $4.8 \mathrm{mi}$ upstream from mouth.

DRAINAGE AREA. $--83.2 \mathrm{mi}^{2}$.

PERIOD OF RECORD.--June 1947 to current year.

REVISED RECORDS.--WSP 1174: 1948(M). WSP 1437: 1949. WSP 2112: Drainage area.

GAGE.--Water-stage recorder. Datum of gage is $593.14 \mathrm{ft}$ above National Geodetic Vertical Datum of 1929. Prior to oct. 20,1948 , nonrecording gage at same site and datum.

REMARKS.--Estimated daily discharges: Dec. 11-14 and Jan. 16 to Mar. 1. Records good except for estimated daily discharges, which are fair. Several measurements of water temperature were made during the year.

AVERAGE DISCHARGE. -40 years, $53.3 \mathrm{ft}^{3} / \mathrm{s}, 8.70 \mathrm{in} / \mathrm{yr}^{\mathrm{r}}$.

EXTREMES FOR PERIOD OF RECORD.--Maximum discharge, 3,600 ft $3 / \mathrm{s}$, June 26,1968, gage height, 13.62 ft; minimum, $0.2 \mathrm{ft}^{3} / \mathrm{s}$, Sept. 13, 1955, Jan. 23, 1961.

EXTREMES FOR CURRENT YEAR.--Maximum discharge, $798 \mathrm{ft}^{3} / \mathrm{s}$, June 21 , gage height, $8.80 \mathrm{ft}$, no peak discharge above base discharge of $900 \mathrm{ft}^{3} / \mathrm{s}$; minimum, $1.2 \mathrm{ft}^{3} / \mathrm{s}$, Aug. 20,21 , gage height, $2.59 \mathrm{ft}$.

DISCHARGE, IN CUBIC FEET PER SECOND, WATER YEAR OCTOBER 1986 TO SEPTEMBER 1987 MEAN VALUES

\begin{tabular}{|c|c|c|c|c|c|c|c|c|c|c|c|c|}
\hline DAY & OCT & NOV & DEC & JAN & FEB & MAR & APR & MAY & JUN & JUL & AUG & SEP \\
\hline $\begin{array}{l}1 \\
2 \\
3 \\
4 \\
5\end{array}$ & $\begin{array}{l}142 \\
154 \\
261 \\
548 \\
216\end{array}$ & $\begin{array}{l}26 \\
41 \\
32 \\
29 \\
24\end{array}$ & $\begin{array}{r}42 \\
151 \\
321 \\
155 \\
86\end{array}$ & $\begin{array}{l}34 \\
41 \\
41 \\
34 \\
31\end{array}$ & $\begin{array}{l}23 \\
25 \\
28 \\
31 \\
30\end{array}$ & $\begin{array}{r}330 \\
370 \\
165 \\
93 \\
86\end{array}$ & $\begin{array}{r}98 \\
227 \\
138 \\
88 \\
395\end{array}$ & $\begin{array}{l}15 \\
16 \\
38 \\
25 \\
17\end{array}$ & $\begin{array}{l}33 \\
70 \\
67 \\
24 \\
14\end{array}$ & $\begin{array}{l}35 \\
17 \\
61 \\
56 \\
18\end{array}$ & $\begin{array}{r}114 \\
68 \\
20 \\
14 \\
8.1\end{array}$ & $\begin{array}{l}20 \\
16 \\
12 \\
11 \\
11\end{array}$ \\
\hline $\begin{array}{r}6 \\
7 \\
8 \\
9 \\
10\end{array}$ & $\begin{array}{r}113 \\
71 \\
51 \\
46 \\
34\end{array}$ & $\begin{array}{l}23 \\
20 \\
24 \\
21 \\
20\end{array}$ & $\begin{array}{r}64 \\
67 \\
115 \\
258 \\
384\end{array}$ & $\begin{array}{l}28 \\
31 \\
30 \\
28 \\
27\end{array}$ & $\begin{array}{l}29 \\
31 \\
35 \\
34 \\
32\end{array}$ & $\begin{array}{r}93 \\
109 \\
92 \\
77 \\
52\end{array}$ & $\begin{array}{r}412 \\
210 \\
121 \\
79 \\
61\end{array}$ & $\begin{array}{l}15 \\
14 \\
14 \\
12 \\
11\end{array}$ & $\begin{array}{r}11 \\
8.8 \\
7.4 \\
5.9 \\
4.5\end{array}$ & $\begin{array}{l}12 \\
8.7 \\
10 \\
18 \\
86\end{array}$ & $\begin{array}{r}7.0 \\
3.9 \\
2.8 \\
18 \\
8.5\end{array}$ & $\begin{array}{l}7 \cdot 3 \\
7.1 \\
13 \\
29 \\
13\end{array}$ \\
\hline $\begin{array}{l}11 \\
12 \\
13 \\
14 \\
15\end{array}$ & $\begin{array}{r}29 \\
26 \\
56 \\
194 \\
118\end{array}$ & $\begin{array}{l}17 \\
16 \\
16 \\
14 \\
13\end{array}$ & $\begin{array}{r}110 \\
60 \\
40 \\
37 \\
32\end{array}$ & $\begin{array}{r}36 \\
32 \\
33 \\
42 \\
131\end{array}$ & $\begin{array}{l}31 \\
32 \\
33 \\
28 \\
23\end{array}$ & $\begin{array}{l}36 \\
34 \\
31 \\
39 \\
44\end{array}$ & $\begin{array}{l}51 \\
58 \\
49 \\
42 \\
48\end{array}$ & $\begin{array}{l}10 \\
18 \\
11 \\
31 \\
76\end{array}$ & $\begin{array}{l}6.5 \\
4.4 \\
3.5 \\
3.0 \\
2.7\end{array}$ & $\begin{array}{l}32 \\
14 \\
8.1 \\
21 \\
24\end{array}$ & $\begin{array}{r}4.4 \\
2.5 \\
2.2 \\
4.3 \\
10\end{array}$ & $\begin{array}{l}28 \\
37 \\
24 \\
16 \\
80\end{array}$ \\
\hline $\begin{array}{l}16 \\
17 \\
18 \\
19 \\
20\end{array}$ & $\begin{array}{l}62 \\
45 \\
36 \\
30 \\
27\end{array}$ & $\begin{array}{l}13 \\
15 \\
15 \\
17 \\
27\end{array}$ & $\begin{array}{l}28 \\
31 \\
74 \\
65 \\
53\end{array}$ & $\begin{array}{r}145 \\
60 \\
45 \\
33 \\
25\end{array}$ & $\begin{array}{l}20 \\
17 \\
16 \\
17 \\
16\end{array}$ & $\begin{array}{l}49 \\
55 \\
52 \\
46 \\
40\end{array}$ & $\begin{array}{l}53 \\
47 \\
38 \\
32 \\
29\end{array}$ & $\begin{array}{l}18 \\
12 \\
44 \\
45 \\
34\end{array}$ & $\begin{array}{l}2.5 \\
2.3 \\
5.5 \\
5.4 \\
5.3\end{array}$ & $\begin{array}{r}21 \\
9.0 \\
5.8 \\
4.4 \\
24\end{array}$ & $\begin{array}{l}2.4 \\
7.0 \\
3.3 \\
2.7 \\
1.3\end{array}$ & $\begin{array}{l}66 \\
84 \\
63 \\
36 \\
26\end{array}$ \\
\hline $\begin{array}{l}21 \\
22 \\
23 \\
24 \\
25\end{array}$ & $\begin{array}{l}24 \\
22 \\
21 \\
21 \\
18\end{array}$ & $\begin{array}{l}41 \\
37 \\
36 \\
39 \\
41\end{array}$ & $\begin{array}{l}46 \\
38 \\
37 \\
33 \\
55\end{array}$ & $\begin{array}{l}23 \\
21 \\
20 \\
19 \\
18\end{array}$ & $\begin{array}{l}15 \\
16 \\
25 \\
29 \\
31\end{array}$ & $\begin{array}{l}35 \\
32 \\
30 \\
27 \\
31\end{array}$ & $\begin{array}{l}27 \\
25 \\
25 \\
25 \\
20\end{array}$ & $\begin{array}{r}19 \\
17 \\
11 \\
9.2 \\
8.1\end{array}$ & $\begin{array}{r}149 \\
371 \\
56 \\
23 \\
17\end{array}$ & $\begin{array}{r}8.7 \\
5.1 \\
5.9 \\
10 \\
8.7\end{array}$ & $\begin{array}{c}7.6 \\
258 \\
69 \\
18 \\
13\end{array}$ & $\begin{array}{l}35 \\
23 \\
17 \\
14 \\
12\end{array}$ \\
\hline $\begin{array}{l}26 \\
27 \\
28 \\
29 \\
30 \\
31\end{array}$ & $\begin{array}{l}39 \\
41 \\
46 \\
41 \\
32 \\
32\end{array}$ & $\begin{array}{r}89 \\
179 \\
92 \\
63 \\
50 \\
--\end{array}$ & $\begin{array}{l}55 \\
48 \\
44 \\
39 \\
37 \\
37\end{array}$ & $\begin{array}{l}17 \\
17 \\
18 \\
19 \\
20 \\
21\end{array}$ & $\begin{array}{r}30 \\
33 \\
40 \\
-- \\
--- \\
---\end{array}$ & $\begin{array}{r}30 \\
28 \\
25 \\
25 \\
186 \\
170\end{array}$ & $\begin{array}{r}21 \\
24 \\
23 \\
20 \\
17 \\
---\end{array}$ & $\begin{array}{l}7.8 \\
7.6 \\
7.2 \\
6.2 \\
6.2 \\
6.1\end{array}$ & $\begin{array}{r}28 \\
12 \\
7.3 \\
29 \\
111 \\
\end{array}$ & $\begin{array}{r}22 \\
11 \\
7.9 \\
6.2 \\
4.5 \\
5.4\end{array}$ & $\begin{array}{r}134 \\
368 \\
145 \\
127 \\
58 \\
32\end{array}$ & $\begin{array}{l}9.9 \\
8.9 \\
8.4 \\
10 \\
23 \\
---\end{array}$ \\
\hline $\begin{array}{l}\text { TOTAL } \\
\text { MEAN } \\
\text { MAX } \\
\text { MIN } \\
\text { CFSM } \\
\text { IN. }\end{array}$ & $\begin{array}{r}2596 \\
83.7 \\
548 \\
18 \\
1.01 \\
1.16\end{array}$ & $\begin{array}{r}1090 \\
36.3 \\
179 \\
13 \\
.44 \\
.49\end{array}$ & $\begin{array}{r}2642 \\
85.2 \\
384 \\
28 \\
1.02 \\
1.18\end{array}$ & $\begin{array}{r}1120 \\
36.1 \\
145 \\
17 \\
.43 \\
.50\end{array}$ & $\begin{array}{r}750 \\
26.8 \\
40 \\
15 \\
.32 \\
.34\end{array}$ & $\begin{array}{r}2512 \\
81.0 \\
370 \\
25 \\
.97 \\
1.12\end{array}$ & $\begin{array}{r}2503 \\
83.4 \\
412 \\
17 \\
1.00 \\
1.12\end{array}$ & $\begin{array}{r}581.4 \\
18.8 \\
76 \\
6.1 \\
.23 \\
.26\end{array}$ & $\begin{array}{r}1090.0 \\
36.3 \\
371 \\
2.3 \\
.44 \\
.49\end{array}$ & $\begin{array}{r}580.4 \\
18.7 \\
86 \\
4.4 \\
.23 \\
.26\end{array}$ & $\begin{array}{r}1534.0 \\
49.5 \\
368 \\
1.3 \\
.60 \\
.69\end{array}$ & $\begin{array}{r}760.6 \\
25.4 \\
84 \\
7.1 \\
.31 \\
.34\end{array}$ \\
\hline
\end{tabular}

$\begin{array}{lllllllllll}\text { CAL YR } 1986 & \text { TOTAL } & 24052.72 & \text { MEAN } 65.9 & \text { MAX } 988 & \text { MIN } & .93 & \text { CFSM } & .79 & \text { IN } & 10.75 \\ \text { WTR YR } 1987 & \text { TOTAL } & 17759.40 & \text { MEAN } 48.7 & \text { MAX } 548 & \text { MIN } 1.3 & \text { CFSM } & .59 & \text { IN } & 7.94\end{array}$ 


\section{HURON RIVER AT MILFORD, MI}

LOCATION.--Lat $42^{\circ} 34^{\prime} 44^{\prime \prime}$, long $83^{\circ} 37^{\prime} 36^{\prime \prime}$, in NEl/4 sec.16, T.2 N., R.7 E. Oakland County, Hydrologic Unit 04090005 , on left bank 40 ft downstream from bridge on General Motors Road, $0.5 \mathrm{mi}$ downstream from Sherwood 'creek, and $0.5 \mathrm{mi}$ west of Milford.

DRAINAGE AREA. $--132 \mathrm{mi}^{2}$.

PERIOD OF RECORD.--September 1948 to current year.

REVISED RECORDS.--WSP 1337: 1952(m). WSP 2112: Drainage area.

GAGE.--Water-stage recorder. Datum of gage is $880.00 \mathrm{ft}$ above National Geodetic Vertical Datum of 1929 . Prior to Apr. 1, 1970, at site 240 ft upstream at same datum.

REMARKS. - No estimated daily discharges. Records good. Flow below about $300 \mathrm{ft} 3 / \mathrm{s}$ regulated by powerplant $1.5 \mathrm{mi}$ upstream from station prior to May 20, 1957; occasional regulation for lake level control since. Several measurements of water temperature were made during the year.

AVERAGE DISCHARGE.--39 years, $98.2 \mathrm{ft}^{3} / \mathrm{s}, 10.10 \mathrm{in} / \mathrm{yr}$.

EXTREMES FOR PERIOD OF RECORD.--Maximum discharge, $648 \mathrm{ft}^{3} / \mathrm{s}$, Oct. 3,1981, gage height, $7.87 \mathrm{ft}$; maximum gage height, $8.26 \mathrm{ft}$, June 28,$1968 ;$ minimum daily discharge, 5.2 ft $3 / \mathrm{s}^{\prime}, 0 \mathrm{ct}$. $2 \mathrm{i}^{\prime}, 1971$.

EXTREMES FOR CURRENT YEAR.--Maximum discharge, $285 \mathrm{ft}^{3} / \mathrm{s}$, Oct. 5 , gage height, $6.70 \mathrm{ft} ; \mathrm{minimum,}$

$28 \mathrm{ft}^{3} / \mathrm{s}$, Aug. 7, 8; minimum gage height, $4.16 \mathrm{ft}$, Aug. 7 .

DISCHARGE, IN CUBIC FEET PER SECOND, WATER YEAR OCTOBER 1986 TO SEPTEMBER 1987 MEAN VALUES

\begin{tabular}{|c|c|c|c|c|c|c|c|c|c|c|c|c|}
\hline DAY & OCT & NOV & DEC & JAN & FEB & MAR & APR & MAY & JUN & JUL & AUG & SEP \\
\hline $\begin{array}{l}1 \\
2 \\
3 \\
4 \\
5\end{array}$ & $\begin{array}{l}261 \\
262 \\
265 \\
278 \\
284\end{array}$ & $\begin{array}{l}128 \\
136 \\
158 \\
152 \\
171\end{array}$ & $\begin{array}{l}129 \\
127 \\
130 \\
134 \\
137\end{array}$ & $\begin{array}{l}120 \\
121 \\
122 \\
118 \\
115\end{array}$ & $\begin{array}{l}110 \\
113 \\
112 \\
110 \\
108\end{array}$ & $\begin{array}{l}142 \\
164 \\
156 \\
146 \\
143\end{array}$ & $\begin{array}{l}114 \\
122 \\
124 \\
116 \\
141\end{array}$ & $\begin{array}{l}67 \\
55 \\
53 \\
54 \\
55\end{array}$ & $\begin{array}{l}66 \\
83 \\
97 \\
96 \\
90\end{array}$ & $\begin{array}{l}61 \\
58 \\
55 \\
59 \\
56\end{array}$ & $\begin{array}{l}44 \\
49 \\
45 \\
42 \\
38\end{array}$ & $\begin{array}{l}70 \\
63 \\
59 \\
54 \\
50\end{array}$ \\
\hline $\begin{array}{r}6 \\
7 \\
8 \\
9 \\
10\end{array}$ & $\begin{array}{l}276 \\
259 \\
244 \\
233 \\
228\end{array}$ & $\begin{array}{l}173 \\
145 \\
144 \\
151 \\
162\end{array}$ & $\begin{array}{l}138 \\
138 \\
149 \\
177 \\
191\end{array}$ & $\begin{array}{l}110 \\
113 \\
112 \\
111 \\
116\end{array}$ & $\begin{array}{l}106 \\
106 \\
107 \\
104 \\
108\end{array}$ & $\begin{array}{l}142 \\
147 \\
159 \\
159 \\
144\end{array}$ & $\begin{array}{l}172 \\
167 \\
150 \\
142 \\
138\end{array}$ & $\begin{array}{l}55 \\
54 \\
53 \\
51 \\
49\end{array}$ & $\begin{array}{l}84 \\
82 \\
78 \\
75 \\
63\end{array}$ & $\begin{array}{l}56 \\
54 \\
52 \\
57 \\
79\end{array}$ & $\begin{array}{l}34 \\
29 \\
30 \\
36 \\
49\end{array}$ & $\begin{array}{l}48 \\
45 \\
44 \\
51 \\
51\end{array}$ \\
\hline $\begin{array}{l}11 \\
12 \\
13 \\
14 \\
15\end{array}$ & $\begin{array}{l}201 \\
188 \\
182 \\
190 \\
188\end{array}$ & $\begin{array}{r}144 \\
112 \\
99 \\
102 \\
111\end{array}$ & $\begin{array}{l}190 \\
158 \\
134 \\
135 \\
100\end{array}$ & $\begin{array}{l}118 \\
117 \\
117 \\
118 \\
130\end{array}$ & $\begin{array}{l}104 \\
103 \\
104 \\
104 \\
102\end{array}$ & $\begin{array}{l}133 \\
126 \\
122 \\
123 \\
120\end{array}$ & $\begin{array}{l}134 \\
129 \\
117 \\
111 \\
108\end{array}$ & $\begin{array}{l}45 \\
46 \\
45 \\
52 \\
83\end{array}$ & $\begin{array}{l}52 \\
51 \\
48 \\
46 \\
45\end{array}$ & $\begin{array}{l}80 \\
70 \\
60 \\
53 \\
54\end{array}$ & $\begin{array}{l}48 \\
42 \\
41 \\
37 \\
38\end{array}$ & $\begin{array}{l}53 \\
53 \\
51 \\
48 \\
51\end{array}$ \\
\hline $\begin{array}{l}16 \\
17 \\
18 \\
19 \\
20\end{array}$ & $\begin{array}{l}175 \\
165 \\
158 \\
152 \\
148\end{array}$ & $\begin{array}{r}104 \\
87 \\
88 \\
96 \\
90\end{array}$ & $\begin{array}{r}87 \\
113 \\
137 \\
144 \\
141\end{array}$ & $\begin{array}{l}131 \\
123 \\
122 \\
120 \\
124\end{array}$ & $\begin{array}{r}100 \\
98 \\
96 \\
95 \\
93\end{array}$ & $\begin{array}{l}119 \\
117 \\
117 \\
115 \\
113\end{array}$ & $\begin{array}{r}111 \\
106 \\
101 \\
97 \\
92\end{array}$ & $\begin{array}{l}79 \\
70 \\
66 \\
66 \\
64\end{array}$ & $\begin{array}{l}43 \\
44 \\
43 \\
42 \\
41\end{array}$ & $\begin{array}{l}67 \\
56 \\
50 \\
47 \\
46\end{array}$ & $\begin{array}{l}37 \\
45 \\
44 \\
43 \\
42\end{array}$ & $\begin{array}{l}57 \\
71 \\
80 \\
82 \\
79\end{array}$ \\
\hline $\begin{array}{l}21 \\
22 \\
23 \\
24 \\
25\end{array}$ & $\begin{array}{l}144 \\
139 \\
135 \\
130 \\
131\end{array}$ & $\begin{array}{r}85 \\
98 \\
132 \\
113 \\
112\end{array}$ & $\begin{array}{l}136 \\
132 \\
129 \\
128 \\
130\end{array}$ & $\begin{array}{l}125 \\
123 \\
121 \\
117 \\
114\end{array}$ & $\begin{array}{l}93 \\
93 \\
96 \\
97 \\
99\end{array}$ & $\begin{array}{l}113 \\
112 \\
107 \\
104 \\
105\end{array}$ & $\begin{array}{l}89 \\
86 \\
84 \\
86 \\
82\end{array}$ & $\begin{array}{l}65 \\
65 \\
67 \\
68 \\
65\end{array}$ & $\begin{array}{r}50 \\
100 \\
121 \\
111 \\
89\end{array}$ & $\begin{array}{l}46 \\
43 \\
43 \\
44 \\
56\end{array}$ & $\begin{array}{l}42 \\
56 \\
61 \\
56 \\
51\end{array}$ & $\begin{array}{l}73 \\
74 \\
72 \\
69 \\
68\end{array}$ \\
\hline $\begin{array}{l}26 \\
27 \\
28 \\
29 \\
30 \\
31\end{array}$ & $\begin{array}{l}134 \\
140 \\
148 \\
144 \\
133 \\
130\end{array}$ & $\begin{array}{l}112 \\
113 \\
124 \\
134 \\
135 \\
---\end{array}$ & $\begin{array}{l}130 \\
127 \\
124 \\
123 \\
121 \\
121\end{array}$ & $\begin{array}{l}111 \\
109 \\
109 \\
110 \\
111 \\
111\end{array}$ & $\begin{array}{r}99 \\
100 \\
102 \\
--- \\
---\end{array}$ & $\begin{array}{l}107 \\
106 \\
104 \\
102 \\
119 \\
118\end{array}$ & $\begin{array}{r}80 \\
76 \\
75 \\
71 \\
69 \\
-\end{array}$ & $\begin{array}{l}66 \\
62 \\
60 \\
57 \\
52 \\
63\end{array}$ & $\begin{array}{r}69 \\
59 \\
53 \\
52 \\
56 \\
\end{array}$ & $\begin{array}{l}60 \\
54 \\
48 \\
45 \\
42 \\
40\end{array}$ & $\begin{array}{r}59 \\
93 \\
103 \\
95 \\
83 \\
75\end{array}$ & $\begin{array}{r}66 \\
58 \\
55 \\
58 \\
59 \\
---\end{array}$ \\
\hline $\begin{array}{l}\text { TOTAL } \\
\text { MEAN } \\
\text { MAX } \\
\text { MIN } \\
\text { CFSM } \\
\text { IN. }\end{array}$ & $\begin{array}{r}5845 \\
189 \\
284 \\
130 \\
1.43 \\
1.65\end{array}$ & $\begin{array}{r}3711 \\
124 \\
173 \\
85 \\
.94 \\
1.05\end{array}$ & $\begin{array}{r}4190 \\
135 \\
191 \\
87 \\
1.02 \\
1.18\end{array}$ & $\begin{array}{r}3639 \\
117 \\
131 \\
109 \\
.89 \\
1.03\end{array}$ & $\begin{array}{r}2862 \\
102 \\
113 \\
93 \\
.77 \\
.81\end{array}$ & $\begin{array}{r}3904 \\
126 \\
164 \\
102 \\
.96 \\
1.10\end{array}$ & $\begin{array}{r}3290 \\
110 \\
172 \\
69 \\
.83 \\
.93\end{array}$ & $\begin{array}{r}1852 \\
59.7 \\
83 \\
45 \\
.45 \\
.52\end{array}$ & $\begin{array}{r}2029 \\
67.6 \\
121 \\
41 \\
.51 \\
.57\end{array}$ & $\begin{array}{r}1691 \\
54.5 \\
80 \\
40 \\
.41 \\
.48\end{array}$ & $\begin{array}{r}1587 \\
51.2 \\
103 \\
29 \\
.39 \\
.45\end{array}$ & $\begin{array}{r}1812 \\
60.4 \\
82 \\
44 \\
.46 \\
.51\end{array}$ \\
\hline
\end{tabular}

$\begin{array}{lllllllllll}\text { CAL YR } 1986 & \text { TOTAL } & 46505 & \text { MEAN } & 127 & \text { MAX } & 305 & \text { MIN } 37 & \text { CFSM } & .96 & \text { IN } \\ \text { WTR YR } 1987 & \text { TOTAL } & 36412 & \text { MEAN } & 99.8 & \text { MAX } & 284 & \text { MIN } 29 & \text { CFSM } & .76 & \text { IN } 10.26\end{array}$ 
04170490 KENT LAKE NEAR NEW HUDSON, MI

LOCATION.--Lat $42^{\circ} 30^{\prime} 45^{\prime \prime}$, long $83^{\circ} 40^{\prime} 34^{\prime \prime}$, in sec.1, T.I N., R.6 E., Livingston County, Hydrologic Unit 04090005 , at Kent Lake Dam, $2 \mathrm{mi}$ upstream from Woodruff' Creek, and $3 \mathrm{mi}$ west of New Hudson.

DRAINAGE AREA. $--148 \mathrm{mi}^{2}$.

PERIOD OF RECORD.--April 1949 to current year.

GAGE.--Water-stage recorder. Datum of gage is $868.00 \mathrm{ft}$ above National Geodetic Vertical Datum of 1929 (Huron-Clinton Metropolitan Authority bench mark).

REMARKS.--The inlet and outlet is the Huron River which enters the northeast end of the lake and leaves the southwest end of the lake. Streamflow records are currently collected on the Huron River at sites about $1 \mathrm{mi}$ upstream (04170000) and $150 \mathrm{ft}$ downstream (04170500) from Kent Lake. Maximum depth 38 ft, surface area 1,200 acres. A concrete dam with steel drum spiliway is used to control the lake level.

EXTREMES FOR PERIOD OF RECORD.--Maximum gage height, $16.68 \mathrm{ft}, \mathrm{Apr} .6,1950$; minimum, 11.60 ft, Mar. 7, 8, 1968 .

EXTREMES FOR CURRENT YEAR.--Maximum gage height, $16.09 \mathrm{ft}$, Oct. 3, 4 ; minimum, $12.58 \mathrm{ft}$, Feb. $19-23$.

GAGE HEIGHT (FEET ABOVE DATUM), WATER YEAR OCTOBER 1986 TO SEPTEMBER 1987 MEAN VALUES

\begin{tabular}{|c|c|c|c|c|c|c|c|c|c|c|c|c|}
\hline DAY & OCT & NOV & DEC & JAN & FEB & MAR & APR & MAY & JUN & JUL & AUG & SEP \\
\hline $\begin{array}{l}1 \\
2 \\
3 \\
4 \\
5\end{array}$ & $\begin{array}{l}16.04 \\
16.03 \\
16.05 \\
16.08 \\
16.06\end{array}$ & $\begin{array}{l}15.76 \\
15.76 \\
15.73 \\
15.66 \\
15.57\end{array}$ & $\begin{array}{l}12.73 \\
12.74 \\
12.73 \\
12.74 \\
12.74\end{array}$ & $\begin{array}{l}12.68 \\
12.69 \\
12.68 \\
12.68 \\
12.67\end{array}$ & $\begin{array}{l}12.67 \\
12.67 \\
12.65 \\
12.65 \\
12.64\end{array}$ & $\begin{array}{l}12.68 \\
12.75 \\
12.78 \\
12.78 \\
12.78\end{array}$ & $\begin{array}{l}13.08 \\
13.21 \\
13.31 \\
13.41 \\
13.44\end{array}$ & $\begin{array}{l}14.92 \\
14.96 \\
14.98 \\
14.99 \\
15.02\end{array}$ & $\begin{array}{l}15.43 \\
15.45 \\
15.49 \\
15.51 \\
15.52\end{array}$ & $\begin{array}{l}15.56 \\
15.55 \\
15.55 \\
15.56 \\
15.55\end{array}$ & $\begin{array}{l}15.52 \\
15.52 \\
15.51 \\
15.50 \\
15.48\end{array}$ & $\begin{array}{l}15.62 \\
15.60 \\
15.58 \\
15.56 \\
15.55\end{array}$ \\
\hline $\begin{array}{r}6 \\
7 \\
8 \\
9 \\
10\end{array}$ & $\begin{array}{r}16.05 \\
16.03 \\
--- \\
--- \\
--\end{array}$ & $\begin{array}{l}15.41 \\
15.26 \\
15.07 \\
14.97 \\
14.86\end{array}$ & $\begin{array}{l}12.74 \\
12.76 \\
12.77 \\
12.80 \\
12.84\end{array}$ & $\begin{array}{l}12.66 \\
12.66 \\
12.65 \\
12.65 \\
12.68\end{array}$ & $\begin{array}{l}12.63 \\
12.63 \\
12.64 \\
12.61 \\
12.63\end{array}$ & $\begin{array}{l}12.77 \\
12.77 \\
12.79 \\
12.80 \\
12.77\end{array}$ & $\begin{array}{l}13.56 \\
13.79 \\
13.91 \\
13.99 \\
14.14\end{array}$ & $\begin{array}{l}15.05 \\
15.08 \\
15.09 \\
15.09 \\
15.10\end{array}$ & $\begin{array}{l}15.56 \\
15.57 \\
15.58 \\
15.58 \\
15.56\end{array}$ & $\begin{array}{l}15.55 \\
15.54 \\
15.53 \\
15.56 \\
15.65\end{array}$ & $\begin{array}{l}15.45 \\
15.43 \\
15.43 \\
15.46 \\
15.49\end{array}$ & $\begin{array}{l}15.54 \\
15.53 \\
15.53 \\
15.53 \\
15.53\end{array}$ \\
\hline $\begin{array}{l}11 \\
12 \\
13 \\
14 \\
15\end{array}$ & $\begin{array}{r}--- \\
--- \\
15.94 \\
15.93\end{array}$ & $\begin{array}{l}14.54 \\
14.35 \\
14.17 \\
13.87 \\
13.59\end{array}$ & $\begin{array}{l}12.86 \\
12.85 \\
12.78 \\
12.74 \\
12.72\end{array}$ & $\begin{array}{l}12.68 \\
12.67 \\
12.67 \\
12.67 \\
12.69\end{array}$ & $\begin{array}{l}12.62 \\
12.62 \\
12.61 \\
12.62 \\
12.61\end{array}$ & $\begin{array}{l}12.74 \\
12.72 \\
12.70 \\
12.71 \\
12.69\end{array}$ & $\begin{array}{l}14.22 \\
14.28 \\
14.28 \\
14.32 \\
14.46\end{array}$ & $\begin{array}{l}15.09 \\
15.11 \\
15.09 \\
15.09 \\
15.18\end{array}$ & $\begin{array}{l}15.53 \\
15.52 \\
15.50 \\
15.48 \\
15.48\end{array}$ & $\begin{array}{l}15.65 \\
15.63 \\
15.61 \\
15.57 \\
15.54\end{array}$ & $\begin{array}{l}15.50 \\
15.50 \\
15.49 \\
15.49 \\
15.48\end{array}$ & $\begin{array}{l}15.56 \\
15.56 \\
15.55 \\
15.53 \\
15.53\end{array}$ \\
\hline $\begin{array}{l}16 \\
17 \\
18 \\
19 \\
20\end{array}$ & $\begin{array}{l}15.92 \\
15.90 \\
15.86 \\
15.83 \\
15.81\end{array}$ & $\begin{array}{l}13.44 \\
13.29 \\
13.04 \\
12.89 \\
12.84\end{array}$ & $\begin{array}{l}12.64 \\
12.64 \\
12.67 \\
12.71 \\
12.73\end{array}$ & $\begin{array}{l}12.70 \\
12.69 \\
12.70 \\
12.70 \\
12.69\end{array}$ & $\begin{array}{l}12.61 \\
12.60 \\
12.59 \\
12.59 \\
12.58\end{array}$ & $\begin{array}{l}12.67 \\
12.66 \\
12.66 \\
12.65 \\
12.64\end{array}$ & $\begin{array}{l}14.58 \\
14.63 \\
14.67 \\
14.78 \\
14.84\end{array}$ & $\begin{array}{l}15.24 \\
15.29 \\
15.33 \\
15.33 \\
15.33\end{array}$ & $\begin{array}{l}15.46 \\
15.45 \\
15.44 \\
15.45 \\
15.45\end{array}$ & $\begin{array}{l}15.55 \\
15.54 \\
15.53 \\
15.51 \\
15.51\end{array}$ & $\begin{array}{l}15.48 \\
15.50 \\
15.50 \\
15.49 \\
15.49\end{array}$ & $\begin{array}{l}15.55 \\
15.57 \\
15.60 \\
15.61 \\
15.61\end{array}$ \\
\hline $\begin{array}{l}21 \\
22 \\
23 \\
24 \\
25\end{array}$ & $\begin{array}{l}15.81 \\
15.80 \\
15.79 \\
15.78 \\
15.77\end{array}$ & $\begin{array}{l}12.79 \\
12.69 \\
12.70 \\
12.71 \\
12.70\end{array}$ & $\begin{array}{l}12.73 \\
12.72 \\
12.71 \\
12.71 \\
12.70\end{array}$ & $\begin{array}{l}12.69 \\
12.69 \\
12.68 \\
12.67 \\
12.67\end{array}$ & $\begin{array}{l}12.58 \\
12.58 \\
12.59 \\
12.59 \\
12.60\end{array}$ & $\begin{array}{l}12.64 \\
12.64 \\
12.64 \\
12.63 \\
12.63\end{array}$ & $\begin{array}{l}14.87 \\
14.89 \\
14.90 \\
14.92 \\
14.89\end{array}$ & $\begin{array}{l}15.34 \\
15.37 \\
15.40 \\
15.42 \\
15.42\end{array}$ & $\begin{array}{l}15.49 \\
15.61 \\
15.65 \\
15.68 \\
15.67\end{array}$ & $\begin{array}{l}15.53 \\
15.51 \\
15.50 \\
15.48 \\
15.54\end{array}$ & $\begin{array}{l}15.49 \\
15.58 \\
15.57 \\
15.55 \\
15.54\end{array}$ & $\begin{array}{l}15.61 \\
15.61 \\
15.59 \\
15.59 \\
15.58\end{array}$ \\
\hline $\begin{array}{l}26 \\
27 \\
28 \\
29 \\
30 \\
31\end{array}$ & $\begin{array}{l}15.77 \\
15.79 \\
15.79 \\
15.80 \\
15.78 \\
15.76\end{array}$ & $\begin{array}{r}12.72 \\
12.70 \\
12.69 \\
12.72 \\
12.74 \\
\end{array}$ & $\begin{array}{l}12.70 \\
12.70 \\
12.69 \\
12.69 \\
12.69 \\
12.68\end{array}$ & $\begin{array}{l}12.67 \\
12.67 \\
12.67 \\
12.67 \\
12.67 \\
12.67\end{array}$ & $\begin{array}{r}12.60 \\
12.60 \\
12.61 \\
---- \\
---\end{array}$ & $\begin{array}{l}12.67 \\
12.70 \\
12.76 \\
12.79 \\
12.88 \\
13.00\end{array}$ & $\begin{array}{r}14.88 \\
14.88 \\
14.88 \\
14.87 \\
14.87 \\
\end{array}$ & $\begin{array}{l}15.42 \\
15.43 \\
15.43 \\
15.42 \\
15.40 \\
15.42\end{array}$ & $\begin{array}{l}15.63 \\
15.59 \\
15.56 \\
15.54 \\
15.55\end{array}$ & $\begin{array}{l}15.55 \\
15.54 \\
15.52 \\
15.49 \\
15.49 \\
15.48\end{array}$ & $\begin{array}{l}15.58 \\
15.68 \\
15.69 \\
15.69 \\
15.66 \\
15.64\end{array}$ & $\begin{array}{r}15.57 \\
15.56 \\
15.55 \\
15.55 \\
15.56 \\
\end{array}$ \\
\hline $\begin{array}{l}\text { MEAN } \\
\text { MAX } \\
\text { MIN }\end{array}$ & $\begin{array}{l}--- \\
--- \\
---\end{array}$ & $\begin{array}{l}13.91 \\
15.76 \\
12.69\end{array}$ & $\begin{array}{l}12.73 \\
12.86 \\
12.64\end{array}$ & $\begin{array}{l}12.68 \\
12.70 \\
12.65\end{array}$ & $\begin{array}{l}12.62 \\
12.67 \\
12.58\end{array}$ & $\begin{array}{l}12.73 \\
13.00 \\
12.63\end{array}$ & $\begin{array}{l}14.33 \\
14.92 \\
13.08\end{array}$ & $\begin{array}{l}15.22 \\
15.43 \\
14.92\end{array}$ & $\begin{array}{l}15.53 \\
15.68 \\
15.43\end{array}$ & $\begin{array}{l}15.54 \\
15.65 \\
15.48\end{array}$ & $\begin{array}{l}15.53 \\
15.69 \\
15.43\end{array}$ & $\begin{array}{l}15.57 \\
15.62 \\
15.53\end{array}$ \\
\hline
\end{tabular}


LOCATION, --Lat $42^{\circ} 30^{\prime} 45^{\prime \prime}$, long $83^{\circ} 40^{\prime} 35^{\prime \prime}$, in NEl/4 sec.l, T.1 N., R.6 E., Livingston County, Hydrologic Unit 04090005, on right bank $150 \mathrm{ft}$ downstream from Kent Lake Dam, 2 mi upstream from Woodruff Creek, and $3 \mathrm{mi}$ west of New Hudson.

DRAINAGE AREA. $--148 \mathrm{mi}^{2}$.

PERIOD OF RECORD.--August 1948 to current year.

REVISED RECORDS.--WSP 2112: Drainage area.

GAGE,--Water-stage recorder. Datum of gage is $868.00 \mathrm{ft}$ above National Geodetic Vertical Datum of 1929 (Huron-clinton Metropolitan Authority bench mark).

REMARKS.--Estimated daily discharges: Aug. 11 to Sept. 12. Records good except for estimated daily discharges, which are fair. Occasional regulation by Kent Lake. Several measurements of water temperature were made during the year.

AVERAGE DISCHARGE. --39 years, $112 \mathrm{ft}^{3} / \mathrm{s}, 10.28 \mathrm{in} / \mathrm{yr}$.

EXTREMES FOR PERIOD OF RECORD.--Maximum discharge, 1,080 $\mathrm{ft}^{3} / \mathrm{s}$, Dec. 29, 1950, gage height, 5.05 ft, from rating curve extended above $600 \mathrm{ft} / \mathrm{s}$; minimum, $2.6 \mathrm{ft} / \mathrm{s}$, May 27,1963 , gage height, $0.53 \mathrm{ft}$; minimum daily, $6.4 \mathrm{ft}^{3} / \mathrm{s}$, May 7 , 1963 .

EXTREMES FOR CURRENT YEAR.--Maximum discharge, $388 \mathrm{ft}^{3} / \mathrm{s}$, Nov. 10 , gage height, $3.17 \mathrm{ft}$; minimum daily, $28 \mathrm{ft}^{3} / \mathrm{s}$, Aug. 8 .

DISCHARGE, IN CUBIC FEET PER SECOND, WATER YEAR OCTOBER 1986 TO SEPTEMBER 1987

\begin{tabular}{|c|c|c|c|c|c|c|c|c|c|c|c|c|}
\hline DAY & OCT & NOV & DEC & JAN & FEB & MAR & APR & MAY & JUN & JUL & AUG & SEP \\
\hline $\begin{array}{l}1 \\
2 \\
3 \\
4 \\
5\end{array}$ & $\begin{array}{l}276 \\
269 \\
275 \\
291 \\
283\end{array}$ & $\begin{array}{l}140 \\
141 \\
185 \\
201 \\
227\end{array}$ & $\begin{array}{l}157 \\
160 \\
157 \\
160 \\
161\end{array}$ & $\begin{array}{l}140 \\
142 \\
141 \\
140 \\
138\end{array}$ & $\begin{array}{l}126 \\
126 \\
126 \\
125 \\
123\end{array}$ & $\begin{array}{l}133 \\
153 \\
162 \\
160 \\
158\end{array}$ & $\begin{array}{r}75 \\
84 \\
95 \\
107 \\
115\end{array}$ & $\begin{array}{l}40 \\
49 \\
53 \\
39 \\
30\end{array}$ & $\begin{array}{l}65 \\
74 \\
86 \\
90 \\
72\end{array}$ & $\begin{array}{l}63 \\
58 \\
57 \\
59 \\
56\end{array}$ & $\begin{array}{r}56 \\
55 \\
54 \\
50 \\
43\end{array}$ & $\begin{array}{l}96 \\
88 \\
74 \\
68 \\
62\end{array}$ \\
\hline $\begin{array}{r}6 \\
7 \\
8 \\
9 \\
10\end{array}$ & $\begin{array}{l}275 \\
261 \\
246 \\
232 \\
222\end{array}$ & $\begin{array}{l}253 \\
253 \\
226 \\
187 \\
292\end{array}$ & $\begin{array}{l}161 \\
167 \\
171 \\
182 \\
197\end{array}$ & $\begin{array}{l}135 \\
134 \\
132 \\
132 \\
141\end{array}$ & $\begin{array}{l}122 \\
121 \\
123 \\
118 \\
121\end{array}$ & $\begin{array}{l}155 \\
155 \\
159 \\
166 \\
156\end{array}$ & $\begin{array}{r}84 \\
79 \\
109 \\
77 \\
80\end{array}$ & $\begin{array}{l}37 \\
43 \\
46 \\
45 \\
48\end{array}$ & $\begin{array}{l}68 \\
75 \\
76 \\
77 \\
69\end{array}$ & $\begin{array}{l}56 \\
53 \\
49 \\
58 \\
86\end{array}$ & $\begin{array}{l}35 \\
29 \\
28 \\
40 \\
49\end{array}$ & $\begin{array}{l}58 \\
56 \\
55 \\
55 \\
54\end{array}$ \\
\hline $\begin{array}{l}11 \\
12 \\
13 \\
14 \\
15\end{array}$ & $\begin{array}{l}216 \\
206 \\
191 \\
192 \\
190\end{array}$ & $\begin{array}{l}292 \\
212 \\
230 \\
267 \\
241\end{array}$ & $\begin{array}{l}201 \\
196 \\
173 \\
161 \\
152\end{array}$ & $\begin{array}{l}138 \\
136 \\
135 \\
135 \\
141\end{array}$ & $\begin{array}{l}119 \\
117 \\
115 \\
118 \\
114\end{array}$ & $\begin{array}{l}147 \\
140 \\
135 \\
139 \\
134\end{array}$ & $\begin{array}{r}100 \\
115 \\
116 \\
52 \\
50\end{array}$ & $\begin{array}{l}47 \\
54 \\
50 \\
54 \\
56\end{array}$ & $\begin{array}{l}61 \\
59 \\
56 \\
50 \\
50\end{array}$ & $\begin{array}{r}88 \\
81 \\
73 \\
60 \\
52\end{array}$ & $\begin{array}{r}49 \\
48 \\
47 \\
45 \\
43\end{array}$ & $\begin{array}{l}64 \\
63 \\
60 \\
55 \\
58\end{array}$ \\
\hline $\begin{array}{l}16 \\
17 \\
18 \\
19 \\
20\end{array}$ & $\begin{array}{l}184 \\
182 \\
173 \\
162 \\
157\end{array}$ & $\begin{array}{l}188 \\
230 \\
216 \\
167 \\
153\end{array}$ & $\begin{array}{l}129 \\
129 \\
140 \\
149 \\
155\end{array}$ & $\begin{array}{l}143 \\
142 \\
144 \\
144 \\
142\end{array}$ & $\begin{array}{l}113 \\
112 \\
111 \\
109 \\
108\end{array}$ & $\begin{array}{l}128 \\
125 \\
124 \\
122 \\
119\end{array}$ & $\begin{array}{l}77 \\
88 \\
56 \\
53 \\
67\end{array}$ & $\begin{array}{l}48 \\
58 \\
68 \\
70 \\
69\end{array}$ & $\begin{array}{l}44 \\
42 \\
41 \\
41 \\
42\end{array}$ & $\begin{array}{l}55 \\
53 \\
51 \\
49 \\
47\end{array}$ & $\begin{array}{r}44 \\
51 \\
48 \\
48 \\
47\end{array}$ & $\begin{array}{l}62 \\
71 \\
81 \\
83 \\
83\end{array}$ \\
\hline $\begin{array}{l}21 \\
22 \\
23 \\
24 \\
25\end{array}$ & $\begin{array}{l}154 \\
150 \\
146 \\
144 \\
141\end{array}$ & $\begin{array}{l}154 \\
149 \\
151 \\
151 \\
148\end{array}$ & $\begin{array}{l}153 \\
151 \\
149 \\
148 \\
148\end{array}$ & $\begin{array}{l}141 \\
139 \\
136 \\
133 \\
131\end{array}$ & $\begin{array}{l}108 \\
107 \\
108 \\
109 \\
111\end{array}$ & $\begin{array}{l}119 \\
118 \\
118 \\
115 \\
107\end{array}$ & $\begin{array}{l}78 \\
79 \\
81 \\
85 \\
76\end{array}$ & $\begin{array}{l}53 \\
50 \\
56 \\
62 \\
63\end{array}$ & $\begin{array}{r}53 \\
86 \\
100 \\
108 \\
101\end{array}$ & $\begin{array}{l}52 \\
47 \\
39 \\
36 \\
55\end{array}$ & $\begin{array}{r}48 \\
81 \\
80 \\
71 \\
64\end{array}$ & $\begin{array}{l}82 \\
80 \\
74 \\
71 \\
67\end{array}$ \\
\hline $\begin{array}{l}26 \\
27 \\
28 \\
29 \\
30 \\
31\end{array}$ & $\begin{array}{l}143 \\
148 \\
152 \\
154 \\
148 \\
140\end{array}$ & $\begin{array}{l}152 \\
148 \\
146 \\
153 \\
159 \\
---\end{array}$ & $\begin{array}{l}148 \\
146 \\
145 \\
143 \\
143 \\
140\end{array}$ & $\begin{array}{l}128 \\
125 \\
125 \\
125 \\
129 \\
128\end{array}$ & $\begin{array}{l}111 \\
112 \\
115 \\
--- \\
---\end{array}$ & $\begin{array}{r}111 \\
98 \\
96 \\
101 \\
85 \\
83\end{array}$ & $\begin{array}{r}76 \\
75 \\
74 \\
72 \\
48 \\
---\end{array}$ & $\begin{array}{l}62 \\
64 \\
64 \\
62 \\
60 \\
64\end{array}$ & $\begin{array}{r}88 \\
73 \\
62 \\
57 \\
60 \\
---\end{array}$ & $\begin{array}{l}62 \\
59 \\
52 \\
46 \\
43 \\
41\end{array}$ & $\begin{array}{r}80 \\
128 \\
131 \\
130 \\
116 \\
107\end{array}$ & $\begin{array}{r}64 \\
62 \\
59 \\
60 \\
62 \\
---\end{array}$ \\
\hline $\begin{array}{l}\text { TOTAL } \\
\text { MEAN } \\
\text { MAX } \\
\text { MIN } \\
\text { CFSM } \\
\text { IN. }\end{array}$ & $\begin{array}{r}6103 \\
197 \\
291 \\
140 \\
1.33 \\
1.53\end{array}$ & $\begin{array}{r}5812 \\
194 \\
292 \\
140 \\
1.31 \\
1.46\end{array}$ & $\begin{array}{r}4872 \\
157 \\
201 \\
129 \\
1.06 \\
1.22\end{array}$ & $\begin{array}{r}4215 \\
136 \\
144 \\
125 \\
.92 \\
1.06\end{array}$ & $\begin{array}{r}3248 \\
116 \\
126 \\
107 \\
.78 \\
.82\end{array}$ & $\begin{array}{r}4021 \\
130 \\
166 \\
83 \\
.88 \\
1.01\end{array}$ & $\begin{array}{r}2423 \\
80.8 \\
116 \\
48 \\
.55 \\
.61\end{array}$ & $\begin{array}{r}1664 \\
53.7 \\
70 \\
30 \\
.36 \\
.42\end{array}$ & $\begin{array}{r}2026 \\
67.5 \\
108 \\
41 \\
.46 \\
.51\end{array}$ & $\begin{array}{r}1736 \\
56.0 \\
88 \\
36 \\
.38 \\
.44\end{array}$ & $\begin{array}{r}1945 \\
62.7 \\
131 \\
28 \\
.42 \\
.49\end{array}$ & $\begin{array}{r}2027 \\
67.6 \\
96 \\
54 \\
.46 \\
.51\end{array}$ \\
\hline
\end{tabular}

$\begin{array}{lllllllllll}\text { CAL YR } 1986 & \text { TOTAL } & 52218 & \text { MEAN } 143 & \text { MAX } 306 & \text { MIN } 39 & \text { CFSM } & .97 & \text { IN } 13.12 \\ \text { WTR YR } 1987 & \text { TOTAL } & 40092 & \text { MEAN } 110 & \text { MAX } 292 & \text { MIN 28 } & \text { CFSM } .74 & \text { IN } 10.08\end{array}$ 


\section{HURON RIVER NEAR HAMBURG, MI}

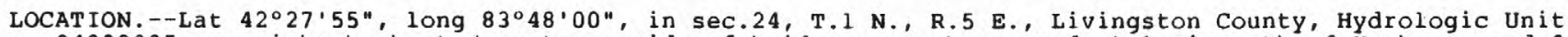
04090005 , on right bank at downstream' side of bridge on Hamburg Road, $1.1 \mathrm{mi}$ north of Hamburg, and $3 \mathrm{mi}$ upstream from Strawberry Lake.

DRAINAGE AREA. - - $308 \mathrm{mi}^{2}$.

PERIOD OF RECORD.--October 1951 to current year.

REVISED RECORDS.--WSP 2112: Drainage area.

GAGE.--Water-stage recorder. Datum of gage is $850.00 \mathrm{ft}$ above National Geodetic Vertical Datum of 1929 (levels by Michigan Department of Natural Resources). Prior to Aug. 12, 1953, nonrecording gage at same site and datum.

REMARKS.--Estimated daily discharges: Oct. 12-14, Oct. 20 to Jan. 8, Jan. 24 to Feb. 3, and Feb. 9-11, 16,17 . Records good except for periods of estimated daily discharges, Oct. 20 to Nov. 2 , Nov. 25 to Jan. 8, Jan. 24 to Feb. 3 , and Feb. 9-11, 16, 17, which are fair and period of estimated daily discharges, Nov. 3-24, which is poor. Occasional regulation by Kent Lake, ll mi upstream from station. Several measurements of water temperature were made during the year.

AVERAGE DISCHARGE. -36 years, $213 \mathrm{ft}^{3} / \mathrm{s}, 9.39 \mathrm{in} / \mathrm{yr}^{\circ}$

EXTREMES FOR PERIOD OF RECORD.--Maximum discharge, 1,560 ft $3 / \mathrm{s}$, May 15, 1956; maximum gage height, $8.46 \mathrm{ft}$, June 30, 1968; minimum discharge, $32 \mathrm{ft}^{3} / \mathrm{s}, \mathrm{July} 2,3,1965$; minimum gage height, $3.16 \mathrm{ft}$, Aug. $1-3,1964$.

EXTREMES FOR CURRENT YEAR.--Maximum discharge, $543 \mathrm{ft}^{3} / \mathrm{s}$, Oct. 5,6 , gage height, $5.81 \mathrm{ft}$; minimum, $70 \mathrm{ft}^{3} / \mathrm{s}$, June 21 ; minimum gage height, $3.62 \mathrm{ft}$, May 6,7 .

DISCHARGE, IN CUBIC FEET PER SECOND, WATER YEAR OCTOBER 1986 TO SEPTEMBER 1987

\begin{tabular}{|c|c|c|c|c|c|c|c|c|c|c|c|c|}
\hline DAY & OCT & NOV & DEC & JAN & FEB & MAR & APR & MAY & JUN & JUL & AUG & SEP \\
\hline $\begin{array}{l}1 \\
2 \\
3 \\
4 \\
5\end{array}$ & $\begin{array}{l}474 \\
496 \\
509 \\
525 \\
537\end{array}$ & $\begin{array}{l}270 \\
280 \\
300 \\
320 \\
340\end{array}$ & $\begin{array}{l}265 \\
265 \\
265 \\
270 \\
270\end{array}$ & $\begin{array}{l}235 \\
240 \\
235 \\
235 \\
237\end{array}$ & $\begin{array}{l}220 \\
220 \\
220 \\
219 \\
214\end{array}$ & $\begin{array}{l}228 \\
268 \\
293 \\
306 \\
313\end{array}$ & $\begin{array}{l}199 \\
197 \\
203 \\
210 \\
227\end{array}$ & $\begin{array}{l}137 \\
131 \\
134 \\
133 \\
121\end{array}$ & $\begin{array}{l}156 \\
162 \\
182 \\
196 \\
197\end{array}$ & $\begin{array}{l}99 \\
98 \\
95 \\
96 \\
92\end{array}$ & $\begin{array}{l}102 \\
113 \\
116 \\
113 \\
106\end{array}$ & $\begin{array}{l}248 \\
251 \\
235 \\
191 \\
162\end{array}$ \\
\hline $\begin{array}{r}6 \\
7 \\
8 \\
9 \\
10\end{array}$ & $\begin{array}{l}543 \\
536 \\
519 \\
497 \\
469\end{array}$ & $\begin{array}{l}350 \\
360 \\
350 \\
330 \\
340\end{array}$ & $\begin{array}{l}275 \\
280 \\
285 \\
300 \\
320\end{array}$ & $\begin{array}{l}230 \\
225 \\
225 \\
224 \\
229\end{array}$ & $\begin{array}{l}215 \\
213 \\
215 \\
215 \\
210\end{array}$ & $\begin{array}{l}315 \\
316 \\
318 \\
323 \\
313\end{array}$ & $\begin{array}{l}261 \\
249 \\
243 \\
253 \\
233\end{array}$ & $\begin{array}{l}113 \\
112 \\
115 \\
114 \\
116\end{array}$ & $\begin{array}{l}185 \\
176 \\
171 \\
168 \\
163\end{array}$ & $\begin{array}{l}93 \\
94 \\
89 \\
84 \\
98\end{array}$ & $\begin{array}{l}97 \\
89 \\
82 \\
86 \\
92\end{array}$ & $\begin{array}{l}143 \\
130 \\
120 \\
117 \\
115\end{array}$ \\
\hline $\begin{array}{l}11 \\
12 \\
13 \\
14 \\
15\end{array}$ & $\begin{array}{l}441 \\
415 \\
400 \\
392 \\
374\end{array}$ & $\begin{array}{l}350 \\
360 \\
330 \\
300 \\
280\end{array}$ & $\begin{array}{l}330 \\
325 \\
300 \\
270 \\
250\end{array}$ & $\begin{array}{l}234 \\
232 \\
227 \\
226 \\
236\end{array}$ & $\begin{array}{l}205 \\
208 \\
204 \\
202 \\
202\end{array}$ & $\begin{array}{l}298 \\
281 \\
264 \\
257 \\
250\end{array}$ & $\begin{array}{l}232 \\
249 \\
262 \\
258 \\
207\end{array}$ & $\begin{array}{l}119 \\
118 \\
117 \\
116 \\
129\end{array}$ & $\begin{array}{l}155 \\
147 \\
141 \\
133 \\
122\end{array}$ & $\begin{array}{l}125 \\
134 \\
130 \\
121 \\
108\end{array}$ & $\begin{array}{r}98 \\
100 \\
99 \\
97 \\
95\end{array}$ & $\begin{array}{l}116 \\
121 \\
120 \\
114 \\
110\end{array}$ \\
\hline $\begin{array}{l}16 \\
17 \\
18 \\
19 \\
20\end{array}$ & $\begin{array}{l}356 \\
343 \\
329 \\
316 \\
300\end{array}$ & $\begin{array}{l}260 \\
240 \\
230 \\
220 \\
210\end{array}$ & $\begin{array}{l}220 \\
220 \\
240 \\
250 \\
260\end{array}$ & $\begin{array}{l}243 \\
244 \\
246 \\
249 \\
253\end{array}$ & $\begin{array}{l}210 \\
190 \\
191 \\
185 \\
181\end{array}$ & $\begin{array}{l}245 \\
242 \\
238 \\
232 \\
226\end{array}$ & $\begin{array}{l}198 \\
202 \\
205 \\
178 \\
172\end{array}$ & $\begin{array}{l}129 \\
129 \\
133 \\
141 \\
146\end{array}$ & $\begin{array}{r}111 \\
99 \\
88 \\
79 \\
74\end{array}$ & $\begin{array}{r}103 \\
99 \\
91 \\
85 \\
80\end{array}$ & $\begin{array}{l}93 \\
93 \\
94 \\
94 \\
92\end{array}$ & $\begin{array}{l}112 \\
119 \\
129 \\
136 \\
137\end{array}$ \\
\hline $\begin{array}{l}21 \\
22 \\
23 \\
24 \\
25\end{array}$ & $\begin{array}{l}290 \\
280 \\
270 \\
260 \\
260\end{array}$ & $\begin{array}{l}210 \\
210 \\
220 \\
230 \\
245\end{array}$ & $\begin{array}{l}250 \\
250 \\
250 \\
250 \\
250\end{array}$ & $\begin{array}{l}248 \\
244 \\
239 \\
230 \\
225\end{array}$ & $\begin{array}{l}179 \\
178 \\
180 \\
182 \\
186\end{array}$ & $\begin{array}{l}219 \\
215 \\
212 \\
210 \\
211\end{array}$ & $\begin{array}{l}179 \\
184 \\
191 \\
194 \\
187\end{array}$ & $\begin{array}{l}148 \\
142 \\
137 \\
138 \\
143\end{array}$ & $\begin{array}{r}73 \\
96 \\
127 \\
149 \\
160\end{array}$ & $\begin{array}{l}83 \\
87 \\
84 \\
77 \\
79\end{array}$ & $\begin{array}{r}90 \\
111 \\
138 \\
144 \\
138\end{array}$ & $\begin{array}{l}141 \\
143 \\
139 \\
131 \\
122\end{array}$ \\
\hline $\begin{array}{l}26 \\
27 \\
28 \\
29 \\
30 \\
31\end{array}$ & $\begin{array}{l}270 \\
280 \\
290 \\
290 \\
280 \\
270\end{array}$ & $\begin{array}{l}255 \\
250 \\
245 \\
250 \\
260 \\
---\end{array}$ & $\begin{array}{l}245 \\
245 \\
240 \\
235 \\
230 \\
230\end{array}$ & $\begin{array}{l}220 \\
215 \\
215 \\
220 \\
220 \\
220\end{array}$ & $\begin{array}{l}190 \\
193 \\
198 \\
--- \\
---\end{array}$ & $\begin{array}{l}215 \\
218 \\
208 \\
204 \\
220 \\
208\end{array}$ & $\begin{array}{l}176 \\
166 \\
162 \\
157 \\
155 \\
---\end{array}$ & $\begin{array}{l}146 \\
150 \\
151 \\
150 \\
148 \\
153\end{array}$ & $\begin{array}{r}156 \\
138 \\
119 \\
103 \\
98 \\
-\end{array}$ & $\begin{array}{r}94 \\
103 \\
102 \\
97 \\
91 \\
89\end{array}$ & $\begin{array}{l}142 \\
199 \\
244 \\
257 \\
249 \\
241\end{array}$ & $\begin{array}{l}115 \\
111 \\
107 \\
104 \\
103 \\
\end{array}$ \\
\hline $\begin{array}{l}\text { TOTAL } \\
\text { MEAN } \\
\text { MAX } \\
\text { MIN } \\
\text { CFSM } \\
\text { IN. }\end{array}$ & $\begin{array}{r}11811 \\
381 \\
543 \\
260 \\
1.24 \\
1.43\end{array}$ & $\begin{array}{r}8395 \\
280 \\
360 \\
210 \\
.91 \\
1.01\end{array}$ & $\begin{array}{r}8135 \\
262 \\
330 \\
220 \\
.85 \\
.98\end{array}$ & $\begin{array}{r}7201 \\
232 \\
253 \\
215 \\
.75 \\
.87\end{array}$ & $\begin{array}{r}5625 \\
201 \\
220 \\
178 \\
.65 \\
.68\end{array}$ & $\begin{array}{r}7866 \\
254 \\
323 \\
204 \\
.83 \\
.95\end{array}$ & $\begin{array}{r}6189 \\
206 \\
262 \\
155 \\
.67 \\
.75\end{array}$ & $\begin{array}{r}4109 \\
133 \\
153 \\
112 \\
.43 \\
.50\end{array}$ & $\begin{array}{r}4124 \\
137 \\
197 \\
73 \\
.45 \\
.50\end{array}$ & $\begin{array}{r}3000 \\
96.8 \\
134 \\
77 \\
.31 \\
.36\end{array}$ & $\begin{array}{r}3904 \\
126 \\
257 \\
82 \\
.41 \\
.47\end{array}$ & $\begin{array}{r}4142 \\
138 \\
251 \\
103 \\
.45 \\
.50\end{array}$ \\
\hline
\end{tabular}

$\begin{array}{lllllllllll}\text { CAL YR } 1986 & \text { TOTAL } & 97777 & \text { MEAN } 268 & \text { MAX } 729 & \text { MIN } 88 & \text { CFSM } & .87 & \text { IN } 11.81\end{array}$ 
LOCATION. - Lat $42^{\circ} 20^{\prime} 01^{\prime \prime}$, long $83^{\circ} 48^{\prime} 34^{\prime \prime}$, in SEl/4 sec.2, T. 2 S., R. 5 E. , Washtenaw County, Hydrologic

Unit 04090005 , at bridge on East Delhi Road, $5.0 \mathrm{mi}$ northwest' of Ann Arbor, $5.2 \mathrm{mi}$ downstream from Mill

Creek, $5.1 \mathrm{mi}$ upstream from Barton Dam, and $60.0 \mathrm{mi}$ upstream from mouth.

DRAINAGE AREA. $--699 \mathrm{mi}^{2}$.

PERIOD OF RECORD.--Water years 1971-81, 1983 to current year.

WATER QUALITY DATA, WATER YEAR OCTOBER 1986 TO SEPTEMBER 1987

\begin{tabular}{|c|c|c|c|c|c|c|c|c|c|c|c|}
\hline DATE & TIME & $\begin{array}{c}\text { SPE- } \\
\text { CIFIC } \\
\text { CON- } \\
\text { DUCT- } \\
\text { ANCE } \\
\text { LAB } \\
\text { (US/CM) }\end{array}$ & $\begin{array}{c}\text { PH } \\
\text { LAB } \\
\text { ( STAND- } \\
\text { ARD } \\
\text { UNITS ) }\end{array}$ & $\begin{array}{l}\text { TEMPER- } \\
\text { ATURE } \\
\text { (DEG C) }\end{array}$ & $\begin{array}{l}\text { CARBON, } \\
\text { ORGANIC } \\
\text { TOTAL } \\
\text { (MG/L } \\
\text { AS C) }\end{array}$ & $\begin{array}{l}\text { PER- } \\
\text { THANE } \\
\text { TOTAL } \\
\text { (UG/L) }\end{array}$ & $\begin{array}{l}\text { NAPH- } \\
\text { THA- } \\
\text { LENES, } \\
\text { POLY- } \\
\text { CHLOR. } \\
\text { TOTAL } \\
\text { (UG/L) }\end{array}$ & $\begin{array}{l}\text { PCB, } \\
\text { TOTALL } \\
\text { (UG/L) }\end{array}$ & $\begin{array}{c}\text { ALDRIN, } \\
\text { TOTAL } \\
\text { (UG/L) }\end{array}$ & $\begin{array}{l}\text { CHLOR- } \\
\text { DANE, } \\
\text { TOTAL } \\
\text { (UG/L) }\end{array}$ & $\begin{array}{l}\text { DDD, } \\
\text { TOTAL } \\
\text { (UG/L) }\end{array}$ \\
\hline . & 1000 & 604 & -- & 2.5 & 8.2 & $<0.1$ & $<0.1$ & $<0.1$ & $<0.01$ & $<0.1$ & $<0.01$ \\
\hline . & 1000 & 670 & 7.70 & 0.0 & 6.4 & $<0.1$ & $<0.1$ & $<0.1$ & $<0.01$ & $<0.1$ & $<0.01$ \\
\hline$\cdots$ & 0930 & 622 & 7.50 & 5.5 & 7.8 & $<0.1$ & $<0.1$ & $<0.1$ & $<0.01$ & $<0.1$ & $<0.01$ \\
\hline & 1500 & 680 & 8.20 & 19.5 & 4.5 & $<0.1$ & $<0.1$ & $<0.1$ & $<0.01$ & $<0.1$ & $<0.01$ \\
\hline . & 1100 & 630 & 8.40 & 26.5 & 6.6 & $<0.1$ & $<0.1$ & $<0.1$ & $<0.01$ & $<0.1$ & $<0.01$ \\
\hline ... & 0850 & 659 & 8.20 & 19.0 & 7.3 & $<0.1$ & $<0.1$ & $<0.1$ & $<0.01$ & $<0.1$ & $<0.01$ \\
\hline
\end{tabular}

\begin{tabular}{|c|c|c|c|c|c|c|c|c|c|c|c|}
\hline DATE & $\begin{array}{c}\text { DDE, } \\
\text { TOTAL } \\
\text { (UG/L ) }\end{array}$ & $\begin{array}{l}\text { DDT, } \\
\text { TOTAL } \\
\text { (UG/L) }\end{array}$ & $\begin{array}{c}\text { DI- } \\
\text { AZINON, } \\
\text { TOTAL } \\
\text { (UG/L) }\end{array}$ & $\begin{array}{l}\text { DI- } \\
\text { ELDR IN } \\
\text { TOTAL } \\
\text { (UG/L) }\end{array}$ & $\begin{array}{l}\text { ENDO- } \\
\text { SULFAN, } \\
\text { TOTAL } \\
\text { (UG/L) }\end{array}$ & $\begin{array}{c}\text { ENDR IN, } \\
\text { TOTAL } \\
\text { (UG/L) }\end{array}$ & $\begin{array}{l}\text { ETHION, } \\
\text { TOTAL } \\
\text { (UG/L) }\end{array}$ & $\begin{array}{l}\text { HEPTA- } \\
\text { CHLOR, } \\
\text { TOTAL } \\
\text { (UG/L) }\end{array}$ & $\begin{array}{l}\text { HEPTA- } \\
\text { CHLOR } \\
\text { EPOXIDE } \\
\text { TOTAL } \\
\text { (UG/L) }\end{array}$ & $\begin{array}{l}\text { LINDANE } \\
\text { TOTAL } \\
\text { (UG/L) }\end{array}$ & $\begin{array}{l}\text { MALA- } \\
\text { THION, } \\
\text { TOTAL, } \\
\text { (UG/L) }\end{array}$ \\
\hline & & & & & & & & & & & \\
\hline $09 \ldots$ & $<0.01$ & $<0.01$ & $<0.01$ & $<0.01$ & $<0.01$ & $<0.01$ & $<0.01$ & $<0.01$ & $<0.01$ & $<0.01$ & $<0.01$ \\
\hline $30 \ldots$ & $<0.01$ & $<0.01$ & $<0.01$ & $<0.01$ & $<0.01$ & $<0.01$ & $<0.01$ & $<0.01$ & $<0.01$ & $<0.01$ & $<0.01$ \\
\hline $23 \ldots$ & $<0.01$ & $<0.01$ & $<0.01$ & $<0.01$ & $<0.01$ & $<0.01$ & $<0.01$ & $<0.01$ & $<0.01$ & $<0.01$ & $<0.01$ \\
\hline $13 \ldots$ & $<0.01$ & $<0.01$ & $<0.01$ & $<0.01$ & $<0.01$ & $<0.01$ & $<0.01$ & $<0.01$ & $<0.01$ & $<0.01$ & $<0.01$ \\
\hline $31 \ldots$ & $<0.01$ & $<0.01$ & $<0.01$ & $<0.01$ & $<0.01$ & $<0.01$ & $<0.01$ & $<0.01$ & $<0.01$ & $<0.01$ & $<0.01$ \\
\hline $14 \ldots$ & $<0.01$ & $<0.01$ & $<0.01$ & $<0.01$ & $<0.01$ & $<0.01$ & $<0.01$ & $<0.01$ & $<0.01$ & $<0.01$ & $<0.01$ \\
\hline DATE & $\begin{array}{l}\text { METH- } \\
\text { OXY- } \\
\text { CHLOR, } \\
\text { TOTAL } \\
\text { (UG/L) }\end{array}$ & $\begin{array}{l}\text { METHYL } \\
\text { PARA- } \\
\text { THION, } \\
\text { TOTAL } \\
\text { (UG/L) }\end{array}$ & $\begin{array}{l}\text { METHYL } \\
\text { TRI- } \\
\text { THION, } \\
\text { TOTAL } \\
\text { (UG/L) }\end{array}$ & $\begin{array}{l}\text { MIREX, } \\
\text { TOTAL } \\
\text { (UG/L) }\end{array}$ & $\begin{array}{l}\text { PARA- } \\
\text { THION, } \\
\text { TOTAL } \\
\text { (UG/L) }\end{array}$ & $\begin{array}{l}\text { TOX- } \\
\text { APHENE, } \\
\text { TOTAL } \\
\text { (UG/L) }\end{array}$ & $\begin{array}{l}\text { TOTAL } \\
\text { TRI- } \\
\text { THION } \\
\text { (UG/L) }\end{array}$ & $\begin{array}{l}\text { 2, 4-D, } \\
\text { TOTAL } \\
\text { (UG/L) }\end{array}$ & $\begin{array}{l}2, \quad 4-D P \\
\text { TOTAL } \\
\text { (UG/L) }\end{array}$ & $\begin{array}{c}2,4,5-\mathrm{T} \\
\text { TOTAL } \\
\text { (UG/L) }\end{array}$ & $\begin{array}{c}\text { SILVEX, } \\
\text { TOTAL } \\
\text { (UG/L) }\end{array}$ \\
\hline $\begin{array}{l}\text { DEC } \\
09 . . .\end{array}$ & $<0.01$ & $<0.01$ & $<0.01$ & $<0.01$ & $<0.01$ & $<1$ & $<0.01$ & 0.03 & $<0.01$ & $<0.01$ & $<0.01$ \\
\hline $30 \ldots$ & $<0.01$ & $<0.01$ & $<0.01$ & $<0.01$ & $<0.01$ & $<1$ & $<0.01$ & 0.02 & $<0.01$ & $<0.01$ & $<0.01$ \\
\hline${ }_{M A Y}^{23} \cdots$ & $<0.01$ & $<0.01$ & $<0.01$ & $<0.01$ & $<0.01$ & $<1$ & $<0.01$ & 0.01 & $<0.01$ & $<0.01$ & $<0.01$ \\
\hline $13 \ldots$ & $<0.01$ & $<0.01$ & $<0.01$ & $<0.01$ & $<0.01$ & $<1$ & $<0.01$ & 0.04 & $<0.01$ & $<0.01$ & $<0.01$ \\
\hline $31 \ldots$ & $<0.01$ & $<0.01$ & $<0.01$ & $<0.01$ & $<0.01$ & $<1$ & $<0.01$ & $<0.01$ & $<0.01$ & $<0.01$ & $<0.01$ \\
\hline $14 \ldots$ & $<0.01$ & $<0.01$ & $<0.01$ & $<0.01$ & $<0.01$ & $<1$ & $<0.01$ & 0.06 & $<0.01$ & $<0.01$ & $<0.01$ \\
\hline
\end{tabular}


04174500 HURON RIVER AT ANN ARBOR, MI

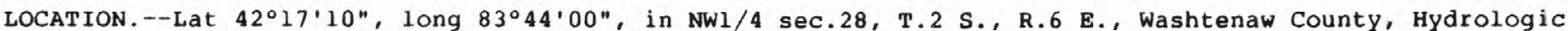
Unit 04090005 , on left bank $100 \mathrm{ft}$ upstream from bridge on wail Street in Ann Arbor, 0.7 mi downstream from Argo Dam, and $4.2 \mathrm{mi}$ upstream from Geddes Dam.

DRAINAGE AREA. $--729 \mathrm{mi}^{2}$.

PERIOD OF RECORD.--February 1904 to current year. Monthly discharge only for some periods, published in WSP 1307. Published as "at Geddes" February 1904 to December 1914 and as "at Barton" January 1914 to September 1940 .

REVISED RECORDS.--WSP 874: 1938, WSP 2112: Drainage area.

GAGE.--Water-stage recorder. Datum of gage is $744.81 \mathrm{ft}$ above National Geodetic Vertical Datum of 1929 (levels by Michigan Department of Natural Resources). February 1904 to December 1914 at Geddes Dam, $4.2 \mathrm{mi}$ downstream, and January 1914 to September 1947 at Barton Dam, $2.6 \mathrm{mi}$ upstream, flow computed from records of operation of powerplants and records of depth of flow over dam and/or flow through undersluices.

REMARKS.--No estimated daily discharges. Records good. Diversion upstream from station for Ann Arbor municipal supply had negligible effect on natural flow prior to 1955 , figures of runoff adjusted since. Flow regulated by powerplants prior to May 1962. From June 1962 to 1975 occasional regulation for lake level control operations upstream from station. Since 1975 extensive regulation of flow exists due to automation of gates at dams upstream from station. Several measurements of water temperature were made during the year.

AVERAGE DISCHARGE. --83 years, $459 \mathrm{ft}^{3} / \mathrm{s}, 8.55 \mathrm{in} / \mathrm{yr}^{\mathrm{r}}$ adjusted for diversion since 1955 .

EXTREMES FOR PERIOD OF RECORD.--Maximum daily discharge, 5,840 ft $3 / \mathrm{s}$, Mar. 14, 19l8; minimum daily, $4 \mathrm{ft}^{3} / \mathrm{s}$, Aug. 2, Sept. 11, 1931, plant leakage, but may be doubtful due to change in leakage.

EXTREMES FOR CURRENT YEAR.--Maximum discharge, 2,470 ft $3 / \mathrm{s}$, Oct. 4, gage height, $14.93 \mathrm{ft} ; \mathrm{minimum}$ daily, $72 \mathrm{ft}^{3} / \mathrm{s}$, Aug. is.

DISCHARGE, IN CUBIC FEET PER SECOND, WATER YEAR OCTOBER 1986 TO SEPTEMBER 1987

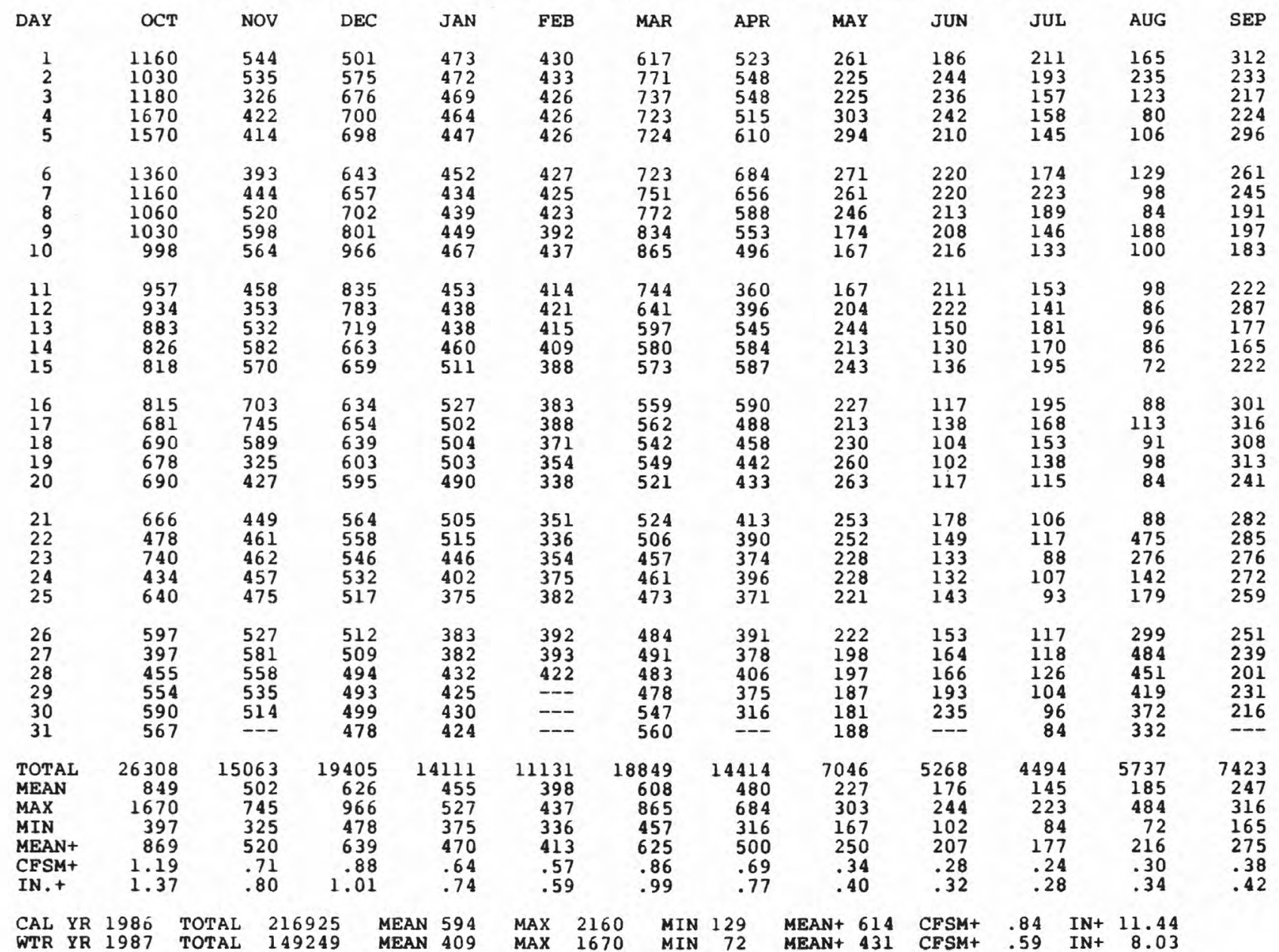

+ Adjusted for diversion for municipal supply; record furnished by City of Ann Arbor. 
LOCATION. - Lat $42^{\circ} 13^{\circ} 09^{\prime \prime}$, long $83^{\circ} 32^{\prime} 13^{\prime \prime}$, in SWl/4 sec.18, T.3 S., R. 8 E., Wayne County, Hydrologic Unit 04090005 , on $r i g h t$ bank $30 \mathrm{ft}$ upstream from culverts on North I-94 Service Road, $0.7 \mathrm{mi}$ upstream from mouth, and $0.8 \mathrm{mi}$ northeast of Rawsonville.

DRAINAGE AREA.--Indeterminate.

PERIOD OF RECORD.--April 1986 to current year (seasonal records only, April to September).

GAGE.--Water-stage recorder. Elevation of gage is $670 \mathrm{ft}$ above National Geodetic Vertical Datum of 1929 , from topographic map.

REMARKS.--No estimated daily discharges. Records good. Actual surface drainage area is 6.28 mi ${ }^{2}$. Flow contains effluent from sewage-treatment plant about 1 mi upstream from station. Some of this flow originates from ground-water sources and other sources outside the basin. Several measurements of water temperature were made during the year.

EXTREMES FOR PERIOD OF RECORD.--Maximum daily discharge during period April to September, 117 ft $3 / 5$, Aug. 22, 1987; minimum daily, $21 \mathrm{ft}^{3} / \mathrm{s}$, Aug. 31, Sept. 1, 18, 1986, July 5, 1987.

DISCHARGE, IN CUBIC FEET PER SECOND, WATER YEAR OCTOBER 1986 TO SEPTEMBER 1987 MEAN VALUES

\begin{tabular}{|c|c|c|c|c|c|c|c|c|c|c|c|c|}
\hline DAY & OCT & NOV & DEC & JAN & FEB & MAR & $\mathrm{APR}$ & MAY & JUN & JUL & AUG & SEP \\
\hline $\begin{array}{l}1 \\
2 \\
3 \\
4 \\
5\end{array}$ & & & & & & & $\begin{array}{l}42 \\
43 \\
39 \\
36 \\
56\end{array}$ & $\begin{array}{l}28 \\
30 \\
35 \\
34 \\
34\end{array}$ & $\begin{array}{l}28 \\
53 \\
34 \\
30 \\
27\end{array}$ & $\begin{array}{l}29 \\
26 \\
31 \\
25 \\
21\end{array}$ & $\begin{array}{l}46 \\
31 \\
30 \\
33 \\
29\end{array}$ & $\begin{array}{l}34 \\
33 \\
31 \\
31 \\
29\end{array}$ \\
\hline $\begin{array}{r}6 \\
7 \\
8 \\
9 \\
10\end{array}$ & & & & & & & $\begin{array}{l}47 \\
41 \\
36 \\
37 \\
40\end{array}$ & $\begin{array}{l}32 \\
31 \\
27 \\
25 \\
26\end{array}$ & $\begin{array}{l}29 \\
26 \\
28 \\
27 \\
24\end{array}$ & $\begin{array}{l}22 \\
23 \\
24 \\
28 \\
29\end{array}$ & $\begin{array}{l}28 \\
29 \\
29 \\
36 \\
27\end{array}$ & $\begin{array}{l}28 \\
27 \\
50 \\
37 \\
33\end{array}$ \\
\hline $\begin{array}{l}11 \\
12 \\
13 \\
14 \\
15\end{array}$ & & & & & & & $\begin{array}{l}38 \\
35 \\
33 \\
34 \\
35\end{array}$ & $\begin{array}{l}29 \\
31 \\
29 \\
34 \\
34\end{array}$ & $\begin{array}{l}25 \\
26 \\
26 \\
23 \\
24\end{array}$ & $\begin{array}{l}26 \\
26 \\
27 \\
28 \\
32\end{array}$ & $\begin{array}{l}29 \\
31 \\
30 \\
30 \\
29\end{array}$ & $\begin{array}{l}43 \\
33 \\
30 \\
32 \\
60\end{array}$ \\
\hline $\begin{array}{l}16 \\
17 \\
18 \\
19 \\
20\end{array}$ & & & & & & & $\begin{array}{l}37 \\
32 \\
31 \\
29 \\
30\end{array}$ & $\begin{array}{l}30 \\
27 \\
34 \\
37 \\
32\end{array}$ & $\begin{array}{l}25 \\
25 \\
23 \\
25 \\
25\end{array}$ & $\begin{array}{l}31 \\
28 \\
27 \\
24 \\
26\end{array}$ & $\begin{array}{l}30 \\
28 \\
30 \\
31 \\
32\end{array}$ & $\begin{array}{l}34 \\
39 \\
38 \\
32 \\
35\end{array}$ \\
\hline $\begin{array}{l}21 \\
22 \\
23 \\
24 \\
25\end{array}$ & & & & & & & $\begin{array}{l}30 \\
32 \\
29 \\
31 \\
31\end{array}$ & $\begin{array}{l}28 \\
32 \\
29 \\
24 \\
22\end{array}$ & $\begin{array}{l}57 \\
47 \\
28 \\
28 \\
25\end{array}$ & $\begin{array}{l}28 \\
71 \\
34 \\
34 \\
32\end{array}$ & $\begin{array}{r}31 \\
117 \\
40 \\
39 \\
37\end{array}$ & $\begin{array}{l}32 \\
33 \\
32 \\
31 \\
29\end{array}$ \\
\hline $\begin{array}{l}26 \\
27 \\
28 \\
29 \\
30 \\
31\end{array}$ & & & & & & & $\begin{array}{r}27 \\
30 \\
30 \\
29 \\
31 \\
-\end{array}$ & $\begin{array}{l}28 \\
29 \\
29 \\
29 \\
25 \\
26\end{array}$ & $\begin{array}{r}29 \\
24 \\
23 \\
37 \\
39 \\
- \\
\end{array}$ & $\begin{array}{l}31 \\
28 \\
29 \\
26 \\
30 \\
27\end{array}$ & $\begin{array}{l}84 \\
69 \\
46 \\
37 \\
33 \\
32\end{array}$ & $\begin{array}{l}29 \\
28 \\
29 \\
31 \\
31\end{array}$ \\
\hline $\begin{array}{l}\text { TOTAL } \\
\text { MEAN } \\
\text { MAX } \\
\text { MIN }\end{array}$ & & & & & & & $\begin{array}{r}1051 \\
35.0 \\
56 \\
27\end{array}$ & $\begin{array}{r}920 \\
29.7 \\
37 \\
22\end{array}$ & $\begin{array}{r}890 \\
29.7 \\
57 \\
23\end{array}$ & $\begin{array}{r}903 \\
29.1 \\
71 \\
21\end{array}$ & $\begin{array}{r}1183 \\
38.2 \\
117 \\
27\end{array}$ & $\begin{array}{r}1014 \\
33.8 \\
60 \\
27\end{array}$ \\
\hline
\end{tabular}


04175600 RIVER RAISIN NEAR MANCHESTER, MI

LOCATION. --Lat $42^{\circ} 10^{\prime} 05^{\prime \prime}$, long $84^{\circ} 04^{\prime} 34^{\prime \prime}$, in NEl/4 SEl/4 sec.33, T. 3 S.. R. 3 E.. Washtenaw County, Hydrologic Unit 04100002 , on left bank at downstream side of bridge on Sharón Valley Road, and 2.5 mi northwest of Manchester.

DRAINAGE AREA.--132 $\mathrm{mi}^{2}$.

PERIOD OF RECORD.--January 1970 to September 1981, January 1985 to current year.

GAGE.--Water-stage recorder. Elevation of gage is $900 \mathrm{ft}$ above National Geodetic Vertical Datum of 1929 , from topographic map. Prior to July 30, 1970, nonrecording gage at same site and datum.

REMARKS.--Estimated daily discharges: Dec. 14, 15, Jan. 20 to Feb. 21, and July 23 to Aug. 7 . Records good except for periods of estimated daily discharges, Dec. 14, 15, and Jan. 20 to Feb. 21 , which are caused by many dams upstream from station. Several measurements of water temperature were made during the year.

AVERAGE DISCHARGE.--13 years (water years 1971-81, 1986-87), $103 \mathrm{ft}^{3} / \mathrm{s}, 10.60 \mathrm{in} / \mathrm{yr}$.

EXTREMES FOR PERIOD OF RECORD,--Maximum discharge, $869 \mathrm{ft} / \mathrm{s}$, Feb. 24, 1985, gage height, $7.21 \mathrm{ft}$; minimum, $4.5 \mathrm{ft}^{3} / \mathrm{s}$, Nov. 29, 1971; minimum gage height, $1.16 \mathrm{ft}$, Oct. 12, Nov. 4, 1978.

EXTREMES FOR CURRENT YEAR.--Peak discharges greater than base discharge of $280 \mathrm{ft}{ }^{3} / \mathrm{s}$ and maximum (*):

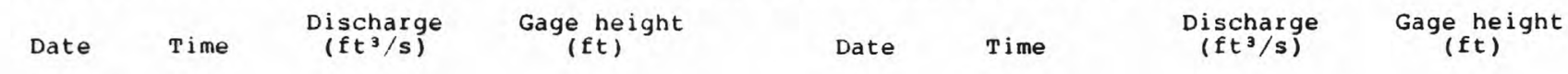

Oct. $41300 \quad \star 331 \quad \star 4.98 \quad$ No other peak greater than base discharge.

Minimum daily discharge, $6.6 \mathrm{ft}^{3} / \mathrm{s}$, Aug. 7 .

DISCHARGE, IN CUBIC FEET PER SECOND, WATER YEAR OCTOBER 1986 TO SEPTEMBER 1987 MEAN VALUES

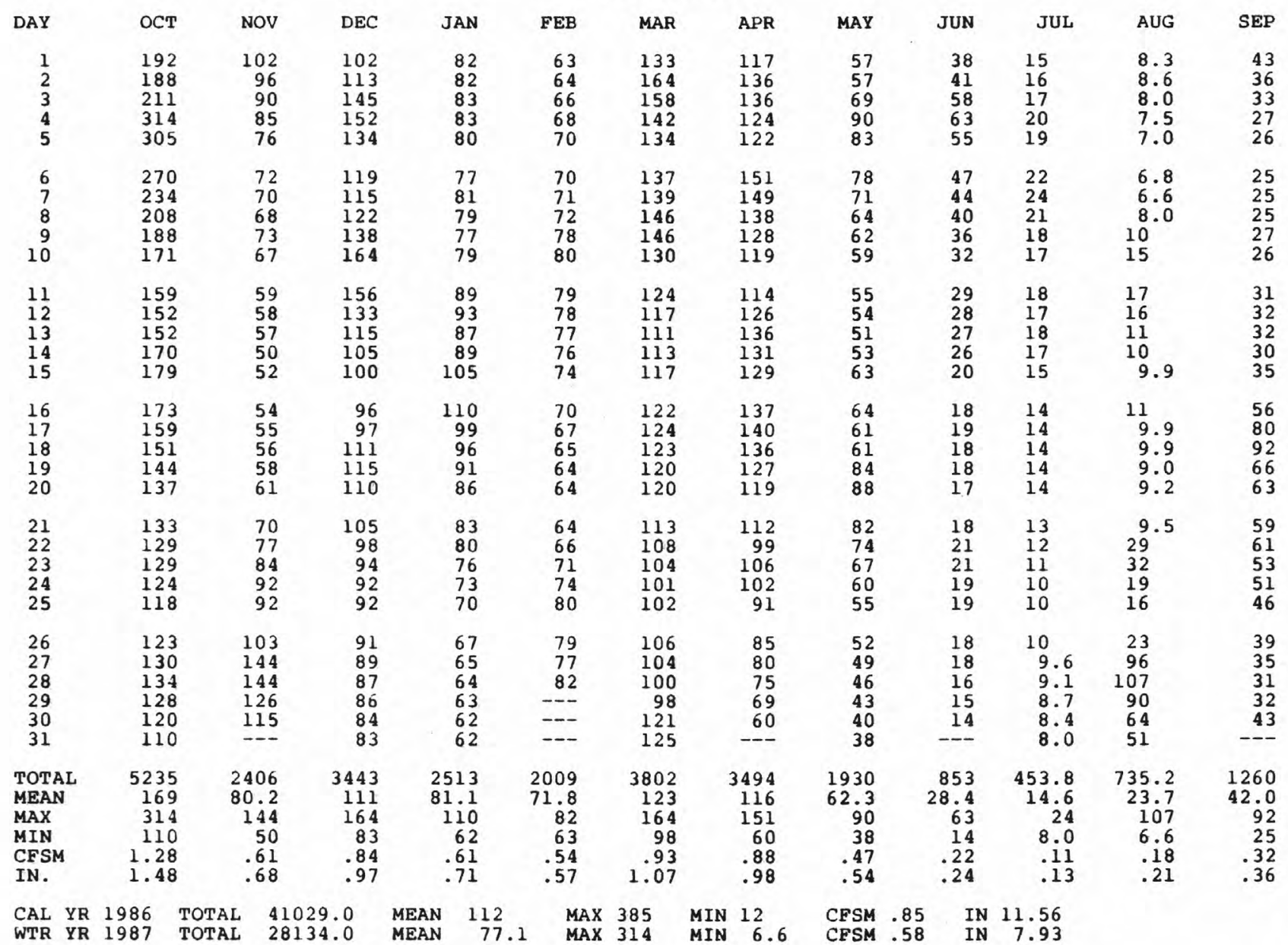




\section{RIVER RAISIN NEAR ADRIAN, MI}

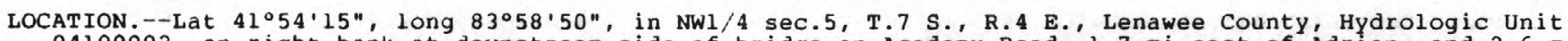
04100002 , on right bank at downstream side of bridge on Academy Road, $1.7 \mathrm{mi}$ east of Adrian, and $2.6 \mathrm{mi}$ downstream from South Branch.

DRAINAGE AREA. $--463 \mathrm{mi}^{2}$.

PERIOD OF RECORD.--October 1953 to September 1978 , October 1978 to September 1984 (operated as a crest-

stage partial-record station only), October 1984 to current year. Records for October 1930 to August

1931 and October 1932 to April 1938, published as "Rais in River" in WSP 714, 744, 759, 784, 804, 824,

and 854 , have been found to be unreliable and should not be used.

REVISED RECORDS.--WSP 2112: Drainage area.

GAGE.--Water-stage recorder. Datum of gage is $693.2 \mathrm{ft}$ above National Geodetic Vertical Datum of 1929.

REMARKS.--Estimated daily discharges: Dec. 14-16 and Jan. 19 to Feb. 21. Records good except for

estimated daily discharges, which are fair. Diurnal fiuctuation caused by powerplant at Tecumseh, 11

$\mathrm{mi}$ upstream from station, prior to June 27, 1968. Several measurements of water temperature were made

during the year. National Weather Service gage-height telemeter at station.

AVERAGE DISCHARGE.--28 years (water years 1954-78, 1985-87), $321 \mathrm{ft}^{3} / \mathrm{s}, 9.42 \mathrm{in} / \mathrm{yr}^{\mathrm{r}}$.

EXTREMES FOR PERIOD OF RECORD.--Maximum discharge, $6,660 \mathrm{ft}^{3} / \mathrm{s}$, Mar. 15, 1982, gage height, $15.77 \mathrm{ft}$;

minimum, $18 \mathrm{ft}^{3} / \mathrm{s}$, Aug. 10, 1964 , gage height, $1.33 \mathrm{ft}$; minimum daily, $25 \mathrm{ft} / \mathrm{s}, 0 c t .26,1965$.

EXTREMES FOR CURRENT YEAR.--Peak discharges greater than base discharge of $1,400 \mathrm{ft}^{3} / \mathrm{s}^{2}$ and maximum (*):

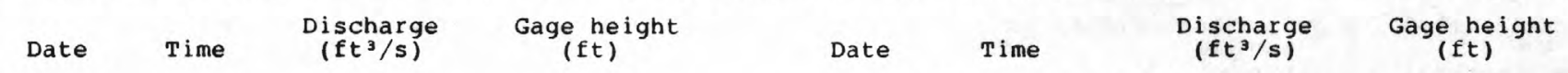

Oct. $52000 \star \star 1,510 \quad$ No other peak greater than base discharge.

Minimum discharge, $47 \mathrm{ft}^{3} / \mathrm{s}$, Aug. 20 , gage height, $2.12 \mathrm{ft}$.

DISCHARGE, IN CUBIC FEET PER SECOND, WATER YEAR OCTOBER 1986 TO SEPTEMBER 1987 MEAN VALUES

\begin{tabular}{|c|c|c|c|c|c|c|c|c|c|c|c|c|}
\hline DAY & OCT & NOV & DEC & JAN & FEB & MAR & APR & MAY & JUN & JUL & AUG & SEP \\
\hline $\begin{array}{l}1 \\
2 \\
3 \\
4 \\
5\end{array}$ & $\begin{array}{r}390 \\
510 \\
665 \\
1120 \\
1420\end{array}$ & $\begin{array}{l}291 \\
291 \\
277 \\
267 \\
266\end{array}$ & $\begin{array}{l}437 \\
465 \\
725 \\
881 \\
725\end{array}$ & $\begin{array}{l}283 \\
286 \\
288 \\
284 \\
278\end{array}$ & $\begin{array}{l}210 \\
215 \\
220 \\
230 \\
240\end{array}$ & $\begin{array}{r}725 \\
1090 \\
1130 \\
1060 \\
747\end{array}$ & $\begin{array}{l}449 \\
497 \\
561 \\
502 \\
491\end{array}$ & $\begin{array}{l}202 \\
211 \\
236 \\
249 \\
254\end{array}$ & $\begin{array}{l}116 \\
138 \\
388 \\
303 \\
242\end{array}$ & $\begin{array}{r}141 \\
140 \\
115 \\
100 \\
92\end{array}$ & $\begin{array}{l}67 \\
61 \\
59 \\
56 \\
53\end{array}$ & $\begin{array}{r}194 \\
163 \\
141 \\
126 \\
95\end{array}$ \\
\hline $\begin{array}{r}6 \\
7 \\
8 \\
9 \\
10\end{array}$ & $\begin{array}{r}1360 \\
1040 \\
743 \\
613 \\
553\end{array}$ & $\begin{array}{l}253 \\
244 \\
242 \\
238 \\
230\end{array}$ & $\begin{array}{r}542 \\
474 \\
482 \\
672 \\
1000\end{array}$ & $\begin{array}{l}273 \\
272 \\
271 \\
270 \\
279\end{array}$ & $\begin{array}{l}240 \\
235 \\
240 \\
250 \\
270\end{array}$ & $\begin{array}{l}617 \\
568 \\
546 \\
519 \\
473\end{array}$ & $\begin{array}{l}622 \\
702 \\
591 \\
497 \\
440\end{array}$ & $\begin{array}{l}243 \\
226 \\
210 \\
195 \\
185\end{array}$ & $\begin{array}{l}210 \\
188 \\
165 \\
149 \\
137\end{array}$ & $\begin{array}{l}96 \\
89 \\
86 \\
84 \\
79\end{array}$ & $\begin{array}{l}51 \\
50 \\
50 \\
60 \\
59\end{array}$ & $\begin{array}{r}98 \\
95 \\
94 \\
109 \\
106\end{array}$ \\
\hline $\begin{array}{l}11 \\
12 \\
13 \\
14 \\
15\end{array}$ & $\begin{array}{l}488 \\
428 \\
415 \\
486 \\
587\end{array}$ & $\begin{array}{l}228 \\
222 \\
214 \\
207 \\
206\end{array}$ & $\begin{array}{r}1080 \\
770 \\
514 \\
400 \\
380\end{array}$ & $\begin{array}{l}284 \\
277 \\
275 \\
278 \\
316\end{array}$ & $\begin{array}{l}280 \\
275 \\
270 \\
255 \\
240\end{array}$ & $\begin{array}{l}425 \\
388 \\
365 \\
368 \\
376\end{array}$ & $\begin{array}{l}407 \\
427 \\
459 \\
463 \\
406\end{array}$ & $\begin{array}{l}177 \\
181 \\
163 \\
162 \\
161\end{array}$ & $\begin{array}{l}126 \\
139 \\
128 \\
117 \\
106\end{array}$ & $\begin{array}{l}76 \\
73 \\
70 \\
69 \\
66\end{array}$ & $\begin{array}{l}57 \\
54 \\
54 \\
54 \\
57\end{array}$ & $\begin{array}{l}129 \\
165 \\
180 \\
142 \\
169\end{array}$ \\
\hline $\begin{array}{l}16 \\
17 \\
18 \\
19 \\
20\end{array}$ & $\begin{array}{l}574 \\
470 \\
418 \\
378 \\
350\end{array}$ & $\begin{array}{l}206 \\
208 \\
214 \\
223 \\
223\end{array}$ & $\begin{array}{l}365 \\
355 \\
377 \\
382 \\
378\end{array}$ & $\begin{array}{l}419 \\
416 \\
370 \\
330 \\
310\end{array}$ & $\begin{array}{l}235 \\
230 \\
220 \\
210 \\
210\end{array}$ & $\begin{array}{l}373 \\
382 \\
417 \\
470 \\
499\end{array}$ & $\begin{array}{l}395 \\
530 \\
490 \\
436 \\
395\end{array}$ & $\begin{array}{l}158 \\
159 \\
165 \\
181 \\
179\end{array}$ & $\begin{array}{r}88 \\
83 \\
81 \\
80 \\
110\end{array}$ & $\begin{array}{l}65 \\
65 \\
65 \\
63 \\
61\end{array}$ & $\begin{array}{l}55 \\
51 \\
52 \\
53 \\
51\end{array}$ & $\begin{array}{l}201 \\
226 \\
279 \\
267 \\
248\end{array}$ \\
\hline $\begin{array}{l}21 \\
22 \\
23 \\
24 \\
25\end{array}$ & $\begin{array}{l}331 \\
319 \\
307 \\
300 \\
297\end{array}$ & $\begin{array}{l}246 \\
247 \\
259 \\
287 \\
329\end{array}$ & $\begin{array}{l}358 \\
340 \\
376 \\
314 \\
276\end{array}$ & $\begin{array}{l}285 \\
270 \\
255 \\
240 \\
230\end{array}$ & $\begin{array}{l}210 \\
225 \\
243 \\
268 \\
304\end{array}$ & $\begin{array}{l}482 \\
424 \\
388 \\
362 \\
349\end{array}$ & $\begin{array}{l}346 \\
338 \\
333 \\
317 \\
288\end{array}$ & $\begin{array}{l}190 \\
194 \\
184 \\
171 \\
162\end{array}$ & $\begin{array}{l}144 \\
303 \\
335 \\
209 \\
144\end{array}$ & $\begin{array}{l}59 \\
57 \\
56 \\
54 \\
54\end{array}$ & $\begin{array}{r}52 \\
115 \\
98 \\
89 \\
80\end{array}$ & $\begin{array}{l}199 \\
188 \\
187 \\
173 \\
159\end{array}$ \\
\hline $\begin{array}{l}26 \\
27 \\
28 \\
29 \\
30 \\
31\end{array}$ & $\begin{array}{l}303 \\
309 \\
321 \\
323 \\
316 \\
304\end{array}$ & $\begin{array}{l}426 \\
712 \\
839 \\
669 \\
509\end{array}$ & $\begin{array}{l}293 \\
299 \\
297 \\
292 \\
290 \\
287\end{array}$ & $\begin{array}{l}225 \\
220 \\
215 \\
210 \\
205 \\
205\end{array}$ & $\begin{array}{r}330 \\
332 \\
341 \\
-- \\
--\end{array}$ & $\begin{array}{l}342 \\
339 \\
333 \\
324 \\
374 \\
445\end{array}$ & $\begin{array}{l}285 \\
272 \\
261 \\
250 \\
234\end{array}$ & $\begin{array}{l}157 \\
176 \\
158 \\
132 \\
101 \\
109\end{array}$ & $\begin{array}{r}116 \\
97 \\
84 \\
80 \\
109\end{array}$ & $\begin{array}{l}54 \\
51 \\
50 \\
50 \\
50 \\
52\end{array}$ & $\begin{array}{r}91 \\
578 \\
546 \\
446 \\
331 \\
254\end{array}$ & $\begin{array}{l}132 \\
123 \\
115 \\
116 \\
133\end{array}$ \\
\hline $\begin{array}{l}\text { TOTAL } \\
\text { MEAN } \\
\text { MAX } \\
\text { MIN } \\
\text { CFSM } \\
\text { IN. }\end{array}$ & $\begin{array}{r}16438 \\
530 \\
1420 \\
297 \\
1.15 \\
1.32\end{array}$ & $\begin{array}{r}9273 \\
309 \\
839 \\
206 \\
.67 \\
.75\end{array}$ & $\begin{array}{r}14826 \\
478 \\
1080 \\
276 \\
1.03 \\
1.19\end{array}$ & $\begin{array}{r}8619 \\
278 \\
419 \\
205 \\
.60 \\
.69\end{array}$ & $\begin{array}{r}7028 \\
251 \\
341 \\
210 \\
.54 \\
.56\end{array}$ & $\begin{array}{r}15700 \\
506 \\
1130 \\
324 \\
1.09 \\
1.26\end{array}$ & $\begin{array}{r}12684 \\
423 \\
702 \\
234 \\
.91 \\
1.02\end{array}$ & $\begin{array}{r}5631 \\
182 \\
254 \\
101 \\
.39 \\
.45\end{array}$ & $\begin{array}{r}4715 \\
157 \\
388 \\
80 \\
.34 \\
.38\end{array}$ & $\begin{array}{r}2282 \\
73.6 \\
141 \\
50 \\
.16 \\
.18\end{array}$ & $\begin{array}{r}3784 \\
122 \\
578 \\
50 \\
.26 \\
.30\end{array}$ & $\begin{array}{r}4752 \\
158 \\
279 \\
94 \\
.34 \\
.38\end{array}$ \\
\hline
\end{tabular}

$\begin{array}{llllllllllll}\text { CAL YR } & 1986 & \text { TOTAL } & 167867 & \text { MEAN 460 } & \text { MAX } & 3000 & \text { MIN } 69 & \text { CFSM } & .99 & \text { IN } 13.49 \\ \text { WTR YR } & 1987 & \text { TOTAL } & 105732 & \text { MEAN } 290 & \text { MAX } & 1420 & \text { MIN } 50 & \text { CFSM } & .63 & \text { IN } & 8.50\end{array}$ 
04176500 RIVER RAISIN NEAR MONROE, MI

(National stream quality accounting network station)

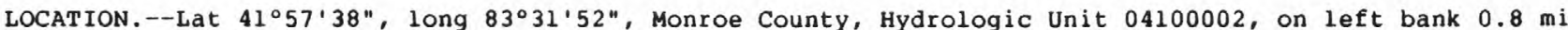
downstream from bridge on Ida Maybee Road, $5.0 \mathrm{mi}$ downstream from Saline River, and $7.5 \mathrm{mi}$ west of Monroe.

DRAINAGE AREA. $--1,042 \mathrm{mi}^{2}$.

\section{WATER-DISCHARGE RECORDS}

PERIOD OF RECORD.--September 1937 to current year. Published as "Raisin River at Monroe" $1937-52$ and as "River Raisin at Monroe" 1952-53.

REVISED RECORDS.--WSP 954: 1938-40(M), 1941. WSP 1437: 1939, 1948, WSP 2112: Drainage area.

GAGE.--Water-stage recorder. Datum of gage is $616.26 \mathrm{ft}$ above National Geodetic Vertical Datum of 1929. Prior to Oct. 1, 1953, at site $9 \mathrm{mi}$ downstream at datum $46.26 \mathrm{ft}$ lower.

REMARKS.--Estimated daily discharges: Dec. 13-15 and Jan. 19 to Feb. 21 . Water-discharge records good except for estimated daily discharges, which are fair. Diurnal fiuctuation caused by powerplants upstream from station prior to June $27,1968$.

AVERAGE DISCHARGE, -50 years, $729 \mathrm{ft}^{3} / \mathrm{s}, 9.50 \mathrm{in} / \mathrm{yr}$.

EXTREMES FOR PERIOD OF RECORD.--Maximum discharge, 15,300 $\mathrm{ft}^{3} / \mathrm{s}$, Mar. 16, 1982, gage height, 10.4 ft; maximum gage height, $11.16 \mathrm{ft}$, Mar. 15, 1982, backwater from ice; minimum discharge, about 2 ft 3 / Sept. 4, 1938, Sept. 19, 20, 1941, site then in use.

EXTREMES FOR CURRENT YEAR, --Peak discharges greater than base discharge of $3,500 \mathrm{ft}^{3} / \mathrm{s}^{\mathrm{and}}$ maximum (*):

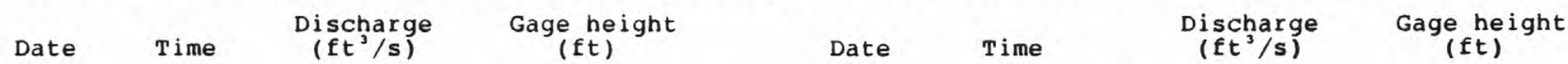
Oct. $41400 \quad \star 4,450 \quad$ No other peak greater than base discharge

Minimum discharge, $54 \mathrm{ft}^{3} / \mathrm{s}, \mathrm{July} 24$, gage height, $1.87 \mathrm{ft}$.

DISCHARGE, IN CUBIC FEET PER SECOND, WATER YEAR OCTOBER 1986 TO SEPTEMBER 1987 MEAN VALUES

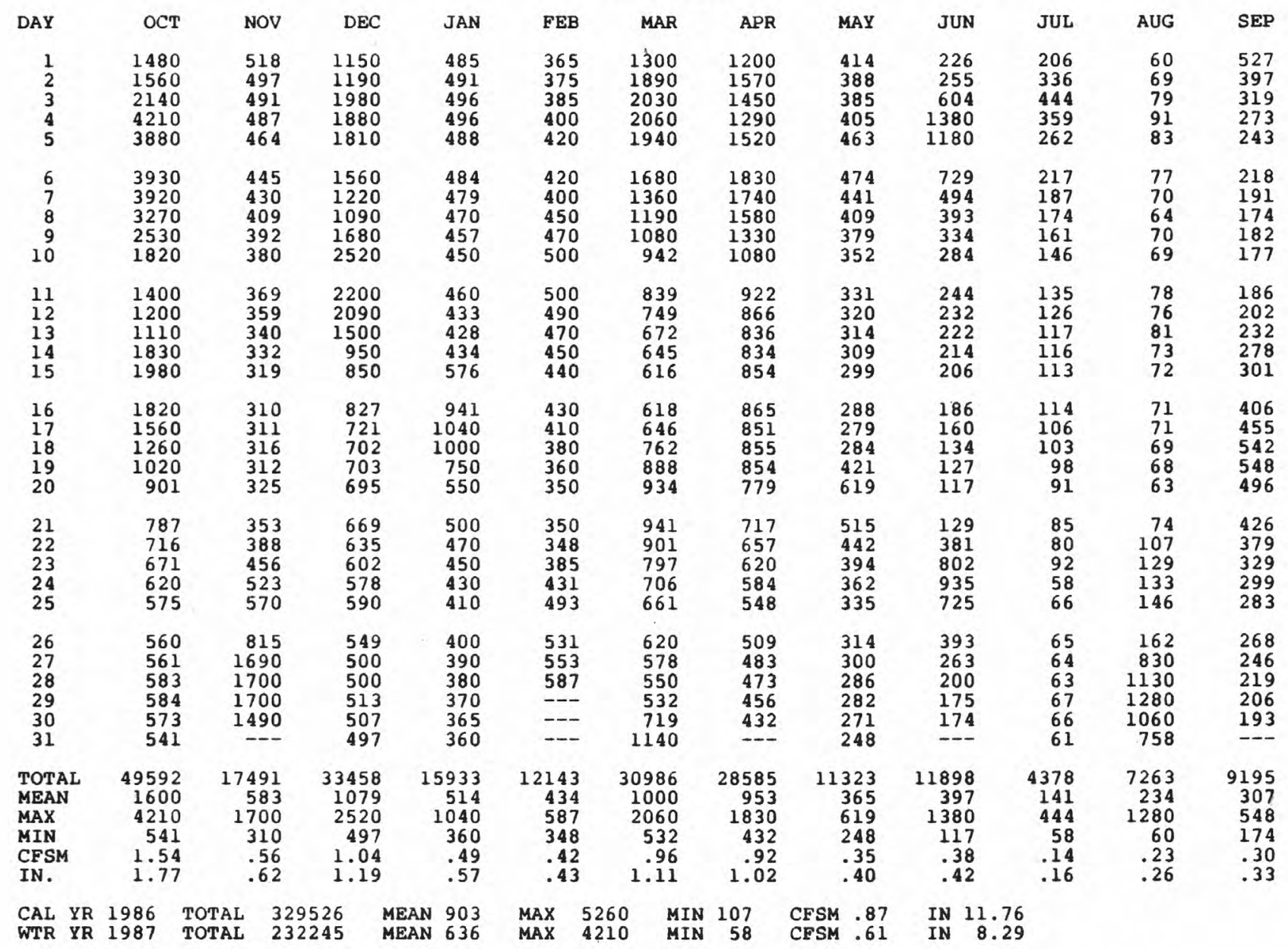


PERIOD OF RECORD.--Water years 1966-72, 1978 to current year.

PERIOD OF DAILY RECORD.--

SPECIFIC CONDUCTANCE: April 1978 to July 1981.

WATER TEMPERATURE: March 1966 to September 1972, April 1978 to July 1981.

SUSPENDED-SEDIMENT DISCHARGE: March 1966 to September 1972 .

INSTRUMENTATION.--Water-quality monitor from Mar. 23 to July 13, 1981.

REMARKS.--Quarterly cross-sectional samples were collected at gaging station, or 0.8 mi upstream from gage at bridge on Ida Maybee Road.

EXTREMES FOR PERIOD OF DAILY RECORD.--

SPECIFIC CONDUCTANCE (water years 1979-81): Maximum daily, 1,020 microsiemens, Feb. 16, 1979; minimum daily recorded (more than 20 percent missing record), 263 microsiemens, Jan. $25,1981$.

WATER TEMPERATURE (water years 1967, 1970-72, 1979-80): Maximum daily recorded (more than 20 percent missing record), $32.0^{\circ} \mathrm{C}$, July 18 , i972; minimum daily, $0.0^{\circ} \mathrm{C}$ on many days during winter.

SEDIMENT CONCENTRATION (water years 1967-72): Maximum daily mean, 1,430 mg/L, Dec. 22, 1967; minimum daily mean, $1 \mathrm{mg} / \mathrm{L}$ on several days in 1969 and 1970 .

SEDIMENT LOAD: Maximum daily, 28,000 tons, Dec. 22, 1967; minimum daily, 0.29 ton, Aug. 31 , 1971.

EXTREMES OUTSIDE PERIOD OF DAILY RECORD.--A specific conductance of 200 microsiemens was measured Feb. 25 , 1985 .

WATER QUALITY DATA, WATER YEAR OCTOBER 1986 TO SEPTEMBER 1987

\begin{tabular}{|c|c|c|c|c|c|c|c|c|c|c|}
\hline DATE & TIME & $\begin{array}{c}\text { DIS- } \\
\text { CHARGE, } \\
\text { IN } \\
\text { CUBIC } \\
\text { FEET } \\
\text { PER } \\
\text { SECOND }\end{array}$ & $\begin{array}{l}\text { SPE- } \\
\text { CIFIC } \\
\text { CON- } \\
\text { DUCT- } \\
\text { ANCE } \\
\text { (US/CM) }\end{array}$ & $\begin{array}{c}\text { PH } \\
\text { ( STAND- } \\
\text { ARD } \\
\text { UNITS) }\end{array}$ & $\begin{array}{l}\text { TEMPER- } \\
\text { ATURE } \\
\text { (DEG C) }\end{array}$ & $\begin{array}{l}\text { TUR- } \\
\text { BID- } \\
\text { ITY } \\
\text { ( NTU ) }\end{array}$ & $\begin{array}{c}\text { OXYGEN, } \\
\text { DIS- } \\
\text { SOLVED } \\
\text { (MG/L) }\end{array}$ & $\begin{array}{c}\text { OXYGEN, } \\
\text { DIS- } \\
\text { SOLVED } \\
\text { (PER- } \\
\text { CENT } \\
\text { SATUR- } \\
\text { ATION) }\end{array}$ & $\begin{array}{l}\text { COLI- } \\
\text { FORM, } \\
\text { FECAL, } \\
0.7 \\
\text { UM-MF } \\
\text { (COLS./ } \\
100 \mathrm{ML} \text { ) }\end{array}$ & $\begin{array}{c}\text { STREP- } \\
\text { TOCOCCI } \\
\text { FECAL, } \\
\text { KF AGAR } \\
\text { (COLS. } \\
\text { PER } \\
100 \mathrm{ML} \text { ) }\end{array}$ \\
\hline $\begin{array}{l}\mathrm{DEC} \\
09 . . . \\
\text { MAR }\end{array}$ & 1430 & 1760 & 671 & 7.9 & 4.0 & 27 & 12.4 & 98 & 680 & -- \\
\hline${ }_{\text {JUN }}^{23} \cdots$ & 1230 & 786 & 599 & 8.2 & 7.0 & 2.8 & 13.1 & 110 & $<7$ & E8 \\
\hline SEP $25 \ldots$ & 1030 & 758 & 505 & 7.8 & 24.0 & 53 & 7.3 & 90 & 420 & 840 \\
\hline $14 \ldots$ & 1230 & 279 & 779 & 8.1 & 22.0 & 9.0 & 11.5 & 134 & 220 & 260 \\
\hline DATE & $\begin{array}{l}\text { HARD- } \\
\text { NESS } \\
\text { (MG/L } \\
\text { AS } \\
\text { CACO3) }\end{array}$ & $\begin{array}{l}\text { HARD- } \\
\text { NESS } \\
\text { NONCARB } \\
\text { WH WAT } \\
\text { TOT FLD } \\
\text { MG/L AS } \\
\text { CACO3 }\end{array}$ & $\begin{array}{l}\text { CALCIUM } \\
\text { DIS- } \\
\text { SOLVED } \\
\text { (MG/L } \\
\text { AS CA) }\end{array}$ & $\begin{array}{l}\text { MAGNE- } \\
\text { SIUM, } \\
\text { DIS- } \\
\text { SOLVED } \\
\text { (MG/L } \\
\text { AS MG) }\end{array}$ & $\begin{array}{l}\text { SODIUM, } \\
\text { DIS- } \\
\text { SOLVED } \\
\text { (MG/L } \\
\text { AS NA) }\end{array}$ & $\begin{array}{l}\text { PERCENT } \\
\text { SODIUM }\end{array}$ & $\begin{array}{c}\text { SODIUM } \\
\text { AD- } \\
\text { SORP- } \\
\text { TION } \\
\text { RATIO }\end{array}$ & $\begin{array}{l}\text { POTAS- } \\
\text { SIUM, } \\
\text { DIS- } \\
\text { SOLVED } \\
\text { (MG/L } \\
\text { AS K) }\end{array}$ & $\begin{array}{l}\text { BICAR- } \\
\text { BONATE } \\
\text { WH WAT } \\
\text { TOTAL } \\
\text { FIELD } \\
\text { MG } / L \text { AS } \\
\text { HCO3 }\end{array}$ & $\begin{array}{l}\text { CAR- } \\
\text { BONATE } \\
\text { WH WAT } \\
\text { TOTAL } \\
\text { FIELD } \\
\text { MG/L AS } \\
\mathrm{CO} 3^{\text {CO }}\end{array}$ \\
\hline $\begin{array}{l}\mathrm{DEC} \\
09 . . .\end{array}$ & 330 & 120 & 97 & 20 & 12 & 7 & 0.3 & 6.9 & 260 & 0 \\
\hline $\begin{array}{l}\text { MAR } \\
23 \ldots \\
\text { JUN }\end{array}$ & 260 & 57 & 68 & 22 & 14 & 10 & 0.4 & 2.8 & 250 & 0 \\
\hline SEP $25 \ldots$ & 250 & 91 & 74 & 16 & 12 & 9 & 0.3 & 3.9 & 200 & 0 \\
\hline $14 \ldots$ & 340 & 140 & 96 & 23 & 31 & 16 & 0.8 & 12 & 240 & 0 \\
\hline DATE & $\begin{array}{l}\text { ALKA- } \\
\text { LINITY } \\
\text { WH WAT } \\
\text { TOTAL } \\
\text { FIELD } \\
\text { MG/L AS } \\
\text { CACO3 }\end{array}$ & $\begin{array}{c}\text { CARBON } \\
\text { DIOXIDE } \\
\text { DIS- } \\
\text { SOLVED } \\
\text { (MG/L } \\
\text { AS CO2) }\end{array}$ & $\begin{array}{l}\text { SULFATE } \\
\text { DIS- } \\
\text { SOLVED } \\
\text { (MG/L } \\
\text { AS SO4) }\end{array}$ & $\begin{array}{l}\text { CHLO- } \\
\text { RIDE, } \\
\text { DIS- } \\
\text { SOLVED } \\
\text { (MG/L } \\
\text { AS CL) }\end{array}$ & $\begin{array}{l}\text { FLUO- } \\
\text { RIDE, } \\
\text { DIS- } \\
\text { SOLVED } \\
\text { (MG/L } \\
\text { AS E) }\end{array}$ & $\begin{array}{l}\text { SILICA, } \\
\text { DIS- } \\
\text { SOLVED } \\
\text { (MG/L } \\
\text { AS } \\
\text { SIO2) }\end{array}$ & $\begin{array}{l}\text { SOLIDS, } \\
\text { RESIDUE } \\
\text { AT } 180 \\
\text { DEG. C } \\
\text { DIS- } \\
\text { SOLVED } \\
(\text { MG/L) }\end{array}$ & $\begin{array}{c}\text { SOLIDS, } \\
\text { SUM OF } \\
\text { CONSTI- } \\
\text { TUENTS, } \\
\text { DIS- } \\
\text { SOLVED } \\
\text { (MG/L) }\end{array}$ & $\begin{array}{c}\text { SOLIDS, } \\
\text { DIS- } \\
\text { SOLVED } \\
\text { (TONS } \\
\text { PER } \\
\text { AC-FT) }\end{array}$ & $\begin{array}{c}\text { SOLIDS, } \\
\text { DIS- } \\
\text { SOLVED } \\
\text { (TONS } \\
\text { PER } \\
\text { DAY) }\end{array}$ \\
\hline $\begin{array}{c}\text { DEC } \\
09 \ldots \\
\text { PAR } \ldots\end{array}$ & 210 & 5.1 & 77 & 48 & 0.2 & 7.8 & 422 & 420 & 0.57 & 2010 \\
\hline $\begin{array}{l}\text { MAR } \\
23 \ldots \\
\text { JUN }\end{array}$ & 204 & 2.5 & 69 & 38 & 0.2 & 2.9 & 395 & 340 & 0.54 & 838 \\
\hline $\operatorname{SEP}^{25 \ldots}$ & 160 & 4.9 & 47 & 29 & 0.2 & 10 & 325 & 290 & 0.44 & 665 \\
\hline $14 \ldots$ & 194 & 3.0 & 110 & 52 & 0.3 & 8.4 & 478 & 450 & 0.65 & 360 \\
\hline
\end{tabular}


04176500 RIVER RAISIN NEAR MONROE, MI--Continued

WATER QUALITY DATA, WATER YEAR OCTOBER 1986 TO SEPTEMBER 1987

\begin{tabular}{|c|c|c|c|c|c|c|c|c|c|c|}
\hline DATE & $\begin{array}{c}\text { NITRO- } \\
\text { GEN, } \\
\text { NITRITE } \\
\text { DIS- } \\
\text { SOLVED } \\
\text { (MG/L } \\
\text { AS N) }\end{array}$ & $\begin{array}{l}\text { NITRO- } \\
\text { GEN, } \\
\text { NO2+NO3 } \\
\text { DIS- } \\
\text { SOLVED } \\
\text { (MG/L } \\
\text { AS N) }\end{array}$ & $\begin{array}{c}\text { NITRO- } \\
\text { GEN, } \\
\text { AMMONIA } \\
\text { TOTAL } \\
\text { (MG/L } \\
\text { AS N) }\end{array}$ & $\begin{array}{l}\text { NITRO- } \\
\text { GEN, } \\
\text { AMMONIA } \\
\text { DIS- } \\
\text { SOLVED } \\
\text { (MG/L } \\
\text { AS N) }\end{array}$ & $\begin{array}{c}\text { NITRO- } \\
\text { GEN, } \\
\text { ORGANIC } \\
\text { TOTAL } \\
\text { (MG/L } \\
\text { AS N) }\end{array}$ & $\begin{array}{l}\text { NITRO- } \\
\text { GEN, AM- } \\
\text { MONIA + } \\
\text { ORGANIC } \\
\text { TOTAL } \\
\text { (MG/L } \\
\text { AS N) }\end{array}$ & $\begin{array}{c}\text { PHOS- } \\
\text { PHORUS, } \\
\text { TOTAL } \\
\text { (MG/L } \\
\text { AS P) }\end{array}$ & $\begin{array}{c}\text { PHOS- } \\
\text { PHORUS, } \\
\text { DIS- } \\
\text { SOLVED } \\
\text { (MG/L } \\
\text { AS P) }\end{array}$ & $\begin{array}{l}\text { PHOS- } \\
\text { PHORUS, } \\
\text { ORTHO, } \\
\text { DIS- } \\
\text { SOLVED } \\
\text { (MG/L } \\
\text { AS P) }\end{array}$ & $\begin{array}{l}\text { ALUM- } \\
\text { INUM, } \\
\text { DIS- } \\
\text { SOLVED } \\
\text { (UG/L } \\
\text { AS AL) }\end{array}$ \\
\hline $\begin{array}{c}\mathrm{EC} \\
09 . .\end{array}$ & 0.03 & 5.00 & 0.20 & 0.17 & 1.6 & 1.8 & 0.06 & 0.03 & 0.03 & 10 \\
\hline $23 \ldots$ & 0.03 & 3.70 & 0.04 & 0.03 & 1.3 & 1.3 & 0.04 & 0.01 & $<0.01$ & $<10$ \\
\hline $25 \ldots$ & 0.21 & 9.00 & 0.13 & 0.14 & 1.9 & 2.0 & 0.21 & 0.08 & 0.06 & $<10$ \\
\hline $14 \ldots$ & 0.02 & 2.00 & 0.03 & 0.02 & 1.4 & 1.4 & 0.07 & 0.05 & 0.03 & $<10$ \\
\hline
\end{tabular}

DATE

$\begin{array}{cc}\text { ARSENIC } & \text { BARIUM, } \\ \text { DIS- } & \text { DIS- } \\ \text { SOLVED } & \text { SOLVED } \\ \text { (UG/L } & \text { (UG/L } \\ \text { AS AS) } & \text { AS BA) }\end{array}$

BERYL-

LIUM, CADMIUM

DIS-

SOLVED

ULV

(US BE)

DIS-

SOLVED

(UG/L)

AS CD)

DEC

09.

MAR $23 \ldots$

JUN $23 . \cdots$

25 ...

SEP $14 .$.

SELE- $\begin{array}{clc} & \text { MANGA- } & \\ & \text { NESE, } & \text { MERCURY } \\ & \text { DIS- } & \text { DIS- } \\ & \text { SOLVED } & \text { SOLVED } \\ \text { DATE } & \text { (UG/L } & \text { (UG/L } \\ & \text { AS MN) } & \text { AS HG) }\end{array}$

MOLYB-

DENUM,

DIS-

SOLVED

( UG / L

NICKEL
DIS-

DIS-

(UG/L

AS NI)

NIUM,

DIS-

SOLVED

(UG/L

AS SE)

SILVER,
DIS-
SOLVED

(UG/I)

AS AG)

STRON-

TIUM,

DIS-

SOLVED

(UG/L

AS SR)

VANA-

DIUM

DIS-

SOLVED

(UG/L

AS V)

ZINC

SUS-

AS $Z N$ ) (MG/L)

DEC
09.

MAR
$23 .$.

$19<0$.

$<10$

$<1$

1

$<1$

350

$<0.1<10$

$<1$

$<1$

180

$<6$

$<6$

3

58

25 ...

14

$<0.1$

$<10$

$<1$

$<1$

$<1$

260

600

$<6$

32

14 ...

$<0.1$

$<1$

$<1$

$<6$

SEDI- SED.

MENT, SUSP.

DIS- SIEVE

CHARGE, DIAM.

DATE SENDED THAN

$\begin{array}{ll}\text { (T/DAY) } & .062 \mathrm{MM}\end{array}$

DEC

$\begin{array}{lrl}\text { DEC } & & \\ 09 \ldots & 276 & 86 \\ \text { MAR } & & \\ 23 \ldots & 68 & 55 \\ \text { JUN } & & \\ 25 \ldots & 82 & 96 \\ \begin{array}{l}\text { SEP } \\ 14 \ldots\end{array} & 32 & 86\end{array}$


As the number of streans on which streamflow information is likely to be desired far exceeds the number of stream-gaging stations feasible to operate at one time, the Geological Survey collects limited streanflow data at sites other than stream-gaging stations. When limited streamflow data are collected on a systematic basis over a period of years for use in hydrologic analyses, the site at which the data are collected is called a partial-record station. Data collected at these partial-record stations are usable in lowflow or floodflow analyses, depending on the type of data collected. In addition, discharge measurements are ade at other sites not included in the partial-record program. These measurements are generally made in time of drought or flood to give better areal coverage to those events. Those measurements and others collected for some special reason are called easurements at iscellaneous sites.

Records collected at partial-record stations are presented in two tables. The first is a table of annual maximum stage and discharge at crest-stage partial-record stations and the second is a table of discharge measurewents at low-flow partial-record stations. Discharge measurements at miscellaneous sites are given in a third table.

\section{Crest-stage partial-record stations}

The following table contains annual maximum discharge for crest-stage stations. A crest-stage gage is a device which will register the peak stage occurring between inspections of the gage. A stage-discharge relation for each gage is developed from discharge measurements made by indirect measurements of peak flow or by current meter. The date of the maximum discharge is not always certain but is usually determined by comparison with nearby continuous-record stations, weather records, or local inquiry. Only the maximu discharge for each water year is given. Information on some lower floods may have been obtained but is not published herein. The years given in the period of record represent water years for which the annual maximu has been deterained.

Annual aximum discharge at crest-stage partial-record stations during water year 1987

\begin{tabular}{|c|c|c|c|c|c|c|c|}
\hline \multirow[b]{2}{*}{$\begin{array}{l}\text { Station } \\
\text { No. }\end{array}$} & \multirow[b]{2}{*}{ Station Name } & \multirow[b]{2}{*}{ Location } & \multirow[b]{2}{*}{$\begin{array}{l}\text { Drainage } \\
\text { area } \\
\left( \pm i^{2}\right)\end{array}$} & \multirow[b]{2}{*}{$\begin{array}{l}\text { Period } \\
\text { of } \\
\text { record }\end{array}$} & \multicolumn{3}{|c|}{ Annual Maximum } \\
\hline & & & & & Date & $\begin{array}{l}\text { Gage } \\
\text { height } \\
(\mathrm{ft})\end{array}$ & $\begin{array}{l}\text { Dis- } \\
\text { charge } \\
\left(\mathrm{ft}^{3} / \mathrm{s}\right)\end{array}$ \\
\hline & & STREAMS TRIBUTARY TO LAKE SUPERIOR & & & & & \\
\hline 04041000 & $\begin{array}{l}\text { Perch River near } \\
\text { Sidnaw, MI }\end{array}$ & $\begin{array}{l}\text { Lat } 46^{\circ} 31^{\prime} 06^{\prime \prime} \text {, long } 88^{\circ} 39^{\prime} 48^{\prime \prime} \text {, in NE } 1 / 4 \mathrm{sec} .34 \text {, } \\
\text { T. } 48 \text { N., R. R5 W., Baraga County, Hydrologic } \\
\text { Unit } 04020104 \text {, at State Highway } 28,2.5 \text { i } \\
\text { east of Sidnaw. }\end{array}$ & 63.1 & $\begin{array}{l}1913-15 \neq \\
1957-87\end{array}$ & $10-13-86$ & $a<8.70$ & $<242$ \\
\hline 04044200 & $\begin{array}{l}\text { Carp Creek at } \\
\text { Ishpewing, MI }\end{array}$ & $\begin{array}{l}\text { Lat } 46^{\circ} 29^{\prime} 11^{\prime \prime} \text {, long } 87.41^{\prime} 21^{\prime \prime} \text {, in NW1/4 sec.9, } \\
\text { T.47 N., R.27 W., Marquette County, Hydrologic } \\
\text { Unit } 04020105 \text {, at Highway } 41 \mathrm{~A} \text { in Ishpeming. }\end{array}$ & 16.5 & $1970-87$ & $10-12-86$ & $<5.90$ & b \\
\hline 04044813 & $\begin{array}{l}\text { Two Hearted River } \\
\text { near Paradise, } \\
\text { MI }\end{array}$ & $\begin{array}{l}\text { Lat } 46^{\circ} 41 \cdot 57^{\prime \prime} \text {, long } 85^{\circ} 25^{\prime} 19^{\prime \prime} \text {, in NW1/4 SWI/4 } \\
\text { sec. } 27 \text {, T.50 N., R.9 W., Luce County, Hydro- } \\
\text { logic Unit } 04020201 \text {, at footbridge in State } \\
\text { Forest Canground, } 0.4 \text { i upstrea from outh, } \\
\text { and } 18 \text { i northwest of Paradise. }\end{array}$ & 201 & $1973-87$ & $07-22-87$ & c5.96 & 908 \\
\hline 04045538 & $\begin{array}{l}\text { West Branch Waiska } \\
\text { River near } \\
\text { Brimley, MI }\end{array}$ & $\begin{array}{l}\text { Lat } 46^{\circ} 21^{\prime} 18^{\prime \prime} \text {, long } 84^{\circ} 35^{\prime} 35^{\prime \prime} \text {, in SWI/4 NWI/4 } \\
\text { sec.29, I. } 46 \text { N., R.2 W., Chippewa County, } \\
\text { Hydrologic Unit } 04020203 \text {, at county road, } 3.2 \\
\text { i upstrea from mouth, and } 3.5 \text { mi south of } \\
\text { Brimley. }\end{array}$ & 40.7 & $1973-87$ & $03-25-87$ & 5.87 & 239 \\
\hline 04045559 & $\begin{array}{l}\text { East Branch Waiska } \\
\text { River near } \\
\text { Brimley, MI }\end{array}$ & $\begin{array}{l}\text { Lat } 46^{\circ} 25^{\prime} 07^{\prime \prime} \text {, long } 84^{\circ} 28^{\prime} 24^{\prime \prime} \text {, in NWI/4 NE } 1 / 4 \\
\text { sec.6, T.46 } N . \text { R. } 1 \text { W., Chippewa County, Hydro- } \\
\text { logic Unit } 04020203 \text {, at county road, } 4.0 \text { i } \\
\text { upstream from mouth, and } 4.7 \text { east of Brim ley. } \\
\text { STREAMS IRIBUTARY TO LAKE MICHIGAN }\end{array}$ & 30.1 & $1973-87$ & $03-25-87$ & d 10.84 & e350 \\
\hline 04046000 & $\begin{array}{l}\text { Black River near } \\
\text { Garnet, MI }\end{array}$ & $\begin{array}{l}\text { Lat } 46^{\circ} 07^{\prime} 05^{\prime \prime} \text {, long } 85^{\circ} 21^{\prime} 55^{\prime \prime} \text {, in SEI/4 sec. } 13 \text {, } \\
\text { I. } 43 \text { N., R.9 W., Mackinac County, Hydrologic } \\
\text { Unit } 04060107 \text {, on right bank } 10 \mathrm{ft} \text { upstream from } \\
\text { footbridge, i5 ft downstream from Peters Creek, } \\
3.5 \text { i upstrean from Lake Michigan, and } 4 \mathrm{i} \\
\text { southwest of Garnet. }\end{array}$ & $f 28$ & $\begin{array}{l}1951-78 \downarrow \\
1979-87\end{array}$ & $10-13-86$ & 3.70 & 97.8 \\
\hline 04057900 & $\begin{array}{c}\text { Black River near } \\
\text { Republic, MI }\end{array}$ & $\begin{array}{l}\text { Lat } 42^{\circ} 25^{\prime} 08^{\prime \prime} \text {, long } 87^{\circ} 53^{\prime} 21^{\prime \prime} \text {, in NE } 1 / 4 \mathrm{sec} .2 \text {, } \\
\text { T. } 46 \text { N., R. R. W. Warquette County, Hydro- } \\
\text { logic Unit } 04030110, \text { at county road, } 4.4 \text { i } \\
\text { east of Republic. }\end{array}$ & 34.4 & $\begin{array}{l}1961-68 \nmid \\
1970-87\end{array}$ & $10-13-86$ & b & el 40 \\
\hline 04059400 & $\begin{array}{l}\text { Tenmile Creek } \\
\text { at Perronville, } \\
\text { MI }\end{array}$ & $\begin{array}{l}\text { Lat } 45^{\circ} 48^{\prime} 38^{\prime \prime} \text {, long } 87^{\circ} 22^{\circ} 00^{\prime \prime} \text {, in NWI/4 NWI/4 } \\
\text { sec.2, T.39 N., R.25 W., Menominee County, } \\
\text { Hydrologic Unit } 04030109,1 \text { i northwest of }\end{array}$ & 38.4 & $\begin{array}{l}1971-77 \uparrow \\
1978-87\end{array}$ & $10-16-86$ & $<4.07$ & $<234$ \\
\hline
\end{tabular}

See footnotes at end of table.

Perronville. 


\begin{tabular}{|c|c|c|c|c|c|c|c|}
\hline \multirow[b]{2}{*}{$\begin{array}{l}\text { Station } \\
\text { No. }\end{array}$} & \multirow[b]{2}{*}{ Station Name } & \multirow[b]{2}{*}{ Location } & \multirow[b]{2}{*}{$\begin{array}{l}\text { Drainage } \\
\text { area } \\
(\mathbf{m i 2})\end{array}$} & \multirow[b]{2}{*}{$\begin{array}{l}\text { Period } \\
\text { of } \\
\text { record }\end{array}$} & \multicolumn{3}{|c|}{ Annual Maximum } \\
\hline & & & & & Date & $\begin{array}{l}\text { Gage } \\
\text { height } \\
(\mathrm{ft})\end{array}$ & $\begin{array}{l}\text { Dis- } \\
\text { charge } \\
\left(\mathrm{ft}^{3} / \mathrm{s}\right)\end{array}$ \\
\hline \multicolumn{8}{|c|}{ SIREAMS TRI BUTARY TO LAKE MICHIGAN--Cont inued } \\
\hline 04062300 & $\begin{array}{l}\text { Michigamae River } \\
\text { at Republic, MI }\end{array}$ & $\begin{array}{l}\text { Lat } 46^{\circ} 23^{\prime} 03^{\prime \prime} \text {, long } 87^{\circ} 58^{\prime} 48^{\prime \prime} \text {, in } \mathrm{SE} 1 / 4 \mathrm{sec} .18 \text {, } \\
\text { T.46 N., R.29 W., Marquette County, Hydrologic } \\
\text { Unit } 04030107 \text {, on left bank } 400 \mathrm{ft} \text { upstream } \\
\text { from county highway, } 0.3 \text { ipstream from Trout } \\
\text { Falls Creek, and } 0.6 \text { i south of Republic. }\end{array}$ & 240 & $\begin{array}{l}1961-75 \uparrow \\
1976-87\end{array}$ & $10-13-86$ & $b$ & e810 \\
\hline 04096272 & $\begin{array}{c}\text { Beebe Creek near } \\
\text { Hillsdale, MI }\end{array}$ & $\begin{array}{l}\text { Lat } 41^{\circ} 57^{\prime} 15^{\prime \prime} \text {, long } 84^{\circ} 38^{\prime} 20^{\prime \prime} \text {, in NE } 1 / 4 \mathrm{NE} 1 / 4 \\
\text { sec. } 15 \text {, T.6 S., R. } \mathrm{W}^{\circ} \text {., Hilisdale County, } \\
\text { Hydrologic Unit } 04050001 \text {, at Moore Road, } 1.2 \\
\text { mi northwest of Hillsdale. }\end{array}$ & 42.4 & $\begin{array}{l}1974-78 \mid \\
1979-87\end{array}$ & $10-04-86$ & 5.53 & 186 \\
\hline 04096340 & $\begin{array}{l}\text { St. Joseph River } \\
\text { at Clarendon, } \\
\text { MI }\end{array}$ & $\begin{array}{l}\text { Lat } 42.07 \cdot 51 " \text {, long } 84^{\circ} 51 \text { '56", in SWI/4 SWI/4 } \\
\text { sec.11, T.4 S., R.5 W., Calhoun County, } \\
\text { Hydrologic Unit } 04050001 \text {, at } 22 \text { Mile Road in } \\
\text { Clarendon. }\end{array}$ & 144 & $\begin{array}{l}1974-77 \dagger \\
1978-87\end{array}$ & $10-04-86$ & 6.70 & 440 \\
\hline 04097170 & $\begin{array}{l}\text { Portage River } \\
\text { near Vicksburg, } \\
\text { MI }\end{array}$ & $\begin{array}{l}\text { Lat } 42^{\circ} 06^{\prime} 53^{\prime \prime} \text {, long } 85^{\circ} 29^{\circ} 08^{\prime \prime} \text {, in SW1/4 sec. } 16 \text {, } \\
\text { T.4 S., R. } 10 \text { W., Kalanazoo County, Hydrologic } \\
\text { Unit } 04050001 \text {, at W Avenue, } 2.4 \text { i east of } \\
\text { Vicksburg. }\end{array}$ & 68.2 & $\begin{array}{l}1946-51 \neq \\
1965-80 \neq \\
1980-87\end{array}$ & $10-03-86$ & 5.17 & 240 \\
\hline 04108645 & $\begin{array}{l}\text { Rabbit River at } \\
\text { Hawilton, MI }\end{array}$ & 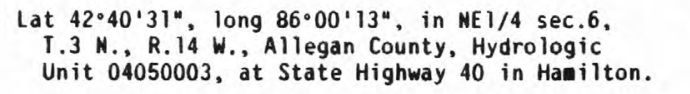 & 274 & $1979-87$ & $10-01-86$ & 14.57 & 1,660 \\
\hline 04112700 & $\begin{array}{l}\text { Sycamore Creek } \\
\text { near Mason, MI }\end{array}$ & $\begin{array}{l}\text { Lat } 42^{\circ} 36^{\prime} 38^{\prime \prime} \text {, long } 84^{\circ} 27^{\prime} 58^{\prime \prime} \text {, in NE } 1 / 4 \mathrm{NE} 1 / 4 \\
\text { sec. } 31 \text {, T.3 N., R. I W., Inghan County, } \\
\text { Hydrologic Unit } 04050004 \text {, at Harper Road, } \\
0.7 \mathrm{~m} \mathrm{downstrea} \text { from Aurel ius and Vevay Orain, } \\
\text { and } 2.6 \mathrm{mi} \text { northwest of Mason. }\end{array}$ & 39.5 & $1975-87$ & $10-03-86$ & 9.64 & $335^{\circ}$ \\
\hline 04113090 & $\begin{array}{l}\text { Carrier Creek } \\
\text { near Grand } \\
\text { Ledge, MI }\end{array}$ & $\begin{array}{l}\text { Lat } 42^{\circ} 43^{\prime} 36^{\prime \prime} \text {, long } 84^{\circ} 39^{\prime} 16^{\prime \prime} \text {, in SE } 1 / 4 \mathrm{SWI} / 4 \\
\text { Sec. } 15 \text {, T.4 N., R.3 W., Eaton County, } \\
\text { Hydrologic Unit } 04050004 \text {, at St. Joe Highway, } \\
3.7 \text { i upstrean from mouth, and } 4.0 \text { mi south- } \\
\text { east of Grand Ledge. }\end{array}$ & 7.18 & $1975-87$ & $10-03-86$ & 6.30 & 131 \\
\hline 04117000 & $\begin{array}{l}\text { Quaker Brook } \\
\text { near Nashville, } \\
\text { MI }\end{array}$ & $\begin{array}{l}\text { Lat } 42.33 \cdot 57 \text { ", long } 85.05137 \text { ", in NWI/4 sec. } \\
13, \mathrm{~T} .2 \mathrm{~N} \text {., R.7 W., Barry County, Hydro- } \\
\text { logic Unit } 04050007 \text {, on left bank } 150 \mathrm{ft} \text { up- } \\
\text { stream from culvert on county road, } 500 \mathrm{ft} \\
\text { upstream from small tributary, and } 2.5 \mathrm{mi} \text { south } \\
\text { of Nashville. }\end{array}$ & 7.60 & $\begin{array}{l}1954-75 \uparrow \\
1976-87\end{array}$ & $10-03-86$ & 3.83 & 107 \\
\hline 04119055 & $\begin{array}{l}\text { Plaster Creek at } \\
\text { Grand Rapids, MI }\end{array}$ & $\begin{array}{l}\text { Lat } 42^{\circ} 54^{\prime} 46^{\prime \prime}, \text { long } 85^{\circ} 39^{\prime} 02^{\prime \prime} \text {, in } \mathrm{SE} 1 / 4 \mathrm{sec} .7 \text {, } \\
\text { T.6 } \mathrm{N} ., \mathrm{R} .1 \mathrm{~W} \text {.. Kent County, Hydrologic Unit } \\
04050006 \text {, at 28th Street in Grand Rapids. }\end{array}$ & 46.6 & $1974-87$ & $10-02-86$ & 8.08 & 606 \\
\hline 04119160 & $\begin{array}{l}\text { Buck Creek at } \\
\text { Grandville, MI }\end{array}$ & $\begin{array}{l}\text { Lat } 42^{\circ} 54^{\prime} 09^{\prime \prime} \text {, long } 85^{\circ} 45^{\prime} 46^{\prime \prime} \text {, in SEl/4 sec. } 18 \text {, } \\
\text { T.6 N., R.12 W., Kent county, Hydrologic Unit } \\
04050006 \text {, at Wilson Avenue in Grandville. }\end{array}$ & 50.5 & $1974-87$ & $09-08-87$ & 8.32 & 714 \\
\hline$\star 04120295$ & $\begin{array}{l}\text { Black Creek near } \\
\text { Muskegon, MI }\end{array}$ & $\begin{array}{l}\text { Lat } 43^{\circ} 12^{\prime} 14^{4} \text {, long } 86^{\circ} 09^{\prime} 52^{4} \text {, in NE1/4 NWI/4 } \\
\text { sec. } 1 \text {, T.9 N., R. } 16 \mathrm{~W} \text {., Muskegon County, } \\
\text { Hydrologic Unit } 04060101, \text { at Mill Iron Road, } \\
4.8 \mathrm{mi} \text { east of Muskegon, and } 4.9 \mathrm{mi} \text { upstream from } \\
\text { mouth. }\end{array}$ & f39 & $\begin{array}{l}1975 \\
1977 \\
1979-87\end{array}$ & $10-04-86$ & 4.27 & 536 \\
\hline 04122230 & $\begin{array}{l}\text { North Branch } \\
\text { Pentwater River } \\
\text { near Pentwater, } \\
\text { MI }\end{array}$ & $\begin{array}{l}\text { Lat } 43^{\circ} 47^{\prime} 42^{\prime \prime} \text {, long } 86^{\circ} 21^{\prime} 30^{\prime \prime} \text {, in ME } 1 / 4 \text { SE } 1 / 4 \\
\text { sec.8, T.16 N., R. } 17 \text { W., Oceana County, } \\
\text { Hydrologic Unit } 0406010 \mathrm{i} \text {, at U.S. Highway } \\
31,3.5 \text { i northeast of Pentwater. }\end{array}$ & 42.3 & $1975-87$ & $10-05-86$ & 2.51 & 187 \\
\hline 04124500 & $\begin{array}{l}\text { East Branch Pine } \\
\text { River near } \\
\text { Tustin, MI }\end{array}$ & $\begin{array}{l}\text { Lat } 44^{\circ} 06 \text { '09", long } 85^{\circ} 311^{\prime} 02^{\prime \prime} \text {, in NE1/4 NW1/4 } \\
\text { sec.28, T.20 N., R.10 W., Osceola County, } \\
\text { Hydrologic Unit } 04060103 \text {, at highway } \\
\text { bridge, } 3.0 \text { i west of Tust in. }\end{array}$ & f63 & $\begin{array}{l}1952-63 \ddagger \\
1964-87\end{array}$ & $10-05-86$ & 3.18 & 113 \\
\hline
\end{tabular}

See footnotes at end of table. 


\begin{tabular}{|c|c|c|c|c|c|c|c|}
\hline \multirow[b]{2}{*}{$\begin{array}{l}\text { Station } \\
\text { No. }\end{array}$} & \multirow[b]{2}{*}{ Station Name } & \multirow[b]{2}{*}{ Location } & \multirow[b]{2}{*}{$\begin{array}{l}\text { Drainage } \\
\quad \text { area } \\
\left(\begin{array}{l}\left.i^{2}\right)\end{array}\right.\end{array}$} & \multirow[b]{2}{*}{$\begin{array}{l}\text { Period } \\
\text { of } \\
\text { record }\end{array}$} & \multicolumn{3}{|c|}{ Annual Maximum } \\
\hline & & & & & Date & $\begin{array}{l}\text { Gage } \\
\text { height } \\
(\mathrm{ft})\end{array}$ & $\begin{array}{l}\text { Dis- } \\
\text { charge } \\
(\mathrm{ft} 3 / \mathrm{s})\end{array}$ \\
\hline \multicolumn{8}{|c|}{ STREAMS TRIBUTARY TO LAKE MICHIGAN--Cont inued } \\
\hline 04126600 & $\begin{array}{l}\text { Betsie River near } \\
\text { Benzonia, MI }\end{array}$ & $\begin{array}{l}\text { Lat } 44^{\circ} 36 \cdot 02^{\prime \prime} \text {, long } 86^{\circ} 05^{\prime} 57^{\prime \prime} \text {, in NWI/4 NW1/4 } \\
\text { sec.2, T.25 N., R. } 15 \text { W., Benzie County, } \\
\text { Hydrologic Unit } 04060104 \text {, at U.S. Highway } \\
31,1.2 \text { i south of Benzonia. }\end{array}$ & $f 170$ & $1975-87$ & $10-04-86$ & 4.71 & 796 \\
\hline 04127850 & $\begin{array}{c}\text { Boyne River near } \\
\text { Boyne City, MI }\end{array}$ & $\begin{array}{l}\text { Lat } 45^{\circ} 11^{\prime} 48^{\prime \prime} \text {, long } 84^{\circ} 57^{\prime} 26^{\prime \prime} \text {, in NW1/4 SW1/4 } \\
\text { Sec.5, T.32 N., R.5 W., Charlevoix County, } \\
\text { Hydrologic Unit } 04060105 \text {, at Dam Road, } 0.3 \text { i } \\
\text { downstrean from nonoperative hydroelectric plant, } \\
\text { and } 2.8 \text { i southeast of Boyne City. } \\
\text { SIREAMS TRIBUTARY TO LAKE HURON }\end{array}$ & 64.2 & $1975-87$ & $10-03-86$ & 3.79 & 362 \\
\hline 04139000 & $\begin{array}{l}\text { Houghton Creek } \\
\text { near Lupton, MI }\end{array}$ & $\begin{array}{l}\text { Lat } 44^{\circ} 23^{\prime} 45^{\prime \prime} \text {, long } 84^{\circ} 02^{\prime} 50^{\prime \prime} \text {, in SE } 1 / 4 \mathrm{SE} 1 / 4 \\
\text { sec. } 10, \mathrm{~T} .23 \mathrm{N.}, \mathrm{R} .3^{\mathrm{E}} \text {., Oegmaw County, } \\
\text { Hydrologic Unit } 04080101,2.7 \text { i southwest } \\
\text { of Lupton. }\end{array}$ & 29.7 & $\begin{array}{l}1950-73 \neq \\
1973-87\end{array}$ & $10-05-86$ & b & e275 \\
\hline 04140200 & $\begin{array}{l}\text { Klacking Creek } \\
\text { near Selkirk, } \\
\text { MI }\end{array}$ & $\begin{array}{l}\text { Lat } 44^{\circ} 20^{\prime} 05^{\prime \prime} \text {, long } 84^{\circ} 08^{\prime} 46^{\prime \prime} \text {, in NE } 1 / 4 \mathrm{NE} 1 / 4 \\
\text { sec.2, T.22 N., R.2 E., Ogemaw County, } \\
\text { Hydrologic Unit } 04080101 \text {, at Campbell Road, } \\
4.0 \text { i northwest of Selkirk. }\end{array}$ & 7.51 & $1953-87$ & $10-05-86$ & b & e86 \\
\hline 04140500 & $\begin{array}{l}\text { Rifle River at } \\
\text { Selkirk, MI }\end{array}$ & $\begin{array}{l}\text { Lat } 44^{\circ} 18^{\prime} 48^{\prime \prime} \text {, long } 84^{\circ} 04^{\prime} 10^{\prime \prime} \text {, in SEl/4 NE } 1 / 4 \\
\text { sec.9, T.22 N., R.3 E., Ogemaw County, } \\
\text { Hydrologic Unit } 04080101 \text {, at State Road in } \\
\text { Selkirk. }\end{array}$ & 117 & $\begin{array}{l}1950-82 \ddagger \\
1983-87\end{array}$ & $10-05-86$ & 93.08 & 596 \\
\hline 04141000 & $\begin{array}{l}\text { South Branch } \\
\text { Shepards Creek } \\
\text { near Selkirk, } \\
\text { MI }\end{array}$ & $\begin{array}{l}\text { Lat } 44^{\circ} 18^{\prime} 28^{\prime \prime} \text {, long } 84^{\circ} 05^{\prime} 13^{\prime \prime} \text {, in SE I/4 SE } 1 / 4 \\
\text { Sec.8, T.22 N., R.3 E., 0geaw County, } \\
\text { Hydrologic Unit } 04080101 \text {, on right bank } \\
200 \mathrm{ft} \text { upstrea fromouth, } 60 \mathrm{ft}^{\mathrm{ft}} \text { west of } \\
\text { Bedtelyon Road, and } 1.1 \text { i southwest of Selkirk. }\end{array}$ & 1.15 & $\begin{array}{l}1952-78 \neq \\
1979-87\end{array}$ & $08-16-87$ & h4.06 & h136 \\
\hline 04146020 & $\begin{array}{l}\text { South Branch Flint } \\
\text { River near Mill- } \\
\text { ville, MI }\end{array}$ & $\begin{array}{l}\text { Lat } 43^{\circ} 04^{\prime} 44^{\prime \prime} \text {, long } 83^{\circ} 18^{\prime} 25^{\prime \prime} \text {, in SE } 1 / 4 \mathrm{sec} \text {. } \\
29, \mathrm{I} .8 \mathrm{~N}, \mathrm{R}^{\prime} 10 \mathrm{E} \text {, Lapeer County, Hydrologic } \\
\text { Unit } 04080204 \text {, at Saginaw Road, } 1.6 \text { i north of } \\
\text { Lapeer. }\end{array}$ & 160 & $1974-87$ & $10-01-86$ & 8.72 & 1,120 \\
\hline 04146450 & $\begin{array}{l}\text { Morth Branch Flint } \\
\text { River near } \\
\text { Columbiaville, MI }\end{array}$ & $\begin{array}{l}\text { Lat } 43^{\circ} 11^{\prime} 18^{\prime \prime} \text {, long } 83^{\circ} 22^{\prime} 03^{\prime \prime} \text {, in } N W 1 / 4 \mathrm{sec} \text {. } \\
24, \mathrm{~T}, 9^{\mathrm{N}} \mathrm{N}, \mathrm{R} .9 \mathrm{E} \text {., Lapeer County, Hydrologic } \\
\text { Unit } 04080204 \text {, at Barnes Lake Road, } 2.9 \text { mi north- } \\
\text { east of Columbiaville. }\end{array}$ & 223 & i1987 & $04-06-87$ & j11.83 & 575 \\
\hline 04148265 & $\begin{array}{l}\text { Kimball Drain near } \\
\text { Swartz Creek, MI }\end{array}$ & $\begin{array}{l}\text { Lat } 42^{\circ} 55^{\prime} 15^{\prime \prime} \text {, long } 83^{\circ} 49^{\prime} 51^{\prime \prime} \text {, in NE } 1 / 4 \mathrm{sec} .14 \text {, } \\
\text { T.6 N., R.5 E., Genesee County, Hydrologic } \\
\text { Unit } 04080204 \text {, at Morrish Road, } 2.4 \text { i south } \\
\text { of Swartz Creek. }\end{array}$ & 10.6 & $1970-87$ & $04-05-87$ & $\mathrm{f} 3.60$ & e70 \\
\hline 04148610 & $\begin{array}{l}\text { Cole Creek near } \\
\text { Flushing, MI }\end{array}$ & $\begin{array}{l}\text { Lat } 43^{\circ} 02 \cdot 44^{\prime \prime} \text {, long } 83^{\circ} 51^{\prime} 06^{\prime \prime} \text {, in Sw1/4 sec. } 35 \text {, } \\
\text { T.8 N., R.5 E., Genesee County, Hydrologic } \\
\text { Unit } 04080204 \text {, at Potter Road, } 1.2 \text { i south } \\
\text { of Flushing. }\end{array}$ & 8.51 & $1970-87$ & $03-01-87$ & 3.31 & 22 \\
\hline \multirow[t]{2}{*}{04148640} & $\begin{array}{l}\text { Arwstrong Creek } \\
\text { near Montrose, MI }\end{array}$ & $\begin{array}{l}\text { Lat } 43^{\circ} 08^{\prime} 04^{\prime \prime} \text {, long } 83^{\circ} 50^{\prime} 03^{\prime \prime} \text {, in SE } 1 / 4 \mathrm{sec} .35 \text {, } \\
\text { J.9 } \mathrm{N} ., \mathrm{R} .5^{\prime} \mathrm{E} . \text {, Genesee County, Hydrologic } \\
\text { Unit } 04080204 \text {, at Morrish Road, } 4.1 \mathrm{mi} \text { south- } \\
\text { east of Montrose. }\end{array}$ & 11.9 & $1970-87$ & $04-05-87$ & 5.71 & 81 \\
\hline & \multicolumn{7}{|c|}{ STREAMS TRIBUTARY TO ST. CLAIR RIVER } \\
\hline 04160350 & $\begin{array}{l}\text { Pine River near } \\
\text { Rattle Run. MI }\end{array}$ & $\begin{array}{l}\text { Lat } 42^{\circ} 52^{\prime} 49^{\prime \prime} \text {, long } 82^{\circ} 34^{\prime} 04^{\prime \prime} \text {, in NE } 1 / 4 \mathrm{sec} .9 \text {, } \\
\text { T.5 N.. R. } 16 \text { E., St. Clair County, Hydro- } \\
\text { logic Unit } 04090001 \text {, at Gratiot Road, } 1.9 \text { i } \\
\text { northeast of Rattle Run. }\end{array}$ & 135 & $1974-87$ & $03-02-87$ & 16.24 & 1,410 \\
\hline & & STREAMS TRIBUTARY TO LAKE ST. CLAIR & & & & & \\
\hline 04161000 & $\begin{array}{l}\text { Clinton River at } \\
\text { Auburn Heights, } \\
\text { MI }\end{array}$ & $\begin{array}{l}\text { Lat } 42^{\circ} 38^{\circ} 00^{\prime \prime} \text {, long } 83^{\circ} 13^{\prime} 28^{\prime \prime} \text {, in NW1/4 sec. } 36 \text {, } \\
\text { T.3 N., R. } 10 \text { E., Oakland County, Hydrologic } \\
\text { Unit } 04090003 \text {, at Auburn Road in Auburn Heights. }\end{array}$ & 123 & $\begin{array}{l}1935-40 \neq \\
1957-82 \neq \\
1983-87\end{array}$ & $06-21-87$ & 5.09 & 1,520 \\
\hline
\end{tabular}

See footnotes at end of table. 


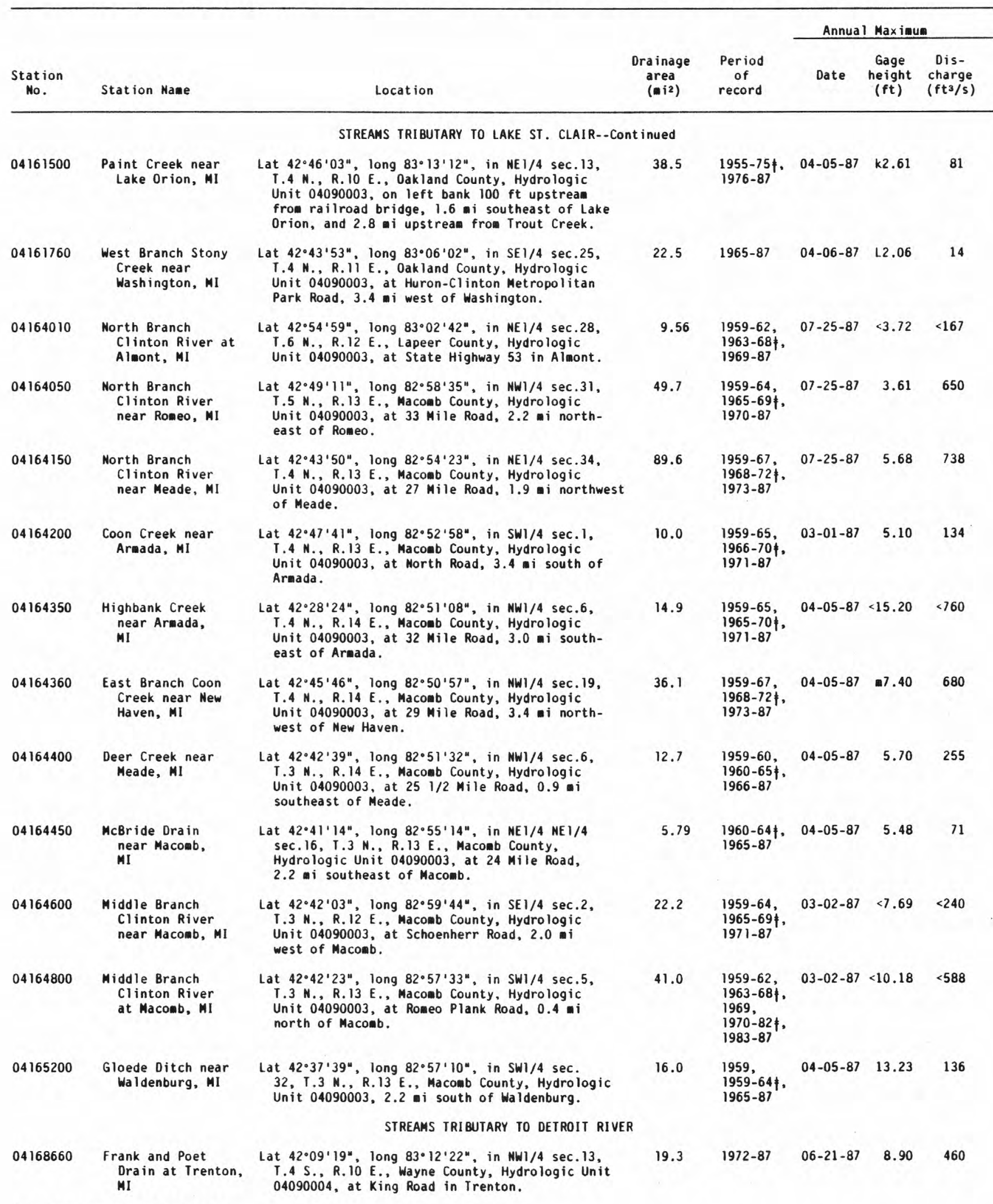

See footnotes at end of table. 


\begin{tabular}{|c|c|c|c|c|c|c|c|}
\hline \multirow[b]{2}{*}{$\begin{array}{l}\text { Station } \\
\text { No. }\end{array}$} & \multirow[b]{2}{*}{ Station Name } & \multirow[b]{2}{*}{ Location } & \multirow[b]{2}{*}{$\begin{array}{l}\text { Drainage } \\
\quad \text { area } \\
\quad\left(\mathbf{m} \mathbf{i}^{2}\right)\end{array}$} & \multirow[b]{2}{*}{$\begin{array}{l}\text { Period } \\
\text { of } \\
\text { record }\end{array}$} & \multicolumn{3}{|c|}{ Annual Maximum } \\
\hline & & & & & Date & $\begin{array}{l}\text { Gage } \\
\text { height } \\
(\mathrm{ft})\end{array}$ & $\begin{array}{l}\text { Dis- } \\
\text { charge } \\
\left(\mathrm{ft}^{3} / \mathrm{s}\right)\end{array}$ \\
\hline & & STREAMS TRIBUTARY TO LAKE ERIE & & & & & \\
\hline 04168800 & $\begin{array}{l}\text { Huron River near } \\
\text { Andersonville, } \\
\text { MI }\end{array}$ & $\begin{array}{l}\text { Lat } 42^{\circ} 41 \cdot 35^{\prime \prime} \text {, long } 83^{\circ} 29^{\prime} 56^{\prime \prime} \text {, in NW1/4 SEl/4 } \\
\text { sec.3, T.3 N., R. } 8 \text { E., Oakland County, } \\
\text { Hydrologic Unit } 04090005 \text {, at White Lake } \\
\text { Road, } 2.5 \text { i south of Andersonville. }\end{array}$ & 14.0 & $1974-87$ & $04-06-87$ & $<1.95$ & $<58$ \\
\hline 04173250 & $\begin{array}{l}\text { Mill Creek near } \\
\text { Lima Center, MI }\end{array}$ & $\begin{array}{l}\text { Lat } 42^{\circ} 15^{\prime} 56^{\prime \prime} \text {, long } 83^{\circ} 56^{\prime} 45^{\prime \prime} \text {, in ME } 1 / 4 \mathrm{sec} .34 \text {, } \\
\text { T.2 S., R.4 E., Washtenaw County, Hydrologic } \\
\text { Unit } 04090005 \text {, at Guenther Road, } 2.0 \text { m i up- } \\
\text { stream from North Fork Mill Creek, and } 2.2 \\
\text { mi south of Lima Center. }\end{array}$ & 47.3 & $1973-87$ & $10-04-86$ & 7.41 & 254 \\
\hline 04175960 & $\begin{array}{l}\text { South Branch River } \\
\text { Raisin near } \\
\text { Adrian, MI }\end{array}$ & $\begin{array}{l}\text { Lat } 41.55^{\prime} 03^{\prime \prime} \text {, long } 84^{\circ} 00^{\prime} 37^{\prime \prime} \text {, in SE } 1 / 4 \mathrm{sec} .25 \text {, } \\
\text { T.6 S., R.3 E., Lenawee County, Hydrologic Unit } \\
04100002 \text {, at Howell Highway, } 2.0 \text { mi northeast } \\
\text { of Adrian. }\end{array}$ & 165 & $1979-87$ & $10-05-86$ & 9.06 & 907 \\
\hline 04176400 & $\begin{array}{l}\text { Saline River near } \\
\text { Saline, MI }\end{array}$ & $\begin{array}{l}\text { Lat } 42^{\circ} 07^{\prime} 50^{\prime \prime} \text {, long } 83^{\circ} 46^{\prime} 35^{\prime \prime} \text {, in } \mathrm{SWl} / 4 \mathrm{sec} .18 \text {, } \\
\text { T.4 S., R.6 E., Washtenaw County, Hydrologic } \\
\text { Unit } 04100002 \text {, at Maple Road, } 2.8 \text { mi south of } \\
\text { Saline. }\end{array}$ & 94.6 & $\begin{array}{l}1966-77 \neq \\
1978-87\end{array}$ & $10-03-86$ & 9.97 & 711 \\
\hline
\end{tabular}

Operated as a continuous-record gaging station.

Also a low-flow partial-record station.

Maximum gage height, $8.73 \mathrm{ft}$, sometime prior to Dec. 29, backwater from ice.

b Not deterwined.

c Maximum gage height, $7.22 \mathrm{ft}$, sometime during the winter period, backwater from ice.

d Backwater from ice.

e Estimated.

f Approximately.

g Gage height of $3.39 \mathrm{ft}$ occurred on Jan. 27 , backwater from ice.

h Probably higher on 0ct. 5.

i Period of record excludes October 1986.

j Maximum gage height, $12.32 \mathrm{ft}$, Mar. 2, backwater from ice.

$k$ Maximum gage height, $2.70 \mathrm{ft}$, sometime prior to Jan. 26 , backwater from ice.

$\mathrm{L}$ Maximum gage height, $2.08 \mathrm{ft}$, Mar. 1, backwater from ice.

maximum gage height, $7.47 \mathrm{ft}$, Mar. 1, backwater from ice. 
Measurements of streamflow in the area covered by this report made at low-flow partial-record stations are given in the following table. These measurements were during periods of base flow when streaflow is primarily from ground-water storage. These measurements, when correlated with the simultaneous discharge of a nearby stream where continuous records are available, will give a picture of the low-flow potentiality of a stream. The column headed "Period of record" shows the water years in which measurements were ade the same. or practically the same, site.

Discharge measurements ade at low-flow partial-record stations during water year 1987

\begin{tabular}{|c|c|c|c|c|c|c|}
\hline \multirow[b]{2}{*}{$\begin{array}{l}\text { Station } \\
\text { No. }\end{array}$} & \multirow[b]{2}{*}{ Station Name } & \multirow[b]{2}{*}{ Location } & \multirow{2}{*}{$\begin{array}{c}\text { Drainage } \\
\text { area } \\
\quad(\text { mi2) }\end{array}$} & \multirow{2}{*}{$\begin{array}{l}\text { Period } \\
\text { of } \\
\text { record }\end{array}$} & \multicolumn{2}{|c|}{ Measurements } \\
\hline & & & & & Date & $\begin{array}{l}\text { Discharge } \\
\left(\mathrm{ft}^{3} / \mathrm{s}\right)\end{array}$ \\
\hline & & STREAMS TRIBUTARY TO LAKE SUPERIOR & & & & \\
\hline \multirow[t]{2}{*}{04044400} & $\begin{array}{l}\text { Carp River near } \\
\text { Negaunee, MI }\end{array}$ & $\begin{array}{l}\text { Lat } 46^{\circ} 31^{\prime} 29^{\prime \prime} \text {, long } 87^{\circ} 34^{\prime} 25^{\prime \prime} \text {, in SE } 1 / 4 \mathrm{sec} .29 \text {, } \\
\text { T.48 } \mathrm{N} . \text { R. R. W., Marquette County, Hydrologic } \\
\text { Unit } 04020105 \text {, at U.S. Highway } 41,2.0 \mathrm{mi} \\
\text { northeast of Negaunee. }\end{array}$ & 51.4 & $\begin{array}{l}1961-86 \nmid a, \\
1987 a\end{array}$ & $\begin{array}{l}10-01-86 \\
11-04-86 \\
12-09-86 \\
12-10-86 \\
05-12-87 \\
09-10-87\end{array}$ & $\begin{array}{l}b 74.9 \\
b 42.8 \\
b 32.3 \\
b 32.7 \\
b 5.36 \\
b 2.52\end{array}$ \\
\hline & & STREAMS TRIBUTARY TO LAKE MICHIGAN & & & & \\
\hline 04057580 & $\begin{array}{l}\text { Whitefish River near } \\
\text { Rapid River, MI }\end{array}$ & $\begin{array}{l}\text { Lat } 45^{\circ} 57^{\prime} 56^{\prime \prime} \text {, long } 86^{\circ} 55^{\prime} 15^{\prime \prime} \text {, in SE1/4 NW1/4 } \\
\text { sec.10, T.41 N.., R.21 W., Delta County, Hydro- } \\
\text { logic Unit } 04030111 \text {, about } 800 \mathrm{ft} \text { downstream } \\
\text { from Chippeny Creek, } 3.5 \text { mi northeast of Rapid } \\
\text { River. }\end{array}$ & 284 & $1973-87$ & $\begin{array}{l}10-29-86 \\
01-14-87 \\
05-13-87 \\
08-28-87\end{array}$ & $\begin{array}{r}233 \\
117 \\
147 \\
83.4\end{array}$ \\
\hline 04058120 & $\begin{array}{l}\text { Green Creek near } \\
\text { Palmer, MI }\end{array}$ & $\begin{array}{l}\text { Lat } 46^{\circ} 22^{\prime} 22^{\prime \prime} \text {, long } 87^{\circ} 36^{\prime} 21^{\prime \prime} \text {, in NW1/4 sec. } 19 \text {, } \\
\text { T.46 N., R.26 W., Marquette County, Hydrologic } \\
\text { Unit } 04030110 \text {, dt County Highway } 565,4.5 \mathrm{mi} \\
\text { south of Palmer. }\end{array}$ & 8.42 & $\begin{array}{l}1961-65 \\
1970-87 \mathrm{c}\end{array}$ & $\begin{array}{l}11-03-86 \\
05-12-87 \\
07-30-87 \\
07-30-87 \\
07-30-87\end{array}$ & $\begin{array}{l}\mathrm{b} 2.88 \\
\mathrm{~b} 1.88 \\
\mathrm{~b} 9.00 \\
\mathrm{~b} 2.14 \\
\mathrm{~b} 0.61\end{array}$ \\
\hline 04059034 & $\begin{array}{l}\text { Escanaba River near } \\
\text { Wells, MI }\end{array}$ & $\begin{array}{l}\text { Lat } 45^{\circ} 48^{\prime} 22^{\prime \prime} \text {, long } 87^{\circ} 05^{\prime} 51^{\prime \prime} \text {, in SW1/4 NW1/4 } \\
\text { sec.1, T.39 N., R.23 W.. Deita County, Hydro- } \\
\text { logic Unit } 04030110,600 \text { ft downstream from } \\
\text { Bichler Creek, } 2.5 \text { ipstream from mouth, } \\
\text { and } 2.0 \text { mi northwest of Wells. }\end{array}$ & d920 & $1981-87 c$ & $\begin{array}{l}01-07-87 \\
06-16-87 \\
07-23-87 \\
09-03-87\end{array}$ & $\begin{array}{l}b 398 \\
b 496 \\
b 604 \\
b 246\end{array}$ \\
\hline 04096517 & $\begin{array}{l}\text { Hog Creek Iributary } \\
\text { near Allen, MI }\end{array}$ & $\begin{array}{l}\text { Lat } 41^{\circ} 57^{\prime} 33^{\prime \prime} \text {, long } 84^{\circ} 49^{\prime} 33^{\prime \prime} \text {, in SW1/4 SWl } / 4 \\
\text { sec.7, T.6 S., R.4 W., Hillsdale County, } \\
\text { Hydrologic Unit } 04050001 \text {, at Squires Road, } 0.3 \\
\text { i upstream from outh, and } 3.0 \text { i west of } \\
\text { Allen. }\end{array}$ & 2.61 & $1969-87$ & $\begin{array}{l}11-17-86 \\
05-05-87 \\
06-15-87 \\
07-27-87\end{array}$ & $\begin{array}{l}4.64 \\
1.64 \\
1.11 \\
1.21\end{array}$ \\
\hline 04114594 & $\begin{array}{l}\text { Maple River near } \\
\text { St. Johns, MI }\end{array}$ & $\begin{array}{l}\text { Lat } 43^{\circ} 02^{\prime} 43^{\prime \prime} \text {, long } 84^{\circ} 28^{\prime} 11^{\prime \prime} \text {, in SE1/4 SE1/4 } \\
\text { sec. } 30 \text {, T.8 N., R.1 W., Clinton County, Hydro- } \\
\text { logic Unit } 04050005 \text {, at Colony Road, } 4.5 \mathrm{mi} \\
\text { northeast of St. Johns. }\end{array}$ & -. & $1981-87$ & $\begin{array}{l}03-12-87 \\
04-21-87 \\
07-16-87 \\
08-27-87\end{array}$ & $\begin{array}{c}106 \\
79.3 \\
15.6 \\
38.5\end{array}$ \\
\hline$\star 04120295$ & $\begin{array}{l}\text { Black Creek near } \\
\text { Muskegon, MI }\end{array}$ & $\begin{array}{l}\text { Lat } 43^{\circ} 12^{\prime} 14^{\prime \prime} \text {, long } 86^{\circ} 09^{\prime} 52^{\prime \prime} \text {, in NE1/4 NW1/4 } \\
\text { sec.1, T.9 N. R.16 W., Muskegon County, } \\
\text { Hydrologic Unit } 04060101 \text {, at Mill Iron Road, } \\
4.8 \text { mi east of Muskegon, and } 4.9 \text { ipstream } \\
\text { from mouth. }\end{array}$ & d39 & $1974-87$ & $\begin{array}{l}11-12-86 \\
04-21-87 \\
07-15-87 \\
08-25-87\end{array}$ & $\begin{array}{l}55.3 \\
56.4 \\
24.0 \\
74.5\end{array}$ \\
\hline 04121239 & $\begin{array}{l}\text { Clam River at } \\
\text { Cadillac, MI }\end{array}$ & $\begin{array}{l}\text { Lat } 44^{\circ} 15^{\prime} 49^{\prime \prime} \text {, long } 85^{\circ} 24^{\prime} 04^{\prime \prime} \text {, in NE } 1 / 4 \mathrm{NE} 1 / 4 \\
\text { sec.33, T.22 N., R.9 W., Wexford County, } \\
\text { Hydrologic Unit } 04060102 \text {, at Somith Street } \\
\text { in Cadillac. }\end{array}$ & d48 & $\begin{array}{l}1983-84, \\
1986-87\end{array}$ & $\begin{array}{l}12-04-86 \\
03-13-87 \\
05-05-87 \\
06-19-87\end{array}$ & $\begin{array}{c}51.7 \\
16.2 \\
4.87 \\
3.89\end{array}$ \\
\hline
\end{tabular}

Operated as a continuous record gaging station.

* Also a crest-stage partial-record station.

a Affected by domestic diversion.

b Not base flow.

c Affected by diversion for industrial use.

d Approximately. 
DISCHARGE AT PARTIAL-RECORD STATIONS AND MISCELLANEOUS SITES

Special study and iscellaneous sites

Discharge measurements in the following table were ade at special study and iscellaneous sites throughout the State.

Discharge measuremts made at special study and iscellaneous sites during water year 1987

\begin{tabular}{|c|c|c|c|c|c|c|c|}
\hline \multirow[b]{2}{*}{$\begin{array}{l}\text { Station } \\
\text { No. }\end{array}$} & \multirow[b]{2}{*}{ Stream } & \multirow[b]{2}{*}{ Tributary to } & \multirow[b]{2}{*}{ Location } & \multirow{2}{*}{$\begin{array}{l}\text { Drainage } \\
\text { area } \\
\quad\left( \pm i^{2}\right)\end{array}$} & \multirow{2}{*}{$\begin{array}{l}\text { Measured } \\
\text { previously } \\
\text { (water } \\
\text { years) }\end{array}$} & \multicolumn{2}{|c|}{ Measurements } \\
\hline & & & & & & Date & $\begin{array}{c}\text { Discharge } \\
(\mathrm{ft} 3 / \mathrm{s})\end{array}$ \\
\hline & & & STREAMS TRIBUTARY TO LAKE SUPERIOR & & & & \\
\hline \multirow[t]{2}{*}{04034100} & $\begin{array}{l}\text { Bond Falls } \\
\text { Lower By- } \\
\text { Pass }\end{array}$ & $\begin{array}{l}\text { Middle Branch } \\
\text { Ontonagon } \\
\text { River }\end{array}$ & $\begin{array}{l}\text { Lat } 46^{\circ} 24^{\prime} 27^{\prime \prime} \text {, long } 89^{\circ} 07^{\prime} 44^{\prime \prime} \text {, in SE } 1 / 4 \\
\text { SWI/4 sec.1, T.46 N., R. } 39 \text { W. Ontonagon } \\
\text { County, Hydrologic Unit } 04020102 \text {, at Bond } \\
\text { Falls Road, } 2.2 \text { iles west of Calderwood. }\end{array}$ & -- & $\begin{array}{l}1942,1945, \\
1963-64, \\
1967,1969, \\
1971-72, \\
1974, \\
1979-81, \\
1983-84\end{array}$ & $03-24-87$ & a 32.7 \\
\hline & & & SIREAMS TRIBUTARY TO LAKE MICHIGAN & & & & \\
\hline 04055000 & $\begin{array}{l}\text { Manistique } \\
\text { River }\end{array}$ & $\begin{array}{l}\text { Lake } \\
\text { Michigan }\end{array}$ & $\begin{array}{l}\text { Lat } 46^{\circ} 05^{\prime} 05^{\prime \prime} \text {, long } 86^{\circ} 03^{\prime} 35^{\prime \prime} \text {, in SWl/4 } \\
\text { SE } 1 / 4 \mathrm{sec} .28 \text {, I. } 43 \mathrm{~N} ., \mathrm{R} .14 \mathrm{~W} \text {., Schoolcraft } \\
\text { County, Hydrologic Unit } 04060106 \text {, at Cookson } \\
\text { Bridge, } 0.5 \text { m i downstream of Duck Creek, } 6.6 \\
\text { i southwest of Blaney. }\end{array}$ & 704 & $1938-70 \neq$ & $07-13-87$ & b368 \\
\hline 04055400 & $\begin{array}{l}\text { Manistique } \\
\text { River }\end{array}$ & $\begin{array}{l}\text { Lake } \\
\text { Michigan }\end{array}$ & $\begin{array}{l}\text { Lat } 46^{\circ} 011^{\prime} 58^{\prime \prime} \text {, long } 86^{\circ} 07^{\prime} 20^{\prime \prime} \text {, in NWl/4 SE } 1 / 4 \\
\text { sec.13, T.42 N., R. } 15 \mathrm{~W} \text {., Schoolcraft County } \\
\text { Hydrologic Unit } 04060106,1,000 \mathrm{ft} \text { downstream } \\
\text { of Merwin Creek Campground boat launch, } 6.0 \\
\text { i northwest of Gulliver. }\end{array}$ & -- & -- & $07-13-87$ & b404 \\
\hline 04063522 & $\begin{array}{l}\text { Menominee } \\
\text { River }\end{array}$ & $\begin{array}{l}\text { Lake } \\
\text { Michigan }\end{array}$ & $\begin{array}{l}\text { Lat } 45^{\circ} 51^{\prime} 57^{\prime \prime} \text {, long } 88^{\circ} 04^{\prime} 28^{\prime \prime} \text {, in NE I/4 } \\
\text { sec.13, T.40 N., R.31 W., Dickinson County, } \\
\text { Hydrologic Unit } 04030108 \text {, at U.S. Highway } \\
2,3.2 \text { i north of Iron Mountain. }\end{array}$ & 1803 & 1984 & $\begin{array}{l}09-23-87 \\
09-23-87 \\
09-23-87\end{array}$ & $\begin{array}{l}\text { a } 432 \\
\text { a } 399 \\
\text { a } 436\end{array}$ \\
\hline 04065110 & $\begin{array}{l}\text { Menom inee } \\
\text { River }\end{array}$ & $\begin{array}{l}\text { Lake } \\
\text { Michigan }\end{array}$ & $\begin{array}{l}\text { Lat } 45^{\circ} 45^{\prime} 53^{\prime \prime} \text {, long } 87.58100 " \text {, in NEI/4 } \\
\text { sec.23, T.39 N.. R.30 W., Dickinson County, } \\
\text { Hydrologic Unit 04030108, at intake at } \\
\text { Champion International Corp. Quinnesec Pulp- } \\
\text { ill, } 2.0 \text { m southeast of Niagra. }\end{array}$ & 2470 &.- & $\begin{array}{l}06-26-87 \\
07-07-87 \\
08-04-87 \\
09-04-87 \\
09-18-87\end{array}$ & $\begin{array}{l}\text { a } 1,560 \\
\text { a } 1,480 \\
\text { a } 1,860 \\
\text { a }, 080 \\
1,100\end{array}$ \\
\hline 04096018 & Galien River & $\begin{array}{l}\text { Lake } \\
\text { Michigan }\end{array}$ & $\begin{array}{l}\text { Lat } 41^{\circ} 50^{\prime} 28^{\prime \prime} \text {, long } 86^{\circ} 37^{\prime} 19^{\prime \prime} \text {, in NEl/4 } \\
\text { NW1/4 sec. } 27 \text {, T.7 S., R. } 20 \text { W. Berrien County, } \\
\text { Hydrologic Unit } 04040001 \text {, at Warren woods Road, } \\
3.0 \mathrm{mi} \text { north northwest of Three Oaks. }\end{array}$ & - & $-\cdot$ & $09-16-87$ & 24.5 \\
\hline 04096110 & $\begin{array}{l}\text { South Branch } \\
\text { Galien } \\
\text { River }\end{array}$ & Galien River & $\begin{array}{l}\text { Lat } 41^{\circ} 46^{\circ} 36^{\prime \prime} \text {, long } 86^{\circ} 39^{\prime} 50^{\mu} \text {, in NWl } / 4 \\
\text { SWI/4 sec. } 17 \text {, T.8 S., R.20 W., Berrien County, } \\
\text { Hydrologic Unit } 04040001 \text {, at Forest Lawn Road, } \\
3.1 \mathrm{mi} \text { southwest of Three Oaks. }\end{array}$ & - & -- & $08-25-87$ & b31.0 \\
\hline 04096115 & $\begin{array}{l}\text { South Branch } \\
\text { Galien } \\
\text { River }\end{array}$ & Galien River & $\begin{array}{l}\text { Lat } 41^{\circ} 47^{\prime} 56^{\prime \prime} \text {, long } 86^{\circ} 4 I^{\prime} 23^{\prime \prime} \text {, in NE } 1 / 4 \\
\text { NE } 1 / 4 \mathrm{sec} .12 \text {, T.8 } \mathrm{S} ., \mathrm{R} .21 \text { W. Berrien County, } \\
\text { Hydrologic Unit } 04040001 \text {, at U.S. Highway } 12 \text {, } \\
2.5 \mathrm{mi} \text { east of New Buffalo. }\end{array}$ & -- & -- & $08-25-87$ & b28.6 \\
\hline 04096120 & $\begin{array}{l}\text { South Branch } \\
\text { Galien } \\
\text { River }\end{array}$ & Galien River & $\begin{array}{l}\text { Lat } 41^{\circ} 48^{\prime} 49^{\prime \prime} \text {, long } 86^{\circ} 41^{\prime} 20^{\prime \prime} \text {, in NE } 1 / 4 \\
\text { NE } 1 / 4 \mathrm{sec} .1 \text {, I.8 S., R.21 W., Berrien County, } \\
\text { Hydrologic Unit } 04040001 \text {, at Kruger Road, } 2.7 \\
\text { i northeast of New Buffalo. }\end{array}$ & -. & -- & $08-24-87$ & b29.3 \\
\hline 04096279 & $\begin{array}{l}\text { St. Joseph } \\
\text { River }\end{array}$ & $\begin{array}{l}\text { Lake } \\
\quad \text { Michigan }\end{array}$ & $\begin{array}{l}\text { Lat } 41^{\circ} 59 \cdot 59^{\prime \prime} \text {, long } 84^{\circ} 41^{\prime} 08^{\prime \prime} \text {, in NW1/4 } \\
\text { NW1/4 sec.32, T.5 S., R.3 W., Hillsdale } \\
\text { County, Hydrologic Unit } 04050001 \text {, at Genessee } \\
\text { Road, } 0.5 \text { i northwest of Jonesville. }\end{array}$ & -- & -- & $07-27-87$ & b 18.6 \\
\hline 04096642 & $\begin{array}{l}\text { St. Joseph } \\
\text { River }\end{array}$ & $\begin{array}{l}\text { Lake } \\
\text { Michigan }\end{array}$ & $\begin{array}{l}\text { Lat } 42^{\circ} 01 \cdot 35^{\prime \prime} \text {, long } 85^{\circ} 14 \cdot 06^{\prime \prime} \text {, in NW1/4 } \\
\text { WW } 1 / 4 \mathrm{sec} .22 \text {, T.5 S. R.8 W., Branch County, } \\
\text { Hydrologic Unit } 04050001 \text {, at Athens Road, } \\
1.5 \text { i north of Sherwood. }\end{array}$ & -- & -- & $07-29-87$ & b 125 \\
\hline 04096768 & $\begin{array}{l}\text { Unnamed } \\
\text { tributary }\end{array}$ & $\begin{array}{l}\text { Little Swan } \\
\text { Creek }\end{array}$ & $\begin{array}{l}\text { Lat } 41.59^{\prime} 06^{\prime \prime} \text {, lang } 85^{\circ} 08^{\prime} 36^{\prime \prime} \text {, in NE } 1 / 4 \\
\text { sec.5, T.6 S., R.7 W., Branch County, } \\
\text { Hydrologic Unit } 04050001 \text {, at Barnhart Road, } \\
3.3 \text { i northeast of Matteson. }\end{array}$ & 2.0 & -- & $\begin{array}{l}03-06-87 \\
03-16-87 \\
04-15-87\end{array}$ & $\begin{array}{l}\text { bl } 1.81 \\
\text { b0.91 } \\
\text { b11.5 }\end{array}$ \\
\hline
\end{tabular}

See footnotes at end of table. 


\begin{tabular}{|c|c|c|c|c|c|c|c|}
\hline \multirow[b]{2}{*}{$\begin{array}{c}\text { Station } \\
\text { No. }\end{array}$} & \multirow[b]{2}{*}{ Stream } & \multirow[b]{2}{*}{ Iributary to } & \multirow[b]{2}{*}{ Location } & \multirow{2}{*}{$\begin{array}{c}\text { Drainage } \\
\text { area } \\
\left(m i^{2}\right)\end{array}$} & \multirow{2}{*}{$\begin{array}{l}\text { Measured } \\
\text { previously } \\
\text { (water } \\
\text { years) }\end{array}$} & \multicolumn{2}{|c|}{ Measurements } \\
\hline & & & & & & Date & $\begin{array}{c}\text { Discharge } \\
\left(\mathrm{ft}^{3} / \mathrm{s}\right)\end{array}$ \\
\hline
\end{tabular}

STREAMS IRIBUTARY IO LAKE MICHIGAN--Cont inued

\begin{tabular}{|c|c|c|c|c|c|c|c|}
\hline 04096770 & $\begin{array}{l}\text { Little Swan } \\
\text { Creek }\end{array}$ & Swan Creek & $\begin{array}{l}\text { Lat } 41.57^{\prime} 20^{\prime \prime} \text {, long } 85^{\circ} 11.00^{\prime \prime} \text {, in NWl/4 } \\
\text { NE } 1 / 4 \text { sec. } 13 \text {, T.6 S., R.8 W., Branch County, } \\
\text { Hydrologic Unit } 04050001 \text {, at Langwell Road, } \\
1.0 \text { m i north of Matteson. }\end{array}$ & 8.94 & $1964-65$ & $\begin{array}{l}03-06-87 \\
03-16-87 \\
04-15-87\end{array}$ & $\begin{array}{r}b 9.22 \\
b 4.92 \\
\text { b52.1 }\end{array}$ \\
\hline 04096775 & $\begin{array}{l}\text { Unnamed } \\
\text { tributary }\end{array}$ & $\begin{array}{l}\text { Little Swan } \\
\text { Creek }\end{array}$ & $\begin{array}{l}\text { Lat } 41^{\circ} 57^{\prime} 20^{\prime \prime} \text {, long } 85^{\circ} 12^{\prime} 10^{\prime \prime} \text {, NWI/4 } \\
\text { NE } 1 / 4 \text { sec. } 14 \text {, I.6 S., R.8 W., Branch County } \\
\text { Hydrologic Unit } 04050001 \text {, at Langwell Road, } \\
1.2 \text { i northwest of Matteson. }\end{array}$ & 2.36 & -- & $\begin{array}{l}03-06-87 \\
03-16-87 \\
04-15-87\end{array}$ & $\begin{array}{l}\text { b2 } 2.96 \\
\text { b2.27 } \\
\text { b6.25 }\end{array}$ \\
\hline 04096776 & $\begin{array}{l}\text { Little Swan } \\
\text { Creek }\end{array}$ & Swan Creek & $\begin{array}{l}\text { Lat } 41.56^{\prime} 28^{\prime \prime} \text {, long } 85^{\circ} 111^{\prime} 50^{\prime \prime} \text {, in SW } 1 / 4 \\
\text { SE } 1 / 4 \mathrm{sec} .14 \text {, T.6 } \mathrm{S} . \mathrm{R} .8 \mathrm{~W} . \text {, Branch County, } \\
\text { Hydrologic Unit } 04050001 \text {, at State Highway } 86 \text {, } \\
.25 \mathrm{mi} \text { west of Matteson. }\end{array}$ & 13.9 & -- & $\begin{array}{l}03-06-87 \\
03-16-87 \\
04-15-87\end{array}$ & $\begin{array}{l}\text { b } 17.5 \\
\text { b } 11.9 \\
\text { b } 75.5\end{array}$ \\
\hline 04096800 & $\begin{array}{l}\text { St. Joseph } \\
\text { River }\end{array}$ & $\begin{array}{l}\text { Lake } \\
\text { Michigan }\end{array}$ & $\begin{array}{l}\text { Lat } 41^{\circ} 59^{\prime} 51^{\prime \prime} \text {, long } 85^{\circ} 22^{\prime} 34^{\prime \prime} \text {, in NE. } 1 / 4 \\
\text { sec.32, T.5 S., R.9 W., St. Joseph County, } \\
\text { Hydrologic Unit } 04050001 \text {, at Bennett Road, } \\
3.7 \text { mi northwest of Colon. }\end{array}$ & -- & 1967 & $08-03-87$ & b 164 \\
\hline 04096878 & $\begin{array}{l}\text { Not tawa } \\
\text { Creek }\end{array}$ & $\begin{array}{l}\text { St. Joseph } \\
\text { River }\end{array}$ & $\begin{array}{l}\text { Lat } 42^{\circ} 05^{\prime} 43^{\prime \prime} \text {, long } 85^{\circ} 12^{\prime} 58^{\prime \prime} \text {, in SWl/4 } \\
\text { NW } 1 / 4 \mathrm{sec} .26 \text {, T.4 } \mathrm{S} ., \mathrm{R} .8 \mathrm{~W} \text {., Calhoun County, } \\
\text { Hydrologic Unit } 04050001 \text {, at } 4 \text { Mile Road, } \\
1.0 \text { mi northeast of Athens. }\end{array}$ & -- & -. & $08-03-87$ & b22.7 \\
\hline 04096950 & Bear Creek & $\begin{array}{r}\text { Not tawa } \\
\text { Creek }\end{array}$ & 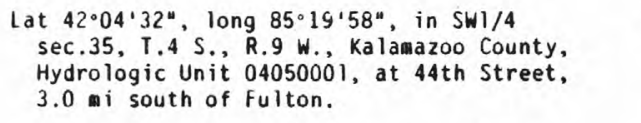 & 10.8 & $\begin{array}{l}1964-67, \\
1986\end{array}$ & $\begin{array}{l}10-07-86 \\
06-15-87 \\
09-10-87\end{array}$ & $\begin{array}{l}\star 51.9 \\
\star 2.81 \\
\star 4.39\end{array}$ \\
\hline 04097040 & $\begin{array}{l}\text { Little } \\
\text { Portage } \\
\text { Creek }\end{array}$ & $\begin{array}{l}\text { St. Joseph } \\
\text { River }\end{array}$ & $\begin{array}{l}\text { Lat } 42^{\circ} 09^{\prime} 51^{\prime \prime} \text {, long } 85^{\circ} 20^{\prime} 18^{\prime \prime} \text {, in NE } 1 / 4 \\
\text { sec.34, T.3 S., R.9 W., Kalamazoo County, } \\
\text { Hydrologic Unit } 04050001 \text {, at TS Avenue, } \\
5.0 \text { i south of Climax. }\end{array}$ & 10.1 & $\begin{array}{l}1964-67 \\
1986\end{array}$ & $\begin{array}{l}10-07-86 \\
06-15-87 \\
09-10-87\end{array}$ & $\begin{array}{l}\star 27.2 \\
\star 1.92 \\
\star 2.36\end{array}$ \\
\hline 04097060 & $\begin{array}{l}\text { Little } \\
\text { Portage } \\
\text { Creek }\end{array}$ & $\begin{array}{l}\text { St. Joseph } \\
\text { River }\end{array}$ & 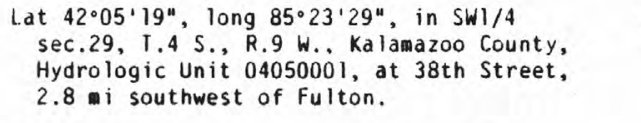 & 27.0 & $\begin{array}{l}1964, \\
1965-67 \neq \\
1972-79 c\end{array}$ & $\begin{array}{l}10-08-86 \\
06-15-87 \\
09-09-87\end{array}$ & $\begin{array}{c}\star 59.7 \\
\star 8.04 \\
\star 10.9\end{array}$ \\
\hline 04097120 & $\begin{array}{c}\text { Portage } \\
\text { River }\end{array}$ & $\begin{array}{l}\text { St. Joseph } \\
\text { River }\end{array}$ & $\begin{array}{l}\text { Lat } 42^{\circ} 10^{\prime} 21^{\prime \prime} \text {, long } 85^{\circ} 28^{\prime} 19^{\prime \prime} \text {, in SE } 1 / 4 \\
\text { Sec. } 28 \text {, T.3 S., R. } 10 \mathrm{~W} ., \text { Kalamazoo } \\
\text { County, Hydrologic Unit } 04050001 \text {, at } \\
\text { S Avenue, } 2.7 \mathrm{mi} \text { southwest of Scotts. }\end{array}$ & 32.8 & $\begin{array}{l}1964-67, \\
1986\end{array}$ & $\begin{array}{l}10-08-86 \\
06-15-87 \\
09-09-87\end{array}$ & $\begin{array}{l}* 69.0 \\
* 15.2 \\
* 15.9\end{array}$ \\
\hline 04097170 & $\begin{array}{l}\text { Portage } \\
\text { River }\end{array}$ & $\begin{array}{l}\text { St. Joseph } \\
\text { River }\end{array}$ & $\begin{array}{l}\text { Lat } 42^{\circ} 06^{\prime} 53^{\prime \prime} \text {, long } 85^{\circ} 29^{\circ} 08^{\prime \prime} \text {, in SWl/4 } \\
\text { sec. } 16 \text {, T.4 S., R. } 10 \mathrm{~W} . \mathrm{G} \text { Ka lamazoo County, } \\
\text { Hydrologic Unit } 0405000 \mathrm{i} \text {, at W Avenue, } 2.4 \\
\text { i east of Vicksburg. }\end{array}$ & 68.2 & $\begin{array}{l}1946-51 \neq, \\
1965-80 \neq, \\
1980-87 \mathrm{c}\end{array}$ & $\begin{array}{r}107-30-86 \\
10-08-86 \\
06-17-87 \\
09-09-87\end{array}$ & $\begin{array}{l}\star 62.6 \\
\star 169 \\
\star 20.6 \\
\star 34.3\end{array}$ \\
\hline 04097205 & $\begin{array}{c}\text { Gourdneck } \\
\text { Creek }\end{array}$ & $\begin{array}{r}\text { Portage } \\
\text { Creek }\end{array}$ & $\begin{array}{l}\text { Lat } 42^{\circ} 08^{\prime} 58^{\prime \prime} \text {, long } 85^{\circ} 32^{\prime} 24^{\prime \prime} \text {, in } 5 W 1 / 4 \\
\text { sec.l, T.4 S., R. } 11 \mathrm{~W} ., \text { Kalamazoo County, } \\
\text { Hydrologic Unit } 04050001 \text {, at } 23 \text { rd Street, } \\
2.0 \mathrm{mi} \text { north of Vicksburg. }\end{array}$ & 13.1 & $\begin{array}{l}1964-69, \\
1986\end{array}$ & $\begin{array}{l}10-07-86 \\
06-15-87 \\
09-09-87\end{array}$ & $\begin{array}{r}* 37.0 \\
* 7.34 \\
* 14.4\end{array}$ \\
\hline 04097207 & $\begin{array}{c}\text { Aust in Lake } \\
\text { Out let }\end{array}$ & $\begin{array}{l}\text { Gourdneck } \\
\text { Creek }\end{array}$ & $\begin{array}{l}\text { Lat } 42^{\circ} 09^{\prime} 03^{\prime \prime} \text {, long } 85^{\circ} 31^{\prime} 59^{\prime \prime} \text {, in SE } 1 / 4 \\
\text { sec.l, T.4 S. R. } 11 \mathrm{~W} \text {., Kalamazoo County, } \\
\text { Hyarologic Unit } 04050001 \text {, at TU Avenue, } \\
2.0 \mathrm{mi} \text { north of Vicksburg. }\end{array}$ & 15.6 & $\begin{array}{l}1964, \\
1966-67, \\
1986\end{array}$ & $\begin{array}{l}10-08-86 \\
06-15-87 \\
09-09-87\end{array}$ & $\begin{array}{l}* 13.7 \\
* 0.69 \\
* 0.52\end{array}$ \\
\hline 04097210 & $\begin{array}{r}\text { Portage } \\
\text { Creek }\end{array}$ & $\begin{array}{r}\text { Portage } \\
\text { River }\end{array}$ & $\begin{array}{l}\text { Lat } 42^{\circ} 06^{\prime} 52^{\prime \prime} \text {, long } 85^{\circ} 32^{\prime} 05^{\prime \prime} \text {, in NE } 1 / 4 \\
\text { sec.24, T.4 S., R. } 11 \mathrm{~W} . \mathrm{K}^{\mathrm{K}} \mathrm{Ka} \text { amazoo } \\
\text { County, Hydrologic Unit } 04050001 \text {, at } \\
\text { W Avenue, at Vicksburg. }\end{array}$ & 35.2 & $\begin{array}{l}1964, \\
1966-67, \\
1986\end{array}$ & $\begin{array}{l}10-08-86 \\
06-17-87 \\
09-09-87\end{array}$ & $\begin{array}{l}* 65.0 \\
* 4.75 \\
* 10.6\end{array}$ \\
\hline 04097240 & $\begin{array}{r}\text { Portage } \\
\text { Creek }\end{array}$ & $\begin{array}{c}\text { Portage } \\
\text { River }\end{array}$ & $\begin{array}{l}\text { Lat } 42^{\circ} 04^{\prime} 25^{\prime \prime} \text {, long } 85^{\circ} 30^{\prime} 55^{\prime \prime} \text {, in SWl } 1 / 4 \\
\text { sec.32, T.4 S., R. } 10 \mathrm{~W} ., \mathrm{Kalamaz} 00 \\
\text { County, Hydrologic Unit } 04050001 \text {, at } \\
Z \text { Avenue, } 3.4 \text { i southeast of Vicksburg. }\end{array}$ & 57.7 & $\begin{array}{l}1964 \\
1966-67 \\
1986\end{array}$ & $\begin{array}{l}10-09-86 \\
06-16-87 \\
09-09-87\end{array}$ & $\begin{array}{l}* 137 \\
* 29.8 \\
* 44.7\end{array}$ \\
\hline
\end{tabular}




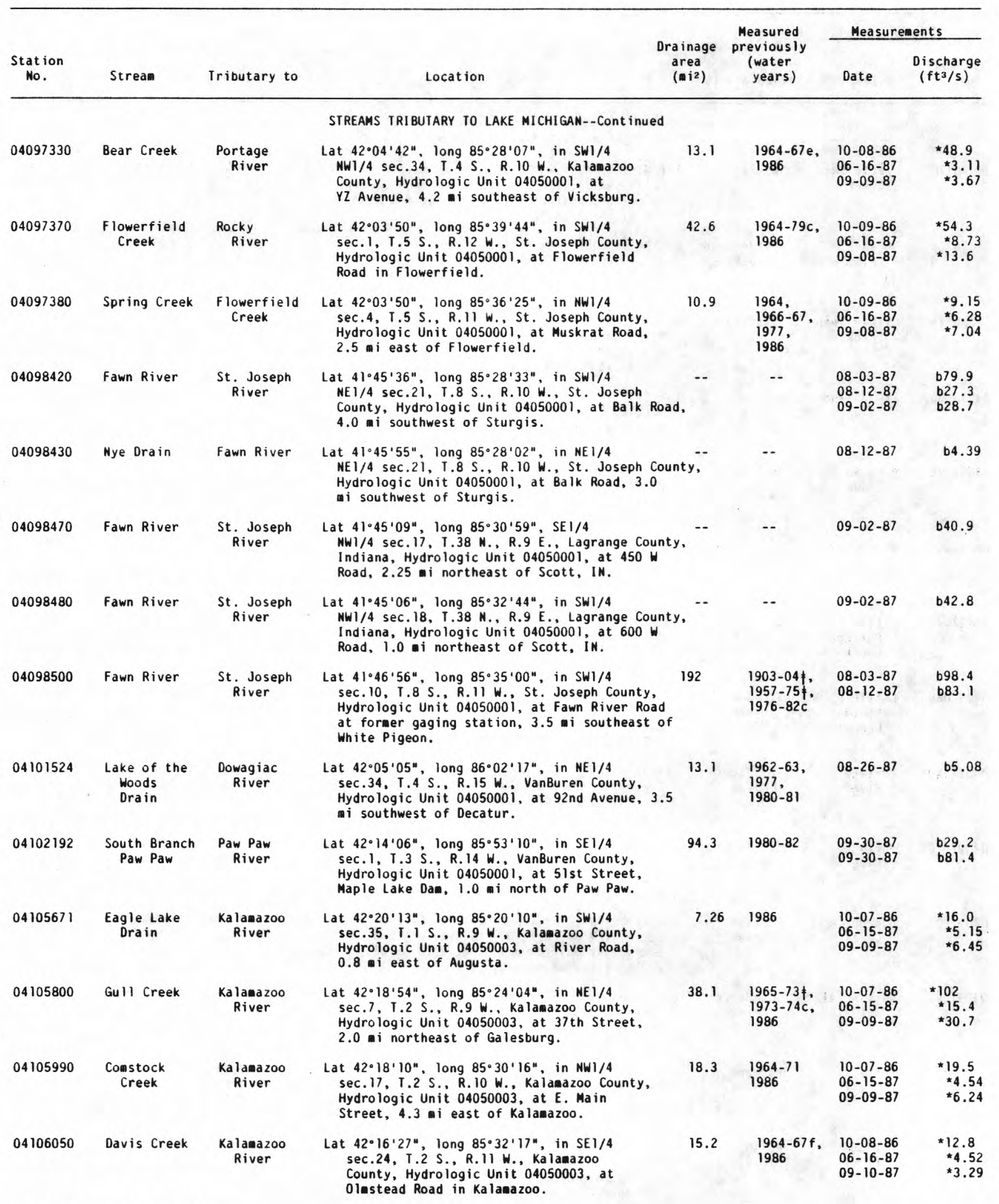

See footnotes at end of table. 


\begin{tabular}{|c|c|c|c|c|c|c|c|}
\hline \multirow[b]{2}{*}{$\begin{array}{l}\text { Station } \\
\text { No. }\end{array}$} & \multirow[b]{2}{*}{ Stream } & \multirow[b]{2}{*}{ Iributary to } & \multirow[b]{2}{*}{ Location } & \multirow{2}{*}{$\begin{array}{l}\text { Drainage } \\
\text { area } \\
\left(\square \mathbf{i}^{2}\right)\end{array}$} & \multirow{2}{*}{$\begin{array}{l}\text { Measured } \\
\text { previously } \\
\text { (water } \\
\text { years) }\end{array}$} & \multicolumn{2}{|c|}{ Measurements } \\
\hline & & & & & & Date & $\begin{array}{c}\text { Discharge } \\
\left(\mathrm{ft}^{3} / \mathrm{s}\right)\end{array}$ \\
\hline & & & STREAMS IRIBUTARY TO LAKE MICHIGAN--Cont inued & & & & \\
\hline 04106500 & $\begin{array}{r}\text { Portage } \\
\text { Creek }\end{array}$ & $\begin{array}{l}\text { Kalamazoo } \\
\text { River }\end{array}$ & $\begin{array}{l}\text { Lat } 42^{\circ} 16^{\prime} 27^{\prime \prime} \text {, long } 85^{\circ} 34^{\prime} 35^{\prime \prime} \text {, in } N W 1 / 4 \\
\text { NE } 1 / 4 \text { sec. } 27 \text {, I.2 S., R. } 11 \text { W., Kalamazoo } \\
\text { County, Hydrologic Unit } 0405003 \text {, at Reed } \\
\text { Avenue in Kalamazoo. }\end{array}$ & 46.8 & $\begin{array}{l}1948-58 \neq \\
1975-86 \mid\end{array}$ & $\begin{array}{l}10-06-86 \\
09-10-87\end{array}$ & $\begin{array}{l}* 76.5 \\
* 33.0\end{array}$ \\
\hline 04106512 & $\begin{array}{r}\text { Portage } \\
\text { Creek }\end{array}$ & $\begin{array}{l}\text { Ka lamazoo } \\
\text { River }\end{array}$ & $\begin{array}{l}\text { Lat } 42^{\circ} 17^{\prime} 40^{\prime \prime} \text {, long } 85^{\circ} 34^{\prime} 25^{\prime \prime} \text {, in SEI/4 } \\
\text { sec.15, T.2 S., R.11 W., Ka lamazoo } \\
\text { County, Hydrologic Unit } 04050003 \text {, at } \\
\text { Kalamazoo Avenue in Kalamazoo. }\end{array}$ & 51.4 & $\begin{array}{l}1946-48 \\
1968,1970 \\
1972,1976 \\
1986\end{array}$ & $\begin{array}{l}06-17-87 \\
09-10-87\end{array}$ & $\begin{array}{l}* 37.9 \\
\star 39.6\end{array}$ \\
\hline 04106513 & $\begin{array}{l}\text { Arcadia } \\
\text { Creek }\end{array}$ & $\begin{array}{l}\text { Kalamazoo } \\
\text { River }\end{array}$ & $\begin{array}{l}\text { Lat } 42^{\circ} 17^{\prime} 40^{\prime \prime} \text {, long } 85^{\circ} 35^{\prime} 28^{\prime \prime} \text {, in SE } 1 / 4 \\
\text { sec. } 16 \text {, T.2 S., R. } 11 \mathrm{~W} \text {., Kalamazoo } \\
\text { County, Hydrologic Unit } 04050003 \text {, at } \\
\text { Kalamazoo Avenue in Kalamazoo. }\end{array}$ & 20.0 & 1986 & $\begin{array}{l}10-08-86 \\
06-16-87 \\
09-10-87\end{array}$ & $\begin{array}{l}\star 6.16 \\
\star 3.39 \\
\star 4.13\end{array}$ \\
\hline 04106750 & Spring Brook & $\begin{array}{l}\text { Kaldamazoo } \\
\text { River }\end{array}$ & $\begin{array}{l}\text { Lat } 42^{\circ} 21^{\prime} 24^{\prime \prime} \text {, long } 85^{\circ} 33^{\prime} 05^{\prime \prime} \text {, in NWl/4 } \\
\text { sec.25, T.I S., R. } 11 \text { W., Ka lamazoo } \\
\text { County, Hydrologic Unit } 04050003 \text {, at River- } \\
\text { view Orive, } 0.6 \text { i north of East Cooper. }\end{array}$ & 31.1 & $\begin{array}{l}1942 \\
1964-71 \\
1984 \\
1986\end{array}$ & $\begin{array}{l}10-08-86 \\
06-16-87 \\
09-10-87\end{array}$ & $\begin{array}{l}\star 30.2 \\
\star 17.6 \\
\star 20.2\end{array}$ \\
\hline 04106770 & $\begin{array}{l}\text { Kalamazoo } \\
\text { River }\end{array}$ & $\begin{array}{l}\text { Lake } \\
\qquad \text { Michigan }\end{array}$ & $\begin{array}{l}\text { Lat } 42^{\circ} 22^{\prime} 35^{\prime \prime} \text {, long } 85^{\circ} 34^{\prime} 47^{\prime \prime} \text {, in } \\
\text { SE } 1 / 4 \text { sec. } 15 \text {, T. } 1 \text { S., R. } 11 \text { W. , } \\
\text { Kalamazoo County, Hydrologic Unit } \\
04050003 \text {, at D Avenue, } 1.5 \text { i east } \\
\text { of Cooper Center. }\end{array}$ & 1,250 & $\begin{array}{l}1965-66 \\
1968-71 \\
1986\end{array}$ & $\begin{array}{l}10-09-86 \\
06-17-87 \\
09-11-87\end{array}$ & $\begin{array}{r}\star 2,980 \\
\star 482 \\
\star 955\end{array}$ \\
\hline 04107215 & Gun River & $\begin{array}{l}\text { Kalamazoo } \\
\text { River }\end{array}$ & $\begin{array}{l}\text { Lat } 42 \cdot 32^{\prime} 17 " \text {, long } 85^{\circ} 33^{\prime} 47 " \text { ", in SE1/4 } \\
\text { sec.23, T.2 N., R. } 11 \mathrm{~W} . \text {. Allegan } \\
\text { County, Hydrologic Unit } 04050003 \text {, at } \\
\text { l16th Avenue, } 4.0 \text { mi east of Martin. }\end{array}$ & 73.3 & $\begin{array}{l}1963 \\
1965 \\
1986\end{array}$ & $\begin{array}{l}11-07-86 \\
07-24-87\end{array}$ & $\begin{array}{l}\text { b77.2 } \\
\text { b } 12.9\end{array}$ \\
\hline 04107220 & Gun River & $\begin{array}{c}\text { Kaldamazoo } \\
\text { River }\end{array}$ & $\begin{array}{l}\text { Lat } 42 \cdot 30^{\prime} 56^{\prime \prime} \text {, long } 85^{\circ} 33^{\prime} 46^{\prime \prime} \text {, in NWl/4 } \\
\text { SWl } / 4 \mathrm{sec} .36 \text {, T.2 N., R. } 11 \text { W.. Allegan } \\
\text { County, Hydrologic Unit } 04050003 \text {, at } \\
\text { 2nd Street, } 0.5 \text { i north of Hooper. }\end{array}$ & $\cdots$ & 1986 & $\begin{array}{l}11-07-86 \\
07-24-87\end{array}$ & $\begin{array}{l}\text { b86.6 } \\
\text { b } 16.6\end{array}$ \\
\hline 04107223 & Gun River & $\begin{array}{l}\text { Kalamazoo } \\
\text { River }\end{array}$ & $\begin{array}{l}\text { Lat } 42^{\circ} 30^{\prime} 34^{\prime \prime} \text {, long } 85^{\circ} 33^{\prime} 36^{\prime \prime} \text {, in SWl/4 } \\
\text { SWl } / 4 \text { sec.36, T.2 N., R. } 11 \text { W., Allegan } \\
\text { County, Hydrologic Unit } 04050003 \text {, at } \\
112 \text { th Avenue in Hooper. }\end{array}$ & -- & 1986 & $11-07-86$ & b93.2 \\
\hline 04107225 & Gun River & $\begin{array}{c}\text { Kalamazoo } \\
\text { River }\end{array}$ & $\begin{array}{l}\text { Lat } 42^{\circ} 29^{\prime} 38^{\prime \prime} \text {, long } 85^{\circ} 35^{\prime} 03^{\prime \prime} \text {, in SE } 1 / 4 \\
\text { sec.3, T.I i., R. } 11 \mathrm{~W} . \text { Allegan County, } \\
\text { Hydrologic Unit } 04050003 \text {, at } 110 \text { th } \\
\text { Avenue, } 5.0 \text { i northeast of Pla inwell. }\end{array}$ & -. & 1986 & $\begin{array}{l}11-07-86 \\
07-24-87\end{array}$ & $\begin{array}{l}\text { b } 101 \\
\text { b22.8 }\end{array}$ \\
\hline 04107228 & Gun River & $\begin{array}{c}\text { Ka lamazoo } \\
\text { River }\end{array}$ & $\begin{array}{l}\text { Lat } 42^{\circ} 28^{\prime} 40^{\prime \prime} \text {, long } 85^{\circ} 36^{\prime} 44^{\prime \prime} \text {, in NW1/4 } \\
\text { NE } 1 / 4 \mathrm{sec} .16 \text {, T. I N., R. } 11 \text { W. Allegan } \\
\text { County, Hydrologic Unit } 04050003 \text {, at } \\
7 \text { th Street, } 3.0 \text { i northeast of Pla inwell. }\end{array}$ & -- & 1986 & $\begin{array}{l}11-07-86 \\
07-24-87\end{array}$ & $\begin{array}{l}\text { b } 111 \\
\text { b24.0 }\end{array}$ \\
\hline 04107233 & Gun River & $\begin{array}{l}\text { Ka lamazoo } \\
\text { River }\end{array}$ & $\begin{array}{l}\text { Lat } 42^{\circ} 28^{\prime} 18^{\prime \prime} \text {, long } 85^{\circ} 39^{\prime} 03^{\prime \prime} \text {, in SWl/4 } \\
\text { NE } 1 / 4 \mathrm{sec} .18 \text {, T. I N., R. } 11 \text { W. Allegan } \\
\text { County. Hydrologic Unit } 04050003 \text {, at } \\
\text { 107th Avenue, } 2.0 \text { i north of Plainwell. }\end{array}$ & -- & 1986 & $\begin{array}{l}11-07-86 \\
07-24-87\end{array}$ & $\begin{array}{l}\text { b } 115 \\
\text { b30.9 }\end{array}$ \\
\hline 04107710 & Sand Creek & Pine Creek & $\begin{array}{l}\text { Lat } 42^{\circ} 21^{\prime} 02^{\prime \prime} \text {, long } 85^{\circ} 44^{\prime} 43^{\prime \prime} \text {, in SWl } / 4 \\
\text { sec. } 29 \text {, T. I S., R. } 12 \mathrm{~W} . \mathrm{Kal} \text { amazoo } \\
\text { County. Hydrologic Unit } 04050003 \text {, at } \\
\text { 2nd Street, } 2.0 \text { i southwest of Alamo. }\end{array}$ & 21.2 & $\begin{array}{l}1964 \\
1966-67 \\
1986\end{array}$ & $\begin{array}{l}10-08-86 \\
06-16-87 \\
09-10-87\end{array}$ & $\begin{aligned} \star & 30.5 \\
\star & 9.33 \\
\star & 11.8\end{aligned}$ \\
\hline 04107750 & $\begin{array}{l}\text { Rupert Lake } \\
\text { Out let }\end{array}$ & Pine Creek & $\begin{array}{l}\text { Lat } 42^{\circ} 24^{\prime} 53^{\prime \prime} \text {, long } 85^{\circ} 44^{\prime} 17^{\prime} \text {, in NEl } / 4 \\
\text { sec.5, T.I S., R. } 12 \mathrm{~W} \text {., Kalamazoo County, } \\
\text { Hydrologic Unit } 04050003 \text {, at AB Avenue, } \\
5.5 \text { i southwest of Plainwell. }\end{array}$ & 5.27 & $\begin{array}{l}1964-67, \\
1986\end{array}$ & $\begin{array}{l}10-08-86 \\
06-16-87 \\
09-10-87\end{array}$ & $\begin{array}{l}\star 30.7 \\
\star 8.32 \\
\star 10.3\end{array}$ \\
\hline
\end{tabular}




\begin{tabular}{|c|c|c|c|c|c|c|c|}
\hline \multirow[b]{2}{*}{$\begin{array}{l}\text { Station } \\
\text { No. }\end{array}$} & \multirow[b]{2}{*}{ Stream } & \multirow[b]{2}{*}{ Iributary to } & \multirow[b]{2}{*}{ Location } & \multirow{2}{*}{$\begin{array}{l}\text { Drainage } \\
\text { area } \\
\qquad\left(m i^{2}\right)\end{array}$} & \multirow{2}{*}{$\begin{array}{l}\text { Measured } \\
\text { previously } \\
\text { (water } \\
\text { years) }\end{array}$} & \multicolumn{2}{|c|}{ Measurements } \\
\hline & & & & & & Date & $\begin{array}{c}\text { Discharge } \\
\left(\mathrm{ft}^{3} / \mathrm{s}\right)\end{array}$ \\
\hline & & & STREAMS TRIBUTARY TO LAKE MICHIGAN--Cont inued & & & & \\
\hline 04108900 & Grand River & $\begin{array}{l}\text { Lake } \\
\qquad \text { Michigan }\end{array}$ & $\begin{array}{l}\text { Lat } 42^{\circ} 10^{\prime} 08^{\prime \prime} \text {, long } 84^{\circ} 23^{\prime} 02^{\prime \prime} \text {, in SE } 1 / 4 \\
\text { NE } 1 / 4 \mathrm{sec} .35 \text {, T.3 S., R. } 1 \text { W., Jackson County, } \\
\text { Hydrologic Unit } 04050004 \text {, at Draper Road, } \\
2.0 \text { i south of Vandercook Lake. }\end{array}$ & -- & $\begin{array}{l}1960 \\
1963-65 \\
1974-79\end{array}$ & $03-20-87$ & b38.1 \\
\hline 04114520 & Grand River & $\begin{array}{l}\text { Lake } \\
\qquad \text { Michigan }\end{array}$ & $\begin{array}{l}\text { Lat } 42^{\circ} 57^{\prime} 10^{\prime \prime} \text {, long } 84^{\circ} 54^{\prime} 10^{\prime \prime} \text {, in NE } 1 / 4 \\
\text { NE } 1 / 4 \mathrm{sec} .33 \text {, T. } 7 \mathrm{~N} . \mathrm{R}^{\circ} \mathrm{W} \text {., Ionia County, } \\
\text { Hydrologic Unit } 04050004 \text { below Webber Daw, } \\
1.5 \text { i southedst of Lyons. }\end{array}$ & -- & 1979 & $\begin{array}{l}08-04-87 \\
08-04-87 \\
08-04-87\end{array}$ & $\begin{array}{l}g 125 \\
9191 \\
g 200\end{array}$ \\
\hline 04115265 & Fish Creek & Maple River & $\begin{array}{l}\text { Lat } 43^{\circ} 14^{\prime} 59^{\prime \prime} \text {, long } 84^{\circ} 58^{\prime} 52^{\prime \prime} \text {, in NW1/4 } \\
\text { NE } 1 / 4 \text { sec. } 23 \text {, T. } 10 \mathrm{~N} . \mathrm{R}^{\mathrm{R} .6} \text { W., Montcalm County, } \\
\text { Hydrologic Unit } 04050005 \text { at Sidney Road, } 3.3 \\
\text { i southwest of Crystal. }\end{array}$ & $\cdots$ & 1983 & $\begin{array}{l}08-04-87 \\
08-26-87\end{array}$ & $\begin{array}{r}\star b 14.9 \\
\quad 39.2\end{array}$ \\
\hline 04121970 & $\begin{array}{l}\text { Muskegon } \\
\text { River }\end{array}$ & $\begin{array}{l}\text { Muskegon } \\
\text { Lake }\end{array}$ & $\begin{array}{l}\text { Lat } 43^{\circ} 26^{\prime} 05^{\prime \prime} \text {, long } 85^{\circ} 39^{\prime} 55^{\prime \prime} \text {, in SE } 1 / 4 \\
\text { NE } 1 / 4 \mathrm{sec} .18 \text {, T. } 12 \mathrm{~N} ., \mathrm{R} .11 \mathrm{~W} \text {., Newaygo County, } \\
\text { Hydrologic Unit } 04060102 \text {, at Croton Drive } \\
\text { below Croton Dam, in Croton. }\end{array}$ & -- & -- & $08-27-87$ & 9940 \\
\hline 04124200 & $\begin{array}{l}\text { Manistee } \\
\text { River }\end{array}$ & $\begin{array}{l}\text { Manistee } \\
\text { Lake }\end{array}$ & $\begin{array}{l}\text { Lat } 44^{\circ} 21^{\prime} 30^{\prime \prime} \text {, long } 85^{\circ} 49^{\prime} 15^{\prime \prime} \text {, in SE } 1 / 4 \\
\text { NE } 1 / 4 \mathrm{sec} .25 \text {, T. } 23 \mathrm{~N} . \mathrm{R}^{\circ} 13^{\mathrm{W}} \text {., Manistee County, } \\
\text { Hydrologic Unit } 04060103 \text {, at Hodenpyle Dam, } \\
3.0 \text { i east of Marilla. }\end{array}$ & 999 & $1969-70$ & $08-18-87$ & 9492 \\
\hline 04125550 & $\begin{array}{l}\text { Manistee } \\
\text { River }\end{array}$ & $\begin{array}{l}\text { Manistee } \\
\text { Lake }\end{array}$ & 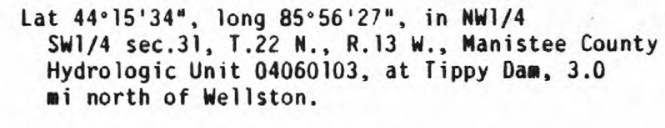 & $\cdots$ & - & $08-18-87$ & 9871 \\
\hline 04126645 & $\begin{array}{l}\text { Platte } \\
\text { River }\end{array}$ & $\begin{array}{l}\text { Lake } \\
\text { Micnigan }\end{array}$ & $\begin{array}{l}\text { Lat } 44^{\circ} 41^{\prime} 13^{\prime \prime} \text {, long } 85^{\circ} 50^{\prime} 16^{\prime \prime} \text {, in NWl/4 } \\
\text { NW1/4 sec. } 1 \text {, T.26 N., R. } 13 \text { W. Benzie County } \\
\text { Hydrologic Unit } 04060104 \text {, at County Road } 665 \text {, } \\
2.6 \text { m i south of Lake Ann. }\end{array}$ & -- & -- & $\begin{array}{l}06-16-87 \\
07-14-87 \\
08-19-87 \\
09-14-87\end{array}$ & $\begin{array}{l}{ }^{\star b} 3.92 \\
{ }^{*} \mathrm{~b} 5.03 \\
{ }^{\star b} 4.89 \\
\mathrm{~b} 4.13\end{array}$ \\
\hline 04126650 & $\begin{array}{l}\text { Unnamed } \\
\text { tributary }\end{array}$ & Lake Ann & $\begin{array}{l}\text { Lat } 44^{\circ} 42^{\prime} 50^{\prime \prime} \text {, long } 85^{\circ} 50^{\prime} 18^{\prime \prime} \text {, in SE } 1 / 4 \\
\text { NE } 1 / 4 \text { sec. } 26 \text {, T.27 N., R. } 13 \text { W., Benzie County, } \\
\text { Hydrologic Unit } 04060104 \text {, at County Road } 665 \text {, } \\
0.8 \text { i south of Lake Ann. }\end{array}$ & 4.78 & 1958 & $\begin{array}{l}06-16-87 \\
07-14-87 \\
08-19-87 \\
09-14-87\end{array}$ & $\begin{array}{l}{ }^{\star b} 5.98 \\
\star b 5.89 \\
{ }^{*} \mathrm{~b} 8.75 \\
\mathrm{~b} 6.05\end{array}$ \\
\hline 04126653 & $\begin{array}{l}\text { Platte } \\
\text { River }\end{array}$ & $\begin{array}{l}\text { Lake } \\
\text { Michigan }\end{array}$ & $\begin{array}{l}\text { Lat } 44^{\circ} 42 \cdot 31^{\prime \prime} \text {, long } 85^{\circ} 51 \cdot 17^{\prime \prime} \text {, in NW1/4 } \\
\text { SW1/4 sec.26, T.27 N., R.13 W., Benzie County, } \\
\text { Hydrologic Unit } 04060104 \text {, at Birchview Trail, } \\
1.1 \text { i southwest of Lake Ann. }\end{array}$ & -- & -- & $\begin{array}{l}06-16-87 \\
07-14-87 \\
08-19-87 \\
09-14-87\end{array}$ & $\begin{aligned} * b 23.1 \\
{ }^{*} \mathrm{~b} 24.7 \\
{ }^{\mathrm{b}} 36.3 \\
\mathrm{~b} 25.6\end{aligned}$ \\
\hline 04126664 & $\begin{array}{l}\text { Platte } \\
\text { River }\end{array}$ & $\begin{array}{l}\text { Lake } \\
\text { Michigan }\end{array}$ & $\begin{array}{l}\text { Lat } 44^{\circ} 39^{\prime} 56^{\prime \prime} \text {, long } 85^{\circ} 55^{\prime} 59^{\prime \prime} \text {, in NE } 1 / 4 \\
\text { SWl/4 sec.7, T.26 N., R. } 13 \text { W. Benzie County, } \\
\text { Hydrologic Unit } 04060104,200 \mathrm{ft} \text { upstream } \\
\text { of Brundage Creek, upstream of State Fish } \\
\text { Hatchery, } 4.0 \text { i east of Honor. }\end{array}$ & -- & 1975 & $\begin{array}{l}06-18-87 \\
07-15-87 \\
08-18-87 \\
09-14-87\end{array}$ & $\begin{array}{l}\star b 56.0 \\
\star b 51.0 \\
b 72.0 \\
b 54.5\end{array}$ \\
\hline 04126695 & $\begin{array}{c}\text { Brundage } \\
\text { Creek }\end{array}$ & $\begin{array}{l}\text { Platte } \\
\text { River }\end{array}$ & $\begin{array}{l}\text { Lat } 44^{\circ} 39^{\prime} 58^{\prime \prime} \text {, long } 85^{\circ} 55^{\prime} 58^{\prime \prime} \text {, in NEl/4 } \\
\text { SW } 1 / 4 \text { sec.7, T.26 N., R.13 W. Benzie County, } \\
\text { Hydrologic Unit } 04060104 \text {, at County Road } 669 \text {, } \\
4.0 \text { i east of Honor. }\end{array}$ & -- & -- & $08-18-87$ & b11.6 \\
\hline 04126700 & $\begin{array}{l}\text { Platte } \\
\text { River }\end{array}$ & $\begin{array}{l}\text { Lake } \\
\quad \text { Michigan }\end{array}$ & 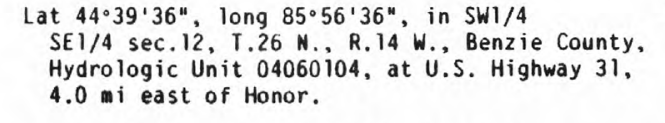 & 91.9 & $\begin{array}{l}1958, \\
1960-69 \\
1980-81\end{array}$ & $\begin{array}{l}06-17-87 \\
07-16-87 \\
08-18-87 \\
09-14-87\end{array}$ & $\begin{aligned} * b 70.8 \\
{ }^{\star} \mathrm{b} 77.6 \\
\mathrm{~b} 98.1 \\
\mathrm{~b} 75.1\end{aligned}$ \\
\hline 04126742 & $\begin{array}{l}\text { Platte } \\
\text { River }\end{array}$ & $\begin{array}{l}\text { Lake } \\
\text { Michigan }\end{array}$ & $\begin{array}{l}\text { Lat } 44^{\circ} 40^{\prime} 17^{\prime \prime} \text {, long } 86^{\circ} 02^{\prime} 12^{\prime \prime} \text {, in NWl/4 } \\
\text { NW1/4 sec.8, T.26 N., R. } 14 \text { W. Benzie County, } \\
\text { Hydrologic Unit } 04060104 \text {, at Indian Hill Road, } \\
1.0 \mathrm{ni} \text { northwest of Honor. }\end{array}$ & 118 & $\begin{array}{l}1958 \\
1968 \\
1980-81\end{array}$ & $\begin{array}{l}06-18-87 \\
07-16-87 \\
08-19-87 \\
09-15-87\end{array}$ & $\begin{array}{l}* b 107 \\
\star b 112 \\
* b 137 \\
\text { b } 112\end{array}$ \\
\hline 04126751 & $\begin{array}{l}\text { North Branch } \\
\text { Platte } \\
\text { River }\end{array}$ & $\begin{array}{l}\text { Platte } \\
\text { River }\end{array}$ & $\begin{array}{l}\text { Lat } 44^{\circ} 41^{\prime} 01^{\prime \prime} \text {, long } 86^{\circ} 03^{\prime} 30^{\prime \prime} \text {, in SEl/4 } \\
\text { NE } 1 / 4 \text { sec. } 1 \text {, T.26 } N . R^{\circ} 15 \text { W. Benzie County, } \\
\text { Hydrologic Unit } 04060104 \text {, at Deadstrea Road, } \\
2.5 \text { m i northwest of Honor. }\end{array}$ & 31.1 & $\begin{array}{l}1958, \\
1980-81\end{array}$ & $\begin{array}{l}06-17-87 \\
07-16-87 \\
08-19-87 \\
09-15-87\end{array}$ & $\begin{array}{l}{ }^{*} \mathrm{~b} 12.1 \\
{ }^{\mathrm{b}} 10.4 \\
{ }^{\mathrm{b}} \mathrm{b} 32.2 \\
\mathrm{~b} 19.2\end{array}$ \\
\hline 04126755 & $\begin{array}{l}\text { Platte } \\
\text { River }\end{array}$ & $\begin{array}{l}\text { Lake } \\
\text { Michigan }\end{array}$ & 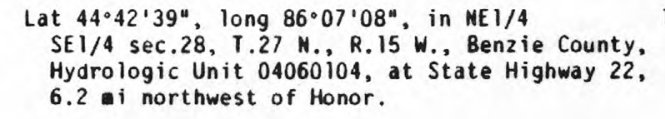 & 166 & $\begin{array}{l}1946-48 \\
1958 \\
1979-82\end{array}$ & $\begin{array}{l}06-17-87 \\
07-15-87 \\
08-19-87 \\
09-15-87\end{array}$ & $\begin{array}{r}\text { *b } 122 \\
\text { *b } 116 \\
\text { *b } 178 \\
\text { b } 140\end{array}$ \\
\hline
\end{tabular}




\begin{tabular}{|c|c|c|c|c|c|c|c|}
\hline \multirow[b]{2}{*}{$\begin{array}{l}\text { Station } \\
\text { No. }\end{array}$} & \multirow[b]{2}{*}{ Stream } & \multirow[b]{2}{*}{ Tributary to } & \multirow[b]{2}{*}{ Location } & \multirow[b]{2}{*}{$\begin{array}{l}\text { Drainage } \\
\text { area } \\
\quad\left(\mathbf{i}^{2}\right)\end{array}$} & \multirow{2}{*}{$\begin{array}{l}\text { Measured } \\
\text { previously } \\
\text { (water } \\
\text { years) }\end{array}$} & \multicolumn{2}{|c|}{ Measurements } \\
\hline & & & & & & Date & $\begin{array}{c}\text { Discharge } \\
\left(\mathrm{ft}^{3} / \mathrm{s}\right)\end{array}$ \\
\hline \multicolumn{8}{|c|}{ STREAMS TRIBUTARY TO LAKE MICHIGAN--Cont inued } \\
\hline 04126758 & $\begin{array}{l}\text { Platte } \\
\text { River }\end{array}$ & $\begin{array}{l}\text { Lake } \\
\text { Michigan }\end{array}$ & 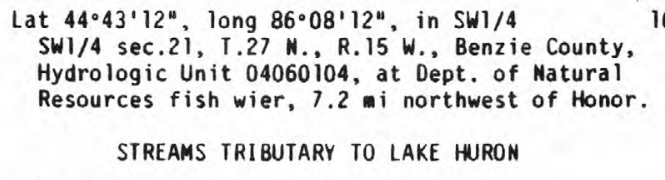 & 169 & $1979-82$ & $\begin{array}{l}07-15-87 \\
09-15-87\end{array}$ & $\begin{array}{r}\text { *b } 115 \\
\text { b } 132\end{array}$ \\
\hline 04137005 & $\begin{array}{l}\text { Au Sable } \\
\text { River }\end{array}$ & Lake Huron & $\begin{array}{l}\text { Lat } 44^{\circ} 33^{\prime} 37^{\prime \prime} \text {, long } 83^{\circ} 48^{\prime} 12^{\prime \prime} \text {, in SW1/4 } \\
\text { NWI/4 sec. } 14 \text {, T. } 25 \mathrm{~N} ., \text { R.5 E., Alcona County, } \\
\text { Hydrologic Unit } 04070007 \text {, at Banfield Road, } \\
3.2 \text { i east of Curtisvilie. }\end{array}$ & -- & -- & $\begin{array}{l}08-11-87 \\
08-12-87\end{array}$ & $\begin{array}{l}9479 \\
9439\end{array}$ \\
\hline 04138615 & Gamble Creek & Rifle River & $\begin{array}{l}\text { Lat } 44^{\circ} 24^{\prime} 53^{\prime \prime} \text {, long } 84^{\circ} 01^{\prime} 45^{\prime \prime} \text {, in SE } 1 / 4 \\
\text { NE } 1 / 4 \text { sec. T, T.23 } \mathrm{N} ., \mathrm{R} .3^{\mathrm{E}} \text {., Ogewaw County, } \\
\text { Hydrologic Unit } 04080101 \text {, at Ranch Road, } 1.2 \\
\text { i south of Lupton. }\end{array}$ & 14.1 & $\begin{array}{l}1951-52 \\
1968-69\end{array}$ & $07-01-87$ & $\star 18.4$ \\
\hline 0413861550 & $\begin{array}{l}\text { Grousehaven } \\
\text { Lake } \\
\text { Out let }\end{array}$ & Gable Creek & 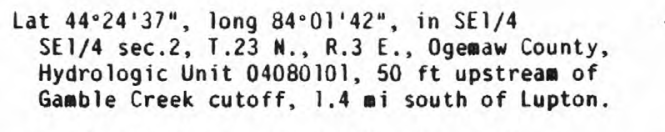 & -- & -- & $07-02-87$ & $\star 3.08$ \\
\hline 04138616 & $\begin{array}{l}\text { Unnamed } \\
\text { tributary }\end{array}$ & Gamble Creek & $\begin{array}{l}\text { Lat } 44^{\circ} 24^{\prime} 53^{\prime \prime} \text {, long } 84^{\circ} 02^{\prime} 08^{\prime \prime} \text {, in SEl/4 } \\
\text { NW1/4 sec.2, T.23 N., R.3 E., Ogemaw County, } \\
\text { Hydrologic Unit } 04080101 \text {, at Ranch Road, } 1.2 \\
\text { i southwest of Lupton. }\end{array}$ & -- & -- & $07-01-87$ & $\star 1.20$ \\
\hline 04138645 & Oyster Creek & Gamble Creek & 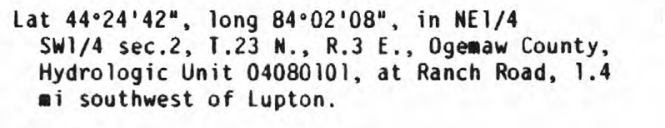 & 10.4 & $\begin{array}{l}1951-52 \\
1968-69\end{array}$ & $07-01-87$ & $\star 2.88$ \\
\hline 04138646 & $\begin{array}{l}\text { Unnamed } \\
\text { tributary }\end{array}$ & Oyster Creek & $\begin{array}{l}\text { Lat } 44^{\circ} 24^{\prime} 34^{\prime \prime} \text {, long } 84^{\circ} 02^{\prime} 08^{\prime \prime} \text {, in SWI/4 } \\
\text { SE } 1 / 4 \mathrm{sec} .2 \text {, T.23 } N ., R .3^{\mathrm{E}} \text {., Ogemaw County, } \\
\text { Hydrologic Unit } 04080101 \text {, at Ranch Road, } 1.5 \\
\text { i southwest of Lupton. }\end{array}$ & -- & -- & $07-01-87$ & $\star 5.63$ \\
\hline 04138652 & $\begin{array}{l}\text { Devoe Lake } \\
\text { Inlet }\end{array}$ & Devoe Lake & $\begin{array}{l}\text { Lat } 44^{\circ} 24^{\prime} 14^{\prime \prime} \text {, long } 84^{\circ} 01^{\prime} 48^{\prime \prime} \text {, in NEI/4 } \\
\text { NE } 1 / 4 \mathrm{sec} .11, \mathrm{~T} .23 \mathrm{~N} ., \mathrm{R} .3 \mathrm{E} . \text {, Ogemaw County, } \\
\text { Hydrologic Unit } 04080101,50 \mathrm{ft} \text { south of Gamble } \\
\text { Creek Diversion, } 1.8 \mathrm{mi} \text { south of Lupton. }\end{array}$ & $-\cdot$ & -- & $07-02-87$ & $\star 2.25$ \\
\hline 04138658 & $\begin{array}{c}\text { Gamble Creek } \\
\text { Diversion }\end{array}$ & Rifle River & 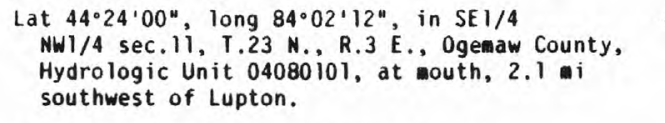 & $-\cdot$ & -- & $07-01-87$ & $\star 34.8$ \\
\hline 04138670 & Rifle River & Lake Huron & $\begin{array}{l}\text { Lat } 44^{\circ} 23^{\prime} 57^{\prime \prime} \text {, long } 84^{\circ} 02^{\prime} 07^{\prime \prime} \text {, in NWI/4 } \\
\text { SE } 1 / 4 \text { sec. II, T. } 23 \mathrm{N.}, \mathrm{R} .3^{\mathrm{E}} \text {. O Ogemaw County, } \\
\text { Hydrologic Unit } 04080101 \text {, at Rifle Road, } 2.3 \\
\text { i south of Lupton. }\end{array}$ & 26.4 & $\begin{array}{l}1945-52 \\
1968-69\end{array}$ & $07-01-87$ & $\star 35.8$ \\
\hline 04144230 & Webb Creek & $\begin{array}{c}\text { Shiawassee } \\
\text { River }\end{array}$ & $\begin{array}{l}\text { Lat } 42^{\circ} 56^{\prime} 27^{\prime \prime} \text {, long } 83^{\circ} 56^{\prime} 35^{\prime \prime} \text {, in NW1/4 } \\
\text { sec. } 12 \text {, T.6 N., R. } 4 \mathrm{E} \text {., Shiawassee County, } \\
\text { Hydrologic Unit } 04080203 \text {, at Bennington Road, } \\
3.0 \text { i northeast of Durand. }\end{array}$ & -- & 1969 & $11-17-86$ & $\star 6.90$ \\
\hline 04144233 & Webb Creek & $\begin{array}{c}\text { Shiawassee } \\
\text { River }\end{array}$ & $\begin{array}{l}\text { Lat } 42^{\circ} 57^{\prime} 05^{\prime \prime} \text {, long } 83^{\circ} 57^{\prime} 16^{\prime \prime} \text {, SEI/4 } \\
\text { NE } 1 / 4 \text { sec.2, T.6 } N ., \text { R.4 E. Shiawassee County, } \\
\text { Hydrologic Unit } 04080203 \text {, at Goodall Road, } \\
2.0 \text { i northeast of Durand. }\end{array}$ & $\cdots$ & -- & $11-17-86$ & $\star 6.99$ \\
\hline 04144234 & Webb Creek & $\begin{array}{c}\text { Shiawassee } \\
\text { River }\end{array}$ & $\begin{array}{l}\text { Lat } 42.57 \cdot 17 \text {, long } 83.57 \cdot 27 \text { ", in NWI/4 } \\
\text { NE } 1 / 4 \text { sec.2, T.6 N., R.4 E., Shiawassee County, } \\
\text { Hydrologic Unit } 04080203 \text {, at Grand Trunk R.R., } \\
2.0 \text { i northeast of Durand. }\end{array}$ & -- & - & $11-17-86$ & $\star 7.81$ \\
\hline 04144238 & Webb Creek & $\begin{array}{l}\text { Shiawassee } \\
\text { River }\end{array}$ & $\begin{array}{l}\text { Lat } 42^{\circ} 57^{\prime} 22^{\prime \prime} \text {, long } 83^{\circ} 58^{\prime} 10^{\prime \prime} \text {, in NE } 1 / 4 \\
\text { NE } 1 / 4 \mathrm{sec} .3 \text {, T.6 N., R.4 E., Shiawassee County, } \\
\text { County, Hydrologic Unit } 04080203 \text {, at Interstate } \\
\text { Highway } 69.2 .0 \text { northeast of Durand. }\end{array}$ & $\cdots$ & -- & $11-17-86$ & $\star 8.45$ \\
\hline
\end{tabular}

See footnotes at end of table. 


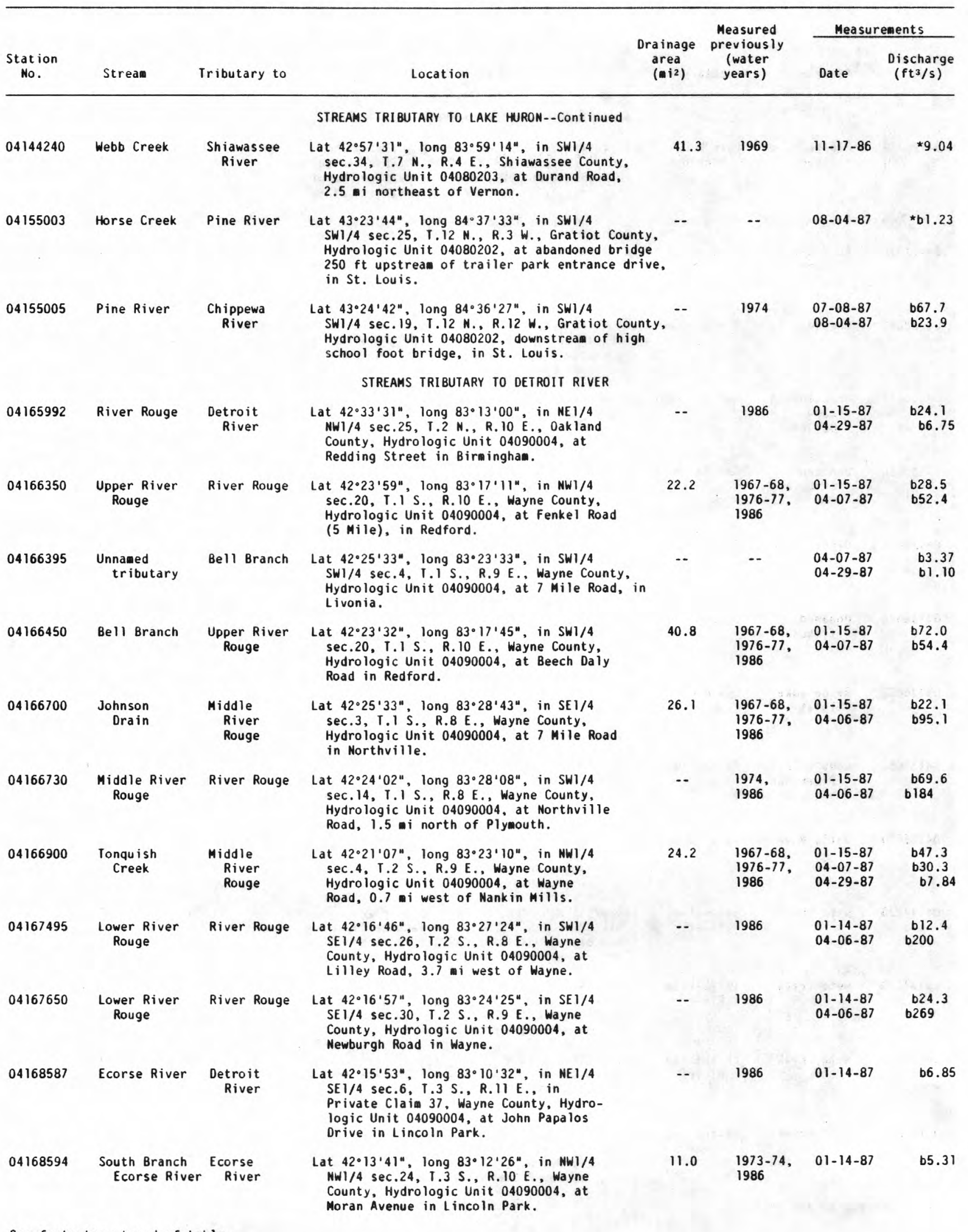

See footnotes at end of table. 
Discharge measurements made at special study and miscellaneous sites during water year 1987--Continued

\begin{tabular}{|c|c|c|c|c|c|c|c|}
\hline \multirow[b]{2}{*}{$\begin{array}{l}\text { Station } \\
\text { No. }\end{array}$} & \multirow[b]{2}{*}{ Stream } & \multirow[b]{2}{*}{ Tributary to } & \multirow[b]{2}{*}{ Location } & \multirow{2}{*}{$\begin{array}{l}\text { Drainage } \\
\text { area } \\
\left( \pm i^{2}\right)\end{array}$} & \multirow{2}{*}{$\begin{array}{l}\text { Measured } \\
\text { previously } \\
\text { (water } \\
\text { years) }\end{array}$} & \multicolumn{2}{|c|}{ Measurements } \\
\hline & & & & & & Date & $\begin{array}{l}\text { Discharge } \\
\left(\mathrm{ft}^{3} / \mathrm{s}\right)\end{array}$ \\
\hline \multicolumn{8}{|c|}{ SIREAMS TRIBUTARY TO LAKE ERIE } \\
\hline 04175207 & $\begin{array}{l}\text { North Branch } \\
\text { Swan Creek }\end{array}$ & Swan Creek & $\begin{array}{l}\text { Lat } 42^{\circ} 04^{\prime} 45^{\prime \prime} \text {, long } 83^{\circ} 22^{\prime} 08^{\prime \prime} \text {, in } S W 1 / 4 \\
\text { SE } 1 / 4 \mathrm{sec} .4 \text {, J.5 S., R.9 E.. Monroe County, } \\
\text { Hydrologic Unit } 04100001 \text {, at Newburg Road, } \\
1.7 \text { i northeast of Carleton. }\end{array}$ & 21.1 & $1971-73$ & d09-09-86 & 0.00 \\
\hline 04175227 & $\begin{array}{l}\text { Little Swan } \\
\text { Creek }\end{array}$ & Swan Creek & $\begin{array}{l}\text { Lat } 42^{\circ} 06^{\prime} 26^{\prime \prime} \text {, long } 83^{\circ} 19^{\prime} 36^{\prime \prime}, S W 1 / 4 \\
\text { sec. } 23 \text {, T.5 S., R.9 E., Monroe County, } \\
\text { Hydrologic Unit } 04100001 \text {, upstrean of } \\
\text { confluence with Swan Creek, } 3.5 \mathrm{mi} \text { southwest } \\
\text { of South Rockford. }\end{array}$ & -- & $\begin{array}{l}1963 \\
1982\end{array}$ & d09-09-86 & 0.00 \\
\hline 04175231 & $\begin{array}{r}\text { Colburn } \\
\text { Drain }\end{array}$ & Swan Creek & $\begin{array}{l}\text { Lat } 42^{\circ} 011^{\prime} 19^{\prime \prime} \text {, long } 83^{\circ} 19^{\prime} 07^{\prime \prime} \text {, SW1/4 } \\
\text { sec.25, I.5 S., R.9 E., Monroe County, } \\
\text { Hydrologic Unit } 04100001 \text {, at Lebo Road, } 1.2 \\
\text { i north of Newport. }\end{array}$ & -- & -- & d09-09-86 & 0.00 \\
\hline 04175235 & Swan Creek & Lake Erie & $\begin{array}{l}\text { Lat } 42^{\circ} 00^{\prime} 12^{\prime \prime} \text {, long } 83^{\circ} 18^{\prime} 02^{\prime \prime} \text {, in NE } 1 / 4 \\
\text { sec.l, T.6 S, R.9 E., Monroe County, } \\
\text { Hydrologic Unit } 04100001 \text {, at Brandon Road, } \\
\text { at Newport. }\end{array}$ & 88.4 & $1971-72$ & $d 09-09-86$ & 0.00 \\
\hline \multicolumn{8}{|c|}{$\begin{array}{l}\text { Base flow. } \\
\text { Operated as a continuous-record gaging station. } \\
\text { a Affected by regulation and diversion. } \\
\text { b Discharge measurement made by employees of Michigan Department of Natural Resources. } \\
\text { c Operated as a crest-stage partial-record station. } \\
\text { d } 1986 \text { water year. } \\
\text { e Previously published as Brown Creek. } \\
\text { f Previously published as Allen Creek. } \\
\text { g Flow regulated by powerplant upstream of measuring site. }\end{array}$} \\
\hline
\end{tabular}


Water-quality partial-record stations are particular sites where chemical-quality, biological and/or sediment data are collected systematically over a period of years for use in hydrologic analyses. These data are collected usually less than quarterly. Samples collected at sites other than gaging stations and partial-record stations to give better areal coverage in a river basin are referred to as miscellaneous sites.

WATER QUALITY DATA, WATER YEAR OCTOBER 1986 TO SEPTEMBER 1987

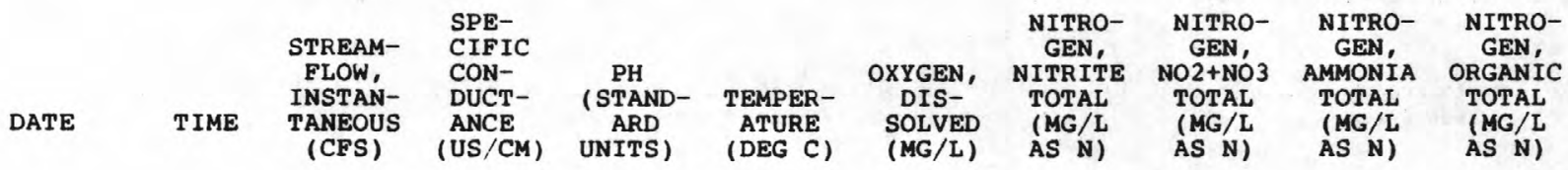

04096950 BEAR CREEK NEAR FULTON, MI

(LAT $\left.\begin{array}{lllllll}42 & 04 & 32 & \text { LONG } & 085 & 19 & 58\end{array}\right)$

\begin{tabular}{|c|c|c|c|c|c|c|c|c|c|c|}
\hline $\begin{array}{c}\text { OCT } 1986 \\
07 \\
\text { JUN } 1987\end{array}$ & 1445 & 52 & 281 & 7.5 & 11.5 & -- & $<0.01$ & 0.10 & 0.04 & 0.86 \\
\hline SEP $15 \ldots$ & 1230 & 2.8 & 470 & 8.1 & 28.0 & 5.8 & 0.02 & 0.20 & 0.10 & 1.4 \\
\hline $10 \ldots$ & 1000 & 4.4 & 450 & 7.9 & 18.5 & 7.0 & 0.01 & 0.20 & 0.06 & 0.94 \\
\hline
\end{tabular}

04097040 LITTLE PORTAGE CREEK NEAR CLIMAX, MI

(LAT $42 \quad 0951$ LONG $085 \quad 20 \quad 18$ )

\begin{tabular}{|c|c|c|c|c|c|c|c|c|c|c|}
\hline $\begin{array}{l}\text { OCT } 1986 \\
07: 9877 \\
\text { JUN } 1987\end{array}$ & 1045 & 27 & 445 & 7.8 & 10.0 & 11.2 & 0.02 & 1.70 & 0.09 & 1.9 \\
\hline SEP $15 \ldots$ & 1050 & 1.9 & 544 & 8.2 & 20.0 & 8.0 & 0.05 & 0.90 & 0.10 & 0.8 \\
\hline $10 \ldots$ & 1130 & 2.4 & 545 & 8.1 & 17.0 & 9.8 & 0.02 & 1.10 & 0.03 & 0.37 \\
\hline
\end{tabular}

04097060 LITTLE PORTAGE CREEK NEAR FULTON, MI

(LAT $\left.\begin{array}{lllllll}42 & 05 & 19 & \text { LONG } & 085 & 23 & 29\end{array}\right)$

OCT 1986

\begin{tabular}{|c|c|c|c|c|c|c|c|c|c|c|}
\hline $\begin{array}{r}\text { OCT } 1986 \\
08 \text { i }\end{array}$ & 1015 & 60 & 479 & 7.9 & 11.5 & 8.6 & 0.02 & 2.40 & 0.07 & 1.5 \\
\hline SEP $15 \ldots$ & 1505 & 8.0 & 566 & 8.1 & 20.0 & 8.3 & 0.03 & 2.60 & 0.06 & 1.6 \\
\hline $09 \ldots$ & 1345 & 11 & 543 & 8.0 & 16.5 & 8.7 & 0.02 & 2.50 & 0.03 & 0.57 \\
\hline
\end{tabular}

04097120 PORTAGE RIVER NEAR SCOTTS, MI

(LAT $42 \quad 10 \quad 21$ LONG $085 \quad 28 \quad 19$ )

\begin{tabular}{|c|c|c|c|c|c|c|c|c|c|c|}
\hline $\begin{array}{l}\text { OCT } 1986 \\
08 \\
\text { JUN } 1987\end{array}$ & 1345 & 69 & 421 & 7.6 & 12.0 & 5.7 & 0.02 & 0.50 & 0.06 & 1.7 \\
\hline SEP $15 \ldots$ & 1100 & 15 & 489 & 7.8 & 20.0 & 7.6 & 0.02 & 0.50 & 0.07 & 0.53 \\
\hline $09 \ldots$ & 1100 & 16 & 506 & 7.7 & 16.0 & 8.0 & 0.01 & 0.60 & 0.04 & 1.1 \\
\hline
\end{tabular}

04097170 PORTAGE RIVER NEAR VICKSBURG， MI

(LAT 420653 LONG $085 \quad 2908$ )

\begin{tabular}{|c|c|c|c|c|c|c|c|c|c|c|}
\hline $\begin{array}{l}\text { OCT } 1986 \\
08 \\
\text { JUN } 1987\end{array}$ & 1515 & 169 & 375 & 7.7 & 14.5 & 4.6 & 0.02 & 0.20 & 0.06 & 1.2 \\
\hline $\operatorname{seP}_{\text {SEP }}$ & 1045 & 21 & 424 & 7.2 & 24.5 & 6.1 & 0.01 & 0.20 & 0.05 & 0.55 \\
\hline $09 \ldots$ & 1500 & 34 & 394 & 7.9 & 23.0 & 6.8 & $<0.01$ & 0.20 & 0.02 & 0.38 \\
\hline
\end{tabular}

GOURDNECK CREEK NEAR VICKSBURG

(LAT $4208 \quad 58$ LONG $085 \quad 32 \quad 24$ )

\begin{tabular}{|c|c|c|c|c|c|c|c|c|c|c|}
\hline $\begin{array}{c}\text { OCT } 1986 \\
07 \\
\text { JUN } 1987\end{array}$ & 1715 & 37 & 359 & 7.5 & 15.0 & 4.6 & $<0.01$ & $<0.10$ & 0.03 & 0.47 \\
\hline $\operatorname{SEP}_{15 \ldots}$ & 1545 & 7.3 & 394 & 7.5 & 28.0 & 5.3 & 0.01 & $<0.10$ & 0.07 & 0.63 \\
\hline $09 \ldots$ & 1430 & 14 & 366 & 7.2 & 21.5 & 4.3 & $<0.01$ & $<0.10$ & $<0.01$ & \\
\hline
\end{tabular}

04097207 AUSTIN LAKE OUTLET NEAR VICKSBURG, MI

(LAT 420903 LONG $08531 \quad 59$ )

\begin{tabular}{|c|c|c|c|c|c|c|c|c|c|c|}
\hline $\begin{array}{l}\text { OCT } 1986 \\
08 \\
\text { JUN } 1987\end{array}$ & 0910 & 14 & 337 & 7.8 & 12.0 & 9.4 & $<0.01$ & $<0.10$ & 0.07 & 0.73 \\
\hline SEP $15 \ldots$ & 1830 & 0.69 & 479 & 7.9 & 19.5 & 5.2 & 0.02 & 0.40 & 0.04 & 0.66 \\
\hline $09 \ldots$ & 1245 & 0.52 & 503 & 7.7 & 15.5 & 6.6 & 0.01 & 0.40 & 0.04 & 0.26 \\
\hline
\end{tabular}

04097210 PORTAGE CREEK AT VICKSBURG, MI

(LAT $4206 \quad 52$ LONG $085 \quad 32 \quad 05$ )

\begin{tabular}{|c|c|c|c|c|c|c|c|c|c|c|}
\hline $\begin{array}{c}\text { OCT } 1986 \\
08 \\
\text { JUN } 1987\end{array}$ & 1420 & 65 & 343 & 7.9 & 14.5 & 8.4 & 0.02 & 1.60 & 0.06 & 1.2 \\
\hline SEP $17 \ldots$ & 0930 & 4.8 & 370 & 8.0 & 24.0 & 5.1 & $<0.01$ & $<0.10$ & 0.05 & 0.35 \\
\hline $09 \ldots$ & 0930 & 11 & 336 & 8.1 & 21.5 & 7.7 & $<0.01$ & $<0.10$ & 0.03 & 0.37 \\
\hline
\end{tabular}


WATER QUALITY DATA, WATER YEAR OCTOBER 1986 TO SEPTEMBER 1987--Cont inued

\begin{tabular}{|c|c|c|c|c|c|c|c|c|c|}
\hline $\begin{array}{l}\text { NEN, AM- } \\
\text { MONIA + } \\
\text { ORGANIC } \\
\text { TOTAL } \\
\text { (MG /L } \\
\text { AS N) }\end{array}$ & $\begin{array}{l}\text { NITRO- } \\
\text { GEN, } \\
\text { TOTAL } \\
\text { (MG/L } \\
\text { AS N) }\end{array}$ & $\begin{array}{l}\text { PHOS- } \\
\text { PHORUS, } \\
\text { TOTAL } \\
\text { (MG /L } \\
\text { AS P) }\end{array}$ & $\begin{array}{c}\text { PHOS- } \\
\text { PHORUS, } \\
\text { ORTHO, } \\
\text { TOTAL } \\
\text { (MG/L } \\
\text { AS P) }\end{array}$ & $\begin{array}{l}\text { PHENOLS } \\
\text { TOTAL } \\
\text { (UG/L) }\end{array}$ & $\begin{array}{c}\text { ALA- } \\
\text { CHLOR } \\
\text { TOTAL } \\
\text { RECOVER } \\
\text { (UG/L) }\end{array}$ & $\begin{array}{l}\text { AME- } \\
\text { TRYNE } \\
\text { TOTAL }\end{array}$ & $\begin{array}{l}\text { ATRA- } \\
\text { 2INE, } \\
\text { TOTAL } \\
\text { (UG/L) }\end{array}$ & $\begin{array}{l}\text { CYAN- } \\
\text { AZINE } \\
\text { TOTAL } \\
\text { (UG/L) }\end{array}$ & $\begin{array}{l}\text { DI- } \\
\text { AZ INON, } \\
\text { TOTAL } \\
\text { (UG/L) }\end{array}$ \\
\hline
\end{tabular}

04096950 BEAR CREEK NEAR FULTON, MI

(LAT 420432 LONG $085 \quad 1958$ )

\begin{tabular}{|c|c|c|c|c|c|c|c|c|c|}
\hline $\begin{array}{l}\text { OCT } 1986 \\
\text { O7 } \ddot{1} 9 \dot{87}\end{array}$ & 0.9 & 1.0 & 0.07 & 0.04 & - & -- & -- & - & -- \\
\hline SEP $15 . \cdots$ & 1.5 & 1.7 & 0.15 & 0.09 & -- & -- & -- & -- & - \\
\hline 10. & 1.0 & 1.2 & 0.11 & 0.14 & -- & -- & -- & - & -- \\
\hline
\end{tabular}

04097040 LITTLE PORTAGE CREEK NEAR CLIMAX, MI

(LAT 420951 LONG $085 \quad 20 \quad 18$ )

\begin{tabular}{|c|c|c|c|c|c|}
\hline $\begin{array}{c}\text { OCT } 1986 \\
07\end{array}$ & 2.0 & 3.7 & 0.08 & 0.03 & -- \\
\hline $15 \ldots$ & 0.9 & 1.8 & 0.09 & 0.02 & - \\
\hline 1 & 0.4 & 1.5 & 0.03 & 0.02 & - \\
\hline
\end{tabular}

04097060 LITTLE PORTAGE CREEK NEAR FULTON, MI

(LAT $\left.\begin{array}{lllllll}42 & 05 & 19 & \text { LONG } & 085 & 23 & 29\end{array}\right)$

$\begin{array}{ccccc}\text { OCT } 1986 & & & & \\ 08.97 & 1.6 & 4.0 & 0.06 & 0.04 \\ \text { JUN } 1987 & 1.7 & 4.3 & 0.05 & 0.02 \\ \text { SEP } & & \\ 09 . . & 0.6 & 3.1 & 0.03 & 0.02\end{array}$

04097120 PORTAGE RIVER NEAR SCOTTS, MI

OCT 1986

JuN 19887

1.8

(LAT $\left.\begin{array}{llllll}42 & 10 & 21 & \text { LONG } 085 & 28 & 19\end{array}\right)$

$15 \ldots$

0.6

2.3

0.04

0.01

1.1

0.04

$<0.01$

$\begin{array}{ll}-- & -- \\ -- & <0.1\end{array}$

$<0.1$

$<0.1$

$<0.1<0.01$

$09 \ldots$

1.1

1.7

$<0.01<0.01$

04097170

PORTAGE RIVER NEAR VICKSBURG, MI

(LAT $4206 \quad 53$ LONG $085 \quad 2908$ )

OCT 1986

OCT 1986
08.1987
JUN 1987
$\quad 17 \ldots$
SEP
O9....

1.3

1.5

$0.03 \quad 0.01$

0.8

0.04

$<0.01$

0.6

$<0.01<0.01$

04097205

GOURDNECK CREEK NEAR VICKSBURG, MI

(LAT $\left.\begin{array}{lllllll}42 & 08 & 58 & \text { LONG } & 085 & 32 & 24\end{array}\right)$

OCT 1986

07.397
JuN 19987
$15 \ldots$.

0.5

$-$

$0.02<0.01$

SEP $09 .$.

0.7

$--$

0.06

0.02

$-<<0.0$

$<0.01$

04097207

AUSTIN LAKE OUTLET NEAR VICKSBURG, MI

(LAT 4209 03 LONG 085:31 59)

OCT 1986

${ }_{\text {JuN }}^{08} 19 \dot{8} 7$

0.8

--

0.02

$<0.01$

1.1

0.04

$<0.01$

SEP 09.

0.7

0.02

$<0.01$

PORTAGE CREEK AT VICKSBURG, MI

(LAT $\begin{array}{lllllll}42 & 06 & 52 & \text { LONG } & 085 & 32 & 05\end{array}$

\begin{tabular}{|c|c|c|c|c|c|c|}
\hline $\begin{array}{l}\text { OCT } 1986 \\
08\end{array}$ & 1.3 & 2.9 & 0.09 & 0.04 & -- & -- \\
\hline $17 \ldots$ & 0.4 & -- & 0.05 & $<0.01$ & 3 & - \\
\hline & 0.4 & -- & $<0.01$ & $<0.01$ & -- & - \\
\hline
\end{tabular}




\begin{tabular}{|c|c|c|c|c|c|c|c|c|c|c|}
\hline ATE & $\begin{array}{c}\text { ETHION, } \\
\text { TOTAL, } \\
\text { (UG/L) }\end{array}$ & $\begin{array}{l}\text { MALA- } \\
\text { THION, } \\
\text { TOTAL } \\
\text { (UG/L) }\end{array}$ & $\begin{array}{l}\text { METHYL } \\
\text { PARA- } \\
\text { THION, } \\
\text { TOTAL } \\
\text { (UG/L) }\end{array}$ & $\begin{array}{l}\text { METHYL } \\
\text { TRI- } \\
\text { THION, } \\
\text { TOTAL } \\
\text { (UG/L) }\end{array}$ & $\begin{array}{l}\text { METOLA- } \\
\text { CHLOR } \\
\text { WATER } \\
\text { WHOLE } \\
\text { TOT.REC } \\
\text { (UG/L) }\end{array}$ & $\begin{array}{l}\text { METRF- } \\
\text { BUZIN } \\
\text { WATER } \\
\text { WHOLE } \\
\text { TOT.REC } \\
\text { (UG/L) }\end{array}$ & $\begin{array}{l}\text { PARA- } \\
\text { THION, } \\
\text { TOTAL } \\
\text { (UG/L) }\end{array}$ & $\begin{array}{l}\text { PROME- } \\
\text { TONE } \\
\text { TOTAL } \\
\text { (UG/L) }\end{array}$ & $\begin{array}{l}\text { PROME- } \\
\text { TRYNE } \\
\text { TOTAL } \\
\text { (UG/L) }\end{array}$ & $\begin{array}{l}\text { PRO- } \\
\text { PAZINE } \\
\text { TOTAL } \\
\text { (UG/L) }\end{array}$ \\
\hline
\end{tabular}

04096950 BEAR CREEK NEAR FULTON, MI

(LAT $4204 \quad 32$ LONG $085 \quad 19 \quad 58$ )

OCT 1986

JUN 19787

$15 \ldots$

10 ...

04097040

OCT 1986

07
JUN 1987

$15 \ldots$

SEP $10 \ldots$

04097060

OCT 1986

JUN 19887

JUN $15 . .$.

SEP $09 .$.

$<0.01$

04097120

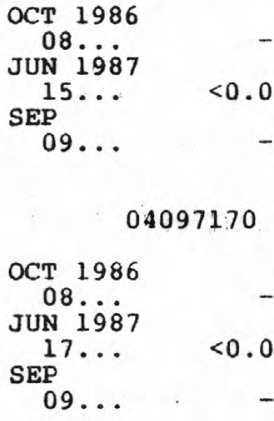

OCT 1986

JUN 1987

$17 \ldots$

SEP

04097205

OCT 1986

07
JUN 1987

$15 \ldots$

SEP $09 .$.

04097207

LITTLE PORTAGE CREEK NEAR FULTON, MI

$<0.01$

$<0.01$

$<0.01$

$<0.1$

$<0.1$

$--$

PORTAGE RIVER NEAR SCOTTS, MI

(LAT $42 \quad 10 \quad 21$ LONG $085 \quad 28 \quad 19$ )

(LAT $4205 \quad 19$ LONG $085 \quad 23 \quad 29$ )

(LAT $42 \quad 0951$ LONG $085 \quad 20 \quad 18$ )

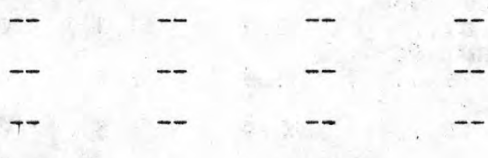

(15AT 42 05 19 LONG 0852329 )

$<0.01<0.1<0.1<0.1$

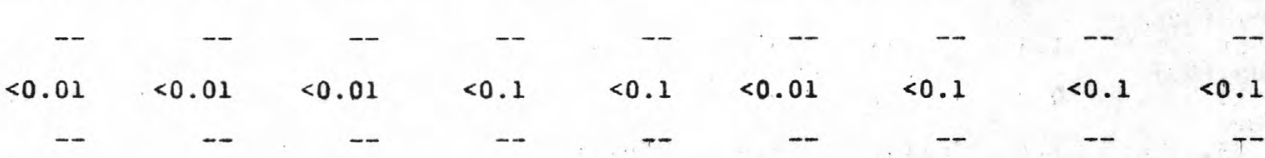

PORTAGE RIVER NEAR VICKSBURG, MI

(LAT $42 \quad 06 \quad 53$ LONG P85 2908 )

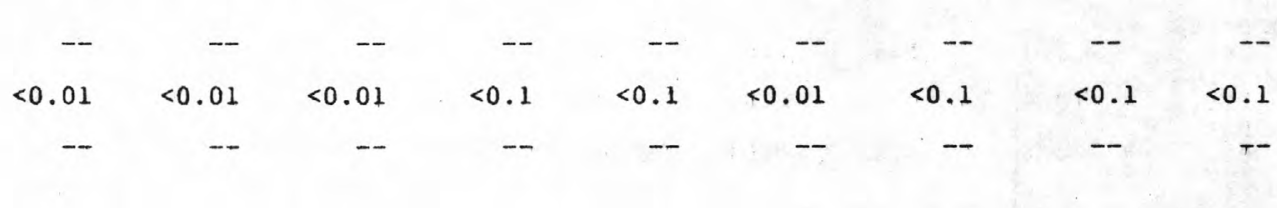

GOURDNECK CREEK NEAR VICKSBURG, MI

(LAT $42 \quad 08 \quad 58$ LONG $085 \quad 32 \quad 24$ )

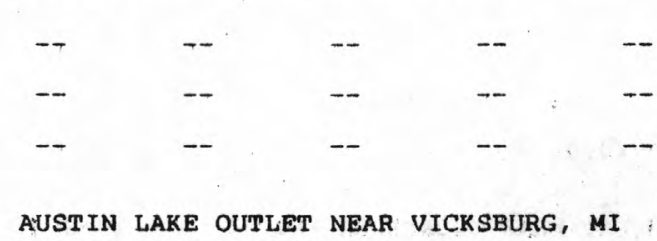

$\begin{array}{llll}-- & -- & -- & -- \\ -- & -- & -- & --\end{array}$

$$
\begin{aligned}
& \text { OCT } 1986 \\
& 08 \text { JUN } 1987 \\
& \text { I5 } \\
& \quad 09 \\
& \text { SEP }
\end{aligned}
$$

04097210

OCT 1986

JUN 19887

JUN 1987

SEP

$09 . .$.

(LAT 420903 LONG 0853159 )

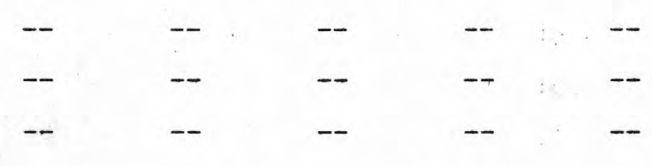

PORTAGE CREEK AT VICKSBURG; MI

(LAT $42 \quad 06 \quad 52$ LONG $085 \quad 32 \quad 05$ ) 
WATER QUALITY DATA, WATER YEAR OCTOBER 1986 TO SEPTEMBER 1987--Continued

\begin{tabular}{|c|c|c|c|c|c|c|c|c|}
\hline $\begin{array}{l}\text { SIME- } \\
\text { TRYNE } \\
\text { TOTAL } \\
\text { (UG/L) }\end{array}$ & $\begin{array}{l}\text { SIMA- } \\
\text { ZINE } \\
\text { TOTAL } \\
\text { (UG/L) }\end{array}$ & $\begin{array}{l}\text { TRI- } \\
\text { FLURA- } \\
\text { LIN } \\
\text { TOTAL } \\
\text { RECOVER } \\
\text { (UG/L) }\end{array}$ & $\begin{array}{c}\text { TOTAL } \\
\text { TRI- } \\
\text { THION } \\
\text { (UG/L) }\end{array}$ & $\begin{array}{l}2,4-D, \\
\text { TOTAL } \\
\text { (UG/L) }\end{array}$ & $\begin{array}{c}2, \quad 4-D P \\
\text { TOTAL } \\
\text { (UG/L) }\end{array}$ & $\begin{array}{c}2,4,5-T \\
\text { TOTAL } \\
\text { (UG/L) }\end{array}$ & $\begin{array}{c}\text { SILVEX, } \\
\text { TOTAL } \\
\text { (UG/L) }\end{array}$ & $\begin{array}{l}\text { SEDI- } \\
\text { MENT, } \\
\text { SUS- } \\
\text { PENDED } \\
\text { (MG/L) }\end{array}$ \\
\hline
\end{tabular}

04096950 BEAR CREEK NEAR FULTON, MI

(LAT $42 \quad 04 \quad 32$ LONG $085 \quad 1958$ )

OCT 1986

JUN 19787

SEP 15 ...

$10 .$.

04097040
OCT 1986
07.987
JUN 1987
$15 \ldots$
SEP $10 \ldots$
$10 \ldots$
04097060

LITTLE PORTAGE CREEK NEAR CLIMAX, MI

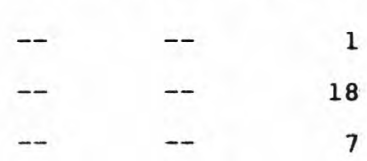

OCT 1986

JUN 19887

$15 \ldots$

SEP $09 .$.

$<0.1$

$--$

$--$

$--$

$--\quad--$

(LAT $\left.\begin{array}{lllllll}42 & 09 & 51 & \text { LONG } & 085 & 20 & 18\end{array}\right)$

$--$

$--$

-- $\quad--\quad 15$

$-$

LITTLE PORTAGE CREEK NEAR FULTON, MI

-- $\quad--\quad 14$

$--\quad--\quad 31$

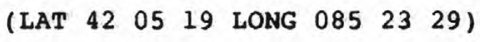

04097120 PORTAGE RIVER NEAR SCOTTS, MI

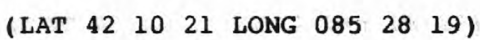

OCT 1986

JUN 19887

SEP $15 .$.

$--$

$\begin{array}{ll}-- & -- \\ -- & <0.1 \\ \text { PORTAGE } & \text { RIVER }\end{array}$

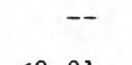

0.01

$<0.01$

$\begin{array}{rrr}-- & -- & 8 \\ <0.01 & <0.01 & 4 \\ -- & -- & 49\end{array}$

$09 .$.

$<0.1$

$\begin{array}{cr}-- & -- \\ 0.6 & <0.1 \\ -- & --\end{array}$

$<0.01$

0.

$<0.01$

$\begin{array}{rrr}-- & -- & 2 \\ <0.01 & <0.01 & 8 \\ -- & -- & <1\end{array}$

04097170

PORTAGE RIVER NEAR VICKSBURG, MI

(LAT $\left.\begin{array}{lllllll}42 & 06 & 53 & \text { LONG } & 085 & 29 & 08\end{array}\right)$

OCT 1986

08
JUN 1987

$17 \ldots$.

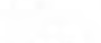

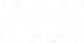

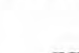

$0.5<0.1$

$<0.01$

$0.1<0.01$

$\begin{array}{rrr}-- & -- & 5 \\ <0.01 & <0.01 & 4 \\ -- & -- & 5\end{array}$

$09 . .$.

04097205

GOURDNECK CREEK NEAR VICKSBURG, MI

(LAT $42 \quad 08 \quad 58$ LONG $085 \quad 32 \quad 24$ )

OCT 1986

JuN 19787

$15 \ldots$

SEP $09 .$.

-

\section{7}

AUSTIN LAKE OUTLET NEAR VICKSBURG, MI

$\begin{array}{lll}-- & -- & 1 \\ -- & -- & 3 \\ -- & -- & 2\end{array}$

OCT 1986

08 T
JUN 1987

JUN 1987

SEP

$09 \ldots$

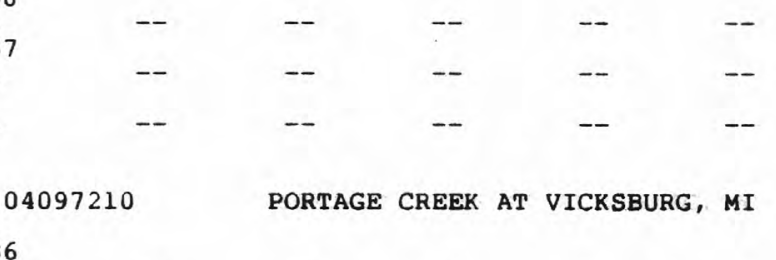

(LAT $\begin{array}{lllllll}42 & 09 & 03 & \text { LONG } & 085 & 31 & 59\end{array}$

OCT 1986

JUN 1987

SEP $17 \ldots$

$\begin{array}{lll}-- & -- & 7 \\ -- & -- & 6 \\ -- & -- & 9\end{array}$

(LAT $42 \quad 06 \quad 52$ LONG $085 \quad 32 \quad 05$ )

$09 . .$. 


\begin{tabular}{|c|c|c|c|c|c|c|c|c|c|c|}
\hline ATE & TIME & $\begin{array}{l}\text { STREAM- } \\
\text { FLOW, } \\
\text { INSTAN- } \\
\text { TANEOUS } \\
\text { (CFS) }\end{array}$ & $\begin{array}{l}\text { SPE- } \\
\text { CIFIC } \\
\text { CON- } \\
\text { DUCT- } \\
\text { ANCE } \\
\text { (US/CM) }\end{array}$ & $\begin{array}{c}\text { PH } \\
\text { (STAND- } \\
\text { ARD } \\
\text { UNITS) }\end{array}$ & $\begin{array}{l}\text { TEMPER- } \\
\text { ATURE } \\
\text { (DEG C) }\end{array}$ & $\begin{array}{c}\text { OXYGEN, } \\
\text { DIS- } \\
\text { SOLVED } \\
\text { (MG/L) }\end{array}$ & $\begin{array}{l}\text { NITRO- } \\
\text { GEN, } \\
\text { NITRITE } \\
\text { TOTAL } \\
\text { (MG/L } \\
\text { AS N) }\end{array}$ & $\begin{array}{c}\text { NITRO- } \\
\text { GEN, } \\
\text { NO2+NO3 } \\
\text { TOTAL } \\
\text { (MG/L } \\
\text { AS N) }\end{array}$ & $\begin{array}{l}\text { NITRO- } \\
\text { GEN, } \\
\text { AMMONIA } \\
\text { TOTAL } \\
\text { (MG/L } \\
\text { AS N) }\end{array}$ & $\begin{array}{c}\text { NITRO- } \\
\text { GEN, } \\
\text { ORGANIC } \\
\text { TOTAL } \\
\text { (MG/L } \\
\text { AS N) }\end{array}$ \\
\hline
\end{tabular}

$04097240 \quad$ PORTAGE CREEK NEAR MENDON, MI

(LAT 420425 LONG $085 \quad 30 \quad 55$ )

\begin{tabular}{|c|c|c|c|c|c|c|c|c|c|c|}
\hline $\begin{array}{c}\text { OCT } 1986 \\
09 \\
\text { JUN } 1987\end{array}$ & 1330 & 137 & 392 & 8.0 & 14.5 & 6.8 & 0.02 & 0.50 & 0.04 & 1.4 \\
\hline SEP $16 \ldots$ & 1410 & 30 & 401 & 8.4 & 28.0 & 9.1 & 0.02 & 0.70 & 0.08 & 1.3 \\
\hline $09 \ldots$ & 1100 & 45 & 369 & 7.8 & 21.0 & 5.8 & 0.01 & 0.30 & 0.02 & 0.58 \\
\hline
\end{tabular}

04097330 BEAR CREEK NEAR VICKSBURG， MI

(LAT $4204 \quad 42$ LONG $085 \quad 28 \quad 07$ )

\begin{tabular}{|c|c|c|c|c|c|c|c|c|c|c|}
\hline $\begin{array}{l}\text { OCT } 1986 \\
08 \text { i } \\
\text { JUN } 1987\end{array}$ & 1200 & 49 & 452 & 7.6 & 11.5 & 4.8 & $<0.01$ & $<0.10$ & 0.05 & 0.45 \\
\hline SEP 16. & 1545 & 3.1 & 525 & 8.3 & 23.5 & 10.0 & 0.03 & 2.80 & 0.03 & 0.77 \\
\hline $09 \ldots$ & 1215 & 3.7 & 534 & 8.1 & 16.5 & 9.3 & 0.02 & 2.20 & 0.03 & \\
\hline
\end{tabular}

04097370 FLOWERFIELD CREEK AT FLOWERFIELD, MI

(LAT $42 \quad 03 \quad 50$ LONG $085 \quad 39 \quad 44$ )

\begin{tabular}{|c|c|c|c|c|c|c|c|c|c|c|}
\hline $\begin{array}{l}\text { OCT } 1986 \\
\text { O9 } 19 \dot{87} \\
\text { JUN } 1987\end{array}$ & 1100 & 54 & 414 & 8.0 & 12.5 & 9.0 & $<0.01$ & 0.80 & 0.04 & 0.86 \\
\hline $16 \ldots$ & 0955 & 8.7 & 500 & 8.0 & 17.0 & 7.6 & 0.02 & 1.90 & 0.03 & 0.17 \\
\hline $08 \ldots$ & 1300 & 14 & 511 & 8.1 & 18.5 & 7.7 & 0.01 & 1.20 & 0.03 & 0.37 \\
\hline
\end{tabular}

04097380 SPRING CREEK NEAR FLOWERFIELD， MI

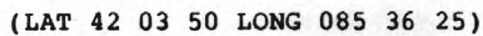

\begin{tabular}{|c|c|c|c|c|c|c|c|c|c|c|}
\hline $\begin{array}{c}\text { OCT } 1986 \\
\text { 09 } 98197 \\
\text { JUN } 1987\end{array}$ & 0930 & 9.1 & 377 & 7.7 & 11.5 & 7.2 & 0.03 & 1.40 & 0.17 & 0.93 \\
\hline $16 \ldots$ & 1110 & 6.3 & 444 & 8.8 & 20.0 & 10.8 & 0.02 & 1.10 & 0.04 & 0.46 \\
\hline $08 \ldots$ & 1500 & 7.0 & 420 & 7.9 & 16.5 & 8.8 & 0.02 & 1.00 & 0.08 & 0.12 \\
\hline
\end{tabular}

04105671 EAGLE LAKE DRAIN NEAR AUGUSTA, MI

(LAT $42 \quad 20 \quad 13$ LONG $085 \quad 20 \quad 10$ )

\begin{tabular}{|c|c|c|c|c|c|c|c|c|c|c|}
\hline $\begin{array}{c}\text { OCT } 1986 \\
07 \\
\text { JUN } 1987\end{array}$ & 1225 & 16 & 372 & 8.0 & 14.5 & 8.2 & 0.01 & $<0.10$ & 0.07 & 0.73 \\
\hline${ }_{S E P}^{15 \ldots}$ & 1120 & 5.1 & 417 & 7.5 & 20.5 & 6.1 & 0.01 & $<0.10$ & 0.05 & 0.95 \\
\hline $09 \ldots$ & 1100 & 6.5 & 395 & 8.1 & 20.0 & 7.5 & $<0.01$ & $<0.10$ & 0.02 & 0.18 \\
\hline
\end{tabular}

04105800 GULL CREEK NEAR GALESBURG, MI

(LAT $\left.\begin{array}{lllllll}42 & 18 & 54 & \text { LONG } & 085 & 24 & 04\end{array}\right)$

\begin{tabular}{|c|c|c|c|c|c|c|c|c|c|c|}
\hline $\begin{array}{c}\text { OCT } 1986 \\
07 \text { ig87 }\end{array}$ & 1445 & 102 & 344 & 8.0 & 15.5 & 9.9 & 0.01 & 0.10 & 0.04 & 0.26 \\
\hline $15 \ldots$ & 1420 & 15 & 410 & 7.6 & 27.0 & 7.1 & $<0.01$ & $<0.10$ & 0.03 & 1.6 \\
\hline $09 \ldots$ & 1430 & 31 & 391 & 8.3 & 24.0 & 9.2 & $<0.01$ & $<0.10$ & 0.01 & 0.29 \\
\hline
\end{tabular}

04105990 COMSTOCK CREEK NEAR KALAMAZOO, MI

(LAT $42 \quad 18 \quad 10$ LONG $085 \quad 30 \quad 16$ )

\begin{tabular}{|c|c|c|c|c|c|c|c|c|c|c|}
\hline $\begin{array}{l}\text { OCT } 1986 \\
07 \\
\text { JUN } 19887\end{array}$ & 1650 & 20 & 367 & 8.0 & 17.0 & 7.5 & 0.01 & 0.20 & 0.09 & 0.71 \\
\hline SEP $15 \ldots$ & 1530 & 4.5 & 371 & 7.7 & 30.0 & 6.9 & $<0.01$ & 0.20 & 0.06 & 0.84 \\
\hline $09 \ldots$ & 1550 & 6.2 & 379 & 8.1 & 25.0 & 8.1 & $<0.01$ & 0.10 & 0.03 & 0.27 \\
\hline
\end{tabular}

$04106050 \quad$ DAVIS CREEK AT KALAMAZOO, MI $\quad$ (LAT $42 \quad 1627$ LONG 0853217 )

\begin{tabular}{|c|c|c|c|c|c|c|c|c|c|c|}
\hline $\begin{array}{l}\text { OCT } 1986 \\
08 \\
\text { JUN } 1987\end{array}$ & 1700 & 13 & 566 & 7.9 & 15.0 & 8.5 & 0.05 & 0.80 & 0.44 & 1.1 \\
\hline SEP $16 \ldots$ & 1830 & 4.5 & 762 & 8.0 & 23.0 & 7.1 & 0.09 & 0.90 & 0.16 & 0.34 \\
\hline $10 \ldots$ & 1500 & 3.3 & 648 & 8.2 & 19.0 & 13.9 & 0.09 & 1.00 & 0.21 & -- \\
\hline
\end{tabular}


WATER QUALITY DATA, WATER YEAR OCTOBER 1986 TO SEPTEMBER 1987--Cont inued

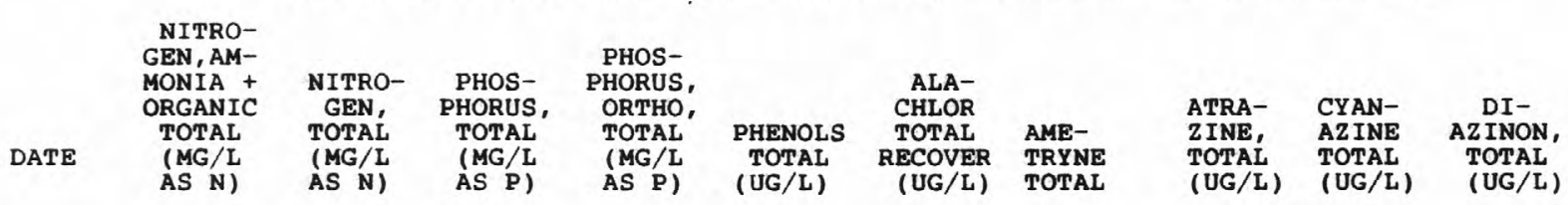

$04097240 \quad$ PORTAGE CREEK NEAR MENDON, MI

(LAT $4204 \quad 25$ LONG $085 \quad 30 \quad 55$ )

\begin{tabular}{|c|c|c|c|c|c|c|c|c|c|c|}
\hline $\begin{array}{l}\text { OCT } 1986 \\
09.987 \\
\text { JUN } 1987\end{array}$ & 1.4 & 1.9 & 0.04 & 0.01 & -- & - & -- & - & -- & - \\
\hline SEP $16 \ldots$ & 1.4 & 2.1 & 0.04 & $<0.01$ & 3 & -- & -- & -- & -- & -- \\
\hline $09 \ldots$ & 0.6 & 0.9 & $<0.01$ & $<0.01$ & -- & - & -- & -- & - & \\
\hline
\end{tabular}

04097330 BEAR CREEK NEAR VICKSBURG, MI

(LAT $\left.\begin{array}{lllllll}42 & 04 & 42 & \text { LONG } & 085 & 28 & 07\end{array}\right)$

OCT 1986

OCT
JUN 19887
SEP

0.5

(0.02

$<0.01$

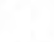

-- -- - - -

$\begin{array}{llll}0.8 & 3.6 & 0.06 & 0.02\end{array}$

$09 .$.

$<0.2$

04097370

$--\quad 0.04$

0.02

FLOWERFIELD CREEK AT FLOWERFIELD, MI

(LAT $4203 \quad 50$ LONG $085 \quad 39 \quad 44$ )

OCT 1986

\begin{tabular}{|c|c|c|c|c|}
\hline $\begin{array}{l}09 \\
\text { JuN } 1987\end{array}$ & 0.9 & 1.7 & 0.04 & 0.02 \\
\hline SEP $16 \ldots$ & 0.2 & 2.1 & 0.04 & $<0.01$ \\
\hline $08 \ldots$ & 0.4 & 1.6 & $<0.01$ & $<0.01$ \\
\hline
\end{tabular}

04097380

SPRING CREEK NEAR FLOWERFIELD, MI

$<0.1<0.1<0.1<0.1<0.01$

SEP $08 \ldots$

0.4

\begin{tabular}{|c|c|c|c|c|}
\hline $\begin{array}{c}\text { OCT } 1986 \\
09 \\
\text { JUN } 1987\end{array}$ & 1.1 & 2.5 & 0.05 & 0.01 \\
\hline SEP $16 \cdots$ & 0.5 & 1.6 & 0.04 & $<0.01$ \\
\hline $08 \ldots$ & 0.2 & 1.2 & $<0.01$ & $<0.01$ \\
\hline
\end{tabular}

04105671 EAGLE LAKE DRAIN NEAR AUGUSTA, MI

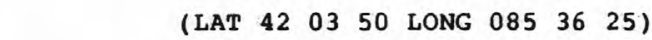

OCT 1986
09.31
JUN 1987
$16 \ldots$
SEP $\ldots$
$08 \ldots$

0.8

$\begin{array}{rrrrr}-- & - & - & - & - \\ 0.2 & <0.1 & 0.2 & <0.1 & 0.01\end{array}$

OCT 1986

JUN 1987

$15 \ldots$

1.0

$--$

0.03

$<0.01$

$0.04<0.01$

$09 \ldots$

0.2

04105800

$-\quad<0.01<0.01$

GULL CREEK NEAR GALESBURG, MI

(LAT $42 \quad 18 \quad 54$ LONG $085 \quad 24 \quad 04$ )

OCT 1986

JUN 198

SEP $15 .$.

0.3

0.4

$0.02<0.01$

$-0.04$

$<0.01$

$09 .$.

1.6

0.04

$<0.01$

04105990

$--$

$<0.01$

.

COMSTOCK CREEK NEAR KALAMAZOO, MI

(LAT $42 \quad 20 \quad 13$ LONG $085 \quad 20 \quad 10$ )

OCT 1986

JUN 19787

JUN $15 \ldots$

0.8

1.0

0.02

$<0.01$

$09 .$.

0.9

1.1

0.04

$<0.01$

0.4

$<0.01$

$<0.01$

04106050

DAVIS CREEK AT KALAMAZOO, MI

$4<0.1$

0.1

$<0.1$

$<0.1$

$<0.1$

$<0.01$

$-$

(LAT $42 \quad 18 \quad 10$ LONG $\left.\begin{array}{lllll}085 & 30 & 16\end{array}\right)$

OCT 1986

OCT
JuN 19887
$16 \ldots$

1.5

2.3

0.07
0.07
0.01

0.04

1.4

0.02

0.01

$10 \ldots$

$<0.2$

--

. 01




\begin{tabular}{|c|c|c|c|c|c|c|c|c|c|c|}
\hline$A$ & $\begin{array}{l}\text { ETHION, } \\
\text { TOTAL } \\
\text { (UG/L) }\end{array}$ & $\begin{array}{l}\text { MALA- } \\
\text { THION, } \\
\text { TOTAL } \\
\text { (UG/L) }\end{array}$ & $\begin{array}{l}\text { METHYL } \\
\text { PARA- } \\
\text { THION, } \\
\text { TOTAL } \\
\text { (UG/L) }\end{array}$ & $\begin{array}{l}\text { METHYL } \\
\text { TRI- } \\
\text { THION, } \\
\text { TOTAL } \\
\text { (UG/L) }\end{array}$ & $\begin{array}{c}\text { METOLA- } \\
\text { CHLOR } \\
\text { WATER } \\
\text { WHOLE } \\
\text { TOT.REC } \\
\text { (UG } / \mathrm{L})\end{array}$ & $\begin{array}{l}\text { METRI- } \\
\text { BUZIN } \\
\text { WATER } \\
\text { WHOLE } \\
\text { TOT .REC } \\
\text { (UG/L) }\end{array}$ & $\begin{array}{l}\text { PARA- } \\
\text { THION, } \\
\text { TOTAL } \\
\text { (UG/L) }\end{array}$ & $\begin{array}{l}\text { PROME- } \\
\text { TONE } \\
\text { TOTAL } \\
\text { (UG/L) }\end{array}$ & $\begin{array}{l}\text { PROME- } \\
\text { TRYNE } \\
\text { TOTAL } \\
\text { (UG/L) }\end{array}$ & $\begin{array}{l}\text { PRO- } \\
\text { PAZ INE } \\
\text { TOTAL } \\
\text { (UG/L) }\end{array}$ \\
\hline
\end{tabular}

$04097240 \quad$ PORTAGE CREEK NEAR MENDON, MI

$$
\begin{aligned}
& \text { OCT } 1986 \\
& 099 \\
& \text { JUN } 1987 \\
& \text { I6P. } \\
& \quad 09
\end{aligned}
$$

04097330

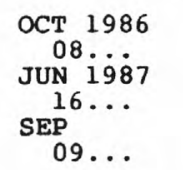

04097370

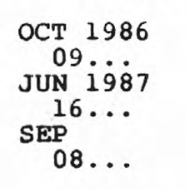

04097380

OCT 1986

09
JUN 1987
$16 \ldots$

SEP
$08 \ldots$

$<0.01$

$<0.01$

$-$

\section{1}

OCT 1986

JUN 19787

JUN 1987

SEP

09 ...

04105800

OCT 1986

JUN 19787

$15 \ldots$

SEP
$09 .$.

$<0.01$

04105990

OCT 1986

JUN 19787

JUN 19.

SEP $09 \ldots$

$<0.01$

04106050

GULL CREEK NEAR GALESBURG, MI

$<0.01<0.01<0.01<0.1$
(LAT $\left.\begin{array}{lllllll}42 & 04 & 25 & \text { LONG } & 085 & 30 & 55\end{array}\right)$
BEAR CREEK NEAR VICKSBURG, MI

$--$

$-$

$-$

FLOWERFIELD CREEK AT FLOWERFIELD, MI

(LAT $42 \quad 03 \quad 50$ LONG $085 \quad 39 \quad 44$ )

$$
\begin{array}{lrrrrr}
<0.01 & <0.01 & <0.01 & <0.1 & <0.1 \\
-- & -- & -- & -- & - \\
& & & &
\end{array}
$$

$<0.1$

(LAT $42 \quad 04 \quad 42$ LONG $085 \quad 2807$ )

$-$

-- $\quad-$

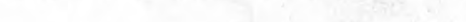

$<0.01<0.1<0.1<0.1$

$--$

(LAT $42 \quad 03 \quad 50$ LONG $085 \quad 36 \quad 25$ )

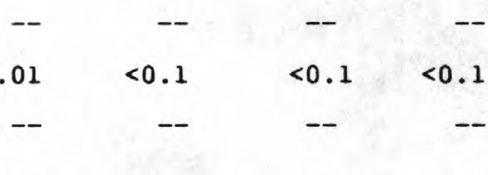

(LAT $42 \quad 20 \quad 13$ LONG $085 \quad 20 \quad 10$ )

EAGLE LAKE DRAIN NEAR AUGUSTA, MI

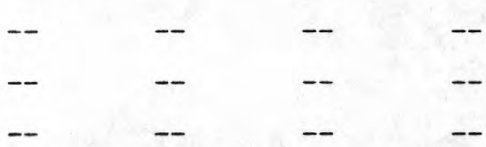

(LAT $42 \quad 18 \quad 54$ LONG $085 \quad 24 \quad 04$ )

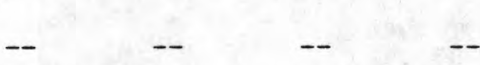

$<0.01<0.1<0.1<0.1$

$<0.1$

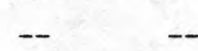

(LAT $42 \quad 18 \quad 10$ LONG $085 \quad 30 \quad 16$ )

COMSTOCK CREEK NEAR KALAMAZOO, MI

(LAT 42 18 10 IONG 085 30 16) $\begin{array}{rrrrrrrrr}<0.01 & <0.01 & <0.01 & <0.1 & <0.1 & <0.01 & <0.1 & <0.1<0.1 \\ -- & -- & -- & -- & -- & - & -- & -\end{array}$ DAVIS CREEK AT KALAMAZOO, MI

(LAT $\left.\begin{array}{lllllll}42 & 16 & 27 & \text { LONG } & 085 & 32 & 17\end{array}\right)$

$$
\begin{aligned}
& \text { OCT } 1986 \\
& 08 \text { ig87 } \\
& \text { JUN } 1987 \\
& 16 \ldots \\
& \text { SEP } \\
& 10 \ldots
\end{aligned}
$$


ANALYSES OF SAMPLES COLLECTED AT WATER-QUALITY PARTIAL-RECORD STATIONS AND MISCELLANEOUS SITES

WATER QUALITY DATA, WATER YEAR OCTOBER 1986 TO SEPTEMBER 1987--Continued

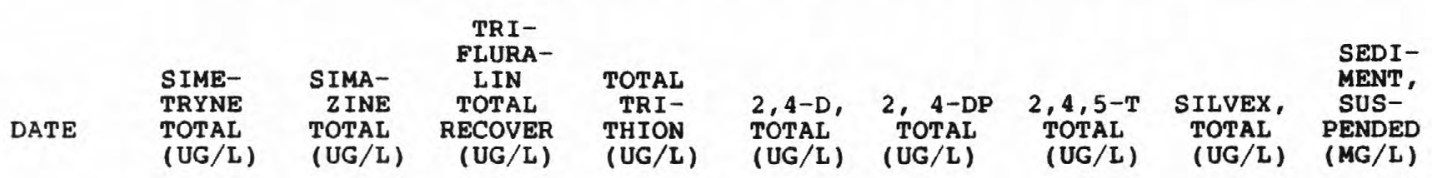

04097240 PORTAGE CREEK NEAR MENDON, MI

(LAT 420425 LONG $08530 \quad 55$ )

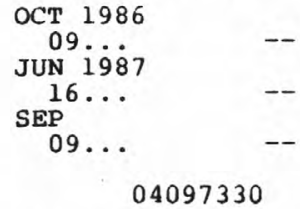

OCT 1986

JUN 1987

SEP $16 .$.

$09 \ldots$

04097370

OCT 1986

JuN 19987

$16 \ldots$

SEP

$08 \ldots$

04097380

OCT 1986

JUN 1987

SEP 8 ...

$<0.1$

$<0.1$

$<0.1$

$--$

$--$

BEAR CREEK NEAR VICKSBURG, MI

$--$

$-$

FLOWERFIELD CREEK AT FLOWERFIELD, MI

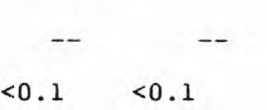

$$
\begin{array}{rrr}
-- & -- \\
<0.01 \quad<0.01 \quad<0.01
\end{array}
$$

$<0.01 \quad<0.01$

$\begin{array}{rr}-- & 5 \\ -- & 19 \\ -- & 4\end{array}$

(LAT $\left.\begin{array}{lllllll}42 & 04 & 42 & \text { LONG } & 085 & 28 & 07\end{array}\right)$

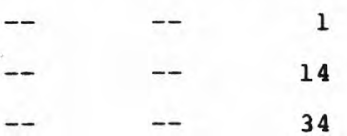

(LAT $42 \quad 03 \quad 50 \quad$ LONG $085 \quad 39 \quad 44$ )

SPRING CREEK NEAR FLOWERFIELD, MI

(LAT $\left.\begin{array}{lllllll}42 & 03 & 50 & \text { LONG } & 085 & 36 & 25\end{array}\right)$

04105671

OCT 1986

$07 \ldots$

JUN 1987

$15 \ldots$

$09 .$.

04105800

OCT 1986

JUN 1987

$15 \ldots$.

SEP

$09 .$.

$<0.1$

0.1

$\begin{array}{rrrrrr}-- & -- & - & - & - \\ <0.1 & <0.1 & <0.01 & <0.01 & <0.01\end{array}$

$\begin{array}{rrr}-- & -- & 16 \\ <0.01 & <0.01 & 8 \\ -- & -- & 31\end{array}$

EAGLE LAKE DRAIN NEAR AUGUSTA, MI

(LAT $4220 \quad 13$ LONG $\left.\begin{array}{lllll}085 & 20 & 10\end{array}\right)$

04105990

OCT 1986

07
JUN 1987
$15 \ldots$

$09 .$.

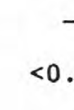

$<0.1$

$-$

04106050

OCT 1986

JUN 1987

JUN 198

SEP 10.

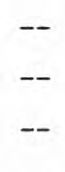

GULL CREEK NEAR GALESBURG, MI

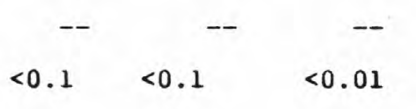

0.02

$<0.01$

COMSTOCK CREEK NEAR KALAMAZOO, MI

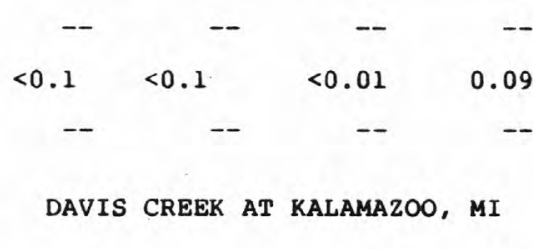

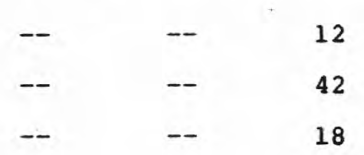

(LAT $42 \quad 18 \quad 54$ LONG $085 \quad 24 \quad 04$ )

$\begin{array}{rrr}-- & -- & 3 \\ <0.01 & <0.01 & 8 \\ -- & -- & 5\end{array}$

(LAT $42 \quad 18 \quad 10$ LONG $\left.\begin{array}{lllll}085 & 30 & 16\end{array}\right)$

$\begin{array}{rrrr}-- & -- & -- & 3 \\ <0.01 & <0.01 & <0.01 & 5 \\ -- & -- & -- & 1\end{array}$

(LAT $\left.\begin{array}{lllllll}42 & 16 & 27 & \text { LONG } & 085 & 32 & 17\end{array}\right)$ 


\begin{tabular}{|c|c|c|c|c|c|c|c|c|c|c|}
\hline TE & IME & $\begin{array}{l}\text { STREAM- } \\
\text { FLOW, } \\
\text { INSTAN- } \\
\text { TANEOUS } \\
\text { (CFS) }\end{array}$ & $\begin{array}{l}\text { SPE- } \\
\text { CIFIC } \\
\text { CON- } \\
\text { DUCT- } \\
\text { ANCE } \\
\text { (US/CM) }\end{array}$ & $\begin{array}{c}\text { PH } \\
\text { (STAND- } \\
\text { ARD } \\
\text { UNITS) }\end{array}$ & $\begin{array}{l}\text { TEMPER- } \\
\text { ATURE } \\
\text { (DEG C) }\end{array}$ & $\begin{array}{c}\text { OXYGEN, } \\
\text { DIS- } \\
\text { SOLVED } \\
\text { (MG/L) }\end{array}$ & $\begin{array}{c}\text { NITRO- } \\
\text { GEN, } \\
\text { NITRITE } \\
\text { TOTAL } \\
\text { (MG/L } \\
\text { AS N) }\end{array}$ & $\begin{array}{c}\text { NITRO- } \\
\text { GEN, } \\
\text { NO2+NO3 } \\
\text { TOTAL } \\
\text { (MG/L } \\
\text { AS N) }\end{array}$ & $\begin{array}{l}\text { NITRO- } \\
\text { GEN, } \\
\text { AMMONIA } \\
\text { TOTAL } \\
\text { (MG/L } \\
\text { AS N) }\end{array}$ & $\begin{array}{c}\text { NITRO- } \\
\text { GEN, } \\
\text { ORGANIC } \\
\text { TOTAL } \\
\text { (MG/L } \\
\text { AS N) }\end{array}$ \\
\hline
\end{tabular}

04106500 PORTAGE CREEK AT KALAMAZOO, MI

(LAT $42 \quad 16 \quad 27$ LONG $085 \quad 34 \quad 35$ )

\begin{tabular}{|c|c|c|c|c|c|c|c|c|c|c|}
\hline JUN 19987 & 1530 & 125 & 576 & 8.1 & 14.0 & 9.6 & 0.03 & 0.70 & 0.11 & 0.69 \\
\hline SEP $16 \ldots$ & 1500 & 30 & 584 & 8.0 & 25.0 & 8.4 & 0.02 & 0.40 & 0.07 & 0.63 \\
\hline $10 \ldots$ & 1120 & 33 & 571 & 7.8 & 18.5 & 9.0 & 0.02 & 0.50 & 0.04 & 0.56 \\
\hline
\end{tabular}

04106512 PORTAGE CREEK AT KALAMAZOO, MI

(LAT $\left.\begin{array}{lllllll}42 & 17 & 40 & \text { LONG } & 085 & 34 & 25\end{array}\right)$

\begin{tabular}{|c|c|c|c|c|c|c|c|c|c|c|}
\hline $\begin{array}{c}\text { OCT } 1986 \\
09 \\
\text { JUN } 1987\end{array}$ & 1300 & -- & 614 & 8.0 & 14.0 & 7.8 & 0.02 & 0.60 & 0.07 & 0.93 \\
\hline $17 \ldots$ & 1400 & 38 & 654 & 7.5 & 23.0 & 7.1 & 0.02 & 0.50 & 0.09 & 0.81 \\
\hline $10 \ldots$ & 1315 & 40 & 632 & 7.9 & 19.0 & 10.0 & 0.02 & 0.50 & 0.04 & 0.16 \\
\hline
\end{tabular}

04106513 ARCADIA CREEK AT KALAMAZOO, MI

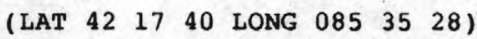

\begin{tabular}{|c|c|c|c|c|c|c|c|c|c|c|}
\hline $\begin{array}{l}\text { OCT } 1986 \\
088 \\
\text { JUN } 1987\end{array}$ & 1535 & 6.2 & 1330 & 7.9 & 16.0 & 9.2 & 0.03 & 1.00 & 0.23 & 0.97 \\
\hline SEP $16 \ldots$ & 1415 & 3.4 & -- & -- & 19.5 & -- & 0.02 & 1.00 & 0.07 & 0.63 \\
\hline $10 \ldots$ & 0945 & 4.1 & 774 & 8.0 & 17.0 & 8.6 & $<0.01$ & 1.20 & 0.02 & 1.8 \\
\hline
\end{tabular}

04106750 SPRING BROOK NEAR EAST COOPER, MI

(LAT $\left.\begin{array}{lllllll}42 & 21 & 24 & \text { LONG } & 085 & 33 & 05\end{array}\right)$

\begin{tabular}{|c|c|c|c|c|c|c|c|c|c|c|}
\hline $\begin{array}{c}\text { OCT } 1986 \\
088 \\
\text { JUN } 1987\end{array}$ & 1345 & 30 & 444 & 8.2 & 12.5 & 10.9 & $<0.01$ & 1.50 & 0.03 & 0.57 \\
\hline $\operatorname{SEP}_{16 \ldots}$ & 1550 & 18 & -- & -- & 17.5 & -- & $<0.01$ & 1.80 & 0.02 & 0.78 \\
\hline $10 \ldots$ & 1035 & 20 & 523 & 8.2 & 13.0 & 10.0 & $<0.01$ & 1.70 & $<0.01$ & \\
\hline
\end{tabular}

KALAMAZOO RIVER NEAR COOPER CENTER, MI

(LAT $\left.\begin{array}{lllllll}42 & 22 & 35 & \text { LONG } & 085 & 34 & 47\end{array}\right)$

\begin{tabular}{|c|c|c|c|c|c|c|c|c|c|c|}
\hline $\begin{array}{l}\text { OCT } 1986 \\
\text { O9 } \\
\text { JUN } 1987\end{array}$ & 1300 & 2,980 & 455 & 8.0 & 13.5 & 9.0 & 0.02 & 0.90 & 0.07 & 1.5 \\
\hline $\operatorname{seP} \cdots$ & 1130 & 482 & 691 & 7.4 & 26.5 & 7.5 & 0.03 & 1.30 & 0.13 & 0.27 \\
\hline $11 \ldots$ & 1115 & 955 & 541 & 8.3 & 22.0 & 7.8 & 0.04 & 0.90 & 0.08 & 0.52 \\
\hline
\end{tabular}

04107710 SAND CREEK NEAR ALAMO, MI

(LAT $\left.\begin{array}{lllllll}42 & 21 & 02 & \text { LONG } & 085 & 44 & 43\end{array}\right)$

\begin{tabular}{|c|c|c|c|c|c|c|c|c|c|c|}
\hline $\begin{array}{l}\text { OCT } 1986 \\
08 \text { i } \\
\text { JUN } 1987\end{array}$ & 1155 & 31 & 502 & 7.9 & 12.5 & 7.2 & 0.02 & 0.40 & 0.09 & 0.41 \\
\hline${ }_{\text {SEP }}^{16 \ldots}$ & 1220 & 9.3 & 511 & 7.5 & 14.0 & -- & $<0.01$ & 0.40 & 0.03 & 0.47 \\
\hline $10 \ldots$ & 1330 & 12 & 535 & 8.1 & 14.0 & 8.3 & 0.01 & 0.40 & 0.02 & 0.28 \\
\hline
\end{tabular}

04107750 RUPERT LAKE OUTLET NEAR PLAINWELL, MI

(LAT $\left.\begin{array}{lllllll}42 & 24 & 53 & \text { LONG } & 085 & 44 & 17\end{array}\right)$

\begin{tabular}{|c|c|c|c|c|c|c|c|c|c|c|}
\hline $\begin{array}{c}\text { OCT } 1986 \\
08 \text {. } \\
\text { JUN } 1987\end{array}$ & 1015 & 31 & 475 & 7.8 & 14.0 & 4.2 & 0.04 & 0.50 & 0.23 & 1.1 \\
\hline$\underset{S E P}{16 \ldots}$ & 1015 & 8.3 & 536 & 7.6 & 20.5 & 6.3 & $<0.01$ & 0.30 & 0.05 & 0.75 \\
\hline $10 \ldots$ & 1215 & 10 & 519 & 8.2 & 19.0 & 8.0 & $<0.01$ & 0.20 & 0.04 & 0.46 \\
\hline
\end{tabular}


WATER QUALITY DATA, WATER YEAR OCTOBER 1986 TO SEPTEMBER 1987--Continued

\begin{tabular}{|c|c|c|c|c|c|c|c|c|c|c|}
\hline DATE & $\begin{array}{l}\text { NITRO- } \\
\text { GEN, AM- } \\
\text { MONIA + } \\
\text { ORGANIC } \\
\text { TOTAL } \\
\text { (MG/L } \\
\text { AS N) }\end{array}$ & $\begin{array}{l}\text { NITRO- } \\
\text { GEN, } \\
\text { TOTAL } \\
\text { (MG/L } \\
\text { AS N) }\end{array}$ & $\begin{array}{c}\text { PHOS- } \\
\text { PHORUS, } \\
\text { TOTAL } \\
\text { (MG/L } \\
\text { AS P) }\end{array}$ & $\begin{array}{l}\text { PHOS- } \\
\text { PHORUS, } \\
\text { ORTHO, } \\
\text { TOTAL } \\
\text { (MG/L } \\
\text { AS P) }\end{array}$ & $\begin{array}{l}\text { PHENOLS } \\
\text { TOTAL } \\
\text { (UG/L) }\end{array}$ & $\begin{array}{c}\text { ALA- } \\
\text { CHLOR } \\
\text { TOTAL } \\
\text { RECOVER } \\
\text { (UG/L) }\end{array}$ & $\begin{array}{l}\text { AME- } \\
\text { TRYNE } \\
\text { TOTAL }\end{array}$ & $\begin{array}{l}\text { ATRA- } \\
\text { Z INE, } \\
\text { TOTAL } \\
\text { (UG/L ) }\end{array}$ & $\begin{array}{l}\text { CYAN- } \\
\text { AZINE } \\
\text { TOTAL } \\
\text { (UG/L) }\end{array}$ & $\begin{array}{l}\text { DI- } \\
\text { AZ INON, } \\
\text { TOTAL } \\
\text { (UG/L) }\end{array}$ \\
\hline
\end{tabular}

04106500 PORTAGE CREEK AT KALAMAZOO, MI

(LAT $42 \quad 16 \quad 27$ LONG $085 \quad 34 \quad 35$ )

\begin{tabular}{|c|c|c|c|c|c|c|}
\hline $\begin{array}{c}\text { OCT } 1986 \\
09.08\end{array}$ & 0.8 & 1.5 & 0.08 & 0.03 & -- & -- \\
\hline SEP $16 \ldots$ & 0.7 & 1.1 & 0.05 & 0.01 & -- & - \\
\hline $10 \ldots$ & 0.6 & 1.1 & 0.02 & $<0.01$ & -- & \\
\hline
\end{tabular}

04106512 PORTAGE CREEK AT KALAMAZOO, MI

(LAT $42 \quad 17 \quad 40$ LONG $085 \quad 34 \quad 25$ )

OCT 1986

$\begin{array}{rrrrr}\text { OCT } 1986 & 1.0 & 1.6 & 0.09 & 0.02 \\ 09907 & 1.0 & 1.4 & 0.05 & 0.02 \\ \begin{array}{r}\text { JUN } 1987 \\ \quad 17 \ldots\end{array} & 0.9 & 0.7 & 0.01 & <0.01\end{array}$

04106513 ARCADIA CREEK AT KALAMAZOO, MI

$\begin{array}{rrrrrr}-- & -- & -- & - & - \\ 3 & <0.1 & <0.1 & <0.1 & <0.1 & <0.01 \\ -- & -- & -- & - & -\end{array}$

OCT 1986

\begin{tabular}{|c|c|c|c|c|}
\hline $\begin{array}{l}01986 \\
08 \\
\text { JUN } 19887\end{array}$ & 1.2 & 2.2 & 0.13 & 0.02 \\
\hline $16 \ldots$ & 0.7 & 1.7 & 0.26 & 0.05 \\
\hline 10. & 1.8 & 3.0 & 0.07 & 0.0 \\
\hline
\end{tabular}

04106750 SPRING BROOK NEAR EAST COOPER, MI

(LAT $42 \quad 17 \quad 40$ LONG $085 \quad 35 \quad 28$ )

2.10 .03

\begin{tabular}{|c|c|c|c|c|c|c|}
\hline $\begin{array}{l}\text { OCT } 1986 \\
08.987 \\
\text { JUN } 1987\end{array}$ & 0.6 & 2.1 & 0.03 & 0.01 & -- & -- \\
\hline${ }_{\text {SEP }} 16 \ldots$ & 0.8 & 2.6 & 0.03 & $<0.01$ & -- & \\
\hline $10 \ldots$ & $<0.2$ & -- & $<0.01$ & $<0.01$ & -- & \\
\hline
\end{tabular}

04106770 KALAMAZOO RIVER NEAR COOPER CENTER, MI

(LAT $42 \quad 22 \quad 35$ LONG $085 \quad 34 \quad 47$ )

$\begin{array}{ccccccc}\text { OCT } 1986 & & & & \\ 09 \\ \text { JUN } 1987 & 1.6 & 2.5 & 0.08 & 0.03 & -- \\ \underset{17 \ldots}{17 \ldots} & 0.4 & 1.7 & 0.08 & 0.02 & 5 & - \\ \begin{array}{l}\text { SEP } \\ 11 \ldots\end{array} & 0.6 & 1.5 & 0.02 & 0.02 & --\end{array}$

04107710 SAND CREEK NEAR ALAMO, MI

(LAT $\left.\begin{array}{lllllll}42 & 21 & 02 & \text { LONG } & 085 & 44 & 43\end{array}\right)$

\begin{tabular}{|c|c|c|c|c|c|c|c|c|c|}
\hline $\begin{array}{c}\text { OCT } 1986 \\
08 \\
\text { JUN } 1987\end{array}$ & 0.5 & 0.9 & 0.03 & $<0.01$ & -- & -- & -- & -- & -- \\
\hline $16 \ldots$ & 0.5 & 0.9 & 0.04 & $<0.01$ & -- & $<0.1$ & $<0.1$ & $<0.1$ & $<0.1$ \\
\hline $10 \ldots$ & 0.3 & 0.7 & $<0.01$ & $<0.01$ & -- & -- & -- & -- & -- \\
\hline
\end{tabular}

04107750 RUPERT LAKE OUTLET NEAR PLAINWELL, MI

(LAT $42 \quad 2453$ LONG $085 \quad 44 \quad 17$ )

\begin{tabular}{|c|c|c|c|c|c|c|}
\hline $\begin{array}{c}\text { OCT } 1986 \\
08 \\
\text { JUN } 1987\end{array}$ & 1.3 & 1.8 & 0.06 & 0.01 & -- & -- \\
\hline SEP $16 \ldots$ & 0.8 & 1.1 & 0.03 & $<0.01$ & -- & - \\
\hline $10 \ldots$ & 0.5 & 0.7 & $<0.01$ & $<0.01$ & - & \\
\hline
\end{tabular}




\begin{tabular}{|c|c|c|c|c|c|c|c|c|c|c|}
\hline ATE & $\begin{array}{l}\text { ETHION, } \\
\text { TOTAL } \\
\text { (UG/L) }\end{array}$ & $\begin{array}{l}\text { MALA- } \\
\text { THION, } \\
\text { TOTAL } \\
\text { (UG/L) }\end{array}$ & $\begin{array}{l}\text { METHYL } \\
\text { PARA- } \\
\text { THION, } \\
\text { TOTAL } \\
\text { (UG/L) }\end{array}$ & $\begin{array}{l}\text { METHYL } \\
\text { TRI- } \\
\text { THION, } \\
\text { TOTAL } \\
\text { (UG/L) }\end{array}$ & $\begin{array}{l}\text { METOLA- } \\
\text { CHLOR } \\
\text { WATER } \\
\text { WHOLE } \\
\text { TOT.REC } \\
\text { (UG } / L \text { ) }\end{array}$ & $\begin{array}{l}\text { METRI- } \\
\text { BUZIN } \\
\text { WATER } \\
\text { WHOLE } \\
\text { TOT.REC } \\
\text { (UG/L) }\end{array}$ & $\begin{array}{l}\text { PARA- } \\
\text { THION, } \\
\text { TOTAL } \\
\text { (UG/L) }\end{array}$ & $\begin{array}{l}\text { PROME- } \\
\text { TONE } \\
\text { TOTAL } \\
\text { (UG/L) }\end{array}$ & $\begin{array}{l}\text { PROME- } \\
\text { TRYNE } \\
\text { TOTAL } \\
\text { (UG/L) }\end{array}$ & $\begin{array}{l}\text { PRO- } \\
\text { PAZINE } \\
\text { TOTAL } \\
\text { (UG/L) }\end{array}$ \\
\hline
\end{tabular}

$04106500 \quad$ PORTAGE CREEK AT KALAMAZOO, MI

(LAT $\left.\begin{array}{lllllll}42 & 16 & 27 & \text { LONG } & 085 & 34 & 35\end{array}\right)$

$$
\begin{aligned}
& \text { OCT } 1986 \\
& 09.9 . \\
& \text { JUN } 1987 \\
& \text { } 16 \ldots \\
& \text { SEP } \\
& 10
\end{aligned}
$$

04106512

OCT 1986

JUN 1998

$17 \ldots$

SEP

$10 .$.

04106513

OCT 1986

JUN 1987

$16 \ldots$

$10 \ldots$

04106750

OCT 1986

JUN 19887

$16 \ldots$

SEP $10 .$.

04106770

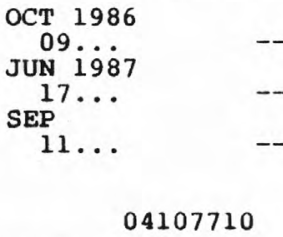

OCT 1986

JUN 1987

$16 \ldots$

SEP

04107750

OCT 1986

08 JUN 1987
$16 \ldots$
SEP
$10 \ldots$

\begin{abstract}
C: CREDK AT KaLAMAZOO, MI
\end{abstract}
-- - -

$\begin{array}{llll}-- & -- & -- & -- \\ -- & -- & -- & --\end{array}$

PORTAGE CREEK AT KalAmazOO, MI

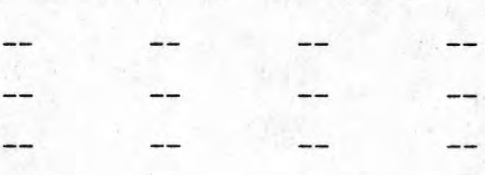

(LAT $\left.\begin{array}{llllllll}42 & 17 & 40 & \text { LONG } & 085 & 34 & 25\end{array}\right)$

$$
\begin{array}{rrrr}
-- & -- & -- & - \\
<0.01 & <0.01 & <0.01 & <0.1 \\
-- & -- & -- & --
\end{array}
$$

ARCADIA CREEK AT KALAMAZOO, MI

(LAT $\begin{array}{lllllll}42 & 17 & 40 & \text { LONG } & 085 & 35 & 28\end{array}$

$$
\begin{array}{llll}
-- & -- & -- & - \\
-- & -- & -- & -- \\
-- & -- & -- & --
\end{array}
$$

SPRING BROOK NEAR EAST COOPER, MI

(LAT $\left.\begin{array}{lllllll}42 & 21 & 24 & \text { LONG } & 085 & 33 & 05\end{array}\right)$

$\begin{array}{lllll}-- & -- & -- & -- & - \\ -- & -- & -- & -- & -- \\ -- & -- & -- & -- & --\end{array}$

KALAMAZOO RIVER NEAR COOPER CENTER, MI

(LAT $\left.\begin{array}{llllllll}42 & 22 & 35 & \text { LONG } & 085 & 34 & 47\end{array}\right)$

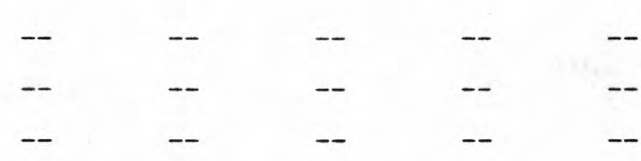

SAND CREEK NEAR ALAMO, MI

(LAT $42 \quad 21 \quad 02$ LONG $085 \quad 44 \quad 43$ )

$$
\begin{array}{rrrrr}
-- & -- & -- & -- & -- \\
-- & -- & -- & <0.1 & <0.1 \\
-- & -- & -- & -- & -- \\
\text { RUPERT } & \text { LAKE } & \text { OUTLET } & \text { NEAR PLAINWELL, MI }
\end{array}
$$

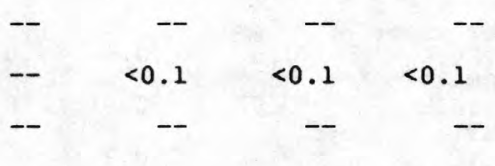

(LAT $\left.\begin{array}{llllllll}42 & 24 & 53 & \text { LONG } & 085 & 44 & 17\end{array}\right)$

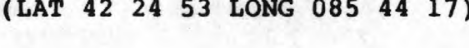

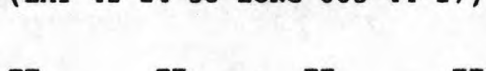


ANALYSES OF SAMPLES COLLECTED AT WATER-QUALITY PARTIAL-RECORD STATIONS AND MISCELLANEOUS SITES WATER QUALITY DATA, WATER YEAR OCTOBER 1986 TO SEPTEMBER 1987--Continued

\begin{tabular}{|c|c|c|c|c|c|c|c|c|}
\hline $\begin{array}{l}\text { SIME- } \\
\text { TRYNE } \\
\text { TOTAL } \\
\text { (UG/L ) }\end{array}$ & $\begin{array}{c}\text { SIMA- } \\
\text { ZINE } \\
\text { TOTAL } \\
\text { (UG/L) }\end{array}$ & $\begin{array}{l}\text { TRI- } \\
\text { FLURA- } \\
\text { LIN } \\
\text { TOTAL } \\
\text { RECOVER } \\
\text { (UG/L) }\end{array}$ & $\begin{array}{l}\text { TOTAL } \\
\text { TRI- } \\
\text { THION } \\
\text { (UG/L) }\end{array}$ & $\begin{array}{l}2,4-D \text {, } \\
\text { TOTAL } \\
\text { (UG/L) }\end{array}$ & 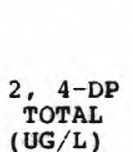 & $\begin{array}{c}2,4,5-\mathrm{T} \\
\text { TOTAL } \\
\text { (UG/L) }\end{array}$ & $\begin{array}{c}\text { SILVEX, } \\
\text { TOTAL } \\
\text { (UG/L) }\end{array}$ & $\begin{array}{l}\text { SEDI- } \\
\text { MENT, } \\
\text { SUS- } \\
\text { PENDED } \\
\text { (MG/L) }\end{array}$ \\
\hline
\end{tabular}

04106500 PORTAGE CREEK AT KALAMA200, MI

(LAT $\left.\begin{array}{llllllll}42 & 16 & 27 & \text { LONG } 085 \quad 34 & 35\end{array}\right)$

\begin{tabular}{|c|c|c|c|c|c|c|c|c|c|}
\hline $\begin{array}{l}\text { OCT } 1986 \\
\text { O9 } 19887\end{array}$ & -- & -- & -- & -- & -- & -- & -- & -- & 60 \\
\hline $16 \ldots$ & -- & -- & -- & -- & -- & -- & -- & -- & 23 \\
\hline $10 \ldots$ & -- & -- & -- & -- & -- & -- & -- & -- & 67 \\
\hline
\end{tabular}

04106512 PORTAGE CREEK AT KALAMAZOO, MI

(LAT $\left.\begin{array}{llllllll}42 & 17 & 40 & \text { LONG } & 085 & 34 & 25\end{array}\right)$

OCT 1986

JUN 19987

JUN $17 . .$.

SEP $10 .$.

PORTAG CREEK AT KALAMAZOO, MI

(LAT 421740 LONG 0853425$)$

04106513 ARCADIA CREEK AT KALAMAZOO, MI

$\begin{array}{rrrr}-- & -- & -- & 32 \\ <0.01 & <0.01 & <0.01 & 44 \\ -- & -- & -- & 45\end{array}$

OCT 1986
O8 1987
JUN 1987
SEP $\ldots$
10...

(LAT $\left.\begin{array}{lllllll}42 & 17 & 40 & \text { LONG } & 085 & 35 & 28\end{array}\right)$

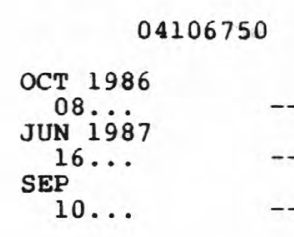

04106770

OCT 1986

JUN 19987

JUN 198

SEP $11 .$.

04107710

OCT 1986
O8. 1987
JUN 1987
I6...
SEP $10 .$.

04107750

OCT 1986

JUN 19887

$16 \ldots$

SEP

$10 .$. $\begin{array}{llll}-- & -- & -- & -- \\ -- & -- & -- & -- \\ -- & -- & -- & --\end{array}$

SPRING BROOK NEAR EAST COOPER, MI

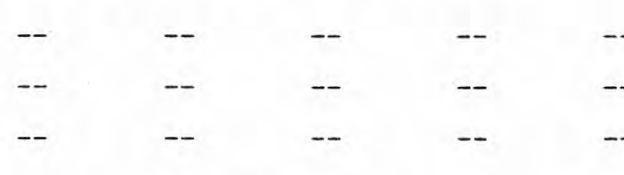

KALAMAZOO RIVER NEAR COOPER CENTER, MI

$\begin{array}{rrrr}-- & -- & -- & 60 \\ -- & -- & -- & 110 \\ -- & -- & -- & 2\end{array}$

(IAT $42 \quad 21 \quad 24$ LONG $085 \quad 33 \quad 05$ )

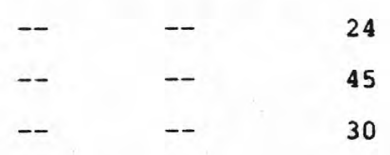

(LAT $\left.\begin{array}{lllllll}42 & 22 & 35 & \text { LONG } & 085 & 34 & 47\end{array}\right)$

$\begin{array}{rrr}-- & -- & 9 \\ -- & -- & 13 \\ -- & -- & 30\end{array}$

(LAT $42 \quad 21 \quad 02$ LONG $085 \quad 44 \quad 43$ )

SAND CREEK NEAR ALAMO, MI

$\begin{array}{lll}-- & -- & 45 \\ -- & -- & 36 \\ -- & -- & 42\end{array}$

(LAT $\left.\begin{array}{lllllll}42 & 24 & 53 & \text { LONG } & 085 & 44 & 17\end{array}\right)$

RUPERT LAKE OUTLET NEAR PLAINWELL, MI

-- -

-- $\quad--\quad 33$

$\begin{array}{lll}-- & - & 32\end{array}$ 


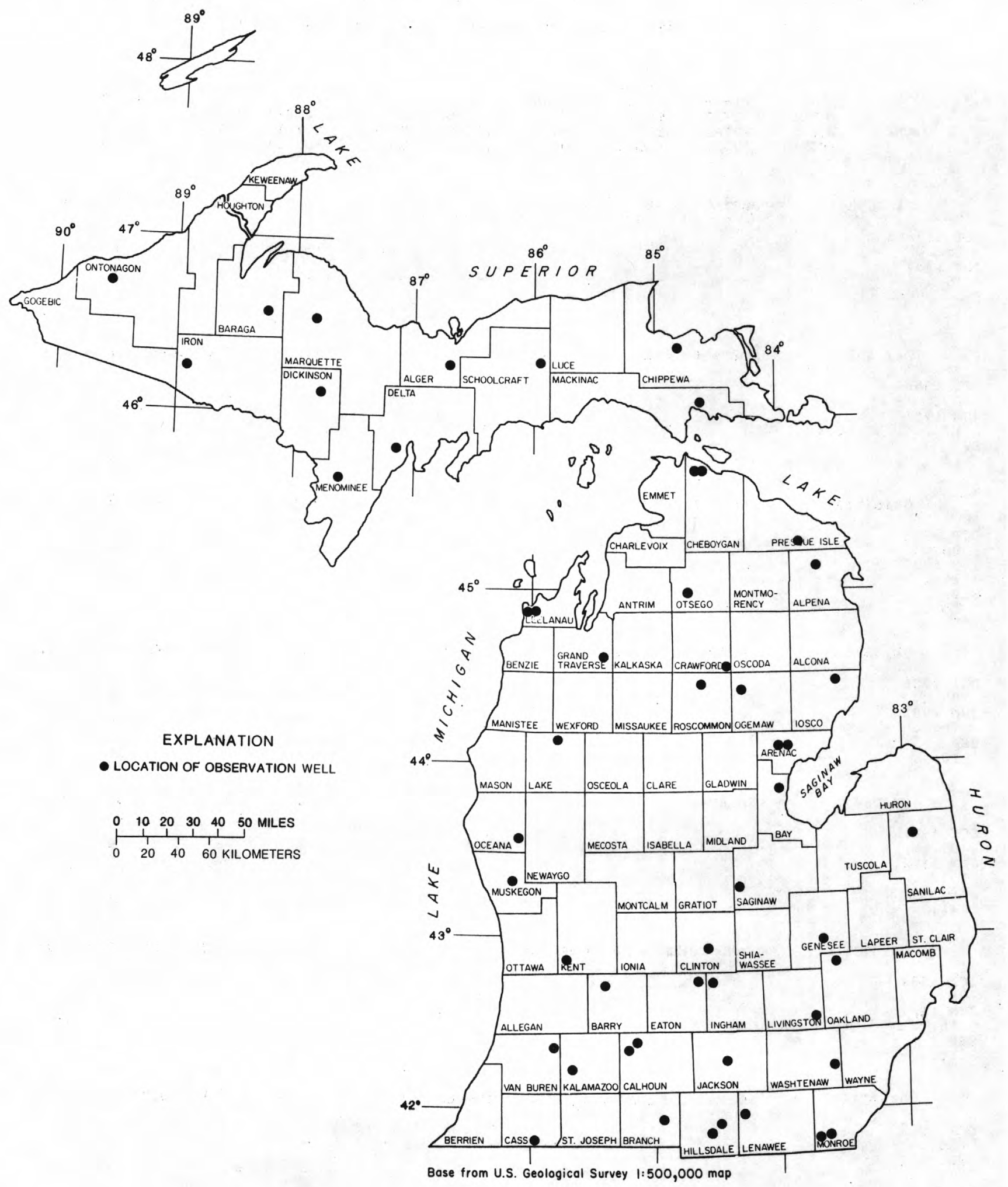

Figure 9.--Lncation of observation wells published in this report. 
461608086373801. Local number, 45N 19W 25BDCD.

LOCATION. - Lat $46^{\circ} 16^{\circ} 08^{\prime \prime}$, long $86^{\circ} 37^{\prime} 38^{\prime \prime}$, Hydrologic Unit 04060106 , 250 ft northwest of state

Highway 44, and $0.2 \mathrm{mi}$ northeast of Kentucky. Owner: U.S. Forest Service.

AQUIFER. - Glacial deposits of Pleistocene age.

WELI CHARACTERISTICS,--Drilled artesian well, diameter 6 in., depth $66 \mathrm{ft}$.

INSTRUMENTATION.--Quarterly measurement.

DATUM.--Elevation of land-surface datum is $850 \mathrm{ft}$ above National Geodetic Vertical Datum of 1929 , from

topographic map. Measuring point: Top of casing, $3.6 \mathrm{ft}$ above land-surface datum.

REMARKS. - Water temperature also measured.

PERIOD OF RECORD. - June 1959 to current year.

EXTREMES FOR PERIOD OF RECORD.--Highest water level measured, 6.35 ft below land-surface datum, June 29,

1960; lowest measured, $14.19 \mathrm{ft}$ below land-surface datum, Apr. 3, 1964.

WATER LEVEL, IN FEET BELOW LAND-SURFACE DATUM, WATER YEAR OCTOBER 1986 TO SEPTEMBER 1987

$\begin{array}{lllll} & & \text { WATER } & \text { WATER }\end{array}$

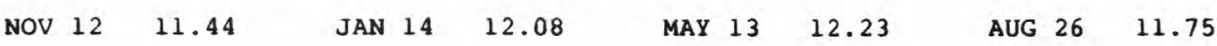

ALPENA COUNTY

450850083393401. Local number, 32N 6E 23DDDA.

LOCATION. - Lat $45^{\circ} 08^{\prime} 50^{\prime \prime}$, long $83^{\circ} 39^{\prime} 34^{\prime \prime}$, Hydrologic Unit 04070006, on Graham Road, $3 \mathrm{mi}$ east and

$1.5 \mathrm{mi}$ north of Long Rapids. Owner: U.S. Geological Survey.

AQUIFER.-- Sand of Pleistocene age.

WELL CHARACTERISTICS.--Drilled water-table observation well, diameter 6 in., depth $88 \mathrm{ft}$, screened 79 to $88 \mathrm{ft}$.

INSTRUMENTATION. --Water-level recorder.

DATUM.--Elevation of land-surface datum is $713 \mathrm{ft}$ above National Geodetic Vertical Datum of 1929 , from

topographic map. Measuring point: Plywood instrument shelf, 2.7 ft above land-surface datum.

REMARKS. - Bottom of hole near top of bedrock.

PERIOD OF RECORD. - November 1976 to current year.

EXTREMES FOR PERIOD OF RECORD.--Highest water level recorded, 13.61 ft below land-surface datum, May 22 ,

1983; lowest recorded, $30.01 \mathrm{ft}$ below land-surface datum, Mar. 27, 1982.

WATER LEVEL, IN FEET BELOW LAND-SURFACE DATUM, WATER YEAR OCTOBER 1986 TO SEPTEMBER 1987 LOWEST VALUES

\begin{tabular}{|c|c|c|c|c|c|c|c|c|c|c|c|c|}
\hline DAY & OCT & NOV & DEC & JAN & FEB & MAR & APR & MAY & JUN & JUL & AUG & SEP \\
\hline $\begin{array}{r}5 \\
10 \\
15 \\
20 \\
25 \\
\text { EOM }\end{array}$ & $\begin{array}{l}17.50 \\
17.03 \\
17.31 \\
17.36 \\
17.57 \\
17.67\end{array}$ & $\begin{array}{l}17.46 \\
17.86 \\
17.70 \\
17.90 \\
18.03 \\
18.23\end{array}$ & $\begin{array}{l}18.25 \\
18.18 \\
18.27 \\
18.40 \\
18.35 \\
18.43\end{array}$ & $\begin{array}{l}18.49 \\
18.44 \\
18.74 \\
18.64 \\
18.92 \\
19.19\end{array}$ & $\begin{array}{l}19.54 \\
19.74 \\
20.00 \\
20.20 \\
20.55 \\
20.50\end{array}$ & $\begin{array}{l}20.81 \\
20.38 \\
20.37 \\
20.34 \\
20.00 \\
18.89\end{array}$ & $\begin{array}{l}18.99 \\
18.59 \\
18.51 \\
18.49 \\
18.59 \\
18.57\end{array}$ & $\begin{array}{l}18.60 \\
18.61 \\
18.71 \\
18.60 \\
18.70 \\
18.46\end{array}$ & $\begin{array}{l}18.45 \\
18.47 \\
18.52 \\
18.64 \\
18.77 \\
18.91\end{array}$ & $\begin{array}{l}19.07 \\
19.20 \\
19.36 \\
19.75 \\
20.19 \\
20.89\end{array}$ & $\begin{array}{l}21.17 \\
21.54 \\
21.80 \\
21.60 \\
21.90 \\
22.22\end{array}$ & $\begin{array}{l}22.53 \\
22.87 \\
23.18 \\
23.39 \\
23.40 \\
23.49\end{array}$ \\
\hline
\end{tabular}

WTR YR 1987

HIGHEST 16.78 OCT 8,1986

LOWEST 23.49 SEP 30,1987

ARENAC COUNTY

440342083542801 . Local number, 19N 5E 7DABAl.

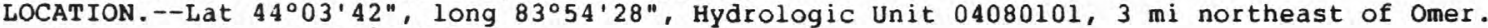

Owner: U.S. Geological Survey.

AQUIFER. --Saginaw Formation of Pennsylvanian age.

WELL CHARACTERISTICS.--Drilled artesian well, diameter $6 \mathrm{in.,}$ depth $185 \mathrm{ft}$., screened 180 to 185 ft.

INSTRUMENTATION.--Monthly measurement.

DATUM.--Elevation of land-surface datum is $667 \mathrm{ft}$ above National Geodetic Vertical Datum of 1929 , from

topographic map. Measuring point: Top of casing, $2.00 \mathrm{ft}$ above land-surface datum.

PERIOD OF RECORD. --June 1980 to current year.

EXTREMES FOR PERIOD OF RECORD.--Highest water level measured, 8.28 ft below land-surface datum, July 15,

1980; lowest measured, $11.35 \mathrm{ft}$ below land-surface datum, Sept. 16, 1987.

WATER LEVEL, IN FEET BELOW LAND-SURFACE DATUM, WATER YEAR OCTOBER 1986 TO SEPTEMBER 1987

$\begin{array}{lllllllll} & \text { WATER } & & \text { WATER } & & \text { WATER } & & \text { WATER } & \text { WATER } \\ \text { DATE } & \text { LEVEL } & \text { DATE } & \text { LEVEL } & \text { DATE } & \text { LEVEL } & \text { DATE } & \text { LEVEL } & \text { DATE }\end{array}$

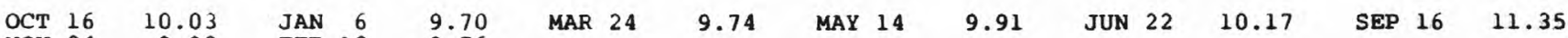


440342083542801 . Local number, 19N 5E 7DABA2.

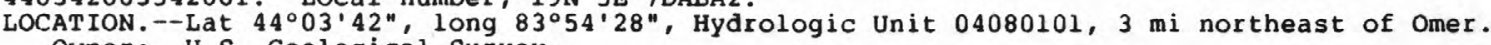

Owner: U.S. Geologicál Survey.

AQUIFER.--Lake bed sand of Pleistocene age.

WELL CHARACTERISTICS.--Drilled water-table well, diameter $6 \mathrm{in}$, , depth $21 \mathrm{ft}$, screened $16 \mathrm{fo} 21 \mathrm{ft}$. INSTRUMENTATION. --Monthly measurement.

DATUM.--Elevation of land-surface datum is $667 \mathrm{ft}$ above National Geodetic vertical Datum of 1929 , from

topographic map. Measuring point: Top of casing, $2.20 \mathrm{ft}$ above land-surface datum.

PERIOD OF RECORD.--June 1980 to current year.

EXTREMES FOR PERIOD OF RECORD.--Highest water level measured, 2.35 ft below land-surface datum, Apr. 29 ,

1985; lowest measured, $6.95 \mathrm{ft}$ below land-surface datum, Aug. 21, 1980.

WATER LEVEL, IN FEET BELOW LAND-SURFACE DATUM, WATER YEAR OCTOBER 1986 TO SEPTEMBER 1987

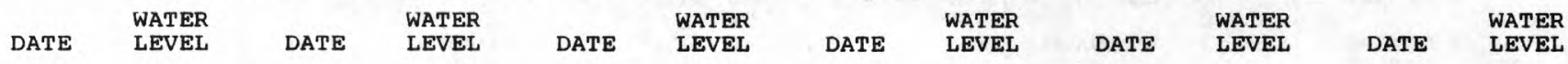

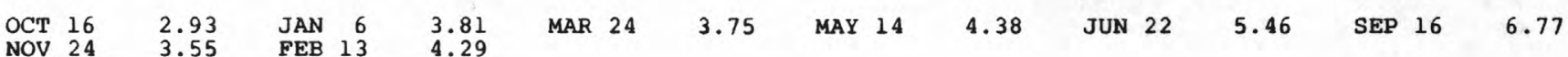

463353088144301 . Local number, 48N 32W 12DDCC.

LOCATION.--Lat $46^{\circ} 33^{\prime} 53^{\prime \prime}$, long $88^{\circ} 14^{\prime} 43^{\prime \prime}$, Hydrologic Unit 04030107 , 95 ft north of U,S. Highway

41 , and $0.5 \mathrm{mi}$ southeast of Nestoria Road. Owner: Michigan Department of State Highways. AQUIFER.--Sand and gravel of Pleistocene age.

WELL CHARACTERISTICS.--Drilled water-table well, diameter $1.5 \mathrm{in}$, depth $10 \mathrm{ft}$, screened 7 to $10 \mathrm{ft}$.

INSTRUMENTATION. - Monthly measurement by observer.

DATUM.--Elevation of land-surface datum is 1,630 ft above National Geodetic Vertical Datum of 1929 , from topographic map. Measuring point: Top of casing, $4.78 \mathrm{ft}$ above land-surface datum.

PERIOD OF RECORD. --September 1948 to current year.

EXTREMES FOR PERIOD OF RECORD. - - Highest water level measured, 3.27 ft below land-surface datum, Apr. 30,

1965 lowest measured, $9.93 \mathrm{ft}$ below land-surface datum, Jan. 30, 1987.

WATER LEVEL, IN FEET BELOW LAND-SURFACE DATUM, WATER YEAR OCTOBER 1986 TO SEPTEMBER 1987

\begin{tabular}{|c|c|c|c|c|c|c|c|c|c|c|}
\hline & $\begin{array}{l}\text { WATER } \\
\text { LEVEL }\end{array}$ & DATE & $\begin{array}{l}\text { WATER } \\
\text { LEVEL }\end{array}$ & DATE & $\begin{array}{l}\text { WATER } \\
\text { LEVEL }\end{array}$ & DATE & $\begin{array}{l}\text { WATER } \\
\text { LEVEL }\end{array}$ & DATE & $\begin{array}{l}\text { WATER } \\
\text { LEVEL }\end{array}$ & DATE \\
\hline $\begin{array}{l}30 \\
30\end{array}$ & $\begin{array}{l}7.44 \\
7.59\end{array}$ & $\begin{array}{ll}\text { DEC } & 31 \\
\text { JAN } & 30\end{array}$ & $\begin{array}{l}7.82 \\
9.93\end{array}$ & $\begin{array}{ll}\text { FEB } & 26 \\
\text { MAR } & 31\end{array}$ & $\begin{array}{l}9.79 \\
8.91\end{array}$ & $\begin{array}{ll}\text { APR } & 30 \\
\text { MAY } & 31\end{array}$ & $\begin{array}{l}9.12 \\
9.29\end{array}$ & $\begin{array}{ll}\text { JUN } & 24 \\
\text { JUL } & 31\end{array}$ & $\begin{array}{l}9.82 \\
7.59\end{array}$ & $\begin{array}{ll}\text { AUG } & 27 \\
\text { SEP } & 30\end{array}$ \\
\hline
\end{tabular}

BARRY COUNTY

424540085232001. Local number, 4N 9W 5DAAA.

LOCATION.--Lat $42^{\circ} 45^{\prime} 40^{\prime \prime}$, long $85^{\circ} 23^{\prime} 20^{\prime \prime}$, Hydrologic Unit 04050007 , on Soloman Road, $4 \mathrm{mi}$ east and

$3.5 \mathrm{mi}$ north of Middleville. Owner: Michigan Department of Natural Resources.

AQUIFER.--Glacial deposits of Pleistocene age.

WELL CHARACTERISTICS.--Drilled water-table weil, diameter 2 in., depth $131 \mathrm{ft}$.

INSTRUMENTATION.--Quarterly measurement.

DATUM.--Elevation of land-surface datum is $860 \mathrm{ft}$ above National Geodetic Vertical Datum of 1929 , from

topographic map. Measuring point: Top of casing, $2.00 \mathrm{ft}$ above land-surface datum.

PERIOD OF RECORD.--December 1964 to current year.

EXTREMES FOR PERIOD OF RECORD.--Highest water level measured, 111.51 ft below land-surface datum, Mar. 20 ,

1978; lowest measured, 122.02 ft below land-surface datum, Mar. 5, 1965.

WATER LEVEL, IN FEET BELOW LAND-SURFACE DATUM, WATER YEAR OCTOBER 1986 TO SEPTEMBER 1987

$\begin{array}{llll} & \text { WATER } & \text { WATER } & \text { WATER } \\ \text { DATE LEVEL } & \text { DATE } & \text { LEVEL } & \text { DATE } \\ \text { LEVEL }\end{array}$

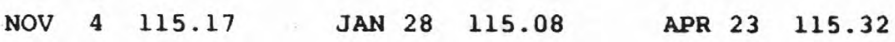




\section{BAY COUNTY}

435128083582401 . Local number, 17N 4E 22DCAA.

LOCATION.--Lat $43^{\circ} 51^{\prime} 28^{\prime \prime}$, long $83^{\circ} 58^{\prime} 24^{\prime \prime}$, Hydrologic Unit 04080102 , at end of second Street in Pinconning: Owner: Pinconning Township.

AQUIFER .--Saginaw Formation of Pennsylvanian age.

WELL CHARACTERISTICS.--Drilled artesian well, diameter $6 \mathrm{in}$., depth $110 \mathrm{ft}$, cased to $60 \mathrm{ft}$, open bottom.

INSTRUMENTATION.--Monthly measurement. Water-level recorder from August 1962 to October 1979.

DATUM.--Elevation of land-surface datum is $620 \mathrm{ft}$ above National Geodetic vertical Datum of 1929 , from

topographic map. Measuring point: Plywood shelter base, $2.00 \mathrm{ft}$ above land-surface datum.

REMARKS. - Water levels affected by regional pumping.

PERIOD OF RECORD.--August 1962 to current year.

EXTREMES FOR PERIOD OF RECORD.--Highest water level recorded, $0.05 \mathrm{ft}$ below land-surface datum, Mar. 5 ,

1976; lowest recorded, $10.53 \mathrm{ft}$ below land-surface datum, Aug. 8, 1963.

WATER LEVEL, IN FEET BELOW LAND-SURFACE DATUM, WATER YEAR OCTOBER 1986 TO SEPTEMBER 1987

DATE WATER N DATE WATER NATE WATER

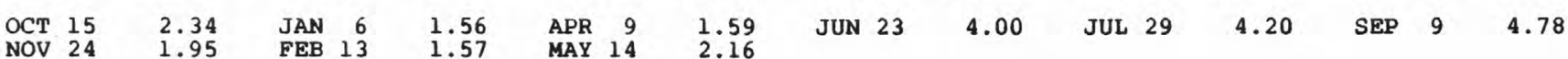

BRANCH COUNTY

415602084593701 . LOCal number, 6S 6W 22CABA.

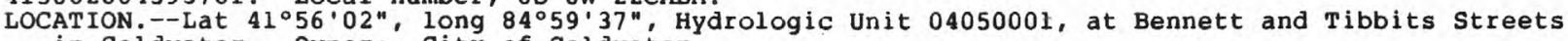
in Coldwater. Owner: City of Coldwater.

AQUIFER.--Sand and gravel of Pleistocene age.

WELL CHARACTERISTICS.--Drilled artesian well, diameter 6 in., depth $113 \mathrm{ft}$, screened 108 to $113 \mathrm{ft}$.

INSTRUMENTATION. --Water-level recorder.

DATUM.--Elevation of land-surface datum is $970 \mathrm{ft}$ above National Geodetic Vertical Datum of 1929, from

topographic map. Measuring point: Plywood shelter base, $2.50 \mathrm{ft}$ above land-surface datum.

REMARKS. - Water levels affected by nearby pumping.

PERIOD OF RECORD.--January 1964 to current year.

EXTREMES FOR PERIOD OF RECORD.--Highest water level recorded, $9.0 \mathrm{ft}$ below land-surface datum, May 6 ,

1975; lowest recorded, $25.9 \mathrm{ft}$ below land-surface datum, May 25, 1977.

WATER LEVEL, IN FEET BELOW LAND-SURFACE DATUM, WATER YEAR OCTOBER 1986 TO SEPTEMBER 1987 LOWEST VALUES

\begin{tabular}{|c|c|c|c|c|c|c|c|c|c|c|c|c|}
\hline DAY & ОСт & NOV & $\mathrm{DEC}$ & JAN & FEB & MAR & APR & MAY & JUN & JUL & AUG & SEP \\
\hline $\begin{array}{r}5 \\
10 \\
15 \\
20 \\
25 \\
\text { EOM }\end{array}$ & $\begin{array}{l}12.83 \\
17.15 \\
15.97 \\
15.96 \\
12.88 \\
21.31\end{array}$ & $\begin{array}{l}21.58 \\
21.58 \\
15.87 \\
21.81 \\
18.54 \\
13.37\end{array}$ & $\begin{array}{l}17.71 \\
21.75 \\
21.01 \\
13.19 \\
12.93 \\
13.09\end{array}$ & $\begin{array}{l}21.64 \\
13.50 \\
17.96 \\
16.50 \\
13.26 \\
16.61\end{array}$ & $\begin{array}{l}18.49 \\
21.76 \\
14.70 \\
21.98 \\
22.94 \\
14.54\end{array}$ & $\begin{array}{l}22.74 \\
23.21 \\
13.40 \\
14.06 \\
22.88 \\
16.57\end{array}$ & $\begin{array}{l}16.46 \\
16.57 \\
18.30 \\
17.52 \\
14.13 \\
16.46\end{array}$ & $\begin{array}{l}14.31 \\
22.58 \\
18.69 \\
22.57 \\
15.44 \\
16.97\end{array}$ & $\begin{array}{l}23.17 \\
19.21 \\
22.61 \\
16.82 \\
16.64 \\
15.61\end{array}$ & $\begin{array}{l}14.49 \\
18.05 \\
22.22 \\
24.22 \\
21.37 \\
17.97\end{array}$ & $\begin{array}{l}24.17 \\
16.66 \\
18.40 \\
23.82 \\
23.99 \\
14.81\end{array}$ & $\begin{array}{l}15.31 \\
24.03 \\
23.86 \\
16.04 \\
19.82 \\
17.31\end{array}$ \\
\hline
\end{tabular}

$\begin{array}{lllllll}\text { WTR YR } 1987 & \text { HIGHEST } & 11.95 & \text { OCT } 7,1986 & \text { LOWEST } & 25.23 & \text { JUL } 13,1987\end{array}$

CALHOUN COUNTY

422422085071501 . Local number, IS 7W 10BBAB

LOCATION.--Lat $42^{\circ} 24^{\prime} 22^{\prime \prime}$, long $85^{\circ} 07^{\prime} 15^{\prime \prime}$, Hydrologic Unit 04050003 , at State Highways 78 and 66 , $5 \mathrm{mi}$ north of Battle Creek. Owner: Rilla Sabin.

AQUIFER.--Glacial deposits of Pleistocene age.

WELL CHARACTERISTICS.--Dug water-table well, diameter $1.25 \mathrm{in}$., depth $12 \mathrm{ft}$, screened 9 to 12 feet. INSTRUMENTATION. - Weekly measurement by observer.

DATUM.--Elevation of land-surface datum is $970.99 \mathrm{ft}$ above National Geodetic Vertical Datum of 1929. Measuring point: Top of casing, $1.50 \mathrm{ft}$ above land-surface datum.

PERIOD OF RECORD.--September 1946 to current year.

EXTREMES FOR PERIOD OF RECORD.--Highest water level measured, $0.89 \mathrm{ft}$ below land-surface datum, Mar. 28,

1950 ; lowest, dry, July 29, 1964 .

WATER LEVEL, IN FEET BELOW LAND-SURFACE DATUM, WATER YEAR OCTOBER 1986 TO SEPTEMBER 1987

\begin{tabular}{|c|c|c|c|c|c|c|c|c|c|c|c|c|c|c|c|}
\hline DATE & $\begin{array}{l}\text { WATER } \\
\text { LEVEL }\end{array}$ & DATE & $\begin{array}{l}\text { WATER } \\
\text { LEVEL }\end{array}$ & DAT & & $\begin{array}{l}\text { WATER } \\
\text { LEVEL }\end{array}$ & DAT & & $\begin{array}{l}\text { WATER } \\
\text { LEVEL }\end{array}$ & DAT & & $\begin{array}{l}\text { WATER } \\
\text { LEVEL }\end{array}$ & DAT & & $\begin{array}{l}\text { WATER } \\
\text { LEVEL }\end{array}$ \\
\hline $\begin{array}{r}1 \\
8 \\
15 \\
22 \\
29 \\
25 \\
5 \\
12 \\
19 \\
26\end{array}$ & $\begin{array}{l}4.00 \\
3.80 \\
3.50 \\
3.04 \\
3.10 \\
3.14 \\
3.20 \\
3.28 \\
3.52\end{array}$ & 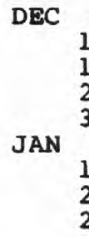 & $\begin{array}{l}3.52 \\
3.60 \\
3.64 \\
3.70 \\
3.77 \\
3.82 \\
3.90 \\
3.91 \\
3.95\end{array}$ & $\begin{array}{l}\text { FEB } \\
\text { MAR }\end{array}$ & $\begin{array}{r}4 \\
11 \\
18 \\
25 \\
4 \\
11 \\
18 \\
25\end{array}$ & $\begin{array}{l}3.98 \\
4.01 \\
4.08 \\
4.12 \\
4.12 \\
4.12 \\
4.11 \\
4.10\end{array}$ & $\begin{array}{l}\text { APR } \\
\text { MAY }\end{array}$ & $\begin{array}{r}1 \\
8 \\
15 \\
22 \\
29 \\
6 \\
13 \\
20 \\
27\end{array}$ & $\begin{array}{l}4.12 \\
4.18 \\
4.20 \\
4.21 \\
4.22 \\
4.30 \\
4.34 \\
4.36 \\
4.40\end{array}$ & $\begin{array}{l}\text { JUN } \\
\text { JUL }\end{array}$ & $\begin{array}{r}3 \\
10 \\
17 \\
24 \\
1 \\
8 \\
15 \\
29\end{array}$ & $\begin{array}{l}4.50 \\
4.54 \\
4.47 \\
4.60 \\
4.64 \\
4.70 \\
4.76 \\
4.83\end{array}$ & $\begin{array}{l}\text { AUG } \\
\text { SEP }\end{array}$ & $\begin{array}{r}5 \\
12 \\
19 \\
26 \\
2 \\
9 \\
16 \\
23 \\
30\end{array}$ & $\begin{array}{l}4.85 \\
4.90 \\
4.94 \\
5.06 \\
5.06 \\
5.04\end{array}$ \\
\hline
\end{tabular}


422025085084001 . Local number, is $7 \mathrm{~W}$ 32DABA.

LOCATION.--Lat $42^{\circ} 20^{\circ} 25^{\prime \prime}$, long $85^{\circ} 08^{\prime} 40^{\prime \prime}$, Hydrologic Unit 04050003 , at Verona well field in Battle Creek. Owner: City of Battle Creek.

AQUIFER.--Marshail Formation of Mississippian age.

WELL CHARACTERISTICS.--Drilled artesian well, diameter $8 \mathrm{in}$, , depth $127 \mathrm{ft}$, cased to $103 \mathrm{ft}$.

INSTRUMENTATION. --Daily measurement by observer.

DATUM.--Elevation of land-surface datum is $830.79 \mathrm{ft}$ above National Geodetic Vertical Datum of 1929. Measuring point: Recorder base, $2.10 \mathrm{ft}$ above land-surface datum.

REMARKS.--Water levels affected by nearby municipal pumping.

PERIOD OF RECORD. - October 1939 to current year.

EXTREMES FOR PERIOD OF RECORD.--Highest water level measured, $0.7 \mathrm{ft}$ below land-surface datum, Apr. 26, 27, 1950; lowest measured, $16.75 \mathrm{ft}$ below land-surface datum, July 16, 1959 .

WATER LEVEL, IN FEET BELOW LAND-SURFACE DATUM, WATER YEAR OCTOBER 1986 TO SEPTEMBER 1987

\begin{tabular}{|c|c|c|c|c|c|c|c|c|c|c|c|c|}
\hline DAY & OCT & NOV & DEC & JAN & FEB & MAR & APR & MAY & JUN & JUL & AUG & SEP \\
\hline $\begin{array}{r}5 \\
10 \\
15 \\
20 \\
25 \\
\text { EOM }\end{array}$ & $\begin{array}{l}8.80 \\
8.25 \\
7.40 \\
7.00 \\
7.50 \\
7.50\end{array}$ & $\begin{array}{l}7.20 \\
7.60 \\
7.50 \\
7.50 \\
6.90 \\
6.30\end{array}$ & $\begin{array}{l}7.80 \\
7.70 \\
7.50 \\
7.60 \\
6.15 \\
6.50\end{array}$ & \begin{tabular}{r}
6.90 \\
7.00 \\
\hdashline-0 \\
7.80 \\
7.25
\end{tabular} & $\begin{array}{l}8.00 \\
7.40 \\
7.70 \\
8.40 \\
8.10 \\
7.80\end{array}$ & $\begin{array}{l}8.00 \\
8.10 \\
8.40 \\
9.00 \\
9.25 \\
9.00\end{array}$ & $\begin{array}{r}8.40 \\
9.75 \\
9.70 \\
9.75 \\
9.45 \\
10.10\end{array}$ & $\begin{array}{r}9.80 \\
9.55 \\
9.40 \\
9.80 \\
9.25 \\
10.55\end{array}$ & $\begin{array}{l}11.05 \\
11.50 \\
11.75 \\
11.60 \\
12.25 \\
11.40\end{array}$ & $\begin{array}{l}10.10 \\
11.50 \\
11.50 \\
12.00 \\
12.20 \\
12.00\end{array}$ & $\begin{array}{l}12.40 \\
12.10 \\
11.80 \\
12.30 \\
11.10 \\
12.40\end{array}$ & $\begin{array}{l}11.20 \\
11.30 \\
11.40 \\
10.80 \\
11.10 \\
11.00\end{array}$ \\
\hline
\end{tabular}

414651085575601. Local number, 8S 14W 17BAAA,

LOCATION.--Lat 41046'51", long $85^{\circ} 57^{\prime} 56^{\prime \prime}$. Hydrologic Unit 04050001, at U.S. Highway 112, 2 mi east of Adamsville. Owner: Ted Little.

AQUIFER.--Glacial deposits of Pleistocene age.

WELL CHARACTERISTICS. --Dug water-table well, diameter $28 \mathrm{in}$., depth $55 \mathrm{ft}$, cribbed with brick to open bottom.

INSTRUMENTATION.--Monthly measurement by observer.

DATUM.--Elevation of land-surface datum is $840 \mathrm{ft}$ above National Geodetic Vertical Datum of 1929 , from topographic map. Measuring point: Top of wooden platform, $1.00 \mathrm{ft}$ above land-surface datum.

PERIOD OF RECORD. --September 1945 to current year.

EXTREMES FOR PERIOD OF RECORD.--Highest water level measured, $46.20 \mathrm{ft}$ below land-surface datum, July 16 , 1950; lowest measured, dry, Mar. 10, 1947. WATER LEVEL, IN FEET BELOW LAND-SURFACE DATUM, WATER YEAR OCTOBER 1986 TO SEPTEMBER 1987

\begin{tabular}{|c|c|c|c|c|c|c|c|c|c|c|c|}
\hline DATE & $\begin{array}{l}\text { WATER } \\
\text { LEVEL }\end{array}$ & DATE & $\begin{array}{l}\text { WATER } \\
\text { LEVEL }\end{array}$ & DATE & $\begin{array}{l}\text { WATER } \\
\text { LEVEL }\end{array}$ & DATE & $\begin{array}{l}\text { WATER } \\
\text { LEVEL }\end{array}$ & DATE & $\begin{array}{l}\text { WATER } \\
\text { LEVEL }\end{array}$ & DATE & $\begin{array}{l}\text { WATER } \\
\text { LEVEL }\end{array}$ \\
\hline $\begin{array}{ll}\text { OCT } & 26 \\
\text { NOV } & 24\end{array}$ & $\begin{array}{l}50.10 \\
50.20\end{array}$ & $\begin{array}{ll}\text { JAN } & 26 \\
\text { FEB } & 19\end{array}$ & $\begin{array}{l}50.70 \\
50.30\end{array}$ & $\begin{array}{ll}\text { MAR } & 24 \\
\text { APR } & 25\end{array}$ & $\begin{array}{l}50.60 \\
50.40\end{array}$ & $\begin{array}{ll}\text { MAY } & 28 \\
\text { JUN } & 25\end{array}$ & $\begin{array}{l}50.70 \\
51.10\end{array}$ & $\begin{array}{ll}\text { JUL } & 21 \\
\text { AUG } & 25\end{array}$ & $\begin{array}{l}50.90 \\
51.05\end{array}$ & SEP 24 & 51.15 \\
\hline
\end{tabular}

454427084424001. Local number, 39N 3W 29CBCBI.

LOCATION.--Lat $45^{\circ} 44^{\prime} 27^{\prime \prime}$, long $84^{\circ} 42^{\prime} 40^{\prime \prime}$, Hydrologic Unit 04070003 , at Stimpson Road, $3 \mathrm{mi}$

southeast of Mackinaw City. Owner: U.s. Geological Survey.

AQUIFER.--Dundee Formation of Devonian age.

WELL CHARACTERISTICS.--Drilled artesian weil, diameter $6 \mathrm{in}$., depth $121 \mathrm{ft}$, cased to $104 \mathrm{ft}$, open bottom. INSTRUMENTATION.--Monthly measurement.

DATUM.--Elevation of land-surface datum is $705 \mathrm{ft}$ above National Geodetic Vertical Datum of 1929, from topographic map. Measuring point: Top of casing, $2.00 \mathrm{ft}$ above land-surface datum.

PERIOD OF RECORD. - January 1979 to current year.

EXTREMES FOR PERIOD OF RECORD.--Highest water level measured, $4.71 \mathrm{ft}$ below land-surface datum, Apr. 8 ,

1986; lowest measured, $11.68 \mathrm{ft}$ below land-surface datum, Feb. 11, 1981.

WATER LEVEL, IN FEET BELOW LAND SURFACE DATUM, WATER YEAR OCTOBER 1986 TO SEPTEMBER 1987

\begin{tabular}{|c|c|c|c|c|c|c|c|c|c|c|c|}
\hline DATE & $\begin{array}{l}\text { WATER } \\
\text { LEVEL }\end{array}$ & DATE & $\begin{array}{l}\text { WATER } \\
\text { LEVEL }\end{array}$ & DATE & $\begin{array}{l}\text { WATER } \\
\text { LEVEL }\end{array}$ & DATE & $\begin{array}{l}\text { WATER } \\
\text { LEVEL }\end{array}$ & DATE & $\begin{array}{l}\text { WATER } \\
\text { LEVEL }\end{array}$ & DATE & $\begin{array}{l}\text { WATER } \\
\text { LEVEL }\end{array}$ \\
\hline $\begin{array}{ll}\text { CT } & 29 \\
\text { EC } & 10\end{array}$ & $\begin{array}{l}7.59 \\
7.04\end{array}$ & $\begin{array}{r}\text { JAN } 21 \\
\text { MAR }\end{array}$ & $\begin{array}{l}7.41 \\
8.10\end{array}$ & APR 17 & 6.26 & MAY 27 & 6.86 & JUL 8 & 8.48 & AUG 19 & 9.94 \\
\hline
\end{tabular}


454427084424002. LoCal number, 39N 3W 29CBCB2.

LOCATION. -- Lat $45^{\circ} 44^{\prime} 27^{\prime \prime}$, long $84^{\circ} 42^{\prime} 40^{\prime \prime}$, Hydrologic Unit 04070003 , at Stimpson Road, $3 \mathrm{mi}$

southeast of Mackinaw City. Owner: U.S. Geological Survey.

AQUIFER. - Sand and gravel of pleistocene age.

WELL CHARACTERISTICS.--Drilled water-table well, diameter $6 \mathrm{in}$, depth $55 \mathrm{ft}$, screened 40 to $55 \mathrm{ft}$. INSTRUMENTATION.--Monthly measurement.

DATUM.--Elevation of land-surface datum is $705 \mathrm{ft}$ above National Geodetic Vertical Datum of 1929 , from topographic map. Measuring point: Top of casing, $2.5 \mathrm{ft}$ above land-surface datum.

PERIOD OF RECORD. - February 1979 to current year.

EXTREMES FOR PERIOD OF RECORD.--Highest water level measured, 1.80 ft below land-surface datum, Apr. 8 ,

1986; lowest measured, 6.47 ft below land-surface datum, Feb. $11,1982$.

WATER LEVEL, IN FEET BELOW LAND-SURFACE DATUM, WATER YEAR OCTOBER 1986 TO SEPTEMBER 1987

$\begin{array}{llllllllllllllllll}\text { OCT } 29 & 3.76 & \text { JAN } & 21 & 3.54 & \text { APR } & 17 & 2.64 & \text { MAY } & 27 & 2.88 & \text { JUL } & 8 & 4.52 & \text { AUG } & 19 & 5.44\end{array}$

462159084442201 . Local number, 46N 4W 24DADA.

LOCATION.--Lat $46^{\circ} 21^{\prime} 59^{\prime \prime}$, long $84^{\circ} 44^{\prime} 22^{\prime \prime}$, Hydrologic Unit 04020203 , on trail $0.2 \mathrm{mi}$ south of State

Highway $28,1 \mathrm{mi}$ west of Raco. Owner: U.S. Forest Service.

AQUIFER.--Glacial deposits of Pleistocene age.

WELL CHARACTERISTICS.--Drilled artesian weli, diameter 6 in., depth $54 \mathrm{ft}$.

INSTRUMENTATION. - -Water-level recorder.

DATUM.--Elevation of land-surface datum is $850 \mathrm{ft}$ above National Geodetic Vertical Datum of 1929 , from topographic map. Measuring point: Top of shelter base, $3.07 \mathrm{ft}$ above land-surface datum.

PERIOD OF RECORD.--June 1952 to April 1965. November 1969 to current year.

EXTREMES FOR PERIOD OF RECORD.--Highest water level recorded, 18.40 ft below land-surface datum, June 7 ,

1971; lowest recorded, $28.43 \mathrm{ft}$ below land-surface datum, Apr. 14, 1964.

WATER LEVEL, IN FEET BELOW LAND-SURFACE DATUM, WATER YEAR OCTOBER 1986 TO SEPTEMBER 1987

\begin{tabular}{|c|c|c|c|c|c|c|c|c|c|c|c|c|}
\hline DAY & OCT & NOV & DEC & JAN & FEB & MAR & APR & MAY & JUN & JUL & AUG & SEP \\
\hline $\begin{array}{r}5 \\
10 \\
15 \\
20 \\
25 \\
\text { EOM }\end{array}$ & $\begin{array}{l}23.62 \\
23.72 \\
23.74 \\
23.74 \\
23.73 \\
23.75\end{array}$ & $\begin{array}{l}23.77 \\
23.84 \\
23.84 \\
23.91 \\
23.95 \\
24.02\end{array}$ & $\begin{array}{l}24.07 \\
24.11 \\
24.17 \\
24.24 \\
24.29 \\
24.36\end{array}$ & $\begin{array}{l}24.42 \\
24.48 \\
24.56 \\
24.60 \\
24.69 \\
24.76\end{array}$ & $\begin{array}{l}24.83 \\
24.91 \\
24.98 \\
25.04 \\
25.13 \\
25.16\end{array}$ & $\begin{array}{l}25.24 \\
25.32 \\
25.40 \\
25.46 \\
25.53 \\
25.61\end{array}$ & $\begin{array}{l}25.64 \\
25.61 \\
25.57 \\
25.45 \\
25.36 \\
25.29\end{array}$ & $\begin{array}{l}25.29 \\
25.27 \\
25.31 \\
25.33 \\
25.38 \\
25.42\end{array}$ & $\begin{array}{l}25.50 \\
25.56 \\
25.62 \\
25.66 \\
25.70 \\
25.75\end{array}$ & $\begin{array}{l}25.79 \\
25.83 \\
25.89 \\
25.94 \\
25.99 \\
26.06\end{array}$ & $\begin{array}{l}26.11 \\
26.18 \\
26.23 \\
26.31 \\
26.37 \\
26.43\end{array}$ & $\begin{array}{l}26.49 \\
26.56 \\
26.62 \\
26.70 \\
26.76 \\
26.83\end{array}$ \\
\hline
\end{tabular}

$\begin{array}{llllllll}\text { WTR YR } 1987 & \text { HIGHEST } & 23.54 & \text { OCT } 3,1986 & \text { LOWEST } 26.83 & \text { SEP } 30,1987\end{array}$

CLINTON COUNTY

425410084323501 Local number, 6N 2W 16DDAD.

LOCATION. - Lat $42^{\circ} 54^{\prime} 10^{\prime \prime}$, long $84^{\circ} 32^{\prime} 35^{\prime \prime}$, Hydrologic Unit 04050005 , at U.S. Highway $27,6 \mathrm{mi}$ south of St. Johns. Owner: Michigan Department of State Highways.

AQUIFER.--Gravel of Pleistocene age.

WELL CHARACTERISTICS.--Driven water-table we11, diameter 2 in., depth $26 \mathrm{ft}$, screened 23 to 26 ft.

INSTRUMENTATION. --Monthly measurement.

DATUM.--Elevation of land-surface datum is $803.32 \mathrm{ft}$ above National Geodetic Vertical Datum of 1929 .

Measuring point: Top of casing, $0.10 \mathrm{ft}$ below land-surface datum.

REMARKS.--Federal key well. Measuring point changed from $1.30 \mathrm{ft}$ above land-surface datum to 0.10 ft below land-surface datum on Sept. 23, 1980.

PERIOD OF RECORD.--August 1948 to current year.

EXTREMES FOR PERIOD OF RECORD.--Highest water level measured, 13.84 ft below land-surface datum, Apr. 30 ,

1974; lowest measured, $19.93 \mathrm{ft}$ below land-surface datum, Feb. 27, 1964.

WATER LEVEL, IN FEET BELOW LAND-SURFACE DATUM, WATER YEAR OCTOBER 1986 TO SEPTEMBER 1987

$\begin{array}{llllllllll} & \text { WATER } & & \text { WATER } & & \text { WATER } & & \text { WATER } & \text { WATER } \\ \text { DATE } & \text { LEVEL } & \text { DATE } & \text { LEVEL } & \text { DATE } & \text { LEVEL } & \text { DATE } & \text { LEVEL } & \text { DATE } & \text { LEVEL }\end{array}$

$\begin{array}{llllllllllllllllll}\text { OCT } & 27 & 15.99 & \text { DEC } & 29 & 16.20 & \text { FEB } & 23 & 16.53 & \text { APR } 27 & 16.35 & \text { JUN } & 26 & 17.36 & \text { AUG } & 25 & 17.86\end{array}$

$\begin{array}{llllllllllll}\text { NOV } 24 & 16.38 & \text { JAN } 29 & 16.29 & \text { MAR } 30 & 16.38 & \text { MAY } 26 & 16.74 & \text { JUL } 29 & 17.75 & \text { SEP } 25 & 17.62\end{array}$


443308084245001. Local number, 25N 1W 15DDCD.

LOCATION. - Lat $44^{\circ} 33^{\prime} 08^{\prime \prime}$, long $84^{\circ} 24^{\prime} 50^{\prime \prime}$, Hydrologic Unit 04070007 , at State Highway 18 , $2.6 \mathrm{mi}$ south of Eldorado. Owner: U.S. Forest Service.

AQUIFER.--Glacial deposits of Pleistocene age.

WELL CHARACTERISTICS.--Drilled artesian well, diameter 6 in., depth $56 \mathrm{ft}$, cased.

INSTRUMENTATION, - Water-level recorder.

DATUM.--Elevation of land-surface datum is $1,190 \mathrm{ft}$ above National Geodetic Vertical Datum of 1929 , from topographic map. Measuring point: Top of shelter base, $2.95 \mathrm{ft}$ above land-surface datum.

PERIOD OF RECORD. - November 1948 to current year.

EXTREMES FOR PERIOD OF RECORD.--Highest water level recorded, 25.55 ft below land-surface datum, Nov.

10, 1986; lowest recorded, $35.97 \mathrm{ft}$ below land-surface datum Apr. 4-6, 1951.

WATER LEVEL, IN FEET BELOW LAND-SURFACE DATUM, WATER YEAR OCTOBER 1986 TO SEPTEMBER 1987

\begin{tabular}{|c|c|c|c|c|c|c|c|c|c|c|c|c|}
\hline DAY & OCT & NOV & DEC & JAN & FEB & MAR & APR & MAY & JUN & JUL & AUG & SEP \\
\hline $\begin{array}{r}5 \\
10 \\
15 \\
20 \\
25 \\
\text { EOM }\end{array}$ & $\begin{array}{l}26.98 \\
26.82 \\
26.53 \\
26.31 \\
26.09 \\
25.92\end{array}$ & $\begin{array}{l}25.79 \\
25.79 \\
25.67 \\
25.68 \\
25.73 \\
25.85\end{array}$ & $\begin{array}{l}25.88 \\
25.88 \\
25.95 \\
26.03 \\
26.05 \\
26.14\end{array}$ & $\begin{array}{l}26.21 \\
26.22 \\
26.33 \\
26.35 \\
26.44 \\
26.49\end{array}$ & $\begin{array}{l}26.59 \\
26.64 \\
26.71 \\
26.77 \\
26.84 \\
26.85\end{array}$ & $\begin{array}{l}26.94 \\
27.01 \\
27.07 \\
27.09 \\
27.12 \\
27.19\end{array}$ & $\begin{array}{l}27.27 \\
27.30 \\
27.36 \\
27.42 \\
27.48 \\
27.50\end{array}$ & $\begin{array}{l}27.58 \\
27.61 \\
27.67 \\
27.72 \\
27.77 \\
27.79\end{array}$ & $\begin{array}{l}27.85 \\
27.90 \\
27.93 \\
27.98 \\
28.01 \\
28.07\end{array}$ & $\begin{array}{l}28.11 \\
28.15 \\
28.20 \\
28.25 \\
28.30 \\
28.35\end{array}$ & $\begin{array}{l}28.39 \\
28.43 \\
28.47 \\
28.51 \\
28.51 \\
28.43\end{array}$ & $\begin{array}{l}28.41 \\
28.33 \\
28.30 \\
28.25 \\
28.27 \\
28.23\end{array}$ \\
\hline
\end{tabular}

WTR YR 1987

HIGHEST 25.55 NOV 10, 1986

LOWEST 28.52 AUG 24, 1987

DELTA COUNTY

454446087090401. Local number, 39N 23W 28ACCC.

LOCATION.--Lat $45^{\circ} 44^{\prime} 46^{\prime \prime}$, long $87^{\circ} 09^{\prime} 04^{\prime \prime}$, Hydrologic Unit $04030111,3.5 \mathrm{mi}$ west of Escanaba.

Owner: M. Blake.

AQUIFER.--Munising Sandstone of Cambrian age.

WELL CHARACTERISTICS.-Drilled artesian well, diameter 5 in., depth $530 \mathrm{ft}$.

INSTRUMENTATION.--Water-level recorder.

DATUM.--Elevation of land-surface datum is $680 \mathrm{ft}$ above National Geodetic Vertical Datum of 1929 , from topographic map. Measuring point: Top of shelter base, 3.39 ft above land-surface datum.

PERIOD OF RECORD.--July 1968 to current year.

EXTREMES FOR PERIOD OF RECORD.--Highest water level recorded, 1.5 ft below land-surface datum, May 6 ,

1960; lowest recorded, $8.9 \mathrm{ft}$ below land-surface datum, Feb. $6,1977$.

WATER LEVEL, IN FEET BELOW LAND-SURFACE DATUM, WATER YEAR OCTOBER 1986 TO SEPTEMBER 1987 LOWEST VÁLUES

\begin{tabular}{|c|c|c|c|c|c|c|c|c|c|c|c|c|}
\hline DAY & OCT & NOV & DEC & JAN & FEB & MAR & APR & MAY & JUN & JUL & AUG & SEP \\
\hline $\begin{array}{r}5 \\
10 \\
15 \\
20 \\
25 \\
\text { EOM }\end{array}$ & $\begin{array}{l}5.96 \\
5.93 \\
5.79 \\
5.81 \\
5.82 \\
5.91\end{array}$ & $\begin{array}{l}5.89 \\
5.95 \\
6.03 \\
6.05 \\
5.98 \\
6.19\end{array}$ & $\begin{array}{l}6.15 \\
6.14 \\
6.24 \\
6.21 \\
6.19 \\
6.24\end{array}$ & $\begin{array}{l}6.18 \\
6.14 \\
6.28 \\
6.23 \\
6.51 \\
6.46\end{array}$ & $\begin{array}{l}6.39 \\
6.46 \\
6.49 \\
6.51 \\
6.60 \\
6.52\end{array}$ & $\begin{array}{l}6.57 \\
6.43 \\
6.49 \\
6.23 \\
5.99 \\
6.04\end{array}$ & $\begin{array}{l}5.94 \\
5.76 \\
5.71 \\
5.81 \\
5.78 \\
5.86\end{array}$ & $\begin{array}{l}5.95 \\
6.01 \\
6.26 \\
6.01 \\
6.20 \\
6.01\end{array}$ & $\begin{array}{r}6.10 \\
6.39 \\
- \\
5.61 \\
5.67\end{array}$ & $\begin{array}{l}6.20 \\
6.03 \\
6.20 \\
6.83 \\
6.36 \\
6.37\end{array}$ & $\begin{array}{l}6.08 \\
6.20 \\
5.94 \\
6.09 \\
6.43 \\
6.43\end{array}$ & $\begin{array}{l}6.88 \\
6.80 \\
6.65 \\
6.16 \\
6.83 \\
6.41\end{array}$ \\
\hline
\end{tabular}

WTR YR 1987 HIGHEST 5.14 JUN $16,1987 \quad$ LOWEST 7.03 SEP 7,1987

DICKINSON COUNTY

460458087493901. Local number, 43N 28W 32ADAB.

LOCATION. - Lat $46^{\circ} 04^{\prime} 58^{\prime \prime}$, long $87^{\circ} 49^{\prime} 39^{\prime \prime}$, Hydrologic Unit 04030109, $6.25 \mathrm{mi}$ north of Felch.

Owner: Michigan Department of Natural Resources.

AQUIFER. - Sand of Pleistocene age.

WELL CHARACTERISTICS.--Augered water-table well, diameter 1.25 in., depth $31 \mathrm{ft}$, screened 29 to 31 ft. INSTRUMENTATION. --Monthly measurement.

DATUM.--Elevation of land-surface datum is 1,160 ft above National Geodetic Vertical Datum of 1929 , from topographic map. Measuring point: Hole in top of cap, $4.00 \mathrm{ft}$ above land-surface datum.

PER IOD OF RECORD. - October 1966 to current year.

EXTREMES FOR PERIOD OF RECORD.--Highest water level measured, 12.95 ft below land-surface datum, Apr. 9, 1986; lowest measured, $16.50 \mathrm{ft}$ below land-surface datum, Mar. 2, 1977.

WATER LEVEL, IN FEET BELOW LAND-SURFACE DATUM, WATER YEAR OCTOBER 1986 TO SEPTEMBER 1987

\begin{tabular}{|c|c|c|c|c|c|c|c|c|c|c|c|c|}
\hline DATE & $\begin{array}{l}\text { WATER } \\
\text { LEVEL }\end{array}$ & DA? & & $\begin{array}{l}\text { WATER } \\
\text { LEVEL }\end{array}$ & DATE & $\begin{array}{l}\text { WATER } \\
\text { LEVEL }\end{array}$ & DATE & $\begin{array}{l}\text { WATER } \\
\text { LEVEL }\end{array}$ & DATE & $\begin{array}{l}\text { WATER } \\
\text { LEVEL }\end{array}$ & DATE & $\begin{array}{l}\text { WATER } \\
\text { LEVEL }\end{array}$ \\
\hline $\begin{array}{lr}\text { CT } & 28 \\
\text { EC } & 1\end{array}$ & $\begin{array}{l}14.17 \\
14.00\end{array}$ & $\begin{array}{l}\text { JAN } \\
\text { MAR }\end{array}$ & $\begin{array}{l}8 \\
4\end{array}$ & $\begin{array}{l}14.86 \\
15.12\end{array}$ & $\begin{array}{lr}\text { MAR } & 26 \\
\text { APR } & 1\end{array}$ & $\begin{array}{l}15.20 \\
15.22\end{array}$ & $\begin{array}{ll}\text { APR } & 28 \\
\text { MAY } & 29\end{array}$ & $\begin{array}{l}14.93 \\
15.03\end{array}$ & $\begin{array}{ll}\text { JUN } & 29 \\
\text { JUL } & 31\end{array}$ & $\begin{array}{l}15.30 \\
14.76\end{array}$ & $\begin{array}{lr}\text { SEP } & 4 \\
\text { SEP } & 24\end{array}$ & $\begin{array}{l}14.92 \\
15.04\end{array}$ \\
\hline
\end{tabular}


EATON COUNTY

424435084365001. Local number, 4N 3W 12CDAD.

LOCATION. - Lat $42^{\circ} 44^{\prime} 35^{\prime \prime}$, long $84^{\circ} 36^{\prime} 50^{\prime \prime}$, Hydrologic Unit 04050004, at Robins Road, in Delta Township, $0.5 \mathrm{mi}$ west of Lansing. Owner: F. Wheeler.

AQUIFER. - Saginaw Formation of Pennsylvanian age.

WELL CHARACTERISTICS.--Drilled artesian well, diameter 6 in., depth 381 ft, cased to 140 ft.

INSTRUMENTATION.--Water-level recorder.

DATUM.--Elevation of land-surface datum is $\mathbf{8 6 2 . 9 1} \mathrm{ft}$ above National Geodetic Vertical Datum of 1929.

Measuring point: Plywood instrument shelf, $1.00 \mathrm{ft}$ above land-surface datum.

REMARKS. - water levels affected by pumping.

PERIOD OF RECORD.--October 1953 to current year.

EXTREMES FOR PERIOD OF RECORD.--Highest water level recorded, 67.5 ft below land-surface datum, Nov. 23,

1953; lowest recorded, $103.6 \mathrm{ft}$ below land-surface datum, Aug. 28, 1969.

WATER LEVEL, IN FEET BELOW LAND-SURFACE DATUM, WATER YEAR OCTOBER 1986 TO SEPTEMBER 1987

\begin{tabular}{|c|c|c|c|c|c|c|c|c|c|c|c|c|}
\hline DAY & OCT & NOV & DEC & JAN & FEB & MAR & APR & MAY & JUN & JUL & AUG & SEP \\
\hline $\begin{array}{r}5 \\
10 \\
15 \\
20 \\
25 \\
\text { EOM }\end{array}$ & $\begin{array}{l}79.08 \\
79.36 \\
80.13 \\
79.77 \\
80.71 \\
81.22\end{array}$ & $\begin{array}{l}79.72 \\
79.30 \\
77.58 \\
76.73 \\
76.53 \\
80.28\end{array}$ & $\begin{array}{l}82.30 \\
82.52 \\
80.00 \\
80.75 \\
77.53 \\
76.62\end{array}$ & $\begin{array}{l}75.91 \\
76.93 \\
75.30 \\
75.90 \\
75.11 \\
76.01\end{array}$ & $\begin{array}{l}77.28 \\
75.67 \\
75.76 \\
76.98 \\
77.03 \\
77.65\end{array}$ & $\begin{array}{l}78.12 \\
78.67 \\
78.20 \\
79.35 \\
79.43 \\
77.32\end{array}$ & $\begin{array}{l}79.97 \\
81.66 \\
81.66 \\
81.30 \\
83.37 \\
81.35\end{array}$ & $\begin{array}{l}83.15 \\
83.63 \\
84.12 \\
84.05 \\
80.11 \\
85.51\end{array}$ & $\begin{array}{l}85.32 \\
82.80 \\
84.82 \\
87.99 \\
85.70 \\
82.81\end{array}$ & $\begin{array}{l}81.09 \\
82.83 \\
82.84 \\
84.86 \\
86.00 \\
85.93\end{array}$ & $\begin{array}{l}83.28 \\
81.96 \\
82.35 \\
82.36 \\
80.84 \\
80.18\end{array}$ & $\begin{array}{l}82.43 \\
83.59 \\
80.21 \\
82.81 \\
82.28 \\
80.93\end{array}$ \\
\hline
\end{tabular}

WTR YR 1987

HIGHEST 74.34 FEB 23, 1987

LOWEST 88.91 JUN $18,19,1987$

GENESEE COUNTY

425552083382801 . Local number, 6N 7E 9DCCC.

LOCATION. - Lat $42^{\circ} 55^{\prime} 52^{\prime \prime}$, long' $83^{\circ} 38^{\prime} 28^{\prime \prime}$. Hydrologic Unit 04080204 , at Fisher Body Plant in Grand Blanc. Owner: General Motors Corporation.

AQUIFER. - Saginaw Formation of Pennsylvanian age.

WELI CHARACTERISTICS.--Drilled artesian well, diameter 10 in., depth $385 \mathrm{ft}$, cased to 150 ft.

INSTRUMENTATION. - Water-level recorder.

DATUM.--Elevation of land-surface datum is $837.0 \mathrm{ft}$ above National Geodetic Vertical Datum of 1929.

Measuring point: Instrument shelf, $1.50 \mathrm{ft}$ above land-surface datum.

REMARKS. - Water levels affected by nearby pumping. Measurements made by plant Water Department.

PERIOD OF RECORD.--January 1974 to current year.

EXTREMES FOR PERIOD OF RECORD.--Highest water level recorded, 52.3 ft below land-surface datum, Dec. 29,

1975; lowest recorded, $87.0 \mathrm{ft}$ below land-surface datum, June 29, 1977.

WATER LEVEL, IN FEET BELOW LAND-SURFACE DATUM, WATER YEAR OCTOBER 1986 TO SEPTEMBER 1987

\begin{tabular}{|c|c|c|c|c|c|c|c|c|c|c|c|c|}
\hline DAY & OCT & NOV & DEC & JAN & FEB & MAR & APR & MAY & JUN & JUL & AUG & SEP \\
\hline $\begin{array}{r}5 \\
10 \\
15 \\
20 \\
25 \\
\text { EOM }\end{array}$ & $\begin{array}{l}65.82 \\
64.81 \\
64.87 \\
64.80 \\
63.78 \\
66.81\end{array}$ & $\begin{array}{l}67.91 \\
65.09 \\
67.92 \\
64.51 \\
66.03 \\
65.45\end{array}$ & $\begin{array}{r}--- \\
--- \\
--- \\
66.36 \\
64.41\end{array}$ & $\begin{array}{l}67.16 \\
64.57 \\
65.90 \\
67.39 \\
64.72 \\
67.39\end{array}$ & $\begin{array}{l}68.98 \\
65.02 \\
70.88 \\
71.74 \\
70.34 \\
69.10\end{array}$ & $\begin{array}{l}69.00 \\
67.77 \\
68.91 \\
70.95 \\
71.36 \\
73.19\end{array}$ & $\begin{array}{l}77.59 \\
73.38 \\
70.45 \\
70.16 \\
69.38 \\
67.98\end{array}$ & $\begin{array}{l}69.80 \\
67.32 \\
68.98 \\
66.97 \\
65.24 \\
67.05\end{array}$ & $\begin{array}{l}65.37 \\
68.59 \\
69.02 \\
75.60 \\
73.48 \\
73.35\end{array}$ & $\begin{array}{l}74.50 \\
71.92 \\
72.51 \\
74.10 \\
76.00 \\
75.72\end{array}$ & $\begin{array}{l}77.83 \\
78.25 \\
78.63 \\
76.56 \\
75.64 \\
68.46\end{array}$ & $\begin{array}{l}69.44 \\
68.36 \\
68.20 \\
68.04 \\
67.91 \\
67.60\end{array}$ \\
\hline
\end{tabular}

WTR YR 1987

HIGHEST 62.44 OCT 26,1986

LOWEST 79.11 AUG $8,9,1987$

GRAND TRAVERSE COUNTY

443921085213501 Local number, 26N 9W 14ABAA.

LOCATION. - Lat $44^{\circ} 39^{\prime} 21^{\prime \prime}$, long $85^{\circ} 21^{\prime} 35^{\prime \prime}$, Hydrologic Unit $04060105,5.5 \mathrm{mi}$ north of Fife Lake.

Owner: U.S. Geological Survey.

AQUIFER.--Sand of Pleistocene age

WELL CHARACTERISTICS.--Drilled water-table well, diameter 6 in., depth $80 \mathrm{ft}$, PVC pipe and screen.

INSTRUMENTATION. --Water-level recorder.

DATUM.--Elevation of land-surface datum is $960 \mathrm{ft}$ above National Geodetic Vertical Datum of 1929 , from topographic map. Measuring point: plywood instrument shelf, 2.85 ft above land-surface datum.

PERIOD OF RECORD. - June 1976 to current year.

EXTREMES FOR PERIOD OF RECORD.--Highest water level recorded, 21.32 ft below land-surface datum, Oct. 22, $26,27,1986$; lowest recorded, $28.05 \mathrm{ft}$ below land-surface datum, Apr. 3, 1982.

WATER LEVEL, IN FEET BELOW LAND-SURFACE DATUM, WATER YEAR OCTOBER 1986 TO SEPTEMBER 1987 LOWEST VALUES

\begin{tabular}{|c|c|c|c|c|c|c|c|c|c|c|c|c|}
\hline DAY & OCT & NOV & DEC & JAN & FEB & MAR & APR & MAY & JUN & JUL & AUG & SEP \\
\hline $\begin{array}{r}5 \\
10 \\
15 \\
20 \\
25 \\
\text { EOM }\end{array}$ & $\begin{array}{l}22.17 \\
21.73 \\
21.40 \\
21.35 \\
21.37 \\
21.45\end{array}$ & $\begin{array}{l}21.48 \\
21.60 \\
21.62 \\
21.73 \\
21.82 \\
21.93\end{array}$ & $\begin{array}{l}22.01 \\
22.09 \\
22.19 \\
22.29 \\
22.38 \\
22.49\end{array}$ & $\begin{array}{l}22.58 \\
22.66 \\
22.78 \\
22.84 \\
22.95 \\
23.04\end{array}$ & $\begin{array}{l}23.13 \\
23.21 \\
23.29 \\
23.37 \\
23.46 \\
23.47\end{array}$ & $\begin{array}{l}23.57 \\
23.65 \\
23.71 \\
23.77 \\
23.82 \\
23.90\end{array}$ & $\begin{array}{l}23.97 \\
24.01 \\
24.06 \\
24.12 \\
24.17 \\
24.20\end{array}$ & $\begin{array}{l}24.25 \\
24.28 \\
24.33 \\
24.36 \\
24.40 \\
24.45\end{array}$ & $\begin{array}{l}24.50 \\
24.54 \\
24.58 \\
24.63 \\
24.67 \\
24.73\end{array}$ & $\begin{array}{l}24.78 \\
24.83 \\
24.89 \\
24.95 \\
25.00 \\
25.06\end{array}$ & $\begin{array}{l}25.13 \\
25.17 \\
25.22 \\
24.86 \\
24.18 \\
23.70\end{array}$ & $\begin{array}{l}23.56 \\
23.51 \\
23.55 \\
23.63 \\
23.74 \\
23.83\end{array}$ \\
\hline
\end{tabular}


415154084315401 . LOCal number, 7S 2W 15BCBAl.

LOCATION.--Lat $41^{\circ} 51^{\prime} 54^{\prime \prime}$, long' $84^{\circ} 31^{\prime} 54^{\prime \prime}$, Hydrologic Unit 04100003 , on Trail Road, 7 mi southeast of Hillsdale. Owner: U.S. Geological survey.

AQUIFER. - Sand of Pleistocene age.

WELL CHARACTERISTICS.--Drilled artesian well, diameter $6 \mathrm{in}$., depth $150 \mathrm{ft}$, screened 135 to $150 \mathrm{ft}$. INSTRUMENTATION.--Monthly measurement.

DATUM.--Elevation of land-surface datum is 1,092 ft above National Geodetic Vertical Datum of 1929, from topographic map. Measuring point: Top of casing, $2.50 \mathrm{ft}$ above land-surface datum.

PERIOD O

EXTREMES FOR PERIOD OF RECORD.--Highest water level measured, $46.14 \mathrm{ft}$ below land-surface datum, Apr. 13, 1982; lowest measured, $49.00 \mathrm{ft}$ below land-surface datum, Mar. 15, 1979.

WATER LEVEL, IN FEET BELOW LAND-SURFACE DATUM, WATER YEAR OCTOBER 1986 TO SEPTEMBER 1987

\begin{tabular}{|c|c|c|c|c|c|c|c|c|c|c|c|}
\hline DATE & $\begin{array}{l}\text { WATER } \\
\text { LEVEL }\end{array}$ & DATE & $\begin{array}{l}\text { WATER } \\
\text { LEVEL }\end{array}$ & DATE & $\begin{array}{l}\text { WATER } \\
\text { LEVEL }\end{array}$ & DATE & $\begin{array}{l}\text { WATER } \\
\text { LEVEL }\end{array}$ & DATE & $\begin{array}{l}\text { WATER } \\
\text { LEVEL }\end{array}$ & DATE & $\begin{array}{l}\text { WATER } \\
\text { LEVEL }\end{array}$ \\
\hline $\begin{array}{lr}\text { OCT } & 6 \\
\text { NOV } & 17\end{array}$ & $\begin{array}{l}48.10 \\
47.94\end{array}$ & $\begin{array}{lr}\text { DEC } & 29 \\
\text { FEB } & 9\end{array}$ & $\begin{array}{l}47.97 \\
48.19\end{array}$ & $\begin{array}{lr}\text { MAR } & 25 \\
\text { MAY } & 5\end{array}$ & $\begin{array}{l}47.82 \\
48.05\end{array}$ & JUN 15 & 48.13 & JUL 27 & 48.48 & SEP & 48.73 \\
\hline
\end{tabular}

415236084313701 . Local number, 7S 2W 10BDDD.

LOCATION.--Lat $41^{\circ} 52^{\prime} 36^{\prime \prime}$, long $84^{\circ} 31^{\prime} 37 "$, Hydrologic Unit 04100003 , at State Highway $34,2.5 \mathrm{mi}$ west of Pittsford. Owner: Michigan Department of Natural Resources.

AQUIFER. - - Sand of Pleistocene age.

WELL CHARACTERISTICS. - Augered water-table well, diameter $1.25 \mathrm{in}$, depth $20 \mathrm{ft}$, screened 17 to $20 \mathrm{ft}$. INSTRUMENTAT ION. --Monthly measurement.

DATUM.--Elevation of land-surface datum is $1,070 \mathrm{ft}$ above National Geodetic Vertical Datum of 1929 , from topographic map. Measuring point: Top of casing, $4.00 \mathrm{ft}$ above land-surface datum.

PERIOD OF RECORD, - December 1965 to current year.

EXTREMES FOR PERIOD OF RECORD.--Highest water level measured, $5.79 \mathrm{ft}$ below land-surface datum, Apr. 13, 1982; lowest measured, 11.1 ft below land-surface datum, Sept. 21, 1967.

WATER LEVEL, IN FEET BELOW LAND-SURFACE DATUM, WATER YEAR OCTOBER 1986 TO SEPTEMBER 1987

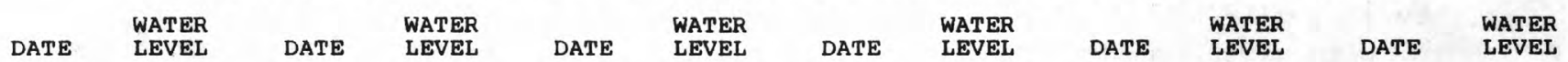

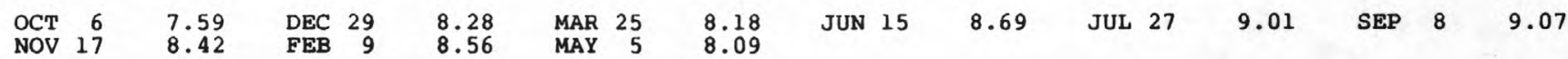

INGHAM COUNTY

424424084340301 . Local number, $4 \mathrm{~N} 2 \mathrm{~W} 17 \mathrm{ABAA}$.

LOCATION. - Lat $42^{\circ} 44^{\prime} 24^{\prime \prime}$, long $84^{\circ} 34^{\circ} 03^{\prime \prime}$, Hydrologic Unit 04050004, at kirby and Logan Streets in Lansing. Owner: City of Lansing.

AQUIFER.--Saginaw Formation of Pennsflivanian age.

WELL CHARACTER IST ICS. --Drilled artes lan well, diameter $20 \mathrm{in}$., depth $424 \mathrm{ft}$.

INSTRUMENTATION. --Water-level recorder. Monthly measurement prior to August 1960.

DATUM.--Elevation of land-surface datum is $858.72 \mathrm{ft}$ above National Geodetic Vertical Datum of 1929. Measuring point: Plywood shelter base, $0.5 \mathrm{ft}$ above land-surface datum.

REMARKS. - Water levels affected by regional pumping.

PERIOD OF RECORD.--December 1929 to current year.

EXTREMES FOR PERIOD OF RECORD.--Highest water level measured, $34.3 \mathrm{ft}$ below land-surface datum, December 1929; lowest recorded, 168.3 ft below land-surface datum, May 7, 1968.

WATER LEVEL, IN FEET BELOW LAND-SURFACE DATUM, WATER YEAR OCTOBER 1986 TO SEPTEMBER 1987 LOWEST VALUES

\begin{tabular}{|c|c|c|c|c|c|c|c|c|c|c|c|}
\hline DAY & OCT & NOV & DEC & JAN & FEB & MAR & APR & MAY & JUN & JUL & AUG \\
\hline $\begin{array}{r}5 \\
10 \\
15 \\
20 \\
25 \\
\text { EOM }\end{array}$ & $\begin{array}{l}79.41 \\
79.87 \\
79.29 \\
79.39 \\
78.98 \\
78.79\end{array}$ & $\begin{array}{l}78.24 \\
78.25 \\
77.60 \\
77.04 \\
76.93 \\
76.78\end{array}$ & $\begin{array}{l}76.54 \\
75.90 \\
76.28 \\
76.09 \\
75.84 \\
75.76\end{array}$ & $\begin{array}{l}75.89 \\
75.49 \\
75.48 \\
75.53 \\
75.35 \\
75.68\end{array}$ & $\begin{array}{r}75.95 \\
75.60 \\
75.53 \\
- \\
-\end{array}$ & $\begin{array}{l}75.30 \\
75.30 \\
75.01 \\
74.67 \\
74.07 \\
73.86\end{array}$ & $\begin{array}{l}73.87 \\
73.53 \\
73.34 \\
73.48 \\
73.66 \\
73.08\end{array}$ & $\begin{array}{l}73.12 \\
72.31 \\
72.47 \\
71.99 \\
71.98 \\
71.96\end{array}$ & $\begin{array}{l}72.37 \\
72.59 \\
72.40 \\
72.84 \\
73.33 \\
74.15\end{array}$ & $\begin{array}{l}74.34 \\
74.34 \\
74.50 \\
74.75 \\
74.91 \\
74.97\end{array}$ & $\begin{array}{l}74.95 \\
75.06 \\
75.10 \\
75.52 \\
75.67 \\
75.41\end{array}$ \\
\hline
\end{tabular}

$\begin{array}{lllllll}\text { WTR YR } 1987 \text { HIGHEST } & 71.68 \text { MAY } 26,1987 & \text { LOWEST } 79.87 & \text { OCT } 10,1986\end{array}$ 
442839083312301 . LOCal number, 24N 7E 13ADAD1.

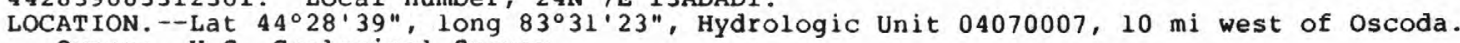

Owner: U.S. Geological Survey.

AOUIFER.--Sand of Pleistocene age.

WELL CHARACTERISTICS.--Drilled water-table well, diameter $6 \mathrm{in}$, depth $69 \mathrm{ft}$, screened 54 to $69 \mathrm{ft}$.

INSTRUMENTATION. --Monthly measurement.

DATUM.--Elevation of land-surface datum is $760 \mathrm{ft}$ above National Geodetic Vertical Datum of 1929 , from topographic map. Measuring point: Top of casing, $2.50 \mathrm{ft}$ above land-surface datum.

PERIOD OF RECORD.--June 1980 to current year.

EXTREMES FOR PERIOD OF RECORD.--Highest water level measured, $25.49 \mathrm{ft}$ below land-surface datum, Sept. 25 , 1986; lowest measured, $32.71 \mathrm{ft}$ below land-surface datum, Mar. 23, 1982 .

WATER LEVEL, IN FEET BELOW LAND-SURFACE DATUM, WATER YEAR OCTOBER 1986 TO SEPTEMBER 1987

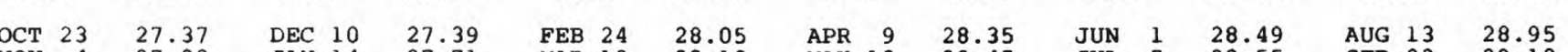

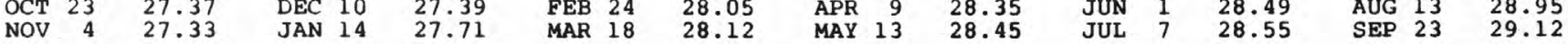

461257088542001 . Local number, 44N 37W 14BBCA.

LOCATION. --Lat $46^{\circ} 12^{\circ} 57^{\prime \prime}$, long $88^{\circ} 54^{\prime} 20^{\prime \prime}$, Hydrologic Unit 04030106, at Federal Forest Highway 16,

$0.5 \mathrm{mi}$ south of Elmwood. Owner: Michigan Department of State Highways.

AOUIFER.--Sand and gravel of Pleistocene age.

WELL CHARACTERISTICS.--Driven water-table weil, diameter 6 in., depth $102 \mathrm{ft}$.

INSTRUMENTATION.--Quarterly measurement.

DATUM.--Elevation of land-surface datum is $1,730 \mathrm{ft}$ above National Geodetic Vertical Datum of 1929 , from

topographic map. Measuring point: Top of plywood shelter base, $4.21 \mathrm{ft}$ above land-surface datum.

PER IOD OF RECORD.--October 1959 to current year.

EXTREMES FOR PERIOD OF RECORD.--Highest water level measured, $90.57 \mathrm{ft}$ below land-surface datum, Sept. 25 ,

1986; lowest measured, $97.11 \mathrm{ft}$ below land-surface datum, Aug. 16, 1982.

WATER LEVEL, IN FEET BELOW LAND-SURFACE DATUM, WATER YEAR OCTOBER 1986 TO SEPTEMBER 1987

$\begin{array}{llllll}\text { DATE } & \text { WATER } & \text { WEVEL } & \text { WATER } & \text { WATER } & \text { WATEL } \\ \text { LEVEL } & \text { DATE } & \text { LEVEL } & \text { DATE } & \text { LEVEL }\end{array}$

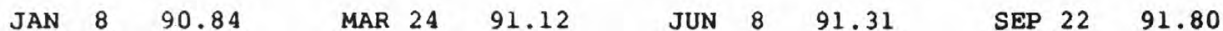

JACKSON COUNTY

421346084230801 . Local number, 3S IW 11AADDI.

LOCATION.--Lat $42^{\circ} 13^{\prime} 46^{\prime \prime}$, long $84^{\circ} 23^{\prime} 08^{\prime \prime}$, Hydrologic Unit 04050004, at Belden and Mansion Streets in Jackson. Owner: City of Jackson.

AQUIFER. --Saginaw Formation of Pennsylvanian age.

WELL CHARACTERISTICS.--Drilled artesian well, diameter $16 \mathrm{in.,}$ depth $360 \mathrm{ft}$, open bottom.

INSTRUMENTATION.--Daily measurement by observer; lowest monthi $1_{Y}$ reading shown.

DATUM.--Elevation of land-surface datum is $935 \mathrm{ft}$ above National Geodetic Vertical Datum of 1929 , from topographic map. Measuring point: Plywood recorder shelf, $5.50 \mathrm{ft}$ above land-surface datum.

REMARKS.--Water levels affected by pumping.

PERIOD OF RECORD. --June 1957 to current year.

EXTREMES FOR PERIOD OF RECORD.--Highest water level measured, $18.6 \mathrm{ft}$ below land-surface datum, Jan. 2 ,

1961; lowest measured, 119.1 ft below land-surface datum, June 30, 1971.

WATER LEVEL, IN FEET BELOW LAND-SURFACE DATUM, WATER YEAR OCTOBER 1986 TO SEPTEMBER 1987

$\begin{array}{llllllll}\text { DATE } & \text { WATER } & \text { WEVE } & \text { DATE } & \text { WATER } \\ \text { LEVEL } & \text { DATE } & \text { WATER } & \text { LEVEL } & \text { WATER } & \text { WATER } & \text { WATER } \\ \text { LEVEL } & \text { DATE } & \text { LEVEL }\end{array}$

$\begin{array}{llllllllllll}\text { OCT } & 2 & 83.3 & \text { NOV } & 6 & 67.3 & \text { DEC } 10 & 68.4 & \text { JAN } 27 & 70.5 & \text { FEB } 26 & 71.9\end{array}$ 


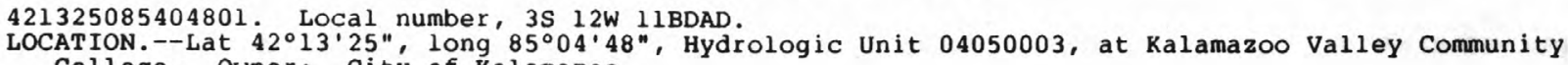
College. Owner: City of Kalamazoo

AQUIFER.--Glacial deposits of Pleistocene age.

WELL CHARACTERISTICS.--Drilled artesian well, diameter $3 \mathrm{in}$., depth $248 \mathrm{ft}$.

INSTRUMENTATION.--Water-level recorder.

DATUM.--Elevation of land-surface datum is $880 \mathrm{ft}$ above National Geodetic Vertical Datum of 1929 , from topographic map. Measuring point: Top of shelter base, $4.00 \mathrm{ft}$ above land-surface datum.

PERIOD OF RECORD.--March 1961 to current year.

EXTREMES FOR PERIOD OF RECORD. - Highest water level recorded, +2.98 ft above land-surface datum, Sept. 4, 1969; lowest recorded, $1.04 \mathrm{ft}$ below land-surface datum, Aug. 4, 1977.

WATER LEVEL, IN FEET ABOVE (+) AND BELOW LAND-SURFACE DATUM, WATER YEAR OCTOBER 1986 TO SEPTEMBER 1987 LOWEST VALUES

\begin{tabular}{|c|c|c|c|c|c|c|c|c|c|c|c|c|}
\hline DAY & OCT & NOV & DEC & JAN & FEB & MAR & APR & MAY & JUN & JUL & AUG & SEP \\
\hline $\begin{array}{r}5 \\
10 \\
15 \\
20 \\
25 \\
\text { EOM }\end{array}$ & $\begin{array}{l}+0.10 \\
+0.13 \\
+0.18 \\
+0.22 \\
+0.24 \\
+0.29\end{array}$ & $\begin{array}{l}+0.31 \\
+0.36 \\
+0.39 \\
+0.43 \\
+0.44 \\
+0.46\end{array}$ & $\begin{array}{l}+0.46 \\
+0.47 \\
+0.48 \\
+0.48 \\
+0.49 \\
+0.49\end{array}$ & $\begin{array}{l}+0.50 \\
+0.51 \\
+0.50 \\
+0.58 \\
+0.61 \\
+0.63\end{array}$ & $\begin{array}{l}+0.63 \\
+0.59 \\
+0.53 \\
+0.54 \\
+0.51 \\
+0.56\end{array}$ & $\begin{array}{l}+0.53 \\
+0.51 \\
+0.52 \\
+0.55 \\
+0.54 \\
+0.52\end{array}$ & $\begin{array}{l}+0.53 \\
+0.52 \\
+0.54 \\
+0.48 \\
+0.18 \\
.00\end{array}$ & $\begin{array}{l}.17 \\
.24 \\
.27 \\
.30 \\
.36 \\
.43\end{array}$ & $\begin{array}{r}.45 \\
.50 \\
.52 \\
-.- \\
-.-\end{array}$ & $\begin{array}{l}--- \\
--- \\
--- \\
--- \\
---\end{array}$ & $\begin{array}{l}--- \\
-- \\
--- \\
.79 \\
.48\end{array}$ & $\begin{array}{l}.45 \\
.39 \\
.33 \\
.30 \\
.29 \\
.29\end{array}$ \\
\hline
\end{tabular}

WTR YR 1987

HIGHEST +0.64 FEB 5, 6, 7, 1987

LOWEST $\quad 0.79$ AUG 25,1987

KENT COUNTY

425030085434901 . Local number, 5N 12W 4DCCD.

LOCATION.--Lat 42.50'30", long $85^{\circ} 43^{\prime} 49^{\prime \prime}$, Hydrologic Unit 04050006, $0.4 \mathrm{mi}$ west of Byron Center

Road, $2.1 \mathrm{mi}$ north of Byron Center. Owner: City of Wyoming.

AQUIFER.--Sand and gravel of Pleistocene age.

WELL CHARACTERISTICS.--Drilled artesian well, diameter 6 in., depth $86 \mathrm{ft}$.

INSTRUMENTATION.--Monthly measurement. Water-level recorder' October 1962 to July 1978.

DATUM.--Elevation of land-surface datum is $685.97 \mathrm{ft}$ above National Geodetic Vertical Datum of 1929.

Measuring point: Top of shelter base, $2.50 \mathrm{ft}$ above land-surface datum.

PERIOD OF RECORD.--October 1962 to current year.

EXTREMES FOR PERIOD OF RECORD.--Highest water level recorded, $8.28 \mathrm{ft}$ below land-surface datum, Apr. 14,

1974; lowest recorded, $12.91 \mathrm{ft}$ below land-surface datum, Aug. 19, 1964.

WATER LEVEL, IN FEET BELOW LAND-SURFACE DATUM, WATER YEAR OCTOBER 1986 TO SEPTEMBER 1987

\begin{tabular}{|c|c|c|c|c|c|c|c|c|c|c|c|}
\hline 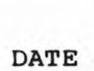 & $\begin{array}{l}\text { WATER } \\
\text { LEVEL }\end{array}$ & DATE & $\begin{array}{l}\text { WATER } \\
\text { LEVEL }\end{array}$ & DATE & $\begin{array}{l}\text { WATER } \\
\text { LEVEL }\end{array}$ & DATE & $\begin{array}{l}\text { WATER } \\
\text { LEVEL }\end{array}$ & DATE & $\begin{array}{l}\text { WATER } \\
\text { LEVEL }\end{array}$ & DATE & $\begin{array}{l}\text { WATER } \\
\text { LEVEL }\end{array}$ \\
\hline & & JAN 28 & 9.52 & APR 22 & 10.13 & JUN & 10.83 & JUL 15 & 11.32 & AUG 25 & 10.85 \\
\hline
\end{tabular}

LAKE COUNTY

440737085483701. Local number, 20N 13W 13ACACl.

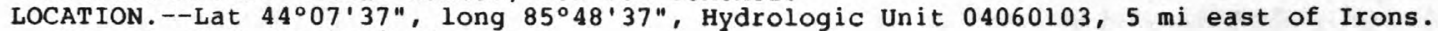

Owner: U.S. Geological Survey.

AOUIFER.--Outwash deposits of Pleistocene age.

WELI CHARACTERISTICS.--Drilled water-table weil, diameter 6 in., depth $57 \mathrm{ft}$, screened 42 to $57 \mathrm{ft}$. INSTRUMENTATION.--Monthly measurement.

DATUM.--Elevation of land-surface datum is $945 \mathrm{ft}$ above National Geodetic Vertical Datum of 1929, from topographic map. Measuring point: Top of casing, $2.00 \mathrm{ft}$ above land-surface datum.

PERIOD OF RECORD. --March 1980 to current year.

EXTREMES FOR PERIOD OF RECORD.--Highest water level measured, $9.13 \mathrm{ft}$ below land-surface datum, Oct. 8 ,

Nov. 12, 1986; lowest measured, $17.71 \mathrm{ft}$ below land-surface datum, Mar. 14, 1980. WATER LEVEL, IN FEET BELOW LAND-SURFACE DATUM, WATER YEAR OCTOBER 1986 TO SEPTEMBER 1987

\begin{tabular}{|c|c|c|c|c|c|c|c|c|c|c|c|}
\hline $\mathrm{AT}$ & $\begin{array}{l}\text { WATER } \\
\text { LEVEL }\end{array}$ & DATE & $\begin{array}{l}\text { WATER } \\
\text { LEVEL }\end{array}$ & DATE & $\begin{array}{l}\text { WATER } \\
\text { LEVEL }\end{array}$ & DATE & $\begin{array}{l}\text { WATER } \\
\text { LEVEL }\end{array}$ & DATE & $\begin{array}{l}\text { WATER } \\
\text { LEVEL }\end{array}$ & DATE & $\begin{array}{l}\text { WATER } \\
\text { LEVEL }\end{array}$ \\
\hline $\begin{array}{ll}T & 8 \\
\mathrm{~V} & 2\end{array}$ & 9.13 & DEC 17 & 9.67 & MAR 10 & 10.85 & JUN & 11.16 & UL 16 & 11.83 & $\mathrm{AU}$ & 2 \\
\hline
\end{tabular}


445020086012201. Local number, 28N 14W 8DDCA1.

LOCATION, - Lat $44^{\circ} 50^{\prime} 20^{\prime \prime}$, Iong $86^{\circ} 01^{\prime} 22^{\prime \prime}$, Hydrologic Unit $04060104,2.5 \mathrm{mi}$ northeast of Empire.

Owner: U.S. Geological Survey.

AQUIFER. --Sand of Pleistocene age.

WELL CHARACTERISTICS.--Drilled water-table well, diameter 6 in., depth $138 \mathrm{ft}$, screened 123 to $138 \mathrm{ft}$. INSTRUMENTATION.--Monthly measurement.

DATUM.--Elevation of land-surface datum is $750 \mathrm{ft}$ above National Geodetic Vertical Datum of 1929 , from topographic map. Measuring point: Top of casing, $2.00 \mathrm{ft}$ above land-surface datum.

PERIOD OF RECORD. - February 1978 to current year.

EXTREMES FOR PERIOD OF RECORD.--Highest water level measured, 111.25 ft below land-surface datum, Apr. 7, 1987; lowest measured, $114.49 \mathrm{ft}$ below land-surface datum, June 21, 1983.

WATER LEVEL, IN FEET BELOW LAND-SURFACE DATUM, WATER YEAR OCTOBER 1986 TO SEPTEMBER 1987

$\begin{array}{lllllllll} & \text { WATER } & & \text { WATER } & & \text { WATER } & & \text { WATER } & \text { WATER } \\ \text { DATE } & \text { LEVEL } & \text { DATE } & \text { LEVEL } & \text { DATE } & \text { LEVEL } & \text { DATE } & \text { LEVEL } & \text { DATE } \\ \text { LEVEL } & \text { DATE } & \text { LEVEL }\end{array}$

$\begin{array}{lllllllllllllllllllll}\text { OCT } & 22 & 111.83 & \text { JAN } & 15 & 111.52 & \text { APR } & 7 & 111.25 & \text { JUL } & 1 & 111.38 & \text { AUG } & 12 & 111.51 & \text { SEP } & 23 & 111.61\end{array}$

445011086031401. Local number, 28N 14W 18BABB1.

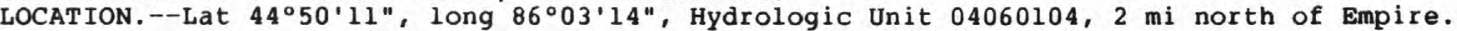

Owner: U.S. Geological Survey.

AOUIFER - - Sand of Pleistocene age.

WELL CHARACTERISTICS.-Drilled water-table well, diameter 6 in., depth $60 \mathrm{ft}$, screened 45 to $60 \mathrm{ft}$.

INSTRUMENTATION. - -Water-level recorder.

DATUM.--Elevation of land-surface datum is $625 \mathrm{ft}$ above National Geodetic Vertical Datum of 1929 , from topographic map. Measuring point: Top of casing, 2.00 ft above land-surface datum.

PERIOD OF RECORD. - November 1979 to current year.

EXTREMES FOR PERIOD OF RECORD.--Highest water level recorded, 20.79 ft below land-surface datum, Oct

14, 15, 1986; lowest recorded, $24.76 \mathrm{ft}$ below land-surface datum, Sept. $29,1982$.

WATER LEVEL, IN FEET BELOW LAND-SURFACE DATUM, WATER YEAR OCTOBER 1986 TO SEPTEMBER 1987 LOWEST VALUES

\begin{tabular}{|c|c|c|c|c|c|c|c|c|c|c|c|c|}
\hline DAY & OCT & NOV & DEC & JAN & FEB & MAR & APR & MAY & JUN & JUL & AUG & SEP \\
\hline $\begin{array}{r}5 \\
10 \\
15 \\
20 \\
25 \\
\text { EOM }\end{array}$ & $\begin{array}{l}21.54 \\
20.95 \\
20.82 \\
20.94 \\
21.08 \\
21.23\end{array}$ & $\begin{array}{r}21.31 \\
21.39 \\
---- \\
---\end{array}$ & $\begin{array}{l}21.73 \\
21.78 \\
21.84 \\
21.90 \\
21.93 \\
21.98\end{array}$ & $\begin{array}{l}22.01 \\
22.06 \\
22.12 \\
22.17 \\
22.23 \\
22.26\end{array}$ & $\begin{array}{l}22.32 \\
22.36 \\
22.41 \\
22.44 \\
22.47 \\
22.46\end{array}$ & $\begin{array}{l}22.48 \\
22.51 \\
22.54 \\
22.56 \\
22.58 \\
22.62\end{array}$ & $\begin{array}{l}22.65 \\
22.64 \\
22.65 \\
22.68 \\
22.71 \\
22.71\end{array}$ & $\begin{array}{l}22.73 \\
22.71 \\
22.75 \\
22.77 \\
22.78 \\
22.78\end{array}$ & $\begin{array}{l}22.81 \\
22.83 \\
22.84 \\
22.87 \\
22.89 \\
22.92\end{array}$ & $\begin{array}{l}22.94 \\
22.96 \\
22.98 \\
23.02 \\
23.04 \\
23.08\end{array}$ & $\begin{array}{l}23.12 \\
23.15 \\
23.16 \\
23.16 \\
23.16 \\
23.18\end{array}$ & $\begin{array}{l}23.21 \\
23.24 \\
23.26 \\
23.27 \\
23.28 \\
23.29\end{array}$ \\
\hline
\end{tabular}

WTR YR 1987 HIGHEST 20.79 OCT 14, 15, 1986 LOWEST $23.29 \quad$ SEP 30,1987

LENAWEE COUNTY

420246084150601. Local number, 5S 1E 12DDBD

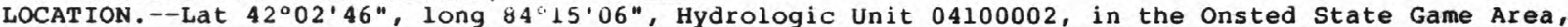

$2 \mathrm{mi}$ west of Cambridge Junction. Owner: Michigan Department of Natural Resources.

AQUIFER - - Sand of Pleistocene age.

WELL CHARACTERISTICS.--Drilled water-table well, diameter $1.25 \mathrm{in.}$ depth $39 \mathrm{ft}$, screened $36 \mathrm{fo} 39 \mathrm{ft}$ INSTRUMENTATION.--Monthly measurement.

DATUM.--Elevation of land-surface datum is 1,000 ft above National Geodetic Vertical Datum of 1929 , from

topographic map. Measuring point: Top of casing, $3.00 \mathrm{ft}$ above land-surface datum.

REMARKS. - Water temperature also measured.

PERIOD OF RECORD.--December 1965 to current year.

EXTREMES FOR PERIOD OF RECORD.--Highest water level measured, 15.89 ft below 1 and-surface datum, Mar. 26 ,

1982; lowest measured, $19.33 \mathrm{ft}$ below land-surface datum, Sept. 2, 1971.

WATER LEVEL, IN FEET BELOW LAND-SURFACE DATUM, WATER YEAR OCTOBER 1986 TO SEPTEMBER 1987

$\begin{array}{lllllllll} & \text { WATER } & & \text { WATER } & & \text { WATER } & & \text { WATER } & \text { WATER } \\ \text { DATE } & \text { LEVEL } & \text { DATE } & \text { LEVEL } & \text { DATE } & \text { LEVEL } & \text { DATE } & \text { LEVEL } & \text { DATE }\end{array}$

$\begin{array}{lllllllllllllllllll}\text { OCT } & 20 & 16.85 & \text { JAN } & 9 & 16.83 & \text { APR } & 3 & 16.61 & \text { JUN } & 24 & 17.54 & \text { AUG } & 7 & 18.35 & \text { SEP } & 18 & 17.29\end{array}$

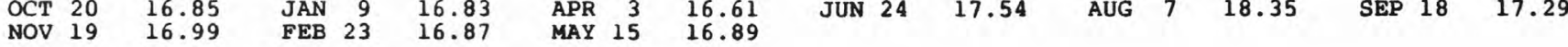


422853083402801 . Local number, 1N 6E $13 \mathrm{DBAB}$.

LOCATION. - Lat $42^{\circ} 28^{\prime} 53^{\prime \prime}$, long' $83^{\circ} 40^{\prime} 28^{\prime \prime}$. Hydrologic Unit 04090005, at Twelve Mile Road, $2 \mathrm{mi}$ northwest of South Lyon. Owner: American Aggregate Corporation.

AQUIFER.--Glacial deposits of Pleistocene age.

WELL CHARACTERISTICS.--Drilled water-table weil, diameter 2 in., depth $29 \mathrm{ft}, 1.25$ in. diameter screen. INSTRUMENTATION.--Water-level recorder.

DATUM.--Elevation of land-surface datum is $930 \mathrm{ft}$ above National Geodetic Vertical Datum of 1929, from topographic map. Measuring point: plywood instrument shelf, $2.50 \mathrm{ft}$ above land-surface datum.

PERIOD OF RECORD.--April 1970 to current year. 1974; lowest recorded, $21.58 \mathrm{ft}$ below land-surface datum, Oct. 30, 31, Nov. 1, 1979.

WATER LEVEL, IN FEET BELOW LAND-SURFACE DATUM, WATER YEAR OCTOBER 1986 TO SEPTEMBER 1987 LOWEST VALUES

\begin{tabular}{|c|c|c|c|c|c|c|c|c|c|c|c|c|}
\hline DAY & OCT & NOV & $\mathrm{DEC}$ & JAN & FEB & MAR & APR & MAY & JUN & JUL & AUG & SEP \\
\hline $\begin{array}{r}5 \\
10 \\
15 \\
20 \\
25 \\
\text { EOM }\end{array}$ & $\begin{array}{l}15.65 \\
15.65 \\
15.70 \\
15.78 \\
15.78 \\
15.81\end{array}$ & $\begin{array}{l}15.85 \\
15.96 \\
15.99 \\
16.06 \\
16.11 \\
16.18\end{array}$ & $\begin{array}{l}16.13 \\
16.07 \\
16.14 \\
16.18 \\
16.20 \\
16.22\end{array}$ & $\begin{array}{l}16.28 \\
16.26 \\
16.27 \\
16.26 \\
16.28 \\
16.30\end{array}$ & $\begin{array}{l}16.33 \\
16.33 \\
16.35 \\
16.38 \\
16.38 \\
16.38\end{array}$ & $\begin{array}{l}16.29 \\
16.24 \\
16.24 \\
16.23 \\
16.21 \\
16.21\end{array}$ & $\begin{array}{l}16.22 \\
16.12 \\
16.09 \\
15.94 \\
15.96 \\
16.03\end{array}$ & $\begin{array}{l}16.05 \\
15.96 \\
15.94 \\
15.98 \\
16.04 \\
16.06\end{array}$ & $\begin{array}{l}16.08 \\
16.15 \\
16.19 \\
16.21 \\
15.96 \\
16.12\end{array}$ & $\begin{array}{l}16.19 \\
16.23 \\
16.26 \\
16.38 \\
16.38 \\
16.45\end{array}$ & $\begin{array}{l}16.29 \\
16.36 \\
16.36 \\
16.42 \\
16.46 \\
16.37\end{array}$ & $\begin{array}{l}16.38 \\
16.50 \\
16.59 \\
16.43 \\
16.49 \\
16.51\end{array}$ \\
\hline
\end{tabular}

WTR YR 1987

HIGHEST 15.65 OCT $4-6,8-12,1987$

LOWEST $\quad 16.59$ SEP $14,15,1987$

\section{MACK INAC COUNTY}

460321084354801. Local number, 42N 2W 7AABB.

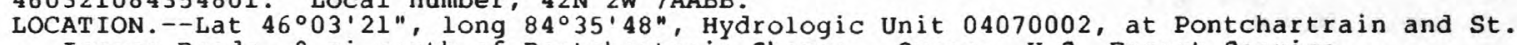
Ignace Roads, $2 \mathrm{mi}$ north of Pontchartrain Shores. Owner: U.S. Forest Service.

AQUIFER.--Manistique Dolomite of Silurian age.

WELL CHARACTERISTICS.--Drilled water-table weil, diameter 6 in., depth $102 \mathrm{ft}$.

INSTRUMENTATION.--Water-level recorder.

DATUM.--Elevation of land-surface datum is $650 \mathrm{ft}$ above National Geodetic Vertical Datum of 1929 , from topographic map. Measuring point: Top of shelter floor, $2.30 \mathrm{ft}$ above land-surface datum.

PERIOD OF RECORD. --June 1956 to current year.

EXTREMES FOR PERIOD OF RECORD.--Highest water level recorded, $12.49 \mathrm{ft}$ below land-surface datum, Apr. 21 , 1985; lowest recorded, $32.3 \mathrm{ft}$ below land-surface datum, Feb. 7, 1977.

WATER LEVEL, IN FEET BELOW LAND-SURFACE DATUM, WATER YEAR OCTOBER 1986 TO SEPTEMBER 1987 LOWEST VALUES

\begin{tabular}{|c|c|c|c|c|c|c|c|c|c|c|c|c|}
\hline DAY & ОСт & Nov & DEC & JAN & FEB & MAR & APR & MAY & JUN & JUL & AUG & SEP \\
\hline $\begin{array}{r}5 \\
10 \\
15 \\
20 \\
25 \\
\text { EOM }\end{array}$ & $\begin{array}{l}24.00 \\
23.66 \\
20.59 \\
21.74 \\
22.75 \\
23.54\end{array}$ & $\begin{array}{l}23.84 \\
24.24 \\
24.48 \\
24.81 \\
24.68 \\
24.49\end{array}$ & $\begin{array}{l}24.46 \\
24.36 \\
24.66 \\
24.91 \\
24.95 \\
25.15\end{array}$ & $\begin{array}{l}25.32 \\
25.40 \\
25.71 \\
25.80 \\
26.12 \\
26.29\end{array}$ & $\begin{array}{l}26.58 \\
26.79 \\
27.03 \\
27.20 \\
27.42 \\
27.41\end{array}$ & $\begin{array}{l}27.60 \\
26.97 \\
26.87 \\
26.86 \\
24.10 \\
22.60\end{array}$ & $\begin{array}{l}23.40 \\
20.96 \\
22.12 \\
22.78 \\
23.17 \\
23.41\end{array}$ & $\begin{array}{l}23.90 \\
24.30 \\
24.84 \\
25.16 \\
25.55 \\
25.67\end{array}$ & $\begin{array}{l}26.04 \\
26.19 \\
26.07 \\
26.32 \\
26.57 \\
26.86\end{array}$ & $\begin{array}{l}27.10 \\
27.33 \\
27.59 \\
27.85 \\
28.15 \\
28.48\end{array}$ & $\begin{array}{l}28.68 \\
28.93 \\
29.07 \\
29.18 \\
29.40 \\
29.55\end{array}$ & $\begin{array}{l}29.78 \\
29.92 \\
30.10 \\
30.20 \\
28.85 \\
28.61\end{array}$ \\
\hline
\end{tabular}

WTR YR 1987

HIGHEST 20.39 OCT 14,1986

LOWEST $30.20 \quad$ SEP 20,1987

\section{MARQUETTE COUNTY}

462938087475901 . LoCal number, 47N 28W 3CCDC.

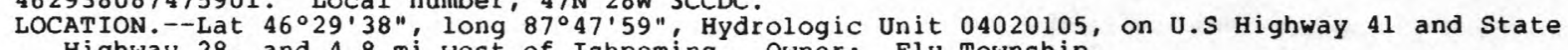
Highway 28 , and $4.8 \mathrm{mi}$ west of Ishpeming. Owner: Ely Township.

AQUIFER. - Sand and gravel of Pleistocene age.

WELL CHARACTERISTICS.--Drilled artesian well, diameter $8 \mathrm{in}$., depth $72 \mathrm{ft}$, screened 68 to $72 \mathrm{ft}$. INSTRUMENTATION. - -Water-level recorder.

DATUM.--Elevation of land-surface datum is $1,571.99 \mathrm{ft}$ above National Geodetic Vertical Datum of 1929. Measuring point: Top of recorder base, $3.00 \mathrm{ft}$ above land-surface datum.

REMARKS. --Federal key well.

PERIOD OF RECORD. - -August 1961 to current year.

EXTREMES FOR PERIOD OF RECORD.--Highest water level recorded, 9.41 ft below land-surface datum, Apr. 21 , 1985; lowest recorded, $19.26 \mathrm{ft}$ below land-surface datum, Apr. 10, 11, 1964 .

WATER LEVEL, IN FEET BELOW LAND-SURFACE DATUM, WATER YEAR OCTOBER 1986 TO SEPTEMBER 1987

\begin{tabular}{|c|c|c|c|c|c|c|c|c|c|c|c|c|}
\hline DAY & OCT & NOV & DEC & JAN & FEB & MAR & APR & MAY & JUN & JUL & AUG & SEP \\
\hline $\begin{array}{r}5 \\
10 \\
15 \\
20 \\
25 \\
\text { EOM }\end{array}$ & $\begin{array}{l}14.37 \\
14.43 \\
13.93 \\
13.78 \\
13.83 \\
14.00\end{array}$ & $\begin{array}{l}14.05 \\
14.19 \\
14.24 \\
14.37 \\
14.46 \\
14.60\end{array}$ & $\begin{array}{l}14.67 \\
14.74 \\
14.86 \\
14.97 \\
15.07 \\
15.18\end{array}$ & $\begin{array}{l}15.26 \\
15.36 \\
15.47 \\
15.54 \\
15.64 \\
15.75\end{array}$ & $\begin{array}{l}15.86 \\
15.97 \\
16.04 \\
16.12 \\
16.23 \\
16.26\end{array}$ & $\begin{array}{l}16.36 \\
16.29 \\
16.33 \\
16.37 \\
16.19 \\
15.89\end{array}$ & $\begin{array}{l}15.80 \\
15.63 \\
15.43 \\
15.34 \\
15.28 \\
15.25\end{array}$ & $\begin{array}{l}15.31 \\
15.36 \\
15.45 \\
15.49 \\
15.41 \\
15.25\end{array}$ & $\begin{array}{l}15.28 \\
15.28 \\
15.30 \\
15.42 \\
15.52 \\
15.64\end{array}$ & $\begin{array}{l}15.74 \\
15.82 \\
15.78 \\
15.74 \\
15.75 \\
15.86\end{array}$ & $\begin{array}{l}15.83 \\
15.90 \\
15.96 \\
16.04 \\
16.13 \\
16.23\end{array}$ & $\begin{array}{l}16.41 \\
16.51 \\
16.61 \\
16.69 \\
16.72 \\
16.79\end{array}$ \\
\hline
\end{tabular}

$\begin{array}{llllllll}\text { WTR YR } 1987 & \text { HIGHEST } & 13.75 & \text { OCT } 22,1986 & \text { LOWEST } & 16.79 & \text { SEP } & 30,1987\end{array}$ 
453504087331301. Local number, 37N 26W 19DADA.

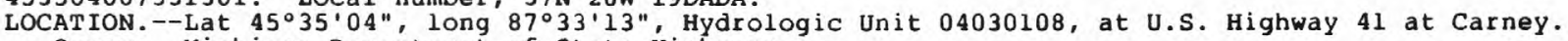

Owner: Michigan Department of State Highways.

AOUIFER.--Trenton Limestone and Black River Formation of Middle Ordovician age.

WELI CHARACTERISTICS. --Water-table well, diameter 4 in., depth $17 \mathrm{ft}$, cased.

INSTRUMENTATION. --Quarterly measurement.

DATUM.--Elevation of land-surface datum is $800 \mathrm{ft}$ above National Geodetic Vertical Datum of 1929, from

topographic map. Measuring point: Top of 2 in. reducing nipple, $1.26 \mathrm{ft}$ above land-surface datum. REMARKS. --Water temperature also measured.

PERIOD OF RECORD. --September 1959 to current year.

EXTREMES FOR PERIOD OF RECORD.--Highest water level measured, $3.32 \mathrm{ft}$ below land-surface datum, Mar. 31 ,

1986; lowest measured, $8.62 \mathrm{ft}$ below land-surface datum, Jan. 17, 1977.

WATER LEVEL, IN FEET BELOW LAND-SURFACE DATUM, WATER YEAR OCTOBER 1986 TO SEPTEMBER 1987

$\begin{array}{lllllll}\text { DATE } & \text { WATER } & \text { WEVEL } & \text { WATE } & \text { WATER } & \text { WATER } & \text { WATER } \\ \text { LEVEL } & \text { DATE } & \text { LEVEL } & \text { DATE LEVEL }\end{array}$

$\begin{array}{llllllllll}\text { DEC } & 31 & 5.34 & \text { MAR } 24 & 4.90 & \text { JUN } & 8 & 4.92 & \text { SEP } 22 & 5.64\end{array}$

MONROE COUNTY

415206083414401 L LOCal number, $7 \mathrm{~S} 6 \mathrm{E} 15 \mathrm{ACAA}$.
LOCATION.--Lat $41^{\circ} 52^{\prime} 06^{\prime \prime}$, long $83^{\circ} 41^{\prime} 44^{\prime \prime}$, Hydrologic Unit 04100002 , at Teal Road, 2 mi southeast

of Petersburg. Owner: U.S. Geologicál Survey.

AQUIFER.--Detroit River Group of Devonian age.

WELL CHARACTERISTICS.--Drilled artesian well, diameter $6 \mathrm{in}$., depth $72 \mathrm{ft}$, cased to $53 \mathrm{ft}$, open bottom.

INSTRUMENTATION.--MonthlY measurement.

DATUM.--Elevation of land-surface datum is $680 \mathrm{ft}$ above National Geodetic Vertical Datum of 1929, from

topographic map. Measuring point: Top of casing, $2.50 \mathrm{ft}$ above land-surface datum.

PERIOD OF RECORD. - November 1978 to current year.

EXTREMES FOR PERIOD OF RECORD.--Highest water level measured, $32.30 \mathrm{ft}$ below land-surface datum, Mar. 26 ,

1982; lowest measured, $43.25 \mathrm{ft}$ below land-surface datum, Oct. $18,1985$.

WATER LEVEL, IN FEET BELOW LAND-SURFACE DATUM, WATER YEAR OCTOBER 1986 TO SEPTEMBER 1987

WATER WATER WATER WATER WATER WATER

$\begin{array}{llllllllllllllll}\text { OCT } 17 & 38.74 & \text { JAN } & 7 & 37.25 & \text { APR } & 2 & 37.85 & \text { JUN } 23 & 38.02 & \text { AUG } & 6 & 42.05 & \text { SEP } & 17 & 41.54\end{array}$

NOV $20 \quad 39.07 \quad$ FEB $20 \quad 35.56 \quad$ MAY $13 \quad 36.33$

415235083414001 . Local number, 7S 6E 15ADBB.

LOCATION.--Lat $41^{\circ} 52^{\prime} 35^{\prime \prime}$, long $83^{\circ} 41^{\prime} 40^{\prime \prime}$, Hydrologic Unit 04100002, at Teal Road, $1.5 \mathrm{mi}$ southeast

of Petersburg. Owner: Michigan Department of Natural Resources.

AQUIFER.--Sand of Pleistocene age.

WELI CHARACTERISTICS.--Drilled water-table well, diameter $1.25 \mathrm{in}$, depth $17 \mathrm{ft}$, screened $14 \mathrm{to} 17 \mathrm{ft}$.

INSTRUMENTATION. --MOnthly measurement.

DATUM.--Elevation of land-surface datum is $675 \mathrm{ft}$ above National Geodetic Vertical Datum of 1929 , from

topographic map. Measuring point: Top of casing, $4.00 \mathrm{ft}$ above land-surface datum.

PERIOD OF RECORD.--December 1965 to current year

EXTREMES FOR PERIOD OF RECORD.--Highest water level measured, $3.00 \mathrm{ft}$ below land-surface datum, Feb. 14 ,

1966 ; lowest measured, $7.40 \mathrm{ft}$ below land-surface datum, Oct. 18, 1985.

WATER LEVEL, IN FEET BELOW LAND-SURFACE DATUM, WATER YEAR OCTOBER 1986 TO SEPTEMBER 1987

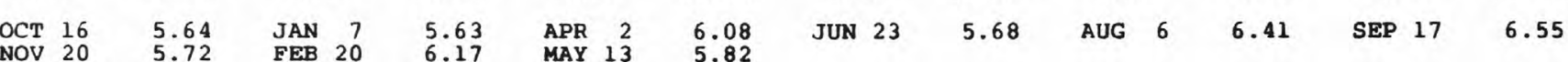


431806086044401 . Local number, 11N 15W 34ADDD.

LOCATION.--Lat $43^{\circ} 18^{\prime} 06^{\prime \prime}$, long $86^{\circ} 04^{\prime} 4^{\prime \prime}$, Hydrologic Unit 04060102, at Holton-Duck Lake Road, $8 \mathrm{mi}$ northeast of Holton. Owner: Michigan Department of Natural Resources.

AQUIFER.--Sand of Pleistocene age.

WELL CHARACTERISTICS.--Drilled water-table well, diameter $1.25 \mathrm{in.,}$ depth $31 \mathrm{ft}$, screened 28 to $31 \mathrm{ft}$. INSTRUMENTATION.--Quarterly measurement.

DATUM.--Elevation of land-surface datum is $595 \mathrm{ft}$ above National Geodetic Vertical Datum of 1929 , from topographic map. Measuring point: Top of casing, $4.00 \mathrm{ft}$ above land-surface datum.

REMARKS. - -Water temperature also measured.

PERIOD OF RECORD. --November 1965 to March 1987 (discontinued).

EXTREMES FOR PERIOD OF RECORD.--Highest water level measured, +0.16 ft above land-surface datum, May 22 ,

1974; lowest measured, $4.74 \mathrm{ft}$ below land-surface datum, Sept. 5, 1972.

WATER LEVEL, IN FEET BELOW LAND-SURFACE DATUM, WATER YEAR OCTOBER 1986 TO SEPTEMBER 1987

$\begin{array}{lll} & \text { WATER } & \text { WATER } \\ \text { DATE LEVEL } & \text { DATE } & \text { LEVEL }\end{array}$

$\begin{array}{llll}\text { DEC } & 15 \quad 0.94 \quad \text { MAR } 10 \quad 0.72\end{array}$

OAKLAND COUNTY

425116083321501 Local number, 5N 8E 8ACAC.

LOCATION. - Lat $42^{\circ} 51^{\prime} 16^{\prime \prime}$, long $83^{\circ} 32^{\prime} 15^{\prime \prime}$, Hydrologic Unit 04080204, at Van Atta Road, $6 \mathrm{mi}$

northeast of Holly. Owner: Michigan Department of Natural Resources.

AQUIFER.--Sand and gravel of Pleistocene age.

WELL CHARACTERISTICS.--Drilled artesian well, diameter $1.25 \mathrm{in}$., depth $42 \mathrm{ft}$, screened 39 to $42 \mathrm{ft}$.

INSTRUMENTATION.--Monthly measurement.

DATUM.--Elevation of land-surface datum is $930 \mathrm{ft}$ above National Geodetic Vertical Datum of 1929 , from

topographic map. Measuring point: Top of casing, $3.00 \mathrm{ft}$ above land-surface datum.

REMARKS. - Water temperature also measured.

PERIOD OF RECORD. --November 1965 to current year.

EXTREMES FOR PERIOD OF RECORD.--Highest water level measured, $22.30 \mathrm{ft}$ below land-surface datum, Apr. 24,

1974; lowest measured, $26.48 \mathrm{ft}$ below land-surface datum, sept. 9, 1966.

WATER LEVEL IN FEET BELOW LAND-SURFACE DATUM, WATER YEAR OCTOBER 1986 TO SEPTEMBER 1987

DATE WATER WATER WATE WATER WATER WATER

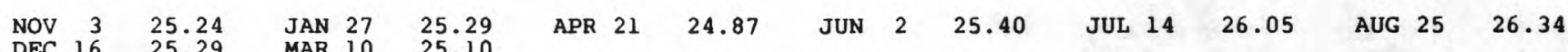

OCEANA COUNTY

433133086082601 . LOCal number, 13N 15W 18AAAA.

LOCATION.--Lat $43^{\circ} 31^{\prime} 3^{\prime \prime}$, long' $86^{\circ} 08^{\prime} 26^{\prime \prime}$, Hydrologic Unit 04060101, $6 \mathrm{mi}$ southwest of Hesperia. Owner: U.S. Geological Survey.

AQUIFER.--Sand of Pleistocene age.

WELL CHARACTERISTICS.--Drilled water-table well, diameter 6 in., depth $79 \mathrm{ft}$, screened 69 to $79 \mathrm{ft}$.

INSTRUMENTATION.--Water-level recorder. Monthly measurements August 1977 to July 1979.

DATUM.--Elevation of land-surface datum is $703 \mathrm{ft}$ above National Geodetic Vertical Datum of 1929 , from topographic map. Measuring point: Top of casing, $2.50 \mathrm{ft}$ above land-surface datum.

PERIOD OF RECORD.--August 1977 to current year.

EXTREMES FOR PERIOD OF RECORD.--Highest water level measured, $35.76 \mathrm{ft}$ below land-surface datum, Dec. 2, 3,1986 ; lowest recorded, $40.99 \mathrm{ft}$ below land-surface datum, Mar. 28, 1982 .

WATER LEVEL, IN FEET BELOW LAND-SURFACE DATUM, WATER YEAR OCTOBER 1986 TO SEPTEMBER 1987

\begin{tabular}{|c|c|c|c|c|c|c|c|c|c|c|c|c|}
\hline DAY & OCT & NOV & DEC & JAN & FEB & MAR & APR & MAY & JUN & JUL & AUG & SEP \\
\hline $\begin{array}{r}5 \\
10 \\
15 \\
20 \\
25 \\
\text { EOM }\end{array}$ & $\begin{array}{l}36.73 \\
36.66 \\
36.51 \\
36.40 \\
36.26 \\
36.14\end{array}$ & $\begin{array}{l}36.03 \\
35.98 \\
35.88 \\
35.83 \\
35.82 \\
35.84\end{array}$ & $\begin{array}{l}35.88 \\
35.85 \\
35.91 \\
35.98 \\
36.01 \\
36.07\end{array}$ & $\begin{array}{l}36.14 \\
36.17 \\
36.26 \\
36.29 \\
36.37 \\
36.44\end{array}$ & $\begin{array}{l}36.51 \\
36.57 \\
36.65 \\
36.71 \\
36.79 \\
36.80\end{array}$ & $\begin{array}{l}36.89 \\
36.95 \\
37.03 \\
37.08 \\
37.03 \\
37.23\end{array}$ & $\begin{array}{l}37.31 \\
37.36 \\
37.44 \\
37.52 \\
37.60 \\
37.65\end{array}$ & $\begin{array}{l}37.72 \\
37.77 \\
37.83 \\
37.86 \\
37.91 \\
37.96\end{array}$ & $\begin{array}{l}38.00 \\
38.04 \\
38.07 \\
38.10 \\
38.14 \\
38.19\end{array}$ & $\begin{array}{l}38.23 \\
38.28 \\
38.34 \\
38.39 \\
38.42 \\
38.49\end{array}$ & $\begin{array}{l}38.56 \\
38.62 \\
38.68 \\
38.73 \\
38.79 \\
38.86\end{array}$ & $\begin{array}{l}38.91 \\
38.97 \\
39.02 \\
39.08 \\
39.14 \\
39.21\end{array}$ \\
\hline
\end{tabular}

WTR YR 1987 HIGHEST 35.76 DEC 2, 3, 1986 LOWEST 39.21 SEP 30,1987 
442514084164702. Local number, 23N 1E 2BAAA.

LOCATION. - Lat $44^{\circ} 25^{\prime} 14^{\prime \prime}$, long $84^{\circ} 16^{\prime} 47^{\prime \prime}$. Hydrologic Unit 04070007 , at south side of Rose City

Road, and $8 \mathrm{mi}$ west of Rose City. Owner: Ogemaw County Road Commission.

AQUIFER.--Sand of Pleistocene age.

WELL CHARACTERISTICS.--Drilled water-table well, diameter 1.25 in., depth $20 \mathrm{ft}$.

INSTRUMENTATION. --Quarterly measurement.

DATUM.--Elevation of land-surface datum is 1,265 ft above National Geodetic Vertical Datum of 1929 , from topographic map. Measuring point: Top of casing, 2.30 ft above land-surface datum.

PERIOD OF RECORD. - November 1968 to October 1971 , April 1974 to current year.

EXTREMES FOR PERIOD OF RECORD.--Highest water level measured, 7.62 ft below land-surface datum, Apr. 13,

1976; lowest measured, $13.6 \mathrm{ft}$ below land-surface datum, December 1972.

WATER LEVEL, IN FEET BELOW LAND-SURFACE DATUM, WATER YEAR OCTOBER 1986 TO SEPTEMBER 1987

$\begin{array}{llllll}\text { WATE } & \text { WATER } & \text { WATER } & & \text { WATER } & \text { WATER } \\ \text { LEVEL } & \text { DATE } & \text { LEVEL } & \text { DATE } & \text { LEVEL } & \text { DATE }\end{array}$

$\begin{array}{llllllllll}\text { OCT } 24 & 8.75 & \text { JAN } 26 & 10.13 & \text { APR } & 9 & 10.00 & \text { JUL } 30 & 11.28\end{array}$

ONTONAGON COUNTY

465002089321601 . Local number, 51N 41W 8BDBC.

LOCATION. - Lat $46^{\circ} 50^{\prime} 02^{\prime \prime}$, long $89^{\circ} 32^{\prime} 16^{\prime \prime}$, Hydrologic Unit 04020101 , 325 ft south of State Highway

$64,1.5 \mathrm{mi}$ east of Silver City. Owner: Michigan Department of Corrections.

AQUIFER.--Freda Sandstone of Keweenawan age.

WELL CHARACTERISTICS.--Drilled artesian well, diameter $6 \mathrm{in.,}$ depth $100 \mathrm{ft}$, cased to $32 \mathrm{ft}$.

INSTRUMENTATION.--Quarterly measurement.

DATUM.--Elevation of land-surface datum is $620 \mathrm{ft}$ above National Geodetic Vertical Datum of 1929 , from

topographic map. Measuring point: Plywood instrument shelf, 3.50 ft above land-surface datum.

PERIOD OF RECORD.--October 1958 to current year.

EXTREMES FOR PERIOD OF RECORD.-Highest water level measured, 8.20 ft below land-surface datum, Apr. 15,

1959; lowest measured, $21.82 \mathrm{ft}$ below land-surface datum, Dec. 15, 1976.

WATER LEVEL, IN FEET BELOW LAND-SURFACE DATUM, WATER YEAR OCTOBER 1986 TO SEPTEMBER 1987

\begin{tabular}{|c|c|c|c|c|c|c|}
\hline DATE & $\begin{array}{l}\text { WATER } \\
\text { LEVEL }\end{array}$ & DATE & $\begin{array}{l}\text { WATER } \\
\text { LEVEL }\end{array}$ & DATE & $\begin{array}{l}\text { WATER } \\
\text { LEVEL }\end{array}$ & DATE \\
\hline & & DATE & & DATE & & DAIE \\
\hline
\end{tabular}

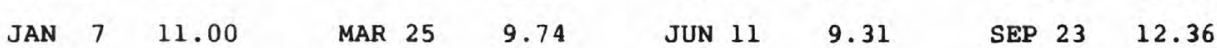

OTSEGO COUNTY

445920084425801 . Local number, 30N 3W 19ABBB.

LOCATION. - Lat $44^{\circ} 59^{\prime} 20^{\prime \prime}$ " long $84^{\circ} 42^{\prime} 58^{\prime \prime}$, Hydrologic Unit 04070007 , at old Alba Road, $3 \mathrm{mi}$

southwest of Gaylord. Owner: U.S. Geological Survey.

AQUIFER.--Sand of Pleistocene age.

WELL CHARACTERISTICS.--Drilled artesian well, diameter 6 in., depth $87 \mathrm{ft}$, screened 72 to 87 ft.

INSTRUMENTATION.--Monthly measurement.

DATUM.--Elevation of land-surface datum is 1,307 ft above National Geodetic Vertical Datum of 1929 , from topographic map. Measuring point: Top of casing, $2.50 \mathrm{ft}$ above land-surface datum.

PERIOD OF RECORD.---January 1979 to current year.

EXTREMES FOR PERIOD OF RECORD.--Highest water level measured $30.56 \mathrm{ft}$ below land-surface datum, Dec. 10,

1986 ; lowest measured, $35.82 \mathrm{ft}$ below land-surface datum, Apr. 1, 1982.

WATER LEVEL, IN FEET BELOW LAND-SURFACE DATUM, WATER YEAR OCTOBER 1986 TO SEPTEMBER 1987

$\begin{array}{lllllllll} & \text { WATER } & & \text { WATER } & & \text { WATER } & & \text { WATER } & \text { WATER } \\ \text { DATE } & \text { LEVEL } & \text { DATE } & \text { LEVEL } & \text { DATE } & \text { LEVEL } & \text { DATE } & \text { LEVEL } & \text { DATE } \\ \text { LEVEL } & \text { DATE } & \text { LEVEL }\end{array}$

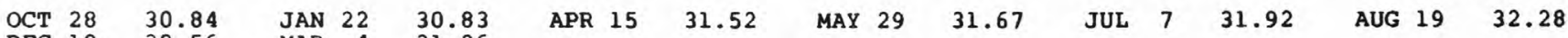


451634083441801 . Local number, 33N 6E 8BBBB.

LOCATION.--Lat $45^{\circ} 16^{\prime 34 "}$, long $83^{\circ} 44^{\prime} 18^{\prime \prime}$, Hydrologic Unit 04070006, at south side of Grand Lake Highway, and $2 \mathrm{mi}$ west and $1 \mathrm{mi}$ north of Posen. Owner: A. Styma.

AQUIFER. - Traverse Group.

WELL CHARACTERISTICS.--Drilled artesian well, diameter $6 \mathrm{in}$., depth $61 \mathrm{ft}$.

INSTRUMENTATION.--Quarterly measurement.

DATUM.--Elevation of land-surface datum is $815 \mathrm{ft}$ above National Geodetic Vertical Datum of 1929, from topographic map. Measuring point: Top of casing, $0.50 \mathrm{ft}$ above land-surface datum.

PERIOD OF RECORD.--December 1959 to current year.

EXTREMES FOR PERIOD OF RECORD.--Highest water level measured, $5.10 \mathrm{ft}$ below land-surface datum, Mar. 2, 1979; lowest measured, $16.83 \mathrm{ft}$ below land-surface datum, Mar. 5, 1963.

WATER LEVEL, IN FEET BELOW LAND-SURFACE DATUM, WATER YEAR OCTOBER 1986 TO SEPTEMBER 1987

$\begin{array}{crcrccccr}\text { DATE } & \begin{array}{r}\text { WATER } \\ \text { LEVEL }\end{array} & \text { DATE } & \begin{array}{r}\text { WATER } \\ \text { LEVEL }\end{array} & \text { DATE } & \begin{array}{c}\text { WATER } \\ \text { LEVEL }\end{array} & \text { DATE } & \begin{array}{l}\text { WATER } \\ \text { LEVEL }\end{array} \\ \text { NOV } 5 & 9.25 & \text { MAR } 17 & 8.76 & \text { MAY } 11 & 10.01 & \text { JUL } 8 & 12.68\end{array}$

\section{ROSCOMMON COUNTY}

442722084350701 . Local number, 24N 2W 20BABA.

LOCATION.--Lat $44^{\circ} 27^{\prime} 22^{\prime \prime}$, long $84^{\circ} 35^{\circ} 07^{\prime \prime}$, Hydrologic Unit 04070007 , at State Highway $103,2 \mathrm{mi}$ south of Roscommon. Owner: Michigan Department of Natural Resources.

AQUIFER.--Sand of Pleistocene age.

WELL CHARACTERISTICS.--Jetted water-table well, diameter $8 \mathrm{in.}$, depth $14 \mathrm{ft}$, open bottom.

INSTRUMENTATION. --Water-level recorder.

DATUM.--Elevation of land-surface datum is $1,145.30 \mathrm{ft}$ above National Geodetic Vertical Datum of 1929.

Measuring point: Top of casing, $2.50 \mathrm{ft}$ above land-surface datum.

REMARKS.--Federal key well.

PERIOD OF RECORD.--December 1934 to current year.

EXTREMES FOR PERIOD OF RECORD.--Highest water level recorded, $2.29 \mathrm{ft}$ below land-surface datum, Apr. 19 1985; lowest recorded, $6.23 \mathrm{ft}$ below land-surface datum, Dec. 6-11, 1949.

WATER LEVEL, IN FEET BELOW LAND-SURFACE DATUM, WATER YEAR OCTOBER 1986 TO SEPTEMBER 1987 LOWEST VALUES

\begin{tabular}{|c|c|c|c|c|c|c|c|c|c|c|c|}
\hline DAY & ОСт & NOV & DEC & JAN & FEB & MAR & APR & MAY & JUN & JUL & AUG \\
\hline $\begin{array}{r}5 \\
10 \\
15 \\
20 \\
25 \\
\text { EOM }\end{array}$ & $\begin{array}{r}3.23 \\
3.24 \\
3.41 \\
-1.42 \\
3.64\end{array}$ & $\begin{array}{r}--- \\
--- \\
--- \\
3.87 \\
---\end{array}$ & $\begin{array}{r}--- \\
--- \\
--\overline{ } \\
4.18 \\
4.24\end{array}$ & $\begin{array}{l}4.29 \\
4.32 \\
4.37 \\
4.41 \\
4.46 \\
4.51\end{array}$ & $\begin{array}{r}--- \\
--- \\
--- \\
4.82 \\
4.84\end{array}$ & $\begin{array}{l}4.86 \\
4.66 \\
4.69 \\
4.74 \\
4.74 \\
4.65\end{array}$ & $\begin{array}{l}4.66 \\
4.69 \\
4.73 \\
4.77 \\
4.82 \\
4.86\end{array}$ & $\begin{array}{l}4.90 \\
4.94 \\
4.97 \\
5.02 \\
5.05 \\
5.10\end{array}$ & $\begin{array}{l}5.17 \\
5.25 \\
5.33 \\
5.41 \\
5.46 \\
5.50\end{array}$ & $\begin{array}{l}5.57 \\
5.59 \\
5.63 \\
5.71 \\
5.77 \\
5.84\end{array}$ & $\begin{array}{l}5.85 \\
5.79 \\
5.75 \\
5.24 \\
5.33 \\
5.44\end{array}$ \\
\hline
\end{tabular}

WTR YR 1987

HIGHEST 3.22 OCT $6-8,9,10,1986$

LOWEST 5.87 AUG $8,9,1987$

SAGINAW COUNTY

431457084194401 . LOCal number, 10N 1E 22DADA1.

LOCATION.--Lat $43^{\circ} 14^{\prime} 57^{\prime \prime}$, long $84^{\circ} 19^{\prime} 44^{\prime \prime}$, Hydrologic Unit 04080203, at west side of Merrill Road, $0.35 \mathrm{mi}$ north of Marion Springs. Owner: U.S. Geological Survey.

AQUIFER.--Saginaw Formation of Pennsylvanian age.

WELL CHARACTERISTICS.--Drilled artesian well, diameter $6 \mathrm{in}$, depth $210 \mathrm{ft}$, cased to $170 \mathrm{ft}$.

INSTRUMENTATION. - -Water-level recorder.

DATUM.--Elevation of land-surface datum is $657 \mathrm{ft}$ above National Geodetic Vertical Datum of 1929, from

topographic map. Measuring point: Plywood instrument shelf, $2.50 \mathrm{ft}$ above land-surface datum. PERIOD OF RECORD. - - December 1977 to current year.

EXTREMES FOR PERIOD OF RECORD.--Highest water level recorded, $7.93 \mathrm{ft}$ below land-surface datum, Feb. 10 ,

1981; lowest recorded, $10.56 \mathrm{ft}$ below land-surface datum, Aug. 24, 1987.

WATER LEVEL, IN FEET BELOW LAND-SURFACE DATUM, WATER YEAR OCTOBER 1986 TO SEPTEMBER 1987

\begin{tabular}{|c|c|c|c|c|c|c|c|c|c|c|c|c|}
\hline DAY & OCT & NOV & DEC & JAN & FEB & MAR & APR & MAY & JUN & JUL & AUG & SEP \\
\hline $\begin{array}{r}5 \\
10 \\
15 \\
20 \\
25 \\
\text { EOM }\end{array}$ & $\begin{array}{l}9.09 \\
9.19 \\
8.99 \\
9.05 \\
8.96 \\
8.98\end{array}$ & $\begin{array}{l}8.90 \\
8.93 \\
8.81 \\
8.77 \\
8.81 \\
8.95\end{array}$ & $\begin{array}{l}8.86 \\
8.77 \\
8.84 \\
8.87 \\
8.82 \\
8.85\end{array}$ & $\begin{array}{l}8.89 \\
8.69 \\
8.85 \\
8.76 \\
8.84 \\
8.80\end{array}$ & $\begin{array}{l}8.93 \\
8.91 \\
8.97 \\
9.00 \\
9.08 \\
8.99\end{array}$ & $\begin{array}{l}9.04 \\
9.10 \\
9.06 \\
9.00 \\
8.93 \\
8.95\end{array}$ & $\begin{array}{l}9.02 \\
8.98 \\
9.01 \\
9.11 \\
9.22 \\
9.14\end{array}$ & $\begin{array}{l}9.27 \\
9.22 \\
9.40 \\
9.32 \\
9.45 \\
9.46\end{array}$ & $\begin{array}{l}9.54 \\
9.62 \\
9.56 \\
9.67 \\
9.68 \\
9.78\end{array}$ & $\begin{array}{r}9.87 \\
9.91 \\
10.00 \\
10.17 \\
10.30 \\
10.39\end{array}$ & $\begin{array}{l}10.44 \\
10.49 \\
10.40 \\
10.52 \\
10.54 \\
10.40\end{array}$ & $\begin{array}{l}10.49 \\
10.48 \\
10.50 \\
10.37 \\
10.47 \\
10.41\end{array}$ \\
\hline
\end{tabular}

$\begin{array}{lllllll}\text { WTR YR } 1987 & \text { HIGHEST } & 8.59 & \text { JAN 22, } 1987 & \text { LOWEST } & 10.56 & \text { AUG 24, } 1987\end{array}$ 
433439082523601 . Local number, 13N 13E 12ADAA.

LOCATION. --Lat $43^{\circ} 34^{\prime} 39^{\prime \prime}$, long $82^{\circ} 52^{\prime} 36^{\prime \prime}$, Hydrologic Unit 04090001, at wheatland Road, 3 mi east and $0.75 \mathrm{mi}$ north of Argyle. Owner: U.S. Geological Survey.

AQUIFER. - Marshall Formation of Mississippian age.

WELI CHARACTERISTICS.--Drilled artesian observation well, diameter 6 in., depth $130 \mathrm{ft}$, cased with plastic pipe to $48 \mathrm{ft}$, open bottom.

INSTRUMENTATION,--Water-level recorder.

DATUM.--Elevation of land-surface datum is $805 \mathrm{ft}$ above National Geodetic Vertical Datum of 1929 , from topographic map. Measuring point: plywood instrument shelf, 2.50 ft above land-surface datum.

PERIOD OF RECORD. - October 1976 to current year

EXTREMES FOR PERIOD OF RECORD.--Highest water level recorded, 15.54 ft below land-surface datum, Apr 6 , 1985; lowest recorded, $22.71 \mathrm{ft}$ below land-surface datum, Nov. 20, 1979.

WATER LEVEL, IN FEET BELOW LAND-SURFACE DATUM, WATER YEAR OCTOBER 1986 TO SEPTEMBER 1987 LOWEST VALUES

\begin{tabular}{|c|c|c|c|c|c|c|c|c|c|c|c|}
\hline DAY & OCT & NOV & DEC & JAN & FEB & MAR & APR & MAY & JUN & JUL & AUG \\
\hline $\begin{array}{r}5 \\
10 \\
15 \\
20 \\
25 \\
\text { EOM }\end{array}$ & $\begin{array}{l}16.62 \\
16.87 \\
16.79 \\
16.87 \\
17.00 \\
17.13\end{array}$ & $\begin{array}{l}17.15 \\
17.32 \\
17.26 \\
17.36 \\
17.22 \\
17.19\end{array}$ & $\begin{array}{l}16.96 \\
16.94 \\
17.08 \\
16.88 \\
16.79 \\
16.88\end{array}$ & $\begin{array}{l}16.97 \\
16.95 \\
17.03 \\
17.07 \\
17.23 \\
17.33\end{array}$ & $\begin{array}{l}17.35 \\
17.36 \\
17.46 \\
17.51 \\
17.52 \\
17.37\end{array}$ & $\begin{array}{l}16.85 \\
16.64 \\
16.80 \\
16.82 \\
16.86 \\
16.79\end{array}$ & $\begin{array}{l}16.72 \\
16.63 \\
16.37 \\
16.63 \\
16.78 \\
16.85\end{array}$ & $\begin{array}{l}17.04 \\
17.28 \\
17.58 \\
17.58 \\
17.83 \\
18.08\end{array}$ & $\begin{array}{l}18.13 \\
18.39 \\
18.65 \\
18.93 \\
19.07 \\
19.27\end{array}$ & $\begin{array}{l}19.49 \\
19.66 \\
19.84 \\
20.17 \\
20.36 \\
20.53\end{array}$ & $\begin{array}{l}20.70 \\
20.78 \\
20.77 \\
20.86 \\
21.07 \\
21.15\end{array}$ \\
\hline
\end{tabular}

WTR YR 1987

HIGHEST 16.34 APR 15,1987

LOWEST 21.33 SEP $7,8,30,1987$

\section{SCHOOLCRAFT COUNTY}

461720085565201. Local number, 45N 13W 16CCCB.

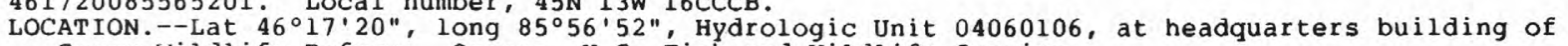
Seney Wildlife Refuge. Owner: U.S. Fish and Wildlife Service.

AQUIFER.--Limestones of Upper Ordovician age.

WELL CHARACTERISTICS.--Drilled artesian well, diameter $4 \mathrm{in}$., depth $151 \mathrm{ft}$, cased to $65 \mathrm{ft}$.

INSTRUMENTATION. - -Water-level recorder.

DATUM.--Elevation of land-surface datum is $710 \mathrm{ft}$ above National Geodetic Vertical Datum of 1929 , from topographic map. Measuring point: Top of casing, $3.60 \mathrm{ft}$ below land-surface datum.

PERIOD OF RECORD.--June 1952 to current year.

EXTREMES FOR PERIOD OF RECORD.--Highest water level recorded, $4.64 \mathrm{ft}$ below land-surface datum, Apr. 13 , 1971; lowest recorded, $6.50 \mathrm{ft}$ below land-surface datum, Oct. 23, 1963.

WATER LEVEL, IN FEET BELOW LAND-SURFACE DATUM, WATER YEAR OCTOBER 1986 TO SEPTEMBER 1987

\begin{tabular}{|c|c|c|c|c|c|c|c|c|c|c|c|c|}
\hline DAY & OCT & NOV & DEC & JAN & FEB & MAR & APR & MAY & JUN & JUL & AUG & SEP \\
\hline $\begin{array}{r}5 \\
10 \\
15 \\
20 \\
25 \\
\text { EOM }\end{array}$ & $\begin{array}{l}5.86 \\
5.86 \\
5.74 \\
5.78 \\
5.79 \\
5.80\end{array}$ & $\begin{array}{l}5.79 \\
5.81 \\
5.75 \\
5.73 \\
5.68 \\
5.77\end{array}$ & $\begin{array}{l}5.71 \\
5.66 \\
5.66 \\
5.67 \\
5.65 \\
5.65\end{array}$ & $\begin{array}{l}5.66 \\
5.64 \\
5.69 \\
5.65 \\
5.64 \\
5.59\end{array}$ & $\begin{array}{l}5.60 \\
5.58 \\
5.60 \\
5.59 \\
5.61 \\
5.58\end{array}$ & $\begin{array}{l}5.55 \\
5.58 \\
5.58 \\
5.56 \\
5.53 \\
5.38\end{array}$ & $\begin{array}{l}5.42 \\
5.39 \\
5.42 \\
5.46 \\
5.49 \\
5.51\end{array}$ & $\begin{array}{l}5.56 \\
5.58 \\
5.60 \\
5.54 \\
5.59 \\
5.57\end{array}$ & $\begin{array}{l}5.59 \\
5.64 \\
5.63 \\
5.69 \\
5.73 \\
5.76\end{array}$ & $\begin{array}{l}5.77 \\
5.82 \\
5.80 \\
5.64 \\
5.73 \\
5.82\end{array}$ & $\begin{array}{l}5.81 \\
5.86 \\
5.83 \\
5.81 \\
5.83 \\
5.85\end{array}$ & $\begin{array}{l}5.90 \\
5.91 \\
5.93 \\
5.91 \\
5.96 \\
5.95\end{array}$ \\
\hline NTR & & HIGHEST & 5.33 & R 1 , & 1987 & LOWEST & 5.97 & SEP 27 & 28,19 & & & \\
\hline
\end{tabular}

VAN BUREN COUNTY

421945085481502 . Local number, 2S 13W 2BBCB2.

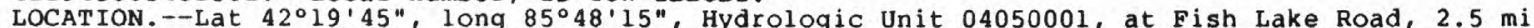

north of State Highway 43, and $16 \mathrm{mi}$ east of Bangor. Owner: Van Buren County Road Commission.

AOUIFER --Sand of Pleistocene age.

WELL CHARACTERISTICS.--Drilled artesian well, diameter $4 \mathrm{in}$., depth $40 \mathrm{ft}$, screened $36 \mathrm{fo} 40 \mathrm{ft}$. INSTRUMENTATION. --Monthly measurement.

DATUM.--Elevation of land-surface datum is $737 \mathrm{ft}$ above National Geodetic Vertical Datum of 1929 , from topographic map. Measuring point: Top of casing, $1.00 \mathrm{ft}$ above land-surface datum.

PERIOD OF RECORD.--May 1981 to current year.

EXTREMES FOR PERIOD OF RECORD.--Highest water level measured, $8.38 \mathrm{ft}$ below land-surface datum, Oct. 6 ,

1986; lowest measured, $12.58 \mathrm{ft}$ below land-surface datum, Sept. 19, 1984.

WATER LEVEL, IN FEET BELOW LAND-SURFACE DATUM, WATER YEAR OCTOBER 1986 TO SEPTEMBER 1987

\begin{tabular}{|c|c|c|c|c|c|c|c|c|c|c|c|}
\hline DATE & $\begin{array}{l}\text { WATER } \\
\text { LEVEL }\end{array}$ & DATE & $\begin{array}{l}\text { WATER } \\
\text { LEVEL }\end{array}$ & DATE & $\begin{array}{l}\text { WATER } \\
\text { LEVEL }\end{array}$ & DATE & $\begin{array}{l}\text { WATER } \\
\text { LEVEL }\end{array}$ & DATE & $\begin{array}{l}\text { WATER } \\
\text { LEVEL }\end{array}$ & DATE & $\begin{array}{l}\text { WATER } \\
\text { LEVEL }\end{array}$ \\
\hline $\begin{array}{lr}\mathrm{CT} & 6 \\
\mathrm{~V} & 17\end{array}$ & $\begin{array}{r}8.38 \\
10.47\end{array}$ & $\begin{array}{lr}\text { DEC } & 30 \\
\text { FEB } & 9\end{array}$ & $\begin{array}{l}10.58 \\
10.68\end{array}$ & $\begin{array}{lr}\text { MAR } & 26 \\
\text { MAY } & 7\end{array}$ & $\begin{array}{l}10.69 \\
10.50\end{array}$ & JUN 17 & 10.56 & JUL 24 & 12.23 & SEP 10 & 11. \\
\hline
\end{tabular}


421228083331601 LOCal number, 3S 7E $24 \mathrm{CADB}$.

LOCATION.--Lat $42^{\circ} 12^{\prime} 28^{\prime \prime}$, long' $83^{\circ} 33^{\prime} 16^{\prime \prime}$, Hydrologic Unit 04090005, at Bridge street, and at

Ypsilanti Township Waterworks. Owner: Ypsilanti Township.

AQUIFER.--Sand of Pleistocene age.

WELL CHARACTERISTICS.--Drilled water-table well, diameter 4 in., depth $80 \mathrm{ft}$, screened 77 to 80 ft.

INSTRUMENTATION. --Water-level recorder.

DATUM.--Elevation of land-surface datum is $665.65 \mathrm{ft}$ above National Geodetic Vertical Datum of 1929 .

Measuring point: Top of coupling, $3.00 \mathrm{ft}$ above land-surface datum.

REMARKS.--water level affected by nearby pumping.

PERIOD OF RECORD. - July 1943 to June 1945 , December 1949 to current year.

EXTREMES FOR PERIOD OF RECORD.-Highest water level recorded, 5.79 ft below land-surface datum, Jan. 5,

1950; lowest recorded, $22.66 \mathrm{ft}$ below land-surface datum, Feb. 13, 1971.

WATER LEVEL, IN FEET BELOW LAND-SURFACE DATUM, WATER YEAR OCTOBER 1986 TO SEPTEMBER 1987 LOWEST VALUES

\begin{tabular}{|c|c|c|c|c|c|c|c|c|c|c|c|c|}
\hline DAY & OCT & NOV & DEC & JAN & FEB & MAR & APR & MAY & JUN & JUL & AUG & SEP \\
\hline $\begin{array}{r}5 \\
10 \\
15 \\
20 \\
25 \\
\text { EOM }\end{array}$ & $\begin{array}{l}14.01 \\
14.22 \\
14.11 \\
14.27 \\
14.15 \\
14.27\end{array}$ & $\begin{array}{l}14.76 \\
15.25 \\
15.41 \\
15.61 \\
15.84 \\
15.96\end{array}$ & $\begin{array}{r}16.03 \\
15.59 \\
- \\
---- \\
--- \\
---\end{array}$ & $\begin{array}{l}15.59 \\
15.67 \\
15.54 \\
15.80 \\
15.81\end{array}$ & $\begin{array}{l}15.75 \\
15.58 \\
15.61 \\
15.62 \\
15.60 \\
15.61\end{array}$ & $\begin{array}{l}15.70 \\
15.70 \\
15.75 \\
15.80 \\
15.85 \\
15.91\end{array}$ & $\begin{array}{l}15.91 \\
15.80 \\
15.79 \\
15.89 \\
15.94 \\
15.77\end{array}$ & $\begin{array}{l}16.05 \\
16.30 \\
17.35 \\
17.06 \\
16.90 \\
18.35\end{array}$ & $\begin{array}{l}18.15 \\
18.15 \\
18.34 \\
19.52 \\
18.44 \\
17.79\end{array}$ & $\begin{array}{l}17.45 \\
17.23 \\
17.21 \\
17.25 \\
17.22 \\
17.21\end{array}$ & $\begin{array}{l}17.11 \\
17.09 \\
17.09 \\
17.11 \\
16.87 \\
16.56\end{array}$ & $\begin{array}{l}16.82 \\
16.83 \\
16.90 \\
16.70 \\
16.75 \\
16.50\end{array}$ \\
\hline
\end{tabular}

WTR YR 1987

HIGHEST 13.90 OCT 4, 1986

LOWEST 19.52 JUN 20-22, 1987 
TEMPERATURE OF GROUND WATER Temperatures of ground water are measured as part of a state-wide water resource investigation in
cooperation with the Michigan Department of Natural Resources. The purpose of these measurements is to determine the natural ground-water temperature of selected points throughout the State. These data can be used to estimate ground-water temperatures in many areas in the State. Measurements of temperature were made by means of "lazy" thermometers (Heath, 1964).

\section{TEMPERATURE $\left({ }^{\circ} \mathrm{C}\right)$ OF GROUND WATER AT INDICATED DEPTH}

\begin{tabular}{|c|c|c|c|c|c|}
\hline & $\begin{array}{l}\text { WATER } \\
\text { TEMPER- } \\
\text { ATURE } \\
\left({ }^{\circ} \mathrm{C}\right)\end{array}$ & & $\begin{array}{l}\text { WATER } \\
\text { TEMPER- } \\
\text { ATURE } \\
\text { (OC) }\end{array}$ & & $\begin{array}{l}\text { WATER } \\
\text { TEMPER- } \\
\text { ATURE } \\
\left({ }^{\circ} \mathrm{C}\right)\end{array}$ \\
\hline DATE & $\left({ }^{\circ} \mathrm{C}\right)$ & DATE & $\left({ }^{\circ} \mathrm{C}\right)$ & DATE & \\
\hline
\end{tabular}

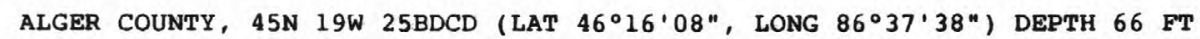

\begin{tabular}{|c|c|c|c|c|c|c|c|c|c|}
\hline \multirow[t]{2}{*}{$\begin{array}{l}\text { NOV } \\
\text { JAN }\end{array}$} & $\begin{array}{ll}12, & 1986 \\
14, & 1987\end{array}$ & $\begin{array}{l}8.5 \\
7.6\end{array}$ & MAY 13. & 6.7 & & AUG 26 . & . & $\cdot$ & 8.5 \\
\hline & & DICKINSON COUNTY, $43 \mathrm{~N} 28 \mathrm{~W}$ & 32ADAB (LAT & $46^{\circ} 04^{\prime} 58^{\prime \prime}$ & LONG $\left.87^{\circ} 49^{\circ} 39^{\prime \prime}\right)$ & DEPTH 31 & FT & & \\
\hline $\begin{array}{l}\text { OCT } \\
\text { DEC } \\
\text { JAN } \\
\text { MAR }\end{array}$ & $\begin{array}{r}28,1986 \\
1, \cdot 1987 \\
4, .0 .\end{array}$ & $\begin{array}{l}8.5 \\
7.8 \\
7.4 \\
6.4\end{array}$ & $\begin{array}{lr}\text { MAR } 26:: \\
\text { APR } & 1:: \\
& 28: \\
\text { MAY } & 29\end{array}:$ & $\begin{array}{l}6.0 \\
6.1 \\
5.8 \\
5.9\end{array}$ & & $\begin{array}{l}\text { JUN } 29 \\
\text { JUL } 31 \\
\text { SEP } \\
24: \\
24:\end{array}$ & : & $:$ & $\begin{array}{l}6.2 \\
6.8 \\
7.5 \\
7.9\end{array}$ \\
\hline
\end{tabular}

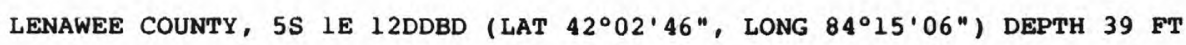

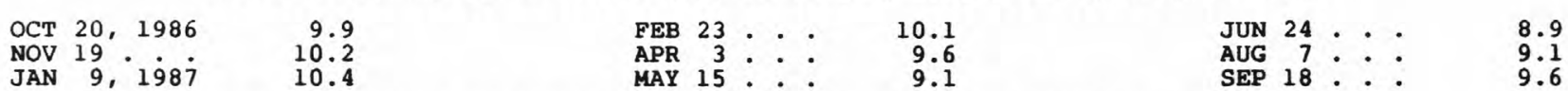

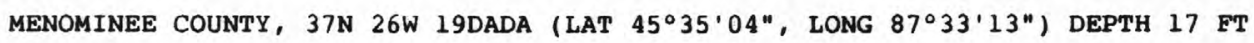

DEC 31,1986

MAR 24,1987

8.5
5.6

JUN $8 \cdot$.

7.4

SEP 22 . .

11.0

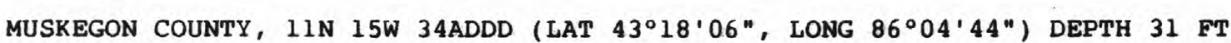

DEC 15,1986

$9.6 \quad$ MAR $10,1987 \quad 9.2$

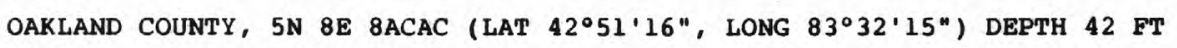

NOV 3, 1986

DEC 16,1987

9.0
9.0
9.0

$\begin{array}{ll}\text { MAR } 10 .: \therefore & 8.0 \\ \text { APR } 21 & 9.0\end{array}$

JUL 14 AUG $25:$ :

11.0
10.0 
The following continuous-record streamflow or stage stations in Michigan have been discontinued or converted to partial-record stations. The column headed "Period of record" shows the water years in which daily streamflow or stage records were collected and published.

\begin{tabular}{|c|c|c|c|}
\hline $\begin{array}{c}\text { Station } \\
\text { No. }\end{array}$ & Station Name & $\begin{array}{c}\text { Drainage } \\
\text { area } \\
\left(\mathrm{mi}^{2}\right)\end{array}$ & $\begin{array}{l}\text { Period } \\
\text { of } \\
\text { record }\end{array}$ \\
\hline
\end{tabular}

STREAMS TRIBUTARY TO LAKE SUPERIOR

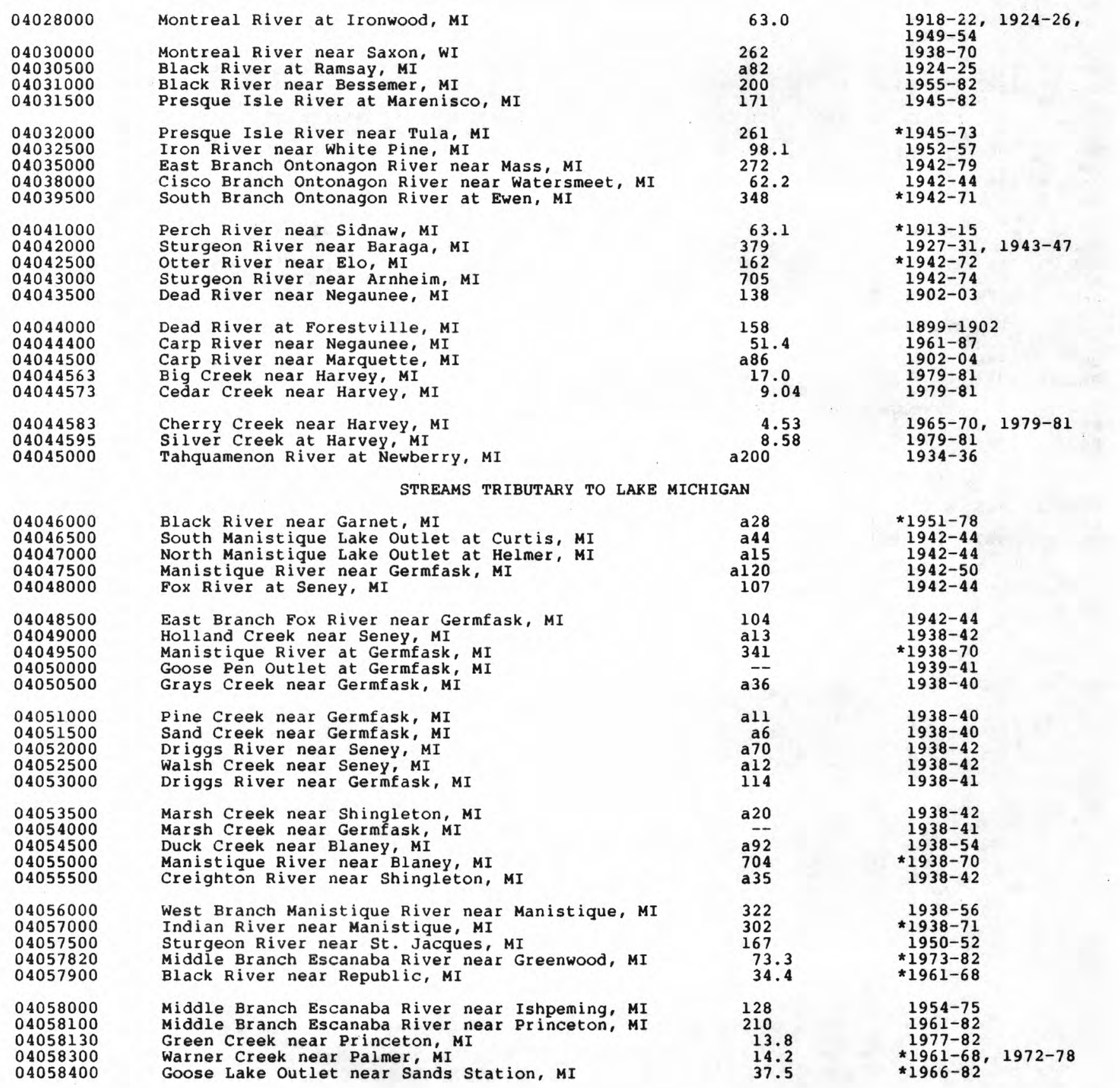

See footnotes at end of table. 


\begin{tabular}{|c|c|c|c|}
\hline $\begin{array}{c}\text { Station } \\
\text { No. }\end{array}$ & Station Name & $\begin{array}{l}\text { Drainage } \\
\text { area } \\
\quad\left(\mathrm{mi}^{2}\right)\end{array}$ & $\begin{array}{l}\text { Period } \\
\text { of } \\
\text { record }\end{array}$ \\
\hline
\end{tabular}

STREAMS TRIBUTARY TO LAKE MICHIGAN--COnt inued

\begin{tabular}{|c|c|c|c|c|}
\hline $\begin{array}{l}04058500 \\
04059400 \\
04060000 \\
04060500 \\
04062100\end{array}$ & $\begin{array}{l}\text { East Branch Escanaba River at Gwinn, MI } \\
\text { Tenmile Creek at Perronville, MI } \\
\text { Iron River near Iron River, MI } \\
\text { Iron River at Caspian, MI } \\
\text { Peshekee River near Michigamme, MI }\end{array}$ & $\begin{array}{l}124 \\
38 \cdot 4 \\
a 65 \\
92 \cdot 1 \\
66 \cdot 5\end{array}$ & $\begin{array}{r}1955-80 \\
* 1971-77 \\
1901-04 \\
1948-80 \\
1961-68\end{array}$ & \\
\hline $\begin{array}{l}04062200 \\
04062230 \\
04062270 \\
04062300 \\
04062400\end{array}$ & $\begin{array}{l}\text { Peshekee River near Champion, MI } \\
\text { Michigamme River near Michigamme, MI } \\
\text { Michigamme River near Champion, MI } \\
\text { Michigamme River at Republic, MI } \\
\text { Michigamme River near Witch Lake, MI }\end{array}$ & $\begin{array}{l}133 \\
194 \\
231 \\
240 \\
316\end{array}$ & $\begin{array}{r}\star 1961-78 \\
1969-82 \\
1964-69 \\
\star 1961-75 \\
1964-80\end{array}$ & \\
\hline $\begin{array}{l}04065000 \\
04065300 \\
04065393\end{array}$ & $\begin{array}{l}\text { Menominee River near Iron Mountain, MI } \\
\text { West Branch Sturgeon River near Randville, MI } \\
\text { East Branch Sturgeon River below Skunk Creek } \\
\quad \text { near Felch, MI }\end{array}$ & $\begin{array}{r}a 2,420 \\
56.1 \\
61.8\end{array}$ & $\begin{array}{l}1898-99 \\
1958-81 \\
1974-84\end{array}$ & $1903-14$ \\
\hline $\begin{array}{l}04065397 \\
04065500\end{array}$ & $\begin{array}{l}\text { East Branch Sturgeon River at Hardwood, MI } \\
\text { Sturgeon River near Foster City, MI }\end{array}$ & $\begin{array}{l}90.8 \\
237\end{array}$ & $\begin{array}{l}1978-83 \\
1955-80\end{array}$ & \\
\hline $\begin{array}{l}04065600 \\
04067000 \\
04095500 \\
04096000 \\
04096272\end{array}$ & $\begin{array}{l}\text { Pine Creek near Iron Mountain, MI } \\
\text { Menominee River below Koss, MI } \\
\text { Galien River near New Troy, MI } \\
\text { East Branch Galien River near New Troy, MI } \\
\text { Beebe Creek near Hillsdale, MI }\end{array}$ & $\begin{array}{l}16.8 \\
730 \\
a 47 \\
19.2 \\
42.4\end{array}$ & $\begin{array}{l}1972-81 \\
1907-09 \\
1945-47 \\
1945-47 \\
\star 1974-78\end{array}$ & $1913-81$ \\
\hline $\begin{array}{l}04096312 \\
04096325 \\
04096340 \\
04096500 \\
04097000\end{array}$ & $\begin{array}{l}\text { Sand Creek at Litchfield, MI } \\
\text { Soap Creek near Litchfield, MI } \\
\text { St. Joseph River at Clarendon, MI } \\
\text { Sauk (East Branch Coldwater) River at Coldwater, MI } \\
\text { St. Joseph River at Mendon, MI }\end{array}$ & $\begin{array}{l}20.6 \\
10 \cdot 9 \\
144 \\
-\overline{918}\end{array}$ & $\begin{array}{r}\star 1974-77 \\
1975-77 \\
\star 1974-77 \\
1938-62 \\
1903-05\end{array}$ & \\
\hline $\begin{array}{l}04097060 \\
04097170 \\
04097200 \\
04097500 \\
04098500\end{array}$ & $\begin{array}{l}\text { Little Portage Creek near Fulton, MI } \\
\text { Portage River near Vicksburg, MI } \\
\text { Gourdneck Creek near Schoolcraft, MI } \\
\text { St. Joseph River at Three Rivers, MI } \\
\text { Fawn River near white Pigeon, MI }\end{array}$ & $\begin{array}{rl}27 & .0 \\
68 & \cdot 2 \\
7 & \cdot 29 \\
1, & 350 \\
192\end{array}$ & $\begin{array}{l}\star 1965-67 \\
\star 1946-51 \\
1964-73 \\
1953-83 \\
\star 1903-04\end{array}$ & $\begin{array}{l}1965-80 \\
1958-75\end{array}$ \\
\hline 04102000 & St. Joseph River at Berrien Springs, MI & 4,081 & $\begin{array}{l}\star 1901-07 \\
1951-56\end{array}$ & $1909-32$ \\
\hline $\begin{array}{l}04102320 \\
04102420 \\
04102850 \\
04103000\end{array}$ & $\begin{array}{l}\text { Paw Paw River near Paw Paw, MI } \\
\text { Paw Paw River near Hartford, MI } \\
\text { South Branch Kalamazoo River near Albion, MI } \\
\text { Reed's Springs near Albion, MI }\end{array}$ & $\begin{array}{l}195 \\
311 \\
146 \\
--\end{array}$ & $\begin{array}{l}1980-82 \\
1980-82 \\
1972-76 \\
1905-06\end{array}$ & \\
\hline $\begin{array}{l}04103500 \\
04104000 \\
04104500 \\
04105800 \\
04106190\end{array}$ & $\begin{array}{l}\text { Kalamazoo River at Marshall, MI } \\
\text { Battle Creek at Charlotte, MI } \\
\text { Battle Creek at Bellevue, MI } \\
\text { Gull Creek near Galesburg, MI } \\
\text { Portage Creek near Portage, MI }\end{array}$ & $\begin{array}{r}449 \\
\mathrm{a} 67 \\
178 \\
38 \\
18.6\end{array}$ & $\begin{array}{r}1949-82 \\
1948-54 \\
1948-53 \\
\star 1965-73 \\
1965-67\end{array}$ & \\
\hline $\begin{array}{l}04106500 \\
04107000 \\
04107500 \\
04108000 \\
04109500\end{array}$ & $\begin{array}{l}\text { Portage Creek at Kalamazoo, MI } \\
\text { Gun River at dam near Shelbyville, MI } \\
\text { Gun River near Martin, MI } \\
\text { Kalamazoo River near Allegan, MI } \\
\text { Portage River below Little Portage Lake } \\
\text { near Munith, MI }\end{array}$ & $\begin{array}{r}46.8 \\
\text { a } 30 \\
\text { a } 35 \\
\text { a1, } 470 \\
\text { a } 55\end{array}$ & $\begin{array}{l}1948-58 \\
1946-47 \\
1946-47 \\
1903-08 \\
1944-56\end{array}$ & $1975-86$ \\
\hline $\begin{array}{l}04110000 \\
04110500 \\
04111000 \\
04112850 \\
04112904\end{array}$ & $\begin{array}{l}\text { Orchard Creek at Munith, MI } \\
\text { Portage River near Munith, MI } \\
\text { Grand River near Eaton Rapids, MI } \\
\text { Sycamore Creek near Holt, MI } \\
\text { Mud Lake Drain at Lansing, MI }\end{array}$ & $\begin{array}{l}249 \\
118 \\
661 \\
80.6 \\
4.28\end{array}$ & $\begin{array}{l}1944-56 \\
1944-46 \\
1951-82 \\
1975-80 \\
1975-76\end{array}$ & \\
\hline $\begin{array}{l}04113097 \\
04113500 \\
04114000 \\
04115500 \\
04116500\end{array}$ & $\begin{array}{l}\text { Carrier Creek near Lansing, MI } \\
\text { Sebewa Creek near Sunfield, MI } \\
\text { Grand River at Portland, MI } \\
\text { Fish Creek near Carson City, MI } \\
\text { Flat River at Smyrna, MI }\end{array}$ & $\begin{array}{r}12.1 \\
24.1 \\
1.185 \\
145 \\
528\end{array}$ & $\begin{array}{l}1975-80 \\
1954-56 \\
1952-82 \\
1936-38 \\
1951-86\end{array}$ & \\
\hline $\begin{array}{l}04117000 \\
04118500 \\
04119300 \\
04120000 \\
04120500\end{array}$ & $\begin{array}{l}\text { Quaker Brook near Nashville, MI } \\
\text { Rogue River near Rockford, MI } \\
\text { Grand River at Eastmanvilie, MI } \\
\text { Crockery Creek at Slocums Grove, MI } \\
\text { Higgins Lake Outlet (head of Muskegon River) } \\
\text { near Roscommon, MI }\end{array}$ & $\begin{array}{l}234^{7.60} \\
\text { a5s } \\
230 \\
58\end{array}$ & $\begin{array}{r}* 1954-75 \\
1952-82 \\
1976-77 \\
1903 \\
1942-50\end{array}$ & \\
\hline
\end{tabular}




\begin{tabular}{|c|c|c|c|}
\hline $\begin{array}{l}\text { Station } \\
\text { No. }\end{array}$ & Station Name & $\begin{array}{c}\text { Drainage } \\
\text { area } \\
\left(\mathrm{mi}^{\left.\frac{2}{2}\right)}\right.\end{array}$ & $\begin{array}{l}\text { Period } \\
\text { of } \\
\text { record }\end{array}$ \\
\hline
\end{tabular}

STREAMS TRIBUTARY TO LAKE MICHIGAN--COntinued

\section{0 \\ 04123000 \\ 04123500 \\ 04124500 \\ 04125000 \\ 04125500 \\ 04126200 \\ 04126500 \\ 04127500}

04128500 04129500

04130000

04131000

04131500

04132000

04132500

04133000

04133500

04134000

04134500

04135600

04136000

04137000

04137500

04138000

04138500

04139000

04139500

04140000

04140500

04141000

04141500

04143000

04143500

04144000

04145000

04145500

04146500

04147990

04148000

04148160

04148200

04148300

04148440

04148720

04149000

04149500

04150000

04151000

04152500

04153000

04153500

04154500

04156500

04157500

04158000

04158500

04159000
Muskegon River near Merritt, MI

Big Sable River near Freesoil, MI

Manistee River near Grayling, MI

East Branch Pine River near Tustin, MI

Pine River near Le Roy, MI

Pine River near Hoxeyville, MI

Little Manistee River near Freesoil, MI

Little Manistee River near Stronach, MI

Boardman River at Traverse City, MI

\section{STREAMS TRIBUTARY TO LAKE HURON}

Indian River at Indian River, MI

Pigeon River at Afton, MI

Cheboygan River near Cheboygan, MI

Rainy River near Onaway, MI

Rainy River near Ocqueoc, MI

$\begin{array}{rr}355 & \star 1947-74 \\ 127 & \star 1942-74 \\ 131 & \star 1943-74 \\ 263 & \star 1952-63 \\ 118 & \star 1952-63 \\ 251 & 1952-82 \\ 200 & \star 1957-75 \\ 233 & 1931 \\ -- & 1903-04\end{array}$

Black River near Cheboygan, MI

Thunder Bay River near Hillman, MI

Thunder Bay River near Bolton, MI

North Branch Thunder Bay River near Bolton, MI

Lower South Branch Thunder Bay River

near Hubbard Lake, MI

East Branch Au Sable River at Grayling, MI

Au Sable River near Red Oak, MI

Au Sable River at Bamfield, MI

Au Sable River near Au Sable, MI

East Branch Au Gres River at McIvor, MI

Au Gres River near National City, MI

Houghton Creek near Lupton, MI

Rifle River at "The Ranch" near Lupton, MI

Prior Creek near Selkirk, MI

Rifle River at Selkirk, MI

South Branch Shepards Creek near Selkirk, MI

West Branch Rifle River near Selkirk, MI

Rifle River at Omer, MI

North Branch Kawkawlin River near Kawkawlin, MI

Shiawassee River at Byron, MI

Shiawassee River near Fergus, MI

Bad River near Brant, MI

Flint River at Columbiaville, MI

Butternut Creek near Genesee, MI

Flint River at Genesee, MI

Gilkey Creek near Flint, MI

Swartz Creek near Holly, MI

Swartz Creek at Flint, MI

Thread Creek near Flint, MI

Brent Run near Montrose, MI

Flint River near Fosters, MI

Flint River near Alicia, MI

South Branch Cass River near Cass City, MI

Cass River at Vassar, MI

583

159

865

a 79
a 85

$1942-81$

$1943-82$

$1942-52$

*1953-79

Tobacco River at Beaverton, MI

Kinney Creek near Clare, MI

Salt River near North Bradley, MI

Chippewa River near Midland, MI

Tittabawassee River at Freeland, MI

Sebewaing River (State Drain) near Sebewaing, MI

East Fork Sebewaing River (Columbia Drain) near Sebewaing, MI

Pigeon River near Owendale, MI

Pigeon River near Pigeon, MI

597

232

171

588

184

146

76.0

al, 000

al, 420

al, 540

164
169
29

56.8

*1943-74

$1945-5$

$1945-80$

$1945-80$
$1945-80$

1945-54

1958-84

$1909-16,1931$

$1902-14$

$1939-40$

*1951-74

1951-81

*1950-73

1950-71

*1950-73

117

a 52

364

101

b365

637

a 89
470

34.7

a593

6.43

12.1

115

54.4

*1950-82

*1952-78

*1952-63

1902-04

1951-82

1948-83

1940-84

$1940-84$
$\times 1949-59$

1932-33, 1948-52

1970-84

$1931-52$

$1970-84$

*1956-75

1970-84

1970-84

20.8
.188

$10-$

238

710

487

a9
138

597

a2, 530

a 62

a 38

1970-84

1940-84

\$1949-84

1949-80

$\star 1910-28,1949-70$

1948-82

$1935-36$

$1934-71$

$\star 1948-73$

1903-10, 1912-36

53.2

1940-54

1940-54

a86

$1953-82$
$1947-52$

See footnotes at end of table. 


\begin{tabular}{|c|c|c|c|}
\hline $\begin{array}{c}\text { Station } \\
\text { No. }\end{array}$ & Station Name & $\begin{array}{c}\text { Drainage } \\
\text { area } \\
\left(\mathrm{mi}^{2}\right)\end{array}$ & $\begin{array}{l}\text { Period } \\
\text { of } \\
\text { record }\end{array}$ \\
\hline
\end{tabular}

STREAMS TRIBUTARY TO ST. CLAIR RIVER

04159488 04159900 04160000 04160050

04161000 04161500 04161820 04161820 04162500

04163000 04163500 04163900 04164010 04164050

04164150 04164200 04164250 04164350 04164360

04164400 04164450 04164600 04164800 04165000

04165200 04165556 04165557

04168500 04169500 04171000 04171500 04172500

04173000

04173500 04174000 04174800

04175340 04175500 04175700 04176400
Silver Creek near Jeddo, MI Mill Creek near Avoca, MI

Mill Creek near Abbottsford, MI

Black River near Port Huron, MI
$1978-82$

*1963-75

*1947-64

$1931,1933-44$

STREAMS TRIBUTARY TO LAKE ST. CLAIR

Clinton River at Auburn Heights, MI

Paint Creek near Lake Orion. MI

Clinton River at Sterling Heights, MI

Red Run near Royal Oak, MI

Bear Creek at Warren, MI

Big Beaver Creek at Warren, MI

Plum Brook near Utica, MI

Red Run near Cady, MI

North Branch Clinton River at Almont, MI

North Branch Clinton River near Romeo, MI

North Branch Clinton River near Meade, MI

Coon Creek near Armada, MI

Tupper Brook at Ray Center, MI

Highbank Creek near Armada. MI

East Branch Coon Creek near New Haven, MI

Deer Creek near Meade, MI

McBride Drain near Macomb, MI

Middle Branch Clinton River near Macomb, MI

Middle Branch Clinton River at Macomb, MI

Middle Branch Clinton River near Mount Clemens, MI

Gloede Ditch near Waldenburg, MI

Clinton River By-Pass below weir at Mount Clemens, MI

Clinton River BY-Pass at mouth at Mount Clemens, MI

\section{STREAMS TRIBUTARY TO DETROIT RIVER}

Lower River Rouge at Dearborn, MI

a96

123
38
309

309.5

$36 \cdot 5$
$17 \cdot 3$

25.2

22.9

9.56

9.56
49.7

89.6

10.0

8.62

14.9

36.1

12.7

5.79
22.2
41.0

16.0

*1935-40, $1957-82$

$\star 1955-75$

$1979-83$

d1953-68

1954-57

1954-58

$1954-66$

$\$ 1980-82$

*1963-68

$1963-68$
$\times 1965-69$

*1968-72

*1966-70

*1960-64

*1965-70

*1968-72

*1960-65

*1960-64

*1965-69

*1963-68, 1970-82

1947-49

*1959-64

$\neq 1980-83$

$\neq 1980-83$

$1931-33$

STREAMS TRIBUTARY TO LAKE ERIE

Hayes Creek at Commerce, MI

Huron River at Commerce, MI

Davis Creek near Whitmore Lake, MI

Ore Creek near Brighton, MI

Portage River near Pinckney, MI

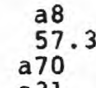

a70

a 70
a 31
79

Huron River near Dexter, MI

522

Mill Creek near Dexter, MI

Huron River at Dexter, MI

Huron River at ypsilanti, MI

128

807

Stony Creek at Oakville, MI

Huron River at Flat Rock, MI

River Raisin near Tecumseh, MI

68.0

68
851
267

Saline River near Saline, MI

$1946-51$

*1946-75

$1953-54$

$1951-68$

$\star 1945-71$

*1904, 1946-72,

1976-77

1952-83

$\$ 1904-16$

$1974-84$

$1970-81$

$1904-11, \$ 1912-22$

$1956-80$

$\star 1966-77$

* Previous or subsequent operation as a crest-stage partial-record station.

\# Stage record only.

a Approximately.

b Revised.

c Includes drainage area of Birch Run above state Highway 13.

d Records available in District office only. 

Access to WATSTORE data $\ldots \ldots \ldots \ldots \ldots \ldots$ Acre-foot, definition of $\ldots \ldots \ldots \ldots$ Adenosine triphosphate, definition of $\ldots .$.

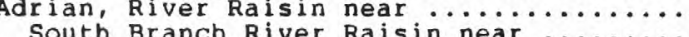
South Branch River Rais in near........... Algae, definition of $\ldots \ldots \ldots$

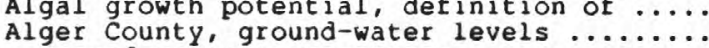

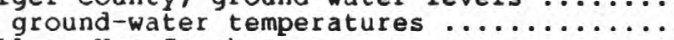

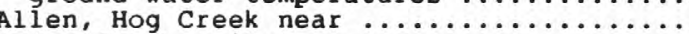
Hog Creek Tributary near $\ldots \ldots \ldots \ldots \ldots \ldots$

Alma, Pine River (tributary to Chippewa

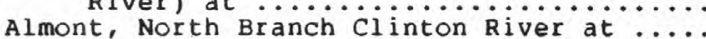

Alpena, Thunder Bay River near ............151-15

Alpena County, ground-water levels ....... 253

Alpha, Paint River near $\ldots \ldots \ldots \ldots \ldots \ldots \ldots$ , Sturgeon River (tributary to Lake

Analyses of samples collected at waterquality partial-record stations and miscellaneous sites ....................

Andersonville, Huron River near $. . . \cdots \cdots . .$.

Ann Arbor, Huron River at $\ldots \ldots \ldots \ldots \ldots \ldots$

Aquifer, definition of $\ldots \ldots \ldots \ldots \ldots \ldots \ldots \ldots \ldots \ldots \ldots$

Arcadia Creek at Kalamazoo ...........235, 248-251

Arenac County, ground-water levels......253,254

Armada, Coon Creek near ................ 229

East Branch Coon Creek at ............. 202

Highbank Creek near .................. 229

Armstrong Creek near Montrose ............ 228

Artesian, definition of $\ldots \ldots \ldots \ldots \ldots \ldots \ldots \ldots$

Artificial substrate, definition of $\ldots \ldots \ldots$

Ash mass, definition of $\ldots \ldots \ldots \ldots \ldots \ldots$

Athens, Nottawa Creek near $\ldots \ldots \ldots \ldots \ldots$

Auburn Heights, Clinton River at ...........

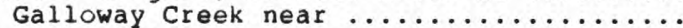

Augusta Creek near Augusta ............ 96. $96-97$

Au Sable, Au Sable River near ........... 158-159

Au Sable River, at Grayling.............

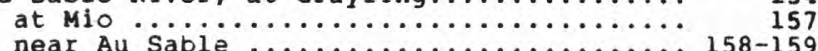

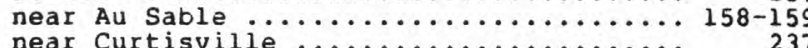

South Branch, near Luzerne ............. 155

Aust in Lake outlet near vicksburg .......233,240-243

Bacteria, definition of

Bangor, South Branch Black River (tributary to Lake Michigan) near ....

Baraga County, ground-water levels ..........

Barry County, ground-water levels .........

Battle Creek, Battle Creek at .................

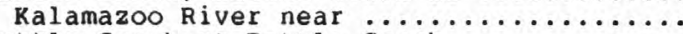

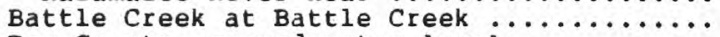

Bay County, ground-water levels .............

Bear Creek' (tributary to Lake Michigan)

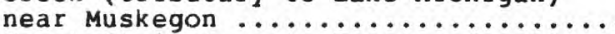

Bear Creek (tributary to Nottawa Creek)

Bear Creek (tributary to Portage River)

$233,240-243$ near vicksburg ............. 234,244-247

Beaverton, South Branch Tobacco River

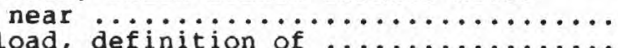

Bed load, definition of $\ldots \ldots \ldots \ldots \ldots \ldots$

Bed material, definition of $\ldots \ldots \ldots \ldots \ldots$

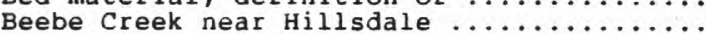

Beebe Creek near Hiflisdale $\ldots \ldots \ldots \ldots \ldots \ldots \ldots$

Bell Branch at Redford.

Belle River, at Memphis $\ldots \ldots \ldots \ldots \ldots \ldots . . .6$.

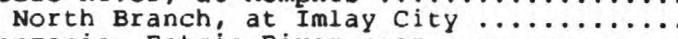

Benzonia, Betsie River near $\ldots \ldots \ldots \ldots \ldots$

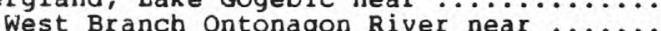

Betsie River near Benzonia ..................

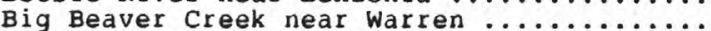

Biochemical oxygen demand, definition of $\ldots$

Biomass, definition of $\ldots \ldots \ldots \ldots \ldots \ldots$

Birmingham, River Rouge at $\ldots \ldots \ldots \ldots \ldots \ldots \ldots \ldots$

Black Creek (tributary to Lake Michigan)

Black River (tributary to Cheboygan

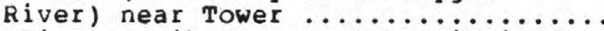

Black River (tributary to Lake Michigan),

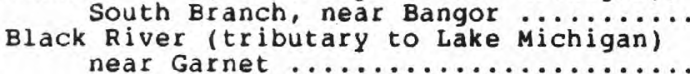

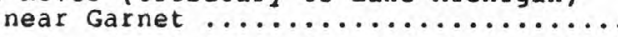

Black River (tributary to Middle Branch Escanaba River) near Republic ........ Black River (tributary to St. Clair

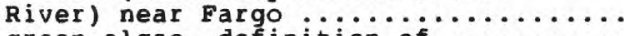

Blue-green algae, definition of $\ldots \ldots \ldots \ldots$

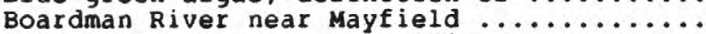
Bond Falls Canal near Paulding $\ldots \ldots \ldots \ldots \ldots$ Bond Falls Lower By-Pass near Calderwood .. Bond Falls Reservolr near Paulding $\ldots \ldots \ldots$ Bottom material, definition of $\ldots \ldots \ldots \ldots \ldots \ldots$ Branch County, ground-water levels ..... 255

Brimley, East Branch Waiska River near .... 226

West Branch Waiska River near .......... 226

Brule River near Florence, WI ........... 69

Brundage Creek near Honor $\ldots \ldots \ldots \ldots \ldots \ldots \ldots \ldots \ldots \ldots \ldots$
Buck Creek at Grandville $\ldots \ldots \ldots \ldots \ldots \ldots$

Burlington, St. Joseph River (tributary

to Lake Michigan) near . . . . . . . . .

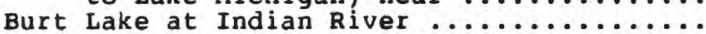

Cadillac, Clam River at $\ldots \ldots \ldots \ldots \ldots \ldots$ Caledonia, Thornapple River near $\ldots \ldots \ldots \ldots$

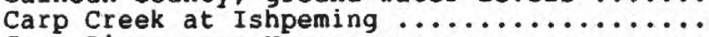

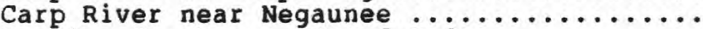

Carrier Creek near Grand Ledge .............

Caseville, Pigeon River near .............. 227

Cass County, ground-water leveis $\ldots \ldots \ldots \ldots .282-184$

Cass River, at Cass City ................ 171

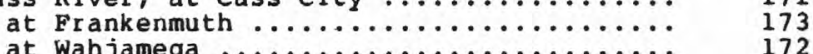

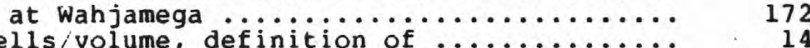

Cheboygan, Cheboygan Pont at $\ldots \ldots \ldots \ldots \ldots \ldots . .150$

Mullett Lake near .................. 148

Cheboygan County, ground-water ieveis $\ldots \ldots .256,257$

Cheboygan Pond at Cheboygan $\ldots \ldots \ldots \ldots \ldots . . . .150$

$\begin{array}{lr}\text { Chemical oxygen demand, definition of } \ldots \ldots & 14 \\ \text { Chippewa County, ground-water levels } \ldots \ldots & 257\end{array}$

Chippewa River near Mount pleasant $\ldots \ldots \ldots, \quad 175$

rophyll, definition of $\ldots \ldots \ldots \ldots \ldots \ldots$

Cisco Branch Ontonagon River at Cisco

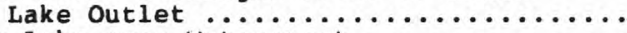

Cisco Lake near watersmeet $. . . \ldots \ldots \ldots \ldots . . . .$.

Champion, Lake Michigamme near .............

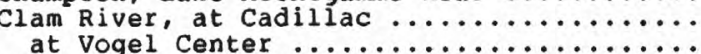

clarendon, st. Joseph River itributary to

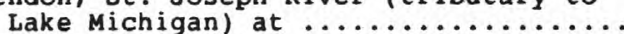

clinton County, ground-water levels ..........

Clinton River, at Auburn Heights ............

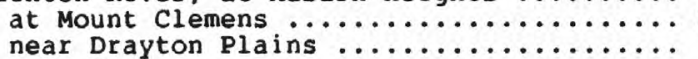

near Drayton Plains.$\ldots \ldots \ldots \ldots \ldots \ldots \ldots$

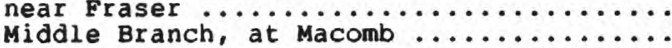

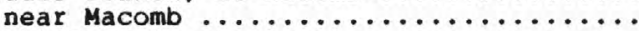

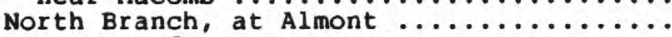
near Meade ..........................

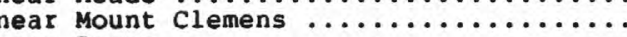

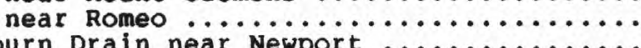

Colburn Drain near Newport $\ldots \ldots \ldots \ldots \ldots$. $\ldots \ldots$ Joph

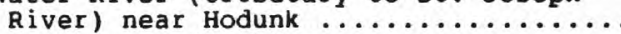

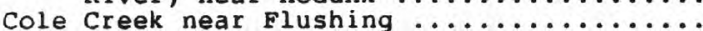

Color unit, definition of $\ldots \ldots \ldots \ldots \ldots \ldots$

Columbiaville, North Branch Fi int kiver

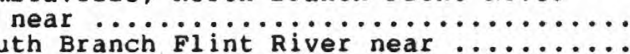

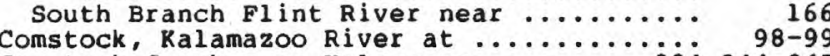
Comstock Creek near Kalamazoo ....... 234,244-247

Contents, definition of $\ldots \ldots \ldots \ldots \ldots \ldots$

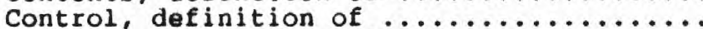

Control structure, definition of $\ldots \ldots \ldots \ldots$

Conway, crooked take near $\ldots \ldots \ldots \ldots \ldots \ldots$

Conway, Crooked Lake near $\ldots \ldots \ldots \ldots \ldots \ldots \ldots \ldots \ldots$

East Branch, at Armada $\ldots \ldots \ldots \ldots \ldots \ldots \ldots$ near New Haven.$\ldots \ldots \ldots \ldots \ldots \ldots \ldots \ldots$

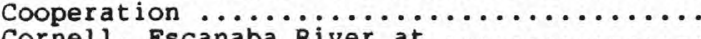

Cornell, Escanaba River

Cosperville, IN, North Branch Elkhart River at $\ldots \ldots \ldots \ldots \ldots \ldots$.

Crawford County, ground-water levels $\ldots \ldots$.

\section{(1)}

231 56 26 
Crystal Falls, Michigamme River near ...... Cubic feet per second per square mile,

$$
\text { definition of ................................. }
$$

Cubic foot per second, definition of ...... cubic foot per second-day, definition of . Curtis, Manistique Lake near ..............

Dansville, Deer Creek (tributary to Red Cedar River) near ................. 113

Davis Creek at Kalamazoo .............. 234, 244-247

Davison, Kearsley Creek near ............ 169

Deer Creek (tributary to Red Cedar River) near Dansville ................... 113

Deer Creek (tributary to North Branch

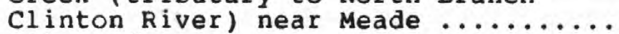
Definition of terms $\ldots \ldots \ldots \ldots \ldots \ldots \ldots$

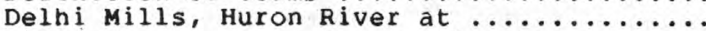
Delta County, ground-water levels ..........

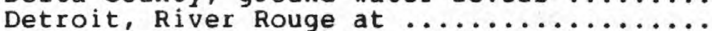
Detroit River, streams tributary to crest-stage partial-record stations . gaging-station records .........................

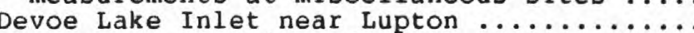

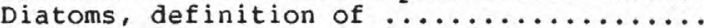
Dickinson County, ground-water levels .... ground-water temperatures..$\ldots \ldots \ldots \ldots$. Discharge, definition of $\ldots \ldots \ldots \ldots \ldots \ldots$. Discontinued gaging stations $\ldots \ldots \ldots \ldots \ldots \ldots$ Dissolved, definition of ........
Dissolved-solids concentration,

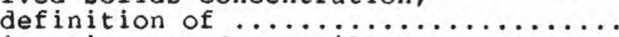

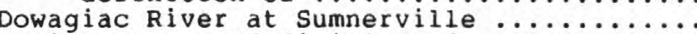
Drainage area, definition of $\ldots \ldots \ldots \ldots \ldots$

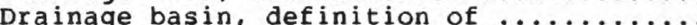
Drayton Plains, Clinton River near .........

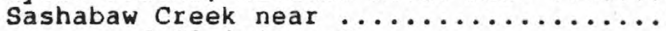

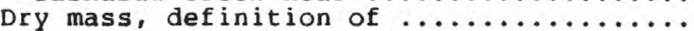

Eagle, Looking Glass River near ......... 117 Eagle Lake Drain near Augusta .......2 234,244-247

East Jordan, Jordan River near $\cdots \cdots \cdots \cdot 234,244-247$

East Lansing, Red Cedar River at $\ldots \ldots \ldots \ldots \ldots, 14$

East Pond Creek at Romeo ................. 201

Eastmanville, Grand River at ............... 123-124

Eaton County, ground-water leveis ......... 259

E orse River, at Lincoln Park $\ldots \ldots \ldots \ldots \ldots .238$

Elk Lake near Elk Rapids .................

Elkhart, IN, st. Joseph River itributary to Lake Michigan) at $\ldots \ldots \ldots \ldots \ldots \ldots$

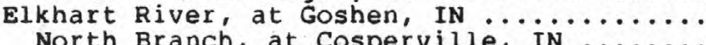

North Branch, at Cosperville, in ..........

Escanaba River, at Cornell $\ldots \ldots \ldots \ldots \ldots \ldots$

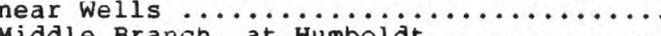

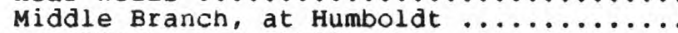

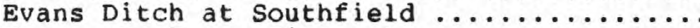

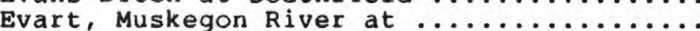

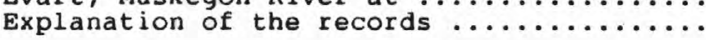

Factors for converting English Units to International System (SI) Units ...... Inside back cover

Fargo, Black River (tributary to st.

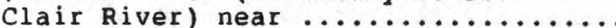

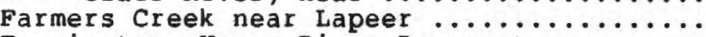

Farmington, Upper River Rouge at $\ldots \ldots \ldots \ldots$.

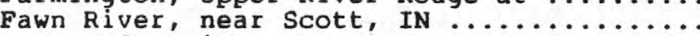

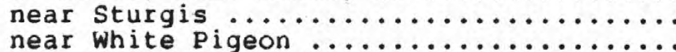

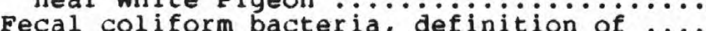

Fecal streptococcal bacteria, definition

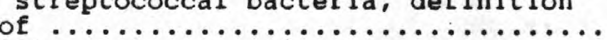

Fennville, Kalamazoo River near ............

Fish Creek near Crystal $\ldots \ldots \ldots \ldots \ldots \ldots \ldots$

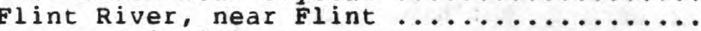

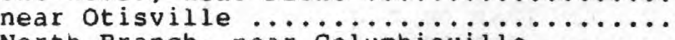
North Branch, near columbiavilie............ South Branch, near Columbiaville ...........

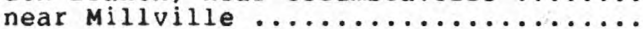

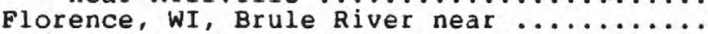

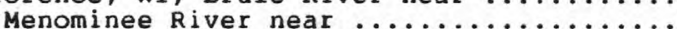
Flowerfield Creek at Flowerfieid ...... 234, 244-24

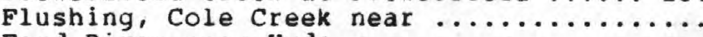

Ford River near Hyde $\ldots \ldots \ldots \ldots \ldots \ldots \ldots \ldots \ldots \ldots$

Frank and Poet Drain at Trenton ...........

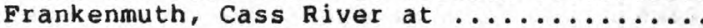

Fraser, Clinton River near $\ldots \ldots \ldots \ldots \ldots$.

Gage height, definition of $\ldots \ldots \ldots \ldots \ldots \ldots$

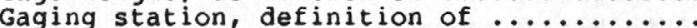
Galien River, near Three Oaks $\ldots \ldots \ldots \ldots \ldots$
South Branch, near New Buffaio $\ldots \ldots \ldots \ldots$

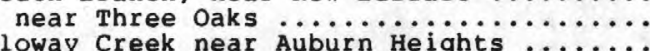
Galloway Creek near Auburn Heights . ................ Gamble Creek, near Lupton $\ldots \ldots \ldots \ldots \ldots \ldots$

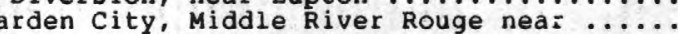
Garnet, Black River (tributary to Lake

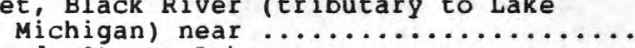
Gaylord, otsego Lake near ................. Genesee County, ground-water leveis ..........

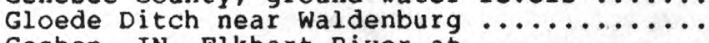

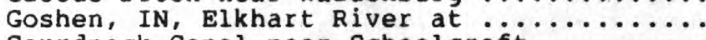

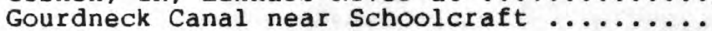
Gourdneck Creek near Vicksburg .....233,240-843

Grand Ledge, Carrier Creek near ......... 227

Grand Rapids, Grand River at ............... 122

Plaster Creek at ................... 227

Grand River, at Eastmanvilie .......... 123-124

at Grand Rapids $\ldots \ldots \ldots \ldots \ldots \ldots \ldots \ldots \ldots .122$

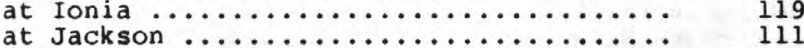

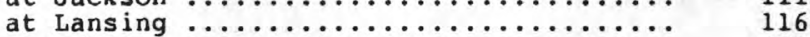

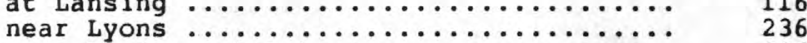

near vandercook lake ................... 236

Grand Traverse County, ground-water

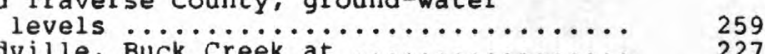

Grandville, Buck Creek at $\ldots \ldots \ldots \ldots \ldots \ldots \ldots \ldots \ldots \ldots \ldots$

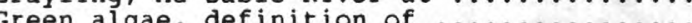

Green Creek near Palmer .................. 231

Greenwood Diversion near Greenwood ......... 59

Greenwood Release (Middle Branch Escanaba

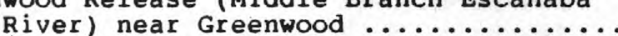

Greenwood Reservoir near Greenwood .........

Ground-water level records by county ...... 253-270

Ground-water temperatures by county ...... 271

Grousehaven Lake Outlet near Lupton ...... 237

Gull Creek near Galesburg ..........234,244-247

Gun River, at Hooper ................. 235

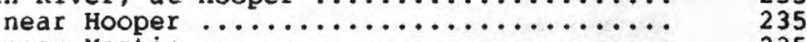

$\begin{array}{ll}\text { near Martin } & \ldots \ldots \ldots \ldots \ldots \ldots \ldots \ldots \ldots \ldots \ldots \ldots \ldots \ldots\end{array}$

Hamburg, Huron River near ........... 217

Hamilton, Rabbit River at ............. 227

Hardness, definition of $\ldots \ldots \ldots \ldots \ldots \ldots \ldots \ldots \ldots . .15$

Hastings, Thornapple River near ............ 120

Higgins lake near Roscommon .............. 125

Highbank Creek near Armada .................. 229

Hillsdale, Beebe Creek near ................. 227

Hodunk, Coldwater River (tributary to

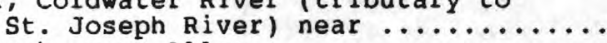

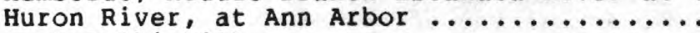

near Andersonville $\ldots \ldots \ldots \ldots \ldots \ldots \ldots \ldots$

near New Hudson $\ldots \ldots \ldots \ldots \ldots \ldots \ldots \ldots \ldots$

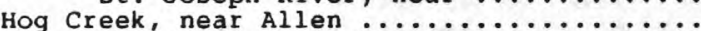

Tributary near Allen $\ldots \ldots \ldots \ldots \ldots \ldots \ldots \ldots \ldots$

Holloway Reservoir near otisvilie ...........

Hopk ins, Rabbit River near $\ldots \ldots \ldots \ldots \ldots \ldots$

Horse Creek at St. Lou is $\ldots \ldots \ldots \ldots \ldots \ldots$

Houghton Creek near Lupton $\ldots \ldots \ldots \ldots \ldots$

Houghton Lake near Houghton Lake Heights..

Humboldt, Middle Branch Escanaba River at.

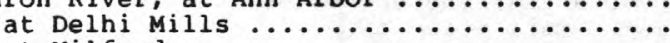

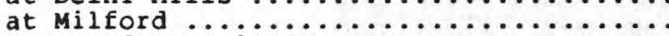

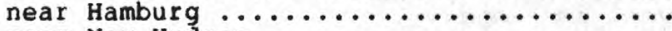

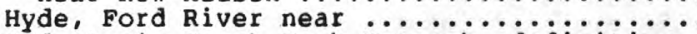

Hydrologic Bench-Mark Network, definition

Hydrologic conditions, summary of $\ldots \ldots \ldots \ldots$

graph of $\ldots \ldots \ldots \ldots \ldots \ldots$

Imlay City, North Branch Belle River at ...

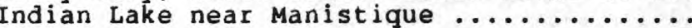
Indian River, Burt Lake at ................ Ingham County, ground-water leveis ......... Inkster, Lower River Rouge at $\ldots \ldots \ldots \ldots$. Instantaneous discharge, definition of .... Introduction $\ldots \ldots \ldots \ldots \ldots \ldots \ldots \ldots \ldots \ldots$

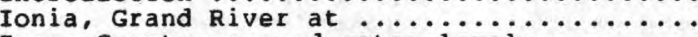
Iosco County, ground-water levels ........

78
77
231
167
109
238
228
126
56
219
218
214
230
217
216
$66-68$
15
$2-5$
3
15

188

54
146

260

213

$66-68$

173 .
5 7 56 5

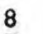
. 
Iron County, ground-water levels ........

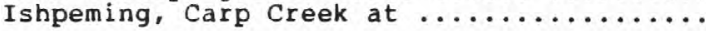

Jackson, Grand River at $\ldots \ldots \ldots \ldots \ldots \ldots$ Jackson County, ground-water levels ...... Johnson Drain at Northville $\ldots \ldots \ldots \ldots \ldots \ldots$

111

\section{Kalamazoo, Portage Creek (tributary to}

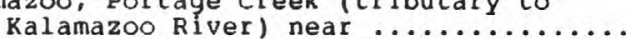

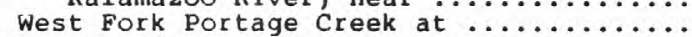

Kalamazoo County, ground-water levels ....

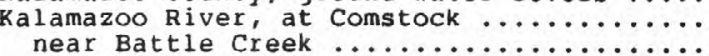

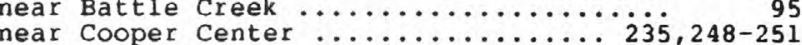

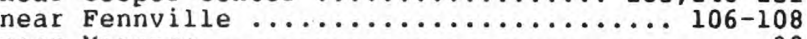

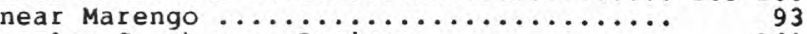

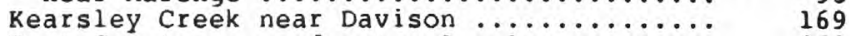

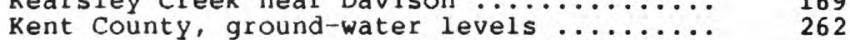

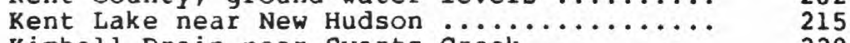

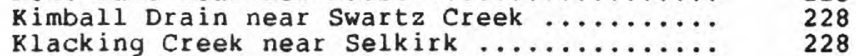

Lake County, ground-water levels .......................... 262

Lake Erie, streams tributary to, creststage partial-record stations ....... 230

$\begin{array}{rr}\text { gaging-station records } \ldots \ldots \ldots \ldots \ldots & \ldots \ldots \ldots \\ \text { measurements at miscellaneous sites } \ldots \ldots & 214-225\end{array}$

Lake Gogebic near Bergland .............. 36

Lake Huron, streams tributary to; crest-stage partial-record stations

gaging-station records ............. 143-184 measurements at miscellaneous sites ..... 237-238

Lake Linden, Trap Rock River near ......... 237-238

$\begin{array}{lll}\text { Lake Linden, Trap Rock River near ......... } & 45 \\ \text { Lake Michigamme near Champion ........... } & 72\end{array}$

Lake michigan, streams tributary to, crest-stage partial-record stations .. 226-228

gaging-station records ........... 52-142

low-flow partial-record stations ....... 231

measurements at miscellaneous sites .... 232-237

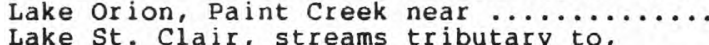
St. Clair, streams tributary to,

crest-stage partial-record stations . 228-229 gaging-station records ................ 190-206

Lake superior, streams tributary to. crest-stage partial-record stations ..

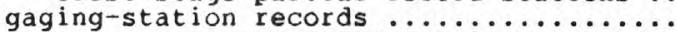

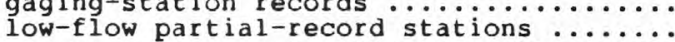

measurements at miscellaneous sites .....

Lakes and Reservoirs:

Bond Falls Reservoir near Paulding ......

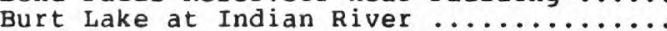

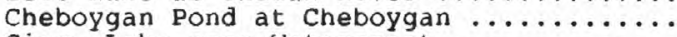

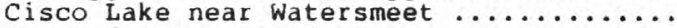

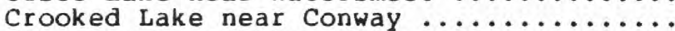

Elk Lake near Elk Rapids $\ldots \ldots \ldots \ldots \ldots \ldots$

Elk Lake near Elk Rapids $\ldots \ldots \ldots \ldots \ldots$

Higgins Lake near Roscommon $\ldots \ldots \ldots \ldots . . . .$.

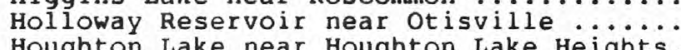

Houghton Lake near Houghton Lake Heights.

Indian Lake near Manistique $\ldots \ldots \ldots \ldots \ldots$

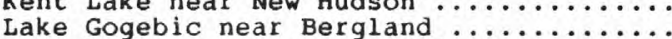

Lake Michigamme near Champion $\ldots \ldots \ldots \ldots$

Lake Michigamme near Champion $\ldots \ldots \ldots \ldots \ldots$

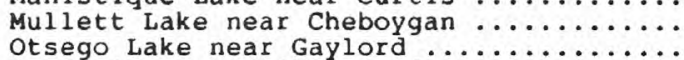

Sand River wildlife Flooding at

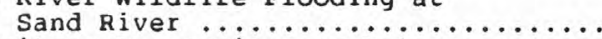

Schweitzer Reservoir near paimer ........

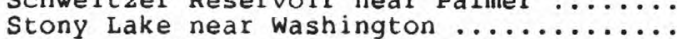

Lake of the Woods Drain near Decatur .......

Land-surface datum, definition of ............

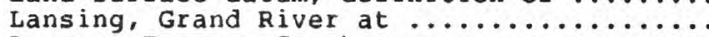

Lapeer, Farmers Creek near

Leelanau County, ground-water level $\ldots . .$.

Lenawee County, ground-water levels .......

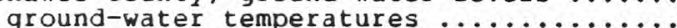

Lima Center, Mill Creek (tributary to

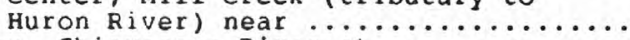

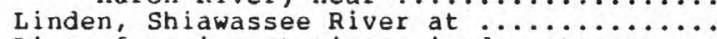

List of gaging stations, in downstream order, for which records are

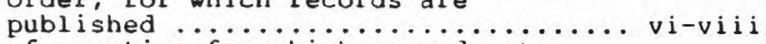

List of counties for which ground-water

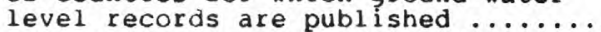

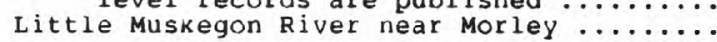

226
$26-49$

$6-49$

232

33
146

150

38

144
141

141
58

125

167

126
54

215

215
36
72

72
52

52
148

156

46
61
195

234
15

15
116

165

263

263

271

230

163

Little Portage Creek, near Climax ....233,240-243

near fulton ................... 233,240-243

Little Swan Creek (tributary to lake Erie)

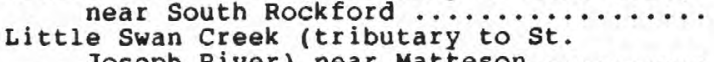

Livingston county, ground-water leveis .....

Look ing Glass River near Eagle ...........

Lower River Rouge, at Inkster ...........

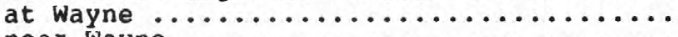

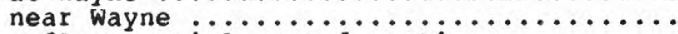

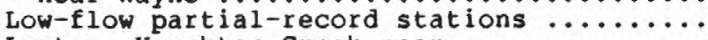

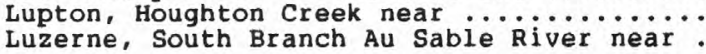

233

264

213

238

238

228

228
155

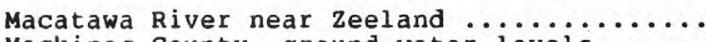

Mack inac County, ground-water levels ......

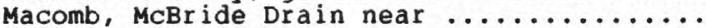

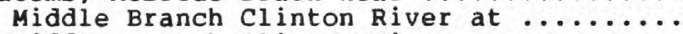

Middle Branch Clinton River near .........

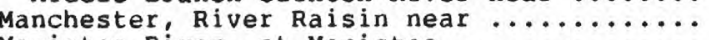

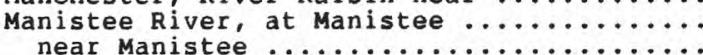

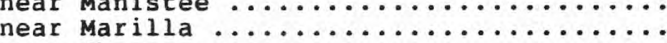

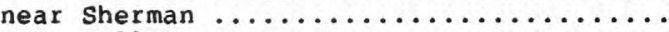

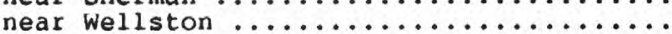

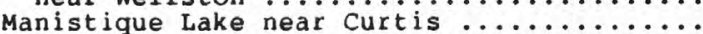

Manistique River, near Manistique $\ldots \ldots \ldots \ldots$

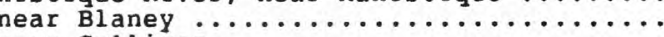

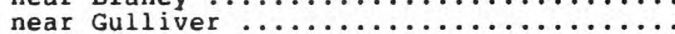

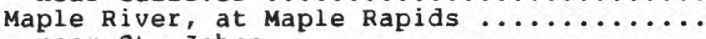
near St. Johns $\ldots \ldots \ldots \ldots \ldots \ldots \ldots \ldots$

Map of Michigan, water-discharge stations. water-quality stations $\ldots \ldots \ldots \ldots \ldots \ldots$

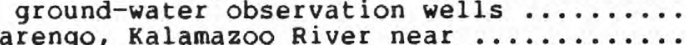

Marengo, Kalamazoo River near $\ldots \ldots \ldots$. . . . . . .

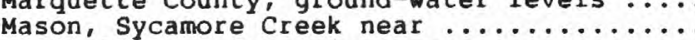

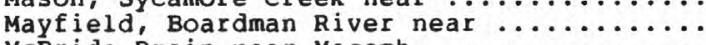

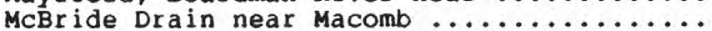

Meade, Deer Creek (tributary to North

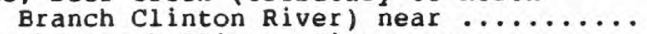
North Branch $\mathrm{Cl}$ inton River near $\ldots \ldots \ldots \ldots$ Mean concentration, definition of $\ldots \ldots \ldots$.

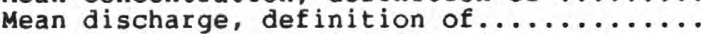

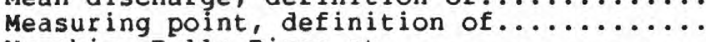

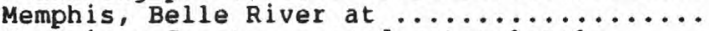

Menominee County, ground-water levels .....

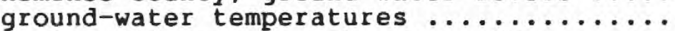

Menominee River, near Florence, $\mathrm{WI} \ldots . . .$.

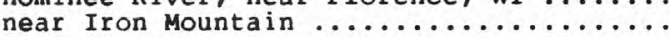

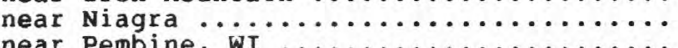
near Pembine, wI $\operatorname{def} i n i t i \ldots \ldots \ldots \ldots$

Methylene blue active substance.

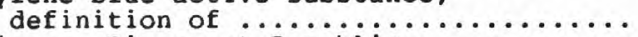

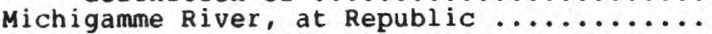

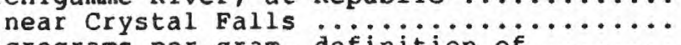

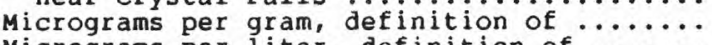

Micrograms per liter, definition of $\ldots \ldots \ldots$ near Rlymouth

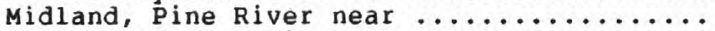

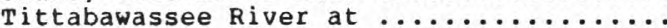
Tittabawassee River near $\ldots \ldots \ldots \ldots \ldots \ldots \ldots$ Milford, Huron River at $\ldots \ldots \ldots \ldots \ldots \ldots \ldots \ldots$ Mill Creek (tributary to Huron River)

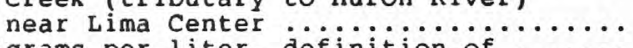
Milligrams per liter, definition of $\ldots \ldots \ldots$ Millville, South Branch Flint River near..

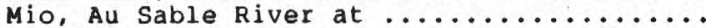
Miscellaneous sites, anaiyses of waterquality samples collected at ....... 240-251 discharge measurements at ............... 232-239

Monroe County, ground-water levels ........

Monroe, River Rais in near $\ldots \ldots \ldots \ldots \ldots \ldots$

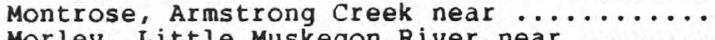

Mottville, st. Joseph River (tributary

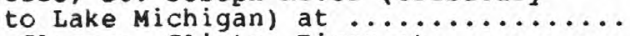

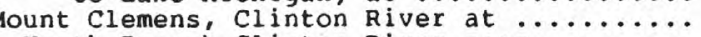

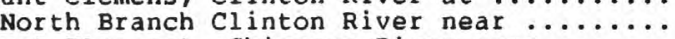
Mount Pleasant, Chippewa River near ........

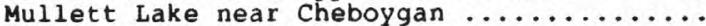

Muskegon, Bear Creek (tríbutary to Lake

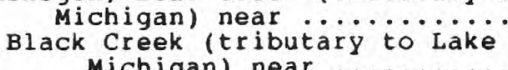

110

229

229

229
221

138-139

137
236

136

236

53

232
232

118

22-23

252

93
264

227

229

229

229

17
14

15
189

265

271
74

232
232

75
15

15

227
73

15
15

212

177

178

$79-180$
214

230

15
228

157

$32-239$
265
$23-225$

228

204-206

203
175

148 Michigan) near ......... 
Page

Muskegon County, ground-water levels .....

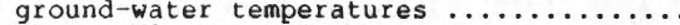

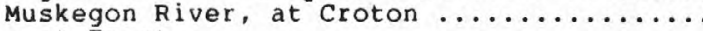

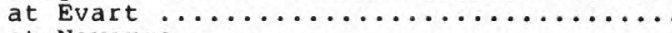

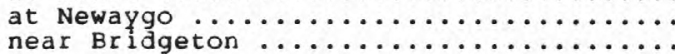

Nahma Junction, Sturgeon River (tributary

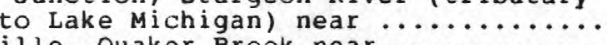

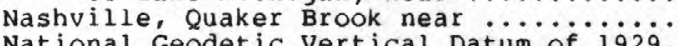
National Geodetic Vertical Datum of 1929, definition of $\ldots \ldots \ldots \ldots \ldots \ldots$. $\ldots$.

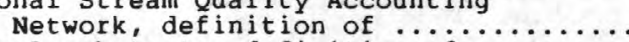
Natural substrate, definition of $\ldots \ldots \ldots \ldots$

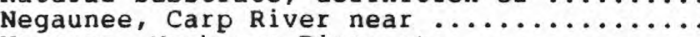
Newaygo, Muskegon River at $\ldots \ldots \ldots \ldots \ldots \ldots$ New Haven, East Branch Coon Creek near ....

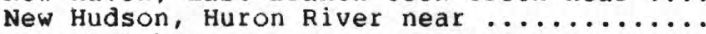

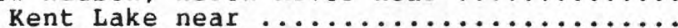
Niles, St. Joseph River itributary to

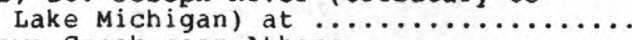

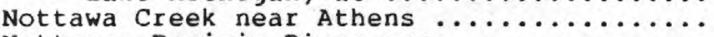

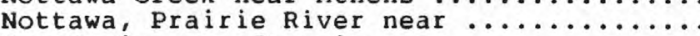

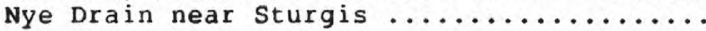

Oakland County, ground-water levels ......

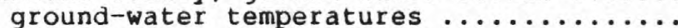
oceana County, ground-water levels .......

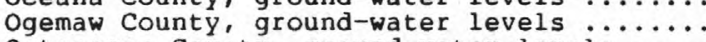
ontonagon County, ground-water levels .... ontonagon River, Cisco Branch, at Cisco

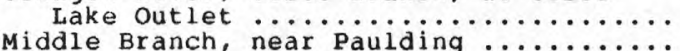
near Rockland

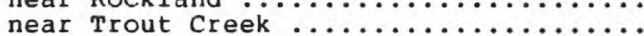

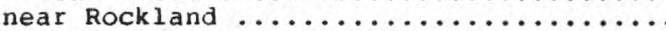

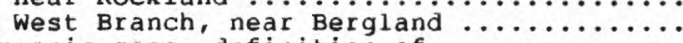

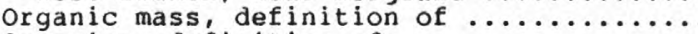

Organism, definition of $\ldots \ldots \ldots \ldots \ldots \ldots$ count/area, definition of $\ldots \ldots \ldots \ldots \ldots$ count/volume, definition of $\ldots \ldots \ldots \ldots \ldots$ Oshtemo, West Fork Portage Creek near ....

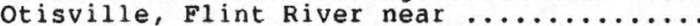

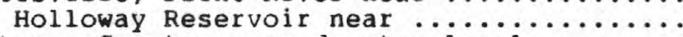
otsego County, ground-water levels ........

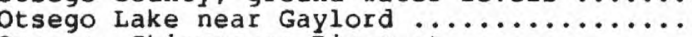

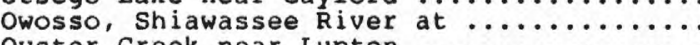

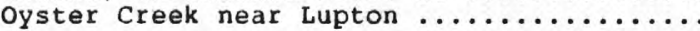

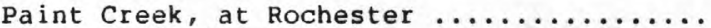
near Lake orion $\ldots \ldots \ldots \ldots \ldots \ldots \ldots \ldots \ldots \ldots$

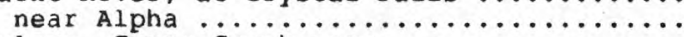

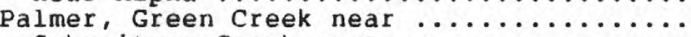

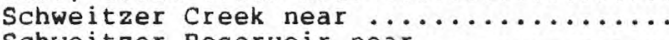

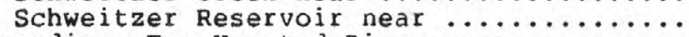
Paradise, Two Hearted River near .........

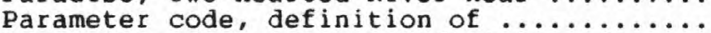
Partial-record station, definition of $\ldots \ldots$. Partial-record station, definition of $\ldots \ldots$. Partical-size classification, definition

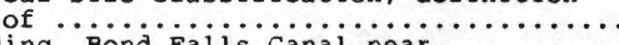

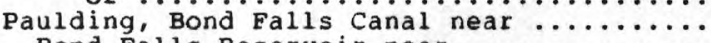

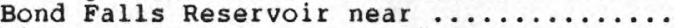
Middle Branch Ontonagon River near ......

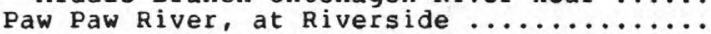

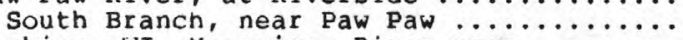

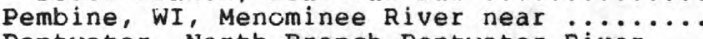
Pentwater, North Branch Pentwater $\dot{R} i \mathrm{ver}$

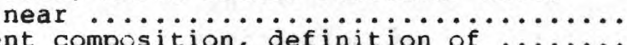

Percent composition, definition of $\ldots \ldots \ldots$

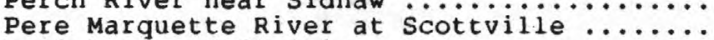

Periphyton, definition of $\ldots \ldots \ldots \ldots \ldots$ Perronville, Tenmile creek at $\ldots \ldots \ldots \ldots \ldots \ldots$ Perronville, Tenmile Creek at $\ldots \ldots \ldots \ldots \ldots \ldots$
Pesticides, definition of $\ldots \ldots \ldots \ldots \ldots \ldots$

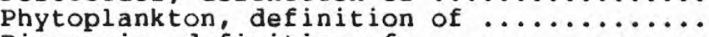

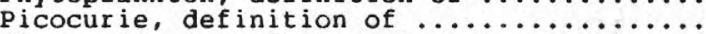
$P$ igeon River (tributary to lake Huron)

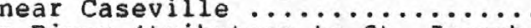

Pigeon River (tributary to St. Joseph

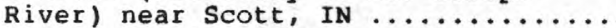

pigeon River (tributary to Indian

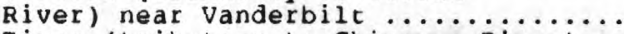

Pine River (tributary to Chippewa River),

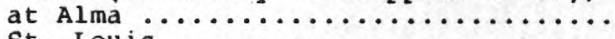

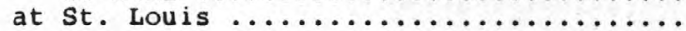

Pine River (tributary to Chippewa River),

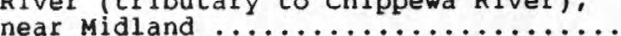

Pine River (tributary to Lake Huron)

Pine River (tributary to Maniste...........

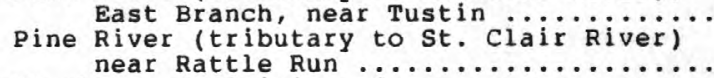

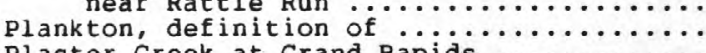

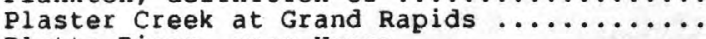

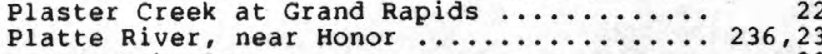

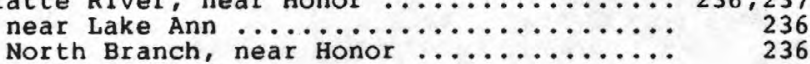

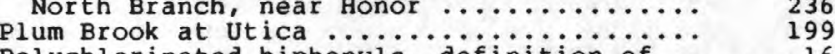

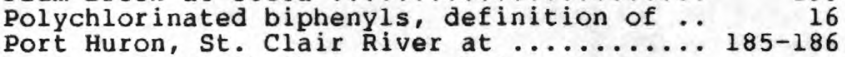

Portage Creek (tributary to Kalamazoo River), at Kalamazoo ...........2 235,248-251

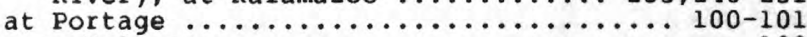

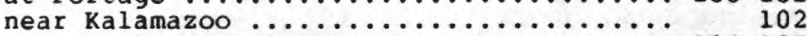

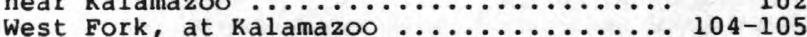

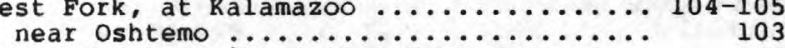

Portage Creek (tributary to Portage River), at vicksburg .........233,240-243

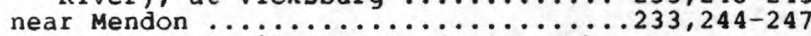
Portage River (tributary to St. Joseph River), near Scotts ............233,240-243 near Vicksburg ..................... $27,233,240-243$

$\begin{array}{ll}\text { Prairie River near Nottawa ................ } & 81 \\ \text { Presque Isle county, ground-water ievels... } & 268\end{array}$

Primary productivity, definition of .......

Publications on Techniques of Water-

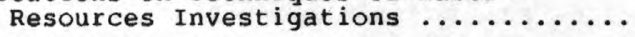

20-21

Quaker Brook near Nashville $\ldots \ldots \ldots \ldots \ldots$

Rabbit River, at Hamilton ............. 227

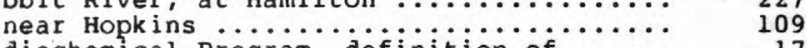

Radiochemical program, definition of ....... 17

Rapid River, whitef ish River near $\ldots \ldots \ldots \ldots . . \ldots \ldots$

Rattle Run, Pine River (tributary to $\ldots \ldots \ldots 228$

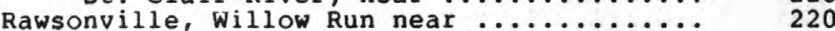

Recoverable from bottom material,

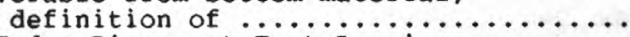

Red Cedar River, at East iansing $\ldots \ldots \ldots \ldots$

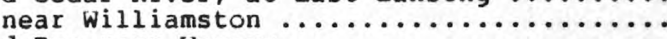

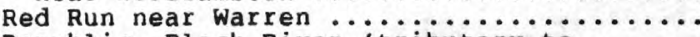
Republic, Black River (tributary to Middle Branch Escanaba River), near..

Michigamme River at ................. Reservoir (see Lakes and Reservoirs)

Return period, definition of $\ldots \ldots \ldots \ldots \ldots$

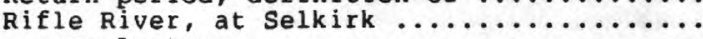

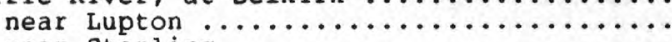
near sterling $\ldots \ldots \ldots \ldots \ldots \ldots \ldots \ldots$

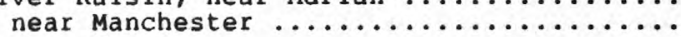

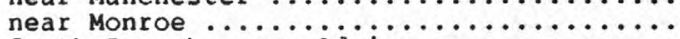

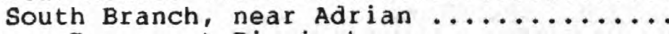

River Rouge, at Birmingham $\ldots \ldots \ldots \ldots \ldots \ldots$

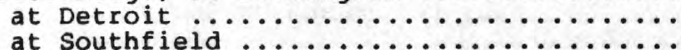

Riverside, Paw Paw $\mathrm{River}$ at $\ldots \ldots \ldots \ldots \ldots \ldots$

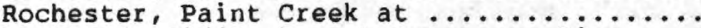

Rockland, Middle Branch Ontonagon River

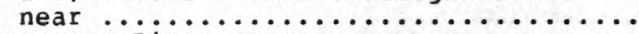

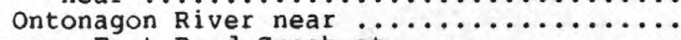

Romeo, East Pond creek at $\ldots \ldots \ldots \ldots \ldots \ldots \ldots$

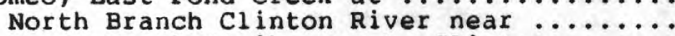
stony Creek (tributary to clinton

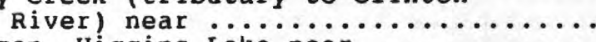

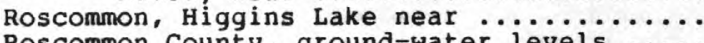
Roscommon County, ground-water levels ..... Rudyard, pine River (tributary to lake Huron near $\ldots \ldots \ldots \ldots \ldots$
Runoff in inches, definition of $\ldots \ldots \ldots \ldots$ Rupert Lake Outlet near Plainweli $\cdots \cdots \cdots 23 \dot{3}, 248-251$

Saginaw County, ground-water levels ....... 268 Saginaw River at Saginaw ............ 181

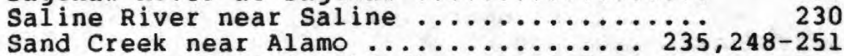
Sand Creek near Alamo ................. River $\ldots \ldots \ldots \ldots \ldots \ldots \ldots \ldots \ldots \ldots$
nilac County, ground-water levels $\ldots \ldots \ldots$ Sanilac County, ground-water leveis $\ldots \ldots \ldots$

Sault Ste. Marie, St. Marys River above ... $50-51$ 46
269
190
17

115
112

197 . . 
Schoolcraft County, ground-water levels ... Schoolcraft, Gourdneck Canal near ........

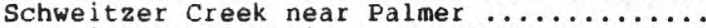

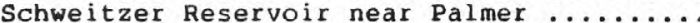
Scott, IN, Pigeon River (tributary to

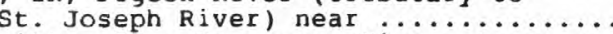
Scottville, Pere Marquette River at .......

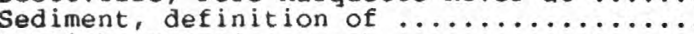

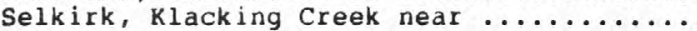

Rifle River at $\ldots \ldots \ldots \ldots \ldots \ldots \ldots \ldots$

South Branch Shepards creek near ........ Seven-day 10-year low flow, definition of Shepards Creek, South Branch, near

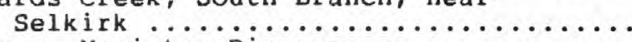

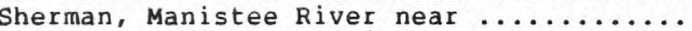

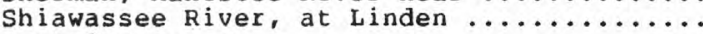

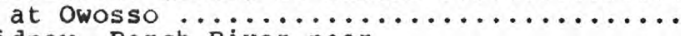

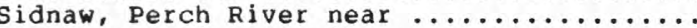
Sturgeon River (tributary to Lake

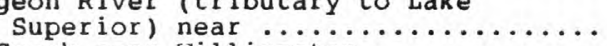

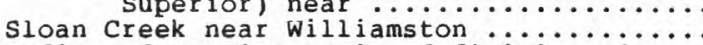
Sodium-adsorption-ratio, definition of $\ldots$ Solute, definition of $\ldots \ldots \ldots \ldots \ldots \ldots \ldots$

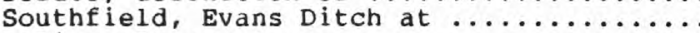

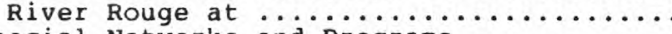

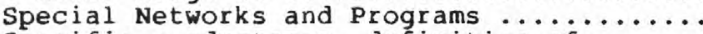
Specific conductance, definition of ................... Spring Brook at East Cooper ............235, 248-25 Spring Creek near Flowerfield ......... 234, 244-247 Stage-discharge relation, definition of ... 17 St. Clair River at Port Huron ..............185-186

St. Clair River, streams tributary to, crest-stage partial-record stations..

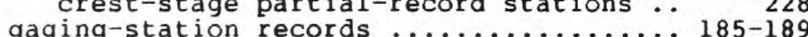

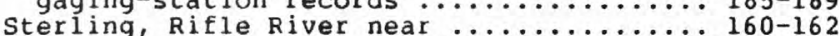
St. Johns, Maple River near ............. 231 St. Joseph River (tributary to Lake

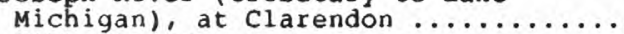
at Elkhart, In . . . . . . . . . . . . . .

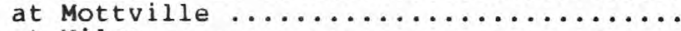

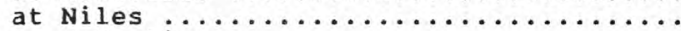

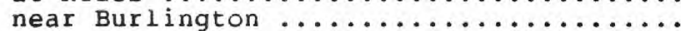
near colon

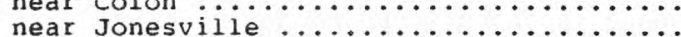

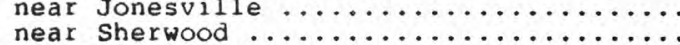
St. Marys River above Sault ste. Marie ... Stony Creek (tributary to Clinton River),

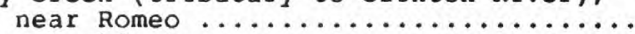

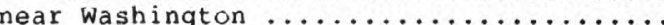

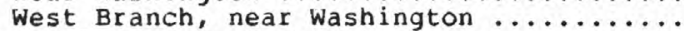

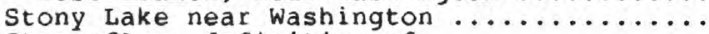
Streamflow, definition of $\ldots \ldots \ldots \ldots \ldots \ldots$ Sturgeon River (tributary to Burt Lake) ............ Sturgeon River (tributary to Lake Michigan) near Nahma Junction ........ sturgeon River (tributary to Lake

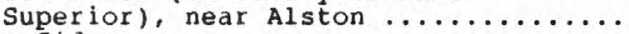

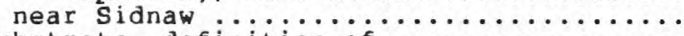
Substrate, definition of $\ldots \ldots \ldots \ldots \ldots \ldots$

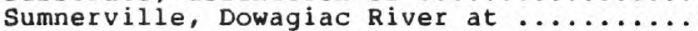
Surface area, definition of $\ldots \ldots \ldots \ldots \ldots$ Surficial bed material, definition of .....

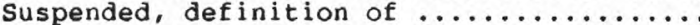

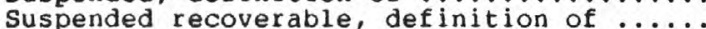
Suspended sediment, definition of $\ldots \ldots \ldots$ Suspended-sediment concentration

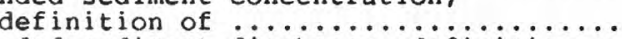
Suspended-sediment discharge, definition

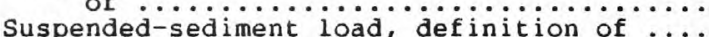

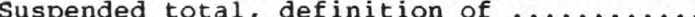
Swan Creek (tributary to Lake Erie),

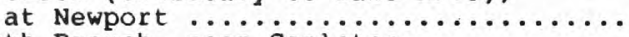

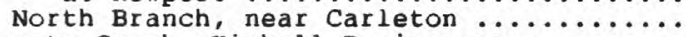

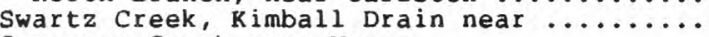

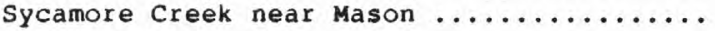
231 8

Tahquamenon River near Tahquamenon

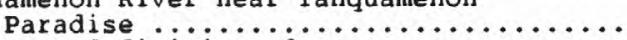

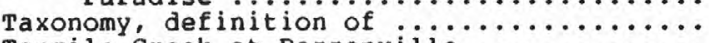

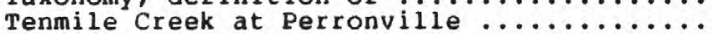

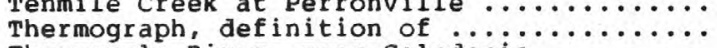
Thermograph, definition of $\ldots \ldots \ldots \ldots$

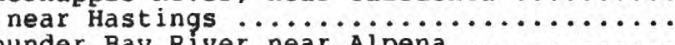
Thunder Bay River near Alpena $\ldots \ldots \ldots \ldots$

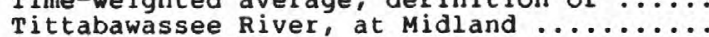

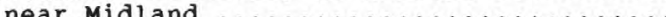

Tobacco River, South Branch, near

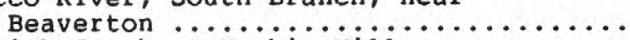

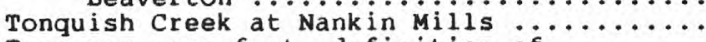

Tons per acre-foot, definition of $\ldots \ldots \ldots$

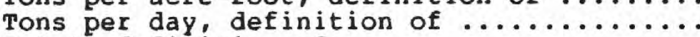

Total, definition of $\ldots \ldots \ldots \ldots \ldots \ldots \ldots \ldots$

Total coliform bacteria, definition of

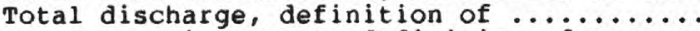

Total organism count, definition of .......

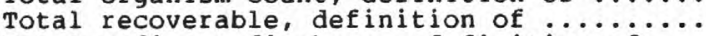

Total-sediment discharge, definition of ...

Total-sediment load, definition of ........

Tower, Black River (tributary to

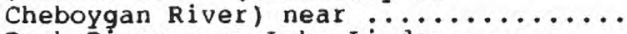

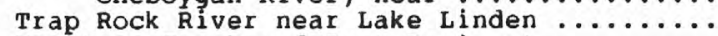

Trenton, Frank and Poet Drain at ...........

Trout Creek, Middle Branch Ontonagon

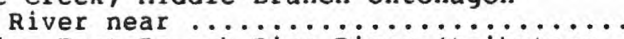

Tustin, East Branch pine $\mathrm{R}$ iver itributary

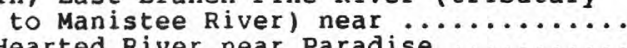

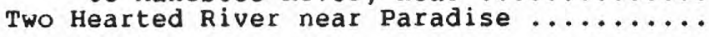

Upper River Rouge, at Farmington ........

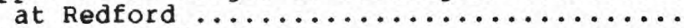

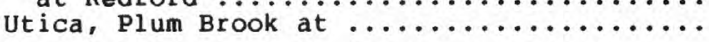

Van Buren County, ground-water levels ..... Vanderbilt, Pigeon River (tributary to

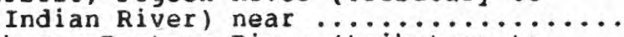

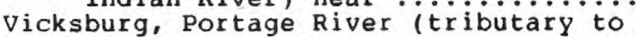

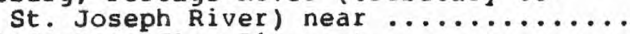

vogel Center, Clam River at $\ldots \ldots \ldots \ldots \ldots \ldots$

Wahjamega, Cass River at $\ldots \ldots \ldots \ldots \ldots \ldots . . . .$. Waiska River, East Branch, near Brimiey ...

West Branch, near Brimley $\ldots \ldots \ldots \ldots \ldots \ldots$
aldenburg, Gloede Ditch near $\ldots \ldots \ldots \ldots \ldots$

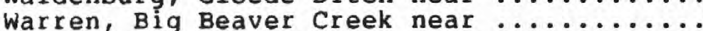

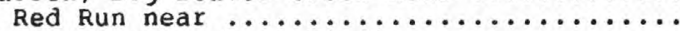

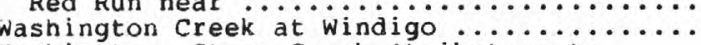
Washington, Stony Creek (tributary to

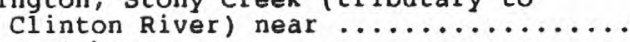

Stony Lake near . . . . . . . . . . . . .

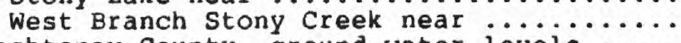
Washtenaw County, ground-water levels .....

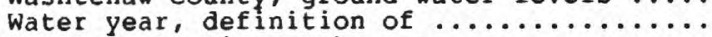
Watersmeet, Cisco Lake near $\ldots \ldots \ldots \ldots \ldots \ldots \ldots$ Watersmeet, Cisco Lake near $\ldots \ldots \ldots \ldots \ldots \ldots \ldots$

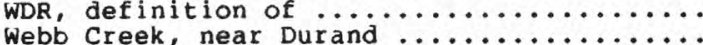
ebb Creek, near Durand $\ldots \ldots \ldots \ldots \ldots \ldots \ldots \ldots$ Weighted average, definition of $\ldots \ldots \ldots \ldots$

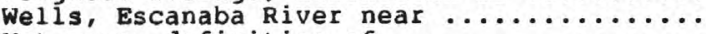
Wet mass, definition of $\ldots \ldots \ldots \ldots \ldots \ldots \ldots$

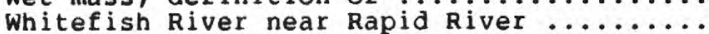

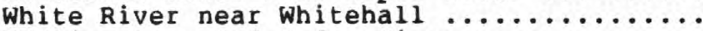
Williamston, Red Cedar River near ..........

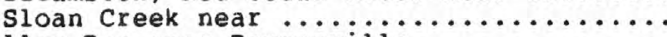
Willow Run near Rawsonvilie $\ldots \ldots \ldots \ldots \ldots$ Windigo, Washington Creek at $\ldots \ldots \ldots \ldots$

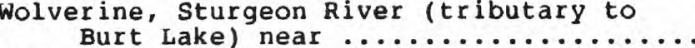
wsp, definition of $\ldots \ldots \ldots \ldots \ldots \ldots \ldots \ldots \ldots \ldots \ldots$

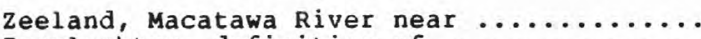
zooplankton, definition of $\ldots \ldots \ldots \ldots \ldots \ldots$
47-49

18

226
18

121

$151-153$

178

178
-180

174

238
18

18

18

18

15 



\section{FACTORS FOR CONVERTING INCH-POUND UNITS TO INTERNATIONAL SYSTEM UNITS (SI)}

The following factors may be used to convert the inch-pound units published herein to the International System of Units (SI).

Multiply inch-pound units

By

To obtain SI units

Length

inches (in)

feet (ft)

miles (mi)

acres

square miles $\left(\mathrm{mi}^{2}\right)$

gallons (gal)

million gallons

cubic feet $\left(\mathrm{ft}^{3}\right)$

cfs-days

acre-feet (acre-ft)

$2.54 \times 10^{1}$

$2.54 \times 10^{-2}$

$3.048 \times 10^{-1}$

$1.609 \times 10^{0}$

Area

$4.047 \times 10^{3}$

$4.047 \times 10^{-1}$

$4.047 \times 10^{-3}$

$2.590 \times 10^{0}$

Volume

$3.785 \times 10^{0}$

$3.785 \times 10^{0}$

$3.785 \times 10^{-3}$

$3.785 \times 10^{3}$

$3.785 \times 10^{-3}$

$2.832 \times 10^{1}$

$2.832 \times 10^{-2}$

$2.447 \times 10^{3}$

$2.447 \times 10^{-3}$

$1.233 \times 10^{3}$

$1.233 \times 10^{-3}$

$1.233 \times 10^{-6}$

Flow

cubic feet per second $\left(\mathrm{ft}^{3} / \mathrm{s}\right)$

gallons per minute (gal/min)

million gallons per day

$2.832 \times 10^{1}$

$2.832 \times 10^{1}$

$2.832 \times 10^{-2}$

$6.309 \times 10^{-2}$

$6.309 \times 10^{-2}$

$6.309 \times 10^{-5}$

$4.381 \times 10^{1}$

$4.381 \times 10^{-2}$

Mass

tons (short) millimeters (mm)

meters (m)

meters (m)

kilometers $(\mathrm{km})$

square meters $\left(\mathrm{m}^{2}\right)$

square hectometers $\left(\mathrm{hm}^{2}\right)$

square kilometers $\left(\mathrm{km}^{2}\right)$

square kilometers $\left(\mathrm{km}^{2}\right)$

liters (L)

cubic decimeters $\left(\mathrm{dm}^{3}\right)$

cubic meters $\left(\mathrm{m}^{3}\right)$

cubic meters $\left(\mathrm{m}^{3}\right)$

cubic hectometers $\left(\mathrm{hm}^{3}\right)$

cubic decimeters $\left(\mathrm{dm}^{3}\right)$

cubic meters $\left(\mathrm{m}^{3}\right)$

cubic meters $\left(\mathrm{m}^{3}\right)$

cubic hectometers $\left(\mathrm{hm}^{3}\right)$

cubic meters $\left(\mathrm{m}^{3}\right)$

cubic hectometers $\left(\mathrm{hm}^{3}\right)$

cubic kilometers $\left(\mathrm{km}^{3}\right)$

liters per second $(\mathrm{L} / \mathrm{s})$

cubic decimeters per second $\left(\mathrm{dm}^{3} / \mathrm{s}\right)$

cubic meters per second $\left(\mathrm{m}^{3} / \mathrm{s}\right)$

liters per second $(\mathrm{L} / \mathrm{s})$

cubic decimeters per second $\left(\mathrm{dm}^{3} / \mathrm{s}\right)$

cubic meters per second $\left(\mathrm{m}^{3} / \mathrm{s}\right)$

cubic decimeters per second $\left(\mathrm{dm}^{3} / \mathrm{s}\right)$

cubic meters per second $\left(\mathrm{m}^{3} / \mathrm{s}\right)$

megagrams $(\mathrm{Mg})$ or metric tons 
US. DEPARTMENT OF THE INTERIOR

Geological Survey

6520 Mercantile Way, Suite 5

Lansing, MI 48911

OFFICIAL BUSINESS

PENALTY FOR PRIVATE USE $\$ 300$

SPECIAL 4TH CLASS BOOK RATE 